DOC.20041109.0004

QA: QA

MDL-NBS-HS-000023 REV 00

November 2004

BECHTEL

SAIC conparrLC

\title{
Simulation of Net Infiltration for Present-Day and Potential Future Climates
}

Prepared for:

U.S. Department of Energy

Office of Civilian Radioactive Waste Management

Office of Repository Development

1551 Hillshire Drive

Las Vegas, Nevada 89134-6321

Prepared by:

Bechtel SAIC Company, LLC

1180 Town Center Drive

Las Vegas, Nevada 89144

Under Contract Number

DE-AC28-01RW12101 


\section{DISCLAIMER}

This report was prepared as an account of work sponsored by an agency of the United States Government. Neither the United States Government nor any agency thereof, nor any of their employees, nor any of their contractors, subcontractors or their employees, makes any warranty, express or implied, or assumes any legal liability or responsibility for the accuracy, completeness, or any third party's use or the results of such use of any information, apparatus, product, or process disclosed, or represents that its use would not infringe privately owned rights. Reference herein to any specific commercial product, process, or service by trade name, trademark, manufacturer, or otherwise, does not necessarily constitute or imply its endorsement, recommendation, or favoring by the United States Government or any agency thereof or its contractors or subcontractors. The views and opinions of authors expressed herein do not necessarily state or reflect those of the United States Government or any agency thereof. 
QA: QA

Simulation of Net Infiltration for Present-Day and Potential Future Climates

MDL-NBS-HS-000023 REV 00

November 2004 
2. Type of Mathernatical Model

$X$ Process Model

Abstraction Model

System Model

Describe Intended Use of Model

The purpose of this model roport is to docurnent the infiltration model that is used to estimate upper-bound, mean, and lower-bound spatially-distributed average annual net infiltration rates for present-day and potential futtre climates at Yucca Mountain, Nevada.

3. Thlle

Simulation of Net Infiltration for Present-Day and Potential Future Climates

4. Dt (including Rev. No., if applicable):

MDL-NBS-HS-000023 REV 00

\section{Total Appendices}

13
6. No. of Pages in Each Appendix

A-28, B-20, C-30, D-42, E-28, F-14, G-26, H-14, 1-16, J-10. $\mathrm{K}-26, \mathrm{~L}-12, \mathrm{M}-14$

\begin{tabular}{|c|c|c|c|}
\hline & Printed Name & Sigpeture & Daie \\
\hline 7. Originator & D.G. Levitt & & $i 1 / 5 / 2004$ \\
\hline $\begin{array}{l}\text { 8. Independent Technical } \\
\text { Reviewer }\end{array}$ & L. Chaturvedi & & $11 /:$ \\
\hline 9. Cheoker & B. Faybishenko/K. Zhang & $B_{3}$ & $711 / 5 / 200$ \\
\hline 10. QER & J. Heaney & & $116 \sqrt{64}$ \\
\hline 11. Responsible Managerflead & H.H. Liu & & $11 / 8 / 04$ \\
\hline 12. Responsible Manager & M. Zhu & & 104 \\
\hline
\end{tabular}

Contributors to the report include: R.D. McCuriey and J.A. Hevesi.

\section{Change History}

\begin{tabular}{|c|c|}
\hline 14. Revision No. & 15. Description of Change \\
\hline REV CO & $\begin{array}{l}\text { Initial lssue } \\
\text { This report is a revision of the scientific analysis by the same title, Document Identifier } \\
\text { ANL-NBS-HS-000032 (USGS } 2003 \text { [DIRS } 166518 \text { ]). In this new model report, changes were } \\
\text { made in response to recommendations from the Regulatory Integration Team/Natural Systems } \\
\text { Team. The entire model documentation was revised. Changes were too extensive to use Step } \\
\text { 5.8D) 1) per AP-SIIL.10Q, REV } 02,1 C N \text {. }\end{array}$ \\
\hline
\end{tabular}




\section{INTENTIONALLY LEFT BLANK}




\section{CONTENTS}

Page

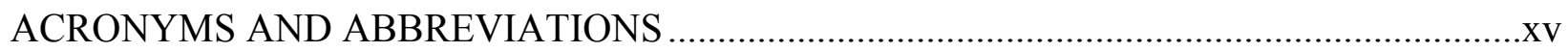

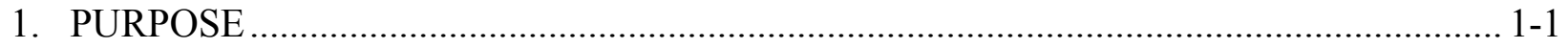

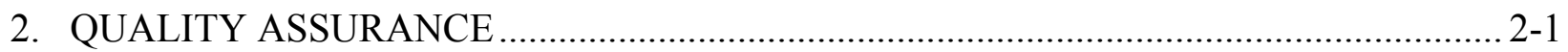

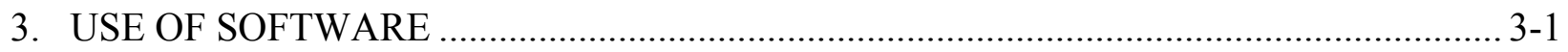

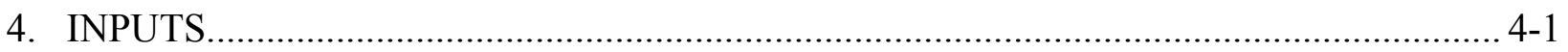

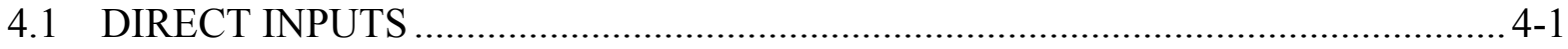

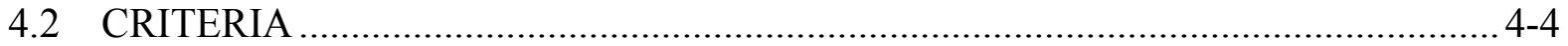

4.3 CODES, STANDARDS, AND REGULATIONS ................................................. 4-6

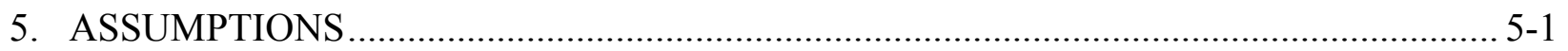

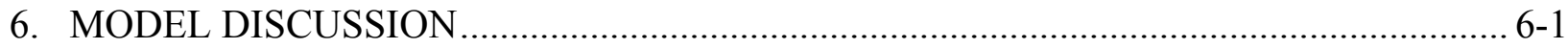

6.1 CONCEPTUAL MODEL OF INFILTRATION .................................................. 6-1

6.1.1 Definition of Net Infiltration.................................................................... 6-2

6.1.2 Overview of the Conceptual Model of Infiltration ........................................... 6-2

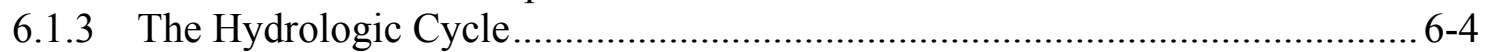

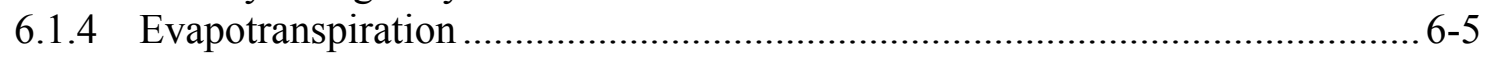

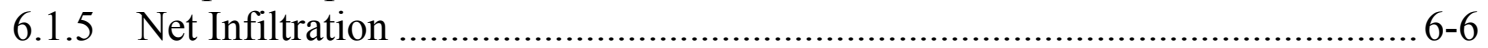

6.2 NUMERICAL REPRESENTATION OF THE CONCEPTUAL MODEL ................. 6-7

6.2.1 Accuracy and Precision of Model Calculations .............................................. 6-8

6.2.2 Accuracy of Input Parameters.................................................................... 6-8

6.3 GENERAL DESCRIPTION OF MODELING PROCEDURE.................................. 6-9

6.3.1 Overview of Distributed-Parameter Water-Balance Model ............................ 6-9

6.3.2 Overview of Modeling Procedure............................................................. 6-12

6.3.3 Overview of Model Input..................................................................... 6-14

6.3.4 Assumptions Concerning Model Calibration................................................... 6-15

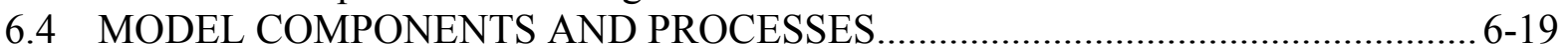

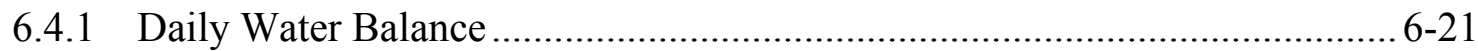

6.4.2 Daily Climate Input............................................................................... 6-22

6.4.3 Snow Pack Submodel ...................................................................... 6-24

6.4.4 Potential Evapotranspiration and the Net Radiation Submodel...................... 6-25

6.4.5 Root-Zone Submodel: Infiltration, Percolation, and Redistribution................ 6-28

6.4.6 Root-Zone Submodel: Evapotranspiration, Runoff, and Net Infiltration ....... 6-29

6.4.7 Surface-Water Flow-Routing Submodel.................................................. 6-29

6.5 MODEL GRID GEOMETRY AND WATERSHED MODELING DOMAINS

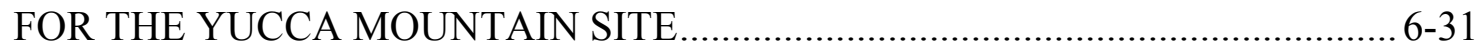

6.5.1 Spatial Discretization and the Base-Grid ...................................................... 6-31

6.5.2 Development of the Surface Drainage Network ……................................... 6-32

6.5.3 Development of Watershed Model Domains.................................................... 6-35 


\section{CONTENTS (Continued)}

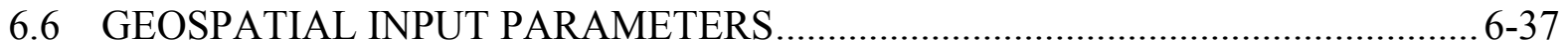

6.6.1 Topographic Parameters (Slope, Aspect, and Blocking Ridges) .................... 6-37

6.6.2 Soil-Depth Classes ................................................................................ 6-39

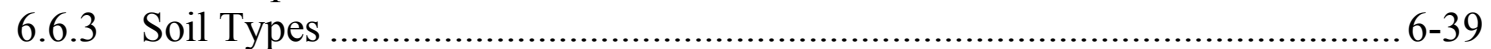

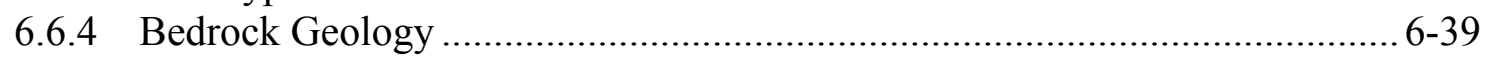

6.7 ESTIMATED ROOT-ZONE DEPTH AND VERTICAL LAYERING .................... 6-44

6.7.1 Estimated Soil Depth ........................................................................... 6-44

6.7.2 Estimated Root-Zone Depth ........................................................................ 6-45

6.7.3 Estimated Root-Zone Layering and Root-Zone Density ............................... 6-47

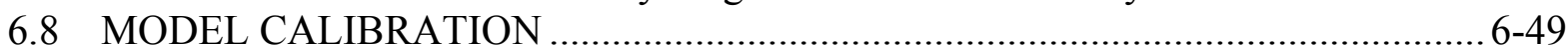

6.8.1 Climate Input Used for Model Calibration ................................................ 6-50

6.8.2 Stream Flow Records Used for Model Calibration........................................ 6-50

6.8.3 Model Calibration Results ..................................................................... 6-54

6.8.3.1 1996 Model Calibration Results................................................ 6-54

6.8.3.2 1999 Model Calibration Results.................................................... 6-57

6.9 REPRESENTATION OF CLIMATES FOR MODEL APPLICATION ………........ 6-59

6.9.1 Assumptions Concerning Future Climate Scenarios Used For Simulation

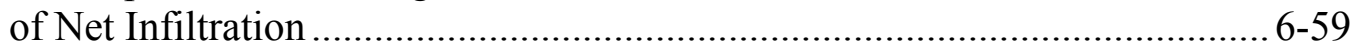

6.9.2 Present-Day Climate Scenarios...................................................................... 6-61

6.9.3 Monsoon Future Climate Scenarios................................................................... 6-62

6.9.4 Glacial-Transition Future Climate Scenarios.................................................. 6-64

6.10 DEVELOPMENT OF INPUTS FOR UNCERTAINTY ANALYSIS ....................... 6-66

6.11 RESULTS OF NET-INFILTRATION ESTIMATES ............................................6-66

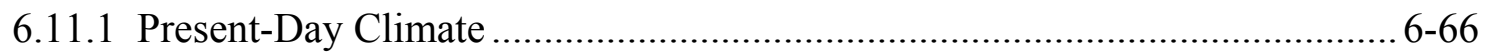

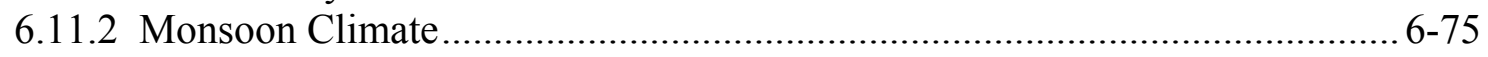

6.11.3 Glacial-Transition Climate...................................................................... 6-81

6.12 FEATURES, EVENTS, AND PROCESSES ……………..................................... 6-97

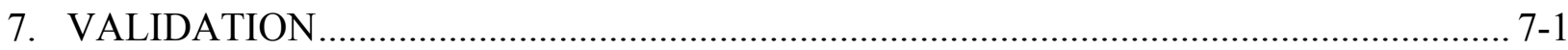

7.1 CONFIDENCE BUILDING DURING MODEL DEVELOPMENT TO ESTABLISH SCIENTIFIC BASIS AND ACCURACY FOR INTENDED USE....... 7-2

7.2 POSTDEVELOPMENT MODEL VALIDATION TO SUPPORT THE SCIENTIFIC BASIS OF THE MODEL ………….................................................. 7-4

7.2.1 Method 1: Comparison of Infiltration Rate with Other Data............................7-4

7.2.2 Method 2: Comparison with An Alternative Model ......................................... 7-8

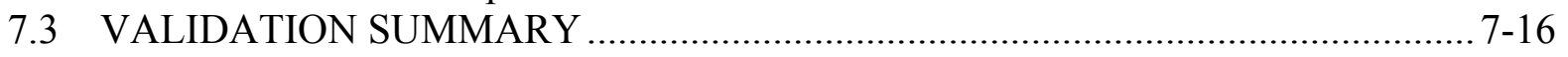

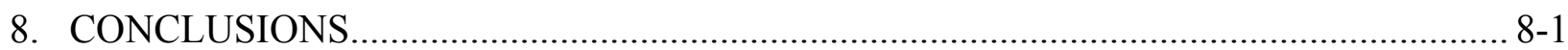

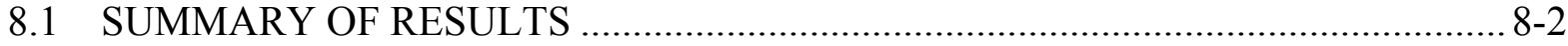

8.2 LIMITATIONS AND UNCERTAINTIES...............................................................

8.3 HOW THE ACCEPTANCE CRITERIA ARE ADDRESSED ….............................. 8-6 


\section{CONTENTS (Continued)}

Page

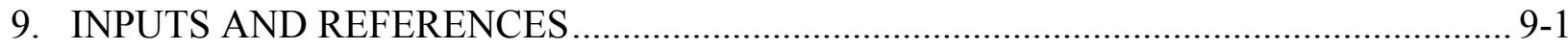

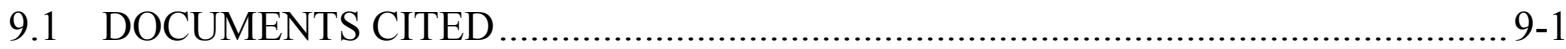

9.2 CODES, STANDARDS, REGULATIONS, AND PROCEDURES .............................9-6

9.3 SOURCE DATA, LISTED BY DATA TRACKING NUMBER …………….............9-8

9.4 OUTPUT DATA, LISTED BY DATA TRACKING NUMBER …….....................9-12

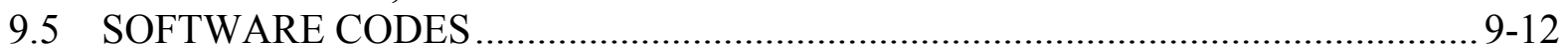

APPENDIX A - YUCCA MOUNTAIN 1980-95 DEVELOPED DAILY PRECIPITATION RECORD................................................................. A-1

APPENDIX B - GEOSPATIAL INPUT DATA FOR INFIL V2.0 FY99 ……………..............

APPENDIX C - DEVELOPMENT OF DAILY CLIMATE INPUT USING

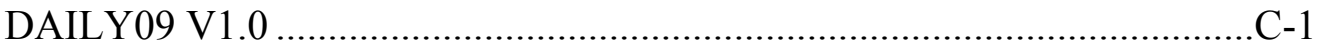

APPENDIX D - CALCULATION OF BLOCKING RIDGES USING

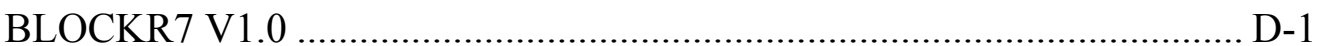

APPENDIX E - INCLUSION OF UPDATED BEDROCK GEOLOGY USING GEOMAP7 V1.0...........................................................................

APPENDIX F - ADJUSTMENT OF THE SOIL DEPTH CLASS MAP

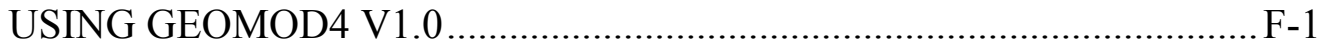

APPENDIX G - ESTIMATION OF SOIL DEPTH USING SOILMAP6 V1.0...................... G-1

APPENDIX H - DEVELOPMENT OF FLOW ROUTING PARAMETERS USING SORTGRD1 V1.0 ........................................................................... $\mathrm{H}-1$

APPENDIX I - CALCULATION OF FLOW ROUTING PARAMETERS USING CHNNET16 V1.0 ......................................................................

APPENDIX J - DEVELOPMENT OF GEOSPATIAL INPUT PARAMETERS USING VEGCOV01 V1.0.....................................................................

APPENDIX K - EXTRACTION OF WATERSHED MODELING DOMAINS USING

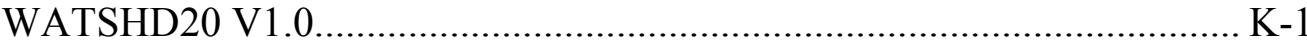

APPENDIX L - POSTPROCESSING OF MODEL RESULTS USING

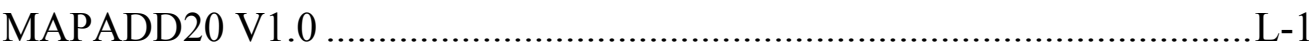

APPENDIX M - POSTPROCESSING OF MODEL RESULTS USING MAPSUM01 V1.0 


\section{INTENTIONALLY LEFT BLANK}




\section{FIGURES}

Page

6-1. Field-Scale Water Balance and Processes Controlling Net Infiltration......................... 6-5

6-2. The Daily Root-Zone Water-Balance Used to Model Net Infiltration .......................... 6-11

6-3. Measured Water-Content Profiles at Borehole UZN-15 for 1993-95 .......................... 6-16

6-4. $\quad$ Estimates of Average Net-Infiltration Rates at Yucca Mountain Calculated Using

Changes in Measured Water-Content Profiles Obtained for the Period 1989-95

From A Network of Monitoring Boreholes, Compared to Depth of Alluvium at Each Borehole

6-5. (A) Graphs of Water-Potential Measurements near Borehole USW UZ-N15 Using

Head Dissipation Probes Measured at Four Depths for 1995, and (B) Water

Content Used to Calculate Flux

6-6. Flow Chart of the Model Algorithm Used for Simulating Net Infiltration

6-7. Relative Effect of Air Temperature Change on the Modeled S/(S+g) Term of the Priestley-Taylor Equation Used for Estimating Potential Evapotranspiration

6-8. Y Yucca Mountain DEM Used to Define Geospatial-Input Parameters and Watershed Modeling Domains

6-9. Number of Upstream Cells Indicating the Numerical Channel Network 6-34

6-10. Isolation of the Drainage Networks Overlying the Area of the UZ Flow Model......... 6-36

6-11. Location of 10 Watershed Model Domains Included in the Composite Watershed Model Area Overlying the Area of the UZ Flow Model

6-12. Recombined Soil Classes Used in the 1996 Net-infiltration Model ............................. 6-40

6-13. Overlay of the Three Geologic Maps Used to Define Rock Types Underlying the Root Zone and Included in the Bottom Root-zone Layer.

6-14. Estimated Field-scale Saturated Hydraulic Conductivity of Bedrock or Soils Underlying the Root Zone

6-15. Estimated Soil Depth Using the 1996 Soil-depth Class Map and Calculated Landsurface Slope

6-16. Total Water-Storage Capacity of the Modeled Root Zone, Including Bedrock and Soil Layers

6-17. Developed 1980-95 Daily Precipitation Record Used as Input for Model Calibration.....

6-18. Location of Stream-Gaging Sites and Calibration Watersheds Defined by the Gaging Sites

6-19. Graphs of Comparisons of Simulated (1996 Model) Net infiltration Using Water Content in Neutron Boreholes (A) USW UZ-N50 and (B) UE-25 UZN \#63 $6-55$

6-20 Graph of Average Annual Precipitation Simulated (1996 Model) at Each Borehole Using Precipitation Record for 1980-95, and Simulated (1996 Model) with a 30-Percent Enhancement in the Channel Grid Blocks Only, Compared to Developed Precipitation Record Distributed Geostatistically to Each Borehole

6-21. Graph of Precipitation Relative to Infiltration Simulated with the 1996 Model for Each Borehole with no Channel-Enhancement Factor and with 30-Percent Channel-enhancement Factor, and Mean Annual Infiltration for all Boreholes.

6-22. Estimated Precipitation (mm/year) for the Mean Present-Day Climate Scenario 


\section{FIGURES (Continued)}

6-23. Estimated Evapotranspiration ( $\mathrm{mm} /$ year) for the Mean Present-Day Climate Scenario

6-24. Estimated Surface-water Run-on Depth (mm/year) for the Mean Present-Day Climate Scenario

6-25. Estimated Net Infiltration ( $\mathrm{mm} /$ year) for the Mean Present-Day Climate Scenario ..... 6-74

6-26. Estimated Net infiltration ( $\mathrm{mm} /$ year) for the Lower Bound Present-day Climate Scenario

6-27. Estimated Net Infiltration ( $\mathrm{mm} /$ year) for the Upper Bound Present-Day Climate Scenario

6-28. Estimated Net Infiltration ( $\mathrm{mm} /$ year) for the Mean Monsoon Climate Scenario 6-82

6-29. Estimated Net Infiltration ( $\mathrm{mm} / \mathrm{year}$ ) for the Upper Bound Monsoon Climate Scenario

6-30. Infiltrated Surface-water Run-on Depth ( $\mathrm{mm} /$ year) for the Upper Bound Monsoon Climate Scenario

6-31. Precipitation ( $\mathrm{mm} /$ year) for the Mean Glacial-Transition Climate Scenario.

6-32. Water-equivalent Snowfall Depth ( $\mathrm{mm} /$ year) for the Mean Glacial-Transition Climate Scenario

6-33. Evapotranspiration ( $\mathrm{mm} /$ year) for the Mean Glacial-Transition Climate Scenario

6-34. Estimated Infiltrated Surface-water Run-on Depth (mm/year) for the Mean Glacial-Transition Climate Scenario.

6-35. Estimated Net Infiltration ( $\mathrm{mm} /$ year) for the Mean Glacial-Transition Climate Scenario.

6-36. Estimated Net Infiltration ( $\mathrm{mm} /$ year) for the Lower Bound Glacial-Transition Climate Scenario

6-37. Estimated Infiltrated Surface-water Run-on Depth ( $\mathrm{mm} /$ year) for the Lower Bound Glacial-Transition Climate Scenario

6-38. Estimated Net Infiltration ( $\mathrm{mm} /$ year) for the Upper Bound Glacial-Transition Climate Scenario

6-39. Estimated Infiltrated Surface-water Run-on Depth (mm/year) for the Upper Bound Glacial-Transition Climate Scenario (DTN: GS000308311221.005)

7-1. Comparison of 1999 INFIL Simulated Average Net-Infiltration Rates at Yucca Mountain (Upper Bound, Lower Bound, and Mean for Three Climates and Three domain Areas)

7-2. Comparison of Various Methods to Estimate Recharge in the Death Valley Region and Yucca Mountain with Selected Results from the 1999 INFIL Model Simulations as a Function of Average Annual Precipitation

7-3. Comparison of Hydraulic Conductivities

7-4. Flux Calculated from Water Content Measurements Versus Modeled Flux at 39 Neutron Logging Boreholes Within the Area of the Five Streamflow Calibration Watersheds. Measured Flux Is Calculated from Neutron Logging Water Content Data Using the 0.012 Filter. 


\section{FIGURES (Continued)}

Page

7-5. Flux Calculated from Water Content Measurements Versus Modeled Flux for 21 Groups of Neutron Logging Boreholes (Based on Topography) Within the Area of the Five Streamflow Calibration Watersheds. Measured Flux Is Calculated from Neutron Logging Water Content Data Using the 0.012 Filter

7-6 Flux Calculated from Water Content Measurements Versus Modeled Flux for Seven Groups of Neutron Logging Boreholes (Based on Topography) Within Pagany Wash Watershed. Measured Flux Is Calculated from Neutron Logging Water Content Data Using the 0.012 Filter

7-7 Measured Versus Modeled Stream Flow for the 1999 and 2004 Model Calibrations for the Five Stream Flow Calibration Watersheds

7-8. Estimated Net Infiltration (mm/year) for the Mean Present-Day Climate Scenario Using the 2004 (H104) Model

7-9. Difference in Net Infiltration (mm/year) for the Mean Present-Day Climate Scenario Between the 2004 (H104) Model and the 1999 Model Outputs 


\section{INTENTIONALLY LEFT BLANK}




\section{TABLES}

Page

3-1. Computer Software Used to Develop Estimates of Net Infiltration ............................ 3-2

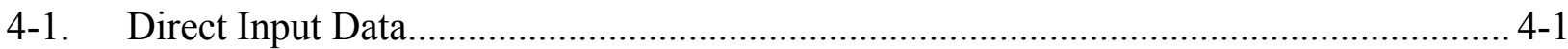

4-2. Project Requirements and Acceptance Criteria Applicable to This Model Report ......... 4-4

6-1. Stations and Precipitation Records Used to Develop the 1980-95 Daily Climate Input Files Used for Model Calibration and for Present-Day Climate Scenarios.

6-2. Comparison of Measured Versus 1999 Model Simulated Daily Mean Discharge at Stream-Gaging Sites for Streamflow Events in 1995.

6-3. Summary of Developed Daily Climate Input Files Used for Present-day Climate Scenarios

6-4. Summary of Analogue Climate Records Used to Develop the Daily Climate Input for the Upper Bound Monsoon Climate Scenario.....

6-5. Summary of Analogue Climate Records Used to Develop the Daily Climate Input for the Lower Bound Glacial-Transition Climate Scenario

6-6. Summary of Analogue Climate Records Used to Develop the Daily Climate Input for the Upper Bound Glacial-Transition Climate Scenario

6-7. Summary of 1999 INFIL Simulation Results Used to Develop Spatially

Distributed Net-infiltration Estimates for Present-Day Climate Scenarios

6-8. Estimation Results for Present-Day Climate Scenarios Over the 123.7- $\mathrm{km}^{2}$ Area of the 1999 Infiltration Model Domain....

6-9. Estimation Results for Present-Day Climate Scenarios Over the $38.7-\mathrm{km}^{2}$ Area of the 1999 UZ Flow Model Domain.

6-10. Estimation Results for Present-Day Climate Scenarios Over the 4.7- $\mathrm{km}^{2}$ Area of the 1999 Repository Footprint

6-11. Summary of 1999 INFIL Simulation Results Used to Develop Spatially Distributed Net-infiltration Estimates for the Upper Bound Monsoon Climate Scenarios

6-12. Estimation Results for the Monsoon Climate Scenarios Over the 123.7- $\mathrm{km}^{2}$ Area of the 1999 Infiltration Model Domain

6-13. Estimation Results for the Monsoon Climate Scenarios over the $38.7-\mathrm{km}^{2}$ Area of the 1999 UZ Flow Model Domain.

6-14. Estimation Results for the Monsoon Climate Scenarios over the $4.7-\mathrm{km}^{2}$ Area of the 1999 Repository Footprint

6-15. 1999 INFIL Simulation Results Used to Develop Spatially Distributed Netinfiltration Estimates for the Lower Bound Glacial-Transition Climate Scenario $6-85$

6-16. 1999 INFIL Simulation Results Used to Develop Spatially Distributed Netinfiltration Estimates for the Upper Bound Glacial-Transition Climate Scenario $6-85$

6-17. Estimation Results for the Glacial-Transition Climate Scenarios over the $123.7-\mathrm{km}^{2}$ Area of the 1999 Infiltration Model Domain

6-18. Estimation Results for the Glacial-Transition Climate Scenarios over the $38.7-\mathrm{km}^{2}$

Area of the 1999 UZ Flow Model Domain $6-88$ 


\section{TABLES (Continued)}

6-19. Estimation Results for the Glacial-Transition Climate Scenarios for the 4.7-km² Area of the 1999 Repository Footprint ................................................................... 6-88

6-20. FEPs Addressed in this Model Report................................................................. 6-100

7-1. Net Infiltration for Different Model Areas for the 1999 and 2004 Model Runs ............. 7-7

7-2. Summary of Input Parameters Changed for the 2004 Model Calibration ..................... 7-11

7-3. Summary of the 1999 and 2004 Model Calibrations Using Stream Flow Data ............ 7-15

8-1. Output Data Sets Generated in the Development and Application of the Net Infiltration Model.............................................................................................................. 8-1

8-2. Summary of Treatment of Uncertainties.................................................................. 8-4 


\section{ACRONYMS AND ABBREVIATIONS}

$\mathrm{cfs}$

cubic feet per second

DEM

digital elevation model

FEP

feature, event, or process

GIS

geographic information system

IFR

instantaneous flow routing

MAP

mean annual precipitation

MAT

mean annual temperature

NCDC

National Climatic Data Center

NOAA

National Oceanic and Atmospheric Administration

NTS

NWS

Nevada Test Site

National Weather Service

PET potential evapotranspiration

RIT Regulatory Integration Team

SZ

saturated zone

TCW

TSPA

Tiva Canyon welded hydrogeologic unit

TWP total system performance assessment technical work plan

USGS

U.S. Geological Survey

UTM

Universal Transverse Mercator

UZ

unsaturated zone

YMRP

Yucca Mountain Review Plan, Final Report 


\section{INTENTIONALLY LEFT BLANK}




\section{PURPOSE}

The purpose of this model report is to document the infiltration model used to estimate upper-bound, mean, and lower-bound spatially-distributed average annual net infiltration rates for present-day and potential future climates at Yucca Mountain, Nevada. Net infiltration is the component of infiltrated precipitation, snowmelt, or surface water run-on that has percolated below the zone of evapotranspiration as defined by the depth of the effective root zone.

The estimates of net infiltration are primarily used for defining the upper boundary condition for the site-scale three-dimensional unsaturated zone (UZ) model. The UZ flow model is one of several process models abstracted by the total system performance assessment (TSPA) model used to evaluate performance of the repository at Yucca Mountain, Nevada. The net-infiltration model is important for assessing repository-system performance because output from this model provides the upper boundary condition for the UZ flow model used to generate flow fields; water percolating downward from the UZ will be the principal means by which radionuclides are potentially released to the saturated zone (SZ). The SZ is the principal pathway to the biosphere where the reasonably maximally exposed individual (RMEI) is exposed to radionuclides.

Reports that use information from this model report as direct input include Calibrated Properties Model; UZ Flow Models and Submodels; Analysis of Infiltration Uncertainty; Mountain-Scale Coupled Processes (TH/THC/THM); and Features, Events, and Processes in UZ Flow and Transport.

Estimates of net infiltration are provided as raster-based, two-dimensional grids of spatially distributed, time-averaged rates for three different climate stages estimated as likely conditions for the next 10,000 years beyond the present. Each climate stage is represented using a lower bound, a mean, and an upper bound climate and corresponding net-infiltration scenario for representing uncertainty in the characterization of daily climate conditions for each climate stage, as well as potential climate variability within each climate stage. The set of nine raster grid maps provides spatially detailed representations of the magnitude and distribution of net-infiltration rates that are used to define specified flux upper boundary conditions for the UZ flow model.

This model report is a revision of the scientific analysis report, Simulation of Net Infiltration for Modern and Potential Future Climates (USGS 2003 [DIRS 166518]). The name of this model report has been changed to reflect that it is a model report, not a scientific analysis, and as a result, this model report is Revision 00. In this model report, changes were made in response to recommendations from the Regulatory Integration Team (RIT)/Natural Systems Team to improve transparency and document the 2004 modeling activities conducted for additional validation of the model results documented in Simulation of Net Infiltration for Modern and Potential Future Climates (USGS 2003 [DIRS 166518]). This model report now consists of the following:

- Modifications to the 1996 model code INFIL V1.0 (Flint et al. 1996 [DIRS 100147], Appendix V) 
- Updates of input parameters defining the new model INFIL V2.0 (USGS 2001 [DIRS 139422])

- Calibration of the new model using stream flow records

- The development of daily climate input representative of potential future climate stages

- Application of the model to provide net-infiltration estimates for lower, mean, and upper bound climate scenarios within each potential future climate stage

- The 2004 model validation activities described in Section 7.

This model report documents the development, calibration, and application of the enhanced model, and also the historical development of the conceptual and numerical models used to provide spatially and temporally distributed estimates of net infiltration over the area of the UZ flow model and the repository. The document describes all inputs, procedures, and assumptions used to obtain estimates of net infiltration and provide a descriptive summary of model results. This model report was prepared under AP-SIII.10Q, Models. The report provides complete documentation of the net-infiltration model and its application, and Scientific Notebooks were not used to document model development, as permitted in procedure AP SIII.10Q, Models.

Estimation of the timing and duration of the potential future climate stages, which consist of a present-day, a monsoon, and a glacial-transition climate stage, is documented in Future Climate Analysis (BSC 2004 [DIRS 170002]). The characterization of precipitation and air temperature for the upper and lower bound climate scenarios within the monsoon and glacial-transition climate stages is also described in Future Climate Analysis (BSC 2004 [DIRS 170002]). 


\section{QUALITY ASSURANCE}

Development of this model report and the supporting modeling activities have been determined to be subject to the Yucca Mountain Project's quality assurance program as indicated in Technical Work Plan for: Unsaturated Zone Flow Analysis and Model Report Integration (BSC 2004 [DIRS 169654], Section 8.1). Approved quality assurance procedures identified in the technical work plan (TWP) (BSC 2004 [DIRS 169654], Section 4) have been used to conduct and document the activities described in this model report. The governing procedure for this model report is AP-SIII.10Q. The TWP also identifies the methods used to control the electronic management of data (BSC 2004 [DIRS 169654], Section 8.4) during the modeling and documentation activities. There were no variances from the TWP during the development of this report.

This model report provides simulation results for infiltration into the UZ under present and potential future climates. The UZ (including soil and rock above the water table) is part of natural barriers that are classified in the Q-List (BSC 2004 [DIRS 168361]) as "Safety Category" because it is important to waste isolation, as defined in AP-2.22Q, Classification Analyses and Maintenance of the Q-List. The report contributes to the process models used to support performance assessment; the conclusions do not directly impact engineered features important to preclosure safety, as defined in AP-2.22Q. 
INTENTIONALLY LEFT BLANK 


\section{USE OF SOFTWARE}

The software codes listed in Table 3-1 are appropriate for the intended application, and were used only within the range of validation. The use of software in modeling work documented in this report was in accordance with the software procedure, AP-SI.1Q, Software Management (REV 2 ICN 4), which was in effect when the modeling analyses were performed. Additional modeling work conducted in 2004 used INFIL version A_2.a1 which was obtained from the Software Configuration Management and used in accordance with LP-SI.11Q-BSC, Software Management. Guidance, as specified in a RIT Broadcast Message dated August 12, 2004, directs that the qualification status of technical product output will not change as a result of changes in the Q status of software, classified under AP-SI.1Q as 'single use routines,' which were used in the calculation of that output. This guidance specifies that:

Output from software qualified under LP-SI.14Q-BSC, Independent Verification and Validation of Legacy Code, and earlier versions may be used provided that both constraints below are met.

1. The original output is used without rerunning the code.

2. The software successfully went through LP-SI.14Q-BSC, Legacy Management (legacy testing), with nothing more than documentation issues.

For clarification:

a. If constraint 1 was violated (i.e., the code is rerun), the software would have to be rebaselined in accordance with LP-SI.11Q-BSC, Software Management.

b. If constraint 2 was violated (i.e., something is found to be wrong with the actual code during legacy testing), the output would be suspect and either an impact review or rebaselining of the software under LP-SI.11Q-BSC would be required.

Software, at the time of use, was confirmed as qualified in the Software Baseline Report and subsequently obtained from Software Configuration Management. The three software items, INFIL V2.0 (USGS 2000 [DIRS 139422]), MARKOV V1.0 (USGS 1996 [DIRS 147316]), and PPTSIM V1.0 (USGS 1996 [DIRS 147317]) (Table 3-1, items 1-3) are on the current baseline of LP-SI.11Q-BSC. The developed FORTRAN pre- and post- processors were developed as single use routines (Table 3-1, items 4-14). Use of the listed software, as single use routines, were subject to the requirements listed in Section 5.1.1.2 of AP-SI.1Q, and documentation to satisfy these requirements is included in this report as Appendices $\mathrm{C}$ through $\mathrm{M}$. Thus, this software meets the criteria specified in the guidance specified above. The primary model program for obtaining estimates of net infiltration maps (as provided to the UZ flow model as described in Section 1.0) is INFIL V2.0, which is a modified version of INFIL V1.0. ARCINFO V6.1.2 was used for visual and graphical representation of ground surface data and parameters. This commercially available software product is an exempt software application in accordance with Section 2.1 of LP-SI.11Q-BSC. 
Table 3-1. Computer Software Used to Develop Estimates of Net Infiltration

\begin{tabular}{|c|c|c|c|c|c|}
\hline $\begin{array}{l}\text { Item } \\
\text { No. }\end{array}$ & $\begin{array}{l}\text { Software } \\
\text { Name }\end{array}$ & Version & $\begin{array}{c}\text { Software Tracking } \\
\text { Number or Location } \\
\text { in Document }\end{array}$ & $\begin{array}{l}\text { Computer } \\
\text { Type Used }\end{array}$ & Description \\
\hline 1 & INFIL & 2.0 & $10307-2.0-00$ & $\begin{array}{l}\text { Pentium Pro } \\
\text { PC, Windows } \\
\text { NT } 4.0 \\
\text { FORTRAN77 }\end{array}$ & \multirow{2}{*}{$\begin{array}{l}\text { Simulates components of the water } \\
\text { balance for watershed input } \\
\text { domains supplied by WATSHD20, } \\
\text { daily climate input, and model } \\
\text { parameters included in the model } \\
\text { control file. Outputs average } \\
\text { annual rates for all components of } \\
\text { the water balance, including net } \\
\text { infiltration rates, for all grid cells } \\
\text { located within the } \\
\text { watershed-modeling domain. }\end{array}$} \\
\hline 2 & INFIL & A_2.a1 & 10253-A_2.a1-00 & $\begin{array}{l}\text { COMPAQ } \\
\text { Alpha, } \\
\text { Operating } \\
\text { System Open } \\
\text { VMS AXP } \\
\text { V7.2-1 } \\
\text { FORTRAN } 77 \\
\end{array}$ & \\
\hline 3 & MARKOV & 1.0 & $10142-1.0-00$ & $\begin{array}{l}\text { Pentium Pro } \\
\text { PC, Windows } \\
\text { NT } 4.0 \\
\text { FORTRAN } 77\end{array}$ & $\begin{array}{l}\text { Calculates monthly MARKOV chain } \\
\text { probabilities for occurrence of daily } \\
\text { precipitation and fits monthly } \\
\text { exponential distribution coefficients } \\
\text { to define the cumulative probability } \\
\text { distribution function for the } \\
\text { magnitude of daily precipitation. } \\
\text { Uses daily precipitation records for } \\
\text { input. }\end{array}$ \\
\hline 4 & PPTSIM & 1.0 & $10143-1.0-00$ & $\begin{array}{l}\text { Pentium Pro } \\
\text { PC, Windows } \\
\text { NT } 4.0 \\
\text { FORTRAN } 77\end{array}$ & $\begin{array}{l}\text { Performs a stochastic simulation of } \\
\text { daily precipitation using input } \\
\text { probabilities and coefficients } \\
\text { provided as output from MARKOV } \\
\text { and a user defined prime seed. }\end{array}$ \\
\hline 5 & BLOCKR7 & 1.0 & Appendix D & $\begin{array}{l}\text { Pentium Pro } \\
\text { PC, Windows } \\
\text { NT } 4.0 \\
\text { FORTRAN77 }\end{array}$ & $\begin{array}{l}\text { Combines ARCINFO raster-grid } \\
\text { export files (30mlat.asc, } \\
\text { 30mlong.asc, 30mslope.asc, } \\
\text { 30maspct.asc, 30melev.asc, } \\
\text { 30msoil.asc, 30mdpth.asc, } \\
\text { 30mrock.asc, and 30mtopo.asc) } \\
\text { into a single column-formatted } \\
\text { ASCIl text file. Calculates } 36 \\
\text { blocking ridge parameters for all } \\
\text { grid locations using the raster-grid } \\
\text { elevation data and adds the } 36 \\
\text { columns to the output file } \\
\text { (30msite.inp). }\end{array}$ \\
\hline 5 & GEOMAP7 & 1.0 & Appendix E & $\begin{array}{l}\text { Pentium Pro } \\
\text { PC, Windows } \\
\text { NT } 4.0 \\
\text { FORTRAN77 }\end{array}$ & $\begin{array}{l}\text { Updates the } 1996 \text { INFIL V1.0 } \\
\text { geospatial input file ( } 30 \mathrm{msite} \text {.inp) to } \\
\text { include the Day et al. (1998 [DIRS } \\
\text { 101557]) central block geology } \\
\text { map. }\end{array}$ \\
\hline 6 & VEGCOV01 & 1.0 & Appendix J & $\begin{array}{l}\text { Pentium Pro } \\
\text { PC, Windows } \\
\text { NT } 4.0 \\
\text { FORTRAN77 }\end{array}$ & $\begin{array}{l}\text { Performs a modification to bedrock } \\
\text { saturated hydraulic conductivity } \\
\text { provided as input to account for a } \\
\text { north-south gradation in bedrock } \\
\text { hydraulic conductivity. }\end{array}$ \\
\hline
\end{tabular}


Table 3-1. Computer Software Used to Develop Estimates of Net Infiltration (Continued)

\begin{tabular}{|c|c|c|c|c|c|}
\hline $\begin{array}{l}\text { Item } \\
\text { No. }\end{array}$ & $\begin{array}{c}\text { Software } \\
\text { Name }\end{array}$ & Version & $\begin{array}{c}\text { Software } \\
\text { Tracking Number }\end{array}$ & $\begin{array}{l}\text { Computer } \\
\text { Type Used }\end{array}$ & Description \\
\hline 7 & GEOMOD4 & 1.0 & Appendix F & $\begin{array}{l}\text { Pentium Pro } \\
\text { PC, Windows } \\
\text { NT } 4.0 \\
\text { FORTRAN77 }\end{array}$ & $\begin{array}{l}\text { Defines an intermediate soil depth } \\
\text { buffer zone between thin upland soils } \\
\text { and thick alluvium using the mapped } \\
\text { alluvium boundary and estimates the } \\
\text { bedrock geology type underlying the } \\
\text { buffer zone. Uses output from } \\
\text { GEOMAP7 as input. }\end{array}$ \\
\hline 8 & SOILMAP6 & 1.0 & Appendix G & $\begin{array}{l}\text { Pentium Pro } \\
\text { PC, Windows } \\
\text { NT } 4.0 \\
\text { FORTRAN77 }\end{array}$ & $\begin{array}{l}\text { Estimates soil depths based on } \\
\text { mapped soil depth classes and } \\
\text { calculated ground surface slope } \\
\text { included as input parameters in the } \\
\text { geospatial parameter input file created } \\
\text { as output from GEOMOD4. }\end{array}$ \\
\hline 9 & SORTGRD1 & 1.0 & Appendix $\mathrm{H}$ & $\begin{array}{l}\text { Pentium Pro } \\
\text { PC, Windows } \\
\text { NT } 4.0 \\
\text { FORTRAN77 }\end{array}$ & $\begin{array}{l}\text { Performs a bubble sort on the } \\
\text { geospatial parameter input file based } \\
\text { on elevation (sorts elevation from } \\
\text { highest to lowest). The sorted file } \\
\text { increases the efficiency of channel } \\
\text { routing. Input is provided by } \\
\text { SOILMAP6. }\end{array}$ \\
\hline 10 & CHNNET16 & 1.0 & Appendix I & $\begin{array}{l}\text { Pentium Pro } \\
\text { PC, Windows } \\
\text { NT } 4.0 \\
\text { FORTRAN77 }\end{array}$ & $\begin{array}{l}\text { Establishes the numerical channel } \\
\text { network using elevations from the } \\
\text { output file generated by SORTGRD1. } \\
\text { Outputs a new file containing flow } \\
\text { routing parameters for all grid cells. } \\
\text { The new output file is used as input to } \\
\text { WATSHD20. }\end{array}$ \\
\hline 11 & WATSHD20 & 1.0 & Appendix K & $\begin{array}{l}\text { Pentium Pro } \\
\text { PC, Windows } \\
\text { NT } 4.0 \\
\text { FORTRAN77 }\end{array}$ & $\begin{array}{l}\text { Extracts the watershed modeling } \\
\text { domains based on a user defined } \\
\text { watershed outflow point and input } \\
\text { supplied from SORTGRD1 and } \\
\text { CHNNET16. The output file is supplied } \\
\text { directly as input to INFIL V2.0. }\end{array}$ \\
\hline 12 & DAILY09 & 1.0 & Appendix C & $\begin{array}{l}\text { Pentium Pro } \\
\text { PC, Windows } \\
\text { NT } 4.0 \\
\text { FORTRAN77 }\end{array}$ & $\begin{array}{l}\text { Reformats daily climate records } \\
\text { exported from the Earthlnfo database. } \\
\text { Checks for data gaps and interpolates } \\
\text { missing data if gaps are small or } \\
\text { discards annual records if gaps are } \\
\text { large. }\end{array}$ \\
\hline 13 & MAPADD20 & 1.0 & Appendix L & $\begin{array}{l}\text { Pentium Pro } \\
\text { PC, Windows } \\
\text { NT } 4.0 \\
\text { FORTRAN77 }\end{array}$ & $\begin{array}{l}\text { Compiles results obtained for individual } \\
\text { watersheds into a single composite } \\
\text { watershed-modeling domain, and } \\
\text { calculates statistics for the composite } \\
\text { watershed-modeling domain. }\end{array}$ \\
\hline 14 & MAPSUM01 & 1.0 & Appendix M & $\begin{array}{l}\text { Pentium Pro } \\
\text { PC, Windows } \\
\text { NT } 4.0 \\
\text { FORTRAN77 }\end{array}$ & $\begin{array}{l}\text { Calculates statistics for subareas within } \\
\text { the composite watershed model } \\
\text { domain. Uses results from MAPADD20 } \\
\text { and a blanked SURFER grid as input. } \\
\text { The blanked SURFER grid is created } \\
\text { using the output from MAPADD20 and } \\
\text { the boundary line of the subarea. }\end{array}$ \\
\hline
\end{tabular}


INFIL VA_2.a1 (SNL 2001 [DIRS 147608], compiled under FORTRAN90), is a modified version of INFIL V2.0 specifically to run on the platform COMPAQ Alpha and Operating System Open VMS AXP V7.3 at Sandia National Laboratories. This software was used for calculation of net infiltration and other output variables (e.g. evapotranspiration, run-off, annual flux, etc.) over the entire infiltration region, for the 2004 model validation activities documented in Section 7. The equivalency of output produced by INFIL VA_2.a1 and INFIL V2.0 is documented in INFIL V2.0, Validation Test Report (USGS 2001 [DIRS 171197]) for INFIL VA_2.a1. All model capabilities and attributes ascribed to INFIL V2.0 in Sections 6.2 through 6.6 apply to INFIL VA_2.a1, as well.

Other than commercial off-the-shelf software (e.g. ARCINFO V6.1.2 or other geographic information system [GIS] products) used in this model report, two versions of standard Microsoft Excel (Office 2002 V10.3506.3501 SP-1 and 2000 V9.0.5121 SP-1) and visual display graphics programs (Adobe Illustrator V8.0) were also used. These commercial off-the-shelf software are not subject to software quality assurance requirements and are exempt from qualification under LP-SI.11Q-BSC.

All electronic files consisting of source data, developed model inputs, model outputs, and postprocessing results were maintained and processed according to the seven compliance criteria listed in AP-SV.1Q, Control of Electronic Management of Information, (Process Control Evaluation for Supplement V). The work activities documented in the model report were dependent on electronic media to store, maintain, retrieve, modify, update, and transmit quality affecting information. As part of the work process, electronic databases, spreadsheets, and sets of files were required to hold information intended for use to support the licensing position. In addition, the work process required the transfer of data and files electronically from one location to another.

The use of the input computer files in developing and applying the net infiltration model is summarized in Section 6 and documented more fully in Appendix B. The model output files are accessible from the Technical Data Management System (TDMS) by data tracking number (DTN). 


\section{INPUTS}

\subsection{DIRECT INPUTS}

All direct data inputs used in the development, calibration, and application of the net infiltration model to estimate net infiltration for modern and potential future climates are listed in Table 4-1. These data and parameters consist of the set of digitized topographic, geologic, and soil maps; soil and bedrock hydrologic properties; and present-day and potential future climatic data that are appropriate to and required for the development and application of the distributed-parameter, quasi-three-dimensional, water-balance approach to watershed modeling that is the basis for the net infiltration model. The data referenced in Table 4-1 contain information necessary to construct the numerical model, set boundary conditions, and to calibrate and validate the model. The data are fully appropriate for the site-scale infiltration model. The qualification status of the input sources is provided in the TDMS and listed in the Document Input Reference System (DIRS) database. Wherever possible, the most recent DTN is used for tables referencing data. All direct inputs listed in Table 4-1 are qualified data, except in the case of Handbook of Hydrology (Maidment 1993 [DIRS 125317]), which is considered an Established Fact per AP-3.15Q, Managing Technical Input Products. Three formerly non-qualified direct inputs were qualified using procedure AP-SIII.2Q, Qualification of Unqualified Data, in this model report. They are: DTNs: GS000208312111.003 [DIRS 147247]; MO0003COV00095.000 [DIRS 146848]; and MO0109HYMXPROP.001 [DIRS 155989].

The precipitation datasets that were selected for use in these simulations are discussed in detail in Section 6.9.2 for present-day climate states, Section 6.9 .3 for potential monsoon climate states, and Section 6.9.4 for potential glacial-transition climate states. The development of a precipitation dataset used for model calibration, and for prediction of net infiltration during present-day climate states is also discussed in Appendix A. The development of the geospatial input file used for all model simulations required inputs of digitized topographic, geologic, and soil maps, and datasets of soil and bedrock hydrologic properties. The development of this geospatial input file and the data required for its development is discussed in detail in Section 6.6, and in Appendices B, D, E, F, G, H, I, and J.

Table 4-1. Direct Input Data

\begin{tabular}{|l|l|}
\hline \multicolumn{1}{|c|}{ Description } & \multicolumn{1}{|c|}{ Data Tracking Number } \\
\hline $\begin{array}{l}\text { Handbook of Hydrology. Maidment, D.R., ed. 1993. New York, New York: } \\
\text { McGraw-Hill. TIC: 236568. }\end{array}$ & $\begin{array}{l}\text { Established Fact } \\
\text { [DIRS 125317] }\end{array}$ \\
\hline $\begin{array}{l}\text { EarthInfo, Inc. Western US Meteorologic Station Weather Data - NCDC Summary } \\
\text { of Day (West 1) and NCDC Summary of Day (West 2). Submittal date: } \\
01 / 25 / 2000 .\end{array}$ & $\begin{array}{l}\text { GS000100001221.001 } \\
\text { [DIRS 146816] }\end{array}$ \\
\hline $\begin{array}{l}\text { Precipitation Data for Nevada Test Site, 1957-1994, from Air Resources } \\
\text { Laboratory, from National Oceanographic and Atmospheric Administration (NOAA) } \\
\text { Precipitation Data. Submittal date: 2/29/2000. }\end{array}$ & $\begin{array}{l}\text { GS000200001221.002 } \\
\text { [DIRS 146277] }\end{array}$ \\
\hline $\begin{array}{l}\text { NAD27 Datum of USGS Digital Elevation Model from Topopah Spring West and } \\
\text { Busted Butte 7.5 Minute Quadrangles. Submittal date: 02/18/2000. }\end{array}$ & $\begin{array}{l}\text { GS000200001221.003 } \\
\text { [DIRS 146278] }\end{array}$ \\
\hline
\end{tabular}


Table 4-1. Direct Input Data (Continued)

\begin{tabular}{|c|c|}
\hline Description & Data Tracking Number \\
\hline $\begin{array}{l}\text { Precipitation Data for May 3, } 1989 \text { through September 30, } 1994 \text { from Weather } \\
\text { Stations } 1 \text { and 3, Yucca Mountain, Nevada. Submittal date: 02/22/2000. }\end{array}$ & $\begin{array}{l}\text { GSO00208312111.001 } \\
\text { [DIRS 147245] }\end{array}$ \\
\hline $\begin{array}{l}\text { Air Temperature Data for Calendar Year } 1992 \text { from Weather Station } 1(\mathrm{Wx}-1) \text {, } \\
\text { Yucca Mountain, Nevada. Submittal date: 02/25/2000. }\end{array}$ & $\begin{array}{l}\text { GSO00208312111.002 } \\
\text { [DIRS 147250] }\end{array}$ \\
\hline $\begin{array}{l}\text { Precipitation Data for July 17, } 1987 \text { through May 2, } 1989 \text { from Weather Stations } 1 \\
\text { and 3, Yucca Mountain, Nevada. Submittal date: 03/01/2000. }\end{array}$ & $\begin{array}{l}\text { GSO00208312111.003 } \\
\text { [DIRS 147247] }\end{array}$ \\
\hline Evapotranspiration Coefficients. Submittal date: 03/02/2000. & $\begin{array}{l}\text { GSO00300001221.009 } \\
\text { [DIRS 147228] }\end{array}$ \\
\hline $\begin{array}{l}\text { Preliminary Digital Geologic Map Database of the Nevada Test Site Area, Nevada } \\
\text { by Sawyer and Wahl, 1995. Submittal date: 03/21/2000. }\end{array}$ & $\begin{array}{l}\text { GS000300001221.010 } \\
\text { [DIRS 147833] }\end{array}$ \\
\hline $\begin{array}{l}\text { Meteorological Stations Selected to Represent Future Climate States at Yucca } \\
\text { Mountain, Nevada. Submittal date: } 03 / 14 / 2000 \text {. }\end{array}$ & $\begin{array}{l}\text { GSO00308315121.003 } \\
\text { [DIRS 151139] }\end{array}$ \\
\hline $\begin{array}{l}\text { Relative Humidity Calculated Porosity Measurements on Samples From Borehole } \\
\text { USW SD-9 Used For Saturated Hydraulic Conductivity. Submittal date: } \\
\text { 04/10/2000. }\end{array}$ & $\begin{array}{l}\text { GS000408312231.003 } \\
\text { [DIRS 149461] }\end{array}$ \\
\hline $\begin{array}{l}\text { Data For Core Dried in RH Oven and } 105^{\circ} \mathrm{C} \text { Oven for USW UZ-N31, UZ-N32, } \\
\text { UZ-33, UZ-N34, UZ-N35, UZ-N38, UZ-N58, UZ-N59, UE-25 UZN\#63, and USW } \\
\text { UZ-N64; Data for Core Dried in } 105^{\circ} \mathrm{C} \text { Oven only for USW UZ-N11, UZ-N15, } \\
\text { UZ-16, UZ-N17, UZ-N27, UZ-N36, and UZ-N37. Submittal date: 04/28/2000. }\end{array}$ & $\begin{array}{l}\text { GSO00408312231.004 } \\
\text { [DIRS 149582] }\end{array}$ \\
\hline UE-25 UZ\#16 Pycnometer Data. Submittal date: 05/03/00. & $\begin{array}{l}\text { GS000508312231.005 } \\
\text { [DIRS 153236] }\end{array}$ \\
\hline $\begin{array}{l}\text { Physical Properties and Water Content from Borehole USW NRG-6, } 19 \text { Mar } 94 \text { to } \\
27 \text { Mar 95. Submittal date: } 05 / 23 / 00 \text {. }\end{array}$ & $\begin{array}{l}\text { GS000508312231.006 } \\
\text { [DIRS 153237] }\end{array}$ \\
\hline $\begin{array}{l}\text { Physical Properties of Core Samples from Borehole USW UZ-14, from 03/09/94 to } \\
07 / 11 / 94 \text {. Submittal date: } 07 / 11 / 2002 \text {. }\end{array}$ & $\begin{array}{l}\text { GS000508312231.007 } \\
\text { [DIRS 163708] }\end{array}$ \\
\hline $\begin{array}{l}\text { Relative Humidity, Temperature, Wind Speed, Wind Direction, Net Solar Radiation } \\
\text { and Precipitation Data from Five Weather Stations in the Yucca Mountain Area for } \\
1995 \text { Water Year. Submittal date: 04/24/2004. }\end{array}$ & $\begin{array}{l}\text { GS010408312111.001 } \\
\text { [DIRS 162978] }\end{array}$ \\
\hline $\begin{array}{l}\text { FY95 Laboratory Measurements of Physical Properties of Surficial Material at } \\
\text { Yucca Mountain, Part II. Submittal date: 01/11/2004. }\end{array}$ & $\begin{array}{l}\text { GS031208312211.001 } \\
\text { [DIRS 171543] }\end{array}$ \\
\hline $\begin{array}{l}\text { USW UZ-N54 and USW UZ-N55 Core Analysis: Bulk Density, Porosity, Particle } \\
\text { Density and In Situ Saturation for Core Dried in } 105^{\circ} \mathrm{C} \text { Oven. Submittal date: } \\
\text { 05/14/1992. }\end{array}$ & $\begin{array}{l}\text { GS920508312231.012 } \\
\text { [DIRS 109001] }\end{array}$ \\
\hline $\begin{array}{l}\text { USW UZ-N53 Core Analysis: Bulk Density, Porosity, Particle Density, and In-Situ } \\
\text { Saturation for Core Dried in } 105^{\circ} \mathrm{C} \text { Oven. Submittal date: } 10 / 05 / 1992 .\end{array}$ & $\begin{array}{l}\text { GS930108312231.006 } \\
\text { [DIRS 108997] }\end{array}$ \\
\hline $\begin{array}{l}\text { Core Analysis of Bulk Density, Porosity, Particle Density, and In-Situ Saturation for } \\
3 \text { Neutron Boreholes, USW UZ-N57, UZ-N61, and UZ-N62. Submittal date: } \\
\text { 04/01/1994. }\end{array}$ & $\begin{array}{l}\text { GS940408312231.004 } \\
\text { [DIRS 109000] }\end{array}$ \\
\hline $\begin{array}{l}\text { Core Analysis of Bulk Density, Porosity, Particle Density and In Situ Saturation for } \\
\text { Borehole UE-25 UZ\#16. Submittal date: 05/04/1994. }\end{array}$ & $\begin{array}{l}\text { GS940508312231.006 } \\
\text { [DIRS 107149] }\end{array}$ \\
\hline $\begin{array}{l}\text { Surface-Water Discharge Data for the Yucca Mountain Area, Southern Nevada } \\
\text { and Southern California, } 1994 \text { Water Year. Submittal date: 11/30/1994. }\end{array}$ & $\begin{array}{l}\text { GS941208312121.001 } \\
\text { [DIRS 107374] }\end{array}$ \\
\hline $\begin{array}{l}\text { Laboratory Measurements of Bulk Density, Porosity, and Water Content for USW } \\
\text { SD-12, from } 19 \text { Mar } 94 \text { to } 11 \text { Aug } 94 \text {, and for Radial Boreholes from } 11 \text { Apr } 94 \text { to } 6 \\
\text { Feb 95. Submittal date: 03/02/1995. }\end{array}$ & $\begin{array}{l}\text { GS950308312231.002 } \\
\text { [DIRS 108990] }\end{array}$ \\
\hline UE-25 UZ\#16 Pycnometer Data. Submittal date: 03/06/1995. & $\begin{array}{l}\text { GS950308312231.003 } \\
\text { [DIRS 149374] }\end{array}$ \\
\hline $\begin{array}{l}\text { Physical Properties and Water Potentials of Core from Borehole USW SD-9. } \\
\text { Submittal date: 03/01/1995. }\end{array}$ & $\begin{array}{l}\text { GS950408312231.004 } \\
\text { [DIRS 108986] }\end{array}$ \\
\hline $\begin{array}{l}\text { Moisture Retention Data from Boreholes USW UZ-N27 and UE-25 UZ\#16. } \\
\text { Submittal date: 06/06/1995. }\end{array}$ & $\begin{array}{l}\text { GS950608312231.008 } \\
\text { [DIRS 144662] }\end{array}$ \\
\hline
\end{tabular}


Table 4-1. Direct Input Data (Continued)

\begin{tabular}{|c|c|}
\hline Description & Data Tracking Number \\
\hline $\begin{array}{l}\text { FY94 and FY95 Laboratory Measurements of Physical Properties of Surficial } \\
\text { Materials at Yucca Mountain, Nevada. Submittal date: 07/18/1995. }\end{array}$ & $\begin{array}{l}\text { GS950708312211.002 } \\
\text { [DIRS 146874] }\end{array}$ \\
\hline Fracture/Fault Properties for Fast Pathways Model. Submittal date: 07/24/1995. & $\begin{array}{l}\text { GS950708312211.003 } \\
\text { [DIRS 146873] }\end{array}$ \\
\hline $\begin{array}{l}\text { Physical Properties, Water Content, and Water Potential for Borehole USW SD-7. } \\
\text { Submittal date: 09/26/1995. }\end{array}$ & $\begin{array}{l}\text { GS951108312231.009 } \\
\text { [DIRS 108984] }\end{array}$ \\
\hline $\begin{array}{l}\text { Physical Properties and Water Content for Borehole USW NRG-7/7A. Submittal } \\
\text { date: 09/26/1995. }\end{array}$ & $\begin{array}{l}\text { GS951108312231.010 } \\
\text { [DIRS 108983] }\end{array}$ \\
\hline $\begin{array}{l}\text { Physical Properties, Water Content, and Water Potential for Borehole USW UZ-7A. } \\
\text { Submittal date: 09/26/1995. }\end{array}$ & $\begin{array}{l}\text { GS951108312231.011 } \\
\text { [DIRS 108992] }\end{array}$ \\
\hline $\begin{array}{l}\text { Gravimetric and Volumetric Water Content and Rock Fragment Content of } 31 \\
\text { Selected Sites at Yucca Mountain, NV: FY95 Laboratory Measurements of } \\
\text { Physical Properties of Surficial Material at Yucca Mountain, Part III. Submittal } \\
\text { date: 01/08/1996. }\end{array}$ & $\begin{array}{l}\text { GS960108312211.002 } \\
\text { [DIRS 149478] }\end{array}$ \\
\hline $\begin{array}{l}\text { Estimated Distribution of Geomorphic Surfaces and Depth to Bedrock for the } \\
\text { Southern Half of the Topopah Spring NW } 7.5 \text { Minute Quadrangle and the Entire } \\
\text { Busted Butte } 7.5 \text { Minute Quadrangle. Submittal date: 04/21/1996. Submit to RPC }\end{array}$ & $\begin{array}{l}\text { GS960508312212.007 } \\
\text { [DIRS 124829] }\end{array}$ \\
\hline $\begin{array}{l}\text { Water Permeability and Relative Humidity Calculated Porosity for Boreholes UE-25 } \\
\text { UZ-16 and USW UZ-N27. Submittal date: 08/28/1996. }\end{array}$ & $\begin{array}{l}\text { GS960808312231.001 } \\
\text { [DIRS 108998] }\end{array}$ \\
\hline $\begin{array}{l}\text { Relative Humidity Calculated Porosity Measurements on Samples from Borehole } \\
\text { USW SD-9 Used for Saturated Hydraulic Conductivity. Submittal date: } \\
08 / 28 / 1996 \text {. }\end{array}$ & $\begin{array}{l}\text { GS960808312231.002 } \\
\text { [DIRS 108988] }\end{array}$ \\
\hline $\begin{array}{l}\text { Moisture Retention Data for Samples from Boreholes USW SD-7, USW SD-9, } \\
\text { USW SD-12 and UE-25 UZ\#16. Submittal date: 08/30/1996. }\end{array}$ & $\begin{array}{l}\text { GS960808312231.003 } \\
\text { [DIRS 147590] }\end{array}$ \\
\hline $\begin{array}{l}\text { Physical Properties, Water Content and Water Potential for Samples from Lower } \\
\text { Depths in Boreholes USW SD- } 7 \text { and USW SD-12. Submittal date: 08/30/1996. }\end{array}$ & $\begin{array}{l}\text { GS960808312231.004 } \\
\text { [DIRS 108985] }\end{array}$ \\
\hline $\begin{array}{l}\text { Water Permeability and Relative Humidity Calculated Porosity for Samples from } \\
\text { Boreholes USW SD-7, USW SD- } 9 \text {, USW SD-12 AND USW UZ-14. Submittal } \\
\text { date: 08/30/1996. }\end{array}$ & $\begin{array}{l}\text { GS960808312231.005 } \\
\text { [DIRS 108995] }\end{array}$ \\
\hline $\begin{array}{l}\text { Surface-Water Discharge Data for the Yucca Mountain Area, Southern Nevada } \\
\text { and Southern California, 1995 Water Year. Submittal date: 10/10/1996. }\end{array}$ & $\begin{array}{l}\text { GS960908312121.001 } \\
\text { [DIRS 107375] }\end{array}$ \\
\hline $\begin{array}{l}\text { Conceptual and Numerical Model of Infiltration at Yucca Mountain, Nevada. } \\
\text { Submittal date: 09/12/1996. }\end{array}$ & $\begin{array}{l}\text { GS960908312211.003 } \\
\text { [DIRS 103775] }\end{array}$ \\
\hline $\begin{array}{l}\text { FY96 Site Meteorology Data: Relative Humidity, Temperature, Wind Speed, Wind } \\
\text { Direction, Net Solar Radiation and Barometric Pressure from Two Weather } \\
\text { Stations in the Yucca Mountain Area, Oct. } 1 \text { - Dec. 3, 1995. Submittal date: } \\
\text { 01/15/1997. }\end{array}$ & $\begin{array}{l}\text { GS970108312111.001 } \\
\text { [DIRS 125899] }\end{array}$ \\
\hline $\begin{array}{l}\text { Revised Bedrock Geologic Map of the Central Block Area, Yucca Mountain, } \\
\text { Nevada. Submittal date: } 12 / 30 / 1997 \text {. }\end{array}$ & $\begin{array}{l}\text { GS971208314221.003 } \\
\text { [DIRS 107128] }\end{array}$ \\
\hline $\begin{array}{l}\text { Saturated Hydraulic Conductivity of Core from SD-9, } 2 / 27-3 / 27 / 95 \text {. Submittal } \\
\text { date: } 04 / 27 / 1999 \text {. }\end{array}$ & $\begin{array}{l}\text { GS990408312231.001 } \\
\text { [DIRS 148711] }\end{array}$ \\
\hline Coverage: Scotbons. Submittal date: $03 / 01 / 2000$. Submit to RPC & $\begin{array}{l}\text { MO0003COV00095.000 } \\
\text { [DIRS 146848] }\end{array}$ \\
\hline
\end{tabular}

$\mathrm{FY}=$ fiscal year; NCDC=National Climatic Data Center; $\mathrm{RH}=$ relative humidity; $\mathrm{RPC}=$ Record Processing Center; USGS= United Sates Geological Survey 


\subsection{CRITERIA}

The general requirements to be satisfied by the TSPA are stated in 10 CFR 63.114 [DIRS 156605]. Technical requirements to be satisfied by the TSPA are identified in Yucca Mountain Project Requirements Document (Canori and Leitner 2003 [DIRS 166275]). The acceptance criteria that will be used by the U.S. Nuclear Regulatory Commission to determine whether the technical requirements have been met are identified in Yucca Mountain Review Plan, Final Report (YMRP) (NRC 2003 [DIRS 163274]). The pertinent requirements and criteria for this report are summarized in Table 4-2.

Table 4-2. Project Requirements and Acceptance Criteria Applicable to This Model Report

\begin{tabular}{|c|c|c|c|}
\hline $\begin{array}{c}\text { Requirement } \\
\text { Number }\end{array}$ & \multicolumn{1}{|c|}{ Requirement Title ${ }^{\mathbf{a}}$} & \multicolumn{1}{|c|}{ 10 CFR 63 Link } & \multicolumn{1}{c|}{$\begin{array}{c}\text { YMRP Acceptance } \\
\text { Criteria }^{\mathbf{b}}\end{array}$} \\
\hline PRD -002/T-015 & Requirements for Performance Assessment & $\begin{array}{l}\text { 10 CFR 63.114 } \\
\text { (a)-(c) and (e)-(g) }\end{array}$ & 2.2.1.3.5.3, criteria 1 to 4 \\
\hline
\end{tabular}

${ }^{a}$ Canori and Leitner (2003 [DIRS 166275]).

${ }^{\mathrm{b}}$ Yucca Mountain Review Plan, Final Report (YMRP) (NRC 2003 [DIRS 163274]).

The acceptance criteria identified in Section 2.2.1.3.5.3 of the YMRP (NRC 2003 [DIRS 163274]) are included below. In cases where subsidiary criteria are listed in the YMRP for a given criterion, only the subsidiary criteria addressed by this model report are listed below. Where a subcriterion includes several components, only some of those components may be addressed. How these components are addressed is summarized in Section 8.4 of this report.

\section{Acceptance Criteria from Section 2.2.1.3.5.3, Climate and Infiltration.}

\section{Acceptance Criterion 1: System Description and Model Integration Are Adequate.}

(1) The total system performance assessment (BSC 2004 [DIRS 168504]) adequately incorporates, or bounds, important design features, physical phenomena, and couplings, and uses consistent and appropriate assumptions throughout the climate and net infiltration abstraction process.

(2) The aspects of geology, hydrology, geochemistry, physical phenomena, and couplings, that may affect climate and net infiltration, are adequately considered. Conditions and assumptions in the abstraction of climate and net infiltration are readily identified and consistent with the body of data presented in the description.

(3) The abstraction of climate and net infiltration uses assumptions, technical bases, data, and models that are appropriate and consistent with other related U.S. Department of Energy abstractions. For example, the assumptions used for climate and net infiltration are consistent with the abstractions of flow paths in the UZ and flow paths in the saturated zone (SZ) (Sections 2.2.1.3.6 and 2.2.1.3.8 of the Yucca Mountain Review Plan (NRC 2003 [DIRS 163274]), respectively). The descriptions and technical bases provide transparent and traceable support for the abstraction of climate and net infiltration. 
(5) Adequate spatial and temporal variability of model parameters and boundary conditions are employed to model the different parts of the system.

(6) Average parameter estimates are used in process-level models over time and space scales that are appropriate for the model discretization.

(8) Guidance in NUREG-1297 (Altman et al. 1988 [DIRS 103597]) and NUREG-1298 (Altman et al. 1988 [DIRS 103750]), or other acceptable approaches for peer reviews and data qualification, is followed.

\section{Acceptance Criterion 2: Data Are Sufficient for Model Justification.}

(1) Climatological and hydrological values used in the license application (e.g., time of onset of climate change, mean annual temperature, mean annual precipitation, mean annual net infiltration, etc.) are adequately justified. Adequate descriptions of how the data were used, interpreted, and appropriately synthesized into the parameters are provided.

(2) Estimates of present-day net infiltration using mathematical models at appropriate time and space scales are reasonably verified with site-specific climatic, surface, and subsurface information.

(3) The effects of fracture properties, fracture distributions, matrix properties, heterogeneities, time-varying boundary conditions, evapotranspiration, depth of soil cover, and surface-water run off and run on are considered, such that net infiltration is not underestimated.

(4) Sensitivity or uncertainty analyses are performed to assess data sufficiency and determine the possible need for additional data;

(5) Accepted and well-documented procedures are used to construct and calibrate numerical models;

(6) Reasonably complete process-level conceptual and mathematical models are used in this model report. In particular: (a) mathematical models provided are consistent with conceptual models and site characteristics; and (b) the robustness of results from different mathematical models is compared.

\section{Acceptance Criterion 3: Data Uncertainty is Characterized and Propagated Through the Model Abstraction.}

(1) Models use parameter values, assumed ranges, probability distributions, and bounding assumptions that are technically defensible, reasonably account for uncertainties and variabilities, and do not result in an under-representation of the risk estimate.

(2) The technical bases for the parameter values used in this abstraction are provided. 
(4) The hydrologic effects of future climate change that may alter the rates and patterns of present-day net infiltration into the UZ are addressed. Such effects may include changes in soil depths, fracture-fill material, and types of vegetation.

Acceptance Criterion 4: Model Uncertainty is Characterized and Propagated Through the Model Abstraction.

(1) Alternative modeling approaches of features, events, and processes, consistent with available data and current scientific understanding, are investigated. The results and limitations are appropriately considered in the abstraction;

(3) Consideration of conceptual model uncertainty is consistent with available site characterization data, laboratory experiments, field measurements, natural analogue information and process-level modeling studies; and the treatment of conceptual model uncertainty does not result in an under-representation of the risk estimate.

\subsection{CODES, STANDARDS, AND REGULATIONS}

No codes, standards, or regulations, other than those identified in Project Requirements Document (Canori and Leitner 2003 [DIRS 166275], Table 2-3), were used in this model report. 


\section{ASSUMPTIONS}

The assumptions pertaining to this model report are grouped according to the following types of investigations conducted: (1) development of the conceptual model of net infiltration, (2) development of the numerical model of net infiltration, (3) model calibration and comparison to independent methods, (4) model application and the representation of three climate stages (present-day, monsoon, and glacial-transition), including the upper bound, mean, and lower bound climate scenarios within each climate stage, and (5) development of estimated input parameter distributions and climate inputs in support of the net infiltration uncertainty analysis as documented in Analysis of Infiltration Uncertainty (BSC 2003 [DIRS 165991]). Significant or general assumptions pertaining to this model are noted below. These assumptions are used throughout this model report and do not require further confirmation.

The infiltration model documented in this model report is based on the assumption that the 1996 infiltration model, which was based on the distributed-parameter, water-balance approach and was calibrated using a variety of field data collected from 1984 through 1995, adequately represents the major features and processes controlling present-day and future infiltration at Yucca Mountain. The principal basis for the assumptions, discussed below, is that the resulting net-infiltration model quantitatively accounts for all major water inflow and outflow processes on a cell-by-cell basis and strictly imposes the conservation of total water mass within each model cell. The calculation results do not account for error propagation from the various components of the mass balance, such as measurement error associated with the various model inputs.

Within each cell of the model domain, water is assumed to move vertically downward within soil and bedrock, and that on a $30 \times 30$ meter grid block scale, no lateral diversion occurs within the root zone. The average land surface slope for the entire model area is $13^{\circ}$ with a range of $0^{\circ}$ to $46^{\circ}$ (DTN: GS000308311221.004 [refer to Appendix B, Table B-2 for the headers for these files]). Given a land surface slope of approximately $4^{\circ}$ to $6^{\circ}$, the sine of the gravity vector is 0.07 to 0.10 . The saturated hydraulic conductivity of the alluvium is $5.6 \times 10^{-6} \mathrm{~m} / \mathrm{s}$ to $3.8 \times 10^{-5} \mathrm{~m} / \mathrm{s}$ and the porosity is 28.1 to 37 percent (Appendix B, Table B-4). Using Darcy's law and assuming fully saturated flow in a lateral downslope direction, with a perched system at the bedrock/alluvium contact that parallels the soil surface, the distance that lateral flow would travel in 30 days is approximately 3 to 6 meters, thereby not moving beyond the $30 \times 30$ meter grid block area. If the slope were $45^{\circ}$, the distance would be an order of magnitude greater. In the case of vertical preferential flow, effective porosity is higher than actual porosity, thereby increasing vertical flow. However, in the case of lateral flow, effective porosity is assumed to be approximately equivalent to actual porosity, so lateral flow is not significantly increased by preferential flow. According to Hatton (1998 [DIRS 149476]), onedimensional, distributed-parameter, water-balance models are appropriate for use unless the excess rainfall generates overland flow (which is accommodated by flow routing in INFIL V 2.0), or with the development of saturated conditions in soil profiles on slopes. The above calculation, and the fact that slopes have very thin soil cover and the underlying fractured bedrock has a high-saturated hydraulic conductivity, suggests that subsurface lateral flow can be assumed to be insignificant. On the other hand, if water were to move from one grid block downslope to the next grid block at the soil/bedrock contact, in a three-dimensional model configuration, this volume would be additive and would continue downslope until the slope was 
reduced, resulting in a shorter lateral travel distance. The total slope would only be affected in the uppermost and lowermost grid blocks. This component of error is considered to be insignificant relative to the spatial resolution required for the site-scale UZ flow model.

The development of the climate inputs to the INFIL model is dependent on limited data. For example, only one year of temperature data (DTN: GS000208312111.002 [DIRS 147250]) was used to develop the relationship in Equation 6-2 for predicting daily air temperature. However, this equation is only used if actual temperature data are missing. The duration of the precipitation datasets vary, but some of these datasets consist of only a few months of data. The precipitation and temperature datasets used in this model report are assumed to be adequate to predict climate for the duration of each of the climate periods. The basis for this assumption is that multiple datasets from multiple locations are combined into one dataset.

Rooting depths are assumed to be equivalent to soil depth, with a maximum rooting depth (and soil depth) of six meters. However, relative root-zone weighting parameters are small for deep roots. Assuming that active roots can extend into bedrock along open or partially filled fractures, a maximum effective rooting depth of approximately two meters is assumed for fractured bedrock, with a much lower root density and water storage capacity relative to soils. For locations with thick soils, the occurrence of net infiltration requires percolation through a deeper average rooting depth that is assumed to be approximately six meters. The basis for this assumption is supported by water content monitoring data provided by neutron logging (Flint et al. 1996 [DIRS 100147]; Flint and Flint 1995 [DIRS 100394]).

Increases in vegetation density and changes in vegetation type were assumed for wetter and colder future climates. For the upper bound monsoon climate, the root-zone weighting parameters were adjusted to approximate a 40 percent vegetation cover (as compared to 20 percent for present-day climate) and the maximum thickness of the bedrock root zone layer was increased from two meters to 2.5 meters. For the upper bound glacial-transition climate, the root-zone weighting parameters were adjusted to approximate an assumed 60 percent vegetation cover and the maximum thickness of the bedrock root zone layer was increased to three meters. All adjustments to root-zone parameters were based on assumed root-zone and vegetation characteristics for the future climate conditions. Calibration of the root-zone parameters to the future climate vegetation characteristics requires developing the net infiltration model for analogue field site appropriate for each climate, and this was beyond the work scope of this model report.

Changes in morphology with time due to erosion processes are assumed to be negligible on the spatial scale used by INFIL. The erosion of the sediments and exposed bedrock over 10,000 years is expected to be on the order of centimeters (BSC 2004 [DIRS 169734], Section 3.4.6), which is within the range of existing surface elevation irregularities and would not significantly affect the processes in the hundreds of meters of UZ. Therefore, the effects of soil erosion on infiltration are considered negligible and are reasonably excluded from the TSPA calculations (BSC 2004 [DIRS 170012], Section 6.4.1).

Parameters related to sublimation of snow and evaporation of snowmelt are assumed due to a paucity of data regarding these parameters. The basis for this assumption comes from Maidment (1993 [DIRS 125317], p. 7.8), who reports sublimation rates for Canada of 41 percent for fallow 
fields, and 34 percent for stubble. A conservative value of 0.1 (10 percent) for the sublimation parameter (A1) was assumed to be representative of conditions at Yucca Mountain. The evaporation of snowmelt parameter (A2) was assumed to be three times greater than the A1 parameter since sublimation increases as temperature increases (Maidment 1993 [DIRS 125317], pp. 7.4 to 7.10), and because it includes the evaporation of snowmelt component as well as the sublimation component. For all simulations using the snow pack submodel, A1 was set to 0.1 and A2 was set to 0.3 in the model control file.

Vapor flow is assumed to be insignificant in comparison to other water balance components (precipitation, evapotranspiration, and runoff) on the spatial scales applied using INFIL in response to isolated but intense storms (Flint et al. 1996 [DIRS 100147]; Flint and Flint 1995 [DIRS 100394]; Hevesi et al. 1994 [DIRS 125315]).

Net infiltration is assumed to occur as fracture flow through the Tiva Canyon welded hydrogeologic unit (TCw) that is considered within the root zone. This assumption is based on relative changes in measured water content profiles that indicate that the penetration rates of the wetting front exceeded that calculated from the saturated hydraulic conductivity of the matrix alone. An assumption is also made that saturated fracture flow is maintained only for the duration that saturated conditions are maintained along the soil-bedrock interface. These two assumptions are based on interpretations of relative changes in the time series of water content profiles measured in boreholes by neutron logging (Flint and Flint 1995 [DIRS 100394]), and corresponding nearby measurements of water potential at the soil/bedrock contact indicating saturated or near saturated conditions (Figure 6-5(A)). The net infiltration rate for the time periods when net infiltration is occurring is assumed to be numerically equivalent to the bulk saturated hydraulic conductivity of the bedrock. This model does not use pressure gradients to induce flow and does not consider positive pressure heads.

An assumption is made in this model report that there is no downward flow during long time periods of no precipitation. This assumption is supported by neutron logging data, which indicate that there is zero to negligible downward flow occurring during long time-periods of no precipitation. In general, the neutron logging data indicate that the volume of net infiltration occurring at Yucca Mountain under conditions of unsaturated flow when the root zone is drier than field capacity either in upland areas with thin soils or in locations with thick soils is considered negligible compared to the volume of net infiltration occurring as saturated flow through bedrock fractures or through thick soils that have reached or exceeded field capacity (Flint et al. 1996 [DIRS 100147]; Flint and Flint 1995 [DIRS 100394]; Hevesi et al. 1994 [DIRS 100582]; Nichols 1987 [DIRS 101273]).

Effects of changes in liquid properties, such as viscosity and density, on the saturated field-scale hydraulic conductivity of soil and bedrock are assumed insignificant. This assumption is justified because temperature variations in the near-surface environment that could affect the viscosity or density of water are expected to be small and because dissolved constituents that could affect the density of water are expected to be present in insignificant concentrations. 


\section{INTENTIONALLY LEFT BLANK}




\section{MODEL DISCUSSION}

The conceptual and numerical models of net infiltration for Yucca Mountain (USGS 2003 [DIRS 166518]) and called the 1999 model, were originally developed and presented in Conceptual and Numerical Model of Infiltration for the Yucca Mountain Area, Nevada (Flint et al. 1996 [DIRS 100147]), called the 1996 model. The 1999 model was used to develop infiltration rate maps that were used in TSPA-LA. The models were based on thorough analysis of extensive field data collected during 1984 through 1995. The 1999 model development (USGS 2003 [DIRS 166518]) does not completely replace the 1996 model, but supplements and enhances the 1996 model, particularly with respect to evapotranspiration from the root zone and the infiltration of surface run-on in the channels of washes. In addition, the 1999 model used updated model inputs for bedrock geology and soil depth. Recently, an alternative conceptual model was developed using updated effective bedrock permeabilities and adjusting other input parameters (such as potential evapotranspiration) in an effort to validate the 1999 model. The 2004 model is otherwise identical to the 1999 model.

The net-infiltration modeling process required a combination of applications using GIS applications, field measurements (or acquisition of existing field data), parameter estimation, visualization and analysis, and the application of developed FORTRAN codes. The FORTRAN codes were used for preprocessing model input, the implementation of process modeling for simulating net infiltration, and for postprocessing of model results, which included the development of net-infiltration estimates for a given climate scenario by averaging separate model simulation results. The process modeling for net infiltration consists primarily of an hourly energy balance and a daily water balance simulation for a continuous multiyear period. The daily net-infiltration rates were averaged over the duration of the simulation for each model node $^{1}$ to obtain spatially distributed, time-averaged net-infiltration rates.

Section 6 is organized as follows. Subsections 6.1 and 6.2 discuss conceptual and numerical models of infiltration. Subsections 6.3 through 6.7 present modeling procedure and model inputs. Subsections 6.8 through 6.12 focus on model calibration, model prediction for different climates and model uncertainties.

\subsection{CONCEPTUAL MODEL OF INFILTRATION}

The following subsections provide a brief overview of the conceptual model of net infiltration for the purpose of describing the physical processes that are represented by the mostly deterministic, process-based, numerical model of net infiltration. A more thorough description of the conceptual model of net infiltration is provided in Conceptual and Numerical Model of Infiltration for the Yucca Mountain Area, Nevada (Flint et al. 1996 [DIRS 100147], pp. 8 to 26).

\footnotetext{
${ }^{1}$ Model nodes are also referred to as model cells or model grid cells, and represent locations in space for which corresponding model calculations are made. The nodes are points at the centers of horizontally equidimensional, square grid cells that can be used to define representative areas for each node.
} 


\subsubsection{Definition of Net Infiltration}

The conceptual model defines net infiltration as water that has percolated from the land surface to below the root zone. The root zone herein is defined as the zone from the ground surface to some variable depth in soil or bedrock from which infiltrated water is readily removed on an annual or seasonal basis by evapotranspiration. The depth of the root zone can be estimated from field studies but cannot be defined precisely. In addition, the depth of the root zone depends on variable climate and surface conditions controlling vegetation and other factors affecting evapotranspiration and is thus transient and spatially variable. Infiltration is the movement of water across the air/soil or air/bedrock interface, and percolation is defined as the downward movement of water within the UZ.

\subsubsection{Overview of the Conceptual Model of Infiltration}

The current conceptual model of infiltration at Yucca Mountain identifies effective precipitation, which is the ratio of precipitation to potential evapotranspiration (PET), as the most significant environmental factor controlling net infiltration at Yucca Mountain. The average annual precipitation value developed for the INFIL simulations for mean present-day climate and for the entire model area is $188.5 \mathrm{~mm} /$ year (DTN: GS000308311221.005). On an annual basis, effective precipitation is low because PET is much higher than precipitation. However, on a daily basis, effective precipitation can be high, particularly during periods with large and frequent winter storms. For example, the average penetration depth of infiltration ${ }^{2}$ into the soil/bedrock profile fluctuates on a seasonal basis for a given location, but tends to be greatest in the winter due to lower evapotranspiration demands, higher amounts of precipitation, and slow snow melt.

The second most significant environmental factor controlling net infiltration is soil depth. When there is sufficient precipitation to produce net infiltration, the spatial distribution is generally defined by the spatial variability of soil depth. Field measurements indicate that when the soil/bedrock contact reaches near-saturated conditions, fracture flow is initiated in the bedrock as evidenced by changes in water content profiles (Flint and Flint 1995 [DIRS 100394], pp. 22 to 46). Soils exceeding $6 \mathrm{~m}$ in thickness eliminate the infiltration of water to the soil/bedrock contact except in some channels (Flint and Flint 1995 [DIRS 100394], pp. 15 to 17, and Table 3). Storage capacity in the soil profile is large enough that most water from precipitation is held in the root zone and removed by evapotranspiration processes. Soils that are less than $6 \mathrm{~m}$ deep do not have enough storage capacity to store the volume of precipitation, and often allow near-ponding conditions to occur at the soil/bedrock contact, particularly when the soil depth is less than $0.5 \mathrm{~m}$.

The third most significant environmental factor controlling net infiltration is PET. The PET rate is determined by the energy balance and depends primarily on net radiation, air temperature, ground heat flux, the slope of the saturation-vapor density curve, and advective energy from wind. Net radiation depends primarily on solar radiation and surface characteristics, including

\footnotetext{
${ }^{2}$ The penetration depth of infiltration is identified by the maximum depth at which a wetting front is observed based on geophysical logs.
} 
topography and albedo. For the current climate at Yucca Mountain, the average annual PET rate is calculated to be approximately nine times greater than the average annual precipitation rate using precipitation data from Yucca Mountain (Hevesi et al. 1992 [DIRS 116809]) and PET rates for a site near Yucca Mountain within the Nevada Test Site (DOE 2001 [DIRS 171281]), and using a PET atlas for Nevada (Shevenell 1996 [DIRS 171280]). Therefore, on an annual basis, most of the precipitation is removed from the site by evapotranspiration. However, on a daily basis, the precipitation, snowmelt, or surface-water run-on rate can be much higher than the PET rate, especially during the winter when the PET rate is at a minimum.

The fourth most significant environmental factor controlling net infiltration is bedrock permeability. At Yucca Mountain welded tuffs of the Tiva Canyon welded (TCw) hydrogeologic unit, and nonfractured, nonwelded tuffs of the Paintbrush nonwelded hydrogeologic unit are the principal rock types present in surface exposures or directly under soils. The saturated hydraulic conductivity of the nonwelded Paintbrush nonwelded matrix is higher than the TCW matrix (Flint 1998 [DIRS 100033], Table 7). The lower storage capacity of the fractured, welded tuffs allows moisture that has infiltrated to penetrate more deeply than in the nonwelded tuffs. Hydraulic properties of fractures calculated for this study depend on fracture aperture and whether or not the fractures are open or filled with calcium carbonate or siliceous materials. Based on numerical simulations of water flow through a block of variably saturated fractured tuff, Kwicklis et al. (1998 [DIRS 102121], p. 60) suggest that the infiltration of water into a fractured welded tuff, such as the $\mathrm{TCw}$, will be controlled by the water potential at the soil-bedrock interface. Because the apertures and the air-entry water potentials (1/alpha parameter) of unfilled fractures (Kwicklis et al. 1998 [DIRS 102121], Table 6) are larger than the overlying soils (Appendix B, Table B-4), the initiation of fracture flow should occur only under saturated or near-saturated conditions. Fracture densities and matrix permeabilities are variable among the geologic units at Yucca Mountain.

Shallow infiltration processes at Yucca Mountain can be described on the basis of four infiltration zones that can be identified based on the manner in which volumetric water content changes with depth and time (Flint and Flint 1995 [DIRS 100394]). The zones, which correlate with topographic position, are described as follows: (1) Ridgetops are flat to gently sloping, of higher elevation than the other zones, and have thin soils composed of both eolian deposits and soils developed in place from the weathering process. These soils often have higher clay content and higher water-holding capacity compared to soils on side slopes and alluvial terraces. The ridge tops generally are located where the bedrock is moderately to densely welded and fractured. The presence of thin soil and fractured bedrock results in the deeper penetration of moisture following precipitation compared to other topographic positions. In some locations where runoff is channeled, large volumes of water can infiltrate. For the present-day arid climate, runoff generally is restricted to the upper headwater portions of drainages and to locations downstream of areas that have very thin soils underlain by relatively impermeable bedrock. (2) Side slopes are steep, commonly have thin to no soil cover, and are usually developed in welded, fractured tuff. The steepness of the slopes creates conditions conducive to rapid run off. The low storage capacity of the thin soil cover and the exposure of fractures at the surface may enable small volumes of water to infiltrate to greater depths, especially on slopes with north-facing exposures and therefore lower evapotranspiration demands. Shallow alluvium at the bases of the slopes can easily become saturated and initiate flow into the underlying fractures. (3) Alluvial terraces are flat, broad deposits of layered rock fragments and fine soil 
with a large storage capacity. Little runoff is generated on the terraces and the precipitation that falls there does not move below a depth of 1 to $2 \mathrm{~m}$ before it is removed by evapotranspiration. Consequently, this zone contributes the least to net infiltration in the drainage basin. (4) Active channels are similar to the terraces but are located in a position to collect and concentrate runoff that, although occurring infrequently, can penetrate deeply. Although local net infiltration can be high for some channel locations, under the current arid climate, this mechanism is not considered a major contributor to the total volume of net infiltration at Yucca Mountain because run off is infrequent and because the channels areas include only a very small percentage of the total drainage basin area.

\subsubsection{The Hydrologic Cycle}

In the conceptual model, the hydrologic cycle is used to identify, define, and separate the various field-scale components and processes controlling net infiltration (Figure 6-1). The hydrologic cycle is a basic conceptual tool used to visualize and define the various components of the field-scale water balance (Maidment 1993 [DIRS 125317], Figure 1.2.1, p. 1.4; Freeze and Cherry 1979 [DIRS 101173], Figure 1.1, p. 3). The hypothetical starting point of the hydrologic cycle is precipitation, which for current (present-day) climate at Yucca Mountain occurs primarily as rain but can also occur as snow. Precipitation can accumulate on the ground surface $^{3}$, infiltrate the soil or exposed bedrock ${ }^{4}$ surfaces, contribute to run off, or accumulate as snow. The contribution of precipitation to runoff generation depends on precipitation intensity relative to soil and exposed bedrock hydraulic conductivity, and also on the available storage capacity of soil and shallow bedrock with thin or no soil cover. Water accumulated in the snow pack can sublimate into the atmosphere or become snowmelt, which can then infiltrate, evaporate, or contribute to run off. Rain or snowmelt that becomes runoff accumulates in surface depressions and basins or contributes to surface water flow, which is routed to downstream locations as run-on. ${ }^{5}$ Run-on contributes to either infiltration or accumulated surface-water run-on at downstream locations.

Infiltrated water percolates through the root zone as either saturated or unsaturated ground water and is subject to evapotranspiration. Water percolating through the root zone is available as potential net infiltration, but the actual net-infiltration rate is limited by the bulk (or field-scale) saturated hydraulic conductivity of the bedrock or soil underlying the root zone. In the conceptual model, the bulk saturated hydraulic conductivity represents a weighted averaging of the field-scale matrix and fracture saturated hydraulic conductivity (Appendix B, Part 2). Estimates of saturated hydraulic conductivity were calculated using the measured values of fracture conductivity and the percentage of area covered by the fracture per square meter of rock, given the fracture density and aperture size available for water to flow through. When infiltration from rain, snowmelt, or surface-water run on occurs at a rate greater than the bulk saturated hydraulic conductivity of a subsurface layer, water will begin to fill the available

\footnotetext{
${ }^{3}$ Some precipitation can also be intercepted and temporarily stored at vegetation surfaces, but this component of the hydrologic cycle is negligible at the study site.

${ }^{4}$ Bedrock is used as a general term referring to all consolidated rock material that is either exposed (outcropping) or overlain by unconsolidated soil material.

${ }^{5}$ Runoff is specifically defined as the volume or depth of water accumulation on the ground surface prior to being routed as surface-water flow, whereas run-on is defined as the volume or depth of the routed surface-water flow.
} 
storage capacity of the overlying soil. When the total storage capacity is exceeded, run off is generated. While run off can occur while the subsurface is still unsaturated due to precipitation exceeding the saturated hydraulic conductivity of the soil, this is on a relatively small scale (less than 30 by $30 \mathrm{~m}$ ), and irrelevant to modeling of 30 by $30 \mathrm{~m}$ grid blocks.

In the Yucca Mountain area, the hydrologic cycle can be limited to atmospheric, surface, and shallow subsurface processes because contributions from ground water discharge and the deep $\mathrm{UZ}$ are insignificant relative to the other components of the cycle (there is no perennial stream flow at the site).

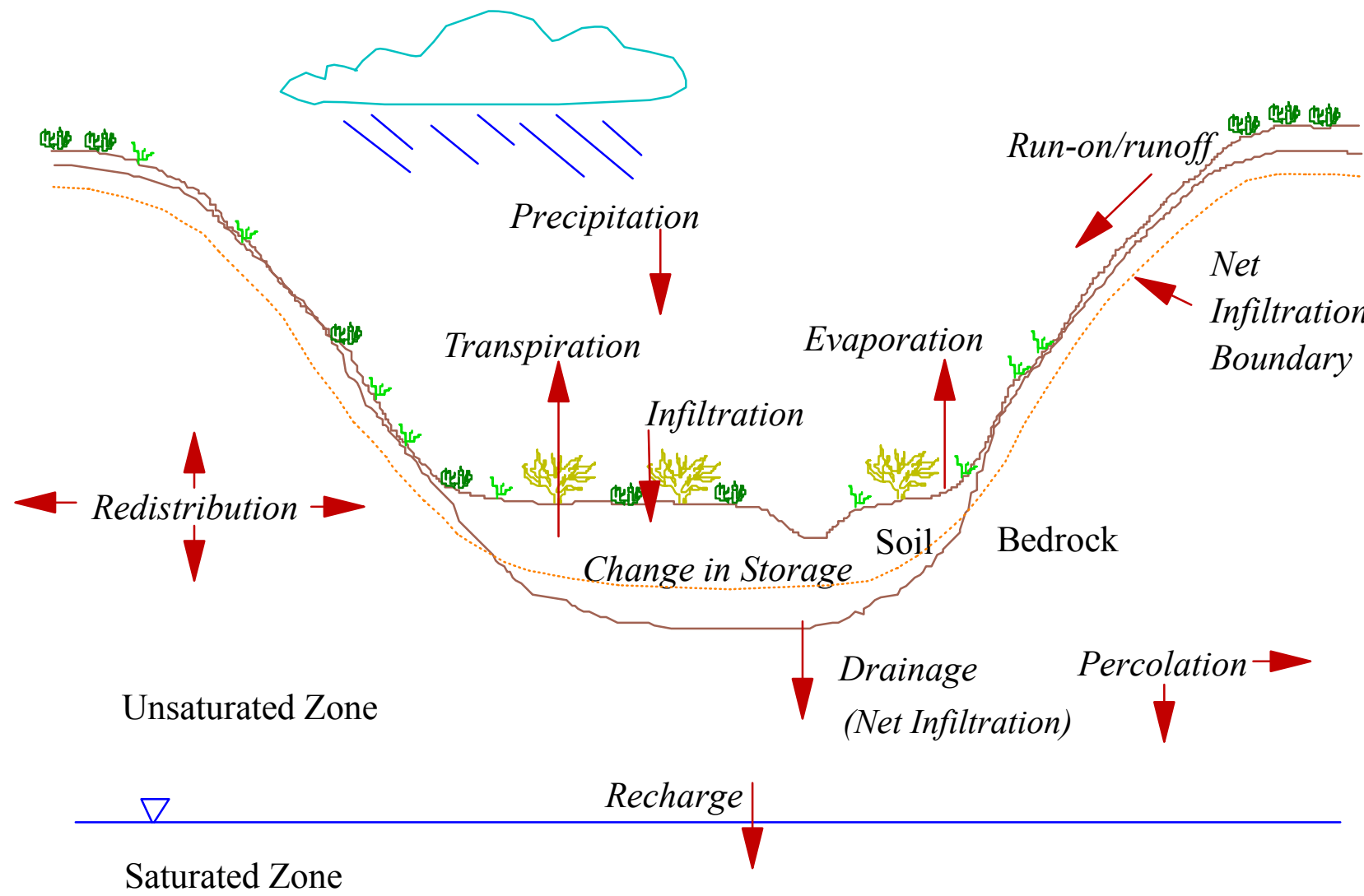

Source: Flint et al. 1996 [DIRS 100147], Figure 3

Figure 6-1. Field-Scale Water Balance and Processes Controlling Net Infiltration

\subsubsection{Evapotranspiration}

Evapotranspiration is the combined process of bare-soil evaporation and transpiration (excluding evaporation from open water bodies) (Freeze and Cherry 1979 [DIRS 101173], p. 4). Transpiration is the uptake and transfer of water to the atmosphere by vegetation. Transpiration is much more efficient than bare-soil evaporation in removing water from subsurface soils and fractured bedrock. Evapotranspiration is a function of the PET rate, the availability of water at the ground surface and within the root zone, vegetation characteristics such as timing of plant growth and root density, and the chemical and hydrologic properties of the root zone. The processes are not independent, but in general, the primary factors controlling evapotranspiration 
are PET, water availability, vegetation density, and seasonal vegetation growth. The more saturated the soil (or fractured bedrock) and the denser the vegetation, the closer the transpiration rate is to the PET rate. If the soil (or fractured bedrock) becomes drier than what is conceptually referred to as the wilting point, transpiration will not occur even though there may be some residual water in the root zone. The redistribution of water within the root zone affects the total evapotranspiration rate because bare-soil evaporation extends to depths of approximately 10 to $30 \mathrm{~cm}$ (Hanks et al. 1967 [DIRS 171454]), and the density and growth of roots within the root zone in general is typically observed to decrease with depth. The more quickly water redistributes to lower depths the greater the potential for net infiltration to occur because the overall susceptibility of water in the root zone to removal by evapotranspiration decreases with depth.

The PET rate is determined by the energy balance and depends primarily on net radiation, air temperature, ground heat flux, the slope of the saturation-vapor density curve, and advective energy from wind (McNaughton and Spriggs 1989 [DIRS 117096]; Priestley and Taylor 1972 [DIRS 125321]; Flint and Childs 1991 [DIRS 124946]). Net radiation depends primarily on solar radiation and surface characteristics including topography and albedo. For the current climate at Yucca Mountain, the average annual PET rate for a site near Yucca Mountain within the Nevada Test Site (DOE 2001 [DIRS 171281]) and using a PET atlas for Nevada, (Shevenell 1996 [DIRS 171280]) is calculated to be approximately nine times greater than the average annual precipitation rate of $170 \mathrm{~mm} /$ year (Hevesi et al. 1992 [DIRS 116809]). Thus, on an annual basis, most of the precipitation is removed from the site by evapotranspiration. However, on a daily basis, the precipitation, snowmelt, or surface-water run-on rate can be much higher than the PET rate, especially during the winter when the PET rate is at a minimum. The precipitation and PET data measured over time periods of between one and 10 years is assumed to be representative of climate conditions for the next 400 to 600 years, described as the remainder of the present-day climate in Future Climate Analysis (BSC 2004 [DIRS 170002]).

\subsubsection{Net Infiltration}

Net infiltration at Yucca Mountain is dominantly an episodic process that tends to occur only under wetter than average conditions or in response to isolated but intense storms (Flint et al. 1996 [DIRS 100147]; Flint and Flint 1995 [DIRS 100394]; Hevesi et al. 1994 [DIRS 125315]). For upland areas having thin soils and rooting depths, the occurrence of net infiltration requires saturated or near-saturated conditions at the soil/bedrock interface and within shallow bedrock fractures to initiate flow through open or filled fractures (Section 6.1.2).

For larger storm or snowmelt events, water can accumulate in the root zone more rapidly than it can be removed by evapotranspiration. This is especially true during winter when PET is at a minimum due to shorter days, lower sun angle, lower air temperatures, and root activity is either diminished or dormant. The downward percolation rate through the root zone under these conditions depends primarily on the storage capacity of the root zone and the field capacity and hydraulic conductivity of the soil and bedrock. The total storage capacity of the soil is defined as the porosity minus the residual water content multiplied by the soil depth. Field capacity is defined as the water content of the near surface soil profile (i.e., the root zone) at which drainage becomes negligible (several orders of magnitude less than the saturated flux rate) (Jury et al. 1991 [DIRS 102010], p. 150). Field capacity is an old soil physics concept intended 
to provide a characteristic index of how much water may be retained from a rainfall event after redistribution has ceased. In actual field conditions, water drains continually under gravity. However, in coarse-textured soils such as those found at Yucca Mountain, the drainage rate falls to an insignificant level within a few days, after which the water content is changing at such a slow rate that a field capacity concept has no practical value (Jury et al. 1991 [DIRS 102010], p. 150). In coarse, skeletal soils found in southwestern Oregon, the water content at a water potential of -0.07 bars corresponds to the soil field capacity (Flint and Childs 1984 [DIRS 147279]). Flint and Childs (1984 [DIRS 147279]) argued that the water content at close to -0.1 bars was more appropriate for field capacity than the assumption of -0.33 bars that was commonly used, based on soil textures common to agricultural fields. For thick soils, reaching or exceeding field capacity at a depth of $6 \mathrm{~m}$ tends to occur only for locations subject to concentrated surface-water flow, such as active stream channels and the base of steep side slopes. For upland areas with thin soils, the percolation rate through the root zone depends on the field-scale storage capacity, and once exceeded, the hydraulic conductivity of bedrock. The effective field capacity of the root zone in upland areas is determined by bedrock lithology, fracture characteristics (density, aperture, filling), and the characteristics of the soil/bedrock interface, in addition to the characteristics of the overlying soil. The volumetric water content of soils (at field capacity) that corresponds to the water potential of -0.1 bars, and is used for modeling infiltration at Yucca Mountain is given in Appendix B, Geospatial Input for INFIL V2.0 (Table B-4).

In general, the volume of net infiltration occurring at Yucca Mountain under conditions of unsaturated flow when the root zone is drier than field capacity either in upland areas with thin soils or in locations with thick soils is considered negligible compared to the volume of net infiltration occurring as saturated flow through bedrock fractures or through thick soils that have reached or exceeded field capacity (Flint et al. 1996 [DIRS 100147]; Flint and Flint 1995 [DIRS 100394]; Hevesi et al. 1994 [DIRS 100582]; Nichols 1987 [DIRS 101273]).

\subsection{NUMERICAL REPRESENTATION OF THE CONCEPTUAL MODEL}

The numerical representation of the conceptual model depends on the modeling decision that simplification of physical processes characterized by the conceptual model can be achieved while maintaining a sufficient level of accuracy in the mathematical approximation of these physical processes. Simplifications of this nature are virtually universal in any modeling of real physical processes. Note that this decision is supported, in part, by model calibration (and recalibration) and model validations. Nevertheless, such simplification to achieve a tractable numerical representation will be only an approximation to reality (by definition) and cannot predict all behaviors of the real system. In view of this fact, the effort has been made to produce a numerical model that produces conservative, if not accurate, results.

On the basis of numerous Yucca Mountain Project (YMP) peer reviews (e.g., CRWMS M\&O 1997 [DIRS 100335], Section 3.4.1) and several publications (e.g., Hatton 1998 [DIRS 149476], pp. 5 to 7, 16), INFIL, which uses a distributed parameter, quasi-three-dimensional water-balance approach, and associated assumptions, is considered appropriate for the complexity of this model and is relevant in this large-scale application of providing the upper boundary condition to the UZ flow model. Note that this approach does not necessarily represent the physics of infiltration in soils, but uses a water-volume calculation 
approach in the mathematical and numerical models. This model has been compared successfully to several independent approaches to estimating net infiltration and recharge, and more rigorous methods based, for example, on detailed numerical solution of the differential equations of groundwater and surface-water flow, which would be computationally intensive for use in this large-scale application. Also note that UZ flow model expert elicitation (CRWMS M\&O 1997 [DIRS 100335], Section 3.4.1) called for consideration of uncertaities in infiltration estimates. As discribed in Section 6.10, the detailed uncertainty analysis was presented in Analysis of Infiltration Uncertainty (BSC 2003 [DIRS 165991]) and a future discussion of effects of bedrock permeability are provided in Section 7 of this report.

\subsubsection{Accuracy and Precision of Model Calculations}

The simulation of net infiltration primarily involved a water-balance calculation and the application of the conservation of mass principle. All water-balance calculations were performed as water-depth balances (which are easily converted to volume balances ${ }^{6}$ ), and thus an assumption has been made that calculation errors due to temperature effects on water density are negligible relative to the level of precision needed for net-infiltration estimates.

Model calculations were performed using double precision variables and standard FORTRAN77 programming language. The model code performs several internal mass balance checking calculations that are used to test the precision of the overall water-balance simulation (program testing and software validation are described thoroughly in the software qualification documentation). For estimated average annual net-infiltration rates, model results are provided for each model grid cell to the nearest 0.00001-millimeter (mm) water depth for all components of the water balance to allow for additional mass-balance checking using postprocessing procedures. This level of precision does not indicate the level of accuracy in model results. Based on the average number of significant figures in model input, the number of significant figures that can be applied to model results should not exceed two. This level of output accuracy is subjectively based on the average level of precision in model inputs.

\subsubsection{Accuracy of Input Parameters}

Uncertainty in the accuracy of model inputs was not incorporated into the results developed in this model report. The uncertainty of the input parameters is bounded by ranges of some selected input parameters, and implemented in an infiltration uncertainty analysis (BSC 2003 [DIRS 165991]). The uncertainty analysis was used to calculate relative weighting factors of mean, lower, and upper bounds of net infiltration, for a given climate state that were used with UZ flow fields in TSPA (BSC 2004 [DIRS 168504]).

\footnotetext{
${ }^{6}$ Model calculations are performed as water-depth balances, and are converted to volume balances based on model grid cell area, which is $900 \mathrm{~m}^{2}$ for all model grid cells.
} 


\subsection{GENERAL DESCRIPTION OF MODELING PROCEDURE}

\subsubsection{Overview of Distributed-Parameter Water-Balance Model}

The distributed-parameter, water-balance model developed as the FORTRAN program INFIL V2.0 (USGS 2000 [DIRS 139422]) follows the conceptual model of infiltration discussed in Section 6.1, and is represented using a storage volume approach for modeling the root-zone. The total root-zone water storage capacity was calculated using the 30 by $30 \mathrm{~m}$ area of each grid cell multiplied by the depth of the root-zone (including soil and bedrock layers). The root-zone water balance calculation used to model net infiltration is illustrated by Figure 6-2. Infiltration into the root-zone and net infiltration below the root-zone was calculated independently for all grid cells and corresponding root-zone storage volumes. Because all grid cells have equal areas, the root-zone water storage terms were calculated as one-dimensional vertical storage depths, which can easily be converted to volumes based on grid cell areas. The components of the root-zone water balance were determined for each layer using the water content of each layer. For water contents less than or equal to the water content at field capacity, infiltration was set to zero and water loss due to evapotranspiration from that layer was modeled as an empirical function of relative saturation (with relative saturation based on porosity and the residual water content) and PET (Flint and Childs 1991 [DIRS 124946]). For water contents greater than the water content at field capacity, water losses due to both infiltration and evapotranspiration from the layer were calculated. Infiltration into the underlying layer was set equal to the bulk saturated hydraulic conductivity of that layer (in millimeters per day). If the available water for net infiltration (calculated based on the amount of water remaining after evapotranspiration losses have been calculated) is less than the maximum infiltration amount determined using saturated hydraulic conductivity, water loss to infiltration was set equal to the amount of available water in the layer. For the lowermost root-zone layer in thick (6 m or greater) soils, the daily water loss to infiltration is used to determine net infiltration. For upland areas with shallow soils where the root-zone is modeled as having a lowermost layer in bedrock, the amount of water available to evapotranspiration losses was calculated using the fracture porosity and the thickness of the bedrock layer. Once the water content of the bedrock layer has reached the limit defined by the fracture porosity, if water continues to infiltrate or percolate into the bedrock layer, net infiltration was calculated based on either the saturated hydraulic conductivity of the bedrock layer or the amount of available water (whichever determines the lower net infiltration amount).

On a daily basis, precipitation, snowmelt, and surface water run-on were added (as water depth) to the top layer of the root-zone profile at each grid cell. The surface water run-on depth was calculated as runoff generated and routed from upstream grid cells. If the amount of precipitation, snowmelt, and run-on added to the top layer exceeds the maximum daily amount calculated using the saturated hydraulic conductivity of the soil, then runoff (set equal to the amount of excess water) occurred at that grid cell location and was routed to the downstream grid cell. Surface-water flow depths were routed as part of an instantaneous flow routing algorithm representing a daily water balance. All overland flow was routed as a time-independent flow depth for each grid cell within a 24-hour time step (the physics of overland flow are not considered in this type of model). Daily surface water flow volumes were calculated using grid cell areas and converted to standard stream discharge units (cubic feet per second and total water volumes (acre-feet) for comparison with measured stream flow records. 
No differential (or approximate difference) equations modeling surface water flow were used to develop the stream-flow routing used here. Furthermore, no kinematic and inertia effects, or flood waves and backwater effects were modeled. As indicated in Section 6.4.7, this treatment is based on a consideration that no need exists to predict a flood wave, peak flows, or backwater effects. Additional factors not being considered are density changes due to temperature changes throughout the water profile, gravitational acceleration, resistance terms, viscosity changes due to sediment load, phase changes, changes in fluid hydraulics due to shifts from turbulent to laminar flow, flow dispersion and dynamic shifts in channel geometry due to concurrent stream bed erosion and deposition. The only physical process being represented by this model is the lateral redistribution and subsequent infiltration of the run off water volume and that this can be adequately modeled based on elevation alone is an assumption. In addition, the details of positive heads in active channels are insignificant relative to the uncertainty of available input parameters required to accurately define stream channel geometry for the entire stream channel network represented by this model.

For locations where the lowermost root-zone layer is in bedrock, net infiltration is numerically equal to the bulk saturated hydraulic conductivity of the underlying bedrock (in millimeter per day) for the period of time where the water content of the lowermost root-zone layer exceeds the field capacity of that layer. Net infiltration was simulated as the bulk saturated hydraulic conductivity of the underlying bedrock when the water content of the bedrock root-zone layer equals the fracture porosity of that layer. This condition was maintained only as long as the field capacity of the bottom soil layer (the soil layer above the bedrock layer) was exceeded. Thus, for upland areas with shallow soils, net infiltration was simulated as an episodic process requiring saturated conditions at the soil/bedrock interface and throughout the effective flow path of the bedrock layer included in the root-zone.

For locations with thick (greater than $6 \mathrm{~m}$ ) soil, net infiltration does not require saturated conditions at the bottom of the root zone, but does require that the water content of the bottom soil layer exceeds the field capacity of the layer. For upland areas, water is assumed to pond at the soil/bedrock interface and after saturating the effective flow path through the bedrock root-zone layer percolates below the root-zone as net infiltration on a daily basis under a unit gradient. In all cases, water losses due to evapotranspiration were simulated for all root zone layers having a water content greater than residual prior to the calculation of net infiltration. During winter when PET is at a minimum, ponded or saturated conditions at the soil/bedrock interface and throughout the effective flow path of the bedrock root-zone layer may exist for several days. Thus, the total net infiltration was calculated as approximately the saturated hydraulic conductivity multiplied by the number of days net infiltration occurred. For days when the amount of water available for net infiltration is less than the limit set by the saturated hydraulic conductivity of the bedrock (this condition applies only to the last day of an extended net infiltration event), net infiltration equals the amount of water available to net infiltration in the lowermost root-zone layer.

The daily water balance model was applied over a continuous multiyear period and was driven by the continuous daily climate input provided for the total simulation period. The daily net infiltration rates calculated for each grid cell location were used to calculate an average annual net infiltration rate for each grid cell based on the total simulation period. The average annual 
net infiltration rate was calculated in units of length per time ( $\mathrm{mm}$ per year), and can be directly applied as a specified flux upper boundary condition for the UZ flow model.

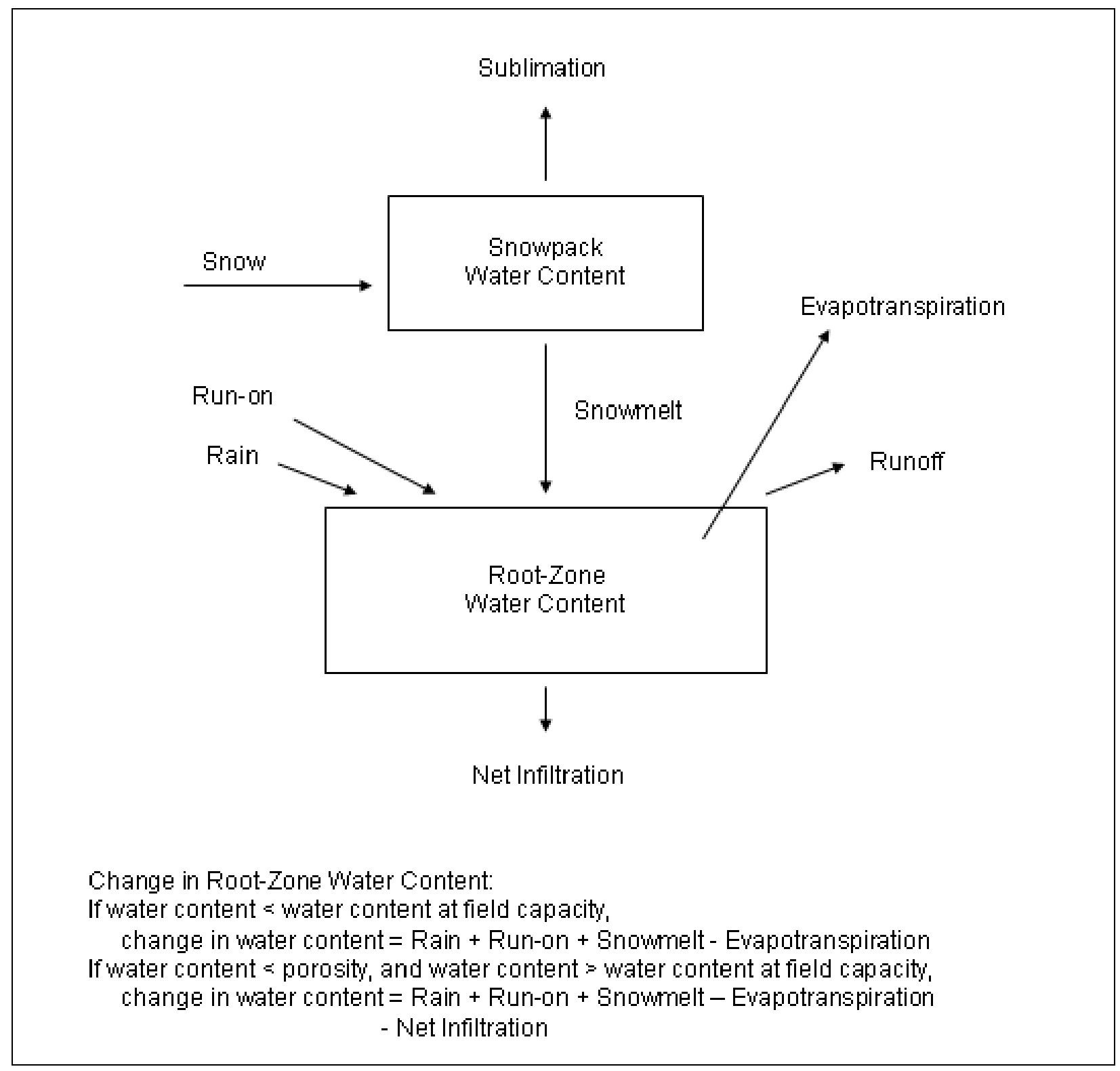

Figure 6-2. The Daily Root-Zone Water-Balance Used to Model Net Infiltration 


\subsubsection{Overview of Modeling Procedure}

The net infiltration modeling procedure begins with building a geospatial input parameter base grid using the selected digital elevation model (DEM) to define the base-grid geometry. The development of the geospatial input parameter base grid and the separate watershed modeling domains requires the application of GIS to transfer available digitized map data, which is in a vector-based format, onto the grid-cell of the raster-based format of the DEM (a process referred to as rasterization). The vector-based map coverages used as input by the net infiltration model include bedrock geology and soil type maps. In addition to the rasterization procedure, GIS applications were also used for calculating slope and aspect as well as latitude and longitude coordinates for all grid cells. Geospatial parameters that are not available as either raster-based or vector-based map coverages were developed using a series of FORTRAN routines that were applied sequentially. The routines were used to overlay three separate bedrock geology maps (after rasterization), estimate soil thickness, calculate the blocking ridge parameters, calculate surface water flow routing parameters, and extract the watershed model domains.

The elevation provided by the composite DEM is the primary geospatial parameter used by the net infiltration model. Elevation was used to define the surface-water flow-routing network, which was in turn used to define watershed-modeling domains, which were extracted from the base grid and modeled separately as closed hydrologic systems. Elevation was used to define slope, aspect, and blocking ridge parameters for modeling incoming solar radiation that was in turn used in an energy balance calculation for modeling PET. The calculated slope was also used to model soil thickness. Additional uses of elevation values in the net infiltration model include estimation of spatially distributed daily climate input (precipitation and air temperature).

In addition to the geospatial input parameters, the daily climate input and the model parameter inputs were defined prior to application of the net infiltration model. Daily climate input includes precipitation and air temperature. Model parameters include soil properties, bedrock properties, and root-zone parameters. An initial condition consisting of the root-zone water content was also defined prior to model application.

The following steps summarize the net-infiltration modeling procedure:

1. Acquisition and/or development of GIS map coverages and the application of ARCINFO V6.1.2. for the rasterization of geospatial parameters onto the base grid defined by the DEM for Yucca Mountain. Conversion of grid cell coordinates to both Universal Transverse Mercator (UTM) zone 11 and geographic (latitude and longitude) using ARCINFO V6.1.2.

2. Calculation of topographic parameters, including grid cell slope and aspect using ARCINFO V6.1.2, and 36 blocking-ridge angles for each grid cell using the routine BLOCKR7 V1.0 (the blocking-ridge angles used in the geospatial-parameter input file for INFIL V2.0 are the same as those used in the input file for the 1996 INFIL V1.0 model).

3. Estimation of soil depth and refinement of bedrock geology (rock-type identification) using the programs GEOMAP7 V1.0, GEOMOD4 V1.0, and SOILMAP6 V1.0. 
4. Adjustment of some bedrock permeability values using the program VEGCOV01 V1.0. The routine changes the saturated hydraulic conductivity of $13.83 \mathrm{~mm} /$ day of the Yucca Mountain Tuff of the Paintbrush Group (rock type 324). The different saturated hydraulic conductivity is assigned if the exposed Yucca Mountain Tuff is north of $4082606.93 \mathrm{~m}$ (rock type 309 is assigned with a saturated hydraulic conductivity of $0.06 \mathrm{~mm} /$ day) or south of $4079955.91 \mathrm{~m}$ north (rock type 308 is assigned with a saturated hydraulic conductivity of $46.66 \mathrm{~mm} /$ day) on Yucca Mountain. Table B-3 lists saturated hydraulic conductivities for all geologic units used with INFIL.

5. Calculation of surface-water flow routing parameters for each model grid cell using the DEM and the programs SORTGRD1 V1.0 and CHNNET16 V1.0.

6. Identification of watershed outflow locations using TRANSFORM ${ }^{7}$ V3.3 for raster data visualization and output from CHNNET16 V1.0. Extraction of watershed modeling domains, including calibration modeling domains, using the DEM, the identified outflow locations, the calculated surface-water flow-routing parameters, and the program WATSHD20 V1.0.

7. Development of a daily climate input file (mod3-ppt.dat) for model calibration and present-day climate simulations using available precipitation records from monitoring sites within the study area and in the proximity of Yucca Mountain. Development of mod3-ppt.dat is performed within an EXCEL spreadsheet (mod3-ppt.xls) using a linear interpolation method.

8. Estimation of precalibration model coefficients and initial conditions for root-zone water contents.

9. Calibration of root-zone model coefficients included as input in model control file for modeling program INFIL V2.0 by comparing simulation results for calibration watersheds against stream flow records.

10. Development of 100-year daily climate input files for present-day climate scenarios using available precipitation records from the Nevada Test Site stations 4JA and Area 12 Mesa and the programs MARKOV V1.0 (USGS 1996 [DIRS 147316]) and PPTSIM V1.0. (USGS 1996 [DIRS 147317]). Development of daily climate input for future climate scenarios using the routine DAILY09 V1.0 and seven selected analogue records from the EARTHINFO ${ }^{8}$ database.

${ }^{7}$ TRANSFORM is a registered trademark of Fortner Software LLC, 100 Carpenter Dr, Sterling, VA 20164.

${ }^{8}$ EARTHINFO is a registered trademark of EarthInfo Inc., 5541 Central Avenue, Boulder, CO 80301. 
11. Application of INFIL V2.0 using developed daily climate input (mod3-ppt.dat, 4ja.s01, area12.s01, nogales.inp, hobbs.inp, rosalia.inp, spokane.inp, stjohn.inp, beowawe.inp, and delta.inp), calibrated or estimated root-zone model coefficients, and watershed modeling domains for net-infiltration simulations.

12. Development of net-infiltration estimates for nine separate climate scenarios (lower, mean, and upper bound for present-day, monsoon, and glacial-transition climates) by averaging or sampling from individual net-infiltration simulations using the routine MAPADD20 V1.0. Development of descriptive statistics for results over the areas of the repository boundary and the UZ flow-modeling domain using SURFER ${ }^{9}$ V6.04 and the routine MAPSUM01 V1.0. Development of model results as GIS coverage using ARCVIEW $^{10}$ V3.1, TRANSFORM V3.3, and SURFER V6.04.

\subsubsection{Overview of Model Input}

User-defined model inputs for INFIL V2.0 consist of four general groups: (1) geospatial parameters, (2) hydrologic properties, (3) empirical model coefficients, and (4) daily climate input. Additional model coefficients are defined within the model source code. A detailed description of model inputs is provided in Sections 6.3 through 6.7. A detailed description of model input files, including descriptions of file formats, model options, and input and output options, is provided in the users manuals for INFIL V2.0, prepared under the software qualification procedure LP-SI.11Q-BSC, Software Management.

The data acquired or developed and used as input for modeling net infiltration consist of either ASCII digital data or proprietary formats for acquired, exempt software applications (ARCINFO map coverages, EARTHINFO data formats). All model input required directly for simulating net infiltration using the developed model code INFIL V2.0 is provided by three ASCII files:

- Model control file: specifies input and output options, input and output file names, modeling options, simulation period, model coefficients, and hydrologic properties.

- Daily climate input file: defines the temporal domain for the model simulation and consists primarily of day number and daily precipitation amount in millimeters. The file can also include daily maximum, minimum, and mean air temperature in degrees Celsius, and snowfall accumulation in water equivalent millimeter data (measured snowfall data are not used by INFIL V2.0, see Section 6.4.3).

- Geospatial parameter input file: consists of location coordinates and spatially variable grid cell parameters for all grid cells defining the model domain. Grid cell variables include elevation, slope, aspect, surface-water flow-routing parameters, soil type, soil depth, bedrock type, and 36 blocking ridge parameters.

${ }^{9}$ SURFER is a registered trademark of Golden Software, Inc, $80914^{\text {th }}$ Street, Golden, CO 80401-1866

${ }^{10}$ ARCVIEW is a registered trademark of ESRI, 210 Business Center Court, Redlands, CA 92373 
The 1999 infiltration model output (DTN: GS000308311221.005) was then applied over the domain of the site-scale UZ flow model (BSC 2004 [DIRS 169861]).

\subsubsection{Assumptions Concerning Model Calibration}

Direct data input used for model calibration are listed in Table 4-1 and in the appendices and are described in detail by Flint et al. (1996 [DIRS 100147]) as well as various sections throughout this report. They include soil hydrologic properties, bedrock hydrologic properties, vertical water-content profiles in soils and bedrock, and meteorological data. The 1996 infiltration model that was calibrated using these data is assumed to be an adequate starting point for the enhancements included in the 1999 model and that the 1999 model calibration may build on the calibration performed in 1996. The calibrations of the 1996 and 1999 models are described in Section 6.8. The 1999 model calibration used stream flow measurements from U.S. Geological Survey (USGS) gauging stations for 1994 and 1995 (DTNs: GS941208312121.001 [DIRS 107374], GS960908312121.001 [DIRS 107375]).

The 1996 infiltration model was calibrated using water-content profiles at Yucca Mountain obtained by geophysical logging a network of up to 98 boreholes with neutron-moisture probes at monthly or weekly intervals during 1984 through 1995. Analysis of depth versus time water-content changes from this network provided critical information for the development of the conceptual model, particularly with respect to relative magnitudes of net infiltration for different topographic locations (Flint et al. 1996 [DIRS 100147]; Flint and Flint 1995 [DIRS 100394]; Hevesi et al. 1994 [DIRS 100582]). Depth versus time water-content profiles indicated the importance of thin soils, saturated fracture flow, periods of heavy precipitation (and/or snowmelt), and surface water run-on; in providing the conditions needed for the occurrence of episodic net-infiltration pulses. For example, the depth versus time watercontent profile measured at borehole UZ-N15 (Flint et al. 1996 [DIRS 100147], Figure 32; DTNs: GS940708312212.011 [DIRS 107136]; GS941208312212.017 [DIRS 107137]; GS950808312212.001 [DIRS 107139]; GS960108312212.001 [DIRS 107141]) indicates the occurrence of three major episodes of net infiltration through bedrock in response to wetter than average conditions during the winters of 1992-93 and 1994-95 (Figure 6-3). The UZ-N15 site is at a ridge top location in the headwater part of the upper Pagany Wash channel, has relatively thin soils, and based on field observations, received surface-water run-on during the winters of 1992-93 and 1994-95. The net-infiltration pulses indicated in Figure 6-3 cannot be supported by the measured bedrock matrix hydraulic conductivity alone. In order to measure the changes in water content noted in this figure using neutron moisture meters, it is necessary to have detectable changes in the volumetric water content. The rapid downward advance of the wetting front observed at this site suggests fracture flow is necessary as the matrix permeability is very low; therefore, fracture flow through welded tuff is required. This was verified by independent measurements of water potential using heat dissipation probes at the soil-bedrock contact at a nearby site not affected by the existence of a borehole (Flint et al. 1996 [DIRS 100147], Figure 35; DTN: GS960908312211.004 [DIRS 146872]). While the fractures may or may not be saturated in all locations during episodic high precipitation events accompanied by surface run-on, in this particular case, field observation at a nearby trench indicated that the fractures were fully saturated. The thin soils, fractured bedrock, and concentrated surface-water flow all contributed to rapid percolation of infiltrated water well below the depth of the effective root zone. In general, the collective time-averaged net-infiltration rates calculated at all borehole 
sites (DTN: GS960508312212.008 [DIRS 122609]) using the measured water-content changes indicate the occurrence of increased net infiltration at Yucca Mountain during 1989 to 1995 (Figure 6-4) and a strong inverse correlation between soil depth (DTN: GS960508312212.007 [DIRS 124829]) and net-infiltration rates (Flint and Flint 1995 [DIRS 100394]).

Drilling neutron-probe boreholes in the fractured tuffs at Yucca Mountain may introduce additional fractures or enhance the flow in the existing network, causing an overestimate of net infiltration. One year of water-potential measurements was performed using heatdissipation probes near borehole USW UZ-N15 (Figure 6-5A). The probes were installed laterally from a small trench that was backfilled. Measurements were made at four depths: 7.0, 15.0, 36.5, and $73.7 \mathrm{~cm}$ (the soil/bedrock interface). By early March, within two weeks of installation, winter precipitation saturated the soil from the soil-bedrock interface to within $36 \mathrm{~cm}$ of the soil surface, and heat-dissipation probes at both $36.5 \mathrm{~cm}$ and $73.7 \mathrm{~cm}$ were saturated. The probe at the soil/bedrock interface $(73.7 \mathrm{~cm})$ remained saturated until the end of March and then dried out to less than -10 bars by September. The probes closer to the surface dried out faster, and the near-surface probes became wetter periodically due to summer precipitation events.

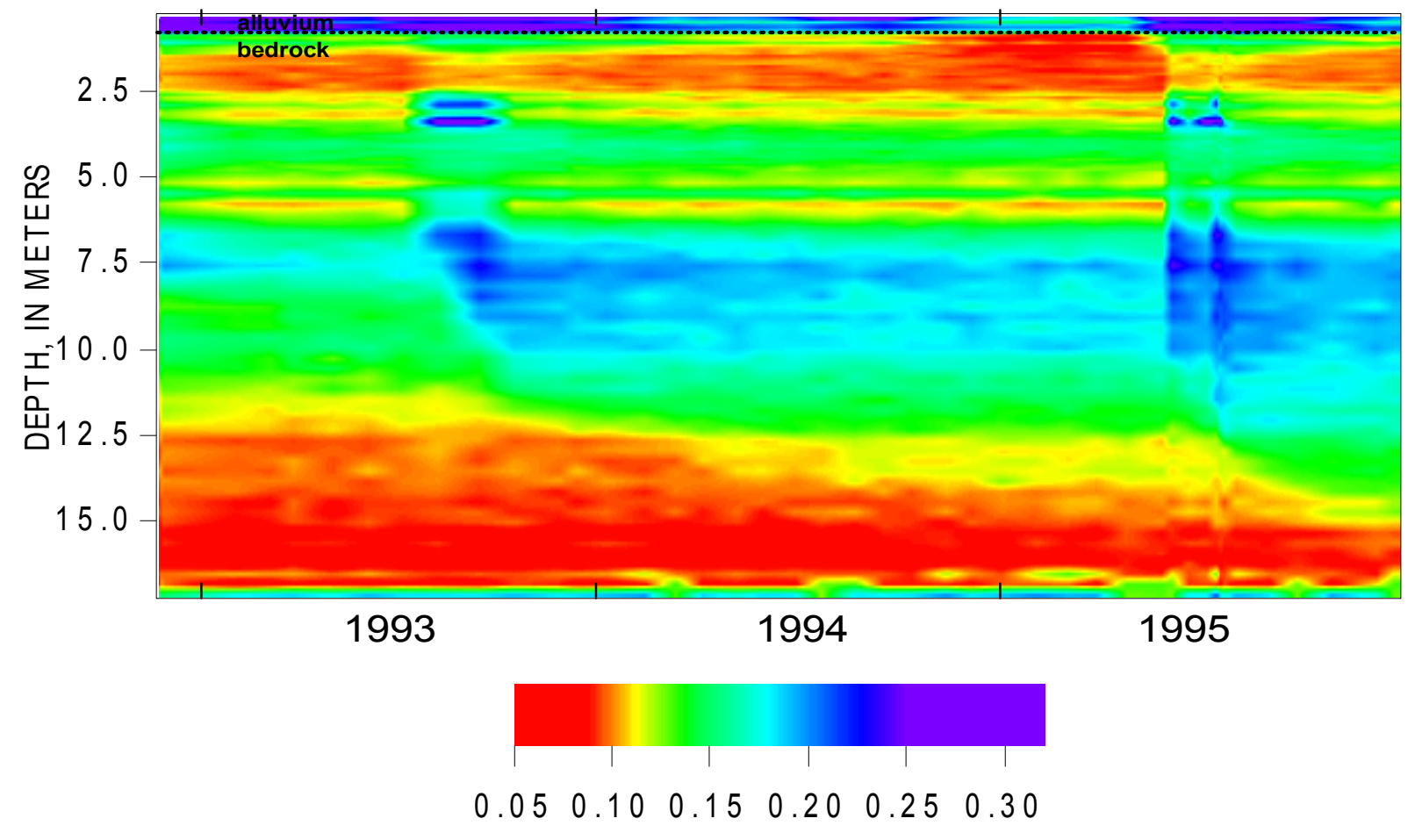

W ATER CONTENT, IN M ETERS PER METER

Source: DTNs: GS940708312212.011 [DIRS 107136]; GS941208312212.017 [DIRS 107137]; GS950808312212.001 [DIRS 107139]; GS960108312212.001 [DIRS 107141].

Figure 6-3. Measured Water-Content Profiles at Borehole UZN-15 for 1993-95 


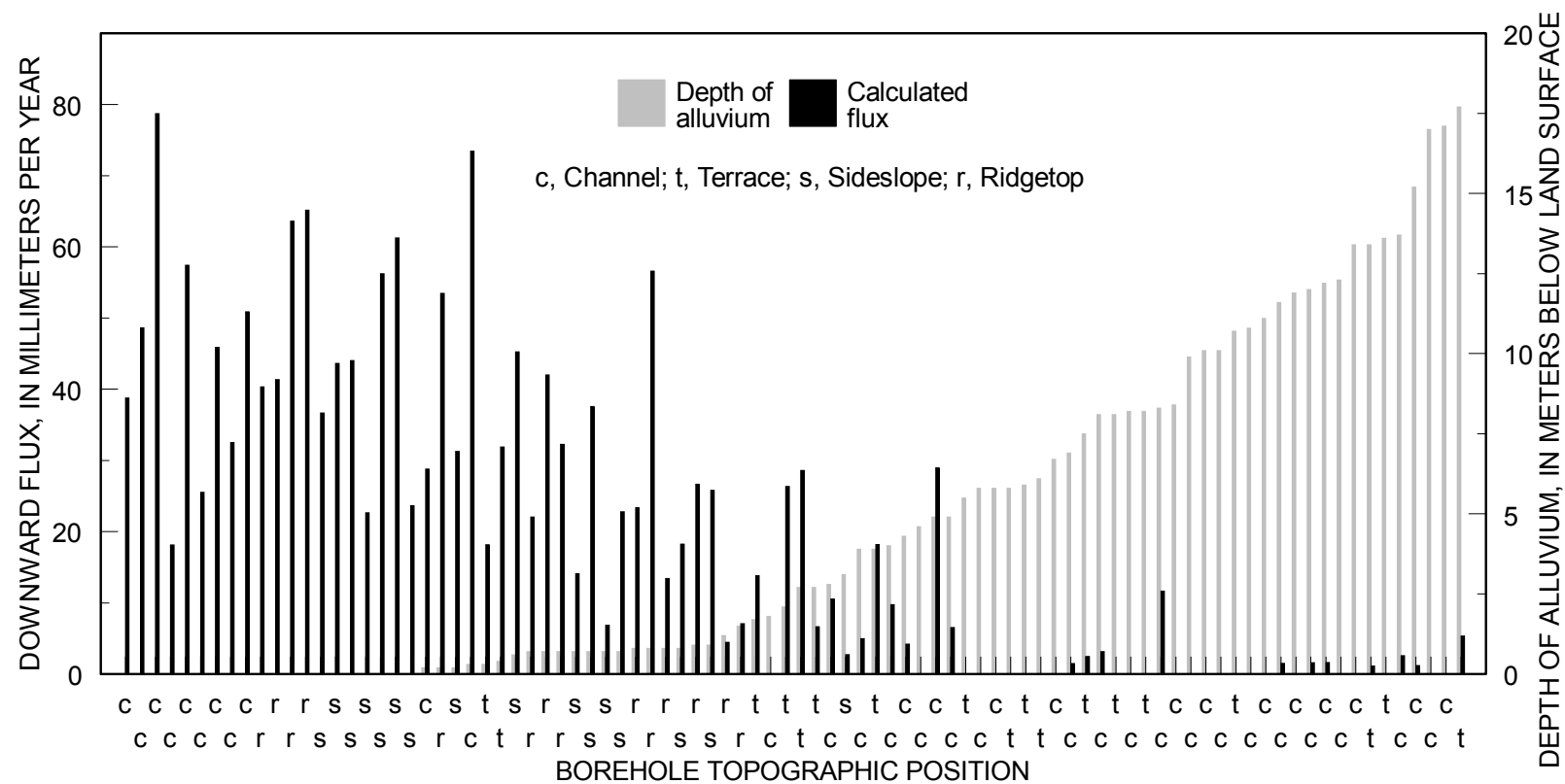

Source: DTNs: GS960508312212.008 [DIRS 122609]); GS960508312212.007 [DIRS 124829].

Figure 6-4. Estimates of Average Net-Infiltration Rates at Yucca Mountain Calculated Using Changes in Measured Water-Content Profiles Obtained for the Period 1989-95 From A Network of Monitoring Boreholes, Compared to Depth of Alluvium at Each Borehole

The moisture-retention curve for this location (Appendix B, Geospatial Input Data for INFIL V2.0 FY99, Table B-4) was used to convert water potential to water content (Figure-6-5B). The rate of water loss was calculated between selected dates by using the change in water content. In early March, the profile changed at a rate of more than $10 \mathrm{~mm} /$ day, but dropped to less than two $\mathrm{mm}$ /day within 30 days. The evaporation rate was estimated to be no more than two $\mathrm{mm}$ /day on the basis of PET calculations using the Priestley-Taylor equation (Priestley and Taylor 1972 [DIRS 125321]), yielding a maximum flux into the bedrock of eight $\mathrm{mm} /$ day. The flux for 30 days averaged five $\mathrm{mm} /$ day to yield a total flux into the bedrock of $150 \mathrm{~mm}$. The estimate for the nearby borehole (USW UZ-N17; DTN: GS960508312212.008 [DIRS 122609]) was $110 \mathrm{~mm}$ for the same time period.

Changes in water-content profiles through time measured in boreholes located in active channels with thick soils were used to develop and calibrate a modified Priestley-Taylor evapotranspiration model (Hevesi et al. 1994 [DIRS 100582]). Initial model calibrations conducted using INFIL V1.0 in 1996 consisted of a generalized (site-wide) calibration of the modified Priestley-Taylor model coefficients (DTN: GS000300001221.009 [DIRS 147228]) were based primarily on the calculated changes in the measured profiles (Flint et al. 1996 [DIRS 100147], Figure 41). Model calibration using INFIL V2.0 was conducted using stream flow records from five gaging sites on Yucca Mountain that were operational from 1994 through 1995 and included two significant storm events measured during the winter of 1994-95 (DTNs: GS941208312121.001 [DIRS 107374]; GS960908312121.001 [DIRS 107375]). 
(A)

(B)
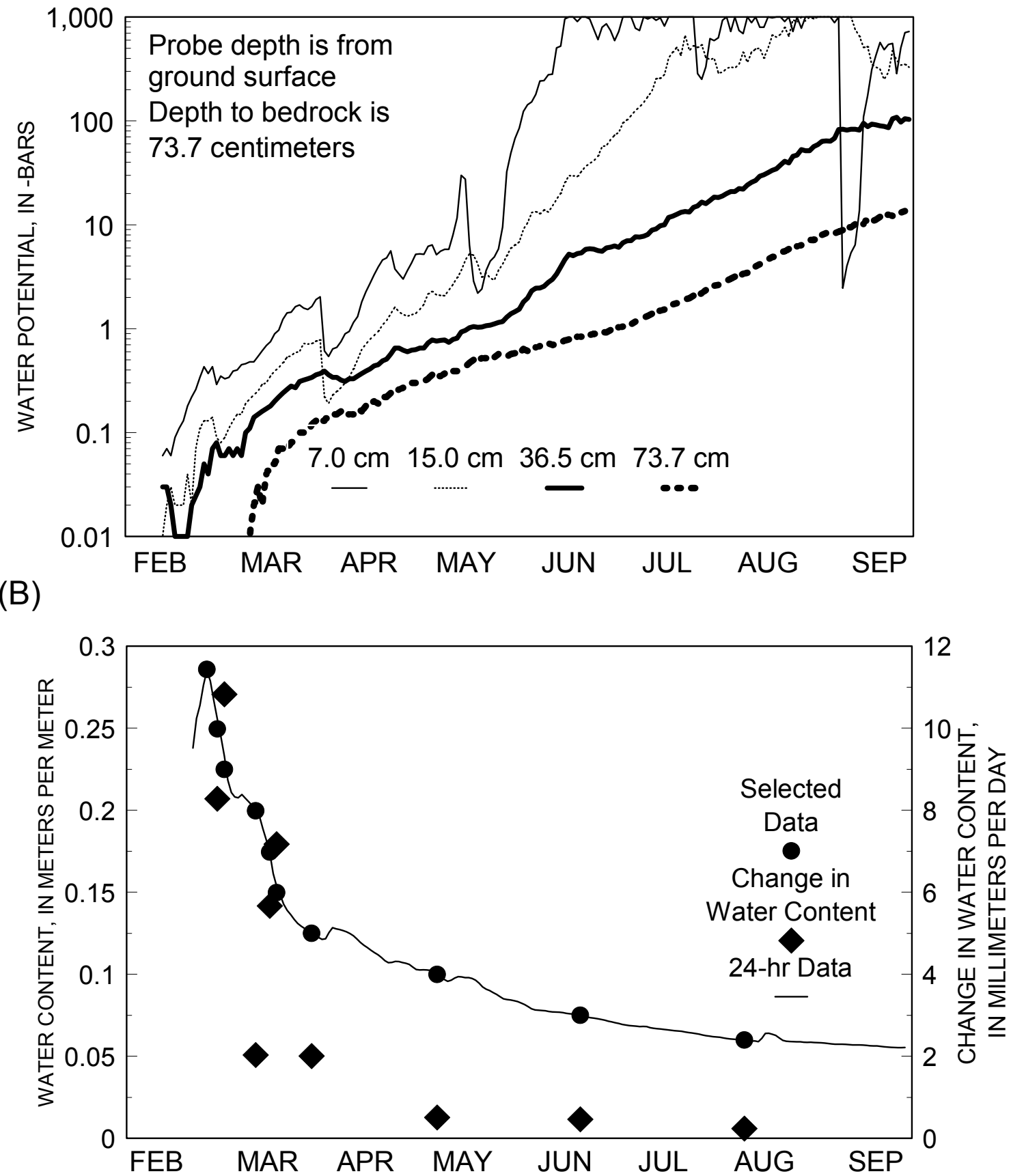

Source: A - DTN: GS960908312211.004 [DIRS 146872]; B - DTN: GS960908312211.004 [DIRS 146872] Calculated from water-potential measurements

NOTE: (A) measured at four depths for 1995 and (B) used to calculate flux.

Figure 6-5. (A) Graphs of Water-Potential Measurements near Borehole USW UZ-N15 Using Head Dissipation Probes Measured at Four Depths for 1995, and (B) Water Content Used to Calculate Flux 
A description of the model calibration procedure and the results of model calibration is provided in Section 6.8. Net infiltration is assumed to occur as saturated, or near-saturated, fracture flow through the TCw. An assumption is made that the fracture flow is maintained only through the thickness of the $\mathrm{TCW}$ within the root-zone, which is assumed to be less than or equal to $2 \mathrm{~m}$. Because of expected capillary barrier effects at the soil bedrock interface, fracture flow is assumed to be maintained only for the duration that saturated conditions are maintained along the soil-bedrock interface. The spatial resolution of this fracture flow is much higher than that of the site-wide model, and therefore may not be well represented by the site-wide model. During infiltration events, the contribution of the matrix of the bedrock to net infiltration is extremely small compared to the flow within the fractures. If the matrix is unsaturated it makes even less of a contribution. Therefore, the saturation of the rock matrix is not taken into consideration. Rather, once the alluvium at the bedrock contact becomes saturated fracture flow is assumed to be initiated, piston flow is assumed, and the fracture flow is accompanied by the small proportion of matrix saturated hydraulic conductivity. This also accounts for those few locations when sparsely fractured, nonwelded tuff is underlying alluvium.

Assumptions regarding the appropriateness of various calibration procedures can be supported using comparisons of model results with independent methods to determine if model results vary considerably from other approaches of estimating net infiltration or recharge in the same environment. In Section 7, the spatially averaged net-infiltration rates for the nine climate scenarios were compared against estimates of recharge obtained using independent studies at various locations in the southern Basin and Range Province as a method of model comparison (Maxey and Eakin 1950 [DIRS 100598]; Winograd 1981 [DIRS 100019]; Lichty and McKinley 1995 [DIRS 100589]; Harrill and Prudic 1998 [DIRS 149377]; Dettinger 1989 [DIRS 105384]).

\subsection{MODEL COMPONENTS AND PROCESSES}

The INFIL V2.0 model algorithm consists of three main loops for performing a daily simulation of net infiltration over all model cells comprising a watershed model domain. Figure 6-6 provides a flow chart illustration of the general model algorithm and the primary loop (day-of-year loop), which is driven by the daily climate input file and carries the simulation through the time domain. Nested within the primary loop is a grid cell loop for performing a daily water balance calculation at each grid cell location and within each layer of the root zone. The root zone was subdivided into layers based on the estimated maximum depth of bare-soil evaporation and an estimated variation in root density. In general, the layering represents a decrease in root density with increased depth in the root zone, particularly at locations with thick soils (greater than $6 \mathrm{~m}$ ).

The daily root-zone water balance consists of simulating precipitation, snowmelt, sublimation, evapotranspiration, changes in water content for each root-zone layer, net infiltration, and runoff generation. Nested within the water-balance loop is an hourly loop for modeling PET based on the simulation of incoming solar radiation and effects on total solar radiation due to blocking ridges using the SOLRAD submodel in INFIL V2.0 and the routine BLOCKR7 (Flint et al. 1996 [DIRS 100147]; Flint and Childs 1987 [DIRS 100571]). 


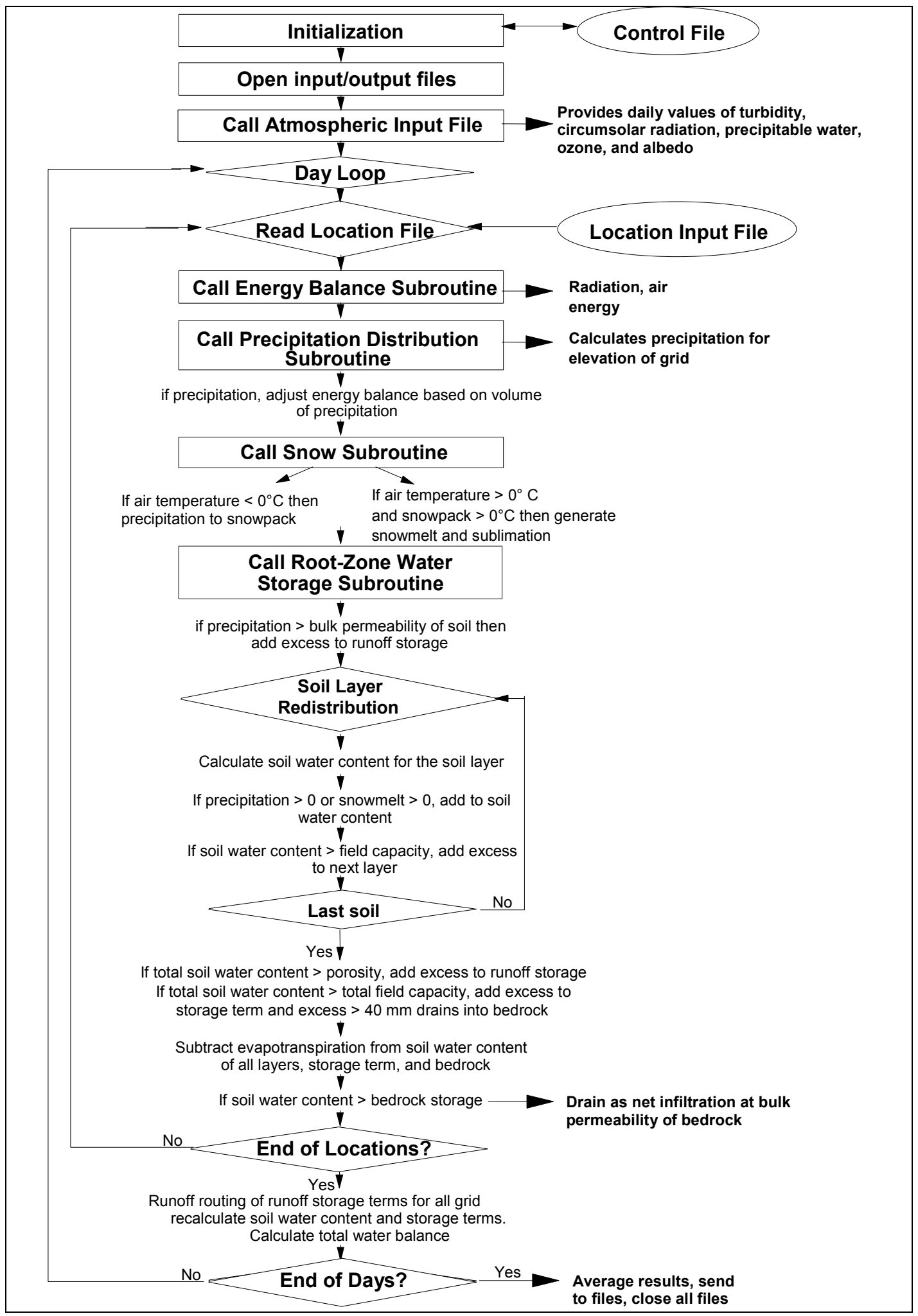

Figure 6-6. Flow Chart of the Model Algorithm Used for Simulating Net Infiltration 
After the completion of the water-balance loop, a surface-water flow-routing subroutine is called if runoff was generated at any grid cell. Surface-water flow is routed at the end of the day as a time-independent (instantaneous) total daily flow depth across each grid cell. The routing algorithm connects all grid cells horizontally using surface-water flow-routing parameters included in the geospatial parameter input file. Surface-water flow is coupled to the water-balance calculation by allowing surface water to infiltrate into downstream grid cells according to the available root-zone storage capacity, soil hydraulic conductivity, and estimates for effective surface-water flow area and stream flow duration. The infiltrated water is added to the grid cell's antecedent root-zone water-content term used in the following day's water-balance calculation. The surface-water flow depth routed across the grid cell defining the outflow location of the watershed is converted to a daily mean discharge flow rate, in cubic feet per second, which can be compared to measured stream flow for model calibration.

Time-averaged net-infiltration rates are calculated by accumulating the simulated daily net-infiltration amounts obtained at the end of the daily water-balance loop. Time average rates also are calculated for the remaining components of the water balance (precipitation, snowmelt, sublimation, evapotranspiration, infiltrated run-on, root-zone water-content change, and runoff) for all model grid cells and are included in the main output file used for developing the net-infiltration results. The time-averaged rates for all components of the water balance simulated at each grid cell are averaged over the watershed model domain and compared against the time-averaged watershed outflow to check the consistency of the simulated water balance for the entire watershed.

Output from INFIL V2.0 also includes spatially averaged daily water-balance terms for all components of the water balance. The daily output indicates the average inflow, outflow, and change in storage rates over the area of the watershed being simulated. The spatially averaged daily water balance is compared against the simulated daily outflow to provide a water-balance check for each day simulated. The simulated daily water balance rates are averaged over time and compared against the spatially averaged water-balance rates simulated at each grid cell as an additional method of checking the consistency of the simulated water balance for the entire watershed.

\subsubsection{Daily Water Balance}

The estimation of spatially distributed net-infiltration rates consists of a daily simulation of net infiltration in response to a daily water- and energy-balance calculation performed separately for all model elements within a watershed bounded by surface-water flow divides. The daily water-balance calculation used in INFIL V2.0 is:

$$
\mathrm{R}_{\mathrm{off}}=\mathrm{P}-\mathrm{SF}+\mathrm{IR}_{\mathrm{on}}+\mathrm{SM}-\mathrm{SB}+\mathrm{SW}-\mathrm{ET}-\mathrm{I}
$$

where I is net infiltration, $\mathrm{P}$ is precipitation (rain and snow), SF is snowfall, SB is sublimation, $\mathrm{SM}$ is snowmelt, SW is change in water-content storage within the root zone, ET is evapotranspiration, $I_{\mathrm{on}}$ is infiltrated surface-water run-on, and $\mathrm{R}_{\text {off }}$ is surface-water runoff generated by excess precipitation, snowmelt, or run-on. Note that runoff, not net infiltration, is calculated as the solution to the water-balance equation. A unit gradient is assumed and net infiltration is incorporated in the water-balance formulation as a temporary net-infiltration term 
and is limited by the field-scale-saturated hydraulic conductivity of the soil or bedrock underlying the root zone. A unit gradient is assumed because INFIL is a simple bucket model, and it cannot accommodate Richards' Equation flow calculations in which a unit gradient is not required. A detailed description of the method used for calculating net infiltration is provided in Sections 6.4.5 and 6.4.6.

The daily water-balance calculation performed for a root zone is illustrated in Figure 6-2, which was discussed in Section 6.3.1. In this figure, water balance of the root zone is schematically represented for a single soil layer. In modeling the daily water-balance, parameters affecting the daily water balance, such as soil thickness, soil and bedrock properties, and various surface and vegetation characteristics, are uniquely defined for each grid cell. The difference between field capacity and residual water content is commonly referred to as available water capacity in soil science terms and that is the water available for plants. Therefore, the transpiration part of evapotranspiration process takes place this is the zone. The infiltration rate of precipitation, snowmelt, or surface-water run-on into the root zone from the land surface is limited by the saturated hydraulic conductivity of the grid cell soil type (or the bulk saturated hydraulic conductivity of the grid cell bedrock type in cases of no soil cover). Precipitation and surface-water flow rates are defined using an estimated 2-hour storm duration for summer storm events and an estimated 12-hour storm duration for winter storm events. This is because summer storms are usually high-intensity short-duration convective storms, while winter storms are usually low-intensity, long-duration low-pressure storms (Winograd and Thordarson 1975 [DIRS 101167]). If the precipitation or snowmelt rate exceeds the saturated hydraulic conductivity of the top root-zone layer, the excess precipitation or snowmelt is added to the runoff term for that grid cell. During the simulation of surface-water flow, the infiltration of surface-water run on is also limited by the saturated hydraulic conductivity of the top rootzone layer. Surface-water run on exceeding the saturated hydraulic conductivity of the top rootzone layer is added to the runoff term routed to the downstream grid cell.

\subsubsection{Daily Climate Input}

Infiltration occurs in response to daily precipitation that occurs in particular temporal and spatial patterns. Stochastic representations of infiltration would be required to predict infiltration for long time periods without daily input; however, no infiltration data are available for the development of long-term patterns. Therefore, using stochastic representations of precipitation and daily input to simulate infiltration is appropriate.

The daily climate input file is the primary control for the timing and duration of the simulation. The daily climate input file defines the time domain through which the simulation occurs by providing a real-time sequential input of daily climate parameters. The file is ASCII column formatted and at minimum consists of the year number, the day of year number, and the total daily precipitation amount but can also consist of maximum, minimum, and average daily air temperature, along with total daily snowfall accumulation. 
The primary input provided by the daily climate-input file is total daily precipitation, in millimeters, and this drives the daily water-balance calculation. Average daily air temperature, in degrees Celsius, is not required as input, because if not provided in the daily climate input file, this parameter is modeled internally by INFIL V2.0 using Equation 20 from (Flint et al. 1996 [DIRS 100147]):

$$
\mathrm{T}=\mathrm{T} 1-\mathrm{T} 2\{\operatorname{Sin}[(\mathrm{D} / 366) * 2 * \pi+1.3]\}
$$

where $\mathrm{T}$ is modeled daily air temperature, $\mathrm{D}$ is day of year number, $\mathrm{T} 1$ is mean annual air temperature, and T2 is mean seasonal variation of average daily air temperatures above the mean during summer and below the mean during winter (the $1 / 2$ amplitude of the sine wave). T1 and T2 were calculated as 17.3 and $11.74^{\circ} \mathrm{C}$, respectively, using measured 1992 air temperature data from Yucca Mountain (DTN: GS000208312111.002 [DIRS 147250]). These parameters were assumed to be representative of present-day climate conditions at Yucca Mountain.

The daily climate input file provides point values of total daily precipitation and average daily air temperature for a given day of the simulation. These values are representative of the conditions at locations having elevations of approximately $1,400 \mathrm{~m}$, which represents the approximate average elevation of the land surface above the repository. Precipitation and air temperature are distributed spatially across all model grid cells using empirical elevation models. The precipitation/elevation correlation, caused by the adiabatic cooling of air masses interacting with mountainous terrain, has been studied in the southern Nevada region and correlation models between elevation and annual as well as seasonal precipitation amounts have been defined (French 1983 [DIRS 125313]; Hevesi et al. 1992 [DIRS 116809]; Hevesi and Flint 1998 [DIRS 125323]). The precipitation/elevation correlation model used in INFIL for present-day climate is from Hevesi and Flint (1998 [DIRS 125323], Table 4, DTN: GS960108312111.001 [DIRS 107131]) for the sample of 114 precipitation stations with a minimum of 8 years of record. The model estimated mean annual precipitation distributions using the relation:

$$
\mathrm{P}_{\mathrm{d}}{ }^{\mathrm{k}}=\mathrm{P}_{\mathrm{d}} * \exp \left(0.0006458^{*} \mathrm{E}^{\mathrm{k}}+4.317\right) / \mathrm{MAP}
$$

where $\mathrm{P}_{\mathrm{d}}{ }^{\mathrm{k}}$ is the elevation-corrected daily precipitation estimate (in millimeters) for day $\mathrm{d}$ at model element $\mathrm{k}, \mathrm{P}_{\mathrm{d}}$ is the point precipitation estimated for day $\mathrm{d}$ provided by the daily climate input file, $\mathrm{E}$ is elevation (in meters), and MAP is mean annual precipitation (in millimeters). Although the precipitation/elevation correlation model used (DTN: GS960108312111.001 [DIRS 107131]) is not qualified data, it is considered to be indirect input and does not require qualification).

For the monsoon and glacial-transition climate scenarios, the slope defined by Equation 6-3 was adjusted to account for assumed changes in the precipitation/elevation correlation based on estimates of precipitation-elevation correlations presented by Thompson et al. (1999 [DIRS 109470]), indicating a reduction in orographic effects on precipitation for wetter paleoclimates.

Atmospheric pressure decreases with increasing altitude. Consequently, stirring of an atmospheric layer causes rising parcels of air to cool by adiabatic expansion, and sinking parcels 
to correspondingly warm by compression. The net effect of this is a vertical decrease in temperature with increase in elevation called the adiabatic lapse rate. The adiabatic lapse rate, or air temperature/elevation correlation is cited in numerous references as about $9.8^{\circ} \mathrm{C}$ per kilometer and was cited for this work using Maidment (1993 [DIRS 125317], p. 2.27):

$$
\mathrm{T}_{\mathrm{d}}^{\mathrm{k}}=0.0098 *\left(1400-\mathrm{E}^{\mathrm{k}}\right)+\mathrm{T}_{\mathrm{d}}
$$

where $T_{d}{ }^{k}$ is the elevation-adjusted air temperature for grid cell $\mathrm{k}$ based on elevation $\mathrm{E}$ and daily air temperature $T_{d}$ (either provided in the daily climate-input file or simulated using Equation 6-2). This adiabatic lapse rate applies to the air temperature/elevation relationship regardless of terrain, so this value should be considered to be approximate for the mountainous terrain of the Yucca Mountain area. The elevation E is subtracted from the estimated mean elevation for the repository area that is indicated in the equation as $1,400 \mathrm{~m}$. This is the approximate average ground surface elevation of the repository. The actual ground surface elevation above the repository ranges from 1,402 to $1,494 \mathrm{~m}$ (Chu and Dyer 2003 [DIRS 171661]).

Cloud cover is a variable affecting the energy-balance calculation and is indirectly accounted for in the model as an empirical function of daily precipitation magnitude. For days with precipitation, the modeled clear-sky PET rate is reduced using the PET reduction equation developed by Flint et al. (1996 [DIRS 100147], page 143):

$$
\mathrm{APET}_{\mathrm{d}}=\mathrm{PET}_{\mathrm{d}} /\left[\left(4 * \mathrm{P}_{\mathrm{d}} / 25.4\right)+1\right]
$$

where APET is adjusted PET for day d (in millimeters), PET $_{d}$ is the Priestley-Taylor modeled clear-sky PET for day $\mathrm{d}$ (PET is discussed further in Section 6.4.4), and $\mathrm{P}_{\mathrm{d}}$ is modeled daily precipitation for day $\mathrm{d}$. The coefficient 25.4 converts inches to millimeters, and the value 4 is an estimate that reduces the PET by approximately 25 percent due to cloud cover that exists whenever it rains. Equation 6-5 is based on the assumption is that the energy for ET is reduced by 25 percent in the presence of clouds (associated with precipitation) and the more rain there is, the less ET there is.

\subsubsection{Snow Pack Submodel}

Precipitation is simulated as snowfall for a grid cell location if the average air temperature is less than or equal to $0^{\circ} \mathrm{C}$. When snowfall occurs, all precipitation for that day is assumed to occur as snow at that location. However, because air temperature is distributed spatially using the elevation correlation model, snowfall and snow pack accumulation may occur at higher elevation cells while rain occurs at lower elevations within the same watershed.

Snowfall is accumulated into a snow pack storage term and is removed from the root-zone water balance. If snow pack exists and the air temperature is less than $0^{\circ} \mathrm{C}$, water is removed from the snow pack by using an empirical sublimation-saltation-suspension model under the assumption that in upland areas advective wind-transport processes tend to cause snow removal rather than deposition over most areas. The three processes are grouped into a single empirical 
"sublimation" model that also includes evaporation of snowmelt and sublimation (but not saltation and suspension) when the air temperature exceeds $0^{\circ} \mathrm{C}$ :

$$
\begin{aligned}
& \mathrm{SB}^{\mathrm{k}}=\mathrm{A} 1 * \mathrm{APET}^{\mathrm{k}}, \mathrm{T}^{\mathrm{k}}<=0 \text { (sublimation/advective losses) } \\
& \mathrm{SB}^{\mathrm{k}}=\mathrm{A} 2 * \mathrm{APET}^{\mathrm{k}}, \mathrm{T}^{\mathrm{k}}>0 \text { (evaporation of snowmelt and sublimation) }
\end{aligned}
$$

where $\mathrm{SB}^{\mathrm{k}}$ is total snow pack losses to the atmosphere (in millimeters), $\mathrm{APET}^{\mathrm{k}}$ is the cloud cover adjusted Priestley-Taylor PET rate ${ }^{11}$, (in millimeters/day), and $\mathrm{T}^{\mathrm{k}}$ is the average air temperature simulated for grid cell $\mathrm{k}$ (in degrees celsius). The model coefficients were estimated based on limited information indicating the average percentage of snow pack losses due to sublimation and advective energy processes (Maidment 1993 [DIRS 125317], pp. 7.4 to 7.10). For example, Maidment (1993 [DIRS 125317], p. 7.8) reports sublimation rates for Canada of 41 percent for fallow fields, and 34 percent for stubble. Due to the lack of data on this parameter, a value of 0.1 (10 percent) for A1 for sublimation was assumed to be representative of conditions at Yucca Mountain. The A2 parameter must be greater than the A1 parameter since it includes the sublimation and evaporation of snowmelt components. The A2 parameter was assumed to be three times greater than the A1 parameter since sublimation increases as temperature increases (Maidment 1993 [DIRS 125317], pp. 7.4 to 7.10), and because it includes the evaporation of snowmelt component as well as the sublimation component. Therefore, for all simulations using the snow pack submodel, A1 was set to 0.1 and A2 was set to 0.3 in the model control file. This is an assumed relation to account for an increase in snow pack losses to the atmosphere when the average daily air temperature is above freezing. If a snow pack exists and air temperature is greater than $0^{\circ} \mathrm{C}$, a combined sublimation of snow and evaporation of snowmelt is simulated, and the APET term is reduced by the sublimation/evaporation rate SB to provide a PET rate for the root zone. Thus, the model allows reduced transpiration to occur when a snow pack exists but only if air temperature is higher than $0^{\circ} \mathrm{C}$. For all days when air temperature is $0^{\circ} \mathrm{C}$ or less, transpiration is set to zero, and only sublimation can occur, provided a snow pack exists.

If air temperature is greater than $0^{\circ} \mathrm{C}$, snowmelt is simulated as an empirical linear function of average daily air temperature (Maidment 1993 [DIRS 125317], pp. 7.4 to 7.10) using a standard temperature index modeling approach:

$$
\mathrm{SM}^{\mathrm{k}}=\mathrm{A} * \mathrm{~T}^{\mathrm{k}}
$$

where SM is the modeled snowmelt (in millimeters) for grid cell $\mathrm{k}$; $\mathrm{T}$ is the modeled average daily air temperature $\left({ }^{\circ} \mathrm{C}\right.$ ) for grid cell $\mathrm{k}$; and $\mathrm{A}$ was set to 1.78 , which is the coefficient used for modeling snowmelt in the Sierra Nevada during April (Maidment 1993 [DIRS 125317], Table 7.3.7, p. 7.24). The simulated snowmelt is carried back into the root-zone water-balance calculation as an influx term.

\footnotetext{
${ }^{11}$ The potential evapotranspiration rate used in the sublimation model uses a Priestley-Taylor $\alpha$ coefficient value of 1.26 to account empirically for the advective component of the total energy balance (Priestley and Taylor 1972 [DIRS 125321]) and is not necessarily equivalent to the values of the coefficient used in the root-zone model.
} 


\subsubsection{Potential Evapotranspiration and the Net Radiation Submodel}

Total daily PET is modeled for each grid cell using the Priestley-Taylor equation (Priestley and Taylor 1972 [DIRS 125321]):

$$
\operatorname{PET}_{\mathrm{d}}{ }^{\mathrm{k}}=\alpha *\left[\mathrm{~s} /(\mathrm{s}+\gamma)_{\mathrm{d}}{ }^{\mathrm{k}} *\left(\mathrm{RN}_{\mathrm{d}}{ }^{\mathrm{k}}-\mathrm{GH}_{\mathrm{d}}{ }^{\mathrm{k}}\right) / 2.45 \times 10^{6}\right]
$$

where $\mathrm{PET}_{\mathrm{d}}{ }^{\mathrm{k}}$ is PET (in millimeters) on day $\mathrm{d}$ for grid cell $\mathrm{k}$; $\mathrm{s}$ is the slope of the saturation vapor pressure-temperature curve; $\gamma$ is the psychometric constant; $\mathrm{RN}$ is modeled net radiation; and $2.45 \times 10^{6}$ converts the energy units to millimeters of water. The term, GH, is estimated ground-heat flux, which is modeled using Equation 22 from Flint et al. (1996 [DIRS 100147]):

$$
\mathrm{GH}=-20+0.386(\mathrm{RN})
$$

In Equation 6-8, $\alpha$ is used as an empirical scaling factor to account for the missing advective energy term in the Priestley-Taylor equation. For wet conditions having freely evaporating surfaces, $\alpha$ is often set to 1.26 (Priestley and Taylor 1972 [DIRS 125321]; Flint and Childs 1991 [DIRS 124946]; DTN: GS000300001221.009 [DIRS 147228]). For dry conditions, available moisture becomes the limiting factor controlling actual evapotranspiration, and $\alpha$ can be modeled as an empirical scaling function, $\alpha^{\prime}$, using a relative saturation term (Flint and Childs 1991 [DIRS 124946]). In the root-zone water-balance submodel, $\alpha$ is defined as an empirical function of relative saturation within the root zone by using a method described in Section 6.4.6.

The $\mathrm{s} /(\mathrm{s}+\gamma)$ term is modeled as a function of average daily air temperature by using Equation 19 from Conceptual and Numerical Model of Infiltration for the Yucca Mountain Area, Nevada (Flint et al. 1996 [DIRS 100147]):

$$
\mathrm{s} /(\mathrm{s}+\gamma)_{\mathrm{d}}{ }^{\mathrm{k}}=-13.281+0.083864 * \mathrm{TA}_{\mathrm{d}}{ }^{\mathrm{k}}-0.00012375 *\left(\mathrm{TA}_{\mathrm{d}}\right)^{\mathrm{k}}{ }^{2}
$$

where $\mathrm{TA}^{\mathrm{k}}$ is the average daily air temperature on day $\mathrm{d}$ for grid cell $\mathrm{k}$, in Kelvins. Equation 6-10 was defined using parameter values obtained from performing a regression on data from $A n$ Introduction to Environmental Biophysics (Campbell 1977 [DIRS 124856], Table A.3) and provides an indication of the relative effect of air temperature on PET, which varies for different temperature ranges. In Figure 6-7, Equation 6-10 is compared with selected values taken from An Introduction to Environmental Biophysics (Campbell 1977 [DIRS 124856], Table A.3) to illustrate the greater relative change in the $\mathrm{s} /(\mathrm{s}+\gamma)$ term for the lower air temperatures in the range $-5^{\circ} \mathrm{C}$ to $5^{\circ} \mathrm{C}$ as compared to temperatures in the range of $25^{\circ} \mathrm{C}$ to $35^{\circ} \mathrm{C}$. For example, a decrease in air temperature from $5^{\circ} \mathrm{C}$ to $0^{\circ} \mathrm{C}$ results in a 17 percent reduction in $\mathrm{s} /(\mathrm{s}+\gamma)$ and thus $\mathrm{PET}$, while a decrease in air temperature from $35^{\circ} \mathrm{C}$ to $30^{\circ} \mathrm{C}$ causes only a 5 percent reduction in the $\mathrm{s} /(\mathrm{s}+\gamma)$ term.

Total daily net radiation is the primary component of the energy balance determining PET and is modeled using Equation 21 from Conceptual and Numerical Model of Infiltration for the Yucca Mountain Area, Nevada (Flint et al. 1996 [DIRS 100147]):

$$
\mathrm{RN}_{\mathrm{d}}{ }^{\mathrm{k}}=-71+0.72 * \mathrm{~K}_{\mathrm{d}}{ }^{\mathrm{k}} \downarrow
$$


where $\mathrm{RN}$ is total net radiation, in $\mathrm{W} / \mathrm{m}^{2}$, on day $\mathrm{d}$ for model element $\mathrm{k}$, and $\mathrm{K} \downarrow$ is simulated incoming solar radiation which is modeled using a version of the SOLRAD, submodel in INFIL V2.0, program as developed by Flint and Childs (1987 [DIRS 100571]). To account for seasonal changes in the solar trajectory as well as terrain effects across model elements, SOLRAD, submodel in INFIL V2.0, calculates solar position on an hourly ${ }^{12}$ basis from sunrise to sunset as a function of the day of year and geographic position of each grid cell (Flint and Childs 1987 [DIRS 100571]). Terrain effects (blocking ridges) on incoming solar radiation are modeled using topographic parameters calculated from the DEM and included as input in the geospatial parameter file. Topographic parameters include grid cell slope, aspect, and 36 blocking ridge angles that define shading effects and reductions in skyview for every $10^{\circ}$ in the horizontal plane, starting with the UTM northing axis as the $0^{\circ}$ azimuth. Shading causes a reduction in direct beam radiation, and diminished skyview decreases diffuse radiation. These effects can become important in rugged mountainous terrain.

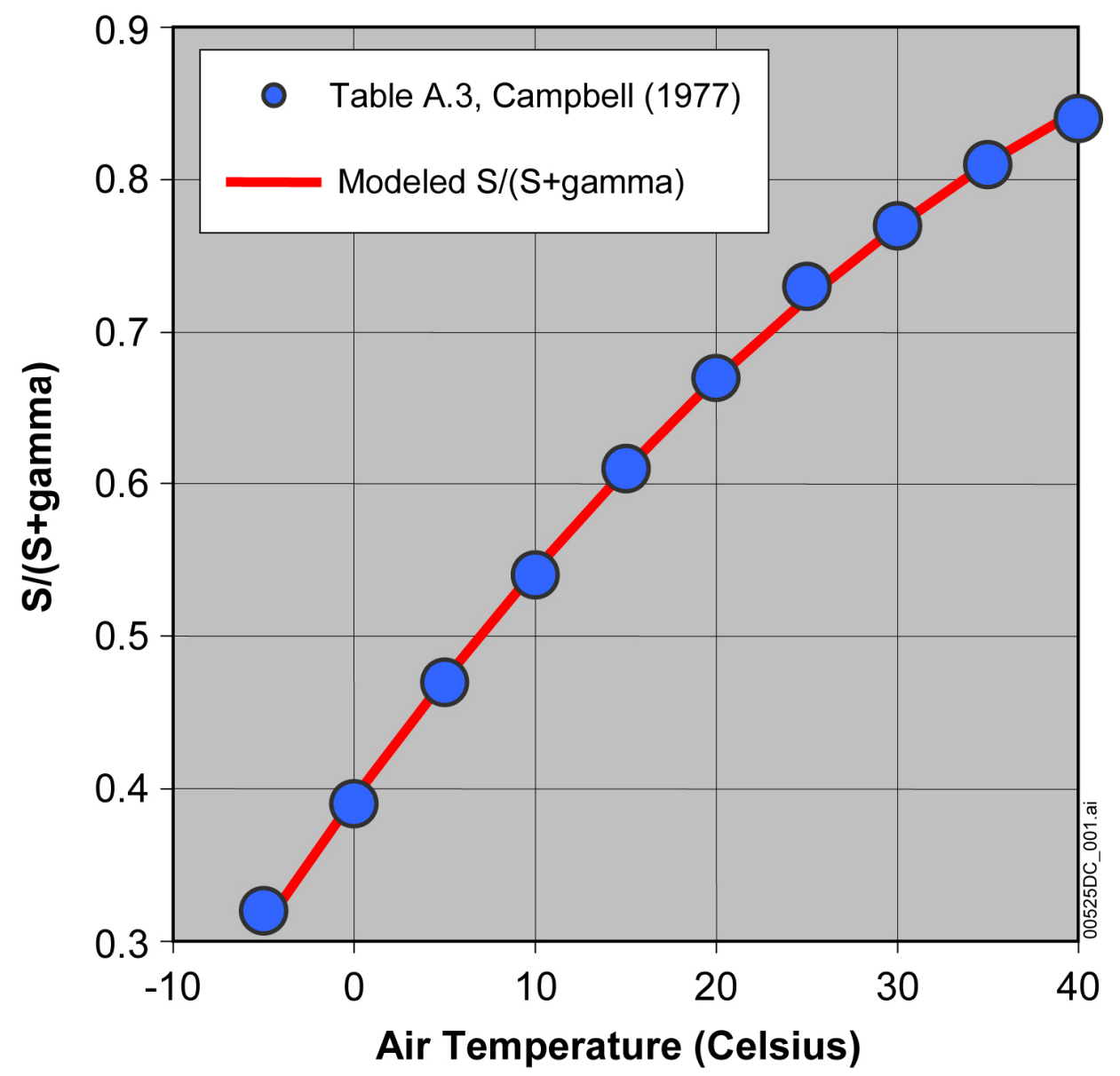

Source: DTN: GS000300001221.009 [DIRS 147228].

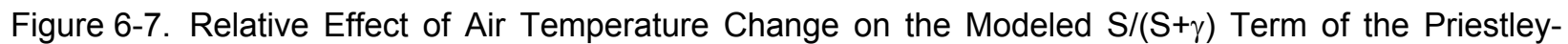
Taylor Equation Used for Estimating Potential Evapotranspiration

\footnotetext{
12 The time step is a user-specified option included in the model control file. Although a 1-hour time step is allowed, a 2-hour time step was used to reduce simulation run time without loss of accuracy.
} 


\subsubsection{Root-Zone Submodel: Infiltration, Percolation, and Redistribution}

Water infiltrating and percolating (see Section 6.1.1 for definitions) through the multilayered root-zone system is modeled as a cascading piston-flow process. Downward percolation is modeled as a "forward" cascade initiated by adding the total volume of water infiltrating the top layer of the root zone to the antecedent water content of the layer. The new water content is calculated using the layer thickness and compared against the field capacity defined by the grid cell soil type. The volume of water exceeding the field capacity becomes downward percolation that is added to the antecedent water content of the underlying layer, and the new water content of the underlying layer is compared against the field capacity of that layer. If the potential percolation volume exceeds the saturated soil hydraulic conductivity or the saturated bulk bedrock hydraulic conductivity of the underlying layer, the downward percolation rate is set equal to the saturated hydraulic conductivity of the underlying layer, and the excess water volume is added to a temporary storage term for the overlying layer. The process is repeated for each soil and bedrock layer in the root zone (a maximum of three soil layers and one bedrock layer were used) until the bottom layer is reached, which completes the forward cascade.

The volume of water that has percolated into the bottom bedrock layer (which may be zero if the field capacity of an overlying layer was not exceeded) is compared against the effective root-zone storage capacity of the bedrock. If a bedrock layer exists in the root zone, the effective root-zone storage capacity of the bedrock layer is calculated based on the estimated root-zone depth, the estimated soil depth, and the estimated effective fracture porosity of the rock type (a more complete description of estimated root-zone depths in bedrock is provided in Section 6.5). The volume of water exceeding the bedrock storage capacity is the potential netinfiltration volume. For thick soils, there is no bedrock layer in the root zone. The thickness of the bedrock root-zone layer is set to zero, the effective fracture porosity for the bottom bedrock layer becomes zero, and all water exceeding the field capacity of the bottom soil layer (the third soil layer) is potential net infiltration unless limited by the saturated bulk hydraulic conductivity of the underlying soil or bedrock. For locations where the soil depth is estimated to be $6 \mathrm{~m}$ or greater, the underlying bedrock properties are defined using alluvium/colluvium properties. Based on analysis of neutron moisture meter data (Flint and Flint 1995 [DIRS 100394]), the maximum depth of infiltration in non-channel alluvial locations is $6 \mathrm{~m}$; therefore, no need exists to provide bedrock properties in these locations. The actual net-infiltration volume is calculated after evapotranspiration is simulated throughout the root zone and is limited by the bulk saturated hydraulic conductivity of the underlying rock type. The potential net-infiltration volume exceeding the bulk saturated hydraulic conductivity is added to the temporary storage term of the bottom root-zone layer.

Starting with the bottom root-zone layer, a reverse cascade is performed to determine if runoff is generated. The volume of water in the temporary storage term is compared against the total storage capacity of each layer defined by the porosity (or effective fracture porosity in the case of bedrock) and layer thickness. If the volume of water in the temporary storage term exceeds the storage capacity, the excess water is added to the temporary storage term of the overlying layer. The process is repeated until the top layer is reached, completing the reverse cascade. The volume of water in the temporary storage term exceeding the storage capacity of the top layer is added to the potential runoff volume calculated for that grid cell. The final runoff volume is calculated following the simulation of evapotranspiration from the root zone. 


\subsubsection{Root-Zone Submodel: Evapotranspiration, Runoff, and Net Infiltration}

After the completion of the reverse cascade and the placement of excess water into temporary storage terms, evapotranspiration is simulated for each root-zone layer using a dynamic root-zone weighting function and the modified Priestley-Taylor equation (discussed in Section 6.4.4). Evapotranspiration is simulated only for days with air temperature greater than $0^{\circ} \mathrm{C}$. The dynamic weighting is based on calculated relative saturations for each root-zone layer and the relative distribution of water (based on saturation) throughout all layers. The purpose of the dynamic weighting ( $\mathrm{wgt}_{\mathrm{i}}$ ) is to increase root activity for the wettest layer. Static root density weights are also incorporated into the dynamic weighting function, setting an upper limit on root activity within each layer. For the topsoil layer, the bare-soil evaporation term is added to the transpiration term. Using the calculated weighting terms, evapotranspiration is simulated by applying a form of the modified Priestley-Taylor equation as developed (Flint and Childs 1991 [DIRS 124946], coefficients in DTN: GS000300001221.009 [DIRS 147228]) to each layer of the root zone:

$$
\begin{aligned}
& \mathrm{ET}^{\mathrm{k}}=\alpha^{\prime} * \mathrm{PET}^{\mathrm{k}} \\
& \alpha^{\prime}=\sum_{\mathrm{i}}\left\{\mathrm{wgt}_{\mathrm{i}} *\left[\mathrm{a}^{\mathrm{k}}\left(1-\exp \left(\mathrm{b}^{\mathrm{k}} * \text { relsat }_{\mathrm{i}}^{\mathrm{k}}\right)\right)\right]\right\}
\end{aligned}
$$

where $\mathrm{ET}^{\mathrm{k}}$ is total root-zone evapotranspiration for grid cell k; $\mathrm{PET}^{\mathrm{k}}$ is the adjusted clear-sky simulated equilibrium PET rate ${ }^{13}$ for grid cell $\mathrm{k}$; relsat $_{\mathrm{i}}{ }^{\mathrm{k}}$ is the relative saturation calculated for layer $\mathrm{i}$ within grid cell $\mathrm{k} ; \mathrm{a}^{\mathrm{k}}$ and $\mathrm{b}^{\mathrm{k}}$ are the Priestley-Taylor model coefficients for grid cell $\mathrm{k}$ supplied as soil- and rock-type input parameters in the model control file (for this submodel, the coefficients were identical for all soil and rock types but were varied between different climate scenarios and between soils and rocks). After water contents for each layer are reduced according to the calculated evapotranspiration rates, the final runoff and net-infiltration terms are calculated, and the new water-content terms for each root-zone layer are up-dated for the following day's water-balance calculation.

The evapotranspiration coefficients, as given in DTN: GS000300001221.009 [DIRS 147228], are assumed to be representative of conditions at Yucca Mountain. The values used for the $\mathrm{a}$ and $\mathrm{b}$ coefficients in Equation 6-12 are based on measurements at other locations and are commonly used and regarded as appropriate within the scientific community (Priestly and Taylor 1972 [DIRS 125321]; Flint and Childs 1991 [DIRS 124946]).

\subsubsection{Surface-Water Flow-Routing Submodel}

At the completion of the root-zone water balance loop, the surface-water flow submodel is called if the runoff accumulation term is greater than zero (at least one grid cell has generated runoff). The submodel uses an instantaneous flow routing (IFR) method to perform an efficient time-independent simulation of surface-water flow. The purpose of the routing algorithm is to calculate the lateral redistribution of water throughout the watershed domain and to allow for the infiltration of surface water as it is routed. The surface water flow routing algorithm is fully coupled with the algorithm used to calculate infiltration into the root zone. No need exists to

\footnotetext{
${ }^{13}$ The equilibrium potential evapotranspiration rate is calculated using $\alpha=1.0$, and is used to represent the non-advective component of the energy balance (Priestley and Taylor 1972 [DIRS 125321]).
} 
predict a flood wave, peak flows, or backwater effects, and thus finite difference approximations of flow equations are not required. The IFR method assumes that the duration of surface-water flow at Yucca Mountain is less than 24 hours, which is generally supported by the available stream flow records and field observations (Savard 1995 [DIRS 101289]; Flint et al. 1996 [DIRS 100147], Figure 23; DTN: GS960908312121.001 [DIRS 107375]). For the purpose of calculating daily net infiltration, it is not necessary to perform surface water flow routing at time steps less then the daily water balance, especially when stream flow events are known to be episodic and have duration less then 24 hours (at least for current climate conditions).

The routing is performed using parameters calculated by the routine CHNNET16 V1.0 and included in the geospatial parameter input file. The routing parameters identify downstream cell connections for all cells in the model domain. The flow routing routine determines which of eight surrounding grid cells is the lowest in elevation and calculates the flow directions for each grid cell by first sorting the entire base-grid based on elevation, then using a standard D8 convergent flow routing algorithm in the routine. Multiple cells are allowed to route to a single cell, but any given cell can route to only one downstream grid cell (as opposed to two in cases of flow dispersion). In this way, channels are defined for every watershed. In general, it is adequate to drive all flow along one connected node pair. The flow routing algorithm models convergent flow only. Inaccuracies resulting from a lack of flow dispersion are not significant within the area of the repository, and are not significant within most areas of the UZ flow model. Inaccuracies resulting from a lack of flow dispersion tend to increase as flow is routed across more gently sloping alluvial fans, particularly in cases where the stream channel becomes braided or is not well defined.

The IFR submodel repeats the infiltration and percolation simulation performed in the water-balance loop, providing a two-dimensional coupling of surface-water flow and infiltration. As with precipitation and snowmelt, infiltration of run-on is a function of the storage capacity and hydraulic conductivity of the underlying soils and bedrock. The fraction of the total grid cell area affected by surface-water flow is defined in the model control file and is used to scale the bulk hydraulic conductivity of the grid cell as a means of limiting total infiltration volumes along the width of the active channel. Saturated conditions along the active channel are assumed for estimated storm duration of 2 hours for summer storms and 12 hours for winter storms. Positive pressure heads are assumed to be negligible and are not included in the calculation of infiltration volumes. Although the exclusion of positive pressure heads during stream flow events is slightly non-conservative, the timing of storm duration is over-estimated (conservative), so these two simplifications tend to cancel each other. The increase in water content for each layer in the root zone is stored and included in the following day's root-zone water-balance calculation.

Surface water that is routed off the model grid is stored as an outflow term. For watershed model domains, there is only one outflow point and the outflow term represents stream discharge from the watershed. The outflow term is incorporated into a global mass-balance calculation using:

$$
\mathrm{D}=\sum \mathrm{R}_{\mathrm{off}}{ }^{\mathrm{k}}-\sum \mathrm{IR}_{\mathrm{on}}{ }^{\mathrm{k}}=\sum \mathrm{P}^{\mathrm{k}}+\sum \mathrm{SM}^{\mathrm{k}}-\sum \mathrm{SB}^{\mathrm{k}}-\sum \mathrm{SW}^{\mathrm{k}}-\sum \mathrm{ET}^{\mathrm{k}}-\sum \mathrm{I}^{\mathrm{k}}
$$

where $\mathrm{D}$ is the watershed outflow, $\mathrm{P}$ is defined for this equation as rainfall, and the water balance terms defined in Equation 6-1 are summed for all grid cells $\mathrm{k}$ in the watershed. Equation 6-13 is 
calculated for each day of the simulation as means of verifying the mass balance over the modeling domain. Note that in Equation 6-13 the term for snowfall is absent. In Equation 6-1, $\mathrm{P}$ includes snowfall (implicitly), which is then subtracted out explicitly. The term $\sum \mathrm{P}^{\mathrm{k}}$ above (in Equation 6-13) does not (implicitly) include snowfall so it does not need to be reduced by the snowfall amount explicitly.

\subsection{MODEL GRID GEOMETRY AND WATERSHED MODELING DOMAINS FOR THE YUCCA MOUNTAIN SITE}

All acquired and estimated geospatial parameters required as input for INFIL V2.0 [and INFIL VA_2.a1 (SNL 2001 [DIRS 147608])] are combined into a single ASCII file defining the base-grid for all extracted watershed model grids (Output DTN: GS000308311221.004). The geospatial parameter input files defining watershed model domains are extracted as separate files from the developed base-grid using the routine WATSHD20 V1.0 (discussed in Section 6.5.3). All FORTRAN routines (GEOMAP7 V1.0, GEOMOD4 V1.0, SOILMAP6 V1.0, VEGCOV01 V1.0, and BLOCKR7 V1.0) used in the development of the base-grid geospatial parameter input file are listed in Table 3-1. The acquired, exempt software ARCINFO V6.1.2 also was used in the development of the base grid geospatial parameter input file.

\subsubsection{Spatial Discretization and the Base-Grid}

The net infiltration modeling procedure begins with building a geospatial input parameter base grid using the selected DEM to define the base-grid geometry. The DEM (DTN: GS000308311221.006), selected for defining the grid geometry is the composite DEM used for the 1996 net infiltration model (Flint et al. 1996 [DIRS 100147]) that was developed from two standard USGS 7.5 minute 30-meter DEMs (Busted Butte and Topopah Spring NW). The two DEMs (DTN: GS000200001221.003 [DIRS 146278]) were combined into a composite DEM (DTN: GS000308311221.006) by using the ARCINFO GRID module. Within this module a command, MERGE is used to perform the combining process. Once the two DEMs are combined, it was necessary to convert the projection coordinates from decimaldegrees into UTM coordinates. This was done using the standard ARCINFO PROJECT command. The grid geometry of the composite DEM (DTN: GS000308311221.006) is based on the Universal Transverse Mercator projection (zone 11, NAD27, DTN: GS000200001221.003 [DIRS 146278]) and consists of 691 rows in the north-south direction and 367 columns in the east-west direction covering a rectangular area centered over Yucca Mountain and the repository site, with the following corner coordinates:

$\begin{array}{ll}\text { Northwest corner: } & 544,661 \mathrm{~m} \text { easting, 4,087,833 m northing } \\ \text { Northeast corner: } & 555,641 \mathrm{~m} \text { easting, 4,087,833 m northing } \\ \text { Southeast corner: } & 555,641 \mathrm{~m} \text { easting, 4,067,133 m northing } \\ \text { Southwest corner: } & 544,661 \mathrm{~m} \text { easting, 4,067,133 m northing }\end{array}$

The 253,597 elevation values provided by the composite DEM is the primary geospatial parameter used by the net infiltration model. The development of the geospatial parameter input grid and the separate watershed modeling domains requires the application of GIS to transfer available digitized map data, which is in a vector-based format, onto the grid-cell or raster-based format of the DEM (a process referred to as rasterization). 
Figure 6-8 is a shaded relief representation of the Yucca Mountain DEM and includes the location of the 1999 UZ flow model boundary, the 1999 design repository boundary, and the trace of the main Exploratory Studies Facility drift. Also shown are the locations of the neutron borehole sites used to calibrate the 1996 model as well as provide core samples for measuring bedrock hydraulic conductivity (Appendix B). Figure 6-8 illustrates the level of detail provided by the DEM in terms of representing discrete topographic features by using elevation, which is the primary geospatial-input parameter for the net-infiltration model. The DEM has an average elevation of $1,237 \mathrm{~m}$, a minimum elevation of $918 \mathrm{~m}$ along the southern perimeter, and a maximum elevation of 1,969 $\mathrm{m}$ along the northern perimeter.

DEM elevations in the base grid are used for calculating and estimating geospatial-input parameters and are also used directly as an input in the developed geospatial-parameter input file. Section 6.3.2 discusses the application of elevation directly as an input parameter for INFIL V2.0 calculations, which includes estimating the spatial distribution of precipitation and air temperature. Sections 6.5.2 and 6.5.3 discuss the application of DEM elevations for calculating flow-routing parameters and developing watershed model domains using the routines SORTGRD1 V1.0, and CHNNET16 V1.0. Section 6.4.4 describes the application of DEM elevations for calculating topographic parameters, which include slope, aspect, and blocking ridge angles, using ARCINFO V6.1.2 and the routine BLOCKR7 V1.0.

\subsubsection{Development of the Surface Drainage Network}

To generate watershed-modeling domains, the surface-water drainage network was defined using the base grid supplied as output from SOILMAP6 V1.0 and GEOMOD4 V1.0. Flow directions were calculated for each grid cell using a 2-step process. For the first step, the entire base grid is sorted by elevation using the routine SORTGRD1 V1.0. In the second step, flow-routing directions are calculated based on a standard D8 routing algorithm (flow is routed to one of eight adjacent grid cells having the lowest elevation) using the routine CHNNET16 V1.0.

CHNNET16 V1.0 is a convergent flow routing algorithm; multiple cells are allowed to route to a single cell, but any given cell can route to only one downstream grid cell (as opposed to two in cases of flow dispersion). The CHNNET16 V1.0 algorithm provides a method for routing through surface depressions in the DEM, which were found to be numerous. The surface depressions are in part a characteristic of poorly established drainage networks across alluvial fans and basins in arid and semiarid environments. Surface depressions are also caused by inaccuracy in the DEM in terms of both elevation values and grid resolution. If the DEM grid is too coarse relative to channel dimensions it cannot accurately capture the natural channel, and this problem tends to be most severe on broad alluvial fans and basins as opposed to upland areas where the drainage network is more accurately defined by the rugged terrain. The CHNNET16 V1.0 routing algorithm allows DEM surface depressions of up to 20 layers deep ( 20 grid cells need to be crossed before surface flow escapes the depression), and this was found to be greater than the largest depression encountered in the Yucca Mountain DEM. In addition to the flow routing parameters, output from CHNNET16 V1.0 includes a flow accumulation term, which indicates the number of upstream cells for each grid cell in the initial model grid (Figure 6-9). 


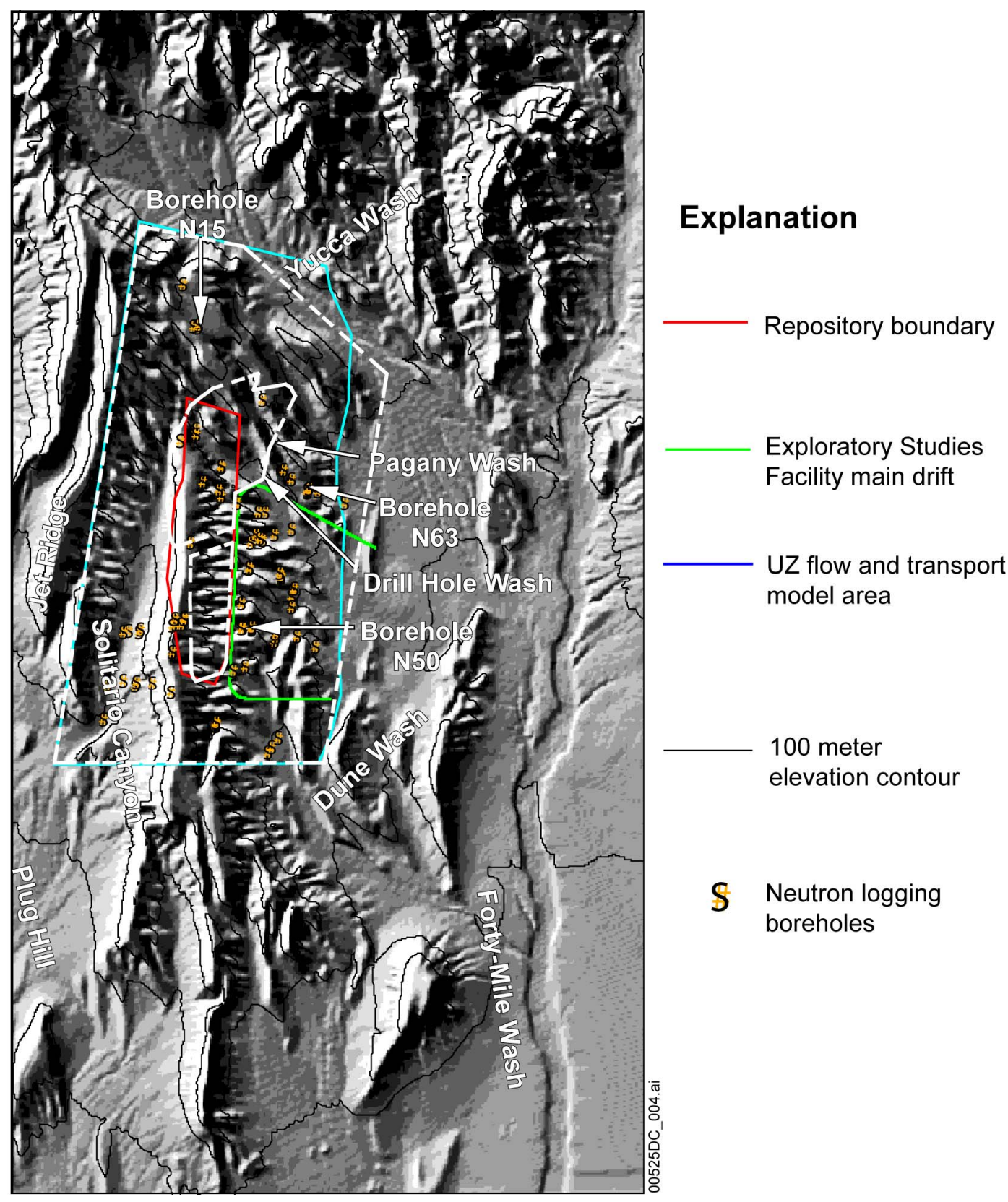

Source: DTN: GS000308311221.006.

NOTE: The 1999 UZ flow model domain (in blue) and the 1999 repository footprint (in red) are site recommendation boundaries, not license application boundaries (white dashed lines).

Figure 6-8. Yucca Mountain DEM Used to Define Geospatial-Input Parameters and Watershed Modeling Domains 


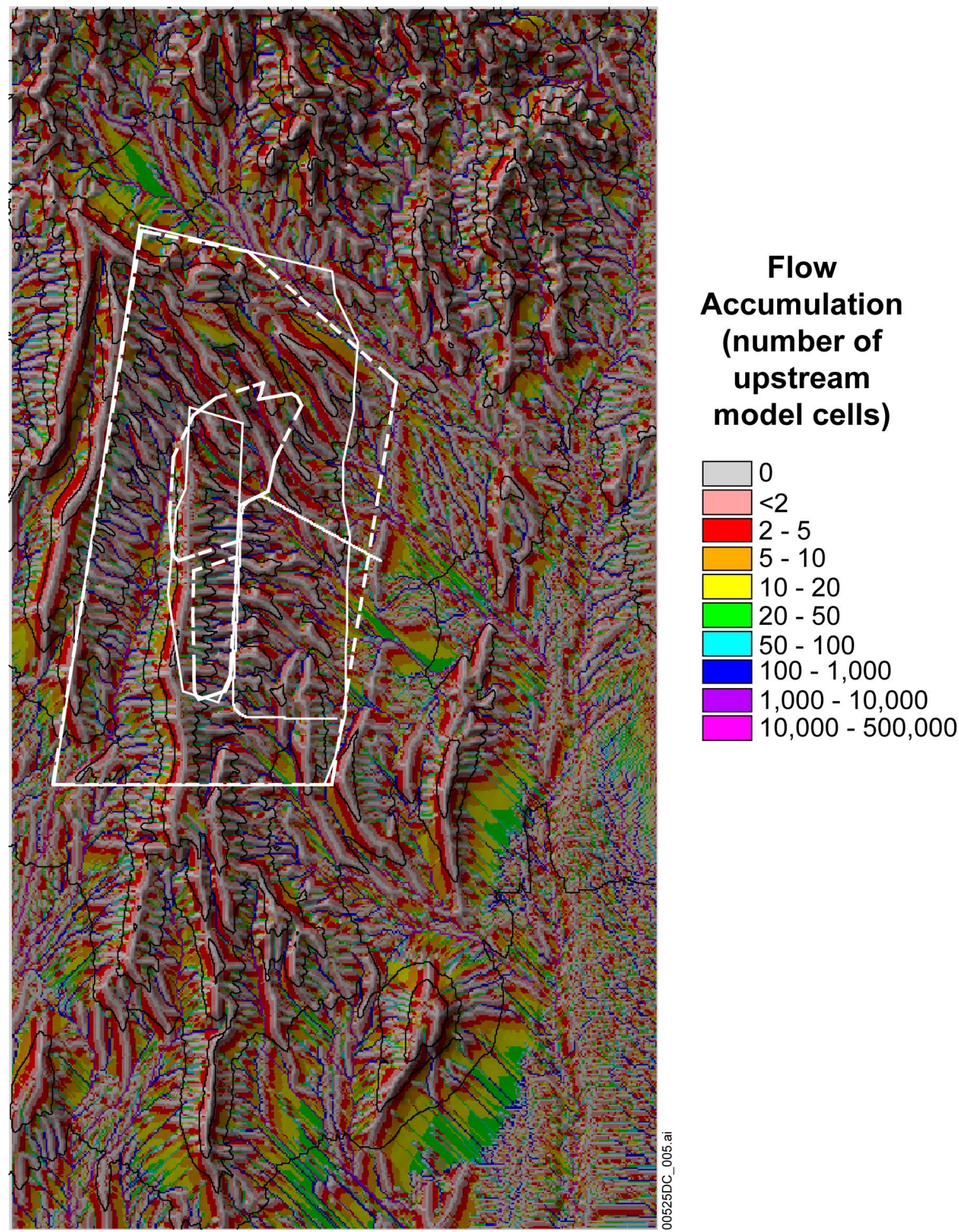

Source: DTN: GS000308311221.006.

NOTES: See Appendix I for details and explanation of Flow Accumulation.

The $1999 \mathrm{UZ}$ flow model domain and the 1999 repository footprint are site recommendation boundaries (solid lines), not license application boundaries (dashed line).

Figure 6-9. Number of Upstream Cells Indicating the Numerical Channel Network 


\subsubsection{Development of Watershed Model Domains}

Division of the net-infiltration model domain into a set of smaller, isolated watershed model domains was needed to decrease simulation run-times for INFIL V2.0 by allowing the simulation to be distributed over multiple computer processors at the time when the modeling work was performed. The isolated watershed domains allow for a more efficient analysis of the impact of watershed characteristics on simulation results. Additionally, the smaller, closed modeling systems enable a more efficient mass balance checking because each model domain is a single watershed with only one outflow location.

To develop a composite watershed-modeling domain consisting of all watersheds either overlying or immediately adjacent to the area of the site-scale UZ flow model, the boundary of the UZ model was overlain on the numerically defined drainage networks obtained from CHNNET16 V1.0. The outflow cell (the discharge point for all upstream grid cells) of each major drainage network affecting the UZ model area was identified using the INFIL subroutine TRANSFORM for a visual analysis of the flow accumulation map (Figure 6-10). A total of 10 separate watershed model grids were extracted using the routine WATSHD20 V1.0, which executes a reverse flow-routing algorithm to identify all model cells upstream from the selected outflow cell. The model grid defining the extracted watershed domain includes the active grid cells upstream from the outflow cell and also an outer perimeter layer of inactive cells that are needed as boundary cells during surface-water flow routing. The perimeter cells are also used in the mass-balance checking calculation performed using Equation 6-13 to ensure that outflow is consistent with the cumulative mass balance calculated for all grid cells in the watershed model domain.

Whether or not the calculated flow divides accurately represents the natural system depends on the resolution and accuracy of the DEM, and the accuracy of the flow routing algorithm in capturing the true channel network. An assumption was made that the accuracy of the DEM and the accuracy of the D8 flow routing algorithm of CHNNET16 V1.0 was adequate for the purpose of this modeling activity. This assumption was based in part on the knowledge that the model results would be interpolated onto the coarser mesh of the UZ flow model. The assumption was also based on the knowledge that a static DEM was being used to represent topography for the next 10,000 years. In other words, an accurate representation of the present-day channel network at Yucca Mountain is considered to be of minor importance given that the active channel network is likely to change significantly over a 10,000-year period, particularly if wetter climates develop. 


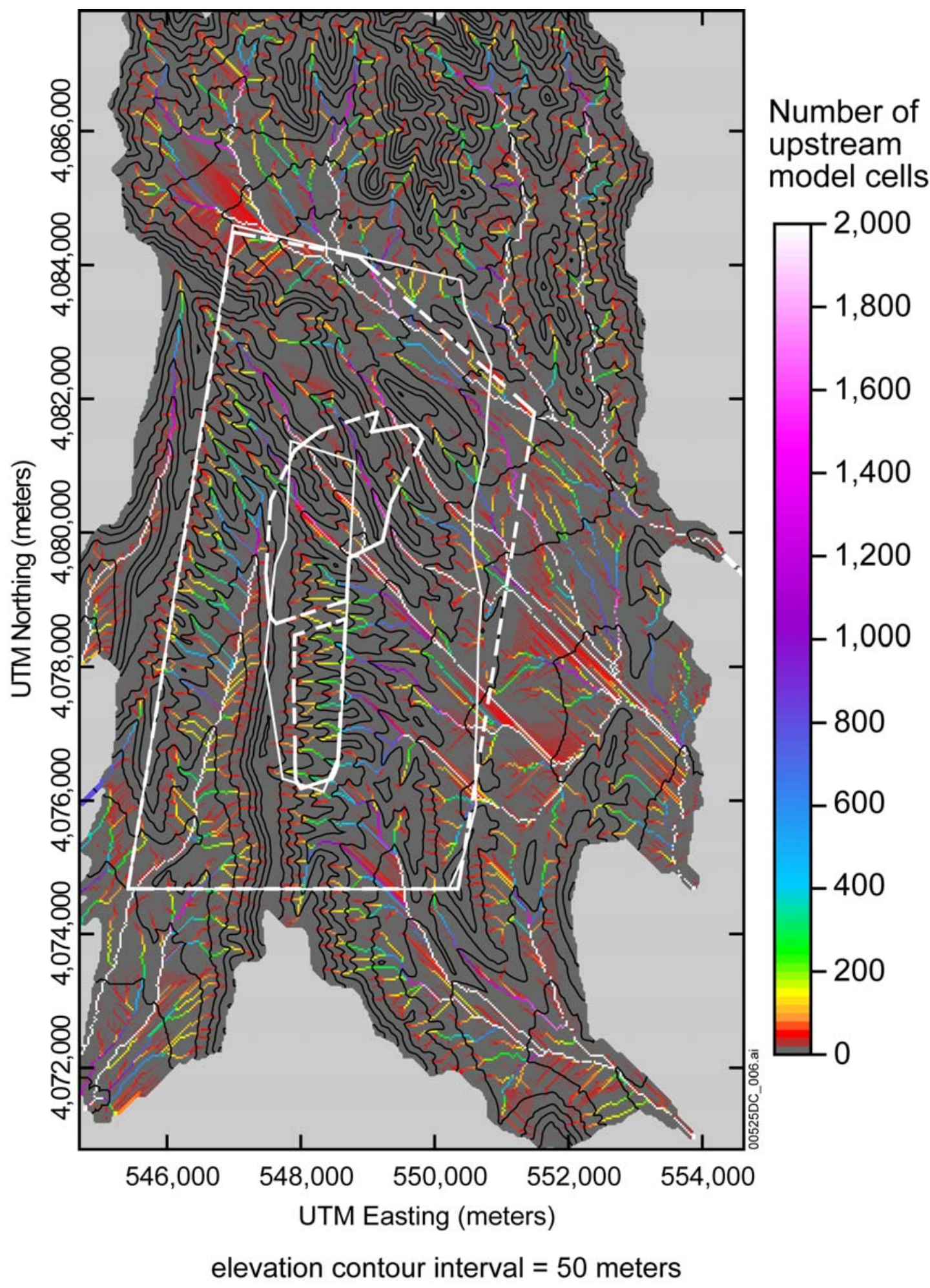

Source: DTN: GS000308311221.006.

NOTES: See Appendix I.

The 1999 UZ flow model domain and the 1999 repository footprint are site recommendation boundaries (solid lines), not license application boundaries (dashed lines).

Figure 6-10. Isolation of the Drainage Networks Overlying the Area of the UZ Flow Model 
The main watersheds included in the composite watershed model area are Yucca Wash, Drill Hole Wash, Dune Wash, Solitario Canyon \#1, and Plug Hill ${ }^{14}$ (Figure 6-11). Additional drainages that were included in the composite model to provide a buffer zone along the western edge of the UZ model are Jet Ridge \#1, Jet Ridge \#2, Jet Ridge \#3, Solitario Canyon \#2, and Solitario Canyon \#4. The watershed model domains were restricted to the western side of the Fortymile Wash channel because the Yucca Mountain DEM captures only a small part of the lower Fortymile Wash drainage, and complete watersheds cannot be defined for most sections of the DEM east of Fortymile Wash. With the exception of Yucca Wash and Jet Ridge \#1, all watersheds are fully defined by the DEM. For Yucca Wash, northern sections of the watershed are missing because the DEM does not extend far enough north (the northern perimeter of the watershed is defined by the DEM boundary). The missing area is small relative to the total watershed area, and the only potential impact occurs in the Yucca Wash channel along the northeastern perimeter of the UZ flow model area. For Jet Ridge \#1, the lowermost segment of the eastern perimeter is defined by the DEM boundary. The missing eastern section of Jet Ridge \#1 is an insignificant area that does not affect results obtained for the UZ flow model area.

\subsection{GEOSPATIAL INPUT PARAMETERS}

The parameters included in the geospatial-parameter input file defining each watershed model domain are: grid cell identifier, UTM easting (meters), UTM northing (meters), latitude (decimal degrees), longitude (decimal degrees), row identifier, column identifier, downstream grid cell identifier, number of upstream cells, elevation (meters), slope (degrees inclination from horizontal), aspect (degrees from north), soil-type identifier, soil depth class identifier, soil depth (meters), rock-type identifier, topographic position identifier, vegetation-type identifier, percent vegetation cover, and 36 blocking-ridge angles.

\subsubsection{Topographic Parameters (Slope, Aspect, and Blocking Ridges)}

Topographic parameters, such as the flow-routing parameters discussed in Section 6.5.2, are calculated directly from the DEM and included in the geospatial-parameter input file. Additional topographic parameters include slope, aspect, and blocking ridge angles, which are required by the SOLRAD, submodel in INFIL V2.0, routine in the PET submodel. Slope is also a required input parameter for estimating soil depths using the routine SOILMAP6 V1.0. Slope and aspect were calculated for the 1996 version of the net-infiltration model (Flint et al. 1996 [DIRS 100147]) using standard GIS applications in ARCINFO V6.1.2.

The 36 blocking ridge angles (degrees of inclination above horizontal) are calculated at each $10^{\circ}$ horizontal arc (with the azimuth aligned in the UTM northing direction) for each grid cell using the routine BLOCKR7 V1.0. Calculations were performed using the DEM as input and a technique for approximating the $10^{\circ}$ horizontal angles based on northing and easting grid cell distances. The blocking ridge parameters cannot account for topographic influences outside of the DEM, and thus the blocking ridge effect is only partly accounted for along the perimeter of the DEM.

\footnotetext{
${ }^{14}$ The names selected for the extracted watershed modeling domains are not necessarily the established geographic names for these physiographic features. They are used here only as a means of identifying the separate watershed models.
} 


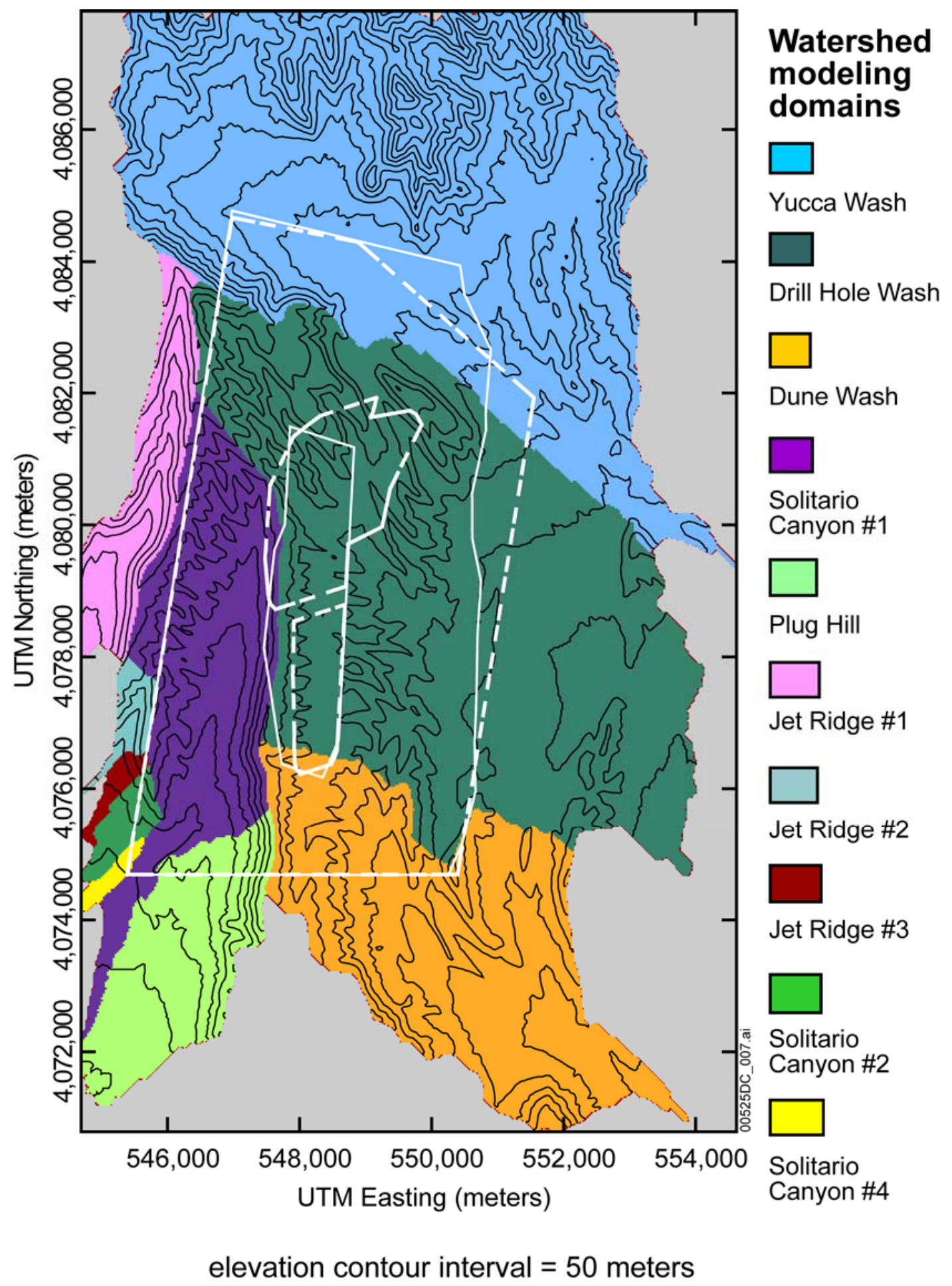

Source: DTN: GS000308311221.006.

NOTE: See Appendix K.

The 1999 UZ flow model domain and the 1999 repository footprint are site recommendation boundaries (solid lines), not license application boundaries (dashed line).

Figure 6-11. Location of 10 Watershed Model Domains Included in the Composite Watershed Model Area Overlying the Area of the UZ Flow Model 


\subsubsection{Soil-Depth Classes}

A soil-depth-class map consisting of four separate soil-depth classes was developed for the 1996 net-infiltration model (Flint et al. 1996 [DIRS 100147], Figure 13; DTN: GS960508312212.007 [DIRS 124829]). The four depth classes represent different ranges in actual soil depths that were estimated using a combination of Quaternary geologic maps, field observations, and soil depth recorded at borehole sites (Flint and Flint 1995 [DIRS 100394], Table 2). Depth class \#1 identifies locations with soil depths ranging from 0 to 0.5 meter and primarily occurs in rugged upland areas. Depth class \#2 identifies deeper soils ranging from 0.5 to $3.0 \mathrm{~m}$ occurring at mid to lower side-slope locations in upland areas affected by slumps, slides, and other mass-wasting processes. Depth class \#3 identifies locations in the transition zone between upland areas and alluvial fans or basins with intermediate soil depths ranging from 3 to $6 \mathrm{~m}$. Depth class \#4 identifies soils with depths of $6 \mathrm{~m}$ or greater. The soil-depth classes were used to estimate soil depths based on calculated slope and an empirical soil-depth model described in Appendix B.

\subsubsection{Soil Types}

A soil-type classification map is defined by Flint et al. (1996 [DIRS 100147]; DTN: GS960508312212.007 [DIRS 124829]). The soil-type classification is based on a recombination of mapped Quaternary surficial deposits and defines ten unique soil types based primarily on differences in soil texture (Figure 6-12). Soil texture and porosity data were obtained using field samples and laboratory measurements (DTN: GS950708312211.002 [DIRS 146874]) as described by Flint et al. (1996 [DIRS 100147]; p. 42). Soil hydrologic properties consisting of hydraulic conductivity, residual water content, and field capacity were both measured and estimated using the soil texture data as described by Flint et al. (1996 [DIRS 100147], p. 41) and Appendix B. The soil hydrologic properties included directly as model input (using the model control file) for INFIL V2.0 consist of porosity, field capacity, residual water content, and saturated hydraulic conductivity. These are the same as the properties used in the 1996 version of the net-infiltration model, which are listed by Flint et al. (1996 [DIRS 100147], Table 4, p. 42) and Appendix B.

\subsubsection{Bedrock Geology}

Bedrock geology was defined for each grid element using three different ARCINFO map coverages and a vector-to-raster conversion performed by ARCINFO. Figure 6-13 indicates the areal coverage of the three maps: the 1:6,000-scale Bedrock Geologic Map of the central block area (Day et al. 1998 [DIRS 101557], DTN: GS971208314221.003 [DIRS 107128]); the Preliminary Geologic Map of Yucca Mountain, Nye County, Nevada, with Geologic Sections (Scott and Bonk 1984 [DIRS 104181], DTN: MO0003COV00095.000 [DIRS 146848]); and the Geologic Map of the Topopah Spring Northwest Quadrangle found in Preliminary Digital Geological Map Database of the Nevada Test Site Area, Nevada (Sawyer et al. 1995 [DIRS 104580], DTN: GS000300001221.010 [DIRS 147833]). Within the UZ flow model area, bedrock geology for the net-infiltration model (which is defined as a unique integer identifier for each rock type in the geospatial-parameter input file) is primarily defined by Day et al. (1998 [DIRS 101557]). Bedrock geology for the northern and southern perimeter sections of the UZ flow model area is defined by Scott and Bonk (1984 [DIRS 104181]). 


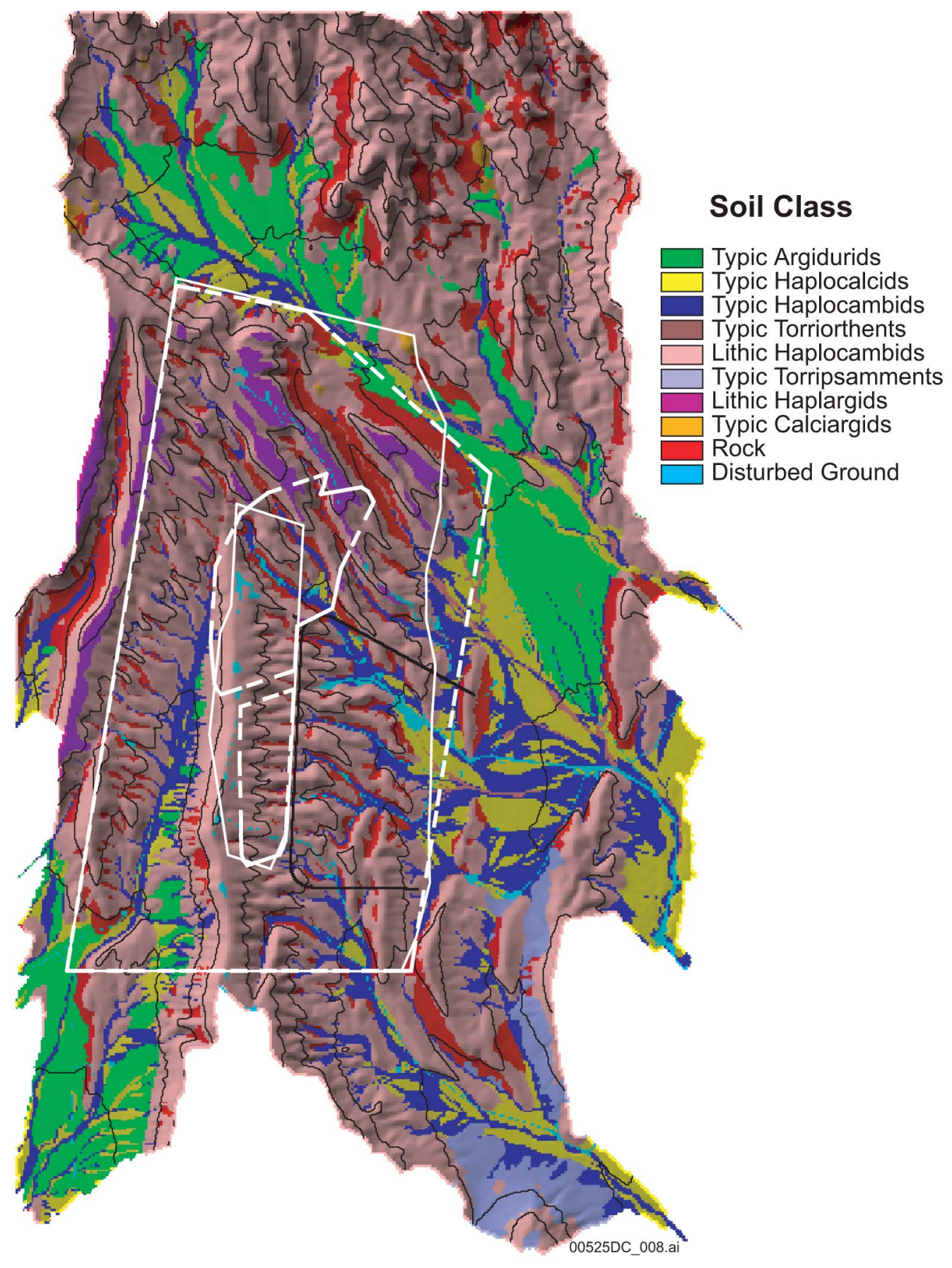

Source: Flint et al. (1996 [DIRS 100147]), Figure 14.

Output DTN: GS000308311221.004.

NOTE: The 1999 UZ flow model domain and the 1999 repository footprint are site recommendation boundaries (solid lines), not license application boundaries (dashed lines).

Figure 6-12. Recombined Soil Classes Used in the 1996 Net-infiltration Model 


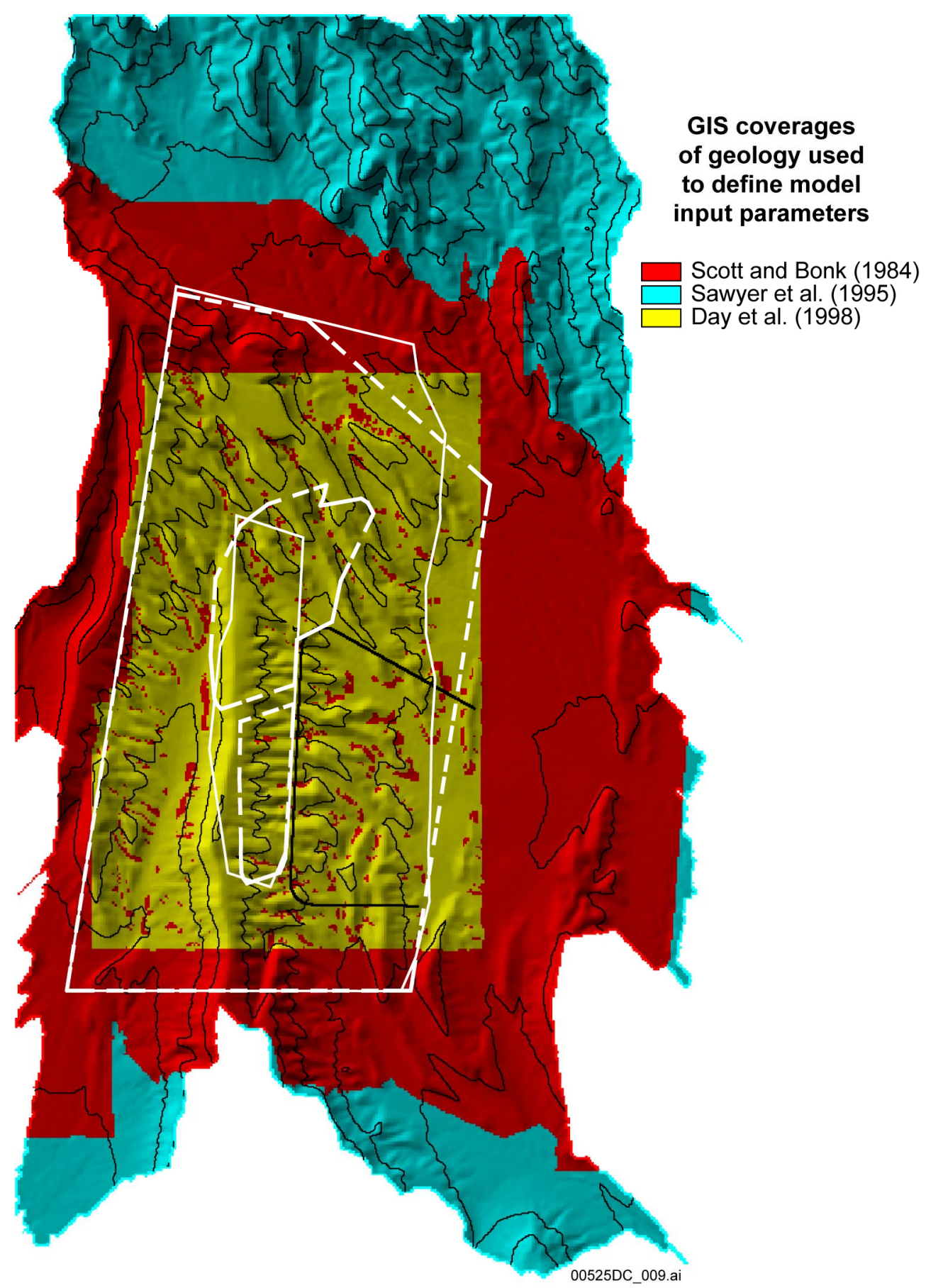

Sources: Day et al. (1998 [DIRS 101557]), DTN: GS971208314221.003 [DIRS 107128]; Scott and Bonk (1984 [DIRS 104181]), DTN: MO0003COV00095.000 [DIRS 146848]; Sawyer et al. (1995 [DIRS 104580]), DTN: GS000300001221.010 [DIRS 147833].

NOTE: The 1999 UZ flow model domain and the 1999 repository footprint are site recommendation boundaries (solid lines), not license application boundaries (dashed lines).

Figure 6-13. Overlay of the Three Geologic Maps Used to Define Rock Types Underlying the Root Zone and Included in the Bottom Root-zone Layer 
Bedrock geology for the 1996 version of the net-infiltration model was defined by Scott and Bonk (1984 [DIRS 104181]; DTN: MO0003COV00095.000 [DIRS 146848]) and Sawyer et al. (1995 [DIRS 104580], DTN: GS000300001221.010 [DIRS 147833]) map coverages (Flint et al. 1996 [DIRS 100147], Figure 10). To incorporate the Day et al. (1998 [DIRS 101557]) geology for INFIL V2.0, the rasterized version of the Day et al. (1998 [DIRS 101557]) map coverages (DTN: GS971208314221.003 [DIRS 107128]) was integrated with the bedrock geology defined by the 1996 version of the geospatial input file (Output DTN: GS000308311221.004) using the routine GEOMAP7 V1.0. Figure 6-14 indicates that for some locations within the geologic map coverages (Day et al. 1998 [DIRS 101557]), bedrock geology for the net-infiltration model is defined by GEOMAP7 V1.0 using the geologic map (Scott and Bonk 1984 [DIRS 104181]; DTN: MO0003COV00095.000 [DIRS 146848]). The purpose of including the Scott and Bonk (1984 [DIRS 104181]) geology (DTN: MO0003COV00095.000 [DIRS 146848]) within the Day et al. (1998 [DIRS 101557]) map coverages (DTN: GS971208314221.003 [DIRS 107128]) is to estimate bedrock geology for some locations mapped by Day et al. (1998 [DIRS 101557]) as alluvium or colluvium and having intermediate soil depths less than $6 \mathrm{~m}$ (as defined by the soil depth class map from Flint et al. (1996 [DIRS 100147], Figure 13; DTN: GS960508312212.007 [DIRS 124829]). Locations having intermediate soil depths primarily occur in the transition from upland areas to alluvial fans and basins. Assigning a bedrock type of colluvium or alluvium to grid cells having a soil depth less than $6 \mathrm{~m}$ was considered problematic in terms of modeling net infiltration. Conceptually, all grid cells with a soil depth less than $6 \mathrm{~m}$ should be underlain by a consolidated bedrock type to avoid inconsistency in terms of the assigned soil depth and the estimated rootzone depth. The available geologic maps, however, are representations of the surface geology and do not necessarily indicate bedrock geology for locations having one to $6 \mathrm{~m}$ of soil cover. In general, the consolidated bedrock geology defined by Scott and Bonk (1984 [DIRS 104181]) extends farther into the intermediate soil-depth areas then the consolidated bedrock geology defined by Day et al. (1998 [DIRS 101557]) and thus was substituted by GEOMAP7 V1.0 for the colluvium or alluvium defined by Day et al. (1998 [DIRS 101557]) at many locations with intermediate soil depths.

To ensure that a consolidated rock type was defined as the bedrock geology for all grid cells having less than $6 \mathrm{~m}$ of soil, the routine GEOMOD4 V1.0 was applied to the geospatial parameter file created by GEOMAP7 V1.0. GEOMOD4 V1.0 also performs a modification of the depth-class \#3 boundary as defined by Flint et al. (1996 [DIRS 100147], p. 40) for all cases where the boundary was found to be inconsistent with the updated bedrock geology. The algorithm creates a new buffer zone of intermediate soil depths defined by depth class \#3 using the updated alluvium/colluvium - consolidated bedrock boundary. The result is that the modified depth-class parameters defined by GEOMOD4 V1.0 do not allow for grid cells with depth class \#4 (thick soils) to be adjacent to grid cells with thin soils (depth classes \#1 and \#2). All thin soils are separated from the thick soils by at least one grid cell assigned to depth class \#3. Once the soil-depth classes are finalized, GEOMOD4 V1.0 identifies all grid cells having less than $6 \mathrm{~m}$ of soil and alluvium or colluvium as bedrock and interpolates the bedrock geology based on the most prevalent consolidated rock type found within a search neighborhood of one to two grid cell layers. 


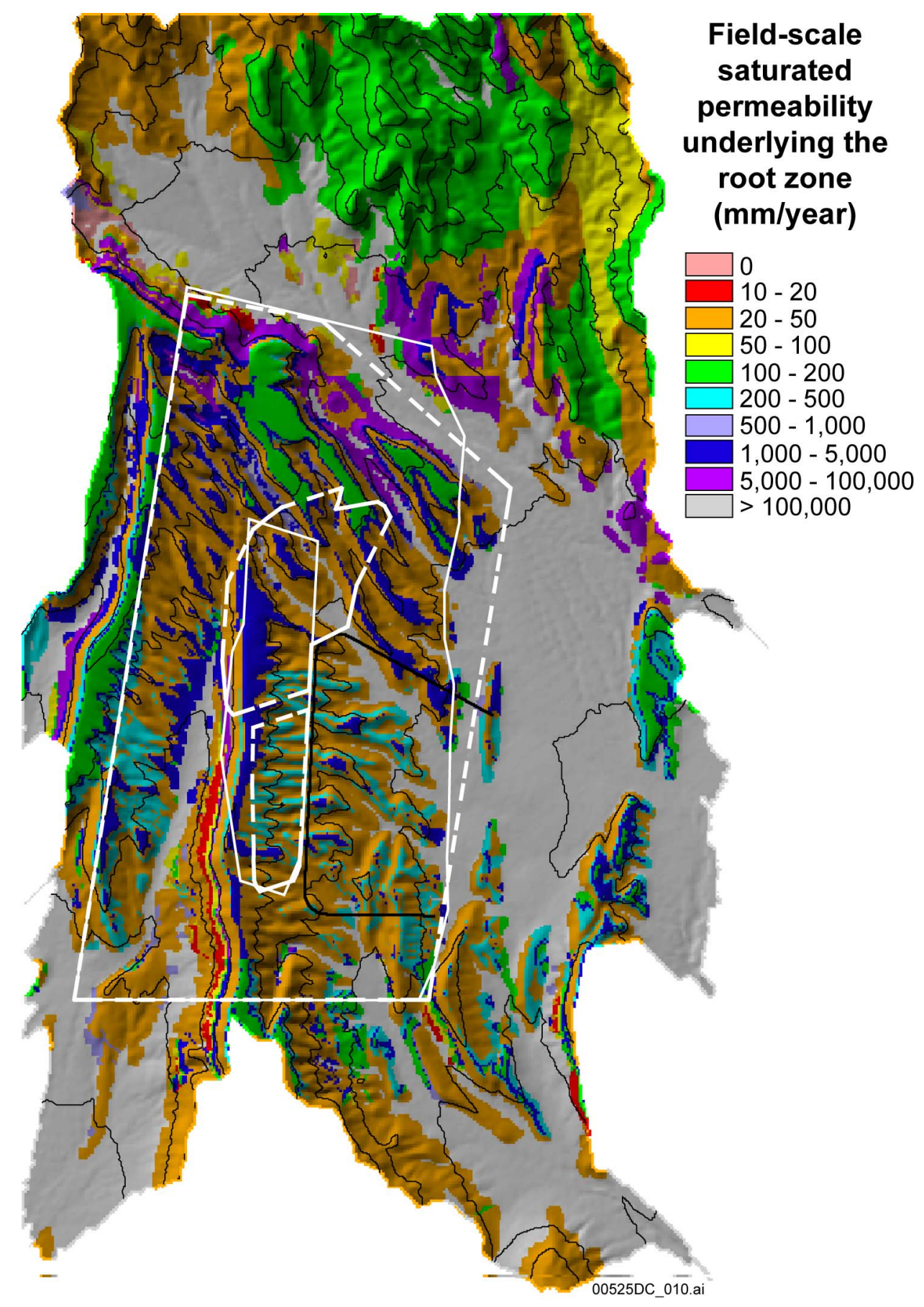

Source: DTN: MO0109HYMXPROP.001 [DIRS 155989].

NOTE: The 1999 UZ flow model domain and the 1999 repository footprint are site recommendation boundaries (solid lines), not license application boundaries (dashed lines).

Figure 6-14. Estimated Field-scale Saturated Hydraulic Conductivity of Bedrock or Soils Underlying the Root Zone 
Bedrock geology is represented in the geospatial-parameter-input file using a unique integer identifier for each rock type (see Appendix B for details). The identifier is linked to an estimated bulk (field-scale) saturated hydraulic conductivity in the model control file. The bulk saturated hydraulic conductivity represents a combination of the saturated hydraulic conductivity of the matrix (Flint 1998 [DIRS 100033]; DTN: MO0109HYMXPROP.001 [DIRS 155989]) and the saturated hydraulic conductivity of fracture-fill material (DTN: GS950708312211.003 [DIRS 146873]) based on the fracture density of the particular rock type. The saturated hydraulic conductivity of the fracture fill material was measured in the laboratory and averaged $43.2 \mathrm{~mm} / \mathrm{d}$ (DTN: GS950708312211.003 [DIRS 146873]) (Appendix B). Estimates of saturated hydraulic conductivity were calculated using these values of fracture conductivity for the percentage of area covered by the fracture per square meter of rock, given the fracture density and size of aperture available through which water can flow. This was added to the saturated hydraulic conductivity of the rock matrix and weighted averages of bulk bedrock saturated hydraulic conductivity were calculated on the basis of percentages of matrix and fractures by lithostratigraphic unit. These calculations are also provided by Flint et al. (1996 [DIRS 100147], Table 2; Output DTN: GS000308311221.004), and in Appendix B. Bulk saturated hydraulic conductivity values for the updated Day et al. (1998 [DIRS 101557]) geology rock types were defined using lithologic correlations with the Scott and Bonk (1984 [DIRS 104181]) geology (DTN: MO0003COV00095.000 [DIRS 146848]). In general, the number of unique bedrock units with different bulk hydraulic conductivity values decreased with the incorporation of the Day et al. (1998 [DIRS 101557]) geology. Figure 6-14 shows the bulk bedrock hydraulic conductivity for the three combined geologic map coverages. The bulk saturated hydraulic conductivities range from a minimum of less than $10 \mathrm{~mm} / \mathrm{year}$ for densely welded tuffs with low matrix hydraulic conductivity and relatively small fracture densities to a maximum of more than $100,000 \mathrm{~mm} /$ year for alluvium and colluvium.

The software routine, VEGCOV01 V1.0, is used in the development of the geospatial parameter input files for INFIL V2.0. The routine changes the saturated hydraulic conductivity of $13.83 \mathrm{~mm} /$ day for the Yucca Mountain Tuff of the Paintbrush Group (rock type 324). The different saturated hydraulic conductivity is assigned if the exposed Yucca Mountain Tuff is north of $4082606.93 \mathrm{~m}$ (rock type 309 is assigned with a saturated hydraulic conductivity of $0.06 \mathrm{~mm} /$ day) or south of $4079955.91 \mathrm{~m}$ north (rock type 308 is assigned with a saturated hydraulic conductivity of $46.66 \mathrm{~mm} /$ day) on Yucca Mountain. Table B-3 lists saturated hydraulic conductivities for all geologic units used with INFIL. Note that this routine also provides estimates of vegetation cover (hence the name of the subroutine) based on slope (steeper slopes are assumed to have less plants), aspect (north facing slopes assumed to have more plants), and geology (colluvium/alluvium assumed to have more plants). However, this component of the routine is not currently used by INFIL.

\subsection{ESTIMATED ROOT-ZONE DEPTH AND VERTICAL LAYERING}

\subsubsection{Estimated Soil Depth}

Soil depth is estimated using a combination of the soil-depth class map and an estimated linear relation between soil depth and slope within each depth class. The empirical soil-depth model is based on an assumed soil depth/slope correlation (Output DTN: GS000308311221.004), Appendix B, within the soil depth classes defined for the 1996 version of the net-infiltration 
model (Flint et al. 1996 [DIRS 100147]; DTN: GS960508312212.007 [DIRS 124829]). The conceptual soil-depth model for depth class $\# 1$ assumes that soils are thinnest at summit and ridge-crest areas as well as steep side slopes. Thicker soils are expected to occur at the relatively gently sloping shoulder areas that define the transition between summit or ridge-crest areas and steep side slope areas. Thicker soils are also expected to occur for more gently sloping foot-slope locations. The model for soil-depth class 1 is defined by:

$$
\begin{array}{ll}
\mathrm{D}=0.03 * \mathrm{~S}+0.1, & \mathrm{~S} \leq 10 \\
\mathrm{D}=0.013 *(10-\mathrm{S})+0.4, & 10<\mathrm{S}<40 \\
\mathrm{D}=0.01, & \mathrm{~S} \geq 40
\end{array}
$$

where $\mathrm{D}$ is soil depth (in meters), and $\mathrm{S}$ is slope (degrees). The model for depth class \#2 is defined by:

$$
\begin{array}{ll}
\mathrm{D}=2-(0.05 * \mathrm{~S}), & \mathrm{S}<32 \\
\mathrm{D}=0.4, & \mathrm{~S} \geq 32
\end{array}
$$

and the model for depth class \#3 is defined by:

$$
\begin{array}{ll}
\mathrm{D}=6-(0.16 * \mathrm{~S}), & \mathrm{S}<25 \\
\mathrm{D}=2.0, & \mathrm{~S} \geq 25
\end{array}
$$

For depth class \#4, soil depth is set to a uniform depth of $6 \mathrm{~m}$.

Figure 6-15 shows the spatial distribution of estimated soil depth (Output DTN: GS000308311221.004) with relatively thin soils less than $0.2 \mathrm{~m}$ deep along steep side slopes, and thicker upland soils 0.3 to $0.4 \mathrm{~m}$ along ridgetop and shoulder areas. All locations having a soil depth of $6 \mathrm{~m}$ (as indicated by the color gray in Figure 6-12) are underlain by alluvium or colluvium rock-types. The six-meter soil depth represents only the depth of the root zone, not the actual soil depth.

\subsubsection{Estimated Root-Zone Depth}

The estimated soil-depth map is used to estimate the depth of the root zone by using an empirical model based on field observations and neutron moisture meter data analyses:

$$
\begin{array}{ll}
\mathrm{RZ}^{\mathrm{k}}=\mathrm{SD}^{\mathrm{k}}+\left[\mathrm{RZc}-\left(\mathrm{SD}^{\mathrm{k}} / \mathrm{RZd}\right)\right], & {\left[\mathrm{RZc}-\left(\mathrm{SD}^{\mathrm{k}} / \mathrm{RZd}\right)\right] \geq 0} \\
\mathrm{RZ} Z^{\mathrm{k}}=\mathrm{SD}^{\mathrm{k},}, & {\left[\mathrm{RZc}-\left(\mathrm{SD}^{\mathrm{k}} / \mathrm{RZd}\right)\right]<0}
\end{array}
$$

where $\mathrm{RZ}^{\mathrm{k}}$ is the estimated root-zone depth (in meters) at grid location $\mathrm{k} ; \mathrm{SD}^{\mathrm{k}}$ is the estimated soil depth at grid location k; and RZc and RZd are coefficients supplied as input in the model control file. The coefficients are used to adjust the depth of the root zone extending into bedrock for locations with thin soils. For example, for the present-day climate simulations, RZc and RZd were both set to 2 , and thus the extension of the root zone into bedrock was limited to locations with soil depth less than $4 \mathrm{~m}$. Using Equation 6-17, the root zone extends $2 \mathrm{~m}$ into bedrock for locations having no soil, one meter into bedrock for locations having $2 \mathrm{~m}$ soil depth, and $1.5 \mathrm{~m}$ into bedrock for locations having $1 \mathrm{~m}$ soil depth. The empirical model defined by Equation 6-17 is consistent with the estimated root-zone depth as defined by Flint et al. (1996 [DIRS 100147] Table 5) and is derived on the basis of field observations of rooting depth into bedrock, and evaluation of measurements of extraction of water within the estimated root zone in bedrock, using neutron moisture meters. 


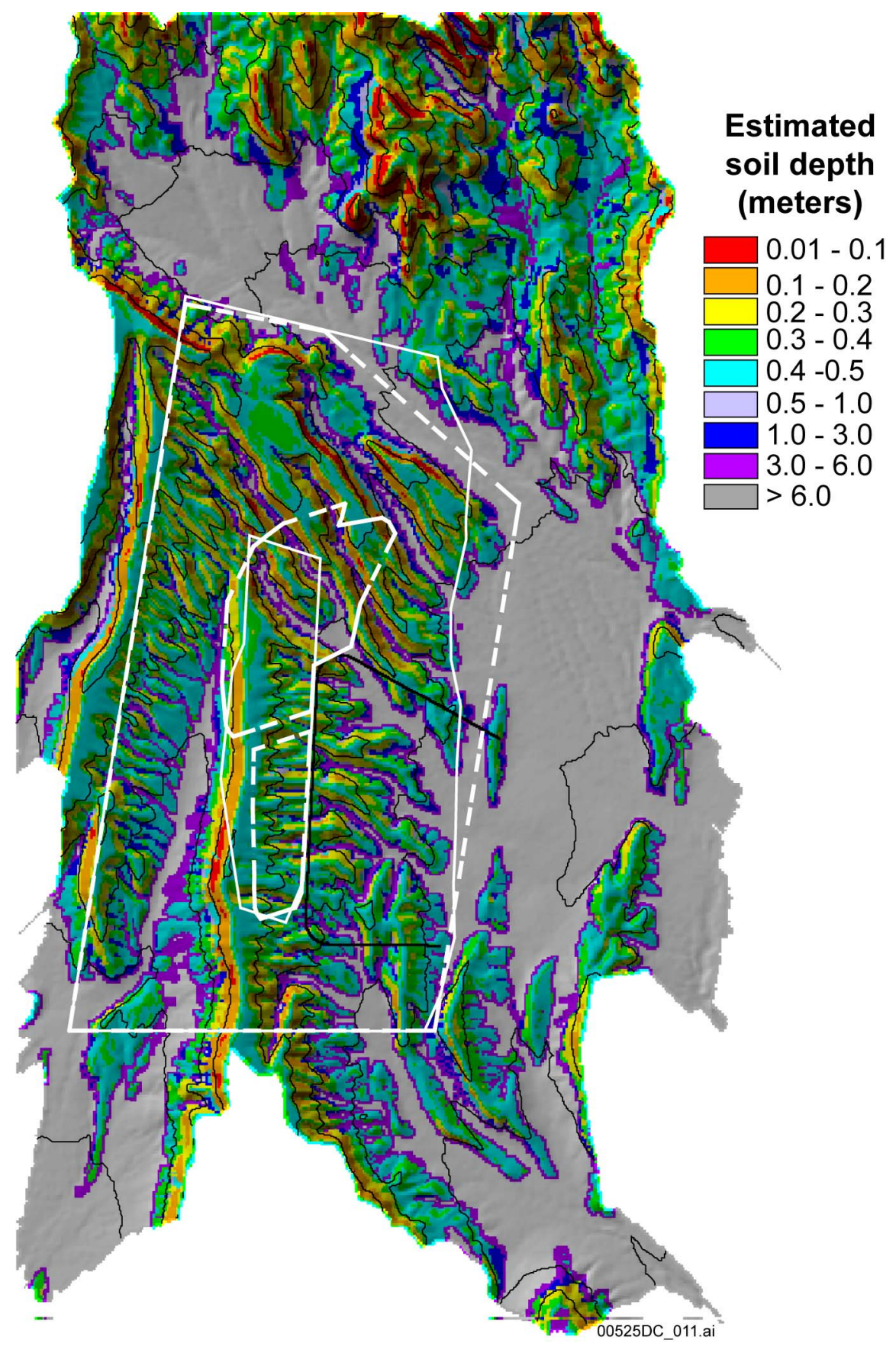

Source: DTN: GS960508312212.007 [DIRS 124829].

Output DTN: GS000308311221.004.

NOTE: The 1999 UZ flow model domain and the 1999 repository footprint are site recommendation boundaries (solid lines), not license application boundaries (dashed lines).

Figure 6-15. Estimated Soil Depth Using the 1996 Soil-depth Class Map and Calculated Land-surface Slope 


\subsubsection{Estimated Root-Zone Layering and Root-Zone Density}

Root-zone layers are defined to represent differences in root-zone density, storage capacity, and hydrologic properties affecting evapotranspiration and percolation within the root zone. The layers are used to model vertical percolation and redistribution of water in the root zone, as described in Sections 6.4.5 and 6.4.6. The top layer is used to model both bare-soil evaporation and shallow transpiration. Three lower root-zone layers, which include two soil layers and the bottom bedrock layer, are used for modeling transpiration only. The thickness of each of the four root-zone layers is variable and is defined by the soil-depth map. The thickness of the

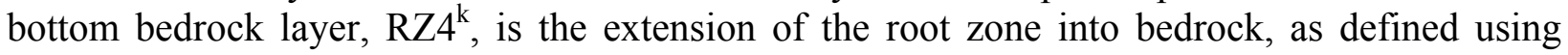
Equation 6-17 above. The thickness of each of the three soil root-zone layers is defined using:

$$
\begin{array}{ll}
\mathrm{RZ1}^{\mathrm{k}}=\mathrm{SD}^{\mathrm{k}} & \mathrm{SD}^{\mathrm{k}} \leq \mathrm{RZa} \\
\mathrm{RZ2}{ }^{\mathrm{k}}=0 & \\
\mathrm{RZ3} 3^{\mathrm{k}}=0 & \\
\mathrm{RZ1k}=\mathrm{RZa} & \mathrm{RZa} \leq \mathrm{SD}^{\mathrm{k}} \leq \mathrm{RZb} \\
\mathrm{RZ2} 2^{\mathrm{k}}=\mathrm{SD}^{\mathrm{k}}-\mathrm{RZa} & \\
\mathrm{RZ3} 3^{\mathrm{k}}=0 & \\
\mathrm{RZ1}^{\mathrm{k}}=\mathrm{RZa} & \mathrm{RZb} \geq \mathrm{SD}^{\mathrm{k}} \\
\mathrm{RZ2}{ }^{\mathrm{k}}=\mathrm{RZb}-\mathrm{RZa} & \\
\mathrm{RZ3} 3^{\mathrm{k}}=\mathrm{SD}^{\mathrm{k}}-\mathrm{RZb} &
\end{array}
$$

where RZ1 is the top root-zone layer thickness (in meters) for grid cell k; RZ2 is the second soil layer thickness; and RZ3 is the third soil layer thickness. Model coefficients RZa and RZb define the maximum thickness of the soil layers. For example, for the present-day climate scenarios, $\mathrm{RZa}=0.3$ and $\mathrm{RZb}=1.5$, and thus the maximum thickness of the top layer is 0.3 meter, the maximum thickness of the second layer is $1.2 \mathrm{~m}$, and the maximum thickness of the third layer is $4.5 \mathrm{~m}$. According to this model, root zones in upland locations with thin soils less than $1.5 \mathrm{~m}$ deep consist of one or two soil layers and one bedrock layer, while alluvial fan terraces having $6 \mathrm{~m}$ or greater soil thickness have three soil layers and no bedrock layer.

The multilayered root-zone model represents variable root-zone properties between layers by using a set of model coefficients specific to each layer. The model coefficients consist of two root-density-weighting factors for each layer (including the bedrock layer) and are defined in the model control file. These root-density-weighting factors were assumed, but are partially based on field observations of root distributions of various plant types at Yucca Mountain. Soil storage capacities are defined for the three soil layers using the soil-type identification assigned to each grid cell in the geospatial-parameter input file, soil porosity, and soil thickness. The bedrock fracture porosity (a coefficient included in the model control file) and the thickness of the bedrock layer define the storage capacity of the bedrock layer. For the 1999 simulations performed in this model activity, a fracture porosity of 0.02 was used for the present-day climate during model calibration based on comparisons of simulated versus measured stream flow. This value is consistent with the fracture porosity value used for TCw in Calibrated Properties Model (BSC 2004 [DIRS 169857], Table 4-3). The total water-storage capacity of the root zone is a function of the estimated root-zone depth, soil depth, soil porosity, and the bedrock fracture porosity. Figure 6-16 illustrates the calculated total water-storage capacity of the root zone. Minimum storage capacities of approximately $40 \mathrm{~mm}$ occur in upland areas with very thin soils 
and indicate the root-zone water storage capacity of fractured bedrock. Maximum storage capacities of more than $1,000 \mathrm{~mm}$ occur at locations with thick alluvium and no bedrock layer included in the root zone.

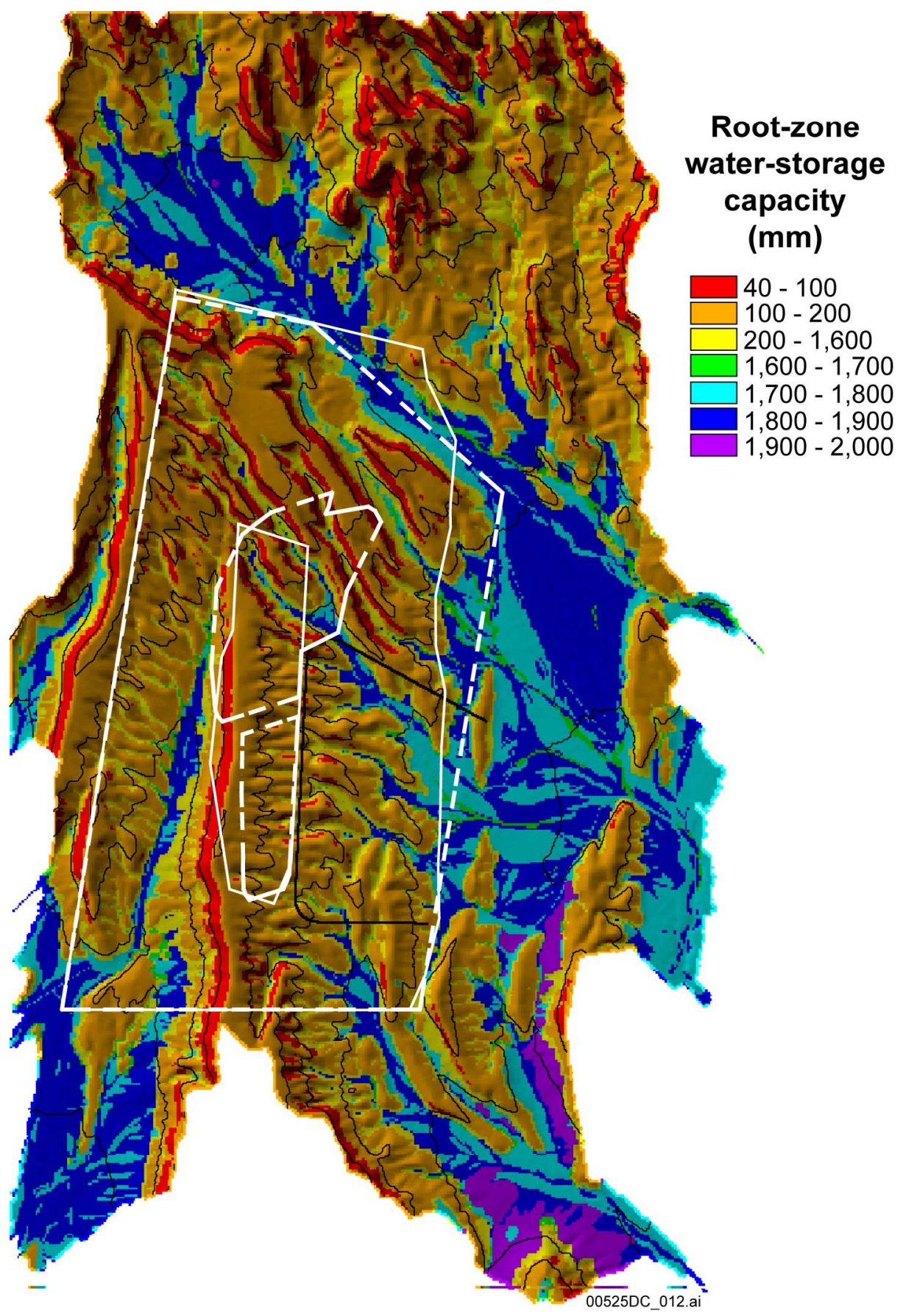

Source: Output DTN: GS000308311221.004.

NOTE: The 1999 UZ flow model domain and the 1999 repository footprint are site recommendation boundaries (solid lines), not license application boundaries (dashed lines).

Figure 6-16. Total Water-Storage Capacity of the Modeled Root Zone, Including Bedrock and Soil Layers 


\subsection{MODEL CALIBRATION}

The 1996 model was initially calibrated by comparing model-calculated volumetric water contents and infiltration rates with those obtained through analysis of time-series water-content profiles from the network of boreholes described in Section 6.3 .4 and by Flint et al. (1996 [DIRS 100147]). Evapotranspiration parameters were adjusted during these calibrations, which are presented in detail in Section 6.8.3. Because the 1996 model did not account for infiltration from surface-water runoff in channels, it was necessary to increase precipitation input to the model to obtain a good match with the borehole water-content profiles, particularly during wet years.

Because the 1999 infiltration model has the capability to route surface run off and calculate the resulting infiltration in channels, the calibration approach for the 1999 model differed from that for the 1996 model. Accordingly, the 1999 infiltration model was calibrated through comparison of simulated and measured daily mean discharge at five stream gages in operation at Yucca Mountain during 1994-95 (DTN: GS941208312121.001 [DIRS 107374]; GS960908312121.001 [DIRS 107375]). To facilitate the trial-and-error calibration process using smaller watershed domains with reduced simulation run-times, calibration watershed models were extracted using the routine WATSHD20 V1.0 (as described in Section 6.5.3) and the locations of the stream-gaging sites. The simulated run-on depth for the grid cells in which the gages were located was converted to a daily mean discharge rate, and compared to the recorded daily mean discharge rate.

Using a manual trial-and-error process, parameters defining the root-zone model were adjusted until a satisfactory fit between simulated and recorded daily mean discharge at all five gaging sites was obtained. The primary parameters adjusted were the thickness of the bedrock layer included in the root-zone for upland areas, the effective storage capacity of the bedrock layer available for evapotranspiration, and the root-zone density weighting parameters for all four root-zone layers. The root-zone weighting parameters mathematically represent the relative density of the roots for the root-zone layers. These are assumed values, and the bounds within which the densities could vary were also assumed. For wetter future climates, the parameters were adjusted to represent an assumed increase in root density and root zone depth with an increase in vegetation cover and a change in vegetation type that was, in turn, assumed to be representative of the predicted future climate conditions provided in Future Climate Analysis (BSC 2004 [DIRS 170002]). The bounds assumed for the thickness of the bedrock layer included in the root-zone for upland areas is 0 to $2 \mathrm{~m}$ (Section 5), the effective storage capacity of the bedrock layer available for evapotranspiration ranges from 0.05 to 0.5 , and the root-zone density weighting parameters for the four root-zone layers range from 0.01 to 0.6 (Section 6.7.3). The parameters were manually adjusted within these bounds until measured runoff could be reasonably matched by the simulation results simultaneously for all five-calibration watersheds.

During the 1999 model calibration, the observation was made that a sufficient bedrock storage term within the root-zone was needed to produce satisfactory model calibration results, given that the effective bedrock hydraulic conductivity and the soil depth parameters were held constant during model calibration. Another parameter that was adjusted during calibrations was effective surface-water flow area. This parameter had little effect on the resultant net infiltration. From field observations, an initial area was assumed to be about 1 to 99 percent of the grid 
block. If the stream discharge generated using this value did not match field observations then this value was changed during model calibration.

\subsubsection{Climate Input Used for Model Calibration}

The climate input file used for model calibration, mod3-ppt.dat (Appendix A, Yucca Mountain 1980-95 Developed Daily Precipitation Record), consists of daily precipitation estimates and was developed using an EXCEL worksheet (mod3-ppt.xls) and daily precipitation records from 1980 through 1995 at Yucca Mountain and from nearby locations (DTNs: GS000200001221.002 [DIRS 146277]; GS000100001221.001 [DIRS 146816]; GS000208312111.001 [DIRS 147245]; [DIRS 147247]; GS970108312111.001 [DIRS 125899]; GS010408312111.001 [DIRS 162978]). The developed record of daily precipitation is only an approximate representation of actual conditions over the general location and ground surface elevation of the repository area. Daily precipitation estimates for 1988 through 1995 were developed using the mean of the measured daily precipitation at USGS weather stations \#1 and \#3 located on Yucca Mountain (DTNs: GS000208312111.001 [DIRS 147245]; GS000208312111.003 [DIRS 147247]; GS970108312111.001 [DIRS 125899]; GS010408312111.001 [DIRS 162978]). For 1980 through 1987, daily precipitation was estimated using a linear interpolation model and available precipitation records from six Nevada Test Site (NTS) monitoring sites (DTN: GS000200001221.002 [DIRS 146277]) and two National Weather Service monitoring sites located near Yucca Mountain (DTN: GS000100001221.001 [DIRS 146816]). The linear interpolation model was developed using a weighted inverse-distance-squared estimation method. The weighting factors were calculated as the ratio of average annual precipitation for each of the eight stations over the mean calculated from the two USGS weather stations for the period July 17, 1987 through September 30, 1994 (this is the period for which the two sets of records overlapped). Table 6-1 provides a listing of all stations and corresponding precipitation records used to develop mod3-ppt.dat. Figure 6-17 shows the temporal distribution of daily precipitation amounts for the 1980-95 developed records.

Daily air-temperature estimates used for model calibration were simulated internally in INFIL V2.0 using the sine wave function defined by Equation 6-2 in Section 6.4.2. The function coefficients are based on air temperature measurements (DTN: GS000208312111.002 [DIRS 147250]) and they are described by Flint et al. (1996 [DIRS 100147], Eq. 20), where $\mathrm{T} 1=17.3^{\circ} \mathrm{C}$ for mean annual temperature and $\mathrm{T} 2=11.74^{\circ} \mathrm{C}$ for the half amplitude of the sine wave function defining the seasonal deviation from mean annual temperature.

\subsubsection{Stream Flow Records Used for Model Calibration}

The gage locations and records for the five stream gaging sites located on Yucca Mountain (Figure 6-18) (and within the area of the UZ flow model) were obtained from stream gaging stations (DTNs: GS941208312121.001 [DIRS 107374]; GS960908312121.001 [DIRS 107375]). The records consist of the estimated daily mean discharge, in cfs, for each day of the period covered by the record. 
Table 6-1. Stations and Precipitation Records Used to Develop the 1980-95 Daily Climate Input Files Used for Model Calibration and for Present-Day Climate Scenarios

\begin{tabular}{|c|c|c|c|c|c|c|c|}
\hline \multicolumn{8}{|c|}{ Precipitation Records Used for Developing 1980-95 Daily Climate Input Used for Model Calibration } \\
\hline $\begin{array}{c}\text { Station } \\
\text { Name }\end{array}$ & Data Source & $\begin{array}{c}\text { UTM } \\
\text { Easting } \\
(\mathbf{m})\end{array}$ & $\begin{array}{l}\text { UTM } \\
\text { Northing } \\
\text { (m) }\end{array}$ & $\begin{array}{l}\text { Station } \\
\text { elevatio } \\
\mathbf{n}(\mathbf{m})\end{array}$ & $\begin{array}{c}\text { Record } \\
\text { Starting } \\
\text { Date }\end{array}$ & $\begin{array}{l}\text { Record } \\
\text { Ending } \\
\text { Date }\end{array}$ & $\begin{array}{c}07 / 17 / 87- \\
09 / 30 / 94 \\
\text { Average } \\
\text { Annual } \\
\text { Precipitation } \\
\text { (mm) }\end{array}$ \\
\hline Beatty $8 \mathrm{~N}$ & $\begin{array}{l}\text { NCDC: } \\
\text { GS000100001221. } \\
001 \text { [DIRS 146816] }\end{array}$ & 525,211 & $4,094,707$ & 1,082 & $12 / 01 / 72$ & $12 / 31 / 94$ & 133 \\
\hline $\begin{array}{l}\text { Amargosa } \\
\text { Farms }\end{array}$ & $\begin{array}{l}\text { NCDC: } \\
\text { GS000100001221. } \\
001 \text { [DIRS 146816] }\end{array}$ & 547,723 & $4,046,733$ & 747 & $12 / 01 / 65$ & $12 / 31 / 94$ & 107 \\
\hline 4JA & $\begin{array}{l}\text { NTS: } \\
\text { GS000200001221. } \\
002 \text { [DIRS 146277] }\end{array}$ & 563,949 & $4,070,874$ & 1,043 & $12 / 01 / 57$ & 09/30/94 & 154 \\
\hline $40 \mathrm{MN}$ & $\begin{array}{l}\text { NTS: } \\
\text { GS000200001221. } \\
002 \text { [DIRS 146277] }\end{array}$ & 563,726 & $4,100,456$ & 1,469 & $02 / 15 / 60$ & 09/30/94 & 201 \\
\hline $\begin{array}{l}\text { Rock } \\
\text { Valley }\end{array}$ & $\begin{array}{l}\text { NTS: } \\
\text { GS000200001221. } \\
002 \text { [DIRS 146277] }\end{array}$ & 571,477 & $4,059,840$ & 1,036 & $02 / 01 / 63$ & 09/30/94 & 155 \\
\hline $\begin{array}{l}\text { Cane } \\
\text { Spring }\end{array}$ & $\begin{array}{l}\text { NTS: } \\
\text { GS000200001221. } \\
002 \text { [DIRS 146277] }\end{array}$ & 580,273 & $4,074,710$ & 1,219 & $09 / 01 / 64$ & 09/30/94 & 202 \\
\hline Mid Valley & $\begin{array}{l}\text { NTS: } \\
\text { GS000200001221. } \\
002 \text { [DIRS 146277] }\end{array}$ & 574,182 & $4,091,296$ & 1,420 & $09 / 01 / 64$ & 09/30/94 & 195 \\
\hline $\begin{array}{l}\text { Tippipah } \\
\text { Spring \#2 }\end{array}$ & $\begin{array}{l}\text { NTS: } \\
\text { GS000200001221. } \\
002 \text { [DIRS 146277] }\end{array}$ & 572,619 & $4,100,528$ & 1,518 & $09 / 01 / 64$ & 09/30/94 & 206 \\
\hline $\begin{array}{l}\text { Weather } \\
\text { station \#1 }\end{array}$ & $\begin{array}{l}\text { USGS: } \\
\text { GS000208312111. } \\
001 \text { [DIRS 147245] } \\
\text { GS000208312111. } \\
003 \text { [DIRS 147247] }\end{array}$ & 550,424 & $4,071,986$ & 1,163 & $04 / 27 / 87$ & 09/30/95 & 157 \\
\hline $\begin{array}{l}\text { Weather } \\
\text { station \#3 }\end{array}$ & $\begin{array}{l}\text { USGS: } \\
\text { GS000208312111. } \\
001 \text { [DIRS 147245] } \\
\text { GS000208312111. } \\
\text { 003 [DIRS 147247] }\end{array}$ & 548,038 & $4,080,316$ & 1,351 & $06 / 06 / 87$ & 09/30/95 & 179 \\
\hline
\end{tabular}


Table 6-1. Stations and Precipitation Records Used to Develop the 1980-95 Daily Climate Input Files Used for Model Calibration and for Present-Day Climate Scenarios (Continued)

\begin{tabular}{|c|c|c|c|c|c|c|c|}
\hline \multicolumn{8}{|c|}{ Precipitation Records Used for Developing 100-Year Stochastic Models of Daily Climate Input } \\
\hline $\begin{array}{c}\text { Station } \\
\text { Name }\end{array}$ & Data Source & $\begin{array}{c}\text { UTM } \\
\text { Easting } \\
(\mathrm{m})\end{array}$ & $\begin{array}{c}\text { UTM } \\
\text { Northing } \\
(m)\end{array}$ & $\begin{array}{c}\text { Station } \\
\text { Elevatio } \\
n(m)\end{array}$ & $\begin{array}{c}\text { Record } \\
\text { Starting } \\
\text { Date }\end{array}$ & $\begin{array}{c}\text { Record } \\
\text { Ending } \\
\text { Date }\end{array}$ & $\begin{array}{c}\text { Complete } \\
\text { Record } \\
\text { Average } \\
\text { Annual } \\
\text { Precipi- } \\
\text { tation (mm) }\end{array}$ \\
\hline 4JA & $\begin{array}{l}\text { NTS: } \\
\text { GS000200001221. } \\
002 \text { [DIRS 146277] }\end{array}$ & 563,949 & $4,070,874$ & 1,043 & $12 / 01 / 57$ & 09/30/94 & 131 \\
\hline $\begin{array}{l}\text { Area } 12 \\
\text { Mesa }\end{array}$ & $\begin{array}{l}\text { NTS: } \\
\text { GS000200001221. } \\
002 \text { [DIRS 146277] }\end{array}$ & 569,533 & $4,115,294$ & 2,283 & $03 / 11 / 59$ & $10 / 04 / 94$ & 315 \\
\hline
\end{tabular}

NCDC=National Climatic Data Center; NTS=Nevada Test Site; USGS= United States Geological Survey; UTM = Universal Transverse Mercator

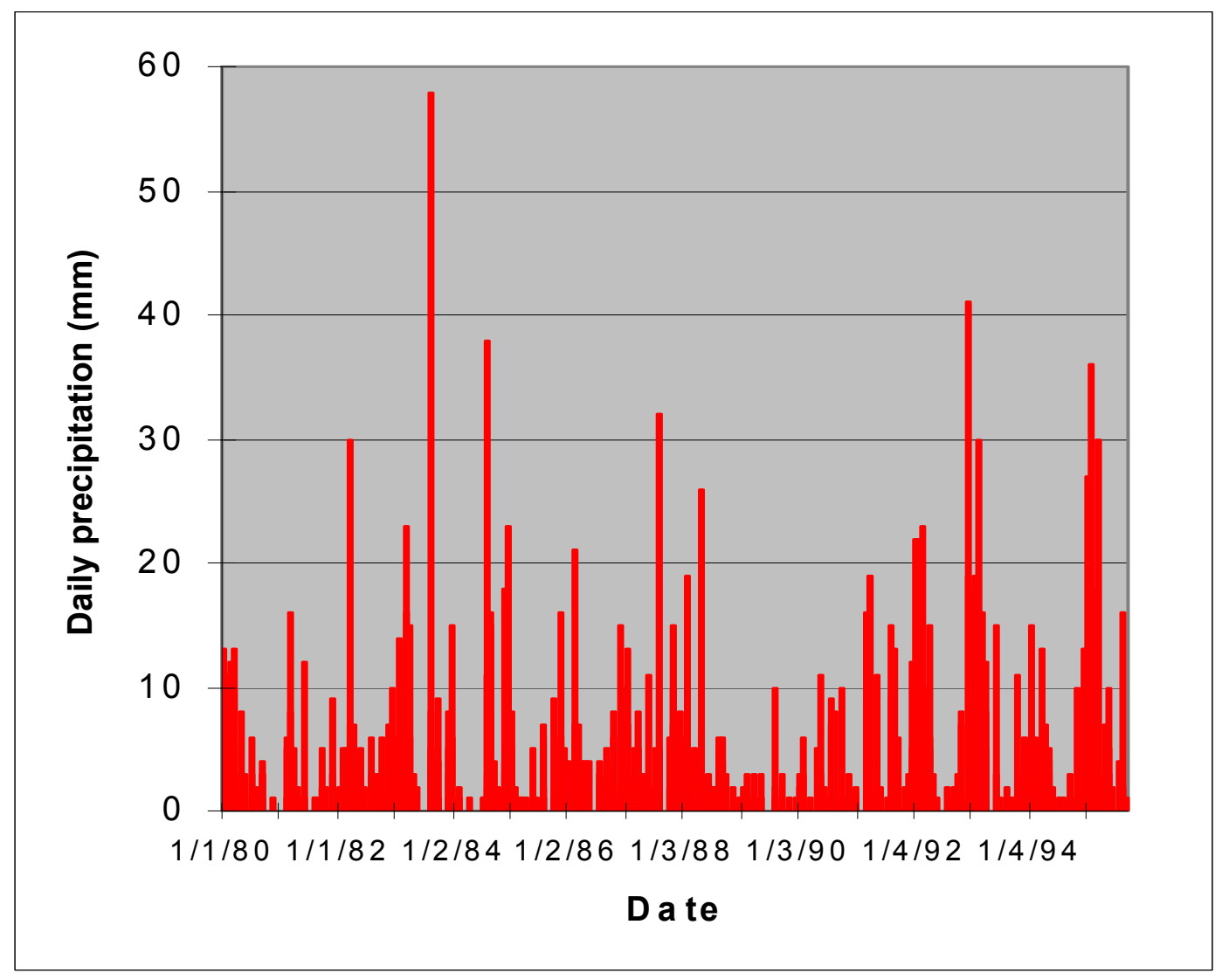

Source DTN: GS000208311221.001.

Figure 6-17. Developed 1980-95 Daily Precipitation Record Used as Input for Model Calibration 


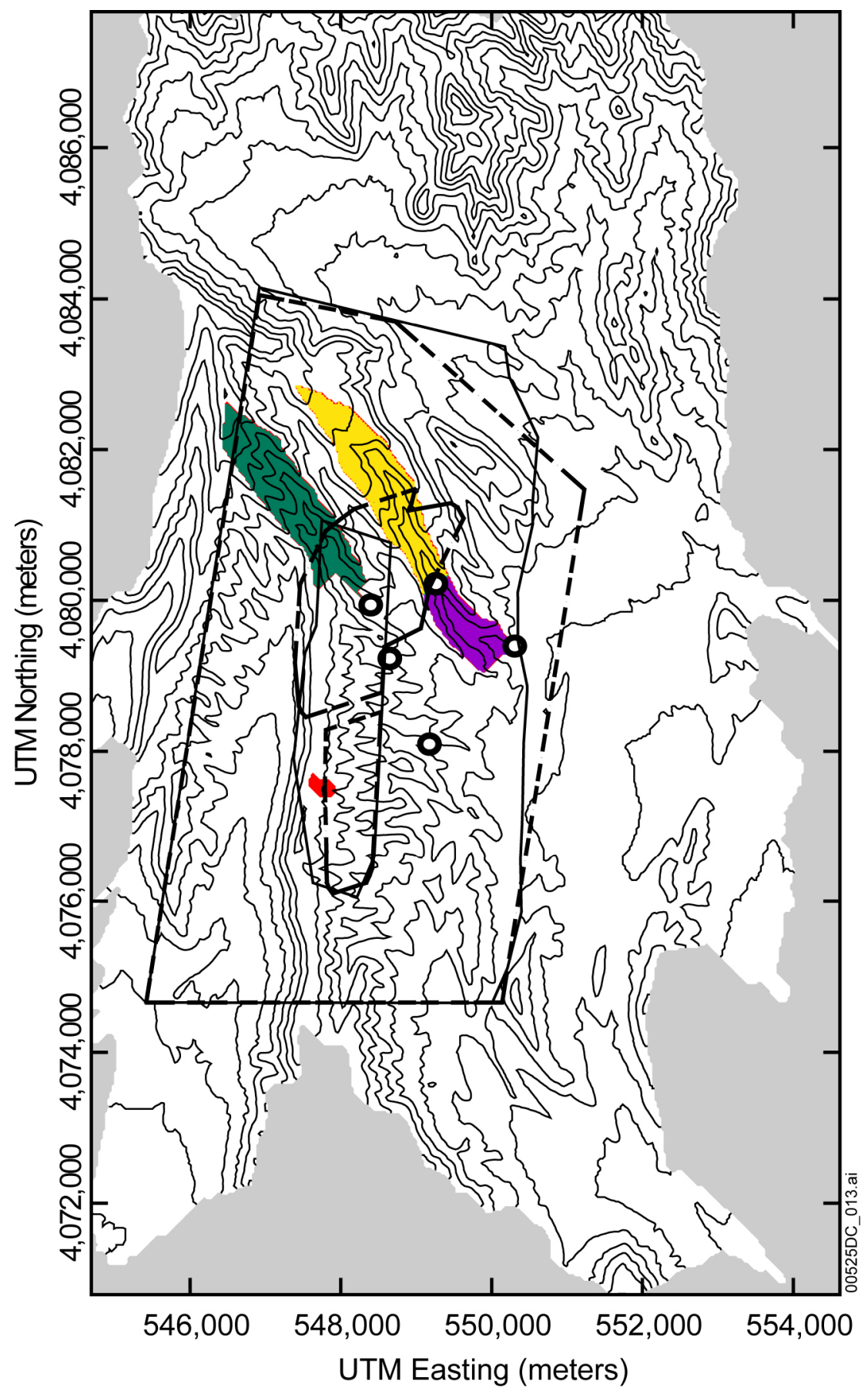

\section{Calibration and testing watershed models}

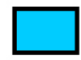

Wren Wash

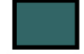

Upper Drill Hole Wash

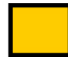

Upper

Pagany Wash
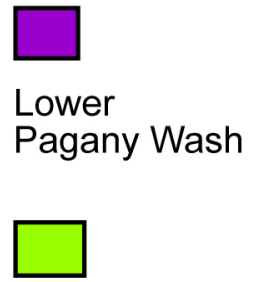

Split Wash

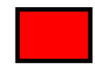

T1 Wash

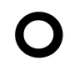

Stream-

flow gages

Source: DTNs: GS960908312121.001 [DIRS 107375]; GS941208312121.001 [DIRS 107374].

NOTE: The 1999 UZ flow model domain and the 1999 repository footprint are site recommendation boundaries (solid lines), not license application boundaries (dashed lines).

Figure 6-18. Location of Stream-Gaging Sites and Calibration Watersheds Defined by the Gaging Sites 


\subsubsection{Model Calibration Results}

\subsubsection{1996 Model Calibration Results}

The 1996 model was calibrated by comparing measured volumetric water contents using neutron moisture meters (DTNs: GS940708312212.011 [DIRS 107136]; GS941208312212.017 [DIRS 107137]; GS950808312212.001 [DIRS 107139]; GS960108312212.001 [DIRS 107141]) and simulated water-content data using the 1996 version of the infiltration model (Flint et al. 1996 [DIRS 100147]) that did not include stream-routing. At selected neutron boreholes, water-content data were summed for the soil profile and compared to the model simulation for the same time period by using the developed site precipitation record (Appendix A, Yucca Mountain 1980-95 Developed Daily Precipitation Record). Two examples are presented: borehole USW UZ-N50, with soil $2.7 \mathrm{~m}$ deep (Figure 6-19A) and borehole UE-25 UZN \#63, with soil $1.7 \mathrm{~m}$ deep (Figure 6-19B). The match of the simulated and measured volumetric water content was improved by varying the $\mathrm{a}$ and $\mathrm{b}$ coefficient values in the Priestley-Taylor equation, which adjusted the evapotranspiration calculations of the simulated water content to better match the measured water content. Simulated water content compared well with measured water content, which indicated that the water-balance technique used in the model to calculate simulated net infiltration could correctly maintain the proper soil moisture. This is important for accurate determination of when the water-storage capacity of the soil was exceeded and ponding at the soil/bedrock interface had occurred, which controls the calculation of net infiltration.

Using the 1996 model calibrated for evapotranspiration, to determine if simulations of net infiltration matched that calculated from the changes in water content in the neutron-borehole data was necessary. A direct comparison of measured neutron-borehole and simulated flux is difficult because the flux measured in the borehole occurs days to months following precipitation. However, annual comparisons between measured and simulated flux at the neutron boreholes can be used.

In order to simulate net infiltration for a comparison at neutron-borehole point locations, precipitation was required at those specific locations. This was done using the developed daily precipitation record described in Section 6.8.1 and spatially distributed to the neutron borehole locations (Flint and Flint 1995 [DIRS 100394]) using Equation 6-3. Measured average annual precipitation is shown as the open squares in Figure 6-20 on a yearly basis, for the years 1985-95 for which neutron-borehole data is available. Some variation in average annual precipitation among boreholes can be seen for any given year (the crosses in Figure 6-20) due to the differences in borehole elevation, especially for those years with higher average annual precipitation. To improve the model calibration, because the infiltration model neglects runoff in channels by not routing runoff between grid cells, precipitation was increased in grid cells where there were channels to simulate increases in water available for infiltration due to concentration of water in the channels. This is indicated by the open circles in Figure 6-20. A 30-percent enhancement factor was chosen on the basis of iterations simulating infiltration from the simulated precipitation as described in the following paragraph. Average annual precipitation simulated including the enhancement factor for neutron boreholes located in channels, increased the variability among boreholes. 

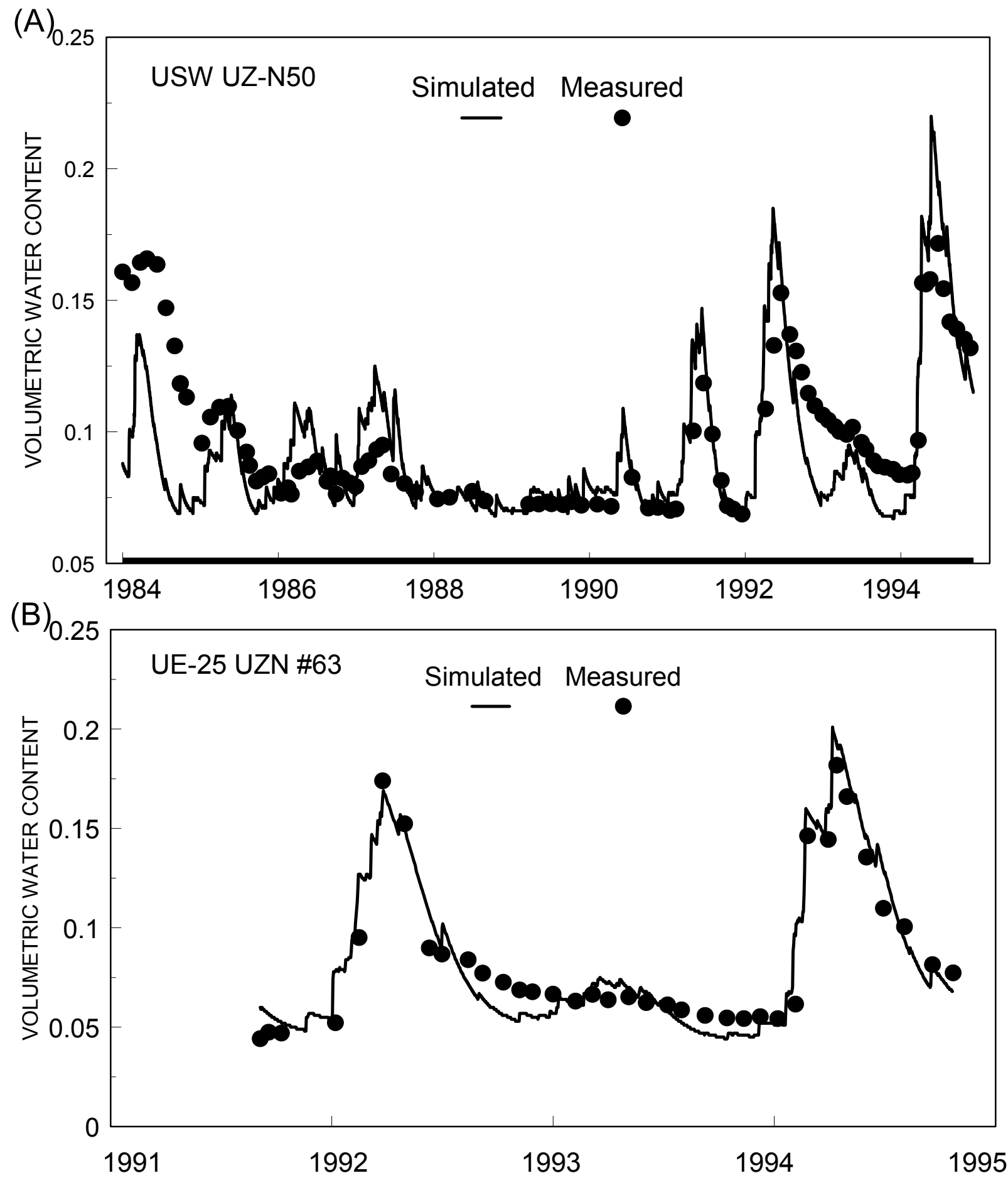

Source: DTNs: $\quad$ GS940708312212.011 [DIRS 107136]; GS941208312212.017 [DIRS 107137]; GS950808312212.001 [DIRS 107139]; GS960108312212.001 [DIRS 107141].

Figure 6-19. Graphs of Comparisons of Simulated (1996 Model) Net infiltration Using Water Content in Neutron Boreholes (A) USW UZ-N50 and (B) UE-25 UZN \#63 


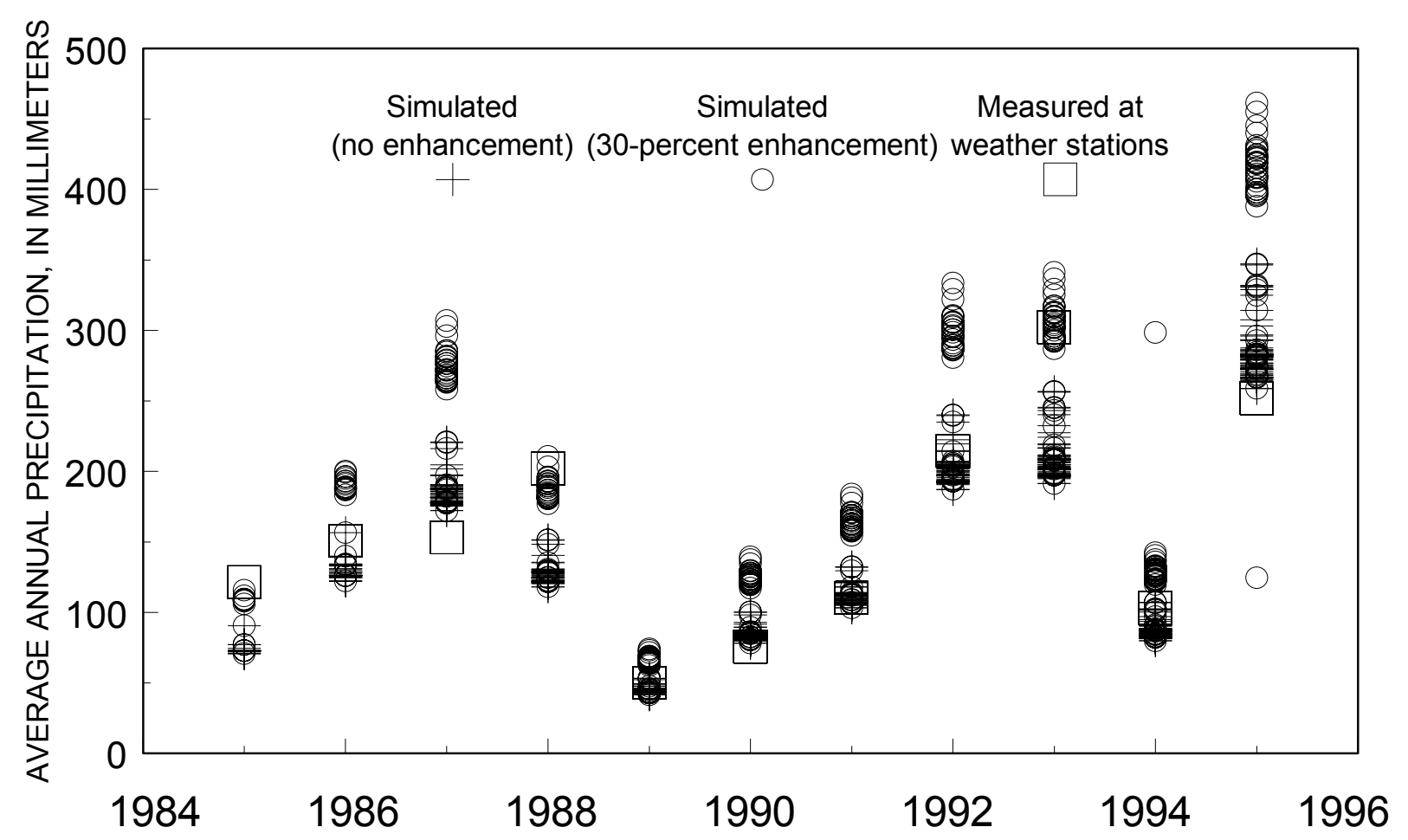

Source: DTN: GS000208311221.001.

Figure 6-20 Graph of Average Annual Precipitation Simulated (1996 Model) at Each Borehole Using Precipitation Record for 1980-95, and Simulated (1996 Model) with a 30-Percent Enhancement in the Channel Grid Blocks Only, Compared to Developed Precipitation Record Distributed Geostatistically to Each Borehole

These simulated precipitation data were then used to simulate net infiltration at each borehole using the 1996 model (Figure 6-21). The average annual precipitation described above and estimates of net infiltration based on neutron-borehole water-content data (DTN: GS960508312212.008 [DIRS 122609]) are again represented by the open squares. Models were fit to each data set, and the results indicated that the regression model of net infiltration simulated with the model, using the 30-percent increase in precipitation at boreholes located in channels, provides a reasonable match to the calculated yearly values of flux (DTN: GS960508312212.008 [DIRS 122609]). Net infiltration simulated without the 30-percent channel enhancement factor is slightly lower (Figure 6-21). The only support for using a 30-percent enhancement factor is the improved match to the neutron-hole flux data. Because average annual precipitation was distributed to each borehole instead of using measured precipitation data at each borehole, detailed statistical analysis of the match would not be appropriate. General trends are adequate to indicate that the model represents the influence of the site characteristics, such as precipitation, topography, and soil and rock properties, as well as they currently are known. 


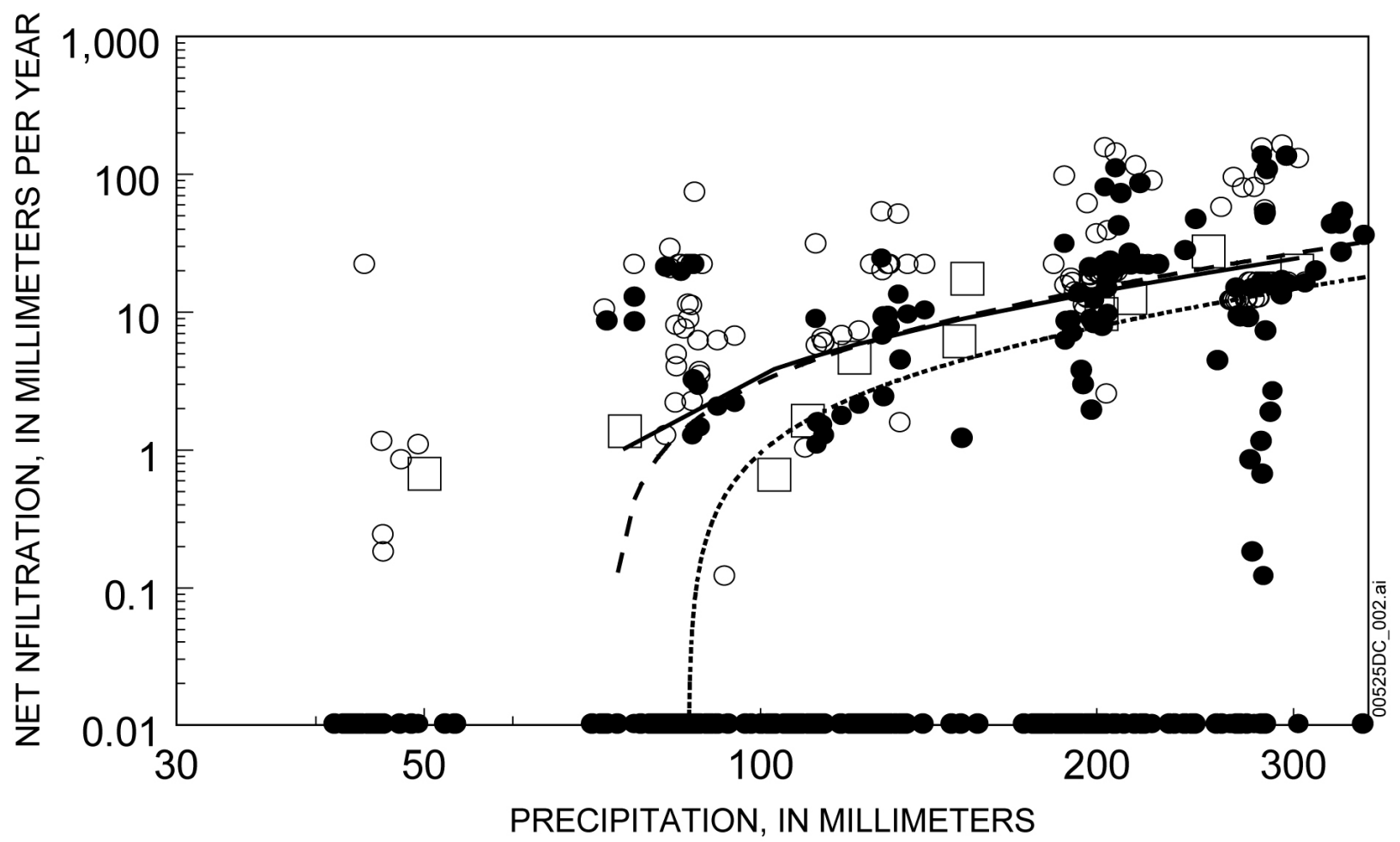

\section{EXPLANATION}

$\square$ Mean annual net infiltration (measured)

- Simulated (no enhancement)

Simulated (30-percent enhancement)

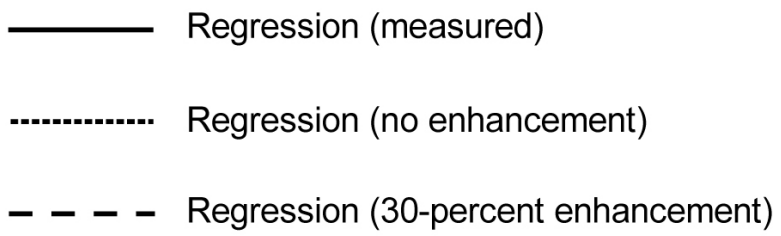

Regression (measured)

- - Regression (30-percent enhancement)

Source DTN: GS960508312212.008 [DIRS 122609].

Output DTN: GS000208311221.002.

Figure 6-21. Graph of Precipitation Relative to Infiltration Simulated with the 1996 Model for Each Borehole with no Channel-Enhancement Factor and with 30-Percent Channelenhancement Factor, and Mean Annual Infiltration for all Boreholes

\subsubsection{1999 Model Calibration Results}

The 1999 model was calibrated by using stream discharge data. Table 6-2 lists the measured versus simulated daily mean discharge values at the five gaging sites for the two recorded 1995 storm events of January 25-26 and March 11, 1995. The results provided a reasonable comparison of simulated to measured stream flow during the March 11,1995 event, which was approximately an order of magnitude greater than the January 25-26 event. The model correctly predicts a higher daily mean discharge at the upper Pagany Wash gage relative to the lower Pagany Wash gage. The total simulated daily mean discharge of $33.63 \mathrm{ft}^{3} / \mathrm{s}$ for the five calibration watersheds provides a good comparison with the total measured daily mean discharge of $31.20 \mathrm{ft}^{3} / \mathrm{s}$ for the March 11, 1995, stream flow event. 
Table 6-2. Comparison of Measured Versus 1999 Model Simulated Daily Mean Discharge at Stream-Gaging Sites for Streamflow Events in 1995

\begin{tabular}{|l|c|c|c|c|c|}
\hline \multicolumn{2}{|c|}{} & \multicolumn{5}{|c|}{$\begin{array}{r}1995 \\
\text { Stream flow events (Daily Mean Discharge, in cfs) } \\
\text { NWIS Database ATS\#-200000269 }\end{array}$} \\
\hline Calibration watershed & Date & $\mathbf{0 1 / 2 5 / 9 5}$ & $\mathbf{0 1 / 2 6 / 9 5}$ & $\mathbf{0 3 / 1 0 / 9 5}$ & $\mathbf{0 3 / 1 1 / 9 5}$ \\
\hline \multirow{2}{*}{ Lower Pagany Wash } & Measured & 0.00 & 0.01 & 0.00 & 8.60 \\
\cline { 2 - 6 } & Simulated & 0.00 & 0.00 & 0.00 & 7.23 \\
\hline \multirow{3}{*}{ Upper Pagany Wash } & Measured & 0.00 & 1.70 & 0.00 & 12.00 \\
\cline { 2 - 6 } & Simulated & 0.34 & 0.00 & 0.13 & 9.46 \\
\hline \multirow{2}{*}{ Upper Drillhole Wash } & Measured & 0.00 & 0.00 & 0.00 & 5.00 \\
\cline { 2 - 6 } & Simulated & 1.55 & 0.00 & 0.00 & 9.33 \\
\hline \multirow{2}{*}{ Upper Split Wash } & Measured & 0.10 & 1.50 & 0.00 & 3.00 \\
\cline { 2 - 6 } & Simulated & 0.07 & 0.02 & 0.28 & 3.69 \\
\hline \multirow{2}{*}{ Wren Wash } & Measured & 0.66 & 0.96 & 0.00 & 2.60 \\
\cline { 2 - 6 } & Simulated & 0.71 & 0.19 & 0.70 & 3.92 \\
\hline
\end{tabular}

Source: DTNs: GS941208312121.001 [DIRS 107374]; GS960908312121.001 [DIRS 107375].

cfs = cubic feet per second; NWIS= National Water Information System

Comparison of model results with the January event indicates greater difficulty in matching the smaller stream flow events. This difficulty is associated with higher variability in predicting the occurrence and magnitude of a small and barely initiated stream flow event versus a large and well-sustained flow event. The January 25-26 event did not include stream flow at the upper Drill Hole Wash gaging site, and only a barely measurable trace flow at the lower Pagany Wash gaging site. In addition, the January 25-26 event may have been affected by snowfall and subsequent snowmelt occurring at higher elevations within the calibration watersheds, which would help explain the one-day delay in the measured stream flow as compared to the simulated flow, and the calibration simulations did not include simulation of snowmelt.

The overall occurrence of stream flow at Yucca Mountain is still correctly predicted for the January 25-26 event, along with the minimal flow volumes and the much higher relative variability in flow across the five gaging sites. The two flow events were the only occurrences of stream flow observed for the entire 1994-95 recording period and this was correctly predicted by the model. The relative magnitude of the smaller January 25-26 event compared to the larger March 11 event was fairly well predicted by the model.

The parameter values used in calibrations discussed above varied during the calibration exercises over the bounds indicated. Selection of the final set of parameter values was based on the combination of values that provided the best match to the measured stream flow records. The final parameter values were consistent across the five watersheds and are as follows: maximum thickness of the bedrock layer is $2 \mathrm{~m}$, the effective storage capacity of the bedrock layer available for ET is 0.02 , root-zone density weighting parameters for the upper soil depth zone is 1.0 , second depth zone is 0.5 , third depth zone is 0.2 and the bedrock zone is 0.01 . The effective surface-water flow area parameter is 0.5 . This is a non-unique solution because various different combinations of parameter values may provide similar or even identical results. The most important parameters adjusted during model calibration were the root zone weighting factors, the effective storage capacity of bedrock in the root zone (the product of the thickness of 
the root zone in bedrock multiplied by the effective bedrock porosity), and the scaling factor used to determine the effective surface-water flow area. Similar calibration results might have been achieved by adjusting the bulk saturated bedrock hydraulic conductivity, soil depth, field capacity, and soil saturated hydraulic conductivity, but a detailed parameter optimization exercise was not necessary because variations in infiltration estimates are captured through the use of lower, mean, and upper bounds in TSPA (Section 6.9). This is supported by an additional calibration using updated bedrock permeability values as described in Section 7.

\subsection{REPRESENTATION OF CLIMATES FOR MODEL APPLICATION}

The present-day, monsoon, and glacial-transition climate stages are each represented with a drier lower bound, a wetter upper bound, and an intermediate mean climate scenario (DTNs: GS000208311221.002 and GS000208311221.001). The lower and upper bound scenarios are developed to account for uncertainty and variability in the characteristics of precipitation and air temperature for each estimated future climate stage. The mean climate scenario is developed to represent average conditions within each stage. To develop nine separate climate scenarios (three for each climate stage), separate INFIL V2.0 simulation results were averaged or sampled using the postprocessing program MAPADD20 V1.0. The program MAPADD20 V1.0 also combines the separate simulation results obtained for each of the 10 watershed modeling domains into a single result for the composite watershed model domain. Each individual simulation is defined by a unique combination of daily climate input and root-zone model coefficients (the coefficients are used to represent different vegetation characteristics). Characteristics of precipitation and air temperature for the estimated drier lower- and wetter- upper-bound monsoon and glacial-transition climate scenarios are defined in Future Climate Analysis (BSC 2004 [DIRS 170002]). To define the mean net-infiltration values for the monsoon and glacial-transition scenarios, the lower and upper bound net-infiltration estimates for each climate stage are averaged for each model grid cell. This implies that the distribution of net infiltration between the lower- and upper-bound scenarios for the monsoon and glacial-transition climate stages is symmetric (e.g., normal or uniform).

To develop the daily climate input for INFIL V2.0 that is considered representative of the characteristics of the estimated upper bound monsoon, lower bound glacial-transition, and upper bound glacial-transition future climate scenario, available daily climate records at present-day analogue sites were used. Selection of the representative analogue sites is defined by Future Climate Analysis (BSC 2004 [DIRS 170002]) and is based on a comparison of predicted versus measured mean annual precipitation (MAP), mean annual temperature (MAT), and the seasonal distribution of MAP and MAT. For each climate scenario, at least two analogue sites were identified. Individual simulations were performed for each analogue site, and the multiple simulations were averaged for all model grid cells to obtain a single net-infiltration estimate for each climate scenario.

\subsubsection{Assumptions Concerning Future Climate Scenarios Used For Simulation of Net Infiltration}

The estimation of potential surface net-infiltration rates and resulting percolation fluxes at the repository horizon, assumes that the climate scenarios developed in Future Climate Analysis (BSC 2004 [DIRS 170002]) are representative of possible future climate conditions. 
Assumptions and uncertainties regarding the estimated monsoon and glacial-transition potential future climate scenarios, including the timing and duration of each estimated future climate stage, are documented in Future Climate Analysis (BSC 2004 [DIRS 170002]).

Estimates of potential future climate conditions at Yucca Mountain for the next 10,000 years were taken directly from Future Climate Analysis (BSC 2004 [DIRS 170002]). The scenarios define the timing, duration, and characteristics of three distinct potential future climate stages based on analysis and interpretations of periodic cycles identified in paleoclimate records. A general assumption is made that patterns in past climate cycles will be repeated in the future. The first climate stage is a continuation of current present-day climate conditions from presentday to approximately 400 to 600 years into the future. The second climate stage begins approximately 400 to 600 years from present-day and is characterized as a monsoon climate with wetter summers relative to present-day climate. The monsoon climate is predicted to last between 900 to 1,400 years long. Therefore, the third climate stage begins at between 1,300 and 2,000 years from present-day and is characterized as a glacial-transition climate with cooler air temperatures and on average higher annual precipitation relative to present-day climate (BSC 2004 [DIRS 170002]). The duration of the glacial-transition climate is estimated to be 10,000 years, extending 2,000 years beyond the required 10,000-year regulatory period (BSC 2003 [DIRS 166296], p. 4).

Results from Future Climate Analysis (BSC 2004 [DIRS 170002]) include the identification of a set of appropriate current climate analogue sites for representing the estimated future climate stages in terms of MAP, MAT, and seasonal distributions of MAP and MAT. To incorporate uncertainty as variability in precipitation, and to a lesser degree air temperature characteristics, in the three estimated climate stages and corresponding estimates of net infiltration, results from Future Climate Analysis (BSC 2004 [DIRS 170002]) define a lower and upper bound climate scenario within each climate stage. To reduce uncertainty in the selection of a single "best" analogue site, the lower and upper bound climate scenarios are represented using a set of two or three analogue sites identified by Future Climate Analysis (BSC 2004 [DIRS 170002]). Net infiltration is simulated using the climate input developed from the records at each analogue site, and the results are averaged to obtain an estimate of net infiltration for a given climate scenario.

Assumptions and uncertainties regarding the estimated monsoon and glacial-transition potential future climate scenarios, including the timing and duration of each estimated future climate stage, are documented by Future Climate Analysis (BSC 2004 [DIRS 170002]). For model application using the developed daily climate input for each climate scenario, assumptions in defining the root-zone model coefficients are required. In developing the net-infiltration estimates for each climate scenario using a simple averaging of multiple simulation results, the length of the various simulation periods are assumed to be adequate for characterizing a given climate scenario. To develop an estimate of net infiltration for the mean climate scenario within the monsoon and glacial-transition climate stages, a uniform distribution of net-infiltration rates is assumed between the upper and lower bound estimates at each model grid cell. Net-infiltration estimates for the mean present-day climate net-infiltration scenario were obtained by averaging simulations performed specifically for the mean present-day climate and thus are not necessarily equivalent to the arithmetic mean of the estimates for the upper and lower bound present-day climate scenarios. 


\subsubsection{Present-Day Climate Scenarios}

Net-infiltration estimates for the mean present-day climate scenario (which is also used to define the lower bound monsoon climate scenario) were calculated using MAPADD20 V1.0, the net-infiltration simulation results for the 1980-95 model calibration period, and results obtained using a 100-year stochastic simulation of daily precipitation modeled with the NTS station 4JA precipitation record (Appendix C, Development of Daily Climate Input using DAILY09 V1.0). A summary of the climate input used for the 1980-95-calibration period and the 100-year 4JA stochastic simulation is provided in Table 6-3. The length of the 1980-95-calibration period is short relative to the length of climate records considered adequate for characterizing climate conditions in the southern Nevada region, and the 4JA record provides a relatively long-term (longer than 30 years) record of precipitation near the repository site. The 100-year stochastic simulation provides an even longer-term representation of climatic conditions while incorporating the magnitudes and temporal distribution of the shorter-term measured record. In performing the INFIL V2.0 simulations, the daily precipitation amounts for the 4JA 100-year stochastic simulation are scaled using the ratio of mean annual precipitation between the Yucca Mountain $(181 \mathrm{~mm})$ and $4 \mathrm{JA}(140 \mathrm{~mm})$ sites in order to account for orographic effects.

The stochastic precipitation model used to develop the 100-year simulation for 4JA consists of a pseudo-random number generator that provides a normalized uniform deviate for a two-step process of simulating daily precipitation. The first step uses a third-order two-state (precipitation either occurs or does not occur) Markov chain process to determine the occurrence of daily precipitation, and the second step uses a modified, exponential, cumulative-probabilitydistribution function to determine the magnitude of daily precipitation. The third-order Markov chain model defines the probability of precipitation for the fourth day of a sequence given the known sequence of precipitation occurrences for the preceding three days. The stochastic simulations are performed using the program PPTSIM V1.0 (STN: 10143-1.0-00), which requires a prime integer seed for the pseudo-random number generator and monthly model parameters for the Markov chain and the cumulative-probability-distribution function. The monthly model parameters are obtained using the program MARKOV V1.0 (STN: 10142-1.0-00) and available records of daily precipitation for the site or station being modeled. For this analysis, the monthly parameters for station 4JA were obtained using the daily precipitation record for 4JA through December 31, 1993 (DTN: GS000200001221.002 [DIRS 146277]), and are identical to the parameters used by Flint et al. (1996 [DIRS 100147]), Table 6).

Mean net-infiltration estimates for the upper bound present-day climate scenario were calculated using MAPADD20 V1.0, the net-infiltration simulation results for the 1980-95 model calibration period, and results obtained using a 100-year stochastic simulation of daily precipitation modeled using the NTS station Area 12 Mesa precipitation record (through December 31, 1993) (DTN: GS000200001221.002 [DIRS 146277]) and the programs MARKOV V1.0 and PPTSIM V1.0. A summary of the Area 12 Mesa 100-year stochastic simulation of daily precipitation is provided in Table 6-3. For this analysis, the monthly parameters for station Area 12 Mesa are identical to the parameters used by Flint et al. (1996 [DIRS 100147]), Table 6). The upper bound present-day climate scenario is 
considered to be representative of wetter conditions from enhanced El Niño Southern Oscillation activity or other sources of present-day climate variability.

Table 6-3. Summary of Developed Daily Climate Input Files Used for Present-day Climate Scenarios

\begin{tabular}{|l|c|c|c|}
\hline & $\begin{array}{c}\text { Yucca Mountain } \\
\text { Calibration Daily } \\
\text { Climate Input }\end{array}$ & $\begin{array}{c}\text { 4JA Stochastic } \\
\text { Simulation }\end{array}$ & $\begin{array}{c}\text { Area 12 Mesa } \\
\text { Stochastic } \\
\text { Simulation }\end{array}$ \\
\hline Filename & Mod3-ppt.dat & 4JA.s01 & Area12.s01 \\
\hline Beginning of record & $01 / 01 / 1980$ & $\mathrm{n} / \mathrm{a}$ & $\mathrm{n} / \mathrm{a}$ \\
\hline Ending of record & $10 / 01 / 1995$ & $\mathrm{n} / \mathrm{a}$ & $\mathrm{n} / \mathrm{a}$ \\
\hline Total number of years for simulation & 15.75 & 100 & 100 \\
\hline Mean annual precipitation $(\mathrm{mm})$ & 181 & 140 & 328 \\
\hline Maximum daily precipitation $(\mathrm{mm})$ & 58 & 82 & 76 \\
\hline
\end{tabular}

Source: DTN: GS000208311221.001.

Net-infiltration estimates for the lower bound present-day climate scenario were obtained using MAPADD20 V1.0 and sampling the 1980-95 simulation, the 4JA 100-year stochastic simulation, and the driest (in terms of net infiltration) 10-year period within the 4JA 100-year simulation for the lowest net infiltration rate at each grid cell. The lower bound present-day climate scenario is considered to be representative of climate conditions resulting in minimum net infiltration, which may not necessarily be representative of the driest climate conditions in terms of mean annual precipitation.

\subsubsection{Monsoon Future Climate Scenarios}

The lower bound monsoon climate scenario is defined by Future Climate Analysis (BSC 2004 [DIRS 170002]) as being equivalent to the mean present-day climate scenario. The upper bound monsoon climate is represented using daily climate records from two analogue sites identified in Future Climate Analysis (BSC 2004 [DIRS 170002], and DTN: GS000308315121.003 [DIRS 151139]): Nogales, Arizona and Hobbs, New Mexico. A summary of the daily climate records, which were obtained as National Climatic Data Center/National Oceanic and Atmospheric Administration (NCDC/NOAA) records from the EARTHINFO database (DTN: GS000100001221.001 [DIRS 146816]), is provided in Table 6-4. The daily climate records from the two sites were exported from the EARTHINFO database (using the NCDC format option), and the exported files (Nogales.dat and Hobbs.dat) were provided as input to the program DAILY09 V1.0, which reformats the NCDC format into the xyz column format required by INFIL V2.0. In addition to reformatting, DAILY09 V1.0 also identifies gaps in the precipitation and the maximum and minimum air temperature records. Minor gaps (10 days or less for precipitation and 20 days or less for air temperature) are filled using an estimate of zero for precipitation and linear interpolation between the days having records on either side of the gap for air temperature. Years having major gaps in the record are identified and omitted from the reformatted output. Average daily air temperature is estimated as the mean of the recorded maximum and minimum daily air temperatures. Output from DAILY09 V1.0, which includes the average daily air temperature estimate is provided directly as input to INFIL V2.0. 
Table 6-4. Summary of Analogue Climate Records Used to Develop the Daily Climate Input for the Upper Bound Monsoon Climate Scenario

\begin{tabular}{|l|c|c|}
\hline & $\begin{array}{c}\text { Monsoon Upper Bound } \\
\text { \#1(MU1) }\end{array}$ & $\begin{array}{c}\text { Monsoon Upper Bound } \\
\text { \#2(MU2) }\end{array}$ \\
\hline Source filename & Nogales. dat & Hobbs.dat \\
\hline Approximate Station Location & Nogales, AZ & Hobbs, NM \\
\hline NCDC Station Code & AZ 5921 & NM 4026 \\
\hline Elevation $(m)$ & 1,162 & 1,102 \\
\hline Latitude (deg, min, sec) & $31,21,00$ & $32,42,00$ \\
\hline Longitude (deg, min, sec) & $110,55,00$ & $103,08,00$ \\
\hline Beginning of record & July, 1948 & January, 1948 \\
\hline Ending of record & June, 1983 & December, 1997 \\
\hline Number of complete years of record & 33 & 50 \\
\hline Mean annual precipitation $(\mathrm{mm})$ & 414.0 & 417.6 \\
\hline Mean January - March precipitation $(\mathrm{mm})$ & 70.6 & 36.8 \\
\hline Mean April - June precipitation $(\mathrm{mm})$ & 20.3 & 120.9 \\
\hline Mean July - September precipitation $(\mathrm{mm})$ & 251.5 & 191.3 \\
\hline Mean October - December precipitation $(\mathrm{mm})$ & 78.5 & 140.2 \\
\hline Maximum daily precipitation $(\mathrm{mm})$ & 77.7 & 190.5 \\
\hline Mean annual snow $(\mathrm{mm})$ & 7.5 & 13.2 \\
\hline Mean October - March snow fall $(\mathrm{mm})$ & 6.8 & 13.1 \\
\hline Mean April - September snow fall $(\mathrm{mm})$ & 0.6 & 0.6 \\
\hline Maximum daily snow fall $(\mathrm{mm})$ & 30.5 & 25.4 \\
\hline Mean daily air temperature $\left({ }^{\circ} \mathrm{C}\right)$ & 15.8 & 16.8 \\
\hline Mean October - March daily air temperature $\left.{ }^{\circ} \mathrm{C}\right)$ & 10.5 & 10.2 \\
\hline Mean April - September daily air temperature $\left.{ }^{\circ} \mathrm{C}\right)$ & 21.2 & 23.2 \\
\hline
\end{tabular}

Source: DTN: GS000100001221.001 [DIRS 146816].

NCDC=National Climatic Data Center

The upper bound monsoon climate net infiltration result is calculated as the arithmetic mean of the separate Nogales (MU1) and Hobbs (MU2) net infiltration simulations using the program MAPADD20 V1.0. The mean monsoon climate net infiltration result is calculated as the arithmetic mean of the lower and upper bound net infiltration results using MAPADD20 V1.0. This method assumes a normal, or symmetrical, distribution in net infiltration results between the lower and upper bound monsoon climate results ${ }^{15}$. The mean values were calculated using a set of two or more simulation results obtained from the daily climate input developed from the analogue sites defined in Future Climate Analysis (BSC 2004 [DIRS 170002]). The purpose of using multiple analogue sites is to reduce the uncertainty involved in the selection of a single analogue site as being representative of the predicted future climate conditions. The fact that UZ processes are non-linear is not relevant to the concept of reducing uncertainty in model results. Each individual simulation is in effect one realization of a set of possible results, based on the uncertainty in climate input as well as geospatial parameters, model coefficients, and material properties.

\footnotetext{
${ }^{15}$ The net infiltration results include the calculated average annual rates for all components of the water balance (precipitation, snow fall, evapotranspiration, root-zone water content change, etc.). A symmetric distribution is assumed for all components of the water balance.
} 


\subsubsection{Glacial-Transition Future Climate Scenarios}

The lower bound glacial-transition climate is represented using daily climate records from two analogue sites identified by Future Climate Analysis (BSC 2004 [DIRS 170002], and DTN: GS000308315121.003 [DIRS 151139]): Beowawe, Nevada and Delta, Utah. A summary of the daily climate records for the two lower bound glacial-transition analogue sites, which were obtained as NCDC/NOAA records from the EARTHINFO database (DTN: GS000100001221.001 [DIRS 146816]), is provided in Table 6-5. Following the methods described in Section 6.9.3, the routine DAILY09 V1.0 is applied to the NCDC format EARTHINFO exported files to develop the daily climate input files for INFIL V2.0. The lower bound glacial-transition net infiltration result is calculated as the arithmetic mean of the separate Beowawe (GL1) and Delta (GL2) net infiltration simulations using the program MAPADD20 V1.0. The upper bound glacial-transition climate is represented using daily climate records from three analogue sites identified by Future Climate Analysis (BSC 2004 [DIRS 170002], and DTN: GS000308315121.003 [DIRS 151139]): Rosalia, Washington; Spokane Washington; and St. John, Washington. A summary of the daily climate records for the three upper bound glacial-transition analogue sites, which were obtained as NCDC/NOAA records from the EARTHINFO database, is provided in Table 6-6. The routine DAILY09 V1.0 is applied to the exported EARTHINFO files for the three analogue sites, and the upper bound glacial-transition net infiltration result is calculated as the arithmetic mean of the separate Rosalia (GU1), Spokane (GU2), and Delta (GU3) net infiltration simulations using the program MAPADD20 V1.0. The mean glacial-transition climate net infiltration result is calculated as the arithmetic mean of the lower and upper bound net infiltration results using MAPADD20 V1.0.

Table 6-5. Summary of Analogue Climate Records Used to Develop the Daily Climate Input for the Lower Bound Glacial-Transition Climate Scenario

\begin{tabular}{|l|c|c|}
\hline & $\begin{array}{c}\text { Glacial-Transition Lower } \\
\text { Bound \#1 (GL1) }\end{array}$ & $\begin{array}{c}\text { Glacial-Transition Lower } \\
\text { Bound \#2 (GL2) }\end{array}$ \\
\hline Source filename & Beowawe.dat & Delta.dat \\
\hline Approximate Station Location & Beowawe, Nevada & Delta, Utah \\
\hline NCDC Station Code & NV 795 & UT 2090 \\
\hline Elevation (m) & 1432 & 1409 \\
\hline Latitude (deg, min, sec) & $40,35,25$ & $39,20,22$ \\
\hline Longitude (deg, min, sec) & $116,28,29$ & $112,35,45$ \\
\hline Beginning of record & July 1949 & June, 1938 \\
\hline Ending of record & December 1997 & December 1997 \\
\hline Number of complete years of record & 42 & 52 \\
\hline Mean annual precipitation (mm) & 219.5 & 197.9 \\
\hline Mean January - March precipitation (mm) & 53.6 & 50.3 \\
\hline Mean April - June precipitation (mm) & 71.9 & 55.6 \\
\hline Mean July - September precipitation (mm) & 31.0 & 40.4 \\
\hline Mean October - December precipitation (mm) & 70.1 & 67.8 \\
\hline Maximum daily precipitation (mm) & 43.2 & 65.8 \\
\hline Mean annual snow fall (mm) & 36.6 & 63.9 \\
\hline Mean October - March snow fall (mm) & 29.7 & 57.3 \\
\hline Mean April - September snow fall (mm) & 1.7 & 5.2 \\
\hline
\end{tabular}


Table 6-5. Summary of Analogue Climate Records Used to Develop the Daily Climate Input for the Lower Bound Glacial-Transition Climate Scenario (Continued)

\begin{tabular}{|l|c|c|}
\hline & $\begin{array}{c}\text { Glacial-Tansition Lower } \\
\text { Bound \#1 (GL1) }\end{array}$ & $\begin{array}{c}\text { Glacial-Tansition Lower } \\
\text { Bound \#2 (GL2) }\end{array}$ \\
\hline Maximum daily snow fall (mm) & 25.4 & 40.6 \\
\hline Mean air temperature (Celsius) & 8.8 & 10.1 \\
\hline Mean October - March air temperature (Celsius) & 1.9 & 2.1 \\
\hline Mean April - September air temperature (Celsius) & 15.7 & 18.0 \\
\hline
\end{tabular}

Source: DTN: GS000100001221.001 [DIRS 146816].

NCDC=National Climatic Data Center

Table 6-6. Summary of Analogue Climate Records Used to Develop the Daily Climate Input for the Upper Bound Glacial-Transition Climate Scenario

\begin{tabular}{|c|c|c|c|}
\hline & $\begin{array}{c}\text { Glacial-Transition } \\
\text { Upper Bound \#1 } \\
\text { (GU1) }\end{array}$ & $\begin{array}{c}\text { Glacial-Transition } \\
\text { Upper Bound \#2 } \\
\text { (GU2) }\end{array}$ & $\begin{array}{c}\text { Glacial-Transition } \\
\text { Upper Bound \#2 } \\
\text { (GU3) }\end{array}$ \\
\hline Source filename & Rosalia.dat & Spokane.dat & Stjohn.dat \\
\hline Approximate Station Location & Rosalia, WA & Spokane, WA & St John, WA \\
\hline NCDC Station Code & WA 7180 & WA 7938 & WA 7267 \\
\hline Elevation $(\mathrm{m})$ & 731 & 718 & 593 \\
\hline Latitude (deg, min, sec) & $47,14,00$ & $47,38,00$ & $47,06,00$ \\
\hline Longitude (deg, min, sec) & $117,22,00$ & $117,32,00$ & $117,35,00$ \\
\hline Beginning of record & June 1948 & August 1889 & August 1963 \\
\hline Ending of record & December 1997 & December 1997 & December 1997 \\
\hline Number of complete years of record & 43 & 108 & 33 \\
\hline Mean annual precipitation $(\mathrm{mm})$ & 459.7 & 410.2 & 433.3 \\
\hline Mean January - March precipitation (mm) & 138.7 & 125.5 & 125.2 \\
\hline Mean April - June precipitation (mm) & 109.7 & 94.0 & 104.6 \\
\hline Mean July - September precipitation (mm) & 56.9 & 51.3 & 56.1 \\
\hline Mean October - December precipitation (mm) & 172.7 & 160.0 & 165.4 \\
\hline Maximum daily precipitation $(\mathrm{mm})$ & 36.8 & 42.2 & 41.1 \\
\hline Mean annual snow fall $(\mathrm{mm})$ & 61.8 & 107.0 & 65.5 \\
\hline Mean October - March snow fall (mm) & 60.9 & 105.7 & 59.8 \\
\hline Mean April - September snow fall (mm) & 0.5 & 1.4 & 0.8 \\
\hline Maximum daily snow fall $(\mathrm{mm})$ & 27.9 & 32.3 & 30.2 \\
\hline Mean daily air temperature (Celsius) & 8.4 & 8.9 & 9.1 \\
\hline $\begin{array}{l}\text { Mean October - March daily air temperature } \\
\text { (Celsius) }\end{array}$ & 2.0 & 1.9 & 2.9 \\
\hline $\begin{array}{l}\text { Mean April - September daily air temperature } \\
\text { (Celsius) }\end{array}$ & 14.5 & 15.8 & 15.1 \\
\hline
\end{tabular}

Source: DTN: GS000100001221.001 [DIRS 146816].

NCDC=National Climatic Data Center 


\subsection{DEVELOPMENT OF INPUTS FOR UNCERTAINTY ANALYSIS}

The purpose of the uncertainty analysis described in Analysis of Infiltration Uncertainty (BSC 2003 [DIRS 165991]), is to provide an estimate of the uncertainty distributions in infiltration rates over the footprint of the repository, which can be used to provide input for calculations carried out in the TSPA. The uncertainty measure is provided by a distribution function resulting from a set of 100 realizations (or vectors); each of which provides a unique representative infiltration rate. This representative rate is obtained by calculating the spatial average for the corresponding infiltration rate map, averaged over an area approximating the footprint of the repository.

For the uncertainty analysis (BSC 2003 [DIRS 165991]), subwatersheds were identified that would be representative of the loaded repository area within the infiltration model domain. Using the procedure described in Section 6.5.3 of this model report, a total of 17 subwatersheds (using the WATSHD20 V1.0 software routine) were extracted from the geospatial parameter base grid for the future climate uncertainty analysis. The 17 subwatersheds were needed for representing the 1999 repository design footprint, however only 11 of these were used, as described in the uncertainty analysis, to represent the 2003 repository design footprint (BSC 2003 [DIRS 165991]). The additional subwatersheds used for the future climate analysis were generated based on a need to increase the run-time efficiency of the sampling algorithm by using smaller modeling domains with fewer grid cells. The total area $(17,678$ grid cells) contained within the 11 subwatersheds (Output DTN: GS000308311221.004) used for the future climate uncertainty analysis is approximately seven percent of the total net infiltration domain (253,597 grid cells) documented in this model report. A listing of the 11 separate subwatersheds generated specifically for the net infiltration uncertainty analysis is provided in Analysis of Infiltration Uncertainty (BSC 2003 [DIRS 165991], Table 4-3).

\subsection{RESULTS OF NET-INFILTRATION ESTIMATES}

Net infiltration modeling results for present-day, monsoon and glacial-transition climate scenarios can be located in data packages listed in Section 9.4.

\subsubsection{Present-Day Climate}

Table 6-7 lists the simulation results for the three model simulations (YM1-4ex, 4JA1-4ex, A121-4ex) used to develop net-infiltration estimates for the present-day climate scenarios. Also listed is the simulation result for the 10-year period (1980-1990) within the 4JA1-4ex stochastic simulation that was used to develop the lower bound present-day climate scenario. The results include an average net-infiltration rate of $5.1 \mathrm{~mm} /$ year over the area of the modeling domain for the 1980-95 calibration period, with a maximum rate of 1,486 $\mathrm{mm} /$ year obtained for a stream channel in the northern part of the Yucca Wash watershed. The 100-year 4JA simulation provided an average net-infiltration rate of $2.2 \mathrm{~mm} /$ year over the model domain, and a maximum rate of $574.4 \mathrm{~mm} /$ year. The wetter A121-4ex 100-year simulation provided an average net-infiltration rate of $14.0 \mathrm{~mm} /$ year, with a maximum rate of $4,354 \mathrm{~mm} /$ year for a stream channel location in Yucca Wash. The results indicate a good correlation between the maximum infiltrated surface-water run-on rates and the maximum net-infiltration rates, indicating the importance of surface-water flow in causing relatively high but localized net-infiltration rates. 
Table 6-7. Summary of 1999 INFIL Simulation Results Used to Develop Spatially Distributed Netinfiltration Estimates for Present-Day Climate Scenarios

\begin{tabular}{|c|c|c|c|c|c|}
\hline \multirow{2}{*}{\multicolumn{2}{|c|}{$\begin{array}{l}\text { INFIL simulation ID used for developing } \\
\text { the present-day climate scenario }\end{array}$}} & \multicolumn{4}{|c|}{$\begin{array}{l}1999 \text { INFIL Simulation Results for the } 123.7-\mathrm{km}^{2} \text { Area of the Ne } \\
\text { Infiltration Model Domain }\end{array}$} \\
\hline & & YM1-4ex & 4JA1-4ex & 4JA1-4ex & A121-4ex \\
\hline \multicolumn{2}{|c|}{ Daily climate input filename } & Mod3-ppt.dat & 4JA.s01 & 4JA.s01 & Area12.s01 \\
\hline \multicolumn{2}{|c|}{ Simulation period (year number) } & $1980-1995$ & $0-100$ & $80-90$ & $0-100$ \\
\hline \multicolumn{2}{|c|}{ Simulation time (years) } & 16 & 100 & 10 & 100 \\
\hline \multirow{3}{*}{$\begin{array}{l}\text { Average annual } \\
\text { precipitation } \\
\text { (mm/year) }\end{array}$} & Mean & 189.3 & 187.7 & 182.8 & 342.8 \\
\hline & Maximum & 282.9 & 280.6 & 273.3 & 512.4 \\
\hline & Minimum & 148.0 & 146.8 & 143.0 & 268.1 \\
\hline \multirow{3}{*}{$\begin{array}{l}\text { Average annual } \\
\text { evapotranspiration } \\
\text { (mm/year) }\end{array}$} & Mean & 182.7 & 185.5 & 181.8 & 326.8 \\
\hline & Maximum & 571.9 & 652.3 & 689.1 & 788.8 \\
\hline & Minimum & 61.9 & 51.1 & 50.6 & 83.4 \\
\hline \multirow{3}{*}{$\begin{array}{l}\text { Average annual } \\
\text { infiltrated surface } \\
\text { water run-on } \\
\text { (mm/year) } \\
\end{array}$} & Mean & 6.0 & 2.7 & 1.6 & 15.1 \\
\hline & Maximum & $1,514.4$ & 669.6 & 599.7 & $4,343.8$ \\
\hline & Minimum & 0.0 & 0.0 & 0.0 & 0.0 \\
\hline \multicolumn{2}{|c|}{ Average annual outflow (mm/year) } & 0.3 & 0.1 & 0.0 & 1.5 \\
\hline \multirow{3}{*}{$\begin{array}{l}\text { Average annual net } \\
\text { infiltration (mm/year) }\end{array}$} & Mean & 5.1 & 2.2 & 1.3 & 14.0 \\
\hline & Maximum & $1,486.2$ & 574.4 & 252.0 & $4,354.3$ \\
\hline & Minimum & 0.0 & 0.0 & 0.0 & 0.0 \\
\hline
\end{tabular}

Output DTN: GS000308311221.005.

Estimation results for the lower bound, mean, and upper bound present-day climate scenarios obtained using the simulations presented in Table 6-7 and the postprocessing methods discussed in Section 6 are tabulated for the areas of the 1999 net-infiltration model (Table 6-8), the 1999 UZ flow model (Table 6-9), and the 1999 repository footprint (Table 6-10). For the net-infiltration model domain, results for the mean present-day climate scenario include an average precipitation rate of $188.5 \mathrm{~mm} / \mathrm{year}$, an average outflow rate of $0.2 \mathrm{~mm} / \mathrm{year}$, and an average net-infiltration rate of $3.6 \mathrm{~mm} /$ year. In comparison, net infiltration is estimated to be $1.2 \mathrm{~mm} /$ year for the lower bound present-day climate and $8.8 \mathrm{~mm} /$ year for the upper bound present-day climate. Note that the average annual precipitation is different between Tables 6-7 and 6-3. This is because INFIL adjusts precipitation amounts to account for elevation at each grid cell.

Table 6-8. Estimation Results for Present-Day Climate Scenarios Over the 123.7- $\mathrm{km}^{2}$ Area of the 1999 Infiltration Model Domain

\begin{tabular}{|c|c|c|c|c|}
\hline \multirow{2}{*}{\multicolumn{2}{|c|}{ Present-day climate scenario }} & \multicolumn{3}{|c|}{$\begin{array}{c}\text { Estimation Results for Present-Day Climate Scenarios for } \\
\text { Total Area of } 1999 \text { Infiltration Model Domain }\end{array}$} \\
\hline & & Lower bound & Mean & Upper bound \\
\hline \multicolumn{2}{|c|}{ Filename for spatial distribution results } & Modernl.dat & Modernm.dat & Modernu.dat \\
\hline \multirow{3}{*}{$\begin{array}{l}\text { Average annual } \\
\text { precipitation ( } \mathrm{mm} / \text { year) }\end{array}$} & Mean & 185.8 & 188.5 & 265.6 \\
\hline & Maximum & 282.2 & 281.8 & 397.1 \\
\hline & Minimum & 148.0 & 147.4 & 207.8 \\
\hline
\end{tabular}


Table 6-8. Estimation Results for Present-Day Climate Scenarios Over the 123.7- $\mathrm{km}^{2}$ Area of the 1999 Infiltration Model Domain (Continued)

\begin{tabular}{|c|c|c|c|c|}
\hline \multirow{2}{*}{\multicolumn{2}{|c|}{ Present-day climate scenario }} & \multicolumn{3}{|c|}{$\begin{array}{c}\text { Estimation Results for Present-Day Climate Scenarios for } \\
\text { Total Area of } 1999 \text { Infiltration Model Domain }\end{array}$} \\
\hline & & Lower bound & Mean & Upper bound \\
\hline \multicolumn{2}{|c|}{ Filename for spatial distribution results } & Modernl.dat & Modernm.dat & Modernu.dat \\
\hline \multirow{3}{*}{$\begin{array}{l}\text { Average annual } \\
\text { evapotranspiration } \\
\text { (mm/year) }\end{array}$} & Mean & 184.8 & 184.1 & 255.5 \\
\hline & Maximum & 571.9 & 612.1 & 700.5 \\
\hline & Minimum & 54.7 & 56.5 & 71.5 \\
\hline \multirow{3}{*}{$\begin{array}{l}\text { Average annual infiltrated } \\
\text { surface water run-on } \\
\text { (mm/year) }\end{array}$} & Mean & 2.1 & 4.4 & 9.7 \\
\hline & Maximum & 474.2 & 994.1 & $2,669.0$ \\
\hline & Minimum & 0.0 & 0.0 & 0.0 \\
\hline \multicolumn{2}{|c|}{ Average annual outflow (mm/year) } & 0.2 & 0.2 & 0.9 \\
\hline \multirow{3}{*}{$\begin{array}{l}\text { Average annual net } \\
\text { infiltration (mm/year) }\end{array}$} & Mean & 1.2 & 3.6 & 8.8 \\
\hline & Maximum & 252.0 & 958.9 & $2,656.6$ \\
\hline & Minimum & 0.0 & 0.0 & 0.0 \\
\hline
\end{tabular}

Output DTN: GS000308311221.005.

NOTE: The maximum and minimum precipitation values for the lower bound present-day climate are higher than those for the mean present-day climate are. This is a result of the algorithm used in MAPADD20 V1.0 to sample these values. When net infiltration is zero for all datasets sampled for a given grid cell, only one precipitation dataset is sampled. Therefore, this algorithm can result in anomalous water balance results, with the exception of net infiltration, when net infiltration is zero.

For the area of the $1999 \mathrm{UZ}$ flow model, results for the mean present-day climate scenario include an average precipitation rate of $190.6 \mathrm{~mm} / \mathrm{year}$, an average outflow rate of $-0.2 \mathrm{~mm} / \mathrm{year}$, and an average net-infiltration rate of $4.6 \mathrm{~mm} / \mathrm{year}$ (Table 6-9). The negative outflow rate indicates that more surface water flows into the 1999 UZ flow model area than flows out (primarily due to inflow from Yucca Wash). For the lower bound present-day climate, net infiltration is estimated to be $1.3 \mathrm{~mm} /$ year for the $1999 \mathrm{UZ}$ flow model area; for the upper bound present-day climate, net infiltration is estimated to be $11.1 \mathrm{~mm} /$ year.

For the area of the repository site, results for the mean present-day climate scenario include an average precipitation rate of $196.9 \mathrm{~mm} /$ year, an average outflow rate of $1.4 \mathrm{~mm} /$ year, and an average net-infiltration rate of $4.7 \mathrm{~mm} / \mathrm{year}$ (Table 6-10). For the lower bound present-day climate, net infiltration is estimated to be $0.4 \mathrm{~mm} /$ year and outflow is estimated to be $-0.3 \mathrm{~mm} /$ year. The negative outflow occurs because surface-water inflow from Drill Hole Wash exceeds outflow. For the upper bound present-day climate, net infiltration is estimated to be $11.6 \mathrm{~mm} /$ year over the area of the repository.

The spatial distribution of estimated precipitation for the mean present-day climate scenario indicates minimum estimates of 140-160 $\mathrm{mm} /$ year occurring along the southern and southeastern parts of the modeling domain, with maximum estimates of more than $260 \mathrm{~mm} /$ year occurring for the summit areas along the northern perimeter of the modeling domain (Figure 6-22). 
Table 6-9. Estimation Results for Present-Day Climate Scenarios Over the 38.7- $\mathrm{km}^{2}$ Area of the 1999 UZ Flow Model Domain

\begin{tabular}{|c|c|c|c|c|}
\hline \multirow{2}{*}{\multicolumn{2}{|c|}{ Present-day climate scenario }} & \multicolumn{3}{|c|}{$\begin{array}{c}\text { Estimation Results for Present-Day Climate Scenarios for } \\
\text { Area of } 1999 \text { UZ Flow Model Domain }\end{array}$} \\
\hline & & Lower bound & Mean & Upper bound \\
\hline \multicolumn{2}{|c|}{ Filename for spatial distribution results } & Modernl.dat & Modernm.dat & Modernu.dat \\
\hline \multirow{3}{*}{$\begin{array}{l}\text { Average annual } \\
\text { precipitation (mm/year) }\end{array}$} & Mean & 186.8 & 190.6 & 268.6 \\
\hline & Maximum & 246.3 & 246.5 & 347.4 \\
\hline & Minimum & 162.7 & 167.1 & 235.5 \\
\hline \multirow{3}{*}{$\begin{array}{l}\text { Average annual } \\
\text { evapotranspiration } \\
\text { (mm/year) }\end{array}$} & Mean & 186.2 & 185.3 & 257.1 \\
\hline & Maximum & 367.9 & 348.2 & 485.6 \\
\hline & Minimum & 62.2 & 59.7 & 77.2 \\
\hline \multirow{3}{*}{$\begin{array}{l}\text { Average annual infiltrated } \\
\text { surface water run-on } \\
\text { (mm/year) }\end{array}$} & Mean & 1.9 & 4.1 & 10.1 \\
\hline & Maximum & 194.9 & 277.0 & 802.9 \\
\hline & Minimum & 0.0 & 0.0 & 0.0 \\
\hline \multicolumn{2}{|c|}{ Average annual outflow (mm/year) } & -0.7 & -0.2 & -0.3 \\
\hline \multirow{3}{*}{$\begin{array}{l}\text { Average annual net } \\
\text { infiltration (mm/year) }\end{array}$} & Mean & 1.3 & 4.6 & 11.1 \\
\hline & Maximum & 218.8 & 263.6 & 784.9 \\
\hline & Minimum & 0.0 & 0.0 & 0.0 \\
\hline
\end{tabular}

Output DTN: GS000308311221.005.

NOTE: Estimates of net infiltration for the UZ flow model area differ slightly from those reported in BSC (2004 [DIRS 169861], Table 6.1-2) because the 1999 UZ flow model boundary for site recommendation is used in this report while the 2003 UZ flow model boundary for license application is used in BSC (2004 [DIRS 169861]).

Table 6-10. Estimation Results for Present-Day Climate Scenarios Over the 4.7- $\mathrm{km}^{2}$ Area of the 1999 Repository Footprint

\begin{tabular}{|c|c|c|c|c|}
\hline & & \multicolumn{3}{|c|}{$\begin{array}{l}\text { Estimation Results for Present-Day Climate Scenarios for } \\
\text { Area of Repository }\end{array}$} \\
\hline \multicolumn{2}{|c|}{ Present-day climate scenario } & Lower bound & Mean & Upper bound \\
\hline \multicolumn{2}{|c|}{ Filename for spatial distribution results } & Modernl.dat & Modernm.dat & Modernu.dat \\
\hline \multirow{3}{*}{$\begin{array}{l}\text { Average annual } \\
\text { precipitation ( } \mathrm{mm} / \text { year) }\end{array}$} & Mean & 191.6 & 196.9 & 277.5 \\
\hline & Maximum & 204.1 & 209.9 & 295.8 \\
\hline & Minimum & 178.2 & 183.4 & 258.5 \\
\hline \multirow{3}{*}{$\begin{array}{l}\text { Average annual } \\
\text { evapotranspiration } \\
\text { (mm/year) }\end{array}$} & Mean & 191.7 & 189.9 & 260.4 \\
\hline & Maximum & 252.9 & 273.3 & 423.0 \\
\hline & Minimum & 155.0 & 154.7 & 203.0 \\
\hline \multirow{3}{*}{$\begin{array}{l}\text { Average annual infiltrated } \\
\text { surface water run-on } \\
\text { (mm/year) }\end{array}$} & Mean & 1.0 & 3.4 & 8.1 \\
\hline & Maximum & 59.8 & 161.1 & 454.8 \\
\hline & Minimum & 0.0 & 0.0 & 0.0 \\
\hline \multicolumn{2}{|c|}{ Average annual outflow (mm/year) } & -0.3 & 1.4 & 4.9 \\
\hline \multirow{3}{*}{$\begin{array}{l}\text { Average annual net } \\
\text { infiltration (mm/year) }\end{array}$} & Mean & 0.4 & 4.7 & 11.6 \\
\hline & Maximum & 26.6 & 120.1 & 387.4 \\
\hline & Minimum & 0.0 & 0.0 & 0.0 \\
\hline
\end{tabular}

Output DTN: GS000308311221.005. 


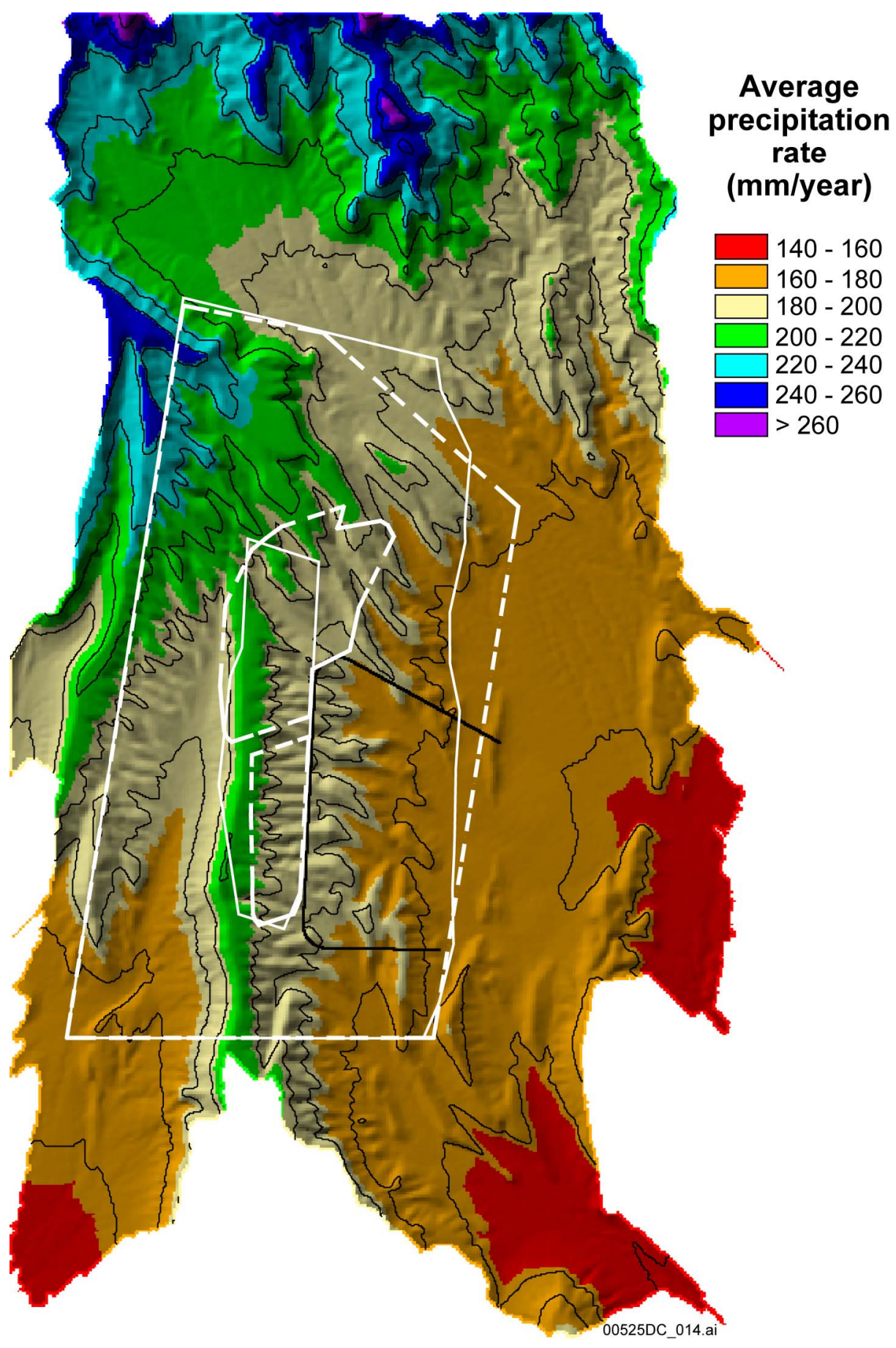

Source: DTN: GS000208311221.001.

NOTE: The 1999 UZ flow model domain and the 1999 repository footprint are site recommendation boundaries (solid lines), not license application boundaries (dashed lines).

Figure 6-22. Estimated Precipitation ( $\mathrm{mm} / \mathrm{year}$ ) for the Mean Present-Day Climate Scenario

Estimated evapotranspiration rates in general reflect the distribution of precipitation but also reflect local terrain and surface-water flow effects (Figure 6-23). Minimum evapotranspiration rates of 140 to $160 \mathrm{~mm} /$ year occur along the southern and southeastern sections of the model 
domain, and maximum rates of 220 to $240 \mathrm{~mm} /$ year occur for higher elevations receiving greater precipitation amounts. Minimum evapotranspiration rates of less than $100 \mathrm{~mm} / \mathrm{year}$ occur for steep north-facing side slopes and areas with minimal soil cover, the west-facing slope of Solitario Canyon, and the rugged terrain in the northern part of Yucca Wash. Maximum evapotranspiration rates of $240 \mathrm{~mm} /$ year and higher, on the other hand, are indicative of locations subject to a high volume or frequency of infiltrated surface-water run-on, particularly when immediately downslope from areas receiving higher precipitation as well as rugged terrain conducive to runoff generation, such as the northern part of Yucca Wash.

Infiltrated surface-water run-on indicates the contribution of surface-water flow to potential net infiltration and evapotranspiration (Figure 6-24). Maximum infiltrated surface-water run-on rates of more than $100 \mathrm{~mm} /$ year occur mostly along the Yucca Wash channel but also at more isolated locations in the upper sections of drainages such as Drill Hole Wash, Solitario Canyon, Pagany Wash, and Abandoned Wash. In general, the higher infiltrated run-on rates occur in the upstream and headwater sections of drainages, possibly indicating a greater contribution from smaller but higher frequency runoff events for the mean present-day climate scenario.

The spatial distribution of estimated net-infiltration rates for the mean present-day climate indicates most net infiltration occurs in upland areas with thin soils (Figure 6-25). The spatial distribution also indicates a strong control of bedrock hydraulic conductivity on spatial distributions and magnitudes, in addition to the effects of thin soils and surface-water run-on. Relatively high net-infiltration rates of $100 \mathrm{~mm} /$ year and higher occur throughout the steep north, north-east facing slope of the Prow due to a combination of higher precipitation rates, reduced PET, frequent surface-water run-on due to very thin soils, and high bedrock hydraulic conductivity associated with non-welded tuffs. Areas of relatively high net-infiltration rates also include the upper channel locations of Solitario Canyon, Drill Hole Wash, Pagany Wash, and Abandoned Wash. Variability in net infiltration caused by topographic effects on PET are illustrated by the higher net-infiltration rates for the north slopes of washes compared to south facing slopes (this is well illustrated by the west-to-east drainages along the east slope of Yucca Mountain and bisected by the Exploratory Studies Facility main drift). Maximum net-infiltration rates of more than $100 \mathrm{~mm} /$ year occur within the UZ flow model domain for isolated areas that include side-slope and channel locations with thin soils and high hydraulic conductivity bedrock. The contribution to the total net-infiltration volume over the area of the UZ flow model is dominated, however, by the lower rates of 1 to $20 \mathrm{~mm} /$ year covering wider areas of side slope and ridge top locations because of a much greater total area of coverage. 


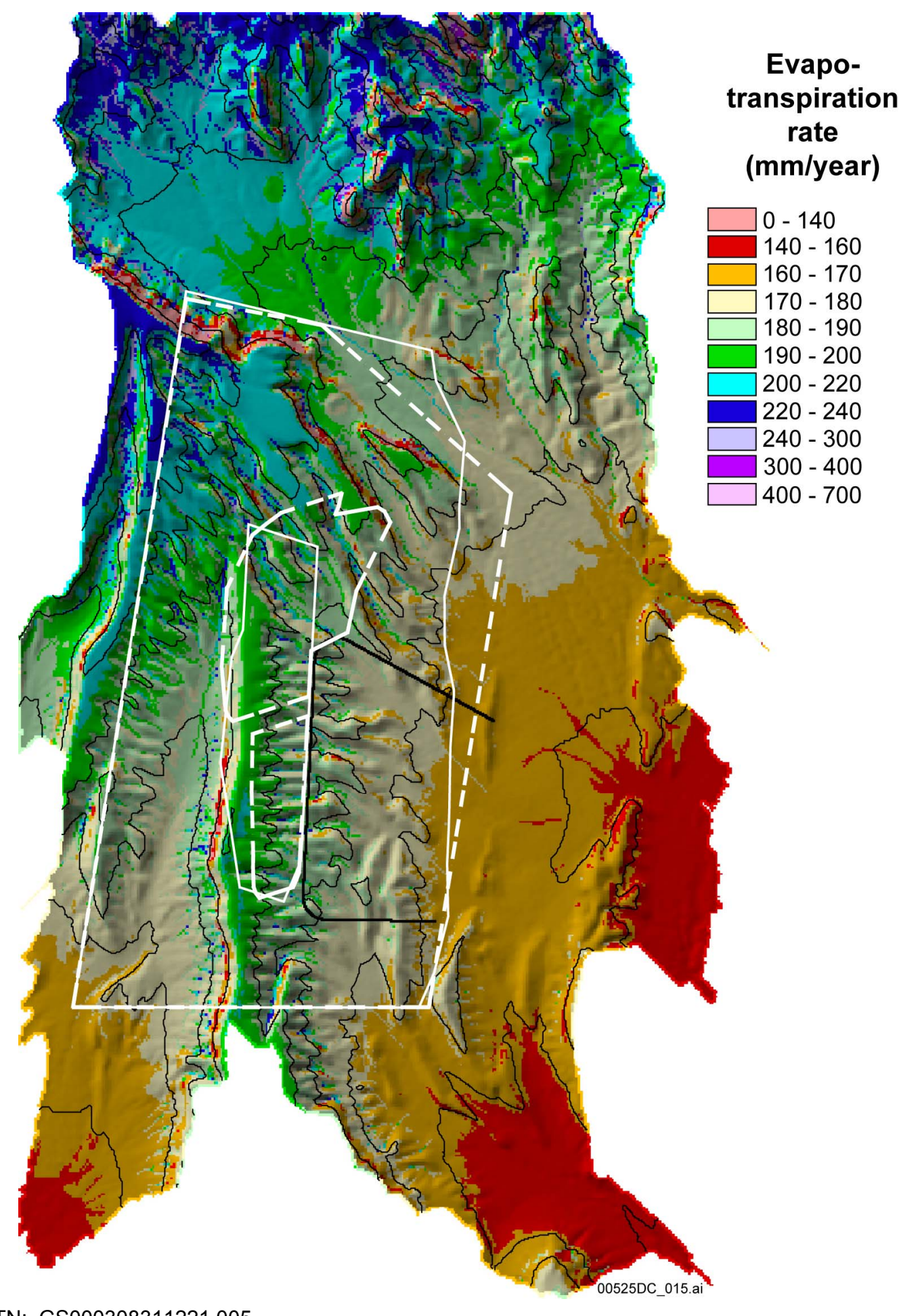

Output DTN: GS000308311221.005.

NOTE: The 1999 UZ flow model domain and the 1999 repository footprint are site recommendation boundaries (solid lines), not license application boundaries (dashed lines).

Figure 6-23. Estimated Evapotranspiration (mm/year) for the Mean Present-Day Climate Scenario 


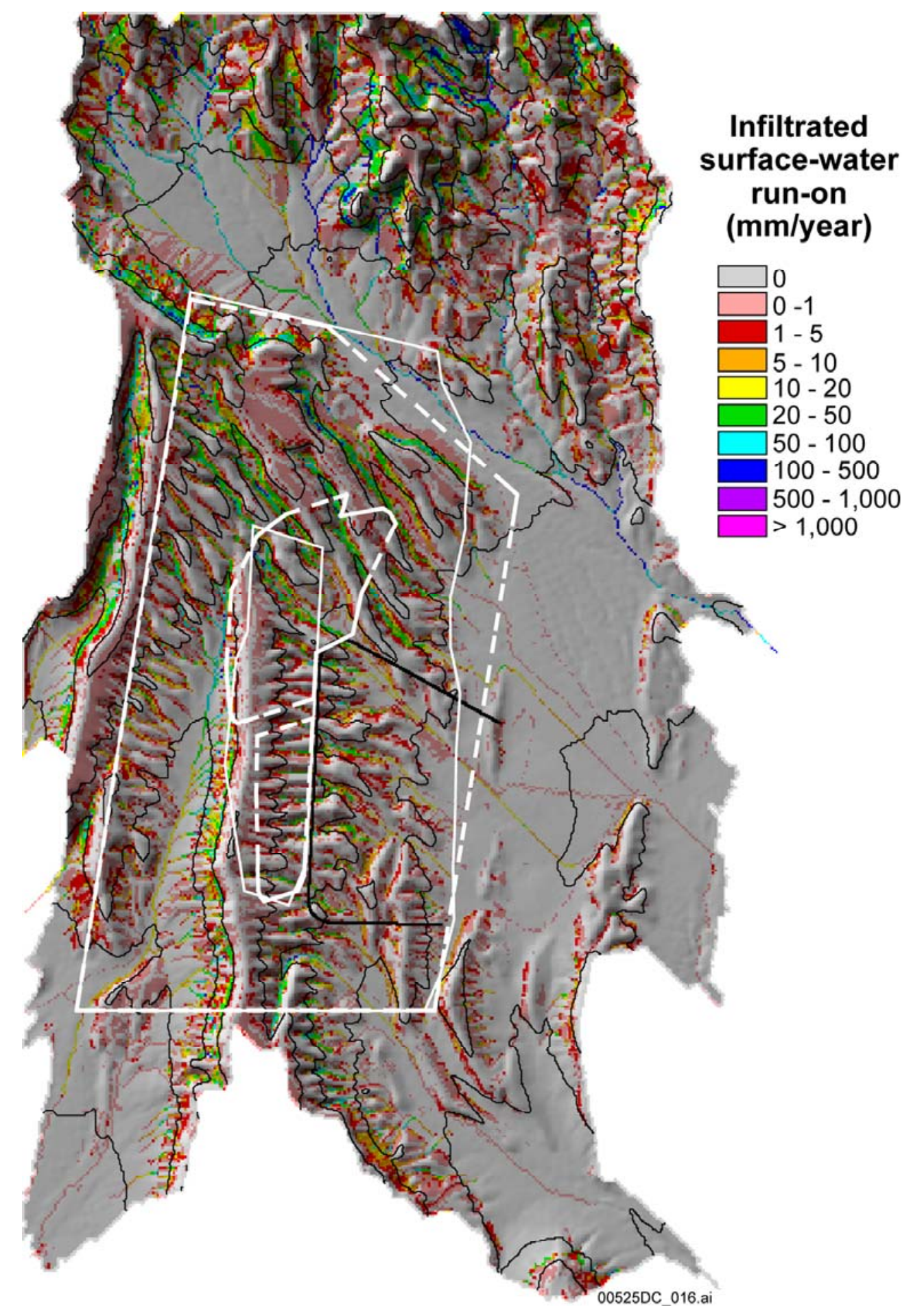

Output DTN: GS000308311221.005.

NOTE: The 1999 UZ flow model domain and the 1999 repository footprint are site recommendation boundaries (solid lines), not license application boundaries (dashed lines).

Figure 6-24. Estimated Surface-water Run-on Depth ( $\mathrm{mm} / \mathrm{year}$ ) for the Mean Present-Day Climate Scenario 


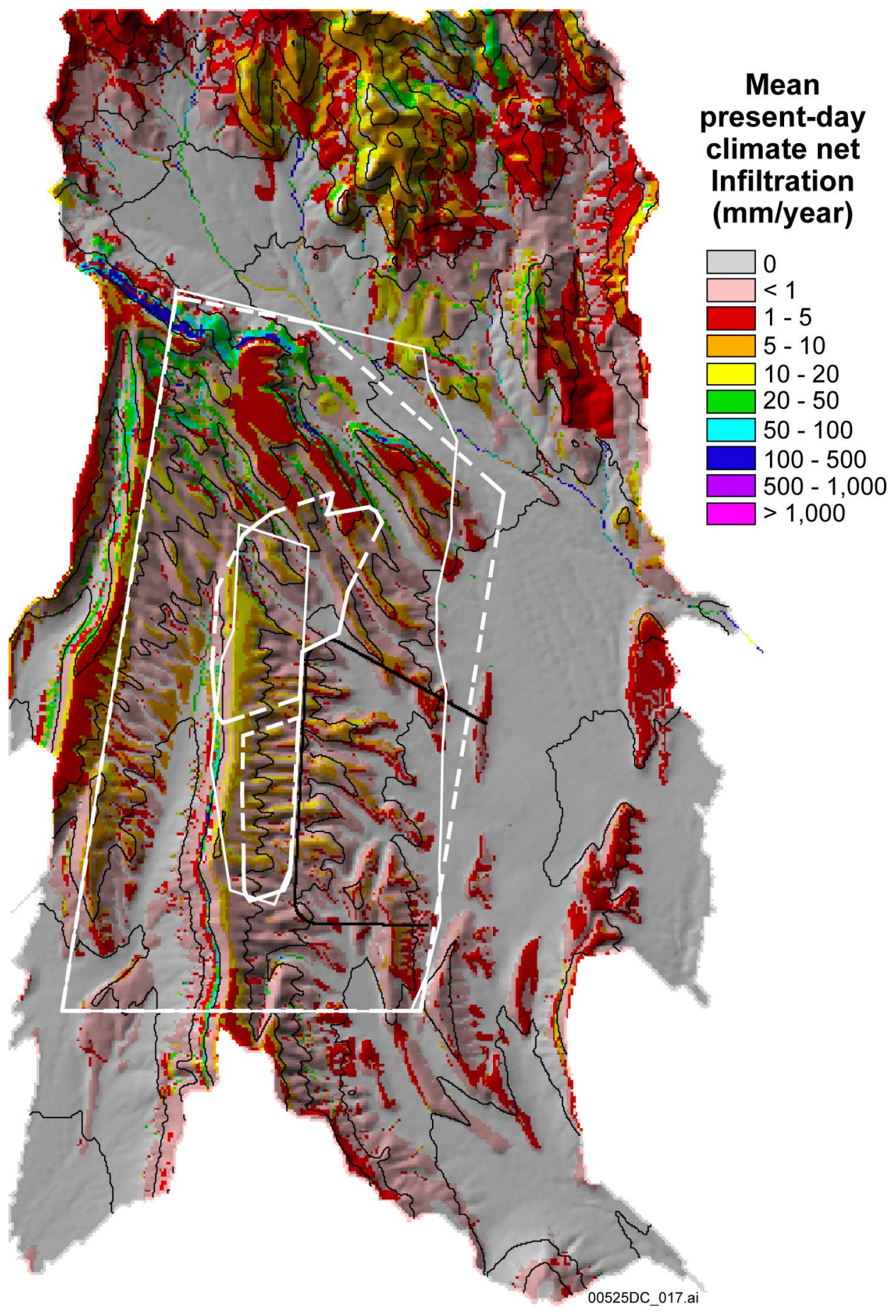

Output DTN: GS000308311221.005.

NOTE: The 1999 UZ flow model domain and the 1999 repository footprint are site recommendation boundaries (solid lines), not license application boundaries (dashed lines).

Figure 6-25. Estimated Net Infiltration (mm/year) for the Mean Present-Day Climate Scenario 
For the lower bound present-day climate scenario, the total area with significant net infiltration is greatly reduced (Figure 6-26). Within the repository area, most areas, including the crest, have no net infiltration. Areas with net-infiltration rates greater than $5 \mathrm{~mm} /$ year are isolated to north-facing side slopes and along the west-facing slope of Solitario Canyon. For the upper bound present-day climate scenario, net infiltration along the crest of Yucca Mountain is more than $20 \mathrm{~mm} /$ year, and the relative contribution of net infiltration along channels to the total net-infiltration volume is greatly increased compared to the mean present-day climate estimates (Figure 6-27). The maximum net-infiltration rate of almost 2,700 mm/year occurs for an active channel location in the northern part of Yucca Wash. Within the repository area, maximum net-infiltration estimates of between 100 and $500 \mathrm{~mm} /$ year occur in Drill Hole Wash and along the west-facing slope of Solitario Canyon.

In general, the maximum net-infiltration estimates for the three climate scenarios are more than two orders of magnitude higher than the spatially averaged net-infiltration rates for the three areas analyzed, indicating a high degree of spatial variability for the estimation results. In all cases, maximum net-infiltration rates occur at locations affected by surface-water run-on, and there is a strong correlation between the maximum infiltrated run-on rates with maximum net-infiltration rates for all areas and for all climate scenarios. However, because the areas with relatively high net-infiltration rates (greater than $100 \mathrm{~mm} /$ year) are small, most of the total net-infiltration volume occurs from upland areas with net-infiltration rates less than $20 \mathrm{~mm} /$ year.

\subsubsection{Monsoon Climate}

The lower bound monsoon climate scenario is defined using the mean present-day day climate result (the lower bound monsoon climate result is equal to the present-day day climate result). The simulation results used to develop the mean present-day climate scenario are equivalent to the lower bound monsoon climate scenario. Net-infiltration estimates for the mean present-day climate scenario were calculated using the net-infiltration simulation results for the 1980-95 model calibration period and results obtained using a 100-year stochastic simulation of daily precipitation modeled with the NTS station 4JA precipitation record. The simulation results for the two analogue upper bound monsoon climate simulations (Nogales, Arizona and Hobbs, New Mexico) used to develop net-infiltration estimates for the mean and upper bound monsoon climate scenarios are provided in Table 6-11. The results indicate an average netinfiltration rate of $15.1 \mathrm{~mm} /$ year for the Nogales analogue climate record and $12.1 \mathrm{~mm} /$ year for the Hobbs analogue climate record, with maximum net-infiltration rates of 2,900 mm/year and 2,330 $\mathrm{mm} /$ year, respectively. As in the case of the present-day climate simulations, the maximum net-infiltration rates occur in the active channel of Yucca Wash. 


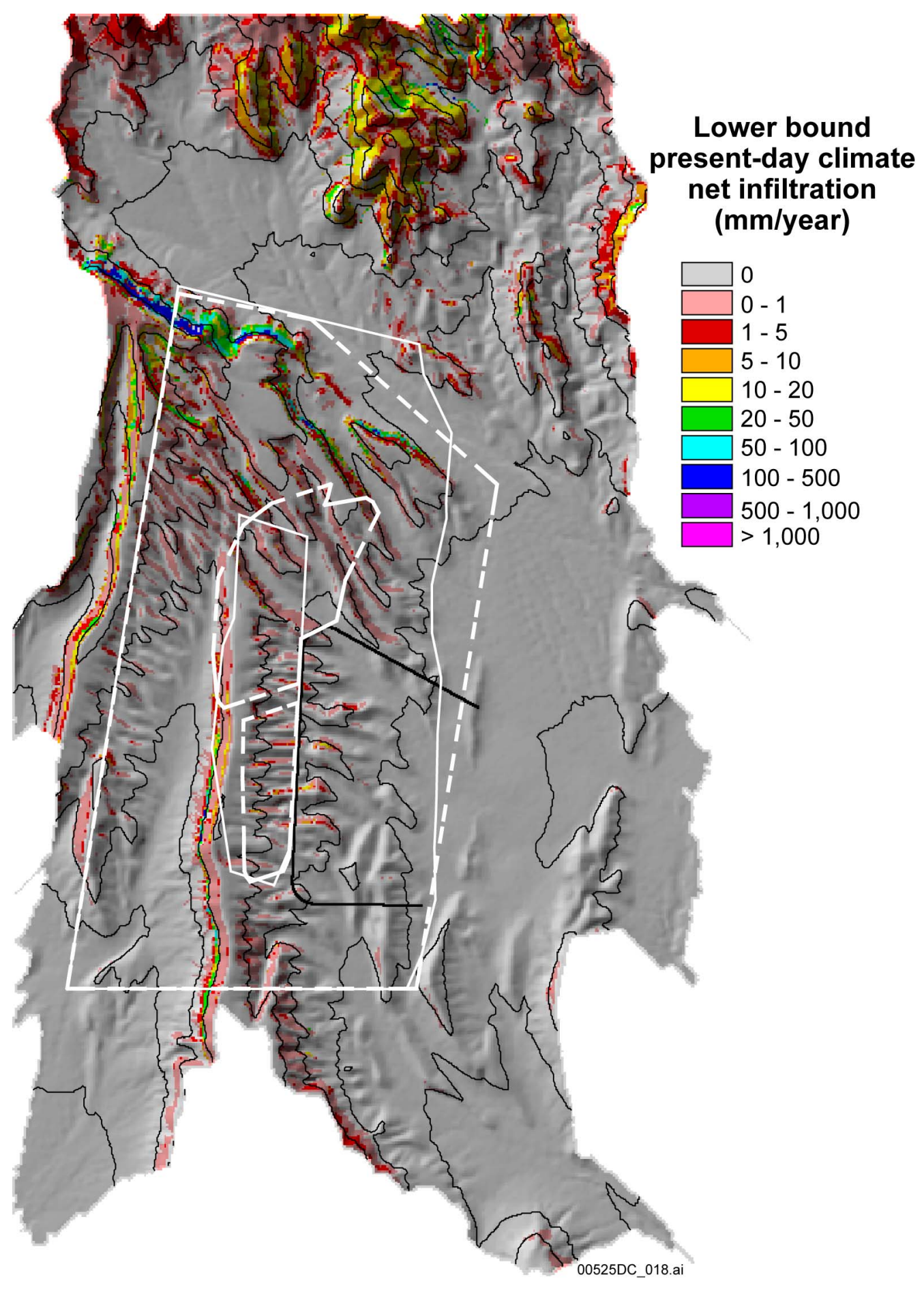

Output DTN: GS000308311221.005.

NOTE: The 1999 UZ flow model domain and the 1999 repository footprint are site recommendation boundaries (solid lines), not license application boundaries (dashed lines).

Figure 6-26. Estimated Net infiltration (mm/year) for the Lower Bound Present-Day Climate Scenario 


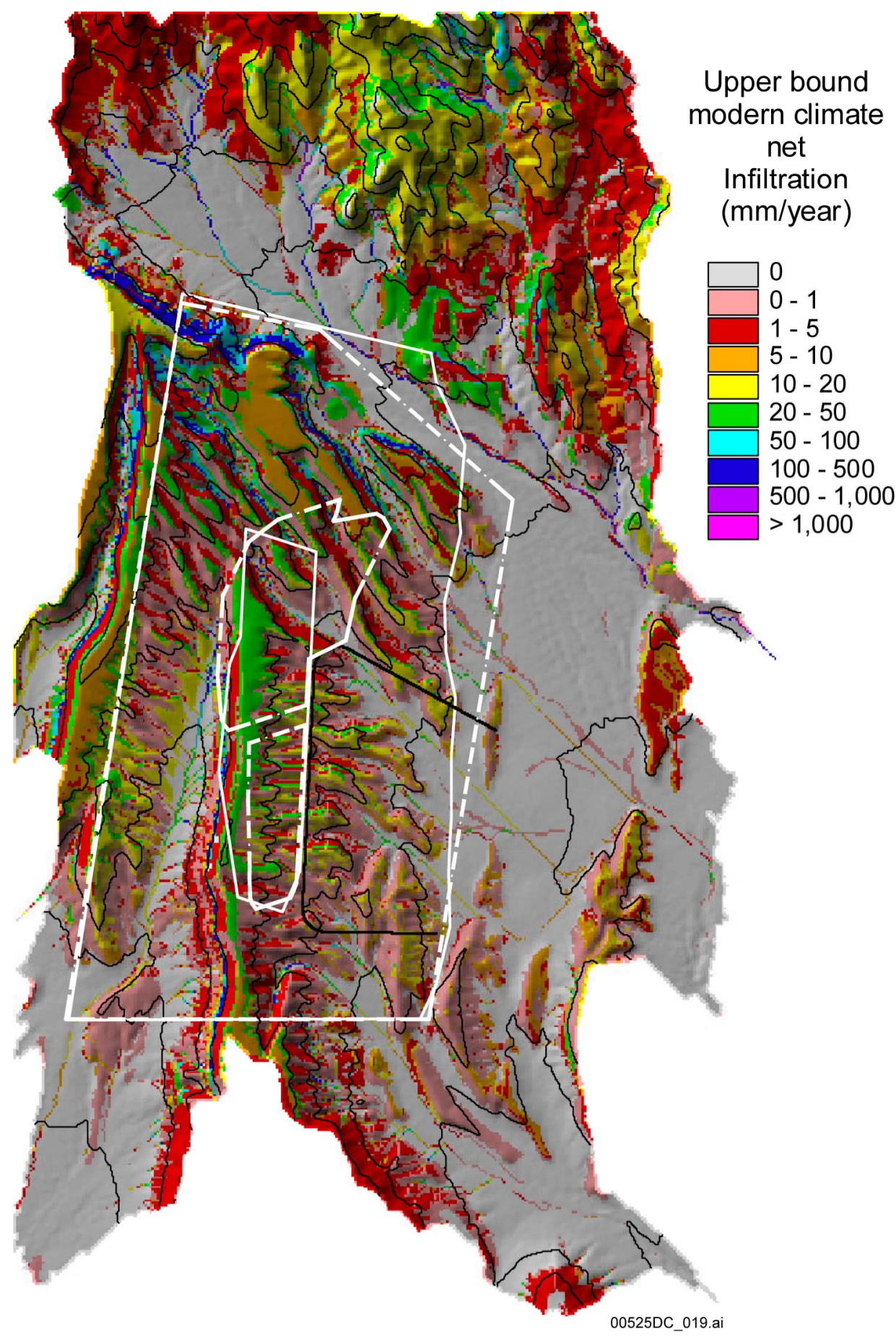

Output DTN: GS000308311221.005.

NOTE: The 1999 UZ flow model domain and the 1999 repository footprint are site recommendation boundaries (solid lines), not license application boundaries (dashed lines).

Figure 6-27. Estimated Net Infiltration (mm/year) for the Upper Bound Present-Day Climate Scenario 
Table 6-11. Summary of 1999 INFIL Simulation Results Used to Develop Spatially Distributed Netinfiltration Estimates for the Upper Bound Monsoon Climate Scenarios

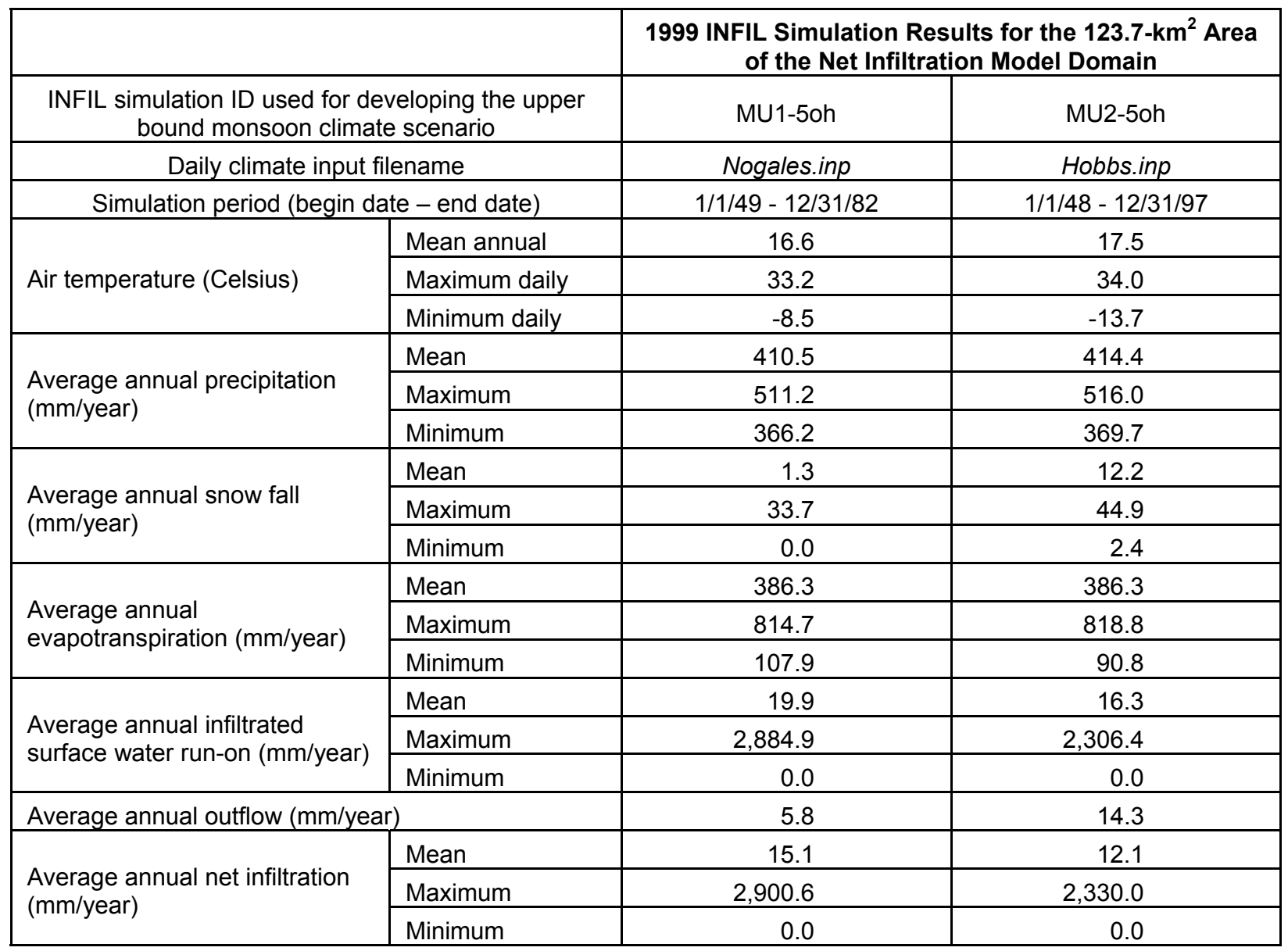

Output DTN: GS000308311221.005.

Estimation results for the lower bound, mean, and upper bound monsoon climate scenarios are tabulated for the areas of the net-infiltration model (Table 6-12), the UZ flow model (Table 6-13), and the repository (Table 6-14). The results for the mean monsoon climate scenario, which were calculated as the arithmetic mean of the lower bound and upper bound monsoon climate scenarios, include an average precipitation rate of $300.5 \mathrm{~mm} / \mathrm{year}$, an average outflow rate of $5.1 \mathrm{~mm} / \mathrm{year}$, and an average net-infiltration rate of $8.6 \mathrm{~mm} / \mathrm{year}$ over the net-infiltration model domain. Results for the upper bound monsoon climate scenario, which were calculated as the arithmetic mean of net infiltration simulations for two analogue sites (Nogales, AZ and Hobbs, NM) include an average precipitation rate of $412.5 \mathrm{~mm} / \mathrm{year}$, an average outflow rate of $10.0 \mathrm{~mm} /$ year, and an average net-infiltration rate of $13.6 \mathrm{~mm} /$ year over the net-infiltration model domain.

For the UZ flow model area, results for the mean monsoon climate scenario include an average precipitation rate of $302.7 \mathrm{~mm} /$ year, an average outflow rate of $4.6 \mathrm{~mm} /$ year, and an average net-infiltration rate of $12.2 \mathrm{~mm} /$ year (Table 6-13). The maximum net-infiltration rate is $629 \mathrm{~mm} /$ year. For the lower bound monsoon climate scenario, average net infiltration is $4.6 \mathrm{~mm} /$ year for the UZ flow model area (the mean present-day climate result). Estimation results for the upper bound monsoon climate scenario include a precipitation 
rate of $414.8 \mathrm{~mm} /$ year, a snowfall rate of $6.8 \mathrm{~mm} /$ year, an average outflow rate of $9.5 \mathrm{~mm} /$ year, and a net-infiltration rate of $19.8 \mathrm{~mm} /$ year. The maximum net-infiltration rate for the upper bound monsoon climate scenario is $1,016 \mathrm{~mm} / \mathrm{year}$ for the UZ flow model area.

Table 6-12. Estimation Results for the Monsoon Climate Scenarios Over the 123.7- $\mathrm{km}^{2}$ Area of the 1999 Infiltration Model Domain

\begin{tabular}{|c|c|c|c|c|}
\hline \multirow{2}{*}{\multicolumn{2}{|c|}{ Monsoon climate scenario }} & \multicolumn{3}{|c|}{$\begin{array}{l}\text { Estimation Results for Monsoon Climate Scenarios for } \\
\text { Total area of Infiltration Model Domain }\end{array}$} \\
\hline & & Lower bound & Mean & Upper bound \\
\hline \multicolumn{2}{|c|}{ Filename for spatial distribution results } & Monsoonl.dat & Monsoonm.dat & Monsoonu.dat \\
\hline \multicolumn{2}{|c|}{ Mean annual air temperature (Celsius) } & 17.3 & 17.2 & 17.0 \\
\hline \multirow{3}{*}{$\begin{array}{l}\text { Average annual } \\
\text { precipitation (mm/year) }\end{array}$} & Mean & 188.5 & 300.5 & 412.5 \\
\hline & Maximum & 281.8 & 397.7 & 513.6 \\
\hline & Minimum & 147.4 & 257.7 & 368.0 \\
\hline \multirow{3}{*}{$\begin{array}{l}\text { Average annual snow fall } \\
\text { (mm/year) }\end{array}$} & Mean & $\mathrm{n} / \mathrm{a}$ & $\mathrm{n} / \mathrm{a}$ & 6.8 \\
\hline & Maximum & $\mathrm{n} / \mathrm{a}$ & $\mathrm{n} / \mathrm{a}$ & 39.3 \\
\hline & Minimum & $\mathrm{n} / \mathrm{a}$ & $\mathrm{n} / \mathrm{a}$ & 1.2 \\
\hline \multirow{3}{*}{$\begin{array}{l}\text { Average annual } \\
\text { evapotranspiration } \\
\text { (mm/year) }\end{array}$} & Mean & 184.1 & 285.2 & 386.3 \\
\hline & Maximum & 612.1 & 714.4 & 816.7 \\
\hline & Minimum & 56.5 & 77.9 & 99.3 \\
\hline \multirow{3}{*}{$\begin{array}{l}\text { Average annual infiltrated } \\
\text { surface-water run-on } \\
\text { (mm/year) }\end{array}$} & Mean & 4.4 & 11.2 & 18.1 \\
\hline & Maximum & 994.1 & 1,795 & 2,596 \\
\hline & Minimum & 0.0 & 0.0 & 0.0 \\
\hline \multicolumn{2}{|c|}{ Average annual outflow (mm/year) } & 0.2 & 5.1 & 10.0 \\
\hline \multirow{3}{*}{$\begin{array}{l}\text { Average annual net } \\
\text { infiltration (mm/year) }\end{array}$} & Mean & 3.6 & 8.6 & 13.6 \\
\hline & Maximum & 958.9 & 1,787 & 2,615 \\
\hline & Minimum & 0.0 & 0.0 & 0.0 \\
\hline
\end{tabular}

Output DTN: GS000308311221.005.

Table 6-13. Estimation Results for the Monsoon Climate Scenarios over the $38.7-\mathrm{km}^{2}$ Area of the 1999 UZ Flow Model Domain

\begin{tabular}{|c|c|c|c|c|}
\hline & & \multicolumn{3}{|c|}{$\begin{array}{c}\text { Estimation Results for Monsoon Climate Scenarios for } \\
\text { Area of UZ Flow Model }\end{array}$} \\
\hline \multicolumn{2}{|c|}{ Monsoon climate scenario } & Lower bound & Mean & Upper bound \\
\hline \multicolumn{2}{|c|}{ Filename for spatial distribution results } & Monsoonl.dat & Monsoonm.dat & Monsoonu.dat \\
\hline \multirow{3}{*}{$\begin{array}{l}\text { Average annual } \\
\text { precipitation (mm/year) }\end{array}$} & Mean & 190.6 & 302.7 & 414.8 \\
\hline & Maximum & 246.5 & 360.9 & 475.4 \\
\hline & Minimum & 167.1 & 278.2 & 389.3 \\
\hline \multirow{3}{*}{$\begin{array}{l}\text { Average annual snow fall } \\
\text { (mm/year) }\end{array}$} & Mean & $\mathrm{n} / \mathrm{a}$ & $\mathrm{n} / \mathrm{a}$ & 6.8 \\
\hline & Maximum & $\mathrm{n} / \mathrm{a}$ & $\mathrm{n} / \mathrm{a}$ & 18.8 \\
\hline & Minimum & $\mathrm{n} / \mathrm{a}$ & $\mathrm{n} / \mathrm{a}$ & 3.0 \\
\hline \multirow{3}{*}{$\begin{array}{l}\text { Average annual } \\
\text { evapotranspiration } \\
\text { (mm/year) }\end{array}$} & Mean & 185.3 & 284.0 & 382.8 \\
\hline & Maximum & 348.2 & 509.9 & 684.7 \\
\hline & Minimum & 59.7 & 81.7 & 103.7 \\
\hline
\end{tabular}


Table 6-13. Estimation Results for the Monsoon Climate Scenarios over the $38.7-\mathrm{km}^{2}$ Area of the 1999 UZ Flow Model Domain (Continued)

\begin{tabular}{|c|c|c|c|c|}
\hline \multirow{2}{*}{\multicolumn{2}{|c|}{ Monsoon climate scenario }} & \multicolumn{3}{|c|}{$\begin{array}{c}\text { Estimation Results for Monsoon Climate Scenarios for } \\
\text { Area of UZ Flow Model }\end{array}$} \\
\hline & & Lower bound & Mean & Upper bound \\
\hline \multicolumn{2}{|c|}{ Filename for spatial distribution results } & Monsoonl.dat & Monsoonm.dat & Monsoonu.dat \\
\hline \multirow{3}{*}{$\begin{array}{l}\text { Average annual infiltrated } \\
\text { surface-water run-on } \\
\text { (mm/year) }\end{array}$} & Mean & 4.1 & 12.2 & 20.4 \\
\hline & Maximum & 277.0 & 642.7 & 1,018 \\
\hline & Minimum & 0.0 & 0.0 & 0.0 \\
\hline \multicolumn{2}{|c|}{ Average annual outflow (mm/year) } & -0.2 & 4.6 & 9.5 \\
\hline \multirow{3}{*}{$\begin{array}{l}\text { Average annual net } \\
\text { infiltration (mm/year) }\end{array}$} & Mean & 4.6 & 12.2 & 19.8 \\
\hline & Maximum & 263.6 & 629.0 & 1,016 \\
\hline & Minimum & 0.0 & 0.0 & 0.0 \\
\hline
\end{tabular}

Output DTN: GS000308311221.005.

NOTE: Estimates of net infiltration for the UZ flow model area differ slightly from those reported in BSC (2004 [DIRS 169861], Table 6.1-2) because the 1999 UZ flow model boundary for site recommendation used in this report while the 2003 UZ flow model boundary for license application is used in BSC (2004 [DIRS 169861]).

For the area of the repository site, results for the mean monsoon climate scenario include an average precipitation rate of $309.3 \mathrm{~mm} /$ year, an average outflow rate of $13.2 \mathrm{~mm} / \mathrm{year}$, and an average net-infiltration rate of $12.5 \mathrm{~mm} /$ year (Table 6-14). For the upper bound present-day climate scenario, precipitation is estimated to be $421.6 \mathrm{~mm} / \mathrm{year}$, outflow is estimated to be $25.1 \mathrm{~mm} /$ year, and net infiltration is estimated to be $20.3 \mathrm{~mm} /$ year over the area of the repository.

Figure 6-28 shows the spatial distribution of net-infiltration estimates for the mean monsoon climate scenario. Estimated net-infiltration rates along the crest of Yucca Mountain are in the range of 20 to $50 \mathrm{~mm} /$ year. Within the repository area, maximum net-infiltration rates of between 100 and $500 \mathrm{~mm} /$ year occur in the active channel of Drill Hole Wash and for outcrop locations of permeable, nonwelded tuffs in the middle section of the west-facing slope of Solitario Canyon. Relatively high net-infiltration rates of 100 to $500 \mathrm{~mm} / \mathrm{year}$ also occur at many steep side-slope locations in the northern part of the UZ flow model area. In contrast, net infiltration at upland locations with thin soils underlain by bedrock with low bulk hydraulic conductivity is less than $1 \mathrm{~mm} /$ year.

The map of net-infiltration estimates for the upper bound monsoon climate scenario indicates a greater percentage of area affected by the relatively high net-infiltration rates of 100 to $500 \mathrm{~mm} /$ year, along with an increase in the moderately high net-infiltration rates along the crest of Yucca Mountain (Figure 6-29). In absolute terms, the increase in net infiltration for locations with bedrock having a high bulk hydraulic conductivity is much greater than the increase for locations with bedrock with a low bulk hydraulic conductivity, which remains less than $1 \mathrm{~mm} /$ year. The infiltrated run-on map indicates the importance of surface-water flow on net infiltration for the upper bound monsoon climate (Figure 6-30). Relatively high run-on infiltration rates of 100 to $500 \mathrm{~mm} /$ year occur throughout the active channels of Drill Hole Wash, Pagany Wash, Solitario Canyon, Dune Wash, and Yucca Wash. 
Table 6-14. Estimation Results for the Monsoon Climate Scenarios over the 4.7-km² Area of the 1999 Repository Footprint

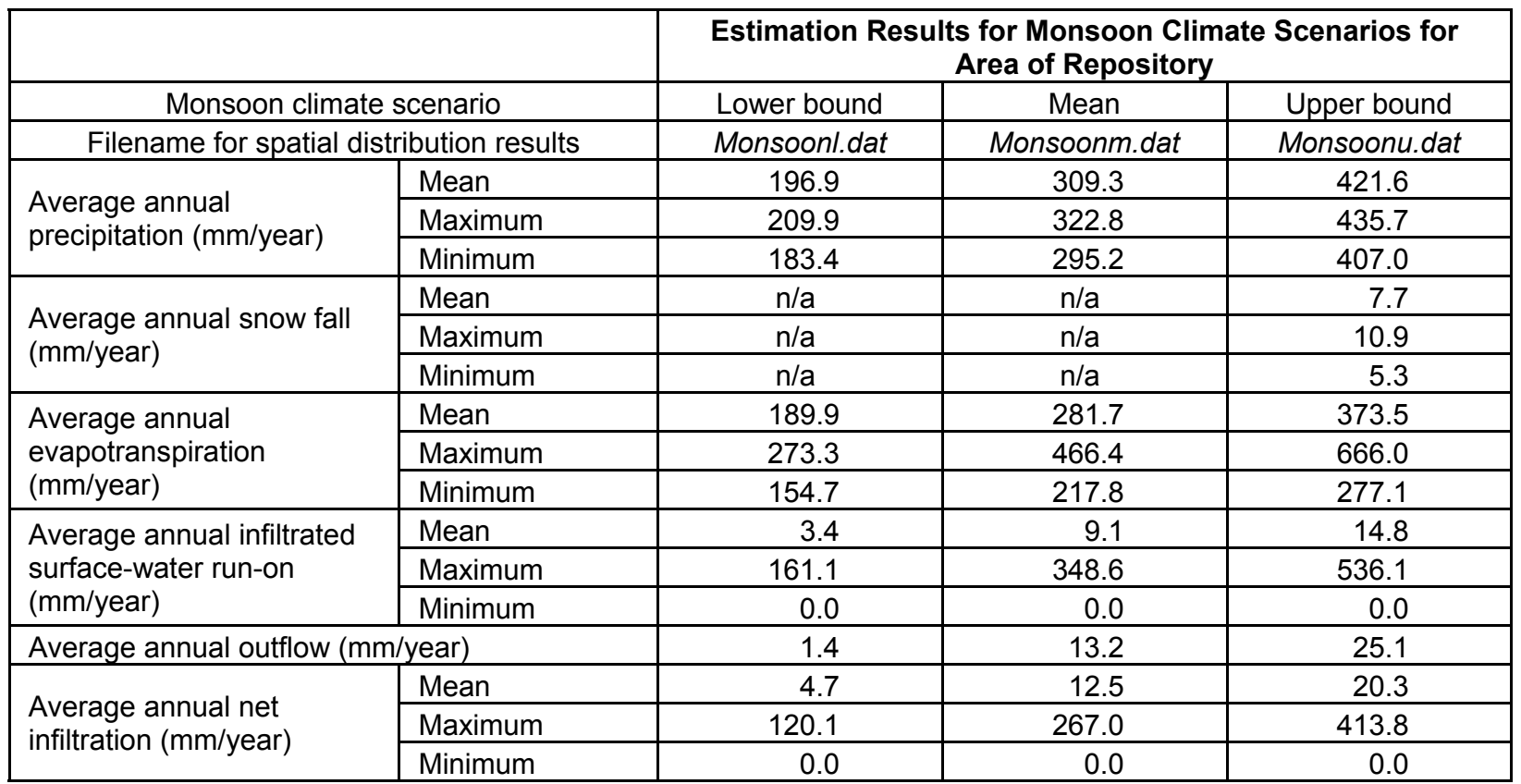

Output DTN: GS000308311221.005.

\subsubsection{Glacial-Transition Climate}

Table 6-15 lists the simulation results for the two analogue lower bound glacial-transition climate simulations (Beowawe, Nevada and Delta, Utah) used to develop net-infiltration estimates for the lower bound and mean glacial-transition climate scenarios. The results for the 32-year Beowawe simulation include a mean air temperature of $9.6^{\circ} \mathrm{C}$, a precipitation rate of $208.4 \mathrm{~mm} /$ year, and a snowfall depth (water equivalent) of $30.7 \mathrm{~mm} /$ year. Net-infiltration estimation results for the Beowawe simulation include an average rate of $2.9 \mathrm{~mm} / \mathrm{year}$. The results for the 45 -year Delta simulation include a mean air temperature of $10.8^{\circ} \mathrm{C}$, a precipitation rate of $193.7 \mathrm{~mm} /$ year, and a snowfall depth (water equivalent) of $27.6 \mathrm{~mm} / \mathrm{year}$. Net-infiltration estimation results for the Delta simulation include an average rate of $1.4 \mathrm{~mm} / \mathrm{year}$.

Table 6-16 lists the simulation results for the three analogue upper bound glacial-transition climate simulations (Rosalia, Washington; Spokane, Washington; and St. John, Washington) used to develop net-infiltration estimates for the upper and mean glacial-transition climate scenarios. The results for the 44-year Rosalia simulation include a mean air temperature of $9.0^{\circ} \mathrm{C}$, a precipitation rate of $454.9 \mathrm{~mm} /$ year, and a snowfall depth (water equivalent) of $67.5 \mathrm{~mm} /$ year. The results for the 50 -year Spokane simulation include a mean air temperature of $9.2^{\circ} \mathrm{C}$, a precipitation rate of $406.2 \mathrm{~mm} / \mathrm{year}$, and a snowfall depth (water equivalent) of $74.3 \mathrm{~mm} /$ year. For the 31-year St. John simulation, results include $9.9^{\circ} \mathrm{C}$ for mean air temperature, $432.1 \mathrm{~mm} /$ year for precipitation, and $44 \mathrm{~mm} /$ year for snowfall. Average net-infiltration rates for the three simulations are $29.7 \mathrm{~mm} /$ year for Rosalia, $21.2 \mathrm{~mm} /$ year for Spokane, and $23.0 \mathrm{~mm} /$ year for St. John. Maximum average annual net-infiltration rates are 9,126.2 mm/year for Rosalia, 7,033.7 mm/year for Spokane, and 6,308.1 mm/year for St. John. 


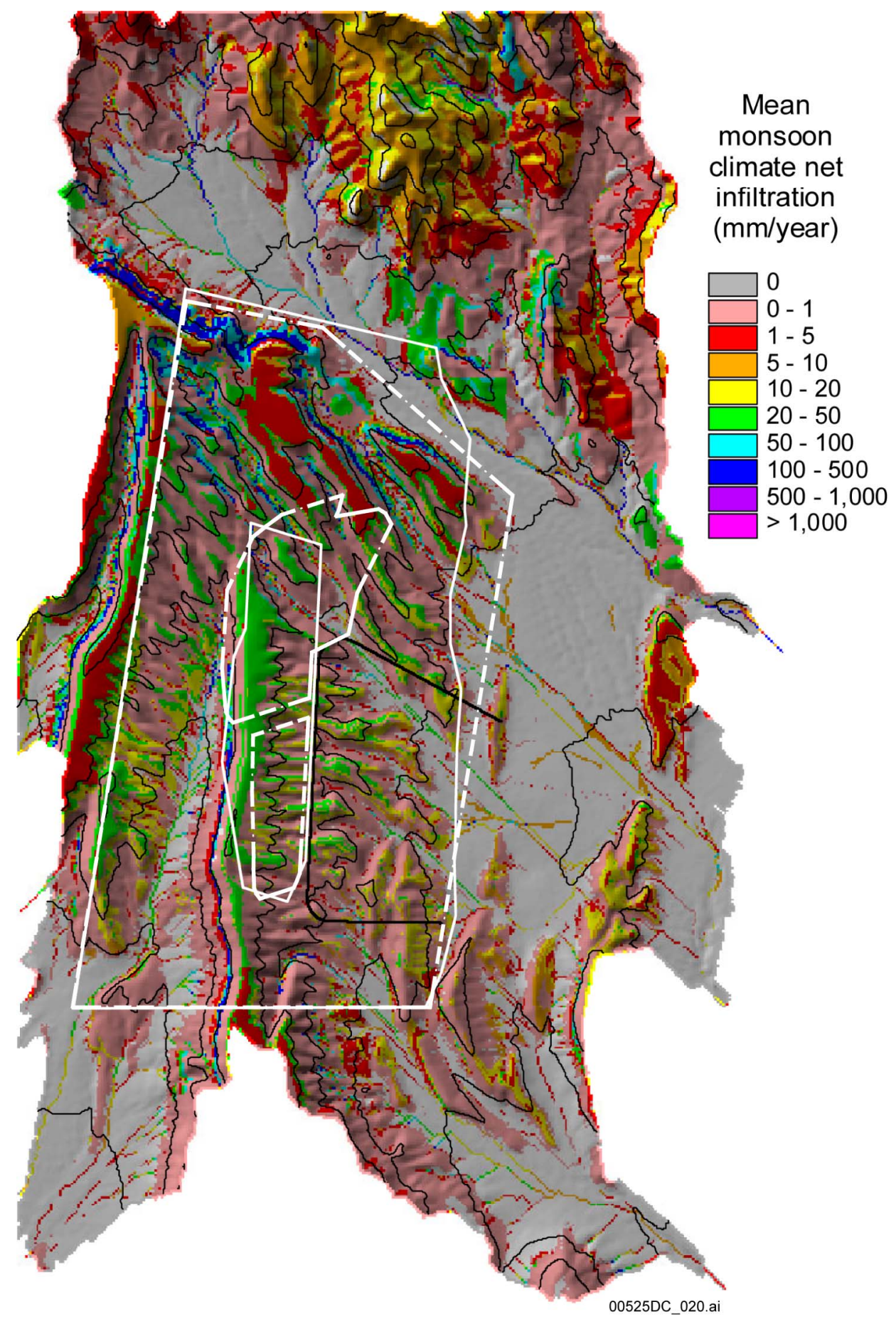

Output DTN: GS000308311221.005.

NOTE: The 1999 UZ flow model domain and the 1999 repository footprint are site recommendation boundaries (solid lines), not license application boundaries (dashed lines).

Figure 6-28. Estimated Net Infiltration (mm/year) for the Mean Monsoon Climate Scenario 


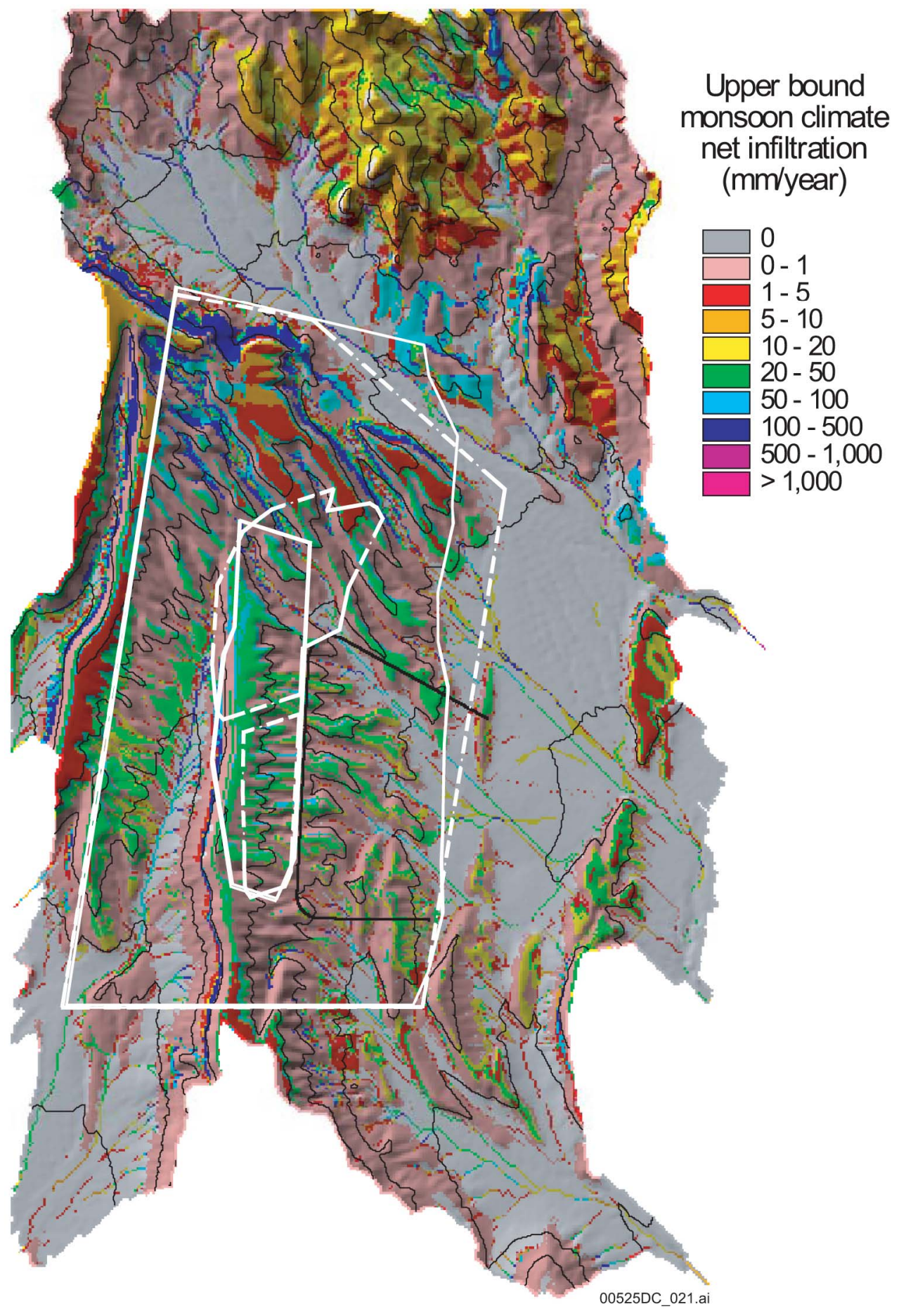

Output DTN: GS000308311221.005.

NOTE: The 1999 UZ flow model domain and the 1999 repository footprint are site recommendation boundaries (solid lines), not license application boundaries (dashed lines).

Figure 6-29. Estimated Net Infiltration ( $\mathrm{mm} / \mathrm{year}$ ) for the Upper Bound Monsoon Climate Scenario 


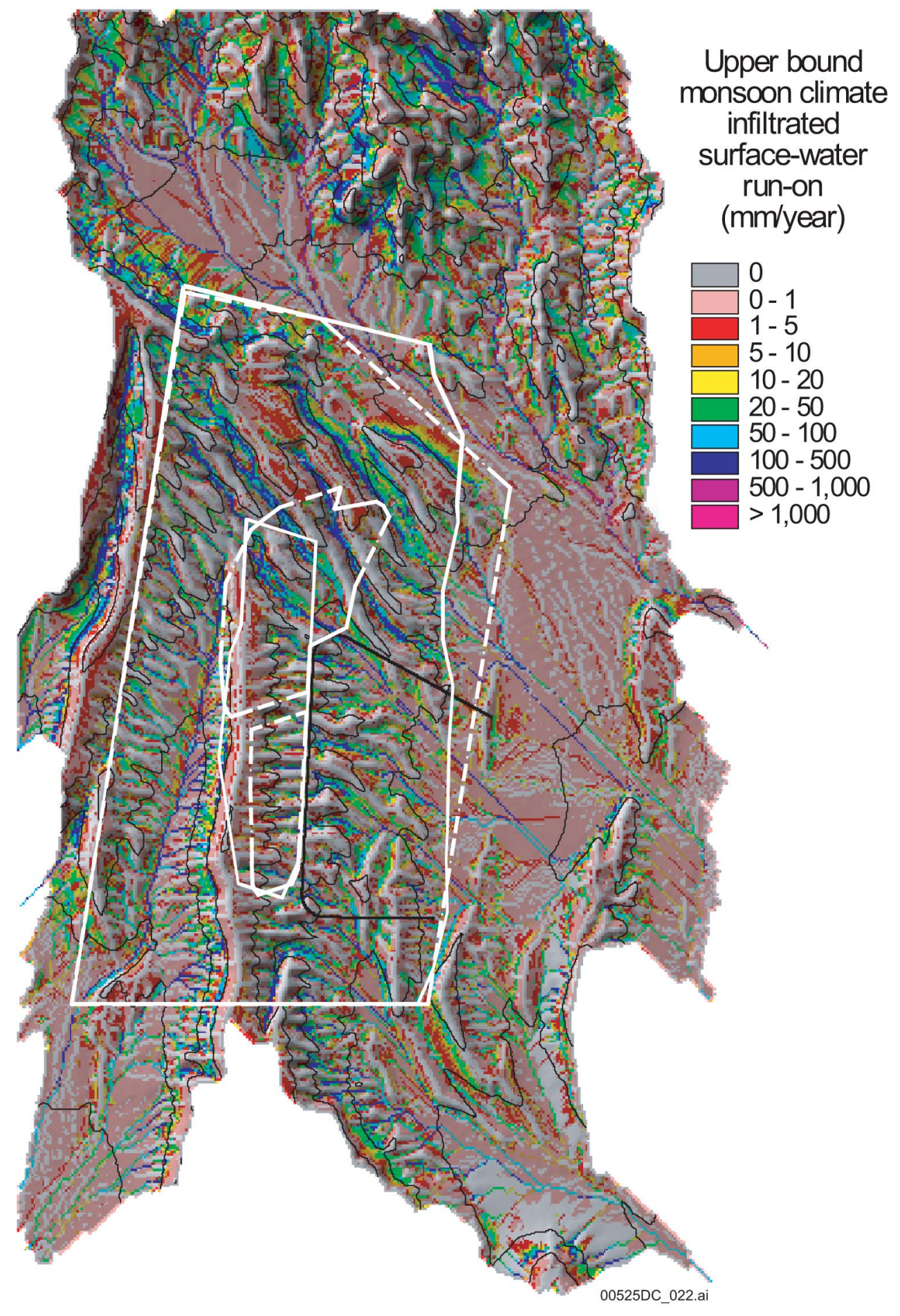

Output DTN: GS000308311221.005.

NOTE: The 1999 UZ flow model domain and the 1999 repository footprint are site recommendation boundaries (solid lines), not license application boundaries (dashed lines).

Figure 6-30. Infiltrated Surface-water Run-on Depth ( $\mathrm{mm} /$ year) for the Upper Bound Monsoon Climate Scenario 
Simulation of Net Infiltration for Present-Day and Potential Future Climates

Table 6-15. 1999 INFIL Simulation Results Used to Develop Spatially Distributed Net-infiltration Estimates for the Lower Bound Glacial-Transition Climate Scenario

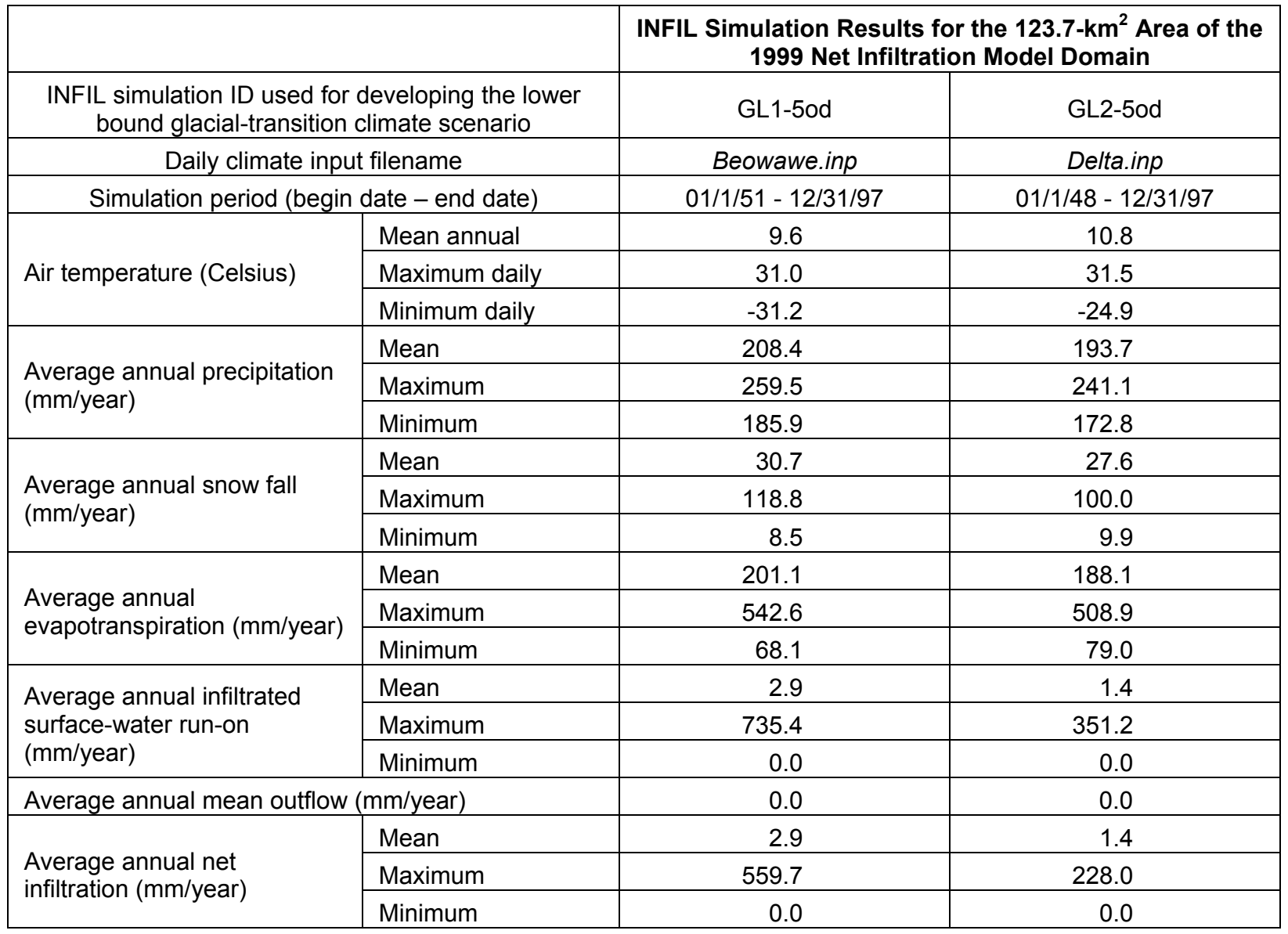

Output DTN: GS000308311221.005.

Table 6-16. 1999 INFIL Simulation Results Used to Develop Spatially Distributed Net-infiltration Estimates for the Upper Bound Glacial-Transition Climate Scenario

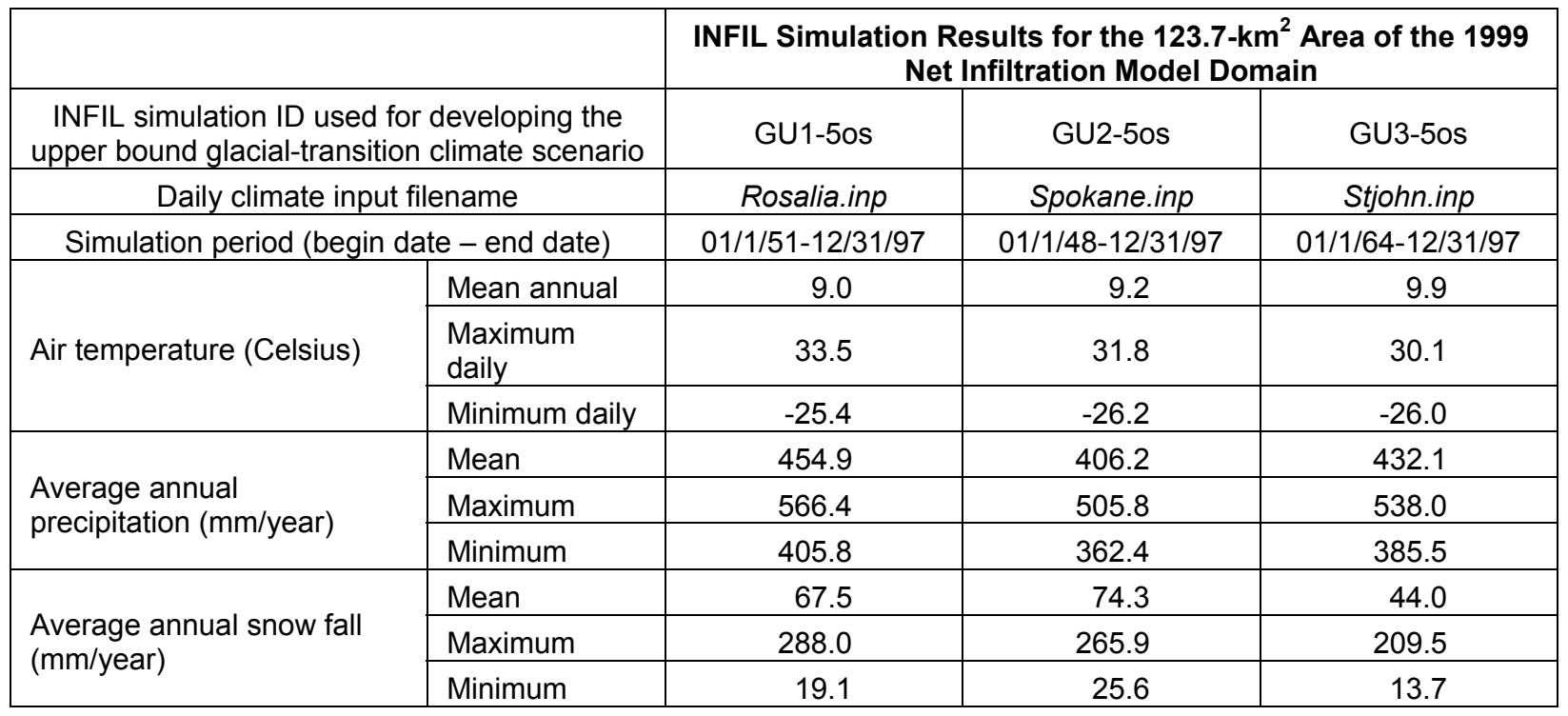


Table 6-16. 1999 INFIL Simulation Results Used to Develop Spatially Distributed Net-infiltration Estimates for the Upper Bound Glacial-Transition Climate Scenario (Continued)

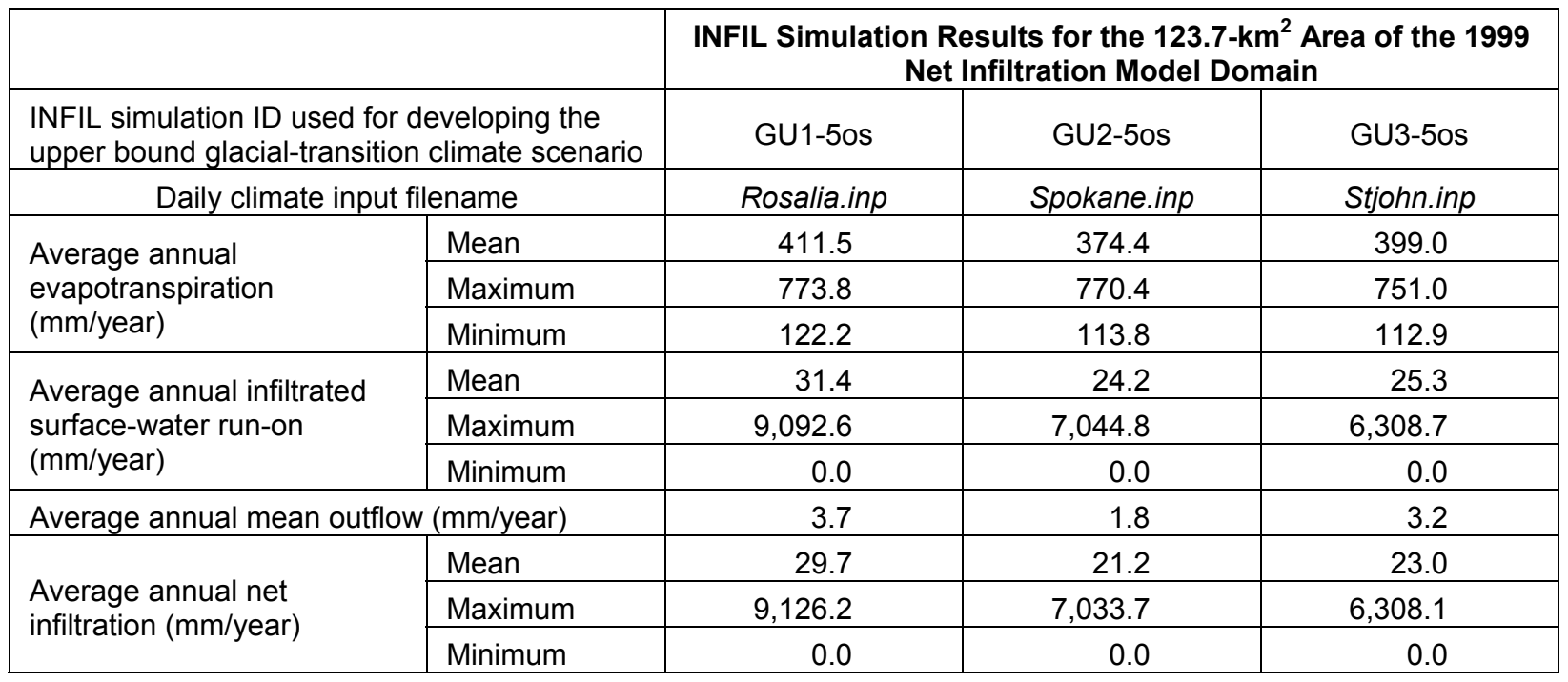

Output DTN: GS000308311221.005.

Estimation results for the lower bound, mean, and upper bound glacial-transition climate scenarios obtained using the simulations presented in Tables 6-15 and 6-16 are tabulated for the areas of the net-infiltration model (Table 6-17), the UZ flow model (Table 6-18), and the repository (Table 6-19). The results for the mean glacial-transition climate scenario, which were calculated as the arithmetic mean of the results for the lower and upper bound glacial-transition scenarios, include an average precipitation rate of $316.1 \mathrm{~mm} / \mathrm{year}$, an average snowfall depth of $45.5 \mathrm{~mm} / \mathrm{year}$, an average infiltrated surface-water run-on depth of $14.6 \mathrm{~mm} / \mathrm{year}$, an average outflow rate of $1.5 \mathrm{~mm} / \mathrm{year}$, and an average net-infiltration rate of $13.4 \mathrm{~mm} / \mathrm{year}$ for the net-infiltration model domain. In comparison, net infiltration is estimated to be $2.2 \mathrm{~mm} / \mathrm{year}$ for the lower bound glacial-transition scenario and $24.6 \mathrm{~mm} / \mathrm{year}$ for the upper bound glacial-transition scenario.

Table 6-17. Estimation Results for the Glacial-Transition Climate Scenarios over the $123.7-\mathrm{km}^{2}$ Area of the 1999 Infiltration Model Domain

\begin{tabular}{|c|c|c|c|c|}
\hline \multirow{2}{*}{\multicolumn{2}{|c|}{ Glacial-transition climate scenario }} & \multicolumn{3}{|c|}{$\begin{array}{c}\text { Estimation Results for Glacial-Transition Climate Scenarios } \\
\text { for Total Area of the } 1999 \text { Infiltration Model Domain }\end{array}$} \\
\hline & & Lower bound & Mean & Upper bound \\
\hline \multicolumn{2}{|c|}{ Filename for spatial distribution results } & Glaciall.dat & Glacialm.dat & Glacialu.dat \\
\hline \multicolumn{2}{|c|}{ Mean annual air temperature (Celsius) } & 10.2 & 9.8 & 9.4 \\
\hline \multirow{3}{*}{$\begin{array}{l}\text { Average annual } \\
\text { precipitation (mm/year) }\end{array}$} & Mean & 201.0 & 316.1 & 431.1 \\
\hline & Maximum & 250.3 & 393.5 & 536.8 \\
\hline & Minimum & 179.4 & 282.0 & 384.6 \\
\hline \multirow{3}{*}{$\begin{array}{l}\text { Average annual snow fall } \\
\text { (mm/year) }\end{array}$} & Mean & 29.1 & 45.5 & 61.9 \\
\hline & Maximum & 109.4 & 181.9 & 254.5 \\
\hline & Minimum & 9.2 & 14.3 & 19.5 \\
\hline
\end{tabular}


Table 6-17. Estimation Results for the Glacial-Transition Climate Scenarios over the $123.7-\mathrm{km}^{2}$ Area of the 1999 Infiltration Model Domain (Continued)

\begin{tabular}{|l|l|c|c|c|}
\hline \multicolumn{2}{|c|}{} & \multicolumn{2}{c|}{$\begin{array}{c}\text { Estimation Results for Glacial-Transition Climate Scenarios } \\
\text { for Total Area of the 1999 Infiltration Model Domain }\end{array}$} \\
\hline \multicolumn{2}{|c|}{ Glacial-transition climate scenario } & Lower bound & Mean & Upper bound \\
\hline \multicolumn{2}{|c|}{ Filename for spatial distribution results } & Glaciall.dat & Glacialm.dat & Glacialu.dat \\
\hline \multirow{2}{*}{$\begin{array}{l}\text { Average annual } \\
\text { evapotranspiration } \\
\text { (mm/year) }\end{array}$} & Mean & 194.6 & 294.8 & 395.0 \\
\cline { 2 - 5 } & Maximum & 525.7 & 600.7 & 751.2 \\
\cline { 2 - 5 } & Minimum & 73.6 & 94.9 & 116.3 \\
\hline \multirow{2}{*}{$\begin{array}{l}\text { Average annual infiltrated } \\
\text { surface-water run-on } \\
\text { (mm/year) }\end{array}$} & Mean & 2.2 & 14.6 & 27.0 \\
\cline { 2 - 5 } & Maximum & 524.3 & $3,913.2$ & $7,482.0$ \\
\cline { 2 - 5 } Average annual outflow (mm/year) & Minimum & 0.0 & 0.0 & 0.0 \\
\hline \multirow{2}{*}{$\begin{array}{l}\text { Average annual net } \\
\text { infiltration (mm/year) }\end{array}$} & Mean & 0.0 & 1.5 & 2.9 \\
\cline { 2 - 5 } & Maximum & 2.2 & 3.9 & 24.6 \\
\cline { 2 - 5 } & Minimum & 370.3 & 0.0 & $7,489.3$ \\
\hline
\end{tabular}

Output DTN: GS000308311221.005.

For the area of the UZ flow model, results for the mean glacial-transition climate scenario include an average precipitation rate of $317.8 \mathrm{~mm} / \mathrm{year}$, an average annual infiltrated surface-water run-on depth of $15.6 \mathrm{~mm} / \mathrm{year}$, an average outflow rate of $-0.2 \mathrm{~mm} / \mathrm{year}$, and an average net-infiltration rate of $17.8 \mathrm{~mm} / \mathrm{year}$ (Table 6-18). For the lower bound glacial-transition scenario, net infiltration is estimated to be $2.5 \mathrm{~mm} /$ year for the UZ flow model area, while for the upper bound glacial-transition scenario, net infiltration is estimated to be $33.0 \mathrm{~mm} /$ year. For the area of the repository site (Table 6-19), results for the mean glacial-transition climate scenario include an average precipitation rate of $323.1 \mathrm{~mm} / \mathrm{year}$, an average annual infiltrated surface-water run-on depth of $12.0 \mathrm{~mm} / \mathrm{year}$, an average outflow rate of $8.0 \mathrm{~mm} /$ year, and an average net-infiltration rate of $19.8 \mathrm{~mm} /$ year. For the lower bound glacial-transition scenario, net infiltration is estimated to be $2.2 \mathrm{~mm} / \mathrm{year}$ and outflow is estimated to be $0.3 \mathrm{~mm} /$ year. For the upper bound glacial-transition scenario, net infiltration is estimated to be $37.3 \mathrm{~mm} /$ year over the UZ flow model area and outflow is estimated to be $15.6 \mathrm{~mm} /$ year.

The spatial distribution of estimated precipitation for the mean glacial-transition climate scenario indicates the reduced precipitation-elevation correlation specified in the model (relative to the present-day climate correlation), with a minimum precipitation rate of approximately $280 \mathrm{~mm} /$ year and a maximum rate of almost $400 \mathrm{~mm} /$ year (Figure 6-31). The spatial distribution of snowfall depth indicates a stronger correlation with elevation because of the combined effects of the precipitation-elevation and the air temperature-elevation correlations (Figure 6-32). The minimum water-equivalent snowfall depth is less than $20 \mathrm{~mm} /$ year in the southern part of the modeling domain, and the maximum snowfall depth is more than $140 \mathrm{~mm} /$ year. 
Table 6-18. Estimation Results for the Glacial-Transition Climate Scenarios over the $38.7-\mathrm{km}^{2}$ Area of the 1999 UZ Flow Model Domain

\begin{tabular}{|c|c|c|c|c|}
\hline \multirow{2}{*}{\multicolumn{2}{|c|}{ Glacial-transition climate scenario }} & \multicolumn{3}{|c|}{$\begin{array}{l}\text { Estimation Results for Glacial-Transition Climate } \\
\text { Scenarios for Area of the } 1999 \text { UZ Flow Model Domain }\end{array}$} \\
\hline & & Lower bound & Mean & Upper bound \\
\hline \multicolumn{2}{|c|}{ Filename for spatial distribution results } & Glaciall.dat & Glacialm.dat & Glacialu.dat \\
\hline \multirow{3}{*}{$\begin{array}{l}\text { Average annual } \\
\text { precipitation ( } \mathrm{mm} / \text { year) }\end{array}$} & Mean & 202.2 & 317.8 & 433.5 \\
\hline & Maximum & 231.7 & 364.3 & 496.8 \\
\hline & Minimum & 189.8 & 298.3 & 406.9 \\
\hline \multirow{3}{*}{$\begin{array}{l}\text { Average annual snow fall } \\
\text { (mm/year) }\end{array}$} & Mean & 29.1 & 45.1 & 61.1 \\
\hline & Maximum & 75.1 & 122.0 & 168.9 \\
\hline & Minimum & 16.3 & 25.3 & 34.2 \\
\hline \multirow{3}{*}{$\begin{array}{l}\text { Average annual } \\
\text { evapotranspiration } \\
\text { (mm/year) }\end{array}$} & Mean & 195.2 & 293.5 & 391.8 \\
\hline & Maximum & 343.3 & 502.3 & 733.9 \\
\hline & Minimum & 76.9 & 99.4 & 121.9 \\
\hline \multirow{3}{*}{$\begin{array}{l}\text { Average annual infiltrated } \\
\text { surface-water run-on } \\
\text { (mm/year) }\end{array}$} & Mean & 1.7 & 15.6 & 29.6 \\
\hline & Maximum & 193.1 & $1,301.1$ & $2,586.2$ \\
\hline & Minimum & 0.0 & 0.0 & 0.0 \\
\hline \multicolumn{2}{|c|}{ Average annual outflow (mm/year) } & -0.1 & -0.2 & -0.3 \\
\hline \multirow{3}{*}{$\begin{array}{l}\text { Average annual net } \\
\text { infiltration (mm/year) }\end{array}$} & Mean & 2.5 & 17.8 & 33.0 \\
\hline & Maximum & 219.2 & $1,282.9$ & $2,555.0$ \\
\hline & Minimum & 0.0 & 0.0 & 0.0 \\
\hline
\end{tabular}

Output DTN: GS000308311221.005.

NOTE: Estimates of net infiltration for the UZ flow model area differ slightly from those reported in BSC (2004 [DIRS 169861], Table 6.1-2) because the $1999 \mathrm{UZ}$ flow model boundary for site recommendation is used in this report while the 2003 UZ flow model boundary for license application is used in BSC (2004 [DIRS 169861]).

Table 6-19. Estimation Results for the Glacial-Transition Climate Scenarios for the $4.7-\mathrm{km}^{2}$ Area of the 1999 Repository Footprint

\begin{tabular}{|c|c|c|c|c|}
\hline & & \multicolumn{3}{|c|}{$\begin{array}{c}\text { Estimation Results for Glacial-Transition Climate } \\
\text { Scenarios for Area of Repository }\end{array}$} \\
\hline \multicolumn{2}{|c|}{ Glacial-transition climate scenario } & Lower bound & Mean & Upper bound \\
\hline \multicolumn{2}{|c|}{ Filename for spatial distribution results } & Glaciall.dat & Glacialm.dat & Glacialu.dat \\
\hline \multirow{3}{*}{$\begin{array}{l}\text { Average annual } \\
\text { precipitation (mm/year) }\end{array}$} & Mean & 205.5 & 323.1 & 440.6 \\
\hline & Maximum & 212.4 & 333.8 & 455.3 \\
\hline & Minimum & 198.4 & 311.8 & 425.3 \\
\hline \multirow{3}{*}{$\begin{array}{l}\text { Average annual snow fall } \\
\text { (mm/year) }\end{array}$} & Mean & 32.5 & 50.3 & 68.1 \\
\hline & Maximum & 42.0 & 65.2 & 88.3 \\
\hline & Minimum & 24.9 & 37.8 & 50.7 \\
\hline \multirow{3}{*}{$\begin{array}{l}\text { Average annual } \\
\text { evapotranspiration } \\
\text { (mm/year) }\end{array}$} & Mean & 197.5 & 287.8 & 378.1 \\
\hline & Maximum & 279.4 & 477.8 & 688.6 \\
\hline & Minimum & 171.0 & 219.3 & 265.3 \\
\hline \multirow{3}{*}{$\begin{array}{l}\text { Average annual infiltrated } \\
\text { surface-water run-on } \\
\text { (mm/year) }\end{array}$} & Mean & 1.4 & 12.0 & 22.5 \\
\hline & Maximum & 100.5 & 676.6 & $1,334.8$ \\
\hline & Minimum & 0.0 & 0.0 & 0.0 \\
\hline
\end{tabular}


Table 6-19. Estimation Results for the Glacial-Transition Climate Scenarios for the $4.7-\mathrm{km}^{2}$ Area of the 1999 Repository Footprint (Continued)

\begin{tabular}{|c|l|c|c|c|}
\hline & \multicolumn{3}{c|}{ EstimationResults for Glacial-Transition Climate Scenarios } \\
\hline \multicolumn{2}{|c|}{ Glacial-transition climate scenario } & Lower bound & Mean & Upper bound \\
\hline \multicolumn{2}{|c|}{ Filename for spatial distribution results } & Glaciall.dat & Glacialm.dat & Glacialu.dat \\
\hline \multicolumn{2}{|c|}{ Average annual outflow (mm/year) } & 0.3 & 8.0 & 15.6 \\
\hline \multirow{2}{*}{$\begin{array}{l}\text { Average annual net } \\
\text { infiltration (mm/year) }\end{array}$} & Mean & 2.2 & 19.8 & 37.3 \\
\cline { 2 - 5 } & Maximum & 116.3 & 591.0 & $1,181.4$ \\
\cline { 2 - 5 } & Minimum & 0.0 & 0.0 & 0.0 \\
\hline
\end{tabular}

Output DTN: GS000308311221.005.

The spatial distribution of estimated evapotranspiration for the mean glacial-transition scenario indicates, in the context of the model, the importance of precipitation, root-zone water-storage capacity, and infiltrated surface-water run-on in affecting the availability of water for evapotranspiration. Minimum evapotranspiration rates are less than $100 \mathrm{~mm} /$ year on steep side slopes with thin soil cover (Table 6-17), while maximum rates are close to $600 \mathrm{~mm} / \mathrm{year}$ in active channel locations.

Estimated infiltrated surface-water run-on rates exceed $100 \mathrm{~mm} /$ year throughout most of the upper channel locations, including Pagany Wash, Drill Hole Wash, Solitario Canyon, and sections of all washes draining the eastern slopes of Yucca Mountain (Figure 6-34). Within the net-infiltration model area, maximum infiltrated surface-water run-on rates of more than $3,000 \mathrm{~mm} /$ year occur along isolated sections of Yucca Wash. The net-infiltration map for the mean glacial-transition climate scenario indicates rates of 20 to $50 \mathrm{~mm} /$ year along the crest of Yucca Mountain, with isolated locations exceeding $50 \mathrm{~mm} /$ year along the crest (Figure 6-35). Within the repository area, a maximum net-infiltration rate exceeding $500 \mathrm{~mm} /$ year occurs in the channel of Drill Hole Wash.

In comparison to net-infiltration estimates for the mean glacial-transition climate scenario, net-infiltration rates for the lower bound glacial-transition climate scenario are greatly reduced due to a more uniform seasonal distribution of precipitation characterized by a lack of severe storms or wetter than normal periods as compared to the upper bound glacial-transition climate scenarios. The average intensity and frequency of precipitation events for the lower bound glacial-transition climates is not sufficient to overcome evapotranspiration from the root zone. Maximum net-infiltration rates of 100 to $500 \mathrm{~mm} /$ year were obtained on the northeastern-facing slope of the Prow, along isolated sections of the west-facing slope of Solitario Canyon, and along isolated sections of upper Yucca Wash (Figure 6-36). Within the repository area, net infiltration does not occur in the channel of Drill Hole Wash and net infiltration along the crest of Yucca Mountain is only 1 to $5 \mathrm{~mm} /$ year. The map of infiltrated surface-water run-on for the lower bound glacial-transition climate scenario indicates significantly less infiltration along channels than the other climate scenarios (Figure 6-37). Within the UZ flow model area, maximum infiltrated surface-water run-on rates of more than $100 \mathrm{~mm} /$ year do not occur in channels, but instead, are limited to lower side slopes. 


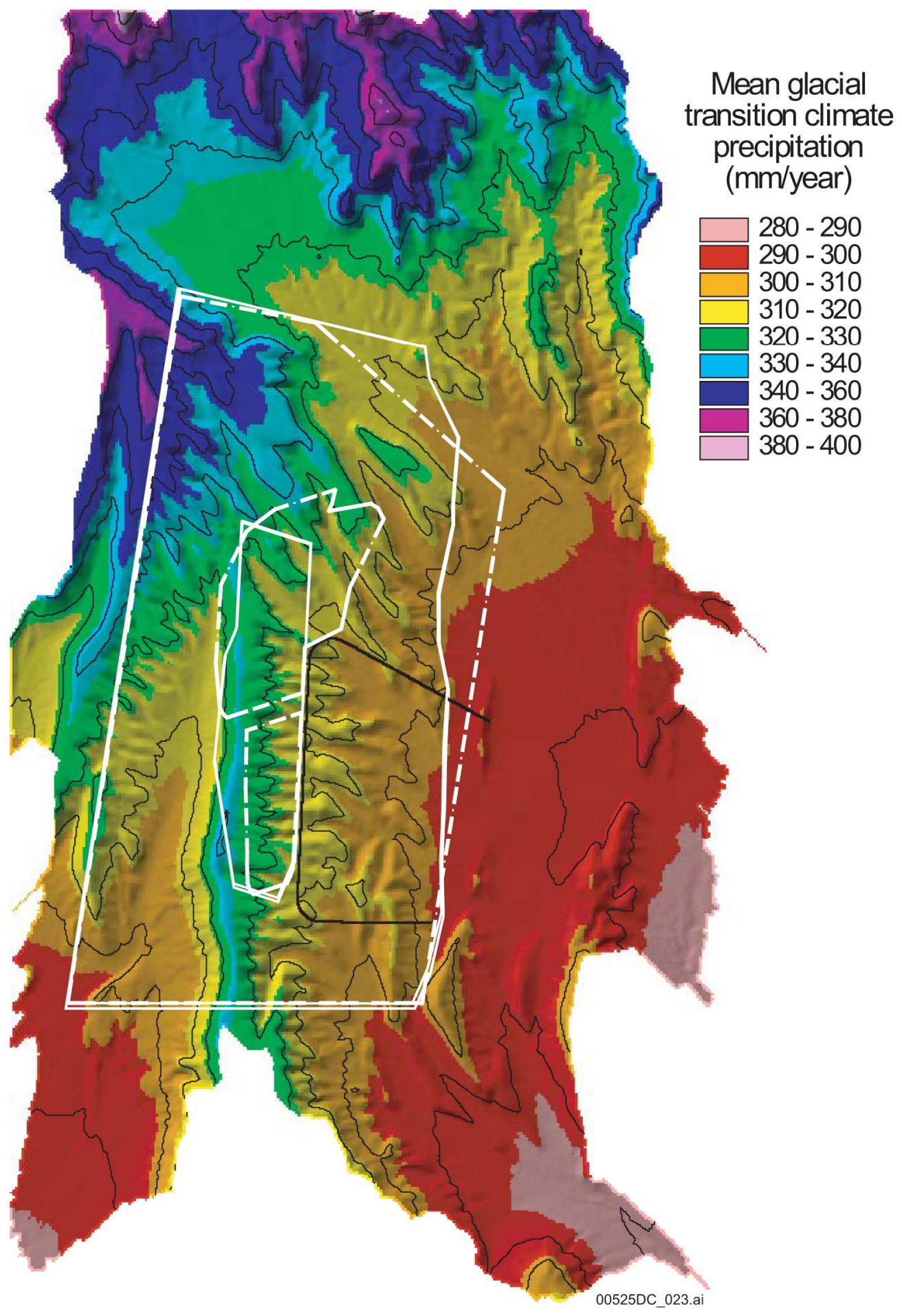

Source: DTN: GS000208311221.002.

NOTE: The 1999 UZ flow model domain and the 1999 repository footprint are site recommendation boundaries (solid lines), not license application boundaries (dashed lines).

Figure 6-31. Precipitation (mm/year) for the Mean Glacial-Transition Climate Scenario 


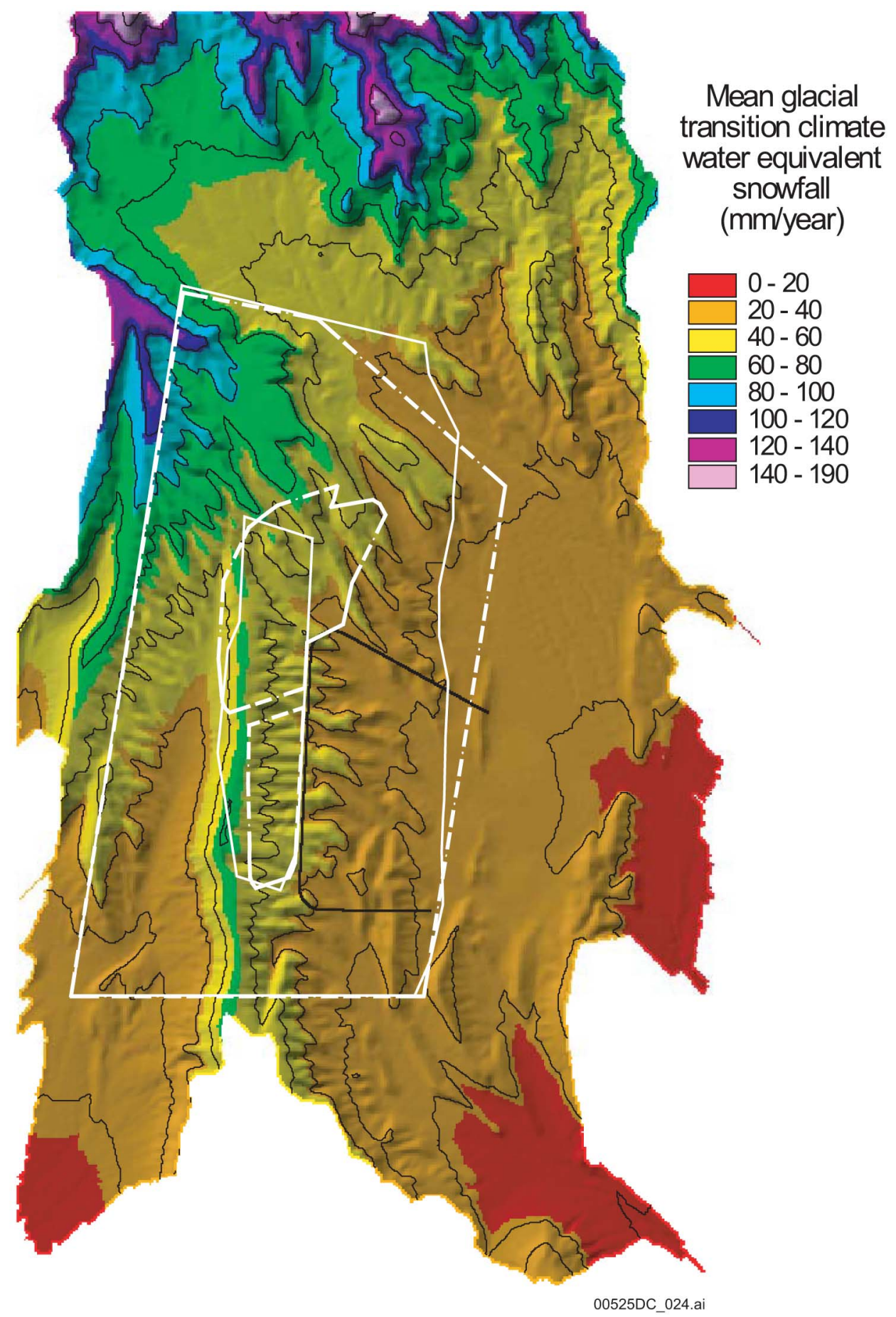

Output DTN: GS000308311221.005.

NOTE: The 1999 UZ flow model domain and the 1999 repository footprint are site recommendation boundaries (solid lines), not license application boundaries (dashed lines).

Figure 6-32. Water-equivalent Snowfall Depth ( $\mathrm{mm} / \mathrm{year}$ ) for the Mean Glacial-Transition Climate Scenario 


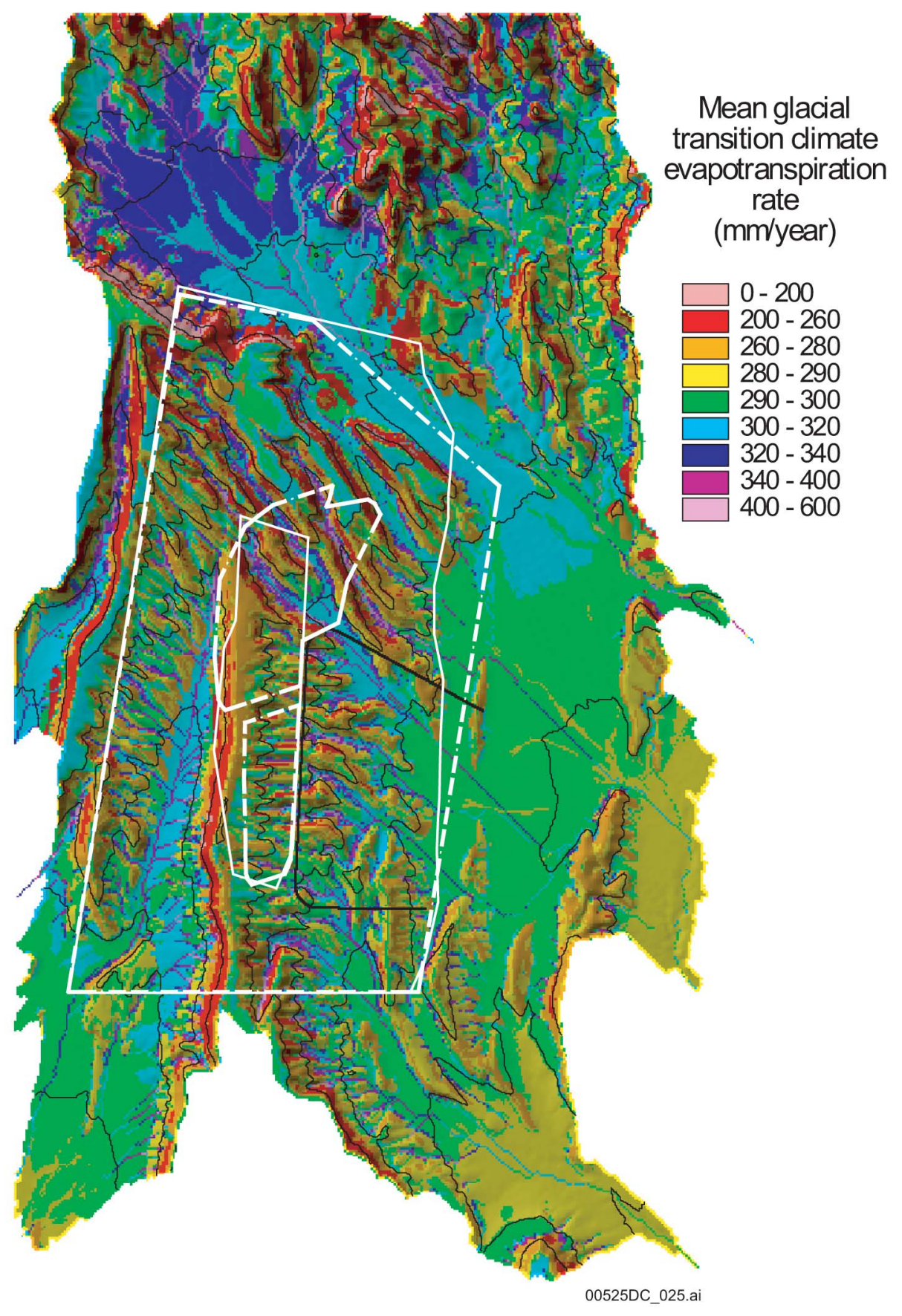

Output DTN: GS000308311221.005.

NOTE: The 1999 UZ flow model domain and the 1999 repository footprint are site recommendation boundaries (solid lines), not license application boundaries (dashed lines).

Figure 6-33. Evapotranspiration (mm/year) for the Mean Glacial-Transition Climate Scenario 


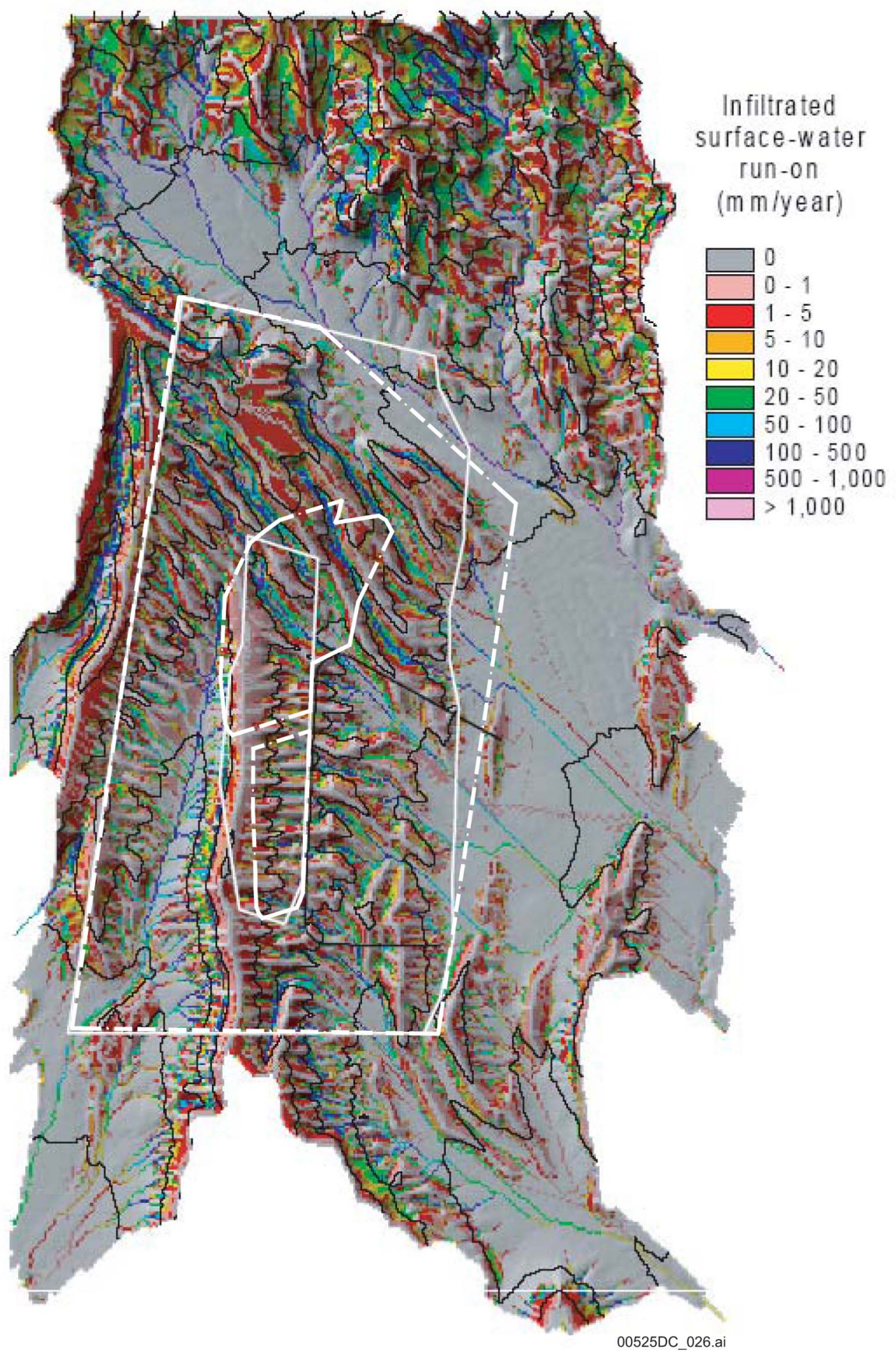

Output DTN: GS000308311221.005.

NOTE: The 1999 UZ flow model domain and the 1999 repository footprint are site recommendation boundaries (solid lines), not license application boundaries (dashed lines).

Figure 6-34. Estimated Infiltrated Surface-water Run-on Depth (mm/year) for the Mean GlacialTransition Climate Scenario 


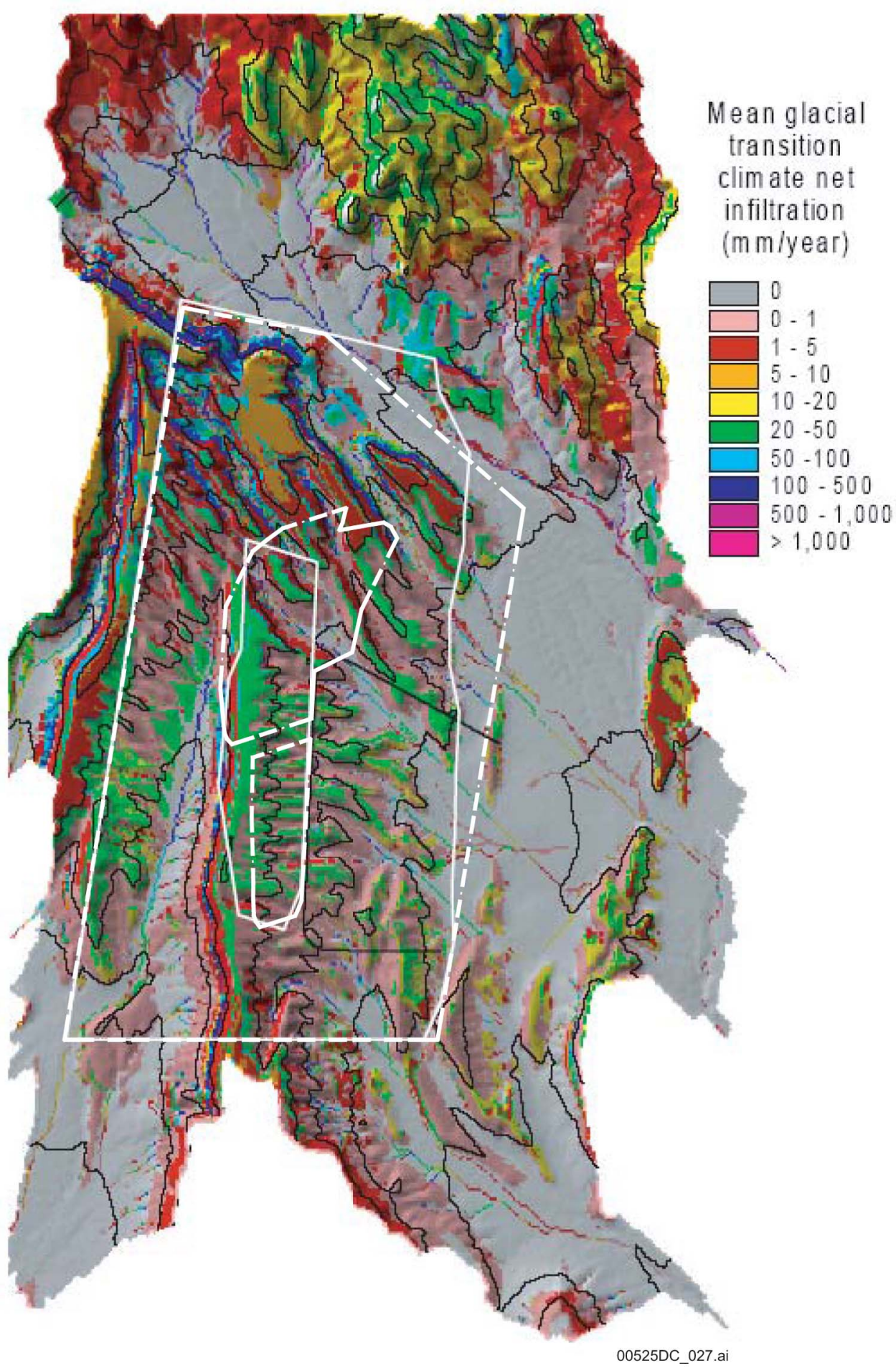

Output DTN: GS000308311221.005.

NOTE: The 1999 UZ flow model domain and the 1999 repository footprint are site recommendation boundaries (solid lines), not license application boundaries (dashed lines).

Figure 6-35. Estimated Net Infiltration ( $\mathrm{mm} / \mathrm{year}$ ) for the Mean Glacial-Transition Climate Scenario 


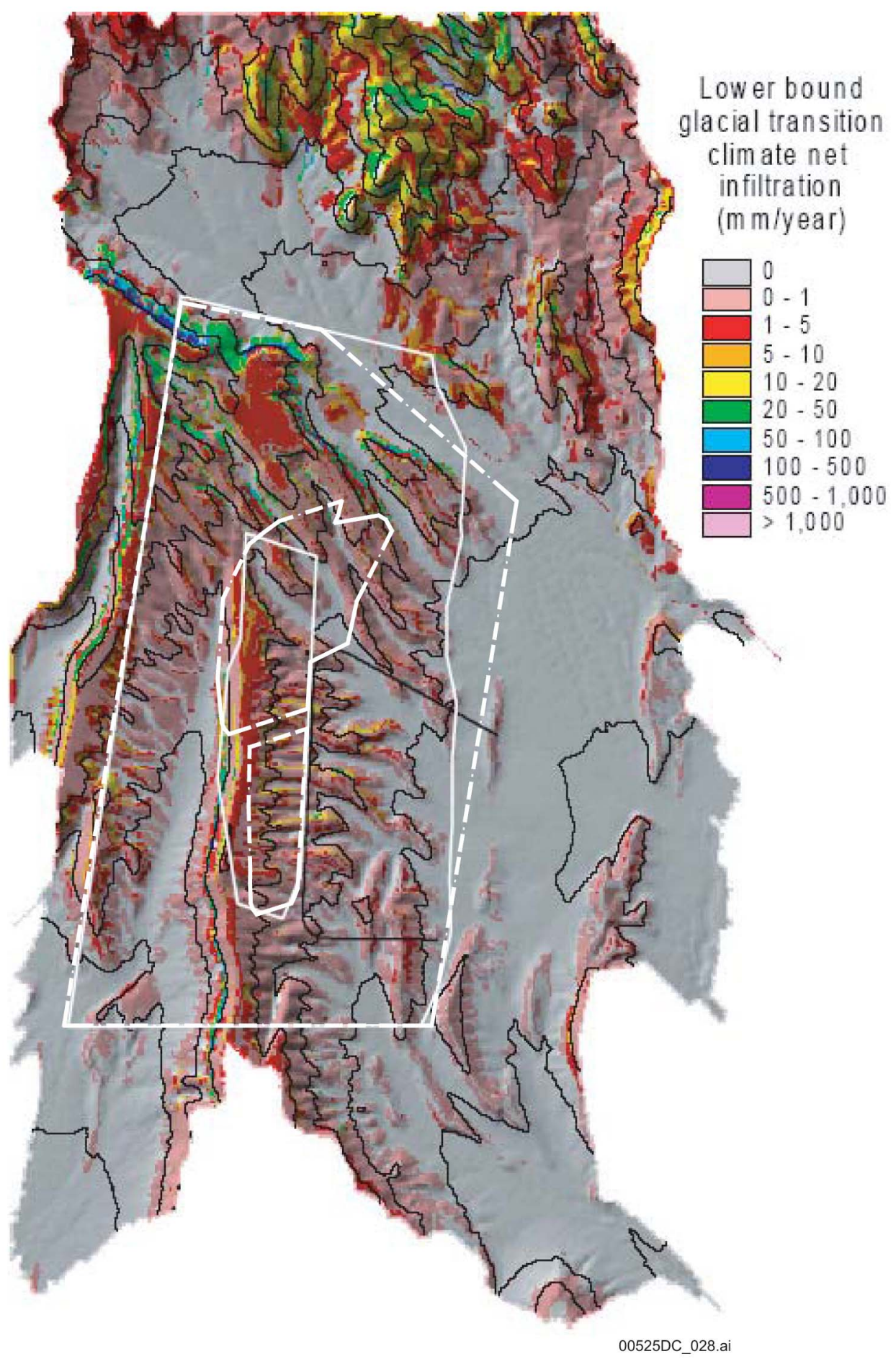

Output DTN: GS000308311221.005.

NOTE: The 1999 UZ flow model domain and the 1999 repository footprint are site recommendation boundaries (solid lines), not license application boundaries (dashed lines).

Figure 6-36. Estimated Net Infiltration (mm/year) for the Lower Bound Glacial-Transition Climate Scenario 


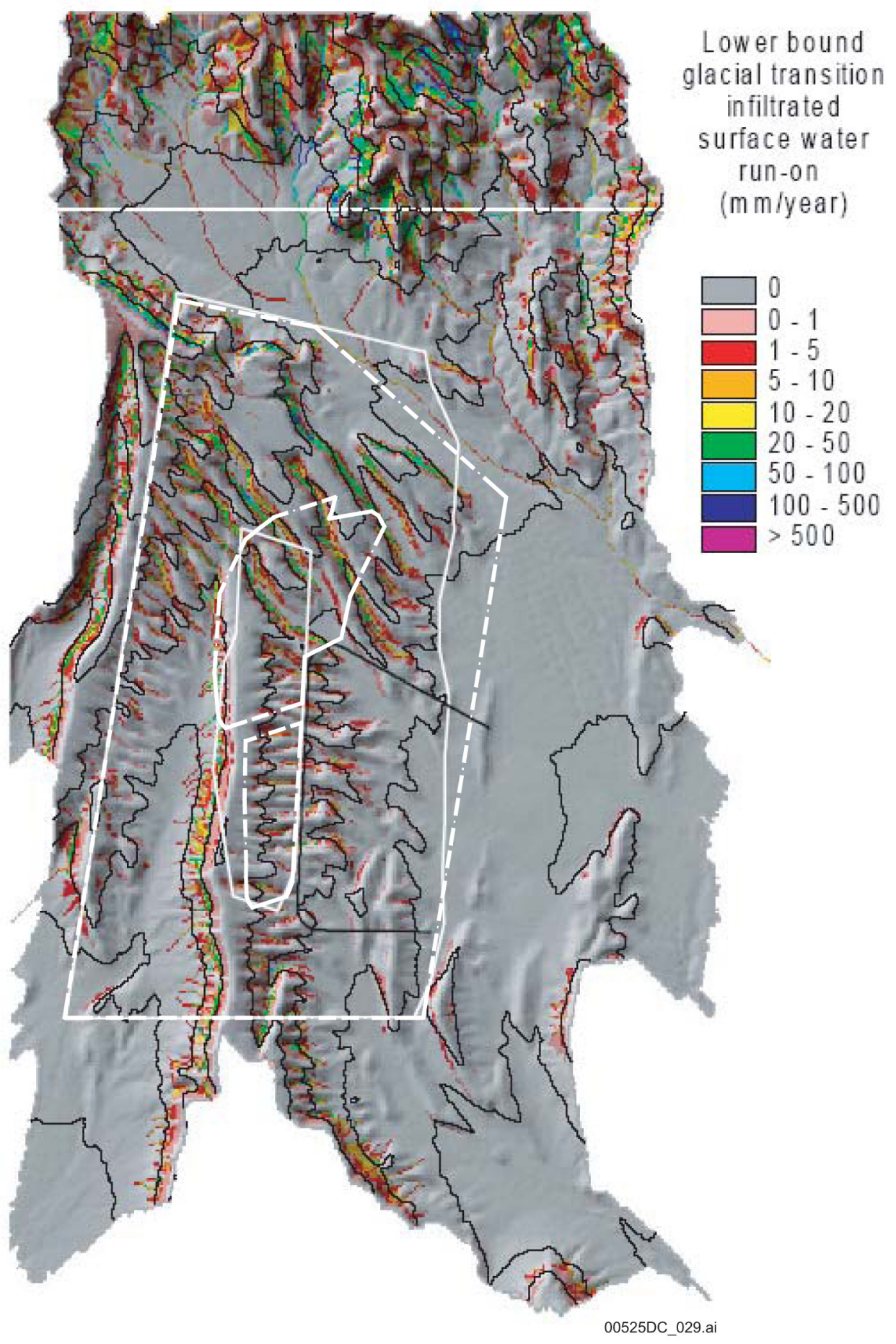

Output DTN: GS000308311221.005.

NOTE: The 1999 UZ flow model domain and the 1999 repository footprint are site recommendation boundaries (solid lines), not license application boundaries (dashed lines). The white line above the model boundary is of no significance.

Figure 6-37. Estimated Infiltrated Surface-water Run-on Depth (mm/year) for the Lower Bound GlacialTransition Climate Scenario 
The map of estimated net infiltration for the upper bound glacial-transition climate scenario indicates relatively high net-infiltration rates of $50-100 \mathrm{~mm} / \mathrm{year}$ throughout the crest area of Yucca Mountain, and relatively high rates of $100-500 \mathrm{~mm} / \mathrm{year}$ for most steep sideslope locations in the northern part of the UZ flow model domain (Figure 6-38). Maximum rates of more than $1,000 \mathrm{~mm} /$ year are common throughout the lower portions of the Yucca Wash channel. Within the repository area, maximum rates between 500 and 1,000 $\mathrm{mm} /$ year occur for isolated sections of the Drill Hole Wash channel.

The map of estimated infiltrated surface-water run-on indicates a maximum run-on infiltration rate of between 500 and $1,000 \mathrm{~mm} /$ year for an isolated section of Drill Hole Wash within the repository area (Figure 6-39). In general, the maximum net-infiltration rates occur at locations where the infiltrated run-on rates are high.

\subsection{FEATURES, EVENTS, AND PROCESSES}

Table 6-20 contains a list of features, events, and processes (FEPs) taken from the LA FEP List (DTN: MO0407SEPFEPLA.000 [DIRS 170760]). The selected FEPs are those taken from the LA FEP List that is associated with the subject matter of this report (BSC 2004 [DIRS 169654], Table 2.1.5-1). The results of this model are part of the basis for the treatment of FEPs as discussed in Features, Events, and Processes in UZ Flow and Transport (BSC 2004 [DIRS 170012], Section 6). The cross-reference for each FEP to the relevant sections of this report is also given in Table 6-20. 




Output DTN: GS000308311221.005.

NOTE: The 1999 UZ flow model domain and the 1999 repository footprint are site recommendation boundaries (solid lines), not license application boundaries (dashed lines).

Figure 6-38. Estimated Net Infiltration ( $\mathrm{mm} / \mathrm{year}$ ) for the Upper Bound Glacial-Transition Climate Scenario 


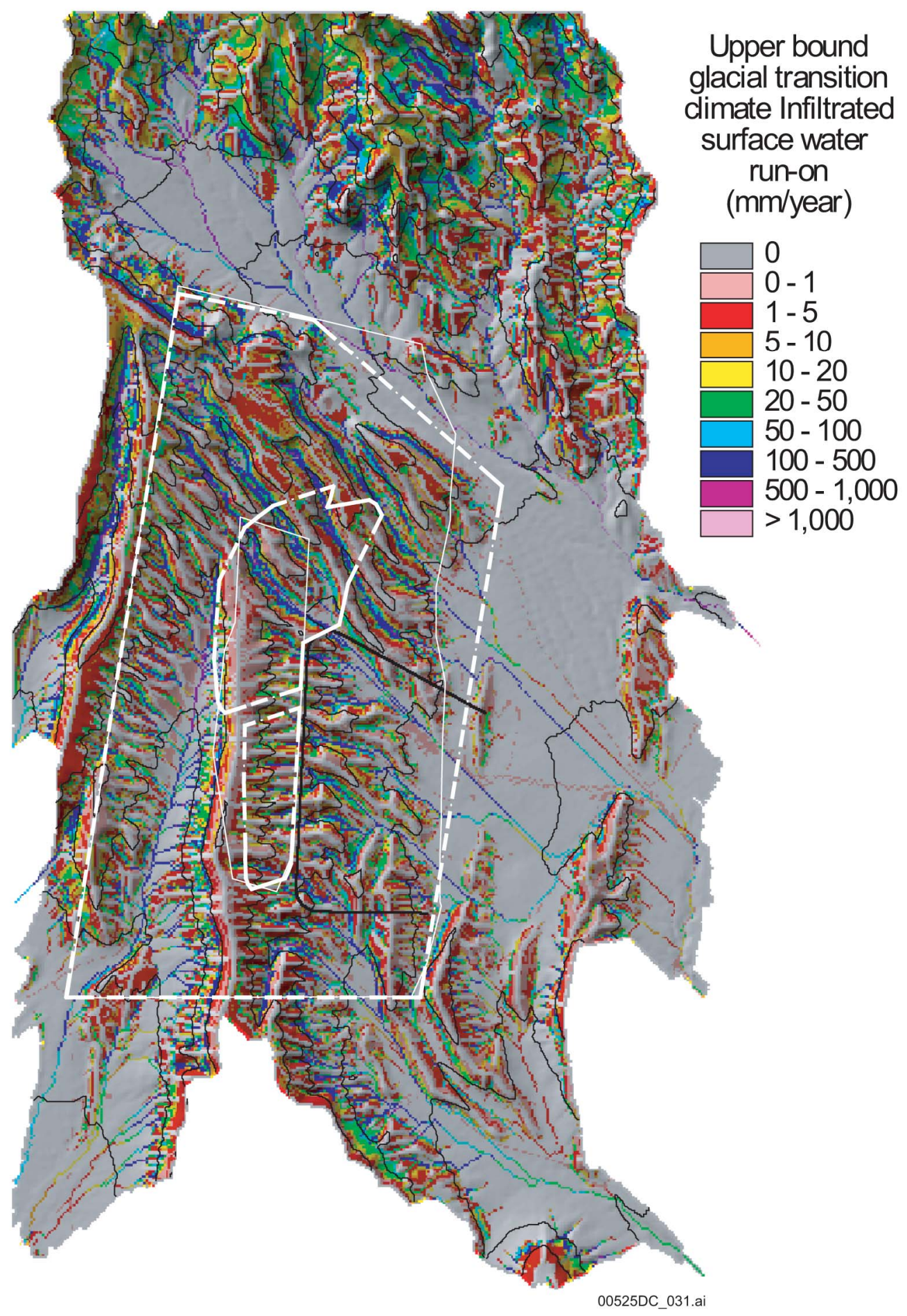

Output DTN: GS000308311221.005.

NOTE: The 1999 UZ flow model domain and the 1999 repository footprint are site recommendation boundaries (solid lines), not license application boundaries (dashed lines).

Figure 6-39. Estimated Infiltrated Surface-water Run-on Depth (mm/year) for the Upper Bound GlacialTransition Climate Scenario (DTN: GS000308311221.005) 
Table 6-20. FEPs Addressed in This Model Report

\begin{tabular}{|l|l|l|}
\hline \multicolumn{1}{|c|}{ FEP Number } & \multicolumn{1}{|c|}{ FEP Name } & \multicolumn{1}{c|}{ Relevant Sections } \\
\hline $1.2 .02 .01 .0 \mathrm{~A}$ & Fractures & $5,6.1 .2,6.1 .3,6.1 .5,6.3 .1,6.3 .4,6.6 .4,6.7 .3,7.2 .2$, Appendix B \\
\hline $1.3 .01 .00 .0 \mathrm{~A}$ & Climate change & $5,6.4 .2,6.9,6.9 .1,6.9 .3,6.9 .4$ \\
\hline $1.4 .01 .01 .0 \mathrm{~A}$ & $\begin{array}{l}\text { Climate modification } \\
\text { increases recharge }\end{array}$ & $6.11 .2,6.11 .3$ \\
\hline $2.1 .08 .01 .0 \mathrm{~A}$ & Water influx at the repository & 6.11 \\
\hline 2.2.03.01.0A & Stratigraphy & $6.3 .1,6.4,6.4 .1,6.4 .5,6.4 .6,6.7 .3$ \\
\hline $2.2 .03 .02 .0 \mathrm{~A}$ & $\begin{array}{l}\text { Rock properties of host rock } \\
\text { and other units }\end{array}$ & $5,6,6.6 .4,7.2 .2, \mathrm{Appendix} \mathrm{B}$ \\
\hline $2.2 .07 .01 .0 \mathrm{~A}$ & $\begin{array}{l}\text { Locally saturated flow at } \\
\text { bedrock/ alluvium contact }\end{array}$ & $5,6.1 .2,6.3 .4$ \\
\hline $2.2 .07 .02 .0 \mathrm{~A}$ & $\begin{array}{l}\text { Unsaturated groundwater flow } \\
\text { in the Geosphere }\end{array}$ & 6.11 \\
\hline $2.2 .07 .08 .0 \mathrm{~A}$ & Fracture flow in the UZ & $5,6.1 .2,6.3 .4,7.2 .2$ \\
\hline $2.3 .01 .00 .0 \mathrm{~A}$ & Topography and morphology & $6.1 .2,6.1 .4,6.5 .3,6.6 .1,6.8 .3$, Appendix D, Appendix I \\
\hline $2.3 .11 .01 .0 \mathrm{~A}$ & Precipitation & $5,6.1,6.1 .2,6.1 .3,6.3 .4,6.4,6.4 .1,6.4 .2,6.8 .1,6.8 .3,6.9,6.9 .1$, \\
\hline $2.3 .11 .02 .0 \mathrm{~A}$ & Surface runoff and flooding & $5,6.1 .2,6.1 .3,6.3 .1,6.4,6.4 .1,6.4 .5,6.4 .6,6.4 .7$ \\
\hline $2.3 .11 .03 .0 \mathrm{~A}$ & Infiltration and recharge. & 6.11 \\
\hline
\end{tabular}

$\mathrm{FEP}=$ feature, event, or process; $\mathrm{LA}=$ license application; TSPA=total system performance assessment; UZ=unsaturated zone 


\section{VALIDATION}

The net infiltration model documented in this model report is concerned specifically with estimating the spatial distribution of net infiltration in the vicinity of the Yucca Mountain repository under present-day and projected future climatic conditions. The net infiltration model is based on the standard distributed-parameter water-balance methods to estimate net infiltration as discussed, for example, by Hatton (1998 [DIRS 149476]), and yields net infiltration estimates that are within the range of and consistent with the results of other methods that have been used to estimate net infiltration and recharge in the Yucca Mountain region. On this basis, the net infiltration model documented in this model report are deemed to be appropriate for providing estimates of net infiltration that serve as input to and the upper boundary condition for the site-scale UZ flow model.

According to AP-SIII.10Q, Models, Section 3.13, model validation is "a process used to establish confidence that a mathematical model and its underlying conceptual model adequately represent with sufficient accuracy the system, process, or phenomenon in question." The model validation process also includes developing a level of confidence as stated in AP-SIII.10Q, Models, Section 5.3: "Validate the model to the level of confidence required in accordance with the TWP and Paragraph 5.3.2c) of AP-SIII.10Q."

Model validation is the process of testing the appropriateness of the conceptual, mathematical, and numeric representation of the system being modeled. The infiltration model is designed to provide an analysis tool that facilitates understanding of infiltration processes. The infiltration model is also a computational tool to provide net infiltration rates as a boundary condition for the calculation of flow fields in the UZ models. For these predictions to be credible, it must be demonstrated that the infiltration model has been validated for its intended use. The intended use of the infiltration model (INFIL) is to develop upper-bound, mean, and lower-bound infiltration maps for present-day and potential future climates (where precipitation and temperature are determined in Future Climate Analysis (BSC 2004 [DIRS 170002]). These infiltration maps are the top boundary flow condition used by the UZ flow model, as documented in UZ Flow Models and Submodels (BSC 2004 [DIRS 169861]).

For confidence building after model development, the TWP (BSC 2004 [DIRS 169654], Section 2.2.1.2, "Post-Development Validation Activities") imposes the following requirements for model validation:

"The process model will be validated - that is, confidence in the models will be gained-by Method 1, comparison with data, and by Method 2, corroboration with alternative mathematical models, identified in Section 5.3.2(c) of AP-SIII.10Q."

1. AP-SIII.10Q, Section 5.3.2(c), Method 1: Comparison with data:

The average annual net infiltration rate over the model domain area will be compared to net infiltration data determined by various methods. Several methods for calculating infiltration rate are detailed by Flint et al. (2002 [DIRS 157411]). For example, bomb-pulse and non-bomb-pulse isotope data constrain the likely range of average flux 
to 1 to $10 \mathrm{~mm} / \mathrm{year}$, carbon- 14 data produce estimates of flux ranging from 4 to $9 \mathrm{~mm} / \mathrm{year}$, and borehole temperature data provide a flux range of 5 to $12 \mathrm{~mm} /$ year for Yucca Mountain (Flint et al. 2002 [DIRS 157411], pp. 201 to 202). The criterion for validation of the 1999 INFIL model will be that model results are within one order of magnitude of the estimate of annual net infiltration by selected alternative models detailed by Flint et al. (2002 [DIRS 157411]), over a similar model domain. One order of magnitude is satisfactory for Level I validation because estimating net infiltration (and recharge) in the desert southwest involves a large degree of relative uncertainty due to low precipitation and high evapotranspiration (Flint et al. 2002 [DIRS 157411], p. 181).

2. AP-SIII.10Q, Section 5.3.2(c), Method 2: Comparison with alternative models:

The average annual net infiltration rate calculated using INFIL with revised input parameters for the UZ flow model domain for the mean present-day climate will be compared to the average annual net infiltration rate from the 1999 INFIL model. INFIL with revised input parameters is intended as an alternative model for validation of the 1999 INFIL model. The criterion for accepting the 1999 INFIL model as valid for its purpose will be that the average annual net infiltration rate calculated using INFIL with revised input parameters for the UZ flow model domain for the mean present-day climate will be within a factor of 2 of the average annual net infiltration rate from the 1999 INFIL model. The justification for the selection of this validation criterion is that the uncertainty in net infiltration for the present-day climate was calculated by the 1999 INFIL model to range from $1.3 \mathrm{~mm} /$ year (lower bound) to $11.1 \mathrm{~mm} /$ year (upper bound) for the UZ flow model domain. Any corroborating estimate of net infiltration should fall within this range of uncertainty to ensure that the uncertainty in infiltration is adequately represented in TSPA by the upper bound, mean, and lower bound infiltration maps. The average annual average net infiltration rate calculated by the 1999 INFIL model is $4.6 \mathrm{~mm} /$ year. Therefore, the average annual average net infiltration rate calculated using revised input parameters will not exceed $9.2 \mathrm{~mm} /$ year, and will not be less than $2.3 \mathrm{~mm} /$ year.

As stated in the TWP (BSC 2004 [DIRS 169654], Section 2.2.1.1), AP-2.27Q (Attachment 3, Table 1) requires Level I validation for models supporting infiltration component of TSPA.

Section 7.1 discusses confidence building during model development, which establishes the reasons for confidence in the infiltration model. Section 7.2 provides a detailed discussion of postdevelopment validation activities, including comparison with data and comparisons with alternative models.

\subsection{CONFIDENCE BUILDING DURING MODEL DEVELOPMENT TO ESTABLISH SCIENTIFIC BASIS AND ACCURACY FOR INTENDED USE}

For Level I validation, criteria from Section 2.2.1.2 of the TWP (BSC 2004 [DIRS 169654]) and AP-SIII.10Q Section 5.3.2(b) specifies the following steps for Confidence Building During Process Model Development: Confidence is built during model development by incorporating qualified topographic, evapotranspiration, air-temperature and precipitation data (digitized 
topographic, geologic, and soil maps; soil and bedrock hydrologic properties; and present-day and projected future climatic data) and by calibrating the model with qualified streamflow data. The development of the infiltration model has been conducted according to these criteria, as follows:

1. Selection of input parameters and/or input data, and a discussion of how the selection process builds confidence in the model. [AP-SIII.10Q 5.3.2(b) (1) and AP-2.27Q Attachment 3 Level I (a)]

The inputs to the infiltration model have all been obtained from controlled sources (Table 4-1 and Section 4.1), including discussion about selection of input and design parameters. Most model inputs originate from site-specific field data. The boundary conditions and inputs are appropriate; they sufficiently cover the expected conditions and ranges at Yucca Mountain, including temporal changes and spatial variability of processes and properties. Model assumptions have been described in detail in Section 5. Detailed discussion about model concepts can be found in Section 6.1. Thus, this requirement can be considered satisfied.

2. Description of calibration activities, and/or initial boundary condition runs, and/or run convergences, simulation conditions set up to span the range of intended use and avoid inconsistent outputs, and a discussion of how the activity or activities build confidence in the model. Inclusion of a discussion of impacts of any non-convergence runs [(AP-SIII.10Q 5.3.2(b)(2) and AP-2.27Q Attachment 3 Level I (e)].

Detailed discussion of initial and boundary conditions for the infiltration model can be found in Sections 6.5, 6.6, and 6.7. Section 6.8 provides a detailed discussion on model calibration, and Section 6.11 provides detailed discussion of the various model results. Discussion about non-convergence runs is not relevant for this model report because all model runs converged. Thus, this requirement can also be considered satisfied.

3. Discussion of the impacts of uncertainties to the model results including how the model results represent the range of possible outcomes consistent with important uncertainties. [(AP-SIII.10Q 5.3.2(b)(3) and AP-2.27Q Attachment 3 Level 1 (d) and (f)].

Discussion of model inputs for uncertainties and sensitivity analyses are discussed briefly in Section 6.10, and a reference to the Analysis of Infiltration Uncertainty (BSC 2003 [DIRS 165991]) is included.

4. Formulation of defensible assumptions and simplifications. [AP-2.27Q Attachment 3 Level I (b)].

Discussion of assumptions and simplifications are provided in detail in Section 5, with some additional information included in Section 6. The basis for all assumptions are discussed in detail in Section 5.

5. Consistency with physical principles, such as conservation of mass, energy, and momentum. [AP-2.27Q Attachment 3 Level I (c)]. 
Consistency with physical principles is demonstrated by the conceptual and mathematical formulation of the infiltration model described in Sections 6.1 and 6.2, and by analysis of the mass balance error in the output files generated by INFIL. Since INFIL is a mass balance model, the mass balance error generated is a good indication of the degree of conservation of mass.

\subsection{POSTDEVELOPMENT MODEL VALIDATION TO SUPPORT THE SCIENTIFIC BASIS OF THE MODEL}

Postdevelopment model validation to support the scientific basis of the model is accomplished by comparison of the infiltration rate calculated using INFIL with other data, and by comparison with an alternative model.

\subsubsection{Method 1: Comparison of Infiltration Rate with Other Data}

Net infiltration and recharge have been estimated for the areas within the Death Valley region using methods appropriate for arid environments, such as water-balance techniques (e.g., basin wide estimates of discharge or numerical models accounting for all significant components of the water balance), soil-physics techniques, geochemistry, and transfer equations based on other variables (such as precipitation). The net infiltration model INFIL is a water-balance technique that can be compared to techniques using geochemistry and transfer functions.

Transfer functions relating recharge to precipitation have been widely used in the Death Valley region. A method was developed (Maxey and Eakin 1950 [DIRS 100598]) for estimating recharge to groundwater basins in Nevada, providing a baseline for the spatial distribution of recharge. This method uses average annual precipitation to classify areas of a basin into five recharge zones. Each zone uses a different percentage of average annual precipitation becoming recharge: zero percent recharge for less than $203 \mathrm{~mm} / \mathrm{year}$ average annual precipitation, 3 percent for 203 to $304 \mathrm{~mm} /$ year, 7 percent for 305 to $380 \mathrm{~mm} /$ year, 15 percent for 381 to $507 \mathrm{~mm} /$ year, and 25 percent for $508 \mathrm{~mm} /$ year or greater (Maxey and Eakin 1950 [DIRS 100598]).

Net-infiltration and recharge estimates for basins in Nevada also have been obtained using chloride mass balance calculations. This method equates chloride in recharge water and runoff to chloride deposited in source areas by precipitation and dry fallout. An analysis of recharge (Lichty and McKinley 1995 [DIRS 100589]) was provided for two basins in central Nevada using a 6-year measurement period and two independent modeling approaches: water balance and chloride mass balance. Their results yielded recharge rates of 10 to $30 \mathrm{~mm} / \mathrm{year}$ for a drainage basin with an average annual precipitation of $270 \mathrm{~mm}$, and 300 to $320 \mathrm{~mm} / \mathrm{year}$ for a drainage basin with an average annual precipitation of $640 \mathrm{~mm}$ (they do not report results for sites with precipitation between 270 and $640 \mathrm{~mm}$ ). They determined that the chloride mass balance method was more viable for their study.

Net-infiltration estimates obtained for the nine climate scenarios over the net-infiltration model area, the UZ flow model area, and the repository area were plotted against the corresponding average annual precipitation rates and compared with recharge and net-infiltration estimates obtained using the independent methods of Maxey and Eakin (1950 [DIRS 100598], 
pp. 40 to 41) and Lichty and McKinley (1995 [DIRS 100589], Table 15). The qualitative comparison with the independent methods is based on the estimated average precipitation rate corresponding to a given recharge or net infiltration estimate. An assumption is made that the spatially averaged net infiltration estimates are approximately equivalent to recharge at Yucca Mountain for a given climate scenario (transient effects are ignored).

The net infiltration estimates were also compared against estimates of average recharge rates obtained using the chloride mass balance method for SZ boreholes at Yucca Mountain These estimates range from 4 to $18 \mathrm{~mm} /$ year for the SZ underlying Yucca Mountain (BSC 2004 DIRS 170037], Table A6-6), and correspond to an average Holocene precipitation rate of $170 \mathrm{~mm} /$ year at Yucca Mountain. These recharge estimates are in good general agreement with the the spatially averaged mean present-day climate $(4.6 \mathrm{~mm} / \mathrm{yr})$, the upper bound present-day climate $(11.1 \mathrm{~mm} / \mathrm{yr})$, the mean monsoon climate $(12.2 \mathrm{~mm} / \mathrm{yr})$, and the mean glacial-transition climate $(17.8 \mathrm{~mm} / \mathrm{yr})$ net infiltration rates for the UZ flow model domain (Tables 6-9, 6-13, and 6-18).

The graph of net infiltration and recharge versus precipitation indicates that the net-infiltration estimates for all lower and mean climate scenarios are in general agreement with independent recharge estimates for precipitation rates of less than approximately $350 \mathrm{~mm} / \mathrm{year}$. The net-infiltration estimates for the upper bound glacial-transition and monsoon climates are low relative to the Maxey-Eakin recharge estimates obtained for precipitation rates of 400 to $450 \mathrm{~mm} /$ year. The higher Maxey-Eakin estimates are 15 percent of average annual precipitation, while the net-infiltration estimates are only 5 to 10 percent of average annual precipitation. For precipitation rates greater than $500 \mathrm{~mm} /$ year, Maxey-Eakin estimates are 25 percent of average annual precipitation. In the Maxey-Eakin method, the higher precipitation rates correspond to higher elevation basins in the central and southern Nevada region (Maxey and Eakin 1950 [DIRS 100598]). Recharge estimates of approximately $300 \mathrm{~mm} /$ year were obtained (Lichty and McKinley 1995 [DIRS 100589]) for a small, relatively high-elevation basin receiving approximately $600-\mathrm{mm} /$ year precipitation (mostly as snow) indicating that recharge (and thus net infiltration) may be as high as 50 percent of precipitation at some locations in the Great Basin.

These methods have also been applied on a larger scale in the Great Basin and can also be compared to the INFIL results for net infiltration. The Maxey-Eakin method was applied to 167 basins in the Great Basin to estimate recharge for locations of MAP in excess of 8 inches (203 mm/year) (Harrill and Prudic 1998 [DIRS 149377], Figure 7-2). The chloride mass balance method was used by Dettinger (1989 [DIRS 105384]), who applied it to 16 basins in Nevada; the estimates were close to those that they obtained using the Maxey-Eakin method and water-balance calculations. Values of recharge estimated for Dettinger's 16 basins, as well as the two points determined by Lichty and McKinley (1995 [DIRS 100589]) presented on Figure 7-1, are included on Figure 7-2. 


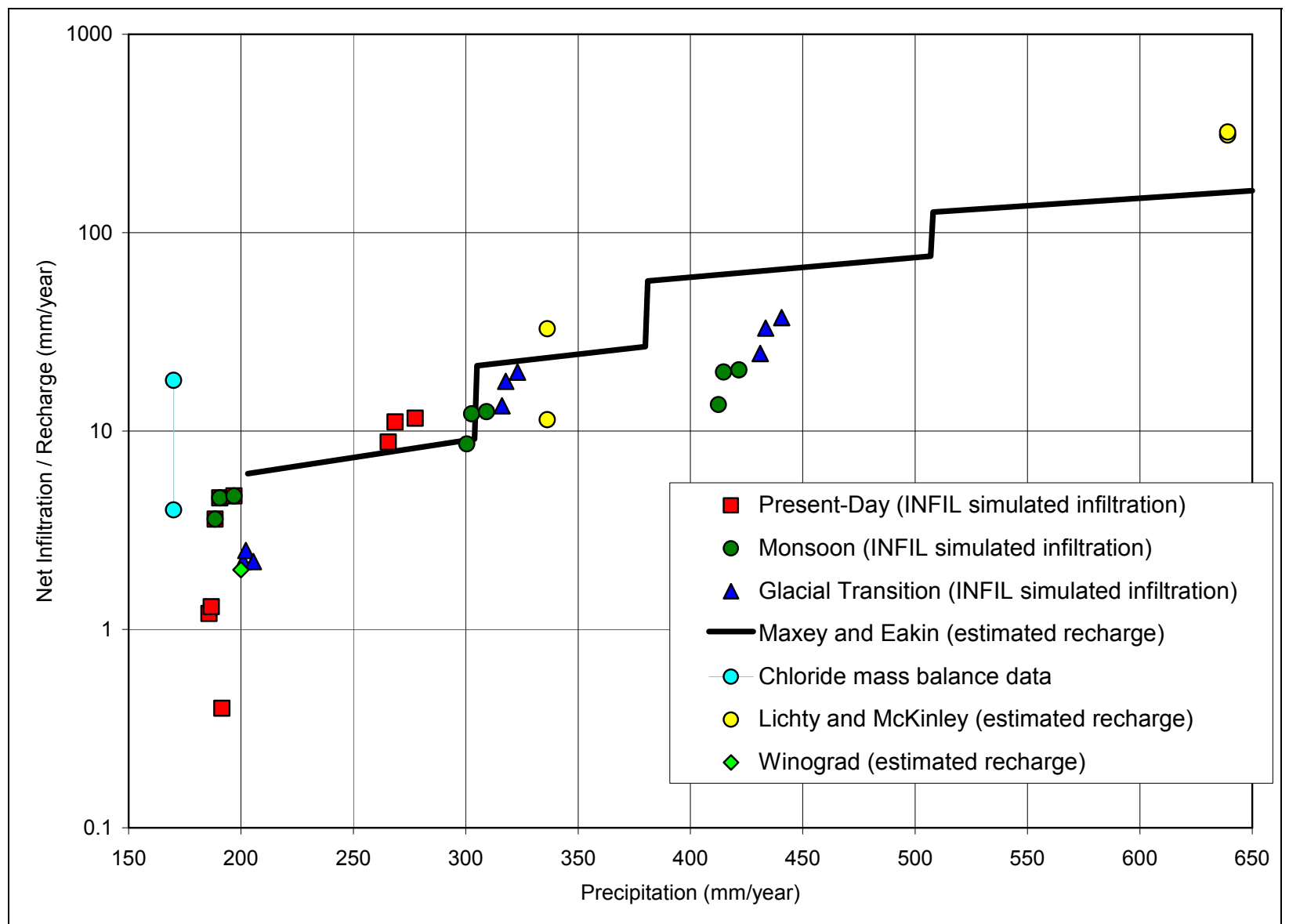

Source: BSC 2004 [DIRS 170037]; Maxey and Eakin 1950 [DIRS 100598]; Lichty and McKinley 1995 [DIRS 100589]; Winograd 1981 [DIRS 100019].

Output DTN: GS000308311221.005.

Figure 7-1. Comparison of 1999 INFIL Simulated Average Net-Infiltration Rates at Yucca Mountain (Upper Bound, Lower Bound, and Mean for Three Climates and Three domain Areas)

The net infiltration for selected modeling domains (Figure 6-11) and calibration watersheds (Figure 6-19) at Yucca Mountain is shown on Figure 7-2. This figure shows recharge, or net infiltration, as a volume calculated per basin area as a function of average annual precipitation volume. The generally good agreement among the various methods for estimating net infiltration indicated by Figures 7-1 and 7-2, including the results from the net-infiltration model, supports the conclusion that the net-infiltration model is appropriate for estimating the spatial distribution of net infiltration within the Yucca Mountain site area.

The 2004 (H104) model (refer to Section 7.2.2) calculated average annual net infiltration values of 4.4, 5.5, and $7.6 \mathrm{~mm} /$ year for the entire model domain, the UZ flow model domain, and the 1999 repository footprint, respectively (Table 7-1). All three of these values are well within an order of magnitude of the mean values of 5, 6.5, and $8.5 \mathrm{~mm} /$ year for the bomb-pulse, carbon-14, and borehole temperature methods reported by Flint et al. (2002 [DIRS 157411], pp. 201 to 202) that were selected as the validation criteria for the revision of the model report. 
Table 7-1. Net Infiltration for Different Model Areas for the 1999 and 2004 Model Runs

\begin{tabular}{|l|c|c|c|}
\hline \multicolumn{1}{|c|}{ Model Area } & 1999 INFIL Results & 2004 INFIL Results & Percent Difference \\
\hline Total infiltration domain & 3.6 & 4.4 & 22.2 \\
\hline UZ flow model domain & 4.6 & 5.5 & 19.6 \\
\hline 1999 Repository Footprint & 4.7 & 7.6 & 61.7 \\
\hline
\end{tabular}

Output DTNs: GS000308311221.005; SN0408T0507804.003.

NOTE: Estimates of net infiltration for the UZ flow model area differ slightly from those reported in BSC (2004

[DIRS 169861], Table 6.1-2) because site recommendation boundaries are used in this report while license application boundaries are used in UZ Flow Models and Submodels (BSC 2004 [DIRS 169861]).

UZ=unsaturated zone

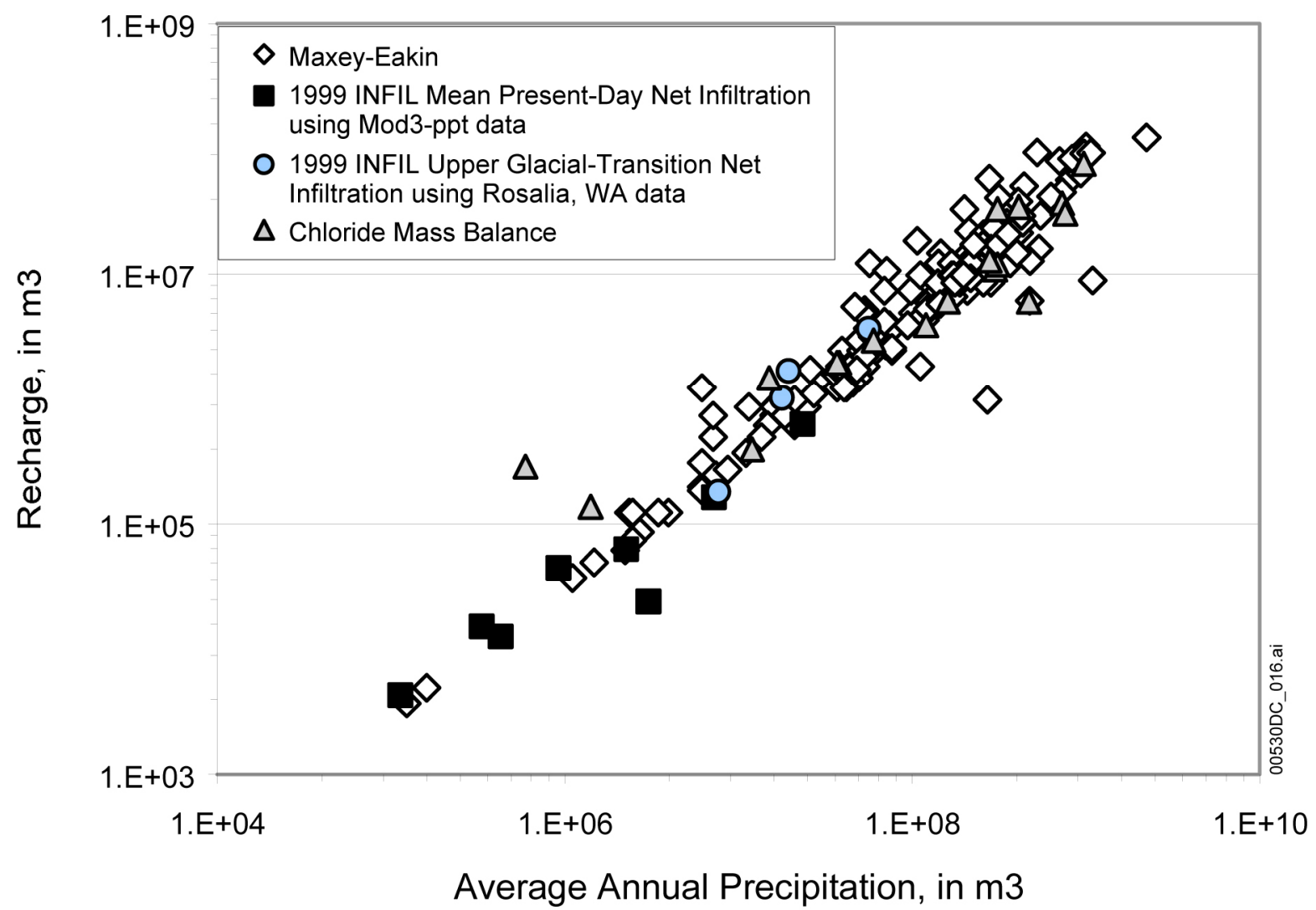

Output DTN: GS000308311221.005.

Figure 7-2. Comparison of Various Methods to Estimate Recharge in the Death Valley Region and Yucca Mountain with Selected Results from the 1999 INFIL Model Simulations as a Function of Average Annual Precipitation 


\subsubsection{Method 2: Comparison with An Alternative Model}

This method of model validation uses the 2004 model recalibration as the alternative model. Comparisons of average annual net infiltration are limited to the mean present-day climate only. The 2004 (recalibrated) model to which the 1999 model is compared is referred to below as the H104 model (parameter set). Note that the 2004 INFIL model is the same as the 1999 INFIL model, except in input parameters values.

\section{Hydraulic Conductivity Data}

During the 2004 model recalibration, effective bedrock permeability was increased by approximately two orders of magnitude. As a result of the 2004 RIT review, the permeabilities used in the 1996 and 1999 model runs were considered to be inconsistent with fracture permeabilities reported in Calibrated Properties Model (BSC 2004 [DIRS 169857], Table 4-3) and with infiltration rates measured during the Alcove 1 infiltration experiments (Liu et al. 2003 [DIRS 162470]). The permeabilities for $250-\mu \mathrm{m}$ filled fractures were used in the 1996 and 1999 models runs, and the fracture permeabilities reported in Calibrated Properties Model (BSC 2004 [DIRS 169857], Table 4-3) and the permeabilities calculated from the Alcove 1 infiltration experiments (Liu et al. 2003 [DIRS 162470]) are considerably higher than permeabilities used in the 1996 and 1999 INFIL calibrations.

The conductivity of the upper lithophysal zone of the Tiva Canyon Tuff reported in Table D-3 of this model report is $1.13 \mathrm{~mm} /$ day, while the permeability of the same unit reported in Calibrated Properties Model (BSC 2004 [DIRS 169857]) is $5.3 \times 10^{-12} \mathrm{~m}^{2}$ (which corresponds to a conductivity of approximately $4482 \mathrm{~mm}$ /day); and the conductivity of the same unit determined during the Alcove 1 infiltration experiments is $21.5 \mathrm{~mm}$ /day (Liu et al. 2003 [DIRS 162470]). The difference in permeabilities between reports and field measurements may partially be a result of scaling effects between laboratory and field scales.

The hydraulic conductivities for all bedrock units, not just the Tiva Canyon Tuff unit, are significantly different between Table D-3 in this model report and Table 4-3 in Calibrated Properties Model (BSC 2004 [DIRS 169857]). This is primarily due to the assumption made during the 1996 and 1999 INFIL model calibrations that all fractures near the ground surface have an aperture of $250-\mu \mathrm{m}$ and they are filled fractures. In contrast, the permeabilities reported in Calibrated Properties Model (BSC 2004 [DIRS 169857], Table 4-3) are primarily for open fractures and may not represent the condition of the fractures near the ground surface. The actual values of bedrock hydraulic conductivities are likely somewhere between those reported in Table D-3 and in Calibrated Properties Model (BSC 2004 [DIRS 169857], Table 4-3), as observed during the Alcove 1 infiltration experiments.

For the 2004 INFIL model calibration, the goal was to use scaled values of bedrock hydraulic conductivities between those reported in Table 4-3 in Calibrated Properties Model (BSC 2004 [DIRS 169857]) and the average value obtained from the Alcove 1 infiltration experiments, such that the actual value used for the Tiva Canyon Tuff unit was equal to that determined from the Alcove 1 experiments (Liu et al. 2003 [DIRS 162470]). This was accomplished by calculating the ratio of the log mean hydraulic conductivities for the Tiva Canyon Tuff from the Alcove 1 experiments (1.33) to the log mean hydraulic conductivities for the Tiva Canyon Tuff from 
Calibrated Properties Model (BSC 2004 [DIRS 169857]) (3.65), and multiplying this ratio $(1.33 / 3.65=0.365)$ to all the $\log$ values of the units reported in Calibrated Properties Model (BSC 2004 [DIRS 169857], Table 4-3). This new set of hydraulic conductivities (DTN: SN0409T0507804.005 [DIRS 171747]) was then used in the 2004 INFIL model recalibration. Refer to Figure 7-3 for a comparison of the hydraulic conductivities discussed above. Some bedrock units are repeated in this figure because more than one value of conductivity was reported for that unit in Table D-3. The net result of the conversion is that the mean of all of the bedrock conductivities (not including soils) used in this model report increased from $0.34 \mathrm{~mm} /$ day (used for 1999 calibration) to $12.3 \mathrm{~mm} /$ day (for 2004 calibration) (DTN: SN0409T0507804.005 [DIRS 171747]).

Values of bedrock permeability were adjusted using a scaling factor as described above, so these values are outside the range assigned in the infiltration uncertainty analysis (BSC 2003 [DIRS 165991], Table 6-2; also see Table 7-2 of this report). The chosen model parameter set for recalibration and validation (H104) satisfied the specified calibration and validation criteria but was not optimal since an optimization method was not employed to determine it.

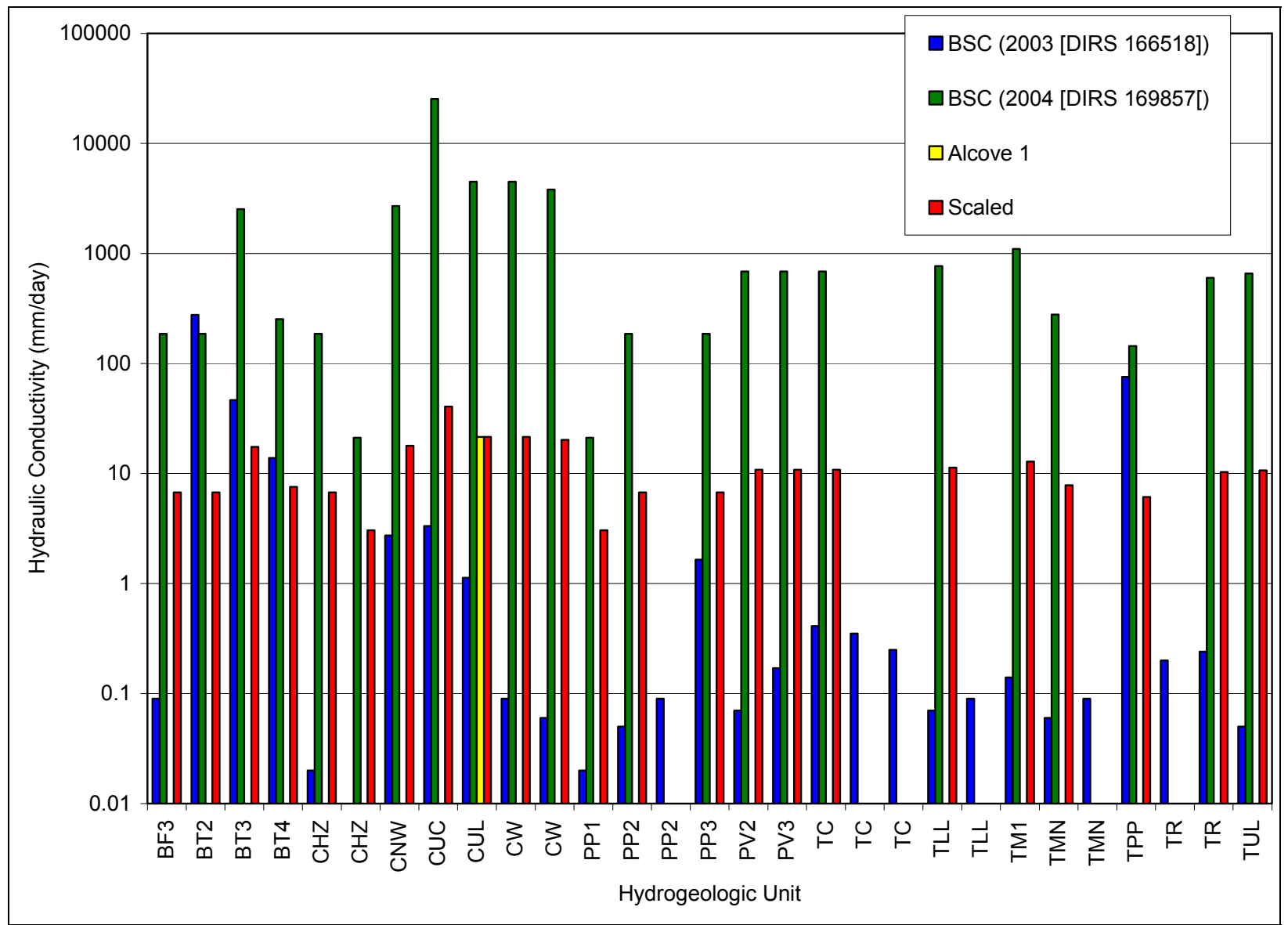

Source: DTN: SN0409T0507804.005 [DIRS 171747].

NOTE: $\quad$ Comparison Between Simulation of Net Infiltration for Modern and Potential Future Climates BSC (2003 [DIRS 166518]), Calibrated Properties Model BSC (2004 [DIRS 169857]), Alcove 1 Field Data, and the Scaled Values Used in the 2004 Model Calibration

Figure 7-3. Comparison of Hydraulic Conductivities 


\section{Net Infiltration (flux) Data}

Net infiltration (flux) at selected grid cells was calculated using water content data (DTN: GS960508312212.008 [DIRS 122609]). The water content data were calculated from neutron logging data (neutron counts) collected at neutron logging boreholes. These flux calculations are considered to be measurements of flux and adequate for calibration of the 2004 model parameter set (H104). However, these measurements can be problematic in that one borehole can yield high flux while an adjacent borehole several meters away, installed in the same topographic domain, can yield zero flux. For this reason, a method of grouping boreholes was used in order to use the average flux values for clusters of boreholes. As described in Section 6.3.4, the installation of these boreholes may have created new fractures and pathways (short-circuiting) for water flow for some boreholes and not for others. This neutron logging - water content - flux dataset has also been used to generate a net infiltration flux map for the entire Yucca Mountain region (Flint et al. 2001 [DIRS 156351], Figure 13). The average net infiltration for the repository footprint used in that study was in the range of 20 to $30 \mathrm{~mm} /$ year. Therefore, the estimates of net infiltration from the neutron logging dataset are considerably higher than the estimates of net infiltration provided during the 1999 INFIL model calibration, and a variety of other independent methods of estimating net infiltration at Yucca Mountain.

During the 2004 model calibration, the model inputs that were adjusted for model calibration were primarily empirical factors such that their values had little or no physical basis. Some physically-based parameters, such as potential evapotranspiration, soil depth, and bedrock porosity, were also adjusted during model calibration. Potential evapotranspiration was increased for the entire model domain using a multiplier of 1.4, applied to all grid cells. The net effect of using a multiplier of 1.4 (along with a value of 1.46 instead of 1.26 for $\alpha$ to account for the missing advective energy term in the Priestley-Taylor equation) is that average annual potential evapotranspiration increased from approximately $800 \mathrm{~mm} /$ year (used in the 1996 and 1999 model calibrations), to approximately $1650 \mathrm{~mm} /$ year, a value that is consistent with other reports (DOE 2001 [DIRS 171281]; Shevenell 1996 [DIRS 171280]). Other combinations of values of the PET multiplier and $\alpha$ may have given similar results but this was not investigated.

Soil depth was reduced by a factor of two for the entire model domain during the 2004 model calibration. This reduction was justified because the root-zone weighing parameters were increased with depth; therefore, the reduced soil depths can be considered to be an effective rooting depth based on the updated weighing parameters (Table 7-2). A value of 0.024 was used for bedrock porosity. This value matches the upper limit for bedrock porosity reported in Analysis of Infiltration Uncertainty (BSC 2003 [DIRS 165991]). However, bedrock near the ground surface should be expected to be more rotten and fractured than at greater depths, so use of a slightly higher porosity in the 2004 model calibration can be justified. Other input parameters that were adjusted for the 2004 model calibration include:

- Root-zone density weighting parameters

- ET-depth weighting factors

- Soil and bedrock layer thicknesses

- Priestley-Taylor evaporation and transpiration coefficients

- Effective wetted area for run-on. 
Table 7-2. Summary of Input Parameters Changed for the 2004 Model Calibration

\begin{tabular}{|c|c|c|c|c|}
\hline Model Parameters Adjusted & $\begin{array}{r}1999 \\
\text { INFIL }\end{array}$ & $\begin{array}{l}2004 \\
\text { INFIL }\end{array}$ & $\begin{array}{l}\text { Upper } \\
\text { Range }^{\text {a }}\end{array}$ & $\begin{array}{l}\text { Lower } \\
\text { Range }^{a}\end{array}$ \\
\hline Bedrock $\mathrm{K}_{\mathrm{s}}$ (average, $\mathrm{mm} /$ day) & 0.34 & 12.32 & 3.38 & 0.03 \\
\hline PET multiplier (effect) & 1 & 1.4 & 1.4 & 0.6 \\
\hline Soil and root-zone thickness multiplier (sdfact) & 1 & 0.5 & 1.9 & 0.1 \\
\hline Root-zone activity for soil layer 2 (rootf2) & 0.5 & 1 & not used & not used \\
\hline Root-zone activity for soil layer 3 (rootf3) & 0.2 & 0.5 & not used & not used \\
\hline Root-zone activity for bedrock layer (rootf4) & 0.01 & 0.2 & not used & not used \\
\hline Maximum ET weighting factor soil layer 2 (maxwgt2) & 0.8 & 1 & not used & not used \\
\hline Maximum ET weighting factor soil layer 3 (maxwgt3) & 0.2 & 0.2 & not used & not used \\
\hline Maximum ET weighting factor bedrock layer 3 (maxwgt4) & 0.05 & 0.2 & not used & not used \\
\hline Soil layer 1 bottom depth (meters) (rdepth1) & 0.3 & 0.02 & not used & not used \\
\hline Soil layer 2 bottom depth (meters) (rdepth2) & 1.5 & 0.3 & not used & not used \\
\hline Bedrock layer thickness coefficient (rdepthf) & 2 & 1 & 2 & 0 \\
\hline Effective root-zone storage capacity for bedrock (rkpor) & 0.02 & 0.024 & 0.024 & 0.002 \\
\hline Effective wetted area for run-on (flarea) & 0.5 & 0.3 & 0.99 & 0.01 \\
\hline Bare-soil ET coefficient (barsoil2) & 1.04 & 1.46 & 1.54 & 0.54 \\
\hline Transpiration coefficient (for soil layer etcoeffa) & -2.5 & -10 & not used & not used \\
\hline Transpiration coefficient (for bedrock layer etcoeffa) & -1.5 & -10 & not used & not used \\
\hline Transpiration coefficient (etcoeffb) & 1.26 & 1.46 & not used & not used \\
\hline Mean daily air temperature (deg. C) (atemp1) & 17.3 & 15.1 & not used & not used \\
\hline Time step for solrad routine (hours) (hstep) & 2 & 1 & not used & not used \\
\hline
\end{tabular}

Output DTNs: SN0407T0507804.001; SN0309T0503100.009.

${ }^{a}$ Refers to Analysis of Infiltration Uncertainty (BSC 2003 [DIRS 165991]).

$\mathrm{ET}=$ evapotranspiration; $\mathrm{K}_{\mathrm{s}}=$ saturated hydraulic conductivity; $\mathrm{PET}=$ potential evapotranspiration

In addition, the average annual temperature was changed because an incorrect value was used in the 1999 model calibration, and the timestep for calculation of PET was reduced from two hours to one hour. This reduction in timestep length was introduced in order to better capture the hourly changes in PET. Refer to Table 7-2 for a summary of all input parameters adjusted during the 2004 model calibration.

\section{Results of Model Recalibration}

The 2004 model was calibrated using flux calculated from neutron logging data and by using the same stream discharge data used for the 1999 model calibration. For the flux data, 41 boreholes were selected from the 84 in the dataset (DTN: GS960508312212.008 [DIRS 122609]). These 41 boreholes were selected because they are located within the areas of the stream flow calibration watersheds used for calibration of stream flow. Of these 41 boreholes, two were thrown out because measured flow at these boreholes was unreasonably large. As previously discussed, these two boreholes may have been affected by short-circuiting of flow by fractures caused by drilling. 
The measured average annual flux (calculated from water content measurements) from these 39 boreholes was $20.3 \mathrm{~mm} / \mathrm{year}$. The modeled average annual flux was exactly the same, $20.3 \mathrm{~mm} / \mathrm{year}$. However, there was large variability between measured and modeled flux among the 39 boreholes (Figure 7-4). There were many boreholes in which measured flux was zero while modeled flux was high, and vice versa. Because of this variability, a method of grouping boreholes was used in which clusters of boreholes within a grid cell were averaged together. The result of this comparison is shown in Figure 7-5. The measured average annual flux from these 21 groups of boreholes was $18.7 \mathrm{~mm} /$ year while the modeled average annual flux was $13.7 \mathrm{~mm} /$ year. Figure 7-6 shows this comparison for Pagany Wash boreholes only. The measured average annual flux from these seven groups of boreholes was $17.8 \mathrm{~mm} /$ year while the modeled average annual flux was $20.6 \mathrm{~mm} /$ year. This figure demonstrates that the flux calibrations work better for some watersheds than for others.

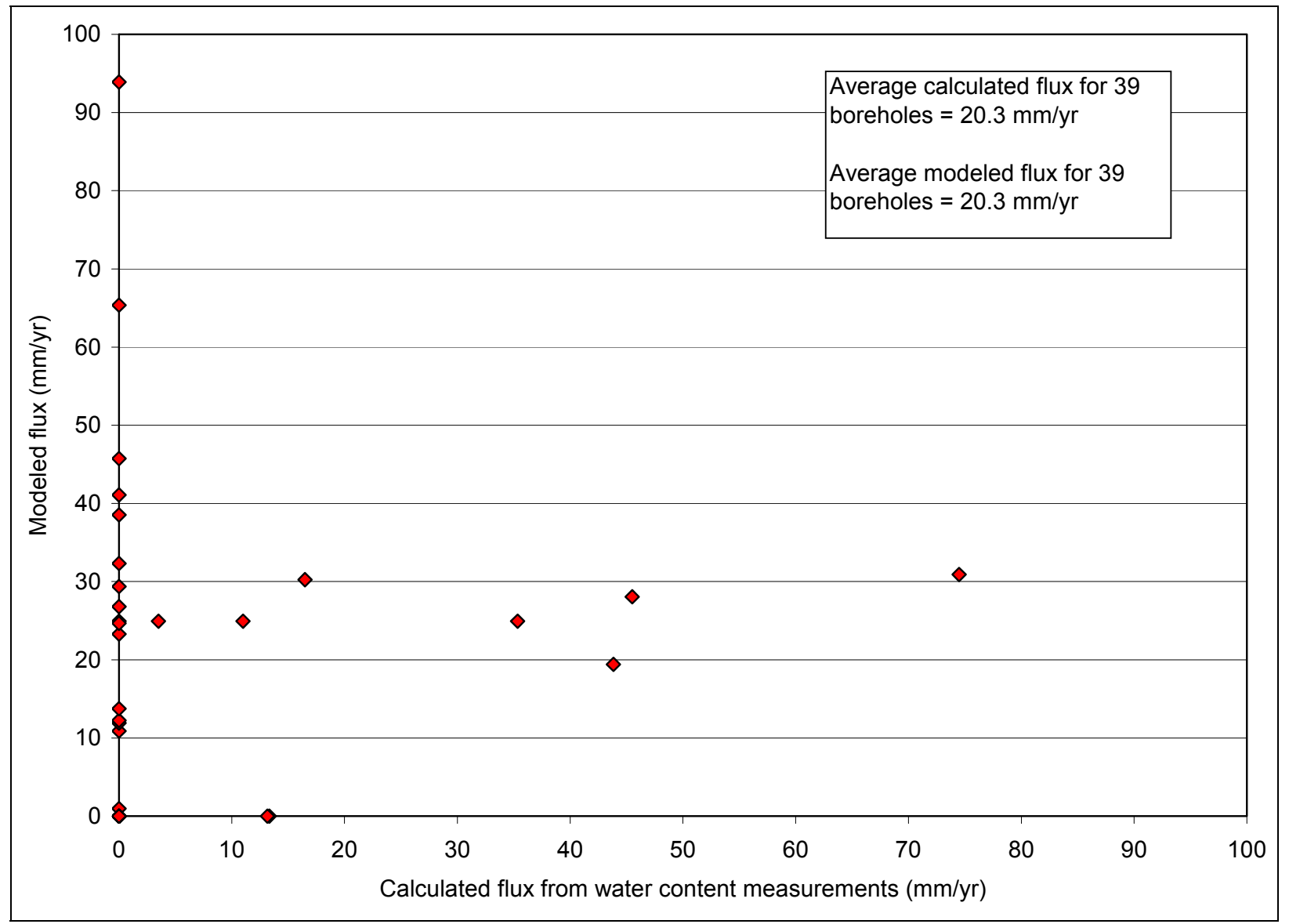

Source: DTNs: GS960508312212.008 [DIRS 122609]; SN0408T0507804.003.

Figure 7-4. Flux Calculated from Water Content Measurements Versus Modeled Flux at 39 Neutron Logging Boreholes Within the Area of the Five Streamflow Calibration Watersheds. Measured Flux Is Calculated from Neutron Logging Water Content Data Using the 0.012 Filter 


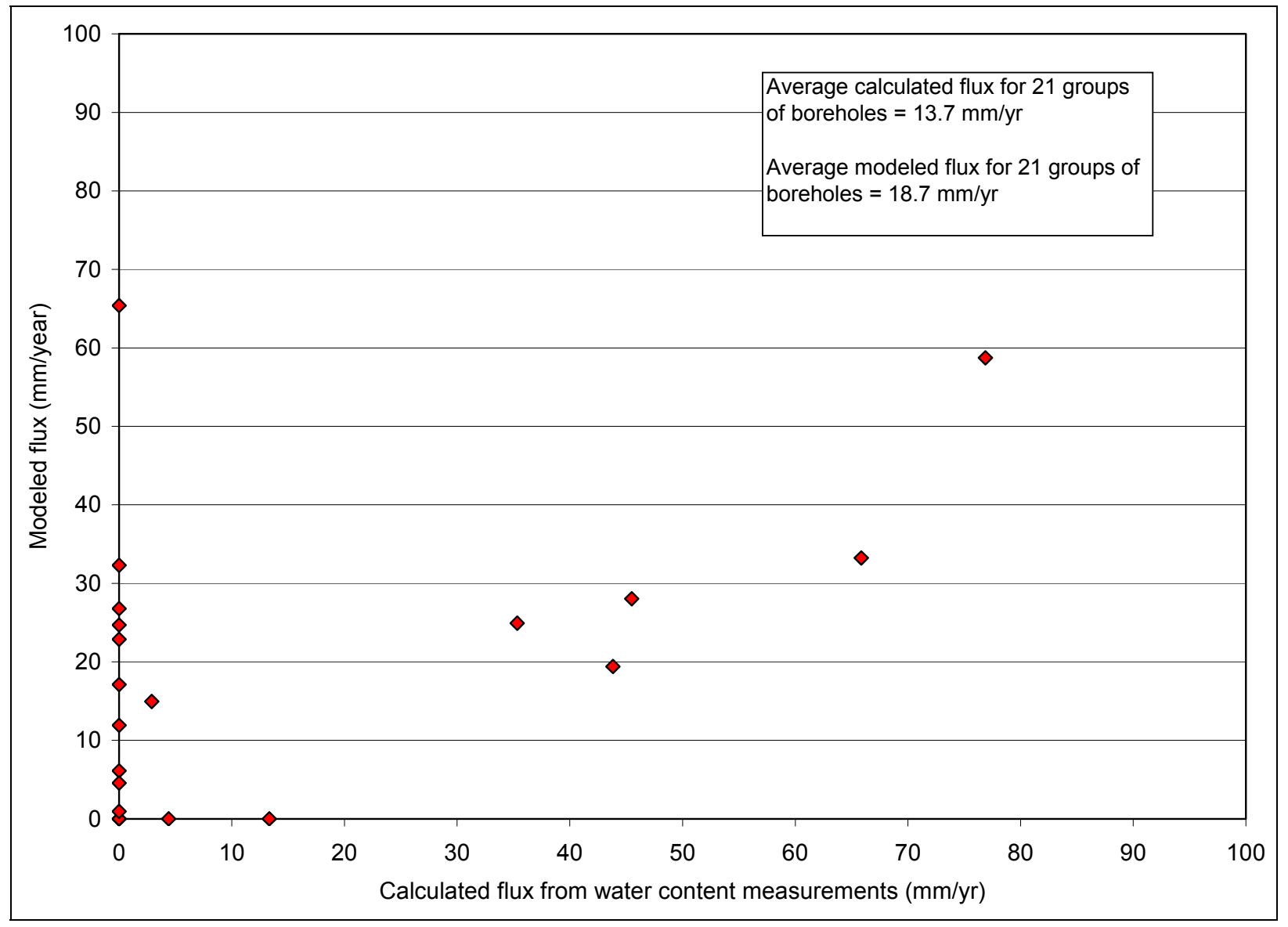

Source: DTNs: GS960508312212.008 [DIRS 122609]; SN0408T0507804.003.

Figure 7-5. Flux Calculated from Water Content Measurements Versus Modeled Flux for 21 Groups of Neutron Logging Boreholes (Based on Topography) Within the Area of the Five Streamflow Calibration Watersheds. Measured Flux Is Calculated from Neutron Logging Water Content Data Using the 0.012 Filter

The 2004 model was also calibrated using stream flow data. Results of this calibration indicate that modeled stream flow was not matched to measured stream flow as well as it was for the 1999 calibration (refer to Figure 7-7 and Table 7-3). However, results of this calibration indicate that stream flow is underestimated, and this adds to the conservatism of the model.

The results for the comparisons of average net infiltration between the 1999 model and the 2004 model (H104 parameter set) are summarized in Table 7-1. It is noteworthy that despite the significantly higher bedrock permeabilities used in the 2004 H104 than in the 1999 model, the net infiltration for both the entire infiltration and the UZ flow domains is only about 20 percent higher in the 2004 H104 model. 


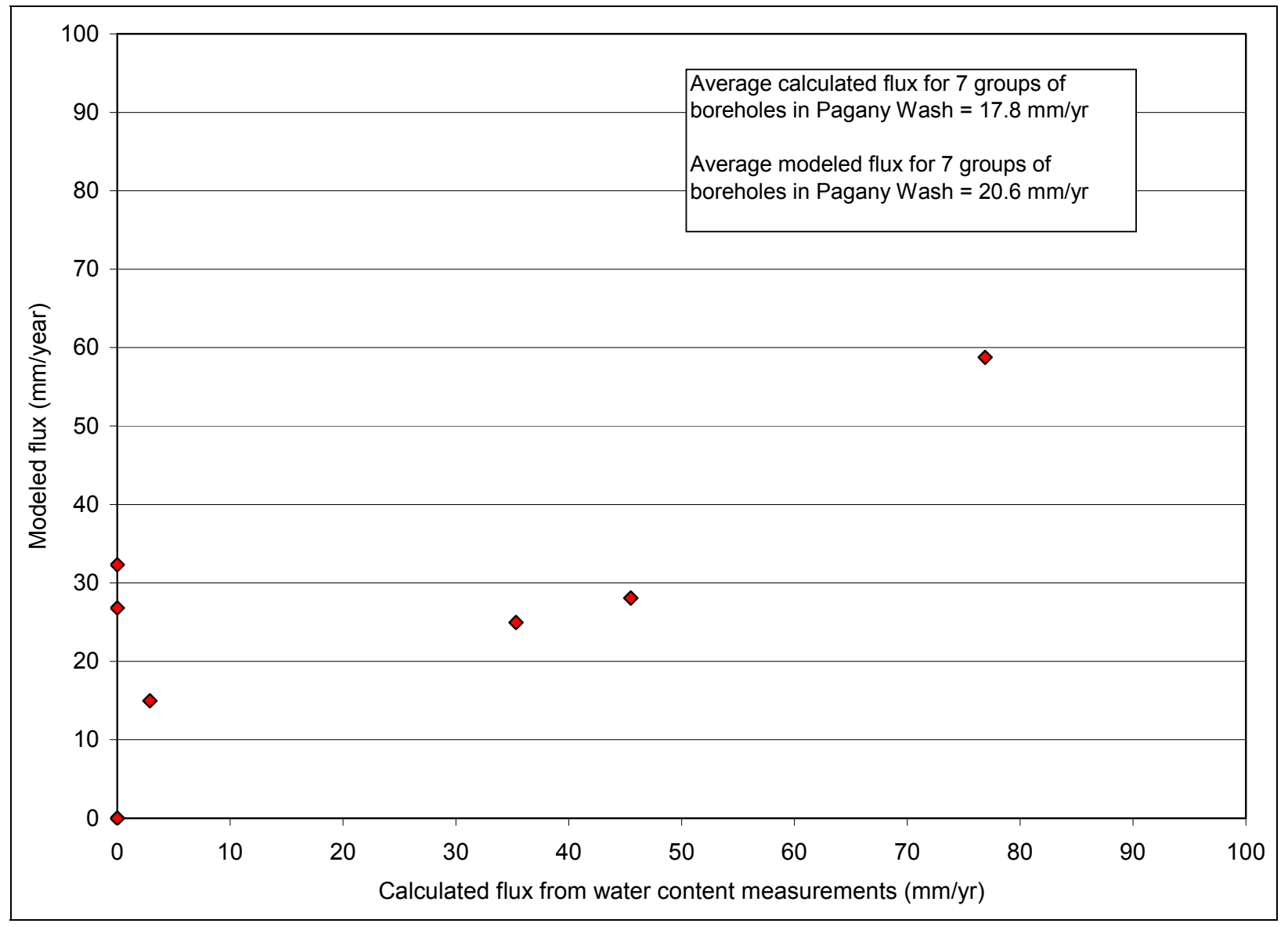

Source: DTNs: GS960508312212.008 [DIRS 122609]; SN0408T0507804.003.

Figure 7-6 Flux Calculated from Water Content Measurements Versus Modeled Flux for Seven Groups of Neutron Logging Boreholes (Based on Topography) Within Pagany Wash Watershed. Measured Flux Is Calculated from Neutron Logging Water Content Data Using the 0.012 Filter

Comparison of results from the 2004 INFIL model and those predicted using the 1999 model simulations indicate that the net infiltration validation criteria are satisfied. Average annual net infiltration was 4.4, 5.5, and $7.6 \mathrm{~mm} /$ year for the entire model area, the UZ flow area, and for the 1999 repository footprint. These results are shown in Table 7-1. These results indicate that the 2004 model yields relatively higher net infiltration over the repository footprint than the 1999 model, because of the reduction in soil depth. At the top of Yucca Mountain (over the repository footprint), soils are much thinner than in surrounding areas, so a reduction in soil depth will have a more notable effect on net infiltration over this area than over areas with deep soils. The net infiltration map for the 2004 model is shown in Figure 7-8, and the net infiltration difference map (1999 model infiltration minus 2004 model infiltration) is shown in Figure 7-9.

The 2004 model results show less variability compared to the 1999 result (BSC 2003 [DIRS 166518], in Figure 7-8 and Figure 6-26). This may be largely due to the reduced relative differences in bedrock saturated hydraulic conductivity due to the scaling down of the values from the values reported in Calibrated Properties Model (BSC 2004 [DIRS 169857], Table 4-3), since net infiltration is sensitive to this parameter. 


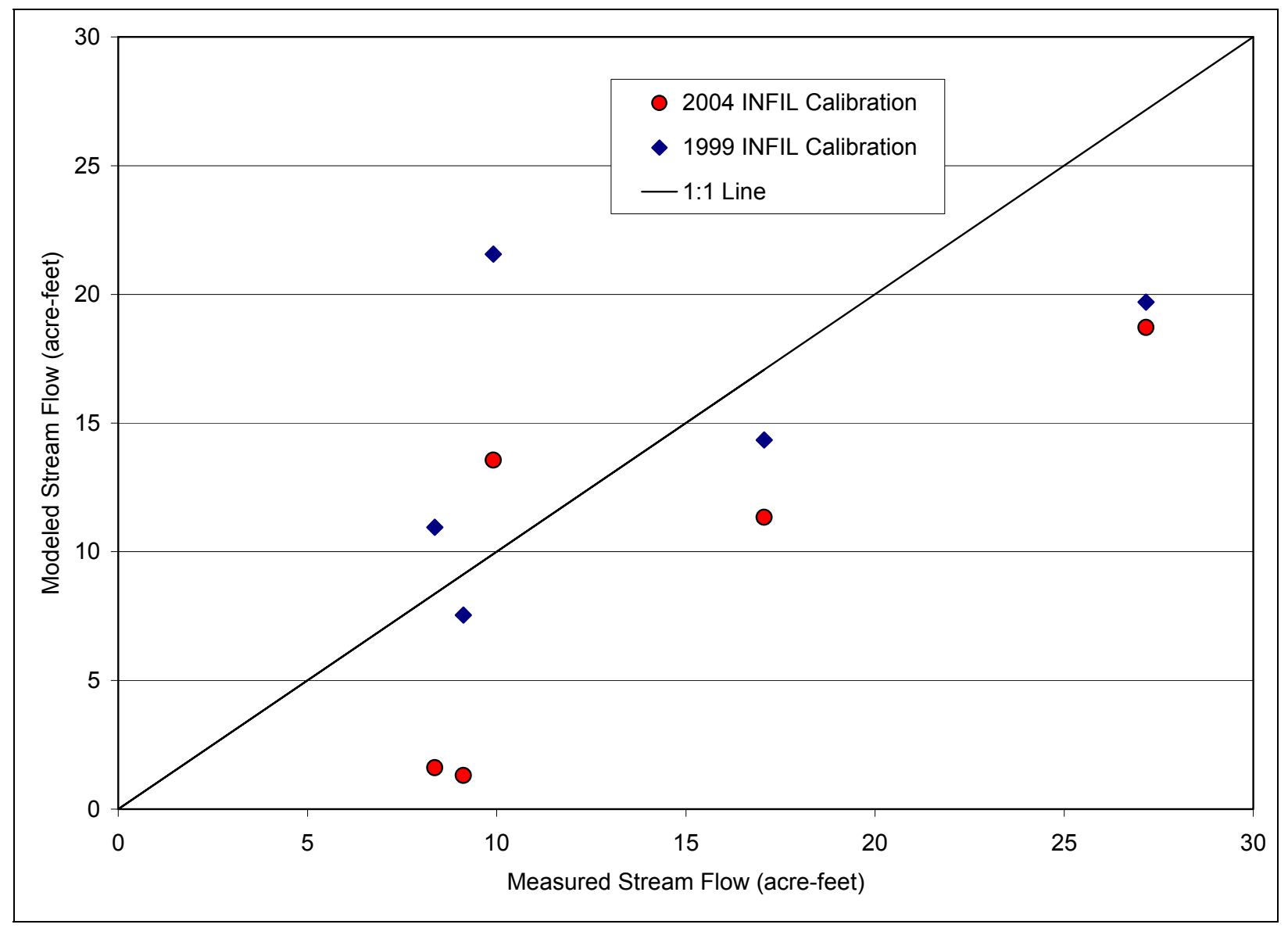

Source: DTNs: GS941208312121.001 [DIRS 107374]; GS960908312121.001 [DIRS 107375].

Output DTN: SN0408T0507804.004.

Figure 7-7 Measured Versus Modeled Stream Flow for the 1999 and 2004 Model Calibrations for the Five Stream Flow Calibration Watersheds

Table 7-3. Summary of the 1999 and 2004 Model Calibrations Using Stream Flow Data

\begin{tabular}{|l|c|c|c|}
\hline \multicolumn{1}{|c|}{ 1995 Streamflow (acre-feet) } & Measured & $\begin{array}{c}\text { Modeled } \\
\text { 1999 INFIL }\end{array}$ & $\begin{array}{c}\text { Modeled } \\
\text { 2004 INFIL }\end{array}$ \\
\hline Lower Pagany Wash & 17.07 & 14.34 & 11.34 \\
\hline Upper Pagany Wash & 27.16 & 19.70 & 18.71 \\
\hline Upper Drill Hole Wash & 9.91 & 21.56 & 13.56 \\
\hline Upper Split Wash & 9.12 & 7.54 & 1.31 \\
\hline Wren Wash & 8.37 & 10.95 & 1.61 \\
\hline
\end{tabular}

Source: DTNs: GS941208312121.001 [DIRS 107374]; GS960908312121.001 [DIRS 107375].

NOTE: Cubic feet per second (cfs) was converted to acre-feet by cfs $/\left(43560^{*} 3600^{*} 24\right)=$ acre-feet. 
The infiltration map generated during the 2004 model recalibration (DTN: SN0408T0507804.003) was used as input to the site-scale UZ flow model (BSC 2004 [DIRS 169861], Appendix I) in a sensitivity study to investigate the impact of the new infiltration map on the flow field. The sensitivity analysis results (BSC 2004 [DIRS 169861], Appendix I) indicate that the new infiltration map results in an 18 percent increase in net infiltration; however, the new infiltration within the repository footprint near the center of the UZ model domain is increased by 73 percent. The main difference between the new infiltration map from the current one is a large decrease in net recharge in the very northern area and some increase along the middle from the Drill Hole Wash fault to the south. On the other hand, the UZ moisture conditions predicted using the new infiltration map are similar to those by the current present-day, mean infiltration map in terms of matching matrix liquid saturation, water potential, and perched water data. Statistics of simulated percolation fluxes, fracture, matrix, and fault flow components with the new infiltration are, in most part, similar to those with the current infiltration map, except for a large decrease in fault flow percentage on repository and water table levels (BSC 2004 [DIRS 169861], Appendix I).

\subsection{VALIDATION SUMMARY}

The results of calculations of net infiltration have been validated by applying acceptance criteria based on an evaluation of the model's relative importance to the potential performance of the repository system. All validation requirements defined in Technical Work Plan for: Unsaturated Zone Flow Analysis and Model Report Integration (BSC 2004 [DIRS 169654], Section 2.2.1.2) have been fulfilled, including corroboration of model results with experimental data, and corroboration with alternative models. Activities requirements for confidence building during model development have also been satisfied. The model development activities and postdevelopment validation activities described establish the scientific bases for the infiltration model. Based on this, the infiltration model used in this report is considered to be sufficiently accurate and adequate for the intended purpose, and to the level of confidence required by the model's relative importance to the potential performance of the repository system. 


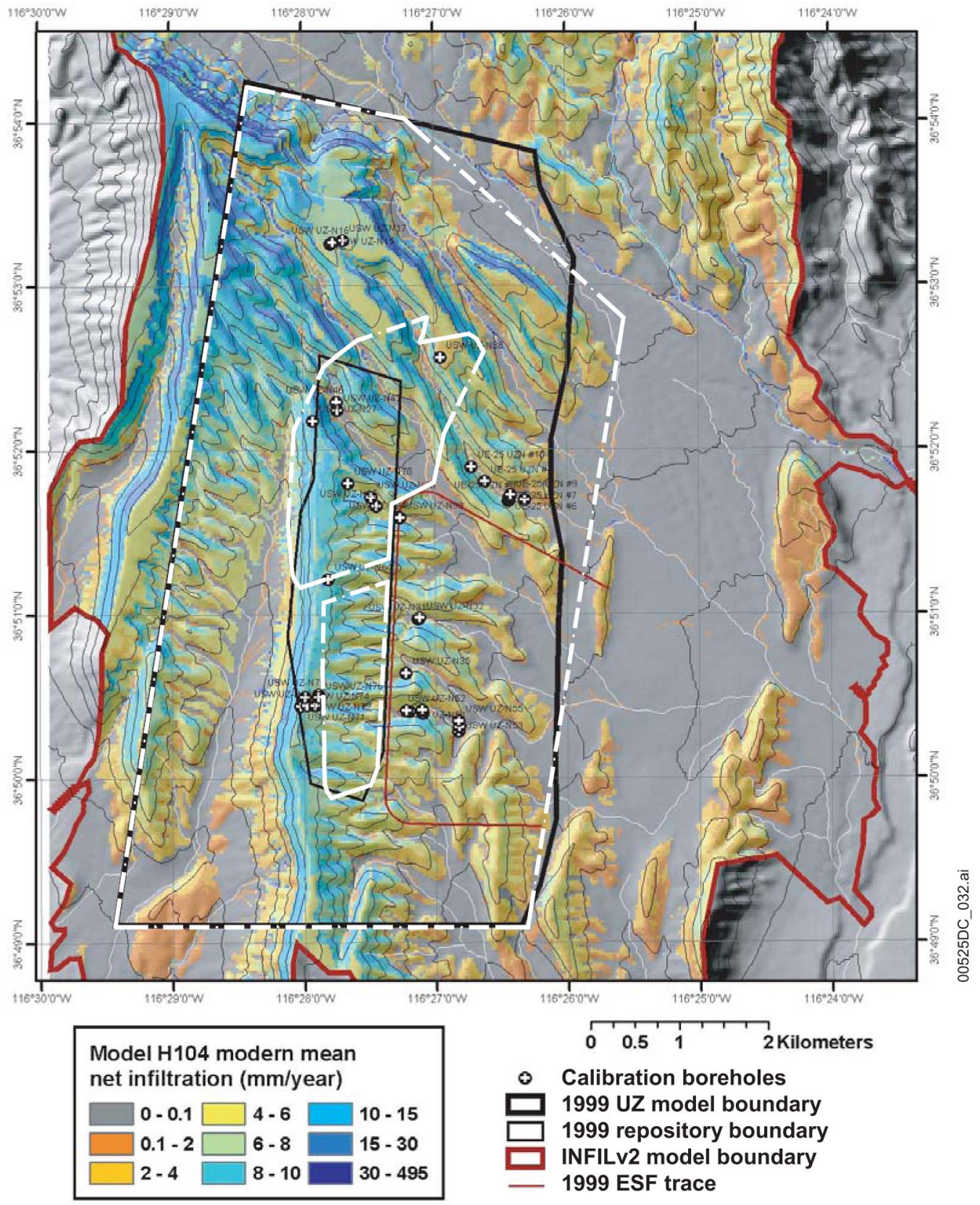

Output DTN: SN0408T0507804.003.

NOTE: The 1999 UZ flow model domain and the 1999 repository footprint are site recommendation boundaries (black solid lines), not license application boundaries (white dashed lines).

Figure 7-8. Estimated Net Infiltration (mm/year) for the Mean Present-Day Climate Scenario Using the 2004 (H104) Model 


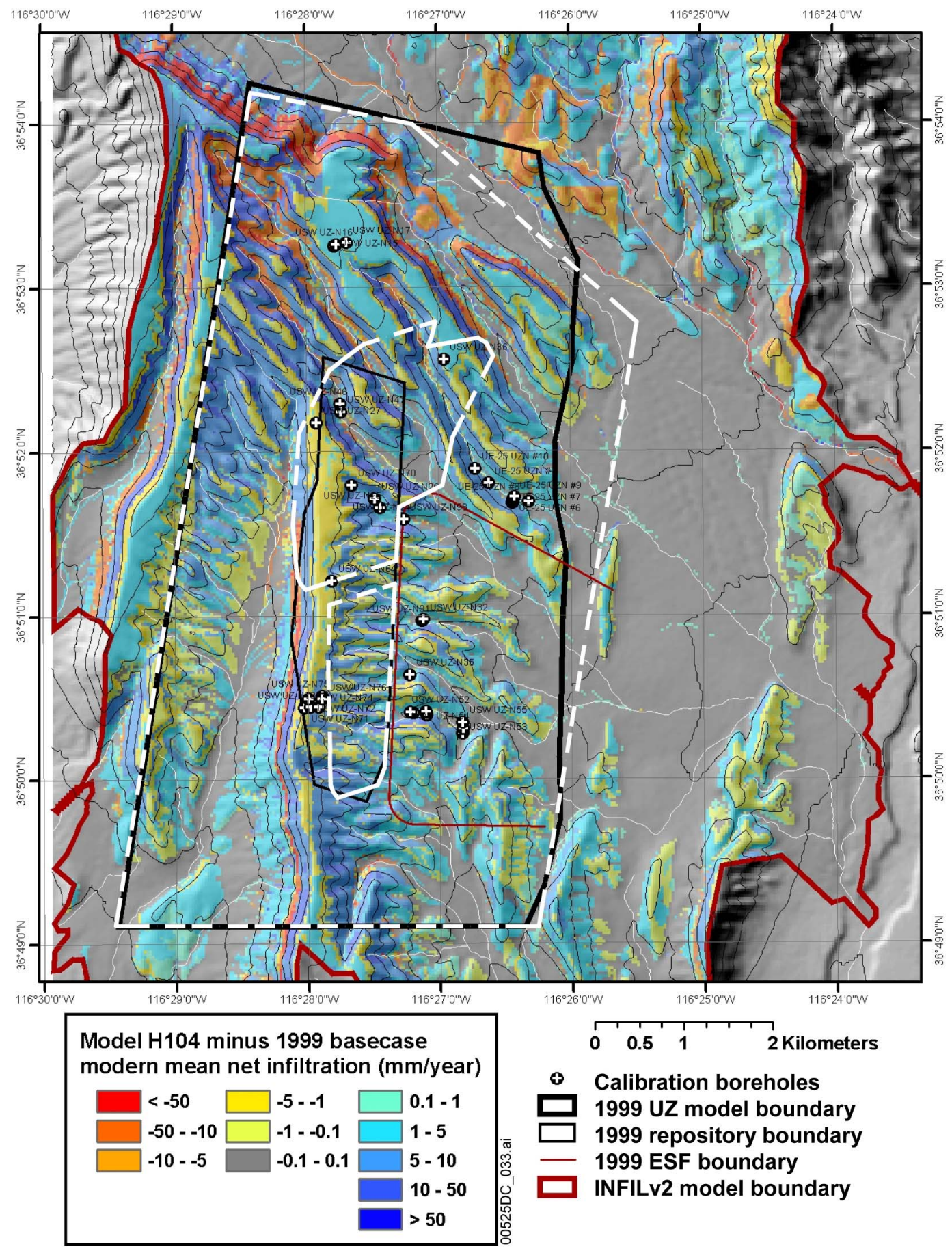

Output DTN: SN0408T0507804.003.

NOTE: The 1999 UZ flow model domain and the 1999 repository footprint are site recommendation boundaries (black solid lines), not license application boundaries (white dashed lines).

Figure 7-9. Difference in Net Infiltration (mm/year) for the Mean Present-Day Climate Scenario Between the 2004 (H104) Model and the 1999 Model Outputs 


\section{CONCLUSIONS}

This model report describes enhancements made to the 1996 infiltration model documented by Flint et al. (1996 [DIRS 100147]) and documents the steps taken to generate spatial and temporal distributions over a model domain encompassing the Yucca Mountain site. Net infiltration is the component of infiltrated precipitation, snowmelt, or surface water run-on that has percolated below the zone of evapotranspiration, as defined by the depth of the effective root zone. The estimate of net infiltration are used for defining the upper boundary condition for the site-scale three-dimensional UZ flow model and the TSPA-LA model. Estimates of net infiltration are provided as raster-based, two-dimensional grids of spatially distributed, time-averaged rates for three different climate stages estimated as likely conditions for the next 10,000 years beyond the present. Each climate stage is represented using a lower bound, a mean, and an upper bound climate and corresponding net-infiltration scenario for representing uncertainty in the characterization of daily climate conditions for each climate stage, as well as potential climate variability within each climate stage. The set of nine raster grid maps provides spatially detailed representations of the magnitude and distribution of net-infiltration rates used to define specified flux upper boundary conditions for the UZ flow models.

All source data, references, models, routines, and procedures are described, noted, or referenced in this report for complete tracking of all modeling activities. All assumptions used to obtain estimates of net infiltration are described. This report consists of (1) modifications to the 1996 model (Flint et al. 1996 [DIRS 100147]); (2) an update of input parameters defining the new model INFIL V2.0 (USGS 2000 [DIRS 139422]); (3) calibration of the new model using stream flow records; (4) the development of daily climate input representative of potential future climate stages; (5) application of the model to provide net-infiltration estimates for a lower, mean, and upper bound climate scenario within each potential future climate stage; and (6) the recalibration and validation of a new parameter set to further validate the 1999 INFIL model results. Developed output data are listed by data tracking number (DTN) in Table 8-1.

Table 8-1. Output Data Sets Generated in the Development and Application of the Net Infiltration Model

\begin{tabular}{|l|l|}
\hline \multicolumn{1}{|c|}{ Description } & Data Tracking Number \\
\hline Preliminary Net Infiltration Modeling Results for 3 Climate Scenarios for FY99 & GS000308311221.005 \\
\hline Template files for Uncertainty Analysis & GS000308311221.011 \\
\hline $\begin{array}{l}\text { Preliminary Developed Daily Climate Data from Tule Lake, California, Used for } \\
\text { Infiltration Uncertainty Analysis }\end{array}$ & GS000308311221.010 \\
\hline Rainfall/Runoff/Run-on 1999 Simulations & GS000399991221.002 \\
\hline Preliminary Geospatial Input Data for INFIL V2.0 FY99 & GS000308311221.004 \\
\hline $\begin{array}{l}\text { Merged USGS Digital Elevation Model from Topopah Spring West and Busted } \\
\text { Butte 7.5' DEMs }\end{array}$ & GS000308311221.006 \\
\hline Yucca Mountain 1980-1995 Developed Daily Precipitation Record & GS000208311221.001 \\
\hline $\begin{array}{l}\text { Preliminary Developed Daily Climate Data for Potential Future Monsoon and } \\
\text { Glacial-Transition Climates Using Records from Selected Analog Sites }\end{array}$ & GS000208311221.002 \\
\hline Model Control Files For Infil V A_2.A1, Submodel Denoted H104 & SN0407T0507804.001 \\
\hline $\begin{array}{l}\text { Model Control Files Of Streamflow Calibration For Infil V 2.0, Submodel Denoted } \\
\text { H104 }\end{array}$ & SN0408T0507804.002 \\
\hline Output Flux Files Calculated Using Infil V A_2.A1, Submodel Denoted H104 & SN0408T0507804.003 \\
\hline $\begin{array}{l}\text { Output Re-Calibration Files Calculated Using Infil V A_2.A1 And Infil V 2.0 (Daily } \\
\text { Output Streamflow Calibration Only) For The (2004) Submodel Denoted H104 }\end{array}$ & SN0408T0507804.004 \\
\hline
\end{tabular}

FY=fiscal year; USGS=United States Geological Survey 


\subsection{SUMMARY OF RESULTS}

The net infiltration simulation results for the 1980 to 1995 calibration period include an average net-infiltration rate of $5.1 \mathrm{~mm} /$ year over the area of the net infiltration model domain, with a maximum rate of 1,486 mm/year obtained for a stream channel location in the northern part of the Yucca Wash watershed. The 4JA current-climate 100-year simulation provided an average net-infiltration rate of $2.2 \mathrm{~mm} /$ year over the net infiltration model domain, and a maximum rate of $574.4 \mathrm{~mm} /$ year. The wetter Area 12 Mesa 100-year simulation provided an average net-infiltration rate of $14.0 \mathrm{~mm} /$ year over the net infiltration model domain, with a maximum rate of $4,354 \mathrm{~mm} /$ year for a stream channel location in Yucca Wash. The results indicate a good correlation between the maximum infiltrated surface-water run-on rates and the maximum net-infiltration rates, indicating the importance of surface-water flow in causing relatively high but localized net-infiltration rates. The three separate net-infiltration simulation results were integrated to provide spatially distributed net-infiltration estimates for the lower bound, mean, and upper bound present-day climate scenarios.

Results for the mean present-day climate scenario include an average precipitation rate of $188.5 \mathrm{~mm} /$ year, an average outflow rate of $0.2 \mathrm{~mm} /$ year (corresponding to an average stream discharge rate of $0.03 \mathrm{cfs}$ ), and an average net-infiltration rate of $3.6 \mathrm{~mm} / \mathrm{year}$ for the area of the net-infiltration model domain. In comparison, net infiltration is estimated to be $1.2 \mathrm{~mm} / \mathrm{year}$ for the lower bound present-day climate and $8.8 \mathrm{~mm} /$ year for the upper bound present-day climate over the area of the net-infiltration model domain. The spatial distribution of estimated precipitation for the mean present-day climate scenario indicates minimum estimates of 140 to $160 \mathrm{~mm} /$ year occurring along the southern and southeastern parts of the modeling domain, with maximum estimates of more than $260 \mathrm{~mm} / \mathrm{year}$ occurring for the summit areas along the northern perimeter of the modeling domain. The spatial distribution of estimated net-infiltration rates for the mean present-day climate indicates most net infiltration occurs in upland areas with thin soils. The spatial distribution also indicates a strong control by bedrock hydraulic conductivity on spatial distributions and magnitudes, in addition to the effects of thin soils and surface-water run-on.

Variability in net infiltration caused by topographic effects on potential evapotranspiration is illustrated by the higher net-infiltration rates for the north-facing slopes of washes compared to south-facing slopes. Maximum net-infiltration rates of more than $100 \mathrm{~mm} /$ year occur within the UZ flow model domain for isolated areas that include side-slope and channel locations with thin soils and high hydraulic conductivity bedrock. The contribution to the total net-infiltration volume over the area of the UZ flow model is dominated, however, by the lower rates of 1 to $20 \mathrm{~mm} /$ year covering wider areas of sideslope and ridgetop locations because of a much greater total area of coverage.

In general, the maximum net-infiltration estimates for the three climate scenarios are more than two orders of magnitude higher than the spatially averaged net-infiltration rates for the three areas analyzed, indicating a high degree of spatial variability for the estimation results. In all cases, maximum net-infiltration rates occur at locations affected by surface-water run-on, and there is a strong correlation between the maximum infiltrated run-on rates with maximum net-infiltration rates for all areas and for all climate scenarios. However, because the areas with 
relatively high net-infiltration rates (greater than $100 \mathrm{~mm} /$ year) are small, most of the total net-infiltration volume occurs from upland areas with net-infiltration rates less than $20 \mathrm{~mm} /$ year.

The results for the mean monsoon climate scenario include an average precipitation rate of $300.5 \mathrm{~mm} /$ year, an average outflow rate of $5.1 \mathrm{~mm} /$ year, and an average net-infiltration rate of $8.6 \mathrm{~mm} /$ year over the net-infiltration model domain. Estimated net-infiltration rates along the crest of Yucca Mountain are in the range of 20 to $50 \mathrm{~mm} /$ year. Within the repository area, maximum net-infiltration rates of between 100 and $500 \mathrm{~mm} /$ year occur in the active channel of Drill Hole Wash and for outcrop locations of permeable, nonwelded tuffs in the middle section of the west-facing slope of Solitario Canyon. Relatively high net-infiltration rates of 100 to $500 \mathrm{~mm} /$ year also occur at many steep side-slope locations in the northern part of the UZ flow model area. In contrast, net infiltration at upland locations with thin soils underlain by bedrock with low bulk hydraulic conductivity is less than $1 \mathrm{~mm} /$ year.

The results for the mean glacial-transition climate scenario, which were calculated as the arithmetic mean of the results for the lower and upper bound glacial-transition scenarios, include an average precipitation rate of $316.1 \mathrm{~mm} /$ year, an average snowfall depth of $45.5 \mathrm{~mm} / \mathrm{year}$, an average infiltrated surface-water run-on depth of $14.6 \mathrm{~mm} / \mathrm{year}$, an average outflow rate of $1.5 \mathrm{~mm} /$ year, and an average net-infiltration rate of $13.4 \mathrm{~mm} /$ year for the net-infiltration model domain. In comparison, net infiltration is estimated to be $2.2 \mathrm{~mm} /$ year for the lower bound glacial-transition scenario and $24.6 \mathrm{~mm} / \mathrm{year}$ for the upper bound glacial-transition scenario. The spatial distribution of estimated precipitation for the mean glacial-transition climate scenario indicates the reduced precipitation-elevation correlation specified in the model (relative to the present-day climate correlation), with a minimum precipitation rate of approximately $280 \mathrm{~mm} /$ year and a maximum rate of almost $400 \mathrm{~mm} /$ year.

Net-infiltration estimates for all lower and mean climate scenarios are in general agreement with independent recharge estimates for precipitation rates of less than approximately $350 \mathrm{~mm} / \mathrm{year}$. The net-infiltration estimates for the upper bound glacial-transition and monsoon climates are low relative to the Maxey-Eakin recharge estimates (Maxey and Eakin 1950 [DIRS 100598]) obtained for precipitation rates of 400 to $450 \mathrm{~mm} /$ year.

Although the paleoclimates are not identical to the estimated monsoon and glacial-transition future climates, results from the geochemistry analysis suggest that net-infiltration rates at Yucca Mountain are likely to be lower than the Maxey-Eakin recharge estimates for the higher elevation present-day analogs corresponding to the estimated average annual precipitation rates for the upper bound monsoon and glacial-transition future climates. Using the estimated duration of the present-day and future climate stages, the weighted average simulated net-infiltration rate for the next 10,000 years is $18 \mathrm{~mm} /$ year over the repository area and $16.4 \mathrm{~mm} /$ year over the area of the UZ flow model. These results indicate that the simulated net-infiltration rates are consistent with results obtained from chloride geochemistry analysis.

\subsection{LIMITATIONS AND UNCERTAINTIES}

Uncertainty in the precipitation and air-temperature characteristics of the estimated future climate stages were represented using lower and upper bound scenarios within each stage. Although a uniform distribution between the lower and upper bound monsoon and 
glacial-transition climate scenarios was assumed for the development of the mean monsoon and glacial-transition climate scenarios, the distribution of precipitation and air temperature characteristics between the upper and lower bound climate scenarios is not known. In addition to assumptions used in defining the daily climate input for the nine climate scenarios, an important source of uncertainty in the net-infiltration estimates for all climate scenarios is the assumptions used in defining root-zone model coefficients. Other sources of model uncertainty include input parameters such as bedrock hydraulic conductivity, soil depth, and soil hydrologic properties. A primary limitation of the model is that it cannot be used to extrapolate beyond the 10,000 years that was used for estimates of climate scenarios using analogue sites.

A more rigorous and physically based model of wind and terrain effects on snow redistribution and the snow pack energy balance was beyond the scope of this report.

Based on the sources of model uncertainty described above and throughout the document, the results presented in this report cannot be interpreted as being exact, but instead, should be interpreted as a single realization of an output distribution that has not yet been fully quantified. Furthermore, based on knowledge of the sources of model uncertainty, the output distribution obtained from multiple stochastic realizations would define a relatively wide output distribution, as shown in the report Analysis of Infiltration Uncertainty (BSC 2003 [DIRS 165991], Figures 6-2, 6-3).

Table 8-2 describes the uncertainties involved in the conceptual model and the results of evaluation of the net-infiltration rate using INFIL in this report.

Table 8-2. Summary of Treatment of Uncertainties

\begin{tabular}{|c|c|}
\hline Uncertainties Identified & Related Technical Issues \\
\hline $\begin{array}{l}\text { Net-infiltration scenarios for a lower bound, a mean, and an upper bound } \\
\text { climate stage represent uncertainty in the characterization of daily climate } \\
\text { conditions for each climate stage, as well as potential climate variability } \\
\text { within each climate stage (Section 1). } \\
\text { The lower and upper bound scenarios are developed to account for } \\
\text { uncertainty and variability in the characteristics of precipitation and air } \\
\text { temperature for each estimated future climate stage (Section 6.9). } \\
\text { The nine developed net infiltration are not intended to be representative of } \\
\text { additional sources of model uncertainty (Section } 8.2 \text { ). }\end{array}$ & $\begin{array}{l}\text { Uncertainties from all sources in } \\
\text { calibrated properties. } \\
\text { Justification for the use of } \\
\text { analogue site temperature model } \\
\text { and the use of evapotranspiration } \\
\text { model. }\end{array}$ \\
\hline $\begin{array}{l}\text { Uncertainty in model inputs was not incorporated into the results } \\
\text { developed in this analysis/model report (Section 6.2.2). } \\
\text { Sources of uncertainty in the net-infiltration estimates for all climate } \\
\text { scenarios are precipitation, potential evapotranspiration (climate } \\
\text { dependent) and root-zone model coefficients, bedrock hydraulic } \\
\text { conductivity, soil depth, and soil hydrologic properties (not necessarily } \\
\text { climate dependent) (Section 8.2). }\end{array}$ & $\begin{array}{l}\text { Uncertainties from all sources in } \\
\text { calibrated properties. }\end{array}$ \\
\hline $\begin{array}{l}\text { Method of model comparison used in this report provides a qualitative } \\
\text { assessment of modeling results, and it does not quantify the model } \\
\text { uncertainty (due, in part, to the unknown accuracy of the independent } \\
\text { results). A comparison with independent results does not necessarily } \\
\text { validate (or invalidate) the accuracy of the model in representing the } \\
\text { physical processes developed in the conceptual model (Subsection 6.3.4). }\end{array}$ & $\begin{array}{l}\text { Use of calibrated properties from } \\
\text { modern climate to forecast flow for } \\
\text { future climate conditions. }\end{array}$ \\
\hline
\end{tabular}


Table 8-2. Summary of Treatment of Uncertainties (Continued)

\begin{tabular}{|l|l|}
\hline \multicolumn{1}{|c|}{ Uncertainties Identified } & \multicolumn{1}{c|}{ Related Technical Issues } \\
\hline $\begin{array}{l}\text { Net infiltration is simulated using the climate input developed from the } \\
\text { records at each analogue site, and the results are averaged to obtain an } \\
\text { estimate of net infiltration for a given climate scenario (Section 6.9.1). }\end{array}$ & $\begin{array}{l}\text { Justification for the use of } \\
\text { analogue site temperature model } \\
\text { and the use of evapotranspiration } \\
\text { model. }\end{array}$ \\
\hline $\begin{array}{l}\text { The fact that UZ processes are non-linear is not relevant to the concept of } \\
\text { reducing uncertainty in model results. (Section 6.9.3). }\end{array}$ & $\begin{array}{l}\text { Nonlinear Richards' equation vs. } \\
\text { water-balance plug glow model } \\
\text { over the repository where there is } \\
\text { thin soil. }\end{array}$ \\
\hline $\begin{array}{l}\text { Although a uniform distribution between the lower and upper bound } \\
\text { monsoon and glacial-transition climate scenarios was assumed at the time } \\
\text { of this analysis for the development of the mean monsoon and glacial- } \\
\text { transition climate scenarios, the distribution of precipitation and air } \\
\text { temperature characteristics between the upper and lower bound climate } \\
\text { scenarios is not known (Section 8.2). }\end{array}$ & $\begin{array}{l}\text { Justification for the use of } \\
\text { analogue site temperature model } \\
\text { and the use of evapotranspiration } \\
\text { model. }\end{array}$ \\
$\begin{array}{l}\text { The mean scenario was developed using an arithmetic mean without a } \\
\text { distribution, so that a method to evaluate the uncertainty in the developed } \\
\text { mean climate scenario was required. }\end{array}$ & \begin{tabular}{l} 
\\
\hline $\begin{array}{l}\text { Analysis of model sensitivity to uncertainty in input parameters and the } \\
\text { impact of parameter accuracy on model results was not complete at the } \\
\text { time of this analysis (Section 8.2). }\end{array}$
\end{tabular} \\
\hline $\begin{array}{l}\text { The results presented in this report cannot be interpreted as being exact } \\
\text { but instead should be interpreted as a single realization of an output } \\
\text { distribution that has not yet been fully quantified. Potential users of the } \\
\text { results presented in this report need to be fully aware that the level of } \\
\text { uncertainty associated with these results is relatively high and this must be } \\
\text { considered in any application of these results (Section 8.2). }\end{array}$ & $\begin{array}{l}\text { Uncertainties from all sources in } \\
\text { calibrated properties. }\end{array}$ \\
\hline
\end{tabular}

Model uncertainty is addressed using parameter input distributions in the net-infiltration model uncertainty analysis (BSC 2003 [DIRS 165991]). Input distributions were developed for 12 selected parameters (selected as being potentially significant) from those included in the model control file. The parameters included in the model control file are discussed in Section 6.3.3. The uncertainty report (BSC 2003 [DIRS 165991]) should be consulted for complete documentation of these parameters and the assigned uncertainty distributions. The analysis is summarized below.

A rigorous sensitivity analysis for net infiltration was addressed in Analysis of Infiltration Uncertainty (BSC 2003 [DIRS 165991]) using 100 realizations (vectors) of a selected set of 12 uncertain input parameters for the glacial-transition climate stage considered in TSPA. The analysis resulted in a distribution of spatially averaged infiltration rates for the glacialtransition climate stage over a region approximating what is referred to as the loaded repository footprint. A sensitivity analysis was performed using the results of the glacial-transition climate to examine the importance of the sampled (uncertain) input parameters used for the uncertainty analysis. A histogram of average annual infiltration for the glacial-transition climate scenario is shown in Figure 6-5 in Analysis of Infiltration Uncertainty (BSC 2003 [DIRS 165991]). The four input parameters that were found to have significant effects on the infiltration rate uncertainty are soil depth, precipitation, potential evapotranspiration, and bulk bedrock saturated hydraulic conductivity. These results and levels of uncertainty are consistent with the conceptual model of net infiltration presented in this report. 
The results from the 100 realizations (without 'contingency' area) include a mean net-infiltration rate of $27.0 \mathrm{~mm} /$ year, a median value of $20.0 \mathrm{~mm} /$ year, and a standard deviation of $17.7 \mathrm{~mm} /$ year (BSC 2003 [DIRS 165991]). These results are consistent with the results presented in Table 6-19 for estimated net-infiltration rates over the area of the repository. The coefficient of variation for the results obtained from the uncertainty analysis is much higher than the apparent coefficient of variation implied by the results obtained for the upper and lower bound climate scenarios. However, this is not an inconsistency because the net-infiltration estimates presented in this model report are only intended to be representative of uncertainty and variability in terms of climate input and, to a lesser degree, vegetation characteristics. The upper and lower bound net-infiltration estimates (in this report) do not necessarily include additional sources of model uncertainty, such as uncertainty in soil and bedrock properties.

The skewed output distribution obtained in the uncertainty analysis indicates a potential inconsistency with the uniform distributions assumed in this model report for developing the results for the mean monsoon and glacial-transition climate scenarios. As discussed in Section 6, the assumption of uniform distributions was preliminary because the results from the uncertainty analysis were not available at the time that the net-infiltration estimates were required for the TSPA schedule. The distributions of the net-infiltration rates in the uncertainty analysis (BSC 2003 [DIRS 165991]) were used to calculate weighting coefficients that are applied to the net-infiltration maps for the three climate scenarios in each climate stage of the simulations for TSPA. The weighting factors were determined to be $0.24,0.41$, and 0.35 (repository footprint without contingency area) for the lower bound, mean, and upper bound climate scenarios in each climate stage (BSC 2003 [DIRS 165991], DTN: SN0308T0503100.008). A general conclusion that can be made is that the additional sources of model uncertainty, in particular, soil and bedrock properties, tend to increase rather than decrease uncertainty in net-infiltration estimates.

\subsection{HOW THE ACCEPTANCE CRITERIA ARE ADDRESSED}

The following information describes how this model report addresses the acceptance criteria in the Yucca Mountain Review Plan (NRC 2003 [DIRS 163274], Section 2.2.1.3.5.3). Only those acceptance criteria that are applicable to this report (Section 4.2) are discussed. In most cases, the applicable acceptance criteria are not addressed solely by this report; rather, the acceptance criteria are fully addressed when this report is considered in conjunction with other analysis and model reports that describe infiltration in the UZ. Where a subcriterion includes several components, only some of those components may be addressed. How these components are addressed is summarized below.

\section{Acceptance Criteria from Section 2.2.1.3.5, Climate and Infiltration.}

\section{Acceptance Criterion 1: System Description and Model Integration Are Adequate.}

Subcriterion (1): The model described by this report adequately incorporates Yucca Mountain physical phenomena, and couplings, and uses consistent and appropriate assumptions from reports and models involving long term climate and site characteristics (Sections 6.5 through 6.9). 
Subcriterion (2): The aspects of geology, hydrology, physical phenomena, and couplings, that may affect climate and net infiltration such as topographic parameters, soil depth, bedrock geometry, bedrock hydraulic conductivity, surface-water flow-routing parameters, root-zone model parameters, and daily climate parameters are adequately considered in Sections 6.2 through 6.11. Conditions and assumptions identified in Section 5 are consistently applied throughout this model and downstream model reports.

Subcriterion (3): The assumptions, technical bases, data, and models described in this report are appropriate and consistent with downstream model reports applying the net-infiltration results to flow in the UZ and SZ. Infiltration as a function of climate scenario is used as boundary conditions for some UZ model reports. The descriptions and technical bases noted in Sections 6.1 through 6.11 provide transparent and traceable support for the abstraction of net-infiltration and consistently apply the results of climate projections.

Subcriterion (5): Sections 6.4.2 and 6.5 through 6.7 describe the temporal considerations of climatic conditions (including daily precipitation and average daily air temperature) and spatial variabilities (terrain, soil and vegetation) that are input to the model. Stochastic representations of precipitation and daily input are used to simulate infiltration that occurs in particular temporal and spatial patterns.

Subcriterion (6): Parameters used in this model reflect appropriate average values for those parameters that are not likely to change over time (geological characteristics) and vary those parameters that would be expected to change (drainage characteristics, soil depth, vegetation type, precipitation amounts, temperature, etc.), (Sections 6.5 through 6.11). These parameters are appropriate for the model discretization as indicated by the calibration and validation processes described in Sections 6.8 and 7., respectively.

Subcriterion (8): This report was developed in accordance with the Quality Assurance Requirements and Description (QARD) (DOE 2004 [DIRS 171539]), which commits to NUREG-1297 (Altman et al. 1988 [DIRS 103597]) and NUREG-1298 (Altman et al. 1988 [DIRS 103750]). Moreover, compliance with the DOE procedures, which are designed to ensure compliance with the QARD, is verified by audits by quality assurance and other oversight activities. Accordingly, the guidance in NUREGs 1297 and 1298 has been followed as appropriate.

\section{Acceptance Criterion 2: Data Are Sufficient for Model Justification.}

Subcriterion (1): Section 6.9.1 describes the assumptions used for climate and hydrology as incorporated in this model. These values are adequately justified as they are derived from projections (BSC 2004 [DIRS 170002]). Sections 6.4 and 6.9 provide adequate and detailed descriptions on how the data were used, interpreted, and synthesized into parameters as applied by this model using upper-bound, median, and lower-bound ranges of climatic conditions for each of the three potential current and future climate stages.

Subcriterion (2): This model was calibrated by a manual process described in Section 6.8 involving adjusting model parameters (over 100 sets of model parameters were used) to reproduce present-day infiltration values within a predetermined range of accuracy. 
Present-day input information included site-specific climatic, surface, and subsurface information. Values compared were flux from neutron logging data and previous-model stream discharge data (Section 6.8.4).

Subcriterion (3): The effects of fracture properties, fracture distributions, matrix properties, heterogeneities, time-varying boundary conditions, evapotranspiration, depth of soil cover, and surface-water runoff and run-on are conservatively considered in Sections 6.4 through 6.6. An example of a conservative assumption is where the soil depth across the model domain was reduced by 50 percent (e.g., the maximum soil depth was reduced to $3 \mathrm{~m}$ from $6 \mathrm{~m}$ ), which adds conservatism to the model (Section 6.1.5). Therefore, net infiltration is not underestimated by this model.

Subcriterion (4): Uncertainty in the precipitation and air-temperature characteristics of future climate stages was represented through the upper and lower bound scenarios. Uncertainty in other parameters, as well as the predicted effects on their net infiltration, is developed in the uncertainty analysis (BSC 2003 [DIRS 165991]).

Subcriterion (5): Approved quality assurance procedures identified in the TWP (BSC 2004 [DIRS 169654], Section 4) have been used to conduct and document the activities described in this model report (Section 2).

Subcriterion (6): The current model represents reasonably complete conceptual and mathematical models of net infiltration because they have evolved from previous models as discussed in Section 6.8. The conceptual model is described in Section 6.1, its numerical representation in Section 6.2, and the modeling procedure, components, processes, and grid geometry in Sections 6.3, 6.4, and 6.5. The conceptual and mathematical models are consistent as discussed in Sections 6.1 through 6.5. The completeness of the current model is demonstrated by its calibration against site characteristics and comparison against previous model versions and other discarded models in Sections 6.8 and 7.

\section{Acceptance Criterion 3, Data Uncertainty is Characterized and Propagated Through the Model Abstraction.}

Subcriterion (1): Sources of data incorporated in the models are listed in Section 4.1. Parameter values, assumed ranges, probability distributions, and bounding assumptions for the model geometry, topographic parameters, root zone depth and layering, and climate assumptions are technically defensible and account for uncertainties as noted in Sections 6.5 through 6.11. This is because the values and assumptions are representative of the Yucca Mountain data, are chosen to represent a high estimate of net-infiltration, which therefore likely overestimates net infiltration, and are calibrated to present-day climate and infiltration measurements. Therefore, these values and assumptions do not result in an under-representation of the risk estimate.

Subcriterion (2): Adequate technical bases for parameter values, assumed ranges, probability distributions, and bounding assumptions for the model geometry, topographic parameters, root zone depth and layering, and climate assumptions are provided in Sections 6.5 through 6.11. 
Subcriterion (4): Section 6.9 describes how model parameters were adjusted for future wetter climates to represent an assumed increase in soil depth, root density, root zone depth, and vegetation cover.

Acceptance Criterion 4, Model Uncertainty is Characterized and Propagated Through the Model Abstraction.

Subcriterion (1): Alternative modeling approaches are represented in the previous models that were considered and either used or discarded due to over-conservatism of the approach (e.g. no generation of stream flow) or accuracy of results (Section 6.8). Results and limitations of alternative approaches are discussed in Section 6.8.

Subcriterion (3): Conceptual model uncertainty is consistent with available site characterization data (soil depth, bedrock hydraulic conductivity, and soil hydrologic properties), laboratory experiments (saturated hydraulic conductivity of the fracture fill material), field measurements, natural analogue information (chlorine mass balance estimates), and process-level modeling studies (climate change studies) as discussed in Sections 6.6 through 6.10 and 8. 


\section{INTENTIONALLY LEFT BLANK}




\section{INPUTS AND REFERENCES}

The following is a list of the references cited in this document. Column 2 represents the unique six digit numerical identifier (the Document Input Reference System number), which is placed in the text following the reference callout (e.g., BSC 2002 [DIRS 160819]). The purpose of these numbers is to assist in locating a specific reference. Within the reference list, multiple sources by the same author (e.g., BSC 2002) are sorted alphabetically by title.

\subsection{DOCUMENTS CITED}

Altman, W.D.; Donnelly, J.P.; and Kennedy, J.E. 1988. Peer Review for High-Level 103597 Nuclear Waste Repositories: Generic Technical Position. NUREG-1297. Washington, D.C.: U.S. Nuclear Regulatory Commission. TIC: 200651.

Altman, W.D.; Donnelly, J.P.; and Kennedy, J.E. 1988. Qualification of Existing 103750 Data for High-Level Nuclear Waste Repositories: Generic Technical Position. NUREG-1298. Washington, D.C.: U.S. Nuclear Regulatory Commission. TIC: 200652.

BSC 2003. Analysis of Infiltration Uncertainty. ANL-NBS-HS-000027 REV 01. 165991 Las Vegas, Nevada: Bechtel SAIC Company. ACC: DOC.20031030.0003.

BSC 2003. Total System Performance Assessment-License Application Methods and Approach. TDR-WIS-PA-000006 REV 00 ICN 01. Las Vegas, Nevada: Bechtel SAIC Company. ACC: DOC.20031215.0001.

BSC 2004. Calibrated Properties Model. MDL-NBS-HS-000003, Rev. 02.

169857 Las Vegas, Nevada: Bechtel SAIC Company.

BSC (Bechtel SAIC Company) 2004. Features, Events, and Processes in UZ Flow 170012 and Transport. ANL-NBS-MD-000001, Rev. 03. Las Vegas, Nevada: Bechtel SAIC Company.

BSC 2004. Future Climate Analysis. ANL-NBS-GS-000008 REV 01. Las Vegas, Nevada: Bechtel SAIC Company. ACC: DOC.20040908.0005.

BSC 2004. Q-List. 000-30R-MGR0-00500-000-000 REV 00. Las Vegas, Nevada: 168361 Bechtel SAIC Company. ACC: ENG.20040721.0007.

BSC 2004. Saturated Zone Site-Scale Flow Model. MDL-NBS-HS-000011, Rev. 02. Las Vegas, Nevada: Bechtel SAIC Company.

BSC 2004. Technical Work Plan for: Unsaturated Zone Flow Analysis and Model Report Integration. TWP-MGR-HS-000001 REV 00. Las Vegas, Nevada: Bechtel 169654 SAIC Company. ACC: DOC.20040701.0005. 
BSC 2004. Total System Performance Assessment (TSPA) Model/Analysis for the 168504

License Application. MDL-WIS-PA-000004, Rev. 00. Las Vegas, Nevada: Bechtel SAIC Company.

BSC 2004. UZ Flow Models and Submodels. MDL-NBS-HS-000006, Rev. 02.

169861

Las Vegas, Nevada: Bechtel SAIC Company.

BSC 2004. Yucca Mountain Site Description. TDR-CRW-GS-000001 REV 02

ICN 01. Two volumes. Las Vegas, Nevada: Bechtel SAIC Company.

ACC: DOC.20040504.0008; Replacement for 168845.

Buesch, D.C.; Spengler, R.W.; Moyer, T.C.; and Geslin, J.K. 1996. Proposed

100106

Stratigraphic Nomenclature and Macroscopic Identification of Lithostratigraphic Units of the Paintbrush Group Exposed at Yucca Mountain, Nevada. Open-File Report 94-469. Denver, Colorado: U.S. Geological Survey.

ACC: MOL.19970205.0061.

Campbell, G.S. 1977. An Introduction to Environmental Biophysics. New York,

124856

New York: Springer-Verlag. TIC: 238256.

Campbell, G.S. 1985. Soil Physics with BASIC Transport Models for Soil-Plant

Systems. Developments in Soil Science 14. Amsterdam, The Netherlands: Elsevier.

TIC: 214477.

Canori, G.F. and Leitner, M.M. 2003. Project Requirements Document.

166275

TER-MGR-MD-000001 REV 02. Las Vegas, Nevada: Bechtel SAIC Company.

ACC: DOC.20031222.0006.

Chu, M.S.Y, and Dyer, J.R. 2003. "Licensing, Design, and Construction of the

Yucca Mountain Repository.” The Bridge, 33, (3), 18-32. Washington, D.C.:

National Academy of Engineering. TIC: 256528. Copyright Requested

CRWMS (Civilian Radioactive Waste Management System) M\&O (Management and Operating Contractor) 1997. Unsaturated Zone Flow Model Expert Elicitation

Project. Las Vegas, Nevada: CRWMS M\&O. ACC: MOL.19971009.0582.

Day, W.C.; Potter, C.J.; Sweetkind, D.S.; Dickerson, R.P.; and San Juan, C.A. 1998.101557

Bedrock Geologic Map of the Central Block Area, Yucca Mountain, Nye County,

Nevada. Miscellaneous Investigations Series Map I-2601. Washington, D.C.: U.S.

Geological Survey. ACC: MOL.19980611.0339.

Dettinger, M.D. 1989. "Reconnaissance Estimates of Natural Recharge to Desert

105384

Basins in Nevada, U.S.A., by Using Chloride-Balance Calculations." Journal of

Hydrology, 106, 55-78. Amsterdam, The Netherlands: Elsevier. TIC: 236967. 
DOE (U.S. Department of Energy) 2001. Nevada Test Site, 2000 Waste

Management Monitoring Report Area 3 and Area 5 Radioactive Waste Management

Sites. DOE/NV/11718--582. Las Vegas, Nevada: U.S. Department of Energy,

National Nuclear Security Administration, Nevada Operations Office.

ACC: MOL.20040820.0136.

DOE 2004. Quality Assurance Requirements and Description. DOE/RW-0333P,

Rev. 16. Washington, D.C.: U.S. Department of Energy, Office of Civilian

Radioactive Waste Management. ACC: DOC.20040907.0002.

Flint, A.L. and Childs, S.W. 1984. "Physical Properties of Rock Fragments and

Their Effect on Available Water in Skeletal Soils." Chapter 10 of Erosion and

Productivity of Soils Containing Rock Fragments. SSSA Special Publication \#13.

Madison, Wisconsin: Soil Science Society of America. TIC: 247223.

Flint, A.L. and Childs, S.W. 1987. "Calculation of Solar Radiation in Mountainous

Terrain." Agricultural and Forest Meteorology, 40, (3), 233-249. Amsterdam,

The Netherlands: Elsevier. TIC: 225242.

Flint, A.L. and Childs, S.W. 1991. "Use of the Priestley-Taylor Evaporation

Equation for Soil Water Limited Conditions in a Small Forest Clearcut." Agricultural and Forest Meteorology, 56, (3-4), 247-260. Amsterdam, The Netherlands: Elsevier. TIC: 241865.

Flint, A.L.; Flint, L.E.; Bodvarsson, G.S.; Kwicklis, E.M.; and Fabryka-Martin, J.

2001. Evolution of the Conceptual Model of Unsaturated Zone Hydrology at Yucca

Mountain, Nevada. Journal of Hydrology, 247, ([1-2]), 1-30. [New York,

New York]: Elsevier. TIC: 250932.

Flint, A.L.; Flint, L.E.; Kwicklis, E.M.; Fabryka-Martin, J.T.; and Bodvarsson, G.S.

157411 2002. "Estimating Recharge at Yucca Mountain, Nevada, USA: Comparison of Methods.” Hydrogeology Journal, 10, (1), 180-204. Berlin, Germany:

Springer-Verlag. TIC: 251765.

Flint, A.L.; Hevesi, J.A.; and Flint, L.E. 1996. Conceptual and Numerical Model of 100147 Infiltration for the Yucca Mountain Area, Nevada. Milestone 3GUI623M. Denver, Colorado: U.S. Geological Survey. ACC: MOL.19970409.0087.

Flint, L.E. 1998. Characterization of Hydrogeologic Units Using Matrix Properties, 100033 Yucca Mountain, Nevada. Water-Resources Investigations Report 97-4243. Denver, Colorado: U.S. Geological Survey. ACC: MOL.19980429.0512.

Flint, L.E. and Flint, A.L. 1995. Shallow Infiltration Processes at Yucca Mountain, Nevada-Neutron Logging Data 1984-93. Water-Resources Investigations Report 95-4035. Denver, Colorado: U.S. Geological Survey. ACC: MOL.19960924.0577. 
Freeze, R.A. and Cherry, J.A. 1979. Groundwater. Englewood Cliffs, New Jersey: 101173 Prentice-Hall. TIC: 217571.

French, R.H. 1983. "Precipitation in Southern Nevada.” Journal of Hydraulic 125313 Engineering, 109, (7), 1023-1036. New York, New York: American Society of Civil Engineers. TIC: 238300.

Hanks, R.J.; Gardner, H.R.; and Fairbourn, M.L. 1967. "Evaporation of Water from Soils as Influenced by Drying with Wind or Radiation." Soil Science Society of America Proceedings, 31, (5), 593-598. Madison, Wisconsin: Soil Science Society of America. TIC: 256519.

Harrill, J.R. and Prudic, D.E. 1998. Aquifer Systems in the Great Basin Region of 149377 Nevada, Utah, and Adjacent States - Summary Report. Professional Paper 1409-A. Denver, Colorado: U.S. Geological Survey. TIC: 247432.

Hatton, T. 1998. Catchment Scale Recharge Modelling. Part 4 of The Basics of Recharge and Discharge. Zhang, L., ed. Collingwood, Victoria, Australia: CSIRO Publishing. TIC: 247711.

Hevesi, J.A. and Flint, A.L. 1998. "Geostatistical Estimates of Future Recharge for 125323 the Death Valley Region." High-Level Radioactive Waste Management, Proceedings of the Eighth International Conference, Las Vegas, Nevada, May 11-14, 1998. Pages 173-177. La Grange Park, Illinois: American Nuclear Society. TIC: 237082.

Hevesi, J.A.; Ambos, D.S.; and Flint, A.L. 1994. "A Preliminary Characterization of 125315 the Spatial Variability of Precipitation at Yucca Mountain, Nevada." High Level Radioactive Waste Management, Proceedings of the Fifth Annual International Conference, Las Vegas, Nevada, May 22-26, 1994. 4, 2520-2529. La Grange Park, Illinois: American Nuclear Society. TIC: 210984.

Hevesi, J.A.; Flint, A.L.; and Flint, L.E. 1994. "Verification of a 1-Dimensional 100582 Model for Predicting Shallow Infiltration at Yucca Mountain." High Level Radioactive Waste Management, Proceedings of the Fifth Annual International Conference, Las Vegas, Nevada, May 22-26, 1994. 4, 2323-2332. La Grange Park, Illinois: American Nuclear Society. TIC: 210984.

Hevesi, J.A.; Flint, A.L.; and Istok, J.D. 1992. "Precipitation Estimation in 116809 Mountainous Terrain Using Multivariate Geostatistics. Part II: Isohyetal Maps." Journal of Applied Meteorology, 31, (7), 677-688. Boston, Massachusetts: American Meteorological Society. TIC: 225248.

Jury, W.A.; Gardner, W.R.; and Gardner, W.H. 1991. Soil Physics. 5th Edition. New York, New York: John Wiley \& Sons. TIC: 241000. 
Kwicklis, E.M.; Thamir, F.; Healy, R.W.; and Hampson, D. 1998. Numerical 102121

Simulation of Air- and Water-Flow Experiments in a Block of Variably Saturated, Fractured Tuff from Yucca Mountain, Nevada. Water-Resources Investigations Report 97-4274. Denver, Colorado: U.S. Geological Survey.

ACC: MOL.19981215.0103.

Lichty, R.W. and McKinley, P.W. 1995. Estimates of Ground-Water Recharge 100589

Rates for Two Small Basins in Central Nevada. Water-Resources Investigations Report 94-4104. Denver, Colorado: U.S. Geological Survey. ACC: MOL.19960924.0524.

Liu, H-H.; Haukwa, C.B.; Ahlers, C.F.; Bodvarsson, G.S.; Flint, A.L.; and Guertal, 162470 W.B. 2003. "Modeling Flow and Transport in Unsaturated Fractured Rock: An Evaluation of the Continuum Approach." Journal of Contaminant Hydrology, 62-63, 173-188. New York, New York: Elsevier. TIC: 254205.

Maidment, D.R., ed. 1993. Handbook of Hydrology. New York, New York:

125317 McGraw-Hill. TIC: 236568.

Maxey, G.B. and Eakin, T.E. 1950. Ground Water in White River Valley, White 100598 Pine, Nye, and Lincoln Counties, Nevada. Water Resources Bulletin No. 8. Carson City, Nevada: State of Nevada, Office of the State Engineer. TIC: 216819.

McNaughton, K.G. and Spriggs, T.W. 1989. "An Evaluation of the Priestley and 117096 Taylor Equation and the Complementary Relationship Using Results from a Mixed-Layer Model of the Convective Boundary Layer.” Estimation of Areal Evapotranspiration, Proceedings of an International Workshop Held During the XIXth General Assembly of the International Union of Geodesy and Geophysics at Vancouver, British Columbia, Canada, 9-22 August, 1987. 177, 89-104. Wallingford, United Kingdom: International Association of Hydrological Sciences. TIC: 245925.

Nichols, W.D. 1987. Geohydrology of the Unsaturated Zone at the Burial Site for 101273 Low-Level Radioactive Waste Near Beatty, Nye County, Nevada. Water-Supply Paper 2312. Denver, Colorado: U.S. Geological Survey. ACC: NNA.19920428.0023.

NRC (U.S. Nuclear Regulatory Commission) 2003. Yucca Mountain Review Plan, 163274 Final Report. NUREG-1804, Rev. 2. Washington, D.C.: U.S. Nuclear Regulatory Commission, Office of Nuclear Material Safety and Safeguards. TIC: 254568.

Priestley, C.H.B. and Taylor, R.J. 1972. "On the Assessment of Surface Heat Flux and Evaporation Using Large-Scale Parameters." Monthly Weather Review, 100, (2), 81-92. Washington, D.C.: U.S. Department of Commerce. TIC: 235941. 
Savard, C.S. 1995. Selected Hydrologic Data from Fortymile Wash in the Yucca

101289

Mountain Area, Nevada, Water Year 1992. Open-File Report 94-317. Denver,

Colorado: U.S. Geological Survey. ACC: MOL.19941208.0002.

Sawyer, D.A.; Wahl, R.R.; Cole, J.C.; Minor, S.A.; Laczniak, R.J.; Warren, R.G.;

104580

Engle, C.M.; and Vega, R.G. 1995. Preliminary Digital Geological Map Database of

the Nevada Test Site Area, Nevada. Open-File Report 95-0567. Denver, Colorado:

U.S. Geological Survey. TIC: 232986.

Scott, R.B. and Bonk, J. 1984. Preliminary Geologic Map of Yucca Mountain, Nye

104181

County, Nevada, with Geologic Sections. Open-File Report 84-494. Denver,

Colorado: U.S. Geological Survey. ACC: HQS.19880517.1443.

Shevenell, L. 1996. Statewide Potential Evapotranspiration Maps for Nevada.

171280

Report 48. Reno, Nevada: Nevada Bureau of Mines and Geology.

ACC: MOL.20040820.0138.

Thompson, R.S.; Anderson, K.H.; and Bartlein, P.J. 1999. Quantitative

109470

Paleoclimatic Reconstructions from Late Pleistocene Plant Macrofossils of the Yucca Mountain Region. Open-File Report 99-338. Denver, Colorado: U.S. Geological

Survey. ACC: MOL.19991015.0296.

USGS (U.S. Geological Survey) 2001. INFIL V2.0, Validation Test Report.

171197

SDN: 10307-VTR-2.0-00. Las Vegas, Nevada: U.S. Department of Energy,

Yucca Mountain Site Characterization Office. ACC: MOL.20011023.0171.

USGS 2003. Simulation of Net Infiltration for Modern and Potential Future

166518

Climates. ANL-NBS-HS-000032 REV 00 ICN 02 Errata 002. Denver, Colorado:

U.S. Geological Survey. ACC: MOL.20011119.0334; DOC.20031014.0004;

DOC.20031015.0001.

Winograd, I.J. 1981. "Radioactive Waste Disposal in Thick Unsaturated Zones."

100019

Science, 212, (4502), 1457-1464. Washington, D.C.: American Association for the Advancement of Science. TIC: 217258.

Winograd, I.J. and Thordarson, W. 1975. Hydrogeologic and Hydrochemical

Framework, South-Central Great Basin, Nevada-California, with Special Reference to the Nevada Test Site. Geological Survey Professional Paper 712-C. Washington, D.C.: United States Government Printing Office. ACC: NNA.19870406.0201.

\subsection{CODES, STANDARDS, REGULATIONS, AND PROCEDURES}

10 CFR 63. Energy: Disposal of High-Level Radioactive Wastes in a Geologic

Repository at Yucca Mountain, Nevada. Readily available. 
AP-2.22Q, Rev. 1, ICN 1. Classification Analyses and Maintenance of the Q-List. Washington, D.C.: U.S. Department of Energy, Office of Civilian Radioactive Waste Management. ACC: DOC.20040714.0002.

AP-2.27Q, Rev. 1, ICN 4. Planning for Science Activities. Washington, D.C.: U.S. Department of Energy, Office of Civilian Radioactive Waste Management.

ACC: DOC.20040610.0006.

AP-3.15Q, Rev. 4, ICN 5. Managing Technical Product Inputs. Washington, D.C.: U.S. Department of Energy, Office of Civilian Radioactive Waste Management. ACC: DOC.20040812.0004.

AP-SI.1Q, Rev. 2, ICN 4. Software Management. Washington, D.C.: U.S. Department of Energy, Office of Civilian Radioactive Waste Management. ACC: MOL.20000223.0508.

AP-SIII.2Q, Rev. 1, ICN 2. Qualification of Unqualified Data. Washington, D.C.: U.S. Department of Energy, Office of Civilian Radioactive Waste Management. ACC: DOC.20040127.0008.

AP-SIII.10Q, Rev. 2, ICN 7. Models. Washington, D.C.: U.S. Department of Energy, Office of Civilian Radioactive Waste Management.

ACC: DOC.20040920.0002.

AP-SV.1Q, Rev. 1, ICN 1. Control of Electronic Management of Information. Washington, D.C.: U.S. Department of Energy, Office of Civilian Radioactive Waste Management. ACC: DOC.20040308.0001.

LP-SI.11Q-BSC, Rev. 0, ICN 1. Software Management. Washington, D.C.: U.S. Department of Energy, Office of Civilian Radioactive Waste Management. ACC: DOC.20041005.0008.

LP-SI.14Q-BSC, Rev. 0, ICN 1. Independent Verification and Validation of Legacy Code. Washington, D.C.: U.S. Department of Energy, Office of Civilian Radioactive Waste Management. ACC: DOC.20040805.0006.

\subsection{SOURCE DATA, LISTED BY DATA TRACKING NUMBER}

GS000100001221.001. EarthInfo, Inc. Western US Meteorologic Station Weather 146816 Data - NCDC Summary of Day (West 1) and NCDC Summary of Day (West 2). Submittal date: 01/25/2000.

GS000200001221.002. Precipitation Data for Nevada Test Site, 1957-1994, from Air 146277 Resources Laboratory, from National Oceanographic and Atmospheric Administration (NOAA) Precipitation Data. Submittal date: 02/29/2000. 
GS000200001221.003. NAD27 Datum of USGS Digital Elevation Model from 146278 Topopah Spring West and Busted Butte 7.5 Minute Quadrangles. Submittal date: $02 / 18 / 2000$.

GS000208312111.001. Precipitation Data for May 3, 1989 through September 30, 147245 1994 from Weather Stations 1 and 3, Yucca Mountain, Nevada. Submittal date: $02 / 22 / 2000$.

GS000208312111.002. Air Temperature Data for Calendar Year 1992 from Weather 147250 Station 1 (Wx-1), Yucca Mountain, Nevada. Submittal date: 02/25/2000.

GS000208312111.003. Precipitation Data for July 17, 1987 through May 2, 1989 from Weather Stations 1 and 3, Yucca Mountain, Nevada. Submittal date: $03 / 01 / 2000$.

GS000300001221.009. Evapotranspiration Coefficients. Submittal 147228 date: $03 / 02 / 2000$.

GS000300001221.010. Preliminary Digital Geologic Map Database of the Nevada 147833 Test Site Area, Nevada by Sawyer and Wahl, 1995. Submittal date: 03/21/2000.

GS000308315121.003. Meteorological Stations Selected to Represent Future 151139 Climate States at Yucca Mountain, Nevada. Submittal date: 03/14/2000.

GS000408312231.003. Relative Humidity Calculated Porosity Measurements on Samples from Borehole USW SD-9 Used for Saturated Hydraulic Conductivity. Submittal date: 04/10/2000.

GS000408312231.004. Data for Core Dried in RH Oven and 105C Oven for USW 149582 UZ-N31, UZ-N32, UZ-N33, UZ-N34, UZ-N35, UZ-N38, UZ-N58, UZ-N59, UE-25 UZN\#63 and USW UZ-N64; Data for Core Dried in 105C Oven Only for USW UZ-N11, UZ-N15, UZ-N16, UZ-N17, UZ-N27, UZ-N36 and UZ-N37. Submittal date: $04 / 28 / 2000$.

GS000508312231.005. UE-25 UZ\#16 Pycnometer Data. Submittal 153236 date: $05 / 03 / 2000$.

GS000508312231.006. Physical Properties and Water Content from Borehole USW 153237 NRG-6, 3/19/94 to 3/27/95. Submittal date: 05/23/2000.

GS000508312231.007. Physical Properties of Core Samples from Borehole USW UZ-14, from 03/09/94 to 07/11/94. Submittal date: 07/11/2002. 
GS031208312211.001. FY95 Laboratory Measurements of Physical Properties of 171543

Surficial Material at Yucca Mountain, Part II. Submittal date: 01/11/2004.

GS920508312231.012. USW UZ-N54 and USW UZ-N55 Core Analysis: Bulk 109001 Density, Porosity, Particle Density and In Situ Saturation for Core Dried in 105C Oven. Submittal date: 05/14/1992.

GS930108312231.006. USW UZ-N53 Core Analysis: Bulk Density, Porosity, Particle Density, and In-Situ Saturation for Core Dried in 105C Oven. Submittal date: 10/05/1992.

GS940408312231.004. Core Analysis of Bulk Density, Porosity, Particle Density, 109000 and In-Situ Saturation for 3 Neutron Boreholes, USW UZ-N57, UZ-N61, and UZ-N62. Submittal date: 04/01/1994.

GS940508312231.006. Core Analysis of Bulk Density, Porosity, Particle Density 107149 and In Situ Saturation for Borehole UE-25 UZ\#16. Submittal date: 05/04/1994.

GS940708312212.011. Volumetric Water Content from Neutron Moisture Meter 107136 Counts for 99 Boreholes from 5/3/89 or from the Time They Were Drilled Until 12/31/93. Submittal date: 07/13/1994.

GS941208312121.001. Surface-Water Discharge Data for the Yucca Mountain Area, 107374 Southern Nevada and Southern California, 1994 Water Year. Submittal date: $11 / 30 / 1994$.

GS941208312212.017. Subsurface Water Content at Yucca Mountain, 107137 Nevada - Neutron Logging Data for 1/1/94 thru FY94. Submittal date: 12/02/1994.

GS950308312231.002. Laboratory Measurements of Core from USW SD-12 and 108990 Radial Boreholes. Submittal date: 03/02/1995.

GS950308312231.003. UE-25 UZ\#16 Pycnometer Data. Submittal 149374 date: $03 / 06 / 1995$.

GS950408312231.004. Physical Properties and Water Potentials of Core from 108986 Borehole USW SD-9. Submittal date: 03/01/1995.

GS950608312231.008. Moisture Retention Data from Boreholes USW UZ-N27 and 144662 UE-25 UZ\#16. Submittal date: 06/06/1995.

GS950708312211.002. FY94 and FY95 Laboratory Measurements of Physical 146874 Properties of Surficial Materials at Yucca Mountain, Nevada.

Submittal date: 07/18/1995.

GS950708312211.003. Fracture/Fault Properties for Fast Pathways Model. 146873 Submittal date: 07/24/1995. 
GS950808312212.001. Volumetric Water Content Calculated from Field Calibration 107139 Equations Using Neutron Counts from 97 Boreholes at Yucca Mountain from 1 Oct 94 to 31 May 95. Submittal date: 08/01/1995.

GS951108312231.009. Physical Properties, Water Content, and Water Potential for 108984 Borehole USW SD-7. Submittal date: 09/26/1995.

GS951108312231.010. Physical Properties and Water Content for Borehole USW NRG-7/7A. Submittal date: 09/26/1995.

GS951108312231.011. Physical Properties, Water Content, and Water Potential for 108992 Borehole USW UZ-7A. Submittal date: 09/26/1995.

GS960108312111.001. Geostatistical Model for Estimating Precipitation and 107131 Recharge in the Yucca Mountain Region, Nevada - California. Submittal date: $01 / 23 / 1996$.

GS960108312211.002. Gravimetric and Volumetric Water Content and Rock 149478 Fragment Content of 31 Selected Sites at Yucca Mountain, NV: FY95 Laboratory Measurements of Physical Properties of Surficial Material at Yucca Mountain, Part III. Submittal date: 01/08/1996.

GS960108312212.001. Volumetric Water Content Calculated from Field Calibration 107141 Equations Using Neutron Counts from 97 Boreholes at Yucca Mountain. Submittal date: $01 / 31 / 1996$.

GS960508312212.007. Estimated Distribution of Geomorphic Surfaces and Depth to 124829 Bedrock for the Southern Half of the Topopah Spring NW 7.5 Minute Quadrangle and the Entire Busted Butte 7.5 Minute Quadrangle. Submittal date: 04/21/1996.

GS960508312212.008. Estimated Annual Shallow Infiltration at 84 Neutron Access Boreholes at Yucca Mountain, Nevada During the Water Years 1990 to 1995. Submittal date: 05/17/1996.

GS960808312231.001. Water Permeability and Relative Humidity Calculated 108998 Porosity for Boreholes UE-25 UZ-16 and USW UZ-N27.

Submittal date: 08/28/1996.

GS960808312231.002. Relative Humidity Calculated Porosity Measurements on 108988 Samples from Borehole USW SD-9 Used for Saturated Hydraulic Conductivity. Submittal date: 08/28/1996.

GS960808312231.003. Moisture Retention Data for Samples from Boreholes USW 147590 SD-7, USW SD-9, USW SD-12 and UE-25 UZ\#16. Submittal date: 08/30/1996. 
GS960808312231.004. Physical Properties, Water Content and Water Potential for 108985 Samples from Lower Depths in Boreholes USW SD- 7 and USW SD-12.

Submittal date: 08/30/1996.

GS960808312231.005. Water Permeability and Relative Humidity Calculated 108995 Porosity for Samples from Boreholes USW SD-7, USW SD-9, USW SD-12 and USW UZ-14. Submittal date: 08/30/1996.

GS960908312121.001. Surface-Water Discharge Data for the Yucca Mountain Area, 107375 Southern Nevada and Southern California, 1995 Water Year.

Submittal date: 10/10/1996.

GS960908312211.003. Conceptual and Numerical Model of Infiltration at Yucca 103775 Mountain, Nevada. Submittal date: 09/12/1996.

GS960908312211.004. Heat Dissipation Probe Data: Bleach Bone Ridge 3/95 - 11/95. Submittal date: 09/19/1996.

GS970108312111.001. FY96 Site Meteorology Data: Relative Humidity, Temperature, Wind Speed, Wind Direction, Net Solar Radiation and Barometric Pressure from Two Weather Stations in the Yucca Mountain Area, Oct. 1 - Dec. 3, 1995. Submittal date: 01/15/1997.

GS971208314221.003. Revised Bedrock Geologic Map of the Central Block Area, Yucca Mountain, Nevada. Submittal date: 12/30/1997.

GS990408312231.001. Saturated Hydraulic Conductivity of Core from SD-9, 2/27 - 3/27/95. Submittal date: 04/27/1999.

MO0003COV00095.000. Coverage: Scotbons. Submittal date: 03/01/2000. 146848

MO0109HYMXPROP.001. Matrix Hydrologic Properties Data.

Submittal date: 09/17/2001.

MO0407SEPFEPLA.000. LA FEP List. Submittal date: 07/20/2004. 170760

SN0409T0507804.005. Input Permeabilities For The Submodel Denoted H104. 171747

Submittal date: 09/22/2004.

SNSAND96081900.000. Flow Calculations for Yucca Mountain Groundwater Travel Time (GWTT-95). Submittal date: 12/17/1996.

\subsection{OUTPUT DATA, LISTED BY DATA TRACKING NUMBER}

GS000308311221.005. Net Infiltration Modeling Results for 3 Climate Scenarios FY99. Submittal date: 03/01/2000. 
GS000308311221.011. Template Files for Uncertainty Analyses. Submittal date: 03/13/2000.

GS000308311221.010. Preliminary Developed Daily Climate Data From Tule Lake, California Used for Infiltration Uncertainty Analysis. Submittal date: 03/07/2000.

GS000399991221.002. Rainfall Runoff/Run-on 1999 Simulations. Submittal date: 03/10/2000.

GS000208311221.001. Yucca Mountain 1980-1995 Developed Daily Precipitation Record. Submittal date: 02/28/2000.

GS000208311221.002. Preliminary Developed Daily Climate Data for Potential Future Monsoon and Glacial-Transition Climates Using Records from Selected Analog Sites. Submittal date: 02/28/2000.

GS000308311221.004. Preliminary Geospatial Input Data for Infil V2.0 FY99. Submittal date: 03/01/2000.

GS000308311221.006. Merged USGS Digital Elevation Model from Topopah Spring West and Busted Butte 7.5' DEMS. Submittal date: 03/02/2000.

SN0407T0507804.001. Model Control Files For INFIL V A_2.A1, Submodel Denoted H104 Submittal date: 07/19/2004.

SN0408T0507804.002. Model Control Files Of Streamflow Calibration For INFIL V 2.0, Submodel Denoted H104 Submittal date: 08/09/2004.

SN0408T0507804.003. Output Flux Files Calculated Using INFIL V A_2.A1, Submodel Denoted H104. Submittal date: 08/17/2004.

SN0408T0507804.004. Output Re-Calibration Files Calculated Using INFIL V A_2.A1 And INFIL V 2.0 (Daily Output Stream Flow Calibration Only) For The (2004) Submodel Denoted H104 Submittal date: 08/18/2004.

\subsection{SOFTWARE CODES}

SNL (Sandia National Laboratories) 2001. Software Code: Infil. VA_2.a1. DEC 147608 Alpha, VMS AXP V7.2-1. 10253-A_2.a1-00.

USGS (U.S. Geological Survey) 2001. INFIL V2.0, Validation Test Report. SDN: 10307-VTR-2.0-00. Las Vegas, Nevada: U.S. Department of Energy, Yucca Mountain Site Characterization Office. ACC: MOL.20011023.0171.

USGS 1996. Software Code: MARKOV. V1.0. 10142-1.0-00.

USGS 1996. Software Code: PPTSIM. V1.0. 10143-1.0-00.

USGS 2001. Software Code: INFIL. V2.0. PC, Windows NT 4.0. 10307-2.0-00. 
APPENDIX A

YUCCA MOUNTAIN 1980-95 DEVELOPED DAILY PRECIPITATION RECORD 


\section{A1. STATEMENT OF INTENDED USE FOR THE DATA}

The purpose of these data is to provide a temporal record of precipitation at one point on Yucca Mountain for the time period 1980 through 1995. These data represent a point near the center of Yucca Mountain approximately $1400 \mathrm{~m}$ in elevation and will be used to spatially distribute precipitation over the site area using correlations with elevation in order to (1) calibrate the net infiltration model, and (2) develop net infiltration results for the modern climate scenarios, which are used as input for UZ ground-water flow and transport models for TSPA.

\section{A2. GENERAL INFORMATION PERTAINING TO THE DATA SET}

The climate input file used for model calibration, MOD3-PPT.DAT, is the same developed daily precipitation record that was used for calibration of the original 1996 (INFIL V1.0) net infiltration model for Yucca Mountain (Flint et al. 1996 [DIRS 100147, Figure 19], DTN: GS960908312211.003 [DIRS 103775]). The file, MOD3-PPT.DAT consists of daily precipitation estimates only and was developed using source data of daily precipitation records from 1980 through 1995.

\section{A. Source data (all data used is shown in Excel file, MOD3-PPT.xls)}

USGS Yucca Mountain precipitation data from weather stations WX1 and WX3.

GS010408312111.001 [DIRS 162978] (1995 water year)

GS970108312111.001 [DIRS 125899] (Oct. 1- Dec. 3, 1995)

GS000208312111.003 [DIRS 147247] (1987-1989)

GS000208312111.001 [DIRS 147245] (1989-1994)

Nevada Test Site (NTS) precipitation data for stations 4JA, 40MN, Rock Valley, Cane Spring, Mid Valley and Tippipah Spring \#2. These data are available in DTN: GS000200001221.002 [DIRS 146277].

National Weather Service (NWS) stations at Beatty $8 \mathrm{~N}$ and Amargosa Farms, from the National Climate Data Center and available through EarthInfo (information provided in DTN: GS000100001221.001 [DIRS 146816]).

\section{B. Development of daily precipitation record}

The developed record of daily precipitation is only an approximate representation of actual conditions over the general location and ground surface elevation of the repository area. Daily precipitation estimates for 1988 through 1995 were developed using the mean of the data from the Yucca Mountain weather stations. For 1980 through 1987, daily precipitation was estimated using a linear interpolation model and available precipitation records from the six NTS monitoring sites and the two NWS monitoring sites located near Yucca Mountain. The model was developed using linear regression of a weighted mean daily precipitation calculated from the eight stations against the mean calculated from the two USGS weather stations for the period July 17, 1987 through September 30, 1994 (this is the period for which the two sets of records overlapped). 
Table A-1 is the developed data precipitation record for Yucca Mountain that was used directly as input for INFIL V2.0 (USGS 2000 [DIRS 139422]). There is an EXCEL spreadsheet used to generate the developed data that is available in DTN: GS000208311221.001, and an identical spreadsheet formatted to display the formulas that can be printed out as hard copies.

Mod3-ppt1.xls: EXCEL spreadsheet used to perform calculations for developing mod3-ppt.dat, with values in cells shown.

Mod3-ppt2.xls: EXCEL spreadsheet used to perform calculations for developing mod3-ppt.dat, with formulas in cells shown.

\section{A3. SPREADSHEET CALCULATIONS}

Calculations in the spreadsheet MOD3-PPT.xls are done following a series of steps outlined in the first sheet of the file, and reiterated here.

Step 1: Average daily precipitation is calculated for USGS weather stations WX1 and WX3 for the period July 17, 1987 through September 30, 1994. For gaps in the record, a value of zero is estimated.

Step 2: Average annual precipitation is calculated for the six NTS stations and two NWS stations for all records beginning on July 17, 1987 and ending on September 30, 1994. This period of time coincides with the period for which precipitation data is available for USGS weather stations WX1 and WX3 (either stations). For all eight stations, the ratio $\mathrm{B}_{\mathrm{i}}=\mathrm{AAP}_{\mathrm{o}} / \mathrm{AAP}_{\mathrm{i}}$ is calculated, where $\mathrm{AAP}_{\mathrm{i}}=$ average annual precipitation for the period July 17, 1987 to July 30,1994 for station $\mathrm{i}$, and $\mathrm{AAP}_{\mathrm{o}}=$ mean average annual precipitation for USGS weather stations WX1 and WX3 (calculated in step 1), rounded to the nearest millimeter. The ratio is then used to scale the daily precipitation records for all eight stations using $\mathrm{PPT}_{\mathrm{i}} *=\mathrm{B}_{\mathrm{i}}\left(\mathrm{PPT}_{\mathrm{i}}\right)$, where $\mathrm{B}_{\mathrm{i}}$ is the scaling factor, $\mathrm{PPT}_{\mathrm{i}}$ is the original daily precipitation record for station $\mathrm{i}$, and $\mathrm{PPT}_{\mathrm{i}}$ is the adjusted daily precipitation record. The scaling function is applied to all eight stations for January 1, 1980 through December 31, 1994.

Step 3: An inverse-distance-squared interpolation is performed to estimate the mean daily precipitation for WX1 and WX3 for the period July 17, 1987 - July 30, 1994. The inverse distance squared interpolation involves the calculation of a linear weighting factor based on the distance between locations. A central location on Yucca Mountain used with UTM coordinates of 548,553 m easting, 4,078,230 m northing. Equation A-1 is as follows:

$$
\text { Weighting factor }{ }_{\mathrm{i}}=\left(1 / \mathrm{d}_{\mathrm{i}}{ }^{2}\right) /\left(\sum_{\mathrm{i}}\left(1 /\left(\mathrm{di}_{\mathrm{i}}{ }^{2}\right)\right)\right.
$$

where di is the distance of station i from the central location having the indicated coordinates. Station coordinates, calculated distances, and calculated weighting factors are listed in the spreadsheet.

Step 4: The inverse distance squared model defined in Step 3 is used to calculate the daily precipitation for the location defined in Step 3. 
Step 5: A linear model, based on a regression of measured precipitation vs. the adjusted daily precipitation record (the inverse-distance-squared interpolated precipitation), is applied to the results of the inverse-distance-squared interpolation for the period January 1, 1980 through September 30, 1994 using Equation A-2:

$$
\mathrm{PPT}_{\mathrm{YM}}=0.946546 *\left(\left[\left(1 / \mathrm{d}_{\mathrm{i}}^{2}\right) / \Sigma_{\mathrm{i}}\left(1 /\left(\mathrm{d}_{\mathrm{i}}^{2}\right)\right)\right] \mathrm{PPT}_{\mathrm{i}}^{*}\right)+0.0821
$$

where $\mathrm{PPT}_{\mathrm{YM}}$ is the estimated daily precipitation amount (to the nearest millimeter only) for the central location defined by the coordinates in Step 3, and $\mathrm{PPT}_{\mathrm{i}}{ }^{*}$ is the scaled daily precipitation amount for station $\mathrm{i}$. The results of the linear model are used to define the Yucca Mountain daily precipitation estimates for January 1, 1980 through May 11, 1989 (file, mod3-ppt.day). The results of Step 1 (to the nearest millimeter only) are used to define the Yucca Mountain daily precipitation estimates for May 11, 1989 through October 1, 1995 (file, mod3-ppt.dat).

Table A-1. Developed Data Precipitation Record for Yucca Mountain that was Used Directly as Input for INFIL V2.0

\begin{tabular}{|c|c|c|c|c|c|c|c|c|c|c|c|c|c|c|}
\hline Year & $\begin{array}{c}\text { Day } \\
\text { of } \\
\text { Year }\end{array}$ & $\begin{array}{l}\text { Daily } \\
\text { Precip- } \\
\text { itation } \\
(\mathrm{mm}) \\
\end{array}$ & Year & $\begin{array}{c}\text { Day } \\
\text { of } \\
\text { Year }\end{array}$ & $\begin{array}{c}\text { Daily } \\
\text { Precip- } \\
\text { itation } \\
(\mathrm{mm}) \\
\end{array}$ & Year & $\begin{array}{c}\text { Day } \\
\text { of } \\
\text { Year }\end{array}$ & $\begin{array}{l}\text { Daily } \\
\text { Precip- } \\
\text { itation } \\
(\mathrm{mm}) \\
\end{array}$ & Year & $\begin{array}{c}\text { Day } \\
\text { of } \\
\text { Year }\end{array}$ & $\begin{array}{c}\text { Daily } \\
\text { Precip- } \\
\text { itation } \\
(\mathrm{mm}) \\
\end{array}$ & Year & $\begin{array}{c}\text { Day } \\
\text { of } \\
\text { Year }\end{array}$ & $\begin{array}{c}\text { Daily } \\
\text { Precip- } \\
\text { itation } \\
(\mathrm{mm}) \\
\end{array}$ \\
\hline 80 & 1 & 0 & 80 & 74 & 0 & 80 & 147 & 0 & 80 & 220 & 0 & 80 & 293 & 0 \\
\hline 80 & 2 & 0 & 80 & 75 & 0 & 80 & 148 & 0 & 80 & 221 & 0 & 80 & 294 & 0 \\
\hline 80 & 3 & 0 & 80 & 76 & 0 & 80 & 149 & 0 & 80 & 222 & 0 & 80 & 295 & 0 \\
\hline 80 & 4 & 0 & 80 & 77 & 0 & 80 & 150 & 0 & 80 & 223 & 0 & 80 & 296 & 0 \\
\hline 80 & 5 & 0 & 80 & 78 & 0 & 80 & 151 & 0 & 80 & 224 & 0 & 80 & 297 & 0 \\
\hline 80 & 6 & 0 & 80 & 79 & 0 & 80 & 152 & 0 & 80 & 225 & 0 & 80 & 298 & 0 \\
\hline 80 & 7 & 0 & 80 & 80 & 0 & 80 & 153 & 0 & 80 & 226 & 0 & 80 & 299 & 0 \\
\hline 80 & 8 & 0 & 80 & 81 & 0 & 80 & 154 & 0 & 80 & 227 & 0 & 80 & 300 & 0 \\
\hline 80 & 9 & 13 & 80 & 82 & 0 & 80 & 155 & 0 & 80 & 228 & 0 & 80 & 301 & 0 \\
\hline 80 & 10 & 0 & 80 & 83 & 0 & 80 & 156 & 0 & 80 & 229 & 0 & 80 & 302 & 0 \\
\hline 80 & 11 & 8 & 80 & 84 & 1 & 80 & 157 & 0 & 80 & 230 & 0 & 80 & 303 & 0 \\
\hline 80 & 12 & 0 & 80 & 85 & 0 & 80 & 158 & 0 & 80 & 231 & 0 & 80 & 304 & 0 \\
\hline 80 & 13 & 1 & 80 & 86 & 0 & 80 & 159 & 0 & 80 & 232 & 0 & 80 & 305 & 0 \\
\hline 80 & 14 & 0 & 80 & 87 & 0 & 80 & 160 & 0 & 80 & 233 & 0 & 80 & 306 & 0 \\
\hline 80 & 15 & 0 & 80 & 88 & 0 & 80 & 161 & 0 & 80 & 234 & 0 & 80 & 307 & 0 \\
\hline 80 & 16 & 0 & 80 & 89 & 0 & 80 & 162 & 0 & 80 & 235 & 0 & 80 & 308 & 0 \\
\hline 80 & 17 & 0 & 80 & 90 & 0 & 80 & 163 & 0 & 80 & 236 & 0 & 80 & 309 & 0 \\
\hline 80 & 18 & 6 & 80 & 91 & 0 & 80 & 164 & 0 & 80 & 237 & 0 & 80 & 310 & 0 \\
\hline 80 & 19 & 2 & 80 & 92 & 0 & 80 & 165 & 0 & 80 & 238 & 1 & 80 & 311 & 0 \\
\hline
\end{tabular}


Table A-1. Developed Data Precipitation Record for Yucca Mountain that was Used Directly as Input for INFIL V2.0 (Continued)

\begin{tabular}{|c|c|c|c|c|c|c|c|c|c|c|c|c|c|c|}
\hline Year & $\begin{array}{c}\text { Day } \\
\text { of } \\
\text { Year }\end{array}$ & $\begin{array}{c}\text { Daily } \\
\text { Precip- } \\
\text { itation } \\
(\mathrm{mm}) \\
\end{array}$ & Year & $\begin{array}{c}\text { Day } \\
\text { of } \\
\text { Year }\end{array}$ & $\begin{array}{c}\text { Daily } \\
\text { Precip- } \\
\text { itation } \\
(\mathrm{mm}) \\
\end{array}$ & Year & $\begin{array}{c}\text { Day } \\
\text { of } \\
\text { Year }\end{array}$ & $\begin{array}{c}\text { Daily } \\
\text { Precip- } \\
\text { itation } \\
(\mathrm{mm}) \\
\end{array}$ & Year & $\begin{array}{c}\text { Day } \\
\text { of } \\
\text { Year }\end{array}$ & $\begin{array}{c}\text { Daily } \\
\text { Precip- } \\
\text { itation } \\
(\mathrm{mm}) \\
\end{array}$ & Year & $\begin{array}{c}\text { Day } \\
\text { of } \\
\text { Year } \\
\end{array}$ & $\begin{array}{c}\text { Daily } \\
\text { Precip- } \\
\text { itation } \\
(\mathrm{mm}) \\
\end{array}$ \\
\hline 80 & 20 & 0 & 80 & 93 & 0 & 80 & 166 & 0 & 80 & 239 & 0 & 80 & 312 & 0 \\
\hline 80 & 21 & 0 & 80 & 94 & 0 & 80 & 167 & 0 & 80 & 240 & 0 & 80 & 313 & 0 \\
\hline 80 & 22 & 0 & 80 & 95 & 0 & 80 & 168 & 0 & 80 & 241 & 0 & 80 & 314 & 0 \\
\hline 80 & 23 & 0 & 80 & 96 & 0 & 80 & 169 & 0 & 80 & 242 & 0 & 80 & 315 & 0 \\
\hline 80 & 24 & 0 & 80 & 97 & 0 & 80 & 170 & 0 & 80 & 243 & 0 & 80 & 316 & 0 \\
\hline 80 & 25 & 0 & 80 & 98 & 0 & 80 & 171 & 0 & 80 & 244 & 0 & 80 & 317 & 1 \\
\hline 80 & 26 & 0 & 80 & 99 & 0 & 80 & 172 & 0 & 80 & 245 & 0 & 80 & 318 & 0 \\
\hline 80 & 27 & 0 & 80 & 100 & 0 & 80 & 173 & 0 & 80 & 246 & 0 & 80 & 319 & 0 \\
\hline 80 & 28 & 2 & 80 & 101 & 0 & 80 & 174 & 0 & 80 & 247 & 0 & 80 & 320 & 0 \\
\hline 80 & 29 & 11 & 80 & 102 & 0 & 80 & 175 & 0 & 80 & 248 & 0 & 80 & 321 & 0 \\
\hline 80 & 30 & 1 & 80 & 103 & 0 & 80 & 176 & 0 & 80 & 249 & 0 & 80 & 322 & 0 \\
\hline 80 & 31 & 0 & 80 & 104 & 0 & 80 & 177 & 0 & 80 & 250 & 0 & 80 & 323 & 0 \\
\hline 80 & 32 & 0 & 80 & 105 & 0 & 80 & 178 & 0 & 80 & 251 & 3 & 80 & 324 & 0 \\
\hline 80 & 33 & 0 & 80 & 106 & 0 & 80 & 179 & 0 & 80 & 252 & 4 & 80 & 325 & 0 \\
\hline 80 & 34 & 0 & 80 & 107 & 0 & 80 & 180 & 0 & 80 & 253 & 3 & 80 & 326 & 0 \\
\hline 80 & 35 & 0 & 80 & 108 & 0 & 80 & 181 & 0 & 80 & 254 & 0 & 80 & 327 & 0 \\
\hline 80 & 36 & 0 & 80 & 109 & 0 & 80 & 182 & 3 & 80 & 255 & 0 & 80 & 328 & 0 \\
\hline 80 & 37 & 0 & 80 & 110 & 0 & 80 & 183 & 6 & 80 & 256 & 0 & 80 & 329 & 0 \\
\hline 80 & 38 & 0 & 80 & 111 & 0 & 80 & 184 & 0 & 80 & 257 & 0 & 80 & 330 & 0 \\
\hline 80 & 39 & 0 & 80 & 112 & 0 & 80 & 185 & 0 & 80 & 258 & 0 & 80 & 331 & 0 \\
\hline 80 & 40 & 0 & 80 & 113 & 0 & 80 & 186 & 0 & 80 & 259 & 0 & 80 & 332 & 0 \\
\hline 80 & 41 & 0 & 80 & 114 & 1 & 80 & 187 & 0 & 80 & 260 & 0 & 80 & 333 & 0 \\
\hline 80 & 42 & 0 & 80 & 115 & 0 & 80 & 188 & 0 & 80 & 261 & 0 & 80 & 334 & 0 \\
\hline 80 & 43 & 0 & 80 & 116 & 0 & 80 & 189 & 0 & 80 & 262 & 0 & 80 & 335 & 0 \\
\hline 80 & 44 & 2 & 80 & 117 & 0 & 80 & 190 & 0 & 80 & 263 & 0 & 80 & 336 & 0 \\
\hline 80 & 45 & 12 & 80 & 118 & 0 & 80 & 191 & 0 & 80 & 264 & 0 & 80 & 337 & 0 \\
\hline 80 & 46 & 0 & 80 & 119 & 1 & 80 & 192 & 0 & 80 & 265 & 0 & 80 & 338 & 0 \\
\hline 80 & 47 & 8 & 80 & 120 & 3 & 80 & 193 & 0 & 80 & 266 & 0 & 80 & 339 & 0 \\
\hline 80 & 48 & 5 & 80 & 121 & 3 & 80 & 194 & 0 & 80 & 267 & 0 & 80 & 340 & 0 \\
\hline 80 & 49 & 1 & 80 & 122 & 8 & 80 & 195 & 0 & 80 & 268 & 0 & 80 & 341 & 0 \\
\hline 80 & 50 & 7 & 80 & 123 & 0 & 80 & 196 & 0 & 80 & 269 & 0 & 80 & 342 & 0 \\
\hline 80 & 51 & 0 & 80 & 124 & 0 & 80 & 197 & 0 & 80 & 270 & 0 & 80 & 343 & 0 \\
\hline 80 & 52 & 0 & 80 & 125 & 0 & 80 & 198 & 0 & 80 & 271 & 0 & 80 & 344 & 0 \\
\hline 80 & 53 & 0 & 80 & 126 & 0 & 80 & 199 & 0 & 80 & 272 & 0 & 80 & 345 & 0 \\
\hline 80 & 54 & 0 & 80 & 127 & 0 & 80 & 200 & 0 & 80 & 273 & 0 & 80 & 346 & 0 \\
\hline 80 & 55 & 0 & 80 & 128 & 0 & 80 & 201 & 0 & 80 & 274 & 0 & 80 & 347 & 0 \\
\hline 80 & 56 & 0 & 80 & 129 & 0 & 80 & 202 & 0 & 80 & 275 & 0 & 80 & 348 & 0 \\
\hline 80 & 57 & 0 & 80 & 130 & 0 & 80 & 203 & 0 & 80 & 276 & 0 & 80 & 349 & 0 \\
\hline 80 & 58 & 0 & 80 & 131 & 0 & 80 & 204 & 0 & 80 & 277 & 0 & 80 & 350 & 0 \\
\hline 80 & 59 & 0 & 80 & 132 & 0 & 80 & 205 & 2 & 80 & 278 & 0 & 80 & 351 & 0 \\
\hline 80 & 60 & 0 & 80 & 133 & 0 & 80 & 206 & 0 & 80 & 279 & 0 & 80 & 352 & 0 \\
\hline 80 & 61 & 0 & 80 & 134 & 0 & 80 & 207 & 0 & 80 & 280 & 0 & 80 & 353 & 0 \\
\hline 80 & 62 & 13 & 80 & 135 & 3 & 80 & 208 & 1 & 80 & 281 & 0 & 80 & 354 & 0 \\
\hline 80 & 63 & 10 & 80 & 136 & 0 & 80 & 209 & 0 & 80 & 282 & 0 & 80 & 355 & 0 \\
\hline
\end{tabular}


Table A-1. Developed Data Precipitation Record for Yucca Mountain that was Used Directly as Input for INFIL V2.0 (Continued)

\begin{tabular}{|c|c|c|c|c|c|c|c|c|c|c|c|c|c|c|}
\hline Year & $\begin{array}{c}\text { Day } \\
\text { of } \\
\text { Year }\end{array}$ & $\begin{array}{c}\text { Daily } \\
\text { Precip- } \\
\text { itation } \\
(\mathrm{mm}) \\
\end{array}$ & Year & $\begin{array}{c}\text { Day } \\
\text { of } \\
\text { Year }\end{array}$ & $\begin{array}{c}\text { Daily } \\
\text { Precip- } \\
\text { itation } \\
(\mathrm{mm}) \\
\end{array}$ & Year & $\begin{array}{c}\text { Day } \\
\text { of } \\
\text { Year }\end{array}$ & $\begin{array}{c}\text { Daily } \\
\text { Precip- } \\
\text { itation } \\
(\mathrm{mm}) \\
\end{array}$ & Year & $\begin{array}{c}\text { Day } \\
\text { of } \\
\text { Year } \\
\end{array}$ & $\begin{array}{c}\text { Daily } \\
\text { Precip- } \\
\text { itation } \\
(\mathrm{mm}) \\
\end{array}$ & Year & $\begin{array}{c}\text { Day } \\
\text { of } \\
\text { Year }\end{array}$ & $\begin{array}{c}\text { Daily } \\
\text { Precip- } \\
\text { itation } \\
(\mathrm{mm}) \\
\end{array}$ \\
\hline 80 & 64 & 0 & 80 & 137 & 0 & 80 & 210 & 0 & 80 & 283 & 0 & 80 & 356 & 0 \\
\hline 80 & 65 & 2 & 80 & 138 & 0 & 80 & 211 & 0 & 80 & 284 & 0 & 80 & 357 & 0 \\
\hline 80 & 66 & 8 & 80 & 139 & 0 & 80 & 212 & 1 & 80 & 285 & 0 & 80 & 358 & 0 \\
\hline 80 & 67 & 5 & 80 & 140 & 0 & 80 & 213 & 0 & 80 & 286 & 0 & 80 & 359 & 0 \\
\hline 80 & 68 & 0 & 80 & 141 & 0 & 80 & 214 & 0 & 80 & 287 & 0 & 80 & 360 & 0 \\
\hline 80 & 69 & 0 & 80 & 142 & 0 & 80 & 215 & 0 & 80 & 288 & 0 & 80 & 361 & 0 \\
\hline 80 & 70 & 0 & 80 & 143 & 0 & 80 & 216 & 0 & 80 & 289 & 0 & 80 & 362 & 0 \\
\hline 80 & 71 & 0 & 80 & 144 & 1 & 80 & 217 & 0 & 80 & 290 & 0 & 80 & 363 & 0 \\
\hline 80 & 72 & 0 & 80 & 145 & 0 & 80 & 218 & 0 & 80 & 291 & 0 & 80 & 364 & 0 \\
\hline 80 & 73 & 0 & 80 & 146 & 0 & 80 & 219 & 0 & 80 & 292 & 0 & 80 & 365 & 0 \\
\hline & & & & & & & & & & & & 80 & 366 & 0 \\
\hline 81 & 1 & 0 & 81 & 74 & 0 & 81 & 147 & 12 & 81 & 220 & 0 & 81 & 293 & 0 \\
\hline 81 & 2 & 0 & 81 & 75 & 0 & 81 & 148 & 0 & 81 & 221 & 0 & 81 & 294 & 0 \\
\hline 81 & 3 & 0 & 81 & 76 & 0 & 81 & 149 & 0 & 81 & 222 & 0 & 81 & 295 & 0 \\
\hline 81 & 4 & 0 & 81 & 77 & 0 & 81 & 150 & 0 & 81 & 223 & 1 & 81 & 296 & 0 \\
\hline 81 & 5 & 0 & 81 & 78 & 5 & 81 & 151 & 0 & 81 & 224 & 1 & 81 & 297 & 0 \\
\hline 81 & 6 & 0 & 81 & 79 & 2 & 81 & 152 & 0 & 81 & 225 & 0 & 81 & 298 & 0 \\
\hline 81 & 7 & 0 & 81 & 80 & 0 & 81 & 153 & 0 & 81 & 226 & 1 & 81 & 299 & 0 \\
\hline 81 & 8 & 0 & 81 & 81 & 0 & 81 & 154 & 0 & 81 & 227 & 0 & 81 & 300 & 0 \\
\hline 81 & 9 & 0 & 81 & 82 & 0 & 81 & 155 & 0 & 81 & 228 & 0 & 81 & 301 & 0 \\
\hline 81 & 10 & 0 & 81 & 83 & 0 & 81 & 156 & 0 & 81 & 229 & 0 & 81 & 302 & 0 \\
\hline 81 & 11 & 0 & 81 & 84 & 0 & 81 & 157 & 0 & 81 & 230 & 0 & 81 & 303 & 0 \\
\hline 81 & 12 & 0 & 81 & 85 & 2 & 81 & 158 & 0 & 81 & 231 & 0 & 81 & 304 & 0 \\
\hline 81 & 13 & 0 & 81 & 86 & 0 & 81 & 159 & 0 & 81 & 232 & 0 & 81 & 305 & 0 \\
\hline 81 & 14 & 0 & 81 & 87 & 0 & 81 & 160 & 0 & 81 & 233 & 0 & 81 & 306 & 0 \\
\hline 81 & 15 & 0 & 81 & 88 & 0 & 81 & 161 & 0 & 81 & 234 & 0 & 81 & 307 & 0 \\
\hline 81 & 16 & 0 & 81 & 89 & 0 & 81 & 162 & 0 & 81 & 235 & 0 & 81 & 308 & 0 \\
\hline 81 & 17 & 0 & 81 & 90 & 0 & 81 & 163 & 0 & 81 & 236 & 0 & 81 & 309 & 0 \\
\hline 81 & 18 & 0 & 81 & 91 & 0 & 81 & 164 & 0 & 81 & 237 & 0 & 81 & 310 & 0 \\
\hline 81 & 19 & 0 & 81 & 92 & 0 & 81 & 165 & 0 & 81 & 238 & 0 & 81 & 311 & 0 \\
\hline 81 & 20 & 0 & 81 & 93 & 0 & 81 & 166 & 0 & 81 & 239 & 0 & 81 & 312 & 0 \\
\hline 81 & 21 & 0 & 81 & 94 & 0 & 81 & 167 & 0 & 81 & 240 & 0 & 81 & 313 & 0 \\
\hline 81 & 22 & 0 & 81 & 95 & 0 & 81 & 168 & 0 & 81 & 241 & 0 & 81 & 314 & 0 \\
\hline 81 & 23 & 0 & 81 & 96 & 0 & 81 & 169 & 0 & 81 & 242 & 0 & 81 & 315 & 0 \\
\hline 81 & 24 & 0 & 81 & 97 & 0 & 81 & 170 & 0 & 81 & 243 & 0 & 81 & 316 & 0 \\
\hline 81 & 25 & 0 & 81 & 98 & 0 & 81 & 171 & 0 & 81 & 244 & 0 & 81 & 317 & 0 \\
\hline 81 & 26 & 0 & 81 & 99 & 0 & 81 & 172 & 0 & 81 & 245 & 0 & 81 & 318 & 0 \\
\hline 81 & 27 & 0 & 81 & 100 & 0 & 81 & 173 & 0 & 81 & 246 & 0 & 81 & 319 & 0 \\
\hline 81 & 28 & 5 & 81 & 101 & 0 & 81 & 174 & 0 & 81 & 247 & 0 & 81 & 320 & 0 \\
\hline 81 & 29 & 6 & 81 & 102 & 0 & 81 & 175 & 0 & 81 & 248 & 0 & 81 & 321 & 0 \\
\hline 81 & 30 & 0 & 81 & 103 & 0 & 81 & 176 & 0 & 81 & 249 & 1 & 81 & 322 & 0 \\
\hline 81 & 31 & 0 & 81 & 104 & 0 & 81 & 177 & 0 & 81 & 250 & 2 & 81 & 323 & 0 \\
\hline 81 & 32 & 0 & 81 & 105 & 0 & 81 & 178 & 0 & 81 & 251 & 5 & 81 & 324 & 0 \\
\hline 81 & 33 & 0 & 81 & 106 & 0 & 81 & 179 & 0 & 81 & 252 & 2 & 81 & 325 & 0 \\
\hline
\end{tabular}


Table A-1. Developed Data Precipitation Record for Yucca Mountain that was Used Directly as Input for INFIL V2.0 (Continued)

\begin{tabular}{|c|c|c|c|c|c|c|c|c|c|c|c|c|c|c|}
\hline Year & $\begin{array}{c}\text { Day } \\
\text { of } \\
\text { Year }\end{array}$ & $\begin{array}{c}\text { Daily } \\
\text { Precip- } \\
\text { itation } \\
(\mathrm{mm}) \\
\end{array}$ & Year & $\begin{array}{c}\text { Day } \\
\text { of } \\
\text { Year }\end{array}$ & $\begin{array}{c}\text { Daily } \\
\text { Precip- } \\
\text { itation } \\
(\mathrm{mm}) \\
\end{array}$ & Year & $\begin{array}{c}\text { Day } \\
\text { of } \\
\text { Year }\end{array}$ & $\begin{array}{c}\text { Daily } \\
\text { Precip- } \\
\text { itation } \\
(\mathrm{mm}) \\
\end{array}$ & Year & $\begin{array}{c}\text { Day } \\
\text { of } \\
\text { Year } \\
\end{array}$ & $\begin{array}{c}\text { Daily } \\
\text { Precip- } \\
\text { itation } \\
(\mathrm{mm}) \\
\end{array}$ & Year & $\begin{array}{c}\text { Day } \\
\text { of } \\
\text { Year }\end{array}$ & $\begin{array}{c}\text { Daily } \\
\text { Precip- } \\
\text { itation } \\
(\mathrm{mm}) \\
\end{array}$ \\
\hline 81 & 34 & 0 & 81 & 107 & 0 & 81 & 180 & 0 & 81 & 253 & 0 & 81 & 326 & 0 \\
\hline 81 & 35 & 0 & 81 & 108 & 2 & 81 & 181 & 0 & 81 & 254 & 0 & 81 & 327 & 0 \\
\hline 81 & 36 & 0 & 81 & 109 & 0 & 81 & 182 & 0 & 81 & 255 & 1 & 81 & 328 & 0 \\
\hline 81 & 37 & 0 & 81 & 110 & 0 & 81 & 183 & 0 & 81 & 256 & 0 & 81 & 329 & 0 \\
\hline 81 & 38 & 0 & 81 & 111 & 0 & 81 & 184 & 0 & 81 & 257 & 0 & 81 & 330 & 2 \\
\hline 81 & 39 & 1 & 81 & 112 & 0 & 81 & 185 & 0 & 81 & 258 & 0 & 81 & 331 & 2 \\
\hline 81 & 40 & 1 & 81 & 113 & 0 & 81 & 186 & 0 & 81 & 259 & 0 & 81 & 332 & 9 \\
\hline 81 & 41 & 0 & 81 & 114 & 0 & 81 & 187 & 0 & 81 & 260 & 0 & 81 & 333 & 3 \\
\hline 81 & 42 & 0 & 81 & 115 & 0 & 81 & 188 & 0 & 81 & 261 & 0 & 81 & 334 & 0 \\
\hline 81 & 43 & 0 & 81 & 116 & 0 & 81 & 189 & 0 & 81 & 262 & 0 & 81 & 335 & 0 \\
\hline 81 & 44 & 0 & 81 & 117 & 0 & 81 & 190 & 0 & 81 & 263 & 0 & 81 & 336 & 0 \\
\hline 81 & 45 & 0 & 81 & 118 & 0 & 81 & 191 & 0 & 81 & 264 & 0 & 81 & 337 & 0 \\
\hline 81 & 46 & 0 & 81 & 119 & 0 & 81 & 192 & 0 & 81 & 265 & 0 & 81 & 338 & 0 \\
\hline 81 & 47 & 0 & 81 & 120 & 0 & 81 & 193 & 0 & 81 & 266 & 0 & 81 & 339 & 0 \\
\hline 81 & 48 & 0 & 81 & 121 & 0 & 81 & 194 & 0 & 81 & 267 & 0 & 81 & 340 & 0 \\
\hline 81 & 49 & 0 & 81 & 122 & 0 & 81 & 195 & 0 & 81 & 268 & 0 & 81 & 341 & 0 \\
\hline 81 & 50 & 0 & 81 & 123 & 0 & 81 & 196 & 0 & 81 & 269 & 0 & 81 & 342 & 0 \\
\hline 81 & 51 & 0 & 81 & 124 & 0 & 81 & 197 & 0 & 81 & 270 & 0 & 81 & 343 & 0 \\
\hline 81 & 52 & 0 & 81 & 125 & 0 & 81 & 198 & 0 & 81 & 271 & 0 & 81 & 344 & 0 \\
\hline 81 & 53 & 0 & 81 & 126 & 0 & 81 & 199 & 0 & 81 & 272 & 0 & 81 & 345 & 0 \\
\hline 81 & 54 & 0 & 81 & 127 & 0 & 81 & 200 & 0 & 81 & 273 & 0 & 81 & 346 & 0 \\
\hline 81 & 55 & 0 & 81 & 128 & 0 & 81 & 201 & 0 & 81 & 274 & 0 & 81 & 347 & 0 \\
\hline 81 & 56 & 0 & 81 & 129 & 0 & 81 & 202 & 0 & 81 & 275 & 2 & 81 & 348 & 0 \\
\hline 81 & 57 & 2 & 81 & 130 & 0 & 81 & 203 & 0 & 81 & 276 & 0 & 81 & 349 & 0 \\
\hline 81 & 58 & 0 & 81 & 131 & 0 & 81 & 204 & 0 & 81 & 277 & 0 & 81 & 350 & 0 \\
\hline 81 & 59 & 0 & 81 & 132 & 0 & 81 & 205 & 0 & 81 & 278 & 0 & 81 & 351 & 0 \\
\hline 81 & 60 & 16 & 81 & 133 & 0 & 81 & 206 & 0 & 81 & 279 & 0 & 81 & 352 & 0 \\
\hline 81 & 61 & 5 & 81 & 134 & 1 & 81 & 207 & 0 & 81 & 280 & 0 & 81 & 353 & 0 \\
\hline 81 & 62 & 0 & 81 & 135 & 1 & 81 & 208 & 0 & 81 & 281 & 0 & 81 & 354 & 0 \\
\hline 81 & 63 & 0 & 81 & 136 & 0 & 81 & 209 & 0 & 81 & 282 & 0 & 81 & 355 & 0 \\
\hline 81 & 64 & 8 & 81 & 137 & 0 & 81 & 210 & 0 & 81 & 283 & 0 & 81 & 356 & 0 \\
\hline 81 & 65 & 2 & 81 & 138 & 0 & 81 & 211 & 0 & 81 & 284 & 0 & 81 & 357 & 0 \\
\hline 81 & 66 & 0 & 81 & 139 & 0 & 81 & 212 & 0 & 81 & 285 & 0 & 81 & 358 & 0 \\
\hline 81 & 67 & 0 & 81 & 140 & 0 & 81 & 213 & 0 & 81 & 286 & 0 & 81 & 359 & 0 \\
\hline 81 & 68 & 0 & 81 & 141 & 0 & 81 & 214 & 0 & 81 & 287 & 0 & 81 & 360 & 0 \\
\hline 81 & 69 & 0 & 81 & 142 & 0 & 81 & 215 & 0 & 81 & 288 & 0 & 81 & 361 & 0 \\
\hline 81 & 70 & 0 & 81 & 143 & 0 & 81 & 216 & 0 & 81 & 289 & 0 & 81 & 362 & 0 \\
\hline 81 & 71 & 0 & 81 & 144 & 0 & 81 & 217 & 0 & 81 & 290 & 0 & 81 & 363 & 0 \\
\hline 81 & 72 & 0 & 81 & 145 & 0 & 81 & 218 & 0 & 81 & 291 & 0 & 81 & 364 & 0 \\
\hline 81 & 73 & 0 & 81 & 146 & 1 & 81 & 219 & 0 & 81 & 292 & 0 & 81 & 365 & 0 \\
\hline 82 & 1 & 1 & 82 & 74 & 2 & 82 & 147 & 0 & 82 & 220 & 0 & 82 & 293 & 0 \\
\hline 82 & 2 & 0 & 82 & 75 & 0 & 82 & 148 & 0 & 82 & 221 & 0 & 82 & 294 & 0 \\
\hline 82 & 3 & 0 & 82 & 76 & 30 & 82 & 149 & 0 & 82 & 222 & 0 & 82 & 295 & 0 \\
\hline 82 & 4 & 0 & 82 & 77 & 7 & 82 & 150 & 0 & 82 & 223 & 0 & 82 & 296 & 0 \\
\hline
\end{tabular}


Table A-1. Developed Data Precipitation Record for Yucca Mountain that was Used Directly as Input for INFIL V2.0 (Continued)

\begin{tabular}{|c|c|c|c|c|c|c|c|c|c|c|c|c|c|c|}
\hline Year & $\begin{array}{c}\text { Day } \\
\text { of } \\
\text { Year } \\
\end{array}$ & $\begin{array}{c}\text { Daily } \\
\text { Precip- } \\
\text { itation } \\
(\mathrm{mm}) \\
\end{array}$ & Year & $\begin{array}{c}\text { Day } \\
\text { of } \\
\text { Year }\end{array}$ & $\begin{array}{c}\text { Daily } \\
\text { Precip- } \\
\text { itation } \\
(\mathrm{mm}) \\
\end{array}$ & Year & $\begin{array}{c}\text { Day } \\
\text { of } \\
\text { Year }\end{array}$ & $\begin{array}{c}\text { Daily } \\
\text { Precip- } \\
\text { itation } \\
(\mathrm{mm}) \\
\end{array}$ & Year & $\begin{array}{c}\text { Day } \\
\text { of } \\
\text { Year }\end{array}$ & $\begin{array}{c}\text { Daily } \\
\text { Precip- } \\
\text { itation } \\
(\mathrm{mm}) \\
\end{array}$ & Year & $\begin{array}{c}\text { Day } \\
\text { of } \\
\text { Year } \\
\end{array}$ & $\begin{array}{c}\text { Daily } \\
\text { Precip- } \\
\text { itation } \\
(\mathrm{mm}) \\
\end{array}$ \\
\hline 82 & 5 & 2 & 82 & 78 & 1 & 82 & 151 & 0 & 82 & 224 & 2 & 82 & 297 & 0 \\
\hline 82 & 6 & 0 & 82 & 79 & 0 & 82 & 152 & 0 & 82 & 225 & 0 & 82 & 298 & 0 \\
\hline 82 & 7 & 0 & 82 & 80 & 0 & 82 & 153 & 0 & 82 & 226 & 0 & 82 & 299 & 1 \\
\hline 82 & 8 & 0 & 82 & 81 & 0 & 82 & 154 & 0 & 82 & 227 & 0 & 82 & 300 & 0 \\
\hline 82 & 9 & 0 & 82 & 82 & 0 & 82 & 155 & 0 & 82 & 228 & 0 & 82 & 301 & 0 \\
\hline 82 & 10 & 0 & 82 & 83 & 0 & 82 & 156 & 0 & 82 & 229 & 0 & 82 & 302 & 0 \\
\hline 82 & 11 & 0 & 82 & 84 & 0 & 82 & 157 & 0 & 82 & 230 & 2 & 82 & 303 & 1 \\
\hline 82 & 12 & 0 & 82 & 85 & 1 & 82 & 158 & 0 & 82 & 231 & 0 & 82 & 304 & 0 \\
\hline 82 & 13 & 0 & 82 & 86 & 0 & 82 & 159 & 0 & 82 & 232 & 0 & 82 & 305 & 0 \\
\hline 82 & 14 & 0 & 82 & 87 & 0 & 82 & 160 & 0 & 82 & 233 & 0 & 82 & 306 & 0 \\
\hline 82 & 15 & 0 & 82 & 88 & 0 & 82 & 161 & 0 & 82 & 234 & 3 & 82 & 307 & 0 \\
\hline 82 & 16 & 0 & 82 & 89 & 0 & 82 & 162 & 0 & 82 & 235 & 3 & 82 & 308 & 0 \\
\hline 82 & 17 & 0 & 82 & 90 & 0 & 82 & 163 & 0 & 82 & 236 & 1 & 82 & 309 & 0 \\
\hline 82 & 18 & 0 & 82 & 91 & 7 & 82 & 164 & 0 & 82 & 237 & 0 & 82 & 310 & 0 \\
\hline 82 & 19 & 0 & 82 & 92 & 0 & 82 & 165 & 0 & 82 & 238 & 0 & 82 & 311 & 0 \\
\hline 82 & 20 & 5 & 82 & 93 & 0 & 82 & 166 & 0 & 82 & 239 & 0 & 82 & 312 & 0 \\
\hline 82 & 21 & 1 & 82 & 94 & 0 & 82 & 167 & 0 & 82 & 240 & 0 & 82 & 313 & 7 \\
\hline 82 & 22 & 0 & 82 & 95 & 0 & 82 & 168 & 0 & 82 & 241 & 0 & 82 & 314 & 6 \\
\hline 82 & 23 & 0 & 82 & 96 & 0 & 82 & 169 & 2 & 82 & 242 & 0 & 82 & 315 & 0 \\
\hline 82 & 24 & 0 & 82 & 97 & 0 & 82 & 170 & 0 & 82 & 243 & 0 & 82 & 316 & 0 \\
\hline 82 & 25 & 0 & 82 & 98 & 0 & 82 & 171 & 0 & 82 & 244 & 0 & 82 & 317 & 0 \\
\hline 82 & 26 & 0 & 82 & 99 & 0 & 82 & 172 & 0 & 82 & 245 & 0 & 82 & 318 & 0 \\
\hline 82 & 27 & 0 & 82 & 100 & 0 & 82 & 173 & 0 & 82 & 246 & 0 & 82 & 319 & 0 \\
\hline 82 & 28 & 0 & 82 & 101 & 3 & 82 & 174 & 0 & 82 & 247 & 0 & 82 & 320 & 0 \\
\hline 82 & 29 & 0 & 82 & 102 & 0 & 82 & 175 & 0 & 82 & 248 & 0 & 82 & 321 & 0 \\
\hline 82 & 30 & 0 & 82 & 103 & 0 & 82 & 176 & 0 & 82 & 249 & 0 & 82 & 322 & 0 \\
\hline 82 & 31 & 0 & 82 & 104 & 0 & 82 & 177 & 0 & 82 & 250 & 0 & 82 & 323 & 0 \\
\hline 82 & 32 & 0 & 82 & 105 & 0 & 82 & 178 & 0 & 82 & 251 & 0 & 82 & 324 & 0 \\
\hline 82 & 33 & 0 & 82 & 106 & 0 & 82 & 179 & 0 & 82 & 252 & 1 & 82 & 325 & 0 \\
\hline 82 & 34 & 0 & 82 & 107 & 0 & 82 & 180 & 0 & 82 & 253 & 3 & 82 & 326 & 1 \\
\hline 82 & 35 & 0 & 82 & 108 & 0 & 82 & 181 & 0 & 82 & 254 & 1 & 82 & 327 & 1 \\
\hline 82 & 36 & 0 & 82 & 109 & 0 & 82 & 182 & 0 & 82 & 255 & 0 & 82 & 328 & 0 \\
\hline 82 & 37 & 0 & 82 & 110 & 0 & 82 & 183 & 0 & 82 & 256 & 0 & 82 & 329 & 0 \\
\hline 82 & 38 & 0 & 82 & 111 & 0 & 82 & 184 & 0 & 82 & 257 & 0 & 82 & 330 & 0 \\
\hline 82 & 39 & 0 & 82 & 112 & 0 & 82 & 185 & 0 & 82 & 258 & 0 & 82 & 331 & 0 \\
\hline 82 & 40 & 0 & 82 & 113 & 0 & 82 & 186 & 0 & 82 & 259 & 0 & 82 & 332 & 0 \\
\hline 82 & 41 & 5 & 82 & 114 & 0 & 82 & 187 & 0 & 82 & 260 & 0 & 82 & 333 & 0 \\
\hline 82 & 42 & 1 & 82 & 115 & 0 & 82 & 188 & 0 & 82 & 261 & 0 & 82 & 334 & 10 \\
\hline 82 & 43 & 0 & 82 & 116 & 0 & 82 & 189 & 0 & 82 & 262 & 0 & 82 & 335 & 0 \\
\hline 82 & 44 & 0 & 82 & 117 & 0 & 82 & 190 & 0 & 82 & 263 & 0 & 82 & 336 & 0 \\
\hline 82 & 45 & 0 & 82 & 118 & 0 & 82 & 191 & 0 & 82 & 264 & 0 & 82 & 337 & 0 \\
\hline 82 & 46 & 0 & 82 & 119 & 0 & 82 & 192 & 0 & 82 & 265 & 0 & 82 & 338 & 0 \\
\hline 82 & 47 & 0 & 82 & 120 & 0 & 82 & 193 & 0 & 82 & 266 & 0 & 82 & 339 & 0 \\
\hline 82 & 48 & 0 & 82 & 121 & 0 & 82 & 194 & 0 & 82 & 267 & 3 & 82 & 340 & 0 \\
\hline
\end{tabular}


Table A-1. Developed Data Precipitation Record for Yucca Mountain that was Used Directly as Input for INFIL V2.0 (Continued)

\begin{tabular}{|c|c|c|c|c|c|c|c|c|c|c|c|c|c|c|}
\hline Year & $\begin{array}{c}\text { Day } \\
\text { of } \\
\text { Year }\end{array}$ & $\begin{array}{c}\text { Daily } \\
\text { Precip- } \\
\text { itation } \\
(\mathrm{mm}) \\
\end{array}$ & Year & $\begin{array}{c}\text { Day } \\
\text { of } \\
\text { Year }\end{array}$ & $\begin{array}{c}\text { Daily } \\
\text { Precip- } \\
\text { itation } \\
(\mathrm{mm}) \\
\end{array}$ & Year & $\begin{array}{c}\text { Day } \\
\text { of } \\
\text { Year }\end{array}$ & $\begin{array}{c}\text { Daily } \\
\text { Precip- } \\
\text { itation } \\
(\mathrm{mm}) \\
\end{array}$ & Year & $\begin{array}{c}\text { Day } \\
\text { of } \\
\text { Year }\end{array}$ & $\begin{array}{c}\text { Daily } \\
\text { Precip- } \\
\text { itation } \\
(\mathrm{mm}) \\
\end{array}$ & Year & $\begin{array}{c}\text { Day } \\
\text { of } \\
\text { Year } \\
\end{array}$ & $\begin{array}{c}\text { Daily } \\
\text { Precip- } \\
\text { itation } \\
(\mathrm{mm}) \\
\end{array}$ \\
\hline 82 & 49 & 0 & 82 & 122 & 3 & 82 & 195 & 0 & 82 & 268 & 6 & 82 & 341 & 0 \\
\hline 82 & 50 & 0 & 82 & 123 & 2 & 82 & 196 & 0 & 82 & 269 & 2 & 82 & 342 & 0 \\
\hline 82 & 51 & 0 & 82 & 124 & 2 & 82 & 197 & 0 & 82 & 270 & 3 & 82 & 343 & 2 \\
\hline 82 & 52 & 0 & 82 & 125 & 0 & 82 & 198 & 0 & 82 & 271 & 0 & 82 & 344 & 1 \\
\hline 82 & 53 & 0 & 82 & 126 & 0 & 82 & 199 & 0 & 82 & 272 & 1 & 82 & 345 & 0 \\
\hline 82 & 54 & 0 & 82 & 127 & 0 & 82 & 200 & 0 & 82 & 273 & 0 & 82 & 346 & 0 \\
\hline 82 & 55 & 0 & 82 & 128 & 0 & 82 & 201 & 0 & 82 & 274 & 0 & 82 & 347 & 0 \\
\hline 82 & 56 & 0 & 82 & 129 & 5 & 82 & 202 & 0 & 82 & 275 & 0 & 82 & 348 & 0 \\
\hline 82 & 57 & 0 & 82 & 130 & 1 & 82 & 203 & 0 & 82 & 276 & 0 & 82 & 349 & 0 \\
\hline 82 & 58 & 0 & 82 & 131 & 0 & 82 & 204 & 0 & 82 & 277 & 0 & 82 & 350 & 0 \\
\hline 82 & 59 & 0 & 82 & 132 & 0 & 82 & 205 & 3 & 82 & 278 & 0 & 82 & 351 & 0 \\
\hline 82 & 60 & 0 & 82 & 133 & 0 & 82 & 206 & 0 & 82 & 279 & 0 & 82 & 352 & 0 \\
\hline 82 & 61 & 1 & 82 & 134 & 0 & 82 & 207 & 2 & 82 & 280 & 0 & 82 & 353 & 0 \\
\hline 82 & 62 & 0 & 82 & 135 & 0 & 82 & 208 & 6 & 82 & 281 & 0 & 82 & 354 & 0 \\
\hline 82 & 63 & 0 & 82 & 136 & 0 & 82 & 209 & 0 & 82 & 282 & 0 & 82 & 355 & 0 \\
\hline 82 & 64 & 0 & 82 & 137 & 0 & 82 & 210 & 0 & 82 & 283 & 0 & 82 & 356 & 6 \\
\hline 82 & 65 & 0 & 82 & 138 & 0 & 82 & 211 & 0 & 82 & 284 & 0 & 82 & 357 & 2 \\
\hline 82 & 66 & 0 & 82 & 139 & 0 & 82 & 212 & 0 & 82 & 285 & 0 & 82 & 358 & 0 \\
\hline 82 & 67 & 0 & 82 & 140 & 0 & 82 & 213 & 0 & 82 & 286 & 0 & 82 & 359 & 0 \\
\hline 82 & 68 & 0 & 82 & 141 & 0 & 82 & 214 & 0 & 82 & 287 & 0 & 82 & 360 & 0 \\
\hline 82 & 69 & 0 & 82 & 142 & 0 & 82 & 215 & 0 & 82 & 288 & 0 & 82 & 361 & 0 \\
\hline 82 & 70 & 0 & 82 & 143 & 0 & 82 & 216 & 0 & 82 & 289 & 0 & 82 & 362 & 0 \\
\hline 82 & 71 & 0 & 82 & 144 & 0 & 82 & 217 & 0 & 82 & 290 & 0 & 82 & 363 & 0 \\
\hline 82 & 72 & 0 & 82 & 145 & 0 & 82 & 218 & 0 & 82 & 291 & 0 & 82 & 364 & 0 \\
\hline 82 & 73 & 7 & 82 & 146 & 0 & 82 & 219 & 0 & 82 & 292 & 0 & 82 & 365 & 0 \\
\hline 83 & 1 & 0 & 83 & 74 & 0 & 83 & 147 & 0 & 83 & 220 & 0 & 83 & 293 & 0 \\
\hline 83 & 2 & 0 & 83 & 75 & 0 & 83 & 148 & 0 & 83 & 221 & 3 & 83 & 294 & 0 \\
\hline 83 & 3 & 0 & 83 & 76 & 0 & 83 & 149 & 0 & 83 & 222 & 5 & 83 & 295 & 0 \\
\hline 83 & 4 & 0 & 83 & 77 & 6 & 83 & 150 & 0 & 83 & 223 & 0 & 83 & 296 & 0 \\
\hline 83 & 5 & 0 & 83 & 78 & 0 & 83 & 151 & 0 & 83 & 224 & 0 & 83 & 297 & 0 \\
\hline 83 & 6 & 0 & 83 & 79 & 0 & 83 & 152 & 0 & 83 & 225 & 0 & 83 & 298 & 0 \\
\hline 83 & 7 & 0 & 83 & 80 & 15 & 83 & 153 & 0 & 83 & 226 & 0 & 83 & 299 & 0 \\
\hline 83 & 8 & 0 & 83 & 81 & 0 & 83 & 154 & 0 & 83 & 227 & 3 & 83 & 300 & 0 \\
\hline 83 & 9 & 0 & 83 & 82 & 0 & 83 & 155 & 0 & 83 & 228 & 8 & 83 & 301 & 0 \\
\hline 83 & 10 & 0 & 83 & 83 & 2 & 83 & 156 & 0 & 83 & 229 & 4 & 83 & 302 & 0 \\
\hline 83 & 11 & 0 & 83 & 84 & 0 & 83 & 157 & 0 & 83 & 230 & 58 & 83 & 303 & 0 \\
\hline 83 & 12 & 0 & 83 & 85 & 0 & 83 & 158 & 0 & 83 & 231 & 5 & 83 & 304 & 0 \\
\hline 83 & 13 & 0 & 83 & 86 & 0 & 83 & 159 & 0 & 83 & 232 & 0 & 83 & 305 & 0 \\
\hline 83 & 14 & 0 & 83 & 87 & 0 & 83 & 160 & 0 & 83 & 233 & 0 & 83 & 306 & 0 \\
\hline 83 & 15 & 0 & 83 & 88 & 0 & 83 & 161 & 0 & 83 & 234 & 0 & 83 & 307 & 0 \\
\hline 83 & 16 & 2 & 83 & 89 & 0 & 83 & 162 & 0 & 83 & 235 & 0 & 83 & 308 & 0 \\
\hline 83 & 17 & 1 & 83 & 90 & 0 & 83 & 163 & 0 & 83 & 236 & 0 & 83 & 309 & 0 \\
\hline 83 & 18 & 0 & 83 & 91 & 0 & 83 & 164 & 0 & 83 & 237 & 0 & 83 & 310 & 0 \\
\hline 83 & 19 & 3 & 83 & 92 & 2 & 83 & 165 & 0 & 83 & 238 & 0 & 83 & 311 & 0 \\
\hline
\end{tabular}


Table A-1. Developed Data Precipitation Record for Yucca Mountain that was Used Directly as Input for INFIL V2.0 (Continued)

\begin{tabular}{|c|c|c|c|c|c|c|c|c|c|c|c|c|c|c|}
\hline Year & $\begin{array}{c}\text { Day } \\
\text { of } \\
\text { Year }\end{array}$ & $\begin{array}{c}\text { Daily } \\
\text { Precip- } \\
\text { itation } \\
(\mathrm{mm}) \\
\end{array}$ & Year & $\begin{array}{c}\text { Day } \\
\text { of } \\
\text { Year }\end{array}$ & $\begin{array}{c}\text { Daily } \\
\text { Precip- } \\
\text { itation } \\
(\mathrm{mm}) \\
\end{array}$ & Year & $\begin{array}{c}\text { Day } \\
\text { of } \\
\text { Year }\end{array}$ & $\begin{array}{c}\text { Daily } \\
\text { Precip- } \\
\text { itation } \\
(\mathrm{mm}) \\
\end{array}$ & Year & $\begin{array}{c}\text { Day } \\
\text { of } \\
\text { Year }\end{array}$ & $\begin{array}{c}\text { Daily } \\
\text { Precip- } \\
\text { itation } \\
(\mathrm{mm}) \\
\end{array}$ & Year & $\begin{array}{c}\text { Day } \\
\text { of } \\
\text { Year } \\
\end{array}$ & $\begin{array}{c}\text { Daily } \\
\text { Precip- } \\
\text { itation } \\
(\mathrm{mm}) \\
\end{array}$ \\
\hline 83 & 20 & 0 & 83 & 93 & 2 & 83 & 166 & 0 & 83 & 239 & 0 & 83 & 312 & 0 \\
\hline 83 & 21 & 0 & 83 & 94 & 2 & 83 & 167 & 0 & 83 & 240 & 0 & 83 & 313 & 0 \\
\hline 83 & 22 & 2 & 83 & 95 & 0 & 83 & 168 & 0 & 83 & 241 & 0 & 83 & 314 & 0 \\
\hline 83 & 23 & 1 & 83 & 96 & 0 & 83 & 169 & 0 & 83 & 242 & 0 & 83 & 315 & 0 \\
\hline 83 & 24 & 6 & 83 & 97 & 0 & 83 & 170 & 0 & 83 & 243 & 0 & 83 & 316 & 0 \\
\hline 83 & 25 & 0 & 83 & 98 & 0 & 83 & 171 & 0 & 83 & 244 & 0 & 83 & 317 & 0 \\
\hline 83 & 26 & 0 & 83 & 99 & 0 & 83 & 172 & 0 & 83 & 245 & 0 & 83 & 318 & 0 \\
\hline 83 & 27 & 6 & 83 & 100 & 0 & 83 & 173 & 0 & 83 & 246 & 0 & 83 & 319 & 0 \\
\hline 83 & 28 & 0 & 83 & 101 & 3 & 83 & 174 & 0 & 83 & 247 & 0 & 83 & 320 & 0 \\
\hline 83 & 29 & 14 & 83 & 102 & 2 & 83 & 175 & 0 & 83 & 248 & 0 & 83 & 321 & 0 \\
\hline 83 & 30 & 0 & 83 & 103 & 0 & 83 & 176 & 0 & 83 & 249 & 0 & 83 & 322 & 0 \\
\hline 83 & 31 & 0 & 83 & 104 & 0 & 83 & 177 & 0 & 83 & 250 & 0 & 83 & 323 & 0 \\
\hline 83 & 32 & 0 & 83 & 105 & 0 & 83 & 178 & 0 & 83 & 251 & 0 & 83 & 324 & 1 \\
\hline 83 & 33 & 0 & 83 & 106 & 0 & 83 & 179 & 0 & 83 & 252 & 0 & 83 & 325 & 0 \\
\hline 83 & 34 & 1 & 83 & 107 & 0 & 83 & 180 & 0 & 83 & 253 & 0 & 83 & 326 & 0 \\
\hline 83 & 35 & 0 & 83 & 108 & 3 & 83 & 181 & 0 & 83 & 254 & 0 & 83 & 327 & 0 \\
\hline 83 & 36 & 3 & 83 & 109 & 0 & 83 & 182 & 0 & 83 & 255 & 0 & 83 & 328 & 8 \\
\hline 83 & 37 & 3 & 83 & 110 & 0 & 83 & 183 & 0 & 83 & 256 & 0 & 83 & 329 & 5 \\
\hline 83 & 38 & 1 & 83 & 111 & 1 & 83 & 184 & 0 & 83 & 257 & 0 & 83 & 330 & 0 \\
\hline 83 & 39 & 2 & 83 & 112 & 0 & 83 & 185 & 0 & 83 & 258 & 0 & 83 & 331 & 0 \\
\hline 83 & 40 & 0 & 83 & 113 & 0 & 83 & 186 & 0 & 83 & 259 & 0 & 83 & 332 & 0 \\
\hline 83 & 41 & 0 & 83 & 114 & 0 & 83 & 187 & 0 & 83 & 260 & 0 & 83 & 333 & 0 \\
\hline 83 & 42 & 0 & 83 & 115 & 0 & 83 & 188 & 0 & 83 & 261 & 0 & 83 & 334 & 0 \\
\hline 83 & 43 & 0 & 83 & 116 & 0 & 83 & 189 & 0 & 83 & 262 & 0 & 83 & 335 & 0 \\
\hline 83 & 44 & 1 & 83 & 117 & 0 & 83 & 190 & 0 & 83 & 263 & 0 & 83 & 336 & 0 \\
\hline 83 & 45 & 0 & 83 & 118 & 0 & 83 & 191 & 0 & 83 & 264 & 0 & 83 & 337 & 3 \\
\hline 83 & 46 & 0 & 83 & 119 & 0 & 83 & 192 & 0 & 83 & 265 & 0 & 83 & 338 & 0 \\
\hline 83 & 47 & 0 & 83 & 120 & 1 & 83 & 193 & 0 & 83 & 266 & 0 & 83 & 339 & 0 \\
\hline 83 & 48 & 0 & 83 & 121 & 2 & 83 & 194 & 0 & 83 & 267 & 0 & 83 & 340 & 0 \\
\hline 83 & 49 & 0 & 83 & 122 & 0 & 83 & 195 & 0 & 83 & 268 & 1 & 83 & 341 & 0 \\
\hline 83 & 50 & 0 & 83 & 123 & 0 & 83 & 196 & 0 & 83 & 269 & 9 & 83 & 342 & 0 \\
\hline 83 & 51 & 0 & 83 & 124 & 0 & 83 & 197 & 0 & 83 & 270 & 1 & 83 & 343 & 0 \\
\hline 83 & 52 & 0 & 83 & 125 & 0 & 83 & 198 & 0 & 83 & 271 & 0 & 83 & 344 & 0 \\
\hline 83 & 53 & 0 & 83 & 126 & 0 & 83 & 199 & 0 & 83 & 272 & 0 & 83 & 345 & 0 \\
\hline 83 & 54 & 0 & 83 & 127 & 0 & 83 & 200 & 0 & 83 & 273 & 1 & 83 & 346 & 0 \\
\hline 83 & 55 & 1 & 83 & 128 & 0 & 83 & 201 & 0 & 83 & 274 & 4 & 83 & 347 & 0 \\
\hline 83 & 56 & 1 & 83 & 129 & 0 & 83 & 202 & 0 & 83 & 275 & 0 & 83 & 348 & 0 \\
\hline 83 & 57 & 0 & 83 & 130 & 0 & 83 & 203 & 0 & 83 & 276 & 0 & 83 & 349 & 0 \\
\hline 83 & 58 & 5 & 83 & 131 & 0 & 83 & 204 & 0 & 83 & 277 & 0 & 83 & 350 & 0 \\
\hline 83 & 59 & 0 & 83 & 132 & 0 & 83 & 205 & 0 & 83 & 278 & 0 & 83 & 351 & 0 \\
\hline 83 & 60 & 16 & 83 & 133 & 0 & 83 & 206 & 0 & 83 & 279 & 0 & 83 & 352 & 0 \\
\hline 83 & 61 & 14 & 83 & 134 & 0 & 83 & 207 & 0 & 83 & 280 & 0 & 83 & 353 & 0 \\
\hline 83 & 62 & 23 & 83 & 135 & 0 & 83 & 208 & 0 & 83 & 281 & 0 & 83 & 354 & 0 \\
\hline 83 & 63 & 0 & 83 & 136 & 0 & 83 & 209 & 0 & 83 & 282 & 0 & 83 & 355 & 0 \\
\hline
\end{tabular}


Table A-1. Developed Data Precipitation Record for Yucca Mountain that was Used Directly as Input for INFIL V2.0 (Continued)

\begin{tabular}{|c|c|c|c|c|c|c|c|c|c|c|c|c|c|c|}
\hline Year & $\begin{array}{l}\text { Day } \\
\text { of } \\
\text { Year }\end{array}$ & $\begin{array}{l}\text { Daily } \\
\text { Precip- } \\
\text { itation } \\
(\mathrm{mm})\end{array}$ & Year & $\begin{array}{l}\text { Day } \\
\text { of } \\
\text { Year }\end{array}$ & $\begin{array}{l}\text { Daily } \\
\text { Precip- } \\
\text { itation } \\
(\mathrm{mm})\end{array}$ & Year & $\begin{array}{l}\text { Day } \\
\text { of } \\
\text { Year }\end{array}$ & $\begin{array}{c}\text { Daily } \\
\text { Precip- } \\
\text { itation } \\
(\mathrm{mm})\end{array}$ & Year & $\begin{array}{l}\text { Day } \\
\text { of } \\
\text { Year }\end{array}$ & $\begin{array}{c}\text { Daily } \\
\text { Precip- } \\
\text { itation } \\
(\mathrm{mm})\end{array}$ & Year & $\begin{array}{l}\text { Day } \\
\text { of } \\
\text { Year }\end{array}$ & $\begin{array}{c}\text { Daily } \\
\text { Precip- } \\
\text { itation } \\
(\mathrm{mm})\end{array}$ \\
\hline 83 & 64 & 0 & 83 & 137 & 0 & 83 & 210 & 0 & 83 & 283 & 0 & 83 & 356 & 0 \\
\hline 83 & 65 & 0 & 83 & 138 & 0 & 83 & 211 & 0 & 83 & 284 & 0 & 83 & 357 & 0 \\
\hline 83 & 66 & 0 & 83 & 139 & 0 & 83 & 212 & 0 & 83 & 285 & 0 & 83 & 358 & 6 \\
\hline 83 & 67 & 0 & 83 & 140 & 0 & 83 & 213 & 0 & 83 & 286 & 0 & 83 & 359 & 15 \\
\hline 83 & 68 & 0 & 83 & 141 & 0 & 83 & 214 & 0 & 83 & 287 & 0 & 83 & 360 & 1 \\
\hline 83 & 69 & 0 & 83 & 142 & 0 & 83 & 215 & 0 & 83 & 288 & 0 & 83 & 361 & 0 \\
\hline 83 & 70 & 0 & 83 & 143 & 0 & 83 & 216 & 0 & 83 & 289 & 0 & 83 & 362 & 0 \\
\hline 83 & 71 & 0 & 83 & 144 & 0 & 83 & 217 & 0 & 83 & 290 & 0 & 83 & 363 & 0 \\
\hline 83 & 72 & 0 & 83 & 145 & 0 & 83 & 218 & 4 & 83 & 291 & 0 & 83 & 364 & 0 \\
\hline 83 & 73 & 0 & 83 & 146 & 0 & 83 & 219 & 2 & 83 & 292 & 0 & 83 & 365 & 0 \\
\hline 84 & 1 & 0 & 84 & 74 & 0 & 84 & 147 & 0 & 84 & 220 & 0 & 84 & 293 & 0 \\
\hline 84 & 2 & 0 & 84 & 75 & 0 & 84 & 148 & 0 & 84 & 221 & 0 & 84 & 294 & 0 \\
\hline 84 & 3 & 0 & 84 & 76 & 0 & 84 & 149 & 0 & 84 & 222 & 0 & 84 & 295 & 0 \\
\hline 84 & 4 & 0 & 84 & 77 & 0 & 84 & 150 & 0 & 84 & 223 & 0 & 84 & 296 & 0 \\
\hline 84 & 5 & 0 & 84 & 78 & 0 & 84 & 151 & 0 & 84 & 224 & 0 & 84 & 297 & 0 \\
\hline 84 & 6 & 0 & 84 & 79 & 0 & 84 & 152 & 0 & 84 & 225 & 0 & 84 & 298 & 0 \\
\hline 84 & 7 & 0 & 84 & 80 & 0 & 84 & 153 & 0 & 84 & 226 & 0 & 84 & 299 & 0 \\
\hline 84 & 8 & 0 & 84 & 81 & 0 & 84 & 154 & 0 & 84 & 227 & 15 & 84 & 300 & 0 \\
\hline 84 & 9 & 0 & 84 & 82 & 0 & 84 & 155 & 0 & 84 & 228 & 8 & 84 & 301 & 0 \\
\hline 84 & 10 & 0 & 84 & 83 & 0 & 84 & 156 & 0 & 84 & 229 & 0 & 84 & 302 & 0 \\
\hline 84 & 11 & 0 & 84 & 84 & 0 & 84 & 157 & 0 & 84 & 230 & 0 & 84 & 303 & 0 \\
\hline 84 & 12 & 0 & 84 & 85 & 0 & 84 & 158 & 0 & 84 & 231 & 5 & 84 & 304 & 0 \\
\hline 84 & 13 & 0 & 84 & 86 & 0 & 84 & 159 & 0 & 84 & 232 & 16 & 84 & 305 & 0 \\
\hline 84 & 14 & 0 & 84 & 87 & 0 & 84 & 160 & 0 & 84 & 233 & 0 & 84 & 306 & 0 \\
\hline 84 & 15 & 0 & 84 & 88 & 0 & 84 & 161 & 0 & 84 & 234 & 0 & 84 & 307 & 0 \\
\hline 84 & 16 & 0 & 84 & 89 & 0 & 84 & 162 & 0 & 84 & 235 & 0 & 84 & 308 & 0 \\
\hline 84 & 17 & 0 & 84 & 90 & 0 & 84 & 163 & 0 & 84 & 236 & 0 & 84 & 309 & 0 \\
\hline 84 & 18 & 0 & 84 & 91 & 0 & 84 & 164 & 0 & 84 & 237 & 0 & 84 & 310 & 0 \\
\hline 84 & 19 & 0 & 84 & 92 & 0 & 84 & 165 & 0 & 84 & 238 & 0 & 84 & 311 & 0 \\
\hline 84 & 20 & 0 & 84 & 93 & 0 & 84 & 166 & 0 & 84 & 239 & 0 & 84 & 312 & 0 \\
\hline 84 & 21 & 0 & 84 & 94 & 0 & 84 & 167 & 0 & 84 & 240 & 0 & 84 & 313 & 0 \\
\hline 84 & 22 & 0 & 84 & 95 & 0 & 84 & 168 & 0 & 84 & 241 & 0 & 84 & 314 & 0 \\
\hline 84 & 23 & 0 & 84 & 96 & 0 & 84 & 169 & 0 & 84 & 242 & 0 & 84 & 315 & 0 \\
\hline 84 & 24 & 0 & 84 & 97 & 1 & 84 & 170 & 0 & 84 & 243 & 0 & 84 & 316 & 0 \\
\hline 84 & 25 & 0 & 84 & 98 & 0 & 84 & 171 & 0 & 84 & 244 & 0 & 84 & 317 & 0 \\
\hline 84 & 26 & 0 & 84 & 99 & 0 & 84 & 172 & 0 & 84 & 245 & 0 & 84 & 318 & 0 \\
\hline 84 & 27 & 0 & 84 & 100 & 0 & 84 & 173 & 0 & 84 & 246 & 0 & 84 & 319 & 0 \\
\hline 84 & 28 & 0 & 84 & 101 & 0 & 84 & 174 & 0 & 84 & 247 & 0 & 84 & 320 & 0 \\
\hline 84 & 29 & 0 & 84 & 102 & 0 & 84 & 175 & 0 & 84 & 248 & 0 & 84 & 321 & 0 \\
\hline 84 & 30 & 0 & 84 & 103 & 0 & 84 & 176 & 0 & 84 & 249 & 0 & 84 & 322 & 0 \\
\hline 84 & 31 & 0 & 84 & 104 & 0 & 84 & 177 & 0 & 84 & 250 & 0 & 84 & 323 & 0 \\
\hline 84 & 32 & 0 & 84 & 105 & 0 & 84 & 178 & 0 & 84 & 251 & 0 & 84 & 324 & 0 \\
\hline 84 & 33 & 0 & 84 & 106 & 0 & 84 & 179 & 0 & 84 & 252 & 0 & 84 & 325 & 0 \\
\hline 84 & 34 & 0 & 84 & 107 & 0 & 84 & 180 & 0 & 84 & 253 & 0 & 84 & 326 & 2 \\
\hline
\end{tabular}


Table A-1. Developed Data Precipitation Record for Yucca Mountain that was Used Directly as Input for INFIL V2.0 (Continued)

\begin{tabular}{|c|c|c|c|c|c|c|c|c|c|c|c|c|c|c|}
\hline Year & $\begin{array}{c}\text { Day } \\
\text { of } \\
\text { Year }\end{array}$ & $\begin{array}{l}\text { Daily } \\
\text { Precip- } \\
\text { itation } \\
(\mathrm{mm})\end{array}$ & Year & $\begin{array}{c}\text { Day } \\
\text { of } \\
\text { Year }\end{array}$ & $\begin{array}{c}\text { Daily } \\
\text { Precip- } \\
\text { itation } \\
(\mathrm{mm}) \\
\end{array}$ & Year & $\begin{array}{c}\text { Day } \\
\text { of } \\
\text { Year }\end{array}$ & $\begin{array}{c}\text { Daily } \\
\text { Precip- } \\
\text { itation } \\
(\mathrm{mm}) \\
\end{array}$ & Year & $\begin{array}{c}\text { Day } \\
\text { of } \\
\text { Year }\end{array}$ & $\begin{array}{c}\text { Daily } \\
\text { Precip- } \\
\text { itation } \\
(\mathrm{mm}) \\
\end{array}$ & Year & $\begin{array}{c}\text { Day } \\
\text { of } \\
\text { Year }\end{array}$ & $\begin{array}{c}\text { Daily } \\
\text { Precip- } \\
\text { itation } \\
(\mathrm{mm})\end{array}$ \\
\hline 84 & 35 & 0 & 84 & 108 & 0 & 84 & 181 & 0 & 84 & 254 & 0 & 84 & 327 & 18 \\
\hline 84 & 36 & 0 & 84 & 109 & 0 & 84 & 182 & 0 & 84 & 255 & 0 & 84 & 328 & 4 \\
\hline 84 & 37 & 0 & 84 & 110 & 0 & 84 & 183 & 0 & 84 & 256 & 0 & 84 & 329 & 3 \\
\hline 84 & 38 & 0 & 84 & 111 & 0 & 84 & 184 & 0 & 84 & 257 & 0 & 84 & 330 & 0 \\
\hline 84 & 39 & 0 & 84 & 112 & 0 & 84 & 185 & 1 & 84 & 258 & 0 & 84 & 331 & 0 \\
\hline 84 & 40 & 0 & 84 & 113 & 0 & 84 & 186 & 0 & 84 & 259 & 0 & 84 & 332 & 0 \\
\hline 84 & 41 & 2 & 84 & 114 & 0 & 84 & 187 & 0 & 84 & 260 & 4 & 84 & 333 & 0 \\
\hline 84 & 42 & 0 & 84 & 115 & 0 & 84 & 188 & 0 & 84 & 261 & 1 & 84 & 334 & 0 \\
\hline 84 & 43 & 0 & 84 & 116 & 0 & 84 & 189 & 0 & 84 & 262 & 0 & 84 & 335 & 0 \\
\hline 84 & 44 & 0 & 84 & 117 & 0 & 84 & 190 & 0 & 84 & 263 & 0 & 84 & 336 & 0 \\
\hline 84 & 45 & 1 & 84 & 118 & 0 & 84 & 191 & 0 & 84 & 264 & 1 & 84 & 337 & 0 \\
\hline 84 & 46 & 0 & 84 & 119 & 0 & 84 & 192 & 0 & 84 & 265 & 0 & 84 & 338 & 0 \\
\hline 84 & 47 & 0 & 84 & 120 & 0 & 84 & 193 & 0 & 84 & 266 & 0 & 84 & 339 & 0 \\
\hline 84 & 48 & 0 & 84 & 121 & 0 & 84 & 194 & 1 & 84 & 267 & 0 & 84 & 340 & 0 \\
\hline 84 & 49 & 0 & 84 & 122 & 0 & 84 & 195 & 1 & 84 & 268 & 0 & 84 & 341 & 0 \\
\hline 84 & 50 & 0 & 84 & 123 & 0 & 84 & 196 & 0 & 84 & 269 & 0 & 84 & 342 & 0 \\
\hline 84 & 51 & 0 & 84 & 124 & 0 & 84 & 197 & 0 & 84 & 270 & 0 & 84 & 343 & 2 \\
\hline 84 & 52 & 0 & 84 & 125 & 0 & 84 & 198 & 0 & 84 & 271 & 0 & 84 & 344 & 0 \\
\hline 84 & 53 & 0 & 84 & 126 & 0 & 84 & 199 & 0 & 84 & 272 & 0 & 84 & 345 & 1 \\
\hline 84 & 54 & 0 & 84 & 127 & 0 & 84 & 200 & 0 & 84 & 273 & 0 & 84 & 346 & 2 \\
\hline 84 & 55 & 0 & 84 & 128 & 0 & 84 & 201 & 1 & 84 & 274 & 0 & 84 & 347 & 1 \\
\hline 84 & 56 & 0 & 84 & 129 & 0 & 84 & 202 & 0 & 84 & 275 & 1 & 84 & 348 & 0 \\
\hline 84 & 57 & 0 & 84 & 130 & 0 & 84 & 203 & 11 & 84 & 276 & 2 & 84 & 349 & 0 \\
\hline 84 & 58 & 0 & 84 & 131 & 0 & 84 & 204 & 38 & 84 & 277 & 0 & 84 & 350 & 1 \\
\hline 84 & 59 & 0 & 84 & 132 & 0 & 84 & 205 & 1 & 84 & 278 & 0 & 84 & 351 & 6 \\
\hline 84 & 60 & 0 & 84 & 133 & 0 & 84 & 206 & 0 & 84 & 279 & 0 & 84 & 352 & 0 \\
\hline 84 & 61 & 0 & 84 & 134 & 0 & 84 & 207 & 0 & 84 & 280 & 0 & 84 & 353 & 10 \\
\hline 84 & 62 & 0 & 84 & 135 & 0 & 84 & 208 & 0 & 84 & 281 & 0 & 84 & 354 & 23 \\
\hline 84 & 63 & 0 & 84 & 136 & 0 & 84 & 209 & 1 & 84 & 282 & 0 & 84 & 355 & 1 \\
\hline 84 & 64 & 0 & 84 & 137 & 0 & 84 & 210 & 3 & 84 & 283 & 0 & 84 & 356 & 0 \\
\hline 84 & 65 & 0 & 84 & 138 & 0 & 84 & 211 & 2 & 84 & 284 & 0 & 84 & 357 & 0 \\
\hline 84 & 66 & 0 & 84 & 139 & 0 & 84 & 212 & 1 & 84 & 285 & 0 & 84 & 358 & 0 \\
\hline 84 & 67 & 0 & 84 & 140 & 0 & 84 & 213 & 11 & 84 & 286 & 0 & 84 & 359 & 0 \\
\hline 84 & 68 & 0 & 84 & 141 & 0 & 84 & 214 & 0 & 84 & 287 & 0 & 84 & 360 & 0 \\
\hline 84 & 69 & 0 & 84 & 142 & 0 & 84 & 215 & 0 & 84 & 288 & 0 & 84 & 361 & 3 \\
\hline 84 & 70 & 0 & 84 & 143 & 0 & 84 & 216 & 0 & 84 & 289 & 0 & 84 & 362 & 8 \\
\hline 84 & 71 & 0 & 84 & 144 & 0 & 84 & 217 & 0 & 84 & 290 & 0 & 84 & 363 & 5 \\
\hline 84 & 72 & 0 & 84 & 145 & 0 & 84 & 218 & 0 & 84 & 291 & 0 & 84 & 364 & 0 \\
\hline \multirow[t]{2}{*}{84} & 73 & 0 & 84 & 146 & 0 & 84 & 219 & 0 & 84 & 292 & 0 & 84 & 365 & 0 \\
\hline & & & & & & & & & & & & 84 & 366 & 0 \\
\hline 85 & 1 & 0 & 85 & 74 & 0 & 85 & 147 & 0 & 85 & 220 & 0 & 85 & 293 & 0 \\
\hline 85 & 2 & 0 & 85 & 75 & 0 & 85 & 148 & 0 & 85 & 221 & 0 & 85 & 294 & 0 \\
\hline 85 & 3 & 0 & 85 & 76 & 0 & 85 & 149 & 0 & 85 & 222 & 0 & 85 & 295 & 0 \\
\hline 85 & 4 & 0 & 85 & 77 & 1 & 85 & 150 & 0 & 85 & 223 & 0 & 85 & 296 & 0 \\
\hline
\end{tabular}


Table A-1. Developed Data Precipitation Record for Yucca Mountain that was Used Directly as Input for INFIL V2.0 (Continued)

\begin{tabular}{|c|c|c|c|c|c|c|c|c|c|c|c|c|c|c|}
\hline Year & $\begin{array}{c}\text { Day } \\
\text { of } \\
\text { Year }\end{array}$ & $\begin{array}{c}\text { Daily } \\
\text { Precip- } \\
\text { itation } \\
(\mathrm{mm}) \\
\end{array}$ & Year & $\begin{array}{c}\text { Day } \\
\text { of } \\
\text { Year }\end{array}$ & $\begin{array}{c}\text { Daily } \\
\text { Precip- } \\
\text { itation } \\
(\mathrm{mm}) \\
\end{array}$ & Year & $\begin{array}{c}\text { Day } \\
\text { of } \\
\text { Year }\end{array}$ & $\begin{array}{c}\text { Daily } \\
\text { Precip- } \\
\text { itation } \\
(\mathrm{mm}) \\
\end{array}$ & Year & $\begin{array}{c}\text { Day } \\
\text { of } \\
\text { Year } \\
\end{array}$ & $\begin{array}{c}\text { Daily } \\
\text { Precip- } \\
\text { itation } \\
(\mathrm{mm}) \\
\end{array}$ & Year & $\begin{array}{c}\text { Day } \\
\text { of } \\
\text { Year }\end{array}$ & $\begin{array}{c}\text { Daily } \\
\text { Precip- } \\
\text { itation } \\
(\mathrm{mm}) \\
\end{array}$ \\
\hline 85 & 5 & 0 & 85 & 78 & 0 & 85 & 151 & 0 & 85 & 224 & 0 & 85 & 297 & 0 \\
\hline 85 & 6 & 0 & 85 & 79 & 0 & 85 & 152 & 0 & 85 & 225 & 0 & 85 & 298 & 0 \\
\hline 85 & 7 & 5 & 85 & 80 & 0 & 85 & 153 & 0 & 85 & 226 & 0 & 85 & 299 & 0 \\
\hline 85 & 8 & 2 & 85 & 81 & 0 & 85 & 154 & 1 & 85 & 227 & 0 & 85 & 300 & 0 \\
\hline 85 & 9 & 0 & 85 & 82 & 0 & 85 & 155 & 0 & 85 & 228 & 0 & 85 & 301 & 0 \\
\hline 85 & 10 & 0 & 85 & 83 & 0 & 85 & 156 & 0 & 85 & 229 & 0 & 85 & 302 & 0 \\
\hline 85 & 11 & 0 & 85 & 84 & 0 & 85 & 157 & 0 & 85 & 230 & 0 & 85 & 303 & 0 \\
\hline 85 & 12 & 0 & 85 & 85 & 0 & 85 & 158 & 0 & 85 & 231 & 0 & 85 & 304 & 0 \\
\hline 85 & 13 & 0 & 85 & 86 & 0 & 85 & 159 & 0 & 85 & 232 & 0 & 85 & 305 & 0 \\
\hline 85 & 14 & 0 & 85 & 87 & 1 & 85 & 160 & 0 & 85 & 233 & 0 & 85 & 306 & 0 \\
\hline 85 & 15 & 0 & 85 & 88 & 0 & 85 & 161 & 0 & 85 & 234 & 0 & 85 & 307 & 0 \\
\hline 85 & 16 & 0 & 85 & 89 & 0 & 85 & 162 & 0 & 85 & 235 & 0 & 85 & 308 & 0 \\
\hline 85 & 17 & 0 & 85 & 90 & 0 & 85 & 163 & 0 & 85 & 236 & 0 & 85 & 309 & 0 \\
\hline 85 & 18 & 0 & 85 & 91 & 0 & 85 & 164 & 0 & 85 & 237 & 0 & 85 & 310 & 0 \\
\hline 85 & 19 & 0 & 85 & 92 & 0 & 85 & 165 & 0 & 85 & 238 & 0 & 85 & 311 & 0 \\
\hline 85 & 20 & 0 & 85 & 93 & 0 & 85 & 166 & 0 & 85 & 239 & 0 & 85 & 312 & 0 \\
\hline 85 & 21 & 0 & 85 & 94 & 0 & 85 & 167 & 0 & 85 & 240 & 0 & 85 & 313 & 0 \\
\hline 85 & 22 & 0 & 85 & 95 & 0 & 85 & 168 & 0 & 85 & 241 & 0 & 85 & 314 & 0 \\
\hline 85 & 23 & 0 & 85 & 96 & 0 & 85 & 169 & 0 & 85 & 242 & 0 & 85 & 315 & 16 \\
\hline 85 & 24 & 0 & 85 & 97 & 0 & 85 & 170 & 0 & 85 & 243 & 0 & 85 & 316 & 6 \\
\hline 85 & 25 & 0 & 85 & 98 & 0 & 85 & 171 & 0 & 85 & 244 & 0 & 85 & 317 & 0 \\
\hline 85 & 26 & 2 & 85 & 99 & 0 & 85 & 172 & 0 & 85 & 245 & 0 & 85 & 318 & 0 \\
\hline 85 & 27 & 1 & 85 & 100 & 0 & 85 & 173 & 0 & 85 & 246 & 0 & 85 & 319 & 0 \\
\hline 85 & 28 & 0 & 85 & 101 & 0 & 85 & 174 & 0 & 85 & 247 & 0 & 85 & 320 & 0 \\
\hline 85 & 29 & 0 & 85 & 102 & 0 & 85 & 175 & 0 & 85 & 248 & 0 & 85 & 321 & 0 \\
\hline 85 & 30 & 0 & 85 & 103 & 0 & 85 & 176 & 0 & 85 & 249 & 0 & 85 & 322 & 0 \\
\hline 85 & 31 & 0 & 85 & 104 & 0 & 85 & 177 & 0 & 85 & 250 & 0 & 85 & 323 & 0 \\
\hline 85 & 32 & 0 & 85 & 105 & 0 & 85 & 178 & 0 & 85 & 251 & 0 & 85 & 324 & 0 \\
\hline 85 & 33 & 0 & 85 & 106 & 0 & 85 & 179 & 0 & 85 & 252 & 0 & 85 & 325 & 0 \\
\hline 85 & 34 & 0 & 85 & 107 & 0 & 85 & 180 & 0 & 85 & 253 & 0 & 85 & 326 & 0 \\
\hline 85 & 35 & 0 & 85 & 108 & 0 & 85 & 181 & 0 & 85 & 254 & 0 & 85 & 327 & 0 \\
\hline 85 & 36 & 0 & 85 & 109 & 0 & 85 & 182 & 0 & 85 & 255 & 0 & 85 & 328 & 2 \\
\hline 85 & 37 & 0 & 85 & 110 & 0 & 85 & 183 & 0 & 85 & 256 & 0 & 85 & 329 & 2 \\
\hline 85 & 38 & 0 & 85 & 111 & 0 & 85 & 184 & 0 & 85 & 257 & 0 & 85 & 330 & 0 \\
\hline 85 & 39 & 0 & 85 & 112 & 0 & 85 & 185 & 0 & 85 & 258 & 0 & 85 & 331 & 0 \\
\hline 85 & 40 & 1 & 85 & 113 & 0 & 85 & 186 & 0 & 85 & 259 & 0 & 85 & 332 & 0 \\
\hline 85 & 41 & 1 & 85 & 114 & 0 & 85 & 187 & 0 & 85 & 260 & 0 & 85 & 333 & 4 \\
\hline 85 & 42 & 0 & 85 & 115 & 0 & 85 & 188 & 0 & 85 & 261 & 9 & 85 & 334 & 0 \\
\hline 85 & 43 & 0 & 85 & 116 & 0 & 85 & 189 & 0 & 85 & 262 & 0 & 85 & 335 & 0 \\
\hline 85 & 44 & 0 & 85 & 117 & 0 & 85 & 190 & 0 & 85 & 263 & 0 & 85 & 336 & 5 \\
\hline 85 & 45 & 0 & 85 & 118 & 0 & 85 & 191 & 0 & 85 & 264 & 0 & 85 & 337 & 0 \\
\hline 85 & 46 & 0 & 85 & 119 & 0 & 85 & 192 & 0 & 85 & 265 & 0 & 85 & 338 & 0 \\
\hline 85 & 47 & 0 & 85 & 120 & 0 & 85 & 193 & 0 & 85 & 266 & 0 & 85 & 339 & 0 \\
\hline 85 & 48 & 0 & 85 & 121 & 0 & 85 & 194 & 0 & 85 & 267 & 0 & 85 & 340 & 0 \\
\hline
\end{tabular}


Table A-1. Developed Data Precipitation Record for Yucca Mountain that was Used Directly as Input for INFIL V2.0 (Continued)

\begin{tabular}{|c|c|c|c|c|c|c|c|c|c|c|c|c|c|c|}
\hline Year & $\begin{array}{c}\text { Day } \\
\text { of } \\
\text { Year }\end{array}$ & $\begin{array}{c}\text { Daily } \\
\text { Precip- } \\
\text { itation } \\
(\mathrm{mm}) \\
\end{array}$ & Year & $\begin{array}{c}\text { Day } \\
\text { of } \\
\text { Year }\end{array}$ & $\begin{array}{c}\text { Daily } \\
\text { Precip- } \\
\text { itation } \\
(\mathrm{mm}) \\
\end{array}$ & Year & $\begin{array}{c}\text { Day } \\
\text { of } \\
\text { Year }\end{array}$ & $\begin{array}{c}\text { Daily } \\
\text { Precip- } \\
\text { itation } \\
(\mathrm{mm}) \\
\end{array}$ & Year & $\begin{array}{c}\text { Day } \\
\text { of } \\
\text { Year } \\
\end{array}$ & $\begin{array}{c}\text { Daily } \\
\text { Precip- } \\
\text { itation } \\
(\mathrm{mm}) \\
\end{array}$ & Year & $\begin{array}{c}\text { Day } \\
\text { of } \\
\text { Year }\end{array}$ & $\begin{array}{c}\text { Daily } \\
\text { Precip- } \\
\text { itation } \\
(\mathrm{mm}) \\
\end{array}$ \\
\hline 85 & 49 & 0 & 85 & 122 & 0 & 85 & 195 & 0 & 85 & 268 & 0 & 85 & 341 & 0 \\
\hline 85 & 50 & 0 & 85 & 123 & 0 & 85 & 196 & 0 & 85 & 269 & 0 & 85 & 342 & 0 \\
\hline 85 & 51 & 0 & 85 & 124 & 0 & 85 & 197 & 0 & 85 & 270 & 1 & 85 & 343 & 0 \\
\hline 85 & 52 & 0 & 85 & 125 & 0 & 85 & 198 & 1 & 85 & 271 & 0 & 85 & 344 & 0 \\
\hline 85 & 53 & 0 & 85 & 126 & 0 & 85 & 199 & 6 & 85 & 272 & 0 & 85 & 345 & 0 \\
\hline 85 & 54 & 0 & 85 & 127 & 0 & 85 & 200 & 2 & 85 & 273 & 0 & 85 & 346 & 0 \\
\hline 85 & 55 & 0 & 85 & 128 & 0 & 85 & 201 & 7 & 85 & 274 & 0 & 85 & 347 & 0 \\
\hline 85 & 56 & 0 & 85 & 129 & 1 & 85 & 202 & 1 & 85 & 275 & 0 & 85 & 348 & 0 \\
\hline 85 & 57 & 0 & 85 & 130 & 5 & 85 & 203 & 0 & 85 & 276 & 0 & 85 & 349 & 0 \\
\hline 85 & 58 & 0 & 85 & 131 & 0 & 85 & 204 & 0 & 85 & 277 & 0 & 85 & 350 & 0 \\
\hline 85 & 59 & 0 & 85 & 132 & 0 & 85 & 205 & 0 & 85 & 278 & 0 & 85 & 351 & 0 \\
\hline 85 & 60 & 0 & 85 & 133 & 0 & 85 & 206 & 0 & 85 & 279 & 0 & 85 & 352 & 0 \\
\hline 85 & 61 & 0 & 85 & 134 & 0 & 85 & 207 & 0 & 85 & 280 & 1 & 85 & 353 & 0 \\
\hline 85 & 62 & 0 & 85 & 135 & 0 & 85 & 208 & 0 & 85 & 281 & 1 & 85 & 354 & 0 \\
\hline 85 & 63 & 0 & 85 & 136 & 0 & 85 & 209 & 0 & 85 & 282 & 0 & 85 & 355 & 0 \\
\hline 85 & 64 & 0 & 85 & 137 & 0 & 85 & 210 & 0 & 85 & 283 & 0 & 85 & 356 & 0 \\
\hline 85 & 65 & 0 & 85 & 138 & 0 & 85 & 211 & 0 & 85 & 284 & 0 & 85 & 357 & 0 \\
\hline 85 & 66 & 0 & 85 & 139 & 0 & 85 & 212 & 0 & 85 & 285 & 0 & 85 & 358 & 0 \\
\hline 85 & 67 & 0 & 85 & 140 & 0 & 85 & 213 & 0 & 85 & 286 & 0 & 85 & 359 & 0 \\
\hline 85 & 68 & 0 & 85 & 141 & 0 & 85 & 214 & 0 & 85 & 287 & 0 & 85 & 360 & 0 \\
\hline 85 & 69 & 0 & 85 & 142 & 0 & 85 & 215 & 0 & 85 & 288 & 0 & 85 & 361 & 0 \\
\hline 85 & 70 & 0 & 85 & 143 & 0 & 85 & 216 & 0 & 85 & 289 & 0 & 85 & 362 & 0 \\
\hline 85 & 71 & 0 & 85 & 144 & 0 & 85 & 217 & 0 & 85 & 290 & 0 & 85 & 363 & 0 \\
\hline 85 & 72 & 0 & 85 & 145 & 0 & 85 & 218 & 0 & 85 & 291 & 0 & 85 & 364 & 0 \\
\hline 85 & 73 & 0 & 85 & 146 & 0 & 85 & 219 & 0 & 85 & 292 & 0 & 85 & 365 & 0 \\
\hline 86 & 1 & 0 & 86 & 74 & 4 & 86 & 147 & 0 & 86 & 220 & 0 & 86 & 293 & 2 \\
\hline 86 & 2 & 0 & 86 & 75 & 1 & 86 & 148 & 0 & 86 & 221 & 0 & 86 & 294 & 0 \\
\hline 86 & 3 & 0 & 86 & 76 & 0 & 86 & 149 & 0 & 86 & 222 & 2 & 86 & 295 & 0 \\
\hline 86 & 4 & 0 & 86 & 77 & 0 & 86 & 150 & 0 & 86 & 223 & 0 & 86 & 296 & 0 \\
\hline 86 & 5 & 4 & 86 & 78 & 0 & 86 & 151 & 0 & 86 & 224 & 0 & 86 & 297 & 0 \\
\hline 86 & 6 & 0 & 86 & 79 & 0 & 86 & 152 & 0 & 86 & 225 & 0 & 86 & 298 & 0 \\
\hline 86 & 7 & 0 & 86 & 80 & 0 & 86 & 153 & 0 & 86 & 226 & 0 & 86 & 299 & 0 \\
\hline 86 & 8 & 0 & 86 & 81 & 0 & 86 & 154 & 0 & 86 & 227 & 0 & 86 & 300 & 0 \\
\hline 86 & 9 & 0 & 86 & 82 & 0 & 86 & 155 & 0 & 86 & 228 & 0 & 86 & 301 & 0 \\
\hline 86 & 10 & 0 & 86 & 83 & 0 & 86 & 156 & 0 & 86 & 229 & 0 & 86 & 302 & 0 \\
\hline 86 & 11 & 0 & 86 & 84 & 0 & 86 & 157 & 0 & 86 & 230 & 1 & 86 & 303 & 0 \\
\hline 86 & 12 & 0 & 86 & 85 & 0 & 86 & 158 & 0 & 86 & 231 & 0 & 86 & 304 & 0 \\
\hline 86 & 13 & 0 & 86 & 86 & 0 & 86 & 159 & 0 & 86 & 232 & 0 & 86 & 305 & 0 \\
\hline 86 & 14 & 0 & 86 & 87 & 0 & 86 & 160 & 0 & 86 & 233 & 0 & 86 & 306 & 0 \\
\hline 86 & 15 & 0 & 86 & 88 & 0 & 86 & 161 & 0 & 86 & 234 & 0 & 86 & 307 & 0 \\
\hline 86 & 16 & 0 & 86 & 89 & 0 & 86 & 162 & 0 & 86 & 235 & 0 & 86 & 308 & 0 \\
\hline 86 & 17 & 0 & 86 & 90 & 0 & 86 & 163 & 0 & 86 & 236 & 0 & 86 & 309 & 0 \\
\hline 86 & 18 & 0 & 86 & 91 & 0 & 86 & 164 & 0 & 86 & 237 & 5 & 86 & 310 & 0 \\
\hline 86 & 19 & 0 & 86 & 92 & 0 & 86 & 165 & 0 & 86 & 238 & 3 & 86 & 311 & 0 \\
\hline
\end{tabular}


Table A-1. Developed Data Precipitation Record for Yucca Mountain that was Used Directly as Input for INFIL V2.0 (Continued)

\begin{tabular}{|c|c|c|c|c|c|c|c|c|c|c|c|c|c|c|}
\hline Year & $\begin{array}{c}\text { Day } \\
\text { of } \\
\text { Year }\end{array}$ & $\begin{array}{c}\text { Daily } \\
\text { Precip- } \\
\text { itation } \\
(\mathrm{mm}) \\
\end{array}$ & Year & $\begin{array}{c}\text { Day } \\
\text { of } \\
\text { Year }\end{array}$ & $\begin{array}{c}\text { Daily } \\
\text { Precip- } \\
\text { itation } \\
(\mathrm{mm}) \\
\end{array}$ & Year & $\begin{array}{c}\text { Day } \\
\text { of } \\
\text { Year }\end{array}$ & $\begin{array}{c}\text { Daily } \\
\text { Precip- } \\
\text { itation } \\
(\mathrm{mm}) \\
\end{array}$ & Year & $\begin{array}{c}\text { Day } \\
\text { of } \\
\text { Year } \\
\end{array}$ & $\begin{array}{c}\text { Daily } \\
\text { Precip- } \\
\text { itation } \\
(\mathrm{mm}) \\
\end{array}$ & Year & $\begin{array}{c}\text { Day } \\
\text { of } \\
\text { Year }\end{array}$ & $\begin{array}{c}\text { Daily } \\
\text { Precip- } \\
\text { itation } \\
(\mathrm{mm}) \\
\end{array}$ \\
\hline 86 & 20 & 0 & 86 & 93 & 0 & 86 & 166 & 0 & 86 & 239 & 4 & 86 & 312 & 0 \\
\hline 86 & 21 & 0 & 86 & 94 & 0 & 86 & 167 & 0 & 86 & 240 & 0 & 86 & 313 & 0 \\
\hline 86 & 22 & 0 & 86 & 95 & 1 & 86 & 168 & 0 & 86 & 241 & 0 & 86 & 314 & 0 \\
\hline 86 & 23 & 0 & 86 & 96 & 4 & 86 & 169 & 0 & 86 & 242 & 0 & 86 & 315 & 0 \\
\hline 86 & 24 & 0 & 86 & 97 & 0 & 86 & 170 & 0 & 86 & 243 & 0 & 86 & 316 & 0 \\
\hline 86 & 25 & 0 & 86 & 98 & 0 & 86 & 171 & 0 & 86 & 244 & 0 & 86 & 317 & 0 \\
\hline 86 & 26 & 0 & 86 & 99 & 0 & 86 & 172 & 0 & 86 & 245 & 0 & 86 & 318 & 0 \\
\hline 86 & 27 & 0 & 86 & 100 & 0 & 86 & 173 & 0 & 86 & 246 & 0 & 86 & 319 & 0 \\
\hline 86 & 28 & 0 & 86 & 101 & 0 & 86 & 174 & 0 & 86 & 247 & 0 & 86 & 320 & 0 \\
\hline 86 & 29 & 0 & 86 & 102 & 0 & 86 & 175 & 0 & 86 & 248 & 0 & 86 & 321 & 0 \\
\hline 86 & 30 & 21 & 86 & 103 & 0 & 86 & 176 & 0 & 86 & 249 & 0 & 86 & 322 & 15 \\
\hline 86 & 31 & 2 & 86 & 104 & 0 & 86 & 177 & 0 & 86 & 250 & 0 & 86 & 323 & 0 \\
\hline 86 & 32 & 0 & 86 & 105 & 0 & 86 & 178 & 0 & 86 & 251 & 0 & 86 & 324 & 0 \\
\hline 86 & 33 & 0 & 86 & 106 & 0 & 86 & 179 & 0 & 86 & 252 & 0 & 86 & 325 & 0 \\
\hline 86 & 34 & 0 & 86 & 107 & 0 & 86 & 180 & 0 & 86 & 253 & 0 & 86 & 326 & 0 \\
\hline 86 & 35 & 1 & 86 & 108 & 0 & 86 & 181 & 0 & 86 & 254 & 0 & 86 & 327 & 0 \\
\hline 86 & 36 & 0 & 86 & 109 & 0 & 86 & 182 & 0 & 86 & 255 & 0 & 86 & 328 & 0 \\
\hline 86 & 37 & 0 & 86 & 110 & 0 & 86 & 183 & 0 & 86 & 256 & 0 & 86 & 329 & 0 \\
\hline 86 & 38 & 0 & 86 & 111 & 0 & 86 & 184 & 0 & 86 & 257 & 0 & 86 & 330 & 0 \\
\hline 86 & 39 & 0 & 86 & 112 & 0 & 86 & 185 & 0 & 86 & 258 & 0 & 86 & 331 & 0 \\
\hline 86 & 40 & 0 & 86 & 113 & 0 & 86 & 186 & 0 & 86 & 259 & 0 & 86 & 332 & 0 \\
\hline 86 & 41 & 0 & 86 & 114 & 0 & 86 & 187 & 0 & 86 & 260 & 0 & 86 & 333 & 0 \\
\hline 86 & 42 & 0 & 86 & 115 & 0 & 86 & 188 & 0 & 86 & 261 & 0 & 86 & 334 & 0 \\
\hline 86 & 43 & 0 & 86 & 116 & 0 & 86 & 189 & 0 & 86 & 262 & 0 & 86 & 335 & 0 \\
\hline 86 & 44 & 1 & 86 & 117 & 0 & 86 & 190 & 0 & 86 & 263 & 0 & 86 & 336 & 0 \\
\hline 86 & 45 & 7 & 86 & 118 & 0 & 86 & 191 & 0 & 86 & 264 & 0 & 86 & 337 & 0 \\
\hline 86 & 46 & 6 & 86 & 119 & 0 & 86 & 192 & 0 & 86 & 265 & 0 & 86 & 338 & 0 \\
\hline 86 & 47 & 0 & 86 & 120 & 0 & 86 & 193 & 0 & 86 & 266 & 1 & 86 & 339 & 0 \\
\hline 86 & 48 & 0 & 86 & 121 & 0 & 86 & 194 & 0 & 86 & 267 & 0 & 86 & 340 & 4 \\
\hline 86 & 49 & 0 & 86 & 122 & 0 & 86 & 195 & 0 & 86 & 268 & 0 & 86 & 341 & 2 \\
\hline 86 & 50 & 0 & 86 & 123 & 0 & 86 & 196 & 3 & 86 & 269 & 0 & 86 & 342 & 0 \\
\hline 86 & 51 & 0 & 86 & 124 & 0 & 86 & 197 & 0 & 86 & 270 & 0 & 86 & 343 & 0 \\
\hline 86 & 52 & 0 & 86 & 125 & 0 & 86 & 198 & 0 & 86 & 271 & 0 & 86 & 344 & 0 \\
\hline 86 & 53 & 0 & 86 & 126 & 4 & 86 & 199 & 0 & 86 & 272 & 0 & 86 & 345 & 0 \\
\hline 86 & 54 & 0 & 86 & 127 & 0 & 86 & 200 & 0 & 86 & 273 & 0 & 86 & 346 & 0 \\
\hline 86 & 55 & 0 & 86 & 128 & 0 & 86 & 201 & 0 & 86 & 274 & 1 & 86 & 347 & 0 \\
\hline 86 & 56 & 0 & 86 & 129 & 0 & 86 & 202 & 4 & 86 & 275 & 8 & 86 & 348 & 0 \\
\hline 86 & 57 & 0 & 86 & 130 & 0 & 86 & 203 & 0 & 86 & 276 & 0 & 86 & 349 & 0 \\
\hline 86 & 58 & 0 & 86 & 131 & 0 & 86 & 204 & 2 & 86 & 277 & 0 & 86 & 350 & 0 \\
\hline 86 & 59 & 0 & 86 & 132 & 0 & 86 & 205 & 0 & 86 & 278 & 0 & 86 & 351 & 0 \\
\hline 86 & 60 & 0 & 86 & 133 & 0 & 86 & 206 & 0 & 86 & 279 & 0 & 86 & 352 & 0 \\
\hline 86 & 61 & 0 & 86 & 134 & 0 & 86 & 207 & 0 & 86 & 280 & 0 & 86 & 353 & 2 \\
\hline 86 & 62 & 0 & 86 & 135 & 0 & 86 & 208 & 0 & 86 & 281 & 0 & 86 & 354 & 10 \\
\hline 86 & 63 & 0 & 86 & 136 & 0 & 86 & 209 & 0 & 86 & 282 & 0 & 86 & 355 & 0 \\
\hline
\end{tabular}


Table A-1. Developed Data Precipitation Record for Yucca Mountain that was Used Directly as Input for INFIL V2.0 (Continued)

\begin{tabular}{|c|c|c|c|c|c|c|c|c|c|c|c|c|c|c|}
\hline Year & $\begin{array}{c}\text { Day } \\
\text { of } \\
\text { Year }\end{array}$ & $\begin{array}{c}\text { Daily } \\
\text { Precip- } \\
\text { itation } \\
(\mathrm{mm}) \\
\end{array}$ & Year & $\begin{array}{c}\text { Day } \\
\text { of } \\
\text { Year }\end{array}$ & $\begin{array}{c}\text { Daily } \\
\text { Precip- } \\
\text { itation } \\
(\mathrm{mm}) \\
\end{array}$ & Year & $\begin{array}{c}\text { Day } \\
\text { of } \\
\text { Year }\end{array}$ & $\begin{array}{c}\text { Daily } \\
\text { Precip- } \\
\text { itation } \\
(\mathrm{mm}) \\
\end{array}$ & Year & $\begin{array}{c}\text { Day } \\
\text { of } \\
\text { Year } \\
\end{array}$ & $\begin{array}{c}\text { Daily } \\
\text { Precip- } \\
\text { itation } \\
(\mathrm{mm}) \\
\end{array}$ & Year & $\begin{array}{c}\text { Day } \\
\text { of } \\
\text { Year } \\
\end{array}$ & $\begin{array}{c}\text { Daily } \\
\text { Precip- } \\
\text { itation } \\
(\mathrm{mm}) \\
\end{array}$ \\
\hline 86 & 64 & 0 & 86 & 137 & 0 & 86 & 210 & 0 & 86 & 283 & 0 & 86 & 356 & 0 \\
\hline 86 & 65 & 0 & 86 & 138 & 0 & 86 & 211 & 0 & 86 & 284 & 0 & 86 & 357 & 0 \\
\hline 86 & 66 & 0 & 86 & 139 & 0 & 86 & 212 & 0 & 86 & 285 & 0 & 86 & 358 & 0 \\
\hline 86 & 67 & 2 & 86 & 140 & 0 & 86 & 213 & 0 & 86 & 286 & 0 & 86 & 359 & 0 \\
\hline 86 & 68 & 0 & 86 & 141 & 0 & 86 & 214 & 0 & 86 & 287 & 0 & 86 & 360 & 0 \\
\hline 86 & 69 & 7 & 86 & 142 & 0 & 86 & 215 & 0 & 86 & 288 & 0 & 86 & 361 & 0 \\
\hline 86 & 70 & 0 & 86 & 143 & 0 & 86 & 216 & 0 & 86 & 289 & 0 & 86 & 362 & 0 \\
\hline 86 & 71 & 1 & 86 & 144 & 0 & 86 & 217 & 0 & 86 & 290 & 0 & 86 & 363 & 0 \\
\hline 86 & 72 & 4 & 86 & 145 & 0 & 86 & 218 & 0 & 86 & 291 & 0 & 86 & 364 & 0 \\
\hline 86 & 73 & 2 & 86 & 146 & 0 & 86 & 219 & 0 & 86 & 292 & 6 & 86 & 365 & 0 \\
\hline 87 & 1 & 0 & 87 & 74 & 8 & 87 & 147 & 0 & 87 & 220 & 0 & 87 & 293 & 0 \\
\hline 87 & 2 & 0 & 87 & 75 & 0 & 87 & 148 & 2 & 87 & 221 & 0 & 87 & 294 & 0 \\
\hline 87 & 3 & 0 & 87 & 76 & 0 & 87 & 149 & 0 & 87 & 222 & 0 & 87 & 295 & 4 \\
\hline 87 & 4 & 13 & 87 & 77 & 0 & 87 & 150 & 0 & 87 & 223 & 0 & 87 & 296 & 0 \\
\hline 87 & 5 & 7 & 87 & 78 & 0 & 87 & 151 & 0 & 87 & 224 & 0 & 87 & 297 & 7 \\
\hline 87 & 6 & 2 & 87 & 79 & 0 & 87 & 152 & 0 & 87 & 225 & 0 & 87 & 298 & 0 \\
\hline 87 & 7 & 2 & 87 & 80 & 2 & 87 & 153 & 0 & 87 & 226 & 0 & 87 & 299 & 0 \\
\hline 87 & 8 & 0 & 87 & 81 & 1 & 87 & 154 & 0 & 87 & 227 & 0 & 87 & 300 & 0 \\
\hline 87 & 9 & 0 & 87 & 82 & 0 & 87 & 155 & 0 & 87 & 228 & 0 & 87 & 301 & 0 \\
\hline 87 & 10 & 0 & 87 & 83 & 0 & 87 & 156 & 0 & 87 & 229 & 0 & 87 & 302 & 2 \\
\hline 87 & 11 & 0 & 87 & 84 & 0 & 87 & 157 & 1 & 87 & 230 & 0 & 87 & 303 & 0 \\
\hline 87 & 12 & 0 & 87 & 85 & 0 & 87 & 158 & 0 & 87 & 231 & 0 & 87 & 304 & 10 \\
\hline 87 & 13 & 0 & 87 & 86 & 0 & 87 & 159 & 1 & 87 & 232 & 0 & 87 & 305 & 6 \\
\hline 87 & 14 & 0 & 87 & 87 & 0 & 87 & 160 & 0 & 87 & 233 & 0 & 87 & 306 & 1 \\
\hline 87 & 15 & 0 & 87 & 88 & 0 & 87 & 161 & 0 & 87 & 234 & 0 & 87 & 307 & 0 \\
\hline 87 & 16 & 0 & 87 & 89 & 0 & 87 & 162 & 0 & 87 & 235 & 0 & 87 & 308 & 0 \\
\hline 87 & 17 & 0 & 87 & 90 & 0 & 87 & 163 & 0 & 87 & 236 & 0 & 87 & 309 & 15 \\
\hline 87 & 18 & 0 & 87 & 91 & 0 & 87 & 164 & 0 & 87 & 237 & 0 & 87 & 310 & 6 \\
\hline 87 & 19 & 0 & 87 & 92 & 0 & 87 & 165 & 0 & 87 & 238 & 0 & 87 & 311 & 0 \\
\hline 87 & 20 & 0 & 87 & 93 & 0 & 87 & 166 & 0 & 87 & 239 & 0 & 87 & 312 & 0 \\
\hline 87 & 21 & 0 & 87 & 94 & 3 & 87 & 167 & 0 & 87 & 240 & 0 & 87 & 313 & 0 \\
\hline 87 & 22 & 0 & 87 & 95 & 0 & 87 & 168 & 0 & 87 & 241 & 0 & 87 & 314 & 0 \\
\hline 87 & 23 & 0 & 87 & 96 & 0 & 87 & 169 & 0 & 87 & 242 & 0 & 87 & 315 & 0 \\
\hline 87 & 24 & 0 & 87 & 97 & 0 & 87 & 170 & 0 & 87 & 243 & 0 & 87 & 316 & 0 \\
\hline 87 & 25 & 0 & 87 & 98 & 0 & 87 & 171 & 0 & 87 & 244 & 0 & 87 & 317 & 0 \\
\hline 87 & 26 & 0 & 87 & 99 & 0 & 87 & 172 & 0 & 87 & 245 & 0 & 87 & 318 & 0 \\
\hline 87 & 27 & 0 & 87 & 100 & 0 & 87 & 173 & 0 & 87 & 246 & 0 & 87 & 319 & 0 \\
\hline 87 & 28 & 0 & 87 & 101 & 0 & 87 & 174 & 0 & 87 & 247 & 0 & 87 & 320 & 0 \\
\hline 87 & 29 & 0 & 87 & 102 & 0 & 87 & 175 & 0 & 87 & 248 & 0 & 87 & 321 & 0 \\
\hline 87 & 30 & 0 & 87 & 103 & 0 & 87 & 176 & 0 & 87 & 249 & 0 & 87 & 322 & 0 \\
\hline 87 & 31 & 0 & 87 & 104 & 0 & 87 & 177 & 0 & 87 & 250 & 0 & 87 & 323 & 0 \\
\hline 87 & 32 & 0 & 87 & 105 & 0 & 87 & 178 & 0 & 87 & 251 & 0 & 87 & 324 & 0 \\
\hline 87 & 33 & 0 & 87 & 106 & 0 & 87 & 179 & 0 & 87 & 252 & 0 & 87 & 325 & 0 \\
\hline 87 & 34 & 0 & 87 & 107 & 0 & 87 & 180 & 0 & 87 & 253 & 0 & 87 & 326 & 0 \\
\hline
\end{tabular}


Table A-1. Developed Data Precipitation Record for Yucca Mountain that was Used Directly as Input for INFIL V2.0 (Continued)

\begin{tabular}{|c|c|c|c|c|c|c|c|c|c|c|c|c|c|c|}
\hline Year & $\begin{array}{c}\text { Day } \\
\text { of } \\
\text { Year }\end{array}$ & $\begin{array}{c}\text { Daily } \\
\text { Precip- } \\
\text { itation } \\
(\mathrm{mm}) \\
\end{array}$ & Year & $\begin{array}{c}\text { Day } \\
\text { of } \\
\text { Year }\end{array}$ & $\begin{array}{c}\text { Daily } \\
\text { Precip- } \\
\text { itation } \\
(\mathrm{mm}) \\
\end{array}$ & Year & $\begin{array}{c}\text { Day } \\
\text { of } \\
\text { Year }\end{array}$ & $\begin{array}{c}\text { Daily } \\
\text { Precip- } \\
\text { itation } \\
(\mathrm{mm}) \\
\end{array}$ & Year & $\begin{array}{c}\text { Day } \\
\text { of } \\
\text { Year }\end{array}$ & $\begin{array}{c}\text { Daily } \\
\text { Precip- } \\
\text { itation } \\
(\mathrm{mm}) \\
\end{array}$ & Year & $\begin{array}{c}\text { Day } \\
\text { of } \\
\text { Year }\end{array}$ & $\begin{array}{c}\text { Daily } \\
\text { Precip- } \\
\text { itation } \\
(\mathrm{mm}) \\
\end{array}$ \\
\hline 87 & 35 & 0 & 87 & 108 & 0 & 87 & 181 & 0 & 87 & 254 & 0 & 87 & 327 & 0 \\
\hline 87 & 36 & 0 & 87 & 109 & 0 & 87 & 182 & 0 & 87 & 255 & 0 & 87 & 328 & 0 \\
\hline 87 & 37 & 0 & 87 & 110 & 0 & 87 & 183 & 0 & 87 & 256 & 0 & 87 & 329 & 0 \\
\hline 87 & 38 & 0 & 87 & 111 & 0 & 87 & 184 & 0 & 87 & 257 & 0 & 87 & 330 & 0 \\
\hline 87 & 39 & 0 & 87 & 112 & 0 & 87 & 185 & 0 & 87 & 258 & 0 & 87 & 331 & 0 \\
\hline 87 & 40 & 0 & 87 & 113 & 0 & 87 & 186 & 0 & 87 & 259 & 0 & 87 & 332 & 0 \\
\hline 87 & 41 & 0 & 87 & 114 & 0 & 87 & 187 & 0 & 87 & 260 & 0 & 87 & 333 & 0 \\
\hline 87 & 42 & 0 & 87 & 115 & 0 & 87 & 188 & 0 & 87 & 261 & 0 & 87 & 334 & 0 \\
\hline 87 & 43 & 0 & 87 & 116 & 0 & 87 & 189 & 0 & 87 & 262 & 0 & 87 & 335 & 0 \\
\hline 87 & 44 & 0 & 87 & 117 & 0 & 87 & 190 & 0 & 87 & 263 & 0 & 87 & 336 & 0 \\
\hline 87 & 45 & 0 & 87 & 118 & 0 & 87 & 191 & 0 & 87 & 264 & 0 & 87 & 337 & 0 \\
\hline 87 & 46 & 1 & 87 & 119 & 3 & 87 & 192 & 0 & 87 & 265 & 0 & 87 & 338 & 4 \\
\hline 87 & 47 & 0 & 87 & 120 & 0 & 87 & 193 & 0 & 87 & 266 & 0 & 87 & 339 & 2 \\
\hline 87 & 48 & 0 & 87 & 121 & 0 & 87 & 194 & 0 & 87 & 267 & 0 & 87 & 340 & 0 \\
\hline 87 & 49 & 0 & 87 & 122 & 0 & 87 & 195 & 0 & 87 & 268 & 0 & 87 & 341 & 0 \\
\hline 87 & 50 & 0 & 87 & 123 & 0 & 87 & 196 & 0 & 87 & 269 & 0 & 87 & 342 & 0 \\
\hline 87 & 51 & 0 & 87 & 124 & 0 & 87 & 197 & 5 & 87 & 270 & 0 & 87 & 343 & 0 \\
\hline 87 & 52 & 0 & 87 & 125 & 0 & 87 & 198 & 0 & 87 & 271 & 0 & 87 & 344 & 0 \\
\hline 87 & 53 & 0 & 87 & 126 & 0 & 87 & 199 & 0 & 87 & 272 & 0 & 87 & 345 & 0 \\
\hline 87 & 54 & 3 & 87 & 127 & 2 & 87 & 200 & 0 & 87 & 273 & 0 & 87 & 346 & 0 \\
\hline 87 & 55 & 1 & 87 & 128 & 1 & 87 & 201 & 32 & 87 & 274 & 0 & 87 & 347 & 0 \\
\hline 87 & 56 & 5 & 87 & 129 & 0 & 87 & 202 & 5 & 87 & 275 & 0 & 87 & 348 & 0 \\
\hline 87 & 57 & 0 & 87 & 130 & 0 & 87 & 203 & 0 & 87 & 276 & 0 & 87 & 349 & 0 \\
\hline 87 & 58 & 0 & 87 & 131 & 0 & 87 & 204 & 0 & 87 & 277 & 0 & 87 & 350 & 0 \\
\hline 87 & 59 & 0 & 87 & 132 & 2 & 87 & 205 & 0 & 87 & 278 & 0 & 87 & 351 & 8 \\
\hline 87 & 60 & 0 & 87 & 133 & 0 & 87 & 206 & 0 & 87 & 279 & 0 & 87 & 352 & 0 \\
\hline 87 & 61 & 0 & 87 & 134 & 0 & 87 & 207 & 0 & 87 & 280 & 0 & 87 & 353 & 1 \\
\hline 87 & 62 & 0 & 87 & 135 & 2 & 87 & 208 & 0 & 87 & 281 & 0 & 87 & 354 & 0 \\
\hline 87 & 63 & 0 & 87 & 136 & 11 & 87 & 209 & 0 & 87 & 282 & 0 & 87 & 355 & 0 \\
\hline 87 & 64 & 3 & 87 & 137 & 1 & 87 & 210 & 0 & 87 & 283 & 0 & 87 & 356 & 2 \\
\hline 87 & 65 & 5 & 87 & 138 & 0 & 87 & 211 & 0 & 87 & 284 & 0 & 87 & 357 & 1 \\
\hline 87 & 66 & 2 & 87 & 139 & 0 & 87 & 212 & 0 & 87 & 285 & 2 & 87 & 358 & 0 \\
\hline 87 & 67 & 0 & 87 & 140 & 0 & 87 & 213 & 0 & 87 & 286 & 6 & 87 & 359 & 0 \\
\hline 87 & 68 & 0 & 87 & 141 & 0 & 87 & 214 & 0 & 87 & 287 & 0 & 87 & 360 & 0 \\
\hline 87 & 69 & 0 & 87 & 142 & 0 & 87 & 215 & 0 & 87 & 288 & 0 & 87 & 361 & 0 \\
\hline 87 & 70 & 0 & 87 & 143 & 0 & 87 & 216 & 1 & 87 & 289 & 0 & 87 & 362 & 0 \\
\hline 87 & 71 & 0 & 87 & 144 & 0 & 87 & 217 & 3 & 87 & 290 & 0 & 87 & 363 & 0 \\
\hline 87 & 72 & 0 & 87 & 145 & 0 & 87 & 218 & 0 & 87 & 291 & 0 & 87 & 364 & 0 \\
\hline 87 & 73 & 0 & 87 & 146 & 0 & 87 & 219 & 0 & 87 & 292 & 0 & 87 & 365 & 0 \\
\hline 88 & 1 & 0 & 88 & 74 & 0 & 88 & 147 & 0 & 88 & 220 & 0 & 88 & 293 & 0 \\
\hline 88 & 2 & 0 & 88 & 75 & 0 & 88 & 148 & 0 & 88 & 221 & 0 & 88 & 294 & 0 \\
\hline 88 & 3 & 0 & 88 & 76 & 0 & 88 & 149 & 0 & 88 & 222 & 0 & 88 & 295 & 0 \\
\hline 88 & 4 & 1 & 88 & 77 & 0 & 88 & 150 & 3 & 88 & 223 & 0 & 88 & 296 & 0 \\
\hline 88 & 5 & 6 & 88 & 78 & 0 & 88 & 151 & 0 & 88 & 224 & 0 & 88 & 297 & 0 \\
\hline
\end{tabular}


Table A-1. Developed Data Precipitation Record for Yucca Mountain that was Used Directly as Input for INFIL V2.0 (Continued)

\begin{tabular}{|c|c|c|c|c|c|c|c|c|c|c|c|c|c|c|}
\hline Year & $\begin{array}{c}\text { Day } \\
\text { of } \\
\text { Year }\end{array}$ & $\begin{array}{c}\text { Daily } \\
\text { Precip- } \\
\text { itation } \\
(\mathrm{mm}) \\
\end{array}$ & Year & $\begin{array}{c}\text { Day } \\
\text { of } \\
\text { Year }\end{array}$ & $\begin{array}{c}\text { Daily } \\
\text { Precip- } \\
\text { itation } \\
(\mathrm{mm}) \\
\end{array}$ & Year & $\begin{array}{c}\text { Day } \\
\text { of } \\
\text { Year }\end{array}$ & $\begin{array}{c}\text { Daily } \\
\text { Precip- } \\
\text { itation } \\
(\mathrm{mm}) \\
\end{array}$ & Year & $\begin{array}{c}\text { Day } \\
\text { of } \\
\text { Year } \\
\end{array}$ & $\begin{array}{c}\text { Daily } \\
\text { Precip- } \\
\text { itation } \\
(\mathrm{mm}) \\
\end{array}$ & Year & $\begin{array}{c}\text { Day } \\
\text { of } \\
\text { Year }\end{array}$ & $\begin{array}{c}\text { Daily } \\
\text { Precip- } \\
\text { itation } \\
(\mathrm{mm}) \\
\end{array}$ \\
\hline 88 & 6 & 0 & 88 & 79 & 0 & 88 & 152 & 0 & 88 & 225 & 0 & 88 & 298 & 0 \\
\hline 88 & 7 & 0 & 88 & 80 & 0 & 88 & 153 & 0 & 88 & 226 & 0 & 88 & 299 & 0 \\
\hline 88 & 8 & 0 & 88 & 81 & 0 & 88 & 154 & 0 & 88 & 227 & 0 & 88 & 300 & 0 \\
\hline 88 & 9 & 0 & 88 & 82 & 0 & 88 & 155 & 0 & 88 & 228 & 0 & 88 & 301 & 0 \\
\hline 88 & 10 & 0 & 88 & 83 & 0 & 88 & 156 & 0 & 88 & 229 & 0 & 88 & 302 & 0 \\
\hline 88 & 11 & 0 & 88 & 84 & 0 & 88 & 157 & 0 & 88 & 230 & 0 & 88 & 303 & 0 \\
\hline 88 & 12 & 0 & 88 & 85 & 0 & 88 & 158 & 0 & 88 & 231 & 0 & 88 & 304 & 0 \\
\hline 88 & 13 & 0 & 88 & 86 & 0 & 88 & 159 & 0 & 88 & 232 & 0 & 88 & 305 & 0 \\
\hline 88 & 14 & 0 & 88 & 87 & 0 & 88 & 160 & 0 & 88 & 233 & 0 & 88 & 306 & 0 \\
\hline 88 & 15 & 0 & 88 & 88 & 0 & 88 & 161 & 0 & 88 & 234 & 0 & 88 & 307 & 0 \\
\hline 88 & 16 & 0 & 88 & 89 & 0 & 88 & 162 & 0 & 88 & 235 & 0 & 88 & 308 & 0 \\
\hline 88 & 17 & 19 & 88 & 90 & 0 & 88 & 163 & 0 & 88 & 236 & 3 & 88 & 309 & 0 \\
\hline 88 & 18 & 4 & 88 & 91 & 0 & 88 & 164 & 0 & 88 & 237 & 1 & 88 & 310 & 0 \\
\hline 88 & 19 & 0 & 88 & 92 & 0 & 88 & 165 & 0 & 88 & 238 & 3 & 88 & 311 & 0 \\
\hline 88 & 20 & 0 & 88 & 93 & 0 & 88 & 166 & 0 & 88 & 239 & 6 & 88 & 312 & 0 \\
\hline 88 & 21 & 0 & 88 & 94 & 0 & 88 & 167 & 0 & 88 & 240 & 2 & 88 & 313 & 0 \\
\hline 88 & 22 & 0 & 88 & 95 & 0 & 88 & 168 & 0 & 88 & 241 & 4 & 88 & 314 & 0 \\
\hline 88 & 23 & 0 & 88 & 96 & 0 & 88 & 169 & 0 & 88 & 242 & 0 & 88 & 315 & 0 \\
\hline 88 & 24 & 0 & 88 & 97 & 0 & 88 & 170 & 0 & 88 & 243 & 1 & 88 & 316 & 0 \\
\hline 88 & 25 & 0 & 88 & 98 & 0 & 88 & 171 & 0 & 88 & 244 & 0 & 88 & 317 & 0 \\
\hline 88 & 26 & 0 & 88 & 99 & 0 & 88 & 172 & 1 & 88 & 245 & 0 & 88 & 318 & 0 \\
\hline 88 & 27 & 0 & 88 & 100 & 0 & 88 & 173 & 1 & 88 & 246 & 0 & 88 & 319 & 2 \\
\hline 88 & 28 & 0 & 88 & 101 & 0 & 88 & 174 & 2 & 88 & 247 & 0 & 88 & 320 & 0 \\
\hline 88 & 29 & 0 & 88 & 102 & 0 & 88 & 175 & 0 & 88 & 248 & 0 & 88 & 321 & 0 \\
\hline 88 & 30 & 0 & 88 & 103 & 0 & 88 & 176 & 0 & 88 & 249 & 0 & 88 & 322 & 0 \\
\hline 88 & 31 & 0 & 88 & 104 & 1 & 88 & 177 & 0 & 88 & 250 & 0 & 88 & 323 & 0 \\
\hline 88 & 32 & 0 & 88 & 105 & 7 & 88 & 178 & 0 & 88 & 251 & 0 & 88 & 324 & 0 \\
\hline 88 & 33 & 2 & 88 & 106 & 26 & 88 & 179 & 0 & 88 & 252 & 0 & 88 & 325 & 0 \\
\hline 88 & 34 & 0 & 88 & 107 & 1 & 88 & 180 & 0 & 88 & 253 & 0 & 88 & 326 & 0 \\
\hline 88 & 35 & 0 & 88 & 108 & 0 & 88 & 181 & 0 & 88 & 254 & 0 & 88 & 327 & 0 \\
\hline 88 & 36 & 0 & 88 & 109 & 0 & 88 & 182 & 0 & 88 & 255 & 0 & 88 & 328 & 0 \\
\hline 88 & 37 & 0 & 88 & 110 & 0 & 88 & 183 & 0 & 88 & 256 & 0 & 88 & 329 & 0 \\
\hline 88 & 38 & 0 & 88 & 111 & 7 & 88 & 184 & 0 & 88 & 257 & 0 & 88 & 330 & 0 \\
\hline 88 & 39 & 0 & 88 & 112 & 2 & 88 & 185 & 0 & 88 & 258 & 0 & 88 & 331 & 0 \\
\hline 88 & 40 & 0 & 88 & 113 & 1 & 88 & 186 & 0 & 88 & 259 & 0 & 88 & 332 & 0 \\
\hline 88 & 41 & 0 & 88 & 114 & 0 & 88 & 187 & 0 & 88 & 260 & 0 & 88 & 333 & 0 \\
\hline 88 & 42 & 0 & 88 & 115 & 0 & 88 & 188 & 0 & 88 & 261 & 0 & 88 & 334 & 0 \\
\hline 88 & 43 & 0 & 88 & 116 & 0 & 88 & 189 & 0 & 88 & 262 & 0 & 88 & 335 & 0 \\
\hline 88 & 44 & 0 & 88 & 117 & 0 & 88 & 190 & 0 & 88 & 263 & 0 & 88 & 336 & 0 \\
\hline 88 & 45 & 0 & 88 & 118 & 0 & 88 & 191 & 0 & 88 & 264 & 1 & 88 & 337 & 0 \\
\hline 88 & 46 & 0 & 88 & 119 & 0 & 88 & 192 & 0 & 88 & 265 & 3 & 88 & 338 & 0 \\
\hline 88 & 47 & 0 & 88 & 120 & 0 & 88 & 193 & 0 & 88 & 266 & 1 & 88 & 339 & 0 \\
\hline 88 & 48 & 0 & 88 & 121 & 0 & 88 & 194 & 0 & 88 & 267 & 0 & 88 & 340 & 0 \\
\hline 88 & 49 & 0 & 88 & 122 & 0 & 88 & 195 & 0 & 88 & 268 & 0 & 88 & 341 & 0 \\
\hline
\end{tabular}


Table A-1. Developed Data Precipitation Record for Yucca Mountain that was Used Directly as Input for INFIL V2.0 (Continued)

\begin{tabular}{|c|c|c|c|c|c|c|c|c|c|c|c|c|c|c|}
\hline Year & $\begin{array}{c}\text { Day } \\
\text { of } \\
\text { Year }\end{array}$ & $\begin{array}{l}\text { Daily } \\
\text { Precip- } \\
\text { itation } \\
(\mathrm{mm})\end{array}$ & Year & $\begin{array}{c}\text { Day } \\
\text { of } \\
\text { Year }\end{array}$ & $\begin{array}{c}\text { Daily } \\
\text { Precip- } \\
\text { itation } \\
(\mathrm{mm}) \\
\end{array}$ & Year & $\begin{array}{c}\text { Day } \\
\text { of } \\
\text { Year }\end{array}$ & $\begin{array}{c}\text { Daily } \\
\text { Precip- } \\
\text { itation } \\
(\mathrm{mm}) \\
\end{array}$ & Year & $\begin{array}{c}\text { Day } \\
\text { of } \\
\text { Year }\end{array}$ & $\begin{array}{c}\text { Daily } \\
\text { Precip- } \\
\text { itation } \\
(\mathrm{mm}) \\
\end{array}$ & Year & $\begin{array}{c}\text { Day } \\
\text { of } \\
\text { Year }\end{array}$ & $\begin{array}{c}\text { Daily } \\
\text { Precip- } \\
\text { itation } \\
(\mathrm{mm})\end{array}$ \\
\hline 88 & 50 & 0 & 88 & 123 & 0 & 88 & 196 & 0 & 88 & 269 & 0 & 88 & 342 & 0 \\
\hline 88 & 51 & 0 & 88 & 124 & 0 & 88 & 197 & 0 & 88 & 270 & 0 & 88 & 343 & 0 \\
\hline 88 & 52 & 0 & 88 & 125 & 0 & 88 & 198 & 0 & 88 & 271 & 0 & 88 & 344 & 0 \\
\hline 88 & 53 & 0 & 88 & 126 & 1 & 88 & 199 & 0 & 88 & 272 & 0 & 88 & 345 & 0 \\
\hline 88 & 54 & 0 & 88 & 127 & 2 & 88 & 200 & 0 & 88 & 273 & 0 & 88 & 346 & 0 \\
\hline 88 & 55 & 0 & 88 & 128 & 0 & 88 & 201 & 0 & 88 & 274 & 0 & 88 & 347 & 0 \\
\hline 88 & 56 & 0 & 88 & 129 & 0 & 88 & 202 & 0 & 88 & 275 & 0 & 88 & 348 & 0 \\
\hline 88 & 57 & 0 & 88 & 130 & 0 & 88 & 203 & 0 & 88 & 276 & 0 & 88 & 349 & 0 \\
\hline 88 & 58 & 5 & 88 & 131 & 0 & 88 & 204 & 1 & 88 & 277 & 0 & 88 & 350 & 0 \\
\hline 88 & 59 & 1 & 88 & 132 & 0 & 88 & 205 & 0 & 88 & 278 & 0 & 88 & 351 & 0 \\
\hline 88 & 60 & 3 & 88 & 133 & 0 & 88 & 206 & 0 & 88 & 279 & 0 & 88 & 352 & 0 \\
\hline 88 & 61 & 2 & 88 & 134 & 0 & 88 & 207 & 0 & 88 & 280 & 0 & 88 & 353 & 1 \\
\hline 88 & 62 & 0 & 88 & 135 & 0 & 88 & 208 & 0 & 88 & 281 & 0 & 88 & 354 & 0 \\
\hline 88 & 63 & 0 & 88 & 136 & 0 & 88 & 209 & 0 & 88 & 282 & 0 & 88 & 355 & 0 \\
\hline 88 & 64 & 0 & 88 & 137 & 0 & 88 & 210 & 0 & 88 & 283 & 0 & 88 & 356 & 1 \\
\hline 88 & 65 & 0 & 88 & 138 & 0 & 88 & 211 & 2 & 88 & 284 & 0 & 88 & 357 & 0 \\
\hline 88 & 66 & 0 & 88 & 139 & 0 & 88 & 212 & 6 & 88 & 285 & 0 & 88 & 358 & 0 \\
\hline 88 & 67 & 0 & 88 & 140 & 0 & 88 & 213 & 1 & 88 & 286 & 0 & 88 & 359 & 0 \\
\hline 88 & 68 & 0 & 88 & 141 & 0 & 88 & 214 & 5 & 88 & 287 & 0 & 88 & 360 & 0 \\
\hline 88 & 69 & 0 & 88 & 142 & 0 & 88 & 215 & 0 & 88 & 288 & 0 & 88 & 361 & 0 \\
\hline 88 & 70 & 0 & 88 & 143 & 0 & 88 & 216 & 0 & 88 & 289 & 0 & 88 & 362 & 0 \\
\hline 88 & 71 & 0 & 88 & 144 & 0 & 88 & 217 & 0 & 88 & 290 & 0 & 88 & 363 & 0 \\
\hline 88 & 72 & 0 & 88 & 145 & 0 & 88 & 218 & 0 & 88 & 291 & 0 & 88 & 364 & 0 \\
\hline \multirow[t]{2}{*}{88} & 73 & 0 & 88 & 146 & 0 & 88 & 219 & 0 & 88 & 292 & 0 & 88 & 365 & 0 \\
\hline & & & & & & & & & & & & 88 & 366 & 0 \\
\hline 89 & 1 & 0 & 89 & 74 & 0 & 89 & 147 & 0 & 89 & 220 & 2 & 89 & 293 & 0 \\
\hline 89 & 2 & 0 & 89 & 75 & 0 & 89 & 148 & 0 & 89 & 221 & 1 & 89 & 294 & 0 \\
\hline 89 & 3 & 0 & 89 & 76 & 0 & 89 & 149 & 0 & 89 & 222 & 0 & 89 & 295 & 0 \\
\hline 89 & 4 & 2 & 89 & 77 & 0 & 89 & 150 & 0 & 89 & 223 & 10 & 89 & 296 & 0 \\
\hline 89 & 5 & 0 & 89 & 78 & 0 & 89 & 151 & 0 & 89 & 224 & 0 & 89 & 297 & 0 \\
\hline 89 & 6 & 0 & 89 & 79 & 0 & 89 & 152 & 0 & 89 & 225 & 0 & 89 & 298 & 1 \\
\hline 89 & 7 & 0 & 89 & 80 & 0 & 89 & 153 & 0 & 89 & 226 & 0 & 89 & 299 & 0 \\
\hline 89 & 8 & 0 & 89 & 81 & 0 & 89 & 154 & 0 & 89 & 227 & 0 & 89 & 300 & 0 \\
\hline 89 & 9 & 0 & 89 & 82 & 0 & 89 & 155 & 0 & 89 & 228 & 0 & 89 & 301 & 0 \\
\hline 89 & 10 & 0 & 89 & 83 & 0 & 89 & 156 & 0 & 89 & 229 & 0 & 89 & 302 & 0 \\
\hline 89 & 11 & 0 & 89 & 84 & 3 & 89 & 157 & 0 & 89 & 230 & 0 & 89 & 303 & 0 \\
\hline 89 & 12 & 0 & 89 & 85 & 1 & 89 & 158 & 0 & 89 & 231 & 0 & 89 & 304 & 0 \\
\hline 89 & 13 & 0 & 89 & 86 & 0 & 89 & 159 & 0 & 89 & 232 & 0 & 89 & 305 & 0 \\
\hline 89 & 14 & 0 & 89 & 87 & 0 & 89 & 160 & 0 & 89 & 233 & 0 & 89 & 306 & 0 \\
\hline 89 & 15 & 0 & 89 & 88 & 0 & 89 & 161 & 0 & 89 & 234 & 0 & 89 & 307 & 0 \\
\hline 89 & 16 & 0 & 89 & 89 & 0 & 89 & 162 & 0 & 89 & 235 & 0 & 89 & 308 & 0 \\
\hline 89 & 17 & 0 & 89 & 90 & 0 & 89 & 163 & 0 & 89 & 236 & 0 & 89 & 309 & 0 \\
\hline 89 & 18 & 0 & 89 & 91 & 0 & 89 & 164 & 0 & 89 & 237 & 0 & 89 & 310 & 0 \\
\hline 89 & 19 & 0 & 89 & 92 & 0 & 89 & 165 & 0 & 89 & 238 & 0 & 89 & 311 & 0 \\
\hline
\end{tabular}


Table A-1. Developed Data Precipitation Record for Yucca Mountain that was Used Directly as Input for INFIL V2.0 (Continued)

\begin{tabular}{|c|c|c|c|c|c|c|c|c|c|c|c|c|c|c|}
\hline Year & $\begin{array}{c}\text { Day } \\
\text { of } \\
\text { Year }\end{array}$ & $\begin{array}{c}\text { Daily } \\
\text { Precip- } \\
\text { itation } \\
(\mathrm{mm}) \\
\end{array}$ & Year & $\begin{array}{c}\text { Day } \\
\text { of } \\
\text { Year }\end{array}$ & $\begin{array}{c}\text { Daily } \\
\text { Precip- } \\
\text { itation } \\
(\mathrm{mm}) \\
\end{array}$ & Year & $\begin{array}{c}\text { Day } \\
\text { of } \\
\text { Year }\end{array}$ & $\begin{array}{c}\text { Daily } \\
\text { Precip- } \\
\text { itation } \\
(\mathrm{mm}) \\
\end{array}$ & Year & $\begin{array}{c}\text { Day } \\
\text { of } \\
\text { Year }\end{array}$ & $\begin{array}{c}\text { Daily } \\
\text { Precip- } \\
\text { itation } \\
(\mathrm{mm}) \\
\end{array}$ & Year & $\begin{array}{c}\text { Day } \\
\text { of } \\
\text { Year }\end{array}$ & $\begin{array}{c}\text { Daily } \\
\text { Precip- } \\
\text { itation } \\
(\mathrm{mm}) \\
\end{array}$ \\
\hline 89 & 20 & 0 & 89 & 93 & 0 & 89 & 166 & 0 & 89 & 239 & 0 & 89 & 312 & 0 \\
\hline 89 & 21 & 0 & 89 & 94 & 0 & 89 & 167 & 0 & 89 & 240 & 0 & 89 & 313 & 0 \\
\hline 89 & 22 & 0 & 89 & 95 & 0 & 89 & 168 & 0 & 89 & 241 & 0 & 89 & 314 & 0 \\
\hline 89 & 23 & 0 & 89 & 96 & 0 & 89 & 169 & 0 & 89 & 242 & 0 & 89 & 315 & 0 \\
\hline 89 & 24 & 0 & 89 & 97 & 0 & 89 & 170 & 0 & 89 & 243 & 0 & 89 & 316 & 0 \\
\hline 89 & 25 & 0 & 89 & 98 & 0 & 89 & 171 & 0 & 89 & 244 & 0 & 89 & 317 & 0 \\
\hline 89 & 26 & 0 & 89 & 99 & 0 & 89 & 172 & 0 & 89 & 245 & 0 & 89 & 318 & 0 \\
\hline 89 & 27 & 0 & 89 & 100 & 0 & 89 & 173 & 0 & 89 & 246 & 0 & 89 & 319 & 0 \\
\hline 89 & 28 & 0 & 89 & 101 & 0 & 89 & 174 & 0 & 89 & 247 & 0 & 89 & 320 & 0 \\
\hline 89 & 29 & 0 & 89 & 102 & 0 & 89 & 175 & 0 & 89 & 248 & 0 & 89 & 321 & 0 \\
\hline 89 & 30 & 0 & 89 & 103 & 0 & 89 & 176 & 0 & 89 & 249 & 0 & 89 & 322 & 0 \\
\hline 89 & 31 & 0 & 89 & 104 & 0 & 89 & 177 & 0 & 89 & 250 & 0 & 89 & 323 & 0 \\
\hline 89 & 32 & 0 & 89 & 105 & 0 & 89 & 178 & 0 & 89 & 251 & 0 & 89 & 324 & 0 \\
\hline 89 & 33 & 0 & 89 & 106 & 0 & 89 & 179 & 0 & 89 & 252 & 0 & 89 & 325 & 0 \\
\hline 89 & 34 & 0 & 89 & 107 & 0 & 89 & 180 & 0 & 89 & 253 & 0 & 89 & 326 & 0 \\
\hline 89 & 35 & 2 & 89 & 108 & 0 & 89 & 181 & 0 & 89 & 254 & 0 & 89 & 327 & 0 \\
\hline 89 & 36 & 0 & 89 & 109 & 0 & 89 & 182 & 0 & 89 & 255 & 0 & 89 & 328 & 0 \\
\hline 89 & 37 & 0 & 89 & 110 & 0 & 89 & 183 & 0 & 89 & 256 & 0 & 89 & 329 & 0 \\
\hline 89 & 38 & 0 & 89 & 111 & 0 & 89 & 184 & 0 & 89 & 257 & 0 & 89 & 330 & 0 \\
\hline 89 & 39 & 1 & 89 & 112 & 0 & 89 & 185 & 0 & 89 & 258 & 0 & 89 & 331 & 0 \\
\hline 89 & 40 & 3 & 89 & 113 & 0 & 89 & 186 & 0 & 89 & 259 & 0 & 89 & 332 & 0 \\
\hline 89 & 41 & 1 & 89 & 114 & 0 & 89 & 187 & 0 & 89 & 260 & 0 & 89 & 333 & 0 \\
\hline 89 & 42 & 0 & 89 & 115 & 0 & 89 & 188 & 0 & 89 & 261 & 0 & 89 & 334 & 0 \\
\hline 89 & 43 & 0 & 89 & 116 & 0 & 89 & 189 & 0 & 89 & 262 & 3 & 89 & 335 & 0 \\
\hline 89 & 44 & 0 & 89 & 117 & 0 & 89 & 190 & 0 & 89 & 263 & 0 & 89 & 336 & 0 \\
\hline 89 & 45 & 0 & 89 & 118 & 0 & 89 & 191 & 0 & 89 & 264 & 0 & 89 & 337 & 0 \\
\hline 89 & 46 & 0 & 89 & 119 & 0 & 89 & 192 & 0 & 89 & 265 & 0 & 89 & 338 & 0 \\
\hline 89 & 47 & 0 & 89 & 120 & 0 & 89 & 193 & 0 & 89 & 266 & 0 & 89 & 339 & 0 \\
\hline 89 & 48 & 0 & 89 & 121 & 0 & 89 & 194 & 0 & 89 & 267 & 0 & 89 & 340 & 0 \\
\hline 89 & 49 & 0 & 89 & 122 & 0 & 89 & 195 & 0 & 89 & 268 & 0 & 89 & 341 & 0 \\
\hline 89 & 50 & 0 & 89 & 123 & 0 & 89 & 196 & 0 & 89 & 269 & 0 & 89 & 342 & 0 \\
\hline 89 & 51 & 0 & 89 & 124 & 0 & 89 & 197 & 0 & 89 & 270 & 0 & 89 & 343 & 0 \\
\hline 89 & 52 & 0 & 89 & 125 & 0 & 89 & 198 & 0 & 89 & 271 & 0 & 89 & 344 & 0 \\
\hline 89 & 53 & 0 & 89 & 126 & 0 & 89 & 199 & 0 & 89 & 272 & 0 & 89 & 345 & 0 \\
\hline 89 & 54 & 0 & 89 & 127 & 0 & 89 & 200 & 0 & 89 & 273 & 0 & 89 & 346 & 0 \\
\hline 89 & 55 & 0 & 89 & 128 & 0 & 89 & 201 & 0 & 89 & 274 & 0 & 89 & 347 & 0 \\
\hline 89 & 56 & 0 & 89 & 129 & 0 & 89 & 202 & 0 & 89 & 275 & 0 & 89 & 348 & 0 \\
\hline 89 & 57 & 0 & 89 & 130 & 0 & 89 & 203 & 0 & 89 & 276 & 0 & 89 & 349 & 0 \\
\hline 89 & 58 & 0 & 89 & 131 & 3 & 89 & 204 & 0 & 89 & 277 & 0 & 89 & 350 & 0 \\
\hline 89 & 59 & 0 & 89 & 132 & 0 & 89 & 205 & 0 & 89 & 278 & 0 & 89 & 351 & 0 \\
\hline 89 & 60 & 0 & 89 & 133 & 1 & 89 & 206 & 0 & 89 & 279 & 0 & 89 & 352 & 0 \\
\hline 89 & 61 & 0 & 89 & 134 & 0 & 89 & 207 & 0 & 89 & 280 & 0 & 89 & 353 & 0 \\
\hline 89 & 62 & 0 & 89 & 135 & 1 & 89 & 208 & 0 & 89 & 281 & 0 & 89 & 354 & 0 \\
\hline 89 & 63 & 0 & 89 & 136 & 0 & 89 & 209 & 0 & 89 & 282 & 0 & 89 & 355 & 1 \\
\hline
\end{tabular}


Table A-1. Developed Data Precipitation Record for Yucca Mountain that was Used Directly as Input for INFIL V2.0 (Continued)

\begin{tabular}{|c|c|c|c|c|c|c|c|c|c|c|c|c|c|c|}
\hline Year & $\begin{array}{c}\text { Day } \\
\text { of } \\
\text { Year }\end{array}$ & $\begin{array}{c}\text { Daily } \\
\text { Precip- } \\
\text { itation } \\
(\mathrm{mm}) \\
\end{array}$ & Year & $\begin{array}{c}\text { Day } \\
\text { of } \\
\text { Year }\end{array}$ & $\begin{array}{c}\text { Daily } \\
\text { Precip- } \\
\text { itation } \\
(\mathrm{mm}) \\
\end{array}$ & Year & $\begin{array}{c}\text { Day } \\
\text { of } \\
\text { Year }\end{array}$ & $\begin{array}{c}\text { Daily } \\
\text { Precip- } \\
\text { itation } \\
(\mathrm{mm}) \\
\end{array}$ & Year & $\begin{array}{c}\text { Day } \\
\text { of } \\
\text { Year } \\
\end{array}$ & $\begin{array}{c}\text { Daily } \\
\text { Precip- } \\
\text { itation } \\
(\mathrm{mm}) \\
\end{array}$ & Year & $\begin{array}{c}\text { Day } \\
\text { of } \\
\text { Year }\end{array}$ & $\begin{array}{c}\text { Daily } \\
\text { Precip- } \\
\text { itation } \\
(\mathrm{mm}) \\
\end{array}$ \\
\hline 89 & 64 & 0 & 89 & 137 & 0 & 89 & 210 & 0 & 89 & 283 & 0 & 89 & 356 & 0 \\
\hline 89 & 65 & 0 & 89 & 138 & 0 & 89 & 211 & 0 & 89 & 284 & 0 & 89 & 357 & 0 \\
\hline 89 & 66 & 0 & 89 & 139 & 0 & 89 & 212 & 0 & 89 & 285 & 0 & 89 & 358 & 0 \\
\hline 89 & 67 & 0 & 89 & 140 & 0 & 89 & 213 & 0 & 89 & 286 & 0 & 89 & 359 & 0 \\
\hline 89 & 68 & 0 & 89 & 141 & 0 & 89 & 214 & 0 & 89 & 287 & 0 & 89 & 360 & 0 \\
\hline 89 & 69 & 0 & 89 & 142 & 0 & 89 & 215 & 0 & 89 & 288 & 0 & 89 & 361 & 0 \\
\hline 89 & 70 & 0 & 89 & 143 & 0 & 89 & 216 & 0 & 89 & 289 & 0 & 89 & 362 & 0 \\
\hline 89 & 71 & 0 & 89 & 144 & 0 & 89 & 217 & 0 & 89 & 290 & 0 & 89 & 363 & 0 \\
\hline 89 & 72 & 0 & 89 & 145 & 0 & 89 & 218 & 0 & 89 & 291 & 0 & 89 & 364 & 0 \\
\hline 89 & 73 & 0 & 89 & 146 & 0 & 89 & 219 & 1 & 89 & 292 & 0 & 89 & 365 & 0 \\
\hline 90 & 1 & 0 & 90 & 74 & 0 & 90 & 147 & 3 & 90 & 220 & 0 & 90 & 293 & 0 \\
\hline 90 & 2 & 1 & 90 & 75 & 0 & 90 & 148 & 11 & 90 & 221 & 0 & 90 & 294 & 0 \\
\hline 90 & 3 & 0 & 90 & 76 & 0 & 90 & 149 & 0 & 90 & 222 & 0 & 90 & 295 & 0 \\
\hline 90 & 4 & 0 & 90 & 77 & 0 & 90 & 150 & 0 & 90 & 223 & 0 & 90 & 296 & 0 \\
\hline 90 & 5 & 0 & 90 & 78 & 0 & 90 & 151 & 0 & 90 & 224 & 1 & 90 & 297 & 0 \\
\hline 90 & 6 & 0 & 90 & 79 & 0 & 90 & 152 & 0 & 90 & 225 & 0 & 90 & 298 & 0 \\
\hline 90 & 7 & 0 & 90 & 80 & 0 & 90 & 153 & 0 & 90 & 226 & 0 & 90 & 299 & 0 \\
\hline 90 & 8 & 0 & 90 & 81 & 0 & 90 & 154 & 0 & 90 & 227 & 8 & 90 & 300 & 0 \\
\hline 90 & 9 & 0 & 90 & 82 & 0 & 90 & 155 & 0 & 90 & 228 & 0 & 90 & 301 & 0 \\
\hline 90 & 10 & 0 & 90 & 83 & 0 & 90 & 156 & 0 & 90 & 229 & 0 & 90 & 302 & 0 \\
\hline 90 & 11 & 0 & 90 & 84 & 0 & 90 & 157 & 0 & 90 & 230 & 0 & 90 & 303 & 0 \\
\hline 90 & 12 & 0 & 90 & 85 & 0 & 90 & 158 & 0 & 90 & 231 & 0 & 90 & 304 & 0 \\
\hline 90 & 13 & 0 & 90 & 86 & 0 & 90 & 159 & 0 & 90 & 232 & 0 & 90 & 305 & 0 \\
\hline 90 & 14 & 3 & 90 & 87 & 0 & 90 & 160 & 1 & 90 & 233 & 0 & 90 & 306 & 0 \\
\hline 90 & 15 & 0 & 90 & 88 & 0 & 90 & 161 & 2 & 90 & 234 & 0 & 90 & 307 & 0 \\
\hline 90 & 16 & 2 & 90 & 89 & 0 & 90 & 162 & 0 & 90 & 235 & 0 & 90 & 308 & 0 \\
\hline 90 & 17 & 6 & 90 & 90 & 0 & 90 & 163 & 0 & 90 & 236 & 0 & 90 & 309 & 0 \\
\hline 90 & 18 & 0 & 90 & 91 & 0 & 90 & 164 & 0 & 90 & 237 & 0 & 90 & 310 & 0 \\
\hline 90 & 19 & 0 & 90 & 92 & 0 & 90 & 165 & 0 & 90 & 238 & 0 & 90 & 311 & 0 \\
\hline 90 & 20 & 0 & 90 & 93 & 0 & 90 & 166 & 0 & 90 & 239 & 0 & 90 & 312 & 0 \\
\hline 90 & 21 & 0 & 90 & 94 & 0 & 90 & 167 & 0 & 90 & 240 & 0 & 90 & 313 & 0 \\
\hline 90 & 22 & 0 & 90 & 95 & 0 & 90 & 168 & 0 & 90 & 241 & 0 & 90 & 314 & 0 \\
\hline 90 & 23 & 0 & 90 & 96 & 0 & 90 & 169 & 0 & 90 & 242 & 0 & 90 & 315 & 0 \\
\hline 90 & 24 & 0 & 90 & 97 & 0 & 90 & 170 & 0 & 90 & 243 & 0 & 90 & 316 & 0 \\
\hline 90 & 25 & 0 & 90 & 98 & 0 & 90 & 171 & 0 & 90 & 244 & 0 & 90 & 317 & 0 \\
\hline 90 & 26 & 0 & 90 & 99 & 0 & 90 & 172 & 0 & 90 & 245 & 0 & 90 & 318 & 0 \\
\hline 90 & 27 & 0 & 90 & 100 & 0 & 90 & 173 & 0 & 90 & 246 & 0 & 90 & 319 & 0 \\
\hline 90 & 28 & 0 & 90 & 101 & 0 & 90 & 174 & 0 & 90 & 247 & 0 & 90 & 320 & 0 \\
\hline 90 & 29 & 0 & 90 & 102 & 0 & 90 & 175 & 0 & 90 & 248 & 0 & 90 & 321 & 0 \\
\hline 90 & 30 & 0 & 90 & 103 & 0 & 90 & 176 & 0 & 90 & 249 & 0 & 90 & 322 & 0 \\
\hline 90 & 31 & 0 & 90 & 104 & 0 & 90 & 177 & 0 & 90 & 250 & 0 & 90 & 323 & 1 \\
\hline 90 & 32 & 3 & 90 & 105 & 0 & 90 & 178 & 0 & 90 & 251 & 0 & 90 & 324 & 3 \\
\hline 90 & 33 & 0 & 90 & 106 & 0 & 90 & 179 & 0 & 90 & 252 & 0 & 90 & 325 & 0 \\
\hline 90 & 34 & 0 & 90 & 107 & 0 & 90 & 180 & 0 & 90 & 253 & 0 & 90 & 326 & 0 \\
\hline
\end{tabular}


Table A-1. Developed Data Precipitation Record for Yucca Mountain that was Used Directly as Input for INFIL V2.0 (Continued)

\begin{tabular}{|c|c|c|c|c|c|c|c|c|c|c|c|c|c|c|}
\hline Year & $\begin{array}{c}\text { Day } \\
\text { of } \\
\text { Year }\end{array}$ & $\begin{array}{c}\text { Daily } \\
\text { Precip- } \\
\text { itation } \\
(\mathrm{mm}) \\
\end{array}$ & Year & $\begin{array}{c}\text { Day } \\
\text { of } \\
\text { Year }\end{array}$ & $\begin{array}{c}\text { Daily } \\
\text { Precip- } \\
\text { itation } \\
(\mathrm{mm}) \\
\end{array}$ & Year & $\begin{array}{c}\text { Day } \\
\text { of } \\
\text { Year }\end{array}$ & $\begin{array}{c}\text { Daily } \\
\text { Precip- } \\
\text { itation } \\
(\mathrm{mm}) \\
\end{array}$ & Year & $\begin{array}{c}\text { Day } \\
\text { of } \\
\text { Year } \\
\end{array}$ & $\begin{array}{c}\text { Daily } \\
\text { Precip- } \\
\text { itation } \\
(\mathrm{mm}) \\
\end{array}$ & Year & $\begin{array}{c}\text { Day } \\
\text { of } \\
\text { Year }\end{array}$ & $\begin{array}{c}\text { Daily } \\
\text { Precip- } \\
\text { itation } \\
(\mathrm{mm}) \\
\end{array}$ \\
\hline 90 & 35 & 0 & 90 & 108 & 0 & 90 & 181 & 0 & 90 & 254 & 0 & 90 & 327 & 0 \\
\hline 90 & 36 & 0 & 90 & 109 & 0 & 90 & 182 & 0 & 90 & 255 & 0 & 90 & 328 & 0 \\
\hline 90 & 37 & 0 & 90 & 110 & 5 & 90 & 183 & 0 & 90 & 256 & 0 & 90 & 329 & 0 \\
\hline 90 & 38 & 0 & 90 & 111 & 0 & 90 & 184 & 0 & 90 & 257 & 0 & 90 & 330 & 0 \\
\hline 90 & 39 & 0 & 90 & 112 & 0 & 90 & 185 & 0 & 90 & 258 & 0 & 90 & 331 & 0 \\
\hline 90 & 40 & 0 & 90 & 113 & 1 & 90 & 186 & 0 & 90 & 259 & 0 & 90 & 332 & 0 \\
\hline 90 & 41 & 0 & 90 & 114 & 0 & 90 & 187 & 0 & 90 & 260 & 0 & 90 & 333 & 0 \\
\hline 90 & 42 & 0 & 90 & 115 & 0 & 90 & 188 & 0 & 90 & 261 & 0 & 90 & 334 & 0 \\
\hline 90 & 43 & 0 & 90 & 116 & 0 & 90 & 189 & 0 & 90 & 262 & 0 & 90 & 335 & 0 \\
\hline 90 & 44 & 0 & 90 & 117 & 0 & 90 & 190 & 0 & 90 & 263 & 0 & 90 & 336 & 0 \\
\hline 90 & 45 & 0 & 90 & 118 & 0 & 90 & 191 & 0 & 90 & 264 & 0 & 90 & 337 & 0 \\
\hline 90 & 46 & 0 & 90 & 119 & 0 & 90 & 192 & 0 & 90 & 265 & 0 & 90 & 338 & 0 \\
\hline 90 & 47 & 0 & 90 & 120 & 0 & 90 & 193 & 0 & 90 & 266 & 10 & 90 & 339 & 0 \\
\hline 90 & 48 & 0 & 90 & 121 & 0 & 90 & 194 & 0 & 90 & 267 & 0 & 90 & 340 & 0 \\
\hline 90 & 49 & 0 & 90 & 122 & 0 & 90 & 195 & 9 & 90 & 268 & 0 & 90 & 341 & 0 \\
\hline 90 & 50 & 0 & 90 & 123 & 0 & 90 & 196 & 0 & 90 & 269 & 0 & 90 & 342 & 0 \\
\hline 90 & 51 & 0 & 90 & 124 & 0 & 90 & 197 & 7 & 90 & 270 & 0 & 90 & 343 & 0 \\
\hline 90 & 52 & 0 & 90 & 125 & 0 & 90 & 198 & 0 & 90 & 271 & 1 & 90 & 344 & 0 \\
\hline 90 & 53 & 0 & 90 & 126 & 0 & 90 & 199 & 0 & 90 & 272 & 0 & 90 & 345 & 0 \\
\hline 90 & 54 & 0 & 90 & 127 & 0 & 90 & 200 & 0 & 90 & 273 & 0 & 90 & 346 & 0 \\
\hline 90 & 55 & 0 & 90 & 128 & 0 & 90 & 201 & 0 & 90 & 274 & 0 & 90 & 347 & 0 \\
\hline 90 & 56 & 0 & 90 & 129 & 0 & 90 & 202 & 0 & 90 & 275 & 0 & 90 & 348 & 0 \\
\hline 90 & 57 & 0 & 90 & 130 & 0 & 90 & 203 & 0 & 90 & 276 & 0 & 90 & 349 & 0 \\
\hline 90 & 58 & 0 & 90 & 131 & 0 & 90 & 204 & 0 & 90 & 277 & 0 & 90 & 350 & 0 \\
\hline 90 & 59 & 0 & 90 & 132 & 0 & 90 & 205 & 0 & 90 & 278 & 0 & 90 & 351 & 0 \\
\hline 90 & 60 & 0 & 90 & 133 & 0 & 90 & 206 & 0 & 90 & 279 & 0 & 90 & 352 & 0 \\
\hline 90 & 61 & 0 & 90 & 134 & 0 & 90 & 207 & 0 & 90 & 280 & 0 & 90 & 353 & 0 \\
\hline 90 & 62 & 0 & 90 & 135 & 0 & 90 & 208 & 0 & 90 & 281 & 0 & 90 & 354 & 0 \\
\hline 90 & 63 & 0 & 90 & 136 & 0 & 90 & 209 & 0 & 90 & 282 & 0 & 90 & 355 & 0 \\
\hline 90 & 64 & 1 & 90 & 137 & 0 & 90 & 210 & 0 & 90 & 283 & 0 & 90 & 356 & 0 \\
\hline 90 & 65 & 0 & 90 & 138 & 0 & 90 & 211 & 0 & 90 & 284 & 0 & 90 & 357 & 0 \\
\hline 90 & 66 & 0 & 90 & 139 & 0 & 90 & 212 & 0 & 90 & 285 & 0 & 90 & 358 & 0 \\
\hline 90 & 67 & 0 & 90 & 140 & 0 & 90 & 213 & 0 & 90 & 286 & 0 & 90 & 359 & 0 \\
\hline 90 & 68 & 0 & 90 & 141 & 0 & 90 & 214 & 0 & 90 & 287 & 0 & 90 & 360 & 0 \\
\hline 90 & 69 & 0 & 90 & 142 & 0 & 90 & 215 & 0 & 90 & 288 & 0 & 90 & 361 & 0 \\
\hline 90 & 70 & 0 & 90 & 143 & 0 & 90 & 216 & 0 & 90 & 289 & 0 & 90 & 362 & 0 \\
\hline 90 & 71 & 0 & 90 & 144 & 0 & 90 & 217 & 0 & 90 & 290 & 0 & 90 & 363 & 0 \\
\hline 90 & 72 & 0 & 90 & 145 & 0 & 90 & 218 & 0 & 90 & 291 & 0 & 90 & 364 & 0 \\
\hline 90 & 73 & 0 & 90 & 146 & 0 & 90 & 219 & 0 & 90 & 292 & 0 & 90 & 365 & 0 \\
\hline 91 & 1 & 0 & 91 & 74 & 0 & 91 & 147 & 0 & 91 & 220 & 0 & 91 & 293 & 0 \\
\hline 91 & 2 & 0 & 91 & 75 & 0 & 91 & 148 & 0 & 91 & 221 & 0 & 91 & 294 & 0 \\
\hline 91 & 3 & 2 & 91 & 76 & 0 & 91 & 149 & 0 & 91 & 222 & 4 & 91 & 295 & 0 \\
\hline 91 & 4 & 1 & 91 & 77 & 0 & 91 & 150 & 0 & 91 & 223 & 1 & 91 & 296 & 0 \\
\hline 91 & 5 & 0 & 91 & 78 & 11 & 91 & 151 & 0 & 91 & 224 & 9 & 91 & 297 & 0 \\
\hline
\end{tabular}


Table A-1. Developed Data Precipitation Record for Yucca Mountain that was Used Directly as Input for INFIL V2.0 (Continued)

\begin{tabular}{|c|c|c|c|c|c|c|c|c|c|c|c|c|c|c|}
\hline Year & $\begin{array}{c}\text { Day } \\
\text { of } \\
\text { Year }\end{array}$ & $\begin{array}{c}\text { Daily } \\
\text { Precip- } \\
\text { itation } \\
(\mathrm{mm}) \\
\end{array}$ & Year & $\begin{array}{c}\text { Day } \\
\text { of } \\
\text { Year }\end{array}$ & $\begin{array}{c}\text { Daily } \\
\text { Precip- } \\
\text { itation } \\
(\mathrm{mm}) \\
\end{array}$ & Year & $\begin{array}{c}\text { Day } \\
\text { of } \\
\text { Year }\end{array}$ & $\begin{array}{c}\text { Daily } \\
\text { Precip- } \\
\text { itation } \\
(\mathrm{mm}) \\
\end{array}$ & Year & $\begin{array}{c}\text { Day } \\
\text { of } \\
\text { Year } \\
\end{array}$ & $\begin{array}{c}\text { Daily } \\
\text { Precip- } \\
\text { itation } \\
(\mathrm{mm}) \\
\end{array}$ & Year & $\begin{array}{c}\text { Day } \\
\text { of } \\
\text { Year }\end{array}$ & $\begin{array}{c}\text { Daily } \\
\text { Precip- } \\
\text { itation } \\
(\mathrm{mm}) \\
\end{array}$ \\
\hline 91 & 6 & 0 & 91 & 79 & 4 & 91 & 152 & 2 & 91 & 225 & 0 & 91 & 298 & 0 \\
\hline 91 & 7 & 0 & 91 & 80 & 19 & 91 & 153 & 0 & 91 & 226 & 0 & 91 & 299 & 2 \\
\hline 91 & 8 & 0 & 91 & 81 & 1 & 91 & 154 & 0 & 91 & 227 & 0 & 91 & 300 & 0 \\
\hline 91 & 9 & 0 & 91 & 82 & 0 & 91 & 155 & 0 & 91 & 228 & 0 & 91 & 301 & 0 \\
\hline 91 & 10 & 0 & 91 & 83 & 0 & 91 & 156 & 0 & 91 & 229 & 0 & 91 & 302 & 0 \\
\hline 91 & 11 & 0 & 91 & 84 & 0 & 91 & 157 & 0 & 91 & 230 & 0 & 91 & 303 & 0 \\
\hline 91 & 12 & 0 & 91 & 85 & 3 & 91 & 158 & 0 & 91 & 231 & 0 & 91 & 304 & 0 \\
\hline 91 & 13 & 0 & 91 & 86 & 19 & 91 & 159 & 0 & 91 & 232 & 0 & 91 & 305 & 0 \\
\hline 91 & 14 & 0 & 91 & 87 & 0 & 91 & 160 & 0 & 91 & 233 & 0 & 91 & 306 & 0 \\
\hline 91 & 15 & 0 & 91 & 88 & 0 & 91 & 161 & 0 & 91 & 234 & 0 & 91 & 307 & 0 \\
\hline 91 & 16 & 0 & 91 & 89 & 0 & 91 & 162 & 0 & 91 & 235 & 0 & 91 & 308 & 0 \\
\hline 91 & 17 & 0 & 91 & 90 & 0 & 91 & 163 & 0 & 91 & 236 & 0 & 91 & 309 & 0 \\
\hline 91 & 18 & 0 & 91 & 91 & 0 & 91 & 164 & 0 & 91 & 237 & 0 & 91 & 310 & 0 \\
\hline 91 & 19 & 0 & 91 & 92 & 0 & 91 & 165 & 0 & 91 & 238 & 0 & 91 & 311 & 0 \\
\hline 91 & 20 & 0 & 91 & 93 & 0 & 91 & 166 & 0 & 91 & 239 & 0 & 91 & 312 & 0 \\
\hline 91 & 21 & 0 & 91 & 94 & 0 & 91 & 167 & 0 & 91 & 240 & 0 & 91 & 313 & 0 \\
\hline 91 & 22 & 0 & 91 & 95 & 0 & 91 & 168 & 0 & 91 & 241 & 0 & 91 & 314 & 0 \\
\hline 91 & 23 & 0 & 91 & 96 & 0 & 91 & 169 & 0 & 91 & 242 & 0 & 91 & 315 & 0 \\
\hline 91 & 24 & 0 & 91 & 97 & 0 & 91 & 170 & 0 & 91 & 243 & 13 & 91 & 316 & 0 \\
\hline 91 & 25 & 0 & 91 & 98 & 0 & 91 & 171 & 0 & 91 & 244 & 0 & 91 & 317 & 0 \\
\hline 91 & 26 & 0 & 91 & 99 & 0 & 91 & 172 & 0 & 91 & 245 & 0 & 91 & 318 & 0 \\
\hline 91 & 27 & 0 & 91 & 100 & 0 & 91 & 173 & 0 & 91 & 246 & 0 & 91 & 319 & 0 \\
\hline 91 & 28 & 0 & 91 & 101 & 0 & 91 & 174 & 0 & 91 & 247 & 0 & 91 & 320 & 0 \\
\hline 91 & 29 & 0 & 91 & 102 & 0 & 91 & 175 & 0 & 91 & 248 & 2 & 91 & 321 & 0 \\
\hline 91 & 30 & 0 & 91 & 103 & 0 & 91 & 176 & 0 & 91 & 249 & 2 & 91 & 322 & 0 \\
\hline 91 & 31 & 0 & 91 & 104 & 0 & 91 & 177 & 0 & 91 & 250 & 0 & 91 & 323 & 0 \\
\hline 91 & 32 & 0 & 91 & 105 & 0 & 91 & 178 & 0 & 91 & 251 & 0 & 91 & 324 & 0 \\
\hline 91 & 33 & 0 & 91 & 106 & 0 & 91 & 179 & 0 & 91 & 252 & 0 & 91 & 325 & 0 \\
\hline 91 & 34 & 0 & 91 & 107 & 0 & 91 & 180 & 0 & 91 & 253 & 0 & 91 & 326 & 0 \\
\hline 91 & 35 & 0 & 91 & 108 & 0 & 91 & 181 & 0 & 91 & 254 & 0 & 91 & 327 & 0 \\
\hline 91 & 36 & 0 & 91 & 109 & 0 & 91 & 182 & 0 & 91 & 255 & 0 & 91 & 328 & 0 \\
\hline 91 & 37 & 0 & 91 & 110 & 0 & 91 & 183 & 0 & 91 & 256 & 0 & 91 & 329 & 0 \\
\hline 91 & 38 & 0 & 91 & 111 & 0 & 91 & 184 & 0 & 91 & 257 & 0 & 91 & 330 & 0 \\
\hline 91 & 39 & 0 & 91 & 112 & 0 & 91 & 185 & 0 & 91 & 258 & 0 & 91 & 331 & 0 \\
\hline 91 & 40 & 0 & 91 & 113 & 0 & 91 & 186 & 0 & 91 & 259 & 0 & 91 & 332 & 0 \\
\hline 91 & 41 & 0 & 91 & 114 & 0 & 91 & 187 & 0 & 91 & 260 & 0 & 91 & 333 & 0 \\
\hline 91 & 42 & 0 & 91 & 115 & 0 & 91 & 188 & 1 & 91 & 261 & 0 & 91 & 334 & 0 \\
\hline 91 & 43 & 0 & 91 & 116 & 0 & 91 & 189 & 0 & 91 & 262 & 0 & 91 & 335 & 0 \\
\hline 91 & 44 & 0 & 91 & 117 & 0 & 91 & 190 & 0 & 91 & 263 & 0 & 91 & 336 & 0 \\
\hline 91 & 45 & 0 & 91 & 118 & 0 & 91 & 191 & 0 & 91 & 264 & 0 & 91 & 337 & 0 \\
\hline 91 & 46 & 0 & 91 & 119 & 0 & 91 & 192 & 0 & 91 & 265 & 0 & 91 & 338 & 0 \\
\hline 91 & 47 & 0 & 91 & 120 & 0 & 91 & 193 & 0 & 91 & 266 & 0 & 91 & 339 & 0 \\
\hline 91 & 48 & 0 & 91 & 121 & 0 & 91 & 194 & 0 & 91 & 267 & 0 & 91 & 340 & 0 \\
\hline 91 & 49 & 0 & 91 & 122 & 11 & 91 & 195 & 0 & 91 & 268 & 0 & 91 & 341 & 2 \\
\hline
\end{tabular}


Table A-1. Developed Data Precipitation Record for Yucca Mountain that was Used Directly as Input for INFIL V2.0 (Continued)

\begin{tabular}{|c|c|c|c|c|c|c|c|c|c|c|c|c|c|c|}
\hline Year & $\begin{array}{c}\text { Day } \\
\text { of } \\
\text { Year }\end{array}$ & $\begin{array}{c}\text { Daily } \\
\text { Precip- } \\
\text { itation } \\
(\mathrm{mm}) \\
\end{array}$ & Year & $\begin{array}{c}\text { Day } \\
\text { of } \\
\text { Year }\end{array}$ & $\begin{array}{c}\text { Daily } \\
\text { Precip- } \\
\text { itation } \\
(\mathrm{mm}) \\
\end{array}$ & Year & $\begin{array}{c}\text { Day } \\
\text { of } \\
\text { Year }\end{array}$ & $\begin{array}{c}\text { Daily } \\
\text { Precip- } \\
\text { itation } \\
(\mathrm{mm}) \\
\end{array}$ & Year & $\begin{array}{c}\text { Day } \\
\text { of } \\
\text { Year } \\
\end{array}$ & $\begin{array}{c}\text { Daily } \\
\text { Precip- } \\
\text { itation } \\
(\mathrm{mm}) \\
\end{array}$ & Year & $\begin{array}{c}\text { Day } \\
\text { of } \\
\text { Year }\end{array}$ & $\begin{array}{c}\text { Daily } \\
\text { Precip- } \\
\text { itation } \\
(\mathrm{mm}) \\
\end{array}$ \\
\hline 91 & 50 & 0 & 91 & 123 & 1 & 91 & 196 & 0 & 91 & 269 & 0 & 91 & 342 & 3 \\
\hline 91 & 51 & 0 & 91 & 124 & 0 & 91 & 197 & 0 & 91 & 270 & 0 & 91 & 343 & 0 \\
\hline 91 & 52 & 0 & 91 & 125 & 0 & 91 & 198 & 0 & 91 & 271 & 6 & 91 & 344 & 1 \\
\hline 91 & 53 & 0 & 91 & 126 & 0 & 91 & 199 & 0 & 91 & 272 & 0 & 91 & 345 & 0 \\
\hline 91 & 54 & 0 & 91 & 127 & 0 & 91 & 200 & 0 & 91 & 273 & 0 & 91 & 346 & 0 \\
\hline 91 & 55 & 0 & 91 & 128 & 0 & 91 & 201 & 0 & 91 & 274 & 0 & 91 & 347 & 0 \\
\hline 91 & 56 & 0 & 91 & 129 & 0 & 91 & 202 & 0 & 91 & 275 & 0 & 91 & 348 & 0 \\
\hline 91 & 57 & 0 & 91 & 130 & 0 & 91 & 203 & 0 & 91 & 276 & 0 & 91 & 349 & 0 \\
\hline 91 & 58 & 8 & 91 & 131 & 0 & 91 & 204 & 0 & 91 & 277 & 0 & 91 & 350 & 0 \\
\hline 91 & 59 & 16 & 91 & 132 & 0 & 91 & 205 & 0 & 91 & 278 & 0 & 91 & 351 & 0 \\
\hline 91 & 60 & 9 & 91 & 133 & 1 & 91 & 206 & 0 & 91 & 279 & 0 & 91 & 352 & 0 \\
\hline 91 & 61 & 0 & 91 & 134 & 0 & 91 & 207 & 0 & 91 & 280 & 0 & 91 & 353 & 4 \\
\hline 91 & 62 & 0 & 91 & 135 & 0 & 91 & 208 & 0 & 91 & 281 & 0 & 91 & 354 & 0 \\
\hline 91 & 63 & 0 & 91 & 136 & 0 & 91 & 209 & 0 & 91 & 282 & 0 & 91 & 355 & 0 \\
\hline 91 & 64 & 0 & 91 & 137 & 0 & 91 & 210 & 0 & 91 & 283 & 0 & 91 & 356 & 0 \\
\hline 91 & 65 & 0 & 91 & 138 & 0 & 91 & 211 & 0 & 91 & 284 & 0 & 91 & 357 & 0 \\
\hline 91 & 66 & 0 & 91 & 139 & 0 & 91 & 212 & 0 & 91 & 285 & 0 & 91 & 358 & 0 \\
\hline 91 & 67 & 0 & 91 & 140 & 0 & 91 & 213 & 15 & 91 & 286 & 0 & 91 & 359 & 0 \\
\hline 91 & 68 & 0 & 91 & 141 & 0 & 91 & 214 & 1 & 91 & 287 & 0 & 91 & 360 & 0 \\
\hline 91 & 69 & 0 & 91 & 142 & 0 & 91 & 215 & 0 & 91 & 288 & 0 & 91 & 361 & 0 \\
\hline 91 & 70 & 0 & 91 & 143 & 0 & 91 & 216 & 0 & 91 & 289 & 0 & 91 & 362 & 0 \\
\hline 91 & 71 & 0 & 91 & 144 & 0 & 91 & 217 & 0 & 91 & 290 & 0 & 91 & 363 & 5 \\
\hline 91 & 72 & 1 & 91 & 145 & 0 & 91 & 218 & 0 & 91 & 291 & 0 & 91 & 364 & 12 \\
\hline 91 & 73 & 2 & 91 & 146 & 0 & 91 & 219 & 0 & 91 & 292 & 0 & 91 & 365 & 0 \\
\hline 92 & 1 & 0 & 92 & 74 & 0 & 92 & 147 & 0 & 92 & 220 & 0 & 92 & 293 & 0 \\
\hline 92 & 2 & 0 & 92 & 75 & 0 & 92 & 148 & 0 & 92 & 221 & 0 & 92 & 294 & 0 \\
\hline 92 & 3 & 3 & 92 & 76 & 0 & 92 & 149 & 0 & 92 & 222 & 0 & 92 & 295 & 0 \\
\hline 92 & 4 & 5 & 92 & 77 & 0 & 92 & 150 & 1 & 92 & 223 & 0 & 92 & 296 & 0 \\
\hline 92 & 5 & 22 & 92 & 78 & 0 & 92 & 151 & 0 & 92 & 224 & 1 & 92 & 297 & 0 \\
\hline 92 & 6 & 8 & 92 & 79 & 0 & 92 & 152 & 0 & 92 & 225 & 0 & 92 & 298 & 8 \\
\hline 92 & 7 & 0 & 92 & 80 & 4 & 92 & 153 & 0 & 92 & 226 & 0 & 92 & 299 & 0 \\
\hline 92 & 8 & 0 & 92 & 81 & 10 & 92 & 154 & 0 & 92 & 227 & 0 & 92 & 300 & 0 \\
\hline 92 & 9 & 0 & 92 & 82 & 2 & 92 & 155 & 0 & 92 & 228 & 0 & 92 & 301 & 7 \\
\hline 92 & 10 & 0 & 92 & 83 & 3 & 92 & 156 & 0 & 92 & 229 & 0 & 92 & 302 & 0 \\
\hline 92 & 11 & 0 & 92 & 84 & 0 & 92 & 157 & 0 & 92 & 230 & 0 & 92 & 303 & 0 \\
\hline 92 & 12 & 0 & 92 & 85 & 0 & 92 & 158 & 0 & 92 & 231 & 0 & 92 & 304 & 1 \\
\hline 92 & 13 & 0 & 92 & 86 & 0 & 92 & 159 & 0 & 92 & 232 & 0 & 92 & 305 & 0 \\
\hline 92 & 14 & 0 & 92 & 87 & 5 & 92 & 160 & 0 & 92 & 233 & 0 & 92 & 306 & 0 \\
\hline 92 & 15 & 0 & 92 & 88 & 0 & 92 & 161 & 0 & 92 & 234 & 0 & 92 & 307 & 0 \\
\hline 92 & 16 & 0 & 92 & 89 & 5 & 92 & 162 & 0 & 92 & 235 & 0 & 92 & 308 & 0 \\
\hline 92 & 17 & 0 & 92 & 90 & 15 & 92 & 163 & 0 & 92 & 236 & 0 & 92 & 309 & 0 \\
\hline 92 & 18 & 0 & 92 & 91 & 6 & 92 & 164 & 0 & 92 & 237 & 0 & 92 & 310 & 0 \\
\hline 92 & 19 & 0 & 92 & 92 & 0 & 92 & 165 & 0 & 92 & 238 & 0 & 92 & 311 & 0 \\
\hline 92 & 20 & 0 & 92 & 93 & 0 & 92 & 166 & 0 & 92 & 239 & 0 & 92 & 312 & 0 \\
\hline
\end{tabular}


Table A-1. Developed Data Precipitation Record for Yucca Mountain that was Used Directly as Input for INFIL V2.0 (Continued)

\begin{tabular}{|c|c|c|c|c|c|c|c|c|c|c|c|c|c|c|}
\hline Year & $\begin{array}{c}\text { Day } \\
\text { of } \\
\text { Year }\end{array}$ & $\begin{array}{c}\text { Daily } \\
\text { Precip- } \\
\text { itation } \\
(\mathrm{mm}) \\
\end{array}$ & Year & $\begin{array}{c}\text { Day } \\
\text { of } \\
\text { Year }\end{array}$ & $\begin{array}{c}\text { Daily } \\
\text { Precip- } \\
\text { itation } \\
(\mathrm{mm}) \\
\end{array}$ & Year & $\begin{array}{c}\text { Day } \\
\text { of } \\
\text { Year }\end{array}$ & $\begin{array}{c}\text { Daily } \\
\text { Precip- } \\
\text { itation } \\
(\mathrm{mm}) \\
\end{array}$ & Year & $\begin{array}{c}\text { Day } \\
\text { of } \\
\text { Year } \\
\end{array}$ & $\begin{array}{c}\text { Daily } \\
\text { Precip- } \\
\text { itation } \\
(\mathrm{mm}) \\
\end{array}$ & Year & $\begin{array}{c}\text { Day } \\
\text { of } \\
\text { Year }\end{array}$ & $\begin{array}{c}\text { Daily } \\
\text { Precip- } \\
\text { itation } \\
(\mathrm{mm}) \\
\end{array}$ \\
\hline 92 & 21 & 0 & 92 & 94 & 0 & 92 & 167 & 0 & 92 & 240 & 0 & 92 & 313 & 0 \\
\hline 92 & 22 & 0 & 92 & 95 & 0 & 92 & 168 & 0 & 92 & 241 & 0 & 92 & 314 & 0 \\
\hline 92 & 23 & 0 & 92 & 96 & 0 & 92 & 169 & 0 & 92 & 242 & 0 & 92 & 315 & 0 \\
\hline 92 & 24 & 0 & 92 & 97 & 0 & 92 & 170 & 0 & 92 & 243 & 0 & 92 & 316 & 0 \\
\hline 92 & 25 & 0 & 92 & 98 & 0 & 92 & 171 & 0 & 92 & 244 & 0 & 92 & 317 & 0 \\
\hline 92 & 26 & 0 & 92 & 99 & 0 & 92 & 172 & 0 & 92 & 245 & 0 & 92 & 318 & 0 \\
\hline 92 & 27 & 0 & 92 & 100 & 0 & 92 & 173 & 0 & 92 & 246 & 0 & 92 & 319 & 0 \\
\hline 92 & 28 & 0 & 92 & 101 & 0 & 92 & 174 & 0 & 92 & 247 & 0 & 92 & 320 & 0 \\
\hline 92 & 29 & 0 & 92 & 102 & 0 & 92 & 175 & 0 & 92 & 248 & 0 & 92 & 321 & 0 \\
\hline 92 & 30 & 0 & 92 & 103 & 0 & 92 & 176 & 0 & 92 & 249 & 0 & 92 & 322 & 0 \\
\hline 92 & 31 & 0 & 92 & 104 & 0 & 92 & 177 & 0 & 92 & 250 & 0 & 92 & 323 & 0 \\
\hline 92 & 32 & 0 & 92 & 105 & 0 & 92 & 178 & 0 & 92 & 251 & 0 & 92 & 324 & 0 \\
\hline 92 & 33 & 0 & 92 & 106 & 0 & 92 & 179 & 0 & 92 & 252 & 0 & 92 & 325 & 0 \\
\hline 92 & 34 & 0 & 92 & 107 & 0 & 92 & 180 & 0 & 92 & 253 & 0 & 92 & 326 & 0 \\
\hline 92 & 35 & 0 & 92 & 108 & 0 & 92 & 181 & 0 & 92 & 254 & 0 & 92 & 327 & 0 \\
\hline 92 & 36 & 0 & 92 & 109 & 0 & 92 & 182 & 0 & 92 & 255 & 0 & 92 & 328 & 0 \\
\hline 92 & 37 & 15 & 92 & 110 & 0 & 92 & 183 & 0 & 92 & 256 & 0 & 92 & 329 & 0 \\
\hline 92 & 38 & 12 & 92 & 111 & 0 & 92 & 184 & 0 & 92 & 257 & 0 & 92 & 330 & 0 \\
\hline 92 & 39 & 0 & 92 & 112 & 0 & 92 & 185 & 0 & 92 & 258 & 0 & 92 & 331 & 0 \\
\hline 92 & 40 & 3 & 92 & 113 & 0 & 92 & 186 & 0 & 92 & 259 & 0 & 92 & 332 & 0 \\
\hline 92 & 41 & 17 & 92 & 114 & 0 & 92 & 187 & 0 & 92 & 260 & 2 & 92 & 333 & 0 \\
\hline 92 & 42 & 7 & 92 & 115 & 0 & 92 & 188 & 0 & 92 & 261 & 0 & 92 & 334 & 0 \\
\hline 92 & 43 & 22 & 92 & 116 & 0 & 92 & 189 & 0 & 92 & 262 & 2 & 92 & 335 & 0 \\
\hline 92 & 44 & 9 & 92 & 117 & 0 & 92 & 190 & 0 & 92 & 263 & 0 & 92 & 336 & 0 \\
\hline 92 & 45 & 0 & 92 & 118 & 0 & 92 & 191 & 0 & 92 & 264 & 0 & 92 & 337 & 0 \\
\hline 92 & 46 & 9 & 92 & 119 & 0 & 92 & 192 & 0 & 92 & 265 & 0 & 92 & 338 & 0 \\
\hline 92 & 47 & 0 & 92 & 120 & 0 & 92 & 193 & 0 & 92 & 266 & 1 & 92 & 339 & 0 \\
\hline 92 & 48 & 0 & 92 & 121 & 0 & 92 & 194 & 0 & 92 & 267 & 0 & 92 & 340 & 1 \\
\hline 92 & 49 & 0 & 92 & 122 & 0 & 92 & 195 & 0 & 92 & 268 & 2 & 92 & 341 & 0 \\
\hline 92 & 50 & 0 & 92 & 123 & 0 & 92 & 196 & 0 & 92 & 269 & 0 & 92 & 342 & 41 \\
\hline 92 & 51 & 0 & 92 & 124 & 0 & 92 & 197 & 0 & 92 & 270 & 0 & 92 & 343 & 19 \\
\hline 92 & 52 & 0 & 92 & 125 & 0 & 92 & 198 & 0 & 92 & 271 & 3 & 92 & 344 & 0 \\
\hline 92 & 53 & 0 & 92 & 126 & 0 & 92 & 199 & 0 & 92 & 272 & 0 & 92 & 345 & 0 \\
\hline 92 & 54 & 0 & 92 & 127 & 0 & 92 & 200 & 0 & 92 & 273 & 0 & 92 & 346 & 2 \\
\hline 92 & 55 & 0 & 92 & 128 & 0 & 92 & 201 & 0 & 92 & 274 & 0 & 92 & 347 & 0 \\
\hline 92 & 56 & 0 & 92 & 129 & 3 & 92 & 202 & 0 & 92 & 275 & 0 & 92 & 348 & 0 \\
\hline 92 & 57 & 0 & 92 & 130 & 0 & 92 & 203 & 0 & 92 & 276 & 0 & 92 & 349 & 0 \\
\hline 92 & 58 & 0 & 92 & 131 & 0 & 92 & 204 & 0 & 92 & 277 & 0 & 92 & 350 & 0 \\
\hline 92 & 59 & 0 & 92 & 132 & 0 & 92 & 205 & 0 & 92 & 278 & 0 & 92 & 351 & 0 \\
\hline 92 & 60 & 0 & 92 & 133 & 0 & 92 & 206 & 0 & 92 & 279 & 0 & 92 & 352 & 0 \\
\hline 92 & 61 & 0 & 92 & 134 & 0 & 92 & 207 & 0 & 92 & 280 & 0 & 92 & 353 & 1 \\
\hline 92 & 62 & 23 & 92 & 135 & 0 & 92 & 208 & 0 & 92 & 281 & 0 & 92 & 354 & 0 \\
\hline 92 & 63 & 3 & 92 & 136 & 0 & 92 & 209 & 0 & 92 & 282 & 0 & 92 & 355 & 0 \\
\hline 92 & 64 & 0 & 92 & 137 & 0 & 92 & 210 & 0 & 92 & 283 & 0 & 92 & 356 & 0 \\
\hline
\end{tabular}


Table A-1. Developed Data Precipitation Record for Yucca Mountain that was Used Directly as Input for INFIL V2.0 (Continued)

\begin{tabular}{|c|c|c|c|c|c|c|c|c|c|c|c|c|c|c|}
\hline Year & $\begin{array}{c}\text { Day } \\
\text { of } \\
\text { Year }\end{array}$ & $\begin{array}{c}\text { Daily } \\
\text { Precip- } \\
\text { itation } \\
(\mathrm{mm})\end{array}$ & Year & $\begin{array}{c}\text { Day } \\
\text { of } \\
\text { Year }\end{array}$ & $\begin{array}{c}\text { Daily } \\
\text { Precip- } \\
\text { itation } \\
(\mathrm{mm})\end{array}$ & Year & $\begin{array}{c}\text { Day } \\
\text { of } \\
\text { Year }\end{array}$ & $\begin{array}{l}\text { Daily } \\
\text { Precip- } \\
\text { itation } \\
(\mathrm{mm})\end{array}$ & Year & $\begin{array}{c}\text { Day } \\
\text { of } \\
\text { Year }\end{array}$ & $\begin{array}{c}\text { Daily } \\
\text { Precip- } \\
\text { itation } \\
(\mathrm{mm})\end{array}$ & Year & $\begin{array}{c}\text { Day } \\
\text { of } \\
\text { Year }\end{array}$ & $\begin{array}{c}\text { Daily } \\
\text { Precip- } \\
\text { itation } \\
(\mathrm{mm})\end{array}$ \\
\hline 92 & 65 & 0 & 92 & 138 & 0 & 92 & 211 & 0 & 92 & 284 & 0 & 92 & 357 & 1 \\
\hline 92 & 66 & 2 & 92 & 139 & 0 & 92 & 212 & 0 & 92 & 285 & 0 & 92 & 358 & 1 \\
\hline 92 & 67 & 5 & 92 & 140 & 0 & 92 & 213 & 2 & 92 & 286 & 0 & 92 & 359 & 0 \\
\hline 92 & 68 & 1 & 92 & 141 & 0 & 92 & 214 & 0 & 92 & 287 & 0 & 92 & 360 & 0 \\
\hline 92 & 69 & 0 & 92 & 142 & 1 & 92 & 215 & 0 & 92 & 288 & 0 & 92 & 361 & 0 \\
\hline 92 & 70 & 0 & 92 & 143 & 0 & 92 & 216 & 0 & 92 & 289 & 0 & 92 & 362 & 1 \\
\hline 92 & 71 & 0 & 92 & 144 & 0 & 92 & 217 & 0 & 92 & 290 & 0 & 92 & 363 & 7 \\
\hline 92 & 72 & 0 & 92 & 145 & 0 & 92 & 218 & 0 & 92 & 291 & 0 & 92 & 364 & 1 \\
\hline \multirow[t]{2}{*}{92} & 73 & 0 & 92 & 146 & 0 & 92 & 219 & 0 & 92 & 292 & 0 & 92 & 365 & 0 \\
\hline & & & & & & & & & & & & 92 & 366 & 0 \\
\hline
\end{tabular}

Source: DTN: GS000208311221.001. 


\section{INTENTIONALLY LEFT BLANK}




\section{APPENDIX B}

\section{GEOSPATIAL INPUT DATA FOR INFIL V2.0 FY99}




\section{B1. STATEMENT OF INTENDED USE FOR THE DATA}

The purpose of these data is to provide spatial information and properties for each grid block necessary to calculate net infiltration at each location for the Yucca Mountain site using the model INFIL V2.0 (USGS 2000 [DIRS 139422]).

\section{B2. GENERAL INFORMATION PERTAINING TO THE DATA SET}

Source data software used for development of geospatial input data are as follows:

(1) Elevation, northing and easting: USGS Digital Elevation Model (DEM) from Topopah Spring West and Busted Butte 7.5-minute quadrangles: DTN: GS000308311221.006, ARCINFO, to produce ASCII file, 30MSITE.INP (DTN: GS000308311221.006)

(2) Downstream grid cell: 30MSITE.INP, SORTGRD1 V1.0, CHNNET16 V1.0 (DTN: GS000308311221.006)

(3) Number of upstream cells: 30MSITE.INP, SORTGRD1 V1.0, CHNNET16 V1.0 (DTN: GS000308311221.006)

(4) Slope: 30MSITE.INP, ARCINFO (DTN: GS000308311221.006)

(5) Aspect: 30MSITE.INP, ARCINFO (DTN: GS000308311221.006)

(6) Soil-type: INFIL V2.0 control file, INFILS5o.CTL and 30MSITE.INP (DTN: GS960508312212.007 [DIRS 124829], DTN: GS000308311221.006)

(7) Soil depth class: soil depth map (DTN: GS960508312212.007 [DIRS 124829]), INFIL V2.0 control file, INFILS5o.CTL, and 30MSITE.INP (DTN: GS000308311221.006)

(8) Modeled soil depth: soil depth class (DTN: GS960508312212.007 [DIRS 124829]), GEOMAP7 V1.0, GEOMOD4 V1.0, and SOILMAP6 V1.0

(9) Rock type: INFIL V2.0 control file, INFILS5o.CTL, and README2.DAY [coverage explanations for Day et al. (1998 [DIRS 101557])], (DTN: GS971208314221.003 [DIRS 107128])

(10) Topographic position: INFIL V2.0 control file, INFILS5o.CTL

(11) Blocking ridges: 30MSITE.INP (DTN: GS000308311221.006), BLOCKR7 V1.0 
This data set consists of three parts. One is a set of 10 files consisting of grid blocks within individual watershed modeling domains and all associated geospatial input listed above. The 10 modeling domains are illustrated in Figure 6-11. These files are in EXCEL worksheets formatted with descriptive column headers and are available in DTN: GS000308311221.004:

- YuccaWash.xls

- DuneWash.xls

- DrillHole.xls

- Solitario1.xls

- Solitario2.xls

- Solitario4.xls

- PlugHill.xls

- JetRidge1.xls

- JetRidge2.xls

- JetRidge3.xls.

The parameters included in each file are grid cell identifier number, UTM easting, UTM northing (m), latitude, longitude (decimal degrees), grid cell row index, grid cell column index, downstream grid cell identifier (used for surface water routing), number of upstream grid cells, elevation (m), slope (degrees inclination from horizontal), aspect (degrees from north), soil-type identifier, soil depth class identifier, modeled soil depth $(\mathrm{m})$, rock-type identifier, topographic position, 36 blocking ridge angles (decimal degrees, inclination above horizontal) (Table B-1). An abbreviated example of the files is shown in Table B-2.

The second part is the lookup table providing properties for each grid. It consists of a spreadsheet called GeoK.xls and consists of rock-type identifier, source, geologic description, hydrogeologic identifier, and bulk bedrock permeability (Table B-3).

Part 3 is the soil properties (Table B-4). These are measured and calculated properties. Measured properties are bulk density, porosity, and rock fragment content. Saturated hydraulic conductivity, moisture retention curve fit parameters alpha and n, water content at -0.1 bar water potential, and water content at -60 bars water potential were estimated using empirical equations from Soil Physics with BASIC Transport Models for Soil-Plant Systems (Campbell 1985 [DIRS 100565]).

\section{Part 1: Geospatial input for each of 10 watersheds}

This input is primarily based on the USGS Digital Elevation Model (DEM) from Topopah Spring West and Busted Butte 7.5-minute quadrangles. The base grid (DTN: GS000308311221.006) was used to define location coordinates for the geospatial parameter input files for the 1996 version of the net infiltration model (Flint et al. 1996 [DIRS 100147]). The DEM is a regular 2-dimensional grid of 253,597 cells having dimensions of $30 \times 30 \mathrm{~m}$ and elevations to the nearest meter. The 30 -meter grid is based on a Universal Transverse Mercator (UTM), zone 11, NAD 1927 projection, consists of 691 northing "rows" (grid cell row index) and 367 easting "columns" (grid cell column index) aligned orthogonal to the UTM coordinate axis, and has a lower left corner coordinate of 544,661 m easting and 4,067,133 m northing. Grid locations are also defined using 
geographic coordinates, latitude and longitude in decimal degrees, which were calculated in ARCINFO and used as input for the SOLRAD submodel in INFIL V2.0. The row and column location indices are used in the flow routing module in INFIL in the calculation of the surface water run-on term.

Downstream grid cell identifier is the flow routing parameter and determines which of eight surrounding grid cells is the lowest in elevation. A value of -3 indicates the downstream grid cell is a drainage boundary. Flow directions were calculated for each grid cell using a two-step process. For the first step, the entire base-grid is sorted by elevation using the routine SORTGRD V1.0. In the second step, flow routing directions are calculated based on a standard D8 routing algorithm using the routine CHNNET16 V1.0. CHNNET16 V1.0 is a convergent flow routing algorithm; multiple cells are allowed to route to a single cell, but any given cell can route to only one downstream grid cell (as opposed to two in cases of flow dispersion). The CHNNET16 V1.0 algorithm provides a method for routing through surface depressions in the DEM. The number of upstream grid cells is included in each file.

Elevation from mean sea level in meters is included in each file.

Slope is a required input parameter for estimating soil depths. Slope and aspect were calculated for the net infiltration model from the DEM (DTN: GS000308311221.006) using standard GIS applications in ARCINFO.

Soil type is indicated by values of between 1 and 10 (Flint et al. 1996 [DIRS 100147], Table 3, DTN: GS960908312211.003 [DIRS 103775]). When encountered in INFIL it uses a lookup table (INFILS5o.CTL) that has all hydrologic parameters for each soil type as listed by Flint et al. (1996 [DIRS 100147]). Depth class identifier is a value between 1 and 6 and is used in the preprocessing routine SOILMAP6 V1.0 with depth to bedrock map (DTN: GS960508312212.007 [DIRS 124829], estimated distribution of geomorphic surfaces and depth to bedrock for the southern half of the Topopah Spring NW 7.5 minute quadrangle and the entire Busted Butte 7.5 minute quadrangle), and slope to calculate soil depth at all grid block locations. Soil depth is estimated using a combination of the soil depth class map and an estimated linear relation between soil depth and slope within each depth class (GEOMAP7 V1.0 and GEOMOD4 V1.0). Soil depth classes represent different ranges in actual soil depths that were estimated using a combination of Quaternary geologic maps, field observations, and soil depth recorded at borehole sites (Flint and Flint 1995 [DIRS 100394], Table 2). Depth class \#1 identifies locations with soil depths ranging from 0 to $0.5 \mathrm{~m}$ and primarily occurs in rugged upland areas. Depth class \#2 identifies deeper soils ranging from 0.5 to $3.0 \mathrm{~m}$ occurring at mid to lower side-slope locations in upland areas affected by slumps, slides, and other mass-wasting processes. Depth class \#3 identifies locations in the transition zone between upland areas and alluvial fans or basins with intermediate soil depths ranging from 3 to $6 \mathrm{~m}$. Depth class \#4 identifies deep soils with depths of $6 \mathrm{~m}$ or greater. Depth class \#5 is an intermediate depth zone equivalent to Depth class \#3, however \#3 did not represent field conditions well when the Day et al. (1998 [DIRS 101557]) map was incorporated into the model. Depth class \#5 is therefore an adjusted version of Depth class \#3 where the geology is represented by Day et al. (1998 [DIRS 101557]). Depth class \#6 occurs where Scott and Bonk (1984 [DIRS 104181]) mapped bedrock and Day et al. (1998 [DIRS 101557]) mapped deep alluvium. A compromise for this depth class was chosen as 3 to $6 \mathrm{~m}$. The soil depth classes were used to estimate soil 
depths based on calculated slope and an empirical soil-depth model (modeled soil depth, in meters). This model is based on an assumed soil depth - slope correlation within the soil depth classes defined for the 1996 version of the net infiltration model (Flint et al. 1996 [DIRS 100147]). The conceptual soil depth model for depth class 1 assumes that soils are thinnest at summit and ridge-crest areas as well as steep side slopes. Deeper soils are assumed to occur at the relatively gently sloping shoulder areas that define the transition between summit or ridge crest areas and steep side slope areas. Deeper soils are also assumed to occur for more gently sloping foot-slope locations. The model for soil depth class 1 is defined by:

$$
\begin{aligned}
& \mathrm{D}=0.03 * \mathrm{~S}+0.1, \quad \mathrm{~S} \leq 10 \\
& \mathrm{D}=0.013 *(10-\mathrm{S})+0.4, \quad 10<\mathrm{S}<40 \\
& \mathrm{D}=0.01,
\end{aligned}
$$

where $\mathrm{D}=$ soil depth (in meters), and $\mathrm{S}=$ slope (degrees). The model for Depth class \#2 is defined by:

$$
\begin{aligned}
& \mathrm{D}=2-(0.05 * \mathrm{~S}), \quad \mathrm{S}<32 \\
& \mathrm{D}=0.4, \backslash
\end{aligned}
$$

and the model for Depth class \# 3 is defined by:

$$
\begin{aligned}
& D=6-(0.16 * \mathrm{~S}), \quad \mathrm{S} \leq 25 \\
& \mathrm{D}=2.0
\end{aligned}
$$

For Depth class \#4, soil depth is set to a uniform depth of $6 \mathrm{~m}$.

Rock-type identifier defines the rock type for each grid cell so that the corresponding bulk bedrock permeability can be found in the look up table shown in Table B-3. Bedrock geology was defined for each grid element using three ARCINFO maps coverages and a vector to raster conversion performed by ARCINFO. The three maps used for the bedrock determinations are the 1:6000 scale Bedrock Geologic Map of the Central block area by Day et al. (1998 [DIRS 101557]), the Preliminary Geologic Map of Yucca Mountain by Scott and Bonk (1984 [DIRS 104181]), and the Geologic Map of the Topopah Spring Northwest Quadrangle by Sawyer et al. (1995 [DIRS 104580]). Within the UZ flow model area, bedrock geology for the net infiltration model (which is defined as a unique integer identifier for each rock-type in the geospatial parameter input file) is primarily defined by Day et al. (1998 [DIRS 101557]). Bedrock geology for the northern and southern perimeter sections of the UZ flow model area is defined by Scott and Bonk (1984 [DIRS 104181]). Bedrock geology is represented in the geospatial parameter input file using a unique integer identifier for each rock-type. The identifier is linked to a bulk (field-scale) saturated permeability in the model control file (represented in GeoK.xls). Multiple rock-types can be assigned the same bulk permeability value in the model control file.

Topographic position is indicated by values ranging from 1 to 4 , corresponding to the classification ridgetop, sideslope, alluvial terrace, and channel discussed in Section 6.1.2 of this report. This information was used in INFIL V1.0 to identify channel locations, but as routing is done in version 2.0, this parameter is not used. It is however maintained as a placeholder. 
The 36 blocking ridge angles (degrees inclination above horizontal) are calculated at each $10^{\circ}$ horizontal arc (with the azimuth aligned in the UTM northing direction) for each grid cell using the routine BLOCKR7. Calculations were performed using the DEM as input and a technique for approximating the $10^{\circ}$ horizontal angles based on grid cell distances. The blocking ridge parameters cannot account for topographic influences outside of the DEM, and thus the blocking ridge effect is only partly accounted for along the perimeter of the DEM.

\section{Part 2: Geologic unit identifier and associated bulk bedrock saturated hydraulic conductivity}

The second part includes only the file, GeoK.xls (Table B-3). The geologic identifier in the first column is a value that allows each grid cell to use this file as a lookup table to identify rock type. The source is the map the rock type was taken from using ARCINFO coverages. The next two columns are geologic descriptions extracted from the sources that, when combined with map location, allow for the interpretation of corresponding lithostratigraphic unit shown in the next column which is represented by nomenclature in Proposed Stratigraphic Nomenclature and Macroscopic Identification of Lithostratigraphic Units of the Paintbrush Group Exposed at Yucca Mountain, Nevada (Buesch et al. 1996 [DIRS 100106]). The determination of corresponding lithostratigraphic unit is typically straightforward based on description. The column with corresponding hydrogeologic unit is based on Characterization of Hydrogeologic Units Using Matrix Properties, Yucca Mountain, Nevada (Flint 1998 [DIRS 100033], Table 1 and DTN: MO0109HYMXPROP.001 [DIRS 155989]) and incorporates data from analyses of samples of most of the rock types for saturated hydraulic conductivity (DTN: MO0109HYMXPROP.001 [DIRS 155989]). Saturated hydraulic conductivity $\left(\mathrm{K}_{\mathrm{s}}\right)$ on individual core samples was determined on subsamples from several boreholes (DTNs: GS990408312231.001 [DIRS 148711], GS960808312231.001 [DIRS 108998], GS960808312231.005 [DIRS 108995]). Cores were vacuum saturated, and $\mathrm{K}_{s}$ was measured using a steady-state permeameter that forces water through the core at a measured pressure while weighing the outflow over time. $\mathrm{K}_{\mathrm{s}}$ was calculated using Darcy's law. Mean values of saturated hydraulic conductivity for each hydrogeologic unit were determined by using a geometric mean calculation for $\mathrm{K}_{\mathrm{s}}$ values found in DTN: MO0109HYMXPROP.001 [DIRS 155989]. The bulk bedrock hydraulic conductivity represents the combined matrix and fracture saturated hydraulic conductivity of each rock-type. Bulk bedrock hydraulic conductivity was calculated using measured saturated hydraulic conductivity of fracture fill material. A value of $43.2 \mathrm{~mm} /$ day was selected and used as a preliminary value. However, a value of $46.7 \mathrm{~mm} /$ day is the average value calculated from all measurements in DTN: GS950708312211.003 [DIRS 146873], Fracture/Fault Properties For Fast Pathways Model; the difference in calculated bulk hydraulic conductivity between these values is insignificant and results in bulk hydraulic conductivities that are less than one percent different. Additional values used to calculate bulk bedrock hydraulic conductivity included an estimate of the percent area occupied by 250 micron fractures [the assumption of this size fracture is discussed by Flint et al. (1996 [DIRS 100147])] and the mean saturated hydraulic conductivity of the bedrock matrix for that rock type (Flint 1998 [DIRS 100033] Table 7; DTN: MO0109HYMXPROP.001 [DIRS 155989]). The percent area occupied by fractures of 250-microns aperture is equal to 250 microns divided by 1,000,000 microns per meter, multiplied by the fracture densities in fractures per meter. The fracture densities for each rock type that were used to calculate the bulk bedrock hydraulic conductivities were estimated from field observations and, subsequently, were corroborated by 
the fracture density data from boreholes NRG-4, NRG-5, NRG-6, NRG-7, SD-9 and SD-12 reported by Altman et al. (1996 [DIRS 100591] Table 3-6, DTN: SNSAND96081900.000 [DIRS 149482]).

For the development of hydrogeologic units, the data originally collected from laboratory measurements on all samples from 31 surface-based boreholes drilled from 1995 through 1997, were analyzed and data were submitted in the following data packages: DTNs: GS920508312231.012 [DIRS 109001], GS930108312231.006 [DIRS 108997], GS940408312231.004 [DIRS 109000], GS000408312231.004 GS940508312231.006 [DIRS 107149], GS950408312231.004 GS950308312231.003 [DIRS 149374], GS951108312231.009 [DIRS 149582], GS951108312231.011 [DIRS 108992], GS951108312231.010 [DIRS 108986], GS950308312231.002

[DIRS 108990], GS960808312231.004

GS960808312231.002 GS950608312231.008 GS960808312231.003 GS990408312231.001 GS000508312231.005 [DIRS 108988], [DIRS 144662], [DIRS 147590], [DIRS 148711], [DIRS 153236], GS000508312231.007 [DIRS 163708]. These are also included in Section 9.3. Data outliers have been removed to allow for a better representation of the hydrogeologic units. Physical properties of bulk density, porosity, and particle density; flow properties of saturated hydraulic conductivity and moisture-retention characteristics; and the state variables (variables describing the current state of field conditions) of saturation and water potential were determined for each unit. Units were defined using the database of physical and hydrologic properties, described lithostratigraphic boundaries and corresponding relations to porosity, recognition of transition zones with pronounced changes in properties over short vertical distances, characterization of the influence of mineral alteration on hydrologic properties such as permeability and moisture-retention characteristics, and a statistical analysis to evaluate where boundaries should be adjusted to minimize the variance within layers. Additional data packages referred to in this appendix pertaining to the development of parameters for geospatial input for the net-infiltration model are also included in Section 9.3.

\section{Part 3: Properties for 10 soil units}

The properties in Table B-4 represent soils located around Yucca Mountain, Nevada. Bulk density, porosity, and rock fragment content were measured using laboratory analyses described by Flint et al. (1996 [DIRS 100147], p. 41). The source data for these measured properties were submitted under the following DTNs:

GS950708312211.002 [DIRS 146874] - "FY94 and FY95 Laboratory Measurements of Physical Properties of Surficial Materials at Yucca Mountain, Nevada."

GS031208312211.001 [DIRS 171543] - "FY95 Lab Measurements of Physical Properties of Surficial Material, at Yucca Mountain, NV PART II." 
GS960108312211.002 [DIRS 149478] - "Gravimetric and Volumetric Water Content and Rock Fragment Content of 31 Selected Sites at Yucca Mountain, NV: FY95 Laboratory Measurements of Physical Properties of Surficial Material at Yucca Mountain, Part III."

Field and laboratory analyses were conducted on the soils around Yucca Mountain. Large-volume, field bulk-density samples were collected from the surface to $0.3 \mathrm{~m}$ by using an irregular-hole, bulk-density device called a bead cone. Bulk density, porosity, rock fragment content, and sand, silt, and clay percentages were determined. Saturated hydraulic conductivity was measured using a double-ring infiltrometer on soils in locations where it could be measured and then compared to conductivity simulated using textural data for the fine-soil fraction (less than $2 \mathrm{~mm}$ ) by using Equation 6.12 of Soil Physic with BASIC Transport Models for Soil-Plant Systems (Campbell 1985 [DIRS 100565]). Log-log water-characteristic curves were determined using Equations 2.15, 2.16, 2.17, 2.18, 5.10, and 5.11 of Soil Physic with BASIC Transport Models for Soil-Plant Systems (Campbell 1985 [DIRS 100565]) and were converted to van Genuchten curves in Excel. Soil-water contents at -0.1 bar and -60 bars water potential were used as field capacity and residual water content, the difference of which is plant available water content. The soil properties are summarized in Table B-4, where the parameters defining the van Genuchten curves (conductivity, alpha, and n) are simulated from texture, rock fragment content, and bulk density measured in the field. Also listed in Table B-4 are the soil-water contents corresponding to -0.1 and -60 bars water potential for each soil type, calculated using the fitted water-retention van Genuchten curve for each soil type.

To test the validity of using textural analysis as a surrogate for measurements of soil properties, field-measured hydraulic conductivities were compared with the geometric-mean particle diameter using a method discussed in Soil Physic with BASIC Transport Models for Soil-Plant Systems (Campbell 1985 [DIRS 100565], Eq. 2.15) and with the model predictions of hydraulic properties made using Equations 5.10 and 5.11 from Soil Physic with BASIC Transport Models for Soil-Plant Systems (Campbell 1985 [DIRS 100565]), which is developed for less than 2-mm particle sizes. The results indicated an adequate correlation to use textural data for particle sizes less than $0.3 \mathrm{~mm}$; however, the presence of rock fragments has a substantial effect on soil properties. To account for the presence of rock fragments, the log of simulated hydraulic conductivity from Campbell (1985 [DIRS 100565]) and the gravimetric rock-fragment content were regressed against the $\log$ of the measured values of hydraulic conductivity to produce a modified Campbell equation with an $r^{2}$ of 0.85 . The equation was then applied to each unit in Table B-4 to determine the saturated hydraulic conductivity. This analysis assumes that textural changes with depth are insignificant and that properties determined from textural sampling from the top $0.3 \mathrm{~m}$ of soil represents the entire soil profile. A large percentage of the surficial deposits in the study area are less than $0.5 \mathrm{~m}$ deep (Flint et al. 1996 [DIRS 100147], Figure 13) and the application of these data for these shallow soils is considered appropriate.

Textural data also were used for the calculation of moisture-retention curves for the surficial soils using Soil Physic with BASIC Transport Models for Soil-Plant Systems (Campbell 1985 [DIRS 100565]). Six moisture-retention curves were measured in the laboratory on soil units 1, 2, and 4 using tempe cells, pressure pots, and chilled-mirror psychrometers to measure water potential over a full range of saturations (Flint et al. 1996 [DIRS 100147], Figures 16A, 16B, and 16C). Curves were fit to the combined data sets for each soil unit. Curves calculated from the average textural data for the soil units are very similar to the curves from the 
measured data for the three units. It was considered, therefore, that texture could be used to calculate curves and associated parameters for the remaining five soil units, and all curves are illustrated by Flint et al. (1996 [DIRS 100147], Figure 16D). These parameters are those listed in Table B-4.

Table B-1. Description of Columns in Output Files with Geospatial Input for INFIL V2.0

\begin{tabular}{|c|c|}
\hline Column & Description \\
\hline 1 & Grid cell identifier number \\
\hline 2 & UTM easting $(\mathrm{m})$ \\
\hline 3 & UTM northing $(\mathrm{m})$ \\
\hline 4 & Latitude (decimal degrees) \\
\hline 5 & Longitude (decimal degrees) \\
\hline 6 & Grid cell row index \\
\hline 7 & Grid cell column index \\
\hline 8 & Downstream grid cell identifier number (used for surface water routing) \\
\hline 9 & Number of upstream grid cells \\
\hline 10 & Elevation $(\mathrm{m})$ \\
\hline 11 & Slope (degrees inclination from horizontal) \\
\hline 12 & Aspect (degrees azimuth from the UTM northing axis, in the horizontal plane) \\
\hline 13 & Soil type identifier \\
\hline 14 & Depth class identifier \\
\hline 15 & Modeled soil depth (m) \\
\hline 16 & Rock type identifier \\
\hline 17 & Topographic position \\
\hline \multirow[t]{5}{*}{18} & $1^{\text {st }}$ of 36 blocking ridge angles (inclination above horizontal, decimal degrees) \\
\hline & - \\
\hline & - \\
\hline & - \\
\hline & - \\
\hline 54 & Last of 36 blocking ridge angles \\
\hline
\end{tabular}

UTM=Universal Transverse Mercator 
Table B-2. Example of Output Found in Files Used as Geospatial Input for INFIL V2.0

\begin{tabular}{|c|c|c|c|c|c|c|c|c|c|c|c|c|c|c|c|c|c|c|}
\hline \begin{tabular}{|l} 
Grid cell \\
identifier
\end{tabular} & $\begin{array}{c}\text { UTM } \\
\text { Easting } \\
(\mathrm{m})\end{array}$ & $\begin{array}{c}\text { UTM } \\
\text { Northing } \\
(\mathrm{m})\end{array}$ & $\begin{array}{l}\text { Latitude } \\
\text { (degrees) }\end{array}$ & $\begin{array}{l}\text { Longitude } \\
\text { (degrees) }\end{array}$ & \begin{tabular}{|c|} 
Grid cell \\
row \\
index
\end{tabular} & $\begin{array}{c}\text { Grid cell } \\
\text { column } \\
\text { index }\end{array}$ & \begin{tabular}{|c} 
Downstream \\
grid cell \\
identifier
\end{tabular} & \begin{tabular}{|l} 
Number of \\
upstream \\
grid cells
\end{tabular} & \begin{tabular}{|c|} 
Elevation \\
$(\mathrm{m})$
\end{tabular} & $\begin{array}{c}\text { Slope } \\
\text { (degrees } \\
\text { inclination } \\
\text { from } \\
\text { horizontal) }\end{array}$ & $\begin{array}{c}\text { Aspect } \\
\text { (degrees } \\
\text { from } \\
\text { northing) }\end{array}$ & $\begin{array}{l}\text { Soil type } \\
\text { identifier } \\
\end{array}$ & \begin{tabular}{|c|}
$\begin{array}{c}\text { Depth } \\
\text { class } \\
\text { identifier }\end{array}$ \\
\end{tabular} & \begin{tabular}{|c|} 
Modeled \\
soil \\
depth \\
$(\mathrm{m})$ \\
\end{tabular} & \begin{tabular}{|c|} 
Rock \\
type \\
identifier
\end{tabular} & $\begin{array}{c}\text { Topo- } \\
\text { graphic } \\
\text { position }\end{array}$ & \begin{tabular}{|} 
Blocking \\
ridge \\
angle 1
\end{tabular} & \begin{tabular}{|c} 
Blocking \\
ridge \\
angle 2 \\
\end{tabular} \\
\hline 59985 & 545681 & 4076613 & 36.8361 & 116.4877 & 375 & 35 & -3 & 0 & 1393 & 9 & 197 & 5 & 1 & 0.48 & 17 & 4 & 2 & 1 \\
\hline 60288 & 545681 & 4076583 & 36.8359 & 116.4877 & 376 & 35 & 62707 & 0 & 1392 & 9 & 199 & 5 & 1 & 0.48 & 17 & 4 & 2 & 1 \\
\hline 60879 & 545681 & 4076553 & 36.8356 & 116.4877 & 377 & 35 & 63010 & 0 & 1390 & 8 & 201 & 5 & 1 & 0.46 & 17 & 5 & 2 & 1 \\
\hline 61172 & 545711 & 4076613 & 36.8361 & 116.4874 & 375 & 36 & -3 & 0 & 1389 & 10 & 109 & 5 & 1 & 0.5 & 17 & 4 & 2 & 1 \\
\hline 61179 & 545681 & 4076523 & 36.8353 & 116.4877 & 378 & 35 & 63573 & 0 & 1389 & 8 & 196 & 5 & 1 & 0.46 & 17 & 5 & 2 & 1 \\
\hline 61794 & 545651 & 4076613 & 36.8361 & 116.488 & 375 & 34 & -3 & 0 & 1387 & 20 & 259 & 5 & 1 & 0.33 & 18 & 4 & 3 & 5 \\
\hline 61795 & 545711 & 4076583 & 36.8359 & 116.4874 & 376 & 36 & -3 & 0 & 1387 & 10 & 108 & 5 & 1 & 0.5 & 17 & 4 & 2 & 1 \\
\hline 62076 & 545711 & 4076553 & 36.8356 & 116.4874 & 377 & 36 & -3 & 0 & 1386 & 10 & 108 & 5 & 1 & 0.5 & 17 & 4 & 2 & 1 \\
\hline 62077 & 545681 & 4076493 & 36.835 & 116.4877 & 379 & 35 & 65103 & 0 & 1386 & 9 & 193 & 5 & 1 & 0.48 & 17 & 4 & 2 & 1 \\
\hline 62706 & 545651 & 4076583 & 36.8359 & 116.488 & 376 & 34 & -3 & 1 & 1384 & 19 & 259 & 5 & 1 & 0.35 & 18 & 4 & 5 & 9 \\
\hline 62707 & 545651 & 4076553 & 36.8356 & 116.488 & 377 & 34 & 66960 & 1 & 1384 & 19 & 263 & 5 & 1 & 0.35 & 18 & 4 & 6 & 7 \\
\hline 62708 & 545711 & 4076523 & 36.8353 & 116.4874 & 378 & 36 & -3 & 0 & 1384 & 10 & 108 & 5 & 1 & 0.5 & 17 & 4 & 2 & 1 \\
\hline 62711 & 545681 & 4076463 & 36.8348 & 116.4877 & 380 & 35 & 67273 & 0 & 1384 & 12 & 197 & 5 & 1 & 0.47 & 17 & 4 & 2 & 1 \\
\hline 63010 & 545651 & 4076523 & 36.8353 & 116.4881 & 378 & 34 & 67584 & 1 & 1383 & 18 & 258 & 5 & 1 & 0.36 & 18 & 4 & 5 & 6 \\
\hline 63011 & 545711 & 4076493 & 36.835 & 116.4874 & 379 & 36 & -3 & 0 & 1383 & 10 & 112 & 5 & 1 & 0.5 & 17 & 5 & 2 & 1 \\
\hline 63573 & 545651 & 4076493 & 36.835 & 116.4881 & 379 & 34 & 68785 & 1 & 1381 & 18 & 248 & 5 & 1 & 0.36 & 18 & 4 & 5 & 6 \\
\hline 63574 & 545711 & 4076463 & 36.8348 & 116.4874 & 380 & 36 & -3 & 0 & 1381 & 9 & 125 & 5 & 1 & 0.48 & 17 & 5 & 2 & 1 \\
\hline
\end{tabular}

Output DTN: GS000308311221.004.

UTM=Universal Transverse Mercator 
Table B-3. Lookup Table in INFIL V2.0 Providing Properties for Each Grid Block, Consisting of RockType Identifier, Source, Geologic Description (Formation and Lithology), Corresponding Lithostratigraphic Unit and Hydrogeologic Identifier, and Estimated Fracture Density and Bulk Bedrock Saturated Hydraulic Conductivity Based on Filled 250- $\mu$ m Fractures

\begin{tabular}{|c|c|c|c|c|c|c|c|}
\hline \multirow[b]{2}{*}{$\begin{array}{l}\text { Geologic } \\
\text { Identifier }\end{array}$} & \multirow[b]{2}{*}{ Source } & \multicolumn{2}{|c|}{$\begin{array}{c}\text { Geologic descriptions from } \\
\text { sources }\end{array}$} & \multirow[b]{2}{*}{$\begin{array}{c}\text { Corres- } \\
\text { ponding } \\
\text { lithostrati } \\
\text { graphic } \\
\text { unit }\end{array}$} & \multirow[b]{2}{*}{$\begin{array}{c}\begin{array}{c}\text { Corres- } \\
\text { ponding } \\
\text { hydrogeo } \\
\text { logic unit }\end{array} \\
\end{array}$} & \multirow[b]{2}{*}{$\begin{array}{c}\text { Estimated } \\
\text { Fracture } \\
\text { density } \\
(\mathrm{F} / \mathrm{m}) \\
\end{array}$} & \multirow{2}{*}{\begin{tabular}{|c|} 
Bulk \\
Bedrock \\
Saturated \\
Hydraulic \\
Conductivity \\
w/filled \\
$250-\mu \mathrm{m}$ \\
fractures \\
$(\mathrm{mm} / \mathrm{d})$ \\
\end{tabular}} \\
\hline & & Formation & Lithology & & & & \\
\hline 2 & $\begin{array}{l}\text { Scott and Bonk (1984 } \\
\text { [DIRS 104181]) }\end{array}$ & \begin{tabular}{|c|} 
Rhyolite of \\
Pinnacles Ridge \\
\end{tabular} & Lava flows & Tptrv1 & $\mathrm{TC}$ & 25.0 & 0.41 \\
\hline 3 & $\begin{array}{l}\text { Scott and Bonk (1984 } \\
\text { [DIRS 104181]) }\end{array}$ & \begin{tabular}{|c|} 
Rhyolite of \\
Pinnacles Ridge \\
\end{tabular} & Pyroclastic rocks & Tpbt2 & BT3 & 0.5 & 46.66 \\
\hline 4 & $\begin{array}{l}\text { Scott and Bonk (1984 } \\
\text { [DIRS 104181]) }\end{array}$ & \begin{tabular}{|c|}
$\begin{array}{c}\text { Rhyolite of Comb } \\
\text { Peak }\end{array}$ \\
\end{tabular} & Lava flows & Tpcpll & $\mathrm{CW}$ & 7.0 & 0.09 \\
\hline 5 & $\begin{array}{l}\text { Scott and Bonk (1984 } \\
\text { [DIRS 104181]) }\end{array}$ & $\begin{array}{c}\text { Rhyolite of Comb } \\
\text { Peak }\end{array}$ & Pyroclastic rocks & Tpbt3 & BT3 & 0.5 & 46.66 \\
\hline 6 & $\begin{array}{l}\text { Scott and Bonk (1984 } \\
\text { [DIRS 104181]) }\end{array}$ & $\begin{array}{c}\text { Rhyolite of Vent } \\
\text { Pass }\end{array}$ & Lava flows & Tptrv1 & $\mathrm{TC}$ & 25.0 & 0.41 \\
\hline 7 & $\begin{array}{l}\text { Scott and Bonk (1984 } \\
\text { [DIRS 104181]) }\end{array}$ & $\begin{array}{c}\text { Rhyolite of Vent } \\
\text { Pass }\end{array}$ & Pyroclastic rocks & Tpbt3 & BT3 & 0.5 & 46.66 \\
\hline 8 & $\begin{array}{l}\text { Scott and Bonk (1984 } \\
\text { [DIRS 104181]) }\end{array}$ & $\begin{array}{c}\text { Rhyolite of Black } \\
\text { Glass Canyon }\end{array}$ & Lava flows & Tpcpll & $\mathrm{CW}$ & 7.0 & 0.09 \\
\hline 9 & $\begin{array}{l}\text { Scott and Bonk (1984 } \\
\text { [DIRS 104181]) }\end{array}$ & \begin{tabular}{|c|}
$\begin{array}{c}\text { Rhyolite of Black } \\
\text { Glass Canyon }\end{array}$ \\
\end{tabular} & Pyroclastic rocks & Tpbt3 & BT3 & 0.5 & 46.66 \\
\hline 10 & $\begin{array}{l}\text { Scott and Bonk (1984 } \\
\text { [DIRS 104181]) }\end{array}$ & $\begin{array}{l}\text { Basalt Dikes of } \\
\text { Yucca Mountain } \\
\end{array}$ & Welded & Tpcplnc & $\mathrm{CW}$ & 7.0 & 0.09 \\
\hline 11 & $\begin{array}{l}\text { Scott and Bonk (1984 } \\
\text { [DIRS 104181]) }\end{array}$ & $\begin{array}{l}\text { Timber Mountain } \\
\text { Tuff-Rainier Mesa } \\
\end{array}$ & $\begin{array}{c}\text { Welded ash-flow } \\
\text { tuff }\end{array}$ & Tptpmn & TMN & 5.0 & 0.06 \\
\hline 12 & $\begin{array}{l}\text { Scott and Bonk (1984 } \\
\text { [DIRS 104181]) }\end{array}$ & \begin{tabular}{|l|} 
Timber Mountain \\
Tuff-Rainier Mesa \\
\end{tabular} & $\begin{array}{c}\text { Nonwelded ash- } \\
\text { flow tuff }\end{array}$ & Tpcpv1 & CNW & 6.0 & 2.74 \\
\hline 13 & $\begin{array}{l}\text { Scott and Bonk (1984 } \\
\text { [DIRS 104181]) }\end{array}$ & Bedded Tuff & Bedded Tuff & Tpbt4 & BT4 & 0.5 & 13.83 \\
\hline 14 & $\begin{array}{l}\text { Scott and Bonk (1984 } \\
\text { [DIRS 104181]) }\end{array}$ & $\begin{array}{c}\text { Rhyolite of Windy } \\
\text { Wash }\end{array}$ & Lava flows & Tpcpll & $\mathrm{CW}$ & 7.0 & 0.09 \\
\hline 15 & $\begin{array}{l}\text { Scott and Bonk (1984 } \\
\text { [DIRS 104181]) }\end{array}$ & $\begin{array}{c}\begin{array}{c}\text { Rhyolite of Windy } \\
\text { Wash }\end{array} \\
\end{array}$ & Pyroclastic rocks & Tpbt3 & BT3 & 0.5 & 46.66 \\
\hline 16 & $\begin{array}{l}\text { Scott and Bonk (1984 } \\
\text { [DIRS 104181]) }\end{array}$ & Tiva Canyon Tuff & Undifferentiated & Tpcpll & $\mathrm{CW}$ & 7.0 & 0.09 \\
\hline 17 & $\begin{array}{l}\text { Scott and Bonk (1984 } \\
\text { [DIRS 104181]) }\end{array}$ & Tiva Canyon Tuff & Caprock & Tpcrv & $\mathrm{TC}$ & 20.0 & 0.35 \\
\hline 18 & $\begin{array}{l}\text { Scott and Bonk (1984 } \\
\text { [DIRS 104181]) }\end{array}$ & Tiva Canyon Tuff & Upper cliff & Tpcrn & CUC & 5.0 & 3.34 \\
\hline 19 & $\begin{array}{l}\text { Scott and Bonk (1984 } \\
\text { [DIRS 104181]) }\end{array}$ & Tiva Canyon Tuff & Upper lithophysal & Tpcpul & CUL & 5.0 & 1.13 \\
\hline 20 & $\begin{array}{l}\text { Scott and Bonk (1984 } \\
\text { [DIRS 104181]) }\end{array}$ & Tiva Canyon Tuff & Clinkstone & Tpcpmn & $\mathrm{CW}$ & 5.0 & 0.06 \\
\hline 21 & $\begin{array}{l}\text { Scott and Bonk (1984 } \\
\text { [DIRS 104181]) }\end{array}$ & Tiva Canyon Tuff & Lower cliff & Tpcpmn & $\mathrm{CW}$ & 5.0 & 0.06 \\
\hline 22 & $\begin{array}{l}\text { Scott and Bonk (1984 } \\
\text { [DIRS 104181]) }\end{array}$ & Tiva Canyon Tuff & Clinkstone & Tpcpmn & $\mathrm{CW}$ & 5.0 & 0.06 \\
\hline
\end{tabular}


Table B-3. Lookup Table In INFIL V2.0 Providing Properties For Each Grid Block, Consisting of RockType Identifier, Source, Geologic Description (Formation and Lithology), Corresponding Lithostratigraphic Unit and Hydrogeologic Identifier, and Estimated Fracture Density and Bulk Bedrock Saturated Hydraulic Conductivity Based on Filled 250-Um Fractures (Continued)

\begin{tabular}{|c|c|c|c|c|c|c|c|}
\hline \multirow{2}{*}{$\begin{array}{l}\text { Geologic } \\
\text { Identifier } \\
23 \\
\end{array}$} & \multirow{2}{*}{\begin{tabular}{|l|}
\multicolumn{1}{|c}{ Source } \\
Scott and Bonk (1984 \\
[DIRS 104181])
\end{tabular}} & \multicolumn{2}{|c|}{$\begin{array}{c}\text { Geologic descriptions from } \\
\text { sources }\end{array}$} & \multirow{2}{*}{\begin{tabular}{|c|}
$\begin{array}{c}\text { Corres- } \\
\text { ponding } \\
\text { lithostrati } \\
\text { graphic } \\
\text { unit }\end{array}$ \\
\\
Tpcpmn \\
\end{tabular}} & \multirow{2}{*}{\begin{tabular}{|c|}
$\begin{array}{c}\text { Corres- } \\
\text { ponding } \\
\text { hydrogeo } \\
\text { logic unit }\end{array}$ \\
$\mathrm{CW}$ \\
\end{tabular}} & \multirow{2}{*}{\begin{tabular}{|c}
$\begin{array}{c}\text { Estimated } \\
\text { Fracture } \\
\text { density } \\
\text { (F/m) }\end{array}$ \\
5.0 \\
\end{tabular}} & \multirow[t]{2}{*}{\begin{tabular}{|c} 
Bulk \\
Bedrock \\
Saturated \\
Hydraulic \\
Conductivity \\
w/filled \\
250-um \\
fractures \\
(mm/d) \\
\\
0.06
\end{tabular}} \\
\hline & & Tiva Canyon Tuff & Clinkstone & & & & \\
\hline 24 & $\begin{array}{l}\text { Scott and Bonk (1984 } \\
\text { [DIRS 104181]) }\end{array}$ & Tiva Canyon Tuff & Clinkstone & Tpcpmn & $\mathrm{CW}$ & 5.0 & 0.06 \\
\hline 25 & $\begin{array}{l}\text { Scott and Bonk (1984 } \\
\text { [DIRS 104181]) }\end{array}$ & Tiva Canyon Tuff & Middle lithophysal & Tpcpmn & $\mathrm{CW}$ & 5.0 & 0.06 \\
\hline 26 & $\begin{array}{l}\text { Scott and Bonk (1984 } \\
\text { [DIRS 104181]) }\end{array}$ & Tiva Canyon Tuff & Clinkstone & Tpcpmn & $\mathrm{CW}$ & 5.0 & 0.06 \\
\hline 27 & $\begin{array}{l}\text { Scott and Bonk (1984 } \\
\text { [DIRS 104181]) }\end{array}$ & Tiva Canyon Tuff & Rounded step & Tpcpmn & $\mathrm{CW}$ & 5.0 & 0.06 \\
\hline 28 & $\begin{array}{l}\text { Scott and Bonk (1984 } \\
\text { [DIRS 104181]) }\end{array}$ & Tiva Canyon Tuff & Lower Lithophysal & Tpcpll & $\mathrm{CW}$ & 5.0 & 0.06 \\
\hline 29 & $\begin{array}{l}\text { Scott and Bonk (1984 } \\
\text { [DIRS 104181]) }\end{array}$ & Tiva Canyon Tuff & Hackly zone & Tpcplnh & $\mathrm{CW}$ & 5.0 & 0.06 \\
\hline 30 & $\begin{array}{l}\text { Scott and Bonk (1984 } \\
\text { [DIRS 104181]) }\end{array}$ & Tiva Canyon Tuff & Hackly zone & Tpcplnh & $\mathrm{CW}$ & 5.0 & 0.06 \\
\hline 31 & $\begin{array}{l}\text { Scott and Bonk (1984 } \\
\text { [DIRS 104181]) }\end{array}$ & Tiva Canyon Tuff & Columnar & Tpcplnc & $\mathrm{CW}$ & 5.0 & 0.06 \\
\hline 32 & $\begin{array}{l}\text { Scott and Bonk (1984 } \\
\text { [DIRS 104181]) }\end{array}$ & Tiva Canyon Tuff & Bedded Tuff & Tpbt4 & BT4 & 0.5 & 13.83 \\
\hline 33 & $\begin{array}{l}\text { Scott and Bonk (1984 } \\
\text { [DIRS 104181]) }\end{array}$ & \begin{tabular}{|c|}
$\begin{array}{c}\text { Yucca Mountain } \\
\text { Tuff }\end{array}$ \\
\end{tabular} & Undifferentiated & Tpbt4 & BT4 & 0.5 & 13.83 \\
\hline 34 & $\begin{array}{l}\text { Scott and Bonk (1984 } \\
\text { [DIRS 104181]) }\end{array}$ & $\begin{array}{c}\text { Yucca Mountain } \\
\text { Tuff }\end{array}$ & Upper & Tpbt4 & BT4 & 0.5 & 13.83 \\
\hline 35 & $\begin{array}{l}\text { Scott and Bonk (1984 } \\
\text { [DIRS 104181]) }\end{array}$ & $\begin{array}{c}\text { Yucca Mountain } \\
\text { Tuff }\end{array}$ & Middle & Tpy & $\mathrm{CW}$ & 5.0 & 0.06 \\
\hline 36 & $\begin{array}{l}\text { Scott and Bonk (1984 } \\
\text { [DIRS 104181]) }\end{array}$ & \begin{tabular}{|c|}
$\begin{array}{c}\text { Yucca Mountain } \\
\text { Tuff }\end{array}$ \\
\end{tabular} & Lower & Tpy & BT3 & 0.5 & 46.66 \\
\hline 37 & $\begin{array}{l}\text { Scott and Bonk (1984 } \\
\text { [DIRS 104181]) }\end{array}$ & \begin{tabular}{|c}
$\begin{array}{c}\text { Yucca Mountain } \\
\text { Tuff }\end{array}$ \\
\end{tabular} & Rhyolite Flows & Tpcpll & $\mathrm{CW}$ & 7.0 & 0.09 \\
\hline 38 & $\begin{array}{l}\text { Scott and Bonk (1984 } \\
\text { [DIRS 104181]) }\end{array}$ & $\begin{array}{c}\text { Yucca Mountain } \\
\text { Tuff }\end{array}$ & Bedded Tuff & Tpbt3 & BT3 & 0.5 & 46.66 \\
\hline 39 & $\begin{array}{l}\text { Scott and Bonk (1984 } \\
\text { [DIRS 104181]) }\end{array}$ & Pah Canyon Tuff & Undifferentiated & Tpp & TPP & 1.0 & 75.62 \\
\hline 40 & $\begin{array}{l}\text { Scott and Bonk (1984 } \\
\text { [DIRS 104181]) }\end{array}$ & Pah Canyon Tuff & Upper & Tpp & TPP & 1.0 & 75.62 \\
\hline 41 & $\begin{array}{l}\text { Scott and Bonk (1984 } \\
\text { [DIRS 104181]) }\end{array}$ & Pah Canyon Tuff & Middle & Tpp & $\mathrm{CW}$ & 5.0 & 0.06 \\
\hline 42 & $\begin{array}{l}\text { Scott and Bonk (1984 } \\
\text { [DIRS 104181]) }\end{array}$ & Pah Canyon Tuff & Lower & Tpbt2 & BT2 & 0.5 & 276.49 \\
\hline 43 & $\begin{array}{l}\text { Scott and Bonk (1984 } \\
\text { [DIRS 104181]) }\end{array}$ & Pah Canyon Tuff & Bedded Tuff & Tpbt2 & BT2 & 0.5 & 276.49 \\
\hline 44 & $\begin{array}{l}\text { Scott and Bonk (1984 } \\
\text { [DIRS 104181]) }\end{array}$ & $\begin{array}{l}\text { Topopah Spring } \\
\text { Tuff }\end{array}$ & Undifferentiated & Tptpll & $\mathrm{CW}$ & 7.0 & 0.09 \\
\hline
\end{tabular}


Table B-3. Lookup Table In INFIL V2.0 Providing Properties For Each Grid Block, Consisting of RockType Identifier, Source, Geologic Description (Formation and Lithology), Corresponding Lithostratigraphic Unit and Hydrogeologic Identifier, and Estimated Fracture Density and Bulk Bedrock Saturated Hydraulic Conductivity Based on Filled 250-Um Fractures (Continued)

\begin{tabular}{|c|c|c|c|c|c|c|c|}
\hline \multirow{2}{*}{$\begin{array}{l}\text { Geologic } \\
\text { Identifier } \\
45 \\
\end{array}$} & \multirow{2}{*}{\begin{tabular}{l}
\multicolumn{1}{c}{ Source } \\
Scott and Bonk (1984 \\
[DIRS 104181])
\end{tabular}} & \multicolumn{2}{|c|}{$\begin{array}{l}\text { Geologic descriptions from } \\
\text { sources }\end{array}$} & \multirow{2}{*}{\begin{tabular}{|c|}
$\begin{array}{c}\text { Corres- } \\
\text { ponding } \\
\text { lithostrati } \\
\text { graphic } \\
\text { unit }\end{array}$ \\
Tptrv1 \\
\end{tabular}} & \multirow{2}{*}{\begin{tabular}{|c|}
$\begin{array}{c}\text { Corres- } \\
\text { ponding } \\
\text { hydrogeo } \\
\text { logic unit }\end{array}$ \\
TC \\
\end{tabular}} & \multirow{2}{*}{\begin{tabular}{|c}
$\begin{array}{c}\text { Estimated } \\
\text { Fracture } \\
\text { density } \\
\text { (F/m) }\end{array}$ \\
\\
25.0 \\
\end{tabular}} & \multirow[t]{2}{*}{\begin{tabular}{|c|} 
Bulk \\
Bedrock \\
Saturated \\
Hydraulic \\
Conductivity \\
w/filled \\
250-um \\
fractures \\
(mm/d) \\
\\
0.41 \\
\end{tabular}} \\
\hline & & $\begin{array}{c}\text { Topopah Spring } \\
\text { Tuff }\end{array}$ & Caprock & & & & \\
\hline 99 & $\begin{array}{l}\text { Scott and Bonk (1984 } \\
\text { [DIRS 104181]) }\end{array}$ & $\begin{array}{c}\text { Topopah Spring } \\
\text { Tuff }\end{array}$ & Caprock/rounded & Tptrn & $\mathrm{TC}$ & 10.0 & 0.25 \\
\hline 46 & $\begin{array}{l}\text { Scott and Bonk (1984 } \\
\text { [DIRS 104181]) }\end{array}$ & $\begin{array}{c}\text { Topopah Spring } \\
\text { Tuff }\end{array}$ & Rounded & Tptrn & TR & 5.0 & 0.20 \\
\hline 47 & $\begin{array}{l}\text { Scott and Bonk (1984 } \\
\text { [DIRS 104181]) }\end{array}$ & $\begin{array}{c}\text { Topopah Spring } \\
\text { Tuff }\end{array}$ & Thin lithophysal & Tptpul & TUL & 3.0 & 0.05 \\
\hline 48 & $\begin{array}{l}\text { Scott and Bonk (1984 } \\
\text { [DIRS 104181]) }\end{array}$ & $\begin{array}{c}\text { Topopah Spring } \\
\text { Tuff }\end{array}$ & Red lithophysal & Tptpul & TUL & 3.0 & 0.05 \\
\hline 49 & $\begin{array}{l}\text { Scott and Bonk (1984 } \\
\text { [DIRS 104181]) }\end{array}$ & $\begin{array}{c}\text { Topopah Spring } \\
\text { Tuff }\end{array}$ & Upper lithophysal & Tptpul & TUL & 3.0 & 0.05 \\
\hline 50 & $\begin{array}{l}\text { Scott and Bonk (1984 } \\
\text { [DIRS 104181]) }\end{array}$ & $\begin{array}{c}\text { Topopah Spring } \\
\text { Tuff }\end{array}$ & Lower lithophysal & Tptpul & TUL & 3.0 & 0.05 \\
\hline 51 & $\begin{array}{l}\text { Scott and Bonk (1984 } \\
\text { [DIRS 104181]) }\end{array}$ & $\begin{array}{c}\text { Topopah Spring } \\
\text { Tuff }\end{array}$ & Lithophysal & Tptpul & TUL & 3.0 & 0.05 \\
\hline 52 & $\begin{array}{l}\text { Scott and Bonk (1984 } \\
\text { [DIRS 104181]) }\end{array}$ & $\begin{array}{c}\text { Topopah Spring } \\
\text { Tuff }\end{array}$ & Nonlithophysal & Tptpmn & TMN & 7.0 & 0.09 \\
\hline 53 & $\begin{array}{l}\text { Scott and Bonk (1984 } \\
\text { [DIRS 104181]) }\end{array}$ & $\begin{array}{c}\text { Topopah Spring } \\
\text { Tuff }\end{array}$ & $\begin{array}{c}\text { Gray } \\
\text { nonlithophysal }\end{array}$ & Tptpmn & TMN & 7.0 & 0.09 \\
\hline 54 & $\begin{array}{l}\text { Scott and Bonk (1984 } \\
\text { [DIRS 104181]) }\end{array}$ & $\begin{array}{c}\text { Topopah Spring } \\
\text { Tuff }\end{array}$ & Nonlithophysal & Tptpmn & TMN & 7.0 & 0.09 \\
\hline 55 & $\begin{array}{l}\text { Scott and Bonk (1984 } \\
\text { [DIRS 104181]) }\end{array}$ & $\begin{array}{c}\text { Topopah Spring } \\
\text { Tuff }\end{array}$ & Brick & Tptpmn & TMN & 7.0 & 0.09 \\
\hline 56 & $\begin{array}{l}\text { Scott and Bonk (1984 } \\
\text { [DIRS 104181]) }\end{array}$ & $\begin{array}{c}\text { Topopah Spring } \\
\text { Tuff }\end{array}$ & $\begin{array}{c}\text { Middle } \\
\text { nonlithophysal }\end{array}$ & Tptpmn & TMN & 7.0 & 0.09 \\
\hline 57 & $\begin{array}{l}\text { Scott and Bonk (1984 } \\
\text { [DIRS 104181]) }\end{array}$ & $\begin{array}{c}\text { Topopah Spring } \\
\text { Tuff }\end{array}$ & $\begin{array}{l}\text { Orange brick } \\
\text { lithophysal }\end{array}$ & Tptpmn & TMN & 7.0 & 0.09 \\
\hline 58 & $\begin{array}{l}\text { Scott and Bonk (1984 } \\
\text { [DIRS 104181]) }\end{array}$ & $\begin{array}{c}\text { Topopah Spring } \\
\text { Tuff }\end{array}$ & Orange brick & Tptpmn & TMN & 7.0 & 0.09 \\
\hline 59 & $\begin{array}{l}\text { Scott and Bonk (1984 } \\
\text { [DIRS 104181]) }\end{array}$ & $\begin{array}{c}\text { Topopah Spring } \\
\text { Tuff }\end{array}$ & & Tptpmn & TMN & 7.0 & 0.09 \\
\hline 60 & $\begin{array}{l}\text { Scott and Bonk (1984 } \\
\text { [DIRS 104181]) }\end{array}$ & $\begin{array}{c}\text { Topopah Spring } \\
\text { Tuff }\end{array}$ & & Tptpmn & TMN & 7.0 & 0.09 \\
\hline 61 & $\begin{array}{l}\text { Scott and Bonk (1984 } \\
\text { [DIRS 104181]) }\end{array}$ & $\begin{array}{c}\text { Topopah Spring } \\
\text { Tuff }\end{array}$ & & Tptpmn & TMN & 7.0 & 0.09 \\
\hline 62 & $\begin{array}{l}\text { Scott and Bonk (1984 } \\
\text { [DIRS 104181]) }\end{array}$ & $\begin{array}{c}\text { Topopah Spring } \\
\text { Tuff }\end{array}$ & Mottled lithophysal & Tptpll & TLL & 5.0 & 0.07 \\
\hline 63 & $\begin{array}{l}\text { Scott and Bonk (1984 } \\
\text { [DIRS 104181]) }\end{array}$ & $\begin{array}{c}\text { Topopah Spring } \\
\text { Tuff }\end{array}$ & Lower Lithophysal & Tptpll & TLL & 5.0 & 0.07 \\
\hline 64 & $\begin{array}{l}\text { Scott and Bonk (1984 } \\
\text { [DIRS 104181]) }\end{array}$ & $\begin{array}{c}\text { Topopah Spring } \\
\text { Tuff }\end{array}$ & Lower Lithophysal & Tptpll & TLL & 5.0 & 0.07 \\
\hline 65 & $\begin{array}{l}\text { Scott and Bonk (1984 } \\
\text { [DIRS 104181]) }\end{array}$ & $\begin{array}{c}\text { Topopah Spring } \\
\text { Tuff }\end{array}$ & Lower Lithophysal & Tptpll & TLL & 5.0 & 0.07 \\
\hline
\end{tabular}


Table B-3. Lookup Table In INFIL V2.0 Providing Properties For Each Grid Block, Consisting of RockType Identifier, Source, Geologic Description (Formation and Lithology), Corresponding Lithostratigraphic Unit and Hydrogeologic Identifier, and Estimated Fracture Density and Bulk Bedrock Saturated Hydraulic Conductivity Based on Filled 250-Um Fractures (Continued)

\begin{tabular}{|c|c|c|c|c|c|c|c|}
\hline \multirow{2}{*}{$\begin{array}{l}\text { Geologic } \\
\text { Identifier } \\
66\end{array}$} & \multirow{2}{*}{\begin{tabular}{|l|}
\multicolumn{1}{|c}{ Source } \\
Scott and Bonk (1984 \\
[DIRS 104181])
\end{tabular}} & \multicolumn{2}{|c|}{$\begin{array}{l}\text { Geologic descriptions from } \\
\text { sources }\end{array}$} & \multirow{2}{*}{ 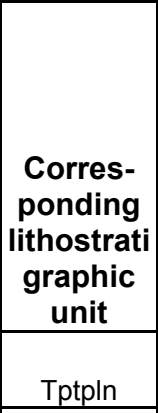 } & \multirow{2}{*}{\begin{tabular}{|c|}
$\begin{array}{c}\text { Corres- } \\
\text { ponding } \\
\text { hydrogeo } \\
\text { logic unit }\end{array}$ \\
TM1 \\
\end{tabular}} & \multirow{2}{*}{$\begin{array}{c}\begin{array}{c}\text { Estimated } \\
\text { Fracture } \\
\text { density } \\
\text { (F/m) }\end{array} \\
12.0 \\
\end{array}$} & \multirow[t]{2}{*}{\begin{tabular}{|c|} 
Bulk \\
Bedrock \\
Saturated \\
Hydraulic \\
Conductivity \\
w/filled \\
250-um \\
fractures \\
(mm/d) \\
\\
0.14 \\
\end{tabular}} \\
\hline & & \begin{tabular}{|c|}
$\begin{array}{c}\text { Topopah Spring } \\
\text { Tuff }\end{array}$ \\
\end{tabular} & Mottled & & & & \\
\hline 67 & $\begin{array}{l}\text { Scott and Bonk (1984 } \\
\text { [DIRS 104181]) }\end{array}$ & \begin{tabular}{|c|}
$\begin{array}{c}\text { Topopah Spring } \\
\text { Tuff }\end{array}$ \\
\end{tabular} & Vitrophyre & Tptpv3 & PV3 & 15.0 & 0.17 \\
\hline 68 & $\begin{array}{l}\text { Scott and Bonk (1984 } \\
\text { [DIRS 104181]) }\end{array}$ & \begin{tabular}{|c|}
$\begin{array}{c}\text { Topopah Spring } \\
\text { Tuff }\end{array}$ \\
\end{tabular} & Partially welded & Tptpv2,1 & PV2 & 0.5 & 0.07 \\
\hline 69 & $\begin{array}{l}\text { Scott and Bonk (1984 } \\
\text { [DIRS 104181]) }\end{array}$ & $\begin{array}{l}\text { Calico Hills } \\
\text { Formation }\end{array}$ & Pyroclastic rocks & Tac & $\mathrm{CHZ}$ & 0.5 & 0.02 \\
\hline 70 & $\begin{array}{l}\text { Scott and Bonk (1984 } \\
\text { [DIRS 104181]) }\end{array}$ & $\begin{array}{l}\text { Calico Hills } \\
\text { Formation }\end{array}$ & Lava flows & Tptpln & TM1 & 12.0 & 0.14 \\
\hline 71 & $\begin{array}{l}\text { Scott and Bonk (1984 } \\
\text { [DIRS 104181]) }\end{array}$ & $\begin{array}{l}\text { Calico Hills } \\
\text { Formation }\end{array}$ & $\begin{array}{l}\text { Autobrecciated } \\
\text { lavas }\end{array}$ & Tac & $\mathrm{CHZ}$ & 0.5 & 0.01 \\
\hline 72 & $\begin{array}{l}\text { Scott and Bonk (1984 } \\
\text { [DIRS 104181]) }\end{array}$ & Prow Pass Tuff & Partially welded & Tcp, unit3 & PP3 & 1.0 & 1.65 \\
\hline 73 & $\begin{array}{l}\text { Scott and Bonk (1984 } \\
\text { [DIRS 104181]) }\end{array}$ & Prow Pass Tuff & Moderately welded & Tcp, unit2 & PP2 & 2.0 & 0.05 \\
\hline 74 & $\begin{array}{l}\text { Scott and Bonk (1984 } \\
\text { [DIRS 104181]) }\end{array}$ & Prow Pass Tuff & Undifferentiated & Tcp, unit2 & PP2 & 2.0 & 0.05 \\
\hline 75 & $\begin{array}{l}\text { Scott and Bonk (1984 } \\
\text { [DIRS 104181]) }\end{array}$ & Prow Pass Tuff & Bedded Tuffs & Tcp, unit1 & PP1 & 1.0 & 0.02 \\
\hline 76 & $\begin{array}{l}\text { Scott and Bonk (1984 } \\
\text { [DIRS 104181]) }\end{array}$ & Bullfrog Tuff & Ash-flow tuff & Tcb, unit3 & BF3 & 1.0 & 0.09 \\
\hline 77 & $\begin{array}{l}\text { Scott and Bonk (1984 } \\
\text { [DIRS 104181]) }\end{array}$ & & Disturbed ground & & & & 0.25 \\
\hline 201 & $\begin{array}{l}\text { Sawyer et al. (1995 } \\
\text { [DIRS 104580]) }\end{array}$ & Tiva Canyon Tuff & Undifferentiated & Tpcpll & $\mathrm{CW}$ & 1.0 & 0.09 \\
\hline 202 & $\begin{array}{l}\text { Sawyer et al. } \\
\text { (1995 [DIRS 104580]) }\end{array}$ & \begin{tabular}{|c|} 
Timber Mountain \\
Tuff-Rainier Mesa \\
\end{tabular} & $\begin{array}{c}\text { Welded ash-flow } \\
\text { tuff }\end{array}$ & Tptpmn & TMN & 5.0 & 0.06 \\
\hline 203 & $\begin{array}{l}\text { Sawyer et al. } \\
\text { (1995 [DIRS 104580]) }\end{array}$ & \begin{tabular}{|c|}
$\begin{array}{c}\text { Rhyolite of Windy } \\
\text { Wash }\end{array}$ \\
\end{tabular} & Lava flows & Tpcpll & $\mathrm{CW}$ & 1.0 & 0.09 \\
\hline 204 & $\begin{array}{l}\text { Sawyer et al. } \\
\text { (1995 [DIRS 104580]) }\end{array}$ & & Alluvium & & & & 500.00 \\
\hline 205 & \begin{tabular}{|l} 
Sawyer et al. \\
(1995 [DIRS 104580])
\end{tabular} & \begin{tabular}{|c|}
$\begin{array}{c}\text { Rhyolite of Vent } \\
\text { Pass }\end{array}$ \\
\end{tabular} & Lava flows & Tptrv1 & $\mathrm{TC}$ & 25.0 & 0.41 \\
\hline 206 & $\begin{array}{l}\text { Sawyer et al. } \\
\text { (1995 [DIRS 104580]) }\end{array}$ & \begin{tabular}{|c|} 
Rhyolite of \\
Pinnacles Ridge \\
\end{tabular} & Lava flows & Tptrv1 & $\mathrm{TC}$ & 25.0 & 0.41 \\
\hline 207 & $\begin{array}{l}\text { Sawyer et al. } \\
\text { (1995 [DIRS 104580]) }\end{array}$ & \begin{tabular}{|c|} 
Rhyolite of \\
Pinnacles Ridge
\end{tabular} & Pyroclastic rocks & Tpbt2 & BT3 & 0.5 & 46.66 \\
\hline 208 & $\begin{array}{l}\text { Sawyer et al. } \\
\text { (1995 [DIRS 104580]) }\end{array}$ & $\begin{array}{l}\text { Calico Hills } \\
\text { Formation }\end{array}$ & Lava flows & Tptpln & TM1 & 12.0 & 0.14 \\
\hline 209 & $\begin{array}{l}\text { Sawyer et al. } \\
\text { (1995 [DIRS 104580]) }\end{array}$ & \begin{tabular}{|c} 
Yucca Mountain \\
Tuff
\end{tabular} & Middle & Tpy & $\mathrm{CW}$ & 5.0 & 0.06 \\
\hline 210 & $\begin{array}{l}\text { Sawyer et al. } \\
\text { (1995 [DIRS 104580]) }\end{array}$ & \begin{tabular}{|c|}
$\begin{array}{c}\text { Rhyolite of Comb } \\
\text { Peak }\end{array}$ \\
\end{tabular} & Lava flows & Tpcpll & $\mathrm{CW}$ & 1.0 & 0.09 \\
\hline
\end{tabular}


Table B-3. Lookup Table In INFIL V2.0 Providing Properties For Each Grid Block, Consisting of RockType Identifier, Source, Geologic Description (Formation and Lithology), Corresponding Lithostratigraphic Unit and Hydrogeologic Identifier, and Estimated Fracture Density and Bulk Bedrock Saturated Hydraulic Conductivity Based on Filled 250-Um Fractures (Continued)

\begin{tabular}{|c|c|c|c|c|c|c|c|}
\hline \multirow{2}{*}{$\begin{array}{l}\text { Geologic } \\
\text { Identifier } \\
211\end{array}$} & \multirow{2}{*}{$\begin{array}{l}\text { Source } \\
\text { Sawyer et al. } \\
\text { (1995 [DIRS 104580]) }\end{array}$} & \multicolumn{2}{|c|}{$\begin{array}{l}\text { Geologic descriptions from } \\
\text { sources }\end{array}$} & \multirow{2}{*}{\begin{tabular}{|c|}
$\begin{array}{c}\text { Corres- } \\
\text { ponding }\end{array}$ \\
lithostrati \\
$\begin{array}{c}\text { graphic } \\
\text { unit }\end{array}$ \\
Tcb, unit3 \\
\end{tabular}} & \multirow{2}{*}{\begin{tabular}{|c|}
$\begin{array}{c}\text { Corres- } \\
\text { ponding } \\
\text { hydrogeo } \\
\text { logic unit }\end{array}$ \\
BF3 \\
\end{tabular}} & \multirow{2}{*}{$\begin{array}{c}\begin{array}{c}\text { Estimated } \\
\text { Fracture } \\
\text { density } \\
\text { (F/m) }\end{array} \\
1.0\end{array}$} & \multirow[t]{2}{*}{\begin{tabular}{|c|} 
Bulk \\
Bedrock \\
Saturated \\
Hydraulic \\
Conductivity \\
w/filled \\
$250-$ um \\
fractures \\
(mm/d) \\
0.09 \\
\end{tabular}} \\
\hline & & Bullfrog Tuff & Ash-flow tuff & & & & \\
\hline 212 & $\begin{array}{l}\text { Sawyer et al. } \\
\text { (1995 [DIRS 104580]) }\end{array}$ & Bullfrog Tuff & Ash-flow tuff & Tcb, unit3 & BF3 & 1.0 & 0.09 \\
\hline 213 & $\begin{array}{l}\text { Sawyer et al. } \\
\text { (1995 [DIRS 104580]) }\end{array}$ & \begin{tabular}{|c|}
$\begin{array}{c}\text { Topopah Spring } \\
\text { Tuff }\end{array}$ \\
\end{tabular} & Nonlithophysal & Tptpmn & TMN & 1.0 & 0.09 \\
\hline 214 & $\begin{array}{l}\text { Sawyer et al. } \\
\text { (1995 [DIRS 104580]) }\end{array}$ & Prow Pass Tuff & Moderately welded & Tcp, unit2 & PP2 & 2.0 & 0.05 \\
\hline 301 & $\begin{array}{l}\text { Day et al. (1998 } \\
\text { [DIRS 101557]) }\end{array}$ & \begin{tabular}{|c|} 
Alluvial \& \\
Colluvial deposits \\
\end{tabular} & $\begin{array}{c}\text { Alluvial \& Colluvial } \\
\text { deposits }\end{array}$ & QTac & QTac & & 500.00 \\
\hline 302 & $\begin{array}{l}\text { Day et al. (1998 } \\
\text { [DIRS 101557]) }\end{array}$ & Colluvial deposits & Colluvial deposits & Qtc & QTac & & 500.00 \\
\hline 303 & $\begin{array}{l}\text { Day et al. (1998 } \\
\text { [DIRS 101557]) }\end{array}$ & $\begin{array}{l}\text { Miocene } \\
\text { Intrusives }\end{array}$ & basalt dike & $\mathrm{Td}$ & $\mathrm{CW}$ & 5.0 & 0.06 \\
\hline 304 & $\begin{array}{l}\text { Day et al. (1998 } \\
\text { [DIRS 101557]) }\end{array}$ & \begin{tabular}{|c|}
$\begin{array}{c}\text { Timber Mountain } \\
\text { Group }\end{array}$ \\
\end{tabular} & $\begin{array}{c}\begin{array}{c}\text { Rainier Mesa Tuff, } \\
\text { welded }\end{array} \\
\end{array}$ & Tmrw & TMN & 1.0 & 0.09 \\
\hline 305 & $\begin{array}{l}\text { Day et al. (1998 } \\
\text { [DIRS 101557]) }\end{array}$ & \begin{tabular}{|c|} 
Timber Mountain \\
Group
\end{tabular} & $\begin{array}{c}\text { Rainier Mesa Tuff, } \\
\text { nonwelded }\end{array}$ & $\mathrm{Tmr}$ & CNW & 6.0 & 2.74 \\
\hline 306 & $\begin{array}{l}\text { Day et al. (1998 } \\
\text { [DIRS 101557]) }\end{array}$ & $\begin{array}{c}\begin{array}{c}\text { Rhyolite of Comb } \\
\text { Peak }\end{array} \\
\end{array}$ & Rhyolite lava flow & Tpkl & BT3 & 0.5 & 46.66 \\
\hline 307 & $\begin{array}{l}\text { Day et al. (1998 } \\
\text { [DIRS 101557]) }\end{array}$ & \begin{tabular}{|c|}
$\begin{array}{c}\text { Rhyolite of Comb } \\
\text { Peak }\end{array}$ \\
\end{tabular} & Ash-flow tuff & Tpkt & BT3 & 0.5 & 46.66 \\
\hline 308 & $\begin{array}{l}\text { Day et al. (1998 } \\
\text { [DIRS 101557]) }\end{array}$ & $\begin{array}{c}\begin{array}{c}\text { Rhyolite of Comb } \\
\text { Peak }\end{array} \\
\end{array}$ & bedded tuff & Tbt5 & BT3 & 0.5 & 46.66 \\
\hline 309 & $\begin{array}{l}\text { Day et al. (1998 } \\
\text { [DIRS 101557]) }\end{array}$ & $\begin{array}{c}\begin{array}{c}\text { Rhyolite of Comb } \\
\text { Peak }\end{array} \\
\end{array}$ & undivided & Tpu & $\mathrm{CW}$ & 5.0 & 0.06 \\
\hline 310 & $\begin{array}{l}\text { Day et al. (1998 } \\
\text { [DIRS 101557]) }\end{array}$ & Tiva Canyon Tuff & undivided & Tcu & $\mathrm{CW}$ & 5.0 & 0.06 \\
\hline 311 & $\begin{array}{l}\text { Day et al. (1998 } \\
\text { [DIRS 101557]) }\end{array}$ & Tiva Canyon Tuff & $\begin{array}{c}\text { crystal rich vitric } \\
\text { zone }\end{array}$ & Tcrv & $\mathrm{TC}$ & 20.0 & 0.35 \\
\hline 312 & $\begin{array}{l}\text { Day et al. (1998 } \\
\text { [DIRS 101557]) }\end{array}$ & Tiva Canyon Tuff & \begin{tabular}{|c|}
$\begin{array}{c}\text { subvitric transition } \\
\text { zone }\end{array}$ \\
\end{tabular} & Tcrn4 & $\mathrm{TC}$ & 20.0 & 0.35 \\
\hline 313 & $\begin{array}{l}\text { Day et al. (1998 } \\
\text { [DIRS 101557]) }\end{array}$ & Tiva Canyon Tuff & pumice-poor zone & Tcrn3 & CUC & 5.0 & 3.34 \\
\hline 314 & $\begin{array}{l}\text { Day et al. (1998 } \\
\text { [DIRS 101557]) }\end{array}$ & Tiva Canyon Tuff & $\begin{array}{l}\text { mixed-pumice } \\
\text { zone }\end{array}$ & Tcr2 & CUC & 5.0 & 3.34 \\
\hline 315 & $\begin{array}{l}\text { Day et al. (1998 } \\
\text { [DIRS 101557]) }\end{array}$ & Tiva Canyon Tuff & $\begin{array}{c}\text { crystal transition } \\
\text { zone } \\
\end{array}$ & Tcr1 & $\mathrm{CW}$ & 5.0 & 0.06 \\
\hline 316 & $\begin{array}{l}\text { Day et al. (1998 } \\
\text { [DIRS 101557]) }\end{array}$ & Tiva Canyon Tuff & upper lithophysal & Tcpul & CUL & 5.0 & 1.13 \\
\hline 317 & $\begin{array}{l}\text { Day et al. (1998 } \\
\text { [DIRS 101557]) }\end{array}$ & Tiva Canyon Tuff & $\begin{array}{c}\text { upper } \\
\text { nonlithophysal }\end{array}$ & Tcpun & $\mathrm{CW}$ & 5.0 & 0.06 \\
\hline 318 & $\begin{array}{l}\text { Day et al. (1998 } \\
\text { [DIRS 101557]) }\end{array}$ & Tiva Canyon Tuff & $\begin{array}{c}\text { middle } \\
\text { nonlithophysal }\end{array}$ & Tcpmn & $\mathrm{CW}$ & 5.0 & 0.06 \\
\hline
\end{tabular}


Table B-3. Lookup Table In INFIL V2.0 Providing Properties For Each Grid Block, Consisting of RockType Identifier, Source, Geologic Description (Formation and Lithology), Corresponding Lithostratigraphic Unit and Hydrogeologic Identifier, and Estimated Fracture Density and Bulk Bedrock Saturated Hydraulic Conductivity Based on Filled 250-Um Fractures (Continued)

\begin{tabular}{|c|c|c|c|c|c|c|c|}
\hline $\begin{array}{l}\text { Geologic } \\
\text { Identifier }\end{array}$ & Source & $\begin{array}{r}\text { Geologic des } \\
\text { sol }\end{array}$ & $\begin{array}{l}\text { criptions from } \\
\text { Irces }\end{array}$ & $\begin{array}{c}\text { Corres- } \\
\text { ponding } \\
\text { lithostrati } \\
\text { graphic } \\
\text { unit }\end{array}$ & \begin{tabular}{|c|} 
Corres- \\
ponding \\
hydrogeo \\
logic unit \\
\end{tabular} & $\begin{array}{c}\text { Estimated } \\
\text { Fracture } \\
\text { density } \\
(\mathrm{F} / \mathrm{m})\end{array}$ & \begin{tabular}{|c|} 
Bulk \\
Bedrock \\
Saturated \\
Hydraulic \\
Conductivity \\
w/filled \\
$250-$ um \\
fractures \\
(mm/d)
\end{tabular} \\
\hline 319 & $\begin{array}{l}\text { Day et al. (1998 } \\
\text { [DIRS 101557]) } \\
\end{array}$ & Tiva Canyon Tuff & $\begin{array}{c}\text { upper \& middle } \\
\text { nonlith, undivided }\end{array}$ & Tcpum & $\mathrm{CW}$ & 5.0 & 0.06 \\
\hline 320 & $\begin{array}{l}\text { Day et al. (1998 } \\
\text { [DIRS 101557]) }\end{array}$ & Tiva Canyon Tuff & lower lith & Tcpll & $\mathrm{CW}$ & 5.0 & 0.06 \\
\hline 321 & $\begin{array}{l}\text { Day et al. (1998 } \\
\text { [DIRS 101557]) }\end{array}$ & Tiva Canyon Tuff & lower nonlith & Tcpln & $\mathrm{CW}$ & 5.0 & 0.06 \\
\hline 322 & $\begin{array}{l}\text { Day et al. (1998 } \\
\text { [DIRS 101557]) }\end{array}$ & Tiva Canyon Tuff & columnar subzone & Tcplnc & $\mathrm{CW}$ & 5.0 & 0.06 \\
\hline 323 & $\begin{array}{l}\text { Day et al. (1998 } \\
\text { [DIRS 101557]) }\end{array}$ & Tiva Canyon Tuff & crystal poor vitric & Tcplncv & CNW & 6.0 & 2.74 \\
\hline 324 & $\begin{array}{l}\text { Day et al. (1998 } \\
\text { [DIRS 101557]) }\end{array}$ & Yucca Mt. Tuff & Yucca Mt. Tuff & Tpy & BT4 & 0.5 & 13.83 \\
\hline 325 & $\begin{array}{l}\text { Day et al. (1998 } \\
\text { [DIRS 101557]) }\end{array}$ & Pah Canyon Tuff & $\begin{array}{c}\text { Pah Canyon Tuff, } \\
\text { nonwelded }\end{array}$ & Tpp & TPP & 1.0 & 75.62 \\
\hline 326 & $\begin{array}{l}\text { Day et al. (1998 } \\
\text { [DIRS 101557]) }\end{array}$ & Pah Canyon Tuff & $\begin{array}{c}\text { Pah Canyon Tuff, } \\
\text { welded }\end{array}$ & Tppw & $\mathrm{CW}$ & 5.0 & 0.06 \\
\hline 327 & $\begin{array}{l}\text { Day et al. (1998 } \\
\text { [DIRS 101557]) }\end{array}$ & $\begin{array}{c}\text { pre-Pah Canyon } \\
\text { Tuff }\end{array}$ & $\begin{array}{c}\text { pre-Pah Canyon } \\
\text { Tuff } \\
\end{array}$ & Tpbt2 & BT2 & 0.5 & 276.49 \\
\hline 328 & $\begin{array}{l}\text { Day et al. (1998 } \\
\text { [DIRS 101557]) }\end{array}$ & $\begin{array}{c}\text { Topopah Spring } \\
\text { Tuff }\end{array}$ & undifferentiated & Tptu & TR & 5.0 & 0.20 \\
\hline 329 & $\begin{array}{l}\text { Day et al. (1998 } \\
\text { [DIRS 101557]) }\end{array}$ & $\begin{array}{l}\text { crystal rich } \\
\text { member }\end{array}$ & $\begin{array}{c}\text { crystal rich vitric, } \\
\text { undivided }\end{array}$ & Tptrv & $\mathrm{TC}$ & 20.0 & 0.35 \\
\hline 330 & \begin{tabular}{|l} 
Day et al. (1998 \\
[DIRS 101557])
\end{tabular} & $\begin{array}{l}\text { crystal rich } \\
\text { member }\end{array}$ & $\begin{array}{c}\text { densely welded } \\
\text { zone }\end{array}$ & Tptrn3 & $\mathrm{TC}$ & 20.0 & 0.35 \\
\hline 331 & $\begin{array}{l}\text { Day et al. (1998 } \\
\text { [DIRS 101557]) }\end{array}$ & $\begin{array}{l}\text { crystal rich } \\
\text { member }\end{array}$ & pumice-rich zone & Tptrn2 & TR & 5.0 & 0.20 \\
\hline 332 & $\begin{array}{l}\text { Day et al. (1998 } \\
\text { [DIRS 101557]) }\end{array}$ & $\begin{array}{l}\text { crystal rich } \\
\text { member }\end{array}$ & $\begin{array}{c}\text { crystal transition } \\
\text { zone }\end{array}$ & Tptr1 & TUL & 3.0 & 0.05 \\
\hline 333 & $\begin{array}{l}\text { Day et al. (1998 } \\
\text { [DIRS 101557]) }\end{array}$ & $\begin{array}{c}\text { crystal poor } \\
\text { member }\end{array}$ & upper lith & Tptpul & TUL & 3.0 & 0.05 \\
\hline 334 & $\begin{array}{l}\text { Day et al. (1998 } \\
\text { [DIRS 101557]) }\end{array}$ & $\begin{array}{l}\text { crystal poor } \\
\text { member }\end{array}$ & middle nonlith & Tptpmn & TMN & 7.0 & 0.09 \\
\hline 335 & $\begin{array}{l}\text { Day et al. (1998 } \\
\text { [DIRS 101557]) }\end{array}$ & $\begin{array}{l}\text { crystal poor } \\
\text { member }\end{array}$ & $\begin{array}{c}\text { lithophysal bearing } \\
\text { subzone }\end{array}$ & Tptmnl & TMN & 7.0 & 0.09 \\
\hline 336 & $\begin{array}{l}\text { Day et al. (1998 } \\
\text { [DIRS 101557]) }\end{array}$ & $\begin{array}{l}\text { crystal poor } \\
\text { member }\end{array}$ & lower lith & Tptpll & TLL & 7.0 & 0.09 \\
\hline 345 & $\begin{array}{l}\text { Day et al. (1998 } \\
\text { [DIRS 101557]) }\end{array}$ & $\begin{array}{c}\text { Topopah Spring } \\
\text { Tuff }\end{array}$ & undivided & Tptrn & TR & 10.0 & 0.24 \\
\hline
\end{tabular}

Source: DTN: GS000308311221.004.

$\mathrm{F} / \mathrm{m}=$ fractures per meter; $\mathrm{mm} / \mathrm{d}=$ millimeters per day 
Table B-4. Summary of soil properties used as input for INFIL V2.0.

\begin{tabular}{|c|c|c|c|c|c|c|c|c|}
\hline $\begin{array}{l}\text { Soil } \\
\text { unit }\end{array}$ & $\begin{array}{c}\text { Saturated } \\
\text { hydraulic } \\
\text { conductivity } \\
\text { (simulated, } \\
\mathrm{m} / \mathrm{s} \text { ) }\end{array}$ & $\begin{array}{l}\text { alpha } \\
(1 / \mathrm{Pa})\end{array}$ & $\mathrm{n}$ & $\begin{array}{c}\text { Porosity } \\
(\%)\end{array}$ & $\begin{array}{c}\text { Rock } \\
\text { fragmen } \\
\text { ts }(\%)\end{array}$ & $\begin{array}{c}\text { Bulk } \\
\text { Density } \\
\left(\mathrm{g} / \mathrm{cm}^{3}\right) \\
\end{array}$ & $\begin{array}{c}\text { Water } \\
\text { content at } \\
-0.1 \text { bar water } \\
\text { potential } \\
(\%) \\
\end{array}$ & $\begin{array}{c}\text { Water } \\
\text { content at } \\
-60 \text { bars } \\
\text { water } \\
\text { potential }(\%)\end{array}$ \\
\hline 1 & $5.6 \times 10^{-6}$ & 0.00052 & 1.24 & 36.6 & 10.5 & 1.60 & 24.2 & 5.4 \\
\hline 2 & $1.2 \times 10^{-5}$ & 0.00062 & 1.31 & 31.5 & 11.6 & 1.73 & 17.3 & 2.3 \\
\hline 3 & $1.3 \times 10^{-5}$ & 0.00066 & 1.36 & 32.5 & 18.7 & 1.70 & 16.3 & 1.7 \\
\hline 4 & $3.8 \times 10^{-5}$ & 0.00087 & 1.62 & 28.1 & 21.9 & 1.81 & 7.3 & 0.2 \\
\hline 5 & $6.7 \times 10^{-6}$ & 0.00056 & 1.28 & 33.0 & 15.2 & 1.69 & 20.0 & 3.5 \\
\hline 6 & $2.7 \times 10^{-5}$ & 0.00074 & 1.40 & 33.9 & 11.7 & 1.66 & 15.0 & 1.1 \\
\hline 7 & $5.6 \times 10^{-6}$ & 0.00055 & 1.26 & 37.0 & 17.1 & 1.58 & 23.4 & 4.6 \\
\hline 9 & $5.7 \times 10^{-6}$ & 0.00055 & 1.30 & 32.2 & 19.1 & 1.72 & 18.9 & 2.8 \\
\hline
\end{tabular}

Output DTN: GS000308311221.004.

$\mathrm{g} / \mathrm{cm}^{3}=$ grams per cubic centimeter; $\mathrm{m} / \mathrm{s}=$ meters per second $; \mathrm{Pa}=$ pascals 


\section{INTENTIONALLY LEFT BLANK}


APPENDIX C

DEVELOPMENT OF DAILY CLIMATE INPUT USING DAILY09 V1.0 


\section{C1. NAME OF ROUTINE/MACRO WITH VERSION/OS/HARDWARE ENVIRONMENT AND USER INFORMATION:}

Name of software routine: DAILY09 V1.0

OS and hardware environment: Windows NT 4.0, Pentium Pro PC

Computer Identification: SM321276 with a USGS specific host-name P720dcasr

Software Users: Joseph Hevesi (916-278-3274), Alan Flint (916-278-3221)

User Location: U.S. Geological Survey, Room 5000E, Placer Hall, 6000 J Street, Sacramento, CA $95819-6129$

\section{C2. NAME OF COMMERCIAL SOFTWARE WITH VERSION/OS/HARDWARE USED TO DEVELOP ROUTINE/MACRO:}

The source code for DAILY09 V1.0 was developed using the standard FORTRAN77 programming language. The source code was written, debugged, and compiled (for PC platforms using INTEL processors) using DIGITAL Visual Fortran with Microsoft Developer Studio, v. 5.0.

\section{C3. GENERAL DESCRIPTION OF ROUTINE/MACRO:}

DAILY09 V1.0 is a FORTRAN77 routine developed in accordance with AP-SI.1Q, specifically for the analysis/model activity documented in this report. The routine source code (DAILY09.FOR), compiled executable file (DAILY09.EXE), routine control file (DAILY09.CTL), input and output files used for routine validation, supplemental files created as part of validation testing, and a copy of this appendix, are located under the directory DAILY09 on a CD-ROM labeled DAYINPUT-1. The routine source code, control file, and the input and output files are ASCII text files that can be read using any standard ASCII text editor and can be imported into standard word processing applications such as Microsoft Word. The executable file can be used to run DAILY09 V1.0 on any PC with an INTEL processor (with adequate RAM).

\section{C4. TEST PLAN FOR THE SOFTWARE ROUTINE DAILY09 V1.0:}

\section{- Explain whether this is a routine or macro and describe what it does:}

DAILY09 V1.0 is a routine that creates a daily climate input file for INFIL. It reformats EARTHINFO precipitation and air temperature files into a format that can be used as input to INFIL V2.0 (USGS 2000 [DIRS 139422]). Daily climate records from the analogue precipitation sites were exported from the EARTHINFO database (using the NCDC format option), and the exported files (Nogales.dat and Hobbs.dat) were provided as input to the program DAILY09, which reformats the NCDC format into the xyz column format required by INFIL V2.0. In addition to reformatting, DAILY09 also identifies gaps in the precipitation and the maximum and minimum air temperature records. Minor gaps (10 days or less for precipitation and 20 days or less for air temperature) are filled using an estimate of zero for precipitation and linear interpolation (arithmetic mean) between the days having records on either side of the gap for air temperature. Years having major gaps in the record are identified and omitted from the reformatted output. Average daily air temperature is estimated as the 
mean of the recorded maximum and minimum daily air temperatures. Output from DAILY09, which includes the average daily air temperature estimate, is provided directly as input to INFIL V2.0.

\section{- Listing of FORTRAN77 Source code:}

A listing of the FORTRAN77 source code for the routine DAILY09 V1.0 along with examples of the input and output files used in the test plan are included at the end of this appendix.

\section{- Description of test(s):}

To evaluate the accuracy of the functions performed by the routine, the test plan utilizes the auxiliary output files created by DAILY09 so that the individual functions can be tested separately. The primary function performed by the routine is the re-formatting of the EARTHINFO export file (exported using the NCDC export format option) consisting of the daily climate record for a selected monitoring site. The EARTHINFO exported file consists of measured daily precipitation (in hundredths of inches), daily maximum air temperature (in degrees Fahrenheit), daily minimum air temperature (in degrees Fahrenheit), and daily snowfall depth (in tenths of inches). It is an ASCII file with the data organized in a pseudo-matrix format.

There are 4 test cases used to evaluate the accuracy of DAILY09 in performing its expected calculations and formatting: (1) A visual inspection to ascertain that the reformatting of the data from the pseudo-matrix (EARTHINFO) into the column format required for input into INFIL doesn't change the values, (2) a visual inspection of the identification of gaps that eliminate years with gaps in precipitation greater than 10 days and air temperature greater than 20 days, (3) an arithmetic check to ensure that the mean of the maximum and minimum air temperature is correctly calculated for the day, and (4) a visual inspection of gaps in the record that identify gaps in precipitation less than 10 days and insert zeros, and a visual and arithmetic check to ensure that gaps in air temperature less than 20 days calculate a linear interpolation between the number preceding the gap and the number at the end of the gap.

\section{- Specify the range of input values to be used and why the range is valid:}

An example input is used for each test case that represents a random selection of values from the EARTHINFO output file that is transformed into the INFIL daily precipitation input file. A matching output file is used to determine if the transformation is accurate.

\section{C5. TEST RESULTS.}

- Output from test (explain difference between input range used and possible input):

The output must provide, for each of the 4 test cases: (1) an accurate representation of the values reformatted, (2) the omission of years with gaps that exceed those number 
of days specified, (3) the correct averaging of minimum and maximum air temperatures for a given day to no greater accuracy than zero decimal places, and (4) the insertion of zeros into precipitation records that have gaps for less than 10 days and the correct interpolation of air temperatures for gaps less than 20 days, to no greater accuracy than zero decimal places.

- Description of how the testing shows that the results are correct for the specified input:

If the testing results in output that conforms to the above criteria then the results are correct for the specified input.

\section{- List limitations or assumptions to this test case and code in general:}

Limitations to the developed test case consist of the selection only of a small number of values that are assumed to be representative of the entire file.

\section{- Electronic files identified by name and location:}

The following electronic files including DAILY09 V1.0 and selected analogue input and output files are provided:

DAILY09.CTL: Input file consisting of the input and output file names for BLOCKR7, along with parameters needed to perform the 36 blocking ridge angle calculations.

DAILY09.FOR: FORTRAN source code listing for the routine BLOCKR7. A printout of the source code is included as part of this appendix.

DAILY09.EXE: Executable file for the routine BLOCKR7, compiled for INTEL processors.

ROSALIA.DAT: ASCII text file exported from the EARTHINFO NOAA daily climate records WEST2 database. This file is the input file to DAILY09 V1.0.

ROSALIA.DAY: Auxiliary output file created by DAILY09 V1.0. The file contains all daily climate data provided by ROSALIA.DAT and is used to test for the proper re-formatting. The calculated average daily air temperature is included. This file is used only as part of the validation test for DAILY09.

ROSALIA.INP: Primary output file created by DAILY09 V1.0. This file is used directly as input to INFIL V2.0 for defining the daily climate input parameters needed for simulating net infiltration. 


\section{C6. SUPPORTING INFORMATION. (INCLUDE BACKGROUND INFORMATION, SUCH AS REVISION TO A PREVIOUS ROUTINE OR MACRO, OR EXPLANATION OF THE STEPS PERFORMED TO RUN THE SOFTWARE. INCLUDE LISTINGS OF ALL ELECTRONIC FILES AND CODES USED).}

\section{- Procedure for running routine:}

To run the routine DAILY09, an executable version of the code and all input files must be placed in the same directory. The routine is executed by typing DAILY09 in a DOS window or by double clicking on the file, DAILY09.EXE in Windows NT. The input and output file names and the parameters used for the blocking ridge calculations must be in the correct sequential order as specified in the routine control file, DAILY09.CTL (see example listing in this section)

\section{- Example listing of ROSALIA.DAT.}

This ASCII file is exported from EARTHINFO using the NCDC export format option. The data shown in this subset is for maximum daily air temperature (TMAX), followed by precipitation (PRCP), with the record starting in May (5) of 1948, continuing through November (11) of 1948. On the first two monthly records it is noted just above the top line how to read the file. Month 5 has no data (-99999) for temperature, month 6 has data in degrees Fahrenheit.

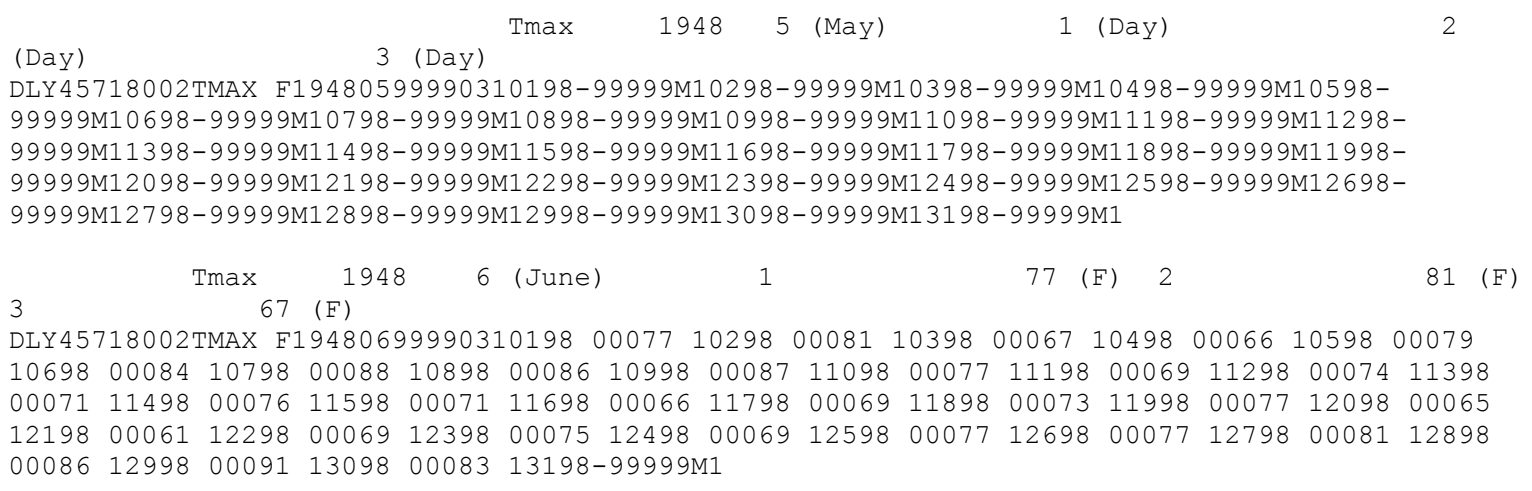

DLY45718002PRCPHI19480599990310198-99999M1 0298-99999M1 0398-99999M10498-99999M1059899999M1 0698-99999M1 0798-99999M1 0898-99999M1 0998-99999M11098-99999M11198-99999M1129899999M11398-99999M11498-99999M11598-99999M11698-99999M11798-99999M11898-99999M1199899999M12098-99999M12198-99999M122 98-99999M12398-99999M12498-99999M12598-99999M1269899999M12798-99999M12898-99999M12998-99999M13098-99999M13198-99999M1

DLY45718002PRCPHI19480699990310198 00000 1029800000103980000010498000171059800001 $10698000001079800000108980000010998000001109800040111980000011298 \quad 00057 \quad 11398$ 000051149800002115980000011698000461179800012118980000011998000001209800000 $\begin{array}{llllllllllllllll}12198 & 00034 & 12298 & 00005 & 12398 & 00004 & 12498 & 00000 & 12598 & 00005 & 12698 & 00005 & 12798 & 00000 & 12898\end{array}$ $0000012998000001309800002 \quad 13198-99999 \mathrm{M} 1$

\section{- Example listing of ROSALIA.DAY.}

DAILY09 uses the EARTHINFO data to reformat into *.DAY format prior to identification of gaps, conversions and averaging. When compared to the above EARTHINFO file it indicates that the reformatting done in DAILY09 is correct. This file also includes the conversion of air temperature from Fahrenheit to Celsius. 
June 1, 1948 in the EARTHINFO file above is $77(\mathrm{~F})$, June 2 is $81(\mathrm{~F})$. In file below the conversion results in June $1=25(\mathrm{C})$ and June $2=27.2(\mathrm{C})$, calculated as degrees $\mathrm{C}=($ degrees $\mathrm{F}-32) *(5 / 9)$.

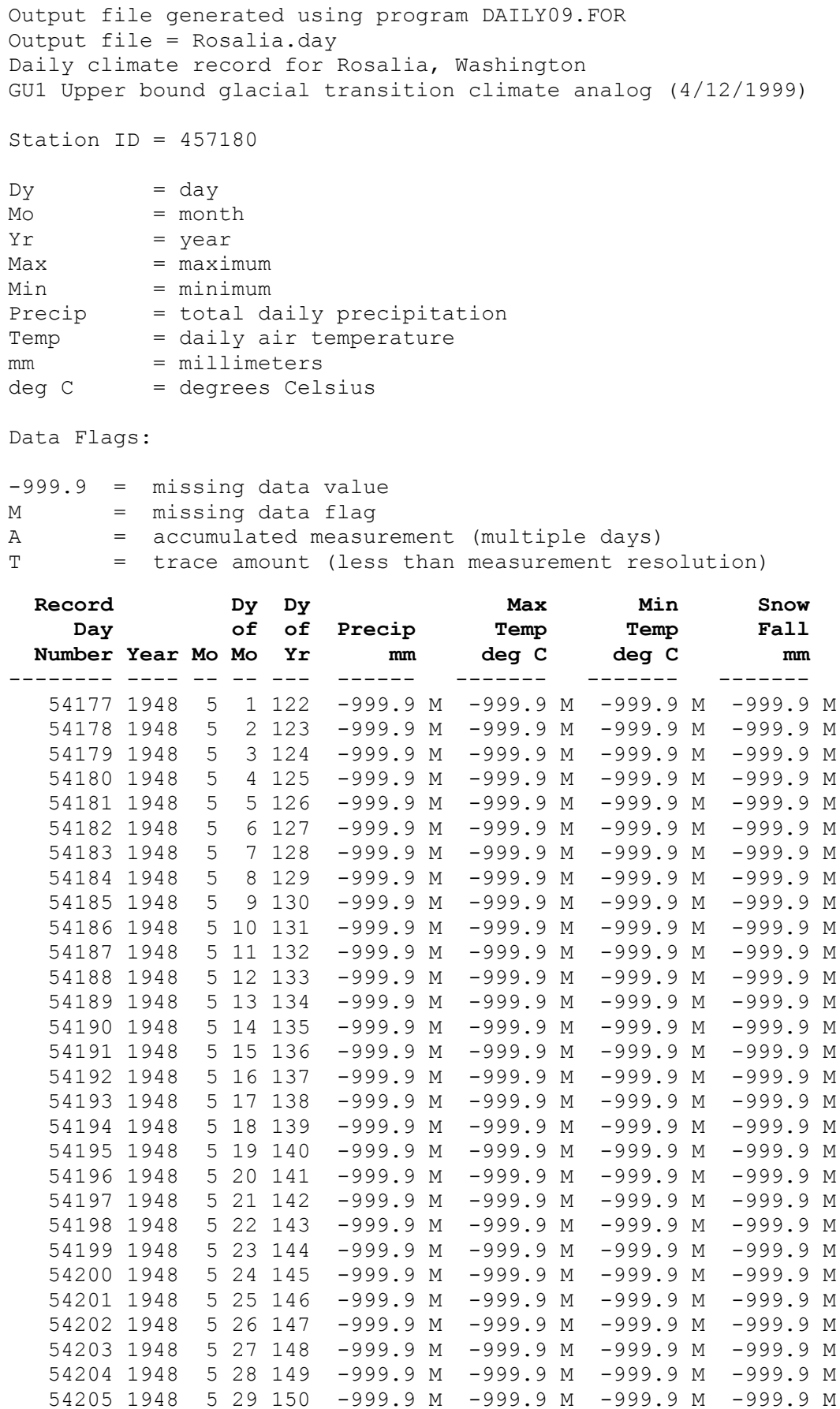




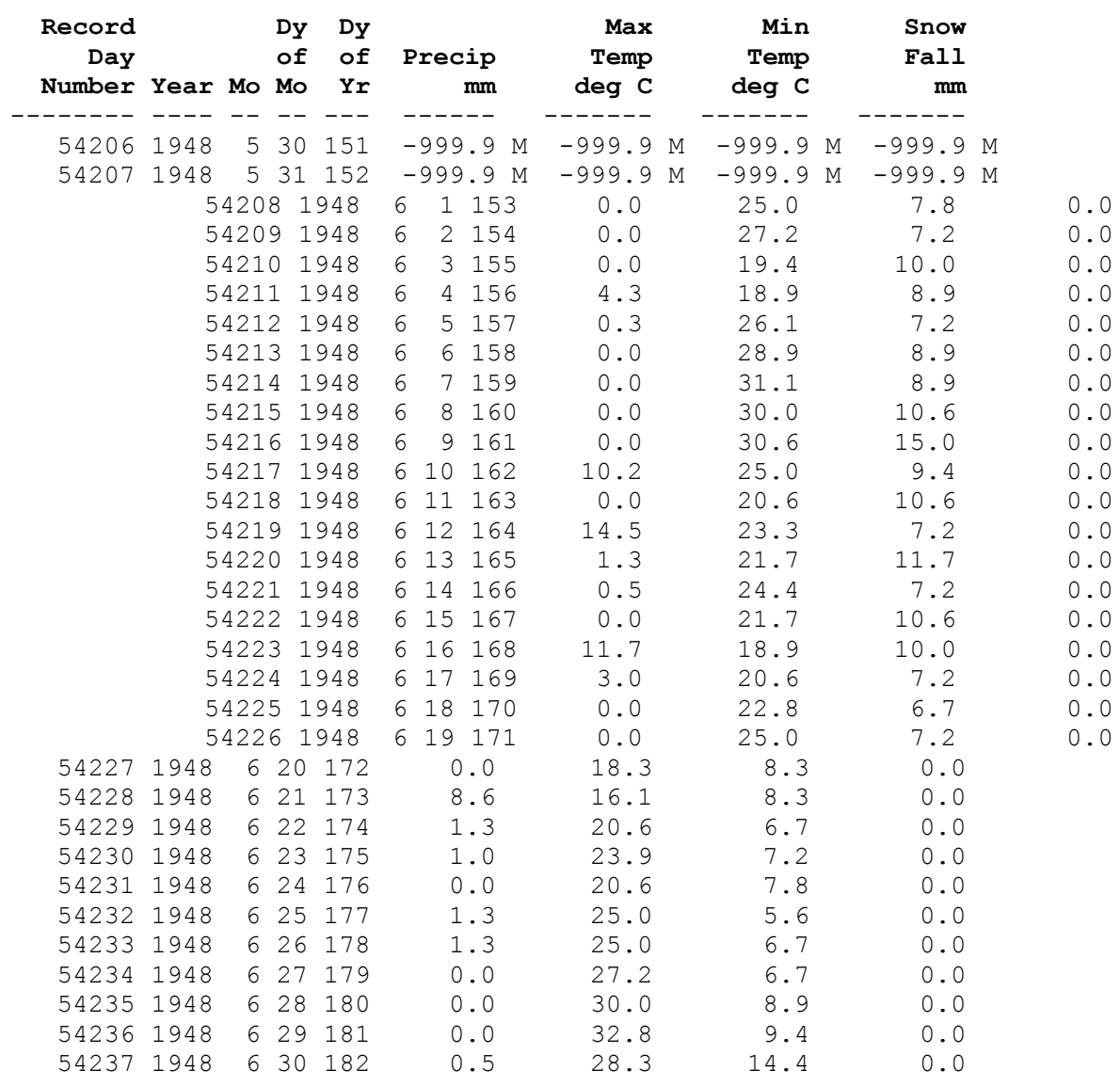

\section{- Example listing of ROSALIA.DAY.}

DAILY09 uses the EARTHINFO data to reformat into *.DAY format prior to identification of gaps and averaging, but following conversion from Fahrenheit to Celsius. The file below is precipitation for 1971 (Dec), 1972 (all) and 1973 (Jan and Feb only), following the reformatting and conversion to Celsius. The year 1972 has large gaps and when compared to the final input file will be omitted.

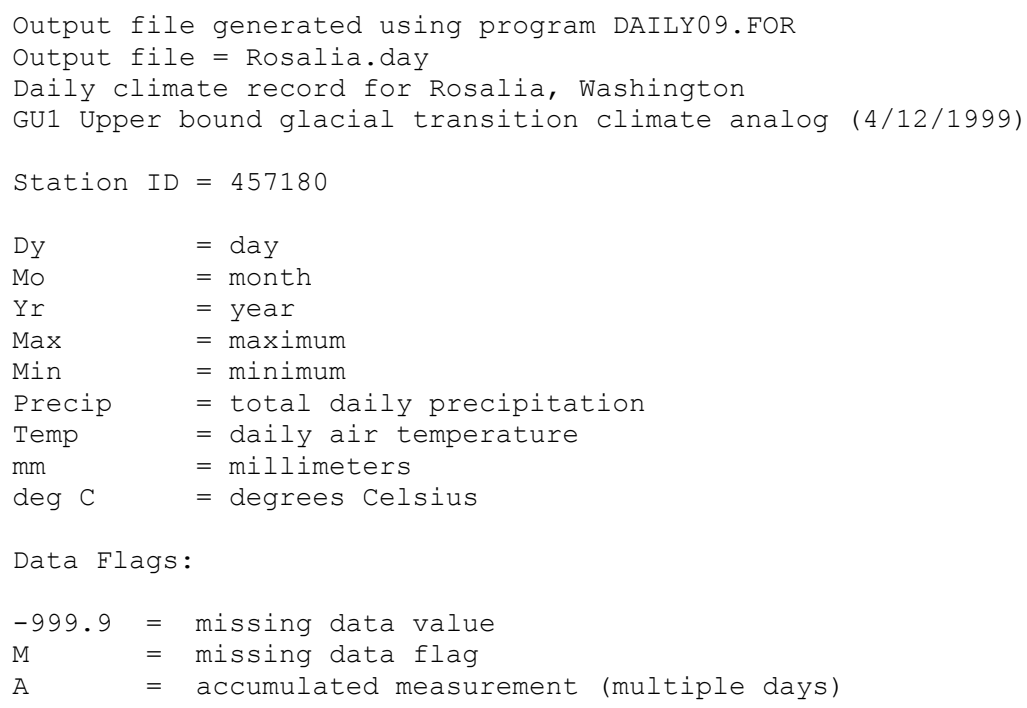


$\mathrm{T} \quad=$ trace amount (less than measurement resolution)

\begin{tabular}{|c|c|c|c|c|c|c|c|c|}
\hline $\begin{array}{r}\text { Record } \\
\text { Day } \\
\text { Number }\end{array}$ & Year & Mo & $\begin{array}{l}\text { Dy } \\
\text { of } \\
\text { Mo }\end{array}$ & $\begin{array}{l}\text { Dy } \\
\text { of } \\
\text { Yr }\end{array}$ & $\begin{array}{r}\text { Precip } \\
\text { mm }\end{array}$ & $\begin{array}{r}\text { Max } \\
\text { Temp } \\
\text { deg C }\end{array}$ & $\begin{array}{r}\text { Min } \\
\text { Temp } \\
\text { deg C }\end{array}$ & $\begin{array}{r}\text { Snow } \\
\text { Fall } \\
\text { mm }\end{array}$ \\
\hline & --- & -- & -- & --- & ------- & ----- & ----- & --- \\
\hline 62791 & 1971 & 12 & 1 & 335 & 0.0 & 1.1 & -3.9 & 0.0 \\
\hline 62792 & 1971 & 12 & 2 & 336 & 0.0 & 3.9 & -2.8 & 0.0 \\
\hline 62793 & 1971 & 12 & 3 & 337 & $0.0 \mathrm{~T}$ & 2.8 & -4.4 & 0.0 \\
\hline 62794 & 1971 & 12 & 4 & 338 & 0.0 & 1.7 & -6.1 & 0.0 \\
\hline 62795 & 1971 & 12 & 5 & 339 & 5.1 & 2.2 & -1.7 & 63.5 \\
\hline 62796 & 1971 & 12 & 6 & 340 & 0.0 & 2.8 & -5.0 & 0.0 \\
\hline 62797 & 1971 & 12 & 7 & 341 & 0.0 & -2.8 & -16.1 & 0.0 \\
\hline 62798 & 1971 & 12 & 8 & 342 & 0.0 & -6.7 & -15.6 & 0.0 \\
\hline 62799 & 1971 & 12 & 9 & 343 & 0.0 & 2.8 & -7.8 & 0.0 \\
\hline 62800 & 1971 & 12 & 10 & 344 & 0.0 & 2.2 & -2.2 & 0.0 \\
\hline 62801 & 1971 & 12 & 11 & 345 & 7.6 & 0.0 & -8.9 & 50.8 \\
\hline 62802 & 1971 & 12 & 12 & 346 & 2.0 & 1.1 & -8.9 & 25.4 \\
\hline 62803 & 1971 & 12 & 13 & 347 & 0.0 & 0.0 & -9.4 & 0.0 \\
\hline 62804 & 1971 & 12 & 14 & 348 & 0.0 & 0.6 & -7.8 & 0.0 \\
\hline 62805 & 1971 & 12 & 15 & 349 & 0.0 & 1.1 & -7.2 & 0.0 \\
\hline 62806 & 1971 & 12 & 16 & 350 & 3.6 & -1.7 & $-13 \cdot 3$ & 76.2 \\
\hline 62807 & 1971 & 12 & 17 & 351 & 0.0 & 4.4 & -1.7 & 0.0 \\
\hline 62808 & 1971 & 12 & 18 & 352 & 0.3 & 5.0 & 0.6 & 0.0 \\
\hline 62809 & 1971 & 12 & 19 & 353 & 0.0 & 3.3 & -3.3 & 0.0 \\
\hline 62810 & 1971 & 12 & 20 & 354 & 0.0 & 0.6 & -1.1 & 0.0 \\
\hline 62811 & 1971 & 12 & 21 & 355 & 3.0 & 2.2 & -0.6 & 12.7 \\
\hline 62812 & 1971 & 12 & 22 & 356 & 2.0 & 3.9 & 0.0 & 0.0 \\
\hline 62813 & 1971 & 12 & 23 & 357 & 0.3 & 5.6 & -1.7 & 0.0 \\
\hline 62814 & 1971 & 12 & 24 & 358 & 0.3 & 3.9 & 0.0 & 0.0 \\
\hline 62815 & 1971 & 12 & 25 & 359 & 0.0 & 6.1 & -0.6 & 0.0 \\
\hline 62816 & 1971 & 12 & 26 & 360 & 0.0 & 3.3 & -4.4 & 0.0 \\
\hline 62817 & 1971 & 12 & 27 & 361 & 0.0 & -3.3 & -10.0 & 0.0 \\
\hline 62818 & 1971 & 12 & 28 & 362 & 0.0 & -1.7 & -10.6 & 0.0 \\
\hline 62819 & 1971 & 12 & 29 & 363 & 3.0 & -4.4 & -8.9 & 25.4 \\
\hline 62820 & 1971 & 12 & 30 & 364 & 0.0 & -5.0 & -16.1 & 0.0 \\
\hline 62821 & 1971 & 12 & 31 & 365 & 0.8 & 0.6 & -9.4 & 25.4 \\
\hline 62822 & 1972 & 1 & 1 & 1 & 0.0 & 0.6 & -5.0 & 0.0 \\
\hline 62823 & 1972 & 1 & 2 & 2 & 0.0 & 2.8 & -2.8 & 0.0 \\
\hline 62824 & 1972 & 1 & 3 & 3 & 0.0 & -1.1 & -12.8 & 0.0 \\
\hline 62825 & 1972 & 1 & 4 & 4 & 0.0 & -3.9 & $-12 \cdot 2$ & 0.0 \\
\hline 62826 & 1972 & 1 & 5 & 5 & 1.3 & -1.1 & -6.7 & 2.5 \\
\hline 62827 & 1972 & 1 & 6 & 6 & 0.0 & 2.2 & -1.7 & 0.0 \\
\hline 62828 & 1972 & 1 & 7 & 7 & 0.0 & 3.3 & 0.6 & 0.0 \\
\hline 62829 & 1972 & 1 & 8 & 8 & 0.5 & 3.9 & -3.3 & 12.7 \\
\hline 62830 & 1972 & 1 & 9 & 9 & 0.0 & 2.8 & -2.8 & 0.0 \\
\hline 62831 & 1972 & 1 & 10 & 10 & 0.0 & 2.2 & -5.0 & 0.0 \\
\hline 62832 & 1972 & 1 & 11 & 11 & 1.8 & 1.7 & -3.9 & 12.7 \\
\hline 62833 & 1972 & 1 & 12 & 12 & 0.0 & 4.4 & -3.9 & 0.0 \\
\hline 62834 & 1972 & 1 & 13 & 13 & 0.0 & -1.7 & -11.7 & 0.0 \\
\hline 62835 & 1972 & 1 & 14 & 14 & 0.0 & -5.0 & $-12 \cdot 2$ & 0.0 \\
\hline 62836 & 1972 & 1 & 15 & 15 & 0.0 & -0.6 & -6.7 & 0.0 \\
\hline 62837 & 1972 & 1 & 16 & 16 & 0.0 & 2.8 & -1.7 & 0.0 \\
\hline 62838 & 1972 & 1 & 17 & 17 & 0.0 & 5.0 & 0.6 & 0.0 \\
\hline 62839 & 1972 & 1 & 18 & 18 & 1.3 & 4.4 & -2.8 & 12.7 \\
\hline 62840 & 1972 & 1 & 19 & 19 & 7.6 & 3.9 & -2.8 & 12.7 \\
\hline 62841 & 1972 & 1 & 20 & 20 & 14.7 & 6.7 & 2.8 & 0.0 \\
\hline 62842 & 1972 & 1 & 21 & 21 & 9.9 & 8.3 & 2.2 & 0.0 \\
\hline 62843 & 1972 & 1 & 22 & 22 & 0.0 & 7.2 & 1.1 & 0.0 \\
\hline 62844 & 1972 & 1 & 23 & 23 & 1.5 & 5.0 & 0.0 & 2.5 \\
\hline 62845 & 1972 & 1 & 24 & 24 & 0.0 & 1.7 & -4.4 & 0.0 \\
\hline 62846 & 1972 & 1 & 25 & 25 & 8.9 & -0.6 & -7.2 & 101.6 \\
\hline 62847 & 1972 & 1 & 26 & 26 & 5.6 & -6.1 & -16.7 & 76.2 \\
\hline 62848 & 1972 & 1 & 27 & 27 & 0.0 & -13.9 & -18.9 & 0.0 \\
\hline 62849 & 1972 & 1 & 28 & 28 & 0.0 & -12.2 & -18.9 & 0.0 \\
\hline 62850 & 1972 & 1 & 29 & 29 & 2.0 & -10.0 & -18.3 & 12.7 \\
\hline 62851 & 1972 & 1 & 30 & 30 & 0.0 & -6.7 & -18.9 & 0.0 \\
\hline 62852 & 1972 & 1 & 31 & 31 & 0.0 & -5.6 & -16.1 & 0.0 \\
\hline 62853 & 1972 & 2 & 1 & 32 & 2.3 & -8.9 & -20.6 & 38.1 \\
\hline 62854 & 1972 & 2 & 2 & 33 & 0.0 & -8.9 & -23.3 & 0.0 \\
\hline 62855 & 1972 & 2 & 3 & 34 & 0.0 & -6.7 & -23.9 & 0.0 \\
\hline 62856 & 1972 & 2 & 4 & 35 & 0.0 & -3.9 & -21.1 & 0.0 \\
\hline
\end{tabular}




\begin{tabular}{|c|c|c|c|c|c|c|c|c|}
\hline $\begin{array}{r}\text { Record } \\
\text { Day } \\
\text { Number }\end{array}$ & Year & Mo & $\begin{array}{l}\text { Dy } \\
\text { of } \\
\text { Mo }\end{array}$ & $\begin{array}{l}\text { Dy } \\
\text { of } \\
\text { Yr }\end{array}$ & $\begin{array}{r}\text { Precip } \\
\text { mm }\end{array}$ & $\begin{array}{r}\text { Max } \\
\text { Temp } \\
\text { deg C }\end{array}$ & $\begin{array}{r}\text { Min } \\
\text { Temp } \\
\text { deg C }\end{array}$ & $\begin{array}{r}\text { Snow } \\
\text { Fall } \\
\text { mm }\end{array}$ \\
\hline & --- & -- & -- & --- & ----- & ----- & ------ & ---- \\
\hline 62857 & 1972 & 2 & 5 & 36 & 3.8 & -3.3 & -16.1 & 50.8 \\
\hline 62858 & 1972 & 2 & 6 & 37 & 5.3 & 0.6 & -7.8 & 76.2 \\
\hline 62859 & 1972 & 2 & 7 & 38 & 0.0 & 1.7 & -2.8 & 0.0 \\
\hline 62860 & 1972 & 2 & 8 & 39 & 0.0 & 3.3 & -2.8 & 0.0 \\
\hline 62861 & 1972 & 2 & 9 & 40 & 0.0 & 2.8 & -3.9 & 0.0 \\
\hline 62862 & 1972 & 2 & 10 & 41 & 0.0 & 1.1 & -6.7 & 0.0 \\
\hline 62863 & 1972 & 2 & 11 & 42 & 0.0 & 1.7 & -6.1 & 0.0 \\
\hline 62864 & 1972 & 2 & 12 & 43 & 0.0 & 3.9 & 0.0 & 0.0 \\
\hline 62865 & 1972 & 2 & 13 & 44 & 3.6 & 6.7 & 0.0 & 0.0 \\
\hline 62866 & 1972 & 2 & 14 & 45 & 0.0 & 3.3 & -1.7 & 0.0 \\
\hline 62867 & 1972 & 2 & 15 & 46 & 5.1 & 2.2 & -1.7 & $0.0 \mathrm{~T}$ \\
\hline 62868 & 1972 & 2 & 16 & 47 & 0.0 & 8.3 & 1.7 & 0.0 \\
\hline 62869 & 1972 & 2 & 17 & 48 & 0.0 & 9.4 & -2.2 & 0.0 \\
\hline 62870 & 1972 & 2 & 18 & 49 & 4.1 & 2.8 & -1.7 & 0.0 \\
\hline 62871 & 1972 & 2 & 19 & 50 & 0.0 & 12.8 & 2.2 & 0.0 \\
\hline 62872 & 1972 & 2 & 20 & 51 & 4.1 & 13.3 & 1.1 & 0.0 \\
\hline 62873 & 1972 & 2 & 21 & 52 & 0.0 & 6.7 & -1.1 & 0.0 \\
\hline 62874 & 1972 & 2 & 22 & 53 & 1.8 & 8.3 & 0.0 & 0.0 \\
\hline 62875 & 1972 & 2 & 23 & 54 & 0.0 & 6.1 & -1.7 & 0.0 \\
\hline 62876 & 1972 & 2 & 24 & 55 & 6.6 & 5.0 & -1.1 & 50.8 \\
\hline 62877 & 1972 & 2 & 25 & 56 & 0.0 & 6.1 & -2.2 & 0.0 \\
\hline 62878 & 1972 & 2 & 26 & 57 & 0.0 & 3.9 & -2.8 & 0.0 \\
\hline 62879 & 1972 & 2 & 27 & 58 & 7.6 & 11.1 & 0.6 & 0.0 \\
\hline 62880 & 1972 & 2 & 28 & 59 & 0.0 & 12.8 & 7.2 & 0.0 \\
\hline 62881 & 1972 & 2 & 29 & 60 & 0.0 & 13.9 & 0.0 & 0.0 \\
\hline 62882 & 1972 & 3 & 1 & 61 & 0.0 & 5.0 & -3.3 & 0.0 \\
\hline 62883 & 1972 & 3 & 2 & 62 & 4.1 & 1.7 & -2.2 & 25.4 \\
\hline 62884 & 1972 & 3 & 3 & 63 & 0.0 & 5.0 & -2.8 & 0.0 \\
\hline 62885 & 1972 & 3 & 4 & 64 & 0.0 & 4.4 & -2.8 & 0.0 \\
\hline 62886 & 1972 & 3 & 5 & 65 & 2.0 & 9.4 & -2.2 & 0.0 \\
\hline 62887 & 1972 & 3 & 6 & 66 & 0.0 & 12.2 & 1.1 & 0.0 \\
\hline 62888 & 1972 & 3 & 7 & 67 & 0.0 & 4.4 & -3.9 & 0.0 \\
\hline 62889 & 1972 & 3 & 8 & 68 & 0.0 & 4.4 & -3.3 & 0.0 \\
\hline 62890 & 1972 & 3 & 9 & 69 & 0.0 & 12.2 & 0.6 & 0.0 \\
\hline 62891 & 1972 & 3 & 10 & 70 & 0.3 & 18.9 & 2.2 & 0.0 \\
\hline 62892 & 1972 & 3 & 11 & 71 & 4.6 & 13.9 & 5.6 & 0.0 \\
\hline 62893 & 1972 & 3 & 12 & 72 & 5.6 & 12.8 & 3.9 & 0.0 \\
\hline 62894 & 1972 & 3 & 13 & 73 & 7.9 & 10.0 & 6.7 & 0.0 \\
\hline 62895 & 1972 & 3 & 14 & 74 & 0.0 & 12.8 & 1.7 & 0.0 \\
\hline 62896 & 1972 & 3 & 15 & 75 & 0.0 & 10.6 & 2.2 & 0.0 \\
\hline 62897 & 1972 & 3 & 16 & 76 & 0.0 & 14.4 & 4.4 & 0.0 \\
\hline 62898 & 1972 & 3 & 17 & 77 & 0.0 & 18.3 & 5.6 & 0.0 \\
\hline 62899 & 1972 & 3 & 18 & 78 & 0.0 & 20.6 & 6.7 & 0.0 \\
\hline 62900 & 1972 & 3 & 19 & 79 & 0.8 & 11.7 & 2.8 & 0.0 \\
\hline 62901 & 1972 & 3 & 20 & 80 & 0.0 & 10.0 & 2.2 & 0.0 \\
\hline 62902 & 1972 & 3 & 21 & 81 & 0.0 & 12.8 & 1.7 & 0.0 \\
\hline 62903 & 1972 & 3 & 22 & 82 & 0.0 & 15.6 & 4.4 & 0.0 \\
\hline 62904 & 1972 & 3 & 23 & 83 & 0.0 & 14.4 & 0.0 & 0.0 \\
\hline 62905 & 1972 & 3 & 24 & 84 & 0.0 & 7.2 & -0.6 & 0.0 \\
\hline 62906 & 1972 & 3 & 25 & 85 & 2.3 & 8.9 & -3.9 & 0.0 \\
\hline 62907 & 1972 & 3 & 26 & 86 & 0.0 & 5.6 & -3.9 & 0.0 \\
\hline 62908 & 1972 & 3 & 27 & 87 & 0.0 & 5.0 & -1.7 & 0.0 \\
\hline 62909 & 1972 & 3 & 28 & 88 & 1.5 & 6.1 & -1.1 & 25.4 \\
\hline 62910 & 1972 & 3 & 29 & 89 & 0.0 & 7.2 & -2.8 & 0.0 \\
\hline 62911 & 1972 & 3 & 30 & 90 & 0.0 & 11.7 & 0.0 & 0.0 \\
\hline 62912 & 1972 & 3 & 31 & 91 & 0.0 & 13.3 & 0.6 & 0.0 \\
\hline 62913 & 1972 & 4 & 1 & 92 & 3.3 & 16.1 & 5.6 & 0.0 \\
\hline 62914 & 1972 & 4 & 2 & 93 & 0.0 & 14.4 & -3.9 & 0.0 \\
\hline 62915 & 1972 & 4 & 3 & 94 & 0.0 & 10.0 & -3.3 & 0.0 \\
\hline 62916 & 1972 & 4 & 4 & 95 & 0.0 & 12.2 & 0.6 & 0.0 \\
\hline 62917 & 1972 & 4 & 5 & 96 & 0.5 & 12.8 & 5.6 & 0.0 \\
\hline 62918 & 1972 & 4 & 6 & 97 & 2.3 & 13.9 & 3.9 & 0.0 \\
\hline 62919 & 1972 & 4 & 7 & 98 & 1.5 & 11.7 & 0.0 & 0.0 \\
\hline 62920 & 1972 & 4 & 8 & 99 & 0.0 & 8.3 & -0.6 & 0.0 \\
\hline 62921 & 1972 & 4 & 9 & 100 & 1.5 & 8.9 & -1.7 & 0.0 \\
\hline 62922 & 1972 & 4 & 10 & 101 & 0.0 & 8.3 & -3.3 & 0.0 \\
\hline
\end{tabular}




\begin{tabular}{|c|c|c|c|c|c|c|c|c|c|c|}
\hline $\begin{array}{r}\text { Record } \\
\text { Day } \\
\text { Number }\end{array}$ & Year & Mo & $\begin{array}{l}\text { Dy } \\
\text { of } \\
\text { Mo }\end{array}$ & $\begin{array}{l}\text { Dy } \\
\text { of } \\
\text { Yr }\end{array}$ & $\begin{array}{r}\text { Precip } \\
\text { mm }\end{array}$ & & $\begin{array}{r}\text { Max } \\
\text { Temp } \\
\text { deg } C\end{array}$ & & $\begin{array}{r}\text { Min } \\
\text { Temp } \\
\operatorname{deg} \mathrm{C}\end{array}$ & $\begin{array}{r}\text { Snow } \\
\text { Fall } \\
\text { mm }\end{array}$ \\
\hline------- & ---- & -- & -- & --- & ------ & & ------- & & ------- & --- \\
\hline 62923 & 1972 & 4 & 11 & 102 & 1.3 & & 10.0 & & 1.7 & 0.0 \\
\hline 62924 & 1972 & 4 & 12 & 103 & 3.3 & & 6.7 & & 1.7 & 0.0 \\
\hline 62925 & 1972 & 4 & 13 & 104 & 1.3 & & 5.6 & & -2.2 & 0.0 \\
\hline 62926 & 1972 & 4 & 14 & 105 & 0.0 & & 8.3 & & -2.2 & 0.0 \\
\hline 62927 & 1972 & 4 & 15 & 106 & 0.0 & & 12.2 & & 2.2 & 0.0 \\
\hline 62928 & 1972 & 4 & 16 & 107 & 0.0 & & 11.7 & & 0.6 & 0.0 \\
\hline 62929 & 1972 & 4 & 17 & 108 & 0.0 & & 7.8 & & -2.8 & 0.0 \\
\hline 62930 & 1972 & 4 & 18 & 109 & 0.0 & & 5.6 & & -5.0 & 0.0 \\
\hline 62931 & 1972 & 4 & 19 & 110 & 0.0 & & 8.9 & & -3.9 & 0.0 \\
\hline 62932 & 1972 & 4 & 20 & 111 & 0.0 & & 12.8 & & 0.0 & 0.0 \\
\hline 62933 & 1972 & 4 & 21 & 112 & 0.0 & & 12.8 & & 3.3 & 0.0 \\
\hline 62934 & 1972 & 4 & 22 & 113 & 0.0 & & 9.4 & & -5.0 & 0.0 \\
\hline 62935 & 1972 & 4 & 23 & 114 & 0.0 & & 8.9 & & -1.1 & 0.0 \\
\hline 62936 & 1972 & 4 & 24 & 115 & 0.0 & & 21.1 & & 7.2 & 0.0 \\
\hline 62937 & 1972 & 4 & 25 & 116 & 0.0 & & 13.3 & & 0.6 & 0.0 \\
\hline 62938 & 1972 & 4 & 26 & 117 & 0.0 & & 11.7 & & -1.7 & 0.0 \\
\hline 62939 & 1972 & 4 & 27 & 118 & 0.0 & & 15.0 & & 0.6 & 0.0 \\
\hline 62940 & 1972 & 4 & 28 & 119 & 0.0 & & 23.3 & & 5.6 & 0.0 \\
\hline 62941 & 1972 & 4 & 29 & 120 & 0.0 & & 8.3 & & -3.3 & 0.0 \\
\hline 62942 & 1972 & 4 & 30 & 121 & 0.0 & & 10.6 & & -3.9 & 0.0 \\
\hline 62943 & 1972 & 5 & 1 & 122 & 0.0 & & 11.7 & & -3.3 & 0.0 \\
\hline 62944 & 1972 & 5 & 2 & 123 & 0.0 & & 16.7 & & 0.6 & 0.0 \\
\hline 62945 & 1972 & 5 & 3 & 124 & 0.0 & & 20.6 & & 2.8 & 0.0 \\
\hline 62946 & 1972 & 5 & 4 & 125 & 0.0 & & 22.2 & & 4.4 & 0.0 \\
\hline 62947 & 1972 & 5 & 5 & 126 & 0.0 & & 23.3 & & 4.4 & 0.0 \\
\hline 62948 & 1972 & 5 & 6 & 127 & 0.0 & & 22.2 & & 8.3 & 0.0 \\
\hline 62949 & 1972 & 5 & 7 & 128 & 0.0 & & 18.9 & & 5.6 & 0.0 \\
\hline 62950 & 1972 & 5 & 8 & 129 & 16.8 & & 15.6 & & 4.4 & 0.0 \\
\hline 62951 & 1972 & 5 & 9 & 130 & 24.4 & & 6.7 & & 2.8 & 0.0 \\
\hline 62952 & 1972 & 5 & 10 & 131 & 1.8 & & 8.9 & & 4.4 & 0.0 \\
\hline 62953 & 1972 & 5 & 11 & 132 & 0.0 & & 15.6 & & 5.6 & 0.0 \\
\hline 62954 & 1972 & 5 & 12 & 133 & 0.0 & & 17.8 & & 6.7 & 0.0 \\
\hline 62955 & 1972 & 5 & 13 & 134 & 0.0 & & 21.7 & & 8.3 & 0.0 \\
\hline 62956 & 1972 & 5 & 14 & 135 & 0.0 & & 25.0 & & 7.2 & 0.0 \\
\hline 62957 & 1972 & 5 & 15 & 136 & 0.0 & & 23.9 & & 10.0 & 0.0 \\
\hline 62958 & 1972 & 5 & 16 & 137 & 0.0 & & 21.1 & & 8.3 & 0.0 \\
\hline 62959 & 1972 & 5 & 17 & 138 & 0.0 & & 22.2 & & 9.4 & 0.0 \\
\hline 62960 & 1972 & 5 & 18 & 139 & 2.3 & & 15.0 & & 2.2 & 0.0 \\
\hline 62961 & 1972 & 5 & 19 & 140 & 0.0 & & 14.4 & & 3.9 & 0.0 \\
\hline 62962 & 1972 & 5 & 20 & 141 & 0.0 & & 25.0 & & 8.9 & 0.0 \\
\hline 62963 & 1972 & 5 & 21 & 142 & 0.0 & & 22.2 & & 8.3 & 0.0 \\
\hline 62964 & 1972 & 5 & 22 & 143 & 5.6 & & 9.4 & & 6.1 & 0.0 \\
\hline 62965 & 1972 & 5 & 23 & 144 & 0.0 & & 15.6 & & 3.3 & 0.0 \\
\hline 62966 & 1972 & 5 & 24 & 145 & 0.0 & & 14.4 & & 3.3 & 0.0 \\
\hline 62967 & 1972 & 5 & 25 & 146 & 0.0 & & 13.9 & & 0.6 & 0.0 \\
\hline 62968 & 1972 & 5 & 26 & 147 & 0.0 & & 18.3 & & 3.9 & 0.0 \\
\hline 62969 & 1972 & 5 & 27 & 148 & 0.0 & & 22.8 & & 8.3 & 0.0 \\
\hline 62970 & 1972 & 5 & 28 & 149 & 0.0 & & 27.2 & & 12.2 & 0.0 \\
\hline 62971 & 1972 & 5 & 29 & 150 & 0.0 & & 28.3 & & 12.2 & 0.0 \\
\hline 62972 & 1972 & 5 & 30 & 151 & 0.0 & & 31.1 & & 13.3 & 0.0 \\
\hline 62973 & 1972 & 5 & 31 & 152 & 0.0 & & 29.4 & & 13.9 & 0.0 \\
\hline 62974 & 1972 & 6 & 1 & 153 & -999.9 & M & -999.9 & M & $-999.9 \mathrm{M}$ & $-999.9 \mathrm{M}$ \\
\hline 62975 & 1972 & 6 & 2 & 154 & -999.9 & M & -999.9 & M & $-999.9 \mathrm{M}$ & $-999.9 \mathrm{M}$ \\
\hline 62976 & 1972 & 6 & 3 & 155 & -999.9 & M & -999.9 & M & $-999.9 \mathrm{M}$ & $-999.9 \mathrm{M}$ \\
\hline 62977 & 1972 & 6 & 4 & 156 & -999.9 & M & -999.9 & M & $-999.9 \mathrm{M}$ & $-999.9 \mathrm{M}$ \\
\hline 62978 & 1972 & 6 & 5 & 157 & -999.9 & M & -999.9 & M & $-999.9 \mathrm{M}$ & $-999.9 \mathrm{M}$ \\
\hline 62979 & 1972 & 6 & 6 & 158 & -999.9 & M & -999.9 & M & $-999.9 \mathrm{M}$ & $-999.9 \mathrm{M}$ \\
\hline 62980 & 1972 & 6 & 7 & 159 & -999.9 & M & -999.9 & M & $-999.9 \mathrm{M}$ & $-999.9 \mathrm{M}$ \\
\hline 62981 & 1972 & 6 & 8 & 160 & -999.9 & M & -999.9 & M & $-999.9 \mathrm{M}$ & $-999.9 \mathrm{M}$ \\
\hline 62982 & 1972 & 6 & 9 & 161 & -999.9 & M & -999.9 & M & $-999.9 \mathrm{M}$ & $-999.9 \mathrm{M}$ \\
\hline 62983 & 1972 & 6 & 10 & 162 & -999.9 & M & -999.9 & M & $-999.9 \mathrm{M}$ & $-999.9 \mathrm{M}$ \\
\hline 62984 & 1972 & 6 & 11 & 163 & -999.9 & M & -999.9 & M & $-999.9 \mathrm{M}$ & $-999.9 \mathrm{M}$ \\
\hline 62985 & 1972 & 6 & 12 & 164 & -999.9 & M & -999.9 & M & $-999.9 \mathrm{M}$ & $-999.9 \mathrm{M}$ \\
\hline 62986 & 1972 & 6 & 13 & 165 & -999.9 & M & -999.9 & M & $-999.9 \mathrm{M}$ & $-999.9 \mathrm{M}$ \\
\hline 62987 & 1972 & 6 & 14 & 166 & -999.9 & M & -999.9 & M & $-999.9 \mathrm{M}$ & $-999.9 \mathrm{M}$ \\
\hline 62988 & 1972 & 6 & 15 & 167 & -999.9 & M & -999.9 & M & $-999.9 \mathrm{M}$ & $-999.9 \mathrm{M}$ \\
\hline
\end{tabular}




\begin{tabular}{|c|c|c|c|c|c|c|c|c|c|c|c|}
\hline $\begin{array}{r}\text { Record } \\
\text { Day } \\
\text { Number }\end{array}$ & Year & Mo & $\begin{array}{l}\text { Dy } \\
\text { of } \\
\text { Mo }\end{array}$ & $\begin{array}{l}\text { Dy } \\
\text { of } \\
\text { Yr }\end{array}$ & $\begin{array}{r}\text { Precip } \\
\mathrm{mm}\end{array}$ & & $\begin{array}{r}\text { Max } \\
\text { Temp } \\
\text { deg } C\end{array}$ & & $\begin{array}{r}\text { Min } \\
\text { Temp } \\
\operatorname{deg} \mathrm{C}\end{array}$ & & $\begin{array}{r}\text { Snow } \\
\text { Fall } \\
\text { mm }\end{array}$ \\
\hline----- & ---- & -- & -- & --- & ------ & & ------- & & ------- & & ---- \\
\hline 62989 & 1972 & 6 & 16 & 168 & -999.9 & M & -999.9 & $\mathrm{M}$ & -999.9 & $\mathrm{M}$ & -999.9 \\
\hline 62990 & 1972 & 6 & 17 & 169 & -999.9 & M & -999.9 & M & -999.9 & M & -999.9 \\
\hline 62991 & 1972 & 6 & 18 & 170 & -999.9 & M & -999.9 & $\mathrm{M}$ & -999.9 & M & -999.9 \\
\hline 62992 & 1972 & 6 & 19 & 171 & -999.9 & M & -999.9 & M & -999.9 & M & -999.9 \\
\hline 62993 & 1972 & 6 & 20 & 172 & -999.9 & M & -999.9 & $\mathrm{M}$ & -999.9 & $\mathrm{M}$ & -999.9 \\
\hline 62994 & 1972 & 6 & 21 & 173 & -999.9 & M & -999.9 & M & -999.9 & M & -999.9 \\
\hline 62995 & 1972 & 6 & 22 & 174 & -999.9 & $\mathrm{M}$ & -999.9 & M & -999.9 & M & -999.9 \\
\hline 62996 & 1972 & 6 & 23 & 175 & -999.9 & M & -999.9 & $\mathrm{M}$ & -999.9 & M & -999.9 \\
\hline 62997 & 1972 & 6 & 24 & 176 & -999.9 & M & -999.9 & M & -999.9 & M & -999.9 \\
\hline 62998 & 1972 & 6 & 25 & 177 & -999.9 & M & -999.9 & $\mathrm{M}$ & -999.9 & M & -999.9 \\
\hline 62999 & 1972 & 6 & 26 & 178 & -999.9 & M & -999.9 & $\mathrm{M}$ & -999.9 & M & -999.9 \\
\hline 63000 & 1972 & 6 & 27 & 179 & -999.9 & M & -999.9 & $\mathrm{M}$ & -999.9 & $\mathrm{M}$ & -999.9 \\
\hline 63001 & 1972 & 6 & 28 & 180 & -999.9 & $\mathrm{M}$ & -999.9 & $\mathrm{M}$ & -999.9 & $\mathrm{M}$ & -999.9 \\
\hline 63002 & 1972 & 6 & 29 & 181 & -999.9 & $\mathrm{M}$ & -999.9 & $\mathrm{M}$ & -999.9 & $\mathrm{M}$ & -999.9 \\
\hline 63003 & 1972 & 6 & 30 & 182 & -999.9 & M & -999.9 & $\mathrm{M}$ & -999.9 & $\mathrm{M}$ & -999.9 \\
\hline 63004 & 1972 & 7 & 1 & 183 & 0.0 & & 27.8 & & 6.1 & & 0.0 \\
\hline 63005 & 1972 & 7 & 2 & 184 & 0.0 & & 23.3 & & 7.8 & & 0.0 \\
\hline 63006 & 1972 & 7 & 3 & 185 & 0.0 & & 23.9 & & 8.3 & & 0.0 \\
\hline 63007 & 1972 & 7 & 4 & 186 & 0.0 & & 26.7 & & 7.8 & & 0.0 \\
\hline 63008 & 1972 & 7 & 5 & 187 & 0.0 & & 31.1 & & 6.7 & & 0.0 \\
\hline 63009 & 1972 & 7 & 6 & 188 & 0.0 & & 32.2 & & 16.1 & & 0.0 \\
\hline 63010 & 1972 & 7 & 7 & 189 & 5.8 & & 33.3 & & 10.6 & & 0.0 \\
\hline 63011 & 1972 & 7 & 8 & 190 & 0.0 & & 27.8 & & 11.1 & & 0.0 \\
\hline 63012 & 1972 & 7 & 9 & 191 & 1.5 & & 25.6 & & 8.9 & & 0.0 \\
\hline 63013 & 1972 & 7 & 10 & 192 & 0.0 & & 20.0 & & 3.3 & & 0.0 \\
\hline 63014 & 1972 & 7 & 11 & 193 & 3.0 & & 21.1 & & 9.4 & & 0.0 \\
\hline 63015 & 1972 & 7 & 12 & 194 & 0.0 & & 20.0 & & 10.6 & & 0.0 \\
\hline 63016 & 1972 & 7 & 13 & 195 & 0.0 & & 29.4 & & 15.6 & & 0.0 \\
\hline 63017 & 1972 & 7 & 14 & 196 & 0.0 & & 26.7 & & 8.3 & & 0.0 \\
\hline 63018 & 1972 & 7 & 15 & 197 & 0.0 & & 27.2 & & 6.1 & & 0.0 \\
\hline 63019 & 1972 & 7 & 16 & 198 & 0.0 & & 27.8 & & 7.2 & & 0.0 \\
\hline 63020 & 1972 & 7 & 17 & 199 & 0.0 & & 29.4 & & 10.6 & & 0.0 \\
\hline 63021 & 1972 & 7 & 18 & 200 & 0.0 & & 28.3 & & 10.0 & & 0.0 \\
\hline 63022 & 1972 & 7 & 19 & 201 & 0.0 & & 26.7 & & 9.4 & & 0.0 \\
\hline 63023 & 1972 & 7 & 20 & 202 & 0.0 & & 20.6 & & 10.6 & & 0.0 \\
\hline 63024 & 1972 & 7 & 21 & 203 & 5.6 & & 21.7 & & 8.9 & & 0.0 \\
\hline 63025 & 1972 & 7 & 22 & 204 & 0.5 & & 18.3 & & 8.9 & & 0.0 \\
\hline 63026 & 1972 & 7 & 23 & 205 & 0.0 & & 27.2 & & 10.6 & & 0.0 \\
\hline 63027 & 1972 & 7 & 24 & 206 & 0.0 & & 28.9 & & 9.4 & & 0.0 \\
\hline 63028 & 1972 & 7 & 25 & 207 & 0.0 & & 24.4 & & 10.0 & & 0.0 \\
\hline 63029 & 1972 & 7 & 26 & 208 & 0.0 & & 28.9 & & 7.2 & & 0.0 \\
\hline 63030 & 1972 & 7 & 27 & 209 & 0.0 & & 30.6 & & 8.3 & & 0.0 \\
\hline 63031 & 1972 & 7 & 28 & 210 & 0.0 & & 29.4 & & 8.9 & & 0.0 \\
\hline 63032 & 1972 & 7 & 29 & 211 & 0.0 & & 33.9 & & 10.0 & & 0.0 \\
\hline 63033 & 1972 & 7 & 30 & 212 & 0.0 & & 35.0 & & 12.8 & & 0.0 \\
\hline 63034 & 1972 & 7 & 31 & 213 & 0.0 & & 33.9 & & 11.1 & & 0.0 \\
\hline 63035 & 1972 & 8 & 1 & 214 & 0.0 & & 33.3 & & 11.7 & & 0.0 \\
\hline 63036 & 1972 & 8 & 2 & 215 & 0.0 & & 30.0 & & 7.8 & & 0.0 \\
\hline 63037 & 1972 & 8 & 3 & 216 & 0.0 & & 28.3 & & 8.9 & & 0.0 \\
\hline 63038 & 1972 & 8 & 4 & 217 & 0.0 & & 30.6 & & 7.8 & & 0.0 \\
\hline 63039 & 1972 & 8 & 5 & 218 & 0.0 & & 32.8 & & 8.9 & & 0.0 \\
\hline 63040 & 1972 & 8 & 6 & 219 & 0.0 & & 35.0 & & 10.0 & & 0.0 \\
\hline 63041 & 1972 & 8 & 7 & 220 & 0.0 & & 37.2 & & 10.6 & & 0.0 \\
\hline 63042 & 1972 & 8 & 8 & 221 & 0.0 & & 38.3 & & 14.4 & & 0.0 \\
\hline 63043 & 1972 & 8 & 9 & 222 & 0.0 & & 39.4 & & 18.3 & & 0.0 \\
\hline 63044 & 1972 & 8 & 10 & 223 & 0.0 & & 35.0 & & 12.8 & & 0.0 \\
\hline 63045 & 1972 & 8 & 11 & 224 & 0.0 & & 32.8 & & 11.7 & & 0.0 \\
\hline 63046 & 1972 & 8 & 12 & 225 & 0.0 & & 29.4 & & 12.2 & & 0.0 \\
\hline 63047 & 1972 & 8 & 13 & 226 & 0.0 & & 27.2 & & 11.7 & & 0.0 \\
\hline 63048 & 1972 & 8 & 14 & 227 & 0.0 & & 26.7 & & 7.8 & & 0.0 \\
\hline 63049 & 1972 & 8 & 15 & 228 & 0.0 & & 32.2 & & 13.3 & & 0.0 \\
\hline 63050 & 1972 & 8 & 16 & 229 & 21.6 & A & 23.3 & & 7.8 & & 0.0 \\
\hline 63051 & 1972 & 8 & 17 & 230 & 0.5 & & 23.9 & & 10.0 & & 0.0 \\
\hline 63052 & 1972 & 8 & 18 & 231 & 0.0 & & 20.0 & & 5.0 & & 0.0 \\
\hline 63053 & 1972 & 8 & 19 & 232 & 0.0 & & 26.7 & & 6.7 & & 0.0 \\
\hline 63054 & 1972 & 8 & 20 & 233 & 0.0 & & 25.6 & & 10.0 & & 0.0 \\
\hline
\end{tabular}




\begin{tabular}{|c|c|c|c|c|c|c|c|c|}
\hline $\begin{array}{r}\text { Record } \\
\text { Day } \\
\text { Number }\end{array}$ & Year & Mo & $\begin{array}{l}\text { Dy } \\
\text { of } \\
\text { Mo }\end{array}$ & $\begin{array}{l}\text { Dy } \\
\text { of } \\
\text { Yr }\end{array}$ & $\begin{array}{r}\text { Precip } \\
\text { mm }\end{array}$ & $\begin{array}{r}\text { Max } \\
\text { Temp } \\
\text { deg C }\end{array}$ & $\begin{array}{r}\text { Min } \\
\text { Temp } \\
\text { deg C }\end{array}$ & $\begin{array}{r}\text { Snow } \\
\text { Fall } \\
\text { mm }\end{array}$ \\
\hline & ---- & -- & -- & --- & --- & ---- & --- & \\
\hline 63055 & 1972 & 8 & 21 & 234 & 0.0 & 31.7 & 12.2 & 0.0 \\
\hline 63056 & 1972 & 8 & 22 & 235 & 0.8 & 29.4 & 9.4 & 0.0 \\
\hline 63057 & 1972 & 8 & 23 & 236 & 2.3 & 23.3 & 4.4 & 0.0 \\
\hline 63058 & 1972 & 8 & 24 & 237 & 0.0 & 23.9 & 7.2 & 0.0 \\
\hline 63059 & 1972 & 8 & 25 & 238 & 0.0 & 26.1 & 8.9 & 0.0 \\
\hline 63060 & 1972 & 8 & 26 & 239 & 0.0 & 31.1 & 11.7 & 0.0 \\
\hline 63061 & 1972 & 8 & 27 & 240 & 0.0 & 32.8 & 11.7 & 0.0 \\
\hline 63062 & 1972 & 8 & 28 & 241 & 0.0 & 35.0 & 13.3 & 0.0 \\
\hline 63063 & 1972 & 8 & 29 & 242 & 0.0 & 36.7 & 11.7 & 0.0 \\
\hline 63064 & 1972 & 8 & 30 & 243 & 0.0 & 33.3 & 10.0 & 0.0 \\
\hline 63065 & 1972 & 8 & 31 & 244 & 0.0 & 25.6 & 2.2 & 0.0 \\
\hline 63066 & 1972 & 9 & 1 & 245 & 0.0 & 26.1 & 4.4 & 0.0 \\
\hline 63067 & 1972 & 9 & 2 & 246 & 0.0 & 26.7 & 2.8 & 0.0 \\
\hline 63068 & 1972 & 9 & 3 & 247 & 0.0 & 29.4 & 5.6 & 0.0 \\
\hline 63069 & 1972 & 9 & 4 & 248 & 0.0 & 30.0 & 5.0 & 0.0 \\
\hline 63070 & 1972 & 9 & 5 & 249 & 0.0 & 31.1 & 9.4 & 0.0 \\
\hline 63071 & 1972 & 9 & 6 & 250 & 0.0 & 22.2 & 5.6 & 0.0 \\
\hline 63072 & 1972 & 9 & 7 & 251 & 0.0 & 19.4 & 3.3 & 0.0 \\
\hline 63073 & 1972 & 9 & 8 & 252 & 0.0 & 22.2 & 7.2 & 0.0 \\
\hline 63074 & 1972 & 9 & 9 & 253 & 0.5 & 23.9 & 5.6 & 0.0 \\
\hline 63075 & 1972 & 9 & 10 & 254 & 0.0 & 18.3 & 0.6 & 0.0 \\
\hline 63076 & 1972 & 9 & 11 & 255 & 0.0 & 20.6 & 1.1 & 0.0 \\
\hline 63077 & 1972 & 9 & 12 & 256 & 6.6 & 21.1 & 6.7 & 0.0 \\
\hline 63078 & 1972 & 9 & 13 & 257 & 0.3 & 13.3 & 1.7 & 0.0 \\
\hline 63079 & 1972 & 9 & 14 & 258 & 0.0 & 22.2 & 3.3 & 0.0 \\
\hline 63080 & 1972 & 9 & 15 & 259 & 0.0 & 25.0 & 4.4 & 0.0 \\
\hline 63081 & 1972 & 9 & 16 & 260 & 0.0 & 25.6 & 6.7 & 0.0 \\
\hline 63082 & 1972 & 9 & 17 & 261 & 0.0 & 25.0 & 10.6 & 0.0 \\
\hline 63083 & 1972 & 9 & 18 & 262 & 0.0 & 20.6 & 2.2 & 0.0 \\
\hline 63084 & 1972 & 9 & 19 & 263 & 0.0 & 22.2 & 6.7 & 0.0 \\
\hline 63085 & 1972 & 9 & 20 & 264 & 0.3 & 14.4 & 3.9 & 0.0 \\
\hline 63086 & 1972 & 9 & 21 & 265 & 0.0 & 15.0 & 3.3 & 0.0 \\
\hline 63087 & 1972 & 9 & 22 & 266 & 7.6 & 19.4 & 1.1 & 0.0 \\
\hline 63088 & 1972 & 9 & 23 & 267 & 5.1 & 14.4 & 2.2 & 0.0 \\
\hline 63089 & 1972 & 9 & 24 & 268 & 3.0 & 12.8 & 0.6 & 0.0 \\
\hline 63090 & 1972 & 9 & 25 & 269 & 0.0 & 10.6 & -2.2 & 0.0 \\
\hline 63091 & 1972 & 9 & 26 & 270 & 0.0 & 12.2 & -0.6 & 0.0 \\
\hline 63092 & 1972 & 9 & 27 & 271 & 0.0 & 13.9 & -3.3 & 0.0 \\
\hline 63093 & 1972 & 9 & 28 & 272 & 0.0 & 11.7 & -1.7 & 0.0 \\
\hline 63094 & 1972 & 9 & 29 & 273 & 0.0 & 14.4 & -0.6 & 0.0 \\
\hline 63095 & 1972 & 9 & 30 & 274 & 0.0 & 18.3 & 0.0 & 0.0 \\
\hline 63096 & 1972 & 10 & 1 & 275 & 0.0 & 23.3 & 1.1 & 0.0 \\
\hline 63097 & 1972 & 10 & 2 & 276 & 0.0 & 22.8 & 4.4 & 0.0 \\
\hline 63098 & 1972 & 10 & 3 & 277 & 0.0 & 23.9 & 2.8 & 0.0 \\
\hline 63099 & 1972 & 10 & 4 & 278 & 0.0 & 23.3 & 3.3 & 0.0 \\
\hline 63100 & 1972 & 10 & 5 & 279 & 0.0 & 19.4 & 2.8 & 0.0 \\
\hline 63101 & 1972 & 10 & 6 & 280 & 0.0 & 20.0 & -3.9 & 0.0 \\
\hline 63102 & 1972 & 10 & 7 & 281 & 0.0 & 20.0 & -2.8 & 0.0 \\
\hline 63103 & 1972 & 10 & 8 & 282 & 0.0 & 21.7 & -1.7 & 0.0 \\
\hline 63104 & 1972 & 10 & 9 & 283 & 0.0 & 23.9 & 3.9 & 0.0 \\
\hline 63105 & 1972 & 10 & 10 & 284 & 0.0 & 18.3 & 5.6 & 0.0 \\
\hline 63106 & 1972 & 10 & 11 & 285 & 4.8 & 14.4 & 3.9 & 0.0 \\
\hline 63107 & 1972 & 10 & 12 & 286 & 0.0 & 15.0 & 1.7 & 0.0 \\
\hline 63108 & 1972 & 10 & 13 & 287 & 0.0 & 18.3 & 1.7 & 0.0 \\
\hline 63109 & 1972 & 10 & 14 & 288 & 0.0 & 11.1 & 3.9 & 0.0 \\
\hline 63110 & 1972 & 10 & 15 & 289 & 0.0 & 18.3 & -1.7 & 0.0 \\
\hline 63111 & 1972 & 10 & 16 & 290 & 0.0 & 16.7 & -1.1 & 0.0 \\
\hline 63112 & 1972 & 10 & 17 & 291 & 0.0 & 17.8 & 0.0 & 0.0 \\
\hline 63113 & 1972 & 10 & 18 & 292 & 0.0 & 17.2 & -1.7 & 0.0 \\
\hline 63114 & 1972 & 10 & 19 & 293 & 0.0 & 18.3 & -2.8 & 0.0 \\
\hline 63115 & 1972 & 10 & 20 & 294 & 0.0 & 17.2 & -3.3 & 0.0 \\
\hline 63116 & 1972 & 10 & 21 & 295 & 0.0 & 17.2 & -1.1 & 0.0 \\
\hline 63117 & 1972 & 10 & 22 & 296 & 0.0 & 17.8 & 1.1 & 0.0 \\
\hline 63118 & 1972 & 10 & 23 & 297 & 0.0 & 18.9 & 2.8 & 0.0 \\
\hline 63119 & 1972 & 10 & 24 & 298 & 0.0 & 13.9 & -4.4 & 0.0 \\
\hline 63120 & 1972 & 10 & 25 & 299 & 0.0 & 12.8 & -2.2 & 0.0 \\
\hline
\end{tabular}




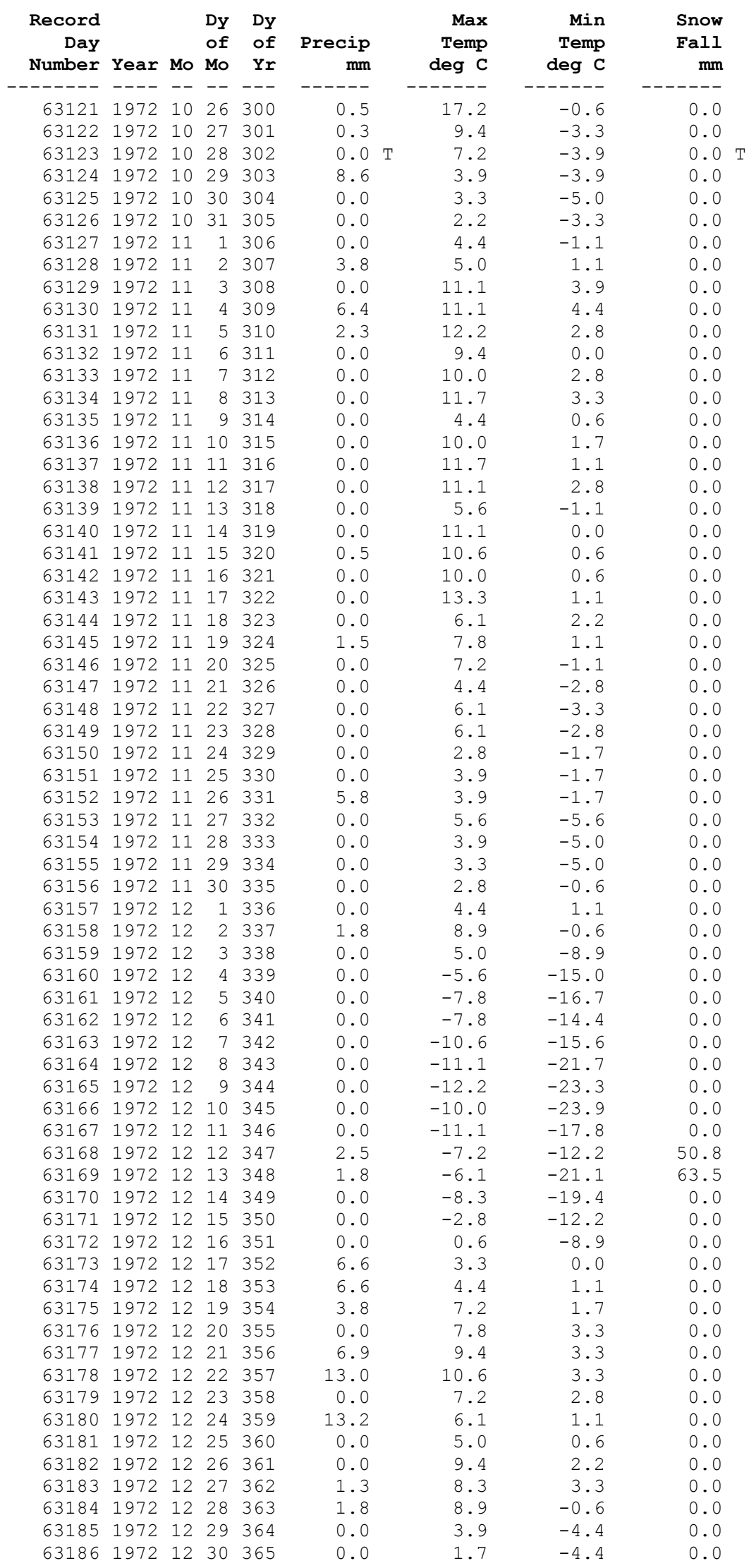




\begin{tabular}{|c|c|c|c|c|c|c|c|c|}
\hline $\begin{array}{r}\text { Record } \\
\text { Day } \\
\text { Number }\end{array}$ & Year & Mo & $\begin{array}{l}\text { Dy } \\
\text { of } \\
\text { Mo }\end{array}$ & $\begin{array}{l}\text { Dy } \\
\text { of } \\
\text { Yr }\end{array}$ & $\begin{array}{r}\text { Precip } \\
\text { mm }\end{array}$ & $\begin{array}{r}\text { Max } \\
\text { Temp } \\
\text { deg C }\end{array}$ & $\begin{array}{r}\text { Min } \\
\text { Temp } \\
\text { deg C }\end{array}$ & $\begin{array}{l}\text { Snow } \\
\text { Fall } \\
\text { mm }\end{array}$ \\
\hline 63187 & ---- & -- & $\begin{array}{l}-- \\
31\end{array}$ & $---\overline{36}$ & --- & -- & --- & --- \\
\hline 63188 & $\begin{array}{l}1912 \\
1973\end{array}$ & $\begin{array}{r}12 \\
1\end{array}$ & $\begin{array}{r}31 \\
1\end{array}$ & $\begin{array}{r}360 \\
1\end{array}$ & 0.0 & $\begin{array}{l}0.6 \\
1.1\end{array}$ & $\begin{array}{l}-4.4 \\
-3.9\end{array}$ & 0.0 \\
\hline 63189 & 1973 & 1 & 2 & 2 & 0.0 & 3.9 & -5.0 & 0.0 \\
\hline 63190 & 1973 & 1 & 3 & 3 & 0.0 & 2.2 & -8.9 & 0.0 \\
\hline 63191 & 1973 & 1 & 4 & 4 & 0.0 & $-1 \cdot 7$ & -13.9 & 0.0 \\
\hline 63192 & 1973 & 1 & 5 & 5 & 0.0 & -5.6 & $-12 \cdot 8$ & 0.0 \\
\hline 63193 & 1973 & 1 & 6 & 6 & 0.0 & -7.8 & -16.7 & 0.0 \\
\hline 63194 & 1973 & 1 & 7 & 7 & 0.0 & -6.7 & -17.2 & 0.0 \\
\hline 63195 & 1973 & 1 & 8 & 8 & 0.0 & -9.4 & -16.1 & 0.0 \\
\hline 63196 & 1973 & 1 & 9 & 9 & 0.0 & -7.8 & -15.6 & 0.0 \\
\hline 63197 & 1973 & 1 & 10 & 10 & 0.0 & -5.0 & -16.1 & 0.0 \\
\hline 63198 & 1973 & 1 & 11 & 11 & 5.6 & -2.8 & -15.6 & 25.4 \\
\hline 63199 & 1973 & 1 & 12 & 12 & 8.4 & 2.8 & -6.7 & 0.0 \\
\hline 63200 & 1973 & 1 & 13 & 13 & 13.5 & 6.1 & -3.9 & 0.0 \\
\hline 63201 & 1973 & 1 & 14 & 14 & 1.3 & 8.9 & 4.4 & 0.0 \\
\hline 63202 & 1973 & 1 & 15 & 15 & 0.0 & 11.1 & 4.4 & 0.0 \\
\hline 63203 & 1973 & 1 & 16 & 16 & 5.6 & 10.6 & 3.9 & 0.0 \\
\hline 63204 & 1973 & 1 & 17 & 17 & 4.3 & 7.2 & 0.6 & 0.0 \\
\hline 63205 & 1973 & 1 & 18 & 18 & 0.0 & 7.2 & 0.0 & 0.0 \\
\hline 63206 & 1973 & 1 & 19 & 19 & 0.0 & 5.0 & -1.7 & 0.0 \\
\hline 63207 & 1973 & 1 & 20 & 20 & 0.0 & 1.7 & -2.8 & 0.0 \\
\hline 63208 & 1973 & 1 & 21 & 21 & 2.5 & 0.6 & -4.4 & 12.7 \\
\hline 63209 & 1973 & 1 & 22 & 22 & 0.0 & 2.8 & -5.0 & 0.0 \\
\hline 63210 & 1973 & 1 & 23 & 23 & 0.0 & 1.7 & -5.6 & 0.0 \\
\hline 63211 & 1973 & 1 & 24 & 24 & 0.0 & 5.6 & -1.1 & 0.0 \\
\hline 63212 & 1973 & 1 & 25 & 25 & 0.0 & 4.4 & 0.0 & 0.0 \\
\hline 63213 & 1973 & 1 & 26 & 26 & 0.0 & 4.4 & -6.1 & 0.0 \\
\hline 63214 & 1973 & 1 & 27 & 27 & 0.0 & 2.8 & -6.7 & 0.0 \\
\hline 63215 & 1973 & 1 & 28 & 28 & 0.0 & 3.9 & -6.1 & 0.0 \\
\hline 63216 & 1973 & 1 & 29 & 29 & 0.0 & 6.1 & -3.3 & 0.0 \\
\hline 63217 & 1973 & 1 & 30 & 30 & 3.0 & 2.8 & -3.3 & 12.7 \\
\hline 63218 & 1973 & 1 & 31 & 31 & 4.1 & 4.4 & -1.7 & 25.4 \\
\hline 63219 & 1973 & 2 & 1 & 32 & 0.0 & 2.2 & -3.9 & 0.0 \\
\hline 63220 & 1973 & 2 & 2 & 33 & 0.0 & 5.0 & -3.9 & 0.0 \\
\hline 63221 & 1973 & 2 & 3 & 34 & 0.0 & 6.1 & 0.6 & 0.0 \\
\hline 63222 & 1973 & 2 & 4 & 35 & 0.0 & 5.6 & -1.7 & 0.0 \\
\hline 63223 & 1973 & 2 & 5 & 36 & 0.0 & 3.9 & -3.9 & 0.0 \\
\hline 63224 & 1973 & 2 & 6 & 37 & 0.0 & 2.8 & -5.6 & 0.0 \\
\hline 63225 & 1973 & 2 & 7 & 38 & 0.0 & 0.0 & -6.7 & 0.0 \\
\hline 63226 & 1973 & 2 & 8 & 39 & 0.0 & 3.9 & -8.9 & 0.0 \\
\hline 63227 & 1973 & 2 & 9 & 40 & 0.0 & 4.4 & -8.9 & 0.0 \\
\hline 63228 & 1973 & 2 & 10 & 41 & 0.0 & 2.2 & -5.0 & 0.0 \\
\hline
\end{tabular}

- Example listing of ROSALIA.INP.

This is the main output file from DAILY09 V1.0, generated using the exported EARTHINFO record for Rosalia, WA. The file is used directly as input to INFIL V2.0. The file includes 1971 and 1973. As the data from the entire month of June in 1972 was missing in the above file, it is omitted from the final file indicated below. This verifies the omission of years when the gap identified is large (greater than 10 days for precipitation and greater than 20 for air temperature). In addition, the following file illustrates the additional column of mean air temperature calculated as $(\mathrm{TMAX}+\mathrm{TMIN}) / 2$. 


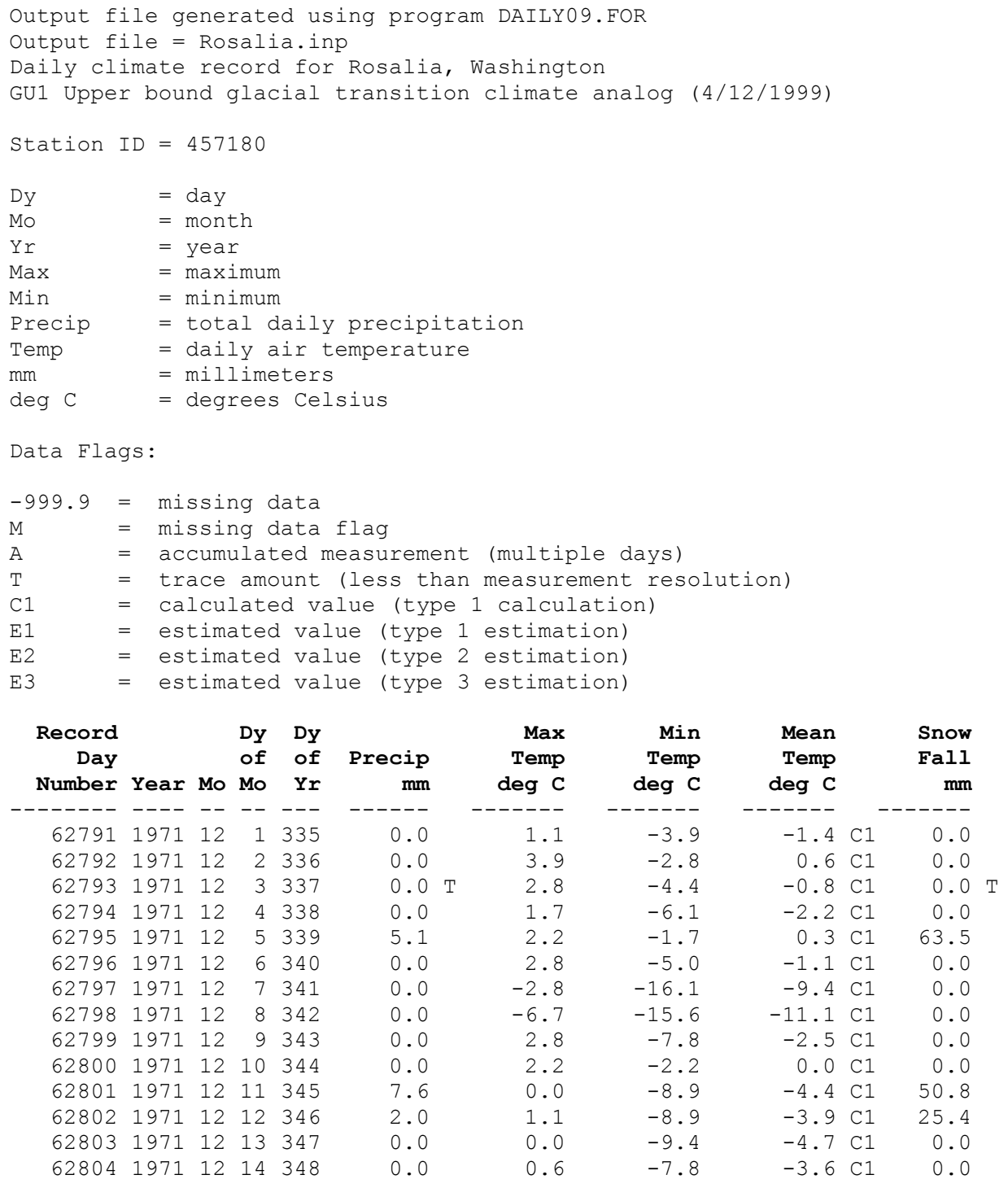

\begin{tabular}{|c|c|c|c|c|c|c|c|c|c|c|}
\hline $\begin{array}{r}\text { Record } \\
\text { Day } \\
\text { Number }\end{array}$ & Year & Mo & $\begin{array}{l}\text { Dy } \\
\text { of } \\
\text { Mo }\end{array}$ & $\begin{array}{l}\text { Dy } \\
\text { of } \\
\text { Yr }\end{array}$ & $\begin{array}{r}\text { Precip } \\
\mathrm{mm}\end{array}$ & $\begin{array}{r}\text { Max } \\
\text { Temp } \\
\operatorname{deg} \mathrm{C}\end{array}$ & $\begin{array}{r}\text { Min } \\
\text { Temp } \\
\operatorname{deg} \mathrm{C}\end{array}$ & $\begin{array}{r}\text { Mean } \\
\text { Temp } \\
\text { deg C }\end{array}$ & & $\begin{array}{r}\text { Snow } \\
\text { Fall } \\
\text { mm }\end{array}$ \\
\hline--- & ---- & -- & -- & --- & ---- & ----- & ------ & ------ & & --- \\
\hline 62791 & 1971 & 12 & 1 & 335 & 0.0 & 1.1 & -3.9 & $-1 \cdot 4$ & $\mathrm{C} 1$ & 0.0 \\
\hline 62792 & 1971 & 12 & 2 & 336 & 0.0 & 3.9 & $-2 \cdot 8$ & 0.6 & $\mathrm{C} 1$ & 0.0 \\
\hline 62793 & 1971 & 12 & 3 & 337 & $0.0 \mathrm{~T}$ & 2.8 & -4.4 & -0.8 & $\mathrm{C} 1$ & 0.0 \\
\hline 62794 & 1971 & 12 & 4 & 338 & 0.0 & 1.7 & -6.1 & -2.2 & $\mathrm{C} 1$ & 0.0 \\
\hline 62795 & 1971 & 12 & 5 & 339 & 5.1 & 2.2 & -1.7 & 0.3 & $\mathrm{C} 1$ & 63.5 \\
\hline 62796 & 1971 & 12 & 6 & 340 & 0.0 & 2.8 & -5.0 & -1.1 & $\mathrm{C} 1$ & 0.0 \\
\hline 62797 & 1971 & 12 & 7 & 341 & 0.0 & -2.8 & -16.1 & -9.4 & $\mathrm{C} 1$ & 0.0 \\
\hline 62798 & 1971 & 12 & 8 & 342 & 0.0 & -6.7 & $-15 \cdot 6$ & -11.1 & $\mathrm{C} 1$ & 0.0 \\
\hline 62799 & 1971 & 12 & 9 & 343 & 0.0 & 2.8 & -7.8 & -2.5 & $\mathrm{C} 1$ & 0.0 \\
\hline 62800 & 1971 & 12 & 10 & 344 & 0.0 & 2.2 & $-2 \cdot 2$ & 0.0 & $\mathrm{C} 1$ & 0.0 \\
\hline 62801 & 1971 & 12 & 11 & 345 & 7.6 & 0.0 & -8.9 & $-4 \cdot 4$ & $\mathrm{C} 1$ & 50.8 \\
\hline 62802 & 1971 & 12 & 12 & 346 & 2.0 & 1.1 & $-8 \cdot 9$ & -3.9 & $\mathrm{C} 1$ & 25.4 \\
\hline 62803 & 1971 & 12 & 13 & 347 & 0.0 & 0.0 & -9.4 & $-4 \cdot 7$ & $\mathrm{C} 1$ & 0.0 \\
\hline 62804 & 1971 & 12 & 14 & 348 & 0.0 & 0.6 & -7.8 & $-3 \cdot 6$ & $\mathrm{C} 1$ & 0.0 \\
\hline
\end{tabular}




\begin{tabular}{|c|c|c|c|c|c|c|c|c|c|c|}
\hline $\begin{array}{r}\text { Record } \\
\text { Day } \\
\text { Number }\end{array}$ & Year & Mo & $\begin{array}{l}\text { Dy } \\
\text { of } \\
\text { Mo }\end{array}$ & $\begin{array}{l}\text { Dy } \\
\text { of } \\
\text { Yr }\end{array}$ & $\begin{array}{r}\text { Precip } \\
\text { mm }\end{array}$ & $\begin{array}{r}\text { Max } \\
\text { Temp } \\
\text { deg } C\end{array}$ & $\begin{array}{r}\text { Min } \\
\text { Temp } \\
\operatorname{deg} \mathrm{C}\end{array}$ & $\begin{array}{r}\text { Mean } \\
\text { Temp } \\
\text { deg } C\end{array}$ & & $\begin{array}{r}\text { Snow } \\
\text { Fall } \\
\text { mm }\end{array}$ \\
\hline 62805 & $\begin{array}{l}---- \\
1971\end{array}$ & $\begin{array}{l}-- \\
12\end{array}$ & $\begin{array}{l}-- \\
15\end{array}$ & $\begin{array}{l}--- \\
349\end{array}$ & 0.0 & 1.1 & $\begin{array}{l}---- \\
-7.2\end{array}$ & -3.1 & $\mathrm{C} 1$ & 0.0 \\
\hline 62806 & 1971 & 12 & 16 & 350 & 3.6 & -1.7 & -13.3 & -7.5 & $\mathrm{C} 1$ & 76.2 \\
\hline 62807 & 1971 & 12 & 17 & 351 & 0.0 & 4.4 & -1.7 & 1.4 & $\mathrm{C} 1$ & 0.0 \\
\hline 62808 & 1971 & 12 & 18 & 352 & 0.3 & 5.0 & 0.6 & 2.8 & $\mathrm{C} 1$ & 0.0 \\
\hline 62809 & 1971 & 12 & 19 & 353 & 0.0 & 3.3 & -3.3 & 0.0 & $\mathrm{C} 1$ & 0.0 \\
\hline 62810 & 1971 & 12 & 20 & 354 & 0.0 & 0.6 & -1.1 & -0.3 & $\mathrm{C} 1$ & 0.0 \\
\hline 62811 & 1971 & 12 & 21 & 355 & 3.0 & 2.2 & -0.6 & 0.8 & $\mathrm{C} 1$ & 12.7 \\
\hline 62812 & 1971 & 12 & 22 & 356 & 2.0 & 3.9 & 0.0 & 1.9 & $\mathrm{C} 1$ & 0.0 \\
\hline 62813 & 1971 & 12 & 23 & 357 & 0.3 & 5.6 & -1.7 & 1.9 & $\mathrm{C} 1$ & 0.0 \\
\hline 62814 & 1971 & 12 & 24 & 358 & 0.3 & 3.9 & 0.0 & 1.9 & $\mathrm{C} 1$ & 0.0 \\
\hline 62815 & 1971 & 12 & 25 & 359 & 0.0 & 6.1 & -0.6 & 2.8 & $\mathrm{C} 1$ & 0.0 \\
\hline 62816 & 1971 & 12 & 26 & 360 & 0.0 & 3.3 & -4.4 & -0.6 & $\mathrm{C} 1$ & 0.0 \\
\hline 62817 & 1971 & 12 & 27 & 361 & 0.0 & -3.3 & -10.0 & -6.7 & $\mathrm{C} 1$ & 0.0 \\
\hline 62818 & 1971 & 12 & 28 & 362 & 0.0 & -1.7 & -10.6 & -6.1 & $\mathrm{C} 1$ & 0.0 \\
\hline 62819 & 1971 & 12 & 29 & 363 & 3.0 & -4.4 & -8.9 & -6.7 & $\mathrm{C} 1$ & 25.4 \\
\hline 62820 & 1971 & 12 & 30 & 364 & 0.0 & -5.0 & -16.1 & -10.6 & $\mathrm{C} 1$ & 0.0 \\
\hline 62821 & 1971 & 12 & 31 & 365 & 0.8 & 0.6 & -9.4 & -4.4 & $\mathrm{C} 1$ & 25.4 \\
\hline 63188 & 1973 & 1 & 1 & 1 & 0.0 & 1.1 & -3.9 & -1.4 & $\mathrm{C} 1$ & 0.0 \\
\hline 63189 & 1973 & 1 & 2 & 2 & 0.0 & 3.9 & -5.0 & -0.6 & $\mathrm{C} 1$ & 0.0 \\
\hline 63190 & 1973 & 1 & 3 & 3 & 0.0 & 2.2 & -8.9 & -3.3 & $\mathrm{C} 1$ & 0.0 \\
\hline 63191 & 1973 & 1 & 4 & 4 & 0.0 & -1.7 & -13.9 & -7.8 & $\mathrm{C} 1$ & 0.0 \\
\hline 63192 & 1973 & 1 & 5 & 5 & 0.0 & -5.6 & -12.8 & -9.2 & $\mathrm{C} 1$ & 0.0 \\
\hline 63193 & 1973 & 1 & 6 & 6 & 0.0 & -7.8 & -16.7 & -12.2 & $\mathrm{C} 1$ & 0.0 \\
\hline 63194 & 1973 & 1 & 7 & 7 & 0.0 & -6.7 & -17.2 & -11.9 & $\mathrm{C} 1$ & 0.0 \\
\hline 63195 & 1973 & 1 & 8 & 8 & 0.0 & -9.4 & -16.1 & -12.8 & $\mathrm{C} 1$ & 0.0 \\
\hline 63196 & 1973 & 1 & 9 & 9 & 0.0 & -7.8 & -15.6 & -11.7 & $\mathrm{C} 1$ & 0.0 \\
\hline 63197 & 1973 & 1 & 10 & 10 & 0.0 & -5.0 & -16.1 & -10.6 & $\mathrm{C} 1$ & 0.0 \\
\hline 63198 & 1973 & 1 & 11 & 11 & 5.6 & -2.8 & -15.6 & -9.2 & $\mathrm{C} 1$ & 25.4 \\
\hline 63199 & 1973 & 1 & 12 & 12 & 8.4 & 2.8 & -6.7 & -1.9 & $\mathrm{C} 1$ & 0.0 \\
\hline 63200 & 1973 & 1 & 13 & 13 & 13.5 & 6.1 & -3.9 & 1.1 & $\mathrm{C} 1$ & 0.0 \\
\hline 63201 & 1973 & 1 & 14 & 14 & 1.3 & 8.9 & 4.4 & 6.7 & $\mathrm{C} 1$ & 0.0 \\
\hline 63202 & 1973 & 1 & 15 & 15 & 0.0 & 11.1 & 4.4 & 7.8 & $\mathrm{C} 1$ & 0.0 \\
\hline 63203 & 1973 & 1 & 16 & 16 & 5.6 & 10.6 & 3.9 & 7.2 & $\mathrm{C} 1$ & 0.0 \\
\hline 63204 & 1973 & 1 & 17 & 17 & 4.3 & 7.2 & 0.6 & 3.9 & $\mathrm{C} 1$ & 0.0 \\
\hline 63205 & 1973 & 1 & 18 & 18 & 0.0 & 7.2 & 0.0 & 3.6 & $\mathrm{C} 1$ & 0.0 \\
\hline 63206 & 1973 & 1 & 19 & 19 & 0.0 & 5.0 & -1.7 & 1.7 & $\mathrm{C} 1$ & 0.0 \\
\hline 63207 & 1973 & 1 & 20 & 20 & 0.0 & 1.7 & -2.8 & -0.6 & $\mathrm{C} 1$ & 0.0 \\
\hline 63208 & 1973 & 1 & 21 & 21 & 2.5 & 0.6 & -4.4 & -1.9 & $\mathrm{C} 1$ & 12.7 \\
\hline 63209 & 1973 & 1 & 22 & 22 & 0.0 & 2.8 & -5.0 & -1.1 & $\mathrm{C} 1$ & 0.0 \\
\hline 63210 & 1973 & 1 & 23 & 23 & 0.0 & 1.7 & -5.6 & -1.9 & $\mathrm{C} 1$ & 0.0 \\
\hline 63211 & 1973 & 1 & 24 & 24 & 0.0 & 5.6 & -1.1 & 2.2 & $\mathrm{C} 1$ & 0.0 \\
\hline 63212 & 1973 & 1 & 25 & 25 & 0.0 & 4.4 & 0.0 & 2.2 & $\mathrm{C} 1$ & 0.0 \\
\hline 63213 & 1973 & 1 & 26 & 26 & 0.0 & 4.4 & -6.1 & -0.8 & $\mathrm{C} 1$ & 0.0 \\
\hline 63214 & 1973 & 1 & 27 & 27 & 0.0 & 2.8 & -6.7 & -1.9 & $\mathrm{C} 1$ & 0.0 \\
\hline 63215 & 1973 & 1 & 28 & 28 & 0.0 & 3.9 & -6.1 & -1.1 & $\mathrm{C} 1$ & 0.0 \\
\hline 63216 & 1973 & 1 & 29 & 29 & 0.0 & 6.1 & -3.3 & 1.4 & $\mathrm{C} 1$ & 0.0 \\
\hline 63217 & 1973 & 1 & 30 & 30 & 3.0 & 2.8 & -3.3 & -0.3 & $\mathrm{C} 1$ & 12.7 \\
\hline 63218 & 1973 & 1 & 31 & 31 & 4.1 & 4.4 & -1.7 & 1.4 & $\mathrm{C} 1$ & 25.4 \\
\hline 63219 & 1973 & 2 & 1 & 32 & 0.0 & 2.2 & -3.9 & -0.8 & $\mathrm{C} 1$ & 0.0 \\
\hline 63220 & 1973 & 2 & 2 & 33 & 0.0 & 5.0 & -3.9 & 0.6 & $\mathrm{C} 1$ & 0.0 \\
\hline 63221 & 1973 & 2 & 3 & 34 & 0.0 & 6.1 & 0.6 & 3.3 & $\mathrm{C} 1$ & 0.0 \\
\hline 63222 & 1973 & 2 & 4 & 35 & 0.0 & 5.6 & -1.7 & 1.9 & $\mathrm{C} 1$ & 0.0 \\
\hline 63223 & 1973 & 2 & 5 & 36 & 0.0 & 3.9 & -3.9 & 0.0 & $\mathrm{C} 1$ & 0.0 \\
\hline 63224 & 1973 & 2 & 6 & 37 & 0.0 & 2.8 & -5.6 & -1.4 & $\mathrm{C} 1$ & 0.0 \\
\hline 63225 & 1973 & 2 & 7 & 38 & 0.0 & 0.0 & -6.7 & -3.3 & $\mathrm{C} 1$ & 0.0 \\
\hline 63226 & 1973 & 2 & 8 & 39 & 0.0 & 3.9 & -8.9 & -2.5 & $\mathrm{C} 1$ & 0.0 \\
\hline 63227 & 1973 & 2 & 9 & 40 & 0.0 & 4.4 & -8.9 & -2.2 & $\mathrm{C} 1$ & 0.0 \\
\hline 63228 & 1973 & 2 & 10 & 41 & 0.0 & 2.2 & -5.0 & -1.4 & $\mathrm{C} 1$ & 0.0 \\
\hline
\end{tabular}


- Example listing of ROSALIA.DAY indicating small gaps in precipitation and air temperature data.

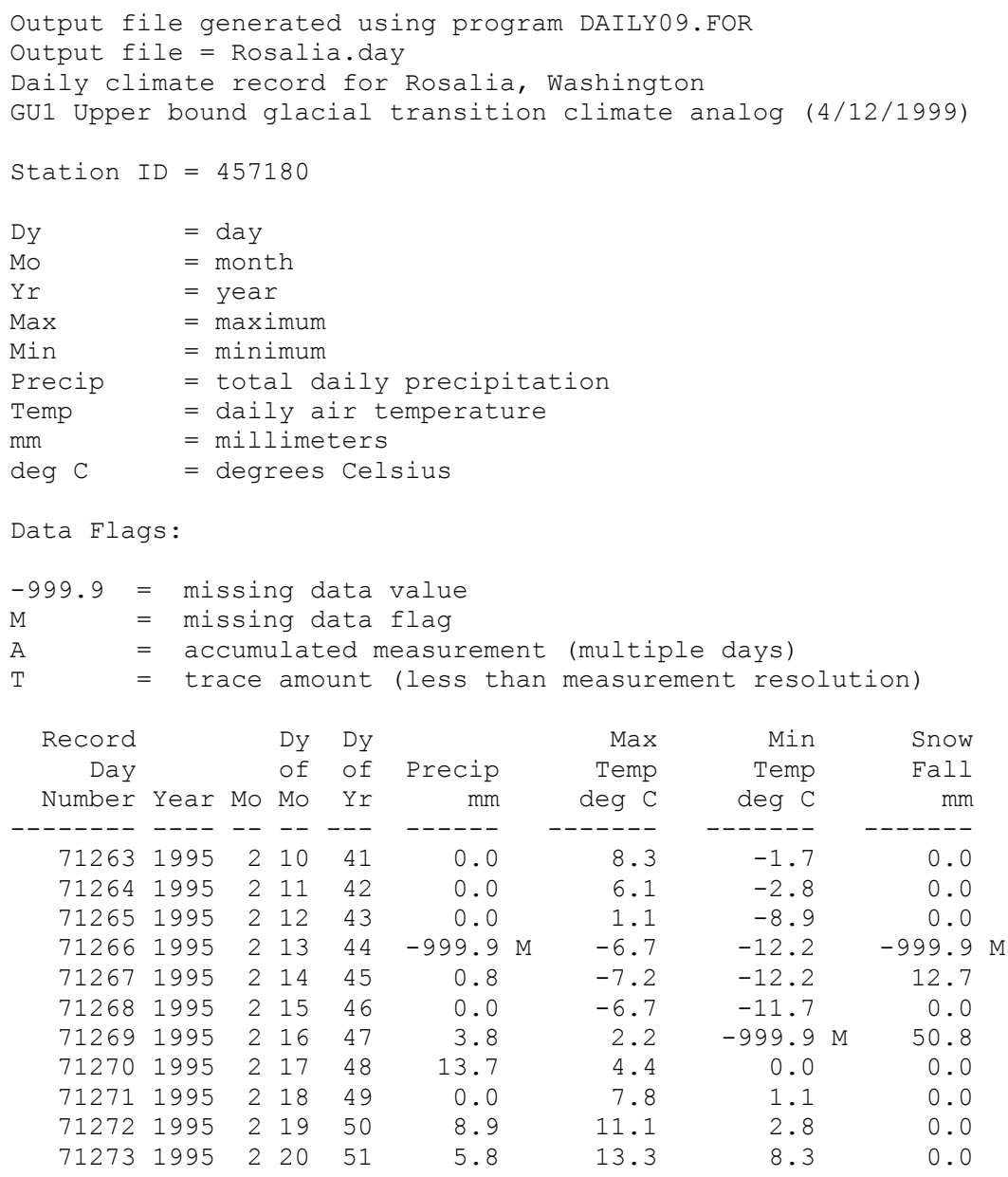

- Example listing of $R O S A L I A . I N P$ illustrating that the gap in precipitation is replaced by a zero, and the gap in air temperature is replaced with a linear interpolation between the numbers on either side of the gap.

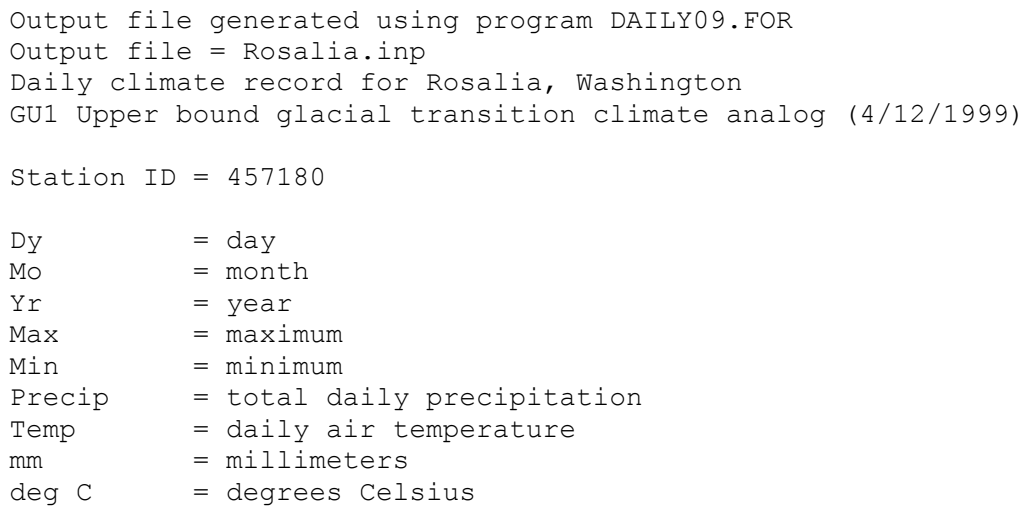




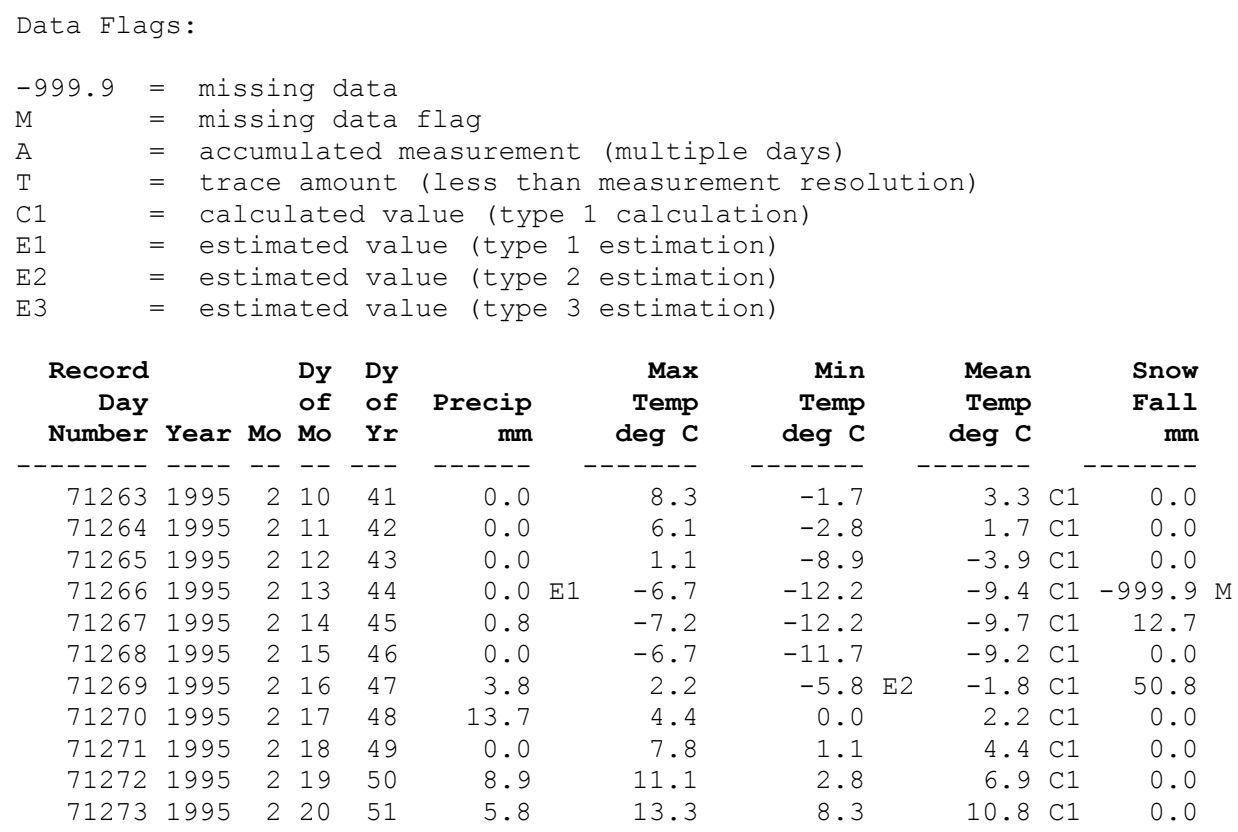

\section{- Listing of source code for routine DAILY09 V1.0:}

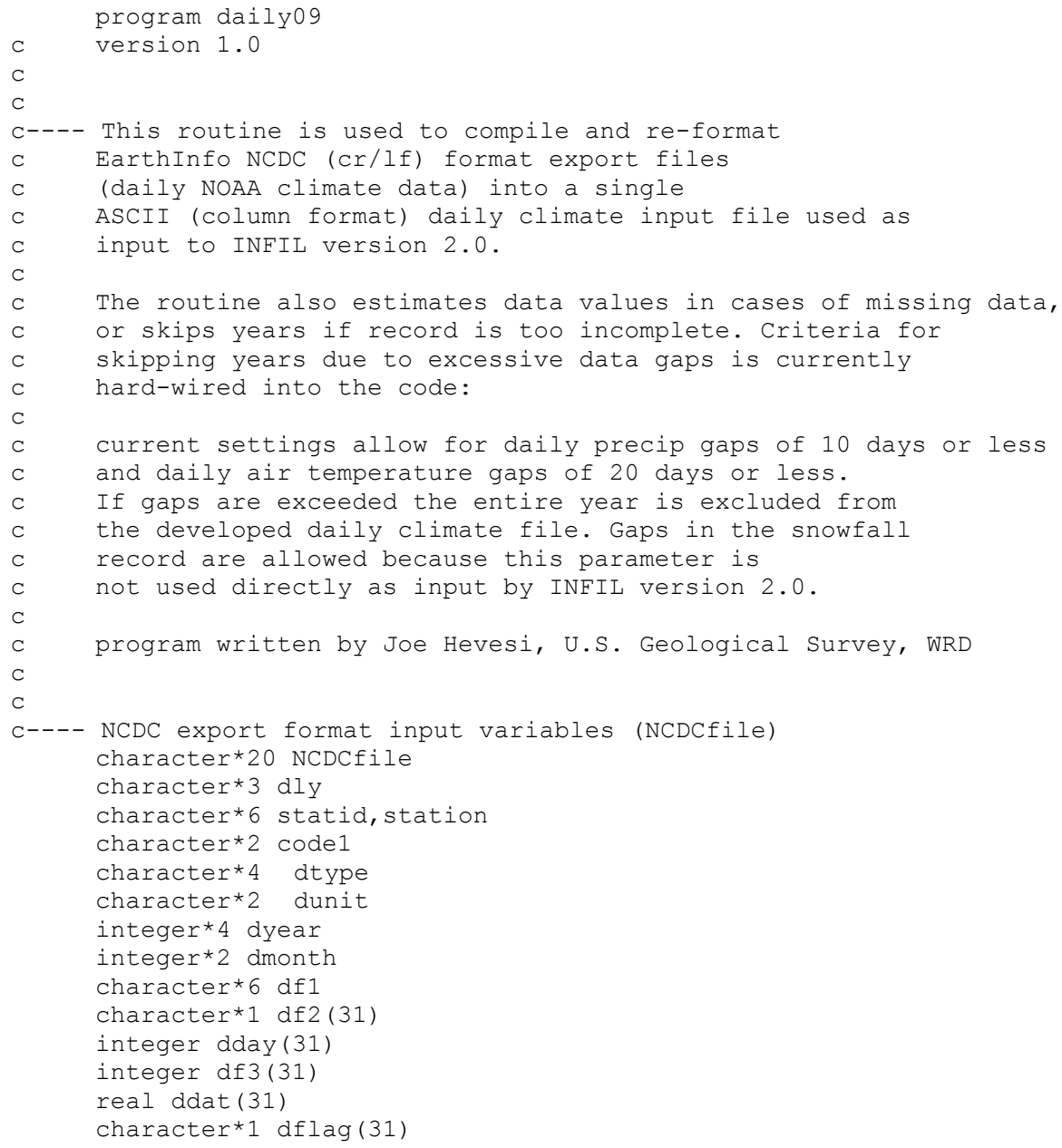




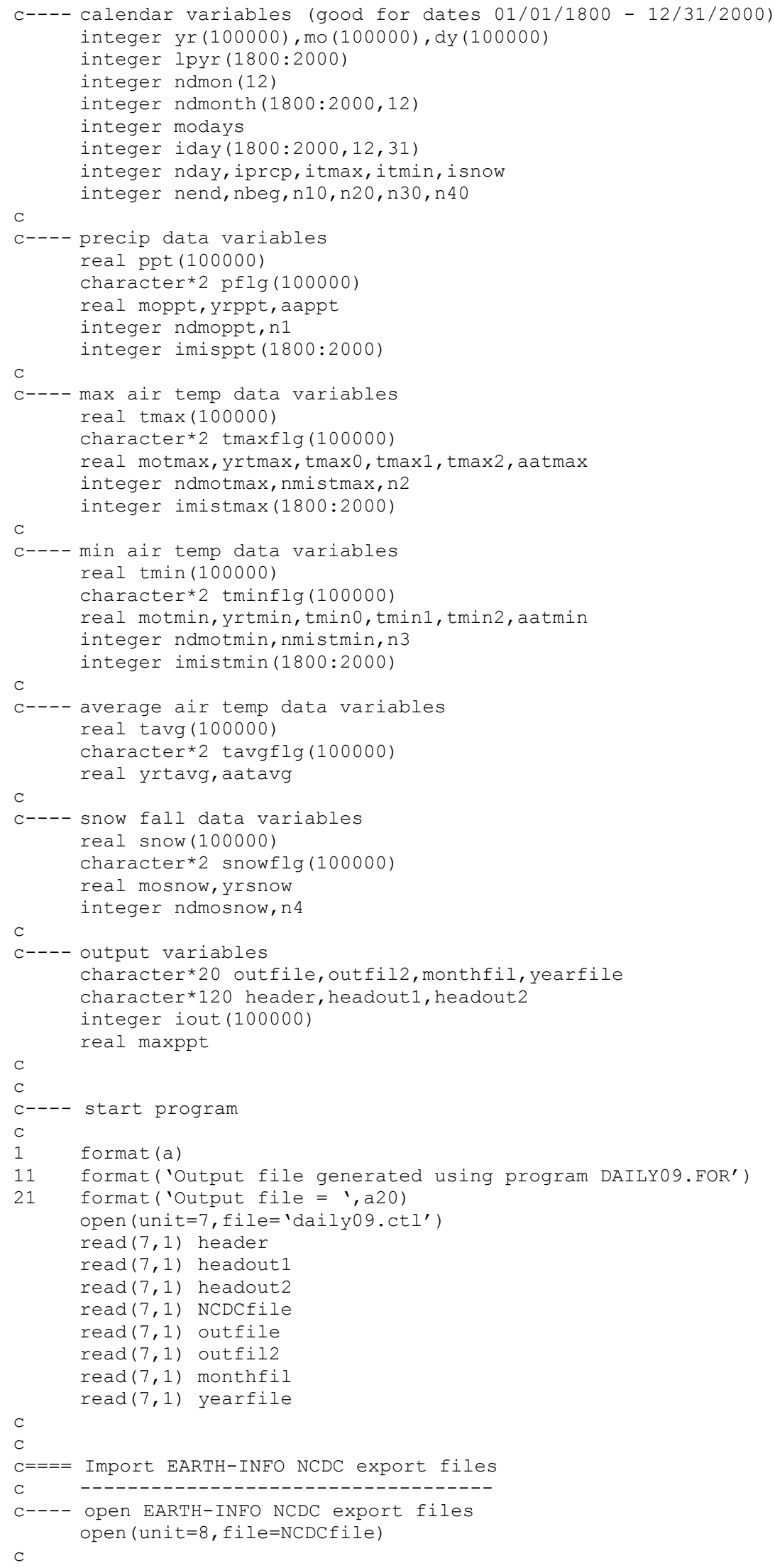




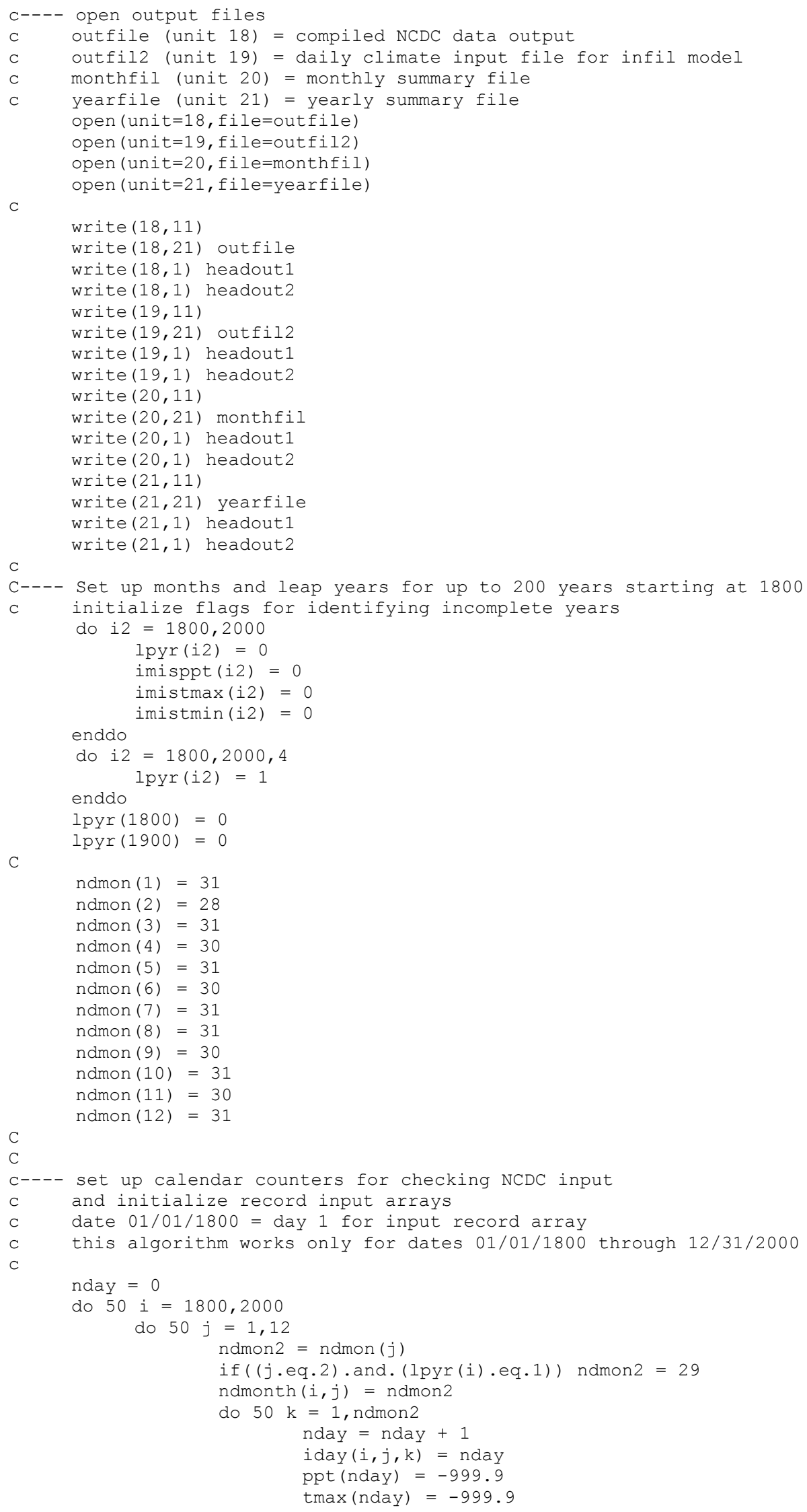


c

$\operatorname{tmin}($ nday $)=-999.9$

snow $($ nday $)=-999.0$

pflg (nday) $={ }^{\prime} M{ }^{\prime}$

tmaxflg $($ nday $)={ }^{\prime} \mathrm{M}^{\prime}$

$\operatorname{tminflg}($ nday $)={ }^{\prime} \mathrm{M}^{\prime}$

50 continue

$\operatorname{snowflg}($ nday $)={ }^{\prime} M '$

nbeg $=i \operatorname{day}(2000,12,31)$

nend $=1$

C

c initialize array counters

iprcp $=0$

itmax $=0$

itmin $=0$

isnow $=0$

C

initialize monthly statistics

moppt $=0$.

maxppt $=-999$.

maxflg $=$ ' -9 '

nmpflg $=0$

napflg $=0$

ntpflg $=0$

nmtmxflg $=0$

natmxflg $=0$

nttmxflg $=0$

nmtmnflg $=0$

natmnflg $=0$

nttmnflg $=0$

nmsnoflg $=0$

nasnoflg $=0$

ntsnoflg $=0$

ndaymo $=0$

$\mathrm{n} 1=0$

$\mathrm{n} 2=0$

$\mathrm{n} 3=0$

$\mathrm{n} 4=0$

C

C---- Read in NCDC format daily data by month (each line = 31 days)

$\mathrm{C}$

ndat $=1$

$200 \operatorname{read}(8,101$, end $=900)$ dly, statid, codel, dtype, dunit,

1 dyear, dmonth, df1,

$2(\operatorname{df} 2(i), \operatorname{dday}(i), \operatorname{df} 3(i), \operatorname{ddat}(i), \operatorname{dflag}(i), i=1,31)$

c

101 format (a3, a6, a2, a4, a2,

$1 \quad$ i $4, i 2, a 6$

$2 \quad 31(a 1, i 2, i 2, f 6.0, a 1))$

C

c------- check station id

if (ndat.eq.1) then

station = statid

ndat $=0$

else

endif

c------ import daily precip data

if (dtype.eq.'PRCP') then

if(iprcp.eq.0) then

$\mathrm{n} 10$ = iday (dyear, dmonth, dday (1))

$\mathrm{n} 1=\mathrm{n} 10-1$

iprcp $=1$

if $(\mathrm{n} 10.1 \mathrm{t} . \mathrm{nbeg})$ nbeg $=\mathrm{n} 10$

endif 
C

$\mathrm{C}$

300

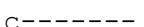

C

C

310 continue

$\mathrm{C}$

C------ -

continue

endif

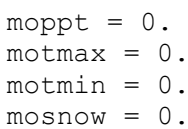

import maximum daily air temp data

else if (dtype.eq.' TMAX') then

if (itmax.eq.0) then

n20 = iday (dyear, dmonth, dday (1))

$\mathrm{n} 2=\mathrm{n} 20-1$

itmax $=1$

if $(n 20.1 t . n b e g)$ nbeg $=n 20$

$\operatorname{motmax}=0$.

read-in maximum daily air temp data for each month

do $310 j=1$, ndmonth (dyear, dmonth)

$\mathrm{n} 2=\mathrm{n} 2+1$

ndaymo $=$ ndaymo +1

get air temp data (convert $\operatorname{deg} \mathrm{F}$ to $\operatorname{deg} \mathrm{C}$ )

if (ddat (j).ne.-99999.) then

$\operatorname{tmax}(n 2)=(\operatorname{ddat}(j)-32) * 5 /$.

$\operatorname{motmax}=\operatorname{motmax}+\operatorname{tmax}(\mathrm{n} 2)$

if $(t \max (n 2) \cdot g t \cdot \operatorname{maxtmax})$ maxtmax $=t \max (n 2)$

endif

$\operatorname{tmax}(n 2)=-999.9$

tmaxflg $(\mathrm{n} 2)=\operatorname{dflag}(j)$

if (tmaxflg(n2).eq.' $\left.M^{\prime}\right)$ nmtmxflg $=n m t m x f l g+1$

if (tmaxflg $\left.(n 2) \cdot e q \cdot{ }^{\prime} A^{\prime}\right)$ natmxflg $=$ natmxflg +1

if $\left(\right.$ tmaxflg $(n 2)$.eq.' $\left.\mathrm{T}^{\prime}\right)$ nttmxflg $=$ nttmxflg +1

import minimum daily air temp data

else if (dtype.eq.' TMIN') then

if (itmin.eq.0) then

n30 = iday (dyear, dmonth, dday (1))

n3 $=$ n30- 1

itmin $=1$

if $(n 30.1 t \cdot n b e g)$ nbeg $=$ n30

endif

motmin $=0$.

C

read-in minimum daily air temp data for each month 
C

$320 \quad$ continue

C

c------ import daily snow fall data

else if (dtype.eq.' SNOW') then

if (isnow.eq.0) then

$\mathrm{n} 40$ = iday (dyear, dmonth, dday (1))

$\mathrm{n} 4=\mathrm{n} 40-1$

isnow $=1$

endif

mosnow $=0$.

$\mathrm{C}$

c

C

C

330 continue

C

endif

goto 200

C

900 continue

C find ending array indices

if (n1.gt. nend) nend $=n 1$

if (n2.gt.nend) nend $=n 2$

if (n3.gt. nend) nend $=n 3$

if ( $\mathrm{n} 4 . \mathrm{gt}$. nend) nend $=\mathrm{n} 4$

C

$\mathrm{C}====$ Process Results

C --------------

c---- output to 1 st output file (data file)

c write header info 1st

c unit 18 = data output file

write $(18,8111)$ station 


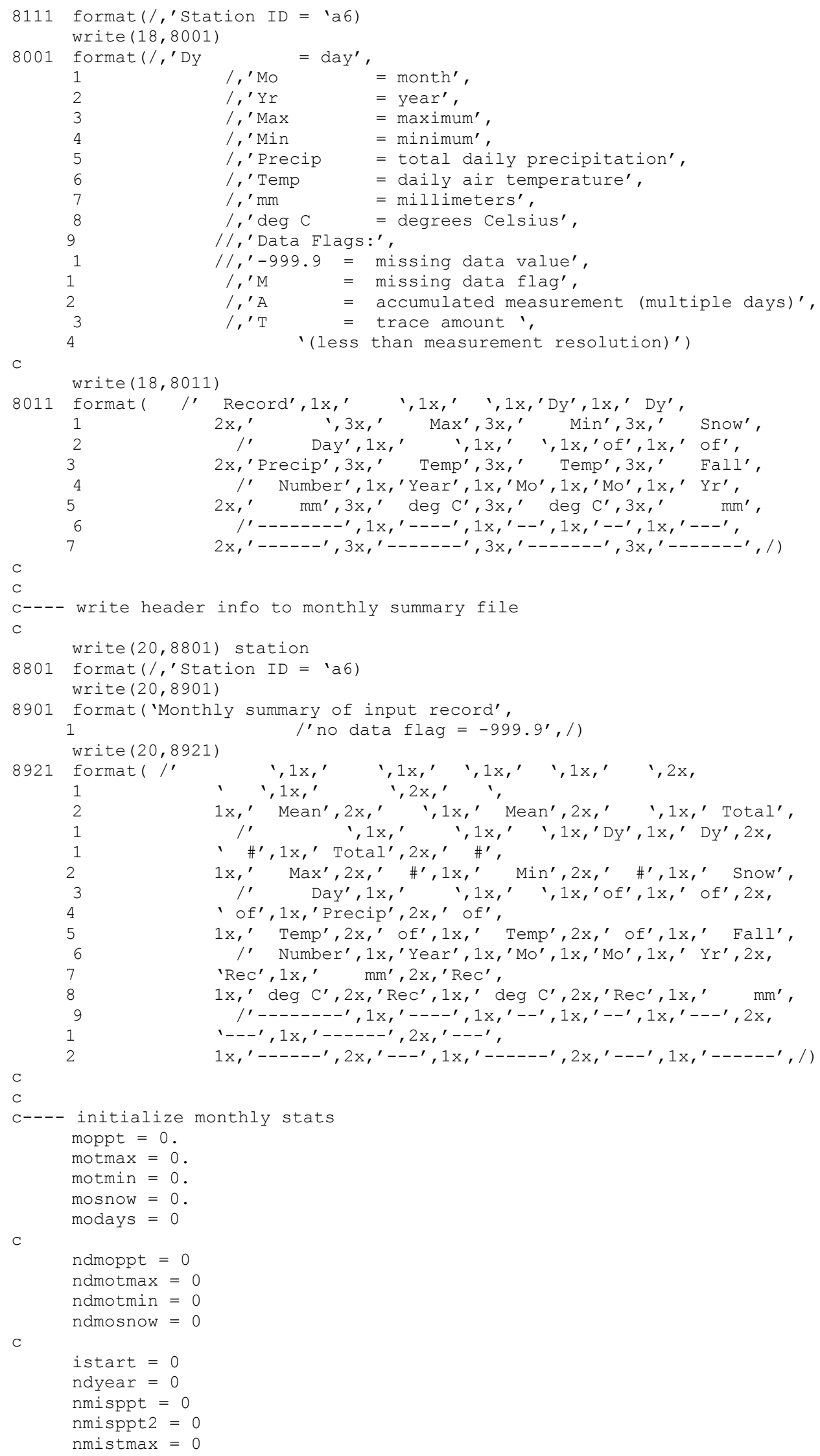


nmistmx $2=0$
nmistmin $=0$

nmistmn $2=0$

C

2

111

1

C

c

C

do $8000 i=$ nbeg, nend

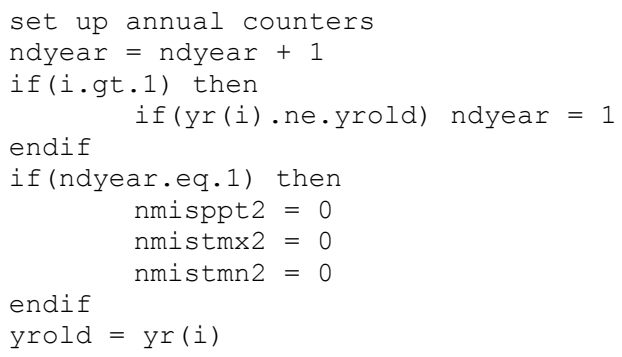




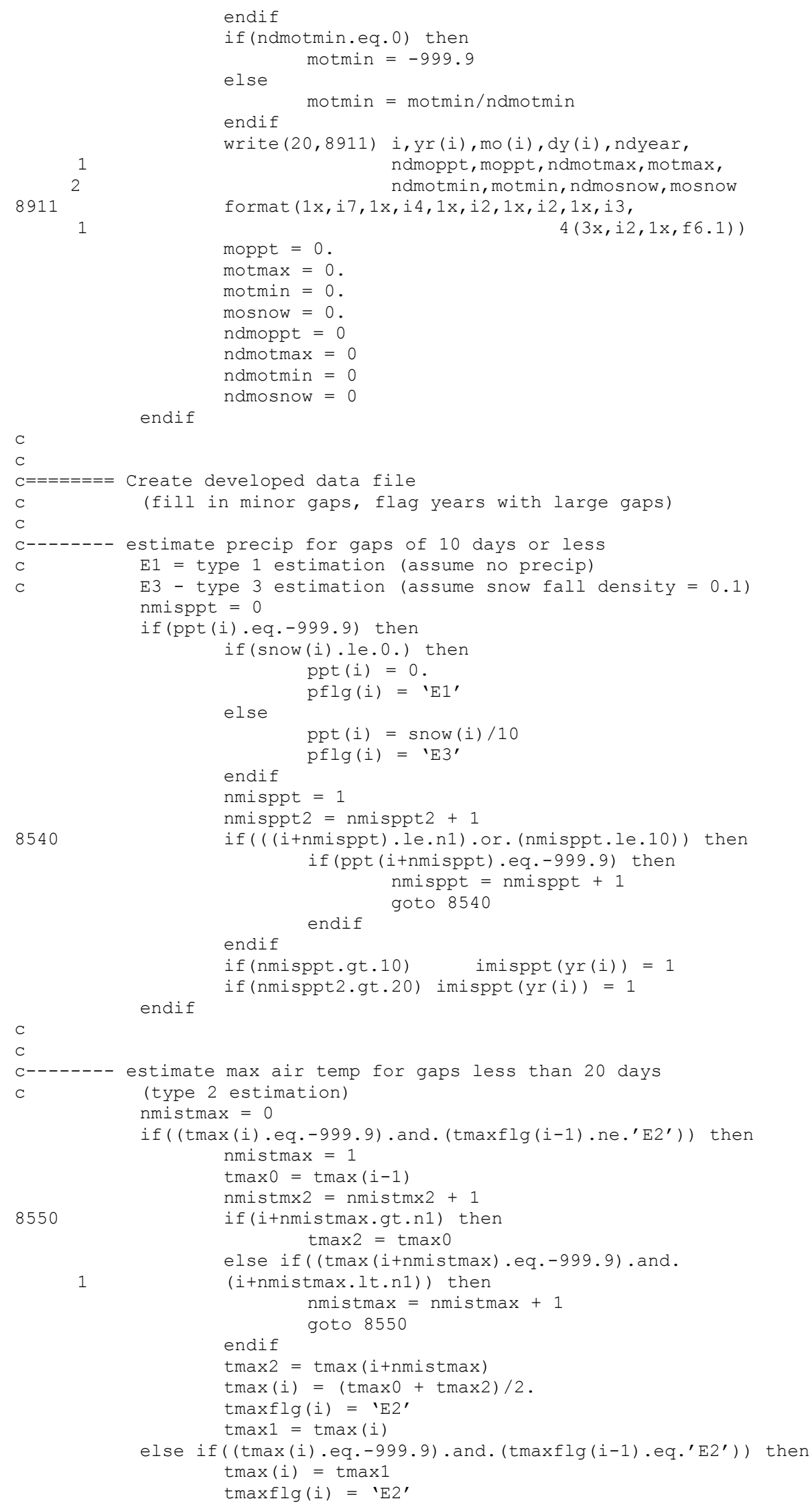




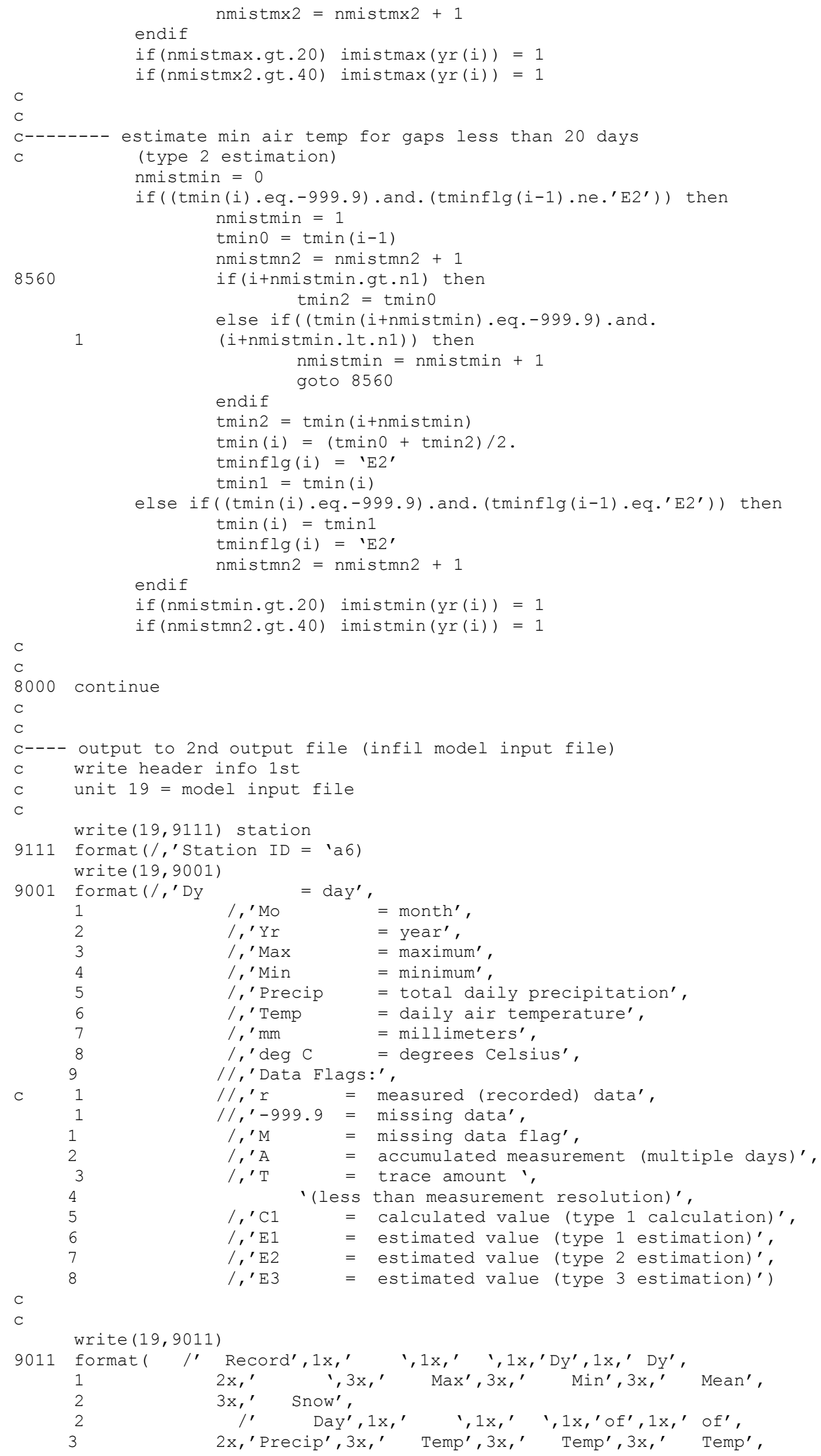




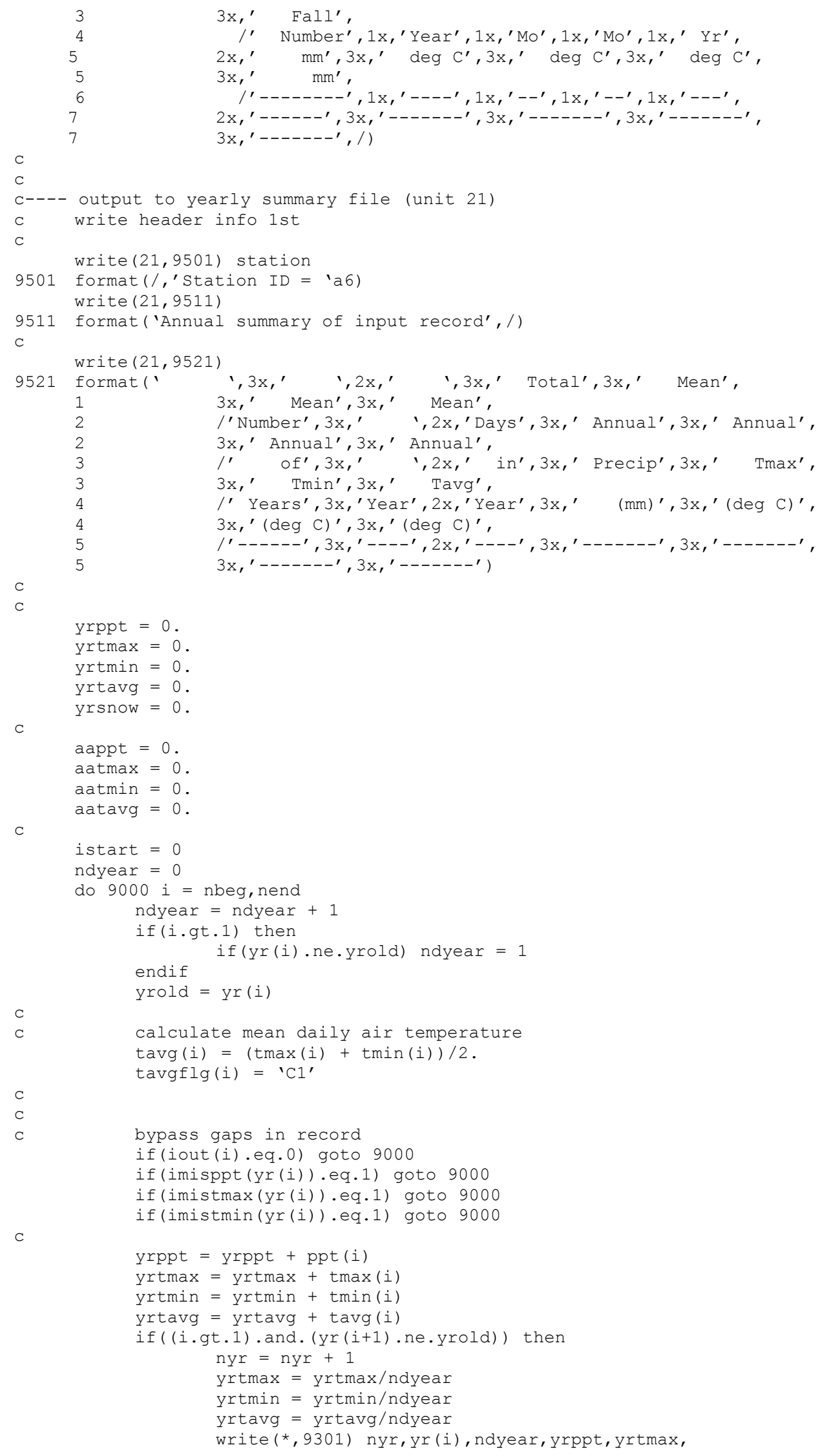


1

9301

1

2

3

4
5

1111

C

C

9000 continue

C

C

9311

C

C yrtmin, yrtavg

write $(21,9301)$ nyr,yr(i), ndyear, yrppt, yrtmax, yrtmin, yrtavg

format (i6, 3x, i4, 3x, i3, 4 (3x, f7.1))

aappt $=$ aappt + yrppt

aatmax $=$ aatmax + yrtmax

aatmin = aatmin + yrtmin

aatavg = aatavg + yrtavg

yrppt $=0$.

yrtmax $=0$.

yrtmin $=0$

endif

yrtavg $=0$

write $(19,1111)$ i, yr(i), mo (i), dy (i), ndyear,

ppt (i), pflg(i),

tmax (i), tmaxflg(i),

tmin(i), tminflg(i),

$\operatorname{tavg}(i), \operatorname{tavgflg}(i)$,

snow (i), snowflg(i)

format (1x, i7 , 1x, i4, 1x, i2, 1x, i2, 1x, i3, 1x,

$5(1 \mathrm{x}, \mathrm{f} 6.1,1 \mathrm{x}, \mathrm{a} 2))$

calculate and print annual averages

aappt $=$ aappt/nyr

aatmax $=$ aatmax $/$ nyr

aatmin = aatmin/nyr

aatavg = aatavg/nyr

write $(*, 9311)$ aappt, aatmax, aatmin, aatavg

write $(21,9311)$ aappt, aatmax, aatmin, aatavg

format (/ ,4x,'Averages:', 6x, 4 (3x, f7.1))

close (18)

close (19)

close (20)

close (21)

stop

end 


\section{APPENDIX D}

\section{CALCULATION OF BLOCKING RIDGES USING BLOCKR7 V1.0}




\section{D1. NAME OF ROUTINE/MACRO WITH VERSION/OS/HARDWARE ENVIRONMENT AND USER INFORMATION}

Name of software routine: BLOCKR7 V1.0,

OS and hardware environment: Windows NT 4.0, Pentium Pro PC

Computer Identification: SM321276 with a USGS specific host-name P720dcasr

Software Users: Joseph Hevesi (916-278-3274), Alan Flint (916-278-3221)

User Location: U.S. Geological Survey, Room 5000E, Placer Hall, 6000 J Street, Sacramento, CA $95819-6129$

\section{D2. NAME OF COMMERCIAL SOFTWARE WITH VERSION/OS/HARDWARE USED TO DEVELOP ROUTINE/MACRO}

The source code for BLOCKR7 V1.0 was developed using the standard FORTRAN77 programming language. The source code was written, debugged, and compiled (for PC platforms using INTEL processors) using DIGITAL Visual FORTRAN with Microsoft Developer Studio, V. 5.0.

\section{D3. GENERAL DESCRIPTION OF ROUTINE/MACRO}

BLOCKR7 V1.0 is a FORTRAN77 routine developed in accordance with AP-SI.1Q, specifically for the analysis/model activity documented in this report. The routine source code $(B L O C K R 7 . F O R)$, compiled executable file (BLOCKR7.EXE), routine control file (BLOCKR7.CTL), input and output files, validation test files, and a copy of this appendix, are located under the directory BLOCKR7 on a CD-ROM labeled GEOINPUT-1. The routine source code, control file, and the input and output files are ASCII text files that can be read using any standard ASCII text editor and can be imported into standard word processing applications such as Microsoft Word. The executable file can be used to run BLOCKR7 V1.0 on any PC with an INTEL processor (with adequate RAM).

All parameters included in the output file developed by BLOCKR7 V1.0 are used for the development of the geospatial parameter input file for INFIL V2.0 (USGS 2000 [DIRS 139422]). The parameters used and developed by BLOCKR7 V1.0 are equivalent to the parameters used in the input file for INFIL V1.0 (Flint et al. 1996 [DIRS 100147]).

\section{D4. TEST PLAN FOR THE SOFTWARE ROUTINE BLOCKR7 V1.0}

\section{- Explain whether this is a routine or macro and describe what it does:}

BLOCKR7 V1.0 is the first routine in a sequence of developed FORTRAN77 routines that are used in the development of the geospatial parameter input files for INFIL V2.0. The routine performs two functions required as part of the development of the geospatial parameter input files for INFIL V2.0. The first function consists of assembling nine individual ASCII matrix grid files developed in ARCINFO (corresponding to 9 separate input parameters) into a single column formatted ASCII output file. The second function consists of the calculation of 36 blocking ridge angles for each grid location defined by the ASCII matrix grids. The blocking ridge angles are defined by the angle of inclination above the horizontal plane that the surrounding 
topography obstructs a location's "view" of the sky and potential direct beam solar radiation. The 36 blocking ridge angles are calculated at each $10^{\circ}$ horizontal arc (with the azimuth aligned in the UTM northing direction) for each grid cell.

The input and output files used by the routine are defined in the routine control file, BLOCKR7.CTL that is itself an input file for the routine. The input files defined in BLOCKR7.CTL consist of the nine ASCII matrix grid files (one file for each parameter defined above). The output files defined in BLOCKR7.CTL consist of 30MSITE.INP, which is the main output file (this file is used as input by GEOMAP7 V1.0) and two auxiliary output files, 30MSITE.SKY and SKYVIEW.ASC, consisting of the calculated sky-view factor for each grid location. Also included in BLOCKR7.CTL are parameters used as input for the calculation of the 36 approximate $10^{\circ}$ azimuth angles based on the input grid geometry.

The calculated sky-view factor that included as output in the two auxiliary output files is the percentage of sky viewed from the ground surface, relative to the sky-view for an infinite horizontal plane, and is calculated for each grid cell location using the 36 blocking ridge angles generated by BLOCKR7. The two auxiliary output files provide the sky-view factor in two different output formats (ASCII column and ASCII matrix) and are used as a part of the test plan for BLOCKR7.

\section{- Listing of FORTRAN77 Source code:}

A listing of the FORTRAN77 source code for the routine BLOCKR7 V1.0 along with examples of the input and output files used in the test plan are included at the end of this appendix.

\section{- Description of test(s):}

To determine that the two functions performed by the routine are operating correctly, two separate test plans are applied. The first test case involves a visual inspection of the column-formatted ASCII output file, 30MSITE.INP to confirm that the file format is correct and that there are a total of 253,597 rows and 48 columns. The testing procedure consists of a direct comparison of parameter values in the input files to the ordering and values of parameters in the corresponding line of the output file. This provides a validation check of the first function performed by BLOCKR7 V1.0, which is the assembling of individual ASCII matrix grids for each of the input parameters into a single column formatted ASCII output file. For example, the parameter value of the first column of the first line of the input matrix for the first input parameter (latitude) must correspond to the parameter value located in the third column of the first line of the output file. The parameter value of the first column of the first line of the input matrix for the second input parameter (longitude) must correspond to the parameter value located in the fourth column of the first line of the output file, and soon for all parameters assembled into the output file.

The second test consists of a visual evaluation of the second function performed by BLOCKR7 that consists of the calculation of the 36 blocking ridge angles and the 
output of these values as 36 separate columns that are included in the output file. To test this function, a visual test is conducted in ARCVIEW by a comparison of the map image obtained using the input elevation grid with the map image obtained using the sky-view values that are included in the auxiliary output file created by BLOCKR7. The sky-view values are calculated using the same 36 blocking ridge values that are included in the main output file. The testing criteria used in this test are based on the following known conditions: 1) Grid locations that are not surrounded by ridges blocking incoming solar radiation will result in a calculation of approximately 100 percent of the sky viewed (the sky-view value is the percentage of the sky viewed). 2) Grid locations in deep valleys and washes where there is blockage of solar radiation by ridges will result in the maximum reduction in sky-view within the model domain of approximately 25 to 30 percent. For the hypothetical upper bound case of an infinite horizontal plane, the calculated sky-view factor is 100 percent (no reduction in the percentage of sky viewed). In the case of mountainous terrain such as the Yucca Mountain site and the area of the net infiltration model, the occurrence of rugged topography including steep ridges with significant relief of $100 \mathrm{~m}$ and greater should result in an appropriate reduction of the percent of sky viewed.

The testing is performed in ARCVIEW by a visual comparison of both a shaded-relief and a contoured representation of the DEM to map images generated using the sky-view factor obtained from the auxiliary output file, SKYVIEW.ASC. The test criteria are subjectively based on the determination that the sky-view factor provides a reasonable representation of the percentage of sky viewed relative to expected reductions in sky view based on the known topography surrounding a given grid cell.

For ridge-top locations and flat or gently sloping terrain where there are no ridges blocking sky-view, expected reductions in sky-view should be minimal (from 90 to 100 percent sky-view). In comparison, for steep side-slopes and deep washes or valleys characterized by more rugged terrain, larger reductions in sky-view are expected (less than 80 percent sky-view).

The subjective acceptance criteria used in the test plan for the calculation of blocking ridges are based on the sensitivity of estimated net infiltration to the inclusion of blocking ridges in the calculation of available energy to drive PET. The inclusion of the reduction in sky-view for locations with surrounding ridges provides a slight increase in the accuracy of estimated net infiltration. For example, the impact of excluding the reduction in sky-view from the estimation of net infiltration is a maximum reduction in net infiltration estimates of approximately two to three percent as compared to estimates obtained if the reduction in sky-view is included.

\section{- Specify the range of input values to be used and why the range is valid:}

All nine ASCII matrix grid files used as input by BLOCKR7 V1.0 consist of six standard ARCINFO and ARCVIEW header lines specifying the dimensions of the input grid (copies of the first nine lines of these input files are included at the end of this appendix). The header lines are followed by a matrix of 691 rows by 367 columns for a total of 253,597 input values for each input file. The matrix consists of the 
parameter values for a specific parameter (one file per parameter) and is the standard raster-data format that can be exported or imported by ARCINFO or ARCVIEW. The nine ASCII matrix grid files listed below consist of one file for each input parameter and must be listed in the same order in the routine control file, BLOCKR7.CTL. The range of input values specified in the listing below is valid because these values were obtained from ARCINFO using the source data as input.

1. 30MLAT.ASC: Latitude coordinate input file (in decimal degrees $\mathrm{f}$ rom 36.7501 to 36.9373 ) for each grid location.

2. 30MLONG.ASC: Absolute-value longitude coordinate input file (in decimal degrees from 116.3752 to 116.4997$)$ for each grid cell location.

3. 30MSLOPE.ASC: Ground surface slope input file (in degrees from 0 to 47).

4. 30MASPCT.ASC: Ground surface aspect input file (in degrees from -1 to 358$)$.

5. 30MELEV.ASC: Ground surface elevation (in meters from 918 to 1969).

6. 30MSOIL.ASC: Soil type identification number (an integer value from 1 to 10$)$.

7. 30MDEPTH.ASC: Soil depth class number (an integer value from 1 to 4 ).

8. 30MROCK.ASC: Rock type identification number (an integer value from 1 to 214).

9. 30MTOPO.ASC: Topographic location number (an integer value from 1 to 6$)$.

\section{D5. TEST RESULTS}

- Output from test (explain difference between input range used and possible input):

The output for the first part of the test (input parameters from ARCINFO are properly combined into a single column formatted ASCII text file) is the main output file, 30MSITE.INP generated by BLOCKR7 V1.0 and the nine ASCII matrix input files (see listing of files below). The output for the second part of the test (qualitative evaluation of blocking ridge angles using sky-view) is the value of calculated percent sky-view for every grid cell and is included in the two auxiliary output files created by BLOCKR7 (30MSITE.SKY and SKYVIEW.ASC). 


\section{- Description of how the testing shows that the results are correct for the specified input:}

A visual inspection of the input and output files indicates that the test criteria for the first part of the test plan is satisfied. Comparison of input and output parameter values shows that all input parameters have been assembled into the correct order and line of the output file, and thus the first function of the routine is being correctly executed. The test results are reproduced in this appendix by including a partial print-out of the input and output files. Inspection of the file copies indicates that the parameter value in the first grid cell position of each matrix (hi-lighted in red) is in the correct column position of the corresponding grid cell location of the output file (first line of the output file, hi-lighted in red), the parameter value in the second grid cell position of each matrix (hi-lighted in blue) is in the correct column position of the corresponding grid cell location of the output file (second line of file, hi-lighted in blue), and so on. Inspection of the complete output file indicates 253,597 rows and 48 columns, with the columns ordered according to the following sequence:

\section{Column number Parameter description}

$\begin{array}{cl}1 & \text { Grid cell location number } \\ 2 & \text { UTM easting coordinate, in meters } \\ 3 & \text { UTM northing coordinate, in meters } \\ 4 & \text { Latitude coordinate, in decimal degrees } \\ 5 & \text { Longitude coordinate, in decimal degrees } \\ 6 & \text { Ground surface slope, in degrees } \\ 7 & \text { Ground surface aspect, in degrees } \\ 8 & \text { Ground surface elevation, in meters } \\ 9 & \text { Soil type identification number, integer value } \\ 10 & \text { Soil depth class number, integer value } \\ 11 & \text { Rock type Identification number, integer value } \\ 12 & \text { Topographic identification number, integer value } \\ 13 & \text { First of 36 blocking ridge angles, in degrees } \\ 14 & \text { Second of 36 blocking ridge angles, in degrees } \\ 15 & \text { Third of 36 blocking ridge angles, in degrees } \\ 16-47 & \text { blocking ridge angles } 4 \text { through 35 } \\ 48 & \text { Last blocking ridge angle, in degrees. }\end{array}$

The second part of the test consists of a visual evaluation of the sky-view factor calculated using the blocking ridge angles generated by BLOCKR7. Comparison of Figures D-1 through D-3 indicates that the test criteria for the second part of the test are satisfied. The elevation values in the main output file are used in ARCVIEW to develop Figure B-1, which is a shaded relief map of the Yucca Mountain site. Both the elevation values in the main output file and the sky-view values provided in the auxiliary output file, 30MSITE.SKY are used in ARCVIEW to develop Figures D-2 and D-3. Overlaying the sky view factor and topography into a combined map image allows for a visual evaluation that the test criteria are satisfied. Visual inspection of Figures D-2 and D-3 indicates a high percentage of sky-view ( 90 percent 
and higher) for ridge-top and flat, open area locations, and a low percentage of skyview (80 percent and lower) for steep side-slope locations and for deep, narrow washes. These test results indicate that the routine is functioning properly for the intended use.

\section{- List limitations or assumptions to this test case and code in general:}

Limitations are only those inherent in the DEM. To provide an enhanced test result, the visual test is performed in ARCVIEW, allowing for the map of calculated sky-view to be draped over the shaded relief map and overlain with elevation contours generated from the DEM.

- Electronic files identified by name and location:

Electronic files are located on CD-ROM labeled GEOINPUT-1, under the directory BLOCKR7, included as an Appendix to the report. The following electronic files are provided:

BLOCKR7.CTL: Input file consisting of the input and output file names for BLOCKR7, along with parameters needed to perform the 36 blocking ridge angle calculations.

BLOCKR7.FOR: FORTRAN source code listing for the routine BLOCKR7. A printout of the source code is included as part of this appendix.

BLOCKR7.EXE: Executable file for the routine BLOCKR7, compiled for INTEL processors.

30MLAT.ASC: Input file consisting of the grid cell latitude coordinates (in decimal degrees) for all 253,597 grid cell locations of the base grid, developed using ARCINFO and exported as a standard ARCINFO format ASCII matrix grid file. A partial printout of the first part of this file is included as part of this appendix.

30MLONG.ASC: Input file consisting of the grid cell longitude coordinates (in decimal degrees) for all 253,597 grid cell locations of the base grid, developed using ARCINFO and exported as a standard ARCINFO format ASCII matrix grid file. A partial printout of the first part of this file is included as part of this appendix.

30MSLOPE.ASC: Input file consisting of ground surface slope (in degrees) for all 253,597 grid cell locations of the base grid, calculated from the DEM using ARCINFO and exported as a standard ARCINFO format ASCII matrix grid file. A partial printout of the first part of this file is included as part of this appendix. 
30MASPCT.ASC: Input file consisting of ground surface aspect (in degrees) for all 253,597 grid cell locations of the base grid, calculated from the DEM using ARCINFO and exported as a standard ARCINFO format ASCII matrix grid file. A partial printout of the first part of this file is included as part of this appendix.

30MELEV.ASC: Input file consisting of ground surface elevation (in meters) for all 253,597 grid cell locations of the base grid. The source data consists of two standard 7.5-minute USGS 30-meter digital elevation models (DEMs), which are merged into a single composite DEM using ARCINFO, and exported as a standard ARCINFO format ASCII matrix grid file. A partial printout of the first part of this file is included as part of this appendix.

30MSOIL.ASC: Input file consisting of the soil type identification number (an integer value from 1 to 10) for all 253,597 grid cell locations of the base grid. The source data consists of a standard ARCINFO vector coverage that is rasterized onto the cell locations of the base grid using ARCINFO and exported as a standard ARCINFO format ASCII matrix grid file. A partial printout of the first part of this file is included as part of this appendix.

30MDEPTH.ASC: Input file consisting of the soil depth class identification number (an integer value from 1 to 4 ) for all 253,597 grid cell locations of the base grid. The source data consists of a standard ARCINFO vector coverage that is rasterized onto the cell locations of the base grid using ARCINFO and exported as a standard ARCINFO format ASCII matrix grid file. A partial printout of the first part of this file is included as part of this appendix.

30MROCK.ASC: Input file consisting of the rock type identification number (an integer value from 1 to 214) for all 253,597 grid cell locations of the base grid. The source data consists of a standard ARCINFO vector coverage that is rasterized onto the cell locations of the base grid using ARCINFO and exported as a standard ARCINFO format ASCII matrix grid file. A partial printout of the first part of this file is included as part of this appendix.

30MTOPO.ASC: Input file consisting of the topographic position identification number (an integer value from 1 to 6) for all 253,597 grid cell locations of the base grid. The parameter is generated in ARCINFO using the source DEM as input, rasterized onto the cell locations of the base grid and exported as a standard ARCINFO format ASCII matrix grid file. A partial printout of the first part of this file is included as part of this appendix. 
30MSITE.INP: $\quad$ Main output file consisting of 253,597 rows and 48 columns (see Section 5 above for column ordering and descriptions. This file includes 36 columns that are the 36 blocking ridge angles calculated by BLOCKR7 for each grid location. A partial printout of the first part of this file is included as part of this appendix.

30MSITE.SKY: Auxiliary output file consisting of 253,597 rows and 3 columns. The first two columns are the UTM coordinates and the third column is the calculated sky-view factor (in percent). This file is used only as part of the test plan. It is not required for the intended application of the routine.

SKYVIEW.ASC: auxiliary output file consisting of the 253,597 sky-view values in the ASCII grid matrix format that is imported directly into ARCVIEW. This file is used only as part of the test plan. It is not required for the intended application of the routine.

6. Supporting Information. (Include background information, such as revision to a previous routine or macro, or explanation of the steps performed to run the software. Include listings of all electronic files and codes used).

\section{- Procedure for running routine:}

To run the routine BLOCKR7, an executable version of the code and all input files must be placed in the same directory. The routine is executed by typing BLOCKR7 in a DOS window, by double clicking on the file, BLOCKR7.EXE in the Microsoft Windows OS, or by typing in the path and filename in the RUN window of the Windows NT or Windows 98 start menu. The input and output file names and the parameters used for the blocking ridge calculations must be in the correct sequential order as specified in the routine control file, BLOCKR7.CTL (see example printouts provided below).

\section{- Example printout of routine control file, $B L O C K R 7 . C T L$}

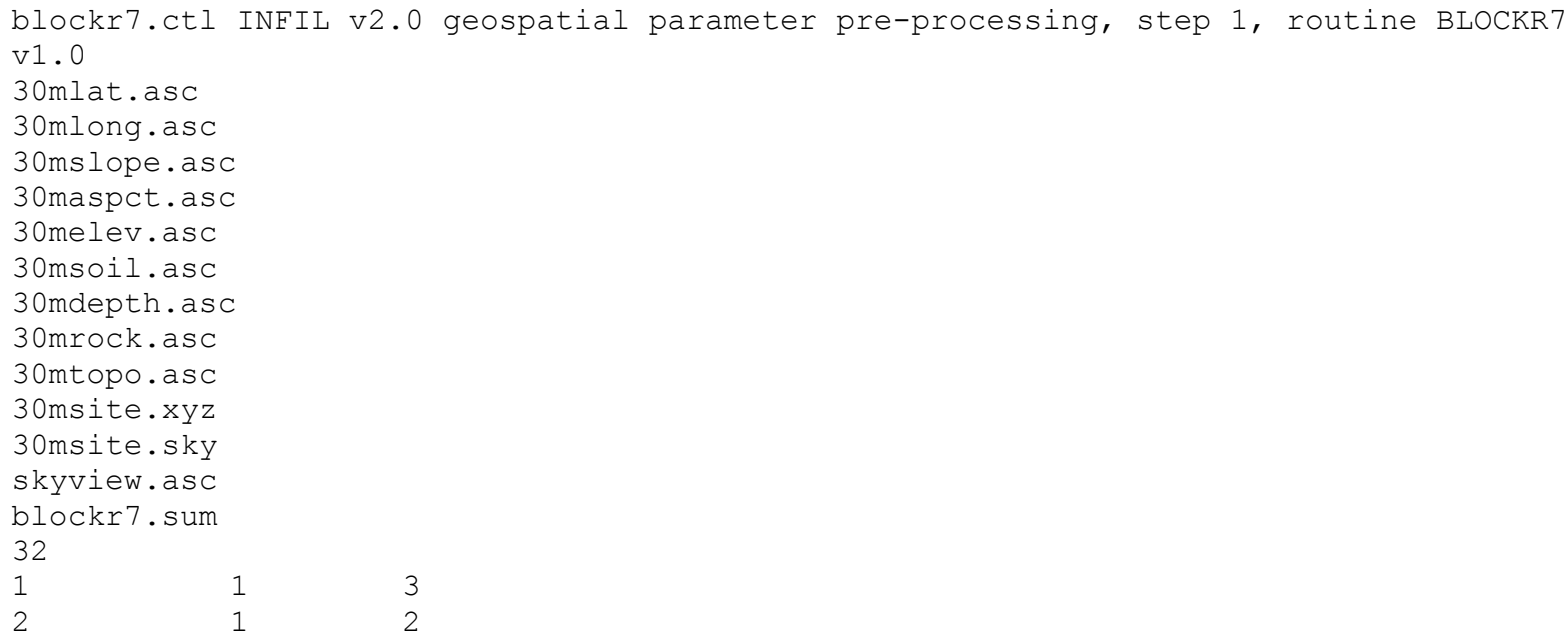




$\begin{array}{lll}3 & 2 & 3 \\ 4 & 1 & 1 \\ 5 & 3 & 2 \\ 6 & 2 & 1 \\ 7 & 3 & 1 \\ 8 & 1 & 0 \\ 9 & 3 & -1 \\ 10 & 2 & -1 \\ 11 & 3 & -2 \\ 12 & 1 & -1 \\ 13 & 2 & -3 \\ 14 & 1 & -2 \\ 15 & 1 & -3 \\ 16 & 0 & -1 \\ 17 & -1 & -3 \\ 18 & -1 & -2 \\ 19 & -2 & -3 \\ 20 & -1 & -1 \\ 21 & -3 & -2 \\ 22 & -2 & -1 \\ 23 & -3 & -1 \\ 24 & -1 & 0 \\ 25 & -3 & 1 \\ 26 & -2 & 1 \\ 27 & -3 & 2 \\ 28 & -1 & 1 \\ 29 & -2 & 3 \\ 30 & -1 & 2 \\ 31 & -1 & 3 \\ 32 & 0 & 1\end{array}$

- Example printout of 30MLAT.ASC: ARCINFO ASCII grid format input file for latitude, in decimal degrees (only the 6 header lines and the first 3 lines of the input matrix are listed).

\begin{tabular}{|c|c|c|c|c|c|c|c|c|}
\hline ols & & 367 & & & & & & \\
\hline rows & & 691 & & & & & & \\
\hline xllcorne & & 544661.00 & 0000 & & & & & \\
\hline yllcorne: & & 67133.00 & 0000 & & & & & \\
\hline cellsize & & 30.00 & 0000 & & & & & \\
\hline ODATA_V & alue & -9999.00 & 0000 & & & & & \\
\hline $36.9 \overline{3} 7$ & $3 \quad 36.9373$ & $3 \quad 36.937$ & $3 \quad 36.9373$ & 36.9373 & 36.9373 & 36.9373 & 36.9373 & 36.9373 \\
\hline 6.9373 & 36.9373 & 36.9373 & 36.9373 & 36.9373 & 36.9373 & 36.9373 & 36.9373 & 36.9373 \\
\hline 36.9373 & 36.9373 & 36.9373 & 36.9373 & 36.9373 & 36.9373 & 36.9373 & 36.9373 & 36.9373 \\
\hline 36.9373 & 36.9373 & 36.9373 & 36.9373 & 36.9373 & 36.9373 & 36.9373 & 36.9373 & 36.9373 \\
\hline 36.9373 & 36.9373 & 36.9373 & 36.9373 & 36.9373 & 36.9373 & 36.9372 & 36.9372 & 36.9372 \\
\hline 9372 & 36.9372 & 36.9372 & 36.9372 & 36.9372 & 36.9372 & 36.9372 & 36.9372 & 36.9372 \\
\hline 9372 & 36.9372 & 36.9372 & 36.9372 & 36.9372 & 36.9372 & 36.9372 & 36.9372 & 36.9372 \\
\hline 36.9372 & 36.9372 & 36.9372 & 36.9372 & 36.9372 & 36.9372 & 36.9372 & 36.9372 & 36.9372 \\
\hline 36.9372 & 36.9372 & 36.9372 & 36.9372 & 36.9372 & 36.9372 & 36.9372 & 36.9372 & 36.9372 \\
\hline 36.9372 & 36.9372 & 36.9372 & 36.9372 & 36.9372 & 36.9372 & 36.9372 & 36.9372 & 36.9372 \\
\hline 36.9372 & 36.9372 & 36.9372 & 36.9372 & 36.9372 & 36.9372 & 36.9372 & 36.9372 & 36.9372 \\
\hline 372 & 36.9372 & 36.9372 & 36.9372 & 36.9372 & 36.9372 & 36.9372 & 36.9372 & 36.9372 \\
\hline 372 & 36.9372 & 36.9372 & 36.9372 & 36.9372 & 36.9372 & 36.9372 & 36.9372 & 36.9371 \\
\hline 36.9371 & 36.9371 & 36.9371 & 36.9371 & 36.9371 & 36.9371 & 36.9371 & 36.9371 & 36.9371 \\
\hline 36.9371 & 36.9371 & 36.9371 & 36.9371 & 36.9371 & 36.9371 & 36.9371 & 36.9371 & 36.9371 \\
\hline 36.9371 & 36.9371 & 36.9371 & 36.9371 & 36.9371 & 36.9371 & 36.9371 & 36.9371 & 36.9371 \\
\hline 36.9371 & 36.9371 & 36.9371 & 36.9371 & 36.9371 & 36.9371 & 36.9371 & 36.9371 & 36.9371 \\
\hline 71 & 36.9371 & 36.9371 & 36.9371 & 36.9371 & 36.9371 & 36.9371 & 36.9371 & 36.9371 \\
\hline 71 & 36.9371 & 36.9371 & 36.9371 & 36.9371 & 36.9371 & 36.9371 & 36.9371 & 36.9371 \\
\hline
\end{tabular}




\begin{tabular}{|c|c|c|c|c|c|c|c|c|}
\hline 36.9371 & 36.9371 & 36.9370 & 36.9370 & 36.9370 & 36.9370 & 36.9370 & 36.9370 & 36.9370 \\
\hline 36.9370 & 36.9370 & 36.9370 & 36.9370 & 36.9370 & 36.9370 & 36.9370 & 36.9370 & 36.9370 \\
\hline 36.9370 & 36.9370 & 36.9370 & 36.9370 & 36.9370 & 36.9370 & 36.9370 & 36.9370 & 36.9370 \\
\hline 6.9370 & 36.9370 & 36.9370 & 36.9370 & 36.9370 & 36.9370 & 36.9370 & 36.9370 & 36.9370 \\
\hline 6.9370 & 36.9370 & 36.9370 & 36.9370 & 36.9370 & 36.9370 & 36.9370 & 36.9370 & 36.9370 \\
\hline .9370 & 36.9370 & 36.9370 & 36.9370 & 36.9370 & 36.9370 & 36.9370 & 36.9370 & 36.9370 \\
\hline .9370 & 36.9370 & 36.9370 & 36.9370 & 36.9370 & 36.9370 & 36.9370 & 36.9370 & 6.9370 \\
\hline .9370 & 36.9370 & 36.9370 & 36.9370 & 36.9370 & 36.9370 & 36.9370 & 36.9369 & 6.9369 \\
\hline 5.9369 & 36.9369 & 36.9369 & 36.9369 & 36.9369 & 36.9369 & 36.9369 & 36.9369 & 36.9369 \\
\hline 5.9369 & 36.9369 & 36.9369 & 36.9369 & 36.9369 & 36.9369 & 36.9369 & 36.9369 & 36.9369 \\
\hline .9369 & 36.9369 & 36.9369 & 36.9369 & 36.9369 & 36.9369 & 36.9369 & 36.9369 & 36.9369 \\
\hline .9369 & 36.9369 & 36.9369 & 36.9369 & 36.9369 & 36.9369 & 36.9369 & 36.9369 & 36.9369 \\
\hline 9369 & 36.9369 & 36.9369 & 36.9369 & 36.9369 & 36.9369 & 36.9369 & 36.9369 & .9369 \\
\hline 9369 & 36.9369 & 36.9369 & 36.9369 & 36.9369 & 36.9369 & 36.9369 & 36.9369 & 5.9369 \\
\hline 5.9369 & 36.9369 & 36.9369 & 36.9369 & 36.9368 & 36.9368 & 36.9368 & 36.9368 & 36.9368 \\
\hline .9368 & 36.9368 & 36.9368 & 36.9368 & 36.9368 & 36.9368 & 36.9368 & 36.9368 & 36.9368 \\
\hline .9368 & 36.9368 & 36.9368 & 36.9368 & 36.9368 & 36.9368 & 36.9368 & 36.9368 & 36.9368 \\
\hline .9368 & 36.9368 & 36.9368 & 36.9368 & 36.9368 & 36.9368 & 36.9368 & 36.9368 & 36.9368 \\
\hline .9368 & 36.9368 & 36.9368 & 36.9368 & 36.9368 & 36.9368 & 36.9368 & .9368 & .9368 \\
\hline 9368 & 36.9368 & 36.9368 & 36.9368 & 36.9368 & 36.9368 & 36.9368 & 9368 & .9368 \\
\hline 9368 & 36.9368 & 36.9368 & 36.9368 & 36.9368 & 36.9368 & 36.9368 & 36.9367 & 36.9367 \\
\hline .9367 & 36.9367 & 36.9367 & 36.9367 & 36.9367 & 36.9367 & 36.9367 & & \\
\hline 36.9370 & $0 \quad 36.9370$ & $0 \quad 36.9370$ & 36.9370 & 36.9370 & 36.9370 & 36.9370 & 36.9370 & \\
\hline 5.9370 & 36.9370 & 36.9370 & 36.9370 & 36. & 36.9370 & 36.9370 & 36.9370 & 36.9370 \\
\hline 9370 & 36.9370 & 36.9370 & 36.9370 & 36.9370 & 36.9370 & 36.9370 & 36.9370 & 36.9370 \\
\hline 9370 & 36.9370 & 36.9370 & 36.9370 & 36.9370 & 36.9370 & 36.9370 & 36.9370 & 36.9370 \\
\hline 9370 & 36.9370 & 36.9370 & 36.9370 & 36.9370 & 36.9370 & 36.9370 & 36.9370 & 36.9370 \\
\hline 9370 & 36.9370 & 36.9370 & 36.9370 & 36.9370 & 36.9370 & 36.9370 & 36.9370 & 36.9370 \\
\hline 9370 & 36.9370 & 36.9370 & 36.9370 & 36.9370 & 36.9370 & 36.9370 & 36.9370 & 36.9370 \\
\hline 9370 & 36.9370 & 36.9370 & 36.9370 & 36.9370 & 36.9370 & 36.9369 & 36.9369 & 36.9369 \\
\hline 9369 & 36.9369 & 36.9369 & 36.9369 & 36.9369 & 36.9369 & 36.9369 & 36.9369 & 36.9369 \\
\hline 9369 & 36.9369 & 36.9369 & 36.9369 & 36.9369 & 36.9369 & 36.9369 & 36.9369 & 36.9369 \\
\hline 369 & 36.9369 & 36.9369 & 36. & 36. & 369 & 36.9369 & 36.9369 & .9369 \\
\hline 9369 & 36.9369 & 36.9369 & 36.9369 & 36.9369 & 36.9369 & 36.9369 & 36.9369 & 36.9369 \\
\hline 9369 & 36.9369 & 36.9369 & 36.9369 & 36.9369 & 36.9369 & 36.9369 & 36.9369 & 36.9369 \\
\hline 6.9369 & 36.9369 & 36.9369 & 36.9369 & 36.9369 & 36.9369 & 36.9369 & 36.9369 & 36.9369 \\
\hline 9369 & 36.9369 & 36.9369 & 36.9369 & 36.9369 & 36.9369 & 36.9369 & 36.9369 & 36.9369 \\
\hline 9368 & 36.9368 & 36.9368 & 36.9368 & 36.9368 & 36.9368 & 36.9368 & 36.9368 & 36.9368 \\
\hline 368 & 36.9368 & 36.9368 & 36.9368 & 36.9368 & 36.9368 & 36.9368 & 36.9368 & 36.9368 \\
\hline 9368 & 36.9368 & 36.9368 & 36.9368 & 36.9368 & 36.9368 & 36.9368 & 36.9368 & 36.9368 \\
\hline .9368 & 36.9368 & 36.9368 & 36.9368 & 36.9368 & 36.9368 & 36.9368 & 36.9368 & 36.9368 \\
\hline 6.9368 & 36.9368 & 36.9368 & 36.9368 & 36.9368 & 36.9368 & 36.9368 & 36.9368 & 36.9368 \\
\hline 9368 & 36.9368 & 36.9368 & 36.9368 & 36.9368 & 36.9368 & 36.9368 & 36.9368 & 36.9368 \\
\hline 6.9368 & 36.9368 & 36.9368 & 36.9368 & 36.9368 & 36.9368 & 36.9368 & 36.9368 & 36.9368 \\
\hline 9367 & 36.9367 & 36.9367 & 36.9367 & 36.9367 & 36.9367 & 36.9367 & 36.9367 & 36.9367 \\
\hline 9367 & 36.9367 & 36.9367 & 36.9367 & 36. & 36.9367 & 36.9367 & 36.9367 & 36.9367 \\
\hline .9367 & 36.9367 & 36.9367 & 36.9367 & 36.9367 & 36.9367 & 36.9367 & 36.9367 & 36.9367 \\
\hline 36.9367 & 36.9367 & 36.9367 & 36.9367 & 36.9367 & 36.9367 & 36.9367 & 36.9367 & 36.9367 \\
\hline 36.9367 & 36.9367 & 36.9367 & 36.9367 & 36.9367 & 36.9367 & 36.9367 & 36.9367 & 36.9367 \\
\hline 36.9367 & 36.9367 & 36.9367 & 36.9367 & 36.9367 & 36.9367 & 36.9367 & 36.9367 & 36.9367 \\
\hline 9367 & 36.9367 & 36.9367 & 36.9367 & 36.9367 & 36.9367 & 36.9367 & 36.9366 & 36.9366 \\
\hline 9366 & 36.9366 & 36.9366 & 36.9366 & 36.9366 & 36.9366 & 36.9366 & 36.9366 & 36.9366 \\
\hline 36.9366 & 36.9366 & 36.9366 & 36.9366 & 36.9366 & 36.9366 & 36.9366 & 36.9366 & 36.9366 \\
\hline 36.9366 & 36.9366 & 36.9366 & 36.9366 & 36.9366 & 36.9366 & 36.9366 & 36.9366 & 36.9366 \\
\hline 36.9366 & 36.9366 & 36.9366 & 36.9366 & 36.9366 & 36.9366 & 36.9366 & 36.9366 & 36.9366 \\
\hline 6.9366 & 36.9366 & 36.9366 & 36.9366 & 36.9366 & 36.9366 & 36.9366 & 36.9366 & 36.9366 \\
\hline .9366 & 36.9366 & 36.9366 & 36.9366 & 36.9366 & 36.9366 & 36.9365 & 36.9365 & 36.9365 \\
\hline .9365 & 36.9365 & 36.9365 & 36.9365 & 36.9365 & 36.9365 & 36.9365 & 36.9365 & 36.9365 \\
\hline 5.9365 & 36.9365 & 36.9365 & 36.9365 & 36.9365 & 36.9365 & 36.9365 & 36.9365 & 36.9365 \\
\hline 36.9365 & 36.9365 & 36.9365 & 36.9365 & 36.9365 & 36.9365 & 36.9365 & 36.9365 & 36.9365 \\
\hline 36.9365 & 36.9365 & 36.9365 & 36.9365 & 36.9365 & 36.9365 & 36.9365 & 36.9365 & 36.9365 \\
\hline 6.9365 & 36.9365 & 36.9365 & 36.9365 & 36.9365 & 36.9365 & 36.9365 & 36.9365 & 36.9365 \\
\hline 5.9365 & 36.9365 & 36.9365 & 36.9365 & 36.9365 & 36.9365 & 36.9365 & & \\
\hline
\end{tabular}




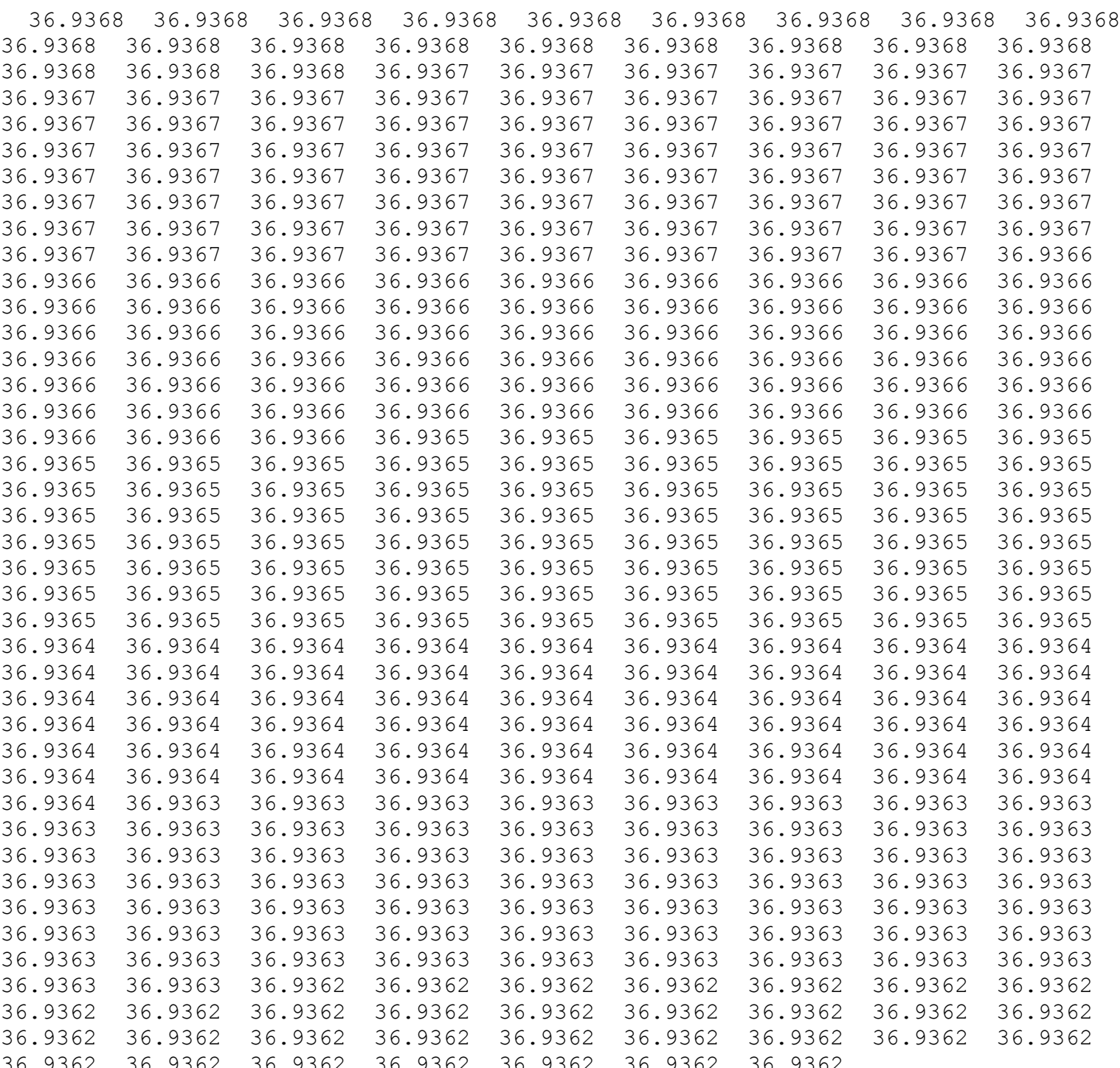

- Example listing of 30MLONG. ASC: ARCINFO ASCII grid format input file for longitude, in decimal degrees (only the 6 header lines and the first 3 lines of the input matrix are listed).

\begin{tabular}{lr} 
ncols & \multicolumn{1}{c}{367} \\
nrows & 691 \\
xllcorner & 544661.000000 \\
yllcorner & 4067133.000000 \\
cellsize & 30.000000 \\
NODATA value & -9999.000000
\end{tabular}

$116.4 \overline{9} 85116.4981 \quad 116.4978 \quad 116.4975 \quad 116.4971 \quad 116.4968 \quad 116.4965116 .4961$

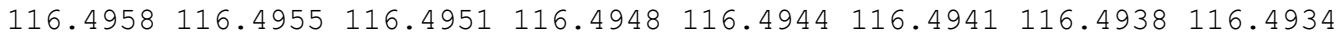
$116.4931 \quad 116.4928116 .4924 \quad 116.4921 \quad 116.4917 \quad 116.4914 \quad 116.4911116 .4907$ $116.4904116 .4901 \quad 116.4897 \quad 116.4894 \quad 116.4891 \quad 116.4887 \quad 116.4884116 .4880$

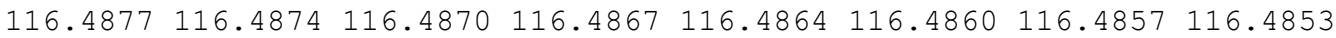

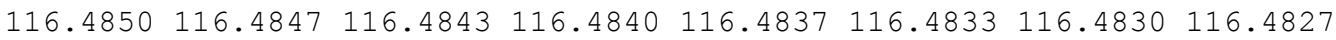
$116.4823 \quad 116.4820116 .4816 \quad 116.4813 \quad 116.4810 \quad 116.4806 \quad 116.4803 \quad 116.4800$

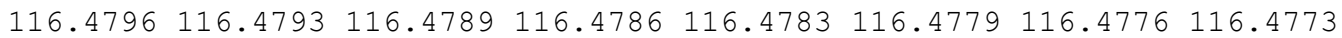
$116.4769116 .4766 \quad 116.4762 \quad 116.4759 \quad 116.4756 \quad 116.4752 \quad 116.4749116 .4746$ 


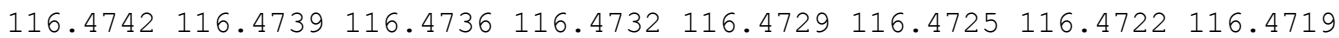
$116.4715116 .4712116 .4709116 .4705 \quad 116.4702 \quad 116.4698 \quad 116.4695116 .4692$

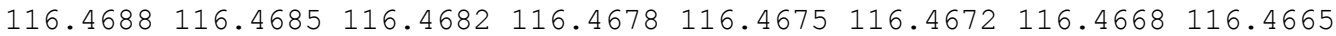

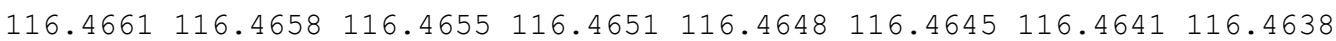

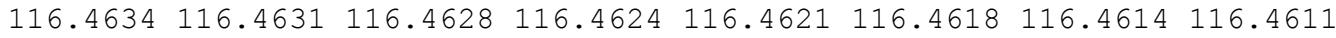
$116.4608116 .4604 \quad 116.4601 \quad 116.4597 \quad 116.4594 \quad 116.4591 \quad 116.4587116 .4584$ $116.4581 \quad 116.4577 \quad 116.4574 \quad 116.4571 \quad 116.4567 \quad 116.4564 \quad 116.4560116 .4557$

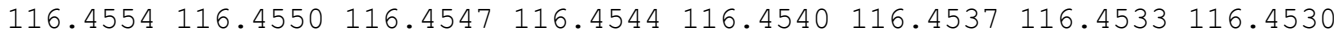

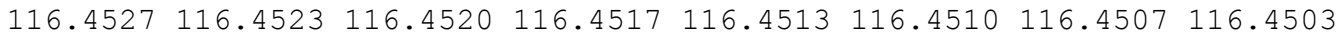

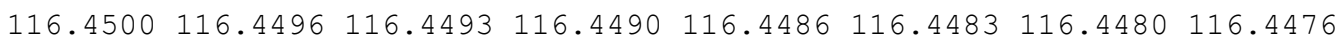

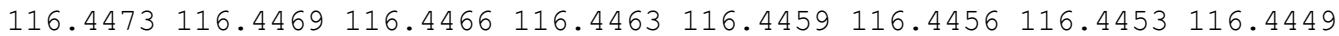

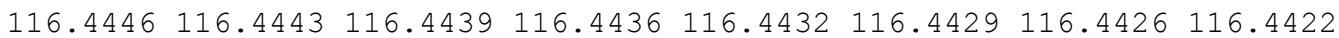
$116.4419116 .4416116 .4412 \quad 116.4409116 .4405116 .4402 \quad 116.4399116 .4395$ $116.4392116 .4389116 .4385116 .4382 \quad 116.4378 \quad 116.4375 \quad 116.4372 \quad 116.4368$

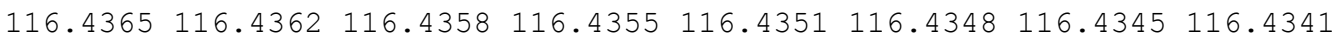

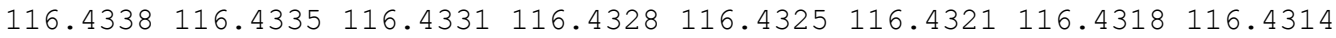

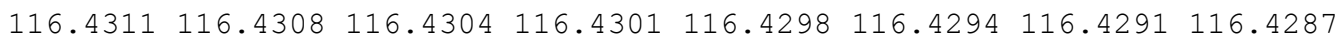
$116.4284116 .4281 \quad 116.4277 \quad 116.4274 \quad 116.4271 \quad 116.4267 \quad 116.4264116 .4261$

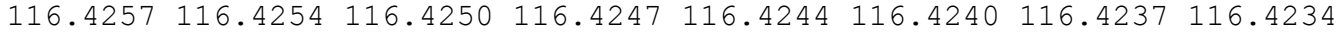

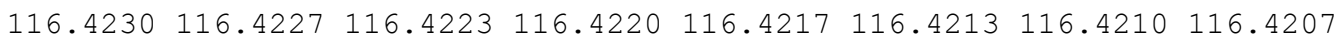

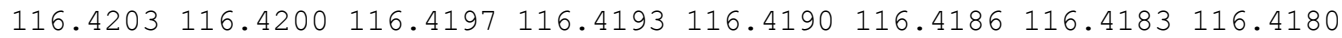

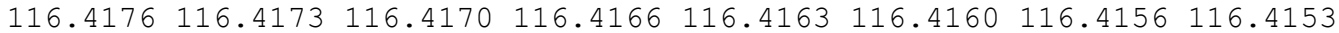

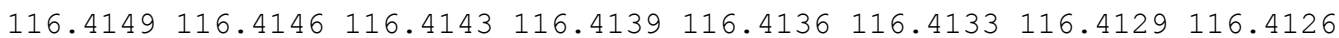
$116.4122116 .4119116 .4116 \quad 116.4112 \quad 116.4109 \quad 116.4106 \quad 116.4102 \quad 116.4099$ $116.4096116 .4092 \quad 116.4089116 .4085116 .4082 \quad 116.4079 \quad 116.4075116 .4072$ $116.4069116 .4065116 .4062 \quad 116.4058 \quad 116.4055 \quad 116.4052 \quad 116.4048116 .4045$ $116.4042116 .4038116 .4035116 .4032 \quad 116.4028116 .4025116 .4021116 .4018$ $116.4015116 .4011 \quad 116.4008 \quad 116.4005 \quad 116.4001 \quad 116.3998116 .3994116 .3991$

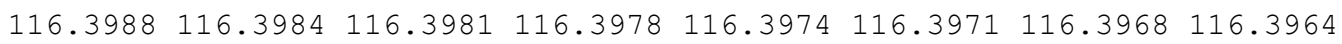

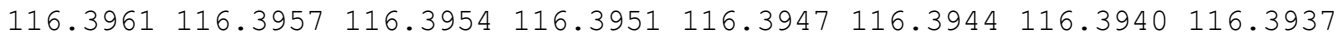

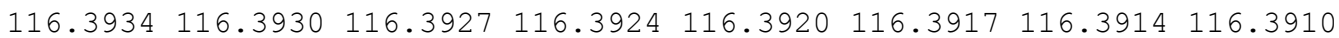

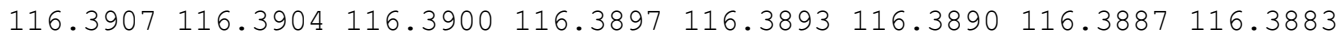

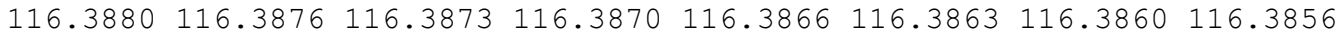

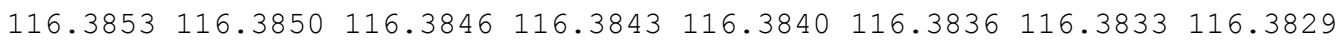
$116.3826116 .3823 \quad 116.3819 \quad 116.3816 \quad 116.3812 \quad 116.3809 \quad 116.3806 \quad 116.3802$

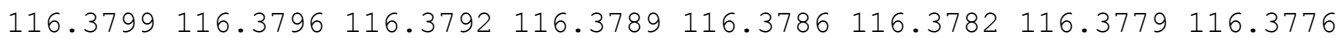
$116.3772 \quad 116.3769116 .3765 \quad 116.3762 \quad 116.3759 \quad 116.3755116 .3752$

$116.4985116 .4982 \quad 116.4978 \quad 116.4975 \quad 116.4971 \quad 116.4968 \quad 116.4965116 .4961$ $116.4958116 .4955 \quad 116.4951 \quad 116.4948 \quad 116.4944 \quad 116.4941 \quad 116.4938116 .4934$

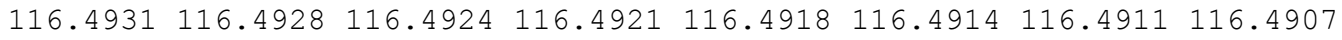

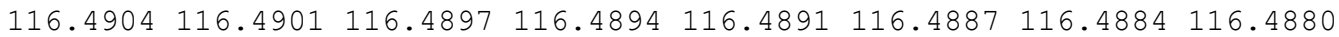

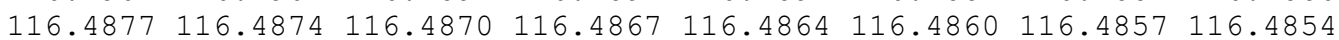

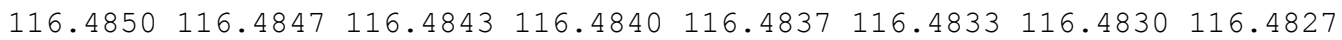

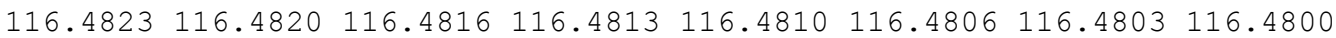

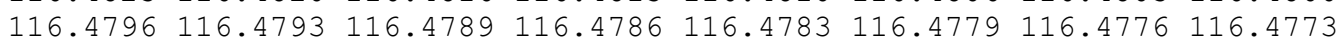

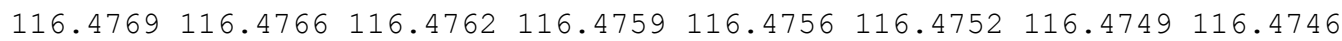

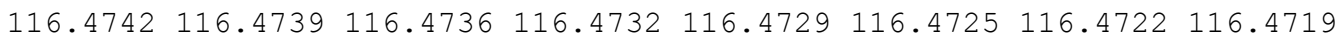
$116.4715116 .4712116 .4709116 .4705116 .4702 \quad 116.4698 \quad 116.4695116 .4692$

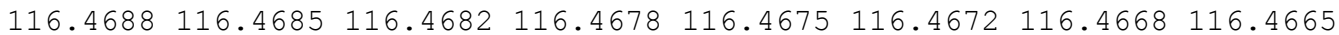

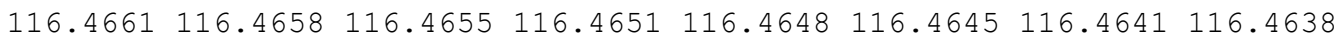

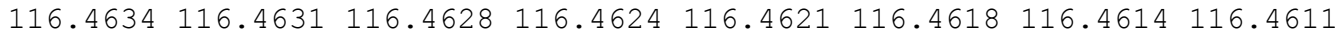
$116.4608 \quad 116.4604 \quad 116.4601 \quad 116.4597 \quad 116.4594 \quad 116.4591 \quad 116.4587 \quad 116.4584$

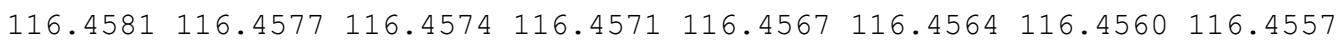

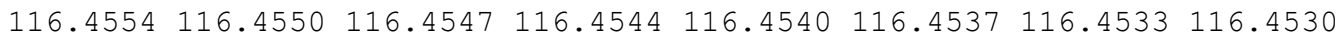

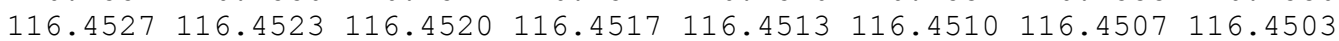

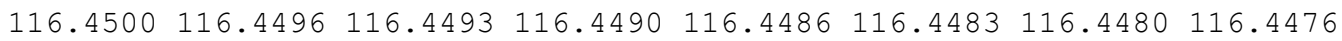

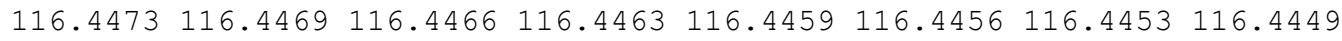

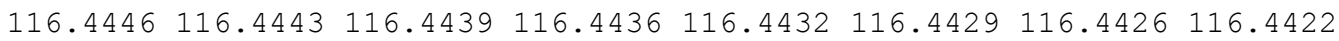

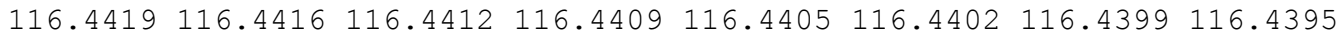
$116.4392 \quad 116.4389116 .4385116 .4382 \quad 116.4379 \quad 116.4375 \quad 116.4372 \quad 116.4368$

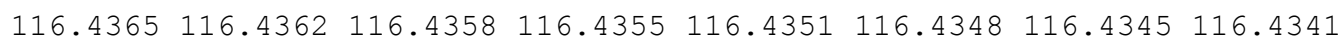

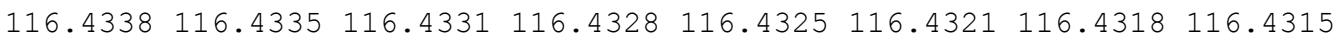
$116.4311 \quad 116.4308 \quad 116.4304 \quad 116.4301 \quad 116.4298116 .4294 \quad 116.4291116 .4287$ 


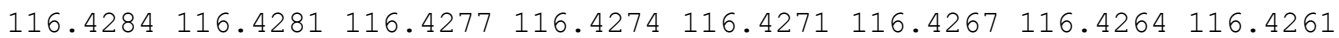

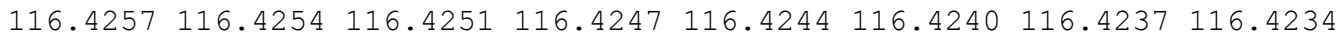

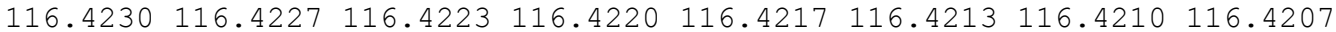

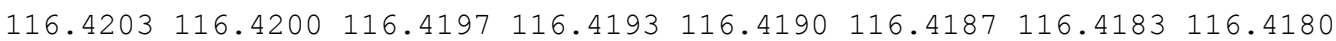
$116.4176 \quad 116.4173 \quad 116.4170 \quad 116.4166 \quad 116.4163 \quad 116.4160116 .4156 \quad 116.4153$

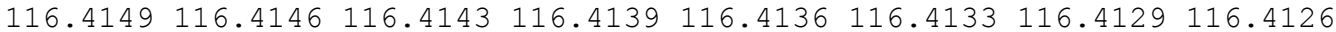
$116.4123116 .4119116 .4116 \quad 116.4112 \quad 116.4109 \quad 116.4106 \quad 116.4102116 .4099$ $116.4096116 .4092116 .4089116 .4085116 .4082 \quad 116.4079116 .4075116 .4072$ $116.4069116 .4065116 .4062 \quad 116.4058 \quad 116.4055 \quad 116.4052 \quad 116.4048116 .4045$ $116.4042116 .4038116 .4035116 .4032 \quad 116.4028116 .4025116 .4021116 .4018$

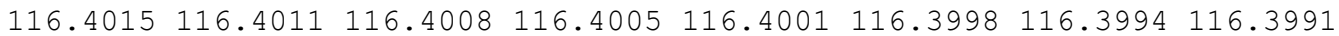

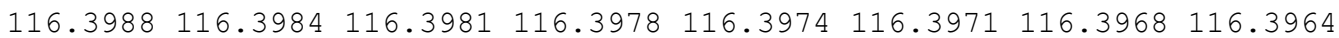

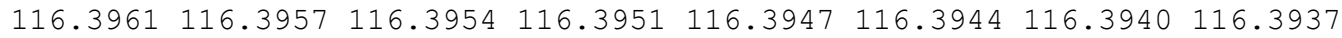

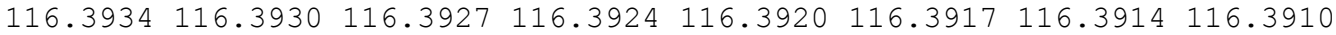

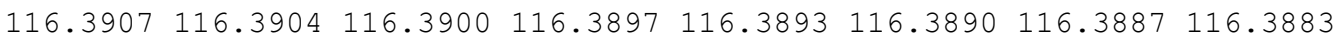

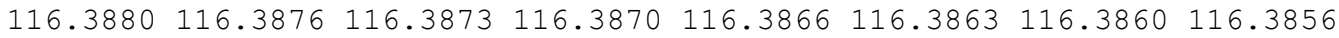

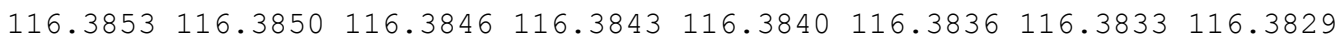
$116.3826116 .3823 \quad 116.3819 \quad 116.3816 \quad 116.3812 \quad 116.3809116 .3806 \quad 116.3802$

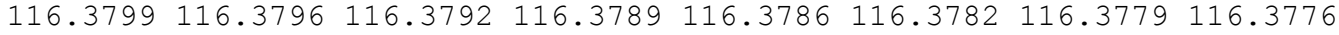
$116.3772 \quad 116.3769116 .3765 \quad 116.3762 \quad 116.3759 \quad 116.3755 \quad 116.3752$

$116.4985116 .4982 \quad 116.4978 \quad 116.4975 \quad 116.4971 \quad 116.4968 \quad 116.4965 \quad 116.4961$

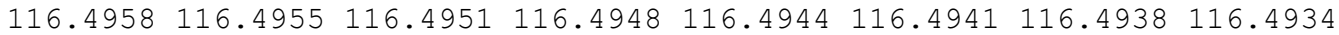

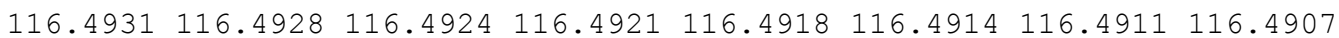
$116.4904 \quad 116.4901 \quad 116.4897 \quad 116.4894 \quad 116.4891 \quad 116.4887 \quad 116.4884 \quad 116.4880$

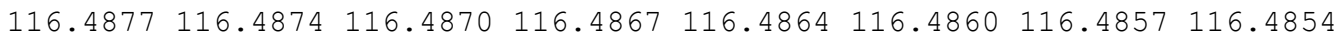

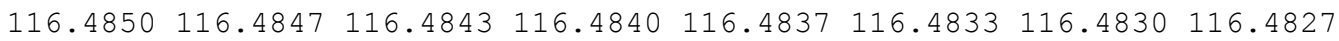
$116.4823116 .4820116 .4816 \quad 116.4813 \quad 116.4810 \quad 116.4806 \quad 116.4803 \quad 116.4800$

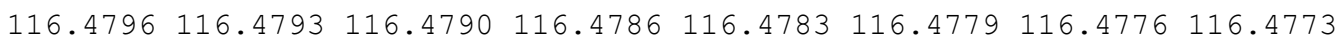

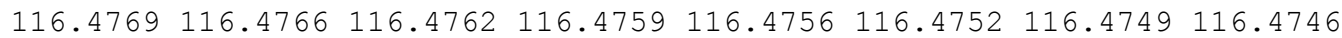

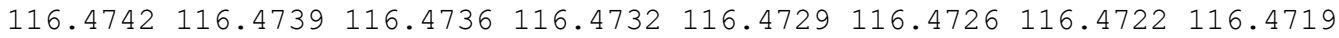

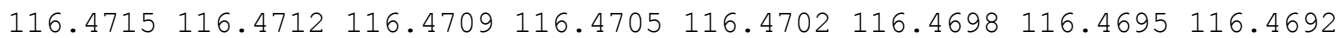

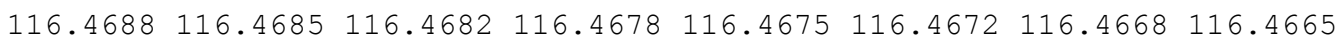

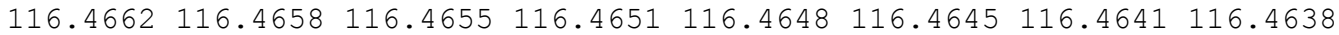

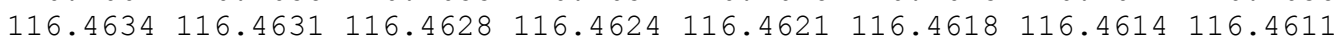
$116.4608 \quad 116.4604 \quad 116.4601 \quad 116.4598 \quad 116.4594 \quad 116.4591 \quad 116.4587 \quad 116.4584$

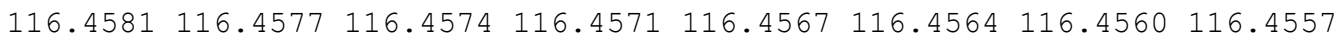

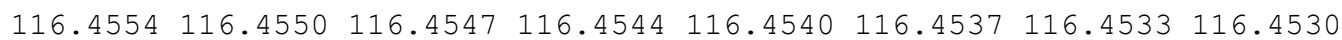

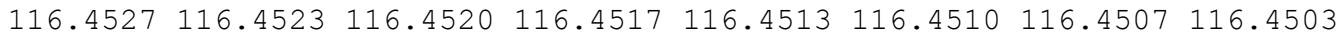

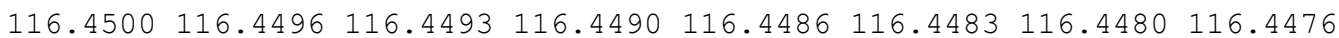

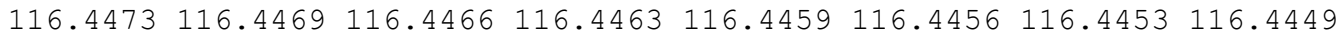

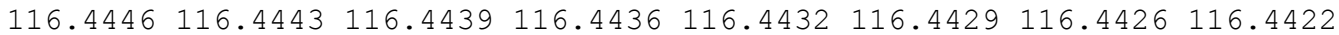

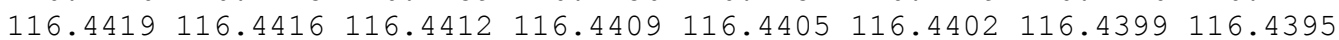
$116.4392 \quad 116.4389116 .4385116 .4382 \quad 116.4379116 .4375 \quad 116.4372 \quad 116.4368$ $116.4365116 .4362116 .4358 \quad 116.4355116 .4351 \quad 116.4348116 .4345116 .4341$

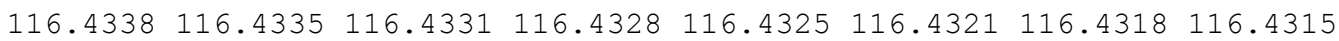

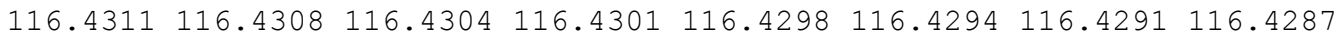
$116.4284116 .4281 \quad 116.4277 \quad 116.4274 \quad 116.4271 \quad 116.4267 \quad 116.4264116 .4261$

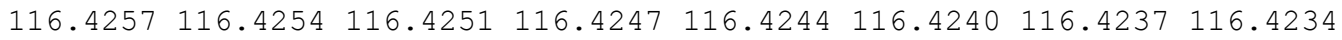

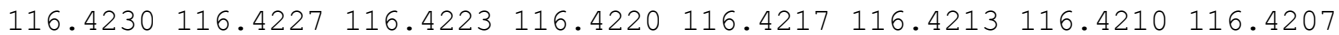

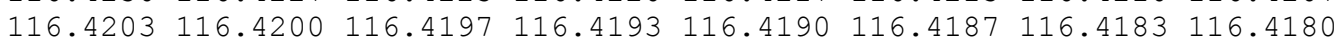
$116.4176116 .4173 \quad 116.4170 \quad 116.4166 \quad 116.4163 \quad 116.4160116 .4156116 .4153$

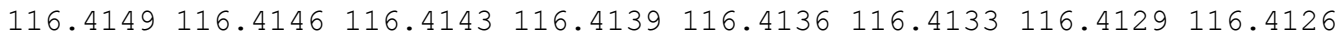

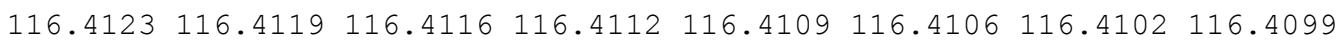
$116.4096116 .4092116 .4089116 .4085116 .4082 \quad 116.4079116 .4075116 .4072$

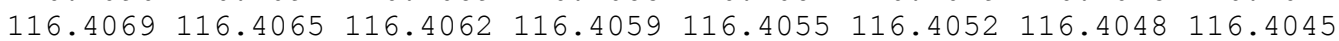
$116.4042116 .4038116 .4035116 .4032 \quad 116.4028 \quad 116.4025116 .4021 \quad 116.4018$ $116.4015116 .4011 \quad 116.4008 \quad 116.4005 \quad 116.4001 \quad 116.3998116 .3995116 .3991$ $116.3988 \quad 116.3984 \quad 116.3981 \quad 116.3978 \quad 116.3974 \quad 116.3971 \quad 116.3968116 .3964$

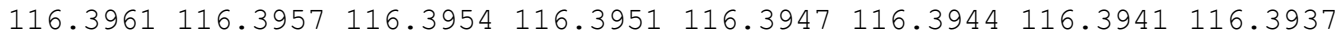

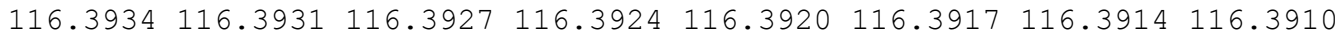
$\begin{array}{llllllll}116.3907 & 116.3904 & 116.3900 & 116.3897 & 116.3893 & 116.3890 & 116.3887 & 116.3883\end{array}$

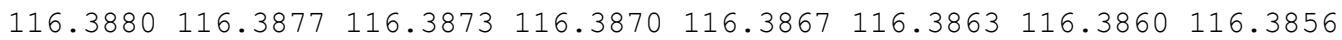
$116.3853116 .3850116 .3846 \quad 116.3843 \quad 116.3840 \quad 116.3836116 .3833116 .3829$ 
$116.3826116 .3823 \quad 116.3819 \quad 116.3816 \quad 116.3813 \quad 116.3809 \quad 116.3806 \quad 116.3803$

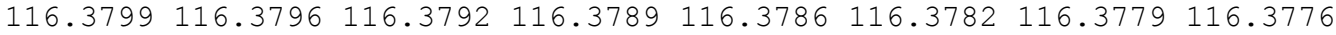
$116.3772116 .3769116 .3765116 .3762 \quad 116.3759 \quad 116.3755116 .3752$

- Example listing of 30MSLOPE.ASC: ARCINFO ASCII grid format input file for ground surface slope, in degrees (only the 6 header lines and the first 3 lines of the input matrix are listed).

\begin{tabular}{|c|c|c|c|c|c|c|c|c|c|c|c|c|}
\hline nco & & & & 367 & & & & & & & & \\
\hline nro & & & & 691 & & & & & & & & \\
\hline$x 11$ & rner & & 5446 & 561.000 & 000 & & & & & & & \\
\hline yll & rner & & 40671 & 33.000 & 000 & & & & & & & \\
\hline $\mathrm{cel}$ & ize & & & 30.000 & 000 & & & & & & & \\
\hline NOD & A_va & lue & & -9999 & & & & & & & & \\
\hline & $1^{-}$ & 25 & 26 & 24 & 25 & 28 & 28 & 24 & 16 & 13 & 21 & 20 \\
\hline 16 & 19 & 22 & 20 & 20 & 21 & 23 & 23 & 22 & 16 & 10 & 18 & 27 \\
\hline 27 & 25 & 23 & 15 & 9 & 14 & 19 & 21 & 23 & 24 & 23 & 23 & 24 \\
\hline 26 & 27 & 23 & 19 & 21 & 24 & 25 & 26 & 30 & 36 & 37 & 33 & 30 \\
\hline 25 & 28 & 36 & 34 & 32 & 31 & 29 & 24 & 20 & 21 & 28 & 34 & 35 \\
\hline 33 & 32 & 30 & 27 & 25 & 23 & 22 & 20 & 17 & 15 & 15 & 16 & 14 \\
\hline 13 & 13 & 11 & 14 & 17 & 16 & 11 & 13 & 20 & 22 & 22 & 19 & 16 \\
\hline 15 & 16 & 18 & 20 & 18 & 16 & 17 & 19 & 21 & 22 & 20 & 19 & 20 \\
\hline 22 & 21 & 18 & 16 & 18 & 22 & 26 & 30 & 29 & 28 & 30 & 29 & 21 \\
\hline 19 & 23 & 24 & 24 & 23 & 23 & 26 & 26 & 26 & 28 & 30 & 28 & 26 \\
\hline 25 & 26 & 26 & 27 & 30 & 33 & 32 & 32 & 30 & 30 & 34 & 37 & 35 \\
\hline 33 & 32 & 32 & 32 & 32 & 32 & 33 & 35 & 38 & 38 & 36 & 32 & 26 \\
\hline 23 & 26 & 27 & 25 & 24 & 28 & 33 & 33 & 29 & 25 & 23 & 20 & 17 \\
\hline 15 & 16 & 17 & 17 & 18 & 18 & 16 & 11 & 12 & 19 & 18 & 16 & 16 \\
\hline 19 & 22 & 20 & 11 & 8 & 18 & 27 & 32 & 36 & 39 & 40 & 41 & 40 \\
\hline 32 & 17 & 14 & 24 & 28 & 28 & 32 & 37 & 33 & 19 & 18 & 26 & 26 \\
\hline 25 & 27 & 30 & 26 & 18 & 19 & 24 & 22 & 18 & 22 & 26 & 28 & 29 \\
\hline 31 & 31 & 31 & 32 & 29 & 24 & 21 & 22 & 25 & 29 & 32 & 37 & 38 \\
\hline 34 & 31 & 31 & 31 & 32 & 30 & 26 & 19 & 18 & 29 & 35 & 35 & 31 \\
\hline 28 & 30 & 33 & 35 & 36 & 32 & 19 & 11 & 18 & 22 & 23 & 21 & 17 \\
\hline 18 & 20 & 18 & 14 & 15 & 19 & 25 & 27 & 26 & 26 & 25 & 17 & 13 \\
\hline 21 & 28 & 30 & 35 & 43 & 46 & 42 & 39 & 35 & 25 & 14 & 12 & 12 \\
\hline 12 & 12 & 13 & 12 & 11 & 10 & 11 & 12 & 13 & 14 & 16 & 13 & 10 \\
\hline 12 & 15 & 16 & 14 & 13 & 15 & 17 & 17 & 15 & 14 & 14 & 15 & 16 \\
\hline 16 & 15 & 13 & 11 & 10 & 11 & 15 & 17 & 19 & 18 & 18 & 19 & 20 \\
\hline 19 & 16 & 15 & 14 & 15 & 16 & 16 & 17 & 21 & 23 & 22 & 19 & 16 \\
\hline 13 & 14 & 16 & 17 & 18 & 21 & 19 & 15 & 12 & 9 & 8 & 7 & 11 \\
\hline 15 & 15 & 16 & 16 & 17 & 16 & 16 & 14 & 12 & 13 & 18 & 18 & 7 \\
\hline 7 & 1 & 2 & 2 & & & & & & & & & \\
\hline & 4 & 28 & 28 & 26 & 27 & 28 & 26 & 19 & 11 & 14 & 20 & 18 \\
\hline 15 & 17 & 22 & 20 & 21 & 22 & 23 & 24 & 21 & 13 & 8 & 15 & 27 \\
\hline 28 & 27 & 25 & 18 & 10 & 12 & 17 & 20 & 22 & 24 & 21 & 20 & 24 \\
\hline 26 & 25 & 19 & 17 & 23 & 25 & 25 & 26 & 30 & 35 & 37 & 33 & 27 \\
\hline 23 & 28 & 35 & 35 & 33 & 30 & 28 & 24 & 16 & 12 & 19 & 32 & 36 \\
\hline 35 & 33 & 31 & 28 & 25 & 25 & 25 & 22 & 17 & 14 & 15 & 17 & 15 \\
\hline 12 & 12 & 12 & 14 & 18 & 15 & 11 & 14 & 20 & 21 & 21 & 18 & 16 \\
\hline 15 & 16 & 17 & 17 & 14 & 15 & 17 & 18 & 22 & 23 & 20 & 17 & 17 \\
\hline 17 & 17 & 15 & 15 & 19 & 21 & 25 & 30 & 30 & 27 & 27 & 28 & 24 \\
\hline 23 & 24 & 23 & 21 & 21 & 21 & 24 & 25 & 28 & 30 & 31 & 28 & 24 \\
\hline 23 & 25 & 22 & 21 & 26 & 27 & 28 & 28 & 27 & 26 & 29 & 33 & 32 \\
\hline 31 & 30 & 30 & 30 & 30 & 31 & 32 & 34 & 38 & 39 & 35 & 29 & 24 \\
\hline 26 & 31 & 31 & 30 & 28 & 26 & 28 & 30 & 28 & 25 & 23 & 20 & 15 \\
\hline 12 & 14 & 18 & 22 & 25 & 26 & 28 & 28 & 23 & 17 & 14 & 15 & 17 \\
\hline 18 & 14 & 12 & 17 & 22 & 18 & 15 & 27 & 35 & 40 & 42 & 43 & 44 \\
\hline 41 & 32 & 19 & 13 & 20 & 25 & 28 & 35 & 38 & 31 & 18 & 13 & 19 \\
\hline 23 & 28 & 31 & 29 & 24 & 21 & 23 & 23 & 21 & 21 & 25 & 26 & 29 \\
\hline 31 & 31 & 32 & 32 & 29 & 23 & 20 & 22 & 29 & 34 & 38 & 40 & 38 \\
\hline 33 & 32 & 32 & 32 & 32 & 30 & 28 & 22 & 18 & 28 & 33 & 33 & 30 \\
\hline
\end{tabular}




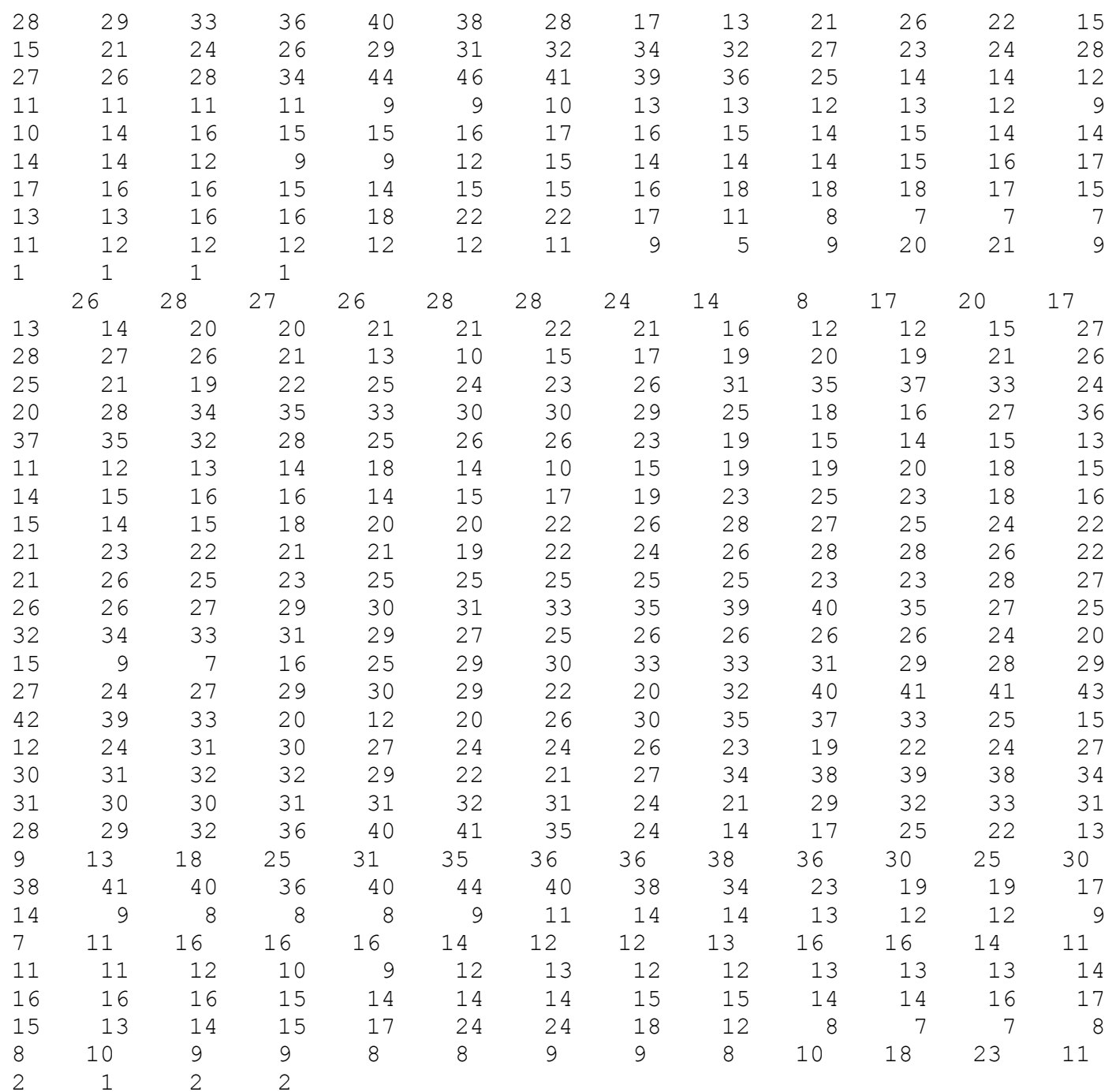

- Example listing of 30MASPCT.ASC: ARCINFO ASCII grid format input file for ground surface aspect, in degrees (only the 6 header lines and the first 3 lines of the input matrix are listed).

\begin{tabular}{|c|c|c|c|c|c|c|c|c|c|c|c|c|}
\hline $\mathrm{COI}$ & & & & 367 & & & & & & & & \\
\hline row & & & & 691 & & & & & & & & \\
\hline 110 & rner & & 5446 & 561.0000 & 000 & & & & & & & \\
\hline 110 & rner & & 40671 & 33.0000 & 000 & & & & & & & \\
\hline ell & ize & & & 30.0000 & 000 & & & & & & & \\
\hline $\mathrm{ODA}$ & A_va. & & & -9999 & & & & & & & & \\
\hline & & & 269 & 277 & 284 & 286 & 284 & 277 & 241 & 169 & 127 & 28 \\
\hline 66 & 220 & 232 & 224 & 204 & 188 & 178 & 162 & 141 & 136 & 122 & 88 & 85 \\
\hline 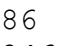 & 88 & 93 & 117 & 174 & 218 & 225 & 225 & 224 & 218 & 202 & 204 & 226 \\
\hline 46 & 253 & 244 & 220 & 193 & 180 & 187 & 208 & 229 & 242 & 247 & 247 & 241 \\
\hline 06 & 147 & 125 & 130 & 143 & 149 & 139 & 118 & 92 & 66 & 57 & 62 & 70 \\
\hline 6 & 80 & 82 & 84 & 84 & 87 & 98 & 113 & 128 & 137 & 128 & 116 & 129 \\
\hline 177 & 206 & 166 & 120 & 120 & 120 & 167 & 251 & 262 & 263 & 259 & 249 & 229 \\
\hline 03 & 179 & 161 & 152 & 170 & 205 & 229 & 228 & 223 & 220 & 209 & 192 & 189 \\
\hline 92 & 184 & 180 & 206 & 244 & 255 & 257 & 258 & 257 & 255 & 251 & 243 & 205 \\
\hline & 148 & 166 & 185 & 179 & 160 & 159 & 169 & 158 & 132 & 122 & 136 & 160 \\
\hline & 208 & 203 & 181 & 159 & 146 & 141 & 141 & 149 & 176 & 204 & 207 & 196 \\
\hline 36 & 191 & 201 & 206 & 211 & 223 & 232 & 238 & 245 & 251 & 253 & 246 & 221 \\
\hline
\end{tabular}




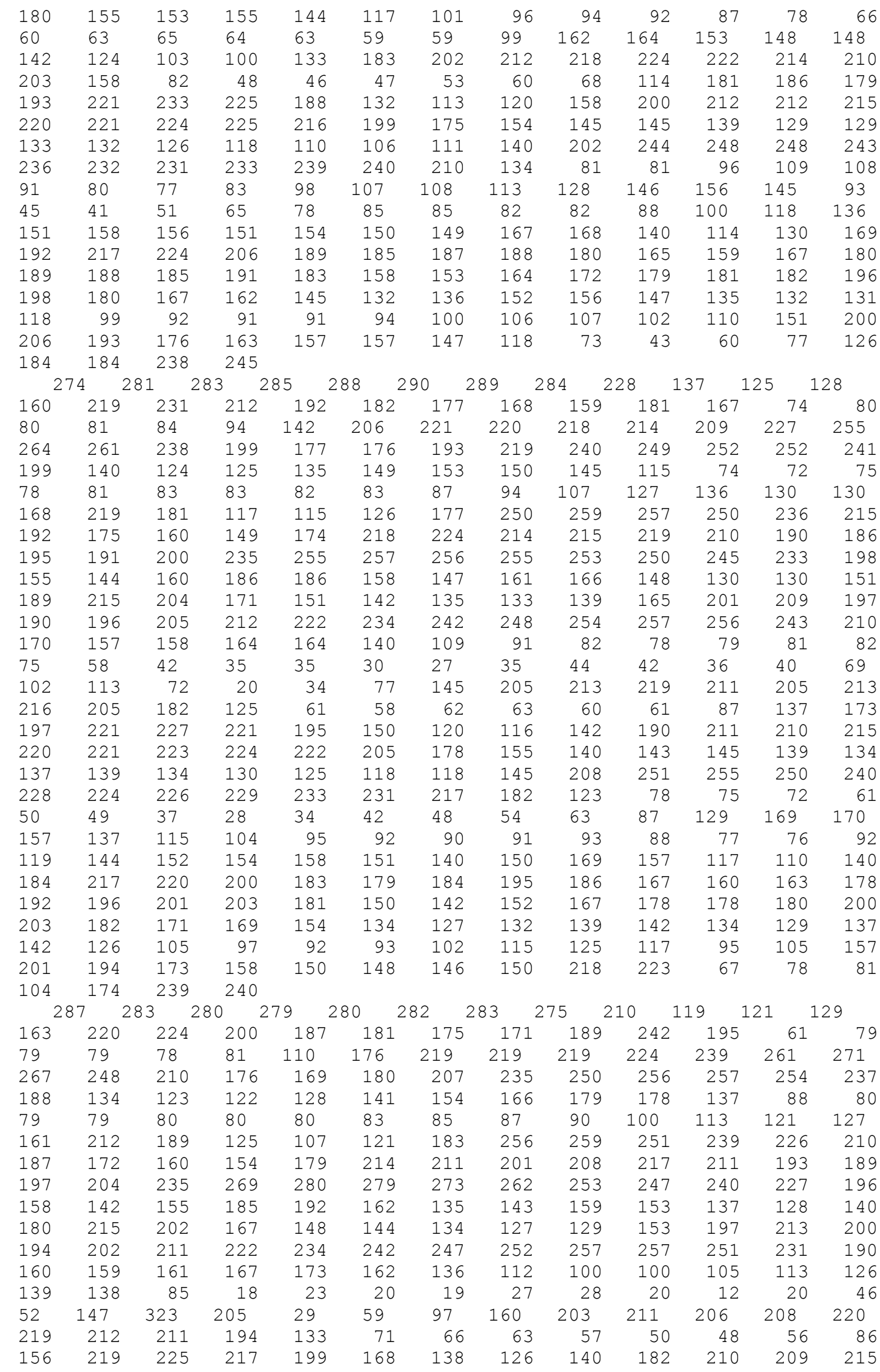




$\begin{array}{llllllllllllr}220 & 223 & 225 & 231 & 232 & 208 & 173 & 155 & 140 & 138 & 143 & 144 & 139 \\ 135 & 136 & 134 & 130 & 129 & 128 & 128 & 157 & 219 & 247 & 245 & 238 & 229 \\ 221 & 220 & 223 & 225 & 228 & 225 & 220 & 220 & 172 & 85 & 80 & 79 & 78 \\ 73 & 54 & 24 & 10 & 22 & 34 & 41 & 48 & 58 & 68 & 85 & 122 & 161 \\ 171 & 166 & 155 & 138 & 110 & 95 & 92 & 90 & 81 & 60 & 47 & 59 & 69 \\ 81 & 97 & 116 & 135 & 152 & 153 & 138 & 135 & 160 & 176 & 147 & 116 & 119 \\ 161 & 210 & 212 & 193 & 181 & 182 & 196 & 204 & 183 & 167 & 163 & 168 & 183 \\ 196 & 204 & 216 & 209 & 171 & 141 & 135 & 142 & 160 & 174 & 174 & 180 & 203 \\ 203 & 180 & 173 & 175 & 165 & 143 & 125 & 118 & 120 & 126 & 126 & 122 & 130 \\ 152 & 150 & 117 & 101 & 96 & 93 & 99 & 113 & 135 & 152 & 134 & 103 & 122 \\ 176 & 197 & 174 & 153 & 142 & 134 & 131 & 159 & 223 & 191 & 81 & 81 & 78 \\ 97 & 169 & 234 & 246 & & & & & & & & & \end{array}$

- Example listing of 30MELEV.ASC: ARCINFO ASCII grid format input file for ground surface elevation, in meters (only the 6 header lines and the first 3 lines of the input matrix are listed).

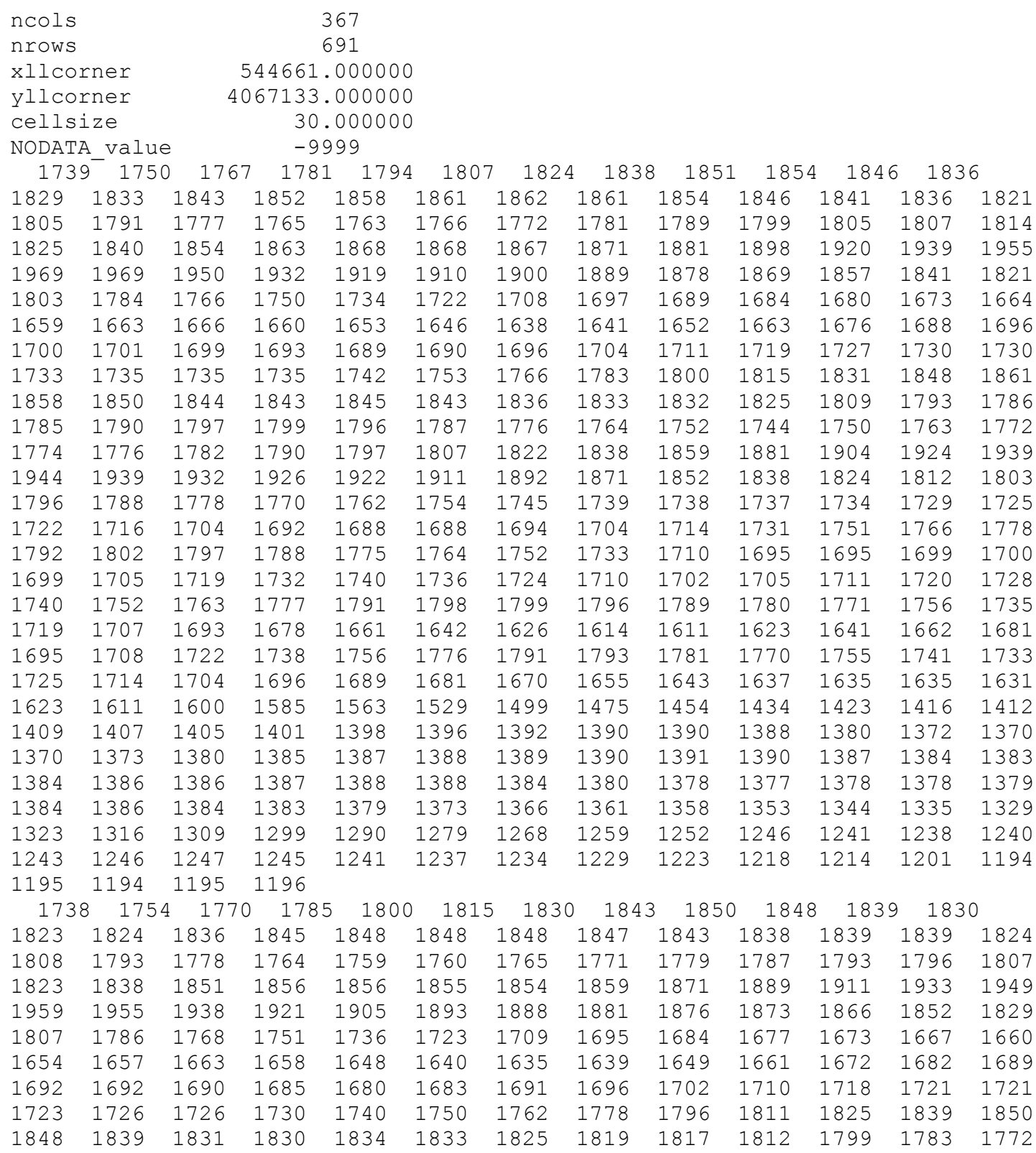




\begin{tabular}{|c|c|c|c|c|c|c|c|c|c|c|c|c|}
\hline 1770 & 1777 & 1787 & 1788 & 1782 & 1774 & 1763 & 1750 & 1739 & 1732 & 1733 & 1743 & 1751 \\
\hline 1755 & 1758 & 1764 & 1772 & 1783 & 1797 & 1813 & 1829 & 1850 & 1876 & 1899 & 1917 & 1929 \\
\hline 931 & 1924 & 1916 & 1910 & 1907 & 1902 & 1889 & 1871 & 1853 & 1839 & 1827 & 1816 & 808 \\
\hline 01 & 1794 & 1787 & 1780 & 1771 & 1763 & 1757 & 1749 & 1738 & 1733 & 1730 & 1728 & 724 \\
\hline 715 & 1706 & 1701 & 1697 & 1696 & 1688 & 1682 & 1690 & 1700 & 1714 & 1732 & 1741 & 5 \\
\hline & 1785 & 1794 & 1793 & 1784 & 1773 & 1761 & 1744 & 1723 & 1701 & 1686 & 1684 & \\
\hline 35 & 1694 & 1708 & 1721 & 1731 & 1730 & 1719 & 1707 & 1696 & 1692 & 1699 & .707 & \\
\hline 26 & 1737 & 1750 & 1763 & 1775 & 1785 & 1787 & 1785 & 1777 & 1765 & 1754 & 1739 & \\
\hline 03 & 1692 & 1680 & 1665 & 1652 & 1637 & 1622 & 1608 & 1605 & 1617 & 1635 & 1655 & 2 \\
\hline 35 & 1696 & 1708 & 1723 & 1744 & 1765 & 1779 & 1784 & 1783 & 1773 & 1759 & 1745 & \\
\hline 733 & 1726 & 1714 & 1707 & 1700 & 1690 & 1678 & 1664 & 1647 & 1631 & 1617 & 1617 & \\
\hline 524 & 1621 & 1608 & 1588 & 1563 & 1526 & 1500 & 1476 & 452 & 1431 & 1422 & 1416 & \\
\hline 3 & 1400 & 1397 & 1395 & 1393 & 1392 & 1389 & 1385 & 1382 & 1382 & 378 & 369 & \\
\hline 4 & 1367 & 1374 & 1379 & 1379 & 1379 & 1378 & 1379 & 1383 & 1382 & 1380 & 377 & \\
\hline 376 & 1378 & 1380 & 1382 & 1384 & 1383 & 1377 & 1372 & 1370 & 1369 & 1370 & 1369 & \\
\hline 5 & 1378 & 1376 & 1375 & 1374 & 1369 & 1361 & 1355 & 1347 & 1341 & 1336 & 1329 & \\
\hline 9 & 1316 & 1307 & 1298 & 1289 & 1277 & 1264 & 1255 & 1249 & 1246 & 1242 & 1237 & \\
\hline 236 & 1239 & 1239 & 1237 & 1234 & 1231 & 1228 & 1225 & 1224 & 1224 & 1218 & 203 & \\
\hline 4 & 1194 & 1194 & 1195 & & & & & & & & & \\
\hline 1742 & 1758 & 1774 & 1788 & 0 & 1820 & 10 & 104 & 1 & 184 & 10 & 182 & \\
\hline 818 & 1819 & 1828 & 1834 & 1836 & 1836 & 1836 & 1834 & 1831 & 1833 & 1841 & 1840 & 827 \\
\hline 811 & 1795 & 1780 & 1766 & 1757 & 1753 & 1759 & 1764 & 1770 & 1776 & 1783 & 1793 & 308 \\
\hline 823 & 1837 & 1846 & 1846 & 1842 & 1838 & 1840 & 1850 & 1865 & 1884 & 1905 & 1927 & 943 \\
\hline 951 & 1944 & 1928 & 1910 & 1891 & 1879 & 1870 & 1865 & 1864 & 1866 & 1865 & 1854 & 834 \\
\hline 811 & 1789 & 1770 & 1753 & 1739 & 1726 & 1710 & 1696 & 1684 & 1675 & 1668 & 1660 & 5 \\
\hline 51 & 1652 & 1658 & 1655 & 1645 & 1635 & 1631 & 1637 & 1648 & 1658 & 1669 & 1677 & \\
\hline 684 & 1683 & 1682 & 1678 & 1675 & 1679 & 1684 & 1688 & 1691 & 1699 & 1708 & 1712 & \\
\hline 714 & 1717 & 1719 & 1728 & 1737 & 1748 & 1760 & 1774 & 1790 & 1806 & 1819 & 1830 & 7 \\
\hline 1836 & 1828 & 1821 & 1819 & 1823 & 1823 & 1816 & 1805 & 1800 & 1796 & 1787 & 1775 & .764 \\
\hline 1760 & 1767 & 1777 & 1778 & 1770 & 1763 & 1754 & 1742 & 1730 & 1720 & 1718 & 1729 & 736 \\
\hline 739 & 1743 & 1750 & 1760 & 1771 & 1786 & 1804 & 1824 & 1845 & 1870 & 1894 & 1911 & 8 \\
\hline 13 & 1904 & 1898 & 1892 & 1889 & 1889 & 1883 & 1872 & 1858 & 1844 & 1829 & 1815 & \\
\hline 798 & 1795 & 1794 & 1791 & 1786 & 1779 & 1775 & 1768 & 1758 & 1748 & 1743 & 1742 & \\
\hline 716 & 1705 & 1706 & 1713 & 1712 & 1699 & 1681 & 1674 & 1679 & 1692 & 1705 & 1713 & -1 \\
\hline 1751 & 1766 & 1778 & 1788 & 1789 & 1779 & 1766 & 1752 & 1736 & 1718 & 1701 & 1686 & 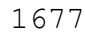 \\
\hline 1675 & 1681 & 1694 & 1707 & 1716 & 1719 & 1712 & 1701 & 1687 & 1681 & 1689 & 1694 & 1702 \\
\hline .712 & 1723 & 1736 & 1749 & 1765 & 1777 & 1778 & 1775 & 1765 & 1747 & 1730 & 1716 & 1704 \\
\hline 691 & 1678 & 1667 & 1653 & 1639 & 1626 & 1612 & 1598 & 1598 & 1614 & 1631 & 1649 & 3 \\
\hline 674 & 1683 & 1695 & 1709 & 1725 & 1746 & 1764 & 1774 & 1780 & 1776 & 1763 & 1749 & \\
\hline 1734 & 1729 & 1724 & 1724 & 1719 & 1708 & 1695 & 1681 & 1664 & 1642 & 1620 & 1605 & 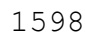 \\
\hline 1596 & 1593 & 1587 & 1576 & 1560 & 1527 & 1500 & 1475 & 1450 & 1432 & 1429 & 1421 & 141 \\
\hline 1403 & 1397 & 1394 & 1391 & 1389 & 1388 & 1385 & 1379 & 1374 & 1376 & 1376 & 1370 & 1363 \\
\hline 1359 & 1361 & 1367 & 1370 & 1370 & 1370 & 1370 & 1373 & 1376 & 1375 & 1372 & 1369 & 1369 \\
\hline 369 & 1371 & 1375 & 1379 & 1380 & 1377 & 1372 & 1367 & 1364 & 1363 & 1362 & 1361 & \\
\hline 367 & 1369 & 1367 & 1367 & 1365 & 1363 & 1357 & 1350 & 1343 & 1337 & 1331 & 1325 & \\
\hline 311 & 1310 & 1304 & 1297 & 1290 & 1279 & 1263 & 1251 & 1244 & 1242 & 1241 & 1238 & \\
\hline 1231 & 1233 & 1234 & 1232 & 1230 & 1227 & 1224 & 1220 & 1222 & 1228 & 1222 & 1206 & 11 \\
\hline 194 & 1194 & 1194 & 1195 & & & & & & & & & \\
\hline
\end{tabular}

- Example listing of 30MSOIL.ASC: ARCINFO ASCII grid format input file for soil type identification (only the 6 header lines and the first 3 lines of the input matrix are listed).

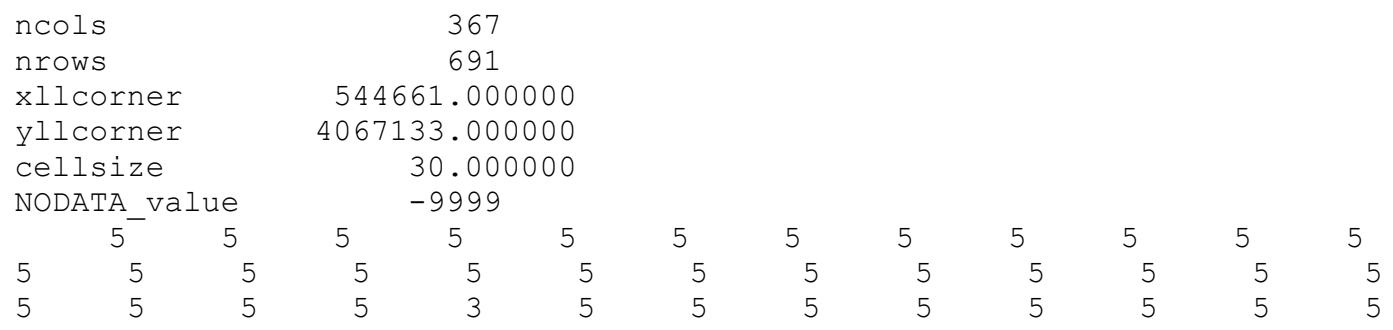




\begin{tabular}{|c|c|c|c|c|c|c|c|c|c|c|c|c|}
\hline 5 & 5 & 5 & 5 & 5 & 5 & 5 & 5 & 5 & 5 & 5 & 5 & 5 \\
\hline 5 & 5 & 5 & 5 & 5 & 5 & 5 & 5 & 5 & 5 & 5 & 5 & 5 \\
\hline 5 & 5 & 5 & 5 & 5 & 5 & 5 & 5 & 5 & 5 & 5 & 5 & 5 \\
\hline 5 & 5 & 5 & 5 & 5 & 5 & 5 & 5 & 5 & 5 & 5 & 5 & 5 \\
\hline 5 & 5 & 5 & 5 & 5 & 5 & 5 & 5 & 5 & 5 & 5 & 5 & 5 \\
\hline 5 & 5 & 5 & 5 & 5 & 5 & 5 & 5 & 5 & 5 & 5 & 5 & 5 \\
\hline 5 & 5 & 5 & 5 & 5 & 5 & 5 & 5 & 5 & 5 & 5 & 5 & 5 \\
\hline 5 & 5 & 5 & 5 & 5 & 5 & 5 & 5 & 5 & 5 & 5 & 5 & 5 \\
\hline 5 & 5 & 5 & 5 & 5 & 5 & 5 & 5 & 5 & 5 & 5 & 5 & 5 \\
\hline 5 & 5 & 5 & 5 & 5 & 5 & 5 & 5 & 5 & 5 & 5 & 5 & 5 \\
\hline 5 & 5 & 5 & 5 & 5 & 5 & 5 & 5 & 5 & 5 & 5 & 5 & 5 \\
\hline 5 & 5 & 5 & 4 & 4 & 9 & 9 & 9 & 5 & 5 & 5 & 5 & 5 \\
\hline 5 & 5 & 5 & 5 & 5 & 5 & 5 & 5 & 5 & 5 & 5 & 5 & 5 \\
\hline 5 & 5 & 5 & 5 & 5 & 5 & 5 & 5 & 9 & 9 & 9 & 9 & 9 \\
\hline 9 & 5 & 5 & 5 & 5 & 5 & 5 & 5 & 5 & 5 & 5 & 5 & 5 \\
\hline 5 & 5 & 5 & 5 & 5 & 5 & 5 & 5 & 5 & 5 & 5 & 5 & 5 \\
\hline 5 & 5 & 5 & 5 & 5 & 5 & 5 & 5 & 5 & 5 & 5 & 5 & 5 \\
\hline 5 & 5 & 5 & 5 & 5 & 5 & 5 & 5 & 5 & 5 & 5 & 5 & 5 \\
\hline 5 & 5 & 5 & 5 & 5 & 5 & 5 & 5 & 5 & 5 & 3 & 3 & 3 \\
\hline 3 & 2 & 2 & 2 & 2 & 2 & 2 & 5 & 5 & 5 & 5 & 5 & 5 \\
\hline 5 & 5 & 5 & 5 & 5 & 5 & 5 & 5 & 5 & 2 & 5 & 9 & 9 \\
\hline 9 & 9 & 9 & 9 & 5 & 5 & 5 & 5 & 5 & 5 & 9 & 9 & 5 \\
\hline 5 & 5 & 5 & 5 & 5 & 5 & 5 & 5 & 5 & 5 & 5 & 5 & 5 \\
\hline 5 & 5 & 5 & 5 & 5 & 5 & 5 & 1 & 1 & 1 & 2 & 5 & 1 \\
\hline 1 & 1 & 1 & 1 & 1 & 1 & 5 & 5 & 5 & 5 & 5 & 3 & 3 \\
\hline \multirow[t]{2}{*}{4} & 4 & 3 & 3 & & & & & & & & & \\
\hline & 5 & 5 & 5 & 5 & 5 & 5 & 5 & 5 & 5 & 5 & 5 & 5 \\
\hline 5 & 5 & 5 & 5 & 5 & 5 & 5 & 5 & 5 & 5 & 5 & 5 & 5 \\
\hline 5 & 5 & 5 & 5 & 3 & 5 & 5 & 5 & 5 & 5 & 5 & 5 & 5 \\
\hline 5 & 5 & 5 & 5 & 5 & 5 & 5 & 5 & 5 & 5 & 5 & 5 & 5 \\
\hline 5 & 5 & 5 & 5 & 5 & 5 & 5 & 5 & 5 & 5 & 5 & 5 & 5 \\
\hline 5 & 5 & 5 & 5 & 5 & 5 & 5 & 5 & 5 & 5 & 5 & 5 & 5 \\
\hline 5 & 5 & 5 & 5 & 5 & 5 & 5 & 5 & 5 & 5 & 5 & 5 & 5 \\
\hline 5 & 5 & 5 & 5 & 5 & 5 & 5 & 5 & 5 & 5 & 5 & 5 & 5 \\
\hline 5 & 5 & 5 & 5 & 5 & 5 & 5 & 5 & 5 & 5 & 5 & 5 & 5 \\
\hline 5 & 5 & 5 & 5 & 5 & 5 & 5 & 5 & 5 & 5 & 5 & 5 & 5 \\
\hline 5 & 5 & 5 & 5 & 5 & 5 & 5 & 5 & 5 & 5 & 5 & 5 & 5 \\
\hline 5 & 5 & 5 & 5 & 5 & 5 & 5 & 5 & 5 & 5 & 5 & 5 & 5 \\
\hline 5 & 5 & 5 & 5 & 5 & 5 & 5 & 5 & 5 & 5 & 5 & 5 & 5 \\
\hline 5 & 5 & 5 & 5 & 5 & 5 & 5 & 5 & 5 & 5 & 5 & 5 & 5 \\
\hline 5 & 5 & 4 & 5 & 5 & 5 & 9 & 9 & 9 & 5 & 5 & 5 & 5 \\
\hline 5 & 5 & 5 & 5 & 5 & 5 & 5 & 5 & 5 & 5 & 5 & 5 & 5 \\
\hline 5 & 5 & 5 & 5 & 5 & 5 & 5 & 5 & 9 & 9 & 9 & 9 & 9 \\
\hline 9 & 9 & 9 & 5 & 5 & 5 & 5 & 5 & 5 & 5 & 5 & 5 & 5 \\
\hline 9 & 5 & 5 & 5 & 5 & 5 & 5 & 5 & 5 & 5 & 5 & 5 & 5 \\
\hline 5 & 5 & 5 & 5 & 5 & 5 & 5 & 5 & 5 & 5 & 5 & 5 & 5 \\
\hline 5 & 5 & 5 & 5 & 5 & 5 & 5 & 5 & 5 & 5 & 5 & 5 & 5 \\
\hline 5 & 5 & 5 & 5 & 5 & 5 & 5 & 5 & 5 & 5 & 3 & 3 & 3 \\
\hline 3 & 3 & 2 & 2 & 2 & 2 & 2 & 5 & 5 & 5 & 5 & 5 & 5 \\
\hline 5 & 5 & 5 & 5 & 5 & 5 & 5 & 5 & 5 & 2 & 5 & 9 & 9 \\
\hline 9 & 9 & 9 & 9 & 5 & 5 & 5 & 5 & 9 & 9 & 9 & 9 & 9 \\
\hline 5 & 5 & 5 & 5 & 5 & 5 & 5 & 5 & 5 & 5 & 5 & 5 & 5 \\
\hline 5 & 5 & 5 & 5 & 5 & 5 & 5 & 9 & 1 & 1 & 1 & 2 & 3 \\
\hline 1 & 1 & 1 & 1 & 1 & 1 & 1 & 5 & 5 & 5 & 5 & 5 & 3 \\
\hline \multirow[t]{2}{*}{4} & 3 & 3 & 3 & & & & & & & & & \\
\hline & 5 & 5 & 5 & 5 & 5 & 5 & 5 & 5 & 5 & 5 & 5 & 5 \\
\hline 5 & 5 & 5 & 5 & 5 & 5 & 5 & 5 & 5 & 5 & 5 & 5 & 5 \\
\hline 5 & 5 & 5 & 5 & 5 & 5 & 5 & 5 & 5 & 5 & 5 & 5 & 5 \\
\hline 5 & 5 & 5 & 5 & 5 & 5 & 5 & 5 & 5 & 5 & 5 & 5 & 5 \\
\hline 5 & 5 & 5 & 5 & 5 & 5 & 5 & 5 & 5 & 5 & 5 & 5 & 5 \\
\hline 5 & 5 & 5 & 5 & 5 & 5 & 5 & 5 & 5 & 5 & 5 & 5 & 5 \\
\hline 5 & 5 & 5 & 5 & 5 & 5 & 5 & 5 & 5 & 5 & 5 & 5 & 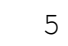 \\
\hline 5 & 5 & 5 & 5 & 5 & 5 & 5 & 5 & 5 & 5 & 5 & 5 & \\
\hline
\end{tabular}




$\begin{array}{lllllllllllll}5 & 5 & 5 & 5 & 5 & 5 & 5 & 5 & 5 & 5 & 5 & 5 & 5 \\ 5 & 5 & 5 & 5 & 5 & 5 & 5 & 5 & 5 & 5 & 5 & 5 & 5 \\ 5 & 5 & 5 & 5 & 5 & 5 & 5 & 5 & 5 & 5 & 5 & 5 & 5 \\ 5 & 5 & 5 & 5 & 5 & 5 & 5 & 5 & 5 & 5 & 5 & 5 & 5 \\ 5 & 5 & 5 & 5 & 5 & 5 & 5 & 5 & 5 & 5 & 5 & 5 & 5 \\ 5 & 5 & 5 & 5 & 5 & 5 & 5 & 5 & 5 & 5 & 5 & 5 & 5 \\ 5 & 5 & 5 & 5 & 5 & 5 & 5 & 9 & 9 & 9 & 5 & 5 & 5 \\ 5 & 5 & 5 & 5 & 5 & 5 & 5 & 5 & 5 & 5 & 5 & 5 & 5 \\ 5 & 5 & 5 & 5 & 5 & 5 & 5 & 9 & 9 & 9 & 9 & 9 & 9 \\ 9 & 9 & 9 & 5 & 5 & 5 & 5 & 5 & 5 & 5 & 5 & 9 & 9 \\ 9 & 9 & 9 & 5 & 5 & 9 & 9 & 5 & 5 & 5 & 5 & 5 & 5 \\ 5 & 5 & 5 & 5 & 5 & 5 & 5 & 5 & 5 & 5 & 5 & 5 & 5 \\ 5 & 5 & 5 & 5 & 5 & 5 & 5 & 5 & 5 & 5 & 5 & 5 & 5 \\ 5 & 5 & 5 & 5 & 5 & 5 & 5 & 5 & 5 & 5 & 5 & 5 & 5 \\ 3 & 3 & 3 & 3 & 2 & 2 & 2 & 2 & 5 & 5 & 5 & 5 & 5 \\ 5 & 5 & 5 & 5 & 5 & 5 & 5 & 5 & 5 & 2 & 5 & 3 & 9 \\ 9 & 9 & 9 & 5 & 5 & 5 & 5 & 5 & 9 & 9 & 9 & 9 & 9 \\ 5 & 5 & 5 & 5 & 5 & 5 & 5 & 5 & 5 & 5 & 5 & 5 & 5 \\ 5 & 5 & 5 & 5 & 5 & 5 & 9 & 9 & 9 & 1 & 1 & 1 & 2 \\ 1 & 1 & 1 & 1 & 1 & 1 & 1 & 1 & 5 & 5 & 5 & 5 & 4 \\ 4 & 3 & 3 & 3 & & & & & & & & & \end{array}$

- Example listing of 30MSOIL.ASC: ARCINFO ASCII grid format input file for soil type identification (only the 6 header lines and the first 3 lines of the input matrix are listed).

\begin{tabular}{|c|c|c|c|c|c|c|c|c|c|c|c|c|}
\hline \multicolumn{3}{|c|}{ ncols } & \multicolumn{3}{|c|}{367} & & & & & & & \\
\hline \multirow{2}{*}{\multicolumn{3}{|c|}{$\begin{array}{l}\text { nrows } \\
\text { xllcorner }\end{array}$}} & \multicolumn{3}{|c|}{691} & & & & & & & \\
\hline & & & \multicolumn{3}{|c|}{544661.000000} & & & & & & & \\
\hline \multirow{2}{*}{\multicolumn{3}{|c|}{$\begin{array}{l}\text { yllcorner } \\
\text { cellsize }\end{array}$}} & 4067 & .0 & & & & & & & & \\
\hline & & & & .0 & & & & & & & & \\
\hline \multicolumn{3}{|c|}{ NODATA value } & & 99 & & & & & & & & \\
\hline & 1 & 1 & 1 & 1 & 1 & 1 & 1 & 1 & 1 & 1 & 1 & 1 \\
\hline 1 & 1 & 1 & 1 & 1 & 1 & 1 & 1 & 1 & 1 & 1 & 1 & 1 \\
\hline 1 & 1 & 1 & 1 & 3 & 1 & 1 & 1 & 1 & 1 & 1 & 1 & 1 \\
\hline 1 & 1 & 1 & 1 & 1 & 1 & 1 & 1 & 1 & 1 & 1 & 1 & 1 \\
\hline 1 & 1 & 1 & 1 & 1 & 1 & 1 & 1 & 1 & 1 & 1 & 1 & 1 \\
\hline 1 & 1 & 1 & 1 & 1 & 1 & 1 & 1 & 1 & 1 & 1 & 1 & 1 \\
\hline 1 & 1 & 1 & 1 & 1 & 1 & 1 & 1 & 1 & 1 & 1 & 1 & 1 \\
\hline 1 & 1 & 1 & 1 & 1 & 1 & 1 & 1 & 1 & 1 & 1 & 1 & 1 \\
\hline 1 & 1 & 1 & 1 & 1 & 1 & 1 & 1 & 1 & 1 & 1 & 1 & 1 \\
\hline 1 & 1 & 1 & 1 & 1 & 1 & 1 & 1 & 1 & 1 & 1 & 1 & 1 \\
\hline 1 & 1 & 1 & 1 & 1 & 1 & 1 & 1 & 1 & 1 & 1 & 1 & 1 \\
\hline 1 & 1 & 1 & 1 & 1 & 1 & 1 & 1 & 1 & 1 & 1 & 1 & 1 \\
\hline 1 & 1 & 1 & 1 & 1 & 1 & 1 & 1 & 1 & 1 & 1 & 1 & 1 \\
\hline 1 & 1 & 1 & 1 & 1 & 1 & 1 & 1 & 1 & 1 & 1 & 1 & 1 \\
\hline 1 & 1 & 1 & 3 & 3 & 2 & 2 & 2 & 1 & 1 & 1 & 1 & 1 \\
\hline 1 & 1 & 1 & 1 & 1 & 1 & 1 & 1 & 1 & 1 & 1 & 1 & 1 \\
\hline 1 & 1 & 1 & 1 & 1 & 1 & 1 & 1 & 2 & 2 & 2 & 2 & 2 \\
\hline 2 & 1 & 1 & 1 & 1 & 1 & 1 & 1 & 1 & 1 & 1 & 1 & 1 \\
\hline 1 & 1 & 1 & 1 & 1 & 1 & 1 & 1 & 1 & 1 & 1 & 1 & 1 \\
\hline 1 & 1 & 1 & 1 & 1 & 1 & 1 & 1 & 1 & 1 & 1 & 1 & 1 \\
\hline 1 & 1 & 1 & 1 & 1 & 1 & 1 & 1 & 1 & 1 & 1 & 1 & 1 \\
\hline 1 & 1 & 1 & 1 & 1 & 1 & 1 & 1 & 1 & 1 & 3 & 4 & 4 \\
\hline 4 & 4 & 4 & 4 & 4 & 3 & 3 & 1 & 1 & 1 & 1 & 1 & 1 \\
\hline 1 & 1 & 1 & 1 & 1 & 1 & 1 & 1 & 1 & 3 & 1 & 2 & 2 \\
\hline 2 & 2 & 2 & 2 & 1 & 1 & 1 & 1 & 1 & 1 & 2 & 2 & 1 \\
\hline 1 & 1 & 1 & 1 & 1 & 1 & 1 & 1 & 1 & 1 & 1 & 1 & 1 \\
\hline 1 & 1 & 1 & 1 & 1 & 1 & 1 & 3 & 4 & 4 & 3 & 1 & 1 \\
\hline 3 & 3 & 3 & 3 & 3 & 3 & 1 & 1 & 1 & 1 & 1 & 3 & 3 \\
\hline 4 & 4 & 4 & 4 & & & & & & & & & \\
\hline
\end{tabular}




\begin{tabular}{|c|c|c|c|c|c|c|c|c|c|c|c|c|}
\hline & 1 & 1 & 1 & 1 & 1 & 1 & 1 & 1 & 1 & 1 & 1 & 1 \\
\hline 1 & 1 & 1 & 1 & 1 & 1 & 1 & 1 & 1 & 1 & 1 & 1 & 1 \\
\hline 1 & 1 & 1 & 1 & 3 & 1 & 1 & 1 & 1 & 1 & 1 & 1 & 1 \\
\hline 1 & 1 & 1 & 1 & 1 & 1 & 1 & 1 & 1 & 1 & 1 & 1 & 1 \\
\hline 1 & 1 & 1 & 1 & 1 & 1 & 1 & 1 & 1 & 1 & 1 & 1 & 1 \\
\hline 1 & 1 & 1 & 1 & 1 & 1 & 1 & 1 & 1 & 1 & 1 & 1 & 1 \\
\hline 1 & 1 & 1 & 1 & 1 & 1 & 1 & 1 & 1 & 1 & 1 & 1 & 1 \\
\hline 1 & 1 & 1 & 1 & 1 & 1 & 1 & 1 & 1 & 1 & 1 & 1 & 1 \\
\hline 1 & 1 & 1 & 1 & 1 & 1 & 1 & 1 & 1 & 1 & 1 & 1 & 1 \\
\hline 1 & 1 & 1 & 1 & 1 & 1 & 1 & 1 & 1 & 1 & 1 & 1 & 1 \\
\hline 1 & 1 & 1 & 1 & 1 & 1 & 1 & 1 & 1 & 1 & 1 & 1 & 1 \\
\hline 1 & 1 & 1 & 1 & 1 & 1 & 1 & 1 & 1 & 1 & 1 & 1 & 1 \\
\hline 1 & 1 & 1 & 1 & 1 & 1 & 1 & 1 & 1 & 1 & 1 & 1 & 1 \\
\hline 1 & 1 & 1 & 1 & 1 & 1 & 1 & 1 & 1 & 1 & 1 & 1 & 1 \\
\hline 1 & 1 & 3 & 1 & 1 & 1 & 2 & 2 & 2 & 1 & 1 & 1 & 1 \\
\hline 1 & 1 & 1 & 1 & 1 & 1 & 1 & 1 & 1 & 1 & 1 & 1 & 1 \\
\hline 1 & 1 & 1 & 1 & 1 & 1 & 1 & 1 & 2 & 2 & 2 & 2 & 2 \\
\hline 2 & 2 & 2 & 1 & 1 & 1 & 1 & 1 & 1 & 1 & 1 & 1 & 1 \\
\hline 2 & 1 & 1 & 1 & 1 & 1 & 1 & 1 & 1 & 1 & 1 & 1 & 1 \\
\hline 1 & 1 & 1 & 1 & 1 & 1 & 1 & 1 & 1 & 1 & 1 & 1 & 1 \\
\hline 1 & 1 & 1 & 1 & 1 & 1 & 1 & 1 & 1 & 1 & 1 & 1 & 1 \\
\hline 1 & 1 & 1 & 1 & 1 & 1 & 1 & 1 & 1 & 1 & 3 & 3 & 3 \\
\hline 4 & 4 & 4 & 4 & 4 & 4 & 3 & 1 & 1 & 1 & 1 & 1 & 1 \\
\hline 1 & 1 & 1 & 1 & 1 & 1 & 1 & 1 & 1 & 3 & 1 & 2 & 2 \\
\hline 2 & 2 & 2 & 2 & 1 & 1 & 1 & 1 & 2 & 2 & 2 & 2 & 2 \\
\hline 1 & 1 & 1 & 1 & 1 & 1 & 1 & 1 & 1 & 1 & 1 & 1 & 1 \\
\hline 1 & 1 & 1 & 1 & 1 & 1 & 1 & 2 & 3 & 4 & 4 & 3 & 3 \\
\hline 4 & 4 & 4 & 4 & 4 & 4 & 3 & 1 & 1 & 1 & 1 & 1 & 3 \\
\hline \multirow[t]{2}{*}{4} & 4 & 4 & 4 & & & & & & & & & \\
\hline & 1 & 1 & 1 & 1 & 1 & 1 & 1 & 1 & 1 & 1 & 1 & 1 \\
\hline 1 & 1 & 1 & 1 & 1 & 1 & 1 & 1 & 1 & 1 & 1 & 1 & 1 \\
\hline 1 & 1 & 1 & 1 & 1 & 1 & 1 & 1 & 1 & 1 & 1 & 1 & 1 \\
\hline 1 & 1 & 1 & 1 & 1 & 1 & 1 & 1 & 1 & 1 & 1 & 1 & 1 \\
\hline 1 & 1 & 1 & 1 & 1 & 1 & 1 & 1 & 1 & 1 & 1 & 1 & 1 \\
\hline 1 & 1 & 1 & 1 & 1 & 1 & 1 & 1 & 1 & 1 & 1 & 1 & 1 \\
\hline 1 & 1 & 1 & 1 & 1 & 1 & 1 & 1 & 1 & 1 & 1 & 1 & 1 \\
\hline 1 & 1 & 1 & 1 & 1 & 1 & 1 & 1 & 1 & 1 & 1 & 1 & 1 \\
\hline 1 & 1 & 1 & 1 & 1 & 1 & 1 & 1 & 1 & 1 & 1 & 1 & 1 \\
\hline 1 & 1 & 1 & 1 & 1 & 1 & 1 & 1 & 1 & 1 & 1 & 1 & 1 \\
\hline 1 & 1 & 1 & 1 & 1 & 1 & 1 & 1 & 1 & 1 & 1 & 1 & 1 \\
\hline 1 & 1 & 1 & 1 & 1 & 1 & 1 & 1 & 1 & 1 & 1 & 1 & 1 \\
\hline 1 & 1 & 1 & 1 & 1 & 1 & 1 & 1 & 1 & 1 & 1 & 1 & 1 \\
\hline 1 & 1 & 1 & 1 & 1 & 1 & 1 & 1 & 1 & 1 & 1 & 1 & 1 \\
\hline 1 & 1 & 1 & 1 & 1 & 1 & 1 & 2 & 2 & 2 & 1 & 1 & 1 \\
\hline 1 & 1 & 1 & 1 & 1 & 1 & 1 & 1 & 1 & 1 & 1 & 1 & 1 \\
\hline 1 & 1 & 1 & 1 & 1 & 1 & 1 & 2 & 2 & 2 & 2 & 2 & 2 \\
\hline 2 & 2 & 2 & 1 & 1 & 1 & 1 & 1 & 1 & 1 & 1 & 2 & 2 \\
\hline 2 & 2 & 2 & 1 & 1 & 2 & 2 & 1 & 1 & 1 & 1 & 1 & 1 \\
\hline 1 & 1 & 1 & 1 & 1 & 1 & 1 & 1 & 1 & 1 & 1 & 1 & 1 \\
\hline 1 & 1 & 1 & 1 & 1 & 1 & 1 & 1 & 1 & 1 & 1 & 1 & 1 \\
\hline 1 & 1 & 1 & 1 & 1 & 1 & 1 & 1 & 1 & 1 & 1 & 1 & 1 \\
\hline 3 & 3 & 4 & 4 & 4 & 4 & 4 & 3 & 1 & 1 & 1 & 1 & 1 \\
\hline 1 & 1 & 1 & 1 & 1 & 1 & 1 & 1 & 1 & 3 & 1 & 3 & 2 \\
\hline 2 & 2 & 2 & 1 & 1 & 1 & 1 & 1 & 2 & 2 & 2 & 2 & 2 \\
\hline 1 & 1 & 1 & 1 & 1 & 1 & 1 & 1 & 1 & 1 & 1 & 1 & 1 \\
\hline 1 & 1 & 1 & 1 & 1 & 1 & 2 & 2 & 2 & 3 & 4 & 4 & 4 \\
\hline 4 & 4 & 4 & 4 & 4 & 4 & 4 & 3 & 1 & 1 & 1 & 1 & 3 \\
\hline 4 & 4 & 4 & 4 & & & & & & & & & \\
\hline
\end{tabular}

- Example listing of 30MDEPTH.ASC: ARCINFO ASCII grid format input file for soil depth class identification (only the 6 header lines and the first 3 lines of the input matrix are listed). 


\begin{tabular}{|c|c|c|c|c|c|c|c|c|c|c|c|c|}
\hline & & & & 36 & & & & & & & & \\
\hline & & & & 69 & & & & & & & & \\
\hline & $r \mathrm{n}$ & & 54 & .0 & & & & & & & & \\
\hline & $r n$ & & 406 & .0 & & & & & & & & \\
\hline & iz & & & .0 & & & & & & & & \\
\hline & A & & & 99 & & & & & & & & \\
\hline & 1 & 1 & 1 & 1 & 1 & 1 & 1 & 1 & 1 & 1 & 1 & 1 \\
\hline 1 & 1 & 1 & 1 & 1 & 1 & 1 & 1 & 1 & 1 & 1 & 1 & 1 \\
\hline 1 & 1 & 1 & 1 & 3 & 1 & 1 & 1 & 1 & 1 & 1 & 1 & 1 \\
\hline 1 & 1 & 1 & 1 & 1 & 1 & 1 & 1 & 1 & 1 & 1 & 1 & 1 \\
\hline 1 & 1 & 1 & 1 & 1 & 1 & 1 & 1 & 1 & 1 & 1 & 1 & 1 \\
\hline 1 & 1 & 1 & 1 & 1 & 1 & 1 & 1 & 1 & 1 & 1 & 1 & 1 \\
\hline 1 & 1 & 1 & 1 & 1 & 1 & 1 & 1 & 1 & 1 & 1 & 1 & 1 \\
\hline 1 & 1 & 1 & 1 & 1 & 1 & 1 & 1 & 1 & 1 & 1 & 1 & 1 \\
\hline 1 & 1 & 1 & 1 & 1 & 1 & 1 & 1 & 1 & 1 & 1 & 1 & 1 \\
\hline 1 & 1 & 1 & 1 & 1 & 1 & 1 & 1 & 1 & 1 & 1 & 1 & 1 \\
\hline 1 & 1 & 1 & 1 & 1 & 1 & 1 & 1 & 1 & 1 & 1 & 1 & 1 \\
\hline 1 & 1 & 1 & 1 & 1 & 1 & 1 & 1 & 1 & 1 & 1 & 1 & 1 \\
\hline 1 & 1 & 1 & 1 & 1 & 1 & 1 & 1 & 1 & 1 & 1 & 1 & 1 \\
\hline 1 & 1 & 1 & 1 & 1 & 1 & 1 & 1 & 1 & 1 & 1 & 1 & 1 \\
\hline 1 & 1 & 1 & 3 & 3 & 2 & 2 & 2 & 1 & 1 & 1 & 1 & 1 \\
\hline 1 & 1 & 1 & 1 & 1 & 1 & 1 & 1 & 1 & 1 & 1 & 1 & 1 \\
\hline 1 & 1 & 1 & 1 & 1 & 1 & 1 & 1 & 2 & 2 & 2 & 2 & 2 \\
\hline 2 & 1 & 1 & 1 & 1 & 1 & 1 & 1 & 1 & 1 & 1 & 1 & 1 \\
\hline 1 & 1 & 1 & 1 & 1 & 1 & 1 & 1 & 1 & 1 & 1 & 1 & 1 \\
\hline 1 & 1 & 1 & 1 & 1 & 1 & 1 & 1 & 1 & 1 & 1 & 1 & 1 \\
\hline 1 & 1 & 1 & 1 & 1 & 1 & 1 & 1 & 1 & 1 & 1 & 1 & 1 \\
\hline 1 & 1 & 1 & 1 & 1 & 1 & 1 & 1 & 1 & 1 & 3 & 4 & 4 \\
\hline 4 & 4 & 4 & 4 & 4 & 3 & 3 & 1 & 1 & 1 & 1 & 1 & 1 \\
\hline 1 & 1 & 1 & 1 & 1 & 1 & 1 & 1 & 1 & 3 & 1 & 2 & 2 \\
\hline 2 & 2 & 2 & 2 & 1 & 1 & 1 & 1 & 1 & 1 & 2 & 2 & 1 \\
\hline 1 & 1 & 1 & 1 & 1 & 1 & 1 & 1 & 1 & 1 & 1 & 1 & 1 \\
\hline 1 & 1 & 1 & 1 & 1 & 1 & 1 & 3 & 4 & 4 & 3 & 1 & 1 \\
\hline 3 & 3 & 3 & 3 & 3 & 3 & 1 & 1 & 1 & 1 & 1 & 3 & 3 \\
\hline 4 & 4 & 4 & 4 & & & & & & & & & \\
\hline & 1 & 1 & 1 & 1 & 1 & 1 & 1 & 1 & 1 & 1 & 1 & 1 \\
\hline 1 & 1 & 1 & 1 & 1 & 1 & 1 & 1 & 1 & 1 & 1 & 1 & 1 \\
\hline 1 & 1 & 1 & 1 & 3 & 1 & 1 & 1 & 1 & 1 & 1 & 1 & 1 \\
\hline 1 & 1 & 1 & 1 & 1 & 1 & 1 & 1 & 1 & 1 & 1 & 1 & 1 \\
\hline 1 & 1 & 1 & 1 & 1 & 1 & 1 & 1 & 1 & 1 & 1 & 1 & 1 \\
\hline 1 & 1 & 1 & 1 & 1 & 1 & 1 & 1 & 1 & 1 & 1 & 1 & 1 \\
\hline 1 & 1 & 1 & 1 & 1 & 1 & 1 & 1 & 1 & 1 & 1 & 1 & 1 \\
\hline 1 & 1 & 1 & 1 & 1 & 1 & 1 & 1 & 1 & 1 & 1 & 1 & 1 \\
\hline 1 & 1 & 1 & 1 & 1 & 1 & 1 & 1 & 1 & 1 & 1 & 1 & 1 \\
\hline 1 & 1 & 1 & 1 & 1 & 1 & 1 & 1 & 1 & 1 & 1 & 1 & 1 \\
\hline 1 & 1 & 1 & 1 & 1 & 1 & 1 & 1 & 1 & 1 & 1 & 1 & 1 \\
\hline 1 & 1 & 1 & 1 & 1 & 1 & 1 & 1 & 1 & 1 & 1 & 1 & 1 \\
\hline 1 & 1 & 1 & 1 & 1 & 1 & 1 & 1 & 1 & 1 & 1 & 1 & 1 \\
\hline 1 & 1 & 1 & 1 & 1 & 1 & 1 & 1 & 1 & 1 & 1 & 1 & 1 \\
\hline 1 & 1 & 3 & 1 & 1 & 1 & 2 & 2 & 2 & 1 & 1 & 1 & 1 \\
\hline 1 & 1 & 1 & 1 & 1 & 1 & 1 & 1 & 1 & 1 & 1 & 1 & 1 \\
\hline 1 & 1 & 1 & 1 & 1 & 1 & 1 & 1 & 2 & 2 & 2 & 2 & 2 \\
\hline 2 & 2 & 2 & 1 & 1 & 1 & 1 & 1 & 1 & 1 & 1 & 1 & 1 \\
\hline 2 & 1 & 1 & 1 & 1 & 1 & 1 & 1 & 1 & 1 & 1 & 1 & 1 \\
\hline 1 & 1 & 1 & 1 & 1 & 1 & 1 & 1 & 1 & 1 & 1 & 1 & 1 \\
\hline 1 & 1 & 1 & 1 & 1 & 1 & 1 & 1 & 1 & 1 & 1 & 1 & 1 \\
\hline 1 & 1 & 1 & 1 & 1 & 1 & 1 & 1 & 1 & 1 & 3 & 3 & 3 \\
\hline 4 & 4 & 4 & 4 & 4 & 4 & 3 & 1 & 1 & 1 & 1 & 1 & 1 \\
\hline 1 & 1 & 1 & 1 & 1 & 1 & 1 & 1 & 1 & 3 & 1 & 2 & 2 \\
\hline 2 & 2 & 2 & 2 & 1 & 1 & 1 & 1 & 2 & 2 & 2 & 2 & 2 \\
\hline 1 & 1 & 1 & 1 & 1 & 1 & 1 & 1 & 1 & 1 & 1 & 1 & 1 \\
\hline 1 & 1 & 1 & 1 & 1 & 1 & 1 & 2 & 3 & 4 & 4 & 3 & 3 \\
\hline
\end{tabular}




$\begin{array}{rrrrrrrrrrrrrrrr}4 & 4 & 4 & 4 & 4 & 4 & 3 & 1 & 1 & 1 & 1 & 1 & 3 \\ 4 & 4 & 4 & 4 & 1 & 1 & 1 & 1 & 1 & 1 & 1 & 1 & 1 & 1 & 1 \\ 1 & 1 & 1 & 1 & 1 & 1 & 1 & 1 & 1 & 1 & 1 & 1 & 1 \\ 1 & 1 & 1 & 1 & 1 & 1 & 1 & 1 & 1 & 1 & 1 & 1 & 1 \\ 1 & 1 & 1 & 1 & 1 & 1 & 1 & 1 & 1 & 1 & 1 & 1 & 1 \\ 1 & 1 & 1 & 1 & 1 & 1 & 1 & 1 & 1 & 1 & 1 & 1 & 1 \\ 1 & 1 & 1 & 1 & 1 & 1 & 1 & 1 & 1 & 1 & 1 & 1 & 1 \\ 1 & 1 & 1 & 1 & 1 & 1 & 1 & 1 & 1 & 1 & 1 & 1 & 1 \\ 1 & 1 & 1 & 1 & 1 & 1 & 1 & 1 & 1 & 1 & 1 & 1 & 1 \\ 1 & 1 & 1 & 1 & 1 & 1 & 1 & 1 & 1 & 1 & 1 & 1 & 1 \\ 1 & 1 & 1 & 1 & 1 & 1 & 1 & 1 & 1 & 1 & 1 & 1 & 1 \\ 1 & 1 & 1 & 1 & 1 & 1 & 1 & 1 & 1 & 1 & 1 & 1 & 1 \\ 1 & 1 & 1 & 1 & 1 & 1 & 1 & 1 & 1 & 1 & 1 & 1 & 1 \\ 1 & 1 & 1 & 1 & 1 & 1 & 1 & 1 & 1 & 1 & 1 & 1 & 1 \\ 1 & 1 & 1 & 1 & 1 & 1 & 1 & 1 & 1 & 1 & 1 & 1 & 1 \\ 1 & 1 & 1 & 1 & 1 & 1 & 1 & 2 & 2 & 2 & 1 & 1 & 1 \\ 1 & 1 & 1 & 1 & 1 & 1 & 1 & 1 & 1 & 1 & 1 & 1 & 1 \\ 1 & 1 & 1 & 1 & 1 & 1 & 1 & 2 & 2 & 2 & 2 & 2 & 2 \\ 2 & 2 & 2 & 1 & 1 & 1 & 1 & 1 & 1 & 1 & 1 & 2 & 2 \\ 2 & 2 & 2 & 1 & 1 & 2 & 2 & 1 & 1 & 1 & 1 & 1 & 1 \\ 1 & 1 & 1 & 1 & 1 & 1 & 1 & 1 & 1 & 1 & 1 & 1 & 1 \\ 1 & 1 & 1 & 1 & 1 & 1 & 1 & 1 & 1 & 1 & 1 & 1 & 1 \\ 1 & 1 & 1 & 1 & 1 & 1 & 1 & 1 & 1 & 1 & 1 & 1 & 1 \\ 3 & 3 & 4 & 4 & 4 & 4 & 4 & 3 & 1 & 1 & 1 & 1 & 1 \\ 1 & 1 & 1 & 1 & 1 & 1 & 1 & 1 & 1 & 3 & 1 & 3 & 2 \\ 2 & 2 & 2 & 1 & 1 & 1 & 1 & 1 & 2 & 2 & 2 & 2 & 2 \\ 1 & 1 & 1 & 1 & 1 & 1 & 1 & 1 & 1 & 1 & 1 & 1 & 1 \\ 1 & 1 & 1 & 1 & 1 & 1 & 2 & 2 & 2 & 3 & 4 & 4 & 4 \\ 4 & 4 & 4 & 4 & 4 & 4 & 4 & 3 & 1 & 1 & 1 & 1 & 3 \\ 4 & 4 & 4 & 4 & & & & & & & & & \end{array}$

- Example listing of 30MROCK.ASC: ARCINFO ASCII grid format input file for rock type identification number (only the 6 header lines and the first 3 lines of the input matrix are listed).

\begin{tabular}{|c|c|c|c|c|c|c|c|c|c|c|c|c|}
\hline $\mathrm{nCO}$ & & & & 367 & & & & & & & & \\
\hline nrov & & & & 691 & & & & & & & & \\
\hline 11 & rner & & 5446 & 561.000 & & & & & & & & \\
\hline 11 & rner & & 40671 & 33.000 & & & & & & & & \\
\hline e] & ize & & & 30.000 & & & & & & & & \\
\hline & A_val & & & -9999 & & & & & & & & \\
\hline & & & 201 & 201 & & 201 & 201 & 201 & 201 & 202 & 202 & 202 \\
\hline 2 & 202 & 201 & 201 & 201 & 201 & 201 & 201 & 201 & 201 & 201 & 201 & 201 \\
\hline 01 & 203 & 203 & 203 & 203 & 203 & 201 & 201 & 201 & 201 & 201 & 201 & 201 \\
\hline & 201 & 201 & 201 & 201 & 201 & 201 & 201 & 201 & 201 & 201 & 201 & 201 \\
\hline 01 & 201 & 201 & 201 & 201 & 201 & 201 & 201 & 201 & 201 & 201 & 201 & 201 \\
\hline & 201 & 201 & 201 & 201 & 201 & 201 & 201 & 201 & 201 & 201 & 201 & 201 \\
\hline & 201 & 201 & 201 & 201 & 201 & 201 & 204 & 204 & 201 & 201 & 201 & 201 \\
\hline & 201 & 201 & 201 & 201 & 201 & 201 & 201 & 201 & 201 & 201 & 201 & 203 \\
\hline & 201 & 201 & 201 & 201 & 201 & 201 & 201 & 201 & 201 & 201 & 201 & 201 \\
\hline & 201 & 201 & 201 & 201 & 201 & 201 & 201 & 201 & 201 & 201 & 201 & 201 \\
\hline & 201 & 201 & 205 & 205 & 205 & 205 & 205 & 205 & 205 & 205 & 205 & 205 \\
\hline & 205 & 206 & 206 & 206 & 206 & 206 & 206 & 206 & 206 & 206 & 206 & 206 \\
\hline & 206 & 206 & 206 & 206 & 206 & 206 & 206 & 206 & 206 & 206 & 206 & 206 \\
\hline & 206 & 206 & 206 & 206 & 206 & 206 & 206 & 206 & 206 & 206 & 206 & 206 \\
\hline & 206 & 206 & 206 & 206 & 204 & 204 & 204 & 206 & 206 & 206 & 206 & 206 \\
\hline & 206 & 206 & 206 & 206 & 206 & 206 & 206 & 206 & 206 & 206 & 206 & 206 \\
\hline & 206 & 207 & 207 & 207 & 207 & 207 & 206 & 206 & 206 & 206 & 206 & 206 \\
\hline & 206 & 206 & 206 & 206 & 206 & 206 & 206 & 206 & 206 & 206 & 206 & 206 \\
\hline & 206 & 206 & 206 & 206 & 206 & 206 & 208 & 208 & 208 & 205 & 205 & 205 \\
\hline
\end{tabular}




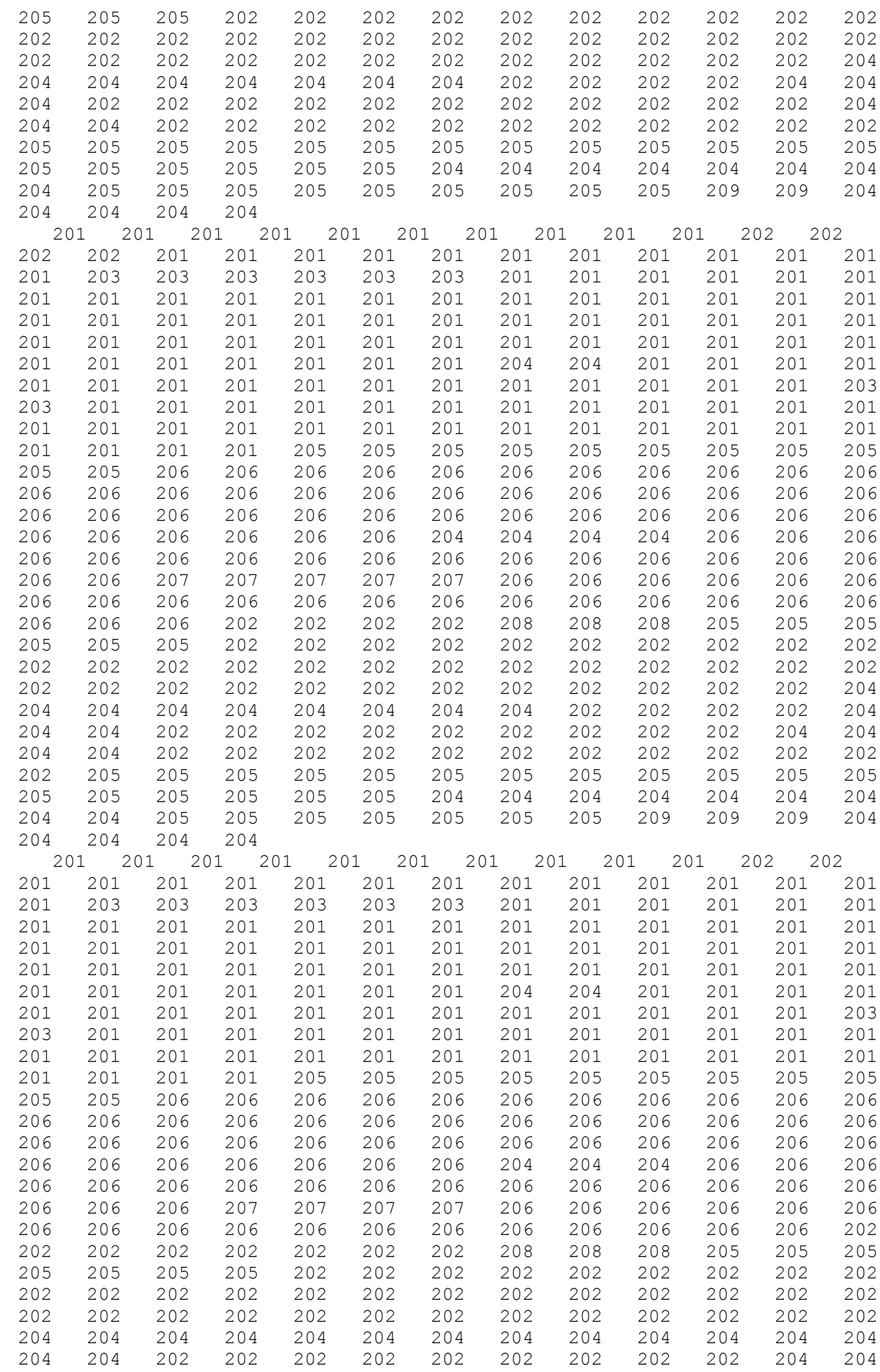




$\begin{array}{lllllllllllll}204 & 202 & 202 & 202 & 202 & 202 & 202 & 202 & 202 & 202 & 202 & 202 & 202 \\ 202 & 205 & 205 & 205 & 205 & 205 & 205 & 205 & 205 & 205 & 205 & 205 & 205 \\ 205 & 205 & 205 & 205 & 205 & 205 & 204 & 204 & 204 & 204 & 204 & 204 & 204 \\ 204 & 204 & 204 & 204 & 205 & 205 & 205 & 205 & 205 & 209 & 209 & 209 & 204 \\ 204 & 204 & 204 & 204 & & & & & & & & \end{array}$

- Example listing of 30MTOPO.ASC: ARCINFO ASCII grid format input file for topographic location number (only the 6 header lines and the first 3 lines of the input matrix are listed).

\begin{tabular}{|c|c|c|c|c|c|c|c|c|c|c|c|c|}
\hline \multicolumn{3}{|c|}{ ncols } & \multicolumn{3}{|c|}{367} & & & & & & & \\
\hline \multicolumn{3}{|c|}{ nrows } & \multicolumn{3}{|c|}{691} & & & & & & & \\
\hline \multicolumn{3}{|c|}{ xllcorner } & \multicolumn{3}{|c|}{544661.000000} & & & & & & & \\
\hline \multicolumn{3}{|c|}{ yllcorner } & \multicolumn{3}{|c|}{4067133.000000} & & & & & & & \\
\hline \multicolumn{3}{|c|}{ cellsize } & \multicolumn{3}{|c|}{30.000000} & & & & & & & \\
\hline \multicolumn{3}{|c|}{ NODATA value } & \multicolumn{3}{|c|}{$\begin{array}{l}30.000000 \\
-9999\end{array}$} & & & & & & & \\
\hline & 4 & 4 & 4 & 4 & 4 & 4 & 4 & 4 & 4 & 4 & 4 & 4 \\
\hline 4 & 4 & 4 & 4 & 4 & 4 & 4 & 4 & 4 & 4 & 4 & 4 & 4 \\
\hline 4 & 4 & 4 & 4 & 2 & 4 & 4 & 4 & 4 & 4 & 4 & 4 & 4 \\
\hline 4 & 4 & 4 & 4 & 4 & 4 & 4 & 4 & 4 & 4 & 4 & 4 & 4 \\
\hline 4 & 4 & 4 & 4 & 4 & 4 & 4 & 4 & 4 & 4 & 4 & 4 & 4 \\
\hline 4 & 4 & 4 & 4 & 4 & 4 & 4 & 4 & 4 & 4 & 4 & 4 & 4 \\
\hline 4 & 4 & 4 & 4 & 4 & 4 & 4 & 4 & 4 & 4 & 4 & 4 & 4 \\
\hline 4 & 4 & 4 & 4 & 4 & 4 & 4 & 4 & 4 & 4 & 4 & 4 & 4 \\
\hline 4 & 4 & 4 & 4 & 4 & 4 & 4 & 4 & 4 & 4 & 4 & 4 & 4 \\
\hline 4 & 4 & 4 & 4 & 4 & 4 & 4 & 4 & 4 & 4 & 4 & 4 & 4 \\
\hline 4 & 4 & 4 & 4 & 4 & 4 & 4 & 4 & 4 & 4 & 4 & 4 & 4 \\
\hline 4 & 4 & 4 & 4 & 4 & 4 & 4 & 4 & 4 & 4 & 4 & 4 & 4 \\
\hline 4 & 4 & 4 & 4 & 4 & 4 & 4 & 4 & 4 & 4 & 4 & 4 & 4 \\
\hline 4 & 4 & 4 & 4 & 4 & 4 & 4 & 4 & 5 & 4 & 4 & 4 & 4 \\
\hline 4 & 4 & 4 & 1 & 1 & 3 & 3 & 3 & 4 & 4 & 4 & 4 & 4 \\
\hline 4 & 4 & 5 & 4 & 4 & 4 & 4 & 4 & 4 & 4 & 4 & 4 & 4 \\
\hline 4 & 4 & 4 & 4 & 4 & 4 & 4 & 4 & 3 & 3 & 3 & 3 & 3 \\
\hline 3 & 4 & 4 & 4 & 4 & 4 & 4 & 4 & 4 & 4 & 4 & 4 & 4 \\
\hline 4 & 4 & 4 & 4 & 4 & 4 & 4 & 4 & 4 & 4 & 4 & 4 & 4 \\
\hline 4 & 4 & 4 & 4 & 4 & 4 & 4 & 5 & 4 & 4 & 4 & 4 & 4 \\
\hline 4 & 4 & 4 & 4 & 4 & 4 & 4 & 4 & 4 & 4 & 4 & 4 & 4 \\
\hline 4 & 4 & 4 & 4 & 4 & 4 & 4 & 4 & 4 & 4 & 2 & 1 & 2 \\
\hline 2 & 2 & 2 & 2 & 2 & 2 & 2 & 4 & 4 & 4 & 4 & 4 & 4 \\
\hline 4 & 4 & 4 & 4 & 4 & 4 & 4 & 4 & 4 & 2 & 4 & 3 & 3 \\
\hline 3 & 3 & 3 & 3 & 2 & 2 & 2 & 2 & 2 & 2 & 3 & 3 & 2 \\
\hline 2 & 2 & 2 & 2 & 2 & 2 & 2 & 2 & 2 & 2 & 2 & 2 & 2 \\
\hline 2 & 2 & 2 & 2 & 2 & 2 & 2 & 2 & 2 & 2 & 2 & 5 & 4 \\
\hline 2 & 2 & 2 & 2 & 2 & 2 & 4 & 4 & 4 & 4 & 4 & 2 & 2 \\
\hline 1 & 1 & 2 & 2 & & & & & & & & & \\
\hline & 4 & 4 & 4 & 4 & 4 & 4 & 4 & 4 & 4 & 4 & 4 & 4 \\
\hline 4 & 4 & 4 & 4 & 4 & 4 & 4 & 4 & 4 & 4 & 5 & 5 & 4 \\
\hline 4 & 4 & 4 & 4 & 2 & 4 & 4 & 4 & 4 & 4 & 4 & 4 & 4 \\
\hline 4 & 4 & 4 & 4 & 4 & 4 & 4 & 4 & 4 & 4 & 4 & 4 & 4 \\
\hline 4 & 4 & 4 & 4 & 4 & 4 & 4 & 4 & 4 & 4 & 4 & 4 & 4 \\
\hline 4 & 4 & 4 & 4 & 4 & 4 & 4 & 4 & 4 & 4 & 4 & 4 & 4 \\
\hline 4 & 4 & 4 & 4 & 4 & 4 & 4 & 4 & 4 & 4 & 4 & 4 & 4 \\
\hline 4 & 4 & 4 & 4 & 4 & 4 & 4 & 4 & 4 & 4 & 4 & 4 & 4 \\
\hline 4 & 4 & 1 & 4 & 4 & 4 & 4 & 4 & 4 & 4 & 4 & 4 & 4 \\
\hline 4 & 4 & 4 & 4 & 4 & 4 & 4 & 4 & 4 & 4 & 4 & 4 & 4 \\
\hline 4 & 4 & 4 & 4 & 4 & 4 & 4 & 4 & 4 & 4 & 4 & 4 & 4 \\
\hline 4 & 4 & 4 & 4 & 4 & 4 & 4 & 4 & 4 & 4 & 4 & 4 & 4 \\
\hline 4 & 4 & 4 & 4 & 4 & 4 & 4 & 4 & 4 & 4 & 4 & 4 & 4 \\
\hline 4 & 4 & 4 & 4 & 4 & 4 & 4 & 4 & 4 & 4 & 4 & 4 & 4 \\
\hline 4 & 4 & 1 & 4 & 4 & 4 & 3 & 3 & 3 & 4 & 4 & 4 & 4 \\
\hline 4 & 4 & 4 & 4 & 4 & 4 & 4 & 4 & 4 & 4 & 4 & 4 & 4 \\
\hline 4 & 4 & 4 & 4 & 4 & 4 & 4 & 4 & 3 & 3 & 3 & 3 & 3 \\
\hline
\end{tabular}




\begin{tabular}{|c|c|c|c|c|c|c|c|c|c|c|c|c|}
\hline 3 & 3 & 3 & 4 & 4 & 4 & 4 & 4 & 4 & 4 & 4 & 4 & 4 \\
\hline 3 & 4 & 4 & 4 & 4 & 4 & 4 & 4 & 4 & 4 & 4 & 4 & 4 \\
\hline 4 & 4 & 4 & 4 & 4 & 4 & 4 & 4 & 4 & 4 & 4 & 4 & 4 \\
\hline 4 & 4 & 4 & 4 & 4 & 4 & 4 & 4 & 4 & 4 & 4 & 4 & 4 \\
\hline 4 & 4 & 4 & 4 & 4 & 4 & 4 & 4 & 4 & 4 & 2 & 2 & 2 \\
\hline 2 & 2 & 2 & 2 & 2 & 2 & 2 & 4 & 4 & 4 & 4 & 4 & 4 \\
\hline 4 & 4 & 4 & 4 & 4 & 4 & 4 & 4 & 4 & 2 & 4 & 3 & 3 \\
\hline 3 & 3 & 3 & 3 & 5 & 2 & 2 & 2 & 3 & 3 & 3 & 3 & 3 \\
\hline 2 & 2 & 2 & 2 & 2 & 2 & 2 & 2 & 2 & 2 & 2 & 2 & 2 \\
\hline 2 & 2 & 2 & 2 & 2 & 2 & 2 & 3 & 2 & 2 & 2 & 2 & 2 \\
\hline 2 & 2 & 2 & 2 & 2 & 2 & 2 & 4 & 5 & 5 & 4 & 4 & 2 \\
\hline \multirow[t]{2}{*}{1} & 2 & 2 & 2 & & & & & & & & & \\
\hline & 4 & 4 & 4 & 4 & 4 & 4 & 4 & 4 & 5 & 4 & 4 & 4 \\
\hline 4 & 4 & 4 & 4 & 4 & 4 & 4 & 4 & 4 & 4 & 4 & 4 & 4 \\
\hline 4 & 4 & 4 & 4 & 4 & 5 & 4 & 4 & 4 & 4 & 4 & 4 & 4 \\
\hline 4 & 4 & 4 & 4 & 4 & 4 & 4 & 4 & 4 & 4 & 4 & 4 & 4 \\
\hline 4 & 4 & 4 & 4 & 4 & 4 & 4 & 4 & 4 & 4 & 4 & 4 & 4 \\
\hline 4 & 4 & 4 & 4 & 4 & 4 & 4 & 4 & 4 & 4 & 4 & 4 & 4 \\
\hline 4 & 4 & 4 & 4 & 4 & 4 & 5 & 4 & 4 & 4 & 4 & 4 & 4 \\
\hline 4 & 4 & 4 & 4 & 4 & 4 & 4 & 4 & 4 & 4 & 4 & 4 & 4 \\
\hline 4 & 4 & 4 & 4 & 4 & 4 & 4 & 4 & 4 & 4 & 4 & 4 & 4 \\
\hline 4 & 4 & 4 & 4 & 4 & 4 & 4 & 4 & 4 & 4 & 4 & 4 & 4 \\
\hline 4 & 4 & 4 & 4 & 4 & 4 & 4 & 4 & 4 & 4 & 4 & 4 & 4 \\
\hline 4 & 4 & 4 & 4 & 4 & 4 & 4 & 4 & 4 & 4 & 4 & 4 & 4 \\
\hline 4 & 4 & 4 & 4 & 4 & 4 & 4 & 4 & 4 & 4 & 4 & 4 & 4 \\
\hline 4 & 4 & 6 & 4 & 4 & 4 & 4 & 4 & 4 & 4 & 4 & 4 & 4 \\
\hline 4 & 4 & 4 & 4 & 4 & 4 & 4 & 3 & 3 & 3 & 4 & 4 & 4 \\
\hline 4 & 4 & 4 & 4 & 5 & 4 & 4 & 4 & 4 & 4 & 4 & 4 & 4 \\
\hline 5 & 4 & 4 & 4 & 4 & 4 & 4 & 3 & 3 & 3 & 3 & 3 & 3 \\
\hline 3 & 3 & 3 & 4 & 4 & 4 & 4 & 4 & 4 & 4 & 4 & 3 & 3 \\
\hline 3 & 3 & 3 & 4 & 4 & 3 & 3 & 4 & 4 & 4 & 4 & 4 & 4 \\
\hline 4 & 4 & 4 & 4 & 4 & 4 & 4 & 4 & 4 & 4 & 4 & 4 & 4 \\
\hline 4 & 4 & 4 & 4 & 4 & 4 & 4 & 4 & 4 & 4 & 4 & 4 & 4 \\
\hline 4 & 4 & 4 & 4 & 4 & 4 & 4 & 4 & 4 & 4 & 4 & 4 & 4 \\
\hline 2 & 2 & 2 & 2 & 2 & 2 & 2 & 2 & 4 & 4 & 4 & 4 & 4 \\
\hline 5 & 5 & 4 & 4 & 4 & 4 & 4 & 4 & 4 & 2 & 4 & 2 & 3 \\
\hline 3 & 3 & 3 & 2 & 5 & 2 & 2 & 2 & 3 & 3 & 3 & 3 & 3 \\
\hline 2 & 2 & 2 & 2 & 2 & 2 & 2 & 2 & 2 & 2 & 2 & 2 & 2 \\
\hline 2 & 2 & 2 & 2 & 2 & 2 & 3 & 3 & 3 & 2 & 2 & 2 & 2 \\
\hline 2 & 2 & 2 & 2 & 2 & 2 & 2 & 2 & 5 & 4 & 4 & 4 & 1 \\
\hline 1 & 2 & 2 & 2 & & & & & & & & & \\
\hline
\end{tabular}

- Example listing of 30MSITE.INP: main output file generated by BLOCKR7 V1.0 and supplied as input to GEOMAP7 (only the 6 header lines and the first 3 lines of the input matrix are listed).

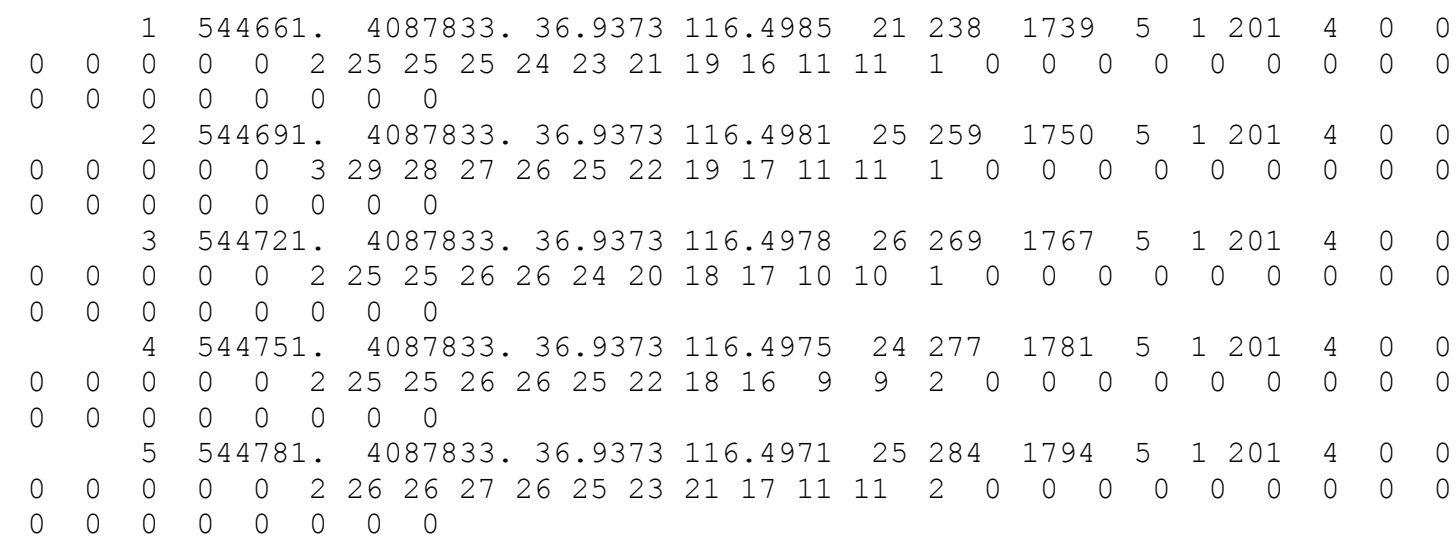




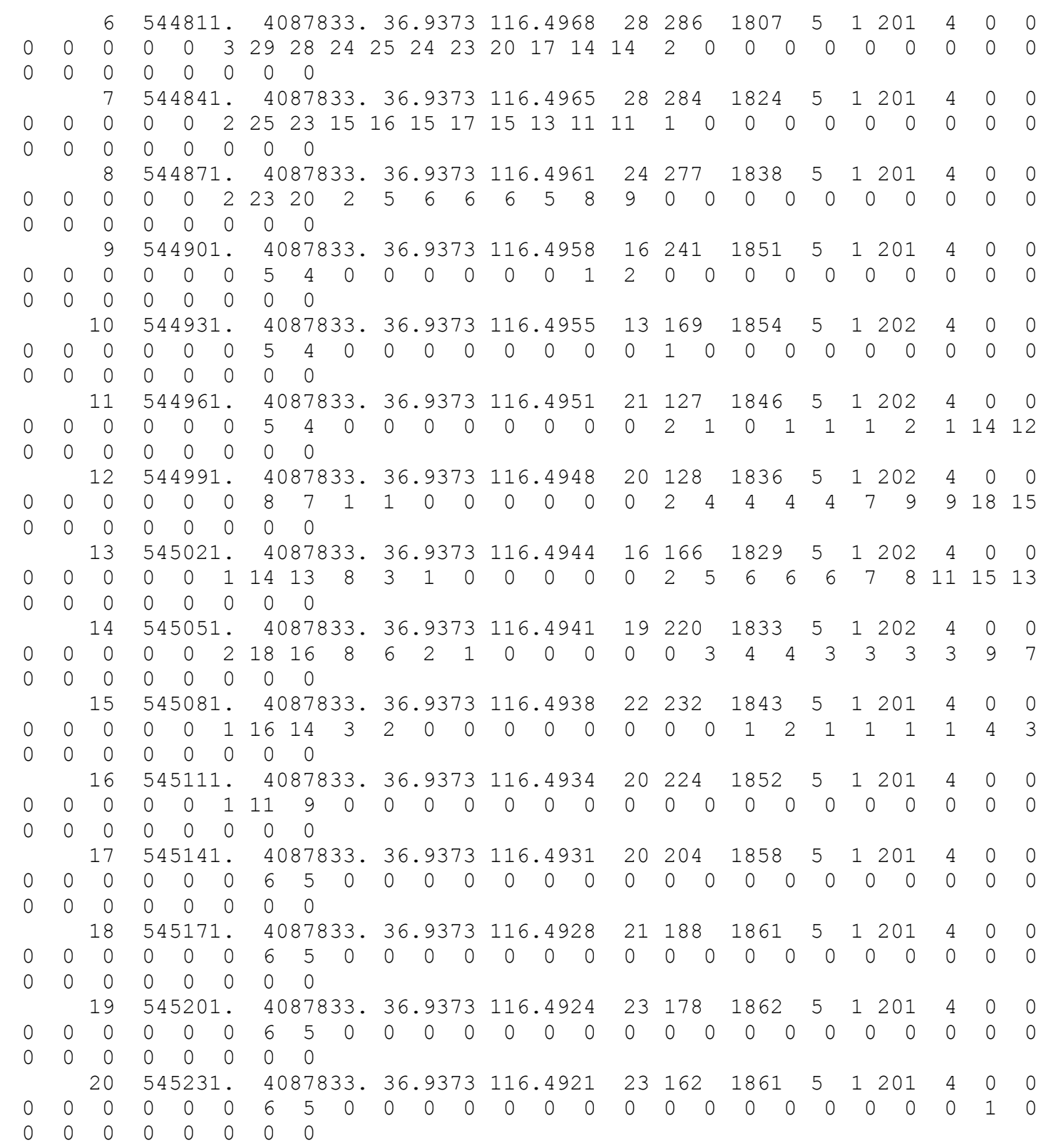

\section{- Figures used as part of the routine test plan:}




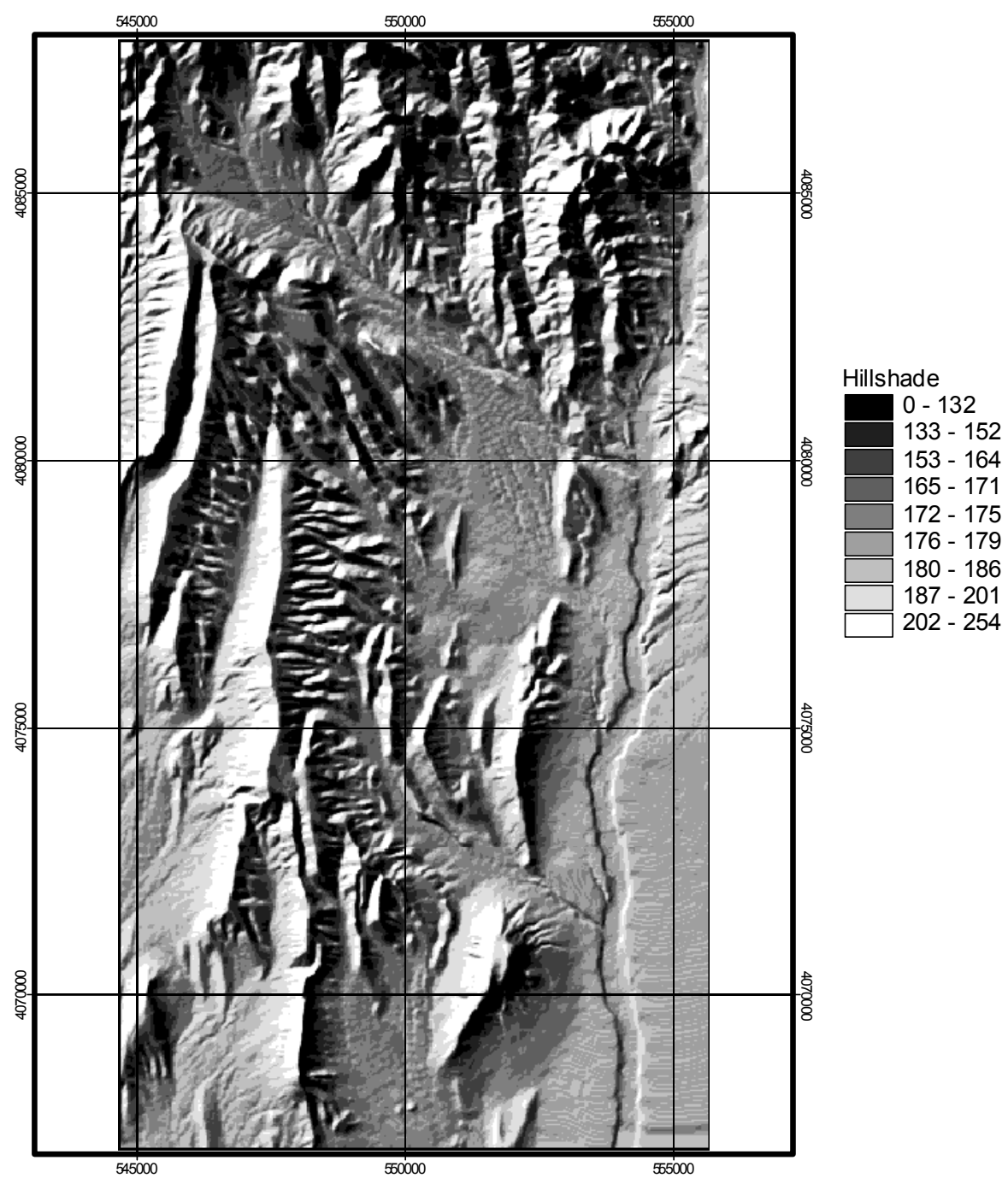

Output DTN: GS000308311221.004.

Figure D-1. Shaded Relief Representation of the Digital Elevation Model (DEM) Used As Input to BLOCKR7 V1.0 for Calculating the Blocking Ridge Angles Required as Input to INFIL V2.0 for the Yucca Mountain Model Domain 


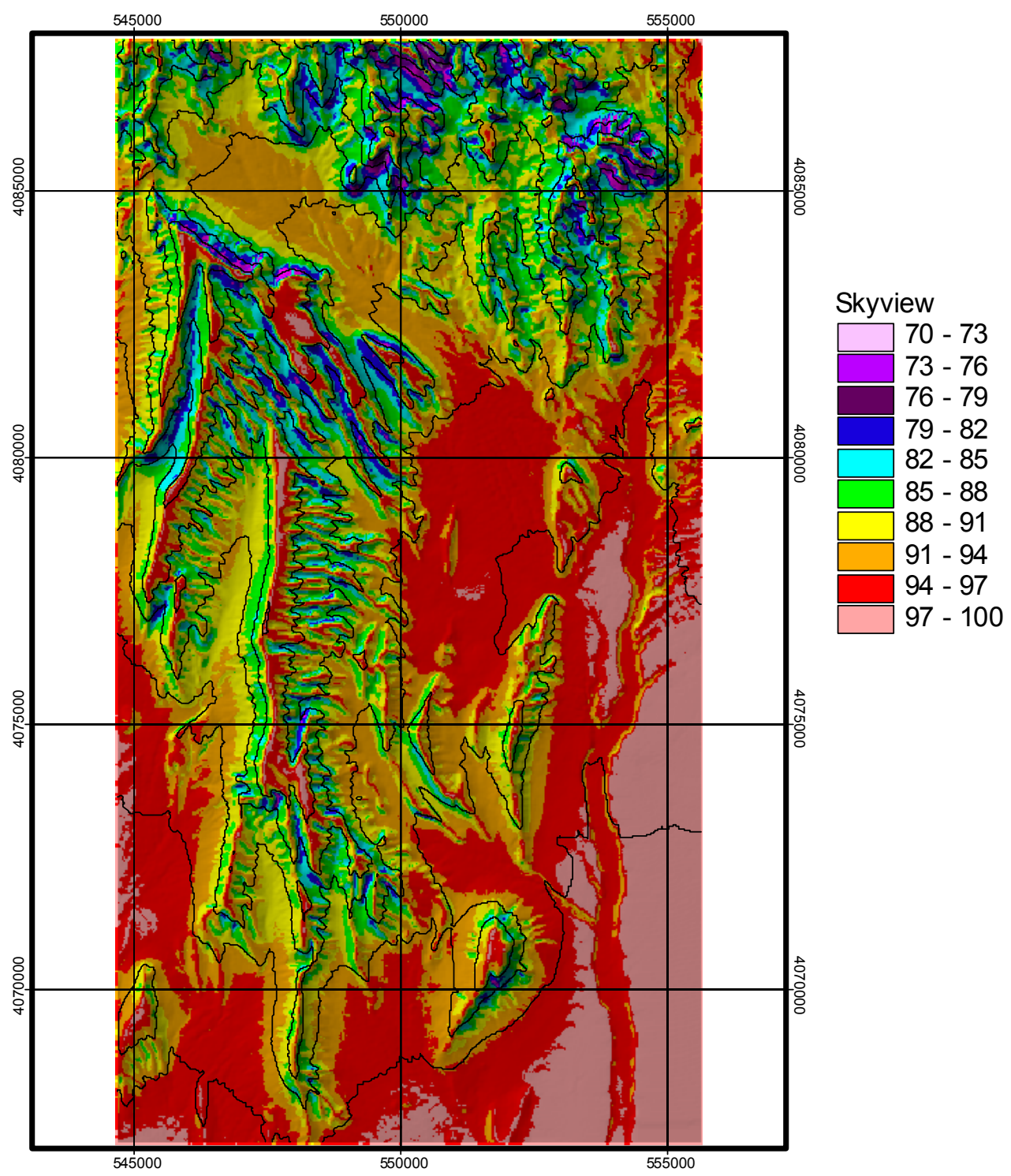

Output DTN: GS000308311221.004.

Figure D-2. Sky-view Factor for Yucca Mountain Model Domain, Indicating the Percentage of Sky Viewed from the Ground Surface Relative to the View from an Infinite Horizontal Plane, Generated for Each Model Grid Cell Location Using the 36 Blocking Ridge Angles Calculated in BLOCKR7 V1.0 


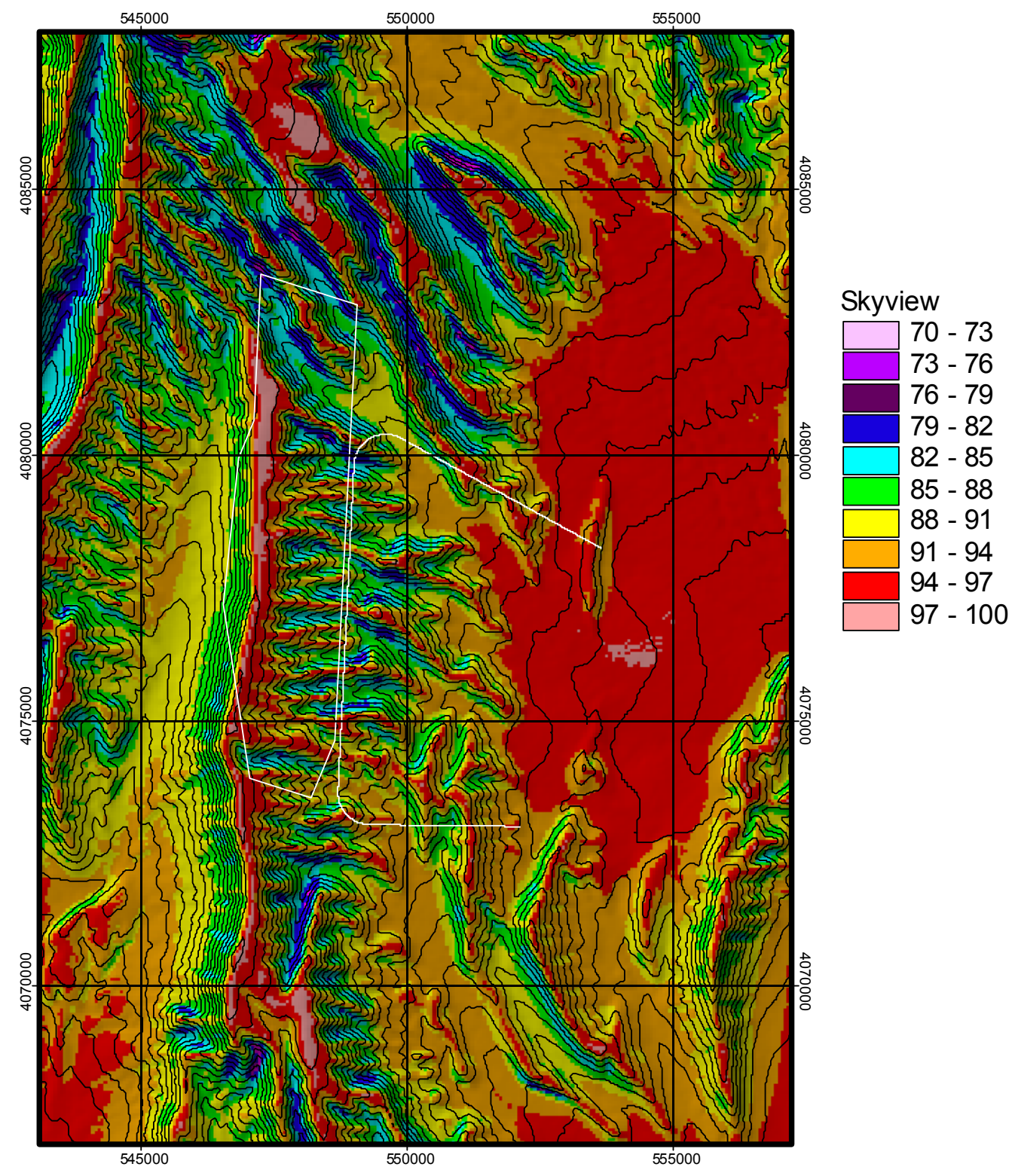

Output DTN: GS000308311221.004.

Figure D-3. Sky-view Factor for the Area of the Repository, Indicating the Expected High (greater than 90 percent) Sky-view Percentages for Ridge-tops and Alluviul Fans, and the Expected Low (less than80 percent) Sky-view Percentages on Steep Side-slopes and Narrow Washes 


\section{- Listing of source code for routine BLOCKR7 V1.0:}

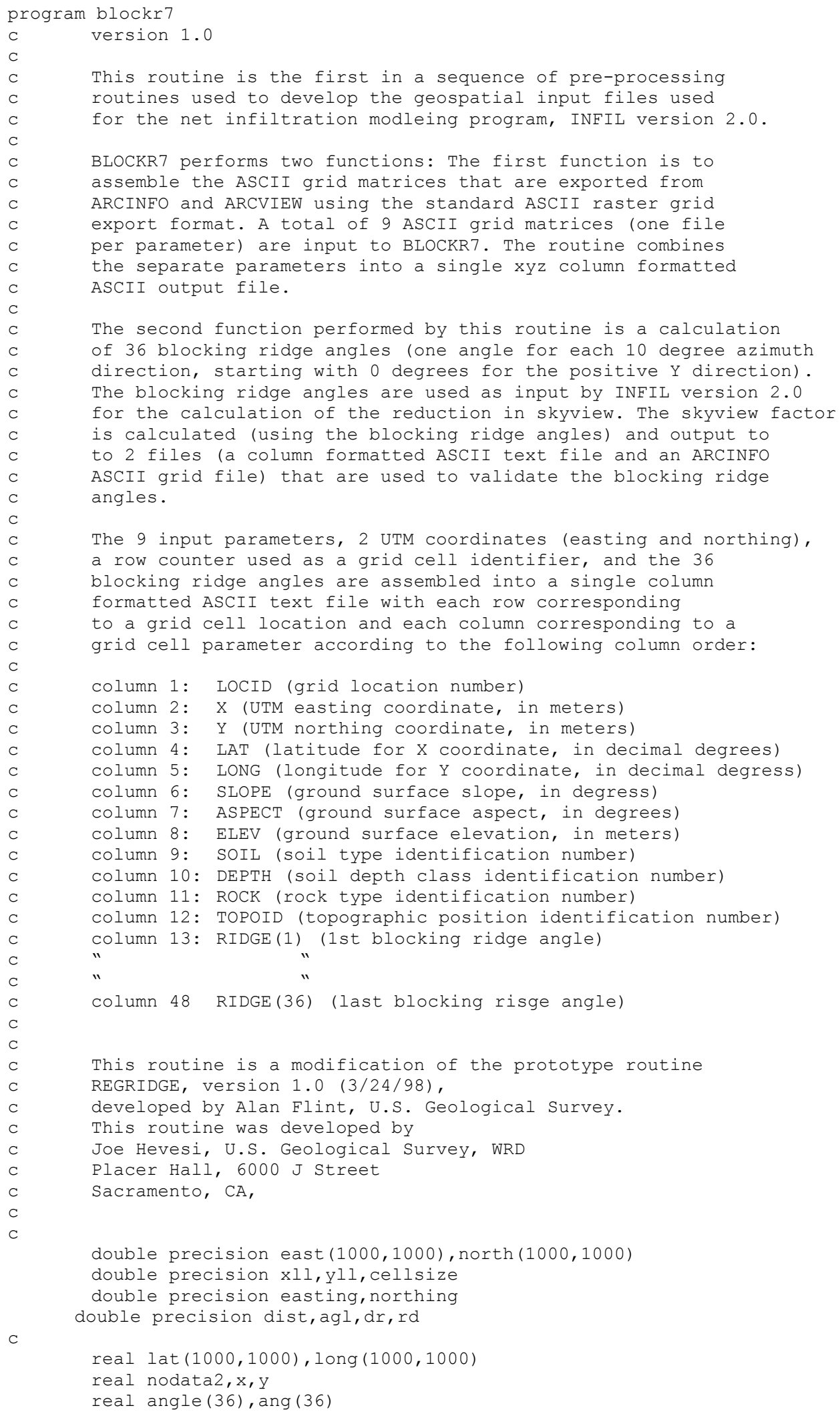




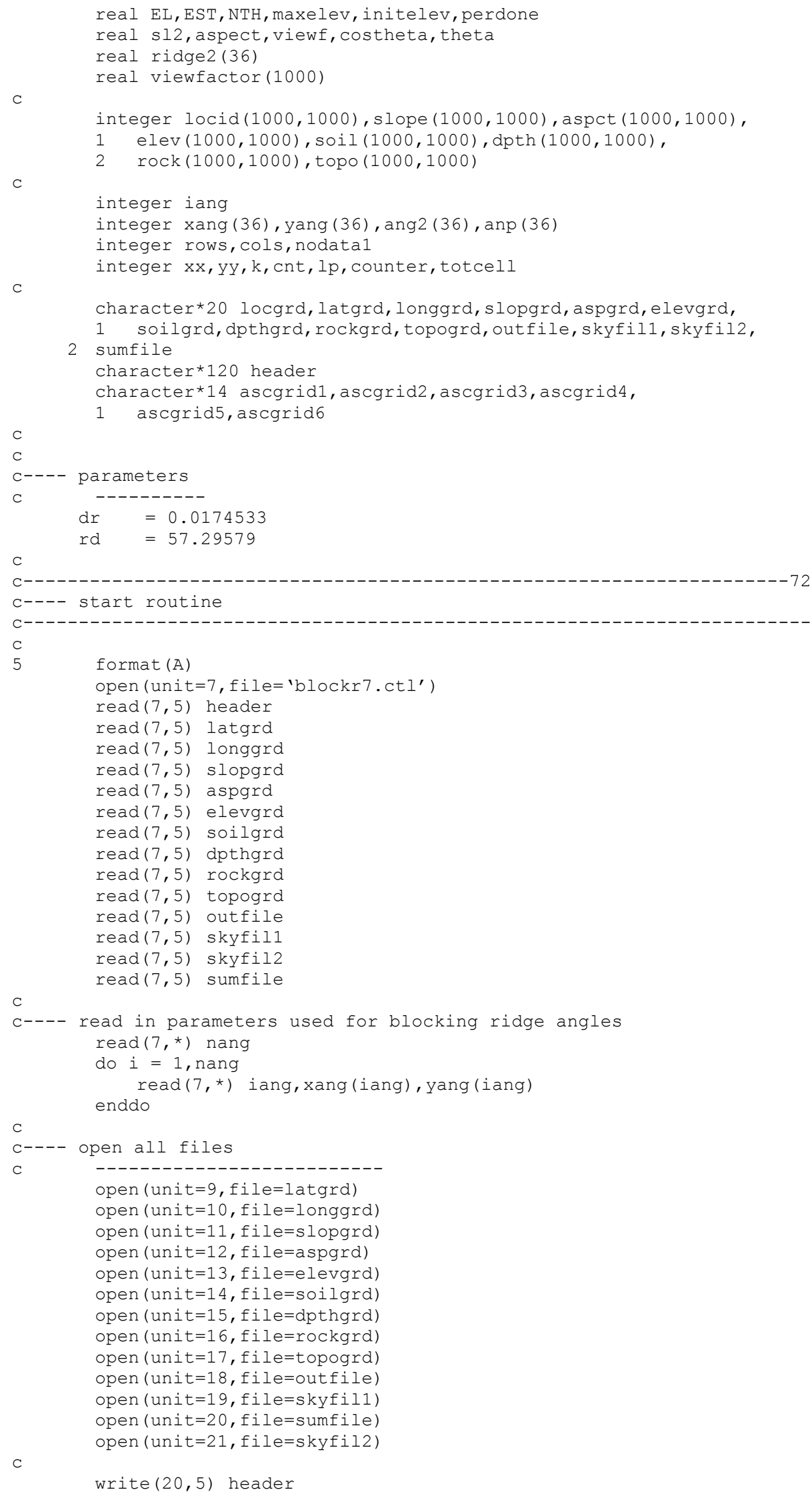




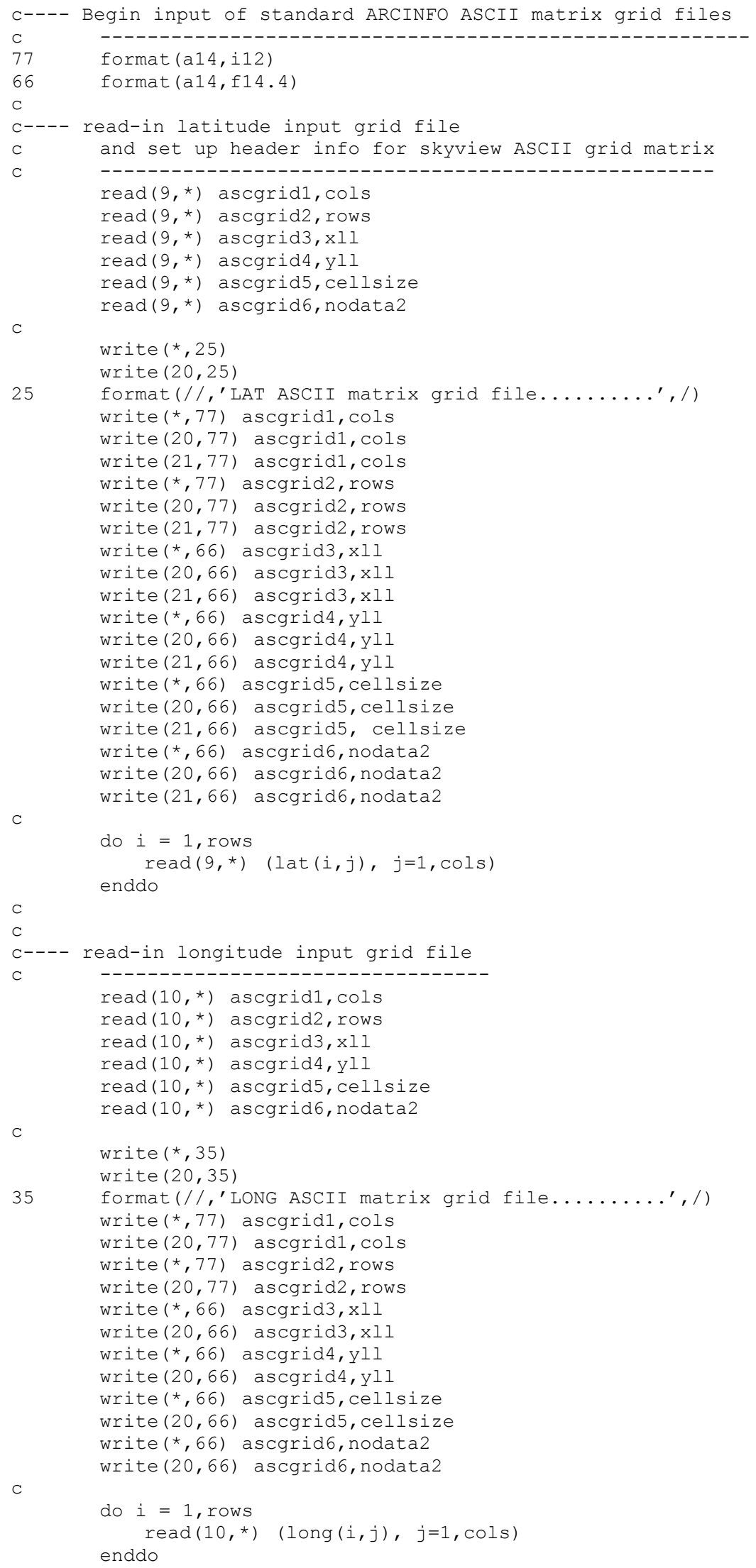




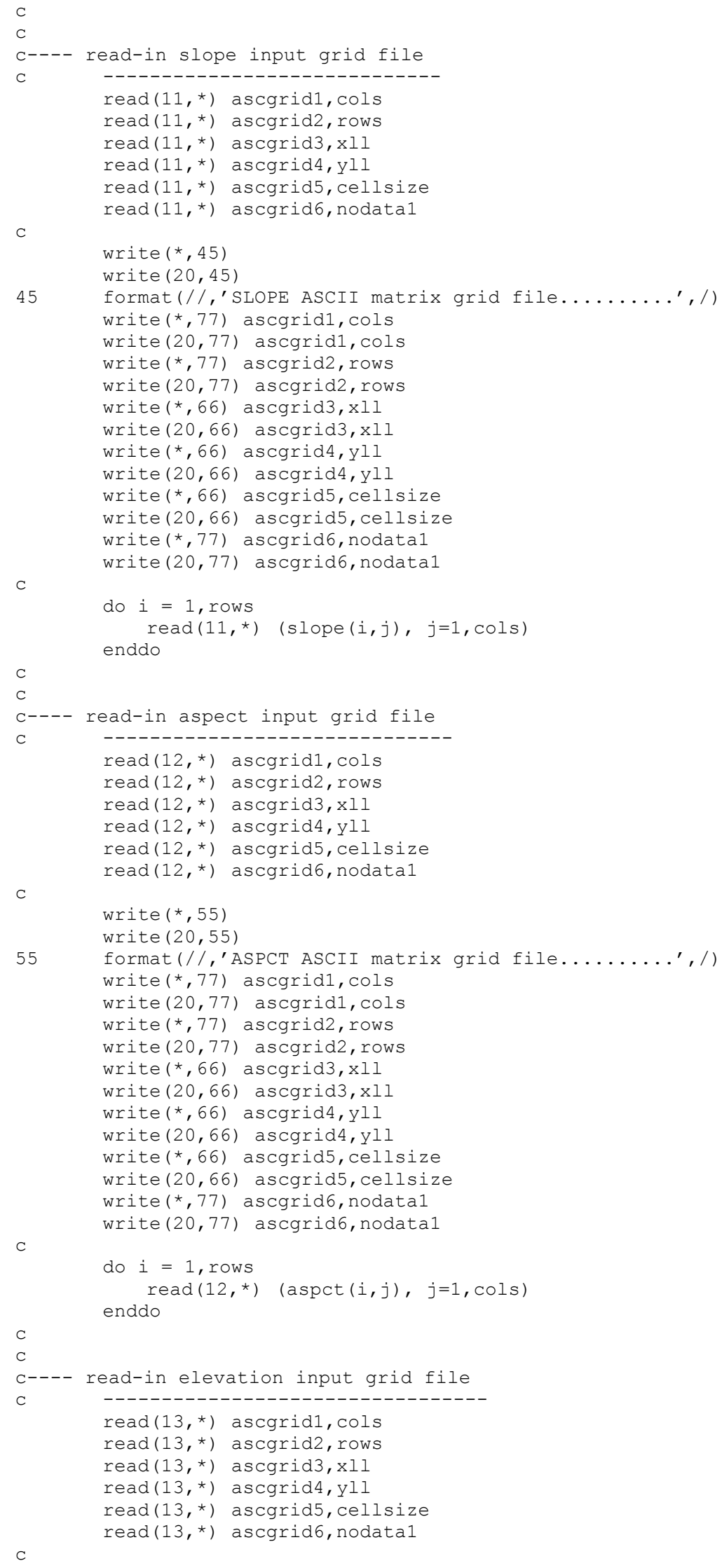




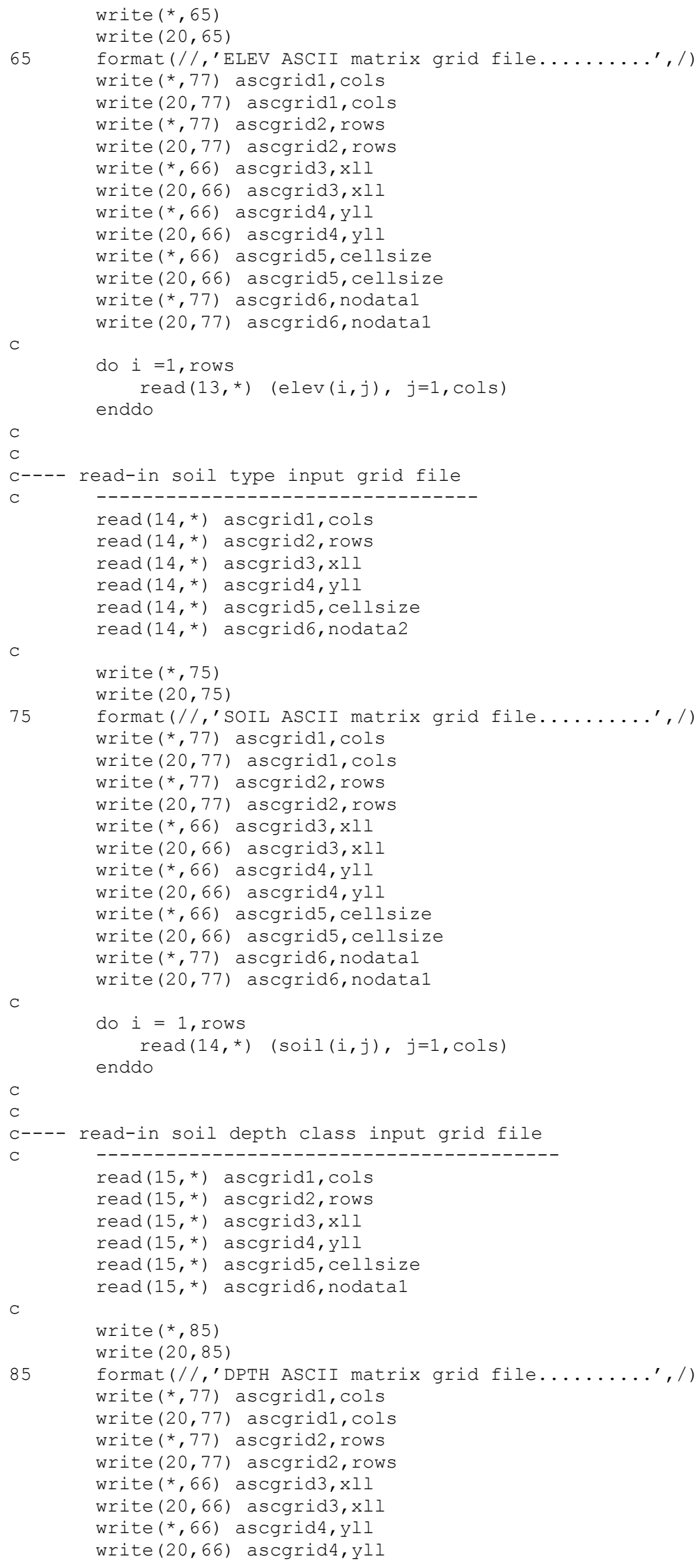


write $(*, 66)$ ascgrid5, cellsize

write $(20,66)$ ascgrid5,cellsize

write $(*, 77)$ ascgrid6, nodatal

write $(20,77)$ ascgrid6, nodatal

do $i=1$, rows

$\operatorname{read}(15, *) \quad(\operatorname{dpth}(i, j), j=1, \operatorname{cols})$

$\mathrm{C}$

enddo

c---- read-in rock type input grid file

read $\left(16,{ }^{*}\right)$ ascgrid1, cols

read $(16, *)$ ascgrid2, rows

$\operatorname{read}\left(16,{ }^{*}\right)$ ascgrid3, xll

$\operatorname{read}(16, *)$ ascgrid4,yll

read $(16, *)$ ascgrid5, cellsize

C

read $(16, *)$ ascgrid6, nodatal

95 format (//,'ROCK ASCII matrix grid file.......',

write $(*, 77)$ ascgridl, cols

write $(20,77)$ ascgrid1, cols

write $(*, 77)$ ascgrid2, rows

write $(20,77)$ ascgrid2, rows

write $(*, 66)$ ascgrid3, xll

write $(20,66)$ ascgrid3,xll

write $(*, 66)$ ascgrid4,yll

write $(20,66)$ ascgrid4,yll

write $(*, 66)$ ascgrid5, cellsize

write $(20,66)$ ascgrid5,cellsize

write $(*, 77)$ ascgrid6, nodatal

C

write $(20,77)$ ascgrid6, nodatal

do $i=1$, rows

$\operatorname{read}(16, *) \quad(\operatorname{rock}(i, j), j=1, \operatorname{cols})$

enddo

C

c---- read-in topographic ID input grid file

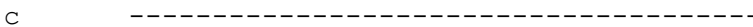

read $(17, *)$ ascgridl, cols

read $\left(17,{ }^{*}\right)$ ascgrid2, rows

read $(17, *)$ ascgrid3, xll

read $(17, *)$ ascgrid4,yll

read $(17, *)$ ascgrid5, cellsize

read $(17, *)$ ascgrid6, nodatal

C

write $(*, 105)$

write $(20,105)$

105 format (//,' TOPOID ASCII matrix grid file.......',/)

write $(*, 77)$ ascgridl, cols

write $(20,77)$ ascgrid1, cols

write $(*, 77)$ ascgrid2, rows

write $(20,77)$ ascgrid2, rows

write $(*, 66)$ ascgrid3, xll

write $(20,66)$ ascgrid3, xll

write $(*, 66)$ ascgrid4,yll

write $(20,66)$ ascgrid4,yll

write $(*, 66)$ ascgrid5, cellsize

write $(20,66)$ ascgrid5, cellsize

write $(*, 77)$ ascgrid6, nodatal

C

write $(20,77)$ ascgrid6, nodatal

do $i=1$, rows

$\operatorname{read}(17, *) \quad(\operatorname{topo}(i, j), j=1, \operatorname{cols})$

enddo

C

totcell $=$ rows $*$ cols 


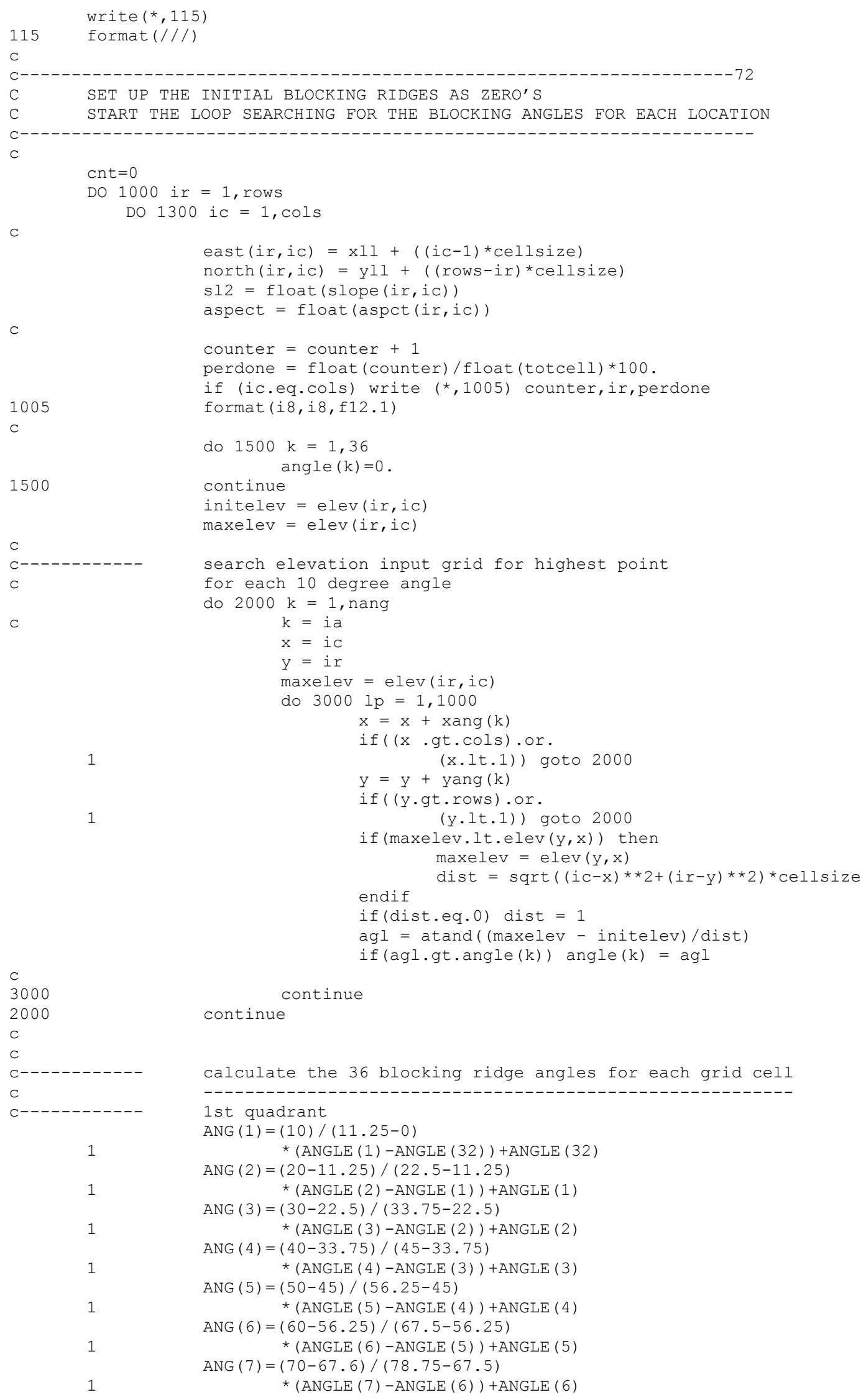




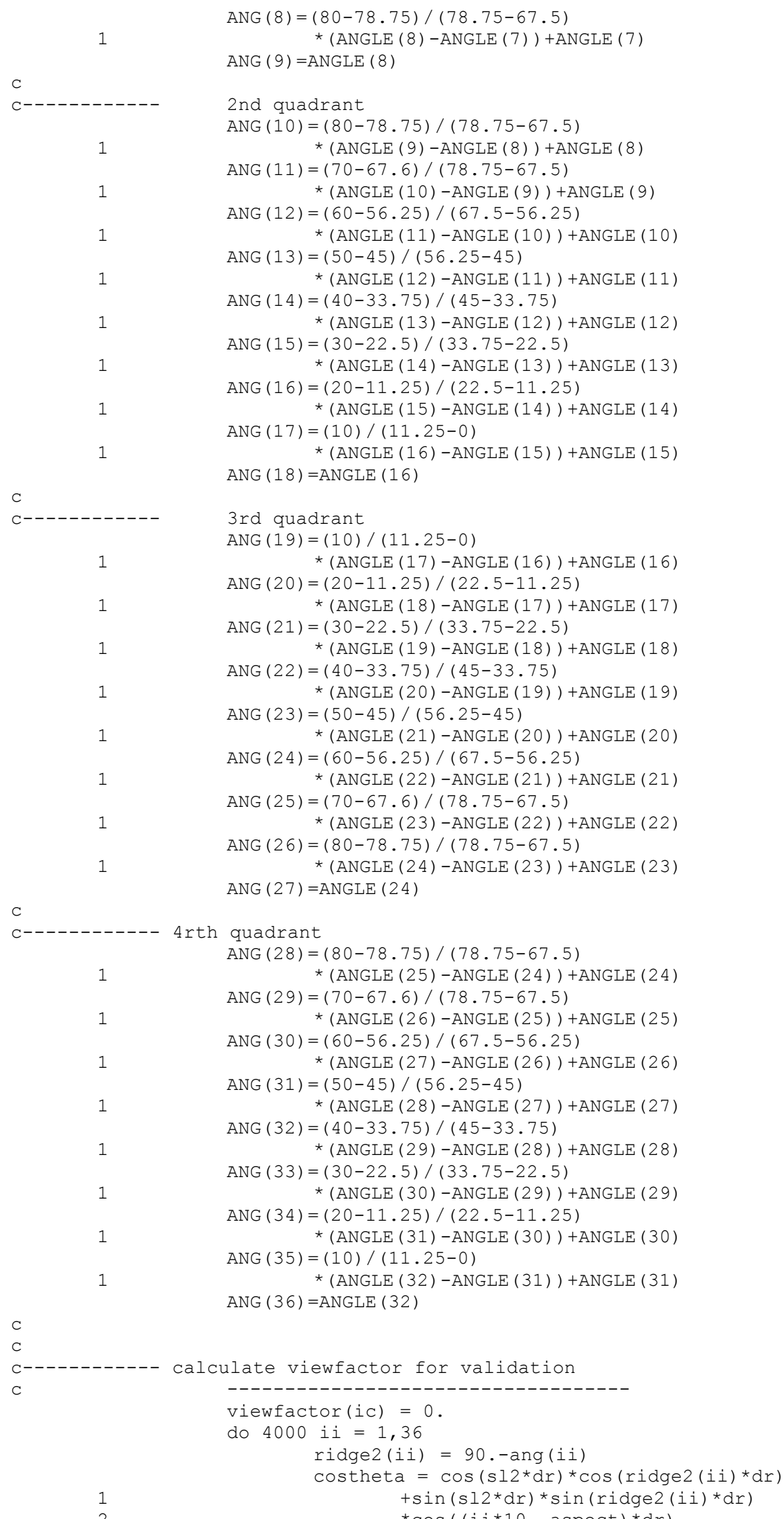

1

$\mathrm{C}$ 


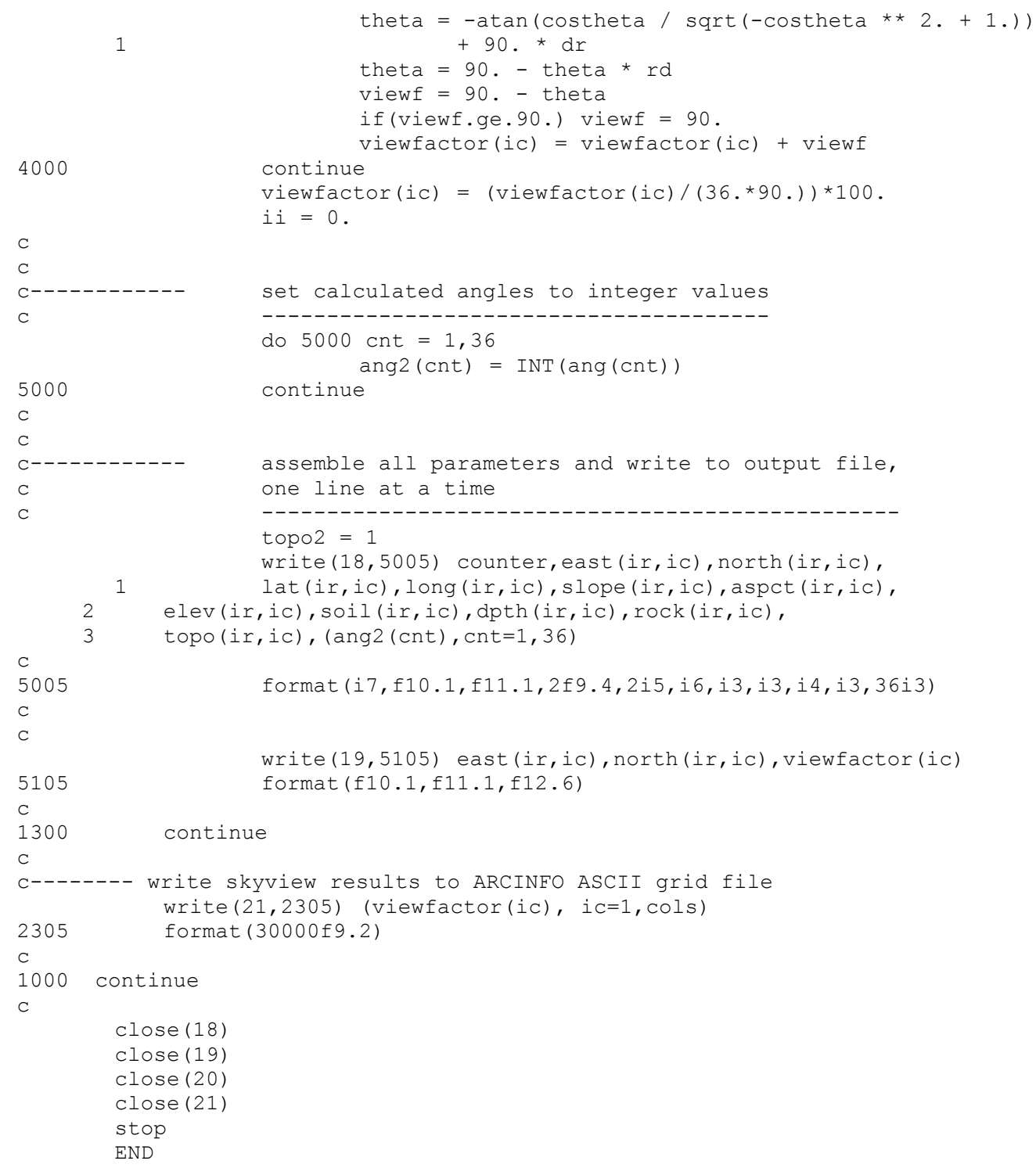




\section{INTENTIONALLY LEFT BLANK}


APPENDIX E

INCLUSION OF UPDATED BEDROCK GEOLOGY USING GEOMAP7 V1.0 


\section{E1. NAME OF ROUTINE/MACRO WITH VERSION/OS/HARDWARE ENVIRONMENT AND USER INFORMATION}

Name of software routine: GEOMAP7 V1.0

OS and hardware environment: Windows NT 4.0, Pentium Pro PC

Computer Identification: SM321276 with a USGS specific host-name P720dcasr

Software Users: Joseph Hevesi (916-278-3274), Alan Flint (916-278-3221)

User Location: U.S. Geological Survey, Room 5000E, Placer Hall, 6000 J Street, Sacramento, CA $95819-6129$

\section{E2. NAME OF COMMERCIAL SOFTWARE WITH VERSION/OS/HARDWARE USED TO DEVELOP ROUTINE/MACRO}

The source code for GEOMAP7 V1.0 was developed using the standard FORTRAN77 programming language. The source code was written, debugged, and compiled (for PC platforms using INTEL processors) using DIGITAL Visual Fortran with Microsoft Developer Studio, V. 5.0.

\section{E3. GENERAL DESCRIPTION OF ROUTINE/MACRO}

GEOMAP7 V1.0 is a FORTRAN77 routine developed in accordance with AP-SI.1Q, specifically for the analysis/model activity documented in this report. The routine source code (GEOMAP7.FOR), compiled executable file (GEOMAP7.EXE), routine control file (GEOMAP7.CTL), input and output files, validation test files, and a copy of this appendix, are located under the directory GEOMAP7 on a CD-ROM labeled GEOINPUT-1. The routine source code, control file, and the input and output files are ASCII text files that can be read using any standard ASCII text editor and can be imported into standard word processing applications such as Microsoft Word. The executable file can be used to run GEOMAP7 V1.0 on any PC with an INTEL processor (with adequate RAM).

All parameters calculated by GEOMAP7 V1.0 that are included in the developed output file, GEOMAP7.INP are used for the development of the geospatial parameter input file for INFIL V2.0 (USGS 2000 [DIRS 139422]). The file, GEOMAP7.INP is used directly as input to the routine SOILMAP6 V1.0 (Appendix G).

\section{E4. TEST PLAN FOR THE SOFTWARE ROUTINE GEOMAP7 V1.0}

\section{- Explain whether this is a routine or macro and describe what it does:}

GEOMAP7 V1.0 is the second routine in a sequence of developed FORTRAN77 routines that are used in the development of the geospatial parameter input files for INFIL V2.0. The primary function performed by the routine is the inclusion of the updated bedrock geology map for the central block area (source data obtained from Day et al. (1998 [DIRS 101557]), DTN: GS971208314221.003 [DIRS 107128] into the original geospatial parameter input file (30MSITE.INP) used as input for INFIL V1.0, the 1996 version of the net infiltration model (Flint et al. 1996 [DIRS 100147]). The modified bedrock geology is defined by the rock-type identification number included in the output file, GEOMAP7.INP. The updated 
bedrock geology map is provided as an ASCII text, column-formatted input file named NEWGEOL.DAT. Using standard ARCINFO applications, NEWGEOL.DAT is developed by rasterizing ${ }^{1}$ the available source data ${ }^{2}$ onto the grid geometry defined by 30MSITE.INP and exporting the rasterized data as a column-formatted, xyz ASCII text file. To incorporate the updated bedrock geology, GEOMAP7 scans the input grid defined by the easting and northing coordinate locations in 30MSITE.INP (columns 2 and 3), matches the grid cells with the corresponding locations of NEWGEOL.DAT, and substitutes the existing rock-type identification number in column 11 of 3OMSITE.INP with the updated rock-type identification number in NEWGEOL.DAT. To identify the new rock-type identification numbers as separate from the original rock-type identification numbers used in 30MSITE.INP, which are based on the geologic maps developed by Scott and Bonk (1984 [DIRS 104181]) (DTN: MO0003COV00095.000 [DIRS 146848]) and Sawyer et al. (1995 [DIRS 104580]) (DTN: GS000300001221.010 [DIRS 147833]), GEOMAP7 adds 300 to the initial integer values provided by NEWGEOL.DAT.

A second function performed by the routine is a back-substitution of the original Scott and Bonk (1984 [DIRS 104181]) rock-type identification number (column 11 in 30MSITE.INP) wherever there are locations with soil thickness less than $6 \mathrm{~m}$ as identified by the soil depth class number (column 10 in 30MSITE.INP), and which are associated with an updated rock-type identification number that corresponds to alluvium. The back-substitution is accomplished by excluding the updated rock-type numbers during the scanning of the input grid and is performed only if the original rock-type defined in 3OMSITE.INP is associated with a consolidated rock-type.

The input and output files used by GEOMAP7 are defined in the routine control file, GEOMAP7.CTL that is itself an input file for the routine. The input files defined in GEOMAP7.CTL consist of 30MSITE.INP, NEWGEOL.DAT, and the output file, GEOMAP7.INP. Two additional lines following the filenames are a lower and upper bound easting coordinate ( $5^{\text {th }}$ line in file, two input values) and a lower and upper bound northing coordinate ( $6^{\text {th }}$ line in file, two input values). These parameters are used only to limit the search area scanned by GEOMAP7 to a rectangular area centered over and fully containing all grid cells in NEWGEOL.DAT associated with rock-type identification numbers from Day et al. (1998 [DIRS 101557]). The purpose of this function is only to decrease routine run-time, and is not associated with functions used in the development of the output file.

\footnotetext{
${ }^{1}$ Rasterization refers to a standard ARCINFO operation of transferring spatial data defined by points, vector lines, and polygons onto the grid-cell areas of a "raster" grid matrix defined by a fixed square cell dimension, the location coordinates of the lower left grid cell included in the matrix, and the number of rows and columns defining the matrix.

${ }^{2}$ The source data consists of an ARCINFO vector-based map coverage (*.e00 file and associated metadata)
} 


\section{- Listing of FORTRAN77 Source code:}

A listing of the FORTRAN77 source code for the routine GEOMAP7 V1.0 along with examples of the input and output files used in the test plan are included at the end of this appendix.

\section{- Description of test(s):}

A validation test of the functions performed by the routine was conducted by a visual comparison between the input files (30MSITE.INP and NEWGEOL.DAT) and the output file (GEOMAP7.INP). The test plan for the primary function performed by GEOMAP7 consists of a visual verification that the rock-type identification numbers defining the updated geology (and provided as input by NEWGEOL.DAT) are associated with the correct grid cell locations defined by the new geospatial parameter input file (GEOMAP7.INP). The test plan involves a visual verification that a value of 300 has been added to the updated rock-type identification numbers. The test plan for the additional function performed by GEOMAP7 (exclusion of the updated rocktype based on a comparison against the soil depth map and the updated geology) consists of a visual verification that the rock-type identification numbers defining the original geology (column 11 in 30MSITE.INP) are associated with the correct grid cell locations based on a comparison against both the soil depth map and the updated geology map. The comparison of input and output grid cell values was facilitated using the raster-based grid and map-imaging utilities available in the acquired software program TRANSFORM. The raster-based grid and map-imaging utilities allow for an analysis of the entire raster grid and also a detailed evaluation of grid cell values for specified grid locations. The criteria applied during this phase of the routine test plan was an indication by the map images generated in TRANSFORM that: 1) a value of 300 had been correctly added to the updated geology, 2) that modifications to the rock-type parameter had been performed to the correct grid cell locations, and 3) that the bedrock geology defined by Day et al. (1998 [DIRS 101557]) had been correctly represented by the modified rock-type parameter.

Additional routine validation tests were performed by extracting and comparing identical subsets (in terms of grid cell locations) from the raster images created in TRANSFORM and by importing identical subsets (based on grid cell locations) of the input file, 30MSITE.INP and the output file, GEOMAP7.INP into an EXCEL worksheet file. This method of testing provided an additional check that the functions performed by GEOMAP7 were operating correctly. The EXCEL worksheet file (GEOMAP7.XLS) was used to perform an inspection of the entire set of geospatial parameters for a selected subset of grid locations. The criteria applied in this method of validation consisted of verifying within the spreadsheet that the intended modification of the geospatial input file had been correctly performed, and that no unintended modifications had occurred during program execution, either to the parameters being modified (in this case, the rock-type identification number) or to any of the other parameters not requiring modification during this stage of the development of the geospatial parameter input files for INFIL V2.0. 


\section{- Specify the range of input values to be used and why the range is valid:}

Two column-formatted ASCII-text files, NEWGEOL.DAT and 30MSITE.INP, are used as input by GEOMAP7 V1.0. Both files consist of a series of rows (one row per grid cell location), two columns defining grid cell locations (NAD27 UTM, zone 11 coordinates, in meters), and additional columns containing the geospatial input parameters associated with each grid cell. The two input files are specified in the routine control file, GEOMAP7.CTL, which is the third input file needed for the execution of GEOMAP7 V1.0. The range of input values specified in the listing below is valid because these values were obtained from ARCINFO using the source data as input and the functions performed by the routine BLOCKR7 V1.0 (see Appendix $\mathrm{D}$ for description of source data used for 30MSITE.INP). The input parameters are identical to the geospatial input parameters used for INFIL V1.0 (Flint et al. 1996 [DIRS 100147]).

1. NEWGEOL.DAT: Column-formatted ASCII text file consisting of 4 columns and 57,038 rows. This file is exported from ARCINFO using the Day et al. (1998 [DIRS 101557]) (DTN: GS971208314221.003 [DIRS 107128]) geology map and the merged digital elevation model (DTN: GS000308311221.006) as input. The first column defines the grid cell location number, the next two columns define the UTM easting and northing coordinates (in meters) for each grid cell location, and the fourth column defines the updated rock-type identification number from Day et al. (1998 [DIRS 101557]) consisting of values ranging from 1 to 45 , and a no-data flag of -99 .

2. 30MSITE.INP: Column-formatted ASCII text file consisting of 48 columns and 253,597 rows. This file is developed as the output from BLOCKR7. The rock-type identification numbers are located in column 11 and consist of integer values ranging from 1 to 214 . The rock-type identification numbers were used as input for INFIL V1.0 (Flint et al. 1996 [DIRS 100147]) and are based on the Scott and Bonk (1984 [DIRS 104181]) (DTN: MO0003COV00095.000 [DIRS 146848]) and the Sawyer et al. (1995 [DIRS 104580]) (DTN: GS000300001221.010 [DIRS 147833]) geology maps. A more complete description of the parameters included in this file, along with input and output ranges, is provided in Appendix D.

\section{E5. TEST RESULTS}

\section{- Output from test:}

The output for the test case is the main output file, GEOMAP7.INP generated by GEOMAP7 V1.0. Additional files developed as part of the testing procedure include four TRANSFORM map image files (NEWGEOL.HDF, 30MGEOL.HDF, $30 M D P T H . H D F$, and GEOMAP7.HDF) that are used to inspect the modified parameters between the input and output files and an EXCEL worksheet 
(GEOMAP7.XLS) used to perform additional inspections of parameter modifications for a selected subset of grid cell locations.

\section{Description of how the testing shows that the results are correct for the specified input:}

The map images developed using TRANSFORM (Figures G-1 through G-3) indicate by visual inspection that the integer values defining the updated bedrock geology from Day et al. (1998 [DIRS 101557]) have been correctly incorporated into the output file, GEOMAP7.INP that is created by GEOMAP7. For example, it is verified by visual inspection that the original rock-type identification parameters (Figure E-2), which range from 1 to 214, have been correctly modified to include the updated rock-types (Figure E-1), which consist of integer values ranging from 1 to 45 , because the rock-type identification numbers of the output file show the correct composite spatial positioning of the three separate geologic maps and the new rock-type identification numbers range from 301 to 345 (Figure E-3). Visual inspection of the map images indicates that the integer values represented by Figure E-1 have been correctly overlain onto the original rock-type integer values shown in Figure E-2 and increased by a value of 300 to produce the final set of rock-type identification numbers represented by Figure E-3. The test criteria of the correct placement of updated rock-type identification numbers and the correct separation of the updated integer values from the original rock-type identification numbers by adding 300 to the integer values provided by NEWGEOL.DAT is satisfied based on the visual comparison of the map images.

Verification that the correct back-substitution of the original rock-type identification numbers for Scott and Bonk (1984 [DIRS 104181]) geology for locations where a soil depth of less than $6 \mathrm{~m}$ (soil depth classes less than 4) coincided with mapped alluvium from Day et al. (1998 [DIRS 101557]) is provided by a comparison of Figures G-4 (indicating the original rock-type identification numbers defined using Scott and Bonk (1984 [DIRS 104181]) and G-5 (indicating the new rock-type identification numbers defined using Day et al. (1998 [DIRS 101557]) with Figure E-4 (the new rock-type identification numbers) and Figure E-6 (the soil depth class map). The locations where the Scott and Bonk (1984 [DIRS 104181]) rock-types were retained coincide with the locations of upper washes and lower sideslopes where mapping bedrock geology is less certain because of increasing soil thickness, and this is the intended result.

Additional validation that the test criteria are satisfied for the two functions performed by GEOMAP7 is provided by Tables G-1 through G-6. Tables G-1 through G-4 were created by selecting in TRANSFORM a subset of the raster matrix grid defined by 30MSITE.INP from the map images of the Day et al. (1998 [DIRS 101557]) geology map (NEWGEOL.HDF) for Table E-1, the soil depth class map (30MDPTH.HDF) for Table E-2, the original rock-type identification numbers in 30MSITE.INP $(30 M G E O L . H D F)$ for Table E-3, and the new rock-types identification numbers created by GEOMAP7 (GEOMAP7.HDF) for Table E-4. A comparison of the four tables indicates that the new rock-type numbers were correctly substituted and increased by 300 (validation of test criteria for the first function) and that the original 
consolidated rock-type number 20 from Scott and Bonk (1984 [DIRS 104181]) was retained for three grid locations were the updated rock-types of 301 and 302 indicated unconsolidated rock-types for a location having only 0 to $0.5 \mathrm{~m}$ of soil cover (which is inconsistent). For satisfying the test criteria that no modifications were made to parameters other than rock-type, identical sections of the files, 30MSITE.INP and GEOMAP7.INP were extracted into an EXCEL worksheet (GEOMAP7.XLS). Table E-5 shows the input parameters obtained from 30MSITE.INP (with the exception of the 36 blocking ridge parameters) and Table E-6 shows that the only parameter modified in the output file, GEOMAP7 is the rock-type identification.

\section{- List limitations or assumptions to this test case and code in general:}

The limitations of the developed test case are based on the practical limitations of verifying modified parameter values for all 253,597 grid cells included in the output file used for the developed test case. Validation of the entire output file used in the test case was performed as a visual evaluation of a map image produced in TRANSFORM. Only a subset of the entire output file could be used for more detailed validation tests that were performed in an EXCEL worksheet.

\section{- Electronic files identified by name and location:}

Electronic files are located on CD-ROM labeled GEOINPUT-1, under the directory GEOMAP7, included as an Appendix to the report. The following electronic files are provided:

GEOMAP7.CTL: Input file consisting of the input and output file names for GEOMAP7 V1.0, along with 4 UTM coordinate parameters that are used to define a rectangular area centered over and containing the updated central block bedrock geology map from Day et al. (1998 [DIRS 101557]).

GEOMAP7.FOR: FORTRAN source code listing for the routine GEOMAP7 V1.0. A printout of the source code is included as part of this appendix.

GEOMAP7.EXE: Executable file for the routine GEOMAP7 V1.0, compiled for INTEL processors.

NEWGEOL.DAT: Input file consisting of a column-formatted, ASCII text file with four columns and 57,038 rows. This file was developed in ARCINFO by a rasterization of the Day et al. (1998 [DIRS 101557]) map coverage, (DTN: GS971208314221.003 [DIRS 107128]) which is an ARCINFO vector-based file (*.e00 file), onto the raster-grid defined by the merged digital elevation model (DTN: GS000308311221.006). The rasterized map was exported from ARCINFO as a column-formatted, ASCII text file. A partial printout of the first part of this file is included as part of this appendix. 
30MSITE.INP: Input file consisting of a column-formatted, ASCII text file with 48 columns and 253,597 rows. Each row corresponds to a grid cell location for the geospatial parameter base grid (the UTM location coordinates are defined by columns 2 and 3 ). This file is developed as output from BLOCKR7 V1.0 (see Appendix D of this report for more details). A partial printout of the first part of this file is included as part of this appendix.

GEOMAP7.INP: Output file consisting of a column-formatted, ASCII text file with 48 columns and 253,597 rows. Each row corresponds to a grid cell location for the geospatial parameter base grid (the UTM location coordinates are defined by columns 2 and 3). Column 11 of this file includes the updated rock-type identification numbers as a result of the functions performed by the routine GEOMAP7 V1.0. A partial printout of the first part of this file is included as part of this appendix.

GEOMAP7.XLS: EXCEL worksheet used to perform the software routine validation test, provided only as supporting information for the validation test. This file is not a part of the routine application.

GEOMAP7.HDF: TRANSFORM raster-based map image of the updated rock-type identification numbers (created using column 11 in GEOMAP7.INP) used to perform the software routine validation test, provided only as supporting information for the validation test. This file is not a part of the routine application.

30MGEOL.HDF: TRANSFORM raster-based map image of the original rock-type identification numbers (created using column 11 in 30MSITE.INP) used to perform the software routine validation test, provided only as supporting information for the validation test. This file is not a part of the routine application.

NEWGEOL.HDF: TRANSFORM raster-based map image of the rasterized central block bedrock geology map from Day et al. (1998 [DIRS 101557]) (created using column 4 in NEWGEOL.DAT) used to perform the software routine validation test, provided only as supporting information for the validation test. This file is not a part of the routine application.

30MDPTH.HDF: TRANSFORM raster-based map image of the soil depth class number (created using column 10 in 30MSITE.INP) used to perform the software routine validation test, provided only as supporting information for the validation test. This file is not a part of the routine application. 
E6. SUPPORTING INFORMATION. (INCLUDE BACKGROUND INFORMATION, SUCH AS REVISION TO A PREVIOUS ROUTINE OR MACRO, OR EXPLANATION OF THE STEPS PERFORMED TO RUN THE SOFTWARE. INCLUDE LISTINGS OF ALL ELECTRONIC FILES AND CODES USED).

\section{- Procedure for running routine:}

To run the routine GEOMAP7 V1.0, an executable version of the code, the input files, NEWGEOL.DAT and 3OMSITE.INP, and the routine control file, GEOMAP7.CTL must be placed in the same directory. The routine is executed by typing GEOMAP7 in a DOS window, or by double clicking on the file, GEOMAP7.EXE in the Microsoft Windows operating system. The input and output file names and the parameters used for the blocking ridge calculations must be in the correct sequential order as specified in the routine control file, GEOMAP7.CTL (see example listing in this section).

\section{- Example listing of routine control file, GEOMAP7.CTL}

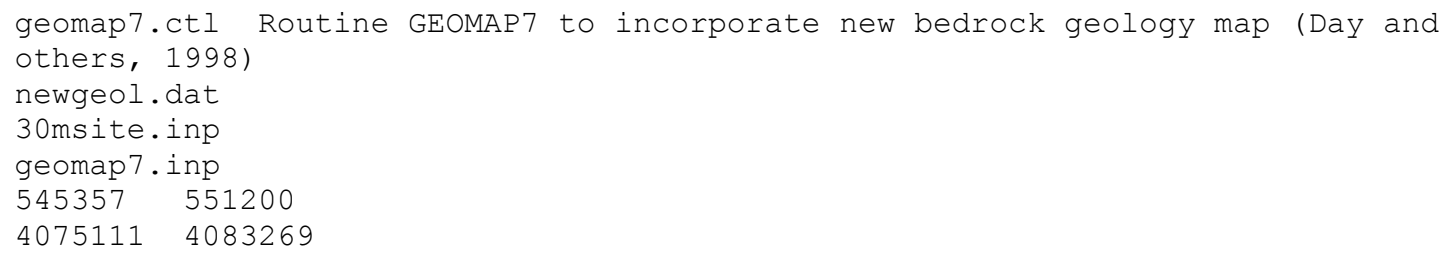

- Example listing of 30MSITE.INP. This is the main input file used by GEOMAP7 V1.0 (only the first 20 lines of the file are listed)

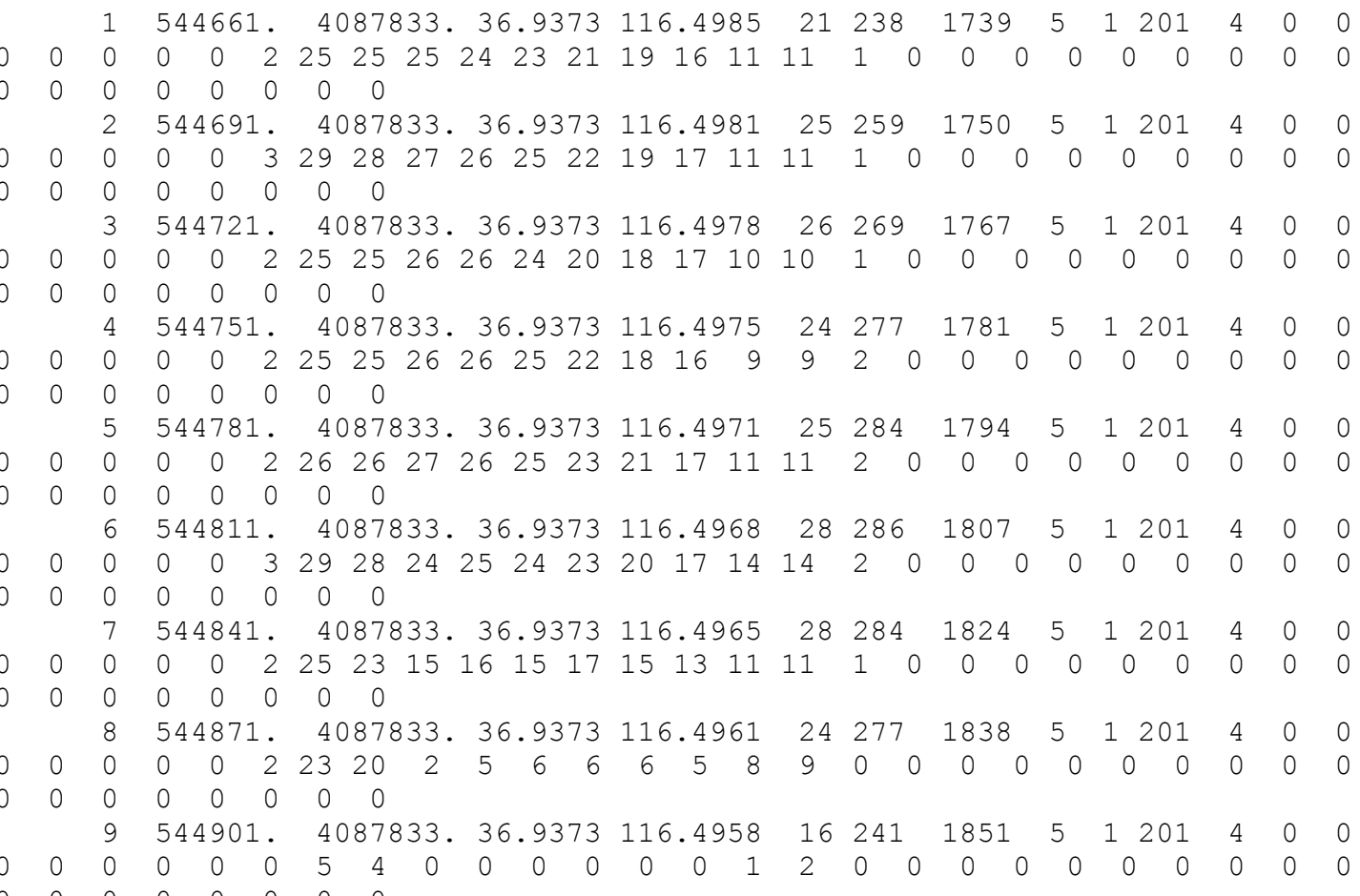




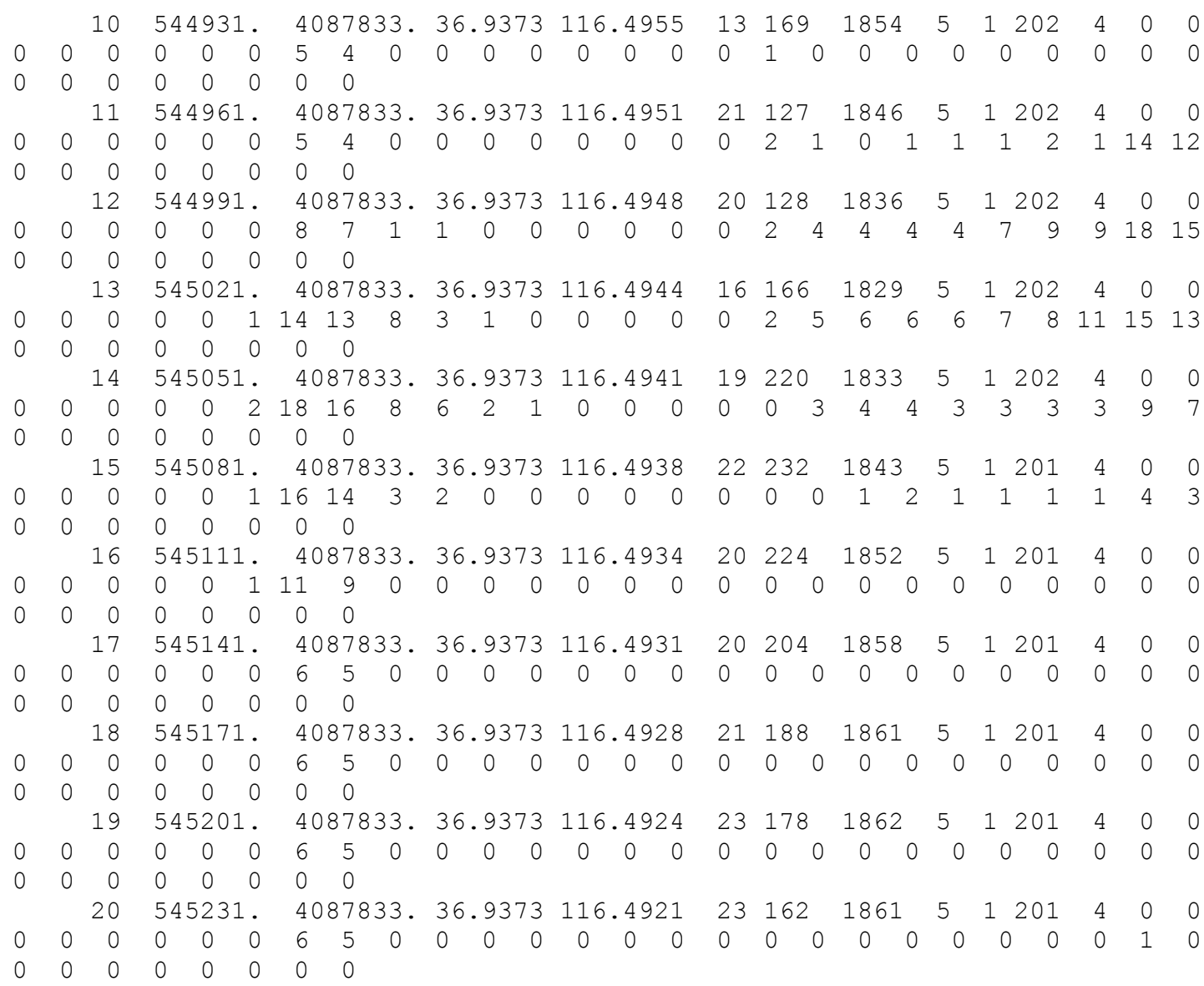

- Example listing of $N E W G E O L . D A T$. This is the ASCII text file exported from ARCINFO and developed as a rasterization of the vector-based bedrock geology map from Day et al. (1998 [DIRS 101557]). The first column is the grid cell location number, columns 2 and 3 are the NAD27 UTM zone 11 coordinates (in meters), and column 4 is the integer code associated with the Day et al. (1998 [DIRS 101557]) (DTN: GS971208314221.003 [DIRS 107128]) central block geology map (values range from 1 to 45 , with a no-data flag of -99).

$\begin{array}{lllr}56812 & 549971 . & 4082283 . & 2 \\ 56813 & 550001 . & 4082283 . & 1 \\ 56814 & 550031 . & 4082283 . & 1 \\ 56815 & 550061 . & 4082283 . & 1 \\ 56816 & 550091 . & 4082283 . & 1 \\ 56817 & 550121 . & 4082283 . & 1 \\ 56818 & 550151 . & 4082283 . & 1 \\ 56819 & 550181 . & 4082283 . & 1 \\ 56820 & 550211 . & 4082283 . & 1 \\ 56821 & 550241 . & 4082283 . & 1 \\ 56822 & 550991 . & 4082283 . & 2 \\ 56823 & 551021 . & 4082283 . & 2 \\ 56824 & 551051 . & 4082283 . & -99 \\ 56825 & 551081 . & 4082283 . & -99 \\ 56826 & 551111 . & 4082283 . & -99 \\ 56827 & 551141 . & 4082283 . & -99 \\ 56828 & 551171 . & 4082283 . & -99\end{array}$




\begin{tabular}{|c|c|c|c|}
\hline 56955 & 545381 . & 4082253 & -99 \\
\hline 56956 & 545411. & 4082253. & -99 \\
\hline 56957 & 545441 . & 4082253. & -99 \\
\hline 56958 & 545471 . & 4082253. & -99 \\
\hline 56959 & 545501 . & 4082253. & -99 \\
\hline 56960 & 545531 . & 4082253. & -99 \\
\hline 56961 & 545561 . & 4082253. & -99 \\
\hline 6962 & 545591 . & 4082253. & -99 \\
\hline 6963 & 545621 . & 4082253. & -99 \\
\hline 56964 & 545651 . & 4082253. & -99 \\
\hline 56965 & 545681 . & 4082253. & -99 \\
\hline 56966 & 545711. & 4082253. & -99 \\
\hline 56967 & 545741 . & 4082253. & -99 \\
\hline 56968 & 545771. & 4082253. & -99 \\
\hline 6969 & 545801. & 4082253. & -99 \\
\hline 56970 & 545831. & 4082253. & -99 \\
\hline 56971 & 545861 . & 4082253. & -99 \\
\hline 56972 & 545891 . & 4082253. & -99 \\
\hline 56973 & 545921. & 4082253. & -99 \\
\hline 56974 & 545951 . & 4082253. & -99 \\
\hline 56975 & 545981 . & 4082253. & -99 \\
\hline 56976 & 546011 . & 4082253 & -99 \\
\hline 56977 & 546041 . & 4082253 & -99 \\
\hline 56978 & 546071 . & 4082253. & -99 \\
\hline 56979 & 546101. & 4082253. & -99 \\
\hline 56980 & 546131. & 4082253. & -99 \\
\hline 56981 & 546161. & 4082253. & -99 \\
\hline 56982 & 546191 . & 4082253. & -99 \\
\hline 56983 & 546221. & 4082253. & -99 \\
\hline 56984 & 546251 . & 4082253. & -99 \\
\hline 56985 & 546281 . & 4082253. & -99 \\
\hline 56986 & 546311. & 4082253. & -99 \\
\hline 56987 & 546341 . & 4082253. & -99 \\
\hline 56988 & 546371 . & 4082253. & -99 \\
\hline 56989 & 546401. & 4082253. & -99 \\
\hline 56990 & 546431 . & 4082253 & 12 \\
\hline 56991 & 546461 . & 4082253. & 12 \\
\hline 56992 & 546491 . & 4082253. & 12 \\
\hline 56993 & 546521 . & 4082253. & 12 \\
\hline 56994 & 546551 . & 4082253. & 12 \\
\hline 56995 & 546581 . & 4082253. & 13 \\
\hline 56996 & 546611. & 4082253 & 13 \\
\hline 56997 & 546641 . & 4082253. & 14 \\
\hline 56998 & 546671 . & 4082253. & 19 \\
\hline 56999 & 546701 . & 4082253. & 19 \\
\hline 57000 & 546731. & 4082253. & 20 \\
\hline 57001 & 546761 . & 4082253 & 21 \\
\hline 57002 & 546791 . & 4082253. & 21 \\
\hline 57003 & 546821 . & 4082253. & 24 \\
\hline 57004 & 546851 . & 4082253. & 23 \\
\hline 57005 & 546881 . & 4082253. & 22 \\
\hline 57006 & 546911 . & 4082253. & 21 \\
\hline 57007 & 546941 . & 4082253. & 21 \\
\hline 57008 & 546971 . & 4082253. & 21 \\
\hline 57009 & 547001 . & 4082253. & 20 \\
\hline 57010 & 547031 . & 4082253. & 20 \\
\hline 57011 & 547061 & 4082253. & 19 \\
\hline 57012 & 547091 & 4082253 & 20 \\
\hline 57013 & 547121 & 4082253. & 20 \\
\hline 57014 & 547151. & 4082253 & 20 \\
\hline 57015 & 547181 . & 40822 & 2 \\
\hline 57016 & 547211 . & 4082253. & 2 \\
\hline 57017 & 547241 . & 408 & 20 \\
\hline
\end{tabular}




$\begin{array}{llll}57018 & 547271 . & 4082253 . & 19 \\ 57019 & 547301 . & 4082253 . & 20 \\ 57020 & 547331 . & 4082253 . & 21 \\ 57021 & 547361 . & 4082253 . & 21 \\ 57022 & 547391 . & 4082253 . & 23 \\ 57023 & 547421 . & 4082253 . & 24 \\ 57024 & 547451 . & 4082253 . & 24 \\ 57025 & 547481 . & 4082253 . & 1 \\ 57026 & 547511 . & 4082253 . & 1 \\ 57027 & 547541 . & 4082253 . & 1 \\ 57028 & 547571 . & 4082253 . & 24 \\ 57029 & 547601 . & 4082253 . & 22 \\ 57030 & 547631 . & 4082253 . & 21 \\ 57031 & 547661 . & 4082253 . & 19 \\ 57032 & 547691 . & 4082253 . & 14 \\ 57033 & 547721 . & 4082253 . & 12 \\ 57034 & 547751 . & 4082253 . & 12 \\ 57035 & 547781 . & 4082253 . & 12 \\ 57036 & 547811 . & 4082253 . & 12 \\ 57037 & 547841 . & 4082253 . & 12 \\ 57038 & 547871 . & 4082253 . & 12 \\ 57039 & 547901 . & 4082253 . & 12 \\ 57040 & 547931 . & 4082253 . & 12 \\ 57041 & 547961 . & 4082253 . & 13 \\ 57042 & 547991 . & 4082253 . & 13 \\ 57043 & 548021 . & 4082253 . & 12 \\ 57044 & 548051 . & 4082253 . & 12 \\ 57045 & 548081 . & 4082253 . & 12 \\ 57046 & 548111 . & 4082253 . & 12 \\ 57047 & 548141 . & 4082253 . & 12\end{array}$

- Example listing of GEOMAP7.INP (only the first 20 lines are included in the printout). This is the output file generated by GEOMAP7 V1.0 and supplied as input to the routine GEOMOD4 V1.0 (Appendix F).

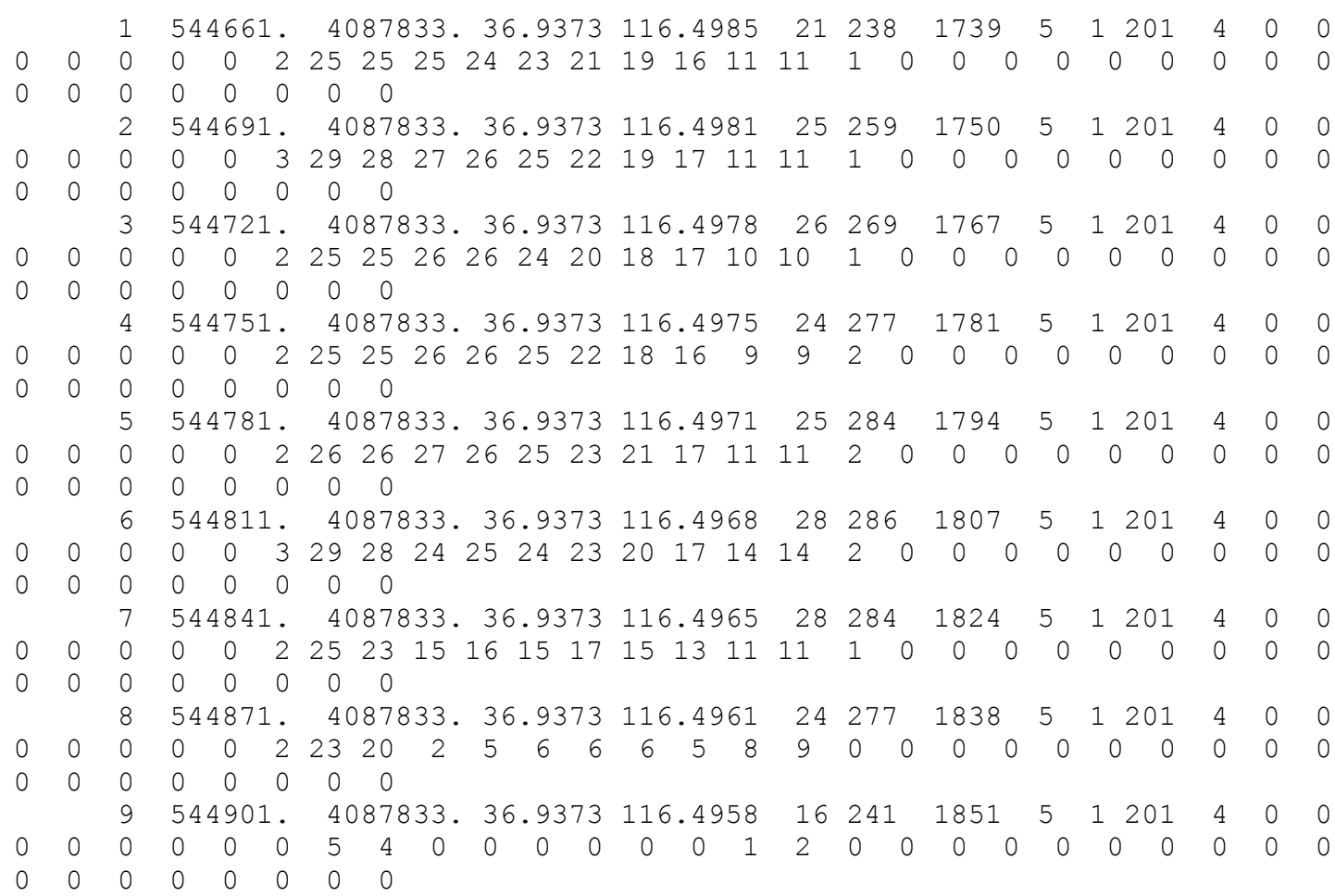




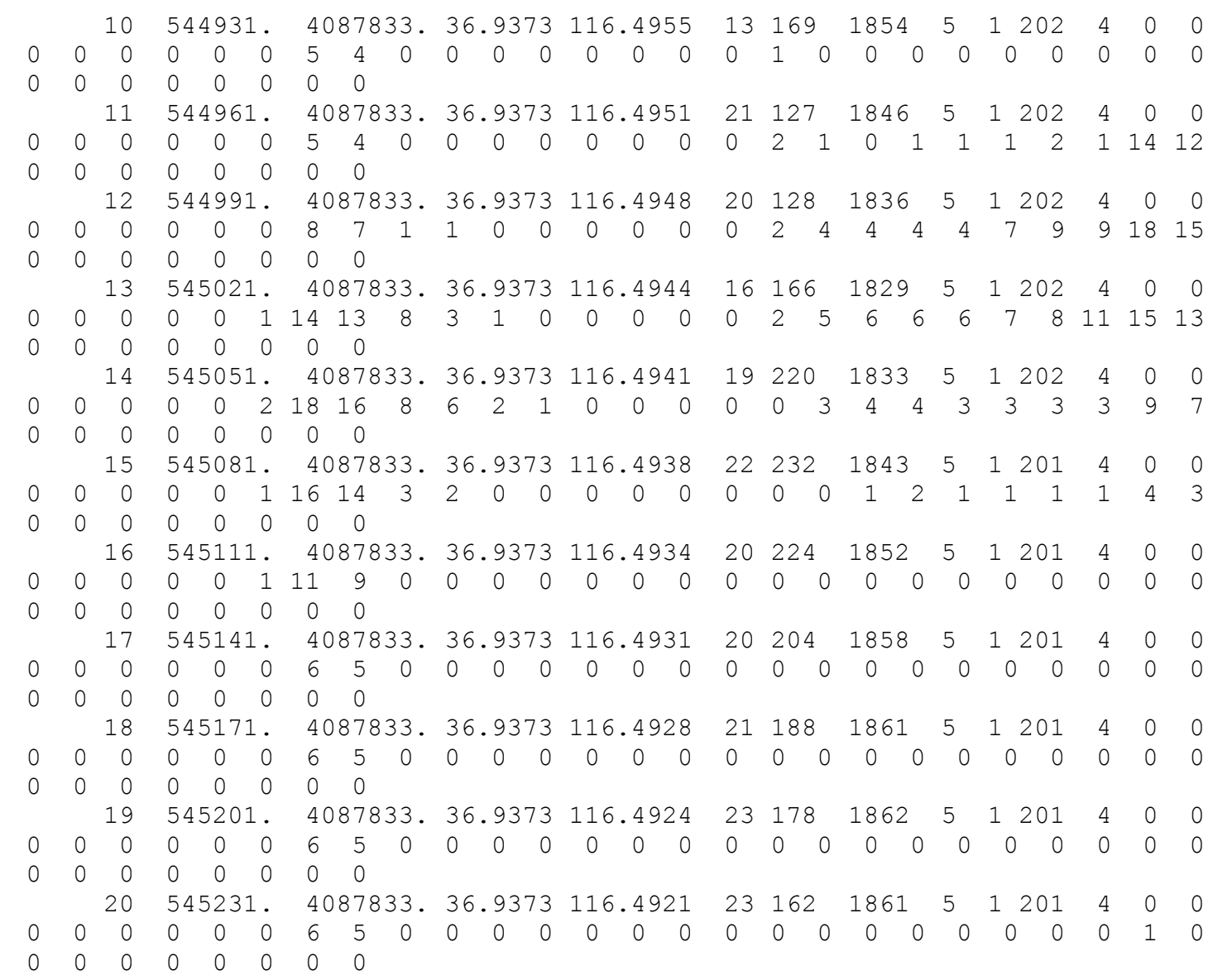




\section{- Figures used as part of the routine test plan:}
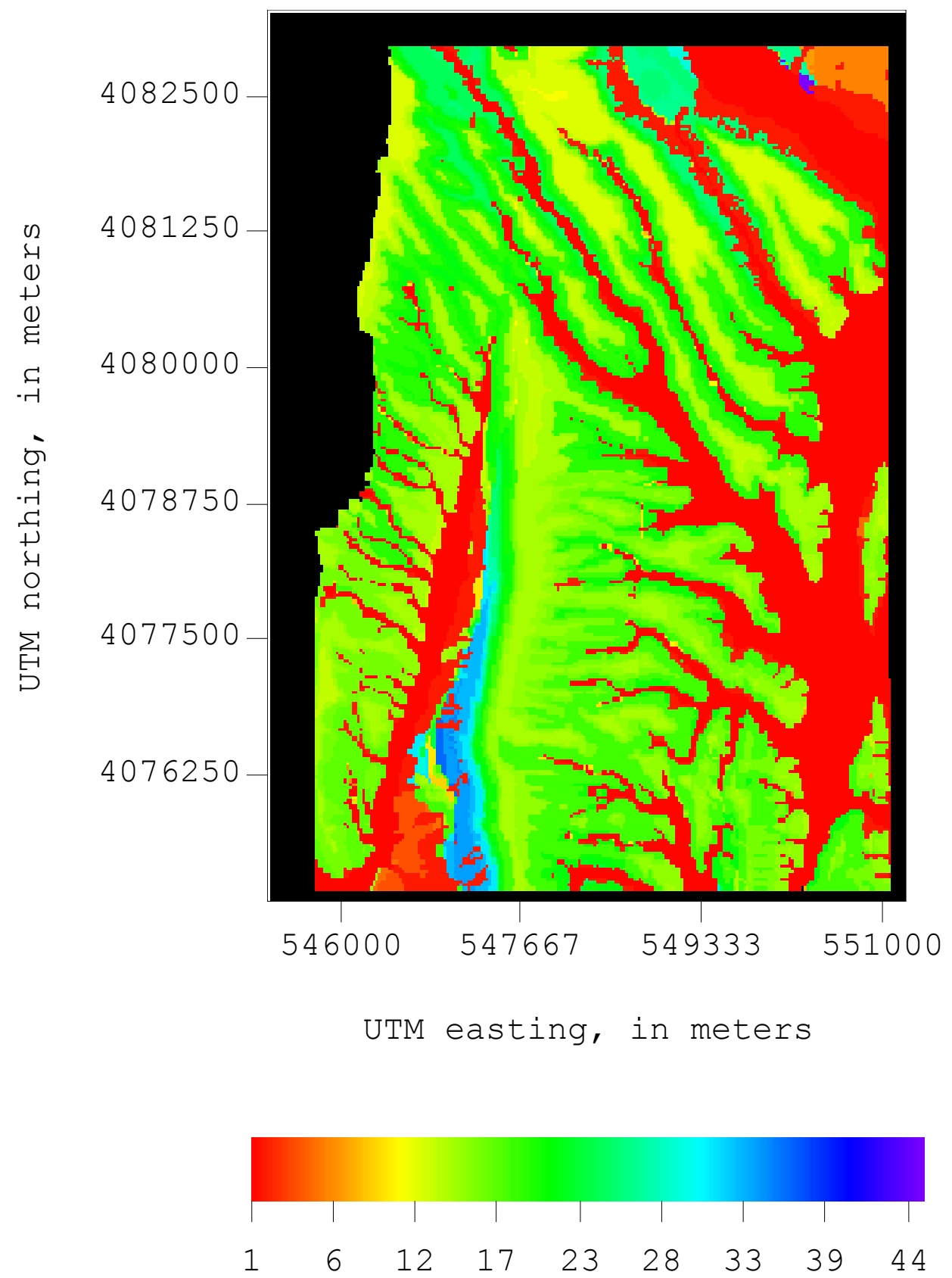

Newgeol_dat_4: rock-type ID number

Source: Day et al. (1998 [DIRS 101557]); DTN: GS971208314221.003 [DIRS 107128].

NOTE: The image (file NEWGEOL.HDF) was developed using column 4 of the file, NEWGEOL.DAT provided as input for GEOMAP7 V1.0. Black indicates grid locations with no data (identified by values of -99).

Figure E-1. TRANSFORM Map Image of the Rasterized Central Block Geology Map Form 

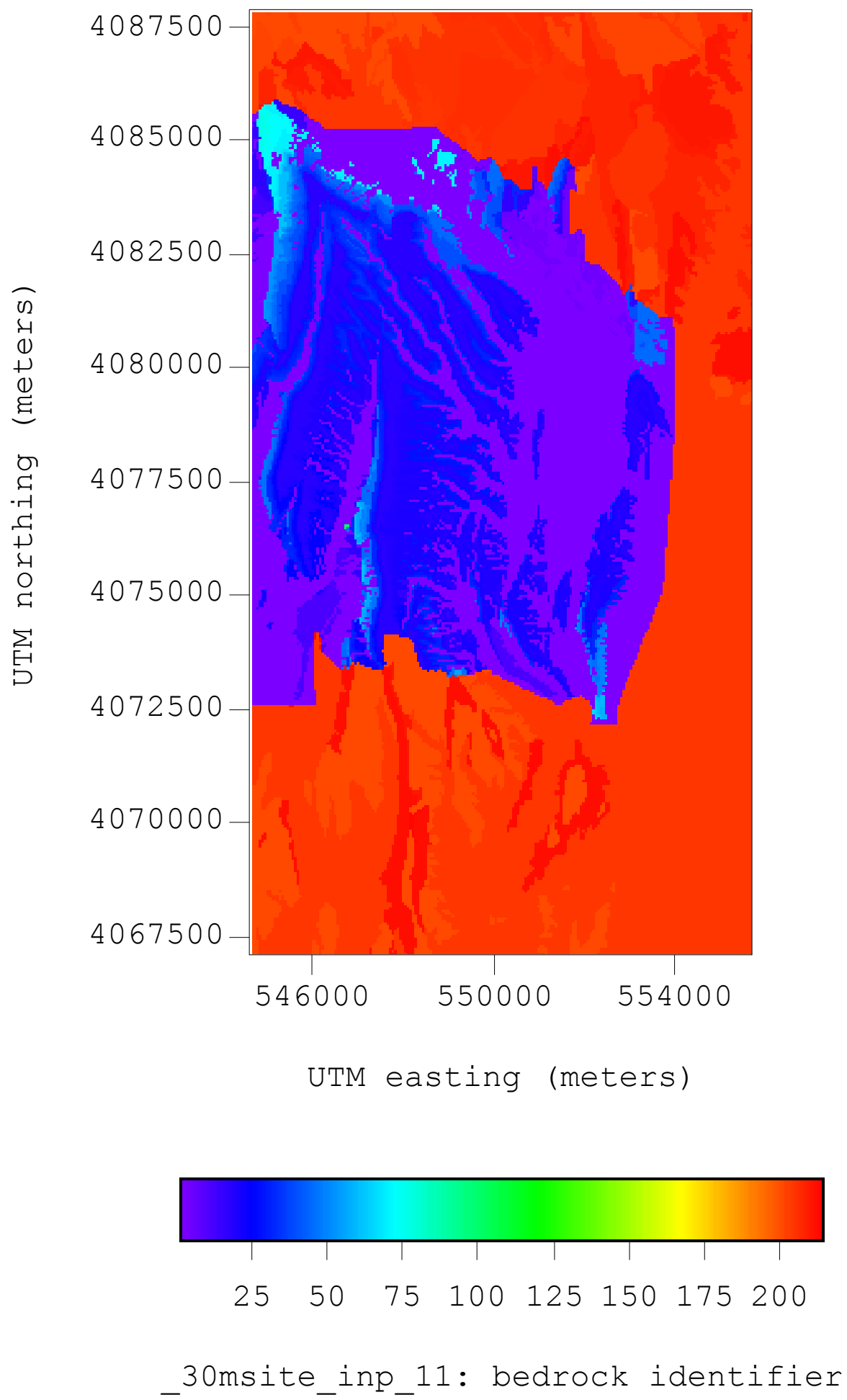

Source: Flint et al. 1996 [DIRS 100147].

NOTE: The map image (file 30MSITE.HDF) was developed using column 11 of the file, 30MSITE.INP that was provided as input to GEOMAP7 V1.0.

Figure E-2. TRANSFORM Map Image of the Rock-type Identification Numbers Representing the Original Bedrock Geology Input for INFIL V1.0 

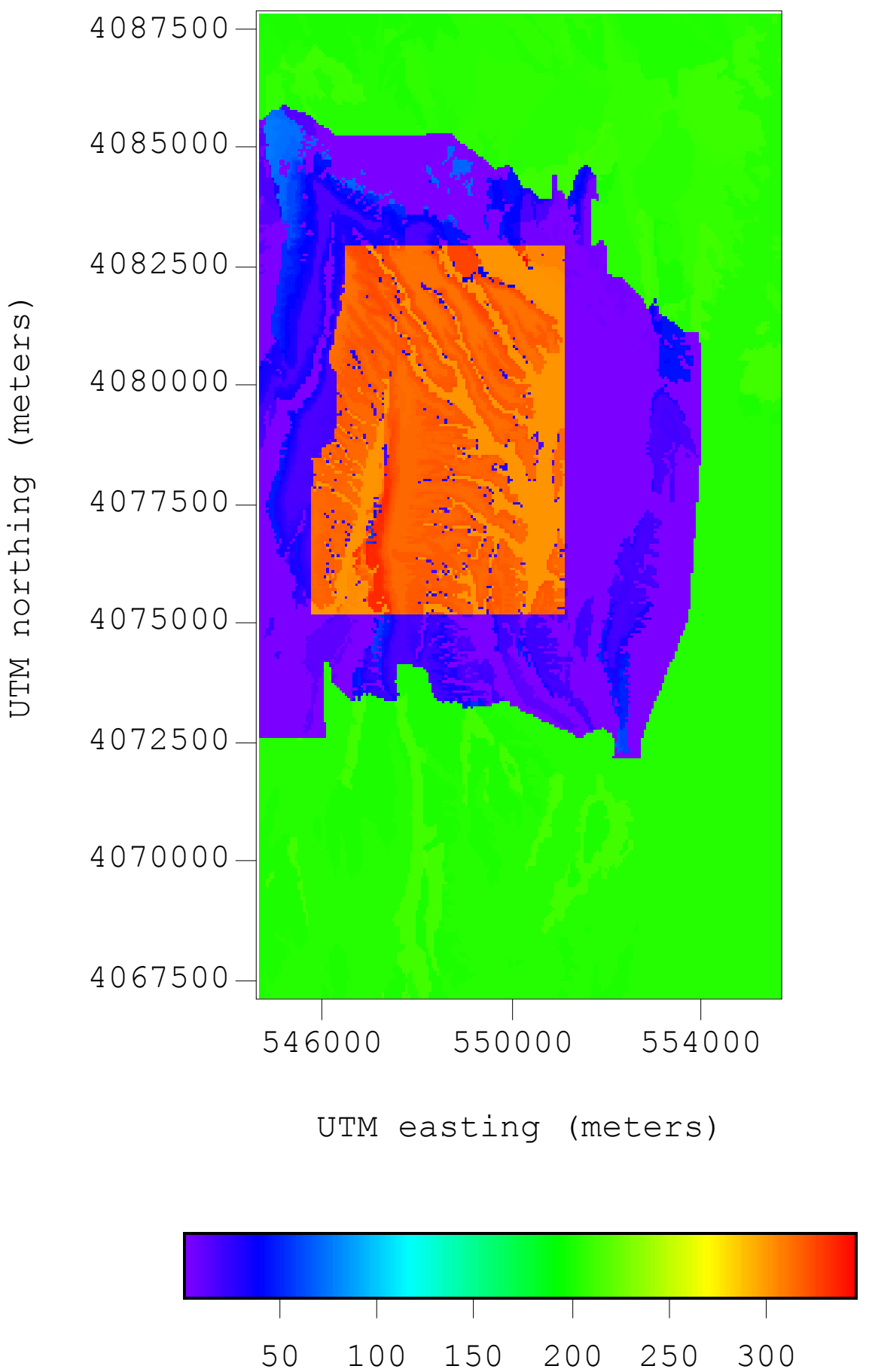

Geomap7_inp: Bedrock identifier

Output DTN: GS000308311221.004.

NOTE: The map image (GEOMAP7.HDF) was developed using column 11 of the file, GEOMAP7.INP generated as output from GEOMAP7 V1.0.

Figure E-3. TRANSFORM Map Image of the Updated Rock-type Identification Numbers Created by GEOMAP7 

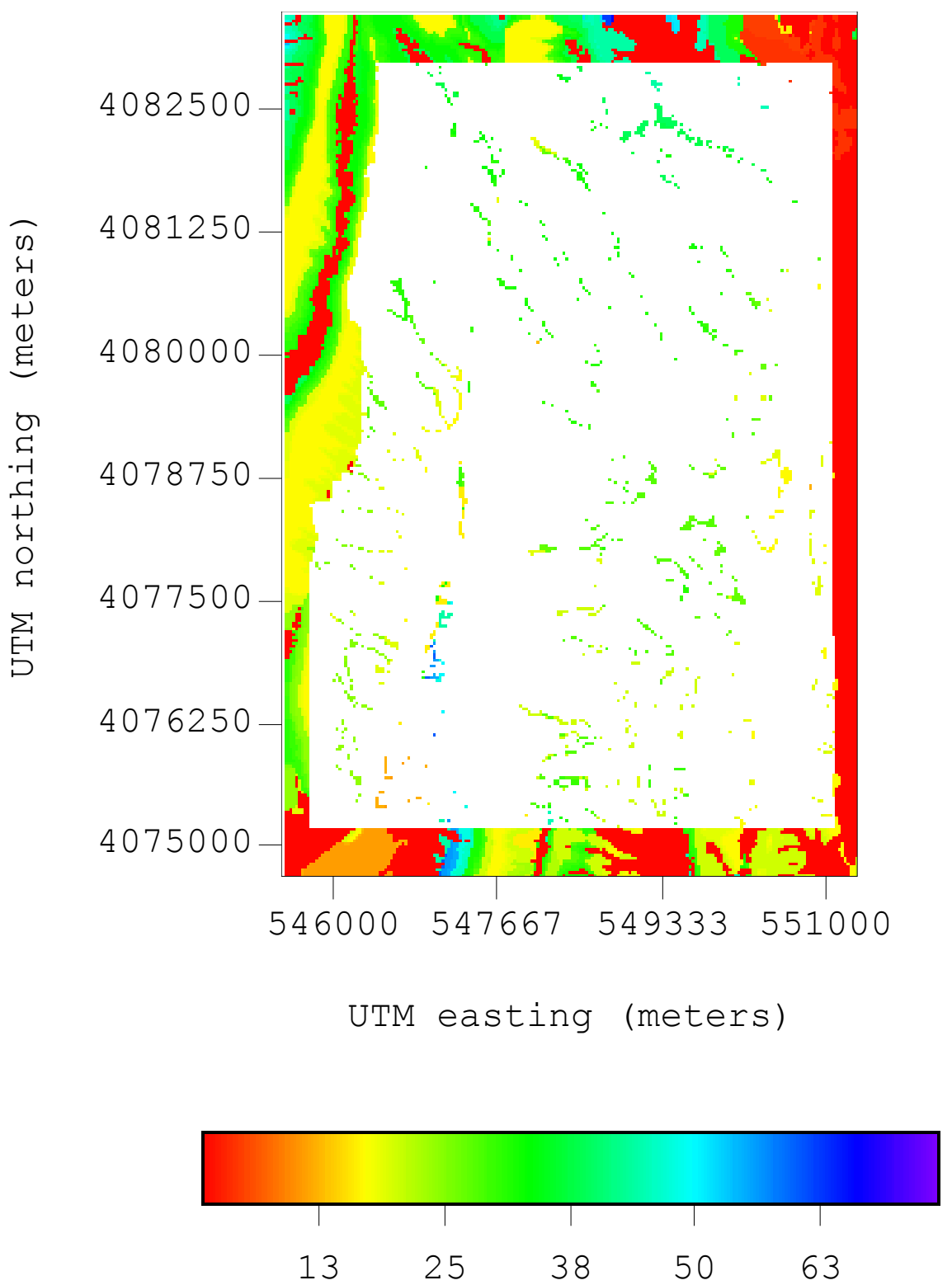

Geomap 7_inp_11_rock-type number

Source: Scott and Bonk (1984 [DIRS 104181]); DTN: MO0003COV00095.000 [DIRS 146848].

NOTE: The map image (file GEOMAP7B.HDF) was developed using column 11 from file, GEOMAP7.INP and is used to indicate grid cells where the original rock-type numbers from the Scott and Bonk (1984 [DIRS 104181]) geology map were left in place.

Figure E-4. TRANSFORM Map Image of the Updated Rock-type Identification Numbers Created by GEOMAP7 

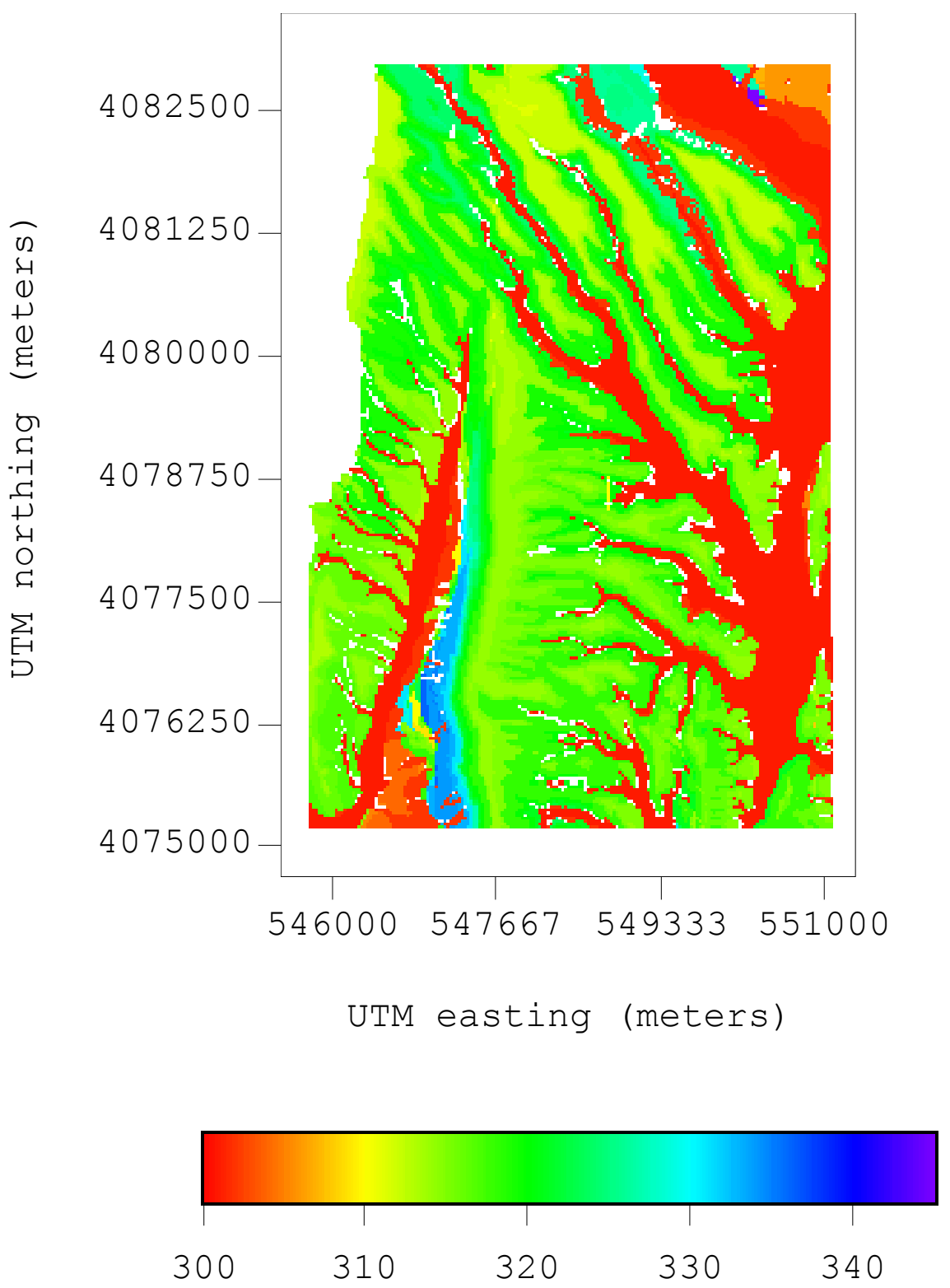

Geomap 7_inp_11_rock-type number

Source: Day et al. (1988 [DIRS 101557]).

Output DTN: GS000308311221.004.

NOTE: The map image (file GEOMAP7C.HDF) was developed using column 11 from file, GEOMAP7.INP and is used to indicate grid cells where the updated rock-type numbers from the Day et al. (1998 [DIRS 101557]) geology map were exchanged for the original rock-type numbers of the input file, 30MSITE.INP.

Figure E-5. TRANSFORM Map Image of the Updated Rock-type Identification Numbers Created by GEOMAP7 

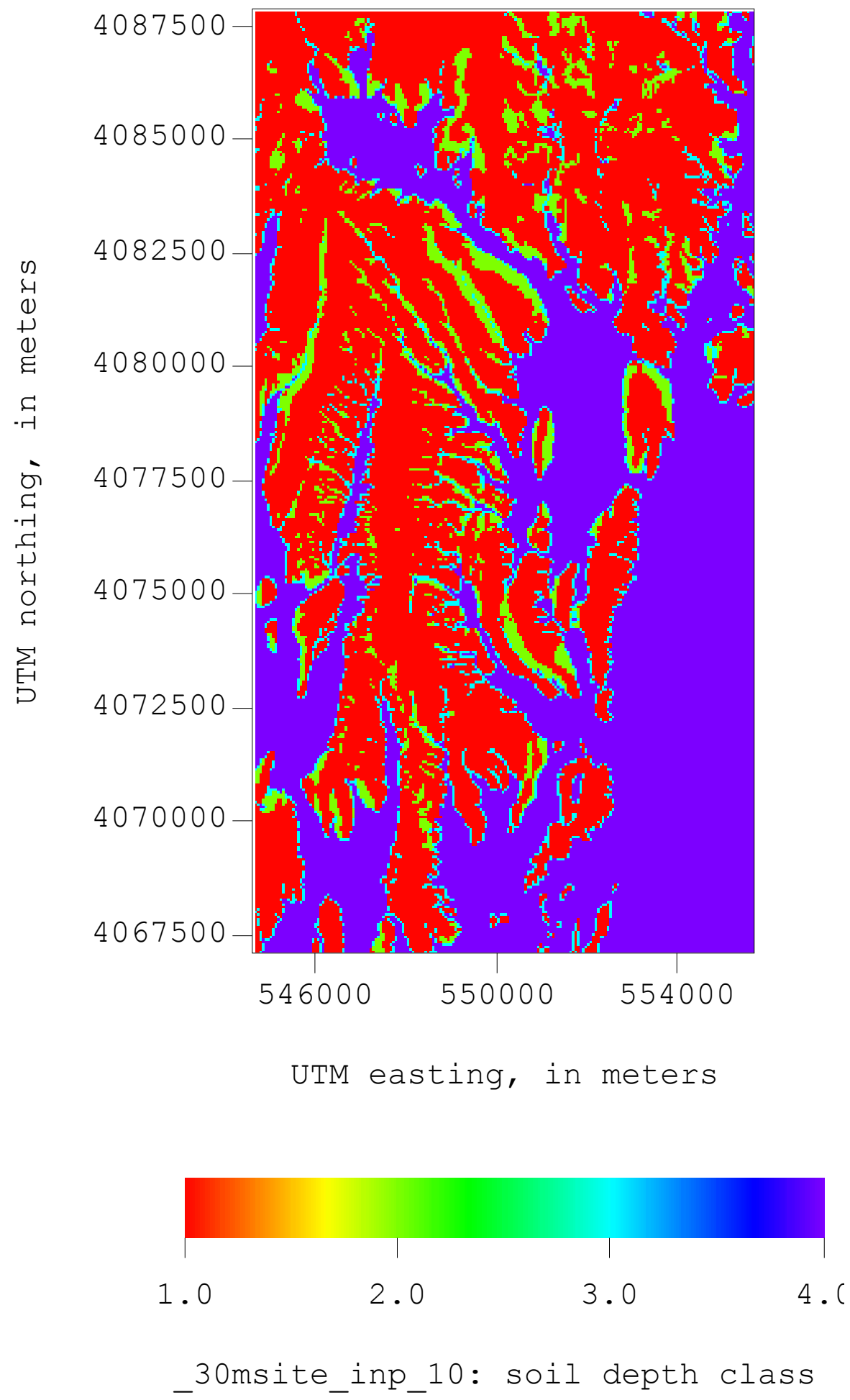

Output DTN: GS000308311221.004.

Figure E-6. TRANSFORM Map Image (file 30MDEPTH.HDF) of Soil Depth Class (integer values from 1 to 4) for the Area of the Yucca Mountain Model Domain, Generated Using Column 10 of the File, 30MSITE.INP and Used as Input for GEOMAP7 


\section{- Tables used as part of the routine test plan:}

Table E-1. Subset of Raster Grid Matrix from the File, NEWGEOL.DAT that is Provided as Input to GEOMAP7 V1.0

\begin{tabular}{|c|c|c|c|}
\hline \multirow{2}{*}{$\begin{array}{c}\text { UTM Northing Grid } \\
\text { Coordinates } \\
\text { (Meters) }\end{array}$} & \multicolumn{3}{|c|}{ UTM Easting Grid Coordinates (Meters) } \\
\cline { 2 - 4 } & 547991 & 548021 & 548051 \\
\hline 4076523 & 18 & 16 & 16 \\
\hline 4076493 & 18 & 18 & 18 \\
\hline 4076463 & 18 & 18 & 18 \\
\hline 4076433 & 18 & 18 & 18 \\
\hline 4076403 & 2 & 1 & 1 \\
\hline 4076373 & 2 & 2 & 2 \\
\hline
\end{tabular}

Source: Day et al. (1988 [DIRS 101557]).

Output DTN: GS000308311221.004.

NOTE: The rock-type identification numbers correspond to the geologic codes provided by Day et al. (1998 [DIRS 101557]) for the central block geology of Yucca Mountain. Rock-type values of 1 and 2 in NEWGEOL.DAT indicate unconsolidated rocks (alluvium and colluvium)

UTM=Universal Transverse Mercator

Table E-2. Subset of Raster Grid Matrix for Soil Depth Class from the File, 30MSITE.INP (Identical To The Grid Cell Locations Used In Table E-1) that is Provided as Input to GEOMAP7 V1.0

\begin{tabular}{|c|c|c|c|}
\hline \multirow{2}{*}{$\begin{array}{c}\text { UTM Northing Grid } \\
\text { Coordinates } \\
\text { (Meters) }\end{array}$} & \multicolumn{3}{|c|}{ UTM Easting Grid Coordinates (Meters) } \\
\cline { 2 - 4 } & $\mathbf{5 4 7 9 9 1}$ & $\mathbf{5 4 8 0 2 1}$ & $\mathbf{5 4 8 0 5 1}$ \\
\hline 4076523 & 1 & 1 & 1 \\
\hline 4076493 & 1 & 1 & 1 \\
\hline 4076463 & 1 & 1 & 1 \\
\hline 4076433 & 1 & 1 & 1 \\
\hline 4076403 & 1 & 1 & 1 \\
\hline 4076373 & 1 & 1 & 1 \\
\hline
\end{tabular}

Source: Scott and Bonk (1984 [DIRS 104181]); DTN: MO0003COV00095.000 [DIRS 146848]).

NOTE: Soil depth class values are provided in column 10 of 3OMSITE.INP, and were used as input for INFIL V1.0 (Flint et al. 1996 [DIRS 100147]). The soil depth class values of 1 indicate thin upland soils ranging from 0 to $0.5 \mathrm{~m}$ in thickness for all grid cell locations in the selected subset .

UTM=Universal Transverse Mercator 
Table E-3. Subset of Raster Grid Matrix from 30MSITE.INP (identical to the grid cell locations used in Table E-1)

\begin{tabular}{|c|c|c|c|}
\hline \multirow{2}{*}{$\begin{array}{c}\text { UTM Northing Grid } \\
\text { Coordinates } \\
\text { (Meters) }\end{array}$} & \multicolumn{3}{|c|}{ UTM Easting Grid Coordinates (Meters) } \\
\cline { 2 - 4 } & $\mathbf{5 4 7 9 9 1}$ & $\mathbf{5 4 8 0 2 1}$ & $\mathbf{5 4 8 0 5 1}$ \\
\hline 4076523 & 20 & 20 & 20 \\
\hline 4076493 & 20 & 20 & 20 \\
\hline 4076463 & 20 & 20 & 20 \\
\hline 4076433 & 20 & 20 & 20 \\
\hline 4076403 & 1 & 1 & 1 \\
\hline 4076373 & 20 & 20 & 20 \\
\hline
\end{tabular}

Source: Scott and Bonk (1984 [DIRS 104181]); DTN: MO0003COV00095.000 [DIRS 146848]).

NOTE: This table shows rock-type identification numbers used in the geospatial parameter input file for INFIL V1.0 (Flint et al. 1996 [DIRS 100147]) and provided as input to GEOMAP7. The rock-type identifier codes correspond to the rasterized bedrock geology map of Scott and Bonk (1984 [DIRS 104181]) .

UTM=Universal Transverse Mercator

Table E-4. Subset of Raster Grid Matrix from GEOMAP7.INP (identical to the grid cell locations used in Tables G-1 and G-2)

\begin{tabular}{|c|c|c|c|}
\hline \multirow{2}{*}{$\begin{array}{c}\text { UTM Northing Grid } \\
\text { Coordinates } \\
\text { (Meters) }\end{array}$} & \multicolumn{3}{|c|}{ UTM Easting Grid Coordinates (Meters) } \\
\cline { 2 - 4 } & $\mathbf{5 4 7 9 9 1}$ & $\mathbf{5 4 8 0 2 1}$ & $\mathbf{5 4 8 0 5 1}$ \\
\hline 4076523 & 318 & 316 & 316 \\
\hline 4076493 & 318 & 318 & 318 \\
\hline 4076463 & 318 & 318 & 318 \\
\hline 4076433 & 318 & 318 & 318 \\
\hline 4076403 & 302 & 301 & 301 \\
\hline 4076373 & 20 & 20 & 20 \\
\hline
\end{tabular}

Source: Day et al. (1988 [DIRS 101557]).

Output DTN: GS000308311221.004.

NOTE: This table shows new rock-type identification numbers (values of 300 and greater) created by GEOMAP7 using updated bedrock geology map from Day et al. (1998 [DIRS 101557]). Rock-type identification numbers less than 300 indicate locations where the original rock-type used for INFIL V1.0 (Flint et al. 1996 [DIRS 100147]) was substituted back because the updated rock-type indicated alluvium or colluvium for locations having less than $6 \mathrm{~m}$ of soil cover, as identified by the soil depth class map.

UTM=Universal Transverse Mercator 
Table E-5. Extracted Section of Input File, 30MSITE.INP Analyzed in the EXCEL Spreadsheet GEOMAP7.XLS as Part of the Test Plan for the Routine GEOMAP7

\begin{tabular}{|c|c|c|c|c|c|c|c|c|c|c|}
\hline $\begin{array}{c}\text { Grid cell } \\
\text { sequence } \\
\text { number }\end{array}$ & $\begin{array}{c}\text { Universal } \\
\text { Transverse } \\
\text { Mercator } \\
\text { Easting } \\
\text { (meters) }\end{array}$ & $\begin{array}{c}\text { Universal } \\
\text { Transverse } \\
\text { Mercator } \\
\text { Northing } \\
\text { (meters) }\end{array}$ & $\begin{array}{l}\text { Latitude } \\
\text { (decimal } \\
\text { degrees) }\end{array}$ & $\begin{array}{c}\text { Longitude } \\
\text { (decimal } \\
\text { degrees) }\end{array}$ & $\begin{array}{l}\text { Slope } \\
\text { (deg) }\end{array}$ & $\begin{array}{c}\text { Aspect } \\
\text { (deg) }\end{array}$ & $\begin{array}{c}\text { Elevation } \\
\text { (meters) }\end{array}$ & $\begin{array}{l}\text { Soil } \\
\text { Type } \\
\text { Code } \\
\text { (ID\#) }\end{array}$ & $\begin{array}{c}\text { Soil } \\
\text { Depth } \\
\text { class }\end{array}$ & $\begin{array}{c}\text { Scott and } \\
\text { Bonk (1984 } \\
\text { [DIRS } \\
\text { 104181]) } \\
\text { Rock type } \\
\text { Map ID } \\
\end{array}$ \\
\hline 112500 & 550571 & 4078653 & 36.8543 & 116.4327 & 5 & 91 & 1159 & 2 & 4 & 1 \\
\hline 112501 & 550601 & 4078653 & 36.8543 & 116.4324 & 4 & 91 & 1157 & 2 & 4 & 1 \\
\hline 112502 & 550631 & 4078653 & 36.8543 & 116.4321 & 3 & 92 & 1155 & 2 & 4 & 1 \\
\hline 112503 & 550661 & 4078653 & 36.8543 & 116.4317 & 3 & 97 & 1153 & 2 & 4 & 1 \\
\hline 112504 & 550691 & 4078653 & 36.8543 & 116.4314 & 3 & 104 & 1152 & 2 & 4 & 1 \\
\hline 112505 & 550721 & 4078653 & 36.8543 & 116.4311 & 2 & 100 & 1151 & 2 & 4 & 1 \\
\hline 112506 & 550751 & 4078653 & 36.8543 & 116.4307 & 2 & 166 & 1150 & 2 & 3 & 1 \\
\hline 112507 & 550781 & 4078653 & 36.8543 & 116.4304 & 6 & 303 & 1151 & 9 & 2 & 1 \\
\hline 112508 & 550811 & 4078653 & 36.8543 & 116.43 & 9 & 309 & 1155 & 9 & 2 & 12 \\
\hline 112509 & 550841 & 4078653 & 36.8543 & 116.4297 & 10 & 318 & 1159 & 5 & 1 & 1 \\
\hline 112510 & 550871 & 4078653 & 36.8543 & 116.4294 & 10 & 327 & 1163 & 5 & 1 & 19 \\
\hline 112511 & 550901 & 4078653 & 36.8543 & 116.429 & 9 & 224 & 1165 & 5 & 1 & 19 \\
\hline 112512 & 550931 & 4078653 & 36.8543 & 116.4287 & 9 & 49 & 1163 & 5 & 1 & 17 \\
\hline 112513 & 550961 & 4078653 & 36.8542 & 116.4284 & 14 & 88 & 1158 & 5 & 1 & 17 \\
\hline 112514 & 550991 & 4078653 & 36.8542 & 116.428 & 17 & 100 & 1149 & 5 & 1 & 17 \\
\hline 112515 & 551021 & 4078653 & 36.8542 & 116.4277 & 14 & 104 & 1140 & 5 & 1 & 1 \\
\hline 112516 & 551051 & 4078653 & 36.8542 & 116.4274 & 10 & 101 & 1134 & 5 & 1 & 1 \\
\hline 112517 & 551081 & 4078653 & 36.8542 & 116.427 & 8 & 99 & 1130 & 9 & 2 & 1 \\
\hline 112518 & 551111 & 4078653 & 36.8542 & 116.4267 & 6 & 104 & 1126 & 9 & 2 & 1 \\
\hline 112519 & 551141 & 4078653 & 36.8542 & 116.4263 & 4 & 115 & 1123 & 9 & 2 & 1 \\
\hline 112520 & 551171 & 4078653 & 36.8542 & 116.426 & 3 & 124 & 1122 & 9 & 2 & 1 \\
\hline
\end{tabular}

Source: Scott and Bonk (1984 [DIRS 104181]); DTN: MO0003COV00095.000 [DIRS 146848]).

NOTE: The table shows the input file format for the first 11 columns in terms of the separate input parameter sets organized by columns and also in terms of the set of different geospatial input parameters associated with specific grid cell locations and organized by rows. 
Table E-6. Extracted Section of the Output file, GEOMAP7.INP Created by GEOMAP7 V1.0 and Analyzed in the EXCEL Spreadsheet GEOMAP7.XLS as Part of the Routine Test Plan

\begin{tabular}{|c|c|c|c|c|c|c|c|c|c|c|}
\hline $\begin{array}{c}\text { Grid Cell } \\
\text { Sequence } \\
\text { Number }\end{array}$ & $\begin{array}{c}\text { Universal } \\
\text { Transverse } \\
\text { Mercator } \\
\text { Easting } \\
\text { (meters) }\end{array}$ & $\begin{array}{c}\text { Universal } \\
\text { Transverse } \\
\text { Mercator } \\
\text { Northing } \\
\text { (meters) }\end{array}$ & $\begin{array}{l}\text { Latitude } \\
\text { (decimal } \\
\text { degrees) }\end{array}$ & $\begin{array}{c}\text { Longitude } \\
\text { (decimal } \\
\text { degrees) }\end{array}$ & $\begin{array}{l}\text { Slope } \\
\text { (deg) }\end{array}$ & $\begin{array}{c}\text { Aspect } \\
\text { (deg) }\end{array}$ & $\begin{array}{c}\text { Elevation } \\
\text { (meters) }\end{array}$ & $\begin{array}{l}\text { Soil } \\
\text { Type } \\
\text { Code } \\
\text { (ID\#) }\end{array}$ & $\begin{array}{l}\text { Soil } \\
\text { Depth } \\
\text { class } \\
\end{array}$ & $\begin{array}{c}\text { Updated } \\
\text { Rock type } \\
\text { Map ID \# using } \\
\text { Day et al. (1998 } \\
\text { [DIRS 101557]) } \\
\text { geology }\end{array}$ \\
\hline 112500 & 550571 & 4078653 & 36.8543 & 116.4327 & 5 & 91 & 1159 & 2 & 4 & 301 \\
\hline 112501 & 550601 & 4078653 & 36.8543 & 116.4324 & 4 & 91 & 1157 & 2 & 4 & 301 \\
\hline 112502 & 550631 & 4078653 & 36.8543 & 116.4321 & 3 & 92 & 1155 & 2 & 4 & 301 \\
\hline 112503 & 550661 & 4078653 & 36.8543 & 116.4317 & 3 & 97 & 1153 & 2 & 4 & 301 \\
\hline 112504 & 550691 & 4078653 & 36.8543 & 116.4314 & 3 & 104 & 1152 & 2 & 4 & 301 \\
\hline 112505 & 550721 & 4078653 & 36.8543 & 116.4311 & 2 & 100 & 1151 & 2 & 4 & 301 \\
\hline 112506 & 550751 & 4078653 & 36.8543 & 116.4307 & 2 & 166 & 1150 & 2 & 3 & 301 \\
\hline 112507 & 550781 & 4078653 & 36.8543 & 116.4304 & 6 & 303 & 1151 & 9 & 2 & 301 \\
\hline 112508 & 550811 & 4078653 & 36.8543 & 116.43 & 9 & 309 & 1155 & 9 & 2 & 12 \\
\hline 112509 & 550841 & 4078653 & 36.8543 & 116.4297 & 10 & 318 & 1159 & 5 & 1 & 302 \\
\hline 112510 & 550871 & 4078653 & 36.8543 & 116.4294 & 10 & 327 & 1163 & 5 & 1 & 315 \\
\hline 112511 & 550901 & 4078653 & 36.8543 & 116.429 & 9 & 224 & 1165 & 5 & 1 & 315 \\
\hline 112512 & 550931 & 4078653 & 36.8543 & 116.4287 & 9 & 49 & 1163 & 5 & 1 & 314 \\
\hline 112513 & 550961 & 4078653 & 36.8542 & 116.4284 & 14 & 88 & 1158 & 5 & 1 & 313 \\
\hline 112514 & 550991 & 4078653 & 36.8542 & 116.428 & 17 & 100 & 1149 & 5 & 1 & 313 \\
\hline 112515 & 551021 & 4078653 & 36.8542 & 116.4277 & 14 & 104 & 1140 & 5 & 1 & 314 \\
\hline 112516 & 551051 & 4078653 & 36.8542 & 116.4274 & 10 & 101 & 1134 & 5 & 1 & 1 \\
\hline 112517 & 551081 & 4078653 & 36.8542 & 116.427 & 8 & 99 & 1130 & 9 & 2 & 1 \\
\hline 112518 & 551111 & 4078653 & 36.8542 & 116.4267 & 6 & 104 & 1126 & 9 & 2 & 1 \\
\hline 112519 & 551141 & 4078653 & 36.8542 & 116.4263 & 4 & 115 & 1123 & 9 & 2 & 1 \\
\hline 112520 & 551171 & 4078653 & 36.8542 & 116.426 & 3 & 124 & 1122 & 9 & 2 & 1 \\
\hline
\end{tabular}

Source: Day et al. (1988 [DIRS 101557]).

Output DTN: GS000308311221.004.

NOTE: The grid cell locations are identical to those indicated in Table E-5. The table indicates that only the rock type map ID number has been modified (values of 300 and greater), and that the original Scott and Bonk (1984 [DIRS 104181]) map type ID number has been preserved for grid cell locations were a soil depth class of 3 or less coincided with an unconsolidated rock-type from Day et al. (1998 [DIRS 101557]). 


\section{- Listing of source code for routine GEOMAP7 V1.0:}

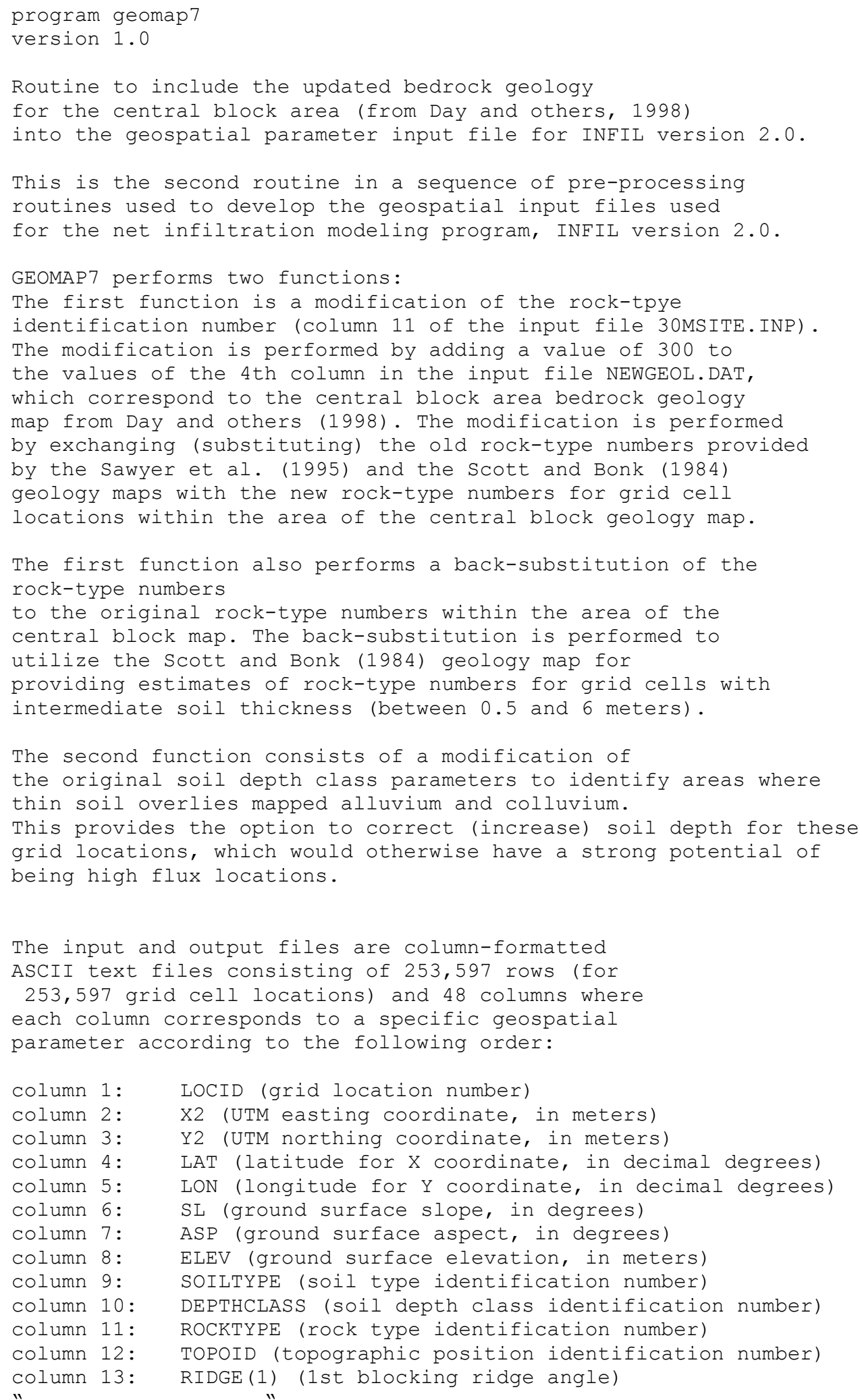




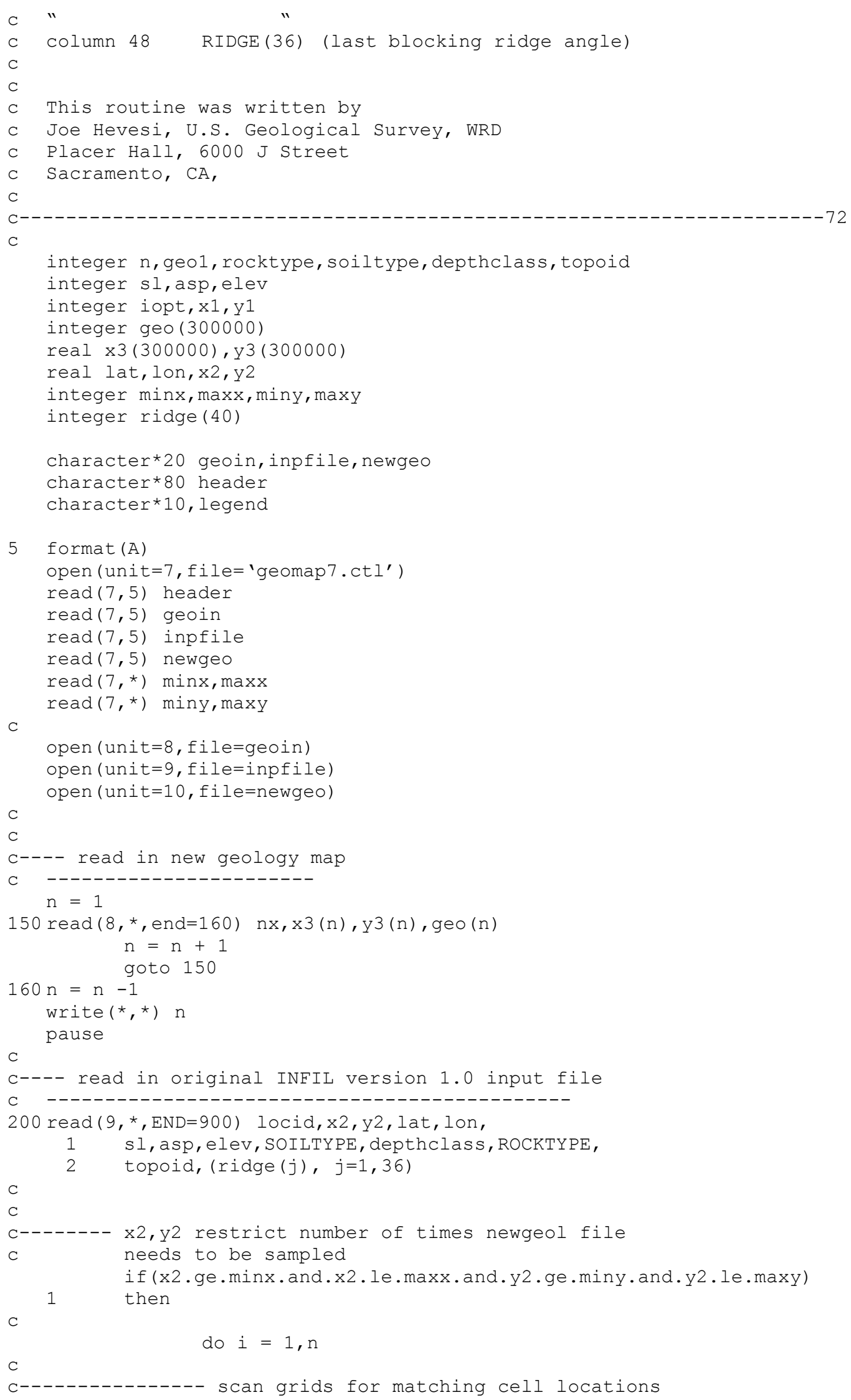




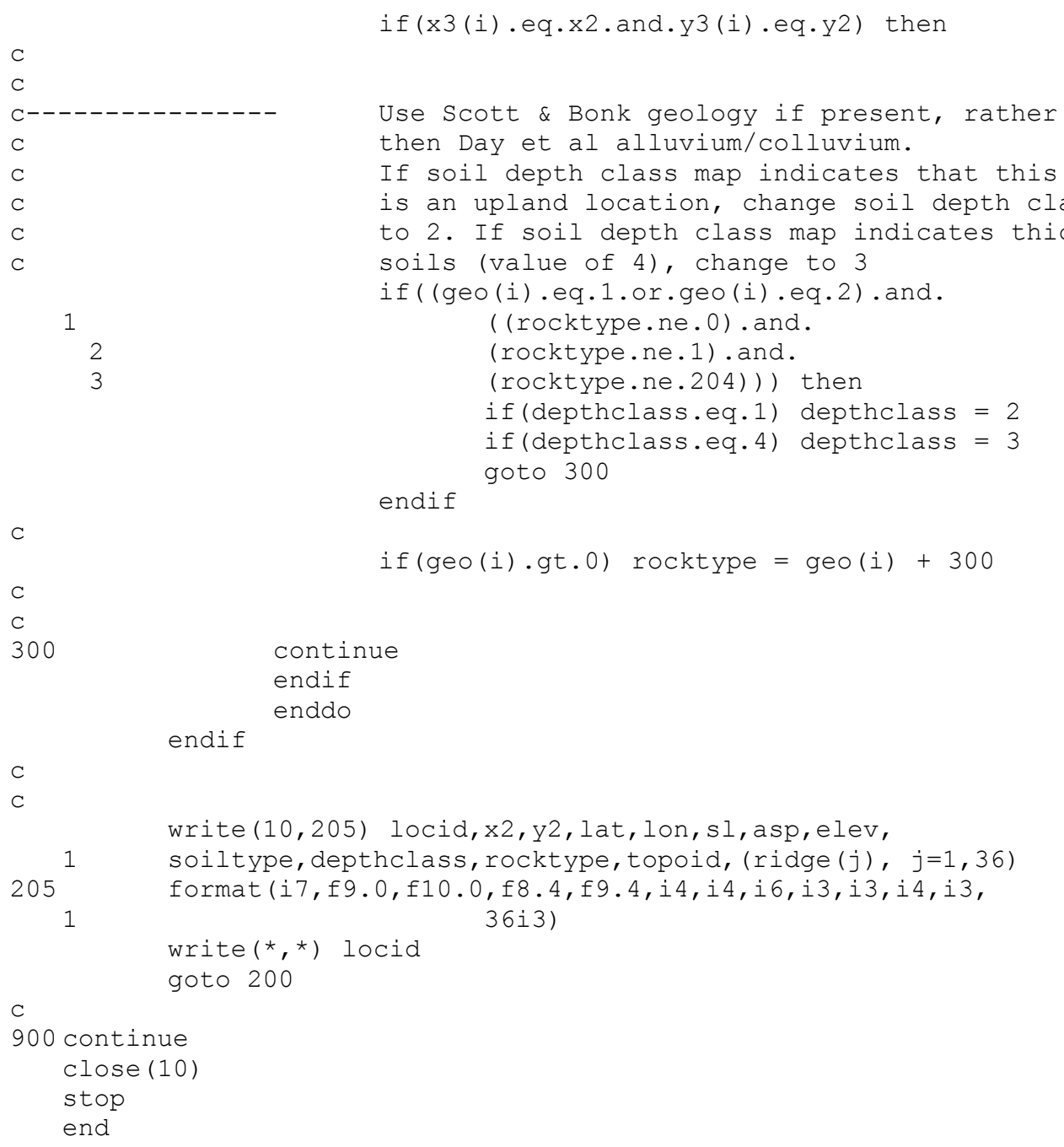




\section{INTENTIONALLY LEFT BLANK}




\section{APPENDIX F}

\section{ADJUSTMENT OF THE SOIL DEPTH CLASS MAP USING GEOMOD4 V1.0}




\section{F1. NAME OF ROUTINE/MACRO WITH VERSION/OS/HARDWARE ENVIRONMENT AND USER INFORMATION}

Name of software routine: GEOMOD4 V1.0

OS and hardware environment: Windows NT 4.0, Pentium Pro PC

Computer Identification: SM321276 with a USGS specific host-name P720dcasr

Software Users: Joseph Hevesi (916-278-3274), Alan Flint (916-278-3221)

User Location: U.S. Geological Survey, Room 5000E, Placer Hall, 6000 J Street, Sacramento, CA 95819-6129

\section{F2. NAME OF COMMERCIAL SOFTWARE WITH VERSION/OS/HARDWARE USED TO DEVELOP ROUTINE/MACRO}

The source code for GEOMOD4 V1.0 was developed using the standard FORTRAN77 programming language. The source code was written, debugged, and compiled (for PC platforms using INTEL processors) using DIGITAL Visual Fortran with Microsoft Developer Studio, V. 5.0.

\section{F3. GENERAL DESCRIPTION OF ROUTINE/MACRO}

GEOMOD4 V1.0 is a FORTRAN77 routine developed in accordance with AP-SI.1Q, specifically for the analysis/model activity documented in this report. The routine source code (GEOMOD4.FOR), compiled executable file (GEOMOD4.EXE), routine control file (GEOMOD4.CTL), input and output files, validation test files, and a copy of this appendix, are located under the directory GEOMOD4 on a CD-ROM labeled GEOINPUT-1. The routine source code, control file, and the input and output files are ASCII text files that can be read using any standard ASCII text editor and can be imported into standard word processing applications such as Microsoft Word. The executable file can be used to run GEOMOD4 V1.0 on any PC with an INTEL processor (with adequate RAM).

The parameters calculated by GEOMOD4 that are included in the developed output file, GEOMOD4.INP, are used for the development of the geospatial parameter input file for INFIL V2.0 (USGS 2000 [DIRS 139422]). The file, GEOMOD4.INP is used directly as input to the routine SOILMAP6 V1.0.

\section{F4. TEST PLAN FOR THE SOFTWARE ROUTINE GEOMOD4 V1.0}

\section{- Explain whether this is a routine or macro and describe what it does:}

GEOMOD4 V1.0, is the third routine applied in a sequence of FORTRAN 77 routines that are used in the development of the geospatial parameter input file for INFIL V2.0. GEOMOD4 V1.0 uses the input file, GEOMAP7.INP (the output file created by GEOMAP7 V1.0) to perform a partial modification of the original soil depth class parameters used as input to INFIL V1.0 (Flint and others, 1996). In addition, GEOMOD4 V1.0 performs an adjustment of the rock-type identification numbers based on the modified soil depth class parameters. 
The modifications to the soil depth class parameters performed by GEOMOD4 V1.0 are required to maintain consistency with the updated bedrock geology obtained from Day et al. (1998 [DIRS 101557]) and incorporated into the geospatial parameter input file using GEOMAP7. Two separate modifications to the soil depth class parameters are performed by GEOMOD4. To perform the first modification, the routine systematically scans the entire input grid and identifies all grid cells with unconsolidated rock-types that are adjacent to grid cells with consolidated rock-types (areas with consolidated rock-types are indicative of upland areas with thin soils). The grid cells defining the modified boundary are assigned a new soil depth class number of 5. Soil depth class 5 is used to represent a transitional soil thickness zone between thick soils defined by mapped areas of unconsolidated materials (alluvium and colluvium) and thin soils defined by mapped areas of consolidated bedrock. The original transitional soil depth class 3 was developed in ARCINFO v6.1.2 using a 30-meter buffer zone along the boundary defined by the alluvium-bedrock or colluvium-bedrock contacts. The buffer zone is thus used to define a 30-meter transitional area of intermediate soil depths between locations with thick soils identified by soil depth class 4 and locations with thin soils identified by soil depth classes 1 and 2. Soil depth class 5 is equivalent to soil depth class 3 obtained form the input file, in terms of defining an intermediate range of potential soil thickness.

The second soil depth class modification is performed by identifying grid cells having soil depth class 4 (soil thickness of $6 \mathrm{~m}$ and greater) and also a consolidated rock-type number. This combination indicates the possibility of an inconsistency between the soil depth class map and the updated rock-type. The soil depth class is changed to 6 for the purpose of identifying these locations as a part of the intermediate soil thickness zone. Depth class 6 is equivalent to depth classes 5 and 3 in terms of the procedure used for estimating soil thickness in the routine SOILMAP6 (Appendix G). The purpose of using three different soil depth class numbers $(3,5$, and 6$)$ for representing an equivalent intermediate soil depth classes is to identify the method used to estimate the depth class. This information is used as part of the test plan.

The second function performed by GEOMOD4 V1.0 is a modification of rock-type parameters for grid cells having an intermediate or thin soil depth class number. This modification is required to prevent the inconsistency of having locations with thin or intermediate soil thickness assigned an unconsolidated rock-type. The routine identifies grid cells having this inconsistency and a consolidated rock-type is estimated by scanning the eight adjacent grid cell locations and identifying the most prevalent consolidated rock-type map number (or the first consolidated rock-type encountered, if there is no prevalent consolidated rock-type). If all adjacent grid cells are associated with unconsolidated rock-types, the inconsistency is corrected by changing the soil depth class to 4 (for thick soils) and the existing unconsolidated rock-type number is not modified. 


\section{- Listing of FORTRAN77 Source code:}

A listing of the FORTRAN77 source code for the routine GEOMAP7 V1.0 along with examples of the input and output files used in the test plan are included at the end of this appendix.

\section{- Description of test(s):}

A validation test of the functions performed by the routine was conducted by a visual comparison between the input files (GEOMAP7.INP) and the output file (GEOMOD4.INP). The test criteria for the functions performed by GEOMOD4 consists of visual verification that the soil depth class parameters have been correctly modified and that the rock-type identification numbers for grid cells assigned to soil depth class 5 have been correctly estimated based on adjacent grid cells. The test plan consists of a 3-step testing procedure using a combination of a visual inspection of map images and a visual inspection of parameter values in the input and output ASCII test files. The comparison of input and output grid cell values and the generation of map images was facilitated using the raster-based grid and map-imaging applications available in the acquired software program TRANSFORM. The raster-based grid and map-imaging utilities allow for an analysis of the entire raster grid and also a detailed evaluation of grid cell values for specified grid locations.

Additional validation tests were also performed by extracting and comparing identical subsets (in terms of grid cell locations) from the raster images created in TRANSFORM and by visually inspecting identical subsets (based on grid cell locations) of the input file, GEOMAP7.INP and the output file, GEOMOD4.INP. This method of testing allowed for quantitative manual checking of the specific operations performed by GEOMOD4 based on the values of the input and output parameters. The criteria applied in this method of validation consisted of a visual verification that the intended modifications of the geospatial input file had been correctly performed. A final test that the routine had functioned correctly was performed by a comparison of the input and output files to verify that no unintended modifications had occurred during program execution.

\section{- Specify the range of input values to be used and why the range is valid:}

GEOMAP7.INP is the main input file used by GEOMOD4 V1.0. The file is specified in the file, GEOMOD4.CTL, which is the routine control file for GEOMOD4 and is required for program execution. GEOMAP7.INP is a column-formatted ASCII file consisting of 253,597 rows and 48 columns (Appendix E). Two parameters provided by GEOMAP7.INP are used by GEOMOD4: the soil depth class number (column 10) and the rock-type number (column 11). The input values for soil depth class are integers from 1 to 4 and the input values for rock-type are integers from 1 to 345 . This input range is valid because the values were obtained from ARCINFO using the source data as input (see Appendix D for description of source data used for 30MSITE.INP) and a sequence of applied software routines described in Appendices D through E of this report. 


\section{F5. TEST RESULTS}

\section{- Output from test:}

The output for the test case is the main output file, GEOMOD4.INP generated by GEOMOD4 V1.0. The output file is used to generate raster-format map image files in TRANSFORM, which are used only as a part of the validation test plan (the map image files are not required as part of the preprocessing procedure for developing the input used by INFIL V2.0).

\section{- Description of how the testing shows that the results are correct for the specified input:}

The map images developed using TRANSFORM indicate by visual inspection that the integer values defining the updated soil depth class parameter have been correctly modified and incorporated into the output file, GEOMOD4.INP that is created by GEOMOD4. Visual comparison of the results from GEOMAP7.INP and GEOMOD4.INP indicates that the intended modification of the soil depth class parameters has been correctly performed.

The subset of grid cell locations (a rectangular area in the upper part of Solitario Canyon) and corresponding input and output parameter values that were used to visually check that the functions performed by the routine had been executed correctly (the intended modifications to the parameters had occurred). The comparison between the input and output verifies that the first soil depth class modification and the rock-type estimation function are being properly executed by the routine.

For the grid cell located at 547391 easting and 4079253 northing, the input soil depth class is 4 representing locations with thick soils of $6 \mathrm{~m}$ and greater and the input rock-type is 321 which is consolidated bedrock and thus indicates an upland location that should be associated with thin to intermediate soil thickness. Table F-3 indicates that GEOMOD4 has correctly identified the inconsistency and has modified the soil depth class to 6 , which is equivalent to depth class 3 and 5 in terms of estimating soil thickness. Table F-4 indicates that no modifications were made to the rock-type for this location. This comparison between the input and output verifies that the second soil depth class modification is being properly executed by the routine.

Comparison of the input and output files indicates that no unintended modifications occurred during program execution (see printouts for input and output files under Section 6). Both the input and output files consist of 253,597 rows and 48 columns, and the order and format of the rows and columns has not been modified. With the exception of the intended modifications made to the soil depth and rock-type parameters, the input and output files were found to be equivalent. 


\section{- List limitations or assumptions to this test case and code in general:}

The limitations of the developed test case are based on the practical limitations of verifying modified parameter values for all 253, 597 grid cells included in the output file used for the developed test case. Validation of the entire output file used in the test case was performed as a visual evaluation of raster-based map images produced in TRANSFORM. Only a representative subset of the entire output file could be used for a more detailed and quantitative testing of the specific functions performed by the routine. However, there is no expected significance to this limitation.

\section{- Electronic files identified by name and location:}

Electronic files are located on CD-ROM labeled GEOINPUT-1, under the directory GEOMOD4, included as an appendix to the report. The following electronic files are provided:

GEOMOD4.CTL: Input file consisting of the input and output file names for GEOMOD4.

GEOMOD4.FOR: FORTRAN source code listing for the routine GEOMOD4 V1.0. A printout of the source code is included as part of this appendix.

GEOMOD4.EXE: Executable file for the routine GEOMOD4 V1.0, compiled for INTEL processors.

GEOMAP7.INP: Input file consisting of a column-formatted, ASCII text file with 253,597 rows and 48 column. This file was developed as the output file from GEOMAP7 version (Appendix E). A partial printout of the first part of this file is included as part of this appendix.

GEOMOD4.INP: Output file consisting of a column-formatted, ASCII text file with 48 columns and 253,597 rows. Each row corresponds to a grid cell location for the geospatial parameter base grid (the UTM location coordinates are defined by columns 2 and 3). Columns 10 (soil depth class) and 11 (rock-type number) of this file contain the parameters modified by GEOMOD4 V1.0. A partial printout of the first part of this file is included as part of this appendix.

GEOMAP7B.HDF: TRANSFORM raster-based map image of the soil depth class parameters obtained from column 10 of the input file, GEOMAP7.INP. The file is used to perform the software routine validation test and is provided as supporting information. This file is not a part of the routine application.

GEOMOD4A.HDF: TRANSFORM raster-based map image of the modified soil depth class parameters obtained from column 10 of the output 
file, GEOMOD4.INP. The file is used to perform the software routine validation test and is provided as supporting information. This file is not a part of the routine application.

F6. SUPPORTING INFORMATION. (INCLUDE BACKGROUND INFORMATION, SUCH AS REVISION TO A PREVIOUS ROUTINE OR MACRO, OR EXPLANATION OF THE STEPS PERFORMED TO RUN THE SOFTWARE. INCLUDE LISTINGS OF ALL ELECTRONIC FILES AND CODES USED).

\section{- Procedure for running routine:}

To run the routine GEOMOD4 V1.0, the executable file (GEOMOD4.EXE), the routine control file (GEOMOD4.CTL), and the input file specified in the routine control file (GEOMAP7.INP) must be placed in the same directory. The routine is executed by typing GEOMOD4 in a DOS window or by double clicking on the file, GEOMOD4.EXE in the Microsoft Windows operating system, or by typing in the path and filename in the RUN window of the Windows NT or Windows 98 start menu. The input and output file names must be in the correct sequential order as specified in the routine control file (see example listing below).

\section{- Example listing of routine control file, GEOMOD4.CTL}

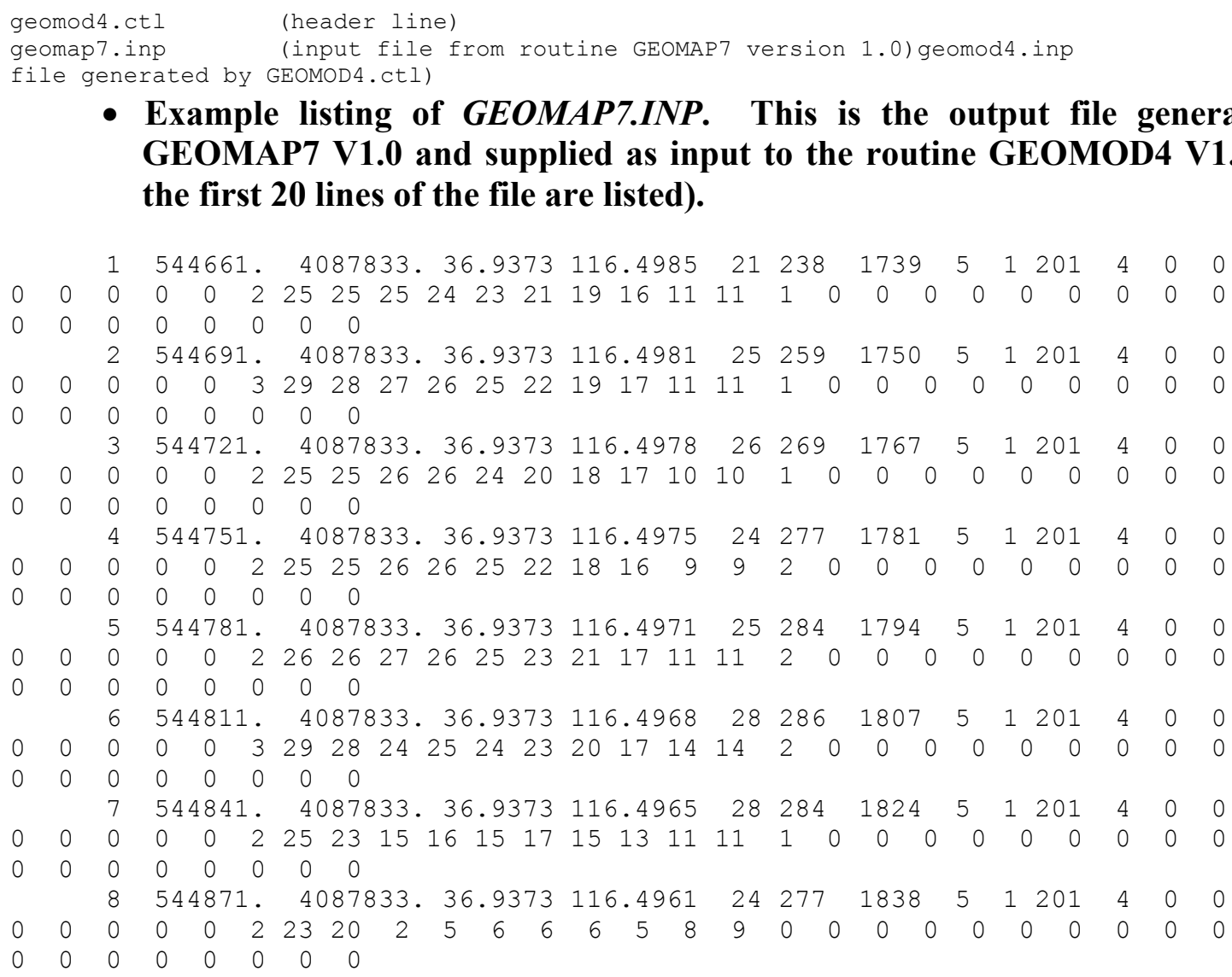




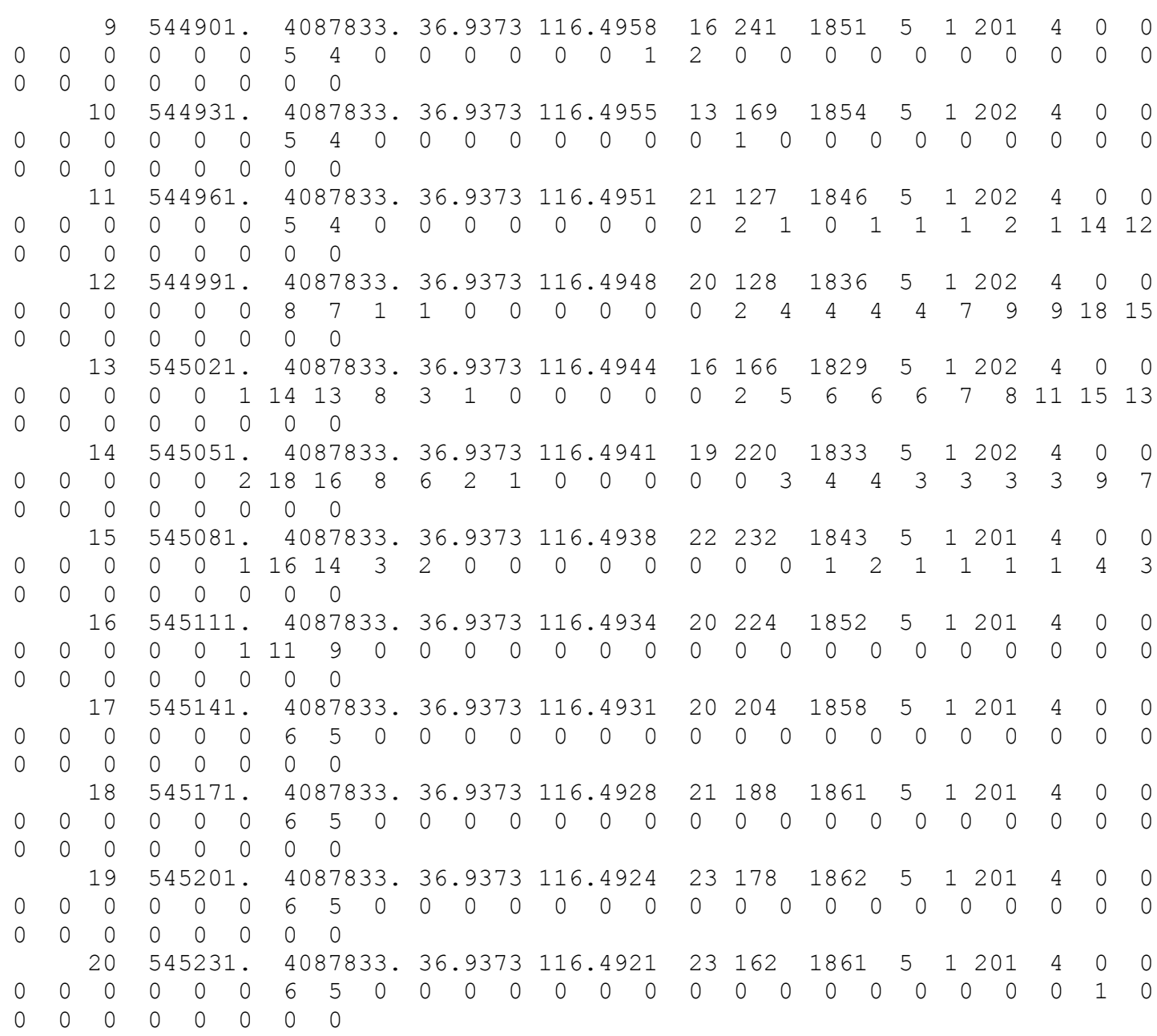

- Example listing of GEOMOD4.INP. This is the output file generated by GEOMOD4 V1.0 and supplied as input to the routine SOILMAP6 V1.0 (only the first 20 lines of the file are listed).

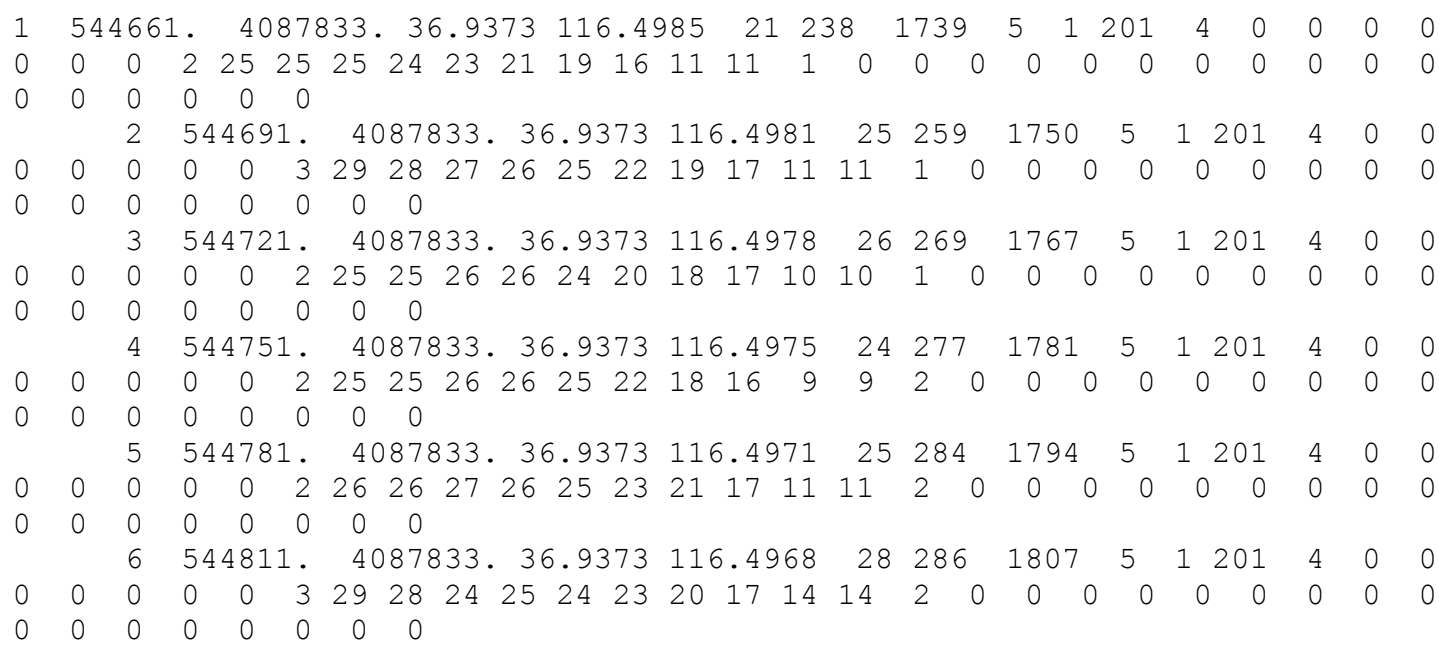




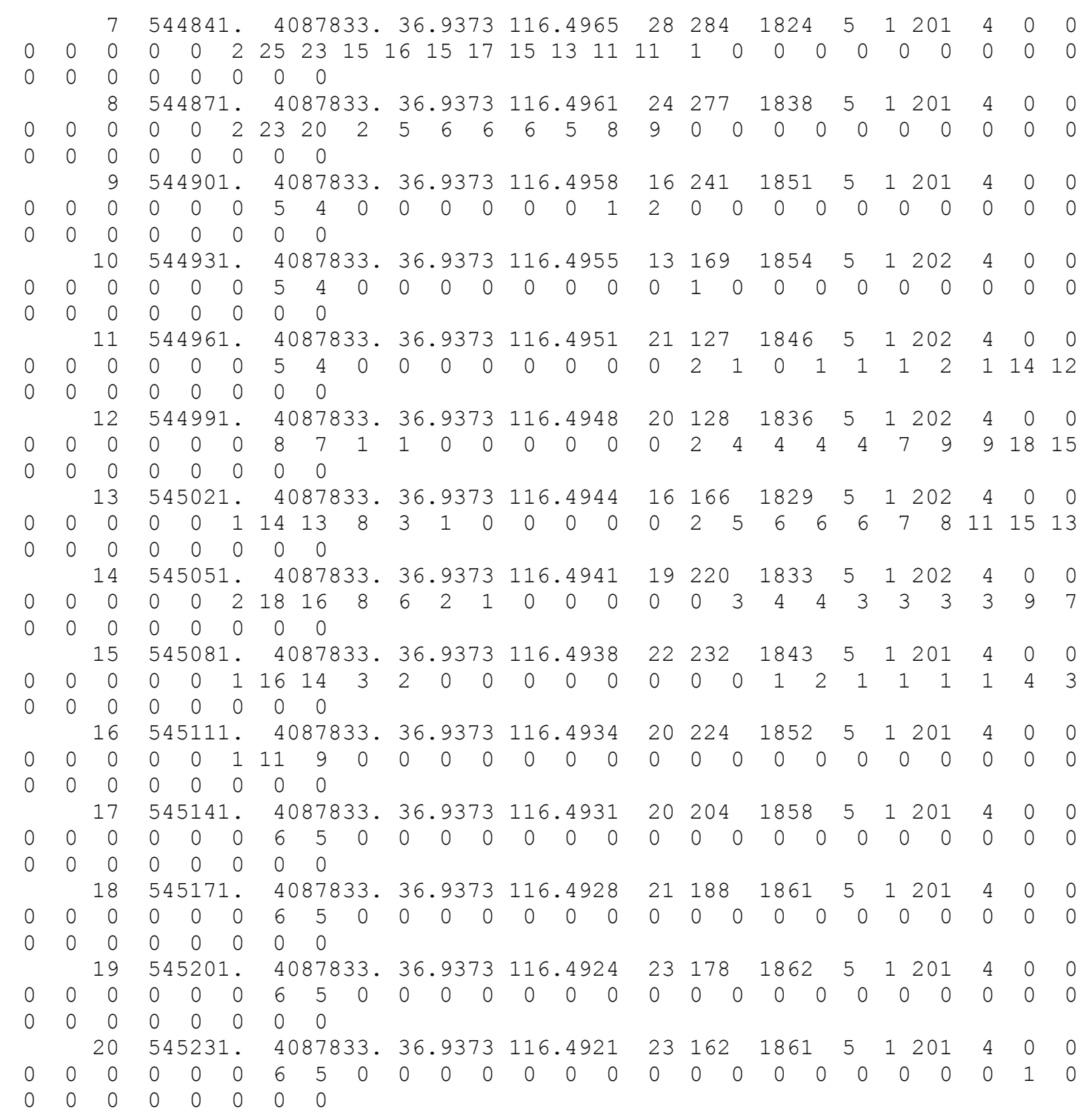

\section{- Listing of source code for routine GEOMOD4 V1.0:}

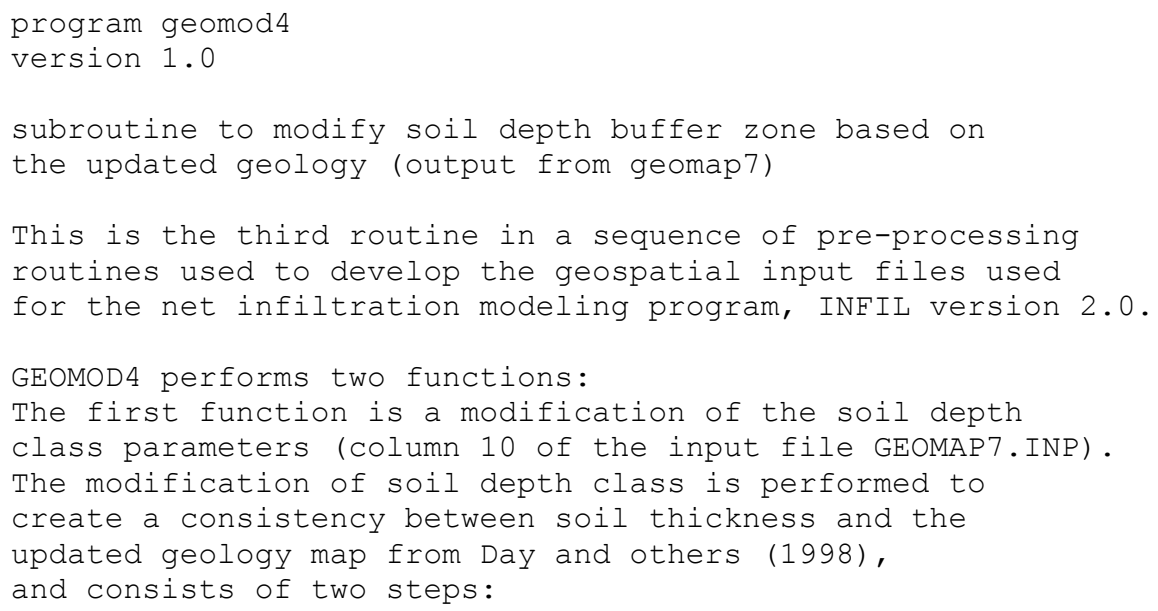




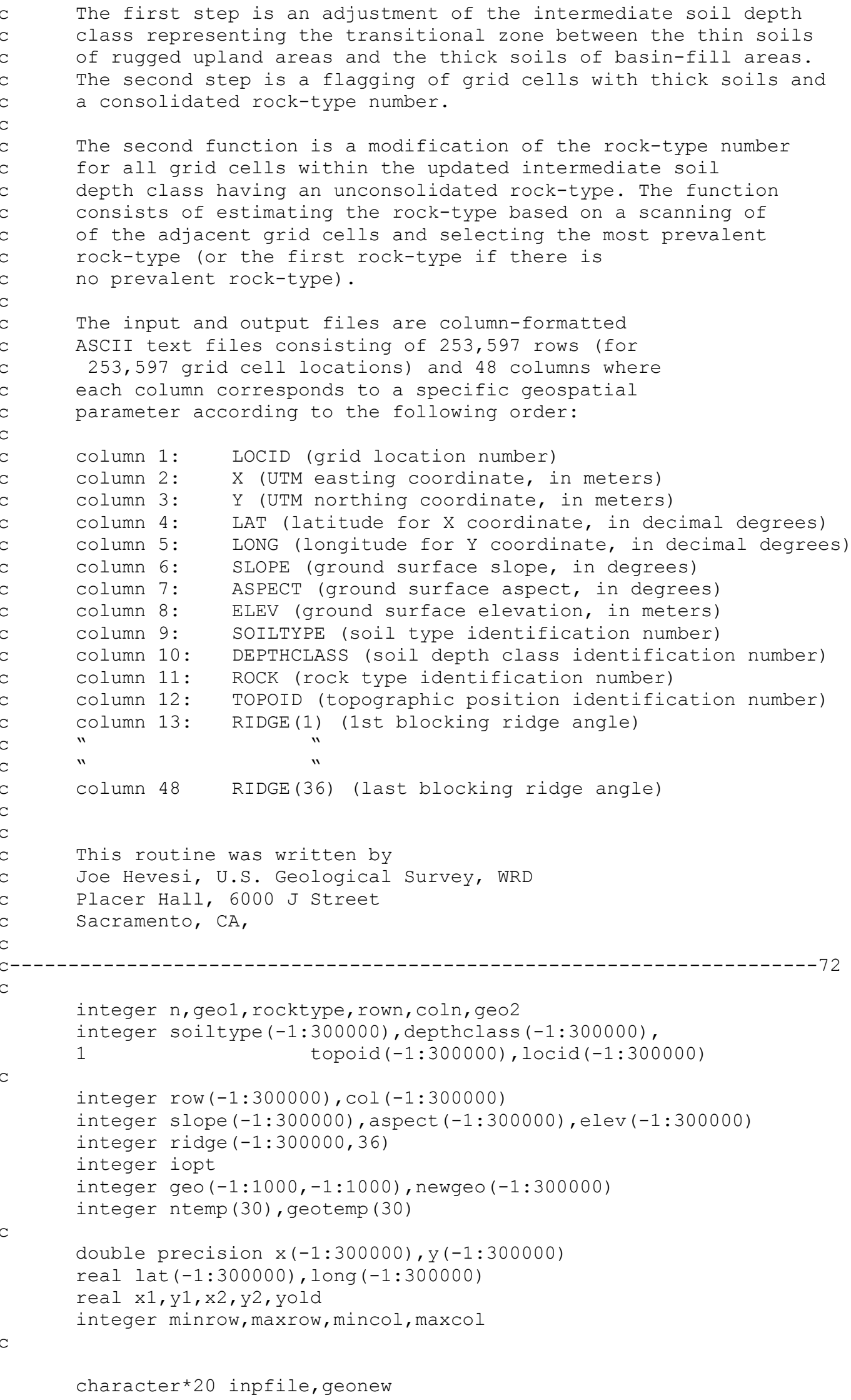




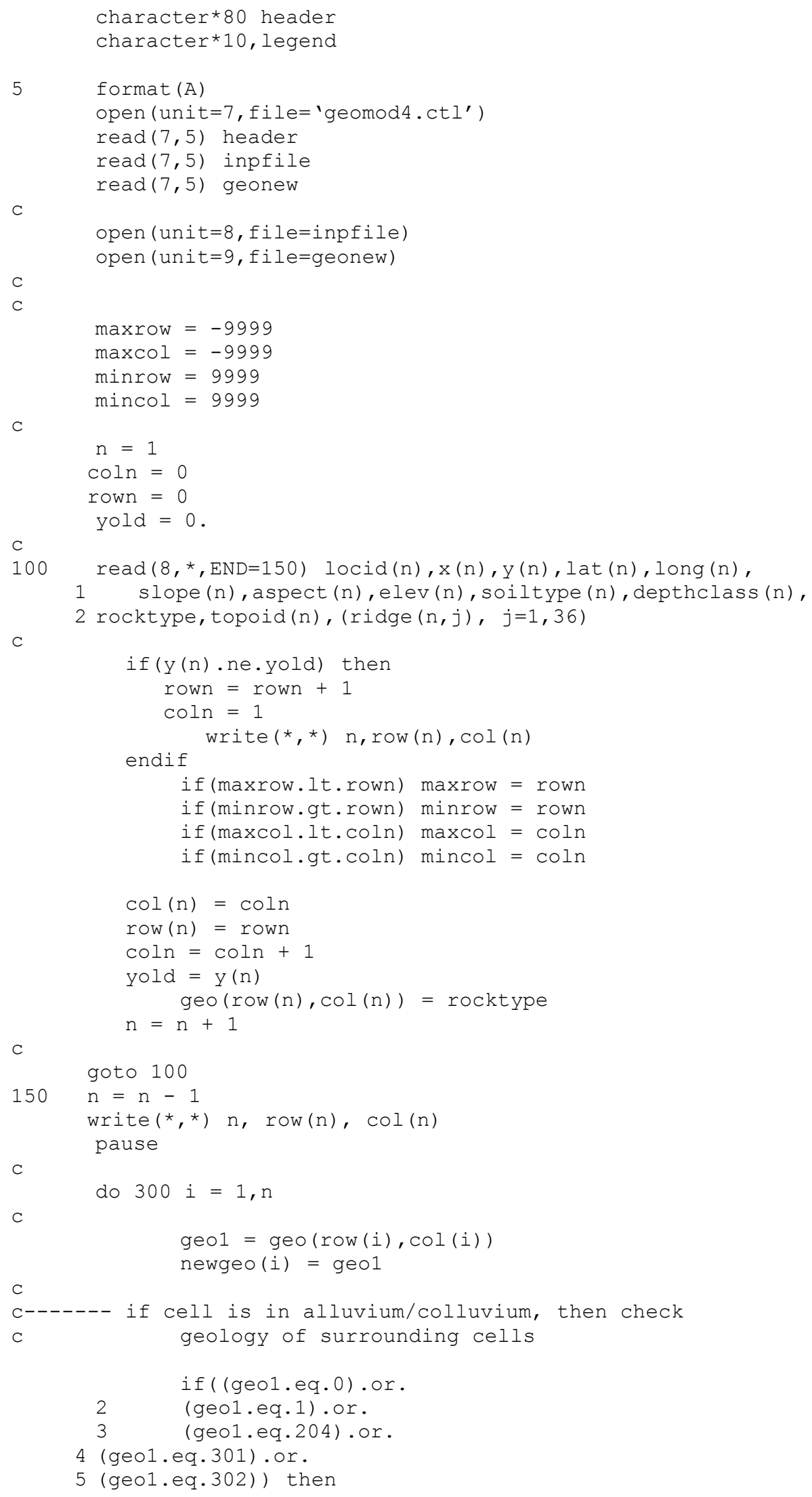




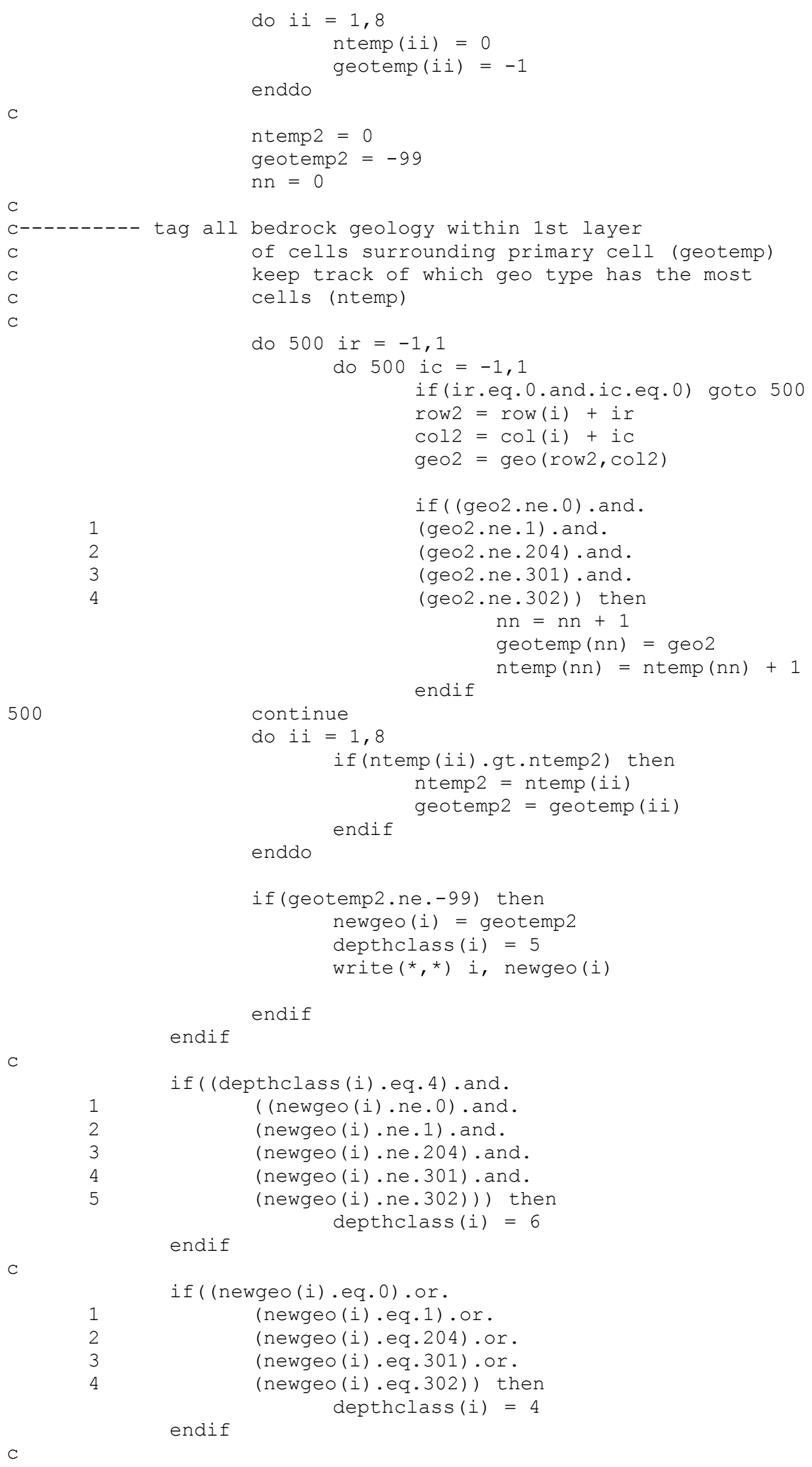




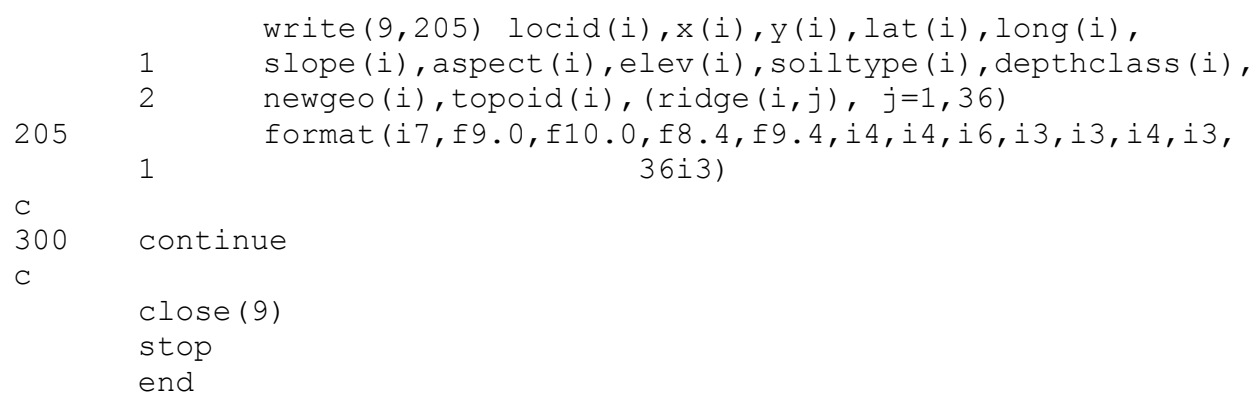




\section{APPENDIX G}

\section{ESTIMATION OF SOIL DEPTH USING SOILMAP6 V1.0}




\section{G1. NAME OF ROUTINE/MACRO WITH VERSION/OS/HARDWARE ENVIRONMENT AND USER INFORMATION}

Name of software routine: SOILMAP6 V1.0,

OS and hardware environment: Windows NT 4.0, Pentium Pro PC

Computer Identification: SM321276 with a USGS specific host-name P720dcasr

Software Users: Joseph Hevesi (916-278-3274), Alan Flint (916-278-3221)

User Location: U.S. Geological Survey, Room 5000E, Placer Hall, 6000 J Street, Sacramento, CA 95819-6129

\section{G2. NAME OF COMMERCIAL SOFTWARE WITH VERSION/OS/HARDWARE USED TO DEVELOP ROUTINE/MACRO}

The source code for SOILMAP6 V1.0 was developed using the standard FORTRAN77 programming language. The source code was written, debugged, and compiled (for PC platforms using INTEL processors) using DIGITAL Visual Fortran with Microsoft Developer Studio, V. 5.0.

\section{G3. GENERAL DESCRIPTION OF ROUTINE/MACRO}

SOILMAP6 V1.0 is a FORTRAN77 routine developed in accordance with AP-SI.1Q, specifically for the analysis/model activity documented in this report. The routine source code (SOILMAP6.FOR), compiled executable file (SOILMAP6.EXE), routine control file (SOILMAP6.CTL), input and output files, validation test files, and a copy of this appendix, are located under the directory SOILMAP6 on a CD-ROM labeled GEOINPUT-1. The routine source code, control file, and the input and output files are ASCII text files that can be read using any standard ASCII text editor and can be imported into standard word processing or spreadsheet applications such as Microsoft WORD and EXCEL. The executable file can be used to run SOILMAP6 V1.0 on any PC with an INTEL processor (with adequate RAM).

All input parameters used by SOILMAP6 V1.0 and the parameters calculated by SOILMAP6 that are included in the developed output file, SOILMAP6.INP, are used for the development of the geospatial parameter input file for INFIL V2.0 (USGS 2000 [DIRS 139422]). The file, SOILMAP6 is used directly as input to the routine SORTGRD1 V1.0

\section{G4. TEST PLAN FOR THE SOFTWARE ROUTINE SOILMAP6 V1.0}

\section{- Explain whether this is a routine or macro and describe what it does:}

SOILMAP6 V1.0 is the fourth routine applied in a sequence of FORTRAN 77 routines that are used in the development of the geospatial parameter input file for INFIL V2.0. Modifications to the geospatial parameter input file performed by SOILMAP6 involve an application of empirical, linear scaling functions to estimate an absolute soil thickness (in meters) for each grid cell location using the up-dated soil depth class and 
ground surface slope parameters obtained from the file, 30msite.inp ${ }^{3 .}$ The linear scaling functions are based on an assumed correlation between calculated ground surface slope and soil thickness within each depth class. The assumed correlation is qualitatively supported by subjective field observations indicating a general decrease in soil thickness with an increase in ground surface slope.

The soil thickness function for depth class 1 is based on an assumption that soils tend to be relatively thin at summit and ridge-crest locations and are the thinnest for steep side slope locations. Thicker soils are assumed to occur at the relatively gently sloping shoulder areas that define the transition between summit or ridge-crest areas and steep sideslope areas. Thicker soils are also assumed to occur for more gently sloping foot-slope locations. Using these assumptions, the linear scaling function used to estimate soil depth for model grid cells assigned a soil-depth class number of 1 (designated for rugged upland areas with thin soils) is defined by:

$$
\begin{array}{ll}
\mathrm{D}=0.03 * \mathrm{~S}+0.1, & \mathrm{~S} \leq 10 \\
\mathrm{D}=0.013 *(10-\mathrm{S})+0.4, & 10<\mathrm{S}<40 \\
\mathrm{D}=0.01, & \mathrm{~S} \geq 40
\end{array}
$$

where $\mathrm{D}=$ soil depth (in meters), and $\mathrm{S}=$ slope (degrees). The soil thickness function for depth class 2, which is defined on the basis of mapped zones of greater soil thickness within upland areas generally associated with soil depth class 1, assumes a simpler correlation between slope and soil thickness. For grid locations associated with soil depth class 2 , absolute soil thickness is estimated using:

$$
\begin{array}{ll}
\mathrm{D}=2-(0.05 * \mathrm{~S}), & \mathrm{S}<32 \\
\mathrm{D}=0.4, & \mathrm{~S} \geq 32
\end{array}
$$

A single soil thickness function is used for depth classes 3,5, and 6. The function is also based on the assumption of a simple linear correlation between slope and soil thickness. For grid locations associated with soil depth classes 3, 5, and 6, absolute soil thickness is estimated by:

$$
\begin{array}{ll}
D=6-(0.16 * \mathrm{~S}), & \mathrm{S} \leq 25 \\
\mathrm{D}=2.0 & \mathrm{~S}>25
\end{array}
$$

For depth class 4, soil depth is set to a uniform depth of $6 \mathrm{~m}$.

Prior to calculating the soil depth estimates, SOILMAP6 V1.0 uses the input file, GEOMOD4.INP (the output file created by GEOMOD4 V1.0) to perform a final adjustment of the original soil depth class parameters. The modifications to the soil depth class parameters performed by SOILMAP6 are based on a comparison between the updated soil depth classes and the updated rock-type parameters. The comparison

\footnotetext{
${ }^{3}$ Ground surface slope is calculated using ARCINFO which provides a standardized approximation of the true ground surface slope using the raster-based grid format of the digital elevation model used as source data and a five-point calculation of the average slope.
} 
provides a final consistency check to ensure that no grid cell locations have a combination of a soil depth class indicating thin soils (associated with rugged upland areas) and a rock-type indicating unconsolidated material (associated with basin-fill areas).

\section{- Listing of FORTRAN77 Source code:}

A listing of the FORTRAN77 source code for the routine SOILMAP6 V1.0 along with examples of the input and output files used in the test plan are included at the end of this appendix.

\section{- Description of test(s):}

A validation test of the functions performed by the routine was conducted by a visual comparison between the input file, GEOMOD4.INP and the output file, SOILMAP6.INP. The visual analysis was facilitated by raster-based map images created using the acquired software program TRANSFORM. The raster-based grid and map-imaging utilities allow for an analysis of the entire raster grid and also a detailed evaluation of grid cell values for specified grid locations.

The test criteria for the functions performed by SOILMAP6 consist of visual verification that the soil depth class parameters have been correctly modified and that the calculations of soil depth estimates have been correctly performed. The test plan consists of a 3-step testing procedure. The first step requires a visual inspection of the TRANSFORM map images. The second step requires a check of the calculations performed by the routine using a comparison of manual calculations against a selected subset of the input and output files. The third step requires a check of the input and output files to ensure that the output file format is correct and that no modifications other than those intended by the routine application have occurred.

The second step of the test plan was facilitated by extracting identical subsets (in terms of grid cell locations) of the input and output files using the raster-based files created by TRANSFORM. The subsets are in the format of ASCII text matrices and are used to check the estimated soil thickness values in the output file against a manual calculation. The criteria applied in the third step of the test plan consists of visually inspecting the input and output files and verifying that the intended modification of the geospatial input file had been correctly performed, and that no unintended modifications had occurred during program execution.

SOILMAP6 V1.0 performs an internal testing of the modified soil depth class parameters by flagging the soil depth class parameter for a given grid cell location with a negative sign if an inconsistency is still identified after the final modification of the soil depth class parameters. If no negative values occur in the output file then the internal validation test performed by the routine is satisfied. 


\section{- Specify the range of input values to be used and why the range is valid:}

GEOMOD4.INP is the main input file used by SOILMAP6 V1.0. The file is specified in the file, SOILMAP6.CTL, which is the routine control file for SOILMAP6 and is required for program execution. GEOMOD4.INP is a column-formatted ASCII file consisting of 253,597 rows and 48 columns (Appendix F). Three parameters provided by GEOMOD4.INP are used by SOILMAP6: the soil depth class number (column 10), the rock-type number (column 11), and the ground surface slope (column 6). The input values for soil depth class are integers from 1 to 6 , the input values for rock-type are integers from 1 to 345, and the input values for slope are integers from 0 to 47 . This input range is valid because the values were obtained from ARCINFO using the source data as input (see Appendix E for description of source data used for 30MSITE.INP) and a sequence of applied software routines described in Appendices $E$ through $F$ of this report.

\section{G5. TEST RESULTS}

\section{- Output from test:}

The output for the test case is the main output file, SOILMAP6.INP generated by SOILMAP6 V1.0. The output file is used to generate raster-format map image files in TRANSFORM, which are used only as a part of the validation test plan (the map image files are not required as part of the preprocessing procedure for developing the input used by INFIL V2.0).

\section{- Description of how the testing shows that the results are correct for the specified input:}

The map images developed using TRANSFORM (Figures G-1 through G-5) indicate by visual inspection that the routine SOILMAP6 V1.0 is functioning correctly for all grid cell locations within the modeling domain. Comparison of Figures G-1 and G-2 indicates that the re-defined soil depth classes are consistent with calculated ground surface slope. Figure G-2 indicates the finalized soil depth class parameters consisting of integer values of 1 to 6 . The figure indicates that no modifications were performed by SOILMAP6 to the soil depth class parameters. Negative soil depth class numbers do not occur in the output from SOILMAP6 and therefore inconsistencies in the soil depth class parameters were not found in the output file created by GEOMOD4. Comparison of Figures G-2 and G-3 indicates that the soil depth classes were correctly applied by the routine in the calculation of soil thickness estimates on the scale of the modeling domain. Thick soils of $6 \mathrm{~m}$ and greater match the area of soil depth class 4 , and thin soils of $0.5 \mathrm{~m}$ and less match the area of depth class 1. Figure G-4 indicates that the calculation of soil thickness estimates for soil depth class 1 was performed correctly and provides reasonable estimates of soil thickness for upland areas. Locations with minimum soil thickness estimates (less than $0.1 \mathrm{~m}$ ) coincide with locations having high slope values (greater than $30^{\circ}$ ). Locations with relatively high soil thickness estimates (greater than $0.35 \mathrm{~m}$ ) for depth class 1 coincide with low and intermediate slope values (less than $20^{\circ}$ ). Figure G-5 indicates the expected result for 
soil thickness estimates in the intermediate depth classes $(2,3,5$, and 6$)$. The soil thickness estimates range from approximately 0.5 to less than $6.0 \mathrm{~m}$ and occur for locations representing the transition between thin upland soils and thick basin-fill soils and areas mapped as having intermediate soil thickness within upland areas.

Tables G-1 and G-2 indicate the values of input parameters obtained from GEOMOD4.INP (Table G-1 shows the soil depth class number and Table G-2 shows the rock-type number) for a subset of grid cells located in upper Solitario Canyon that are extracted from the input file. The input data is used by SOILMAP6 to perform a final consistency check of the modified soil depth class parameters relative to the updated rock-type parameters. Table G-3 indicates that the finalized soil depth class parameters included in the output file, SOILMAP6.INP are identical to the soil depth class parameters in the input file, GEOMDO4.INP (no modifications were performed by the routine). Table G-4 indicates the values of calculated ground surface slope obtained from the input file that are used in calculating soil thickness estimates. Table G-5 shows the values of soil thickness estimates obtained from the output file. A manual check of the soil thickness estimates indicates that the routine is functioning correctly. For example, for the grid cell located at 547421 easting and 4079643 northing, a manual check of the equation used for soil depth class 1 and a slope value of 22 indicates a value of $0.24 \mathrm{~m}$ for estimated soil thickness, and this agrees with the value obtained from the output file. For the grid cell located at 547211 easting and 4079673 northing, a manual check of the equation used for soil depth class 2 and a slope value of 15 indicates a value of $1.25 \mathrm{~m}$ for estimated soil thickness, which agrees with the output.

Visual inspection of the input and output files (see partial listing of files, GEOMOD4.INP and SOILMAP6.INP provided under supporting information) indicates that the soil thickness estimates were correctly included as column 11 in the output file and that no unintended modifications of the input parameters and input file format occurred. The output file has the correct number of lines $(253,597)$, the correct number of columns (49), and the position of the columns and rows is correct.

\section{- List limitations or assumptions to this test case and code in general:}

The limitations of the developed test case are based on the practical limitations of verifying modified parameter values for all 253,597 grid cells included in the output file used for the developed test case. Validation of the entire output file used in the test case was performed as a visual evaluation of raster-based map images produced in TRANSFORM. Only a subset of the entire output file could be used for more detailed validation tests that included a manual check of the equations used by the routine. 
- Electronic files identified by name and location:

Electronic files are located on CD-ROM labeled GEOINPUT-1, under the directory SOILMAP6, included as an Appendix to the report. The following electronic files are provided:

SOILMAP6.CTL: Input file consisting of the input and output file names for SOILMAP6 V1.0.

SOILMAP6.FOR: FORTRAN source code listing for the routine SOILMAP6 V1.0. A printout of the source code is included as part of this appendix.

SOILMAP6.EXE: Executable file for the routine SOILMAP6 V1.0, compiled for INTEL processors.

GEOMOD4.INP: Input file consisting of a column-formatted, ASCII text file with 253,597 rows and 48 column. This file was developed as the output file from GEOMOD4 version (Appendix F). A partial printout of the first part of this file is included as part of this appendix.

SOILMAP6.INP: Output file consisting of a column-formatted, ASCII text file with 49 columns and 253,597 rows. Estimates of soil depth, in meters, are added as a new column between columns 10 and 11 (rock-type number) of the input file column order. Each row corresponds to a grid cell location for the geospatial parameter base grid (the UTM location coordinates are defined by columns 2 and 3). Columns 10 (soil depth class) and 11 (estimated soil depth in meters) of this file contain the parameters modified by SOILMAP6 V1.0. A partial printout of the first part of this file is included as part of this appendix.

30MSLOPE.HDF: TRANSFORM raster-based map image (Figure G-1) of calculated ground surface slope obtained from column 6 of the input file, GEOMOD4.INP. The file is used to perform the software routine validation test and is provided as supporting information. This file is not a part of the routine application

SOILM6DC.HDF: TRANSFORM raster-based map image (Figure G-2) of the soil depth class parameters obtained from column 10 of the output file, SOILMAP6.INP. The file is used to perform the software routine validation test and is provided as supporting information. This file is not a part of the routine application. 


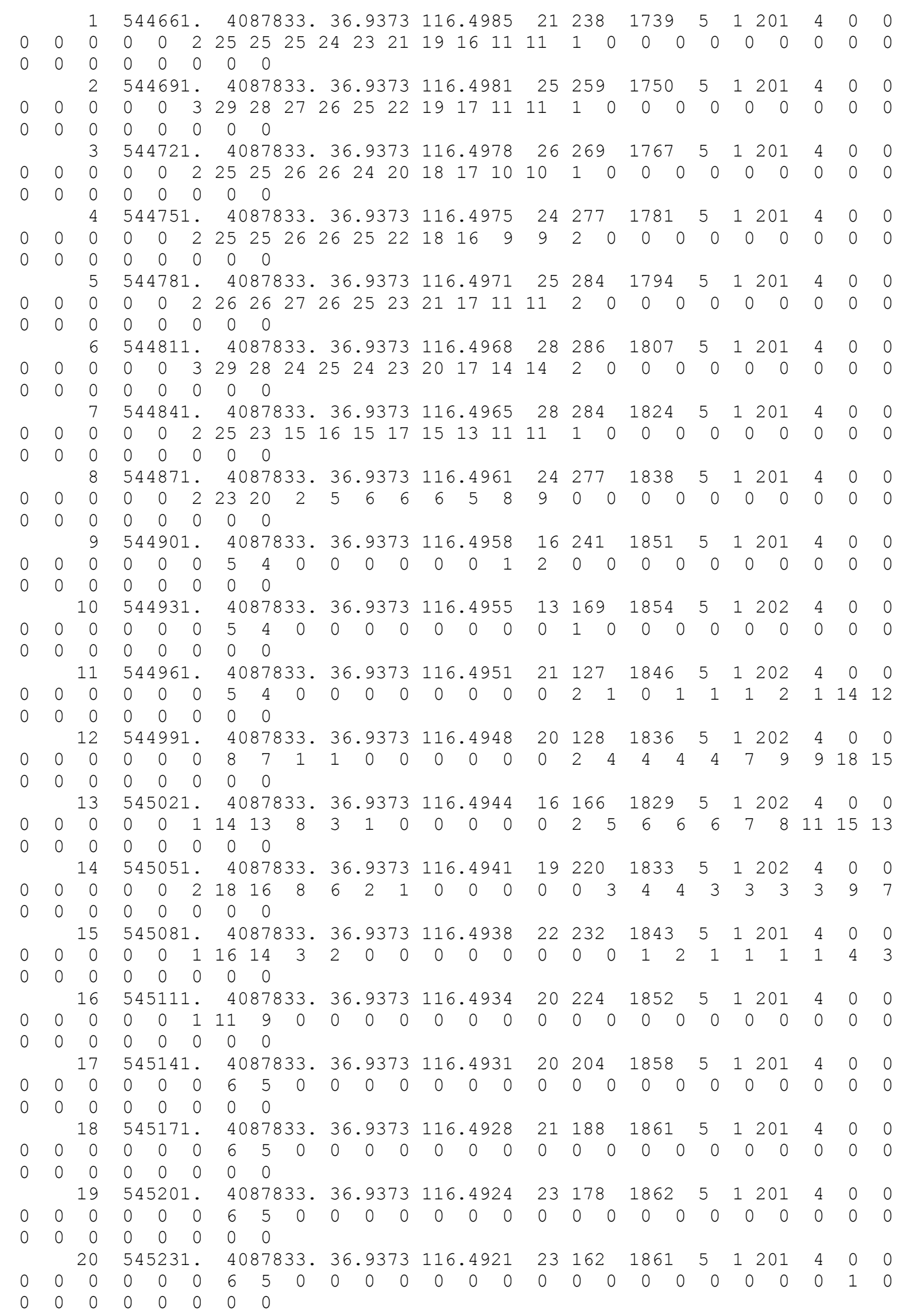


- Example listing of the output file, SOILMAP6.INP (only the first 20 lines of the file are listed). The modified output consists of the addition of a new column consisting of the estimated soil thickness, in meters (column 11).

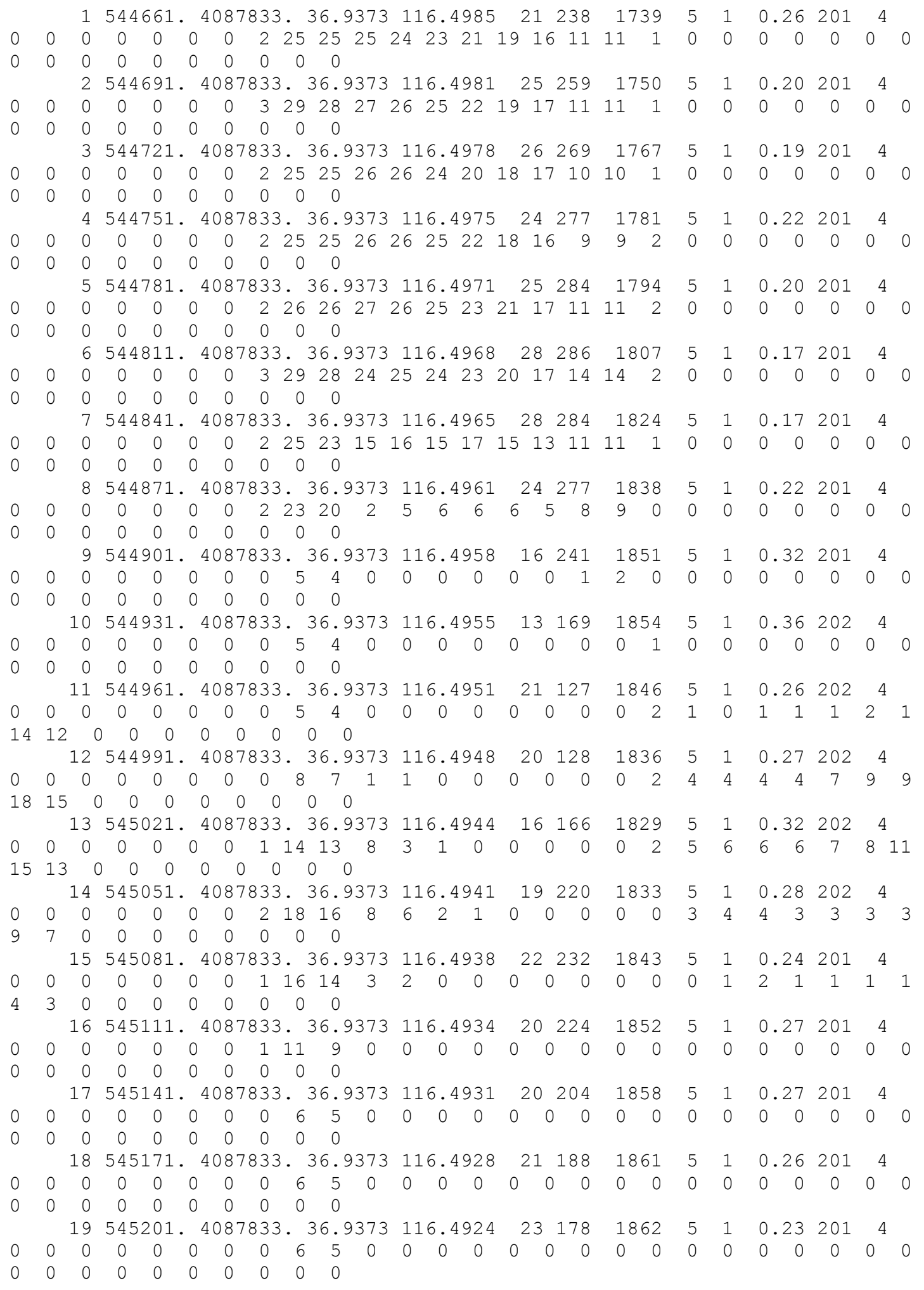




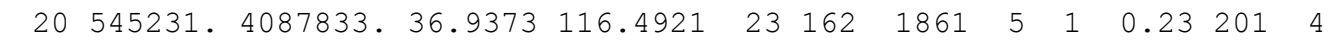

$$
\begin{aligned}
& \begin{array}{llllllllllllllllllllllllll}
0 & 0 & 0 & 0 & 0 & 0 & 0 & 0 & 6 & 5 & 0 & 0 & 0 & 0 & 0 & 0 & 0 & 0 & 0 & 0 & 0 & 0 & 0 & 0 & 0 & 0
\end{array}
\end{aligned}
$$

- Figures used as part of the routine test plan:
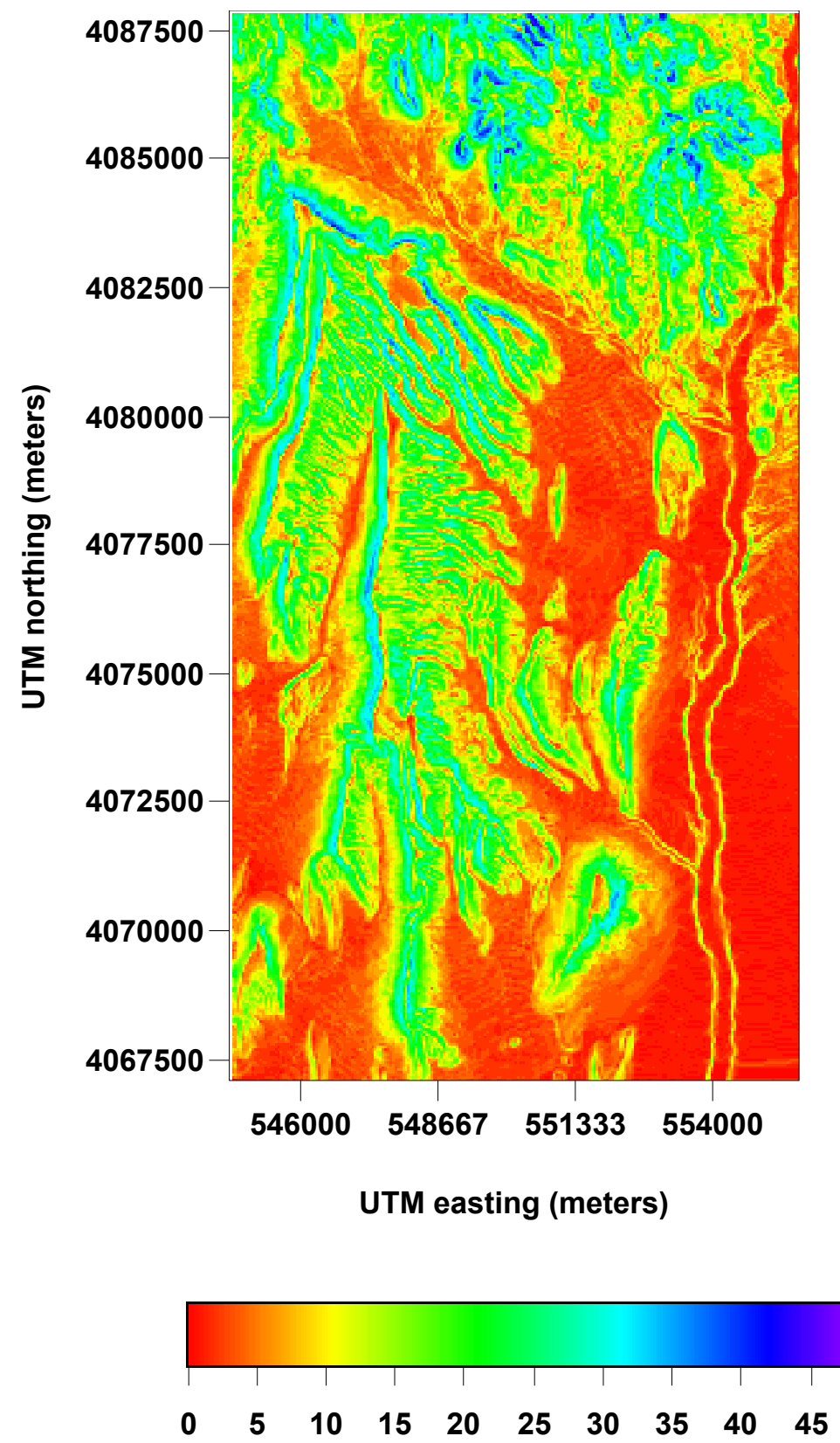

_30msite_inp_6: ground surface slope (degrees)

Output DTN: GS000308311221.004.

Figure G-1. TRANSFORM Map Image (file 3OMSLOPE.HDF) Created Using the Input Parameter Ground Surface Slope from Column 6 of the Input File, GEOMOD4.INP 

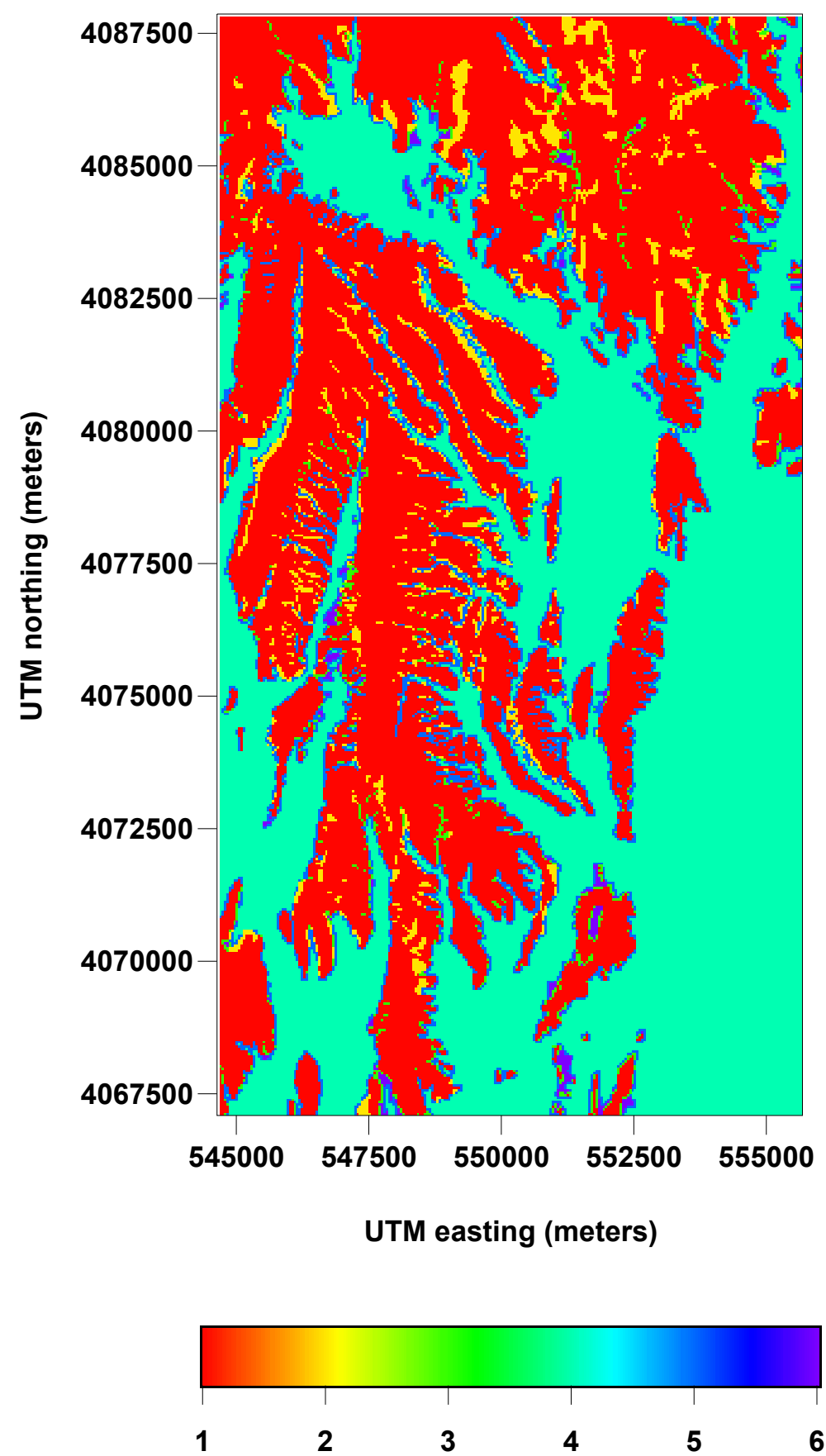

soilmap6_inp_10: output soil depth class

Output DTN: GS000308311221.004.

NOTE: Figure shows integer values ranging from 1 to 6 .

Figure G-2. TRANSFORM Map Image (file SOILM6DC.HDF) of the Finalized Soil Depth Class Obtained from Column 10 of the Output file, SOILMAP6.INP 

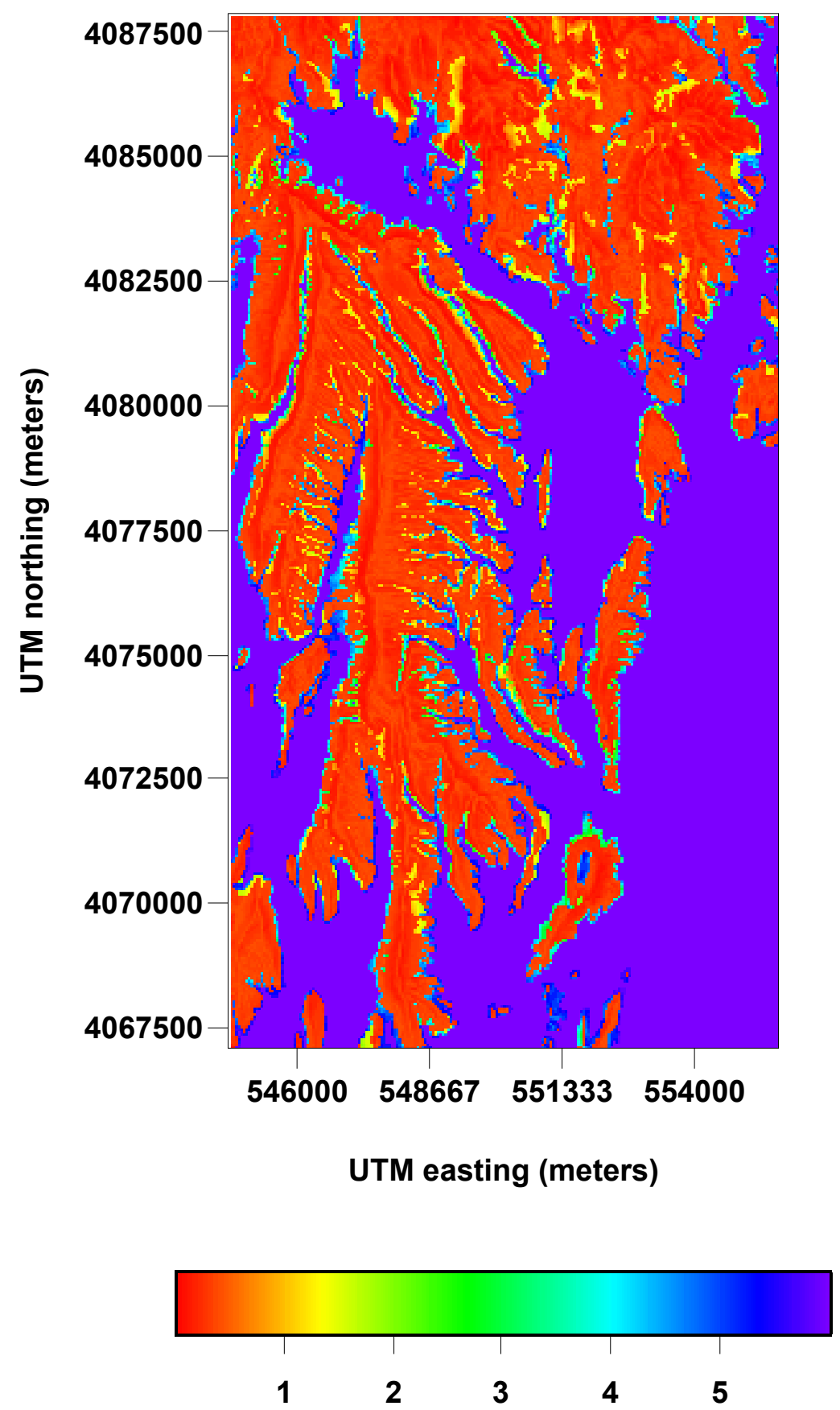

\section{soilmap6_inp_11: output soil depth (meters)}

Output DTN: GS000308311221.004.

NOTE: Figure shows the full range of estimated soil thickness of 0.01 to $6 \mathrm{~m}$ (a soil thickness of $6 \mathrm{~m}$ represents locations where actual soil thickness is $6 \mathrm{~m}$ and greater) .

Figure G-3. TRANSFORM Map Image (file SOILMP61.HDF) Created Using the Estimated Soil Thickness from Column 11 of the Output File, SOILMAP6.INP 


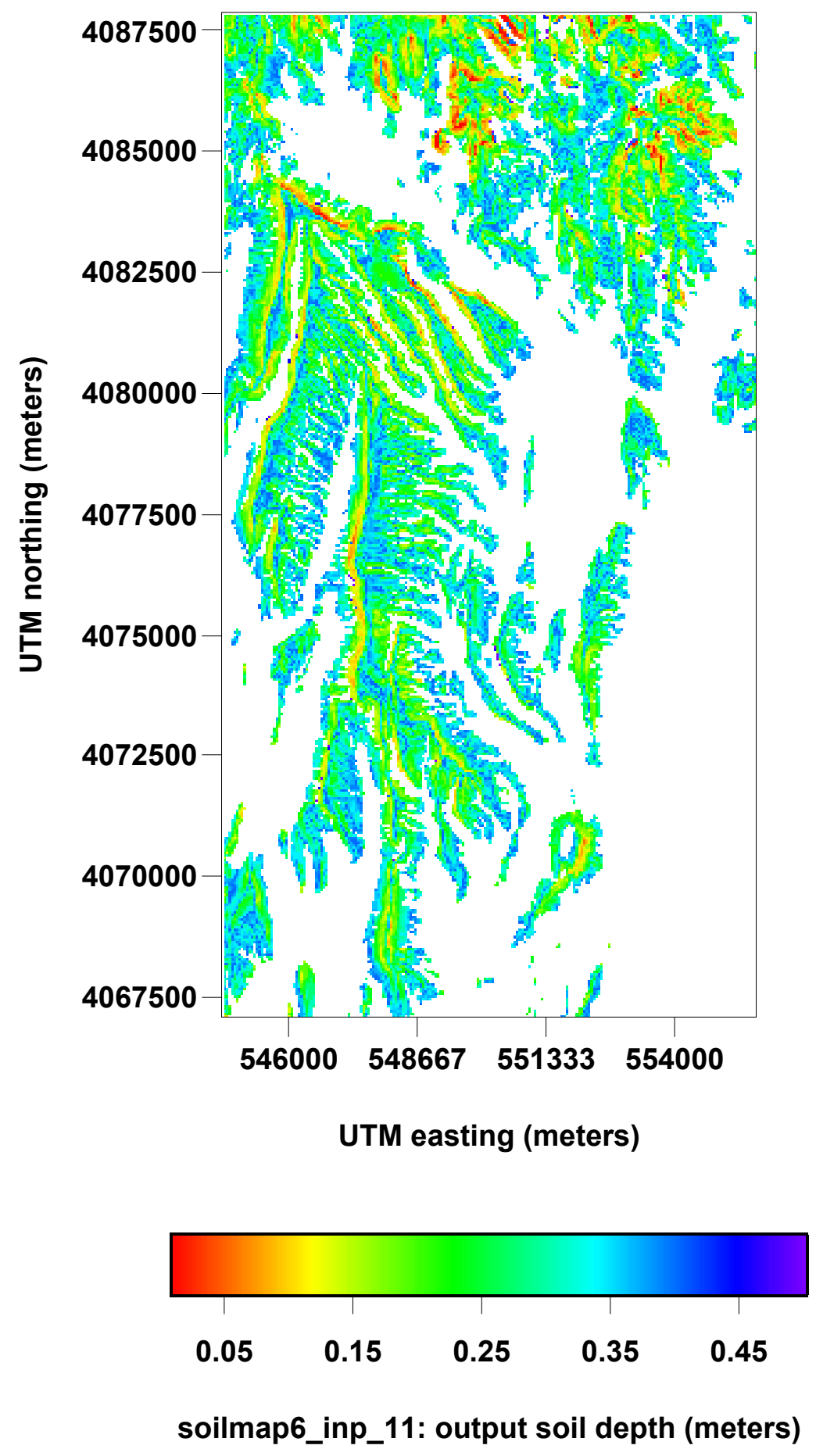

Output DTN: GS000308311221.004.

NOTE: Figure shows estimated soil thickness for locations with thin soils.

Figure G-4. TRANSFORM Map Image (file SOILMP62.HDF) Created Using the Estimated Soil Thickness from Column 11 of the Output File, SOILMAP6.INP 

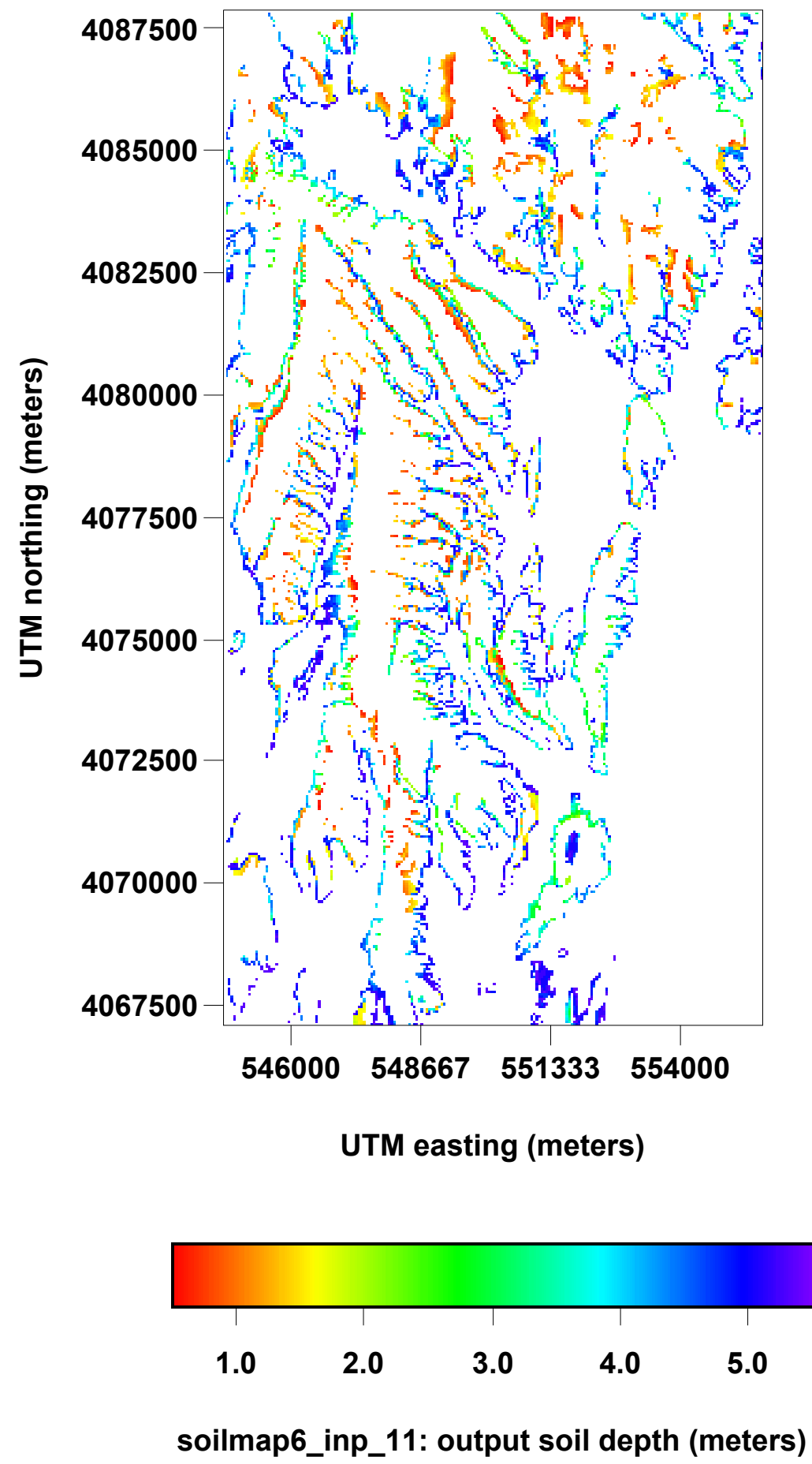

Output DTN: GS000308311221.004.

NOTE: Figure shows estimated soil thickness for locations with intermediate soil thickness.

Figure G-5. TRANSFORM Map Image (file SOILMP63.HDF) Created Using the Estimated Soil Thickness from Column 11 of the Output File, SOILMAP6.INP 


\section{- Tables used as part of the routine test plan:}

Table G-1. Soil Depth Classes Obtained from Column 10 of the Input File, GEOMOD4.INP

\begin{tabular}{|c|c|c|c|c|c|c|c|c|}
\hline \multirow{2}{*}{$\begin{array}{c}\text { UTM Northing } \\
\text { Grid } \\
\text { Coordinates } \\
\text { (meters) }\end{array}$} & \multicolumn{8}{|c|}{ UTM Easting Grid Coordinates (meters) } \\
\hline & 547211 & 547241 & 547271 & 547301 & 547331 & 547361 & 547391 & 547421 \\
\hline 4079703 & 5 & 5 & 4 & 4 & 5 & 2 & 1 & 1 \\
\hline 4079673 & 2 & 5 & 5 & 4 & 5 & 2 & 1 & 1 \\
\hline 4079643 & 1 & 2 & 5 & 5 & 5 & 2 & 1 & 1 \\
\hline 4079613 & 1 & 1 & 2 & 5 & 5 & 1 & 1 & 1 \\
\hline 4079583 & 1 & 1 & 2 & 5 & 5 & 1 & 1 & 1 \\
\hline 4079553 & 1 & 1 & 2 & 5 & 3 & 1 & 1 & 1 \\
\hline 4079523 & 1 & 1 & 3 & 5 & 3 & 1 & 1 & 1 \\
\hline 4079493 & 1 & 1 & 3 & 5 & 1 & 1 & 1 & 1 \\
\hline 4079463 & 1 & 1 & 5 & 3 & 1 & 1 & 1 & 1 \\
\hline 4079433 & 1 & 3 & 5 & 3 & 1 & 1 & 1 & 1 \\
\hline 4079403 & 1 & 3 & 5 & 3 & 1 & 1 & 1 & 1 \\
\hline 4079373 & 3 & 3 & 5 & 3 & 1 & 1 & 1 & 1 \\
\hline 4079343 & 3 & 5 & 5 & 3 & 1 & 1 & 3 & 3 \\
\hline 4079313 & 5 & 5 & 5 & 6 & 3 & 3 & 3 & 3 \\
\hline 4079283 & 5 & 4 & 5 & 6 & 6 & 6 & 3 & 1 \\
\hline 4079253 & 4 & 4 & 5 & 6 & 6 & 6 & 6 & 3 \\
\hline 4079223 & 4 & 4 & 5 & 6 & 6 & 3 & 3 & 3 \\
\hline 4079193 & 4 & 4 & 5 & 6 & 3 & 1 & 1 & 1 \\
\hline 4079163 & 4 & 4 & 5 & 6 & 3 & 1 & 1 & 1 \\
\hline 4079133 & 4 & 4 & 5 & 3 & 1 & 1 & 1 & 1 \\
\hline 4079103 & 4 & 5 & 5 & 1 & 1 & 1 & 1 & 1 \\
\hline 4079073 & 4 & 5 & 3 & 3 & 1 & 1 & 1 & 1 \\
\hline 4079043 & 4 & 5 & 3 & 3 & 1 & 1 & 1 & 1 \\
\hline 4079013 & 4 & 5 & 1 & 1 & 1 & 1 & 1 & 1 \\
\hline 4078983 & 4 & 5 & 1 & 1 & 1 & 1 & 1 & 1 \\
\hline 4078953 & 4 & 5 & 1 & 1 & 1 & 1 & 1 & 1 \\
\hline 4078923 & 4 & 5 & 2 & 1 & 1 & 1 & 1 & 1 \\
\hline 4078893 & 4 & 5 & 1 & 1 & 1 & 1 & 1 & 1 \\
\hline 4078863 & 4 & 5 & 2 & 1 & 1 & 1 & 1 & 1 \\
\hline 4078833 & 4 & 5 & 2 & 1 & 1 & 1 & 1 & 1 \\
\hline 4078803 & 4 & 5 & 2 & 2 & 1 & 1 & 1 & 1 \\
\hline 4078773 & 4 & 5 & 2 & 2 & 1 & 1 & 1 & 1 \\
\hline 4078743 & 5 & 5 & 2 & 1 & 1 & 1 & 1 & 1 \\
\hline
\end{tabular}

Output DTN: GS000308311221.004.

NOTE: Table shows integer values ranging from 1 to 6 for a subset of grid cells located in upper Solitario Canyon.

UTM=Universal Transverse Mercator 
Table G-2. Rock-type Numbers Obtained from Column 11 of the Input File, GEOMOD4.INP

\begin{tabular}{|c|c|c|c|c|c|c|c|c|}
\hline \multirow{2}{*}{$\begin{array}{c}\text { UTM Northing } \\
\text { Grid } \\
\text { Coordinates } \\
\text { (meters) }\end{array}$} & \multicolumn{8}{|c|}{ UTM Easting Grid Coordinates (meters) } \\
\hline & 547211 & 547241 & 547271 & 547301 & 547331 & 547361 & 547391 & 547421 \\
\hline 4079703 & 319 & 19 & 301 & 301 & 30 & 31 & 320 & 319 \\
\hline 4079673 & 19 & 19 & 19 & 301 & 31 & 31 & 320 & 319 \\
\hline 4079643 & 314 & 19 & 19 & 18 & 31 & 31 & 320 & 319 \\
\hline 4079613 & 314 & 314 & 18 & 18 & 31 & 321 & 320 & 320 \\
\hline 4079583 & 314 & 314 & 17 & 18 & 321 & 321 & 320 & 320 \\
\hline 4079553 & 314 & 314 & 17 & 17 & 313 & 321 & 321 & 320 \\
\hline 4079523 & 314 & 314 & 17 & 17 & 313 & 321 & 320 & 320 \\
\hline 4079493 & 314 & 314 & 17 & 17 & 313 & 321 & 320 & 320 \\
\hline 4079463 & 314 & 314 & 314 & 313 & 313 & 321 & 320 & 320 \\
\hline 4079433 & 314 & 17 & 314 & 313 & 320 & 321 & 320 & 320 \\
\hline 4079403 & 314 & 17 & 17 & 313 & 320 & 321 & 320 & 320 \\
\hline 4079373 & 17 & 17 & 17 & 313 & 320 & 321 & 320 & 320 \\
\hline 4079343 & 17 & 17 & 17 & 313 & 320 & 321 & 321 & 320 \\
\hline 4079313 & 314 & 17 & 313 & 313 & 320 & 321 & 321 & 320 \\
\hline 4079283 & 17 & 301 & 313 & 313 & 320 & 321 & 321 & 320 \\
\hline 4079253 & 301 & 301 & 313 & 313 & 320 & 321 & 321 & 324 \\
\hline 4079223 & 301 & 301 & 313 & 313 & 320 & 321 & 321 & 324 \\
\hline 4079193 & 301 & 301 & 313 & 313 & 320 & 321 & 321 & 324 \\
\hline 4079163 & 301 & 301 & 313 & 313 & 319 & 321 & 321 & 324 \\
\hline 4079133 & 301 & 301 & 313 & 313 & 314 & 319 & 321 & 324 \\
\hline 4079103 & 301 & 313 & 313 & 313 & 314 & 319 & 319 & 324 \\
\hline 4079073 & 301 & 313 & 313 & 313 & 314 & 319 & 319 & 324 \\
\hline 4079043 & 301 & 313 & 313 & 313 & 314 & 319 & 319 & 324 \\
\hline 4079013 & 301 & 313 & 313 & 313 & 314 & 319 & 319 & 325 \\
\hline 4078983 & 301 & 313 & 313 & 313 & 314 & 314 & 319 & 325 \\
\hline 4078953 & 301 & 313 & 313 & 314 & 314 & 313 & 323 & 325 \\
\hline 4078923 & 301 & 313 & 16 & 314 & 313 & 311 & 323 & 325 \\
\hline 4078893 & 301 & 16 & 313 & 314 & 314 & 313 & 325 & 325 \\
\hline 4078863 & 301 & 313 & 30 & 314 & 314 & 314 & 325 & 324 \\
\hline 4078833 & 301 & 30 & 30 & 314 & 314 & 314 & 325 & 324 \\
\hline 4078803 & 301 & 30 & 30 & 28 & 315 & 315 & 325 & 324 \\
\hline 4078773 & 302 & 30 & 30 & 28 & 315 & 319 & 325 & 324 \\
\hline 4078743 & 30 & 30 & 30 & 314 & 314 & 319 & 325 & 324 \\
\hline
\end{tabular}

Output DTN: GS000308311221.004.

NOTE: Table shows integer values ranging from 16 to 325 for a subset of grid cells located in upper Solitario Canyon.

UTM=Universal Transverse Mercator 
Table G-3. Finalized Soil Depth Classes Generated by SOILMAP6 and Included in Column 10 of the Output File, SOILMAP6.INP

\begin{tabular}{|c|c|c|c|c|c|c|c|c|}
\hline \multirow{2}{*}{$\begin{array}{c}\text { UTM Northing } \\
\text { Grid } \\
\text { Coordinates } \\
\text { (meters) }\end{array}$} & \multicolumn{8}{|c|}{ UTM Easting Grid Coordinates (meters) } \\
\hline & 547211 & 547241 & 547271 & 547301 & 547331 & 547361 & 547391 & 547421 \\
\hline 4079703 & 5 & 5 & 4 & 4 & 5 & 2 & 1 & 1 \\
\hline 4079673 & 2 & 5 & 5 & 4 & 5 & 2 & 1 & 1 \\
\hline 4079643 & 1 & 2 & 5 & 5 & 5 & 2 & 1 & 1 \\
\hline 4079613 & 1 & 1 & 2 & 5 & 5 & 1 & 1 & 1 \\
\hline 4079583 & 1 & 1 & 2 & 5 & 5 & 1 & 1 & 1 \\
\hline 4079553 & 1 & 1 & 2 & 5 & 3 & 1 & 1 & 1 \\
\hline 4079523 & 1 & 1 & 3 & 5 & 3 & 1 & 1 & 1 \\
\hline 4079493 & 1 & 1 & 3 & 5 & 1 & 1 & 1 & 1 \\
\hline 4079463 & 1 & 1 & 5 & 3 & 1 & 1 & 1 & 1 \\
\hline 4079433 & 1 & 3 & 5 & 3 & 1 & 1 & 1 & 1 \\
\hline 4079403 & 1 & 3 & 5 & 3 & 1 & 1 & 1 & 1 \\
\hline 4079373 & 3 & 3 & 5 & 3 & 1 & 1 & 1 & 1 \\
\hline 4079343 & 3 & 5 & 5 & 3 & 1 & 1 & 3 & 3 \\
\hline 4079313 & 5 & 5 & 5 & 6 & 3 & 3 & 3 & 3 \\
\hline 4079283 & 5 & 4 & 5 & 6 & 6 & 6 & 3 & 1 \\
\hline 4079253 & 4 & 4 & 5 & 6 & 6 & 6 & 6 & 3 \\
\hline 4079223 & 4 & 4 & 5 & 6 & 6 & 3 & 3 & 3 \\
\hline 4079193 & 4 & 4 & 5 & 6 & 3 & 1 & 1 & 1 \\
\hline 4079163 & 4 & 4 & 5 & 6 & 3 & 1 & 1 & 1 \\
\hline 4079133 & 4 & 4 & 5 & 3 & 1 & 1 & 1 & 1 \\
\hline 4079103 & 4 & 5 & 5 & 1 & 1 & 1 & 1 & 1 \\
\hline 4079073 & 4 & 5 & 3 & 3 & 1 & 1 & 1 & 1 \\
\hline 4079043 & 4 & 5 & 3 & 3 & 1 & 1 & 1 & 1 \\
\hline 4079013 & 4 & 5 & 1 & 1 & 1 & 1 & 1 & 1 \\
\hline 4078983 & 4 & 5 & 1 & 1 & 1 & 1 & 1 & 1 \\
\hline 4078953 & 4 & 5 & 1 & 1 & 1 & 1 & 1 & 1 \\
\hline 4078923 & 4 & 5 & 2 & 1 & 1 & 1 & 1 & 1 \\
\hline 4078893 & 4 & 5 & 1 & 1 & 1 & 1 & 1 & 1 \\
\hline 4078863 & 4 & 5 & 2 & 1 & 1 & 1 & 1 & 1 \\
\hline 4078833 & 4 & 5 & 2 & 1 & 1 & 1 & 1 & 1 \\
\hline 4078803 & 4 & 5 & 2 & 2 & 1 & 1 & 1 & 1 \\
\hline 4078773 & 4 & 5 & 2 & 2 & 1 & 1 & 1 & 1 \\
\hline 4078743 & 5 & 5 & 2 & 1 & 1 & 1 & 1 & 1 \\
\hline
\end{tabular}

Output DTN: GS000308311221.004.

NOTE: Table shows values ranging from 1 to 6 for a subset of grid cells located in upper Solitario Canyon.

UTM=Universal Transverse Mercator 
Table G-4. Calculated Ground Surface Slope Obtained from Column 6 of the Input File, GEOMOD4.INP

\begin{tabular}{|c|c|c|c|c|c|c|c|c|}
\hline \multirow{2}{*}{$\begin{array}{c}\text { UTM Northing } \\
\text { Grid } \\
\text { Coordinates } \\
\text { (meters) }\end{array}$} & \multicolumn{8}{|c|}{ UTM Easting Grid Coordinates (meters) } \\
\hline & 547211 & 547241 & 547271 & 547301 & 547331 & 547361 & 547391 & 547421 \\
\hline 4079703 & 10 & 4 & 4 & 4 & 6 & 12 & 17 & 20 \\
\hline 4079673 & 15 & 7 & 3 & 5 & 6 & 13 & 19 & 21 \\
\hline 4079643 & 16 & 10 & 5 & 5 & 7 & 13 & 19 & 22 \\
\hline 4079613 & 14 & 11 & 7 & 4 & 5 & 13 & 18 & 22 \\
\hline 4079583 & 14 & 11 & 7 & 4 & 4 & 12 & 17 & 21 \\
\hline 4079553 & 14 & 11 & 7 & 4 & 5 & 11 & 16 & 19 \\
\hline 4079523 & 14 & 9 & 5 & 4 & 6 & 13 & 17 & 19 \\
\hline 4079493 & 13 & 8 & 4 & 4 & 7 & 14 & 17 & 19 \\
\hline 4079463 & 11 & 6 & 3 & 3 & 8 & 14 & 17 & 19 \\
\hline 4079433 & 9 & 5 & 3 & 4 & 9 & 14 & 16 & 18 \\
\hline 4079403 & 7 & 3 & 2 & 4 & 10 & 14 & 15 & 17 \\
\hline 4079373 & 6 & 3 & 3 & 5 & 10 & 14 & 15 & 17 \\
\hline 4079343 & 5 & 3 & 4 & 6 & 9 & 13 & 15 & 18 \\
\hline 4079313 & 4 & 3 & 4 & 7 & 9 & 12 & 15 & 19 \\
\hline 4079283 & 3 & 3 & 5 & 7 & 10 & 13 & 16 & 19 \\
\hline 4079253 & 3 & 3 & 5 & 7 & 10 & 14 & 16 & 18 \\
\hline 4079223 & 3 & 3 & 5 & 7 & 10 & 14 & 17 & 18 \\
\hline 4079193 & 3 & 3 & 5 & 8 & 10 & 13 & 16 & 18 \\
\hline 4079163 & 2 & 3 & 5 & 8 & 11 & 13 & 15 & 17 \\
\hline 4079133 & 2 & 3 & 5 & 9 & 12 & 13 & 14 & 17 \\
\hline 4079103 & 3 & 4 & 6 & 10 & 12 & 13 & 14 & 17 \\
\hline 4079073 & 3 & 4 & 8 & 10 & 12 & 13 & 14 & 16 \\
\hline 4079043 & 3 & 5 & 9 & 11 & 12 & 13 & 14 & 15 \\
\hline 4079013 & 3 & 6 & 10 & 12 & 12 & 13 & 14 & 16 \\
\hline 4078983 & 4 & 7 & 10 & 12 & 12 & 12 & 14 & 16 \\
\hline 4078953 & 4 & 8 & 12 & 12 & 12 & 14 & 15 & 16 \\
\hline 4078923 & 5 & 10 & 13 & 12 & 13 & 14 & 14 & 16 \\
\hline 4078893 & 5 & 10 & 13 & 13 & 13 & 13 & 14 & 17 \\
\hline 4078863 & 5 & 10 & 13 & 14 & 14 & 13 & 14 & 18 \\
\hline 4078833 & 6 & 11 & 13 & 14 & 14 & 13 & 14 & 18 \\
\hline 4078803 & 7 & 11 & 13 & 14 & 14 & 13 & 14 & 18 \\
\hline 4078773 & 8 & 11 & 13 & 13 & 13 & 13 & 14 & 18 \\
\hline 4078743 & 8 & 12 & 14 & 12 & 12 & 13 & 14 & 18 \\
\hline
\end{tabular}

Ouptut DTN: GS000308311221.004.

NOTE: Table shows values ranging from 1 to 345 for a subset of grid cells located in upper Solitario Canyon.

UTM=Universal Transverse Mercator 
Table G-5. Soil Thickness Estimates Obtained from Column 11 of the Output File, SOILMAP6.INP. (For The Indicated Subset Of Grid Cells Located In Upper Solitario Canyon.)

\begin{tabular}{|c|c|c|c|c|c|c|c|c|}
\hline \multirow{2}{*}{$\begin{array}{c}\text { UTM Northing } \\
\text { Grid } \\
\text { Coordinates } \\
\text { (meters) }\end{array}$} & \multicolumn{8}{|c|}{ UTM Easting Grid Coordinates (meters) } \\
\hline & 547211 & 547241 & 547271 & 547301 & 547331 & 547361 & 547391 & 547421 \\
\hline 4079703 & 4.4 & 5.36 & 6 & 6 & 5.04 & 1.4 & 0.31 & 0.27 \\
\hline 4079673 & 1.25 & 4.88 & 5.52 & 6 & 5.04 & 1.35 & 0.28 & 0.26 \\
\hline 4079643 & 0.32 & 1.5 & 5.2 & 5.2 & 4.88 & 1.35 & 0.28 & 0.24 \\
\hline 4079613 & 0.35 & 0.39 & 1.65 & 5.36 & 5.2 & 0.36 & 0.3 & 0.24 \\
\hline 4079583 & 0.35 & 0.39 & 1.65 & 5.36 & 5.36 & 0.37 & 0.31 & 0.26 \\
\hline 4079553 & 0.35 & 0.39 & 1.65 & 5.36 & 5.2 & 0.39 & 0.32 & 0.28 \\
\hline 4079523 & 0.35 & 0.37 & 5.2 & 5.36 & 5.04 & 0.36 & 0.31 & 0.28 \\
\hline 4079493 & 0.36 & 0.34 & 5.36 & 5.36 & 0.31 & 0.35 & 0.31 & 0.28 \\
\hline 4079463 & 0.39 & 0.28 & 5.52 & 5.52 & 0.34 & 0.35 & 0.31 & 0.28 \\
\hline 4079433 & 0.37 & 5.2 & 5.52 & 5.36 & 0.37 & 0.35 & 0.32 & 0.3 \\
\hline 4079403 & 0.31 & 5.52 & 5.68 & 5.36 & 0.4 & 0.35 & 0.34 & 0.31 \\
\hline 4079373 & 5.04 & 5.52 & 5.52 & 5.2 & 0.4 & 0.35 & 0.34 & 0.31 \\
\hline 4079343 & 5.2 & 5.52 & 5.36 & 5.04 & 0.37 & 0.36 & 3.6 & 3.12 \\
\hline 4079313 & 5.36 & 5.52 & 5.36 & 4.88 & 4.56 & 4.08 & 3.6 & 2.96 \\
\hline 4079283 & 5.52 & 6 & 5.2 & 4.88 & 4.4 & 3.92 & 3.44 & 0.28 \\
\hline 4079253 & 6 & 6 & 5.2 & 4.88 & 4.4 & 3.76 & 3.44 & 3.12 \\
\hline 4079223 & 6 & 6 & 5.2 & 4.88 & 4.4 & 3.76 & 3.28 & 3.12 \\
\hline 4079193 & 6 & 6 & 5.2 & 4.72 & 4.4 & 0.36 & 0.32 & 0.3 \\
\hline 4079163 & 6 & 6 & 5.2 & 4.72 & 4.24 & 0.36 & 0.34 & 0.31 \\
\hline 4079133 & 6 & 6 & 5.2 & 4.56 & 0.37 & 0.36 & 0.35 & 0.31 \\
\hline 4079103 & 6 & 5.36 & 5.04 & 0.4 & 0.37 & 0.36 & 0.35 & 0.31 \\
\hline 4079073 & 6 & 5.36 & 4.72 & 4.4 & 0.37 & 0.36 & 0.35 & 0.32 \\
\hline 4079043 & 6 & 5.2 & 4.56 & 4.24 & 0.37 & 0.36 & 0.35 & 0.34 \\
\hline 4079013 & 6 & 5.04 & 0.4 & 0.37 & 0.37 & 0.36 & 0.35 & 0.32 \\
\hline 4078983 & 6 & 4.88 & 0.4 & 0.37 & 0.37 & 0.37 & 0.35 & 0.32 \\
\hline 4078953 & 6 & 4.72 & 0.37 & 0.37 & 0.37 & 0.35 & 0.34 & 0.32 \\
\hline 4078923 & 6 & 4.4 & 1.35 & 0.37 & 0.36 & 0.35 & 0.35 & 0.32 \\
\hline 4078893 & 6 & 4.4 & 0.36 & 0.36 & 0.36 & 0.36 & 0.35 & 0.31 \\
\hline 4078863 & 6 & 4.4 & 1.35 & 0.35 & 0.35 & 0.36 & 0.35 & 0.3 \\
\hline 4078833 & 6 & 4.24 & 1.35 & 0.35 & 0.35 & 0.36 & 0.35 & 0.3 \\
\hline 4078803 & 6 & 4.24 & 1.35 & 1.3 & 0.35 & 0.36 & 0.35 & 0.3 \\
\hline 4078773 & 6 & 4.24 & 1.35 & 1.35 & 0.36 & 0.36 & 0.35 & 0.3 \\
\hline 4078743 & 4.72 & 4.08 & 1.3 & 0.37 & 0.37 & 0.36 & 0.35 & 0.3 \\
\hline
\end{tabular}

Output DTN: GS000308311221.004.

NOTE: Table shows estimated soil thickness ranging from $0.24 \mathrm{~m}$ for grid cells in soil depth class 1 with a slope of 22 degrees to $6 \mathrm{~m}$ and greater for grid cells in soil depth class 4 .

UTM=Universal Transverse Mercator 


\section{- Listing of source code for routine SOILMAP6 V1.0:}

program soilmap6

version 1.0

Routine to estimate soil thickness (in meters)

using an empirical linear function based on

the updated soil depth class parameter and the

the calculated ground surface slope obtained from

from the input file GEOMOD4.INP.

This is the fourth routine in a sequence of pre-processing

routines used to develop the geospatial input files used

for the net infiltration modeling program, INFIL version 2.0 .

SOILMAP6 performs two functions:

The first function is a final adjustment of the soil depth

class parameters defined by GEOMOD4 based on a check for

the occurrence of inconsistencies between the updated soil

depth class parameters and the updated rock-type parameters.

A final set of depth class parameters is created to flag

specific combinations of soil depth class and rock-types,

and the modified depth class parameters are included in the

output file SOILMAP6.INP.

The second function consists of an estimation of

soil thickness (in meters) based on the finalized depth class

parameters and the calculated ground surface slope. The estimates

are obtained using a simple empirical linear function

specific to each depth class.

The input and output files are column-formatted

ASCII text files consisting of 253,597 rows (for

253,597 grid cell locations). The input file consists

of 48 columns where each column corresponds to a specific geospatial

parameter according to the following order:

column 1: LOCID (grid location number)

column 2: X2 (UTM easting coordinate, in meters)

column 3: Y2 (UTM northing coordinate, in meters)

column 4: LAT (latitude for X coordinate, in decimal degrees)

column 5: LON (longitude for Y coordinate, in decimal degress)

column 6: SL (ground surface slope, in degress)

column 7: ASP (ground surface aspect, in degrees)

column 8: ELEV (ground surface elevation, in meters)

column 9: SOILTYPE (soil type identification number)

column 10: DEPTHCLASS (soil depth class identification number)

column 11: ROCKTYPE (rock type identification number)

column 12: TOPOID (topographic position identification number)

column 13: RIDGE(1) (1st blocking ridge angle)

"

"

column 48 RIDGE(36) (last blocking ridge angle)

The output file consists of an additional column following

the depth class parameter (column 10) and consists of the estimated

soil thickness, in meters.

This routine was written by

Joe Hevesi, U.S. Geological Survey, WRD

Placer Hall, $6000 \mathrm{~J}$ street 


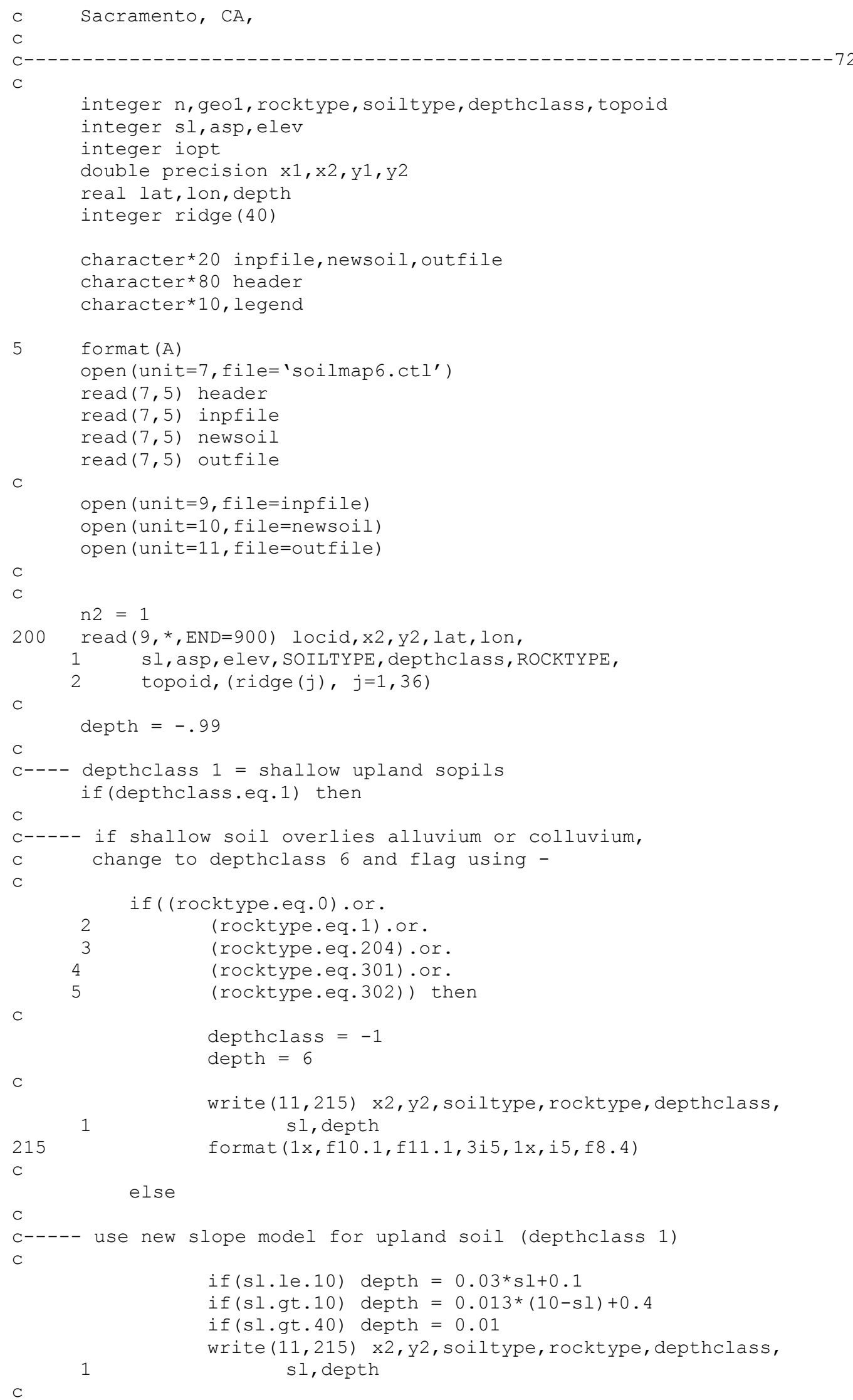




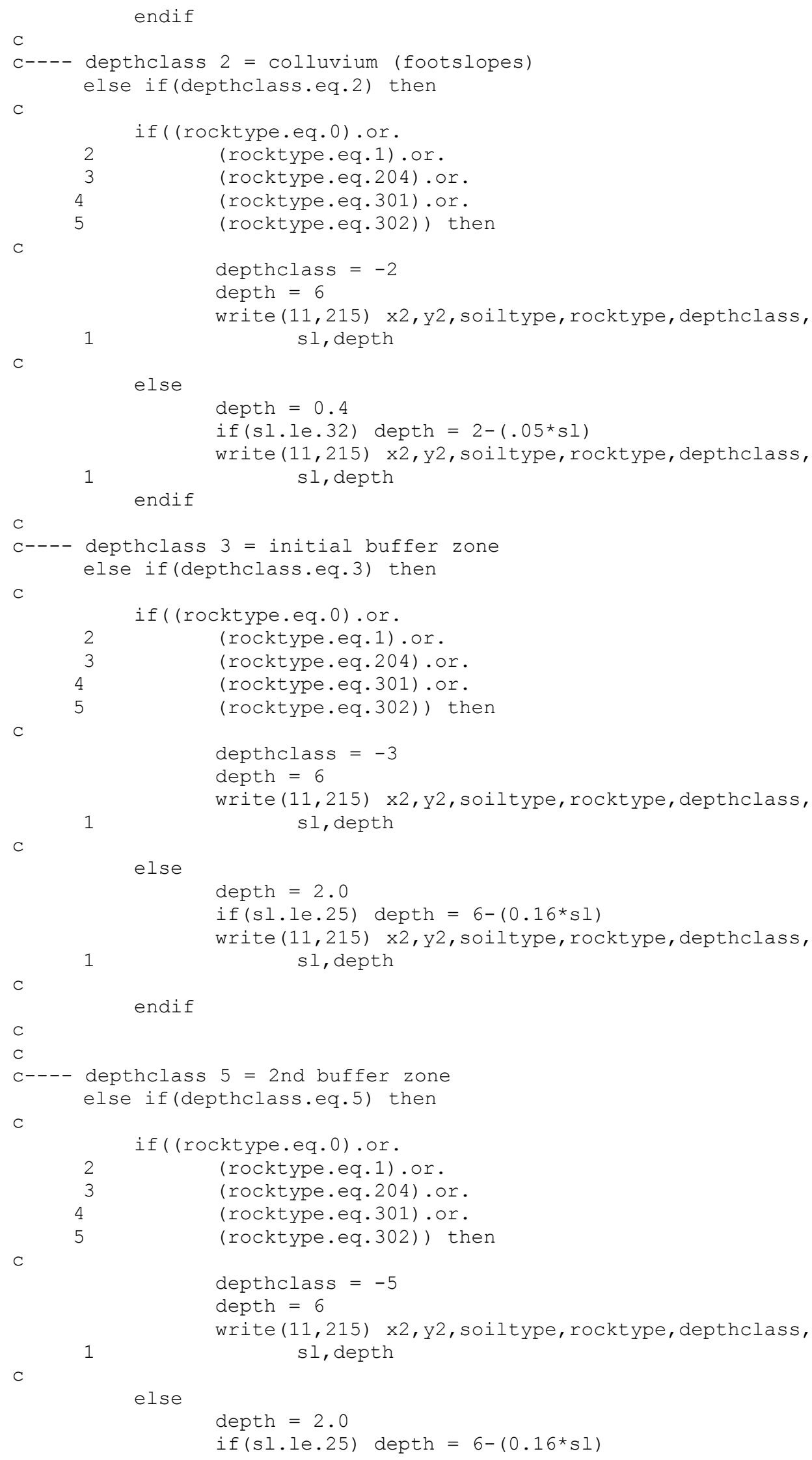


write $(11,215)$ x2,y2, soiltype, rocktype, depthclass,

endif

$\mathrm{C}$

$\mathrm{C}$

c---- depthclass 6 = bedrock geology within buffer zone else if(depthclass.eq.6) then

C

1

if ( (rocktype.eq.0).or.

(rocktype.eq.1).or.

$\begin{array}{ll}3 & (\text { rocktype.eq.204).or. } \\ 4 & \text { (rocktype.eq.301).or. } \\ 5 & \text { (rocktype.eq.302)) then }\end{array}$

$\begin{array}{ll}3 & (\text { rocktype.eq.204).or. } \\ 4 & \text { (rocktype.eq.301).or. } \\ 5 & \text { (rocktype.eq.302)) then }\end{array}$

C

depthclass $=-6$

depth $=6$

write $(11,215)$ x2,y2, soiltype, rocktype, depthclass,

$$
\text { else }
$$

sl, depth

depth $=2.0$

if $(\mathrm{sl} .1 \mathrm{l} .25)$ depth $=6-(0.16 * \mathrm{sl})$

1 write $(11,215)$ x2, y2, soiltype, rocktype, depthclass,

$$
\text { endif }
$$

C

$\mathrm{C}$

c---- depthclass 4 = deep alluvium

else if(depthclass.eq.4) then

if ( (rocktype.ne.0) . and.

(rocktype.ne.1). and.

(rocktype.ne.204). and.

(rocktype.ne.301). and.

(rocktype.ne.302)) then

depthclass $=-4$

depth $=2.0$

if $(\mathrm{sl} .1 \mathrm{e} .25)$ depth $=6-(0.16 * \mathrm{~s} l)$

write $(11,215)$ x2,y2, soiltype, rocktype, depthclass,

1

sl, depth

C

else

depth $=6$

1

write $(11,215)$ x2,y2, soiltype, rocktype, depthclass, sl, depth

C

endif

C

endif

C

C 
C

$\mathrm{n} 2=\mathrm{n} 2+1$

goto 200

C

900 continue

close (10)

close (11)

stop

end 
APPENDIX H

DEVELOPMENT OF FLOW ROUTING PARAMETERS USING SORTGRD1 V1.0 


\section{H1. NAME OF ROUTINE/MACRO WITH VERSION/OS/HARDWARE ENVIRONMENT AND USER INFORMATION}

Name of software routine: SORTGRD1 V1.0

OS and hardware environment: Windows NT 4.0, Pentium Pro PC

Software Users: Joseph Hevesi (916-278-3274), Alan Flint (916-278-3221)

User Location: U.S. Geological Survey, Room 5000E, Placer Hall, 6000 J Street, Sacramento, CA 95819-6129

Computer Identification: SM321276 with a USGS specific hostname P720dcasr

\section{H2. NAME OF COMMERCIAL SOFTWARE WITH VERSION/OS/HARDWARE USED TO DEVELOP ROUTINE/MACRO}

The source code for SORTGRD1 V1.0 was developed using the standard FORTRAN77 programming language. The source code was written, debugged, and compiled (for PC platforms using INTEL processors) using DIGITAL Visual Fortran with Microsoft Developer Studio, V. 5.0 .

\section{H3. GENERAL DESCRIPTION OF ROUTINE/MACRO}

SORTGRD1 V1.0 is a FORTRAN77 routine developed in accordance with AP-SI.1Q, specifically for the analysis/model activity documented in this report. The routine source code (SORTGRDI.FOR), compiled executable file (SORTGRD1.EXE), routine control file (SORTGRD1.CTL), input and output files, validation test files, and a copy of this appendix, are located under the directory SORTGRD1 on a CD-ROM labeled GEOINPUT 2. The routine source code, control file, and the input and output files are ASCII text files that can be read using any standard ASCII text editor and can be imported into standard word processing or spreadsheet applications such as Microsoft WORD and EXCEL. The executable file can be used to run SORTGRD1 V1.0 on any PC with an INTEL processor (with adequate RAM).

All input parameters used by SORTGRD1 V1.0 and the parameters calculated by SORTGRD1 that are included in the developed output file, 30MGRD01.SR1, are used for the development of the geospatial parameter input file for INFIL V2.0 (USGS 2000 [DIRS 139422]). The file, 30MGRD01.SR1 is used directly as input to the routines CHNNET16 V1.0 and VEGCOV01 V1.0.

\section{H4. TEST PLAN FOR THE SOFTWARE ROUTINE SORTGRD1 V1.0}

\section{- Explain whether this is a routine or macro and describe what it does:}

SORTGRD1 V1.0 is the fifth routine applied in a sequence of FORTRAN 77 routines that are used in the development of the geospatial parameter input file for INFIL V2.0. The routine's primary function is an application of a basic bubble-sort algorithm to perform an ascending sort (highest values at the top of the list, lowest values at the bottom) of the ground surface elevation values included in the developed geospatial parameter input file, SOILMAP6.INP (which is the output file from SOILMAP6 V1.0). The preprocessing application performed by SORTGRD1 V1.0 is the initial phase of the preprocessing applications required to develop surface water flow routing 
parameters and to extract watershed-modeling domains from the geospatial parameter base grid. The output file created by SORTGRD1 V1.0 is 30MGRD01.SR1, which is supplied directly as input to the routines CHNNET16 V1.0 and VEGCOV01 V1.0.

The sorting function performed by SORTGRD1 V1.0 moves the entire row of the input file, SOILMAP6.INP during the sorting process. Thus, the sorting performs a shuffling of the input deck, one row at a time, until the row or grid cell sequence of the entire input deck has been re-organized based on the ascending order of elevation values. Because the entire line is moved as a unit during the re-ordering, the raster-based grid geometry defined by the UTM coordinates for each grid cell is maintained for all geospatial parameters, with the exception of the grid cell number. SORTGRD1 modifies the grid cell number according to the results of the sorting. The new grid cell number is the new row sequence number (the grid cell number for the top row is 1 and the grid cell number for the bottom row is 253,597).

A second function performed by SORTGRD1 is the addition of the raster-grid row and column indices to the output file. These are created by SORTGRD1 using the UTM grid cell easting and northing coordinates obtained from the input file, SOILMAP6.INP. The row and column indices are used by CHNNET16 V1.0 and by INFIL V2.0 to increase the efficiency of the flow routing algorithm.

A third function performed by SORTGRD1 V1.0 is the re-positioning of the column sequence and the addition of two columns to the output file that identify the column position for the vegetation parameters using a place holder value of -99 .

\section{- Listing of FORTRAN77 Source code:}

A listing of the FORTRAN77 source code for the routine SORTGRD1 V1.0 along with examples of the input and output files used in the test plan are included at the end of this appendix.

\section{- Description of test(s):}

To test that the first function performed by the routine is working properly, a selection of the input and output from the routine is printed out and visually inspected. The test involves determining whether the sequence of rows in the output file is sorted correctly according to a descending sequence of elevations. To satisfy the test criteria, the highest elevation value from the input file must be in the first row of the output file and the lowest elevation value from the input file must be in the last row of the output file.

To test the second function of generating row and column grid cell indices, map images of the row and column indices included in the output file (columns 6 and 7) are created in TRANSFORM and visually inspected. To satisfy the test criteria, the map image of the row index must show a north-south linear increase of row indices from 1 to 691, and the map image of the column index must show a west-east linear increase of column indices from 1 to 367. 
To test the third function performed by the SORTGRD1 V1.0, the format and column ordering of the output files is visually inspected. To satisfy the test criteria, the output file must consist of 253,597 rows and 53 columns. The modified grid cell number must be in column 1, the new row and column indices must be in columns 6 and 7, and the slope and aspect parameters must be re-positioned to columns 9 and 10. The -99 placeholder values for the vegetation parameters must be in columns 16 and 17 .

\section{- Specify the range of input values to be used and why the range is valid:}

SOILMAP6.INP is the input file used by SORTGRD1 V1.0. The file is specified in the file, SORTGRD1.CTL, which is the routine control file for SORTGRD1 and is required for program execution. SOILMAP6.INP is a column-formatted ASCII file consisting of 253,597 rows and 49 columns (Appendix G). The parameters provided by SOILMAP6.INP and used or modified by SORTGRD1 are elevation (values are in meters, from 918 to 1969), UTM easting coordinate (from 544,661 to 555,641 m), UTM northing coordinate values $(4,067,133$ to $4,087,833 \mathrm{~m})$, and the grid cell number (integers from 1 to 253,597 ).

\section{H5. TEST RESULTS}

\section{- Output from test:}

The output for the test case is the main output file, 30MGRD01.SR1 generated by SORTGRD1. The output file is used to generate raster-format map image files in TRANSFORM, which are used only as a part of the validation test plan (the map image files are not required as part of the preprocessing procedure for developing the input used by INFIL V2.0).

\section{- Description of how the testing shows that the results are correct for the specified input:}

A comparison of the input and output files shows the unsorted row-sequence of elevation values in the input file and the sorted (descending order) row-sequence of elevation values in the output file. The printout of the first 20 lines of the output file shows the first line of the file has the highest elevation and the last line of the file has the lowest elevation (see file printouts for SOILMAP6.INP and 30MGRD01.SRI provided under section 6 as supporting information). These results indicate that the test criteria for the first function are satisfied.

The TRANSFORM map image of the row index obtained from the output file indicates the correct north-to-south linearly increasing row sequence of 1 to 691. The TRANSFORM map image of the column index obtained from the output file indicates the correct west-to-east linearly increasing column sequence of 1 to 367). These results indicate that the test criteria for the second function are satisfied.

Visual inspection of the input and output files (see printouts in section 6) indicates that the row and column indices were correctly included as columns 6 and 7 in the output 
file, the -99 place holder values for the vegetation parameters were correctly added as columns 16 and 17, and the slope and aspect parameters were correctly re-positioned to columns 9 and 10. Only the intended modifications of the input parameters and input file format are observed. The output file has the correct number of lines $(253,597)$, the correct number of columns $(53)$, and the sequencing of columns and rows is correct. These results indicate that the test criteria for the third function are satisfied.

\section{- List limitations or assumptions to this test case and code in general:}

The limitations of the developed test case are based on the practical limitations of verifying modified parameter values for all 253,597 grid cells included in the output file used for the developed test case. Validation of the entire output file used in the test case was performed as a visual evaluation of raster-based map images produced in TRANSFORM. Only a subset of the entire output file could be used for more detailed validation tests that included a manual check of the equations used by the routine.

\section{- Electronic files identified by name and location:}

Electronic files are located on CD-ROM labeled GEOINPUT-2, under the directory SORTGRD12. The following electronic files are provided:

SORTGRD1.CTL: Input file consisting of the input and output file names for SORTGRD1 V1.0.

SORTGRDI.FOR: FORTRAN source code listing for the routine SORTGRD1 V1.0. A printout of the source code is included as part of this appendix.

SORTGRD1.EXE: Executable file for the routine SORTGRD1 V1.0, compiled for INTEL processors.

SOILMAP6.INP: Input file consisting of a column-formatted, ASCII text file with 253,597 rows and 49 columns. This file was developed as the output file from SOILMAP6 V1.0 (Appendix G). A partial printout of the first part of this file is included as part of this appendix.

30MGRD01.SR1: Output file consisting of a column-formatted, ASCII text file with 253,597 rows and 53 columns. Each row corresponds to a grid cell location for the geospatial parameter base grid (the UTM location coordinates are defined by columns 2 and 3). Columns 6 and 7 are the row and column grid cell indices added by SORTGRD1 and used as input for CHNNET16 V1.0 (Appendix I). Columns 9 and 10 are placeholder values added by SORTGRD1 for two vegetation parameters (all values are 
-99). A partial printout of the first part of this file is included as part of this appendix.

SRT-ROW.HDF: TRANSFORM map image of the row index. This file is used only as supporting information for the test plan.

SRT-COL.HDF: TRANSFORM map image of the column index. This file is used only as supporting information for the test plan.

H6. SUPPORTING INFORMATION. (INCLUDE BACKGROUND INFORMATION, SUCH AS REVISION TO A PREVIOUS ROUTINE OR MACRO, OR EXPLANATION OF THE STEPS PERFORMED TO RUN THE SOFTWARE. INCLUDE LISTINGS OF ALL ELECTRONIC FILES AND CODES USED).

- Procedure for running routine:

To run the routine SORTGRD1 V1.0, the executable file (SORTGRD1.EXE), the routine control file (SORTGRD1.CTL), and the input file (SOILMAP6.INP) specified in the routine control file must be placed in the same directory. The routine is executed by typing SORTGRD1 in a DOS command line, by double clicking on the file, SORTGRD1.EXE in the Microsoft Windows operating system, or by typing in the path and filename in the RUN window of the Windows NT or Windows 98 start menu. The input and output file names must be in the correct sequential order as specified in the routine control file (see example listing below).

- Example listing of routine control file, SORTGRD1.CTL

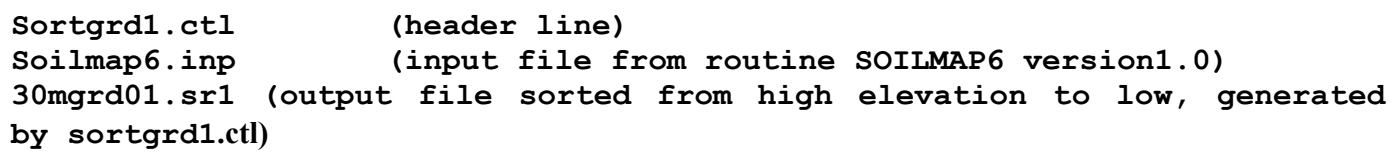

- Example listing of the input file, SOILMAP6.INP (only the first 20 lines of the file are listed).

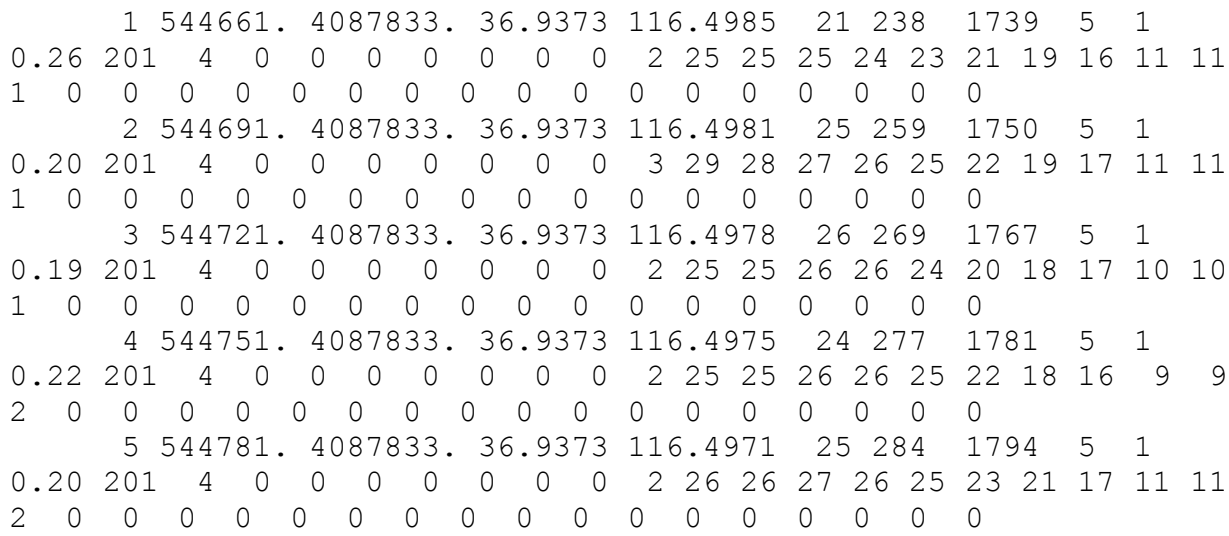




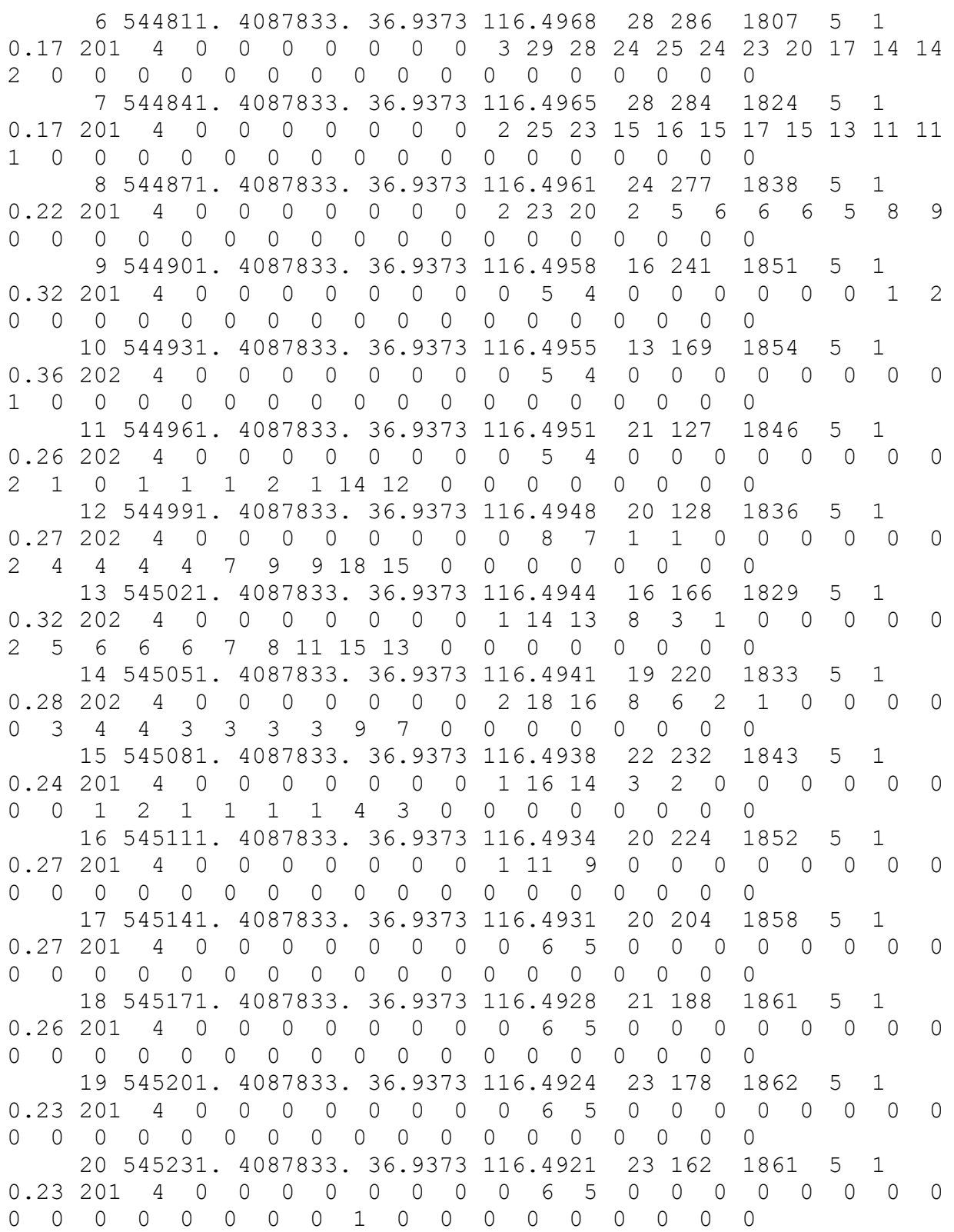

- Example listing of the output file, 30MGRD01.SR1 (only the first 20 lines of the file are listed). The row and column grid cell indices have been added as column 6 and 7, the slope and aspect columns have been shifted to columns 9 and 10, and place holders (values of -99) for two vegetation parameters have been added as columns 16 and 17 .

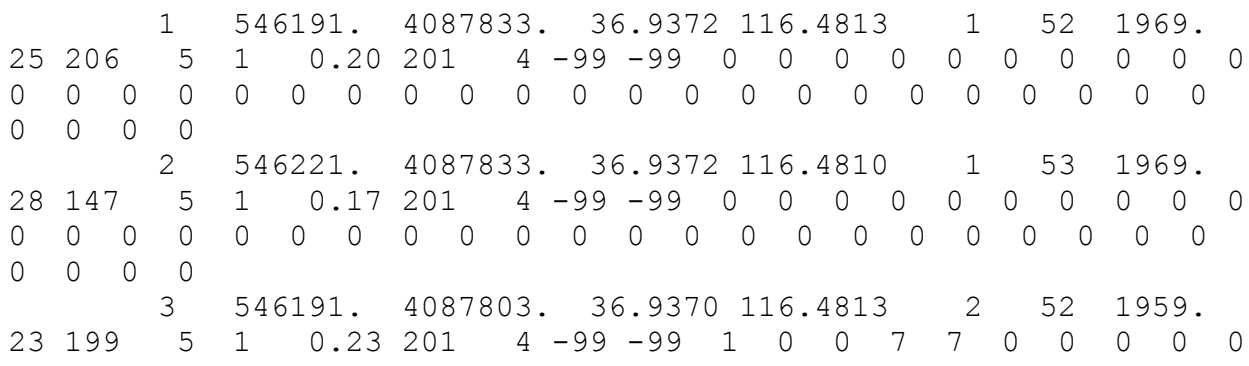




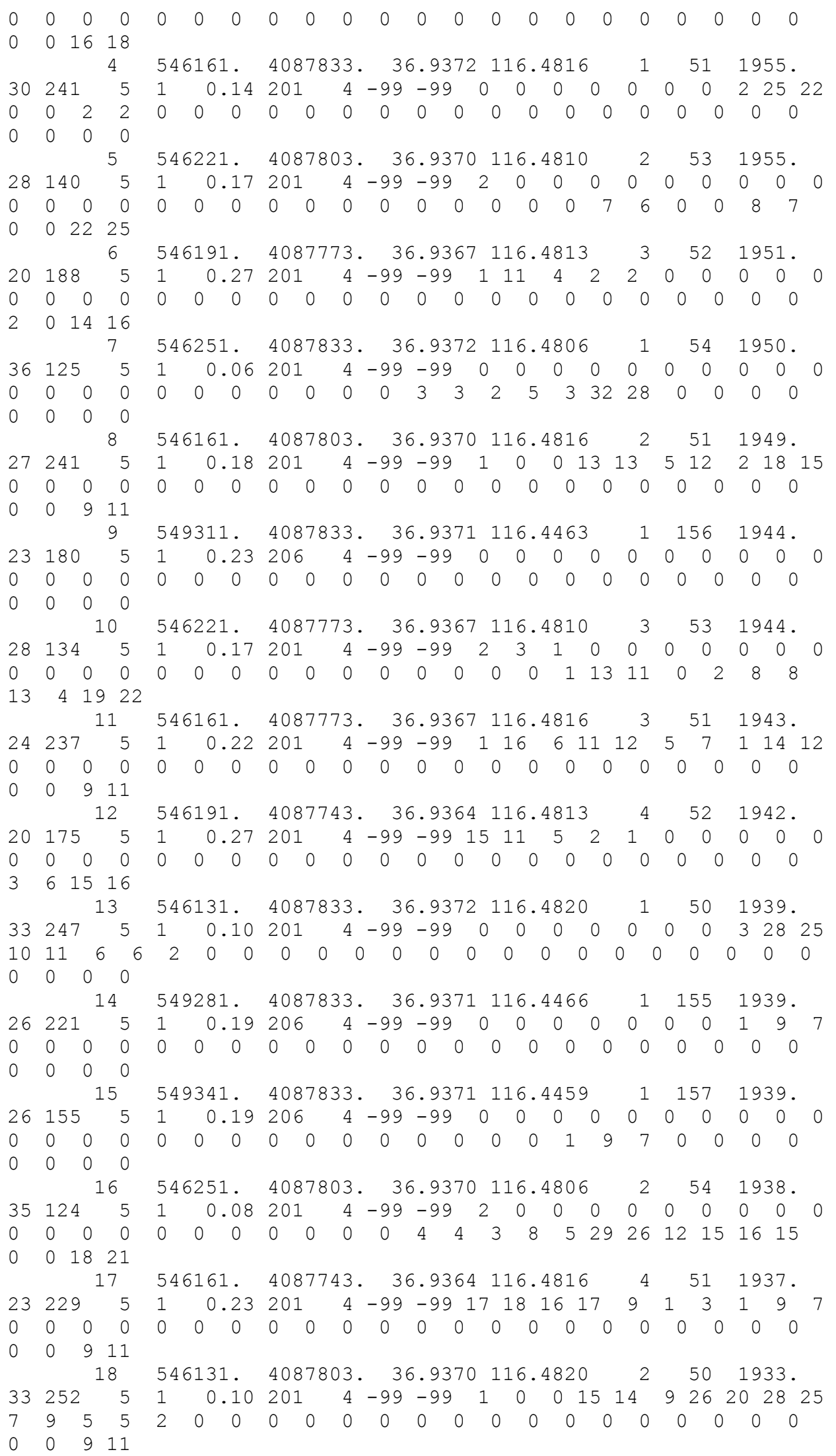




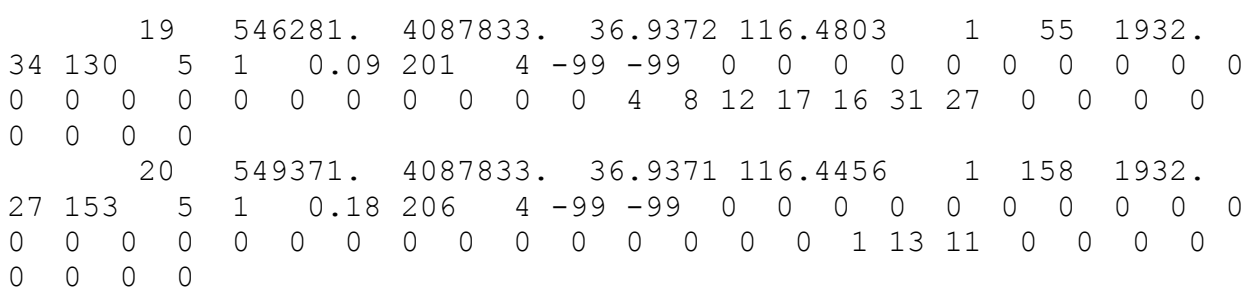

- Example listing of the output file, 30MGRD01.SR1 (only the last 20 lines of the file are listed). The row and column grid cell indices have been added as column 6 and 7, the slope and aspect columns have been shifted to columns 9 and 10, and place holders (values of -99) for two vegetation parameters have been added as columns 16 and 17.

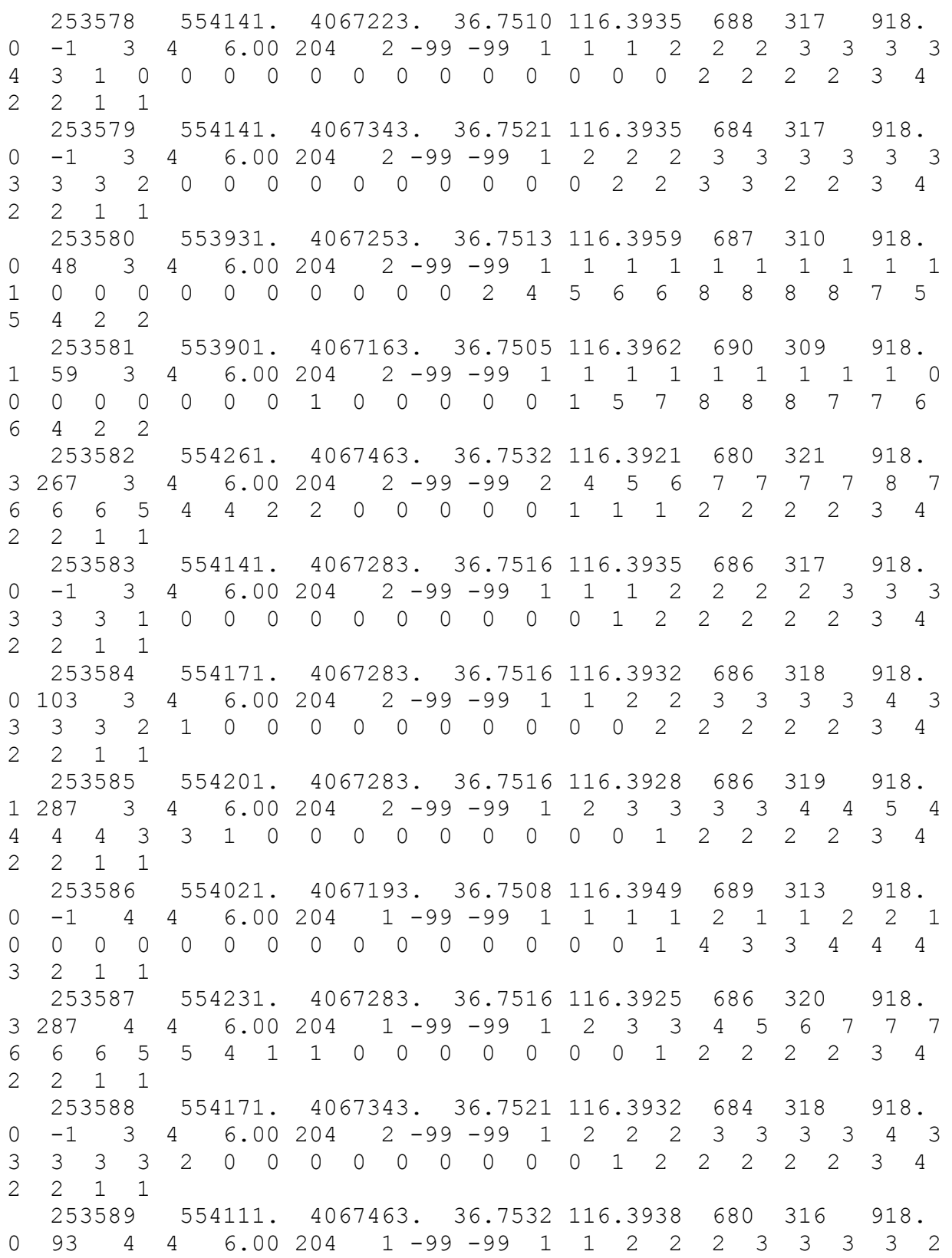




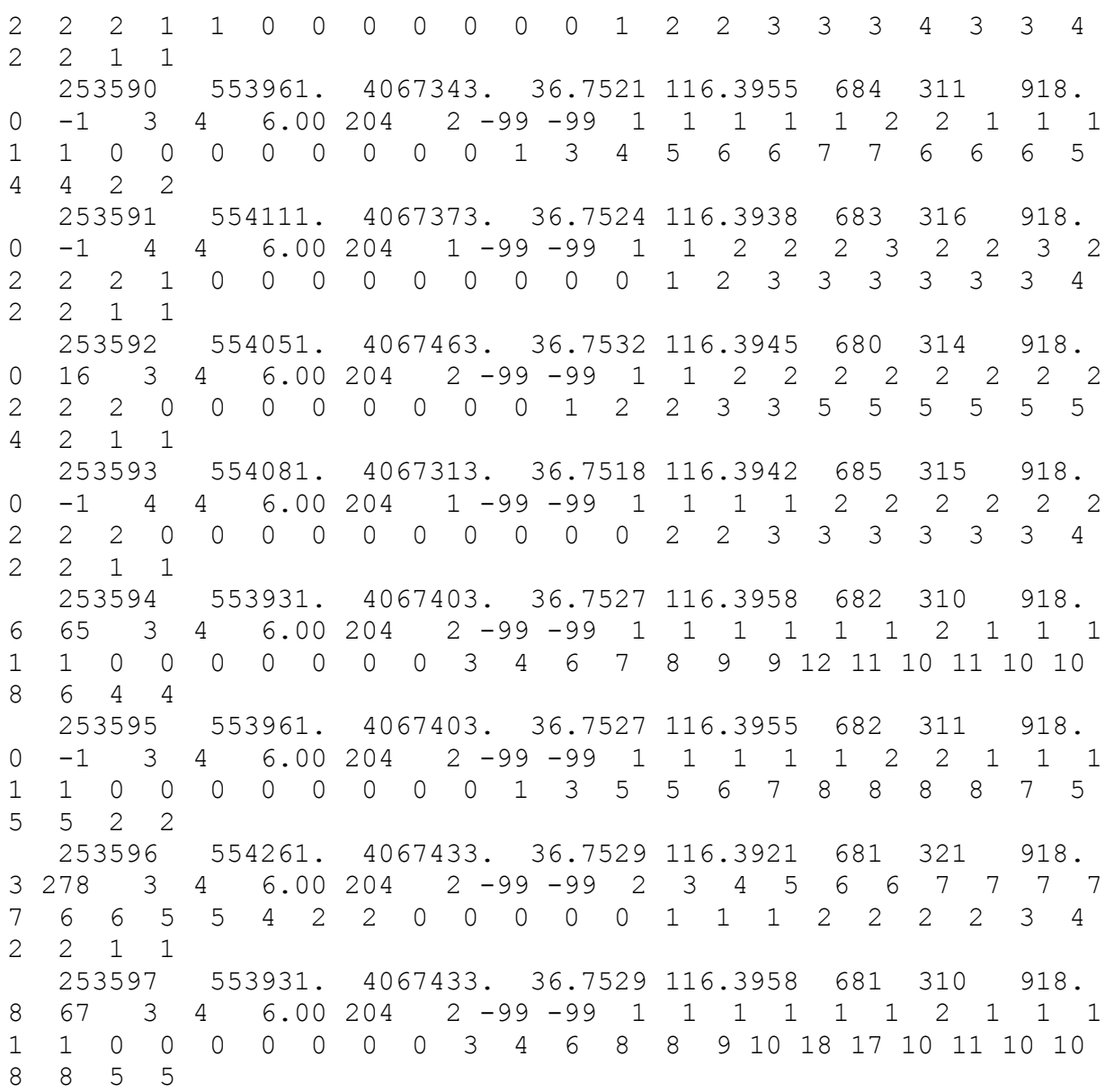

- Example listing of a randomly selected row from the input file, SOILMAP6.INP, used to compare against corresponding row of the output file, 30MGRD01.SR1. The row number in the input file is 24404.

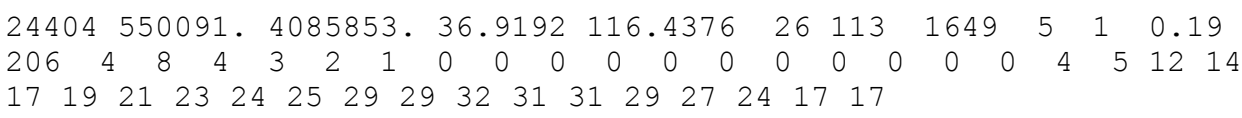

- Example listing of the row in the output file, 30MGRD01.SR1 corresponding to row 24404 of the input file, showing the modified grid cell number indicating the new row sequence number $(\mathbf{1 0 9 9 4 )}$ created by the elevation sort. With the exception of the modified grid cell number, the addition of the row and column indices (columns 6 and 7), the re-positioning of the slope and aspect parameters to columns 9 and 10, and the addition of the two place holder columns for the vegetation parameters (columns 16 and 17), no other modifications were performed.

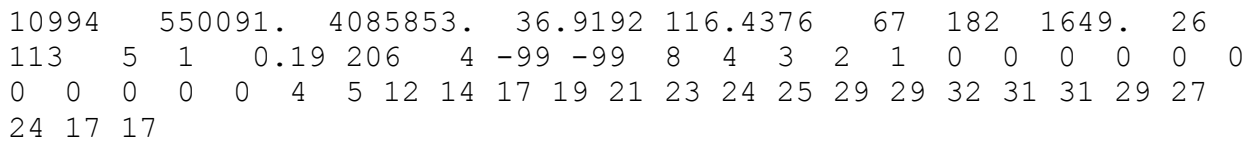




\section{- Listing of source code for routine SORTGRD1 V1.0:}

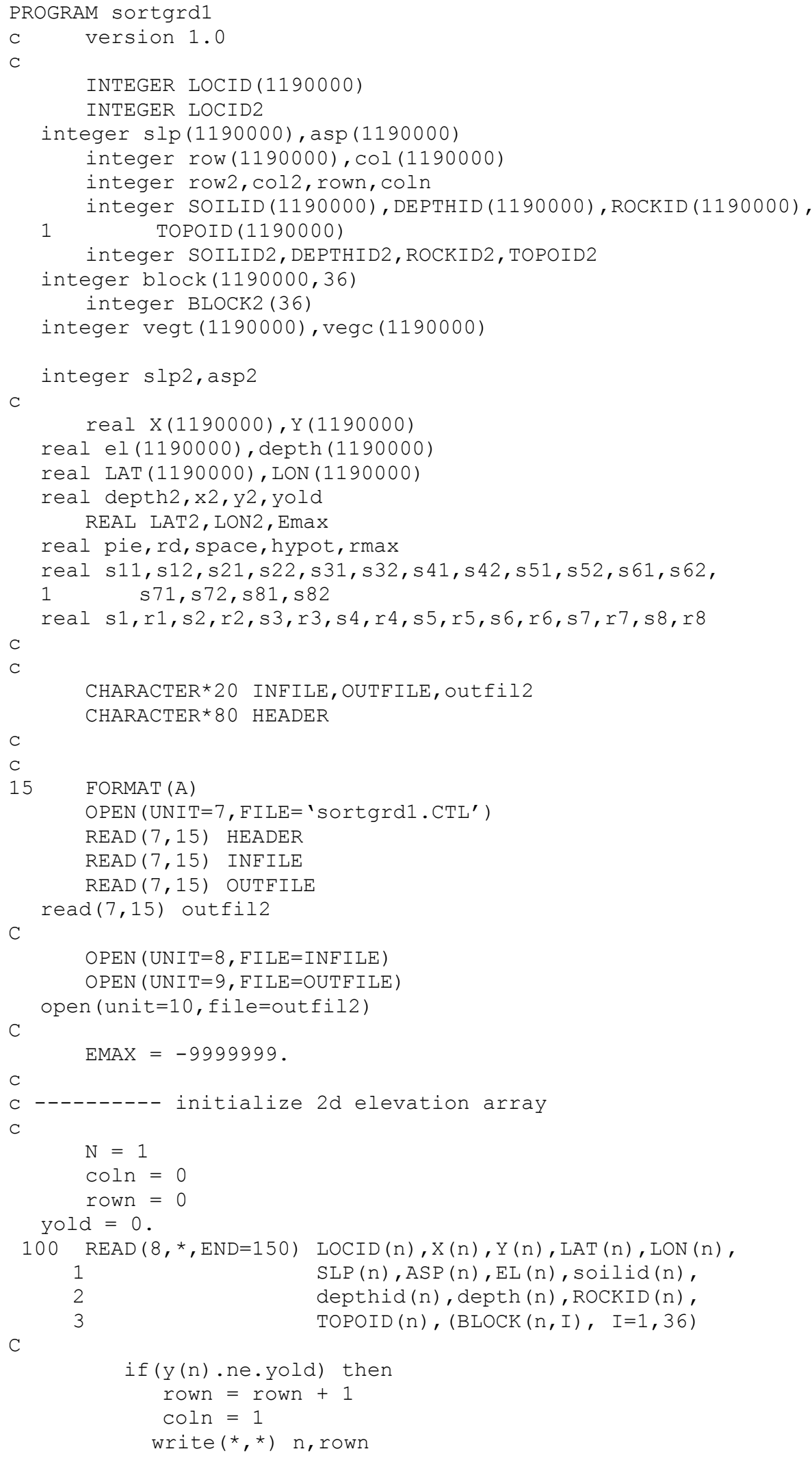




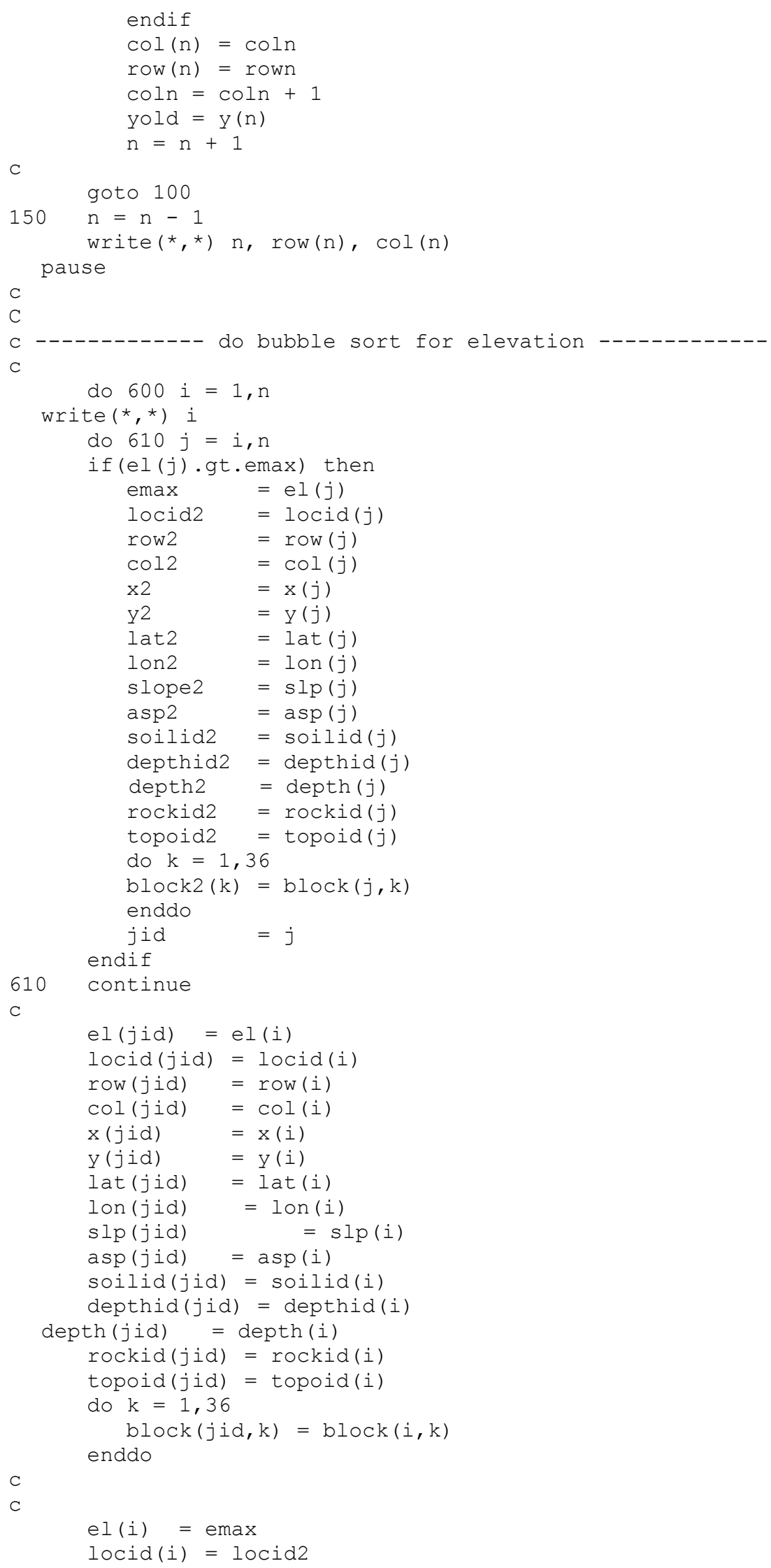




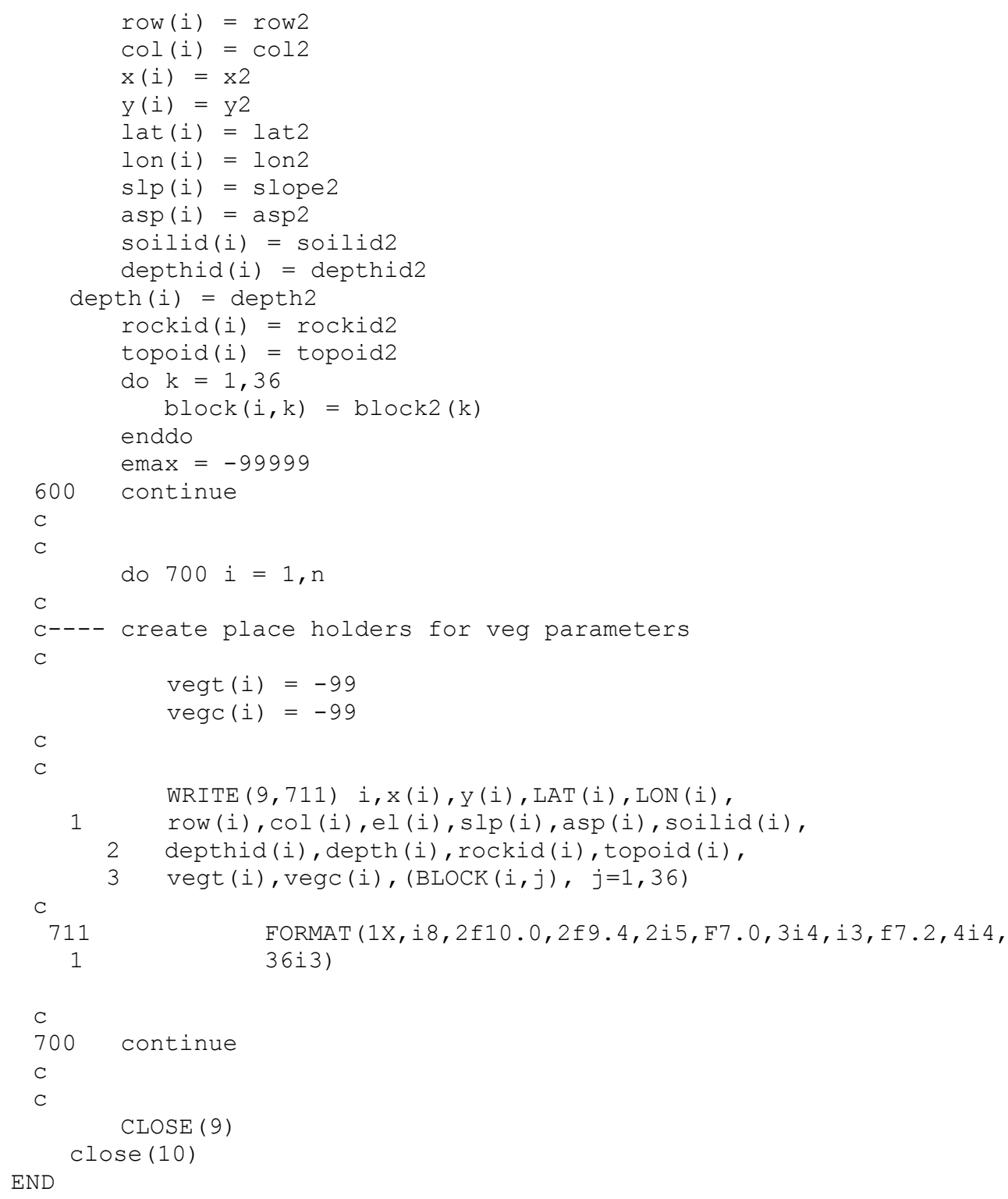




\section{APPENDIX I}

\section{CALCULATION OF FLOW ROUTING PARAMETERS USING CHNNET16 V1.0}




\section{I1. NAME OF ROUTINE/MACRO WITH VERSION/OS/HARDWARE ENVIRONMENT AND USER INFORMATION}

Name of software routine: CHNNET16 V1.0

OS and hardware environment: Windows NT 4.0, Pentium Pro PC

Computer Identification: SM321276 with a USGS specific host-name P720dcasr

Software Users: Joseph Hevesi (916-278-3274), Alan Flint (916-278-3221)

User Location: U.S. Geological Survey, Room 5000E, Placer Hall, 6000 J Street, Sacramento, CA 95819-6129

\section{I2. NAME OF COMMERCIAL SOFTWARE WITH VERSION/OS/HARDWARE USED TO DEVELOP ROUTINE/MACRO}

The source code for CHNNET16 V1.0 was developed using the standard FORTRAN77 programming language. The source code was written, debugged, and compiled (for PC platforms using INTEL processors) using DIGITAL Visual Fortran with Microsoft Developer Studio, V. 5.0 .

\section{I3. GENERAL DESCRIPTION OF ROUTINE/MACRO}

CHNNET16 V1.0 is a FORTRAN77 routine developed in accordance with AP-SI.1Q, specifically for the analysis/model activity documented in this report. The routine source code (CHNNET16.FOR), compiled executable file (CHNNET16.EXE), routine control file (CHNNET16.CTL), input and output files, validation test files, and a copy of this appendix, are located under the directory CHNNET16 on a CD-ROM labeled GEOINPUT-2. The routine source code, control file, and the input and output files are ASCII text files that can be read using any standard ASCII text editor and can be imported into standard word processing or spreadsheet applications such as Microsoft WORD and EXCEL. The executable file can be used to run CHNNET16 V1.0 on any PC with an INTEL processor (with adequate RAM).

The output developed by CHNNET16 V1.0 is required for the development of the geospatial parameter input file for INFIL V2.0 (USGS 2000 [DIRS 139422]). The output file created by CHNNET16 is used directly as input to the routine WATSHD20 V1.0.

\section{I4. TEST PLAN FOR THE SOFTWARE ROUTINE CHNNET16 V1.0}

\section{- Explain whether this is a routine or macro and describe what it does:}

CHNNET16 V1.0 is the eighth routine applied in a sequence of FORTRAN 77 routines that are used in the development of the geospatial parameter input files for INFIL V2.0. The first function performed by CHNNET16 is the calculation of the second flow routing parameter using input from 30MGRD01.SR1, which is the elevation-sorted output file from SORTGRD1 V1.0 (Appendix H). The flow routing calculation is based on a standard D-8 routing scheme in which the eight grid cells surrounding a given grid cell location are scanned and flow is routed to the lowest elevation cell. The first flow routing parameter is the current grid cell identification number provided as input from 30MGRD01.SR1. This parameter is generated by SORTGRD1 and indicates the sequence of sorted elevation values. The second flow routing parameter is generated by CHNNET16 using the grid cell elevations obtained 
from 30MGRD01.SR1 and is the grid cell identification number for the downstream grid cell that surface water flow is being routed to. In most cases the downstream cell is one of eight adjacent cells surrounding a given grid cell. In cases where all adjacent grid cells have elevations higher than the current grid cell, the next surrounding layer of grid cells is scanned. This process is repeated until a grid cell is located with an elevation less than the current grid cell, or 20 layers have been scanned (which ever occurs first). If 20 layers have been scanned and a routing cell is not located, the current grid cell is designated as a sink (closed basin).

A second function performed by CHNNET16 V1.0 is the calculation of the flow accumulation term (the number of upstream cells for each grid cell location). The calculation is performed by routing a uniformly distributed precipitation input of one unit (in this case, 1.0 millimeters) using the two flow routing parameters. The flow accumulation term is used to identify grid cell locations needed as input for extracting watershed modeling domains using the routine WATSHD20 (Appendix K). In addition, the flow accumulation term is used as part of the routine test plan for evaluating if CHNNET16 V1.0 is functioning correctly.

The second flow routing parameter (downstream grid cell number) and the flow accumulation term are included in the output file, 30MGRD01.C16 generated by CHNNET16 (this file is provided as input to WATSHD20). Additional parameters included in the output file are the easting and northing grid cell coordinates, the row and column grid cell indices, and the first flow routing parameter (the grid cell number). These additional parameters are obtained from the input file, 30MGRD01.SR1. Additional columns in the output file, 30MGRD01.C16 are optional parameters generated by CHNNET16 V1.0 that are not used in the development of the geospatial parameter input files for INFIL V2.0.

\section{- Listing of FORTRAN77 Source code:}

A listing of the FORTRAN77 source code for the routine CHNNET16 V1.0 along with examples of the input and output files used in the test plan are included at the end of this appendix.

\section{- Description of test(s):}

A validation test of the functions performed by the routine was conducted by a visual evaluation of the calculated flow accumulation term included in the output file generated by the routine. The flow accumulation term is calculated based on the result of routing a uniform precipitation input of $1 \mathrm{~mm}$. The flow accumulation term is thus equal to the number of upstream grid cells for a given grid cell location. Map images of the flow accumulation term are created in TRANSFORM and ARCVIEW to provide visual representations of the channel network defined by the calculated flow routing parameters. Using applications in ARCVIEW the map image of the channel network is superimposed with a contour or shaded relief image of the topography to provide a method of testing that the routine has functioned correctly. The test criterion is that the channel network defined by CHNNET16 must agree with the expected channel network defined by the topography (within the limitations of the 
standard D8 routing algorithm). For example, all grid cells having a flow accumulation term of 0 (no upstream cells) indicate flow divides and must occur for ridgetop and summit locations or for high points within the more flat lying basin fill areas. In contrast, all grid cells having approximately 10 or more upstream cells define stream channel locations and must occur along mid to lower sideslopes and the bottom of washes as opposed to ridgetop and summit locations. Major stream channels consisting of approximately 1,000 or more upstream cells must occur in the mid- to downstream-sections of the larger washes and drainages in upland areas or far downslope in gently sloping basin-fill areas with poorly defined drainages.

The flow accumulation term must systematically increase with decreasing elevation in the downstream direction (up-hill flow cannot occur), and must exactly equal the sum of all contributing upstream grid cells. Major channels cannot cross drainage divides formed by ridges. All flow routing must be convergent and cannot terminate unless a major sink is reached. A grid cell can be routed to by up to 7 adjacent cells (or even more for locations defined as a sinks), but all cells can only rout to one cell (divergent flow is not allowed).

A visual check that the flow routing and the flow accumulation terms are being calculated correctly is also conducted using TRANSFORM to create raster-based map images and extracting input and output parameter values for a subset of grid cells identified in the TRANSFORM file. The input and output parameter values for the subset of grid cells are visually inspected to determine that the functions performed by CHNNET16 have operated correctly and have provided the intended result.

An additional test performed as part of the routine validation is an inspection of the output file containing the flow routing parameters. The criteria of the test is that the output file must be in the proper format with the correct number and sequencing of 10 columns and 253,597 rows. The UTM coordinates and the grid cell number of the output file, 30MGRD01.C16 must match the UTM coordinates and the grid cell number of the corresponding line in the input file, 30MGRD01.SR1.

\section{- Specify the range of input values to be used and why the range is valid:}

The input range is completely determined by the parameters in the file, $30 M G R D 01 . S R 1$ because this is the only source of input provided to the routine. The file is specified in the file, CHNNET16.CTL, which is the routine control file for CHNNET16 and is required for the execution of the routine. 30MGRD01.SR1 is a column-formatted ASCII file consisting of 253,597 rows and 53 columns (Appendices $\mathrm{J}$ and $\mathrm{K}$ ). For the parameters used by the routine, the input ranges are specified by the following:

SORTGRD01.SR1 is the main input file used by CHNNET16 V1.0. Four parameters provided by the input file, SORTGRD01.SR 1 are used by functions in CHNNET16 V1.0: the grid cell number (column 1), the grid cell row index (column 6), the grid cell column index (column 7), and the grid cell elevation. The input values for the grid cell number are integers from 1 to 253,597. The input values for grid cell row index are integers from 1 to 691 . 
The input values for grid cell column index are integers from 1 to 367 . The input values for grid cell elevation are real numbers from 918 to 1,969 (the elevation values are to the nearest meter). This input range is valid because the values were obtained from ARCINFO using the source data as input (see Appendix D for description of source data used for 30MSITE.INP) and a sequence of applied software routines described in Appendices E through $\mathrm{H}$ of this report.

\section{I5. TEST RESULTS}

\section{- Output from test:}

The output for the test case is the main output file, 30MGRD01.C16 generated by CHNNET16 V1.0. The output file is used to generate raster-format map image files in TRANSFORM and ARCVIEW which are used only as a part of the validation test plan (the map image files are not required as part of the preprocessing procedure for developing the input used by INFIL V2.0).

\section{- Description of how the testing shows that the results are correct for the specified input:}

The ARCVIEW map images of the flow accumulation term obtained from column 8 of the output file, 30MGRD01.C16 indicate that the flow routing parameters are being calculated correctly by the routine CHNNET16 V1.0. The overlay of the flow accumulation term with a shaded relief image of the topography indicates that the stream channel network defined by the flow routing parameters is correctly positioned relative to topography. The locations of the major channels defined by the flow accumulation term are generally consistent with the known locations of the main channels for Yucca Wash, Drill Hole Wash, Dune Wash, and Solitario Canyon. Deviations of the channel network defined by the flow accumulation term relative to the known locations of channels are within the expected level of accuracy based on the limitations of the digital elevation grid and the D8 routing directions in representing the true locations of channels.

Visual inspection of the input and output files (see example printouts below) indicated that the format of the output file is correct and consists of the intended 253,597 rows and 10 columns, with the columns and rows occurring in the correct sequence. The UTM coordinates, grid cell number, and the row and column indices for each line of the output file matches the UTM coordinates, grid cell number, and row and column indices of the corresponding line of the input file, indicating that no unintended modifications were performed by the routine.

\section{- List limitations or assumptions to this test case and code in general:}

The limitations of the developed test case are based on the practical limitations of verifying calculated parameter values for all 253, 597 grid cells included in the output file used for the developed test case. Validation of the entire output file used in the test case was performed as a visual evaluation of raster-based map images produced in TRANSFORM and ARCVIEW. Only a subset of the entire output file could be 
used for more detailed validation tests that were performed in an EXCEL worksheet. However, there is no expected significance to this limitation.

\section{- Electronic files identified by name and location:}

Electronic files are located on CD-ROM labeled GEOINPUT-2, under the directory CHNNET16. The following electronic files are provided:

CHNNET16.CTL: Input file consisting of the input and output file names for CHNNET16 V1.0.

CHNNET16.FOR: FORTRAN source code listing for the routine CHNNET16 V1.0. A printout of the source code is included as part of this appendix.

CHNNET16.EXE: Executable file for the routine CHNNET16 V1.0, compiled for INTEL processors.

30MGRD01.SR1: Input file consisting of a column-formatted, ASCII text file with 253,597 rows and 53 columns. This file was developed as the output file from SORTGRD1 V1.0 (Appendix H). A partial printout of the first part of this file is included as part of this appendix.

30MGRD01.C16: Output file consisting of a column-formatted, ASCII text file with 10 columns and 253,597 rows. The first two columns are the easting and northing coordinates, columns 3 and 4 are the row and column indices. The flow routing parameters consist of the grid cell number (column 5), the boundary cell parameter (column 6), the downstream cell number (column 7), and the flow accumulation term (column 9).

CHN16-A.APR: $\quad$ ARCVIEW project file (including all files in associated directories) used to create the raster-based map image of flow accumulation for the area of the net infiltration model. The files are used to perform the software routine validation test and are provided as supporting information only.

CHN16-B.APR: ARCVIEW project file (including all files in associated directories) used to create the raster-based map image of flow accumulation for the area of the UZ ground water flow model. The files are used to perform the software routine validation test and are provided as supporting information only.

CHN16-C.APR: ARCVIEW project file (including all files in associated directories) used to create the raster-based map image of 
flow accumulation for the repository area. The files are used to perform the software routine validation test and are provided as supporting information only.

CHN-ELEV.HDF: TRANSFORM raster-based map image of grid cell elevation obtained from column 8 of the input file, 30MGRD01.SR1.

CHN-R1.HDF: $\quad$ TRANSFORM raster-based map image of the first flow routing parameter obtained from column 1 of the input file, 30MGRD01.SR1.

CHN-R2.HDF: $\quad$ TRANSFORM raster-based map image of the second flow routing parameter obtained from column 7 of the output file, 30MGRD01.C16. This file is not a part of the routine application.

CHN-C16.HDF: TRANSFORM raster-based map image of the flow accumulation term (number of upstream grid cells) obtained from column 8 of the output file, 30MGRD01.C16. This file is not a part of the routine application.

I6. SUPPORTING INFORMATION. (INCLUDE BACKGROUND INFORMATION, SUCH AS REVISION TO A PREVIOUS ROUTINE OR MACRO, OR EXPLANATION OF THE STEPS PERFORMED TO RUN THE SOFTWARE. INCLUDE LISTINGS OF ALL ELECTRONIC FILES AND CODES USED).

- Procedure for running routine:

To run the routine CHNNET16 V1.0, the executable file (CHNNET16.EXE), the routine control file (CHNNET16.CTL), and the input file specified in the routine control file (CHNNET16.INP) must be placed in the same directory. The routine is executed by typing CHNNET16 in a DOS window, by double clicking on the file, CHNNET16.EXE in the Microsoft Windows operating system, or by typing in the path and filename in the RUN window of the Windows NT or Windows 98 start menu. The input and output file names must be in the correct sequential order as specified in the routine control file (see example listing below).

- $\quad$ Example listing of routine control file, CHNNET16.CTL

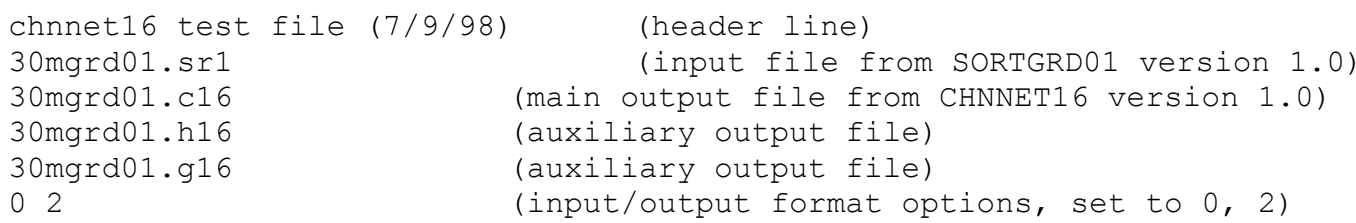

- Example listing of the input file, 30MGRD01.SR1. The file contains 253,597 lines and 53 columns (only the first 20 lines of the file are listed). The input 


\section{parameters used by CHNNET16 V1.0 are grid cell number (column 1), grid cell row index (column 6), grid cell column index (column 7), and grid cell elevation (column 8).}

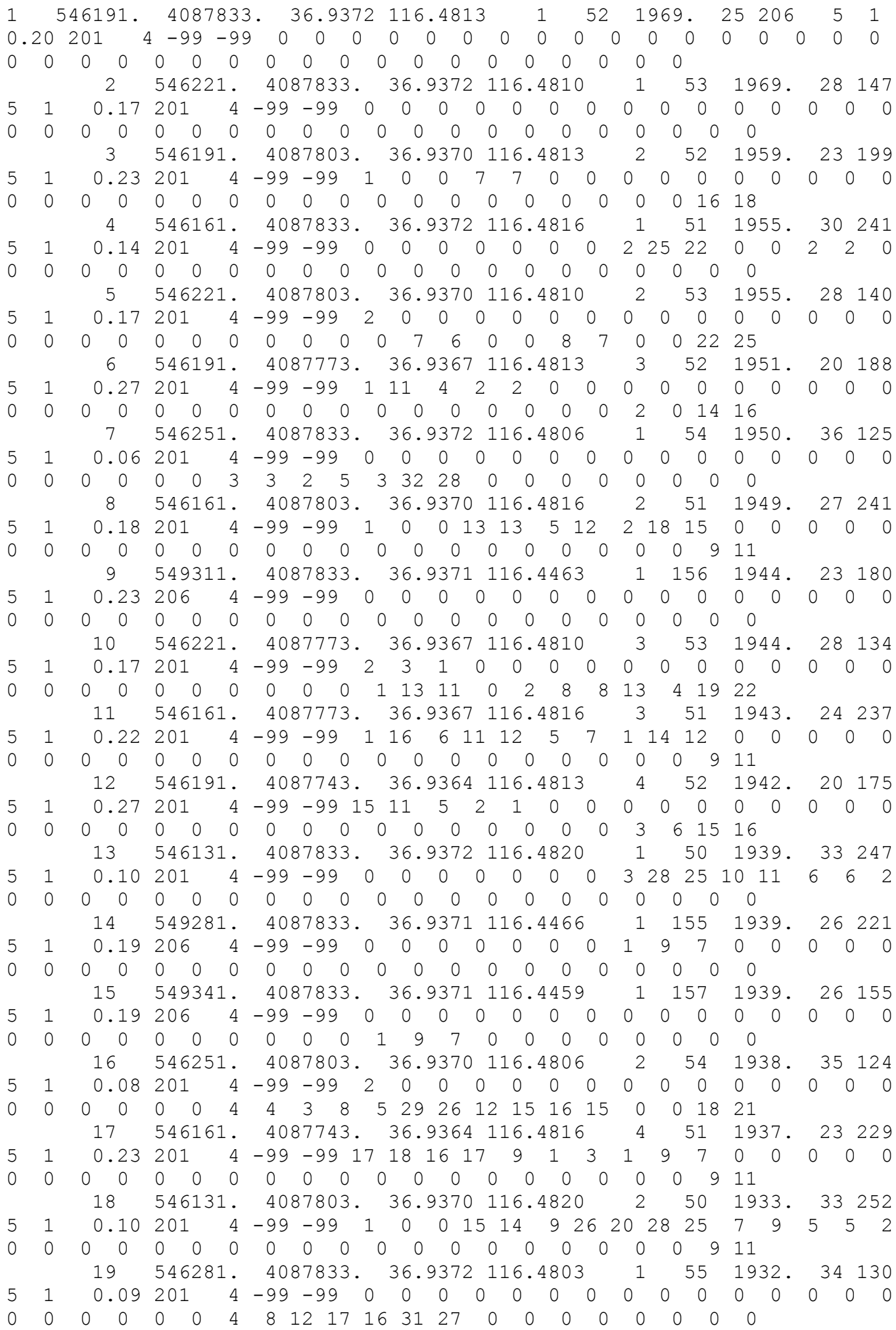




$\begin{array}{llllllllllllllllllllllllll} & & 20 & 549371 & 4087833 & 36.9371 & 116.4456 & & 1 & 158 & 1932 . & 27 & 153 \\ 5 & 1 & 0.18 & 206 & 4 & -99 & -99 & 0 & 0 & 0 & 0 & 0 & 0 & 0 & 0 & 0 & 0 & 0 & 0 & 0 & 0 & 0 \\ 0 & 0 & 0 & 0 & 0 & 0 & 0 & 0 & 0 & 0 & 1 & 13 & 11 & 0 & 0 & 0 & 0 & 0 & 0 & 0 & 0 & & & \end{array}$

- Example listing of the output file, 30MGRD01.C16. The file contains 253, 597 lines and 10 columns (only the first 20 lines of the file are listed). The UTM easting and northing coordinates (columns 1 and 2), the grid cell row and column indices (columns 3 and 4), and the grid cell number (column 5) are identical to the values in the input file. The grid cell number is the first flow routing parameter. Column 6 is the watershed boundary parameter created by CHNNET16, where -3 indicates grid cells on the perimeter of the grid and 0 indicates grid cells on watershed divides (these are grid cells with no upstream cells). Column 7 is the second flow routing parameter and indicates the grid cell number of the downstream cell. Column 9 is the flow accumulation term (number of upstream cells) used to map the stream channel network defined by the 2 flow routing parameters.

\begin{tabular}{|c|c|c|c|c|c|c|c|c|c|}
\hline 546191.0 & 4087833.0 & 1 & 52 & 1 & -3 & 0 & 0 & 0.00000 & $-1 \cdot 0$ \\
\hline 546221.0 & 4087833.0 & 1 & 53 & 2 & -3 & 0 & 0 & 0.00000 & $-1 \cdot 0$ \\
\hline 546191.0 & 4087803.0 & 2 & 52 & 3 & 0 & 11 & 0 & 0.00000 & -1.0 \\
\hline 546161.0 & 4087833.0 & 1 & 51 & 4 & -3 & 0 & 0 & 0.00000 & -1.0 \\
\hline 546221.0 & 4087803.0 & 2 & 53 & 5 & 0 & 26 & 0 & 0.00000 & -1.0 \\
\hline 546191.0 & 4087773.0 & 3 & 52 & 6 & 0 & 21 & 0 & 0.00000 & -1.0 \\
\hline 546251.0 & 4087833.0 & 1 & 54 & 7 & -3 & 0 & 0 & 0.00000 & -1.0 \\
\hline 546161.0 & 4087803.0 & 2 & 51 & 8 & 0 & 27 & 0 & 0.00000 & $-1 \cdot 0$ \\
\hline 549311.0 & 4087833.0 & 1 & 156 & 9 & -3 & 0 & 0 & 0.00000 & -1.0 \\
\hline 546221.0 & 4087773.0 & 3 & 53 & 10 & 0 & 43 & 0 & 0.00000 & $-1 \cdot 0$ \\
\hline 546161.0 & 4087773.0 & 3 & 51 & 11 & 11 & 32 & 0 & 1.00000 & -1.0 \\
\hline 546191.0 & 4087743.0 & 4 & 52 & 12 & 0 & 33 & 0 & 0.00000 & $-1 \cdot 0$ \\
\hline 546131.0 & 4087833.0 & 1 & 50 & 13 & -3 & 0 & 0 & 0.00000 & -1 \\
\hline 549281.0 & 4087833.0 & 1 & 155 & 14 & -3 & 0 & 0 & 0.00000 & -1.0 \\
\hline 549341.0 & 4087833.0 & 1 & 157 & 15 & -3 & 0 & 0 & 0.00000 & -1 \\
\hline 546251.0 & 4087803.0 & 2 & 54 & 16 & 0 & 52 & 0 & 0.00000 & -1.0 \\
\hline 546161.0 & 4087743.0 & 4 & 51 & 17 & 0 & 41 & 0 & 0.00000 & $-1 \cdot 0$ \\
\hline 546131.0 & 4087803.0 & 2 & 50 & 18 & 0 & 57 & 0 & 0.00000 & -1.0 \\
\hline 81.0 & 4087833.0 & 1 & 55 & 19 & -3 & 0 & 0 & 0.00000 & -1.0 \\
\hline 49371.0 & 4087833.0 & 1 & 158 & 20 & -3 & 0 & 0 & 0.00000 & -1.0 \\
\hline
\end{tabular}

- Listing of source code for routine CHNNET16 V1.0:

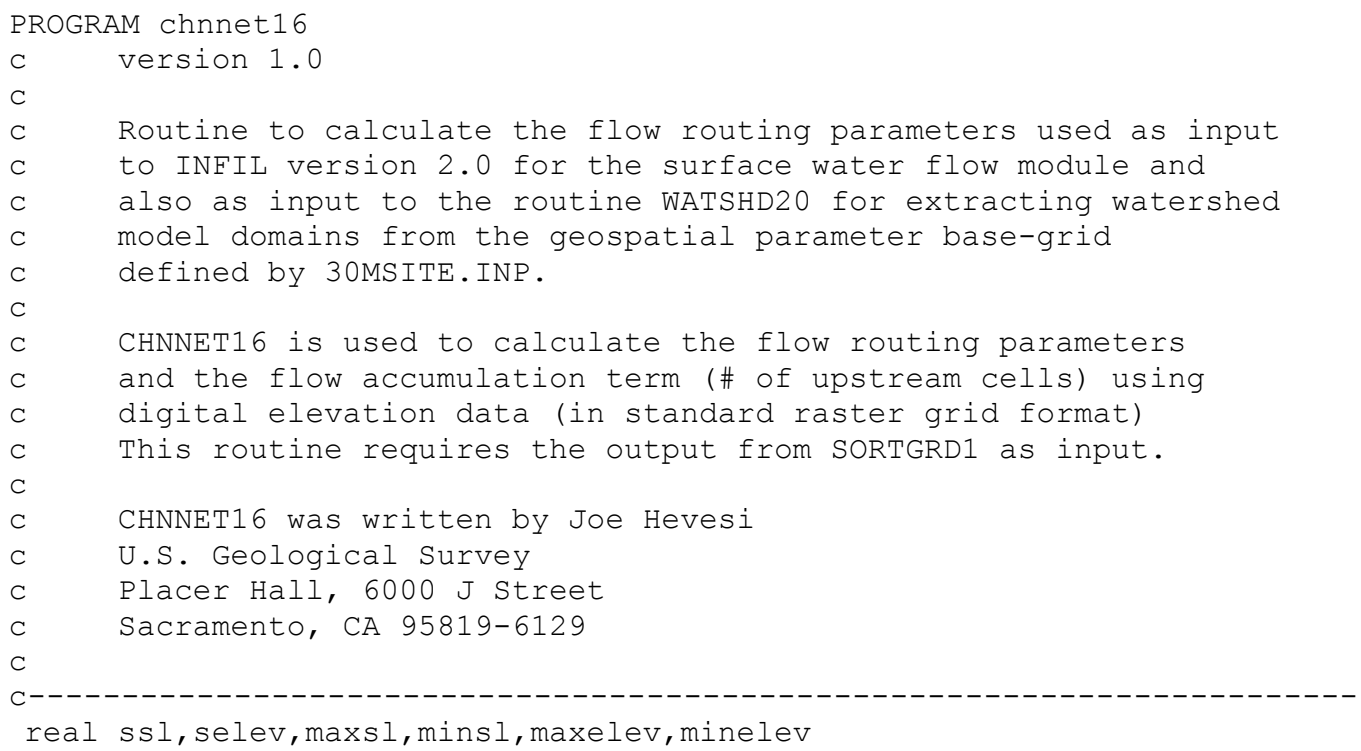




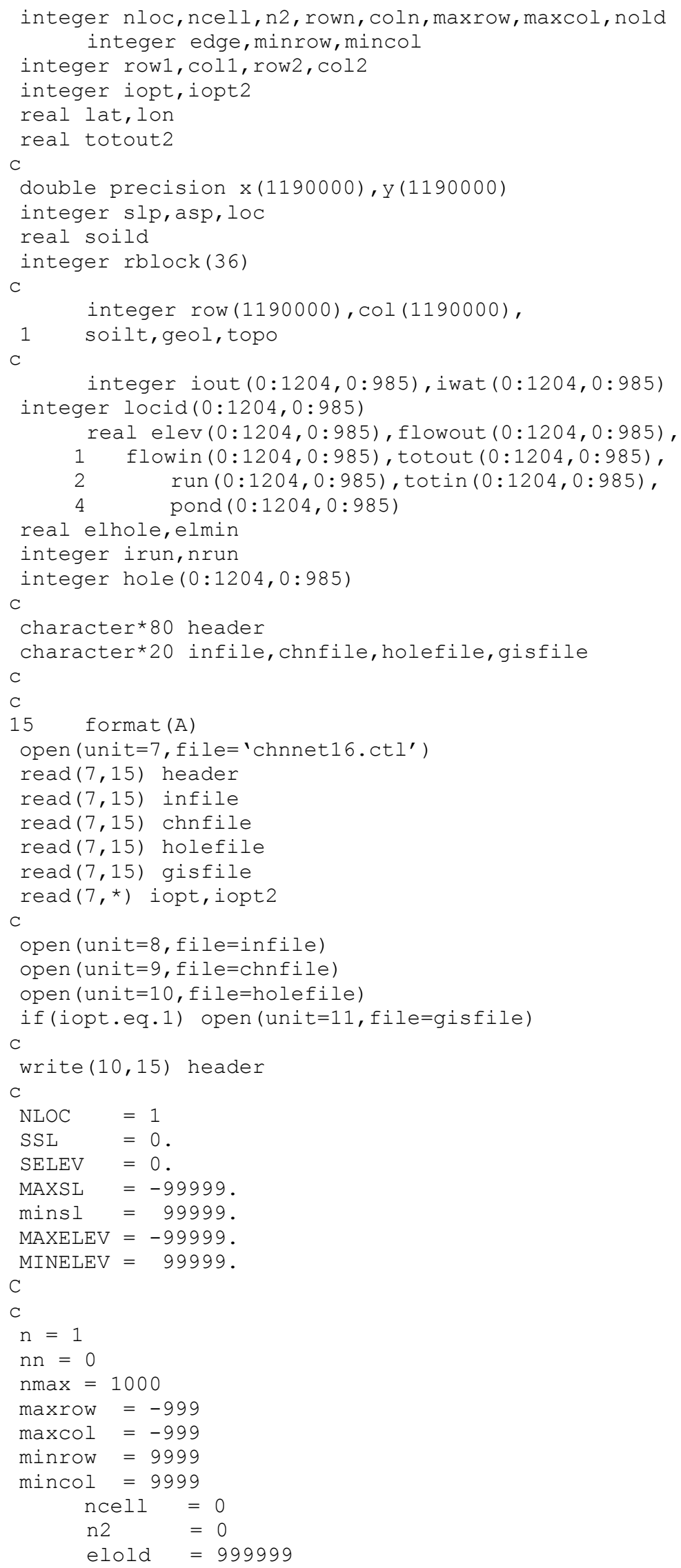




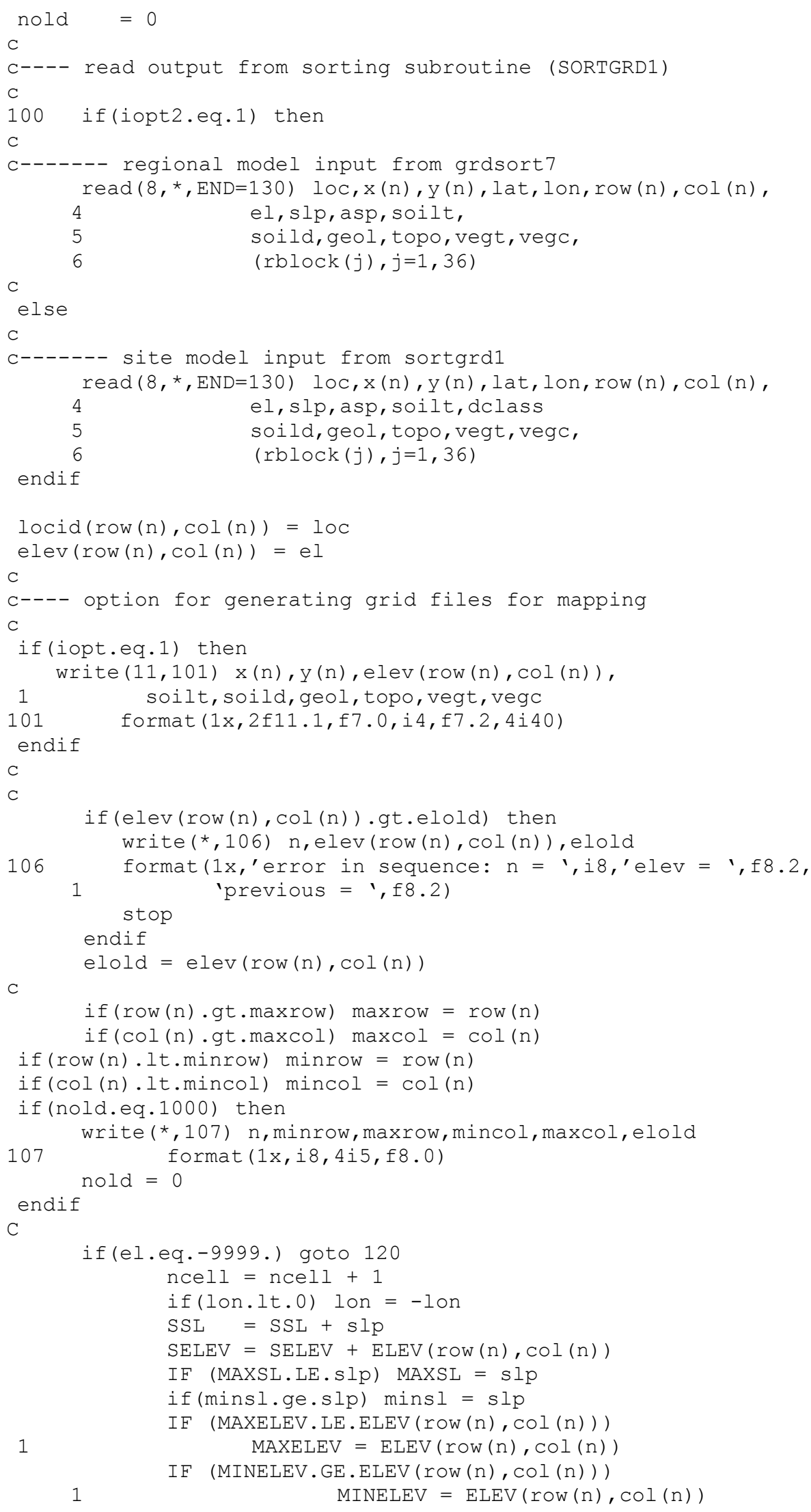




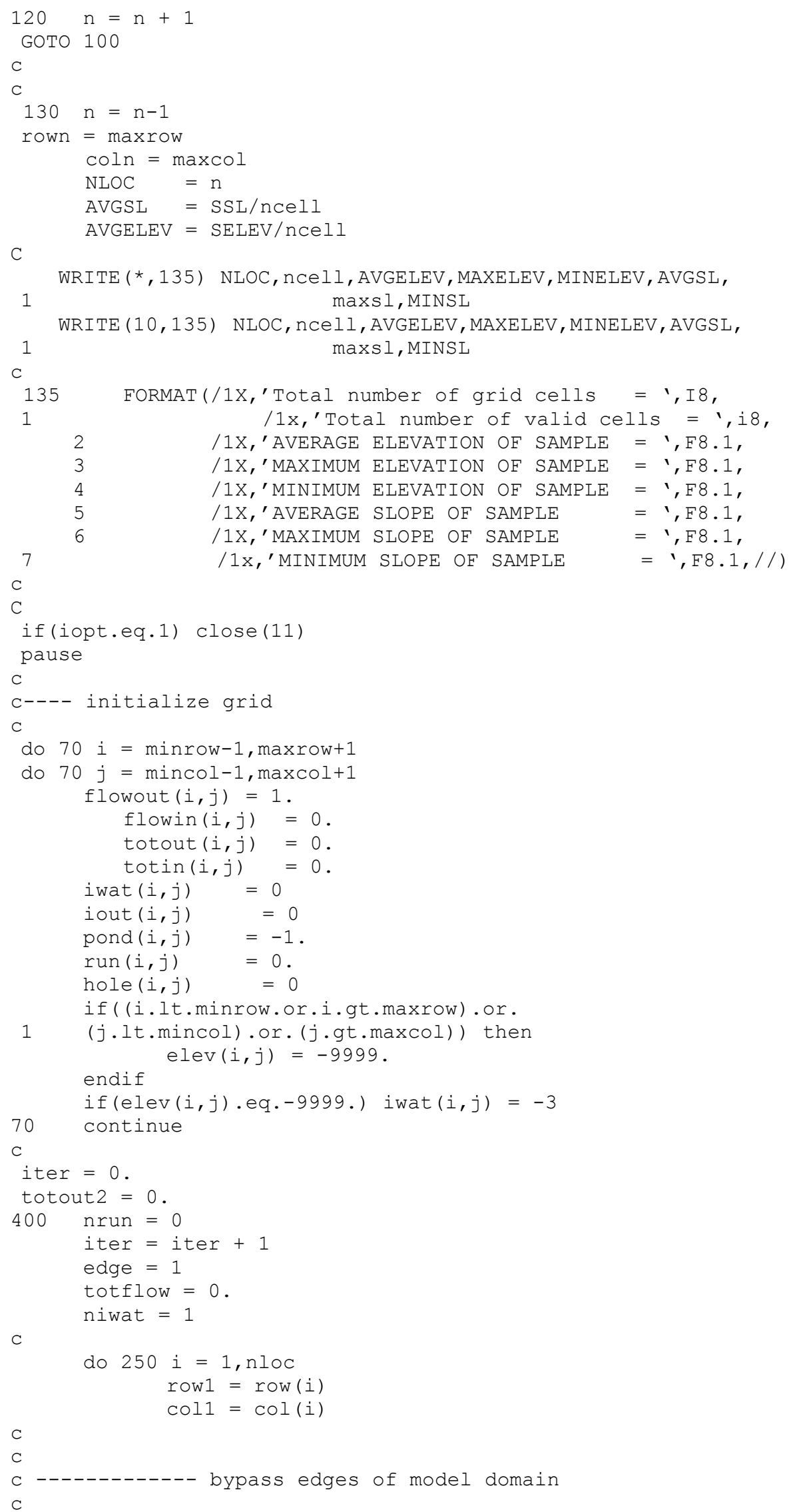


c

if (iwat (row1, col1).eq.-3) goto 250

if (row1.le.minrow.or.row1.ge.maxrow) then iwat $($ row 1, coll $)=-3$

goto 250

endif

if (coll.le.mincol.or.coll.ge.maxcol) then iwat $($ row $1, \operatorname{col} 1)=-3$

endif goto 250

elmin $=$ elev $($ row $1, \operatorname{col} 1)$

iout $(r o w 1, \operatorname{col} 1)=0$

if(iter.gt.1) then

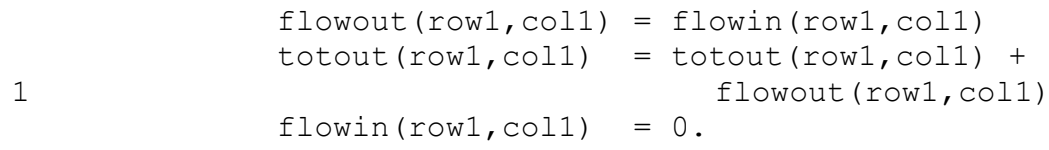

C

endif

$\mathrm{C}$

C

C

do 230 ir $=-1,1$

do 230 ic $=-1,1$

if(ir.eq.0.and.ic.eq.0) goto 230

if (elhole.gt.elev(rowl+ir, colltic))

1

elhole $=$ elev(rowltir, colltic)

if ( (elev(row1+ir, colltic).le.elmin).and.

1 (locid (row1, col1).lt.locid(row1+ir, col1tic)) ) then if (iout (row1+ir, colltic).eq.locid (row1, col1))

1 goto 230

row2 = row $1+i r$

$\operatorname{col} 2=\operatorname{coll}+i \mathrm{c}$

elmin = elev (row2, col2)

endif

iout $($ row $1, \operatorname{col} 1)=\operatorname{locid}($ row $2, \operatorname{col} 2)$

230

continue

if (iout (row1, col1). ne.0) then

flowin(row2, col2) = flowout (row1, col1)

1

+ flowin (row2, col2)

$\operatorname{run}(r \circ w 2, \operatorname{col} 2)=$ flowin $(r o w 2, \operatorname{col} 2)$

if (iwat (row2, col2) .eq.0)

1

iwat $($ row2, $\operatorname{col} 2)=$ locid $($ row2, $\operatorname{col} 2)$

else

c ----------- 20th order hole effect correction

$\mathrm{C}$

245

pond $($ row $1, \operatorname{col} 1)=$ elhole - elmin

ih $=1$

$i h=i h+1$

if(ih.gt.20) goto 285

hole $($ rowl, coll $)=$ ih 


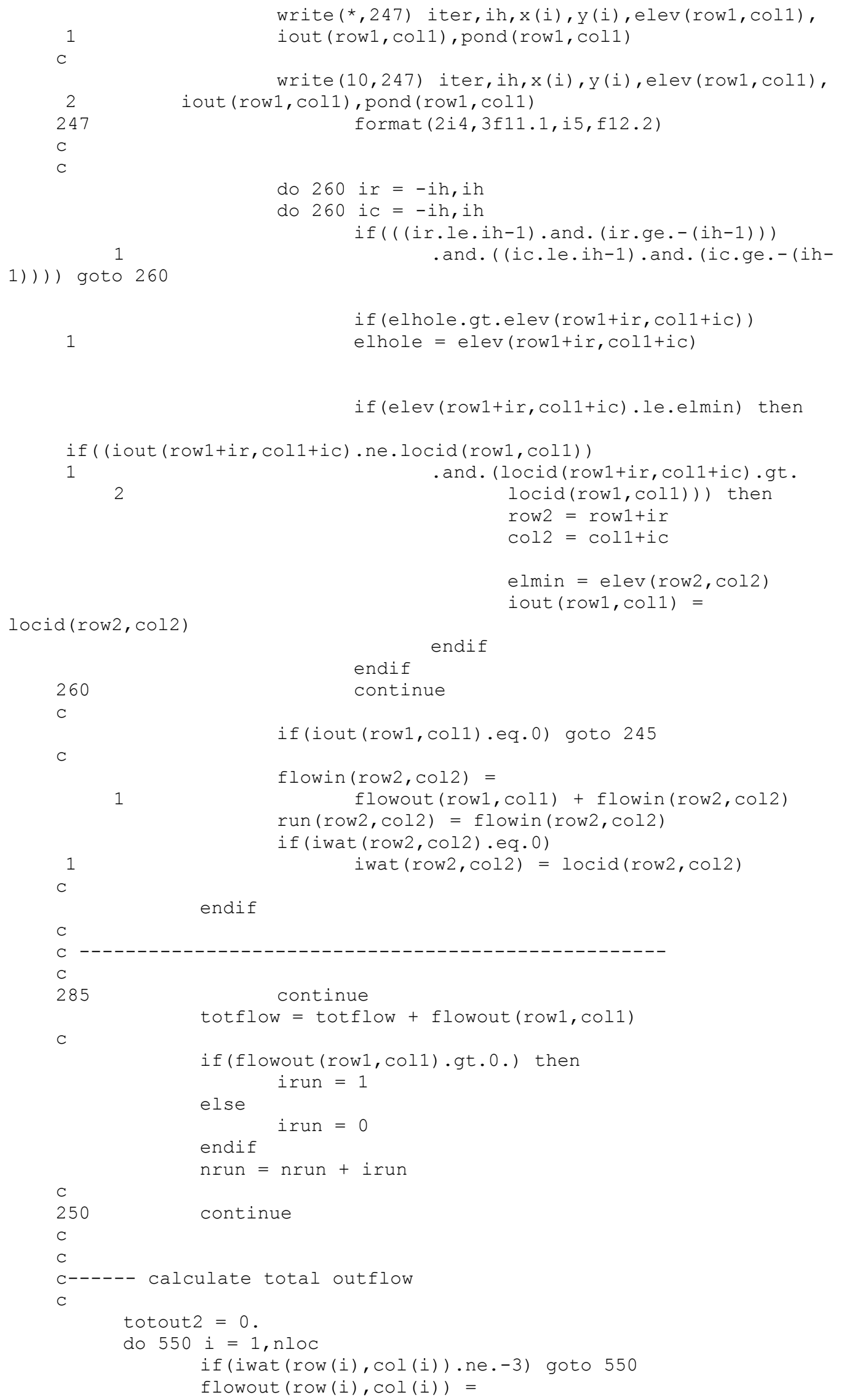




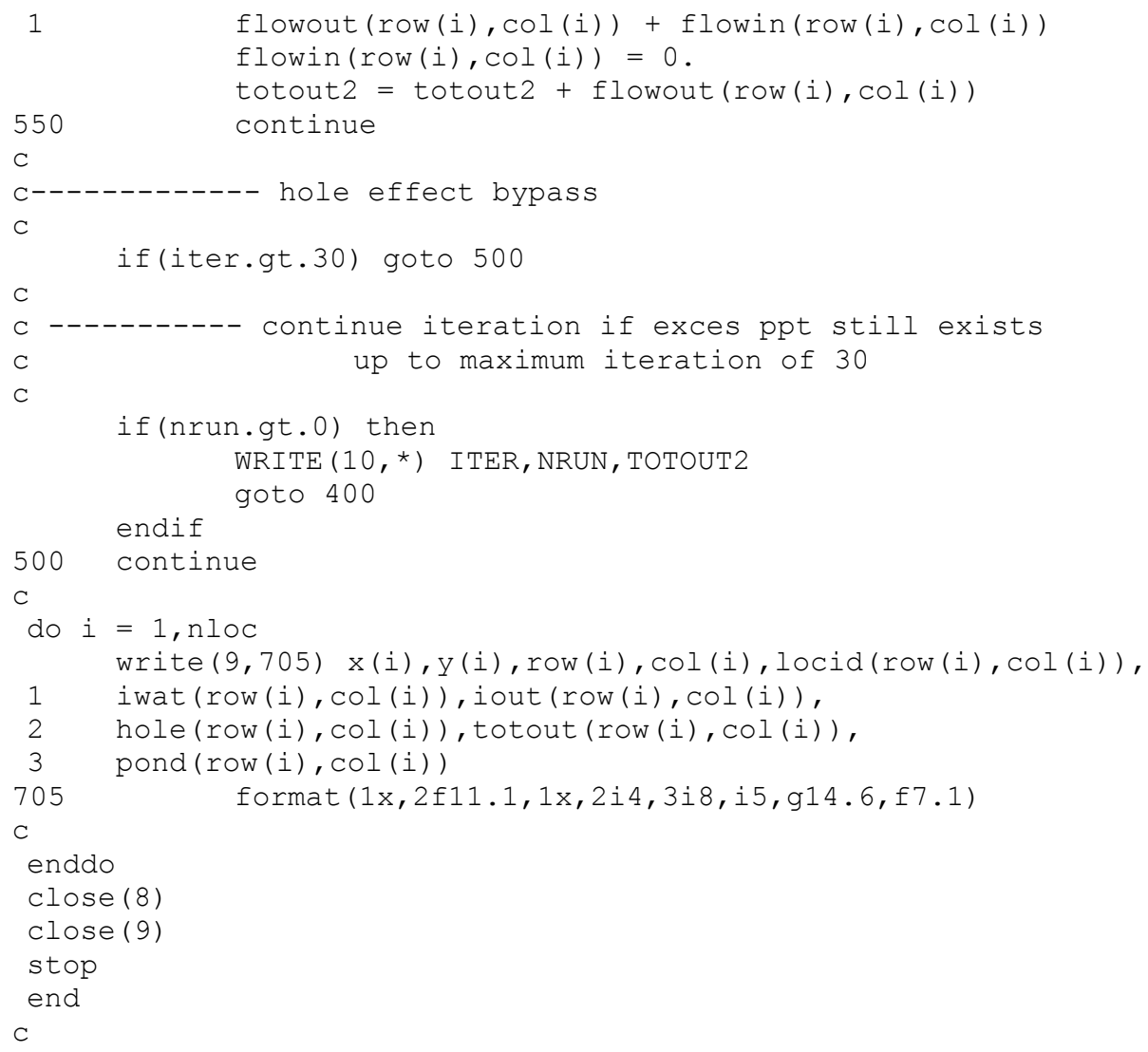




\section{APPENDIX J}

\section{DEVELOPMENT OF GEOSPATIAL INPUT PARAMETERS USING VEGCOVO1 V1.0}




\section{J1. NAME OF ROUTINE/MACRO WITH VERSION/OS/HARDWARE ENVIRONMENT AND USER INFORMATION}

Name of software routine: VEGCOV01 V1.0, OS and hardware environment: Windows NT 4.0, Pentium Pro PC

Computer Identification: SM321276 with a USGS specific host-name P720dcasr

Software Users: Joseph Hevesi (916-278-3274), Alan Flint (916-278-3221)

User Location: U.S. Geological Survey, Room 5000E, Placer Hall, 6000 J Street, Sacramento, CA 95819-6129

\section{J2. NAME OF COMMERCIAL SOFTWARE WITH VERSION/OS/HARDWARE USED TO DEVELOP ROUTINE/MACRO}

The source code for VEGCOV01 V1.0 was developed using the standard FORTRAN77 programming language. The source code was written, debugged, and compiled (for PC platforms using INTEL processors) using DIGITAL Visual Fortran with Microsoft Developer Studio, V. 5.0.

\section{J3. GENERAL DESCRIPTION OF ROUTINE/MACRO}

VEGCOV01 V1.0 is a FORTRAN77 routine developed in accordance with AP-SI.1Q, specifically for the analysis/model activity documented in this report. The routine source code (VEGCOV01.FOR), compiled executable file (VEGCOV01.EXE), routine control file (VEGCOV01.CTL), input and output files used for routine validation, supplemental files created as part of validation testing, and a copy of this appendix, are located under the directory VEGCOV01 on a CD-ROM labeled GEOINPUT-2. The routine source code, control file, and the input and output files are ASCII text files that can be read using any standard ASCII text editor and can be imported into standard word processing applications such as Microsoft Word. The executable file can be used to run VEGCOV01 V1.0 on any PC with an INTEL processor (with adequate RAM).

\section{J4. TEST PLAN FOR THE SOFTWARE ROUTINE VEGCOV01 V1.0:}

\section{- Explain whether this is a routine or macro and describe what it does:}

The software routine, VEGCOV01 V1.0, is used in the development of the geospatial parameter input files for INFIL 2.0. The routine changes the saturated hydraulic conductivity of the Yucca Mountain Tuff of the Paintbrush Group (rock type 324). The different saturated hydraulic conductivity is assigned if the exposed Yucca Mountain Tuff is north of $4082606.93 \mathrm{~m}$ (rock type 309 is assigned) or south of $4079955.91 \mathrm{~m}$ north (rock type 308 is assigned) on Yucca Mountain.

The functions of VEGCOV01 V1.0 are executed using a single routine control file named VEGCOV01.CTL. The file defines the input and output file names.

- Listing of Control File (VEGCOV01.CTL)

vegcov01.ctl

$30 \mathrm{mgrd} 01$. sr 1

vegtyp 01 .xyz

$30 \operatorname{mgrd} 04 . \operatorname{sr} 1$

00 (header line)

(primary input file)

(auxiliary input file)

(output file)

(control options set to 0,0 ) 


\section{- Example listing of input file, 30MGRD01.SR1 (only the first 20 lines of the file are shown):}

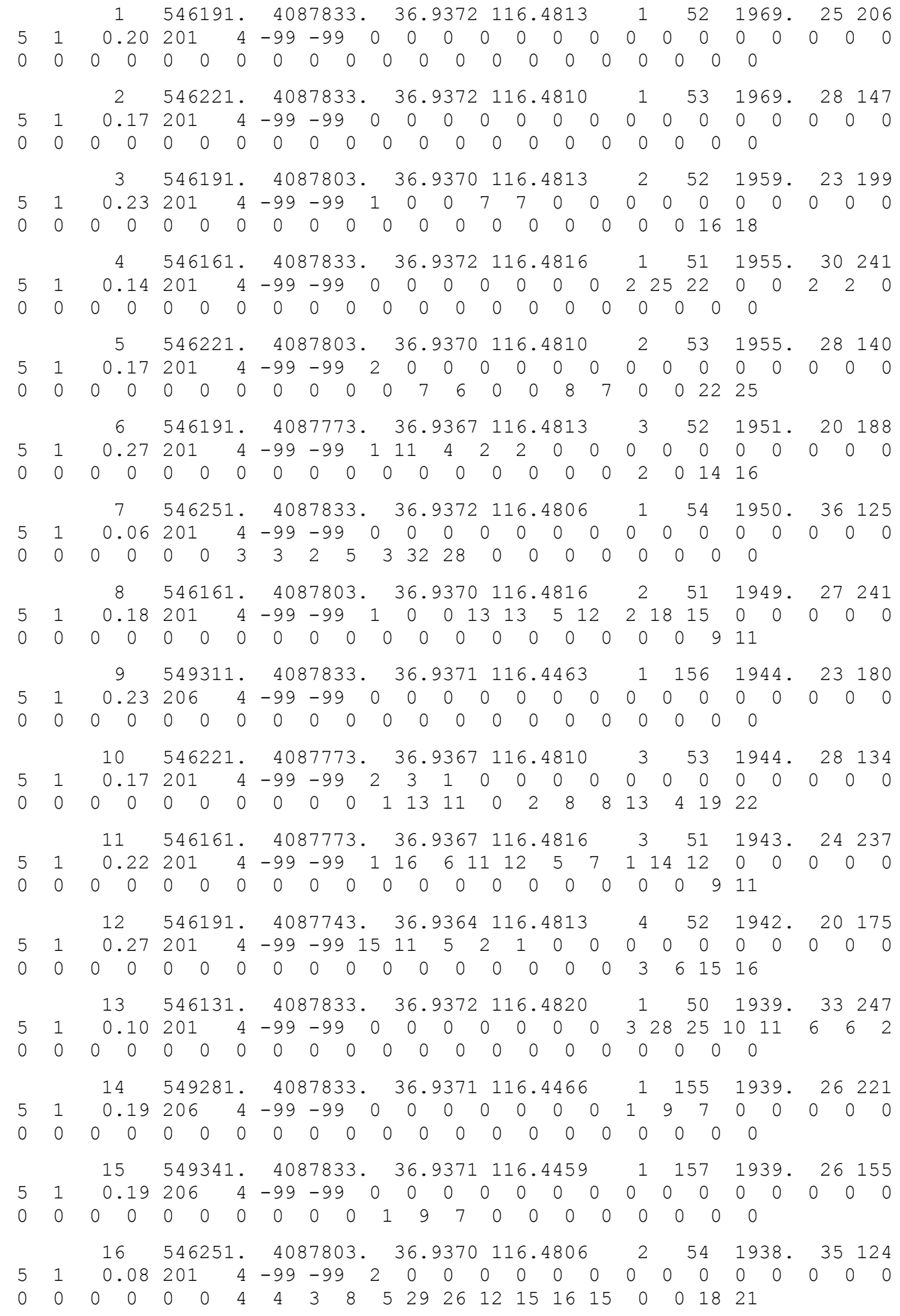




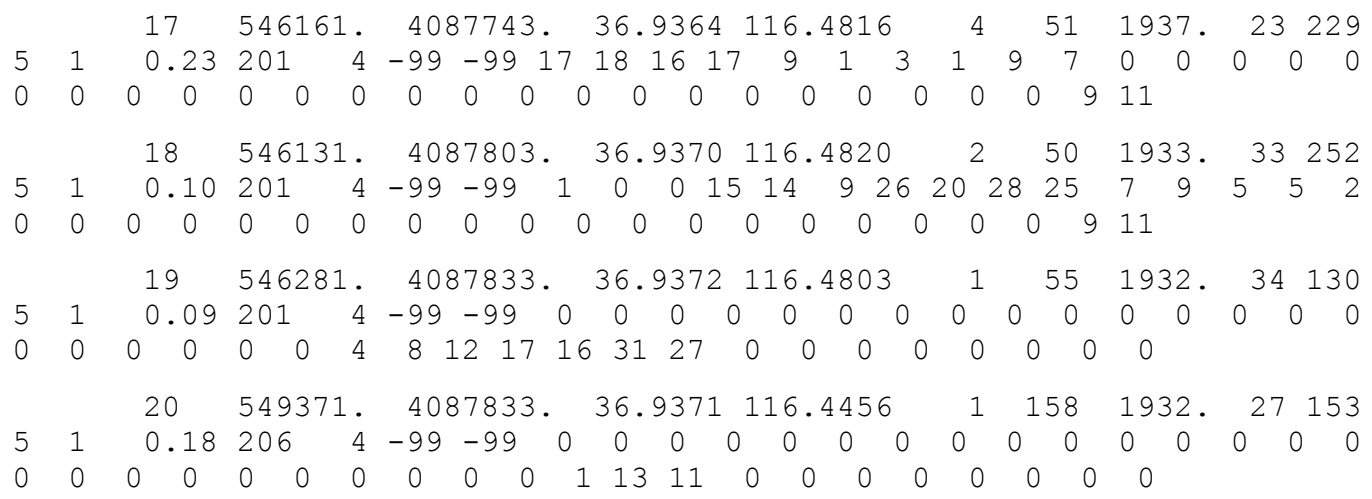

\section{- Example listing of output file, 30MGRD04.SR1 (only the first 20 lines of the file are shown):}

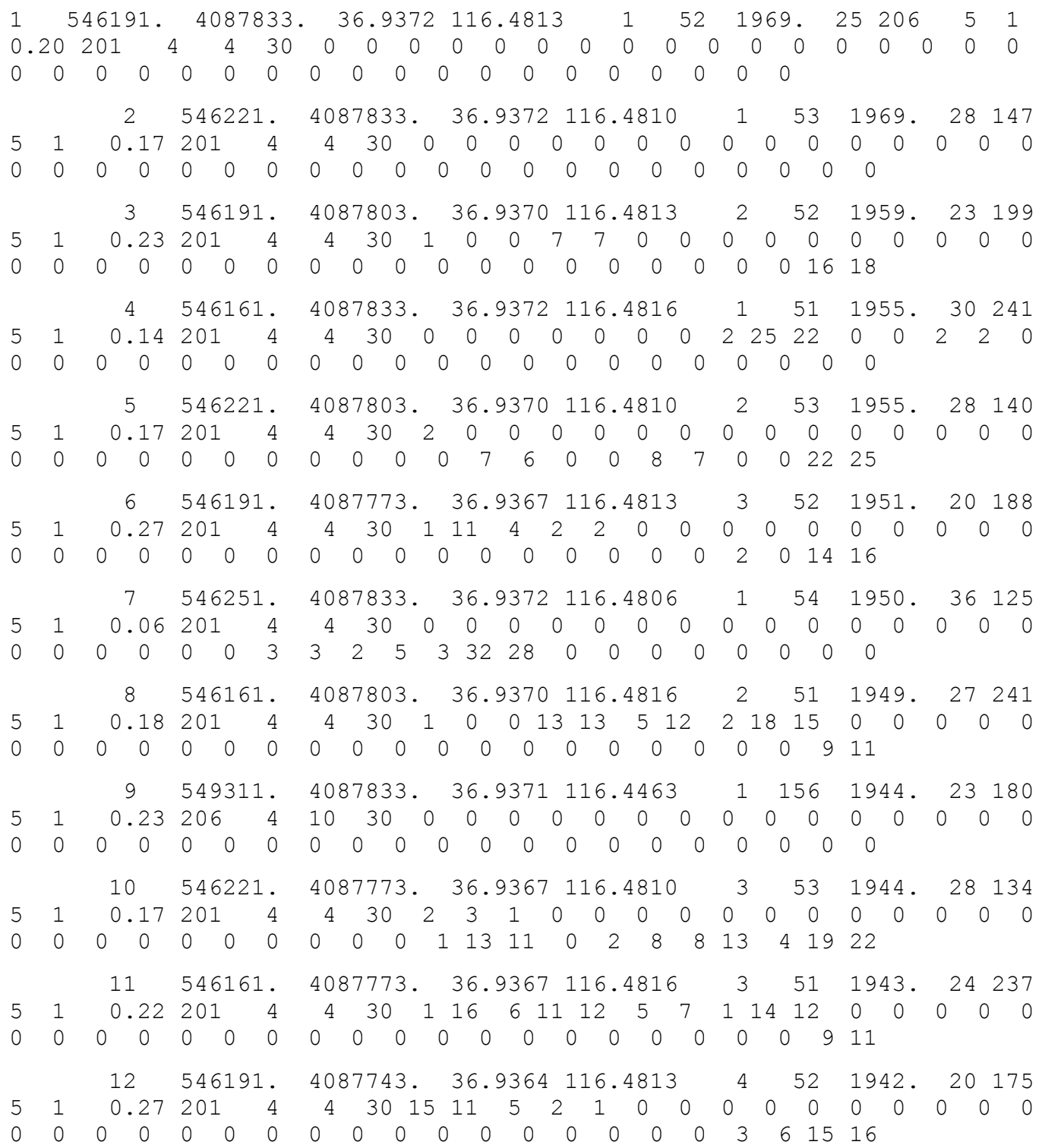




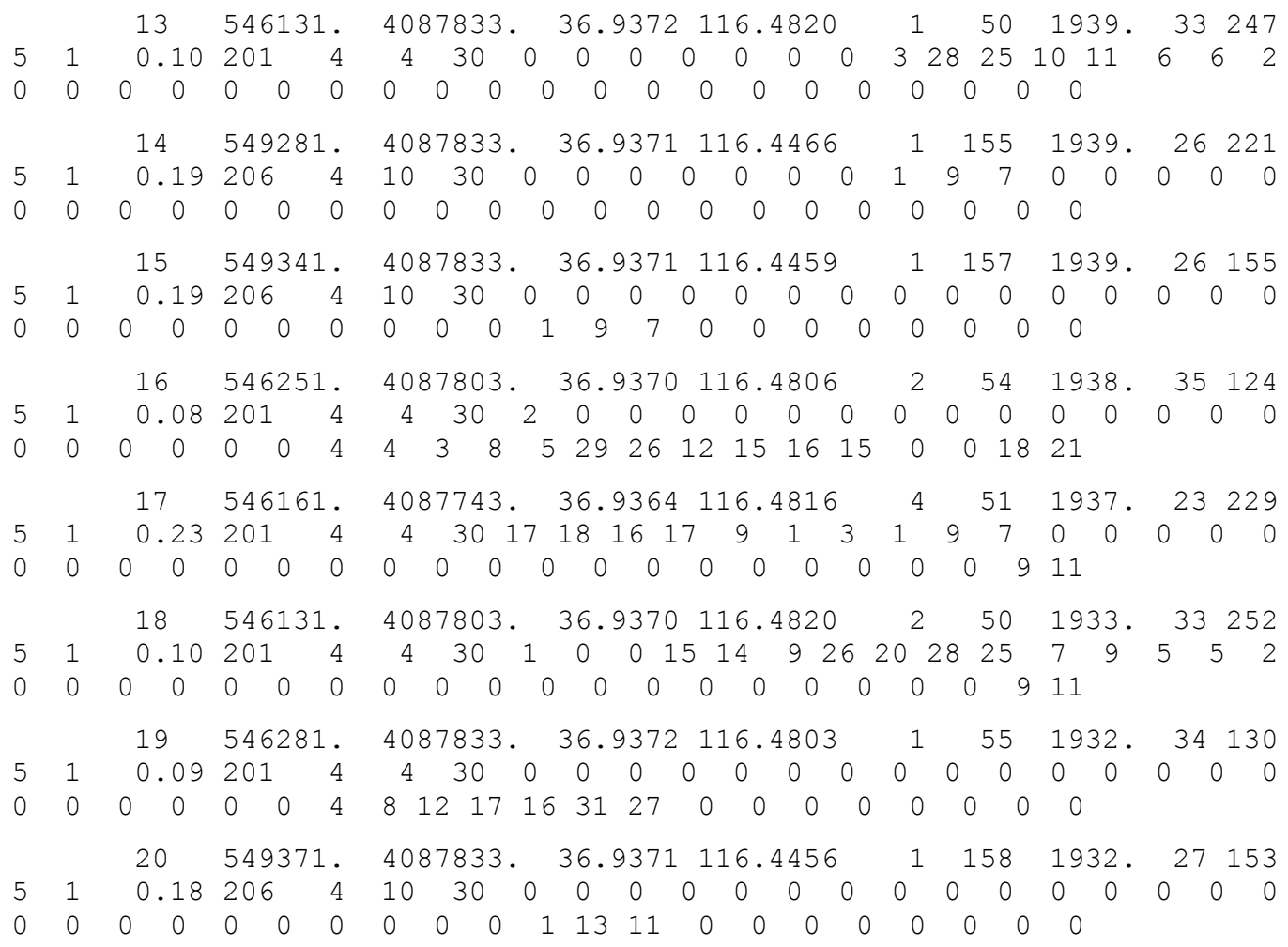

\section{- Listing of FORTRAN77 Source code:}

A listing of the FORTRAN77 source code for the routine VEGCOV01 V1.0 along with examples of the input and output files used in the test plan are included at the end of this appendix.

\section{- Description of test(s):}

To evaluate the accuracy of the functions performed by the routine, it is necessary to perform a visual inspection of the input file, 30MGRD01.SR1 for rock type 324 and verify that the rock type was changed in file, 30MGRD04.SR1 to 309 if the grid block location is north of northing $4082606.93 \mathrm{~m}$ and changed to rock type 308 if the grid block location is south of $4079955.91 \mathrm{~m}$. Extractions of the input file and output file will be imported into EXCEL and it will be determined visually that the criteria are met.

\section{- Specify the range of input values to be used and why the range is valid:}

The input values used are those grid block locations for which the original map unit rock type is 324 .

\section{J5. TEST RESULTS}

\section{- Output from test (explain difference between input range used and possible input):}


The acceptance criteria for the testing of VEGCOV01 is that the rock type 324 is changed in the output file to 309 if the grid block location is north of northing $4082606.93 \mathrm{~m}$ and changed to rock type 308 if the grid block location is south of $4079955.91 \mathrm{~m}$.

- Description of how the testing shows that the results are correct for the specified input:

If the testing results in output that conforms to the above criteria then the results are correct acceptable.

- List limitations or assumptions to this test case and code in general:

The test case is limited to geospatial input rock type 324 .

- Electronic files identified by name and location:

The following electronic files including VEGCOV01 V1.0 and selected input and output files are provided:

VEGCOV01.CTL: Control file used for specifying input and output files. A printout of the control file is included as part of this appendix.

VEGCOV01.FOR: FORTRAN source code listing for the routine VEGCOV01. A printout of the source code is included as part of this appendix.

VEGCOV01.EXE: Executable file for the routine VEGCOV01, compiled for INTEL processors.

Input file for test case: $\quad 30 M G R D 01 . S R 1$

Output file for test case: $\quad 30 M G R D 04 . S R 1$

\section{Results from test case}

The comparison between data in the input file and output file for VEGCOV01 confirm that the routine performs as required and meets the acceptance criteria.

- Listing of source code for VEGCOV01 V1.0

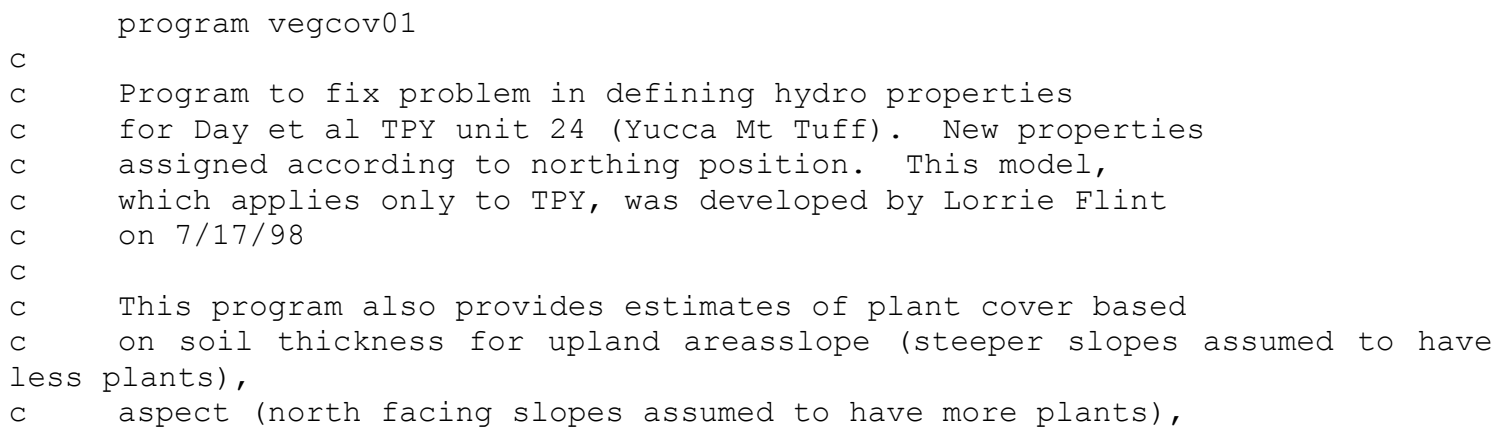




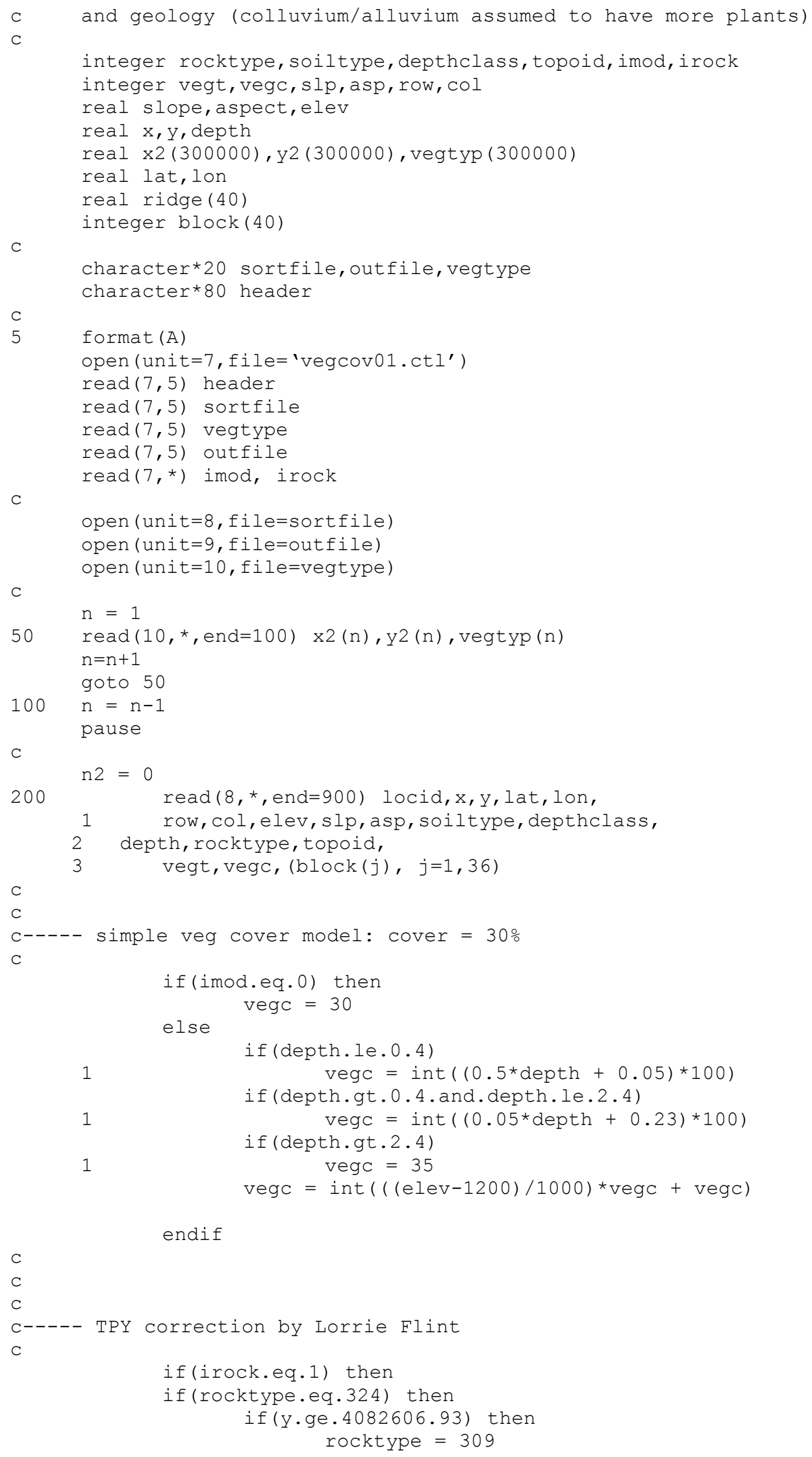




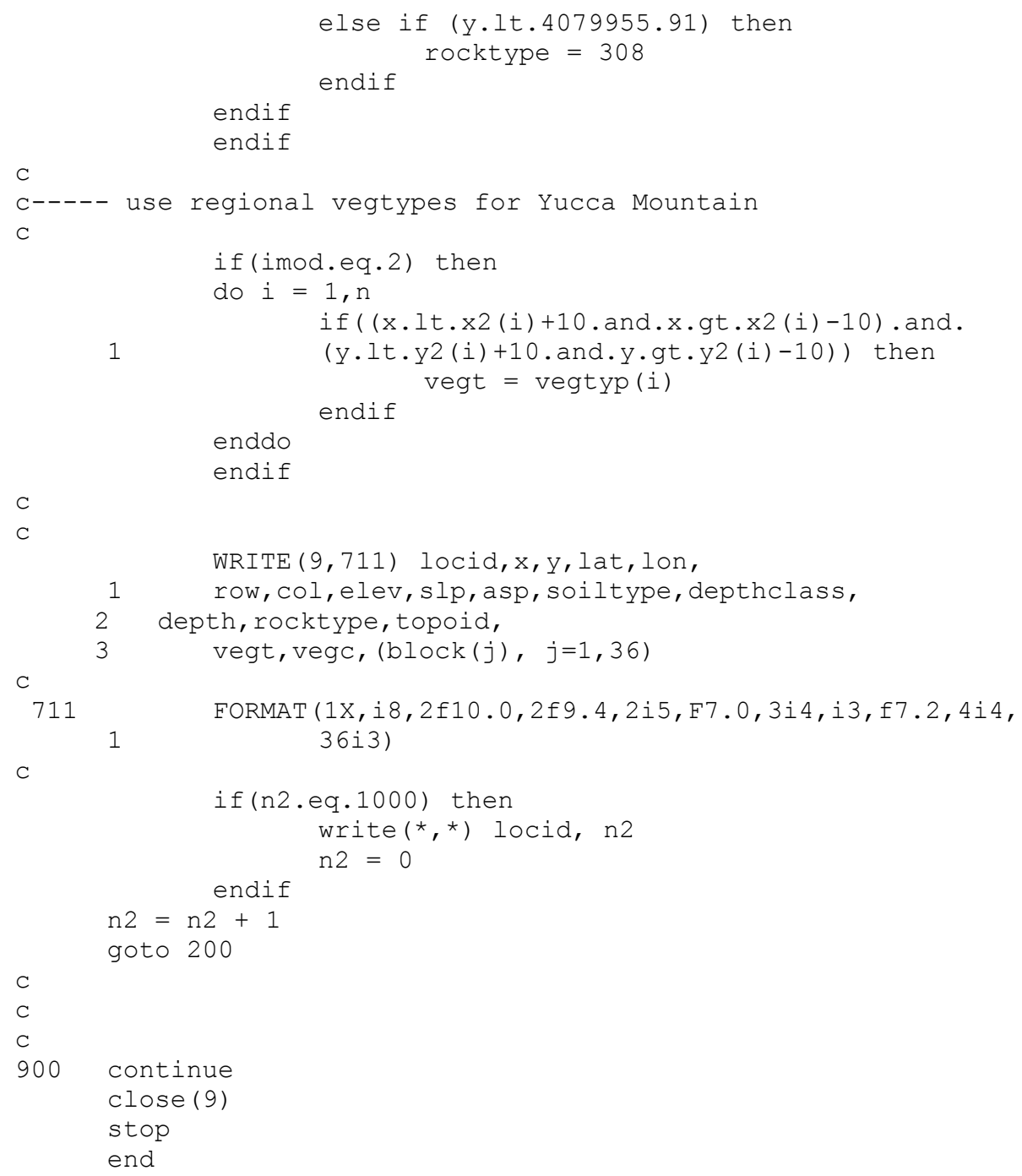




\section{INTENTIONALLY LEFT BLANK}


APPENDIX K

EXTRACTION OF WATERSHED MODELING DOMAINS USING WATSHD20 V1.0 


\section{K1. NAME OF ROUTINE/MACRO WITH VERSION/OS/HARDWARE ENVIRONMENT AND USER INFORMATION}

Name of software routine: WATSHD20 V1.0, OS and hardware environment: Windows NT 4.0, Pentium Pro PC

Computer Identification: SM321276 with a USGS specific host-name P720dcasr

Software Users: Joseph Hevesi (916-278-3274), Alan Flint (916-278-3221)

User Location: U.S. Geological Survey, Room 5000E, Placer Hall, 6000 J Street, Sacramento, CA $95819-6129$

\section{K2. NAME OF COMMERCIAL SOFTWARE WITH VERSION/OS/HARDWARE USED TO DEVELOP ROUTINE/MACRO}

The source code for WATSHD20 V1.0 was developed using the standard FORTRAN77 programming language. The source code was written, debugged, and compiled (for PC platforms using INTEL processors) using DIGITAL Visual Fortran with Microsoft Developer Studio, V. 5.0 .

\section{K3. GENERAL DESCRIPTION OF ROUTINE/MACRO}

WATSHD20 V1.0 is a FORTRAN77 routine developed in accordance with AP-SI.1Q, specifically for the analysis/model activity documented in this report. The routine source code (WATSHD20.FOR), compiled executable file (WATSHD20.EXE), routine control file (WATSHD20.CTL), input and output files, validation test files, and a copy of this appendix, are located under the directory WATSHD20 on a CD-ROM labeled GEOINPUT-2. The routine source code, control file, and the input and output files are ASCII text files that can be read using any standard ASCII text editor and can be imported into standard word processing or spreadsheet applications such as Microsoft WORD and EXCEL. The executable file can be used to run WATSHD20 V1.0 on any PC with an INTEL processor (with adequate RAM).

The output developed by WATSHD20 V1.0 is required for the development of the geospatial parameter input file for INFIL V2.0 (USGS 2000 [DIRS 139422]). The output files created by WATSHD20 are used directly as input to the program INFIL V2.0.

\section{K4. TEST PLAN FOR THE SOFTWARE ROUTINE WATSHD20 V1.0}

\section{- Explain whether this is a routine or macro and describe what it does:}

WATSHD20 V1.0 is the final routine applied in a sequence of FORTRAN 77 routines that are used in the development of the geospatial parameter input files for INFIL V2.0. The first function performed by WATSHD20 is the extraction of a watershed model domain based on the surface water flow routing parameters obtained from the input file, $30 M G R D 01 . C 16$ and the specified easting and northing coordinates of the grid cell for which the upstream area is being extracted. The grid cell coordinates are supplied as input in the routine control file and are selected based on the flow accumulation term included in the file, 30MGRD01.C16. 
A second function performed by WATSHD20 V1.0 is the transfer of the flow routing terms from the input file (30MGRD01.SR1) to the output file defining the watershed being modeled. This includes the second flow routing term (the downstream grid cell number) and the flow accumulation term calculated by CHNNET16. WATSHD20 modifies the second flow routing term, which is the downstream grid cell number, by identifying the perimeter grid cells surrounding the active cells for the extracted watershed model area and assigning these cells a downstream grid cell number of -3 . If the grid cells have already been assigned a value of -3 in column 6 of 30MGRD01.C16 (these are the edges of the base-grid), The -3 value is carried over by WATSHD20 as the downstream cell number. The -3 values are used for identifying the perimeter grid cells, which are on the outer side of the surface water flow divide defining the active cells in the watershed model domain. The perimeter cells can rout to other perimeter cells, but cannot rout to the active watershed cells.

\section{- Listing of FORTRAN77 Source code:}

A listing of the FORTRAN77 source code for the routine WATSHD20 V1.0 along with examples of the input and output files used in the test plan are included at the end of this appendix.

\section{- Description of test(s):}

A validation test of the functions performed by the routine was conducted by a visual evaluation of the extracted watershed area with the topography defined by the elevation values. Using applications in ARCVIEW the map image of the extracted watershed area and the flow accumulation term is superimposed with a contour or shaded relief image of the topography to provide a method of testing that the routine has functioned correctly. The test criteria used in the visual evaluation consists of verifying that the extracted active model grid cells included in the output file created by WATSHD20 define an area that is completely bounded by surface water flow divides, with the exception of the grid cell defining the watershed outflow location. The grid cells defining the watershed perimeter must all have values of -3 for the downstream grid cell parameter, and the watershed perimeter cells must completely enclose the active model cells. The grid cell defining the watershed outflow location is specified in the routine control file, and the total number of active cells in the watershed model domain must equal 1 plus the number of cells upstream from the cell defining the watershed outflow location. The total number of lines or cells included in the output file must be equal to the number of active cells plus the number of perimeters cells.

Additional test criteria are similar to those applied in the test plan for CHNNET16 V1.0. The flow accumulation term is used to visualize the surface water routing network within the extracted watershed area, which in turn provides a method of testing the calculated flow routing parameters. The flow accumulation term must agree with the expected channel network defined by the topography (within the limitations of the standard D8 routing algorithm). Major stream channels consisting of hundreds or thousands of upstream cells must occur along the bottom of washes and not along ridgetops. The flow accumulation term must systematically increase in the downstream 
direction (up-hill flow cannot occur). The flow accumulation term must systematically increase with a decrease in elevation, but cannot become greater than the sum of all contributing upstream grid cells. All flow routing must be convergent and cannot terminate unless a major sink is reached. All cells can only rout to one cell (divergent flow is not allowed).

An additional test performed as part of the routine validation is an inspection of the output file containing the flow routing parameters. The criteria of the test is that the output file must be in the proper format with the correct number and sequencing of 55 columns. The number of rows is equal to the total number of grid cells used to define the watershed model domain, including both the active model cells and the inactive perimeter cells that are used to define the watershed boundary.

\section{- Specify the range of input values to be used and why the range is valid:}

The input range is completely determined by the parameters in the files, 30MGRD04.SRI and 30MGRD01.C16 because this is the only source of input provided to the routine. The files are specified in the file, WATSHD20.CTL, which is the routine control file for WATSHD20 and is required for the execution of the routine. 30MGRD04.SR1 is a column-formatted ASCII file consisting of 253,597 rows and 53 columns (Appendix J). 30MGRD01.C16 is a column formatted ASCII file consisting of 253, 597 rows and 10 columns. For the parameters used by the routine, the input ranges are specified by the following:

30MGRD01.C16 is the main input file used by WATSHD20 V1.0. Parameters in the first 9 columns provided by $30 M G R D 01 . C 16$ are used as input by functions in WATSHD20 V1.0:

1. Grid cell easting coordinate (column 1)

2. Grid cell northing coordinate (column 2)

3. Grid cell row index (column 3, integers from 1 to 691)

4. Grid cell column index (column 4, integers from 1 to 367)

5. Grid cell number (column 5, integers from 1 to 253,597)

6. Perimeter grid cell identifier (column 6 , integers from -3 to 253,597 )

7. The downstream grid cell number (column 7, integers from 1 to 253,597)

8. Index for identifying grid cells in depressions (column 8, integers from 0 to 20 )

9. The flow accumulation term (column 9, integers from 0 to 155,471 ) 
The input range provided by the input file, 30MGRD01.C16 is valid because the values were obtained from ARCINFO using the source data as input (see Appendix D for description of source data used for 30MSITE.INP) and a sequence of applied software routines described in Appendices $\mathrm{F}$ through $\mathrm{L}$ of this report.

All Parameters provided as input from the file, 30MGRD04.SR 1 are transferred to the output file. WATSHD20 does not modify any of the 53 input columns provided by 30MGRD04.SR1.

\section{K5. TEST RESULTS}

\section{- Output from test:}

The output for the test case is the main output file, WT2.W20 generated by WATSHD20 V1.0. The output file is used to generate raster-format map image files in TRANSFORM and ARCVIEW, which are used only as a part of the validation test plan.

\section{- Description of how the testing shows that the results are correct for the specified input:}

The ARCVIEW map image of the main output file used for the test plan (file $W T 2 . W 20$ ) shows that the correct watershed area has been extracted from the input file (30MGRD04.SR 1) based on the comparison of the 3,142 extracted cells with the topography.

The TRANSFORM map image of elevation for the grid cells included in the output file shows that the elevations of all grid cells upstream of the outflow cell specified in the control file have higher elevations than the outflow cell. The only exception to this are the inactive perimeter cells downstream of the specified outflow cell. The TRANSFORM map image of the $2^{\text {nd }}$ flow routing parameter (the downstream cell number) indicates that the 282 perimeter cells have been correctly identified by WATSHD20. The perimeter cells completely enclose the active model cells, and with the exception of the one grid cell downstream from the outflow cell identified in the control file, all perimeter cells are along surface water flow divides.

These results indicate that the test criteria for WATSHD20 have been met and the routine is functioning correctly.

The TRANSFORM map image of the flow accumulation term indicates that the number of upstream cells for the identified outflow cell $(2,859)$ matches the total number of active grid cells extracted by WATSHD20, minus 1 for the outflow cell which is itself an active model cell. These results were verified in the EXCEL worksheet file, WT2-W20.XLS included as part of the supporting information. The worksheet was also used to verify that the total number of grid cells in WT2.W20 equals the 2,860 active cells plus the 282 perimeter cells.

The TRANSFORM map images of the flow accumulation term indicate that surface water flow is being routed correctly within the watershed. All flow is convergent and is 
routed towards the watershed outflow location. Major stream channels consisting of hundreds or thousands of upstream cells occur along the bottom of washes and not along ridgetops. The flow accumulation term systematically increase in the downstream direction (up-hill flow doe not occur). The flow accumulation term systematically increases with a decrease in elevation, but cannot does not become greater than the sum of all contributing upstream grid cells.

These results indicate that the test criteria for WATSHD20 have been met and the routine is functioning correctly.

Visual comparison of the input and output files indicates the correct format and ordering of columns for the output file (see example printouts included under supporting information). The output file has 55 columns, the first flow routing parameter is in column 1 , and the $2^{\text {nd }}$ flow routing parameter and the flow accumulation term have been correctly added as columns 8 and 9 .

Inspection of the last 20 lines of the output file, WT2.W20 (see printout provided under supporting information) indicates that the fifth to last line (hi-lighted in red) is the watershed outflow cell identified in the control file with the coordinates 549,671 easting, 4,076,913 northing. The grid cell has 2,859 upstream cells (indicated in column 9) and routs surface water to cell number 121,694 (indicated in column 8), which is the grid cell identified by the last line of the file. Values of -3 in column 8 identify perimeter cells that are used only to define the boundary of the watershed. The seventh to last line (hi-lighted in blue) is the one grid cell upstream of the watershed outflow cell, and has 2,858 upstream cells. These results indicate that WATSHD20 correctly performed the intended modifications to the $2^{\text {nd }}$ flow routing term and that the watershed outflow location is correctly defined. No unintended modifications occurred to input parameters obtained from 30MGRD04.SR1, and thus all test criteria are satisfied.

\section{- List limitations or assumptions to this test case and code in general:}

The limitations of the developed test case are based on the practical limitations of verifying calculated parameter values for all 253,597 grid cells included in the output file used for the developed test case. Validation of the entire output file used in the test case was performed as a visual evaluation of raster-based map images produced in TRANSFORM and ARCVIEW.

- Electronic files identified by name and location:

Electronic files are located on CD-ROM labeled GEOINPUT-2, under the directory WATSHD20, included as an Appendix to the report. The following electronic files are provided:

WATSHD20.CTL: Input file consisting of the input and output file names for WATSHD20 V1.0. 
WATSHD20.FOR: FORTRAN source code listing for the routine WATSHD20 V1.0. A printout of the source code is included as part of this appendix.

WATSHD20.EXE: Executable file for the routine WATSHD20 V1.0, compiled for INTEL processors.

30MGRD04.SR1: Input file consisting of a column-formatted, ASCII text file with 253,597 rows and 53 columns. This file was developed as the output file from VEGCOV01 V1.0 (Appendix J). A partial printout of the first part of this file is included as part of this appendix.

30MGRD01.C16: Input file consisting of a column-formatted, ASCII text file with 10 columns and 253,597 rows. This file contains all flow routing parameters developed by SORTGRD1 and CHNNET16 that are used by WATSHD20 to extract watershed model domains.

WT2-W20.APR: ARCVIEW project file (including all files in associated directories) used to create the raster-based map image of the extracted watershed area using the output from the test case (the test file, WT2.W20).

WT2-ELEV.HDF: TRANSFORM map image of elevation for the grid cells in the test file, WT2.W20, used to visually evaluate the extracted watershed area. The file is used to create the software routine validation test. This file is not a part of the routine application.

WT2-8.HDF: TRANSFORM map image of the 2nd flow routing parameter (downstream cell number) obtained from the output file, WT2.W20. The file is used to create the software routine validation test. This file is not a part of the routine application.

WT2-9.HDF: $\quad$ TRANSFORM map image of the flow accumulation term obtained from WT2.W20. The file is used to create the software routine validation test. This file is not a part of the routine application.

WT2-9B.HDF: $\quad$ TRANSFORM map image of the flow accumulation term obtained from WT2.W20. The file is used to create the software routine validation test. This file is not a part of the routine application.

WT2-9C.HDF: TRANSFORM map image of the flow accumulation term obtained from WT2.W20. The file is used to create the 
WT2-W20.XLS: $\quad$ EXCEL worksheet used to check the number of upstream cells defined by the flow accumulation term for the watershed outflow cell against the total number of active cells extracted. The worksheet is also used to check that the total number of lines in the output file is equal to the number of active cells plus the number of perimeter cells. This file is not a part of the routine application.

6. Supporting Information. (Include background information, such as revision to a previous routine or macro, or explanation of the steps performed to run the software. Include listings of all electronic files and codes used).

- Procedure for running routine:

To run the routine WATSHD20 V1.0, the executable file (WATSHD20.EXE), the routine control file (WATSHD20.CTL), and the input file specified in the routine control file (WATSHD20.INP) must be placed in the same directory. The routine is executed by typing WATSHD20 in a DOS window, by double clicking on the file, WATSHD20.EXE in the Microsoft Windows operating system, or by typing in the path and filename in the RUN window of the Windows NT or Windows 98 start menu. The input and output file names must be in the correct sequential order as specified in the routine control file (see example listing below).

Example listing of routine control file, WATSHD20.CTL

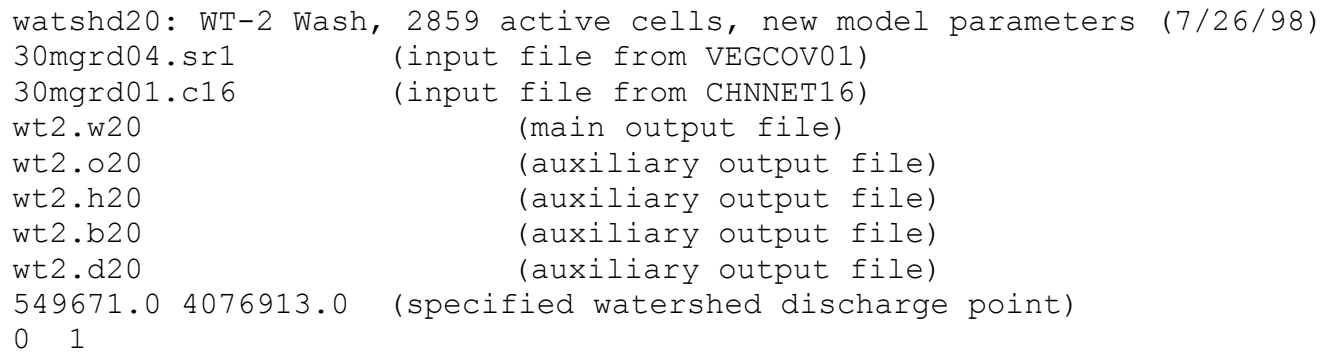

- Example listing of the input file, 30MGRD04.SR1. The file contains 253,597 lines and 53 columns (only the first 20 lines of the file are listed).

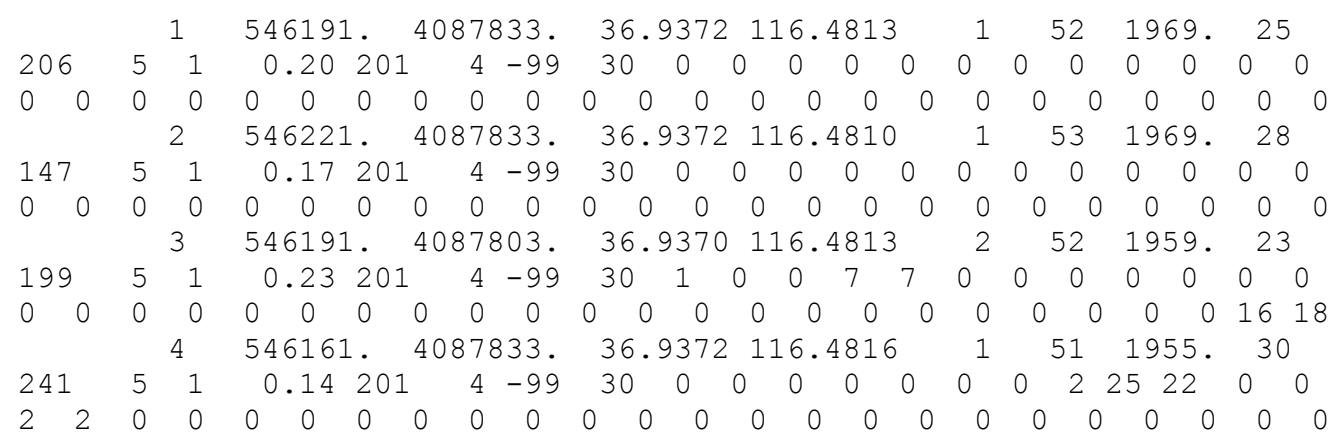




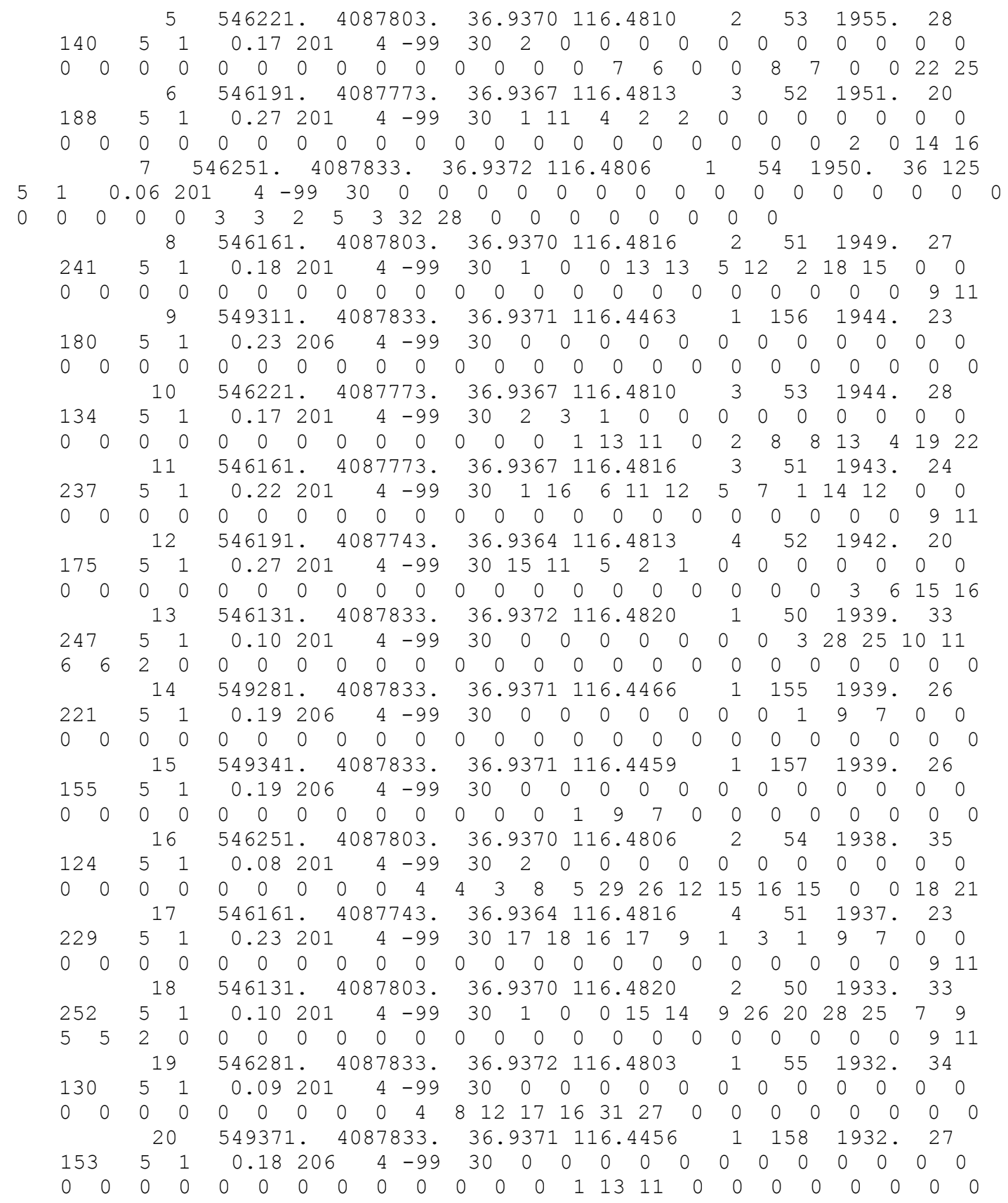

- Example listing of the input file, 30MGRD01.C16 (see Appendix J for a more detailed explaination. The file contains 253, 597 lines and 10 columns (only the first 20 lines of the file are listed).

$\begin{array}{clllllll}546191.0 & 4087833.0 & 1 & 52 & 1 & -3 & 0 & 0 \\ 0.00000 & -1.0 & & & & & & \\ 546221.0 & 4087833.0 & 1 & 53 & 2 & -3 & 0 & 0 \\ 0.00000 & -1.0 & & & & & & \\ 546191.0 & 4087803.0 & 2 & 52 & 3 & 0 & 11 & 0 \\ 0.00000 & -1.0 & & & & & & \\ 546161.0 & 4087833.0 & 1 & 51 & 4 & -3 & 0 & 0 \\ 0.00000 & -1.0 & & & & & & \end{array}$




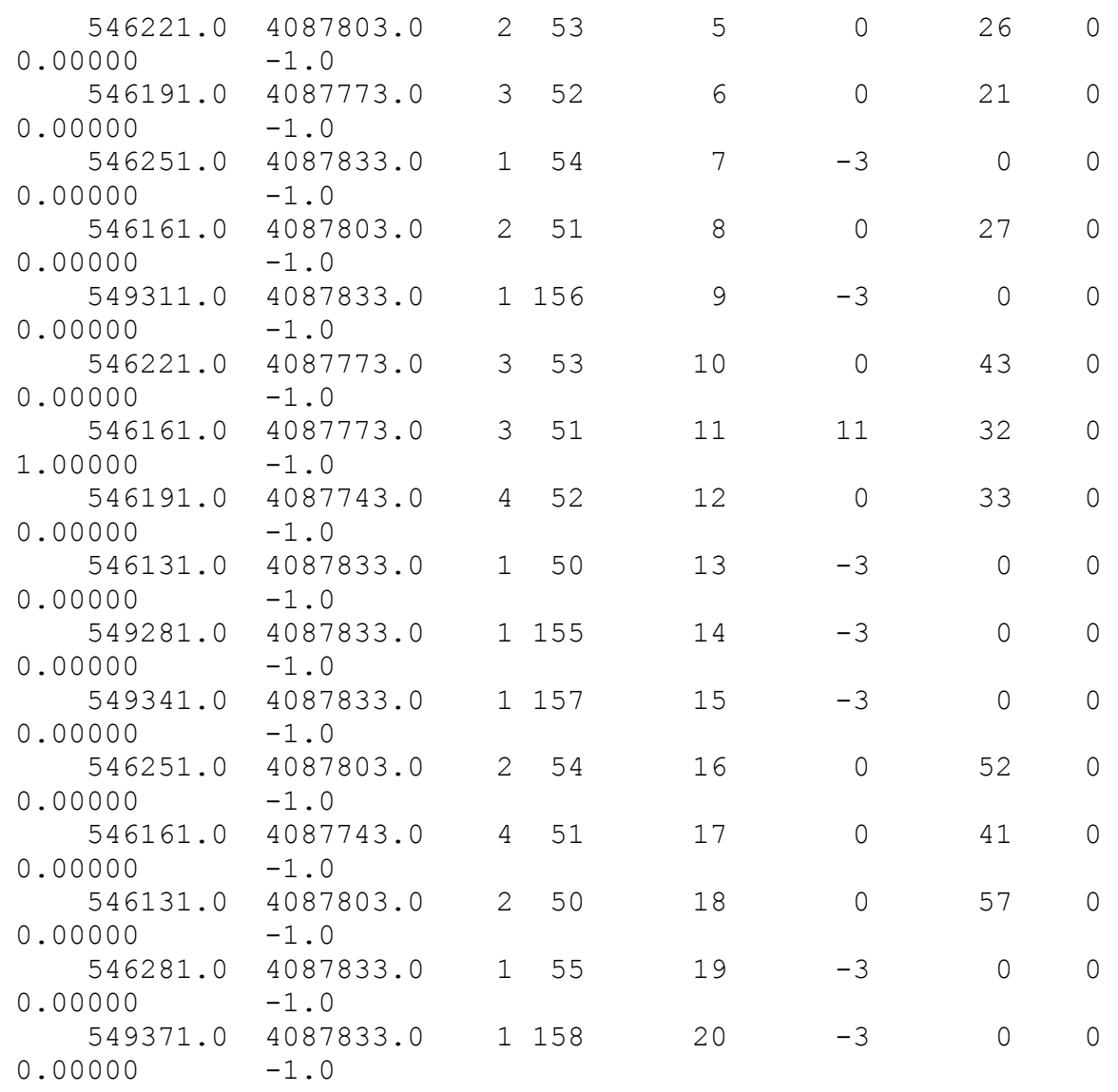

- Example listing of the output file, WT2.W20 created for the test case (only the first 20 lines of the file are shown). This file defines a watershed model domain and is supplied directly to INFIL V2.0 as the geospatial parameter input file. Column 8 is the modified second flow routing parameter obtained from 30MGRD01.C16. Column 9 is the flow accumulation term obtained from 30MGRD01.C16.

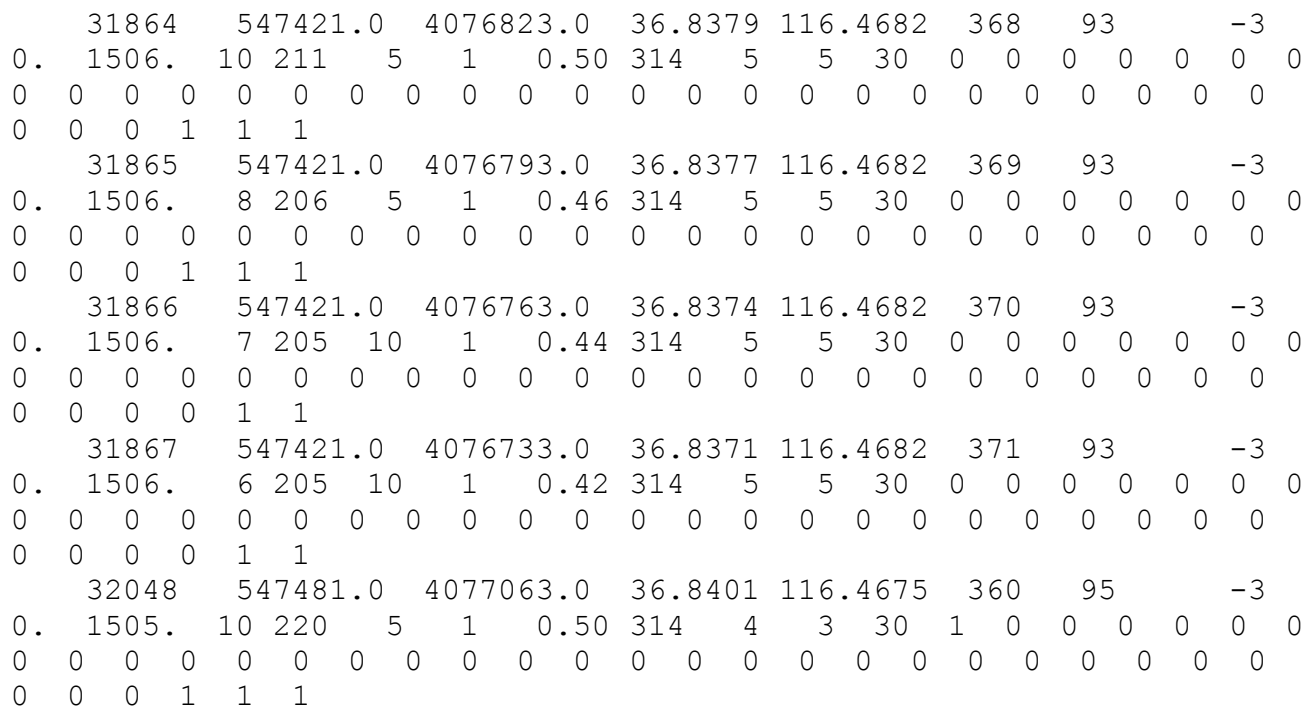




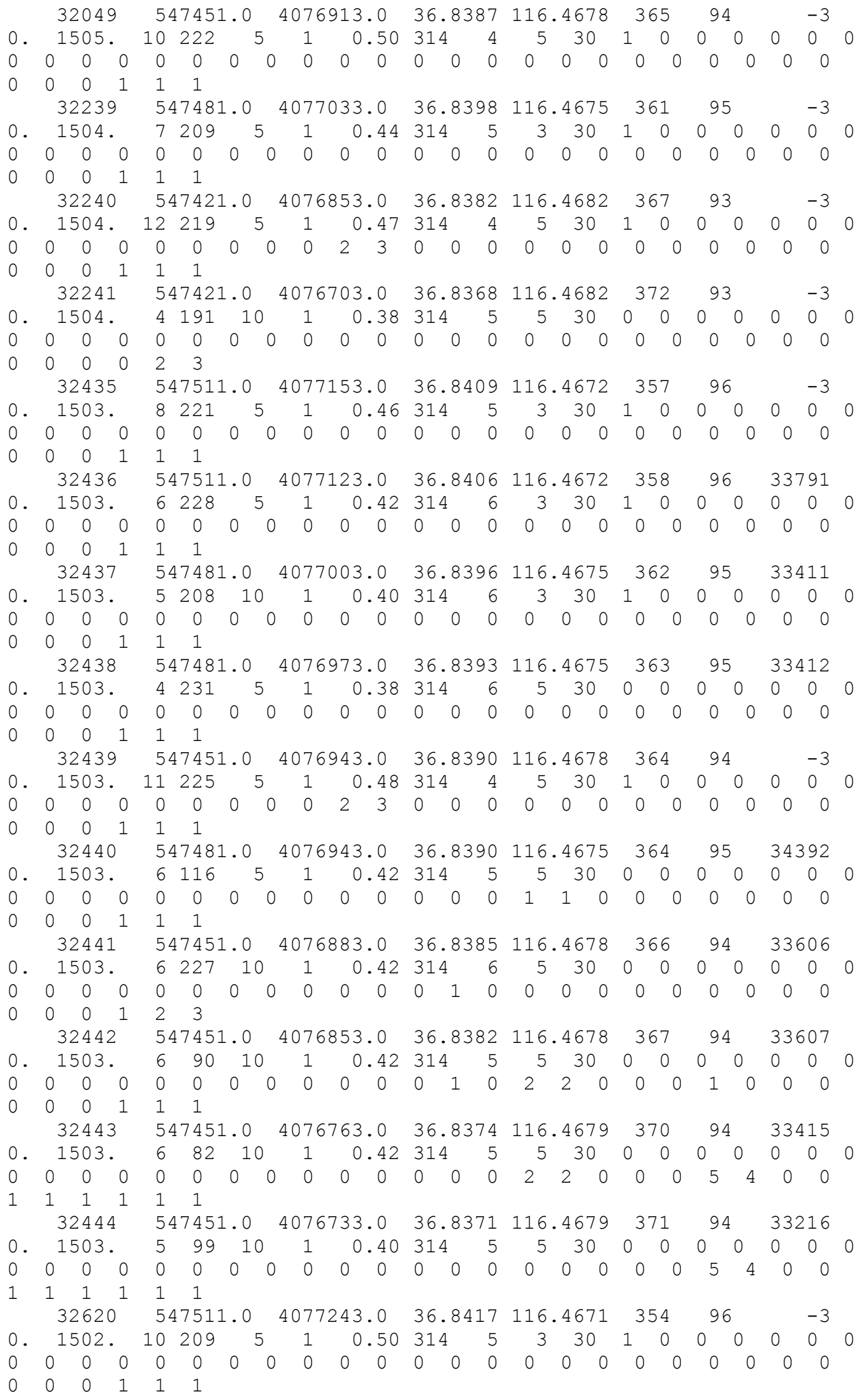


- Example listing of the output file, WT2.W20 created for the test case (only the last 20 lines of the file are shown). The fifth to last line (hi-lighted in red) is the watershed outflow cell identified in the control file with the coordinates 549,671 easting, 4,076,913 northing. The grid cell has 2,859 upstream cells (indicated in column 9) and routs surface water to cell number 121,694 (indicated in column 8), which is the grid cell identified by the last line of the file. Values of -3 in column 8 identify perimeter cells that are used only to define the boundary of the watershed. The seventh to last line (hi-lighted in blue) is the one grid cell upstream of the watershed outflow cell, and has 2,858 upstream cells.

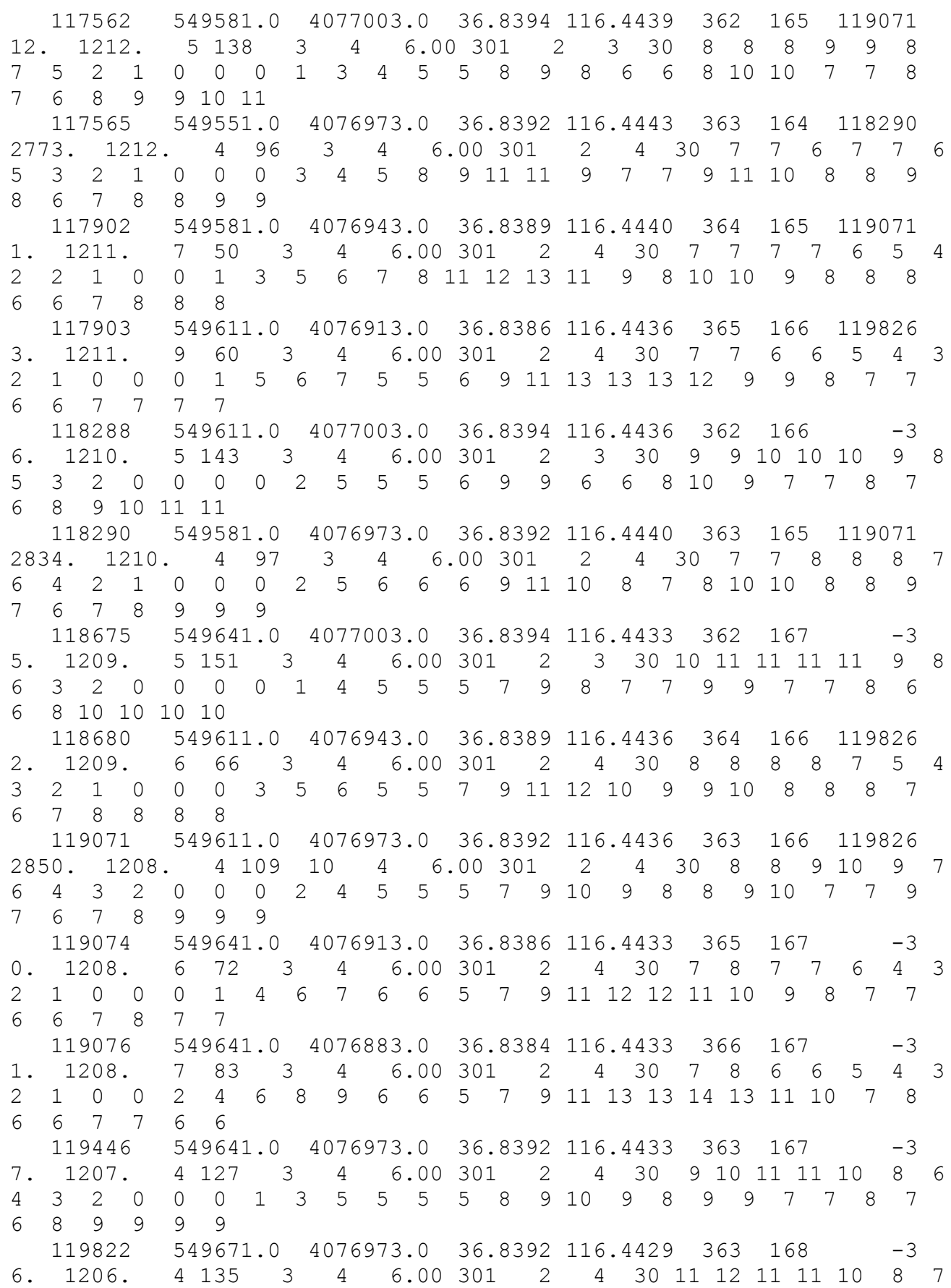




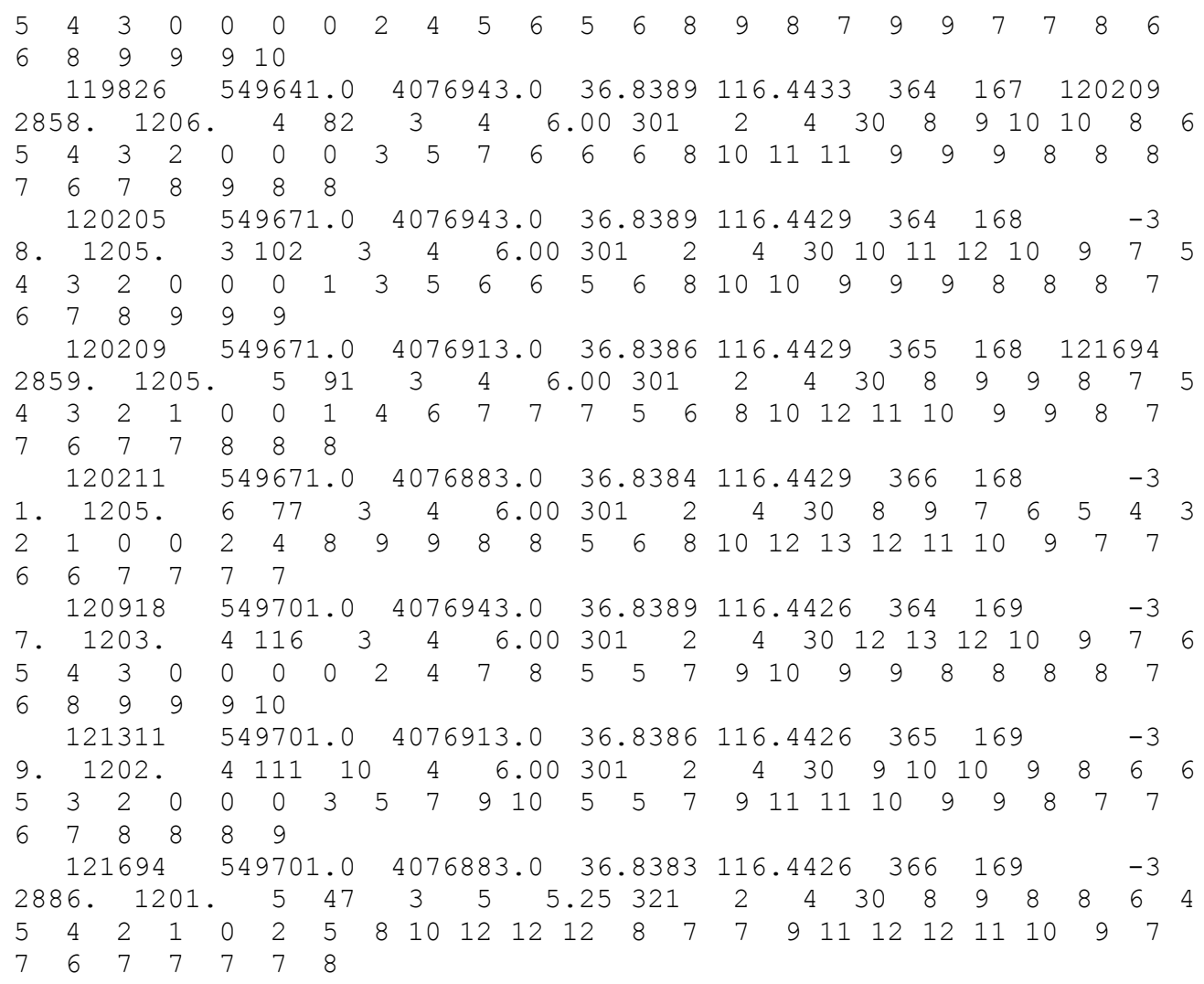

- Example listing of the output file, WT2.B20 created for the test case (only the first 26 lines are shown). This file indicates the easting and northing coordinates of the $\mathbf{2 8 2}$ perimeter cells defining the watershed boundary (all grid cells having a value of -3 in column 8 of the file, WT2.W20) and is used only to provide supporting information for the routine test plan.

$\begin{array}{lll}547421.0 & 4076823.0 & -3 \\ 547421.0 & 4076793.0 & -3 \\ 547421.0 & 4076763.0 & -3 \\ 547421.0 & 4076733.0 & -3 \\ 547481.0 & 4077063.0 & -3 \\ 547451.0 & 4076913.0 & -3 \\ 547481.0 & 4077033.0 & -3 \\ 547421.0 & 4076853.0 & -3 \\ 547421.0 & 4076703.0 & -3 \\ 547511.0 & 4077153.0 & -3 \\ 547451.0 & 4076943.0 & -3 \\ 547511.0 & 4077243.0 & -3 \\ 547481.0 & 4077093.0 & -3 \\ 547451.0 & 4076703.0 & -3 \\ 547511.0 & 4077213.0 & -3 \\ 547511.0 & 4077183.0 & -3 \\ 547451.0 & 4076973.0 & -3 \\ 547481.0 & 4076703.0 & -3 \\ 547511.0 & 4077273.0 & -3 \\ 547481.0 & 4077123.0 & -3 \\ 547451.0 & 4077003.0 & -3 \\ 547421.0 & 4076883.0 & -3 \\ 547451.0 & 4077033.0 & -3 \\ 547511.0 & 4077303.0 & -3\end{array}$




$\begin{array}{lll}547481.0 & 4076673.0 & -3 \\ 547541.0 & 4077363.0 & -3\end{array}$

\section{- Listing of source code for routine WATSHD20 V1.0:}

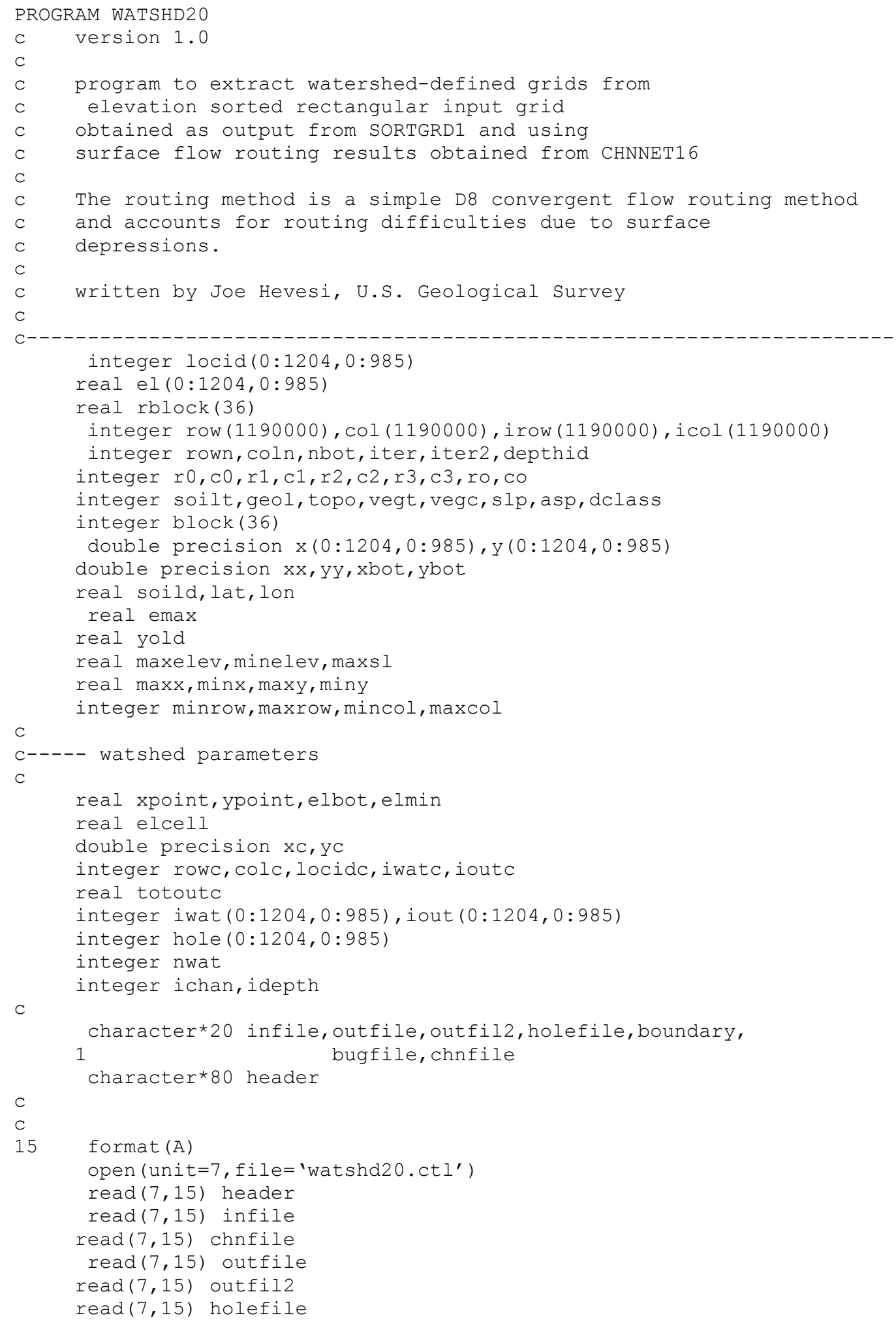




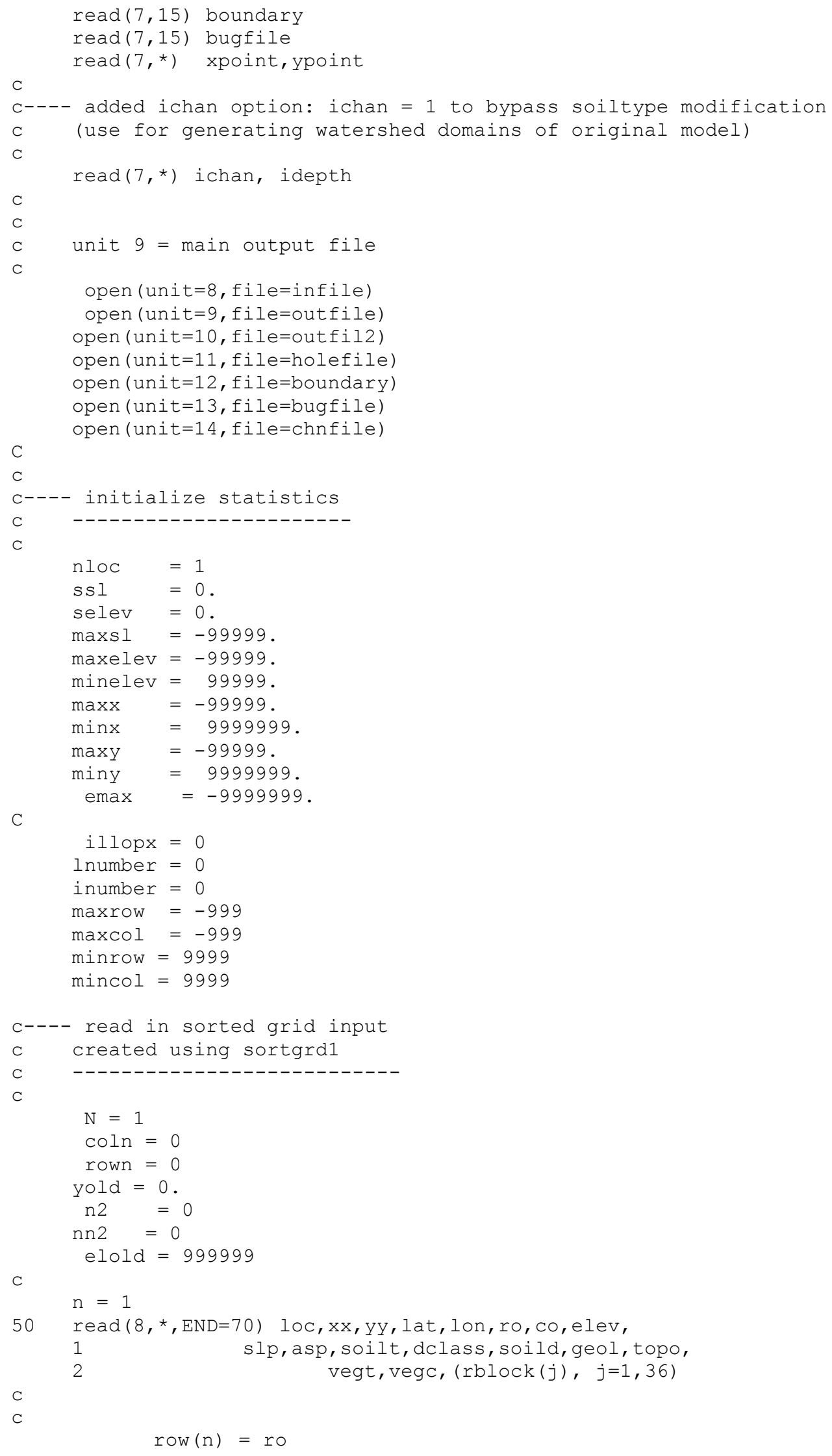




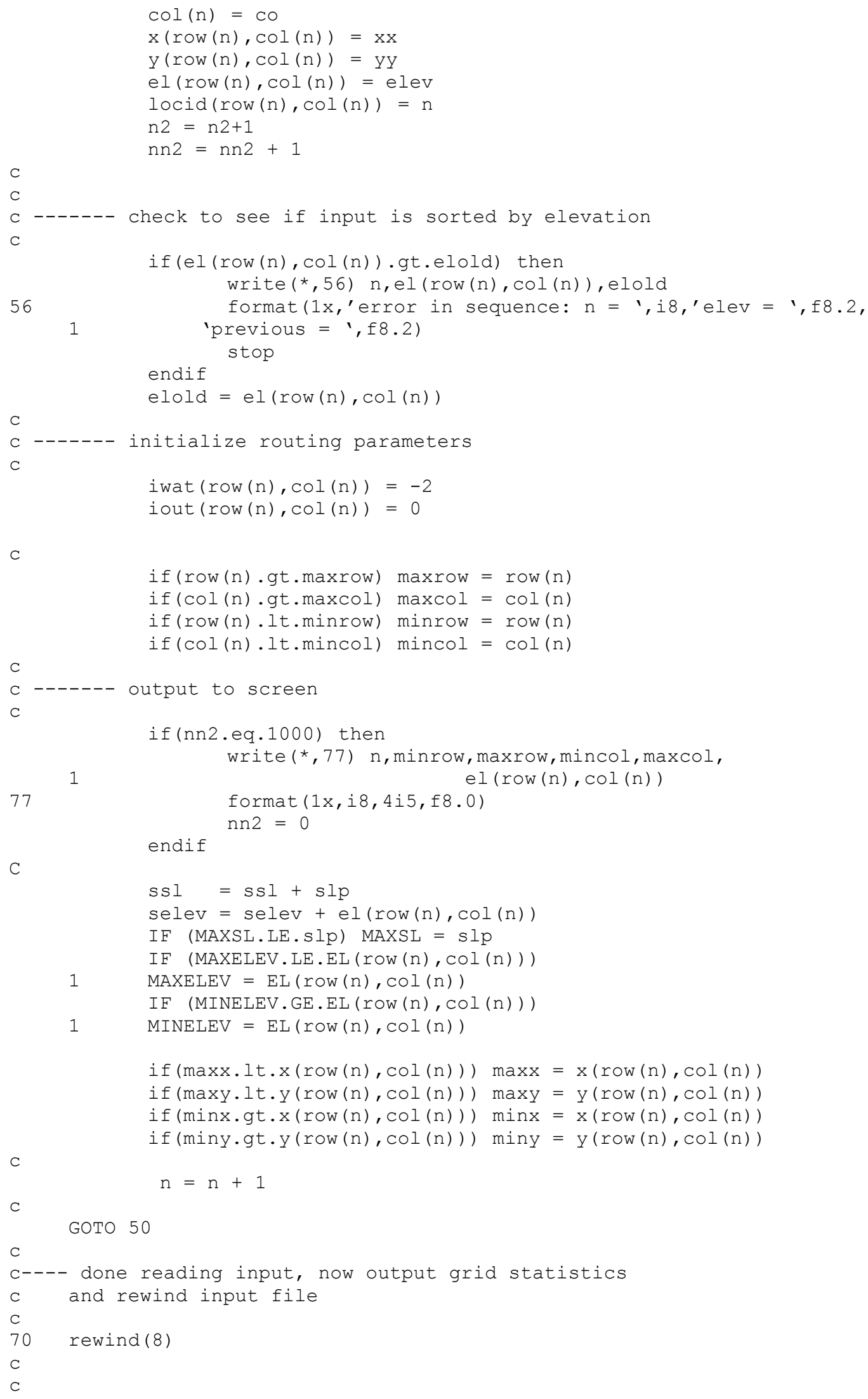




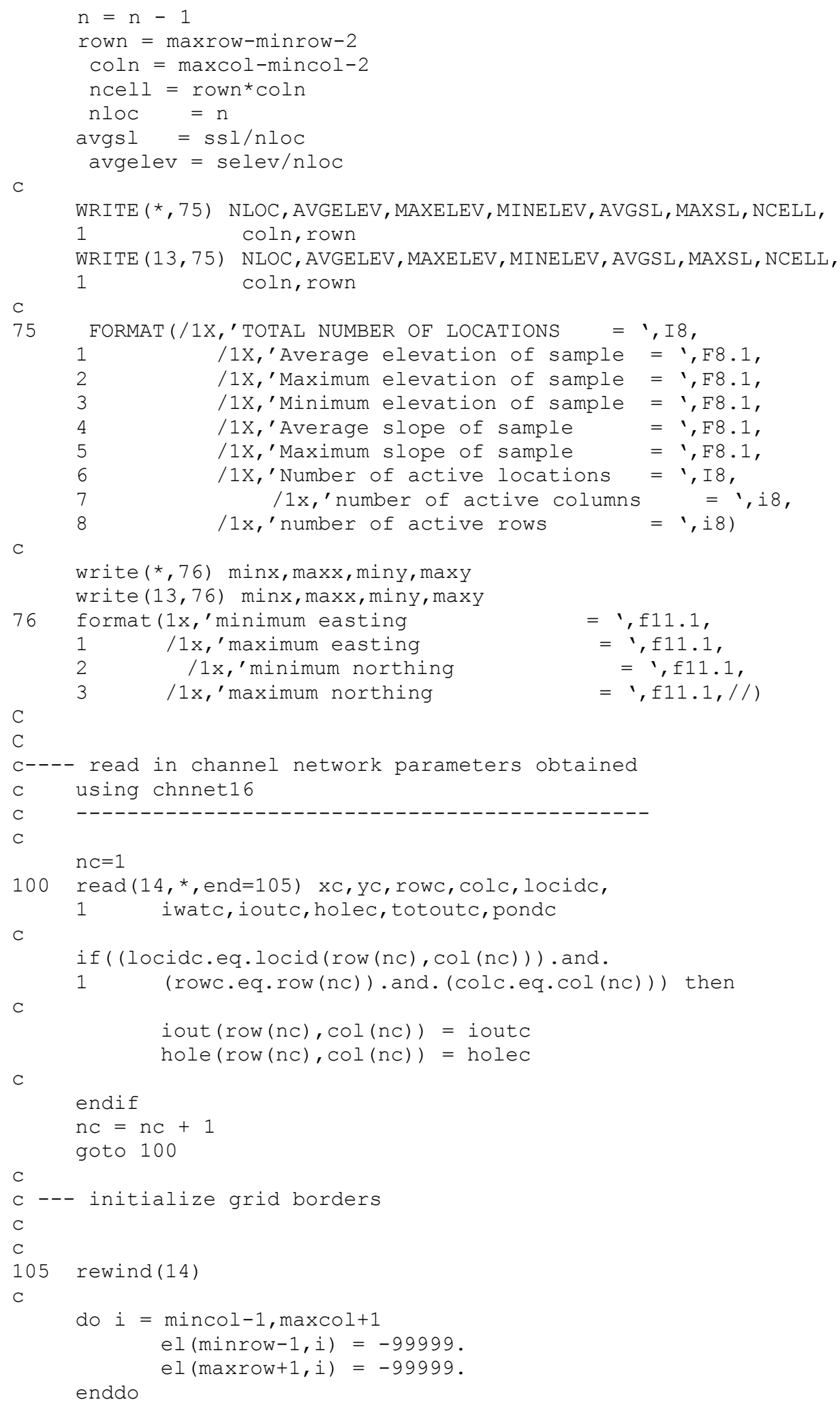


C

do $i=$ minrow -1, maxrow +1 el $(i, \operatorname{mincol}-1)=-99999$.

enddo el $(i, \operatorname{maxcol}+1)=-99999$.

$\mathrm{C}$

c---- find specified starting point

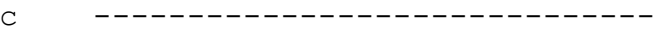

C

do $i=1$, nloc

if( (xpoint.ge.x(row(i), col (i))-15.) .and.

1 (xpoint.lt.x (row(i), col (i)) +15.$)$. and.

(ypoint.ge.y (row(i), col(i)) -15.). and.

(ypoint.lt.y(row(i), col(i))+15.)) then xbot $=x(r o w(i), \operatorname{col}(i))$

ybot $=y(r o w(i), \operatorname{col}(i))$ elbot $=$ el (row(i), col(i)) nbot $=i$

endif

enddo

C

$\mathrm{nw}=0$

C

write (*,300) xbot,

1 ybot, elbot,

2 locid(row (nbot), col (nbot)),

3 iout (row (nbot), col (nbot)),

4 iwat (row (nbot), col (nbot))

C

write $(13,300)$ xbot,

1 ybot, elbot,

2 locid(row (nbot), col (nbot)),

3 iout (row (nbot), col (nbot)),

4 iwat (row (nbot), col (nbot))

$\mathrm{C}$

c---- start uphill search from 1st point

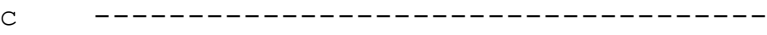

C

elmin $=$ elbot

nwat $=0$

$r 0=\operatorname{row}($ nbot $)$

$\mathrm{c} 0=\operatorname{col}(\mathrm{nbot})$

iwat $(r 0, \mathrm{c} 0)=0$

c ----- 1st loop for cells surrounding starting cell

$\mathrm{C}$

do 200 ir $=-1,1$

do 200 ic $=-1,1$

if (ir.eq.0.and.ic.eq.0) goto 200

C

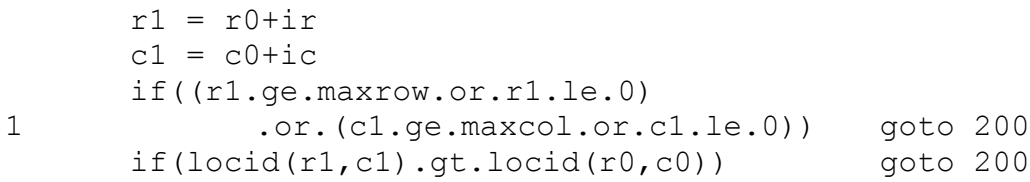




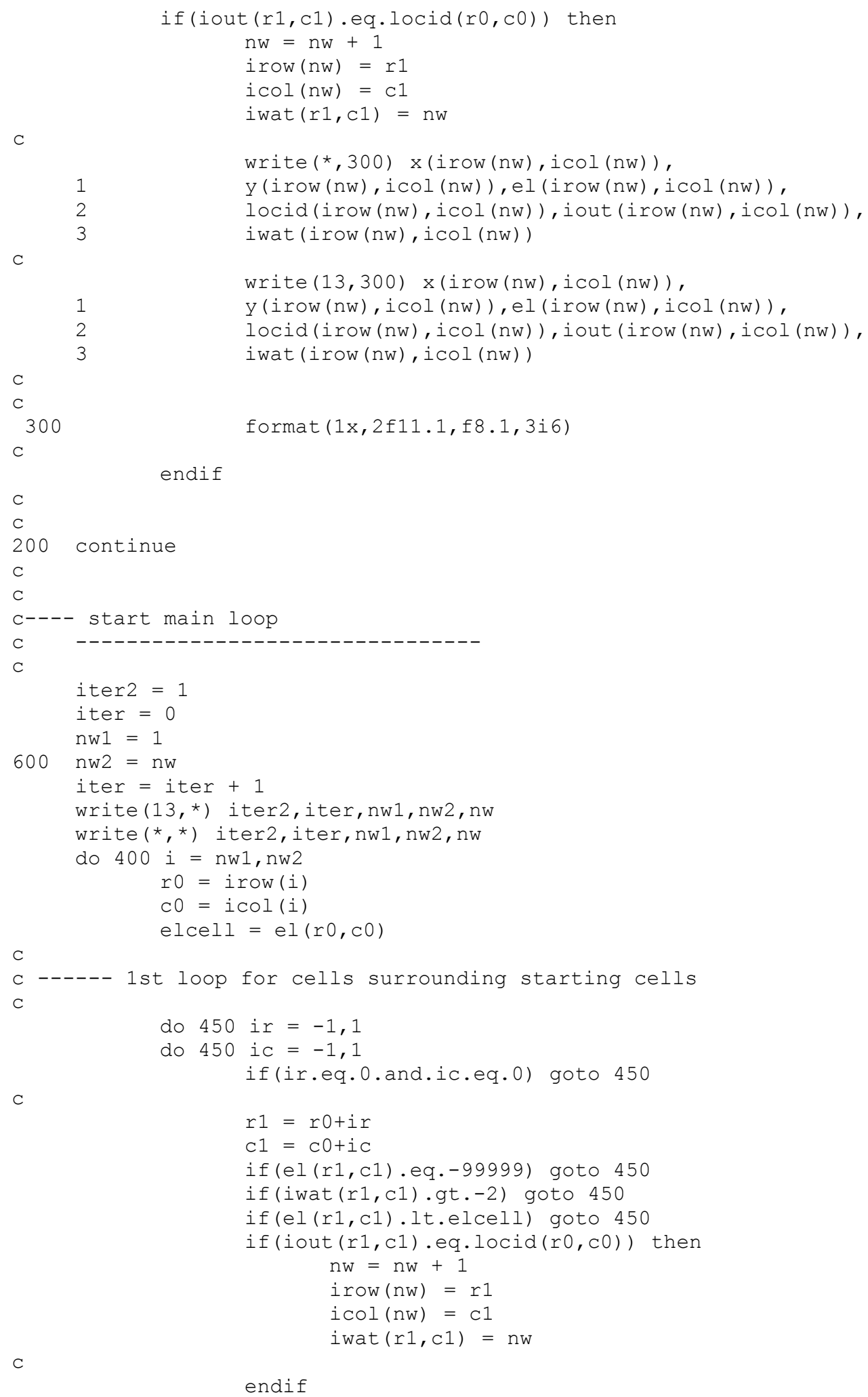




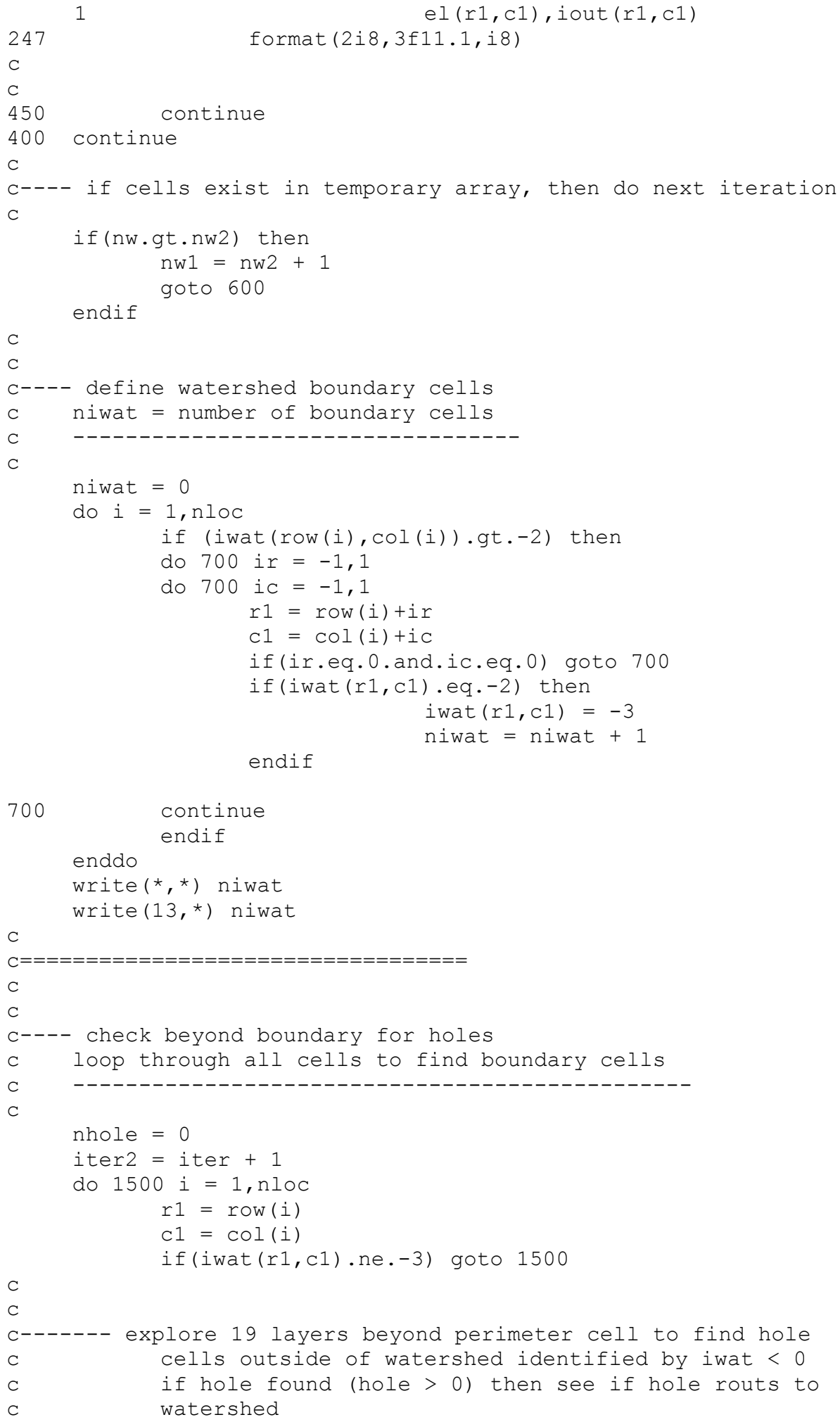


$\mathrm{C}$

C

$$
\text { do } 1000 j=1,19
$$

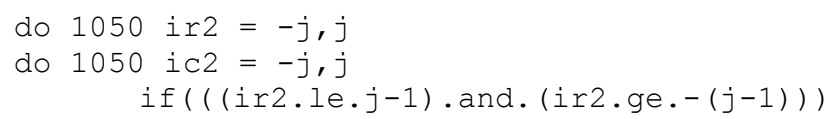
nhole $=$ nhole

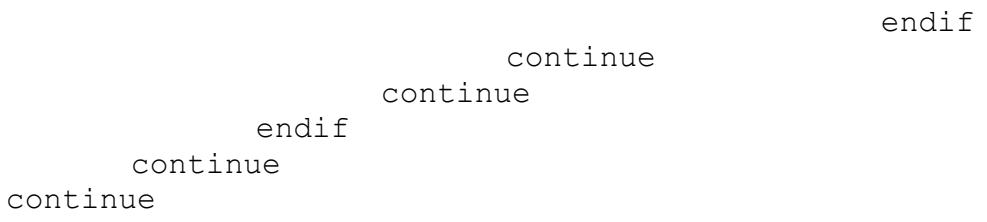

continue 


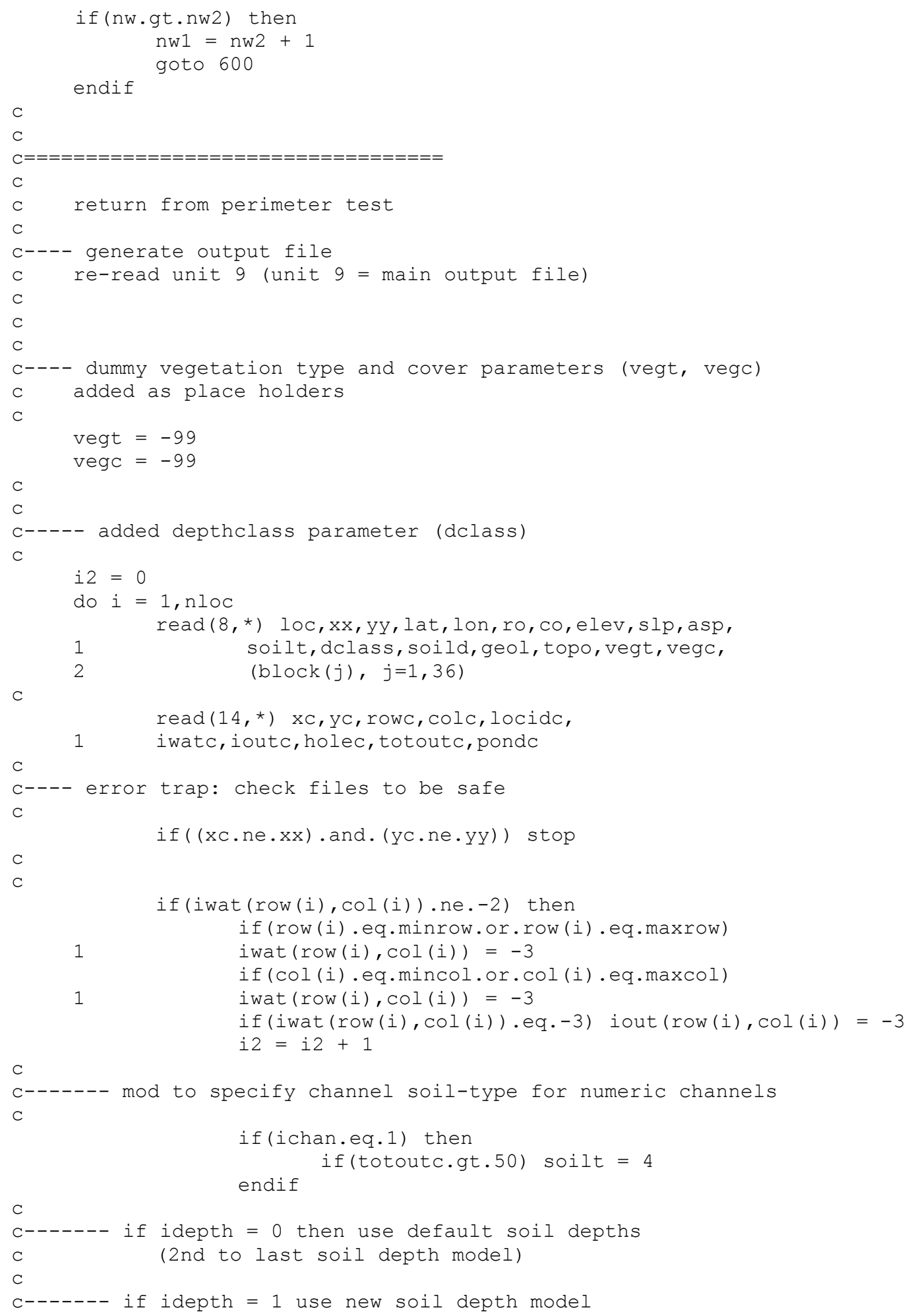




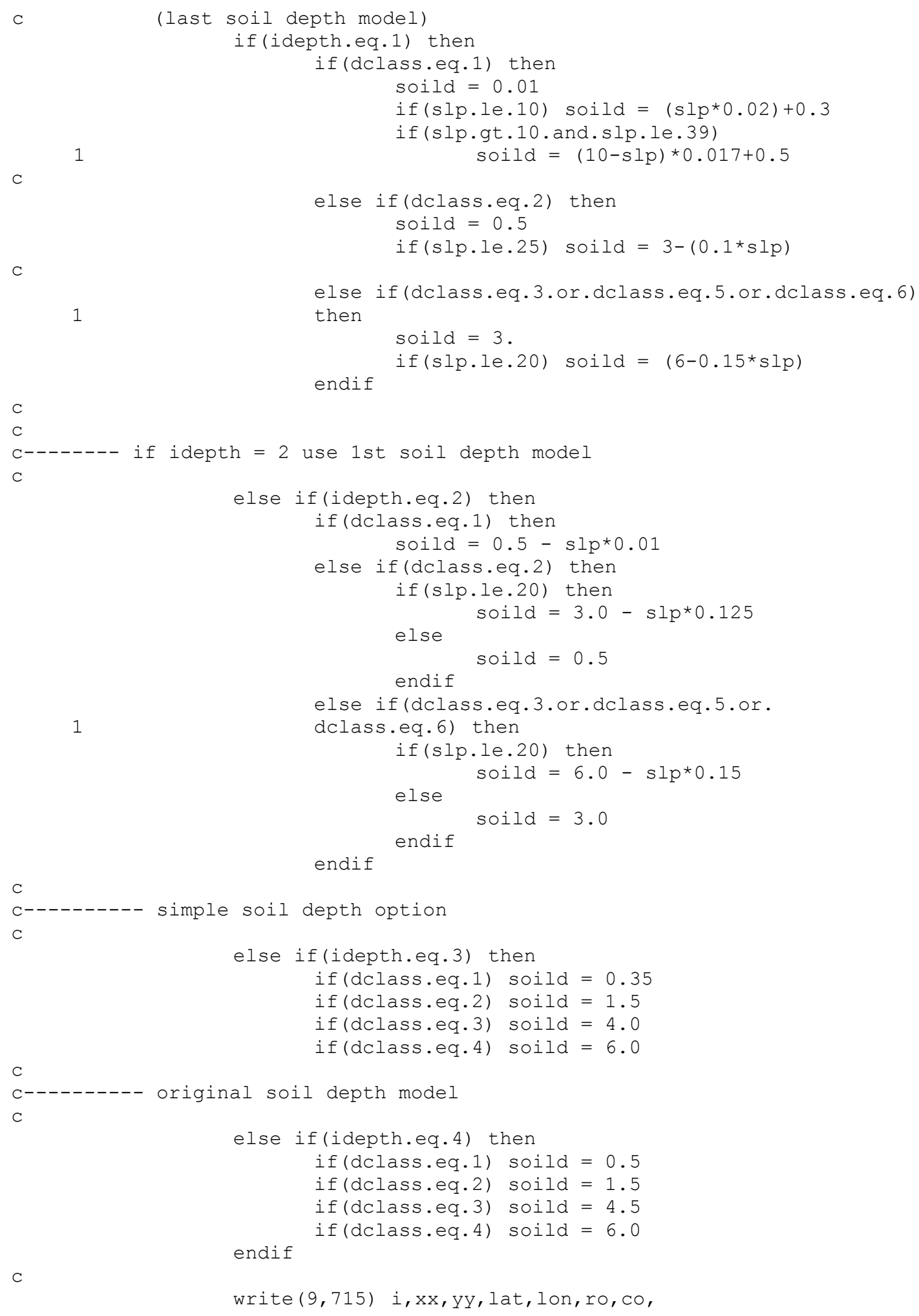




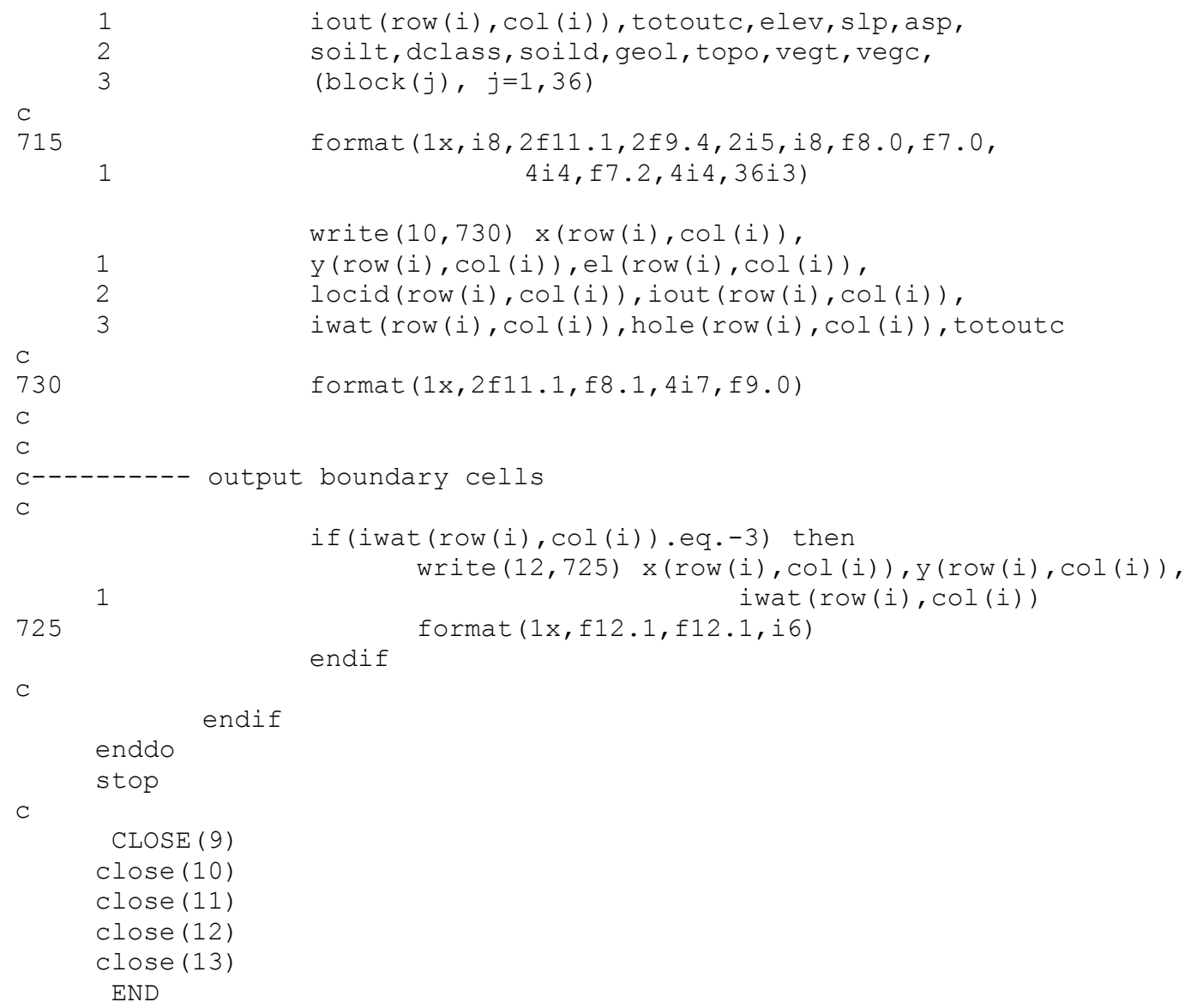




\section{INTENTIONALLY LEFT BLANK}


APPENDIX L

POSTPROCESSING OF MODEL RESULTS USING MAPADD20 V1.0 


\section{L1. NAME OF ROUTINE/MACRO WITH VERSION/OS/HARDWARE ENVIRONMENT AND USER INFORMATION}

Name of software routine: MAPADD20 V1.0, OS and hardware environment: Windows NT 4.0, Pentium Pro PC Computer Identification: SM321276 with a USGS specific host-name P720dcasr Software Users: Joseph Hevesi (916-278-3274), Alan Flint (916-278-3221) User Location: U.S. Geological Survey, Room 5000E, Placer Hall, 6000 J Street, Sacramento, CA 95819-6129

\section{L2. NAME OF COMMERCIAL SOFTWARE WITH VERSION/OS/HARDWARE USED TO DEVELOP ROUTINE/MACRO}

The source code for MAPADD20 V1.0 was developed using the standard FORTRAN77 programming language. The source code was written, debugged, and compiled (for PC platforms using INTEL processors) using DIGITAL Visual Fortran with Microsoft Developer Studio, V. 5.0 .

\section{L3. GENERAL DESCRIPTION OF ROUTINE/MACRO}

MAPADD20 V1.0 is a FORTRAN77 routine developed in accordance with AP-SI.1Q, specifically for the analysis/model activity documented in this report. The routine source code (MAPADD20.FOR), compiled executable file (MAPADD20.EXE), routine control file (MAPADD20.CTL), input and output files used for routine validation, supplemental files created as part of validation testing, and a copy of this appendix, are located under the directory MAPADD20 on a CD-ROM labeled POSTINF-1. The routine source code, control file, and the input and output files are ASCII text files that can be read using any standard ASCII text editor and can be imported into standard word processing applications such as Microsoft Word. The executable file can be used to run MAPADD20 V1.0 on any PC with an INTEL processor (with adequate RAM).

\section{L4. TEST PLAN FOR THE SOFTWARE ROUTINE MAPADD20 V1.0}

- Explain whether this is a routine or macro and describe what it does:

MAPADD20 is a post processing routine that uses output from INFIL V2.0 computer software (USGS 2000 [DIRS 139422]) to perform three tasks in the process of developing net-infiltration estimates for nine separate climate scenarios: (1) the routine averages results in files from individual simulations into a single result, (2) the routine adds together simulation files for several watersheds into single files, and (3) the routine compares selected files to determine the minimum net infiltration value among the files for a given grid block and produces a new file with the minimum net infiltration values for all grid blocks in the original files.

The specific rationale for these tasks is described in detail in the main document (Section 6.9). Briefly, task (1) is used to determine the average result of simulations run for several analogue sites that represent a given climate scenario, task (2) is used to combine results from individual watersheds into the entire composite watershed model domain, and task (3) is done to define the minimum 
net-infiltration estimates for the lower bound modern climate scenario by sampling the 1980-95 simulation, the 4JA 100-year stochastic simulation, and the driest (in terms of net infiltration) 10-year period within the 4JA 100-year simulation, which is 1980-1990.

\section{- Listing of FORTRAN77 Source code:}

A listing of the FORTRAN77 source code for the routine MAPADD20 V1.0 along with examples of the input and output files used in the test plan are included at the end of this appendix.

\section{- Description of test(s):}

To evaluate the accuracy of the functions performed by the routine, there are 3 test cases used to evaluate the accuracy of MAPADD20 in performing its expected calculations. Task (1) will use MAPADD20 to calculate an arithmetic mean of values of simulated net infiltration from two files. This will be verified for the values by calculating the final mean as (File1+File2)/2. Task (2) will be verified visually using maps of the individual watersheds and the final composite watershed model domain to evaluate if they occupy the same space. Task (3) will be evaluated by calculating a minimum with MAPADD20 using three input files of values and producing an output file. The input files and the output file will be imported into EXCEL and it will be determined for a selection of the data if the output value for a given grid block is the minimum value of the three input values for the grid block.

\section{- Specify the range of input values to be used and why the range is valid:}

For task (1) the routine needs to be able to compute an arithmetic mean and any range of data chosen from the simulated infiltration test for the evaluation is valid. For task (2) all of the ten watersheds are used to visually ascertain if the final composite watershed model domain is produced using MAPADD20. For task (3) the routine needs to be able to calculate a minimum value from a selection of values and any range of data chosen from simulated infiltration values is acceptable.

\section{L5. TEST RESULTS}

- Output from test (explain difference between input range used and possible input):

The acceptance criteria for the testing of MAPADD20 is that the output must provide for task (1), an accurate arithmetic mean to zero decimal places, for task (2) that a visual determination that the files of the 10 individual watersheds occupy the same space as the final composite file when illustrated graphically, and for task (3), that for a selection of values MAPADD20 accurately selects the minimum value. 
- Description of how the testing shows that the results are correct for the specified input:

If the testing results in output that conforms to the above criteria then the results are correct for the specified input.

- List limitations or assumptions to this test case and code in general:

Limitations to the developed test cases (1) and (3) consist of the selection only of a small number of values that are assumed to be representative of the entire data sets. However, the assumption of representativeness for text cases (1) and (3) is adequate for its intended use.

- Electronic files identified by name and location:

The following electronic files including MAPADD20 V1.0 and selected input and output files are provided:

MAPADD20.FOR: FORTRAN source code listing for the routine MAPADD20. A printout of the source code is included as part of this appendix.

MAPADD20.EXE: $\quad$ Executable file for the routine MAPADD20, compiled for INTEL processors.

Test Case for task (1): Input files SC2-MU1.504 and SC2-MU2.504 and output file, OUTPUT.TXT.

Test Case for task (3): Input files, YM1-X.4E4, 4JA1-X.4E4 and 4JA1-90.4E4 and output file, MODERN1.OUT.

\section{L6. TEST CASE FOR TASK (1): CALCULATION OF ARITHMETIC MEAN}

Comparison between input file SC2MU1.504 and output file OUTPUT.TXT indicates that values for corresponding grid block locations match, suggesting that the routine MAPADD20 correctly performs the specified function.

\section{L7. TEST CASE FOR TASK (2)}

A good match between the boundaries for the 10 watersheds used as input to MAPADD20 and the final boundary of the composite model domain as produced by MAPADD20, indicating a successful verification of routine function for this task.

\section{L8. TEST CASE FOR TASK (3)}

This test case uses files as input to MAPADD20 that are output files from INFIL simulating infiltration. The net infiltration column, along with the easting and northing grid block location for each file, were extracted from the files that were used as input to MAPADD20. The minimum infiltration value was chosen for the three input files for each grid block location. This value is then compared to the net-infil column extracted from the output file from MAPADD20 
for the same grid block locations. The values match exactly, indicating a successful routine function for this task.

\section{L9. LISTING OF SOURCE CODE FOR MAPADD20 V1.0}

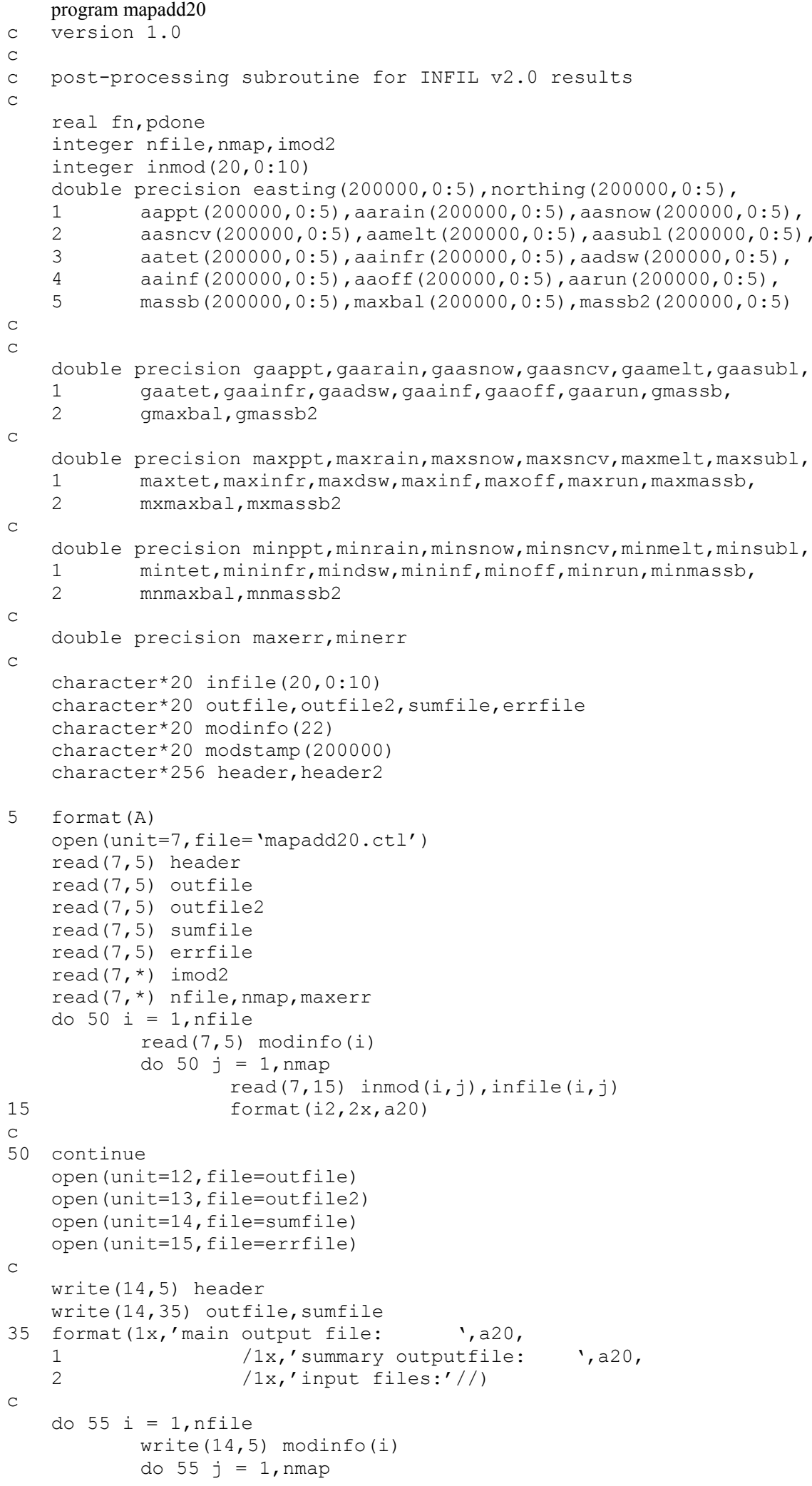




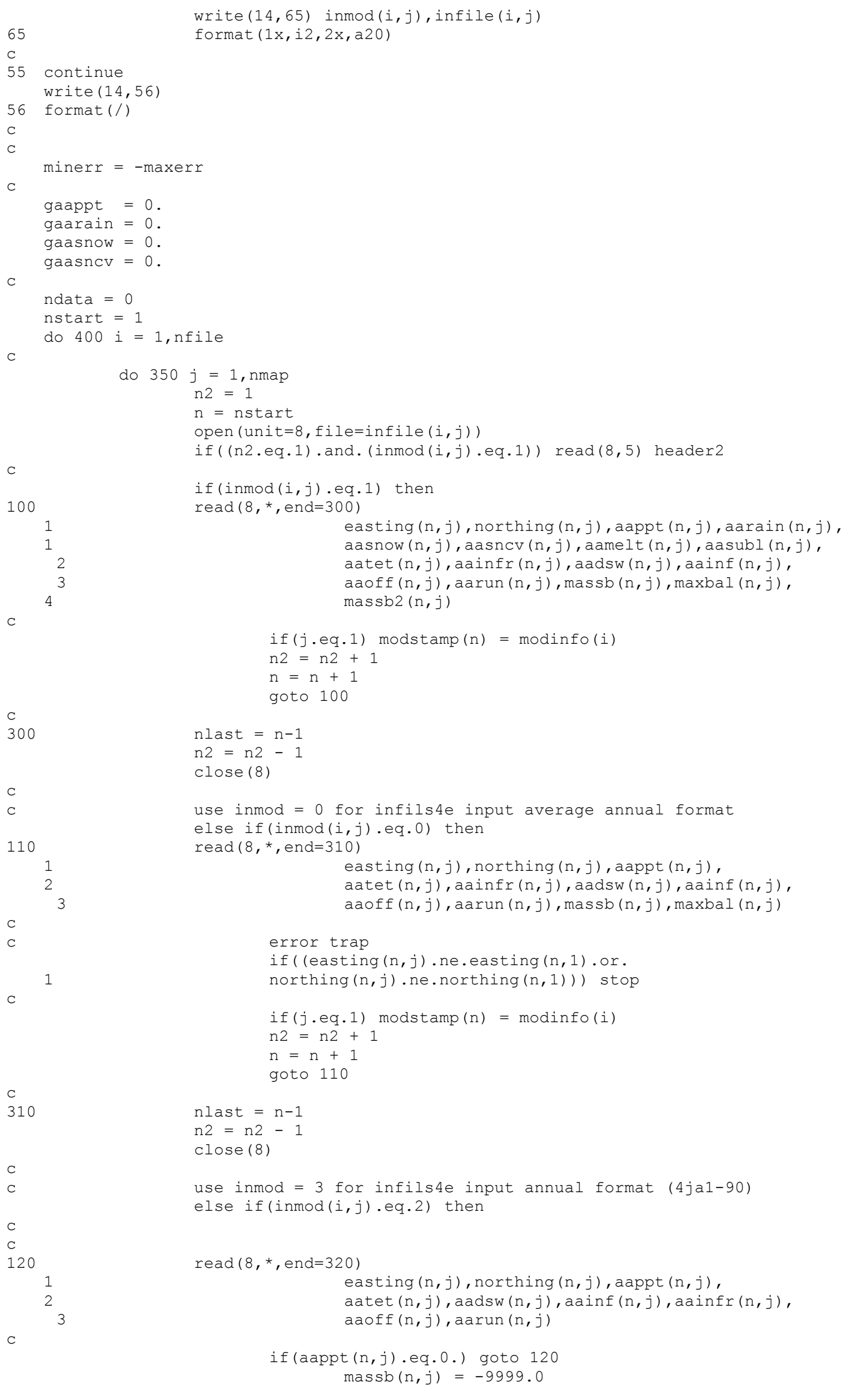




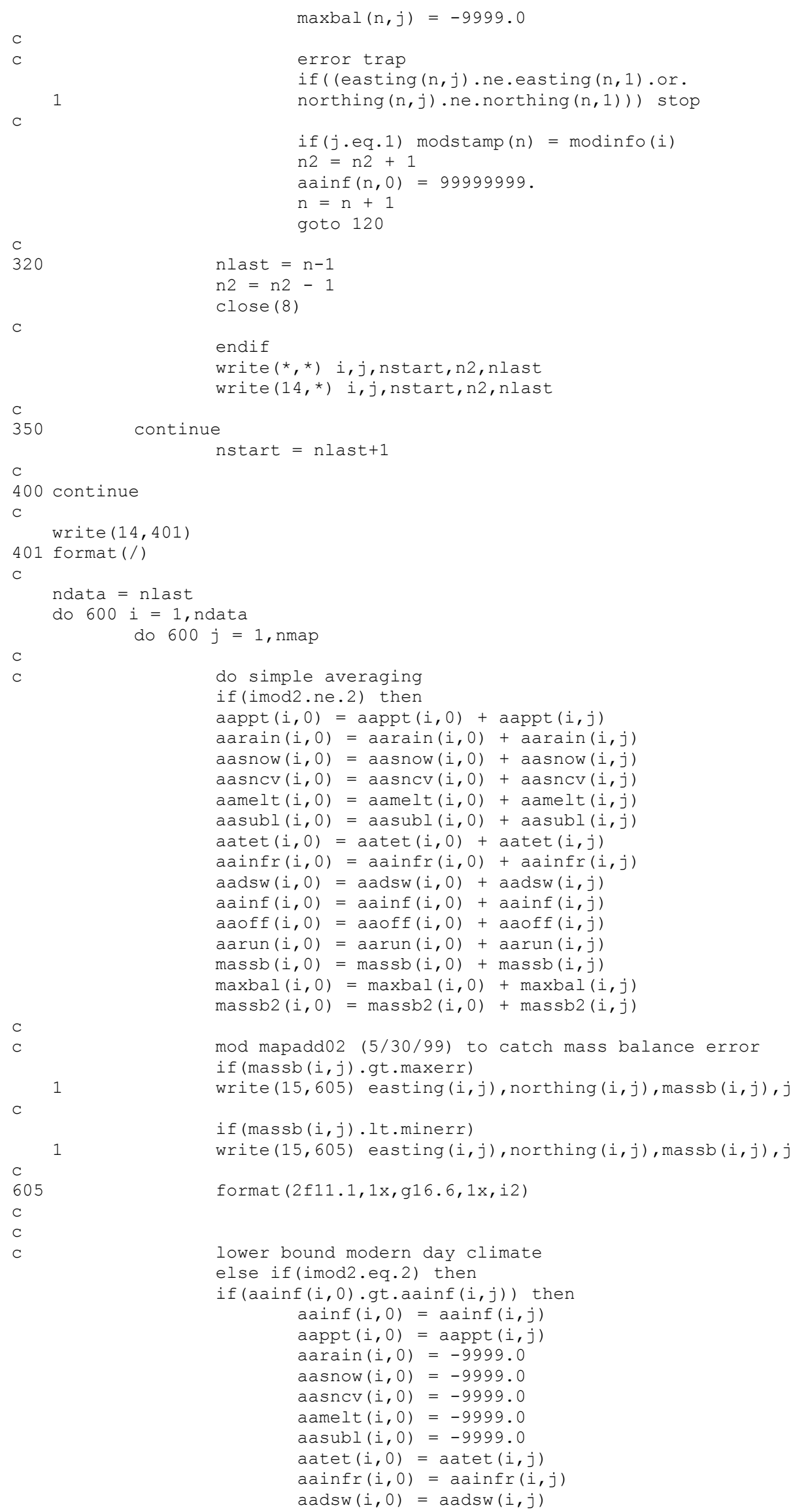




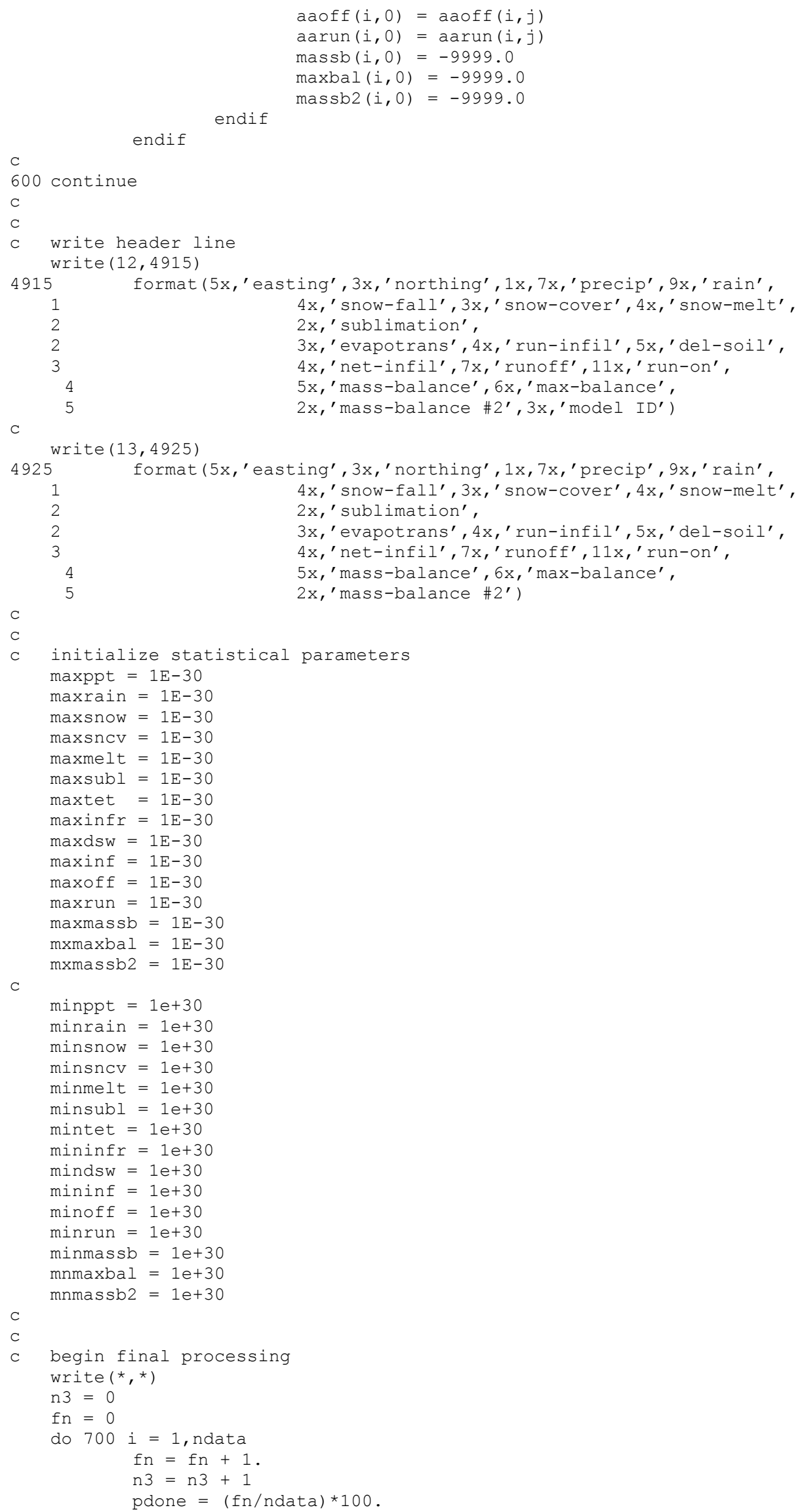




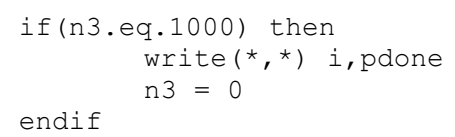

endif

if (aappt $(i, 0) \cdot g t \cdot m a x p p t)$ maxppt $=\operatorname{aappt}(i, 0)$ if (aarain( $i, 0) \cdot g t$.maxrain) maxrain = aarain $(i, 0)$ if (aasnow $(i, 0) \cdot g t$ maxsnow) maxsnow $=$ aasnow $(i, 0)$ if (aasncv $(i, 0) \cdot g t \cdot \operatorname{maxsncv})$ maxsncv $=\operatorname{aasncv}(i, 0)$ if (aamelt $(i, 0) \cdot g t \cdot$ maxmelt) maxmelt $=\operatorname{aamelt}(i, 0)$ if (aasubl $(i, 0) \cdot g t \cdot$ maxsubl) maxsubl $=$ aasubl $(i, 0)$ if (aatet $(i, 0) \cdot g t \cdot$ maxtet $)$ maxtet $=\operatorname{aatet}(i, 0)$ if (ainfr( $i, 0) \cdot g t \cdot \operatorname{maxinfr})$ maxinfr $=\operatorname{aainfr}(i, 0)$ if $(\operatorname{aadsw}(i, 0) \cdot g t \cdot \operatorname{maxdsw}) \operatorname{maxdsw}=\operatorname{aadsw}(i, 0)$ if $(\operatorname{aainf}(i, 0) \cdot g t \cdot \operatorname{maxinf}) \operatorname{maxinf}=\operatorname{aainf}(i, 0)$ if $(\operatorname{aaoff}(i, 0) \cdot g t \cdot \operatorname{maxoff})$ maxoff $=\operatorname{aaoff}(i, 0)$ if (aarun $(i, 0) \cdot g t \cdot$ maxrun) maxrun $=\operatorname{aarun}(i, 0)$ if (massb $(i, 0) \cdot g t \cdot \operatorname{maxmassb})$ maxmassb $=\operatorname{massb}(i, 0)$ if $(\operatorname{maxbal}(i, 0) \cdot g t \cdot m x m a x b a l)$ mxmaxbal $=\operatorname{maxbal}(i, 0)$ if $($ massb2 $(i, 0) \cdot g t \cdot m x m a s s b 2) \operatorname{mxmassb2}=\operatorname{massb} 2(i, 0)$

if (aappt $(i, 0) \cdot$ lt.minppt) minppt $=\operatorname{aappt}(i, 0)$ if (aarain $(i, 0)$.lt.minrain) minrain = aarain $(i, 0)$ if (aasnow $(i, 0)$.lt.minsnow) minsnow = aasnow $(i, 0)$ if (aasncv $(i, 0) \cdot l t \cdot \operatorname{minsncv})$ minsncv $=\operatorname{aasncv}(i, 0)$ if (aamelt $(i, 0) . l t \cdot m i n m e l t)$ minmelt $=\operatorname{aamelt}(i, 0)$ if $(\operatorname{aasubl}(i, 0) \cdot 1 t \cdot$ minsubl $)$ minsubl $=$ aasubl $(i, 0)$ if $($ aatet $(i, 0) . l t . m i n t e t)$ mintet $=\operatorname{aatet}(i, 0)$ if (aainfr( $i, 0) \cdot$ lt.mininfr) mininfr $=\operatorname{aainfr}(i, 0)$ if $(\operatorname{aadsw}(i, 0)$.lt.mindsw) mindsw $=\operatorname{aadsw}(i, 0)$ if $(\operatorname{aainf}(i, 0) \cdot$ lt.mininf $)$ mininf $=\operatorname{aainf}(i, 0)$ if $(\operatorname{aaoff}(i, 0) \cdot$ lt.minoff $)$ minoff $=\operatorname{aaoff}(i, 0)$ if (aarun( $(i, 0) . l t \cdot m i n r u n)$ minrun $=\operatorname{aarun}(i, 0)$ if (massb $(i, 0) \cdot$ lt.minmassb) minmassb $=\operatorname{massb}(i, 0)$ if $(\operatorname{maxbal}(i, 0) \cdot l t \cdot \operatorname{mnmaxbal})$ mnmaxbal $=\operatorname{maxbal}(i, 0)$

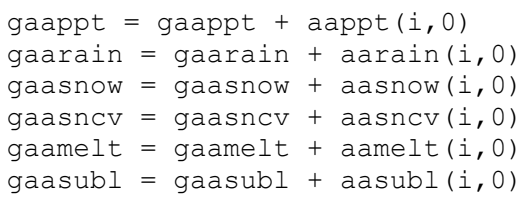




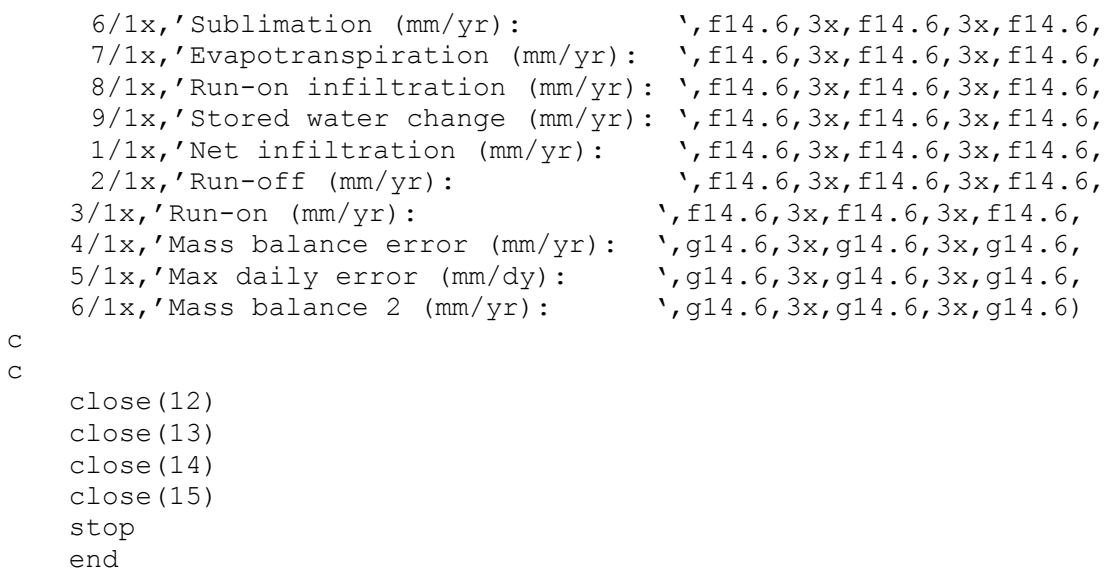


APPENDIX M

POSTPROCESSING OF MODEL RESULTS USING MAPSUM01 V1.0 


\section{M1. NAME OF ROUTINE/MACRO WITH VERSION/OS/HARDWARE ENVIRONMENT AND USER INFORMATION}

Name of software routine: MAPSUM01 V1.0

OS and hardware environment: Windows NT 4.0, Pentium Pro PC

Computer Identification: SM321276 with a USGS specific host-name P720dcasr

Software Users: Joseph Hevesi (916-278-3274), Alan Flint (916-278-3221)

User Location: U.S. Geological Survey, Room 5000E, Placer Hall, 6000 J Street, Sacramento, CA 95819-6129

\section{M2. NAME OF COMMERCIAL SOFTWARE WITH VERSION/OS/HARDWARE USED TO DEVELOP ROUTINE/MACRO}

The source code for MAPSUM01 V1.0 was developed using the standard FORTRAN77 programming language. The source code was written, debugged, and compiled (for PC platforms using INTEL processors) using DIGITAL Visual Fortran with Microsoft Developer Studio, V. 5.0 .

M3. TEST PLAN.

- Explain whether this is a routine or macro and describe what it does:

The software routine, MAPSUM01 V1.0, is a FORTRAN77 routine developed in accordance with AP-SI.1Q, Section 5.1.12, specifically for the analysis/model activity documented in this report. The documentation provided in this appendix is used to satisfy software quality assurance requirements for software routines as defined under AP-SI.1Q.

MAPSUM01 V1.0 is a FORTRAN routine developed to calculate simple summary statistics for results obtained from the postprocessing routine MAPADD20 V1.0 [which is a postprocessing routine for results obtained using INFIL V2.0 (USGS 2000 [DIRS 139422])]. The summary statistics are calculated for the subset of grid cells located within areas defined by SURFER V6.04 output files. The results from these calculations are included in tables in the report that are used to compare the results obtained for the various different climate scenarios.

The SURFER V6.04 output files consist of masked raster-based grid files with the masked areas defined by vector-based irregular boundary lines that are imported into the SURFER V6.04 grid utility application using the standard boundary line file format (*.bln format) under the GRID/BLANK menu option. The masked grid is created by importing the geospatial input parameter base grid into SURFER V6.04 and creating a new master grid based on ground surface elevation. In all cases, the developed SURFER V6.04 master grid file is used only to define the grid cell coordinates for the masking process and is equivalent to the base grid used to define the geospatial parameter input files (Appendices G through $\mathrm{N}$ ). To complete the masking process, the base grid is combined with the imported boundary line and all grid cells located outside of the closed boundary are flagged with the standard default null value used by SURFER V6.04 
(1.70141E+038). The masked grid is exported as an xyz column formatted ASCII text file (the values of the non-masked z-values are irrelevant). Using the masked grid as a template for identifying the grid cells located within the area defined by the boundary line file specified in SURFER V6.04, MAPSUM01 V1.0 calculates a set of $1^{\text {st }}$-order summary statistics for all the water balance terms (precipitation, evapotranspiration, change in root-zone water content, runoff, run-on, net infiltration). The grid cell coordinates and the water balance terms are obtained from the input file created by the postprocessing of the INFIL V2.0 results using the routine MAPADD20 V1.0. The water balance terms have units of millimeters/year.

For the application of MAPSUM01 used in this report, summary statistics were calculated for two different subareas defined by boundary line files imported into SURFER V6.04: the Site-Scale Unsaturated Zone Flow and Transport model area and the repository area.

The functions of MAPSUM01 V1.0 are executed using a single routine control file named MAPSUM01.CTL. The file defines the input and output file names, and specifies a distance tolerance parameter, in units of meters. The distance tolerance parameter (set to $10.0 \mathrm{~m}$ in all applications of MAPSUM01 used in this report) is needed to compensate for differences in the precision of raster grid coordinates used by SURFER V6.04 relative to the precision of the input grid defined by the geospatial input parameter base grid discussed in section 6.5 of this report. The two input files listed consist of the masked SURFER grid (either uzmod2.dat or repos8.dat) saved using the ASCII xyz column formatted option and the final output file created by MAPADD20 consisting of the developed net infiltration estimates for one of the nine climate scenarios (for example, glacialu.dat or modernl.dat)

The routine source code, compiled executable file, example input and output files, and example validation test files are located under the directory MAPSUM01 on the CD-ROM labeled POSTINF-1.

\section{- Source code: (including equations or algorithms from software setup (LabView, Excel, etc.):}

A listing of the FORTRAN77 source code for the routine MAPSUM01 V1.0 along with examples of the input and output files used in the test plan are included at the end of this appendix.

\section{- Description of test(s):}

To evaluate the accuracy of the routine calculations and output, a test calculation was performed. The test involves determining whether the summary statistics calculated using the routine are correct. A test was completed using an input file (Glacialm.dat) and a boundary file (REPOS8.BLN). For the first part of the test, the auxiliary output file created by MAPSUM01, GM-REP8.MAP, was imported into the EXCEL worksheet MAPSUM01.XLS and the summary statistics (average, maximum, and minimum values) were calculated using functions in EXCEL (AVERAGE, MAX, MIN). The calculated 
results were compared against the results listed in the output file, GM-REP8.SUM. For the second part of the test, SURFER V6.04 was used to create a masked grid output file called Netinfilb.dat. The file was creating using the same technique described in section 2 above. GLACIALM.DAT was combined with the imported boundary line (REPOS8.BLN) and all grid cells located outside of the closed boundary were flagged with the standard default null value used by SURFER V6.04. The masked grid was exported as an xyz column formatted ASCII text file (NETINFILB.DAT). The data included in the exported file (NETINFILB.DAT) includes northing, easting, and net infiltration. NETINFILB.DAT was imported into MAPSUM01.XLS and summary statistics for net infiltration were calculated using EXCEL commands (AVERAGE, MAX, MIN). In both test cases, if the values calculated in MAPSUM01.XLS were found to be within the acceptance criteria defined as + or -0.01 , then the routine correctly calculated the summary statistics.

\section{- Specify the range of input values to be used and why the range is valid:}

The range of input values to be used is equivalent to the range of output values calculated by INFIL V2.0. There are no criteria for the range of input values.

\section{M4. TEST RESULTS}

\section{- Output from test:}

The output from the test is located in attached file, MAPSUM01.XLS. This file is too large to be included in the appendix as a printed table.

\section{- Description of how the testing shows that the results are correct for the specified input:}

The sequence of calculations performed using MAPSUM01 is very basic and were easily compared to calculations performed by EXCEL. Summary statistics were calculated in the EXCEL worksheet MAPSUM01.XLS using the auxiliary output file, GM-REP8.MAP. The calculated statistics exactly matched the output in the summary file, GM-REP8.SUM. The summary statistics (average, maximum, and minimum values) for net infiltration were also calculated in MAPSUM01.XLS using a manually extracted subset of the grid cells located within the boundary defined by REPOS8.BLN. The calculated statistics were found to be within the output values in GM-REP8.SUM and were found to be within the acceptance criteria defined as + or -0.01 .

\section{- List limitations or assumptions to this test case and code in general:}

Limitations are only those inherent in the input files, and in the ability of the reviewer to determine if the summary statistics calculated using EXCEL are within the acceptance criteria. 
- Electronic files identified by name and location (include disc if necessary):

Electronic files are located on CD-ROM labeled POSTINF-1, under the directory MAPSUM01, included as an Appendix to the report. The following electronic files are provided:

REPOS8.BLN: $\quad$ boundary line file for the repository area

REPOS8.DAT: $\quad$ Masking file creating by SURFER V6.04

GLACIALM.DAT: input file used to create Netinfilb.dat

GM-REP8.SUM: $\quad$ MAPSUM01 output file with summary statistics.

GM-REP8.MAP: $\quad$ subset of results extracted from the input file, GLACIALM.DAT using the SURFER V6.04 masking file, REPOS8.DAT. This file is created as an auxiliary output file and is used as part of the test plan.

NETINFILB.DAT: $\quad$ the masked file used to test summary statistic calculations

MAPSUM01.XLS: $\quad$ the EXCEL file used to calculate summary statistics

M5. SUPPORTING INFORMATION. INCLUDE BACKGROUND INFORMATION, SUCH AS REVISION TO A PREVIOUS ROUTINE OR MACRO, OR EXPLANATION OF THE STEPS PERFORMED TO RUN THE SOFTWARE. INCLUDE LISTINGS OF ALL ELECTRONIC FILES AND CODES USED

\section{- Procedure for running routine:}

To run the routine, MAPSUM01 V1.0, the executable file (MAPSUM01.EXE), the routine control file (MAPSUM01.CTL), and the input files specified in the routine control file (REPOS8.DAT and GLACIALM.DAT) must be placed in the same directory. The routine is executed by typing MAPSUM01 in a DOS window or by double clicking on the file, MAPSUM01.EXE in the Microsoft Windows operating system, or by typing in the path and filename in the RUN window of the Windows NT or Windows 98 start menu. The input and output file names must be in the correct sequential order as specified in the routine control file (see example listing below).

- Example listing of routine control file, MAPSUM01.CTL

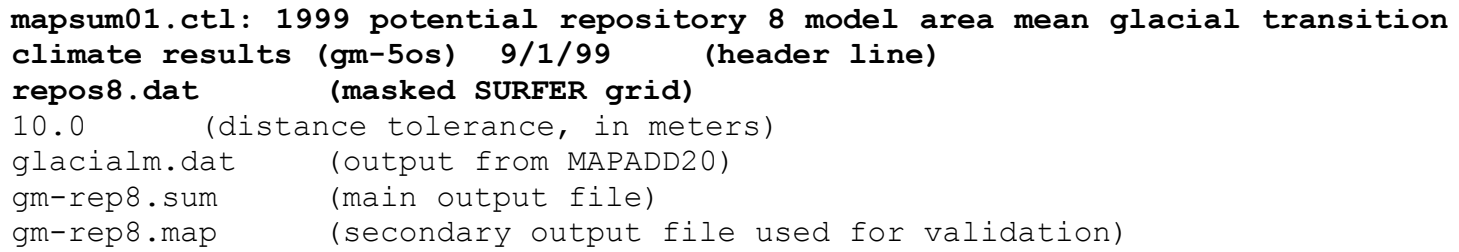


- Example listing of input file, GLACIALM.DAT developed as output from MAPADD20 V1.0 (Appendix L). Only the first 10 lines of the file are listed.

\begin{tabular}{|c|c|c|c|c|c|}
\hline $\begin{array}{c}\text { easting } \\
\text { snow-melt si }\end{array}$ & $\begin{array}{r}\text { northing } \\
\text { blimation }\end{array}$ & $\begin{array}{l}\text { precip } \\
\text { vapotrans }\end{array}$ & $\underset{n-i n f i l}{\operatorname{rain}}$ & $\begin{array}{l}\text { snow-fall } \\
\text { del-soil }\end{array}$ & $\begin{array}{l}\text { snow-cover } \\
\text { net-infil }\end{array}$ \\
\hline unoff & run-on & mass-balance & $\max -b a$ & lance & s-balance \#2 \\
\hline 546521.0 & 4083693.0 & 368.26735 & 237.21505 & 131.05230 & 6014.18170 \\
\hline 11.78057 & 18.73772 & 295.42480 & 0.00000 & 1.64116 & 8.36099 \\
\hline 3.56865 & 0.000000 & $-0.1900702 \mathrm{E}-1$ & -0.5748 & $180 E-13$ & $0.4144834 \mathrm{E}-12$ \\
\hline 546491.0 & 4083693.0 & 368.13263 & 237.12826 & 131.00436 & 5982.74314 \\
\hline 11.45309 & 2130 & 299.99299 & 0.00000 & 1.61317 & 7.53981 \\
\hline 9.43538 & 0.000000 & $-0.1474375 \mathrm{E}-1$ & -0.4412 & $211 E-13$ & $-0.4950116 \mathrm{E}-12$ \\
\hline 546461.0 & 4083693.0 & 367.86326 & 236.95475 & 130.90850 & 5940.35044 \\
\hline 11.21879 & 479 & 300.29268 & 0.00000 & 1.60110 & 7.40576 \\
\hline 8.87402 & 0.000000 & $-0.8467299 \mathrm{E}-1$ & -0.3442 & $54 E-13$ & -0.1243 \\
\hline 546551.0 & 4083663.0 & 367.72877 & 236.86812 & 130.86064 & 5919.97186 \\
\hline 11.12073 & 19.21742 & 300.43058 & 0.00000 & 1.59464 & 7.34809 \\
\hline 8.61555 & 0.000000 & $-0.3262575 \mathrm{E}-1$ & -0.3953 & $319 E-13$ & $-0.6394882 E-13$ \\
\hline 546521.0 & 663.0 & 367.59435 & 236.78154 & 130.81281 & 5891.78511 \\
\hline 862 & 19 & 297.85613 & 0.00000 & 1.57294 & 7.65572 \\
\hline 55952 & 0.000000 & $-0.4571159 \mathrm{E}-1$ & -0.3654 & $484 E-13$ & $0.4736952 \mathrm{E}-14$ \\
\hline 546581.0 & 4083663.0 & 367.59435 & 236.78154 & 130.81281 & 5916.66076 \\
\hline 11.39227 & 18.89784 & 301.85962 & 0.00000 & 1.61581 & 7.21073 \\
\hline 7.48765 & 0.000000 & $-0.4979722 \mathrm{E}-1$ & -0.1243 & $450 E-13$ & $0.4736952 \mathrm{E}-14$ \\
\hline 546491.0 & 4083663.0 & 367.32570 & 236.60850 & 130.71721 & 5842.78144 \\
\hline 47885 & 574 & 293.19867 & 2.88793 & 1.57708 & 8.34757 \\
\hline 6.85196 & 40.68072 & $-0.2291500 \mathrm{E}-1$ & $-0.105 \varepsilon$ & $413 E-13$ & $0.1918465 \mathrm{E}-12$ \\
\hline 546461.0 & 4083663.0 & 367.05740 & 236.43568 & 130.62173 & 5804.76115 \\
\hline 10.32784 & 19.78588 & 290.94198 & 2.61177 & 1.58257 & 8.62725 \\
\hline B. 22348 & 36.82361 & $-0.3440211 \mathrm{E}-1$ & -0.557 & $544 E-13$ & $0.3884299 \mathrm{E}-12$ \\
\hline 546641.0 & 4083633.0 & 366.92344 & 236.34938 & 130.57405 & 5821.65830 \\
\hline .01392 & 19.04874 & 299.54145 & 0.00000 & 1.58696 & 7.43119 \\
\hline 80370 & 0.000000 & $-0.4825768 \mathrm{E}-1$ & -0.913 & $85 E-14$ & $-0.6335671 \mathrm{E}-12$ \\
\hline 546551.0 & 4083633.0 & 366.78944 & 236.26307 & 130.52638 & 5747.27079 \\
\hline .73212 & 20.29416 & 281.71067 & 0.00000 & 1.60689 & 9.76482 \\
\hline .91281 & 0.000000 & $-0.8052816 \mathrm{E}-1$ & -0.4 & $57 E-13$ & $0.2250050 \mathrm{E}-13$ \\
\hline
\end{tabular}

- Example listing of input file, REPOS8.DAT developed as output from SURFER V6.04. Only the first 10 lines of the file are listed.

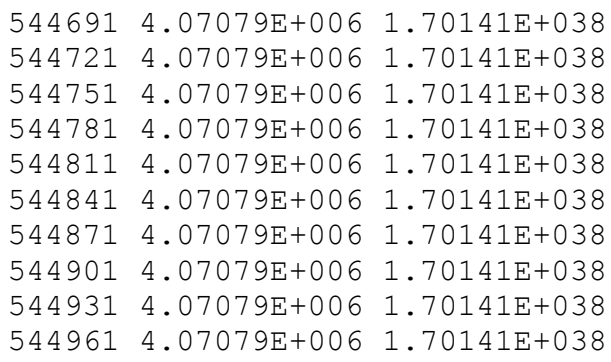

- Example listing of input file, GM-REP8.MAP developed as output from SURFER V6.04. Only the first 20 lines of the file are listed.

$\begin{array}{lccccr}\text { easting } & \text { northing } & \text { precip } & \text { rain } & \text { snow-fall } & \text { snow- } \\ \text { cover } & \text { snow-melt } & \text { sublimation } & \text { evapotrans } & \text { run-infil } & \text { del- } \\ \text { soil } & \text { net-infil } & \text { runoff } & \text { run-on } & \text { mass-balance }\end{array}$




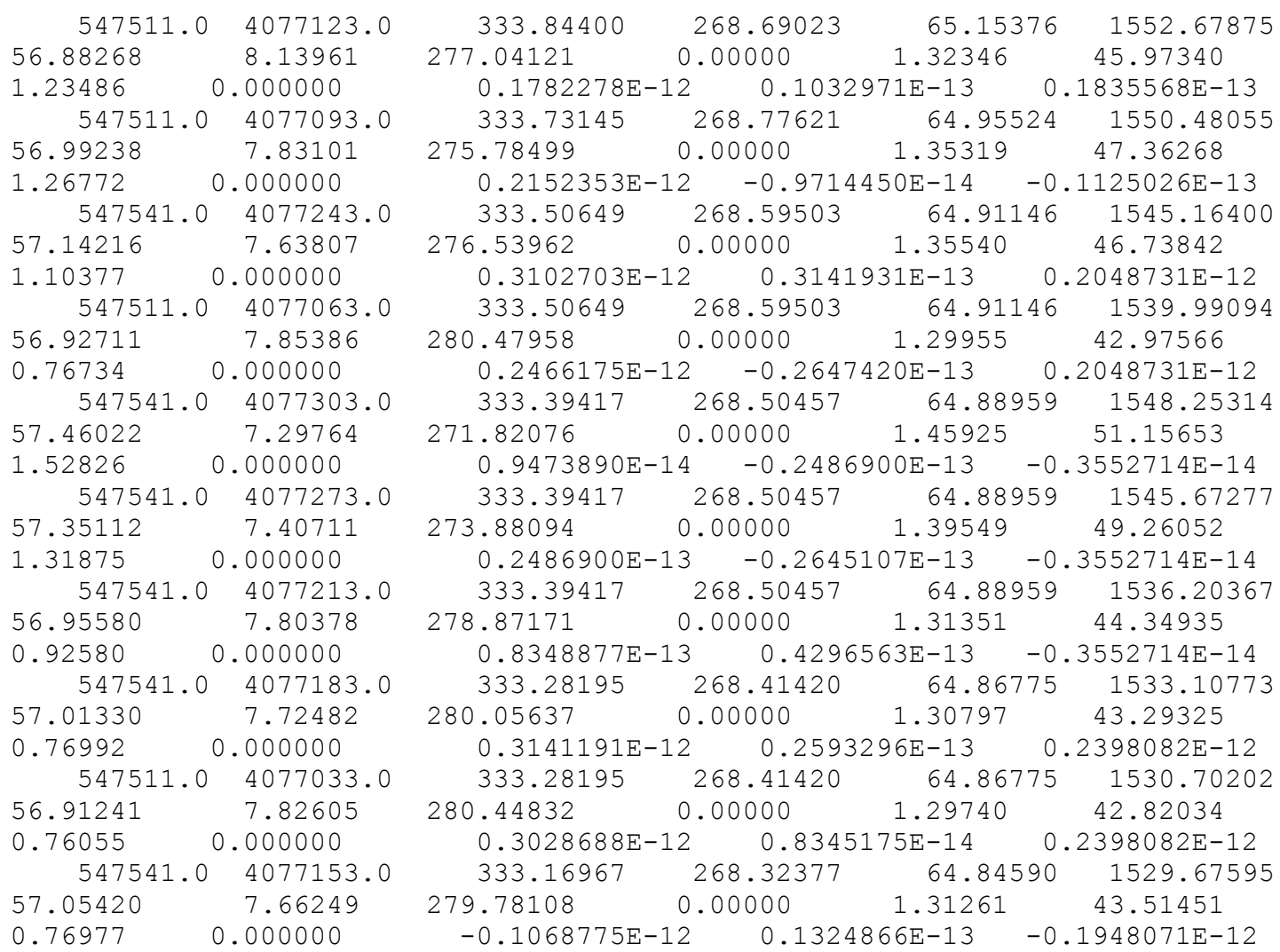

\section{- Example listing of output file, GM-REP8.SUM developed as output from MAPSUM01 V1.0.}

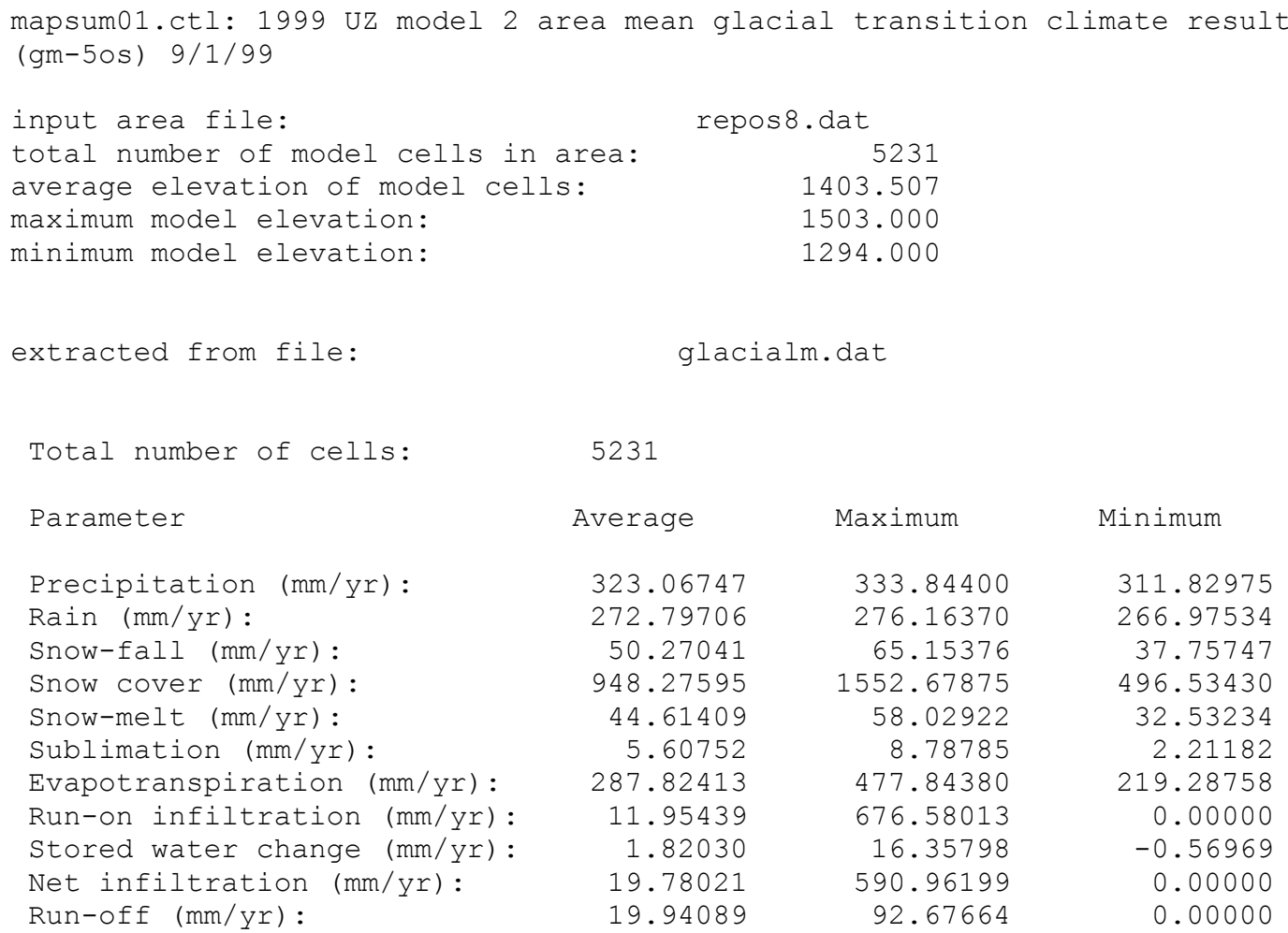




$\begin{array}{lrrr}\text { Run-on (mm/yr): } & 202.82021 & 11553.51000 & 0.00000 \\ \text { Mass balance error (mm/yr): } & -0.16082 \mathrm{E}-13 & 0.79992 \mathrm{E}-11 & -0.49241 \mathrm{E}-11 \\ \text { Max daily error (mm/dy): } & -0.26853 \mathrm{E}-15 & 0.49614 \mathrm{E}-12 & -0.39888 \mathrm{E}-12 \\ \text { Mass balance 2 (mm/yr): } & 0.14078 \mathrm{E}-13 & 0.30553 \mathrm{E}-12 & -0.32389 \mathrm{E}-12\end{array}$

M6. LISTING OF SOURCE CODE FOR MAPSUM01 V1.0

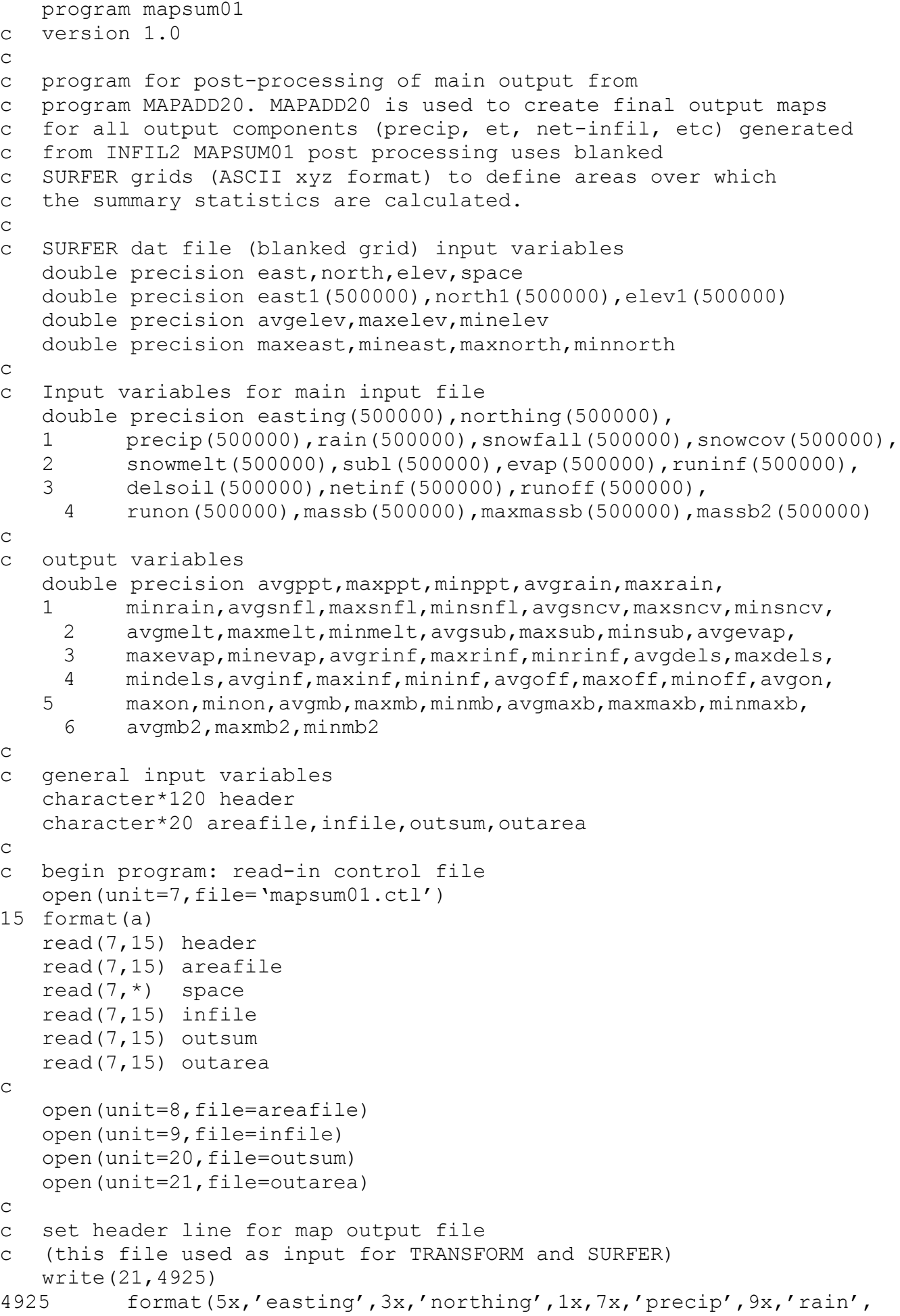




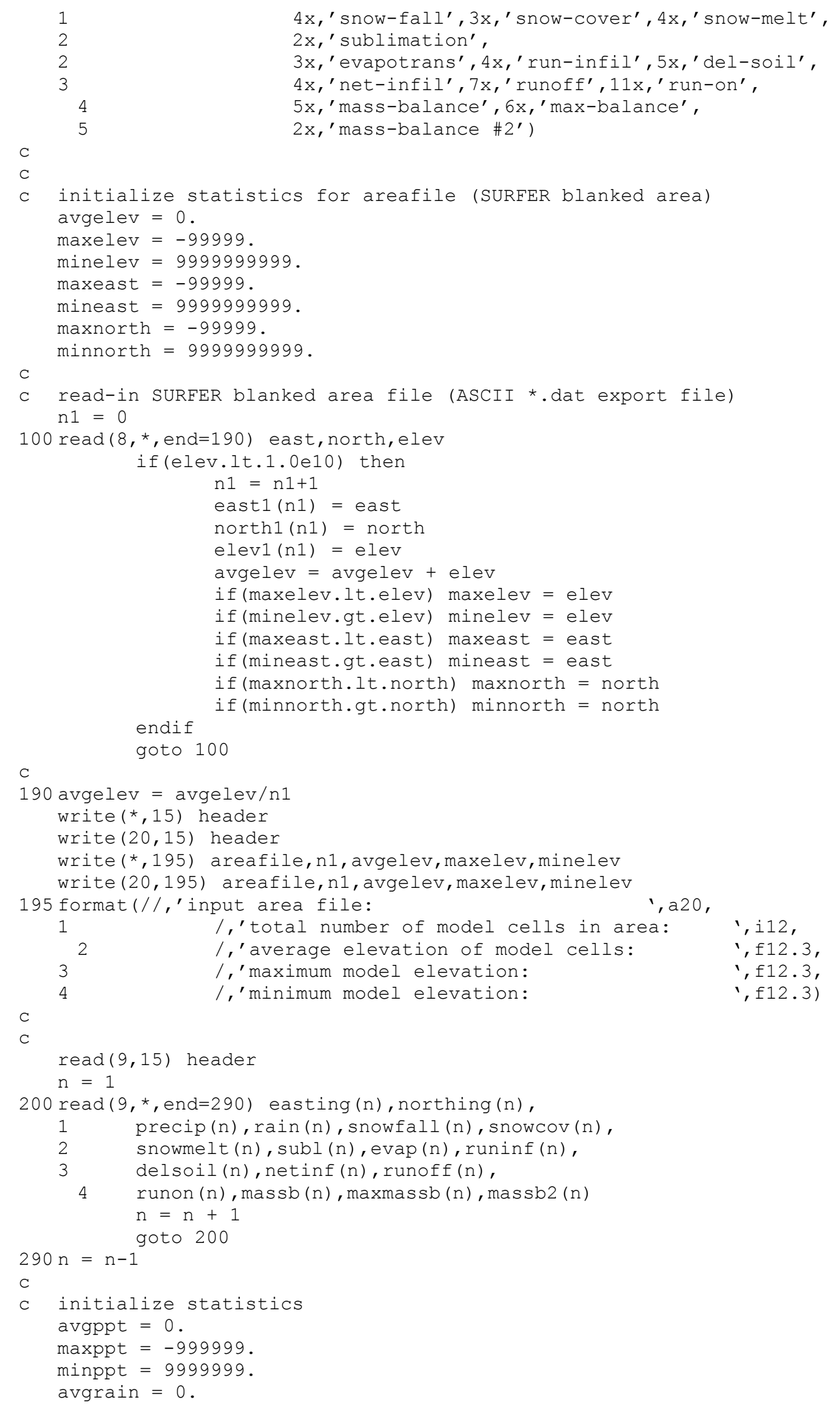




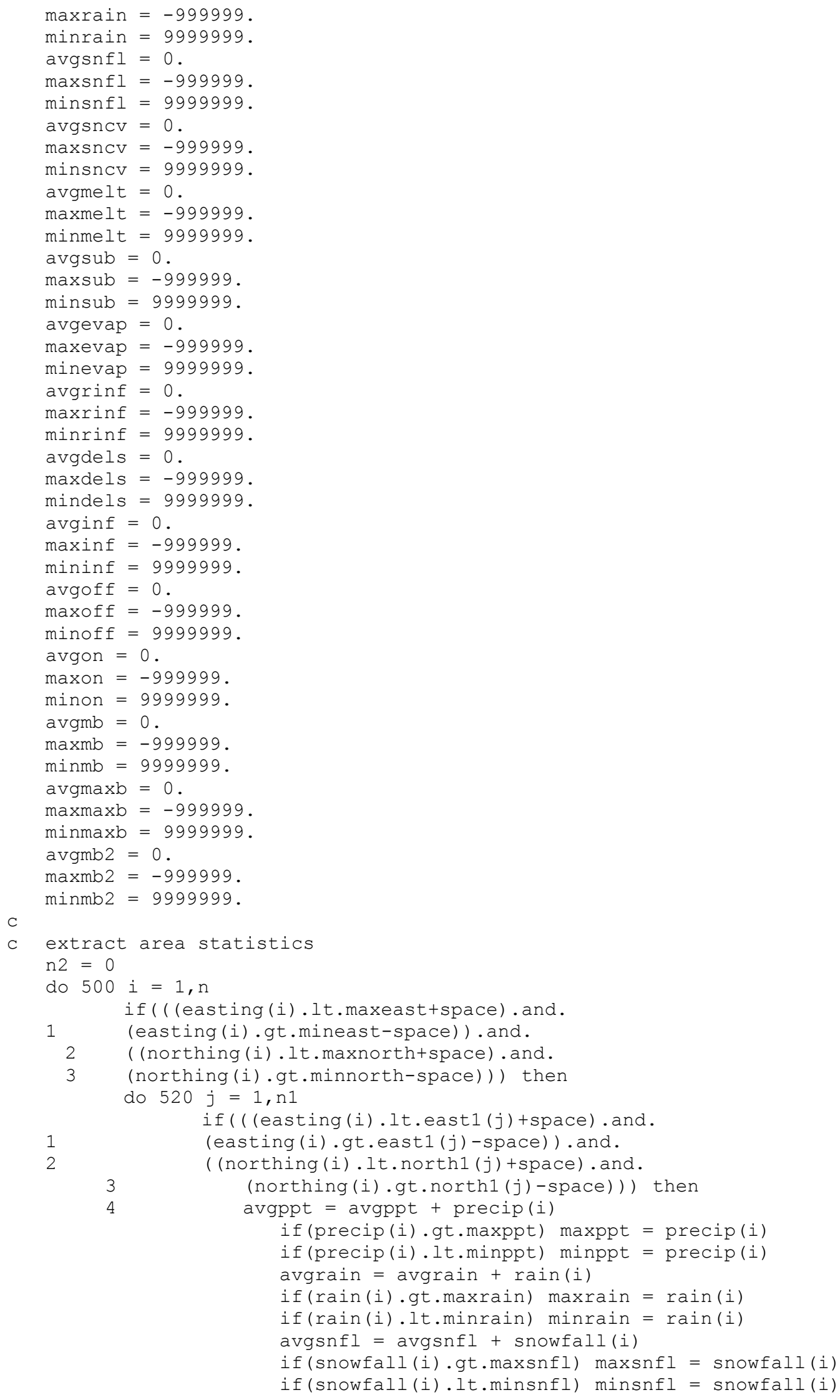




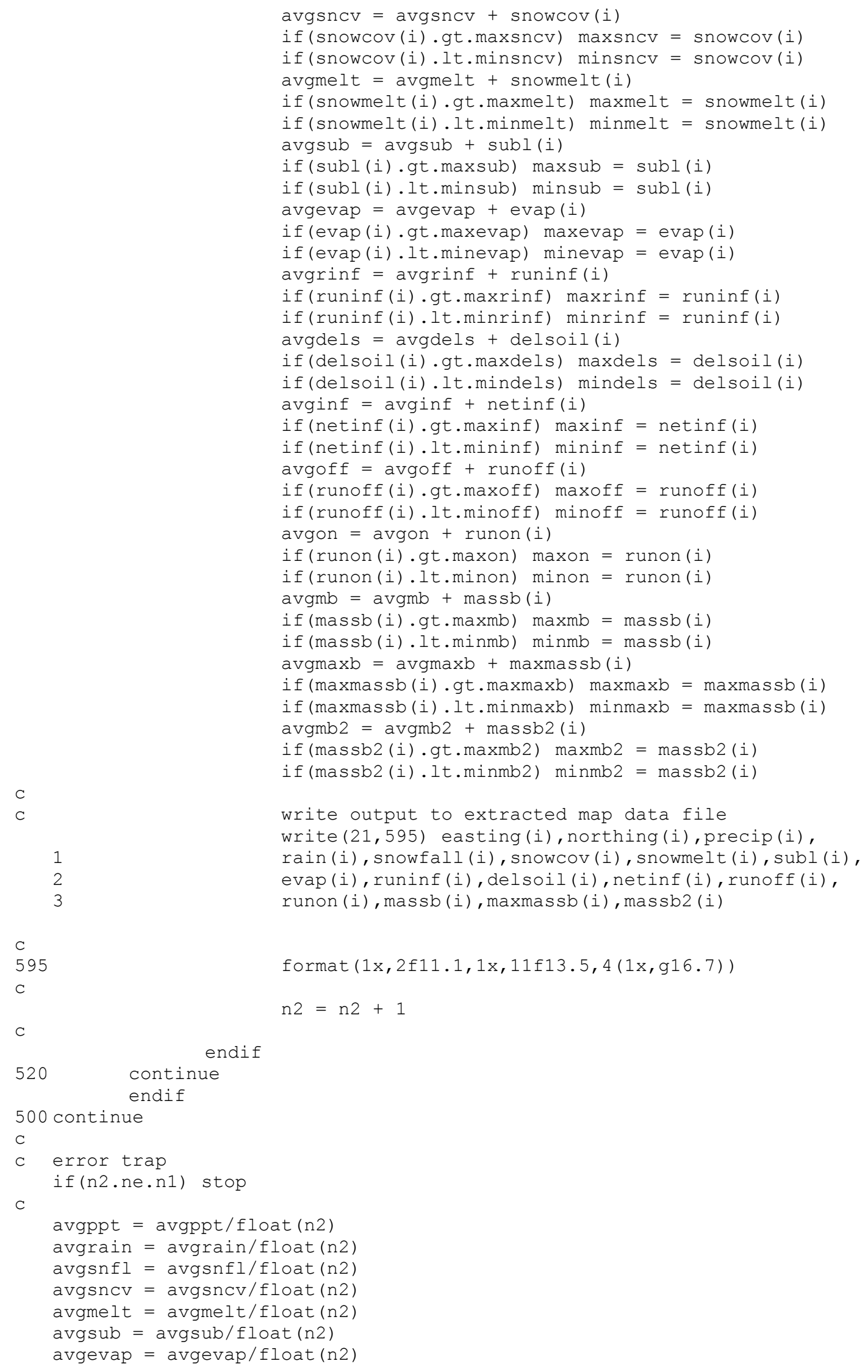




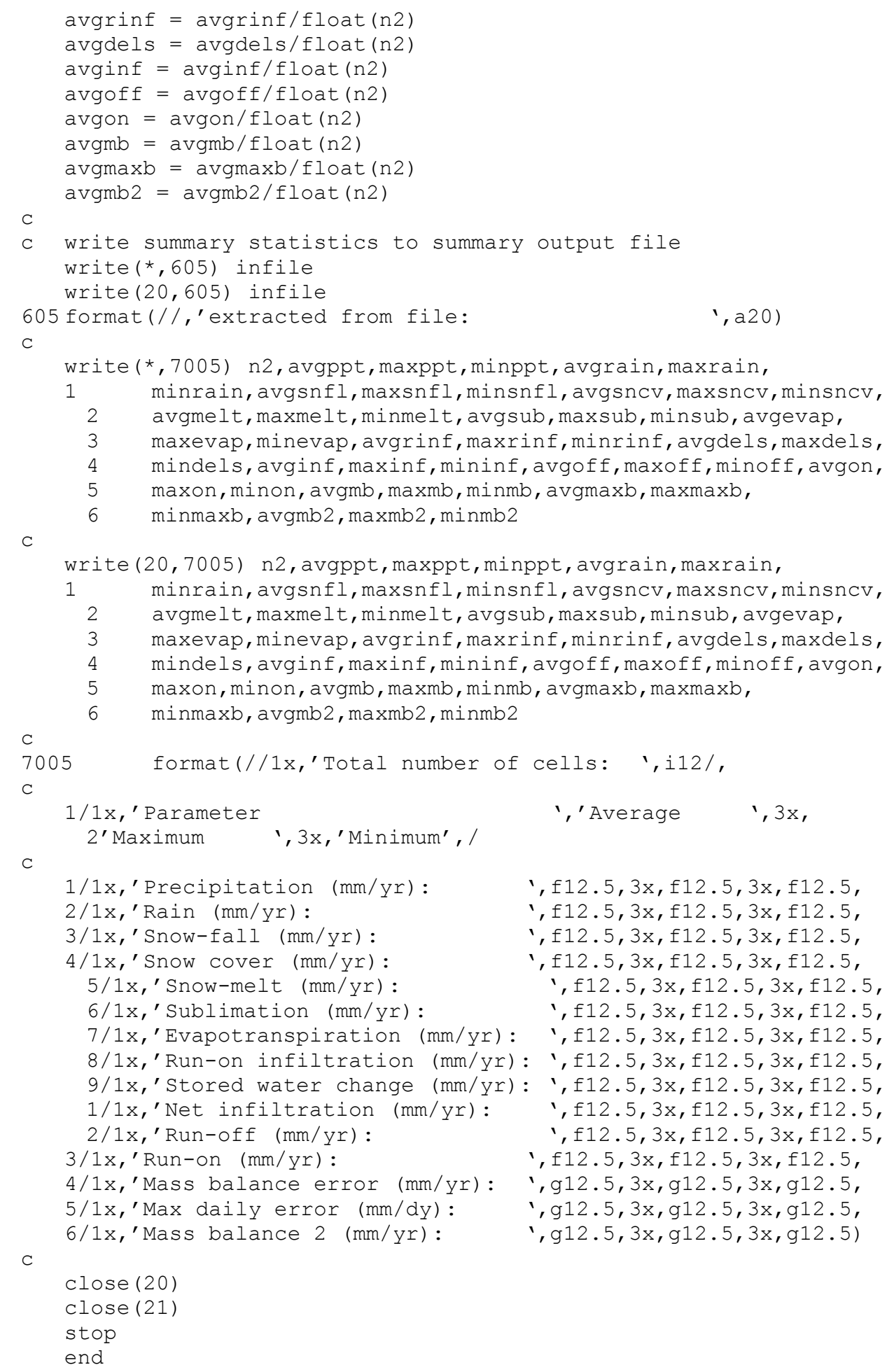




\section{INTENTIONALLY LEFT BLANK}

